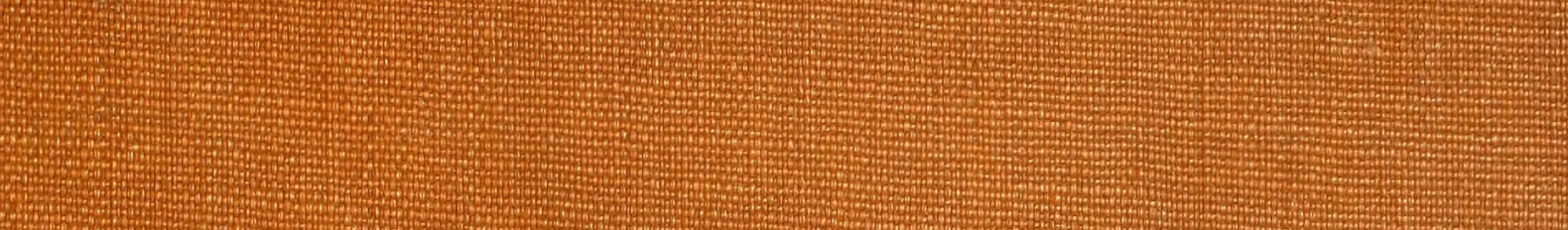

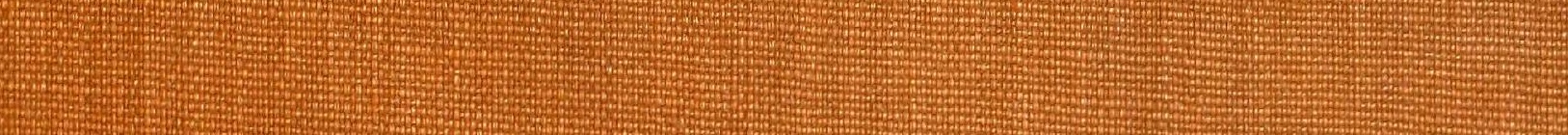
$-3$

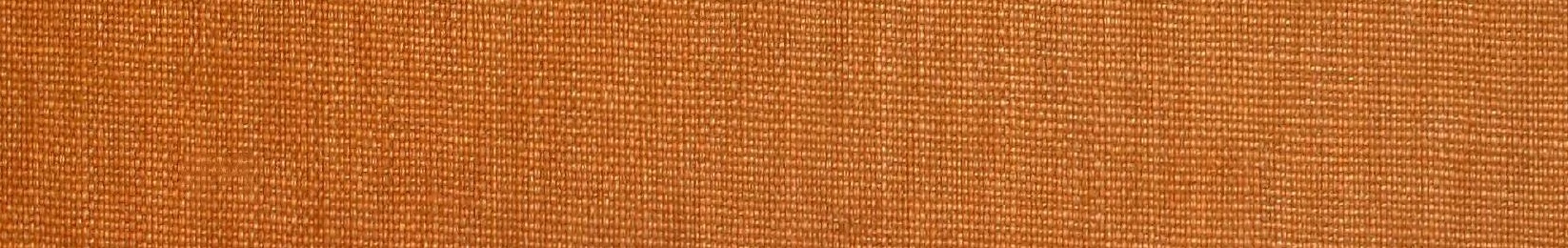

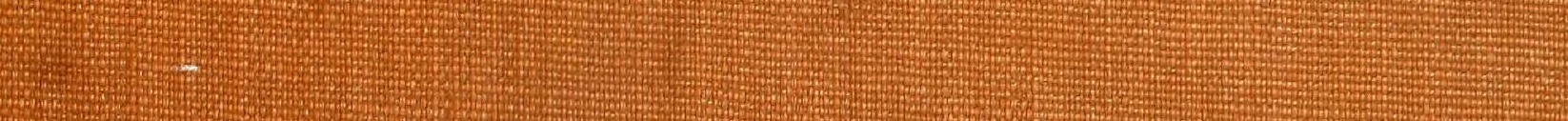

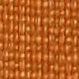

(4)

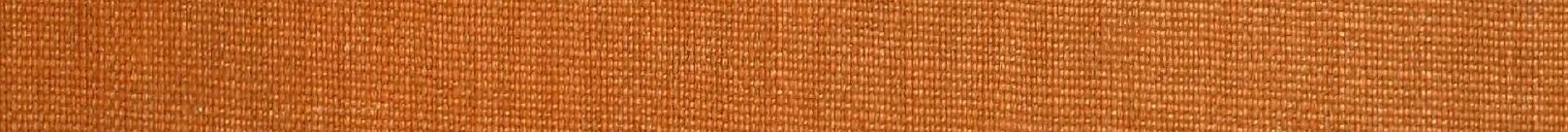

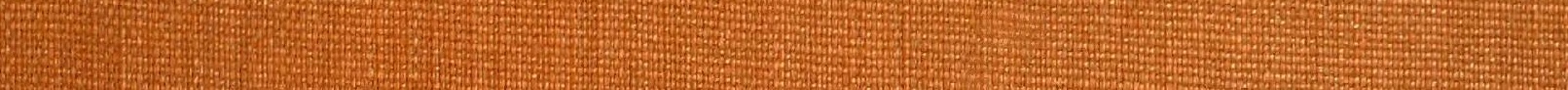

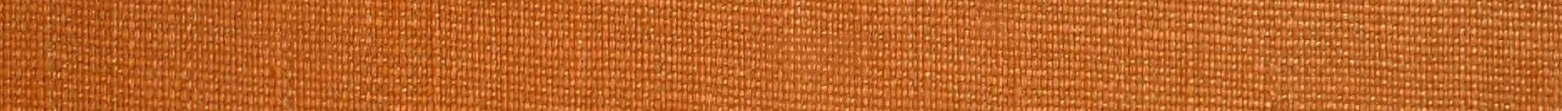
(5) (4) (3)

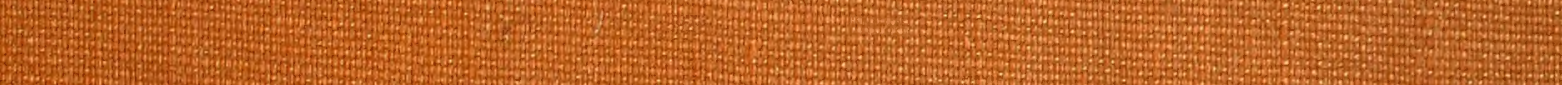
E. $+5 x^{2}+x^{2}$

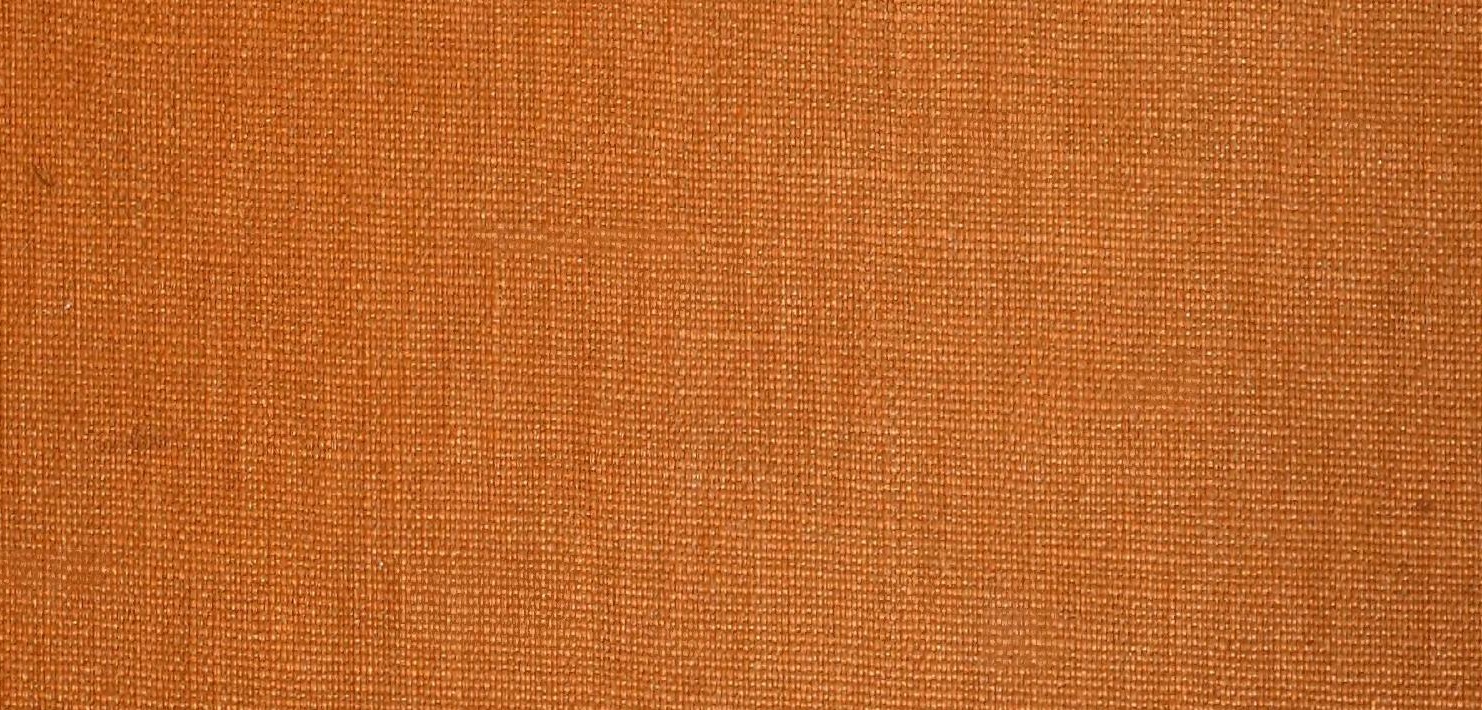

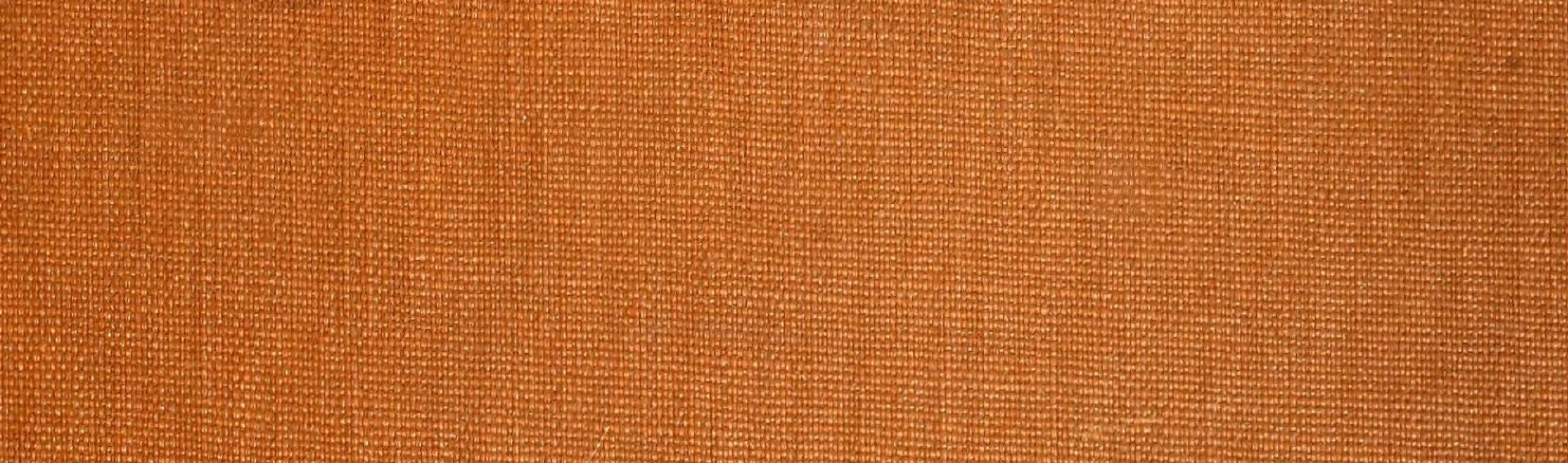
(5)

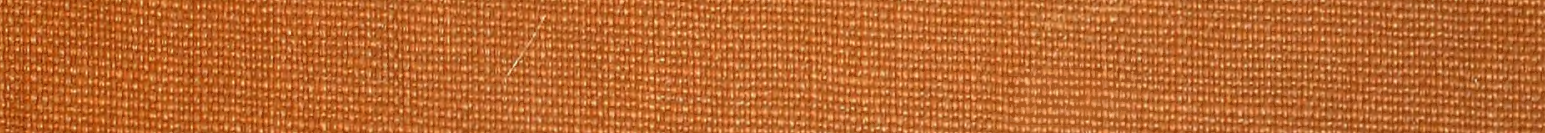

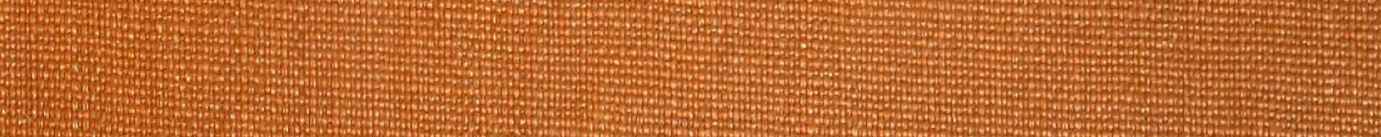

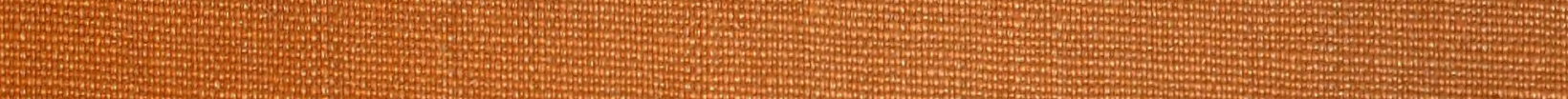

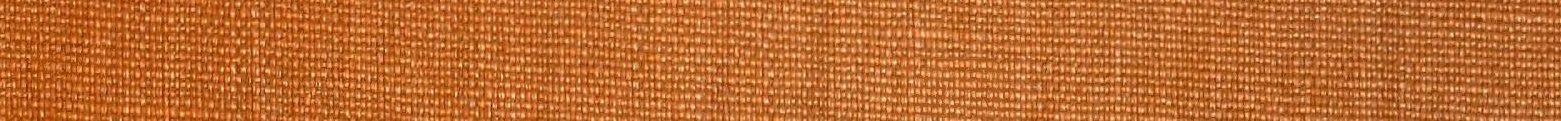

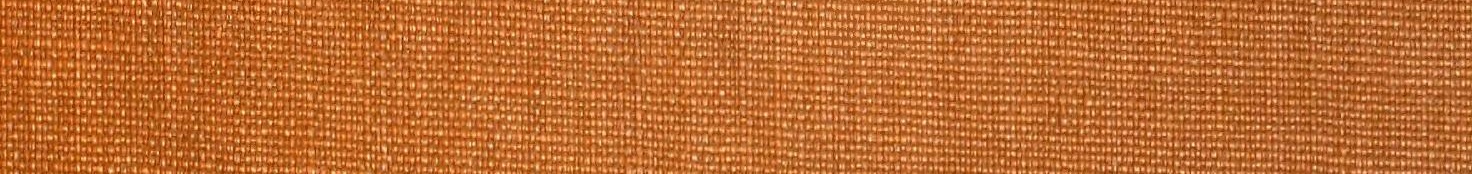

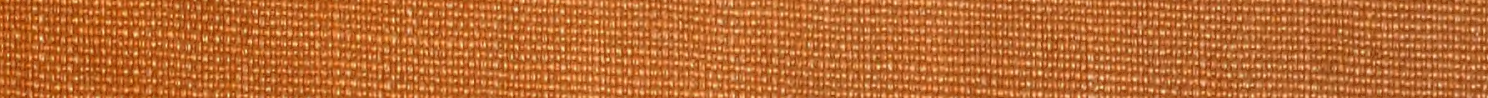




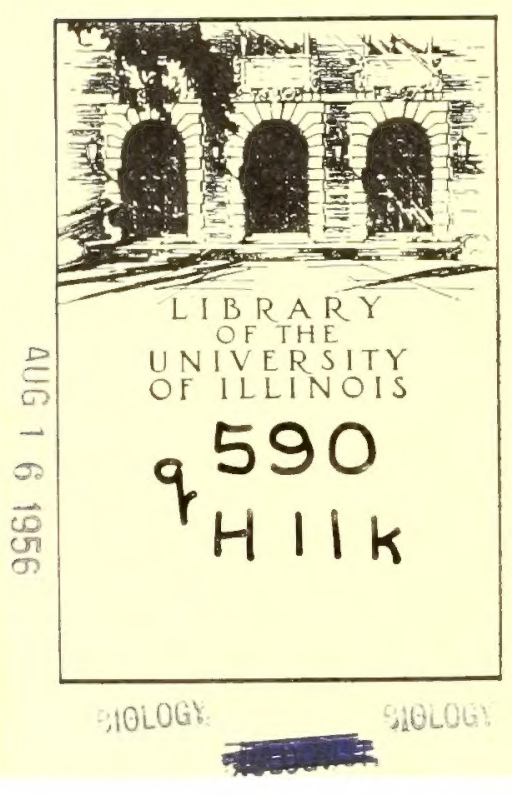


Digitized by the Internet Archive in 2011 with funding from

University of Illinois Urbana-Champaign 





\section{Kuniffiormen der Matur.}

Von

Prof. Dr. Ernit Haeckel.

L5

\section{Erife Sammlung.}

Fünizig Illuifrrationstaieln mit beictreibendem $\tau e x t$.

Cख्वाप्त

Lseipzigg und Wien.

Verlag des Bibliographilitien Inifituts. 



\section{Boxinguxf.}

(D)

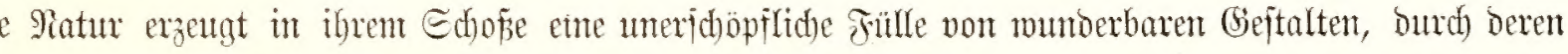

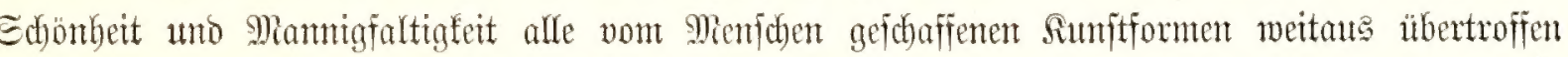

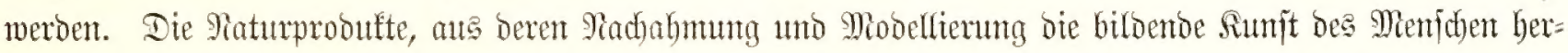

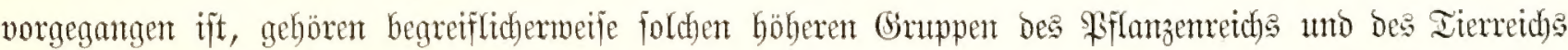

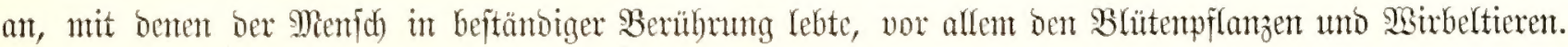

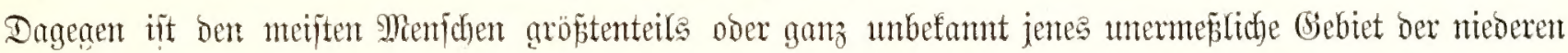
Sebengformen, bie verịteft in ben Iiefen bes Meeres wohnen ober wegen ihrer geringen Gröbe bem un=

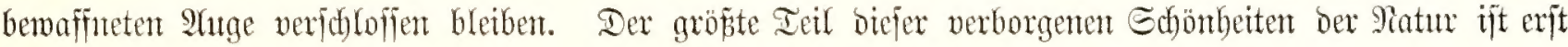

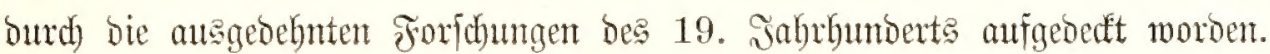

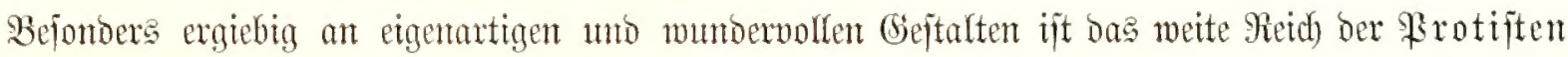
ooer Berlinge, jener einfadjiten Srganienten, beren ganzer lebentiger Sörper mur aus einer eintigen

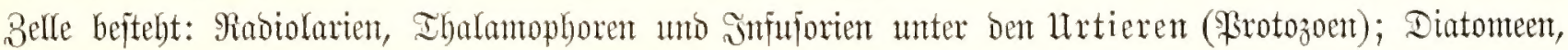

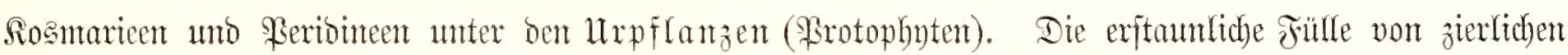

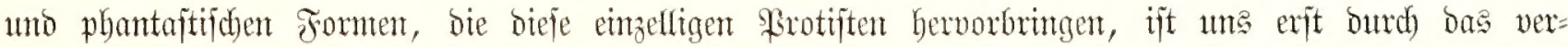

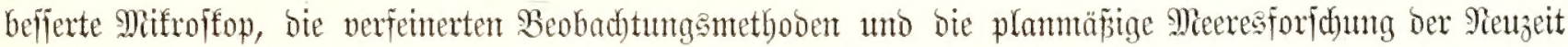
żugänglich) geworden. Diefen verbanfen wir aber auch eimen überrafdenton Reidftum an Entberfungen

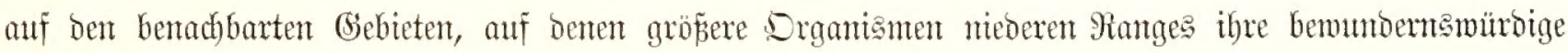

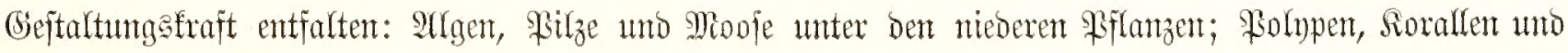

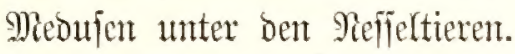

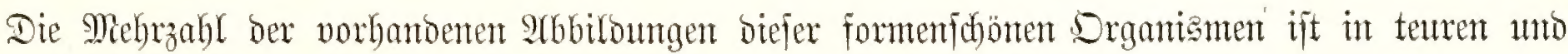

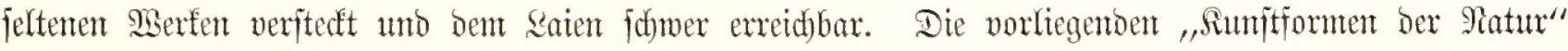

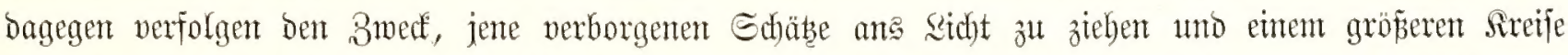

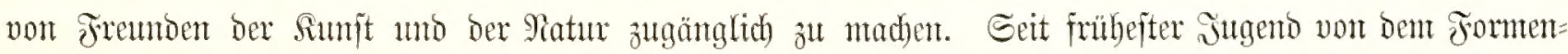

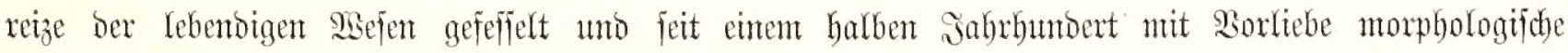

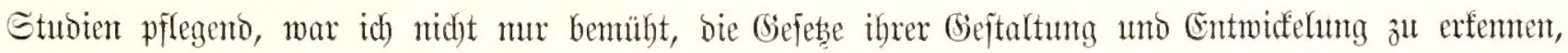

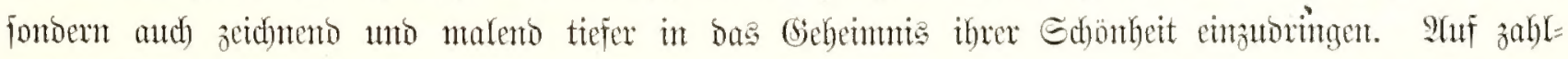

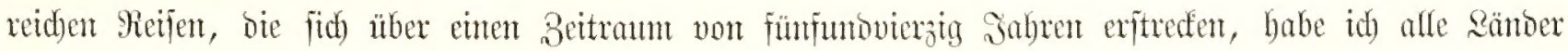

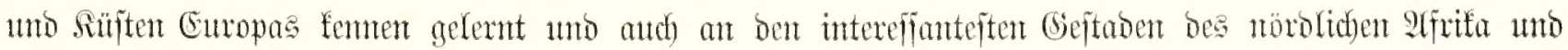

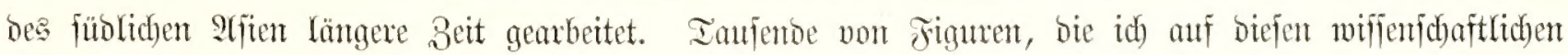

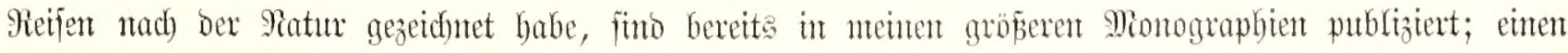

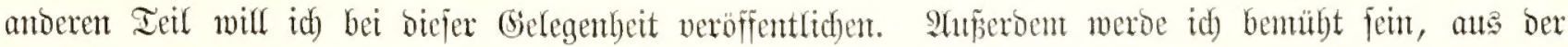




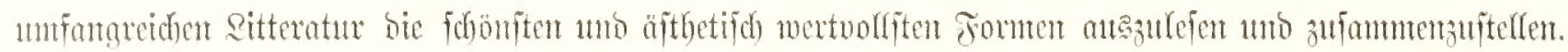

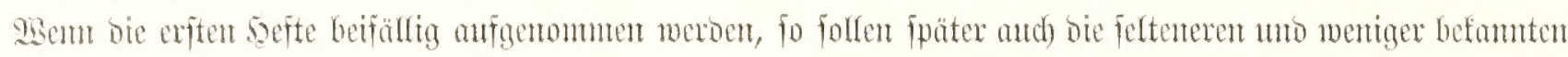

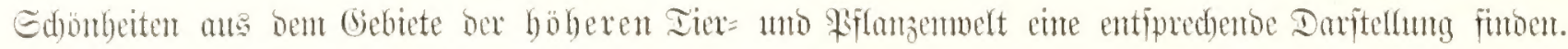

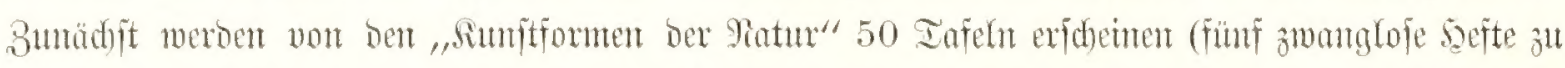

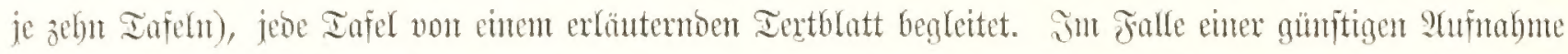

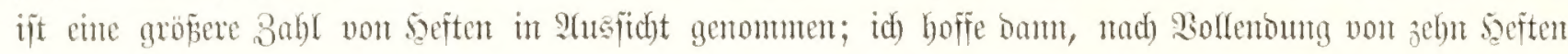

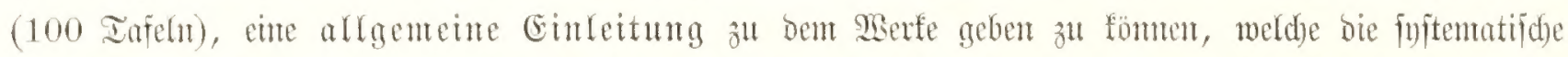

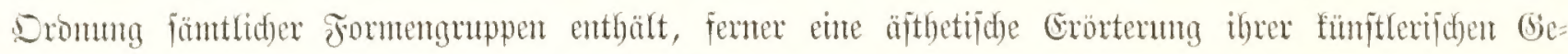

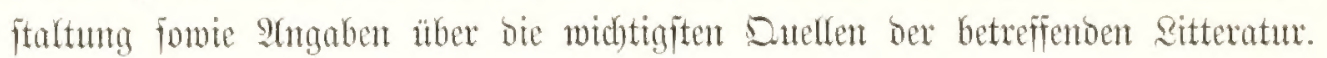

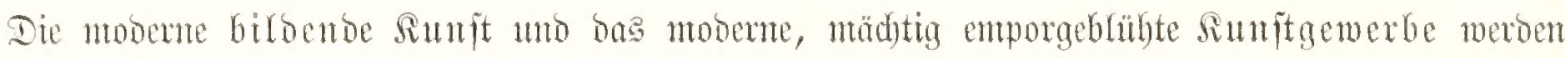

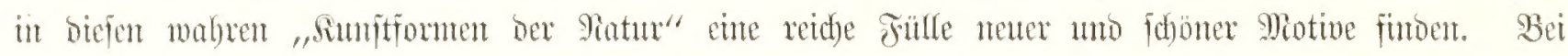

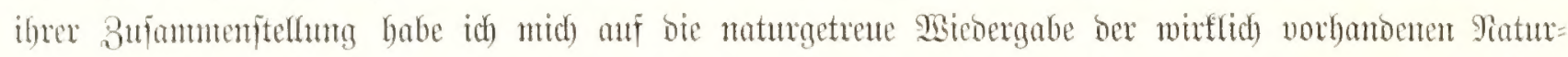

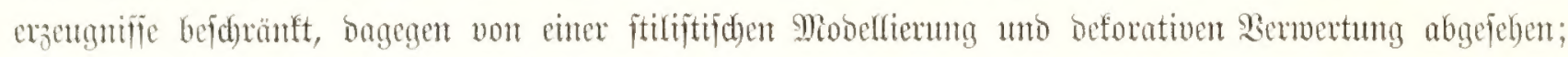
Diefe überlaffe idy ben biloenden siunftern felbft.

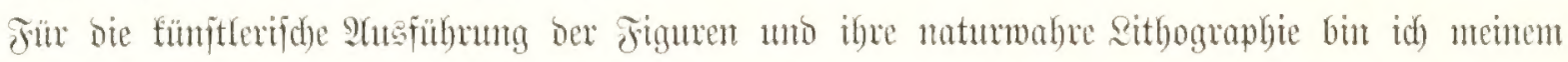

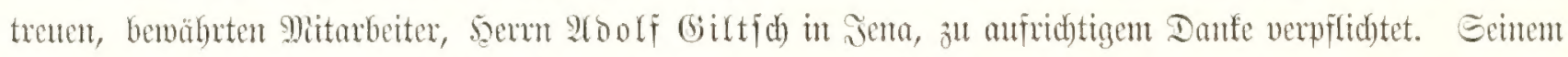

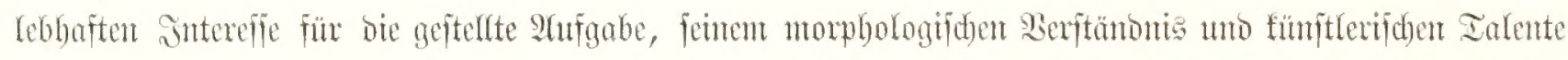

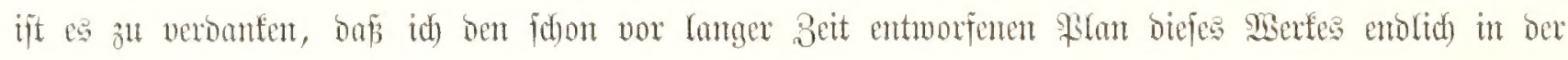
gewünfduten frorm ausfübren fornte.

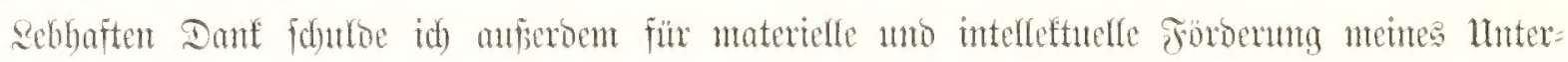

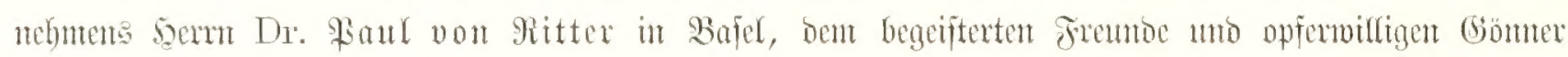

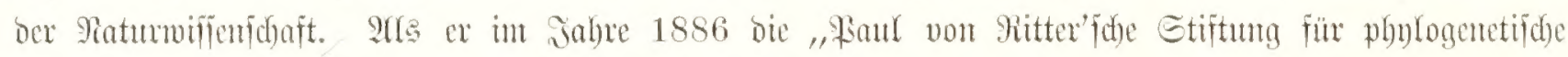

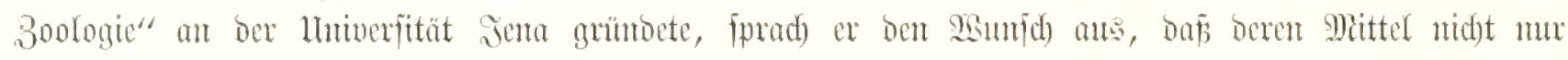

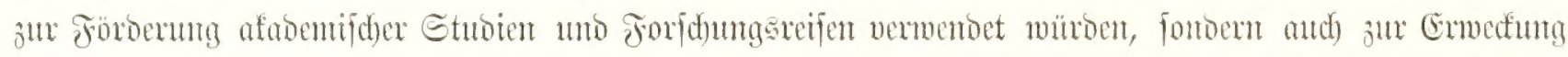

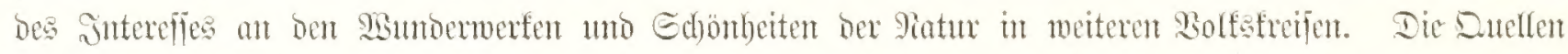

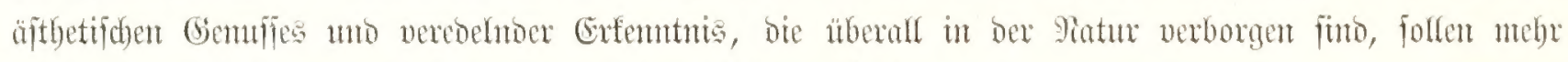

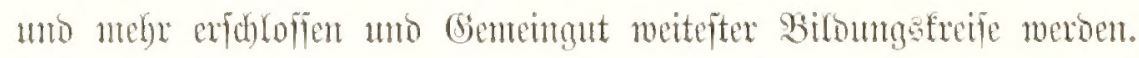

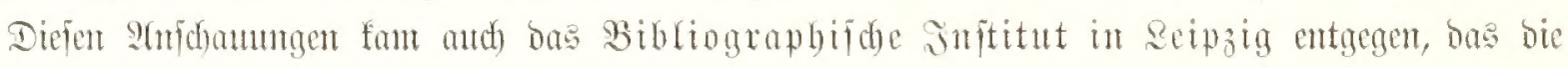

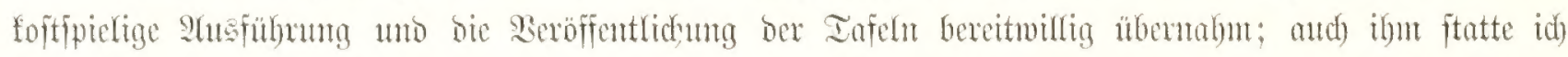

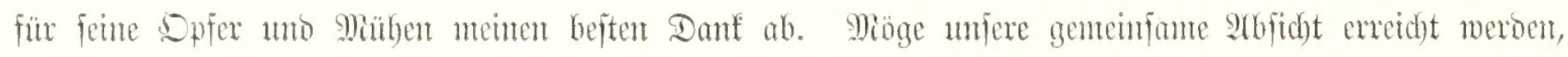

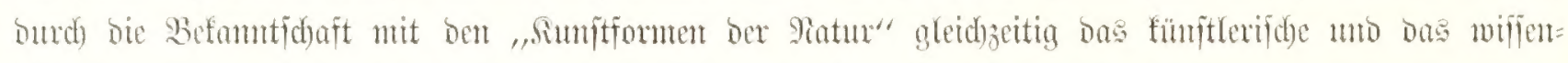

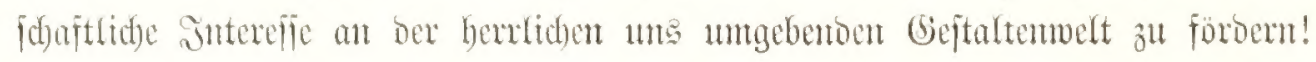

$$
\text { Šna, am 16. Jebruar } 1899 .
$$




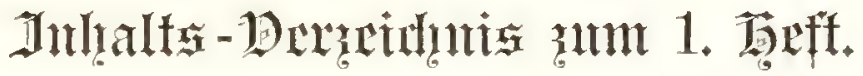

Iafel 1. Cincogonia. Hrticre ane ber filafic der Madiolarien (Eegion ber \$igäodarien).

Iafel 2. GIobigerina. Urtiere ats ber Slajle der Thalamoploren (Region der Fora= minţeren).

Iafel 3. Stentor. Untiere aus dex Sauptflaffe der Snfuprien (Slafje ber Cirtaten).

Iafel t. Triceratium. Llrpílanzen aus der Samptflafie ber Mrgarien (Slafle der Dia= tomeent).

Iafel 5. Aseandra. Riebertiere aus bon Stanm ber Spongien (Silafịe der Saltejd) wämme).
Iafel 6. Tubuletta. Mefielticre ate bor sifafic ber Sybropolypen (Droutung ber Iubu= Iaricul).

Iafef 7. Epibulia. Seffertiere ans der Sifafie der Siphonophoren (Dromung oer Enftoneften).

Infel 8. Desmonema. Miffeltiere ang ber Slafie ber Straspedon (Dromm ber Disco=

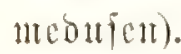

Iafer 9. Maeandrina. Fenleltere aus ber Stafic Dex Soralfen (Drommg ber secraforalfen).

Iafel 10. Ophiothrix. Stemtiere aus der Silafle Der Dphiodecn (Dromm ber C olophiuren). 



\section{Phacodaria. Rulneltralntunge.}

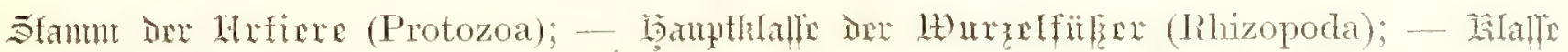

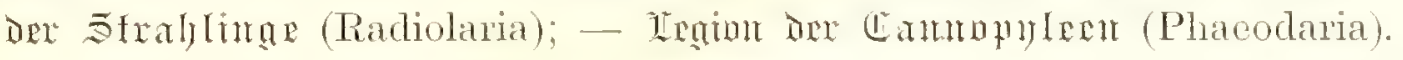

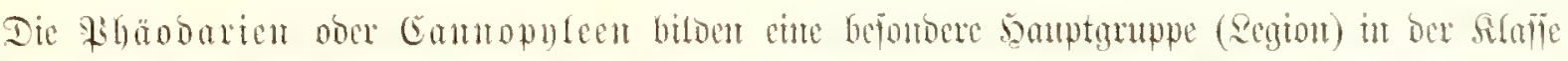

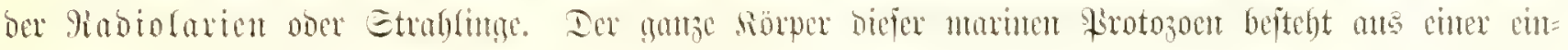

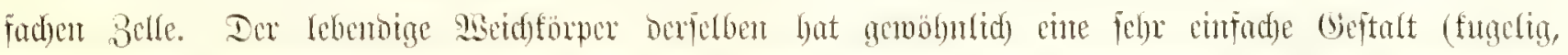

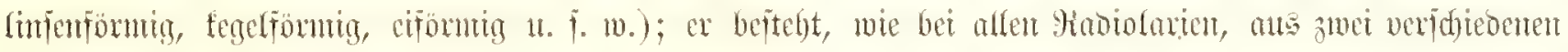

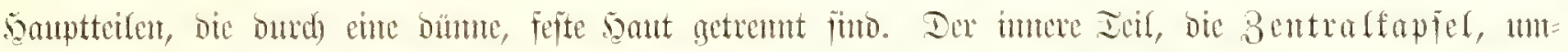

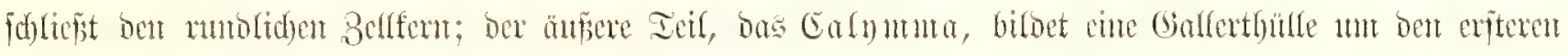

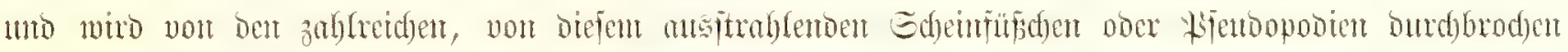

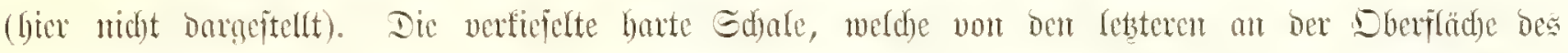

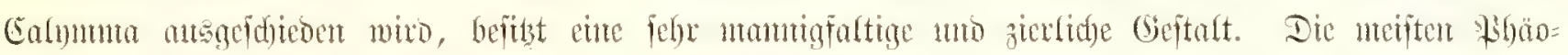

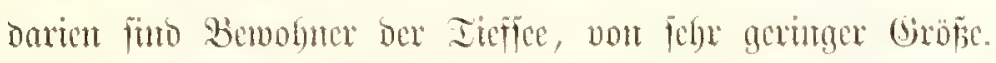

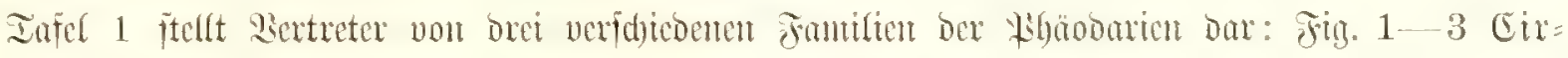
coporiou, Fig. 4 mo 5 Micoufettion, Fig. 6 eme Chaflengerioc.

Jig. 1. Circogonia icosahedra (Haeckel). Familie ber tirterporionen.

Die Edhale hat $0,7 \mathrm{~mm}$ Durchuneffer und bie Form eimes regulärem Stofacoes ; fic ijt begrentat

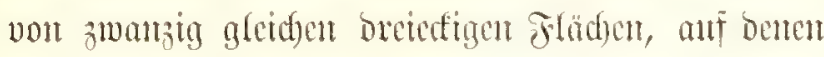

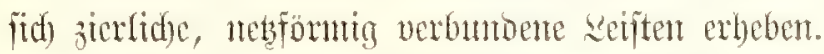
Eime von befen Grentiläd)en (in ber Mlitte) zetigt

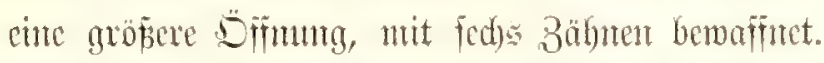

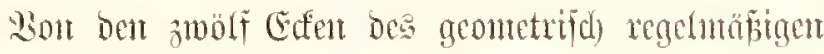
Rörpers geben zwölf holfe ftrahlige Stad)én ab,

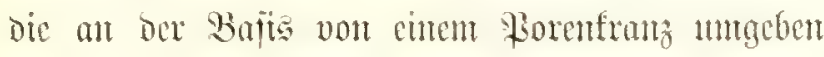

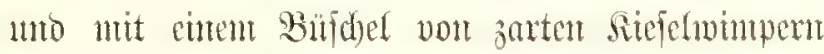

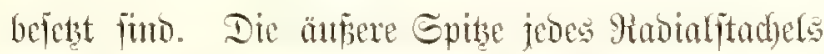

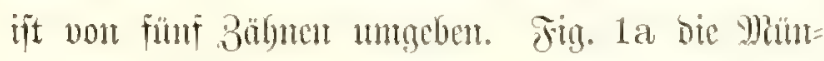

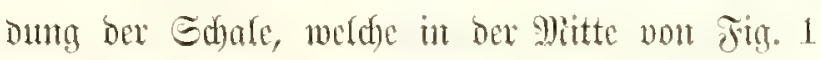
jitdotbar iit, ftärfer vergröņ̃ert.

Fig. 2. Uircostephanus coronarius (Haeckel). Familie der U⿺辶一巛工

Die Edyale hat $0,5 \mathrm{~mm}$ Durchumeffer unb bic

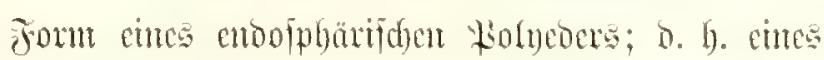

vielfettigen geometrijden Sörpers, beflen E⿺fen fänt= (id) in cine Sungeffläd)e fatfen. Die gleidjen bret= exfigen flädyen (32- 10 ) finto vertieft uno ourd) erfabene Reiften getremut. S(us ben $(2 t-30)$ pura=

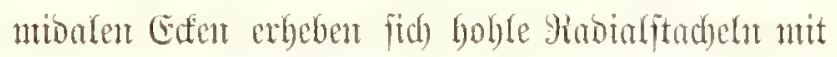

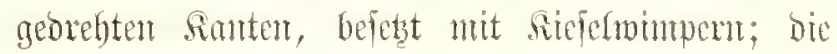

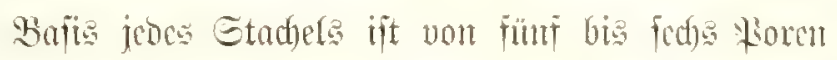

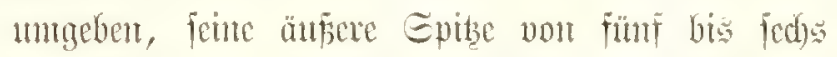

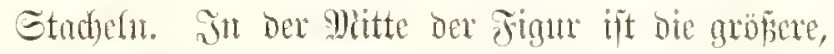

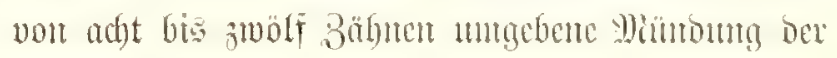
Edale fidstbar.

Fig. 3. Haeckeliana porcellana (John Muray). Familie Det

Die fugctige Edule, von $0,4 \mathrm{~mm}$ Durdmeñer, ift ourd) cigentüm(id)e porzelfantartige Befd)affenheit

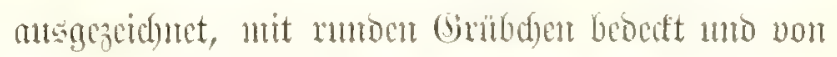

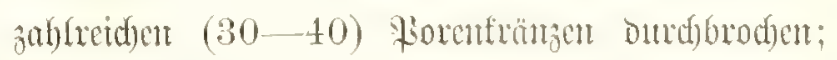
gewohntid) zeigt jober sirurs für foren (Jig. 3a).

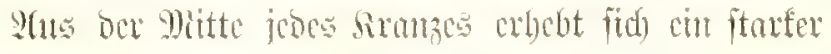

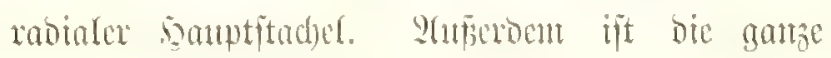




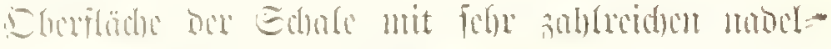

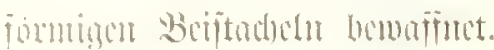

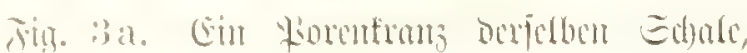
iturtex vergropit.

\section{Ning. 4. Cortimetta tripodisens (Heceled).}

Familin on if?

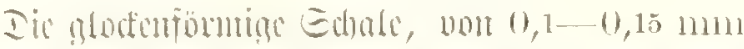

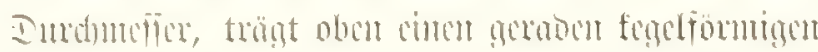

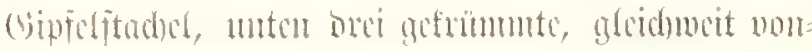

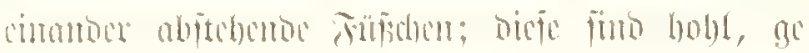

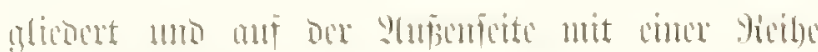

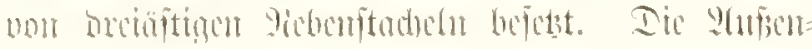

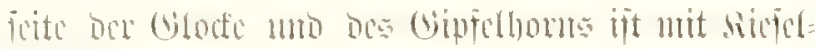

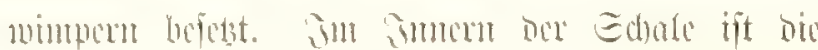

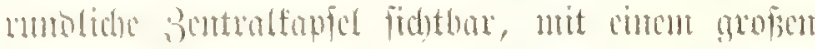

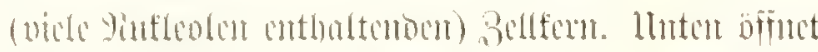

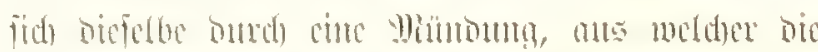

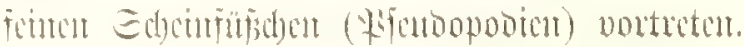

Fig. 5. Medusetta tetranema (Haeckel).

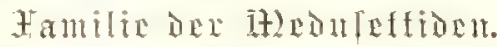

Iit glofentoumige Edyale, von fanm $0,1 \mathrm{~mm}$

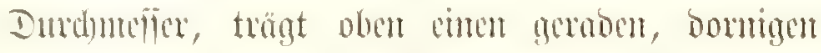

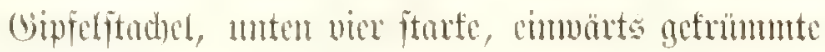

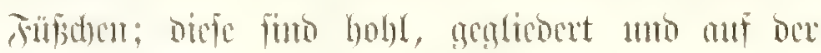

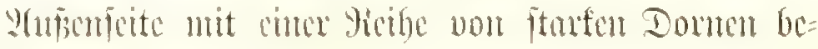
matiut.

\section{Jim. 6. Challengeria murrayi (Hackel). familie one cinallemerion.}

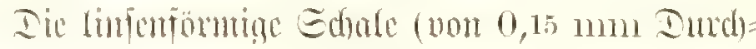

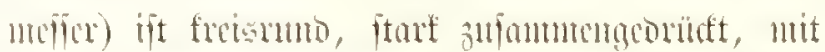
Febre sierlider (Gitterftruttur; oben bifnet fie fid ourd)

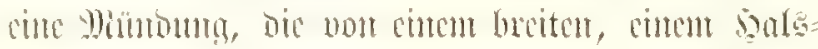

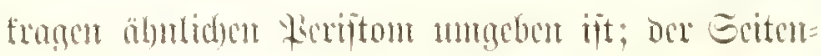

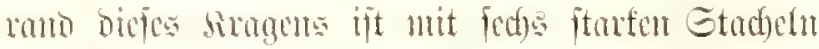

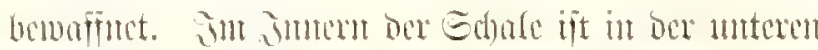

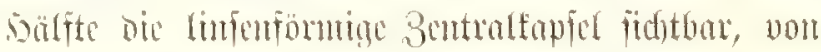

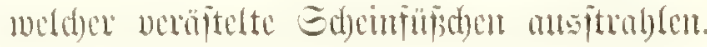




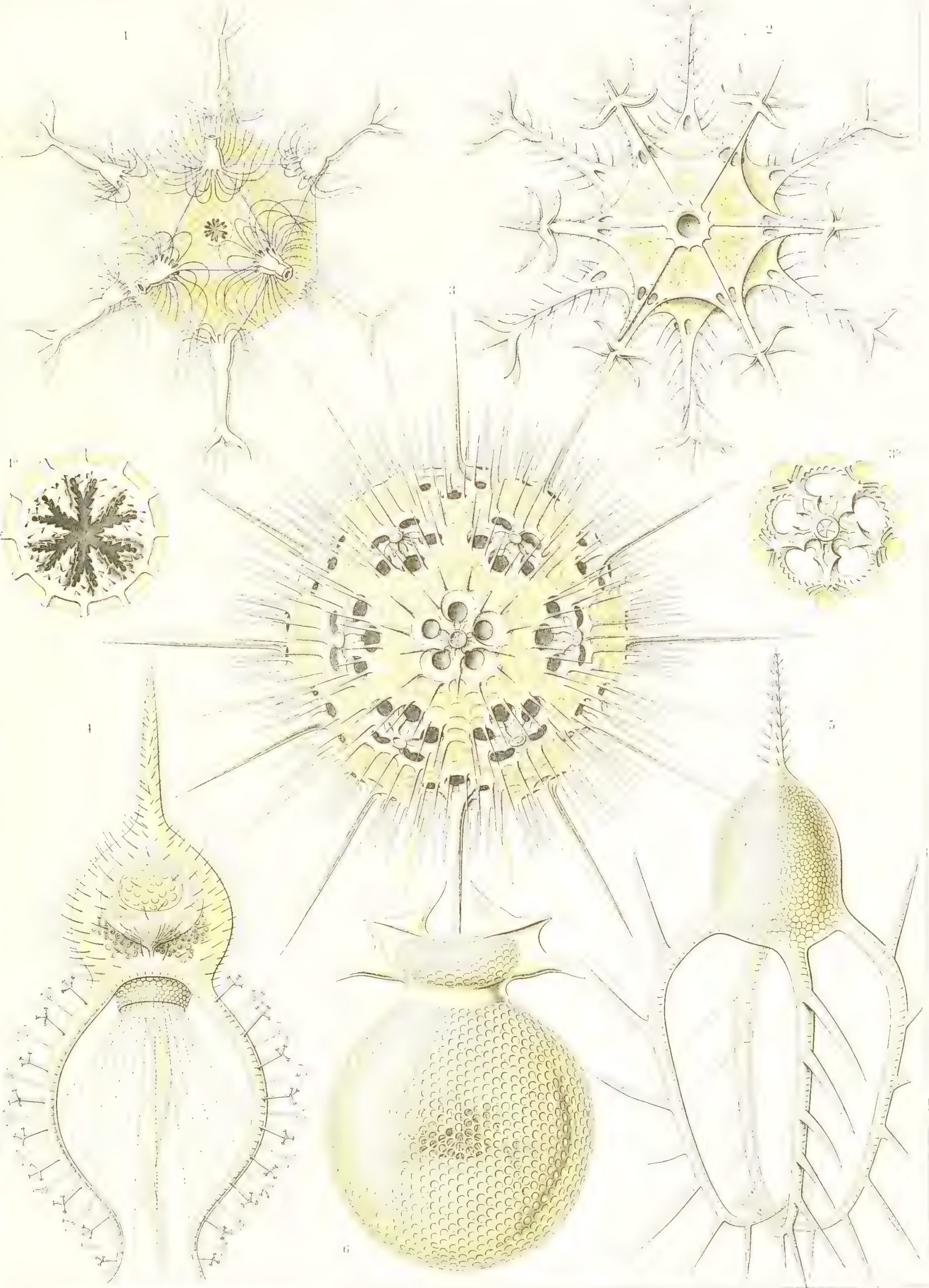

Phaeodaria. Biobutroblintye. 



\section{Thalamophora. 筑anmertinge.}

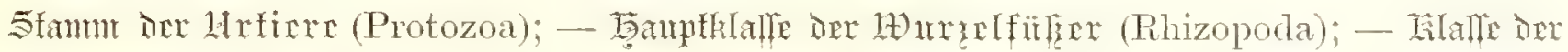

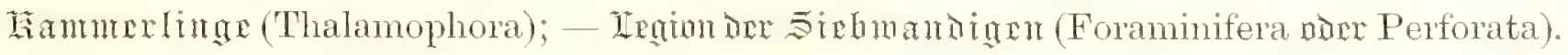

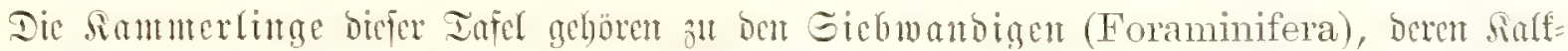

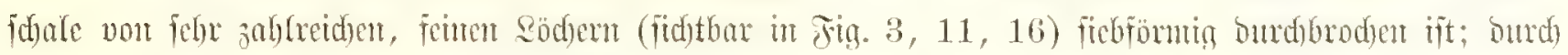

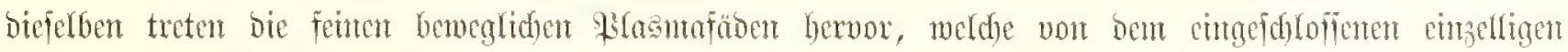

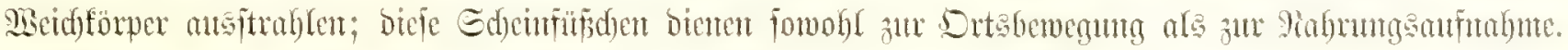

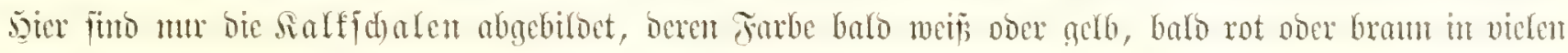

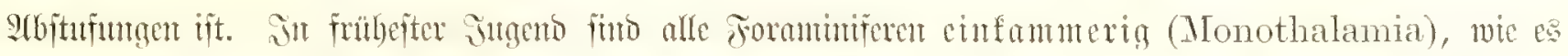

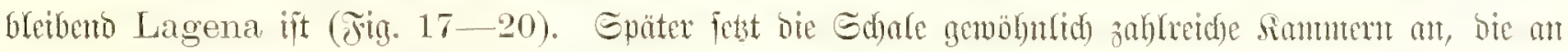

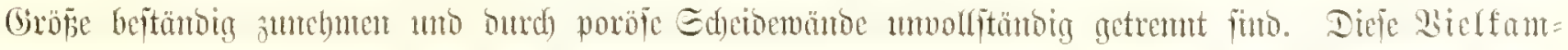

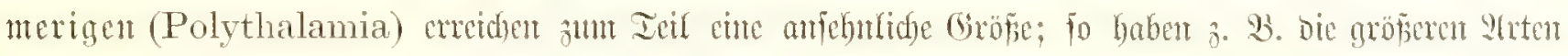

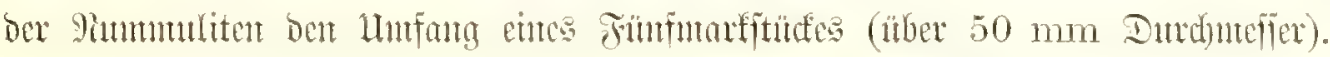

\section{Jig. 1. Nodosaria spinicosta (d'Orbigny).}

Die fegefförminge Sdyale ift $1 \mathrm{~mm}$ lantg unto

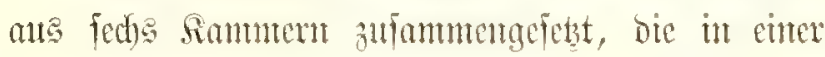
geraben Meife Ginteremmoc liegen. Fig. 1a. Die

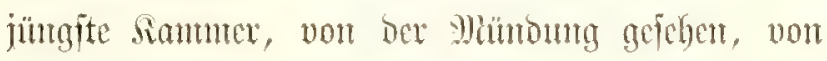
meld)er 16 gitppen ftrablenförmig ansfoufen.

\section{Fig. 2. Uvigerina aculenta (d'Obrigny).}

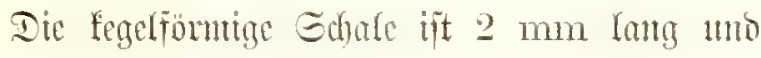

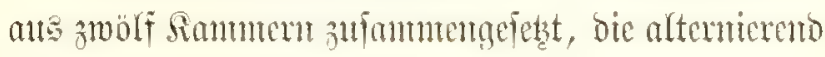
int żwei Reifen gegenüberjterben.

\section{Fig. 3. Bolivina alata (Seguenza).}

Die Edhale ift $1 \mathrm{~mm}$ lang, zöpfdentformto,

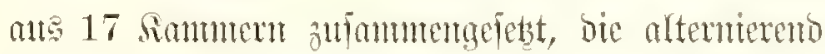

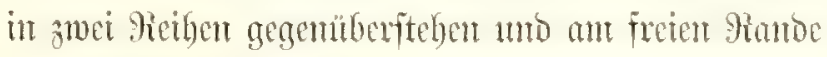
cinen Flitgel tragen.

\section{Fing. 4. Cristellaria echinata (d'Orbigmy).}

Die linfenfömige, bifonere Edjate bat $2 \mathrm{~mm}$ Durdumefler. Dic Edhetocnänto ber Sammern glci=

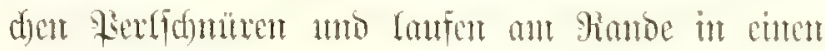
rabialen Gtadel an. Fin. ta. Dinferbe Edjare

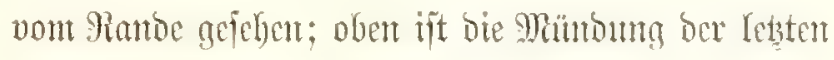
(grö̉̆ten) Sammer fiddtbar.

\section{Fig. 5. Cristellaria siddalliana (Brady).}

Die bümte, blattfönmige Edyale ift $1-2 \mathrm{~mm}$ lang utmo in cinter Ebene fpiralförntig aufgecrollt. Die Sammern Deffen fith mit bem linteren Rano.

Jig. 6. Cristellaria compressa (d'Orbigny).

Die büme, blattfömige Edjale hat $t-6 \mathrm{~mm}$

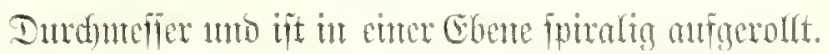

Fig. 7. Polystomella aculeata (d'Orbigmy).

Die Yinjentönmige Edale (von $1 \mathrm{~mm}$ Durd)= meffer) ijt nautifus=ähulich, am ganbe grgahnut.

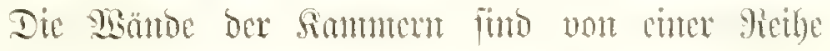

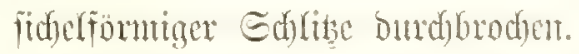

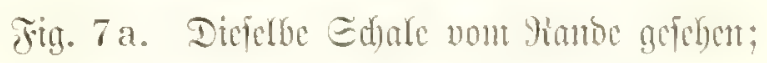

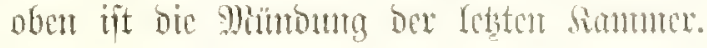

Fig. S. Polystomella venusta (Max Schultze).

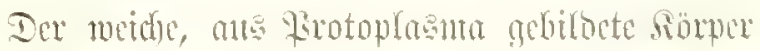

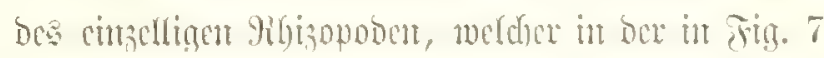

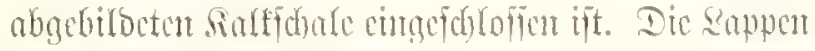

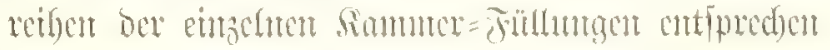

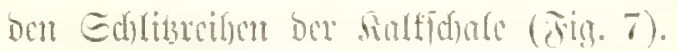


Tig. A. Nummulites orbiculatus (Ehrenterg).

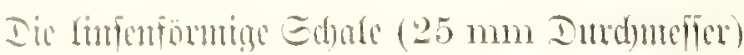

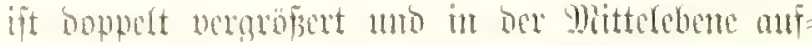

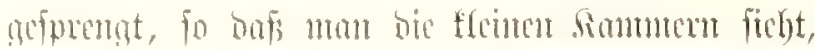

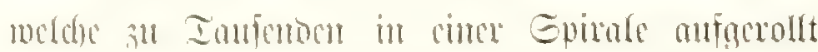

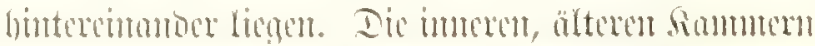
fumb bedentemo flciner als bic änseren, jüntgerent.

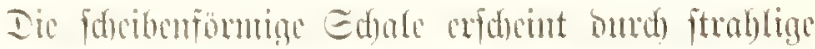

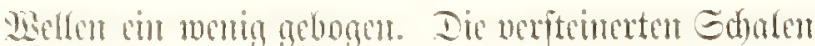
Diefer Yumuntiten (bis a $30 \mathrm{~mm}$ Durd)meffer)

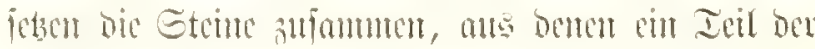

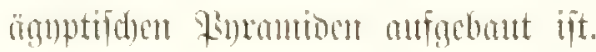

\section{Jig. 10. Cilobigerina bulloides (d'Orhigm!).}

Dic Eduate (nou $0,5-1 \mathrm{~mm}$ Durd)menfier) ift

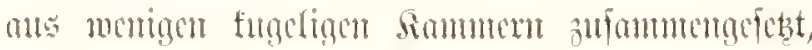
won bemen bic lebte (jüngfte) vid groffer ift als bie worheragchemen. Son ber wabigen Eberflädhe ber

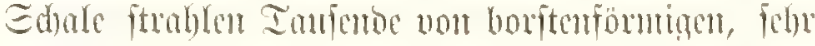
tangen umb büunen falfnabedn ans; fie bienen als

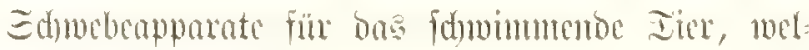

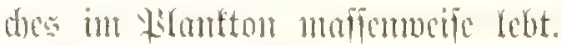

Titg. 11. Pavonina flabelliformis (a'Obigmy).

Die flade Edhate (vor $1 \mathrm{~mm}$ Dutrdmeffer) hat

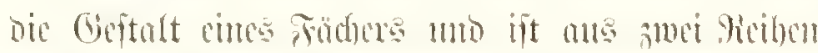

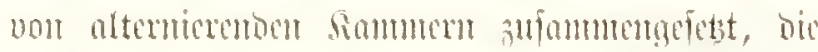

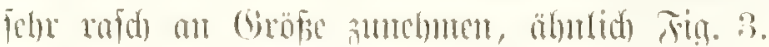

Tita. 12. Bulimina inflata (Semenza).

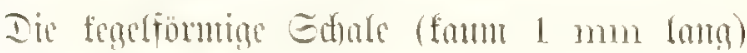

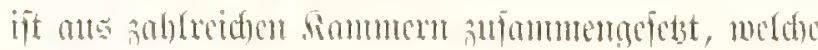

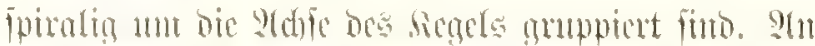
Dor jumaiten gropten frommer firbt man obou bie

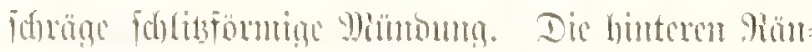

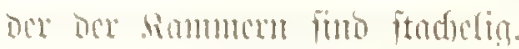

\section{Titg. 13. Fondicularia alata (d'OBbimm).}

Dis flache Edyale (sünge $3 \mathrm{mmm}$ ) hat bie (65:

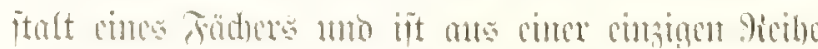

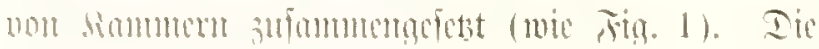

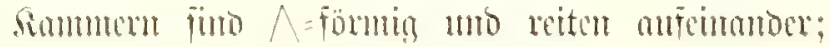

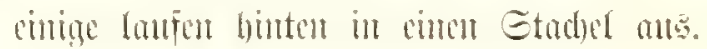

\section{Fing. 14. Calcarina clatrigera (d'Orbigny).}

Dir limfentanmige Githate (von $1-2 \mathrm{~mm}$

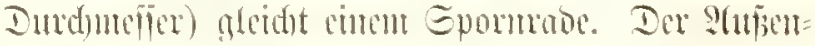

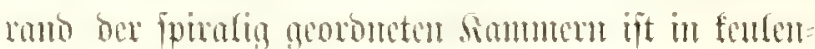
förmig̣e raube Strablen vertängert.

\section{Tig. 15. 'Tinoportus baculatus (Carpenter).}

Dic limfenfoumige Gdule (non 1 - $2 \mathrm{~mm}$

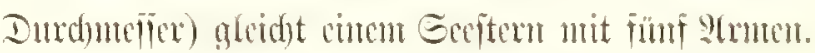

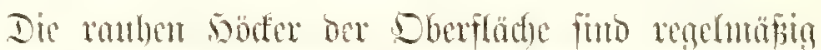
nerteilt, burd) erbabene seiften metfönmis nerbumben.

\section{sig. 16. Orbulina unirersa (d'Obimmy).}

Die cinfanmerige fungelige Edhate ift von zahl=

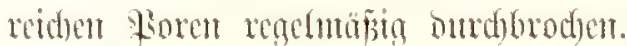

\section{Fig. 17. Lagena alata (Brady).}

Dic cinfanmerige Edhate (non $1 \mathrm{~mm}$ Dumd)=

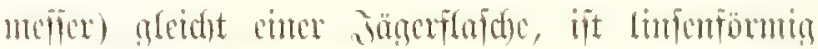
infanmengeonüft, zierlide getäfelt ano an breiten Viontoe arflügert.

\section{ritg. 18. Lagena interiupta (Williamsom).}

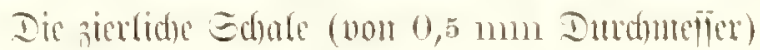

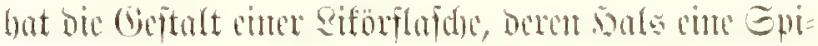

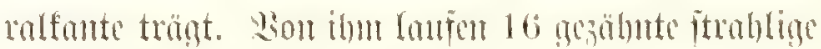

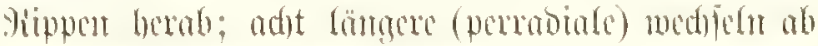

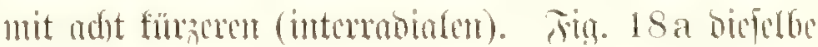

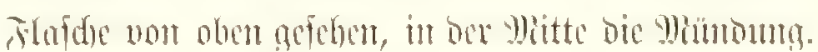

\section{Ving. 19. Lagena acuticosta (Reuss).}

Dis tuachige Gdate (nont $0,3 \mathrm{~mm}$. Durdmenter)

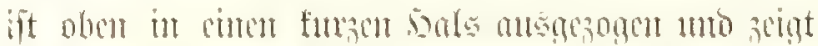

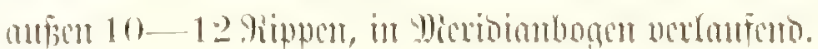

\section{Titi. 20. Lagena spiralis (Brady).}

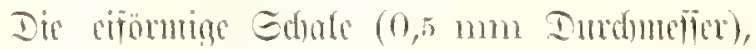

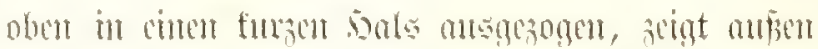

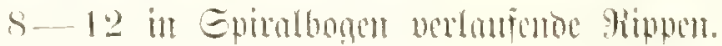




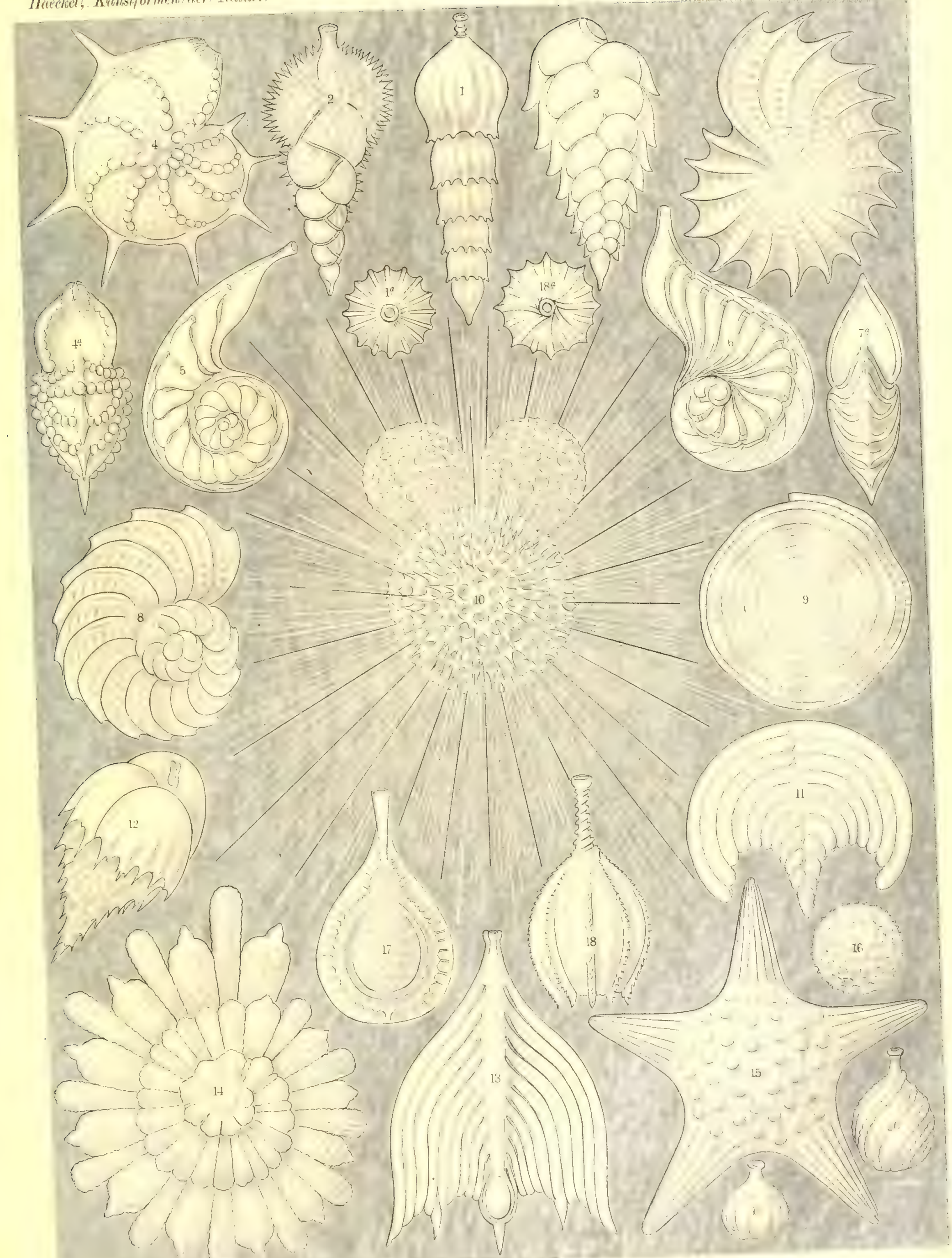




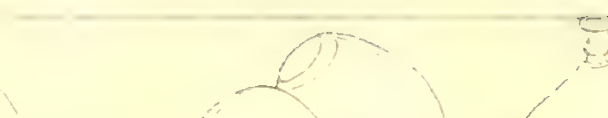

-

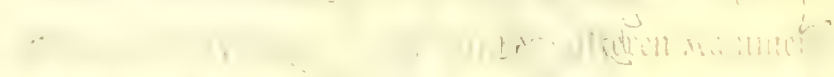
19 - int in $(1, \cdots)+2$

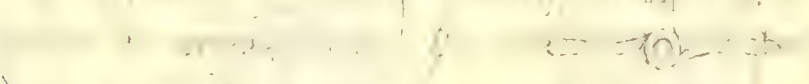

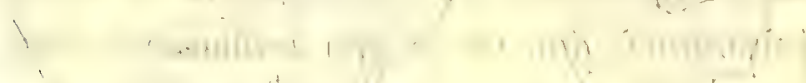

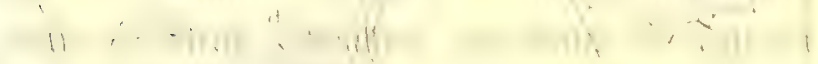
(1)

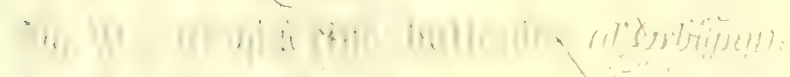

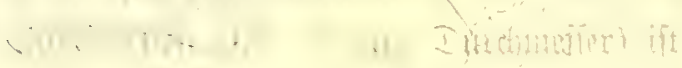

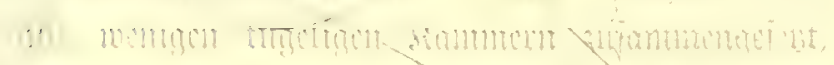

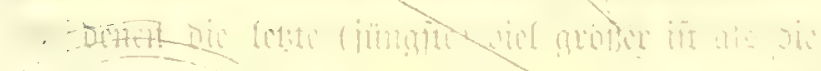

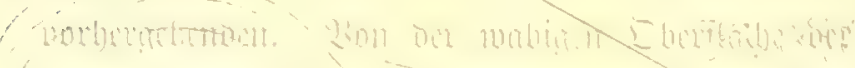

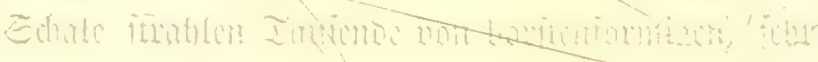

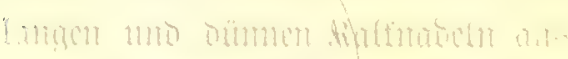

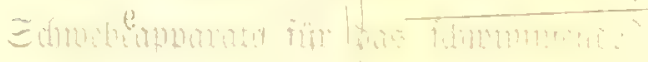

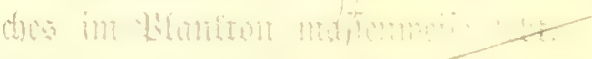

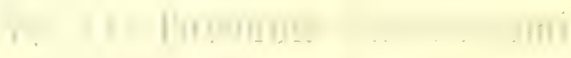

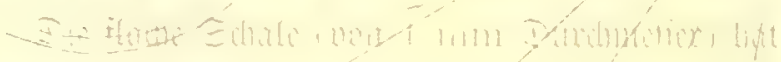

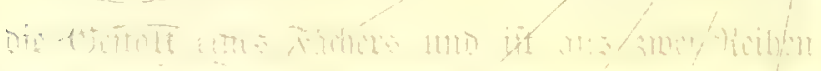

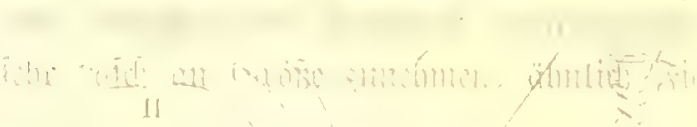

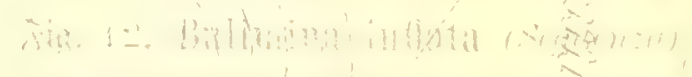

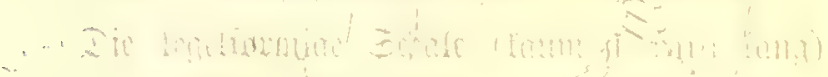

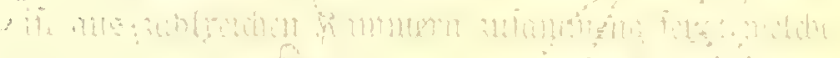

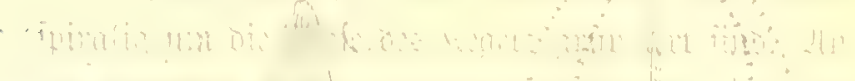

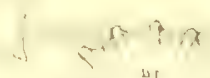

$$
\begin{aligned}
& 5{ }^{2} \\
& \text { 红, 近 } \\
& \because \text { “. yin }
\end{aligned}
$$

Inaining

(0) jingoris

(1)

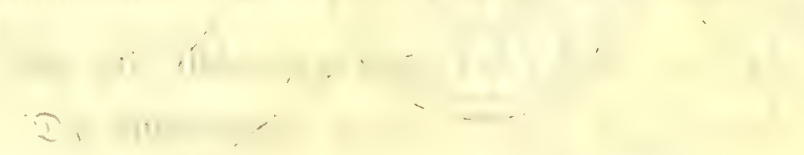

initien

$$
\text { 1 }
$$

E

Dinititit

A13

vit
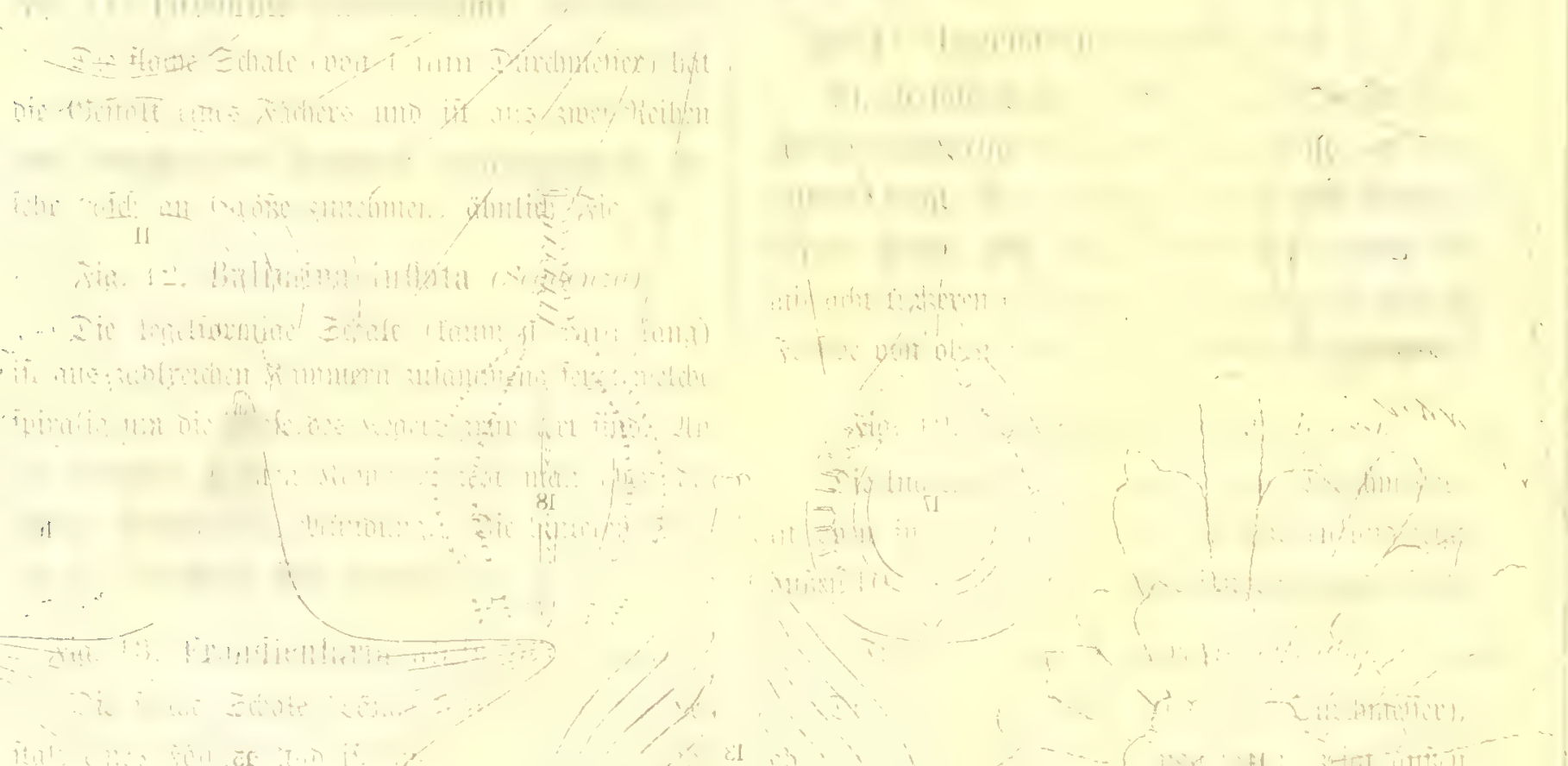


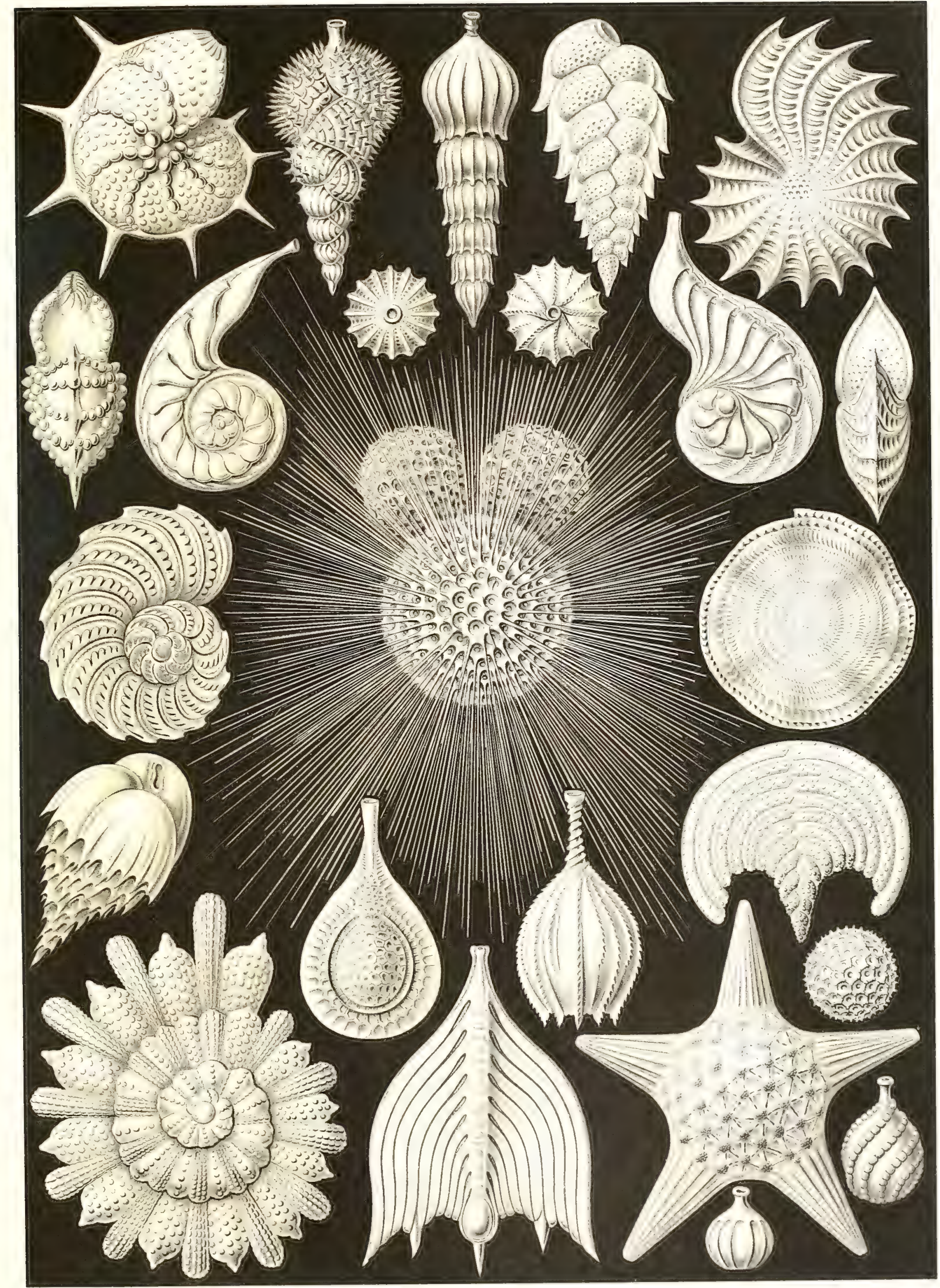

Thalamophora. - sicrutateraliztco 



\section{Ciliata. Homnuxlintre.}

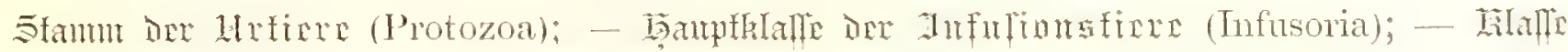

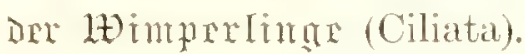

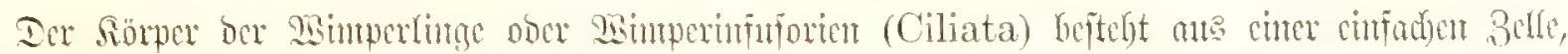

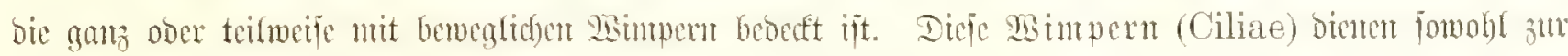

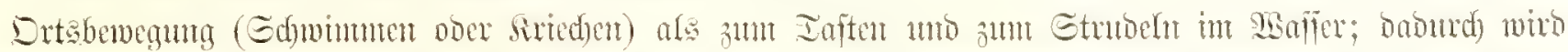

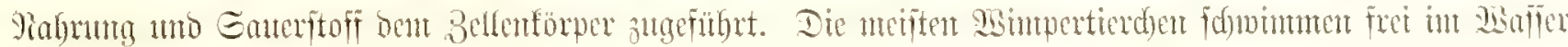

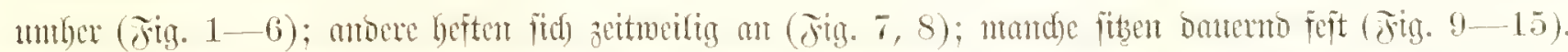

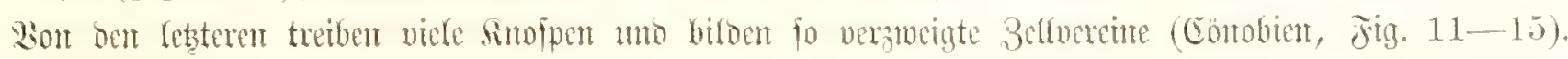

Fig. 1. Codonella campanella (Haeckel). Familie dex Tinfinnoiont.

Der idminnmente Bellenteib, welder untent ans

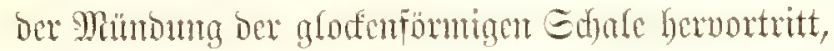

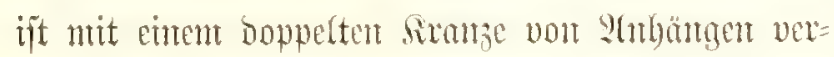
fehen, mit fongen simmerbanen anto mit furzent adoralent simperplättchen.

\section{Fig. 2. Dictyocysta tiara (Haechel).}

Familie Der Tinfimmion.

Die fegelförntige Garte Edyale hat fait dic Gies italt cimer päpitliden Iiara uno iit gitterförutig

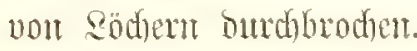

Jig. 3. Dictyocrsta templum (Haeckel). Familie Der Tinfinnoion.

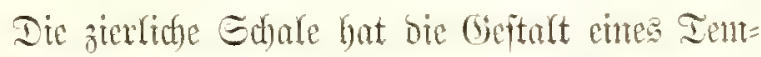
pels, bellen gitterförmig Durdjbrodiene Sinppel auf fïcben fofräg ftebentoen Gänten rubt; unten an ber

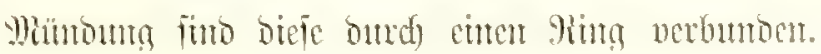

Ting. t. Tintimnopsis campanula (Claparète). Famile one Tinfintrinen.

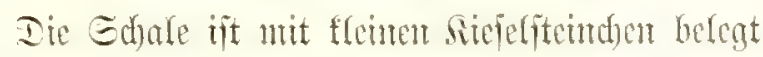
unt hat bie Gicitalt cinter idulanfur Gifode, beren Bando unten verbreitert iit.

\section{Jin. อ. Oyttaroecylis cistellula (Fot).} fauntie one Tinfumaion.

Dic Edjale trägt añ cintem tridfectöntigen Gals cirtent futgeligent fopr.

Jig. 6. Petalotricha galea (Haeckel).

Familie one Tinfunnisen.

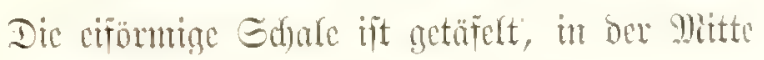
mit cinten Ming von Gteindent belegt, untent an Dex B)itnoumg tridsterförmig ermocitert.

Fitg. 7. Stentor polymorpluns (Ehrenberg). tautilie ber sfenturimen.

Der jarte, fod Iante fegelförmige Sörper biefes "Tronpctentierdjens" ijt unten ant Bobent ange= Geftet, oben in cine Muntufdectbe verbreitert; cime

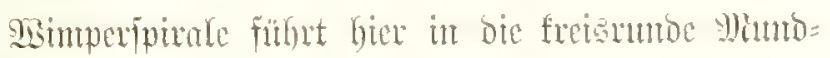
offrntung ber Belle. Die fömigen Gtreifen, welde

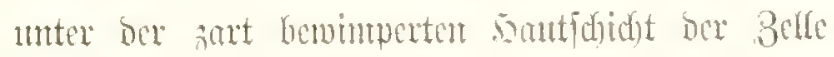

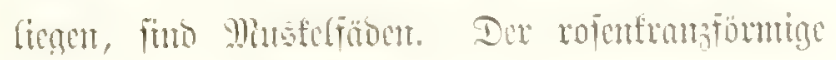
Siorper it Der Bellenterut.

jig. S. Stentor polymorphus (Ehwnherg). Familte one senfoxion.

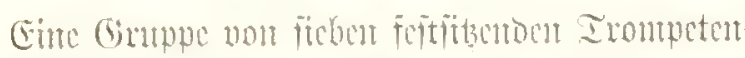

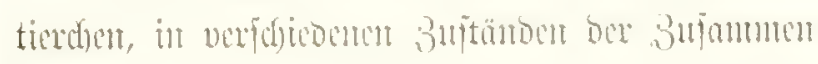
jichmom. 


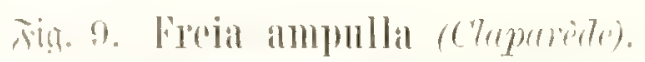

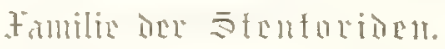

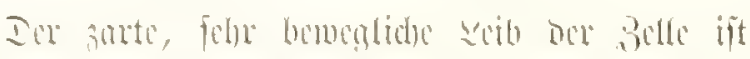

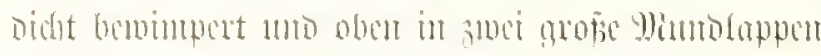

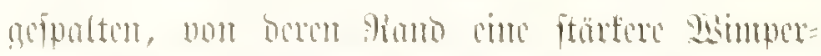

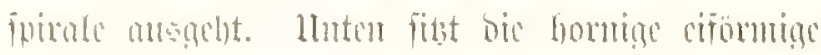

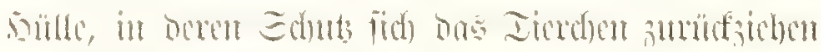

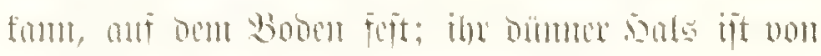

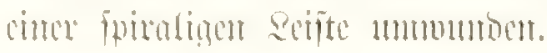

Fitg. 10. Vorticella convallaria (Ekmonberg). Familie one Burfichlion.

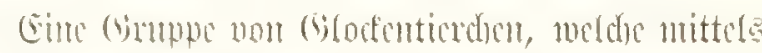

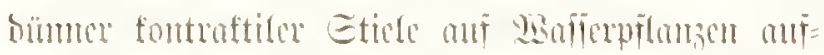

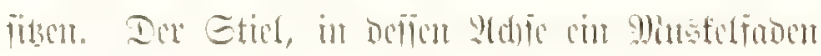

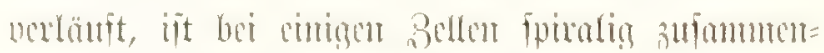

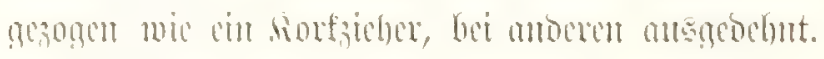

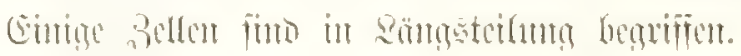

\section{Jin. 11 14. 12. Carehesium polypinum (Ekrentiery).}

Familie Der Donfierlion.

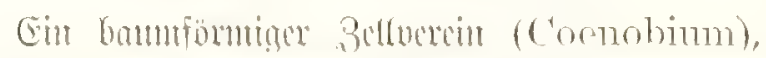

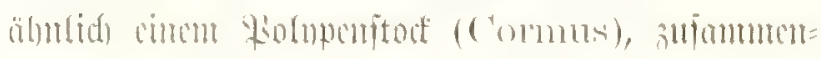

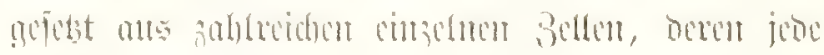

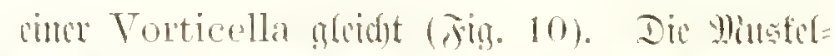
füben

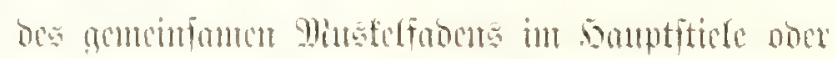

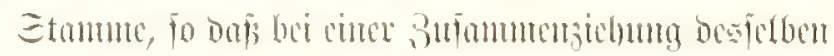

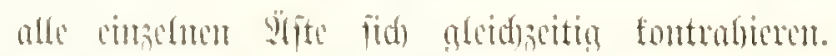

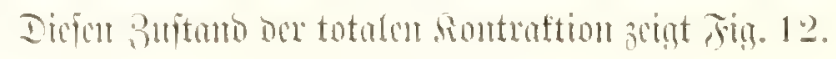

\section{Fin. 13. Epistylis flaricaus (Elmentery).

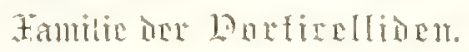

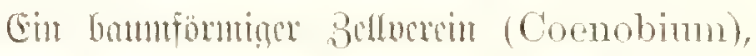

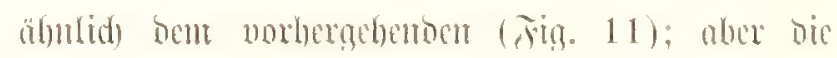
bümen, fteifen Etide ber. Bellen fino nidht bemenlide,

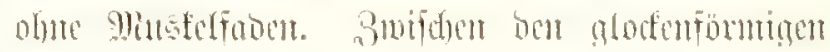

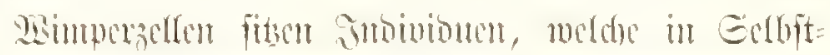

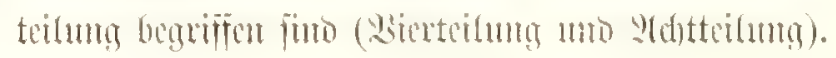

\section{Sig. 14 1. 15. Zoothamnimm arbuseula (Elwenberg). Familir ier Borfirelliont.}

Cin bammformtager Befluctur (Coenobium), äfunfich bem won Carchesium (Fitg. 11); aher ber

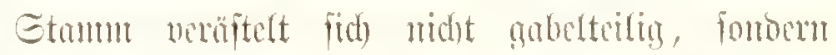

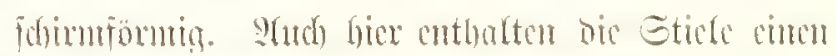

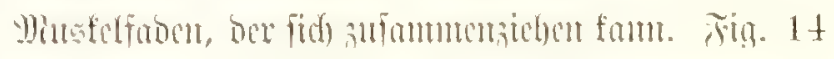

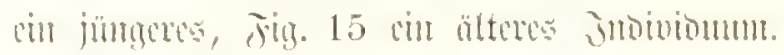




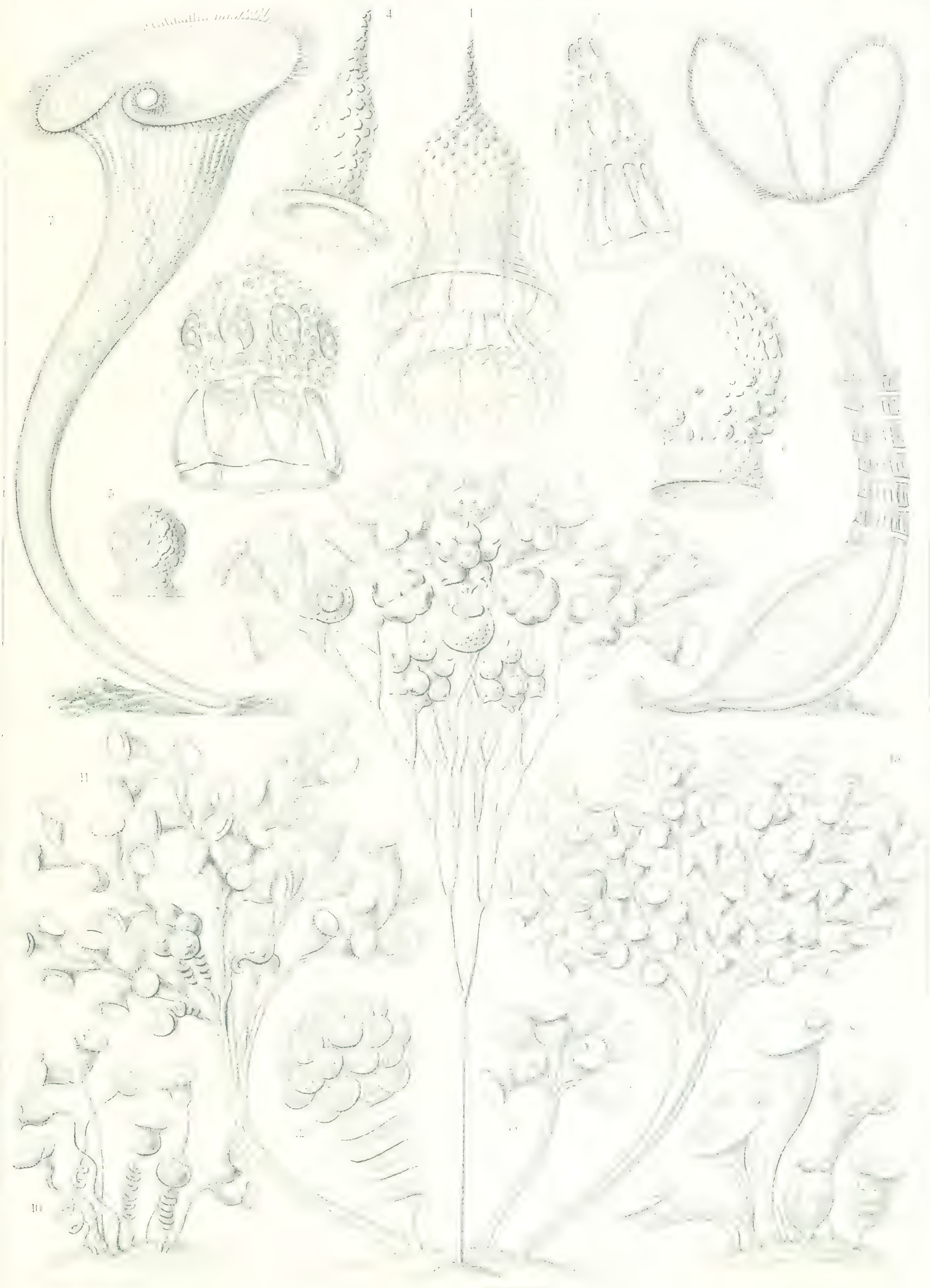

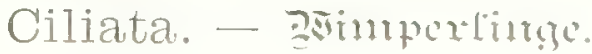


. 


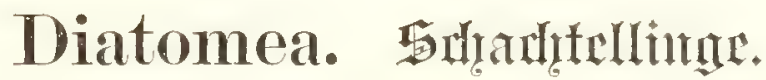

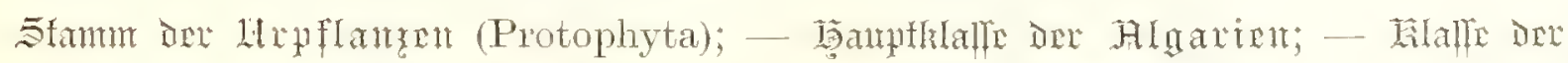

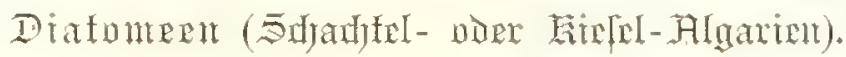

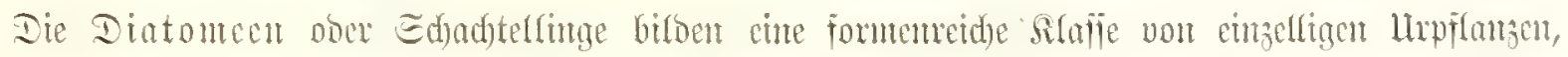

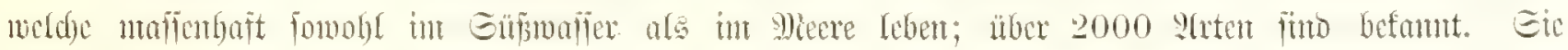

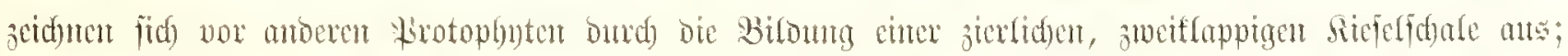

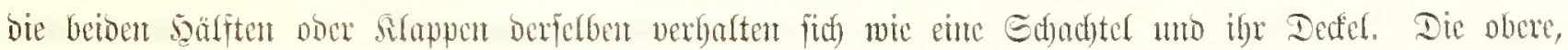

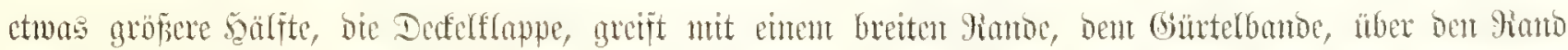

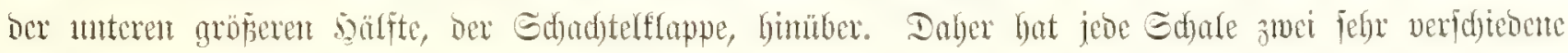

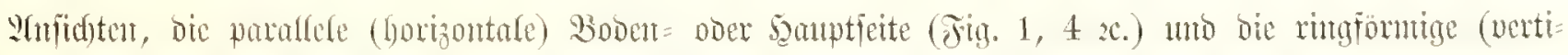

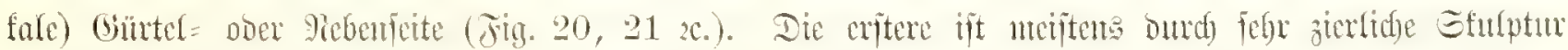

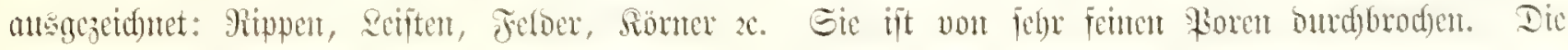

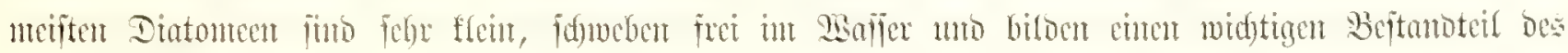

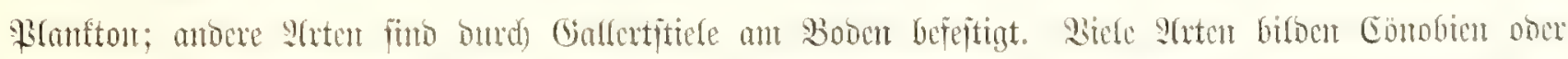

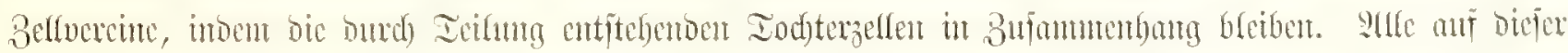

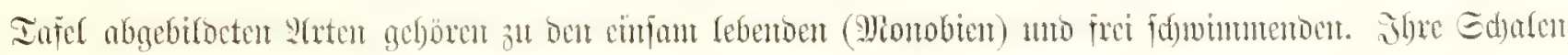

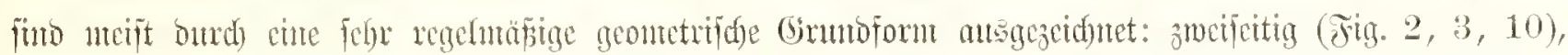

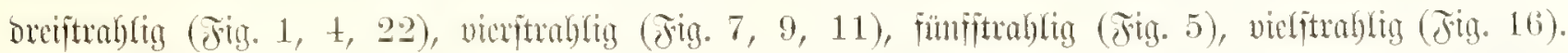

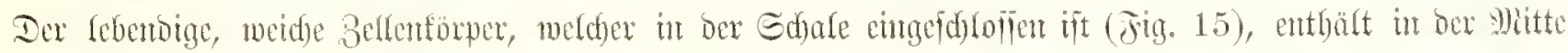

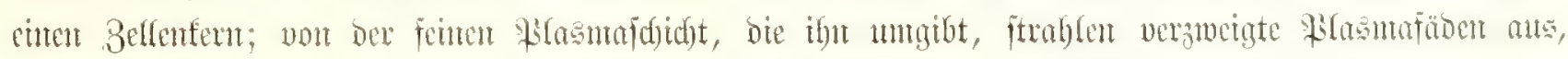

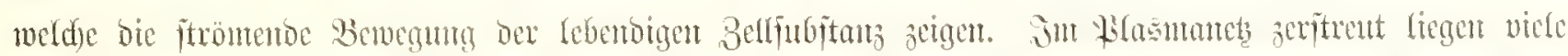

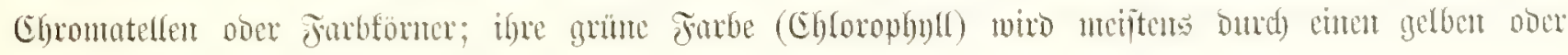
brumen Furbifoff verbect (Dintouriu).

Fig. 1. Triceratium digitale (Brun).

2. Navicula lyra (Elrenberig).

3. Navicula excavata (Greville).

4. Triceration mirificum (Brun).

5. Triceratium pentacrinus (Wallich). 录gl. Firg. 21.

6. Actinoptychus constellatus (Brm).

7. Anlacodiscus mammosus (Greville).

8. Navienla Wrightii (Afeure).

9. Auliseus crucifer (Brun).

10. Biddulphia pulchella (Gray).

11. Aulisens craterifer (Brun).
Jig. 12. Auliseus mirabilis (Greville).

13. Aulacodiscus Grevilleams (Noman).

14. Surirella Vacraeama (Grecille).

15. Denticella regia (1Lex Schultze).

16. Asterolampra eximia (Crrecille).

17. Actinoptychus heliopelta (Bren).

18. Plagiogramma barbadense (Brum).

19. Pinnularia Mïlleri (Hueckel).

20. Biddulphial gramulata (Smith).

21. Triceratium pentacriuns (Hallich). Wigl. Ting. 5.

22. I'riceratium moronense (Grocille). 



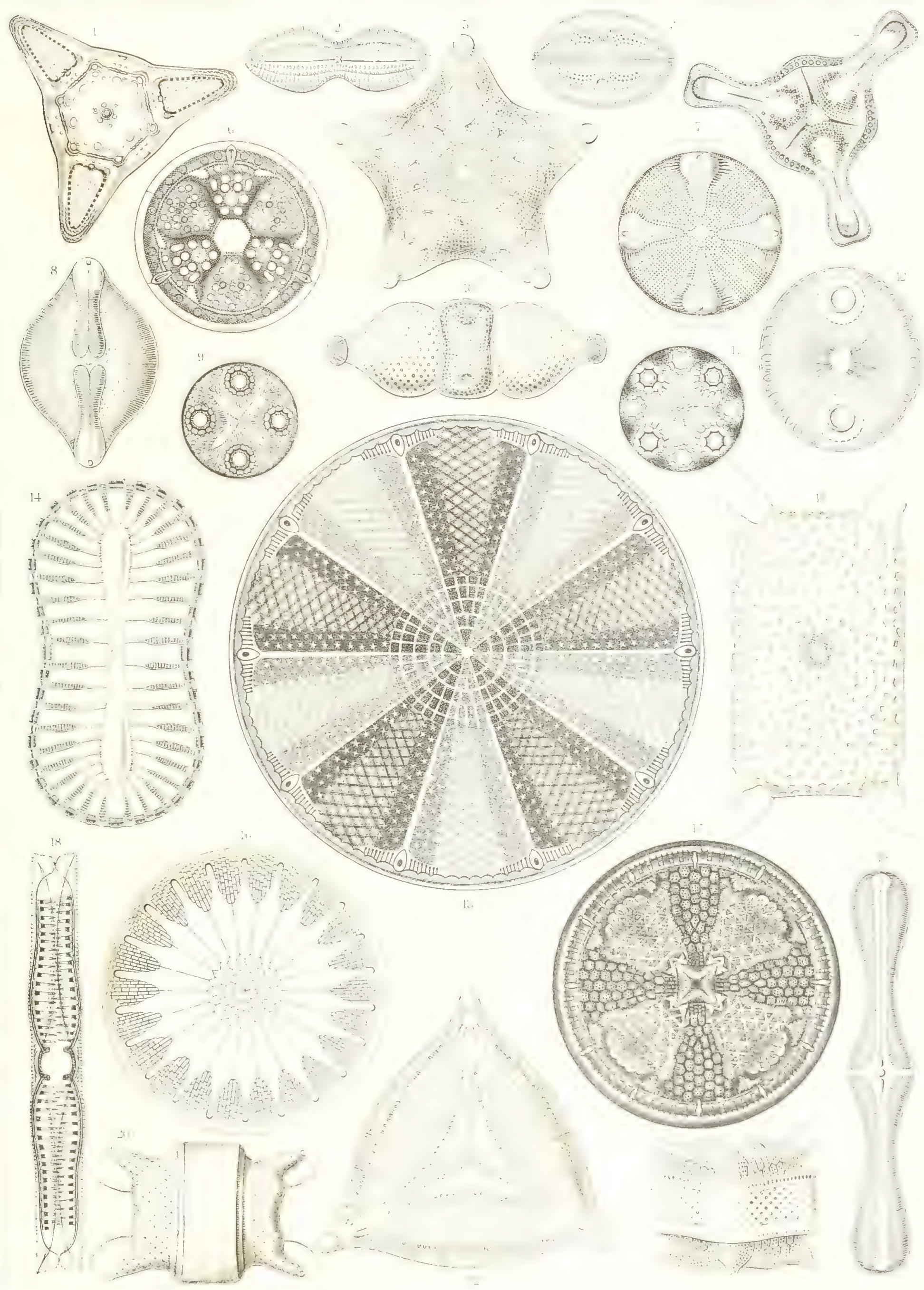

Diatomea. - sodictitellintuge. 


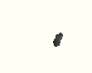




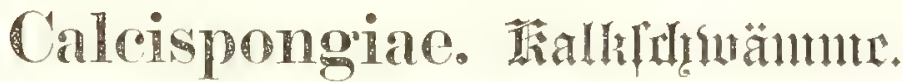

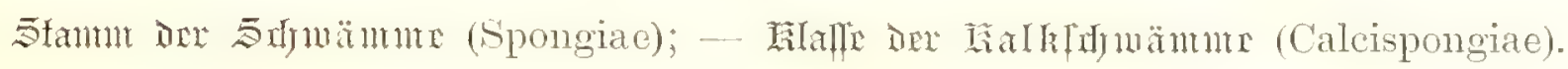

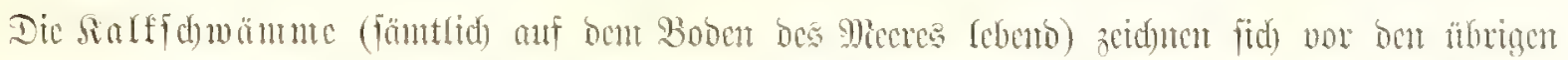

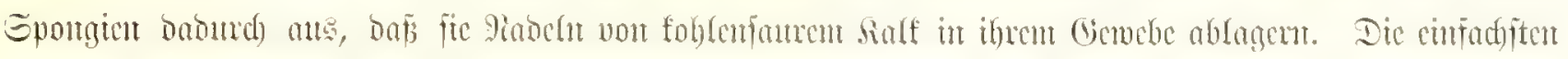

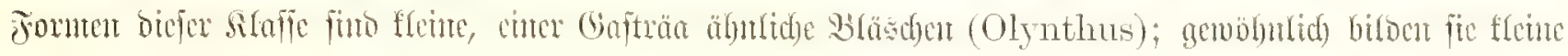

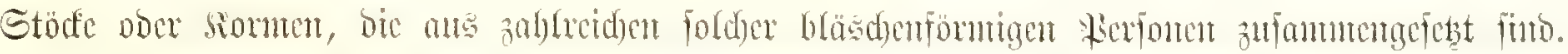

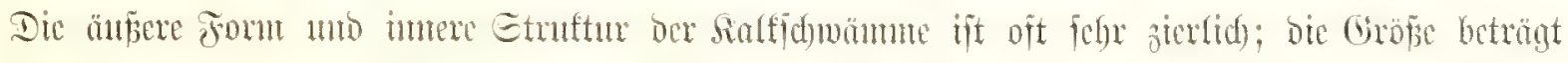

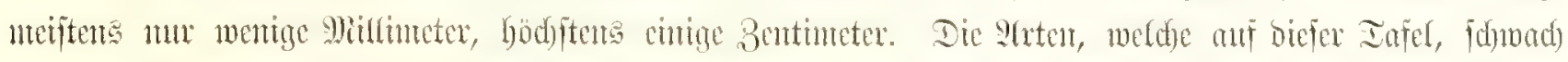

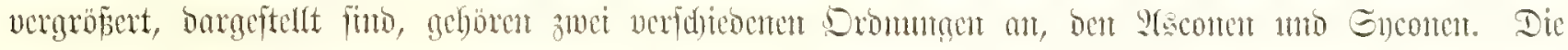

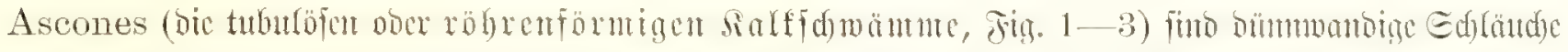
mit poröfer

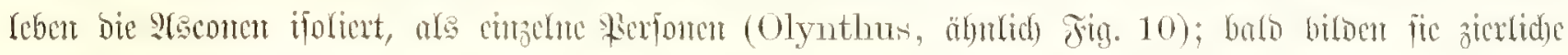

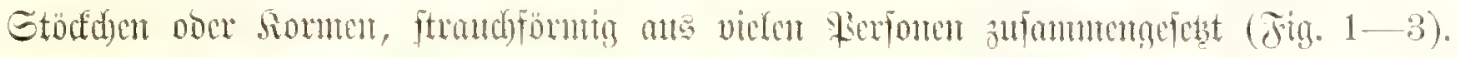

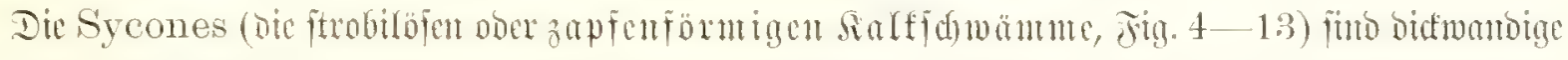

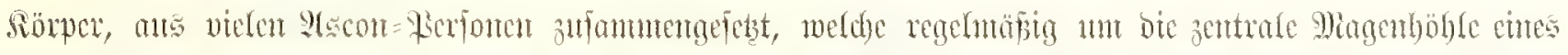

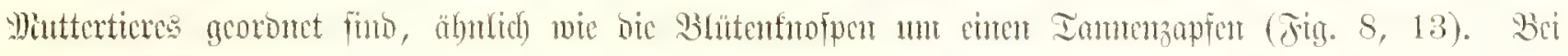

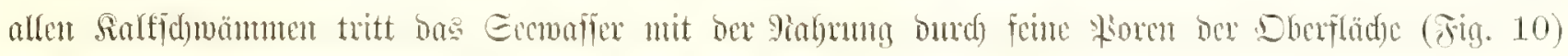

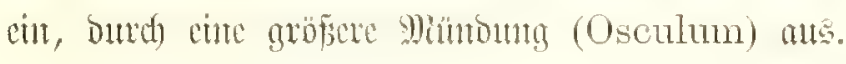

Jig. 1. Ascandra pimus (Hueckel).

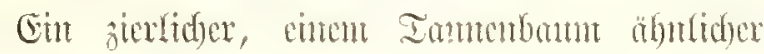

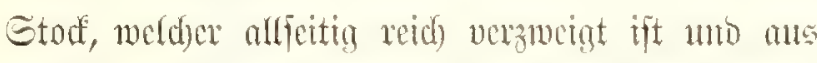

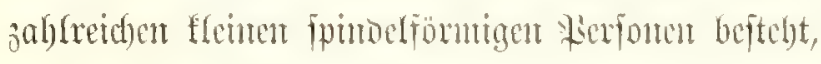
jeoc mit cinter Mimnooffrumg.

Fig. 2. Ascandra sertularia (Haeckel).

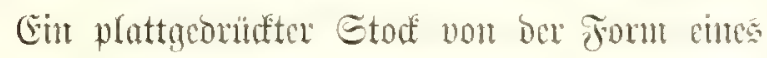
Doppeltgeficoerten Blatte: Dic zweizerligen, in cumex

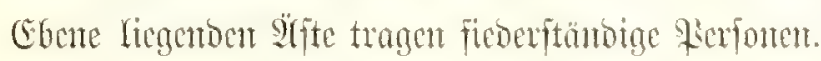

Fitg. 3. Ascilla gracilis (Haeckel).

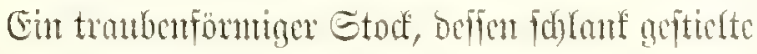

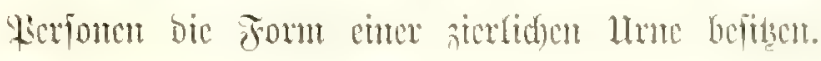

\section{Fitg. 4, 5. Syculmis symapta (Haeckel).}

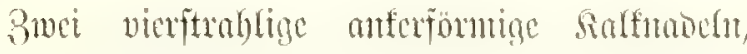
weld)e sum Serantem des Encou=Edhwanmes im Ed) (antute bes Micerestbobens bicnen.
Fig. 6. Syeurus primitivus (Haceled).

Eir forbenfömiger Sycon (ntit Bupfontant

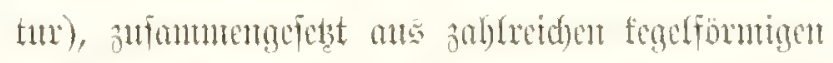
Sd)lätden, wetde in bie gencinfante Bentrathöhle rabial muntoent. Diefe öfinet fird) oben Burde cine Mäntoung (Oscuhmo). Sut ber Mitte ift cin Ethat

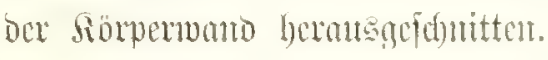

Jign. 7. Sycodendrou ampulla (Hacekel).

Eir tranbentöntiger Etod, Dor ans ettent

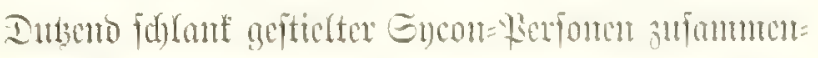

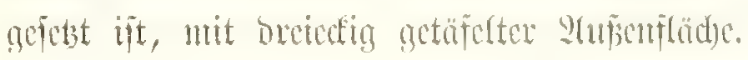

Fig. 8. Syearimm clegans (Hueckel).

Ein ciföminger Encon mit regehntäpinger Bapfon:

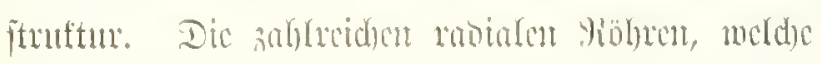
be Syeurus primitivas (Tin. 6) getremet beteben,

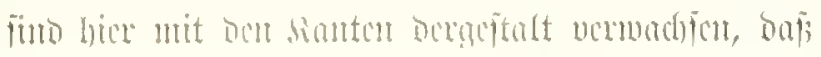

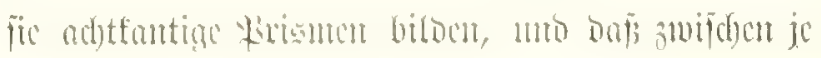




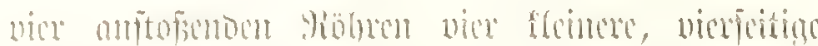

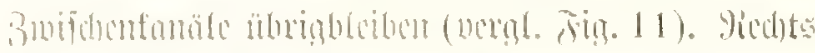

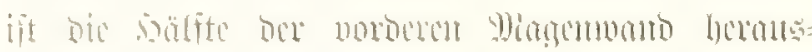

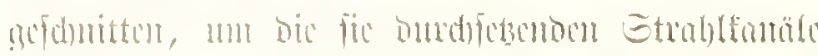

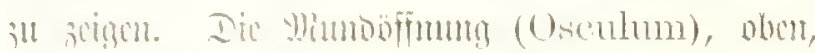

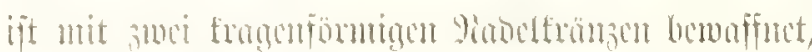
cimen horisontalen mo cincur vertifalen.

\section{Fin. 9. Sreoptis quadrangulata (Huectid).}

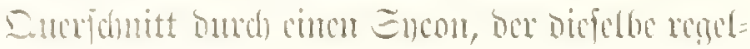

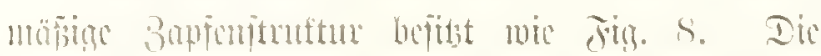

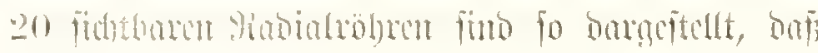

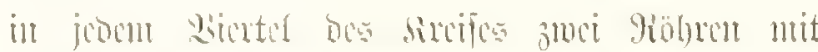

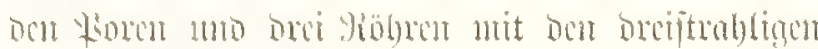
sialfunded widecimen.

Fing. 10. Nycamblat compressal (Haceticl).

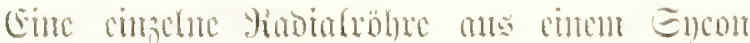

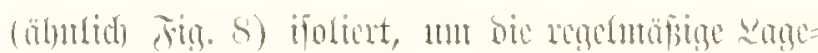

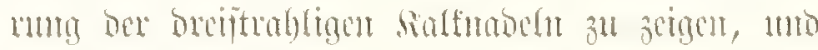

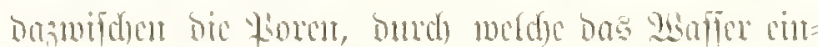

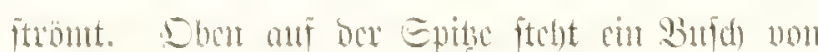

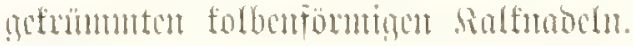

Fin. 11. Sycatrium elegans (Hecetert).

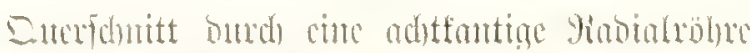
bes Encon Fin. S, ftarf verumbert. Bubifon ben

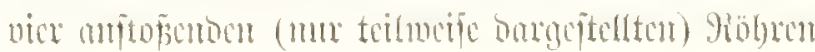

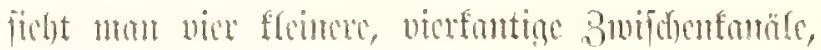

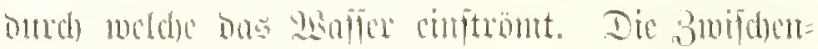

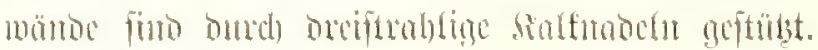

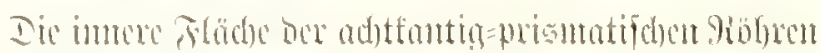

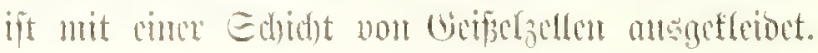

\section{Ting. 12. Syealtis perforata (Hecelel).}

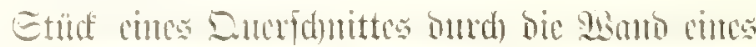

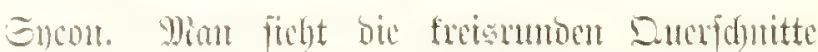

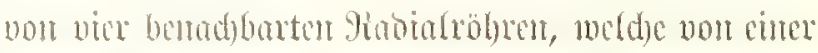

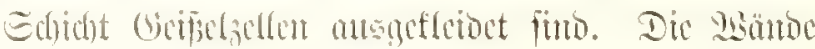

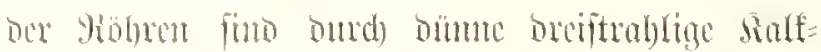
moda geftutst; Der vierte Etrahl fprimgt fret in bie

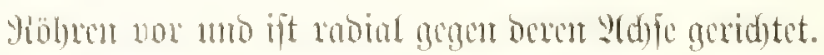

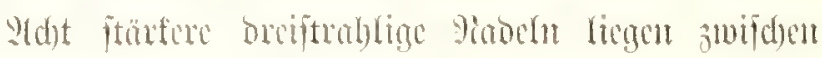

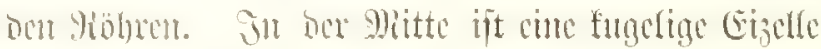

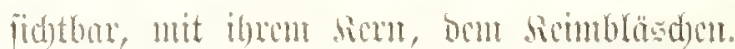

\section{Fitg. 13. Syeetta strobilus (Hackel).}

Ein ciföntiger Encon mit regehnäpigen 3apfon=

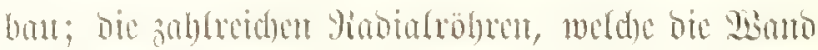

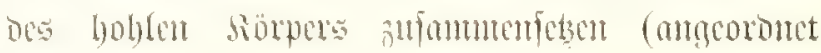

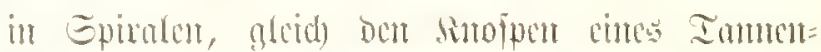

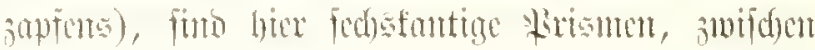

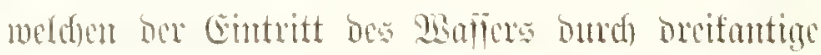

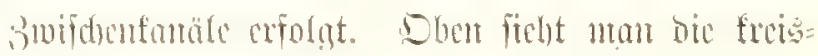

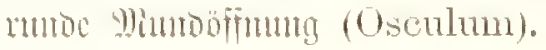




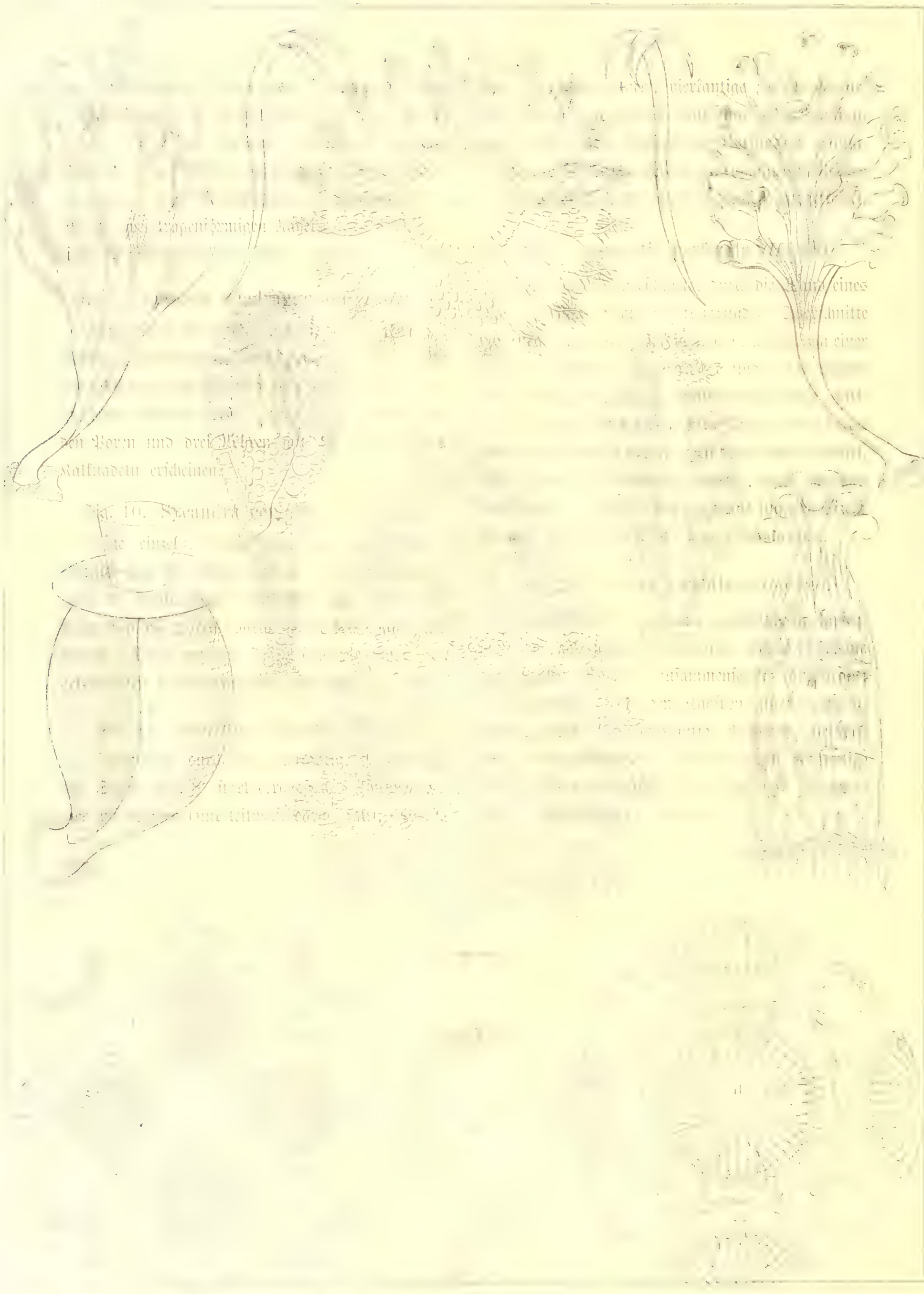




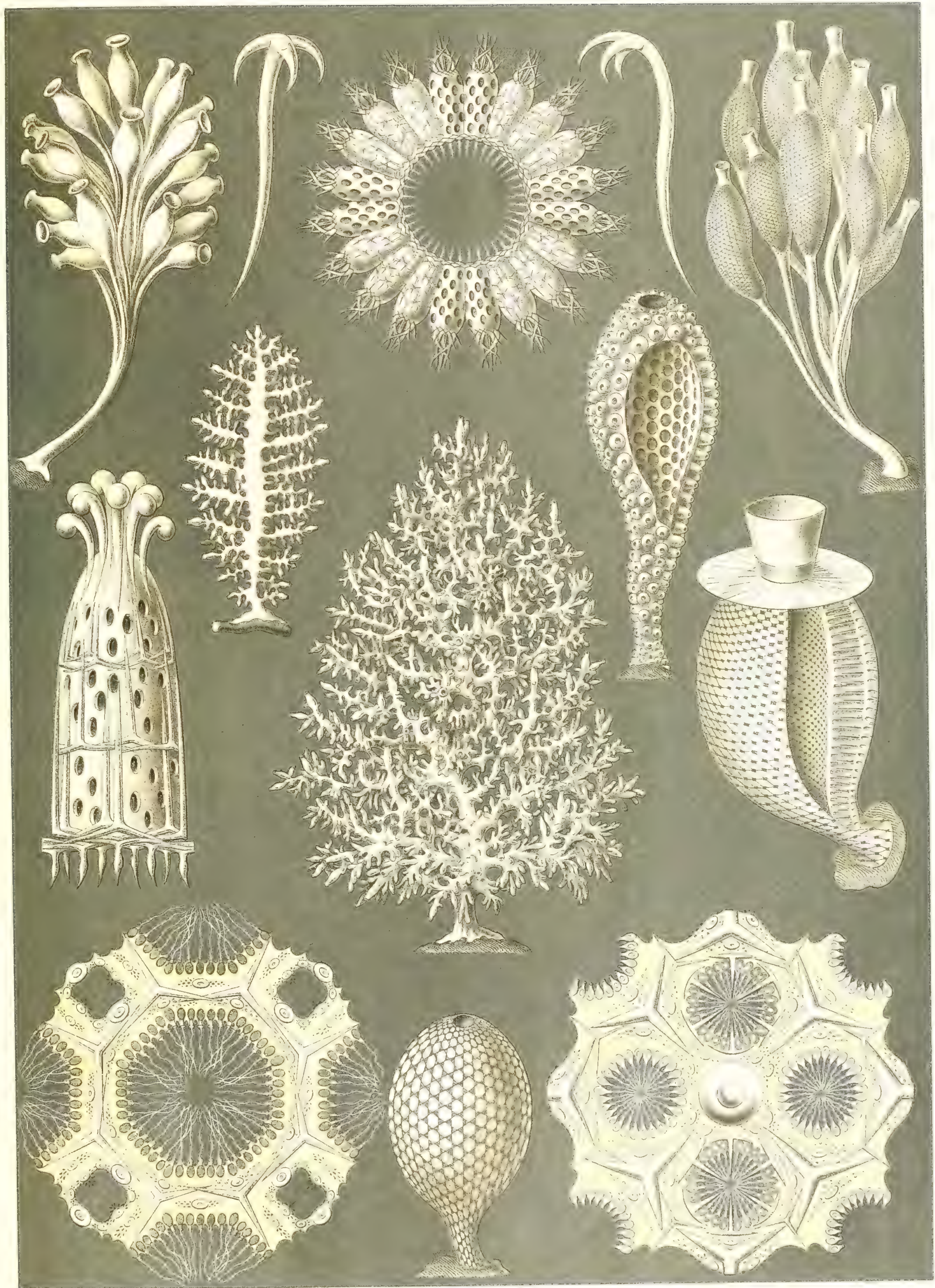

Calcispongiae. - Sicrlitimuämmus. 


\section{Tubulariae. Rathrumuturtent.}

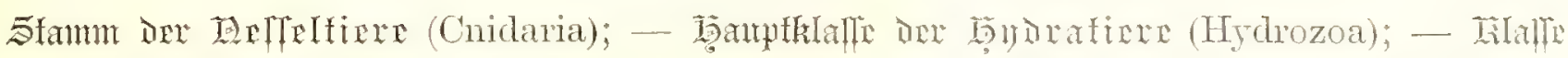

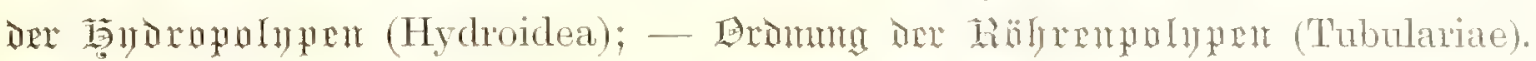

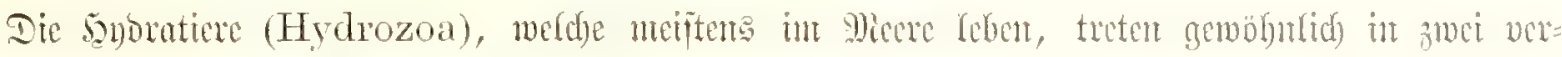

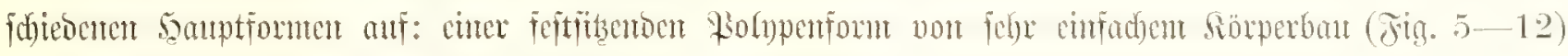

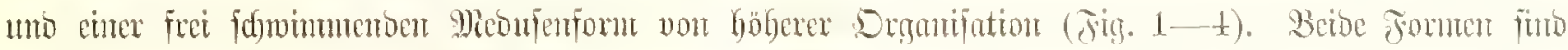

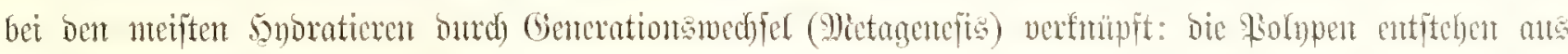

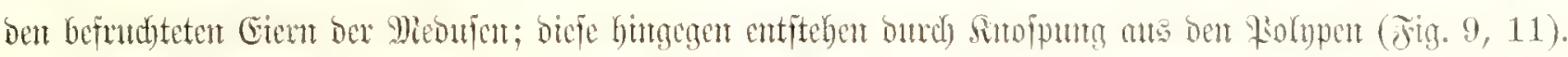

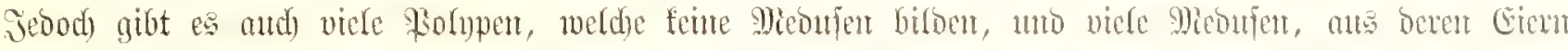

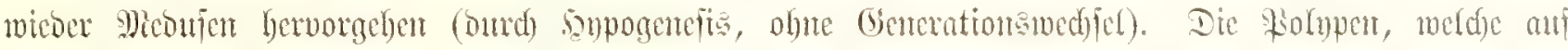

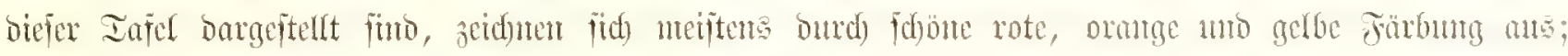

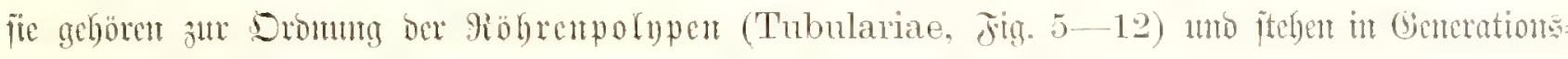

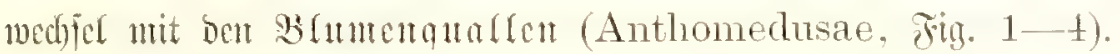

Fig. 1. Codonium codonophorum (Haeckel).

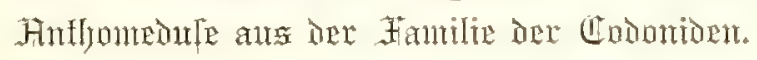

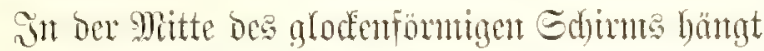
ber ciförmige Miagenfad herub, vou befien Grumbe vicr Bindialfantäle zum Gdjimmanto geben. San Dicfent fitsen vier anfgerollte Fantgräbent ober Ient=

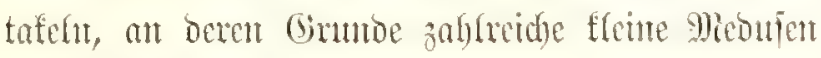
burd) Sinopintg cutitchert.

\section{Jig. 2. Dipurena dolichogaster (Haeckel).}

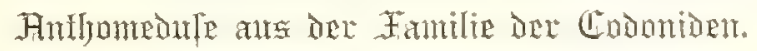

Sn ber Mitte des ciförntign Gujume bäntgt bas felde lange unt beweglide Miagentohe herath,

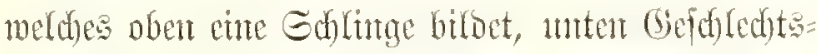

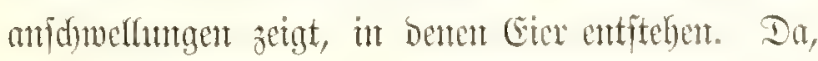
10o bie vier Ientafelt von Edjimtranto abgeben, jithen vier Altgen. Der obere Ietl ber Ientufelnt iit feulenförmig, bex untere Ieil nit Peffefringen befert.

Jing. 3. Sarsia tubulosa (Lesson).

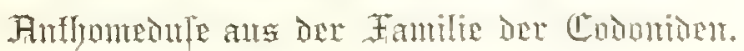

J̆t der Mitte bes cifömtigen Gdhirm hängt das fehr Canne Magentrobr herab, in beffen

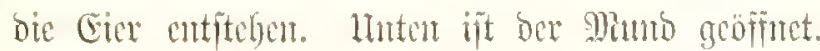

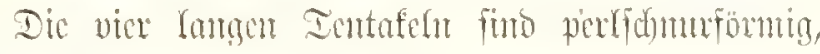
mit Peiffelfutópfen befebt.

grign. t. Sarsia tubulosa (Lesson).

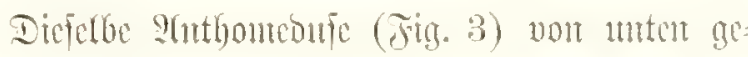
Fehen, ftart sufanmentgezogen, nad) Entfornum bes

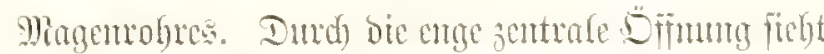

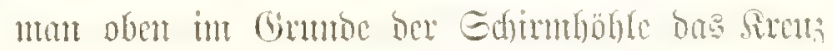

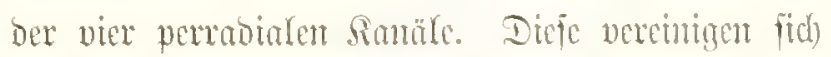
unten it bent qutabratiface Riungfontal, ant befien vier perrabialen Esten bie vier slugen liegen. Dis ad)t geffeocrten släter find bie ftorf fontrahierten Munfert ber Eubmtbrella.

Fitg. 5-7. Thamnoenidia coromata ( L. Agassiz).

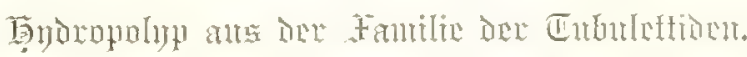

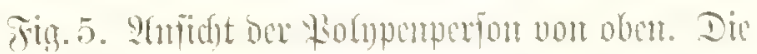

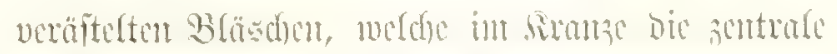

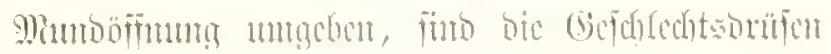

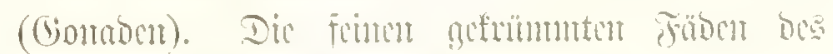

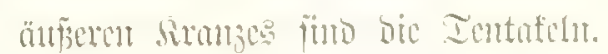

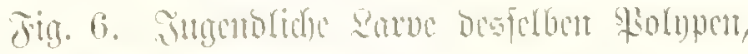

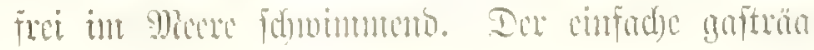




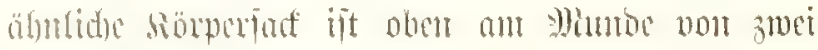

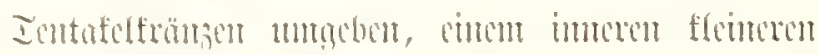

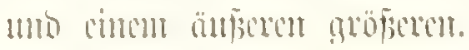

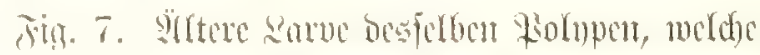

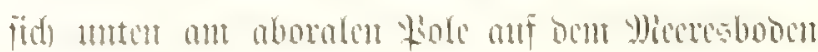
fertucuedst bat (Actimula).

Tig. S. Monocaulus pentulus (Alman).

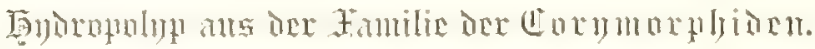

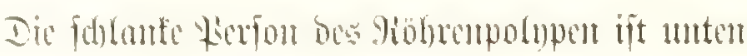

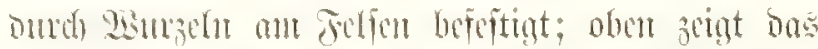

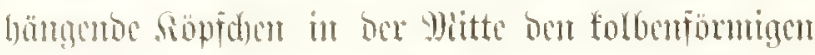

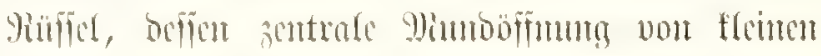

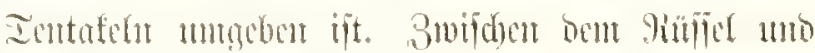
Den angebreteten stranje ber gebogenen Ientafeln

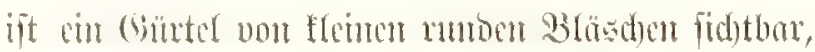

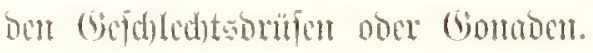

\section{Fin. 9. Corymorpha nutans (Sars).}

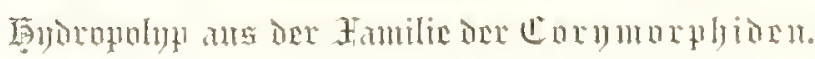

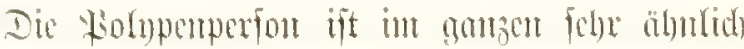

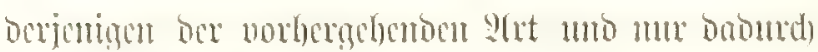

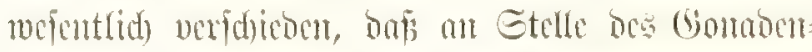

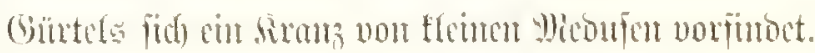

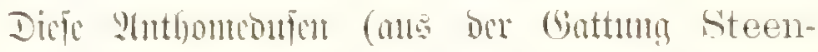
strupia, mit me cincur Ientafel) mtiteben aus bom Whagen des Riobrempolupen omd Sinofpum.

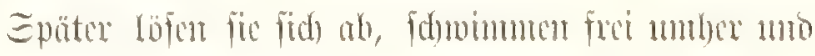

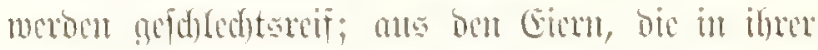

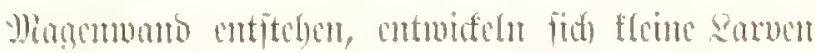

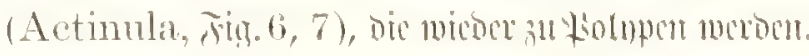

Fitg. 10. T'ubuletta splendida (Harelin),

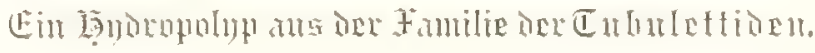

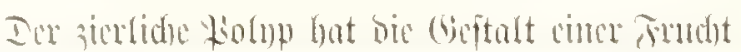

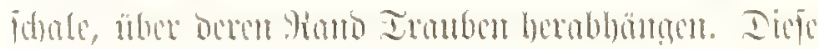

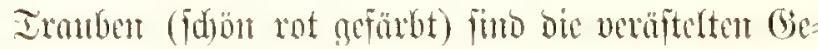

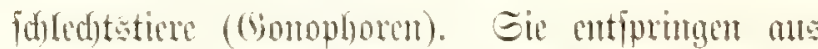

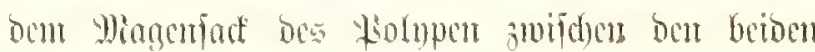
sirünzen von Iantafeln obre Frangfäben. Dex obere

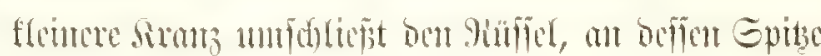

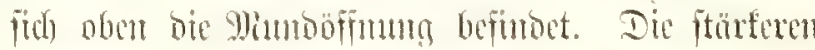

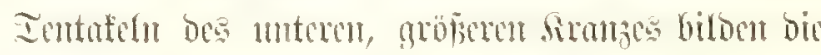

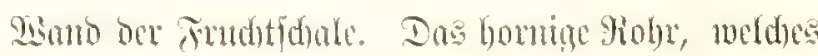

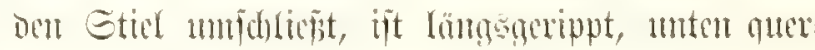

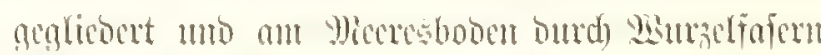
beficitigt.

Fig. 11. Syncoryne pulchella (Allmun).

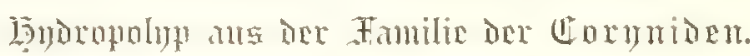

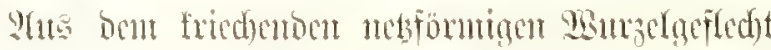

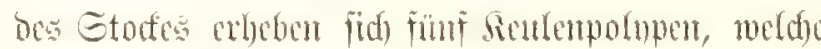

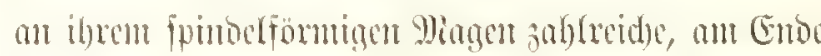

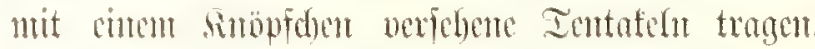

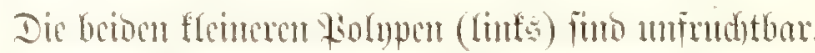

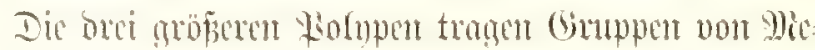

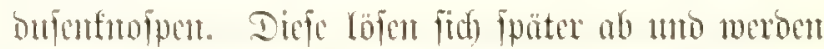

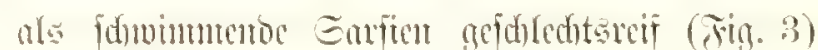

Fig. 12. Uyriothela plurgia (Fabricius).

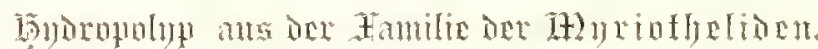

Der arofie samptpolup fint untur aul bent Mecresboben feit mittel cincr cifömigen ftad)efigen

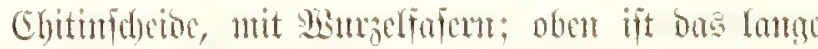

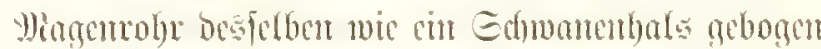
mo mit flemen gefuopiten Icutafeln belest; an ber

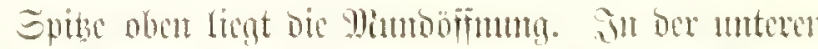

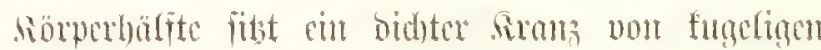

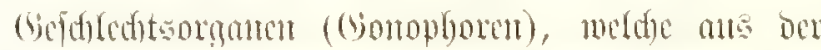

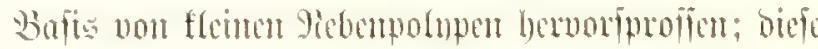

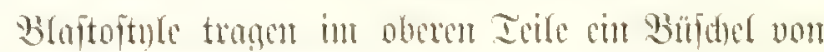
getröpiten Ientateh. 


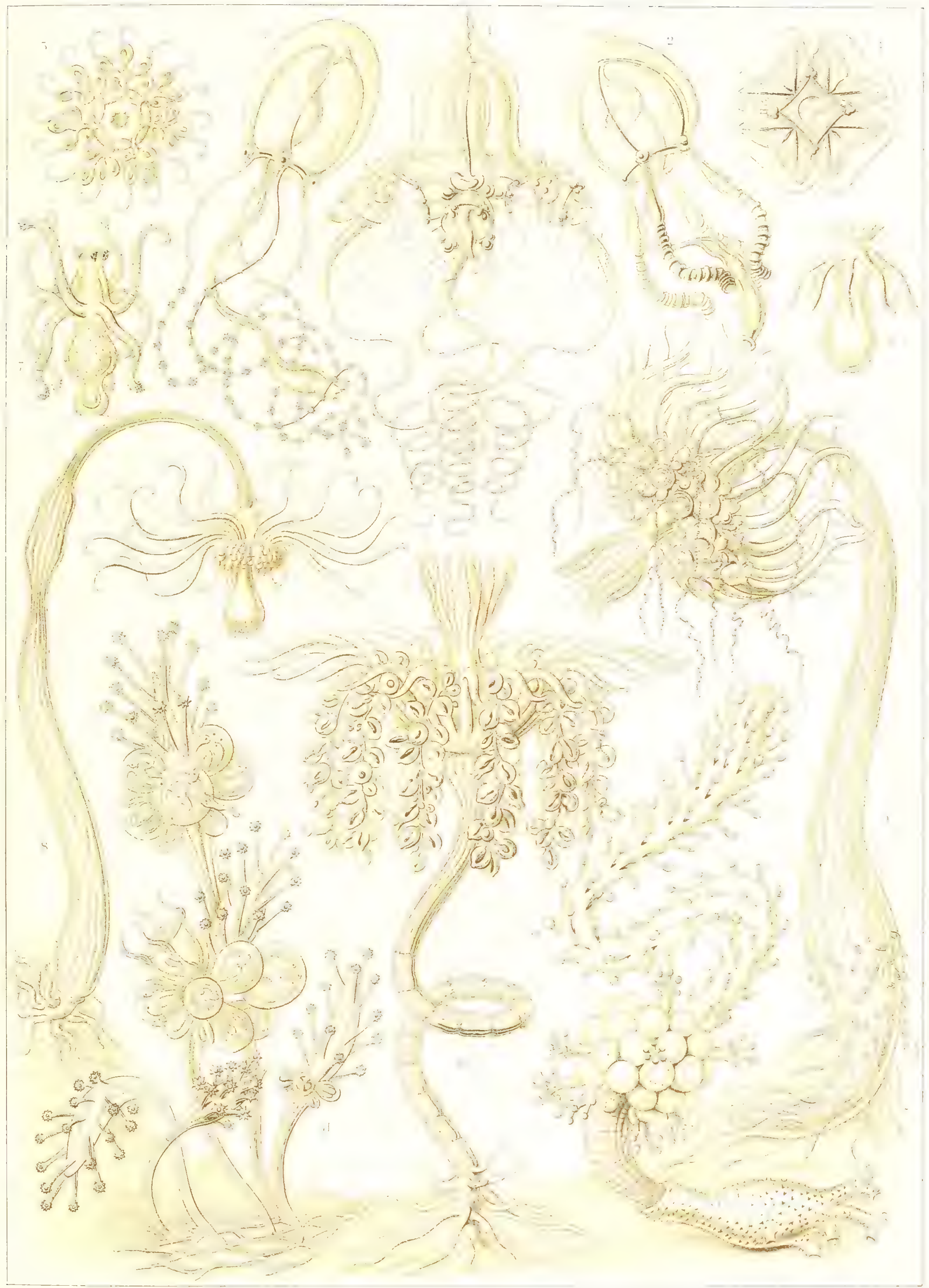

Tubulariae. - כistinentrontror. 



\section{Siphonophorae. Statatinnallen.}

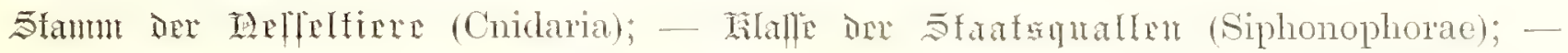

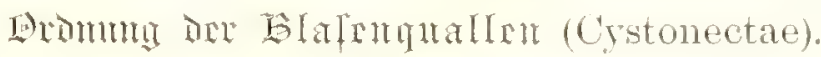

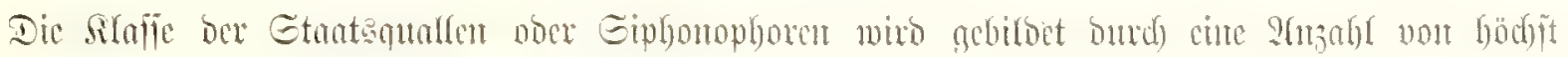

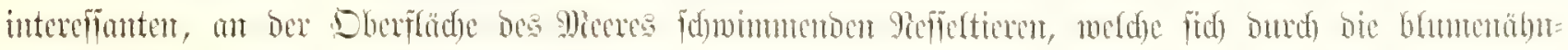

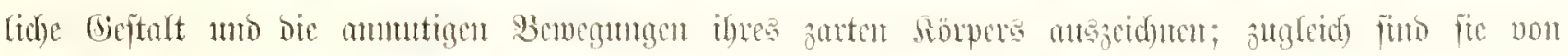

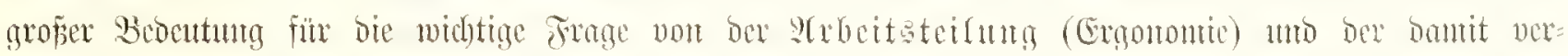

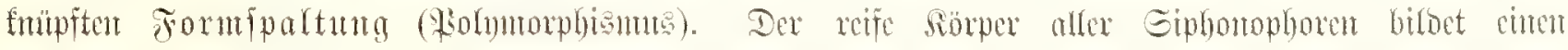

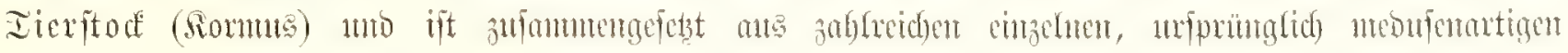

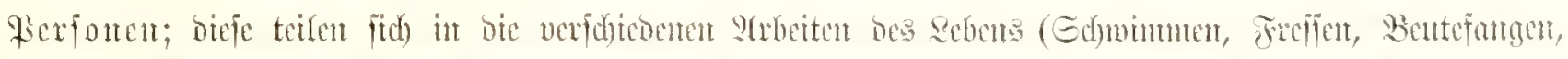

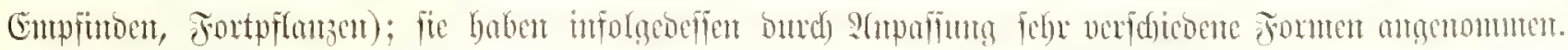

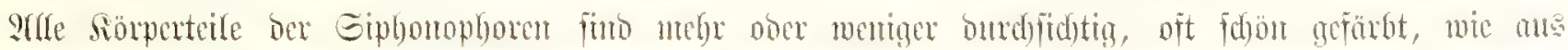

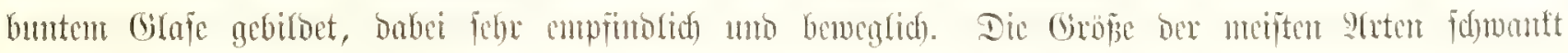

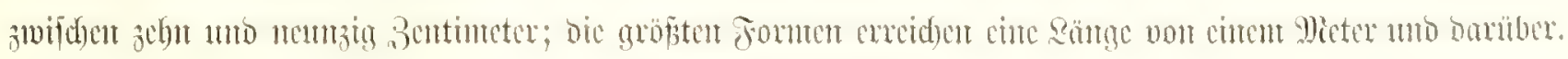

\section{Fing. 1. Epibulia Ritteriana (Hacekel).}

(Eine Cujtontefte ans bent Simbifd)en Dzent (Belligenuma auf Eenton). Y(at ber unteren Geite Der

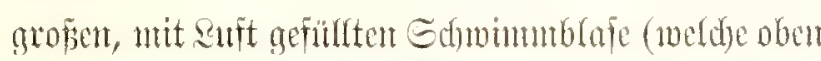

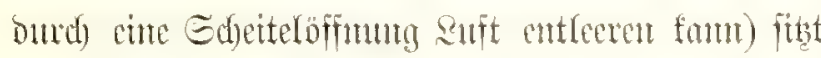

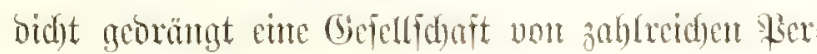
jonen, von vier verfojiconen Formen. Inmittelfor

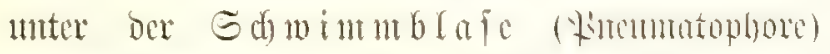

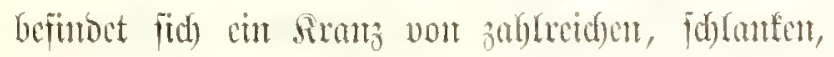
rofaroten Iaftern (Fialponten); jebe von diefen

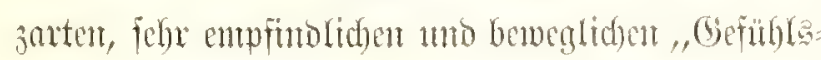
perfonen" zeigt ant ber Dberfeite ber Eptize cint rotes Stuge (Deelfus). Luterbalb berfelbet büngen int Der Mlitte vier fange rote Irmben berab, sulfant mengejebt ans zablreiden rumblidgen Beeren, Den

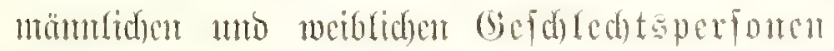
(Gonophorem). Dic jecteg gröperen getben Iicre find bie Grep̃perfonen ober Gaugrögren (Siphonent).

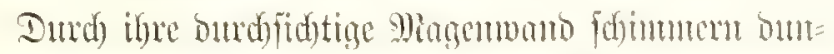

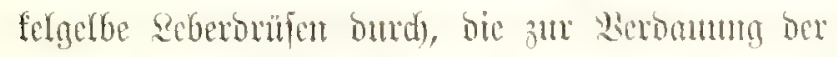

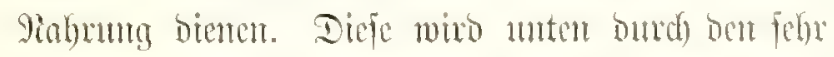

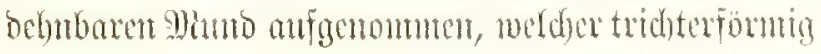

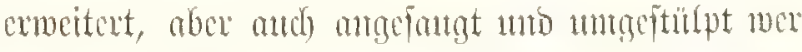
ben foum. Bunt Fongen ber Bente bienen bie fantgen, febre bervegliden Fangföben (Ientafent); je enter futht ant Grumbe jeoer Sangröhre. Die Iut= tafeln tragen cine Meibe von Fenten Geitenfäden

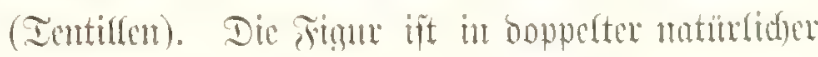

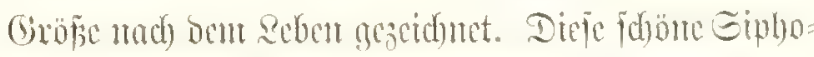

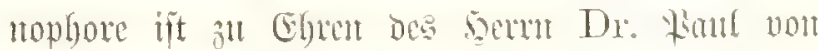

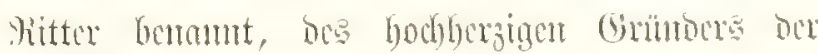

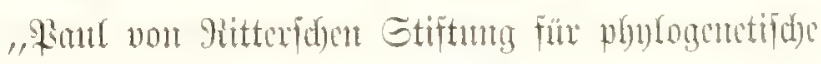
Boologie" ant ber Intwerfität Senta.

Jig. 2. Cystalia monogastrica (Haeckel).

Eure Cuftontefte an beut Smbifdent Dzent (Welli gemma, Eenlont). Diefe freme S(rt ijt Fene äburtich

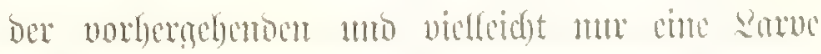

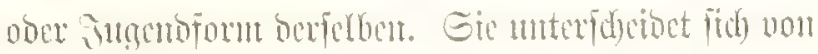

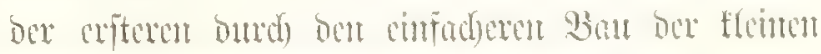

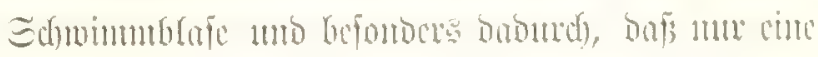

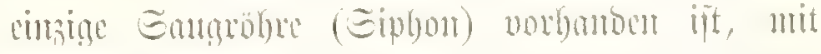

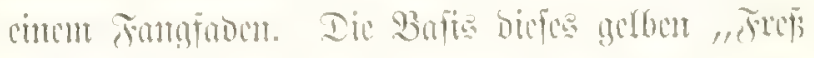

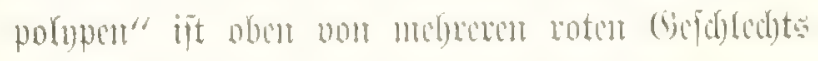

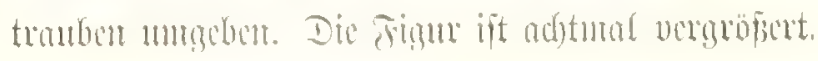


Fig. 3-6. Salacia polygastrica (Haccket).

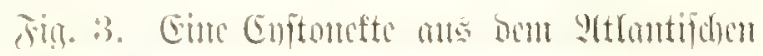

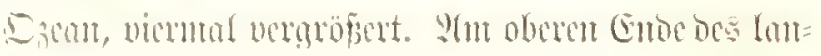

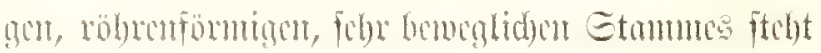

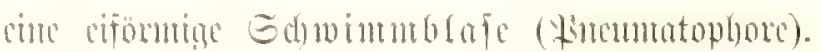

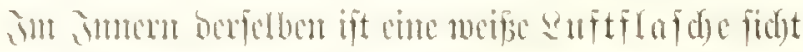

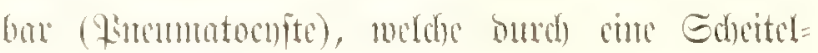

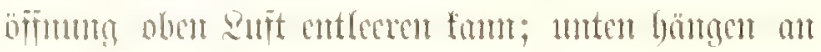

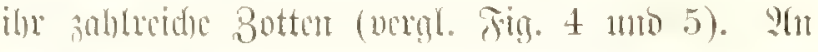

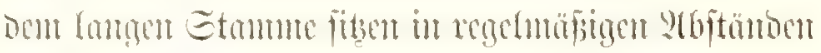

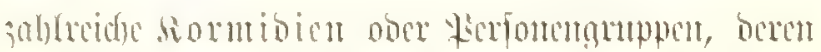

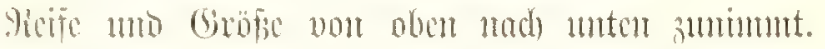

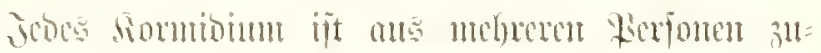

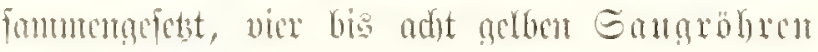

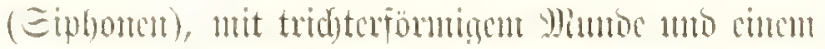

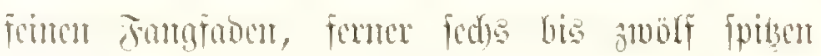

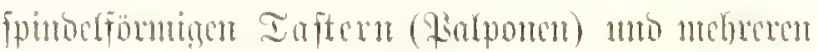

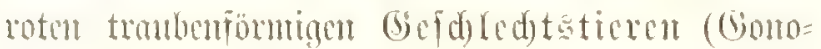
phorent).

Fig. 4. Gonummblafe ber Salacia, in ho=

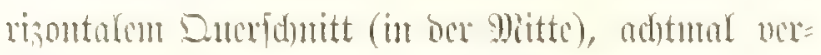
merisert. Die zentrale sufftfafde ift nont adst Botton=

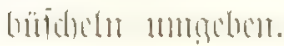

Tig. 5. Gdyimublafe oer Salacia, von

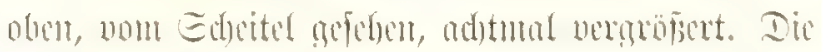

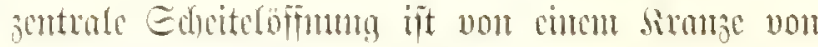

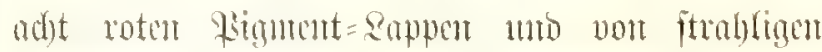

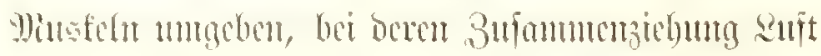

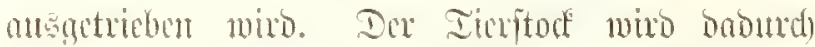
fohnerer und font in

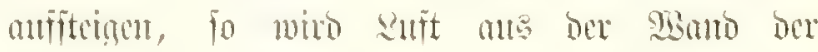

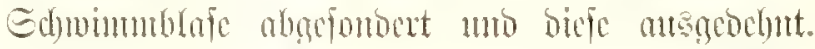

Big. 6. Ein Rormionu ber Salacia. Dic

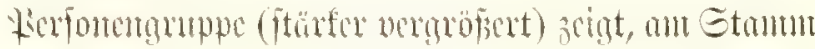

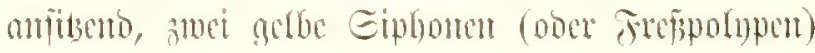

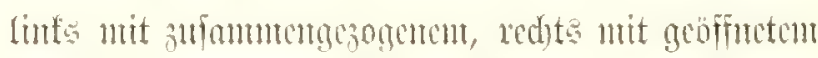

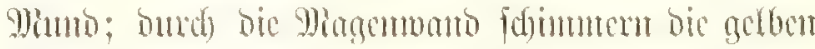

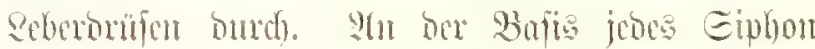

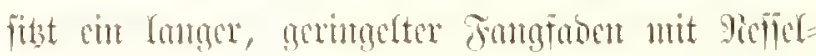
fnöpfen (Ed)utwaffen). 3mitaen betoen Eiphonen

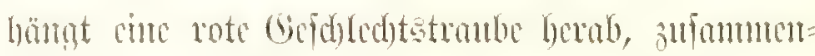

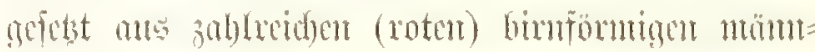

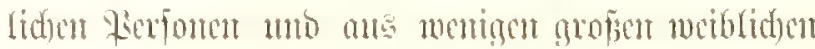

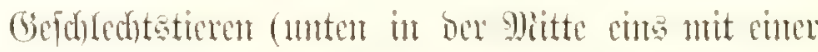

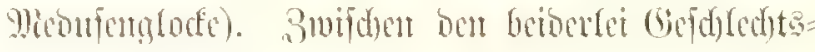

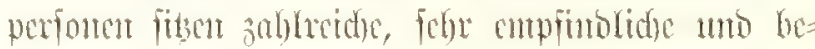

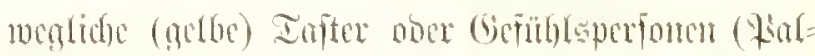

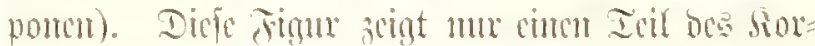

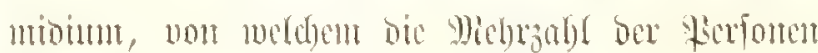
abgeclait it. 

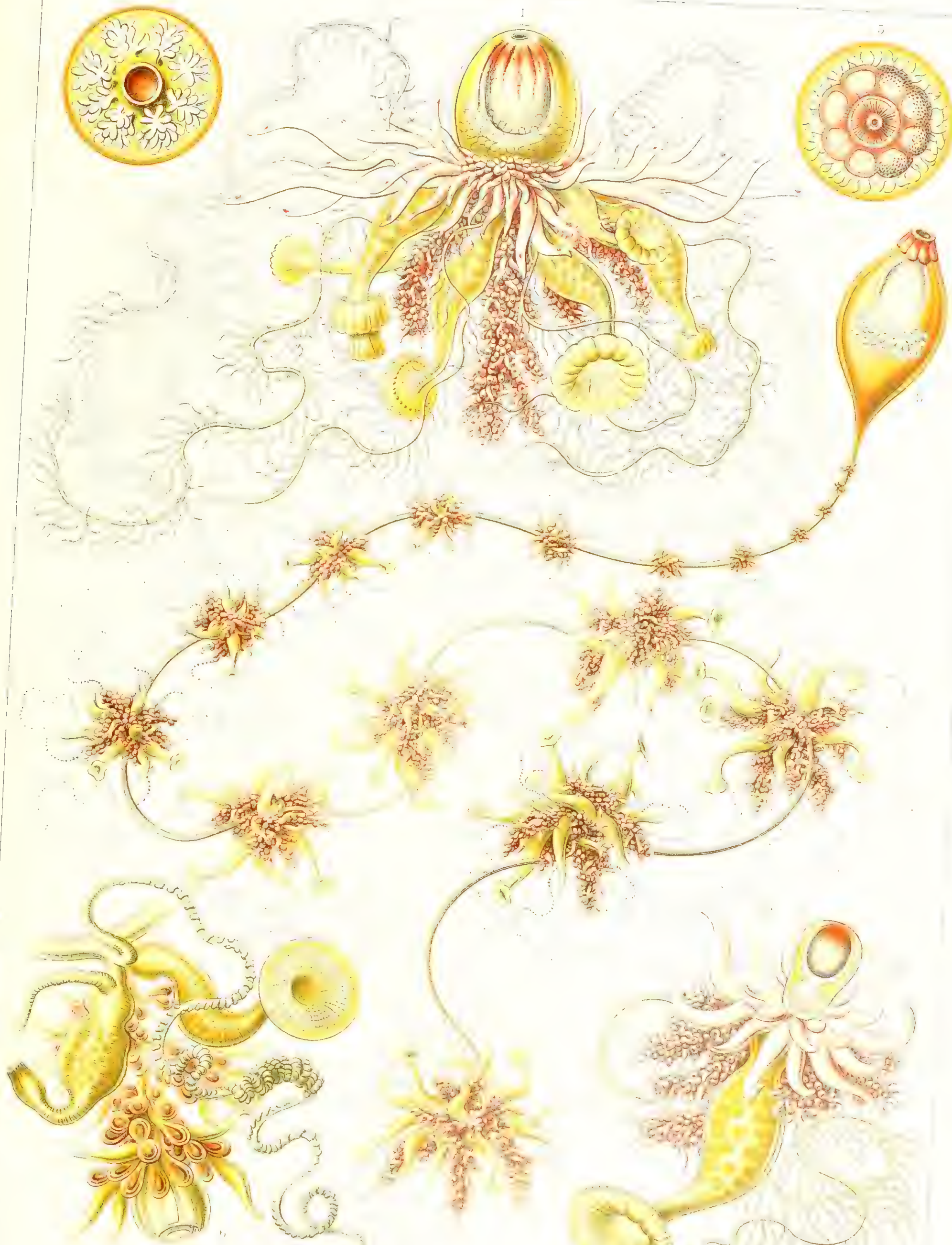


$$
\text { - }
$$




\title{
Discomedusae。 Sthithenuallen.
}

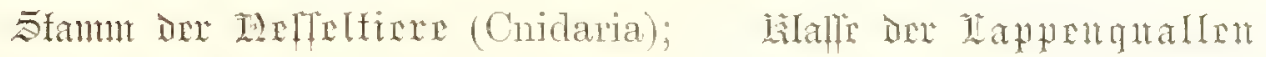

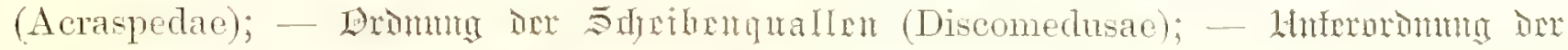

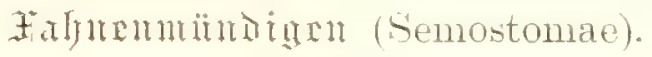

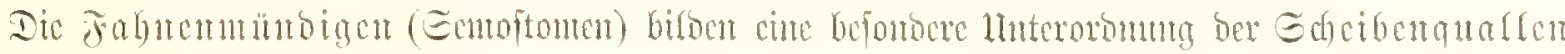

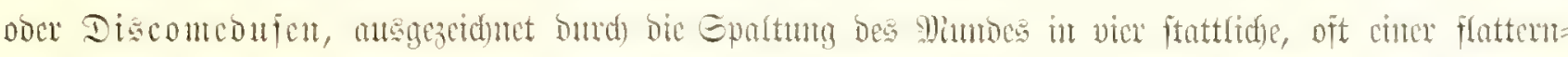

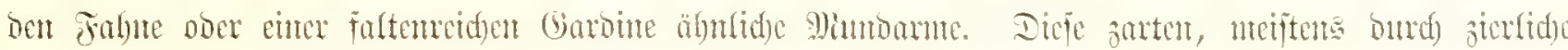

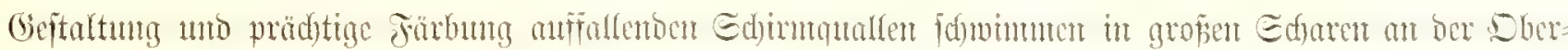

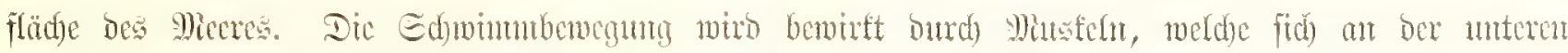

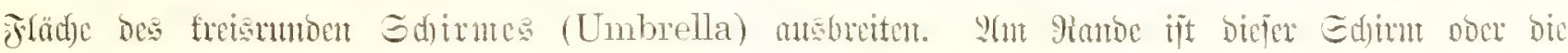

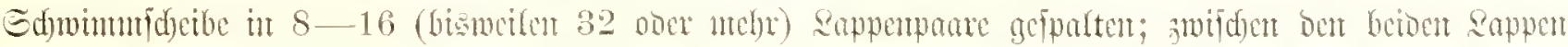

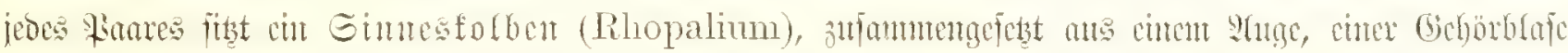

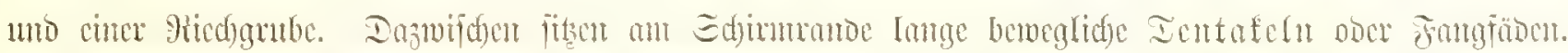

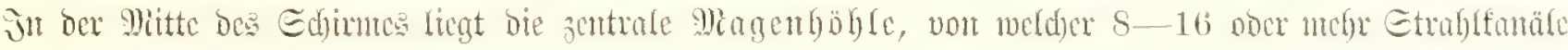

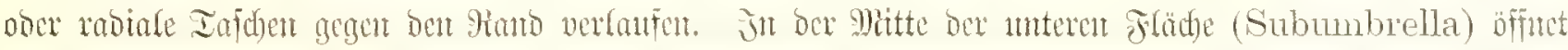

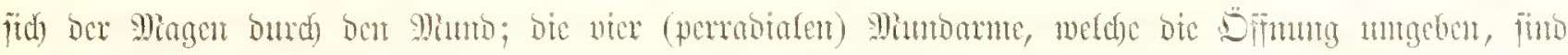

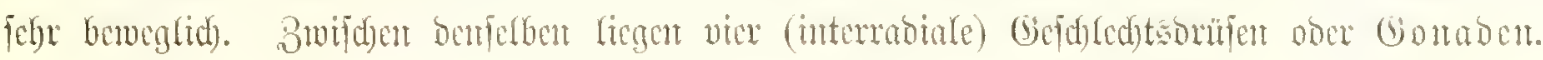

Fig. 1. Desmonema Amuasethe (Haeckel).

Cine Emoitome ans ber Fomilic ber Cras meiben (von bor fübafrifanifocm silifte) in matür=

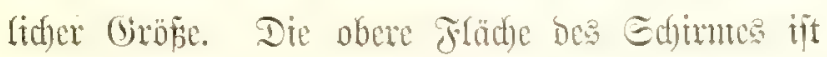
verticft uno mit 16 ftrahligen, geffebertent Hitppent

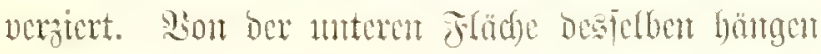
in ber 思itte vicr zarte blane, 9lintogarbinen" herab, breite Miunotappen, bic ant gianthe umter ftart ge=

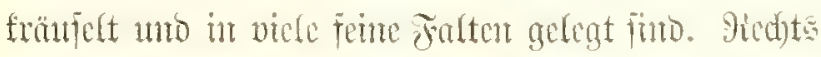

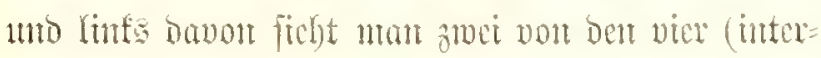
rabialen) orangegelfen Giomben, arfgebüngt an

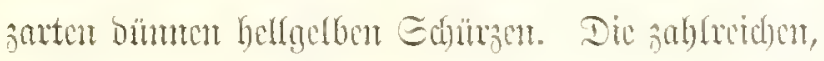

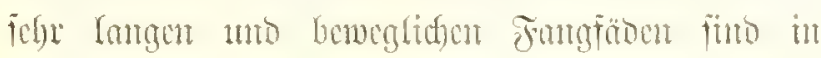

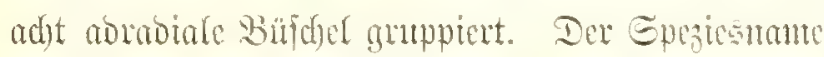

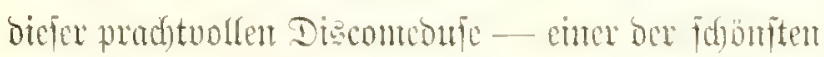
unb interefiantefen unter allen Miendicen - veremigt

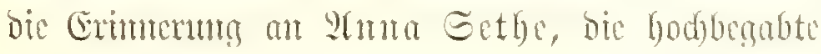

Femintmige Frau (geb. 1835, goft. 1S6t), weld)er ber

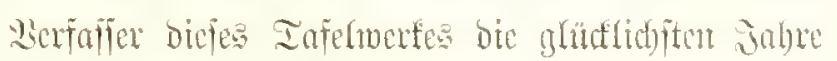
Feines sebens verountt.

\section{Fing. 2. Desmonema Ammasethe (Hacekel).}

Der Edym (Umbrella) von unten geford,

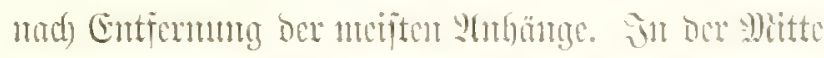
Der Unterfläd)e (Subumbrella) ift Dog somofrus

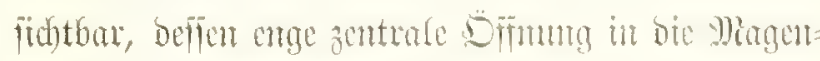

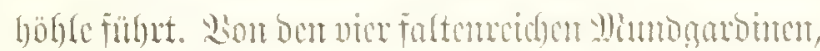

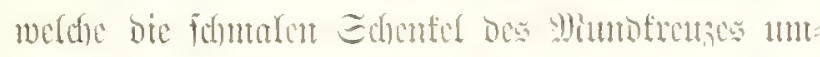

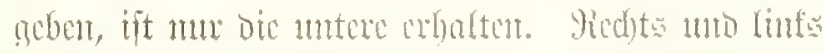

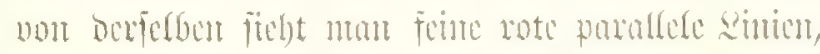

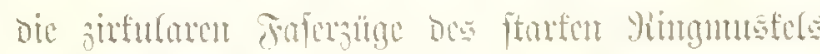

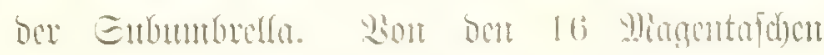

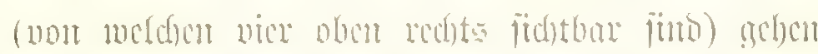

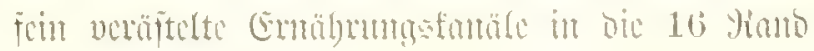




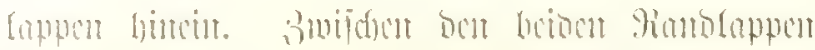

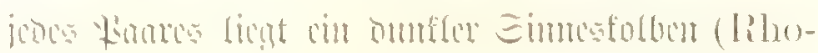

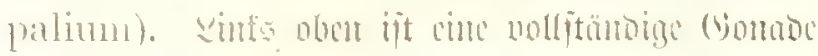

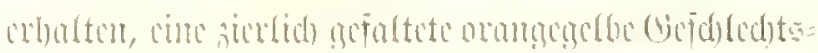

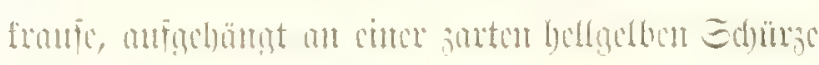

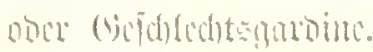

\section{Fin. :3. Foseula Promethea (Herelint).}

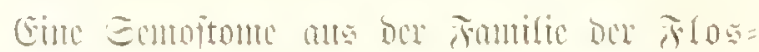

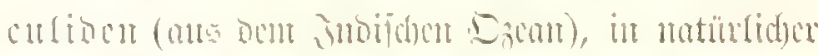

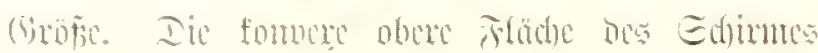

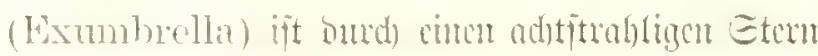

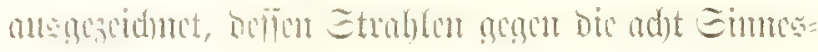

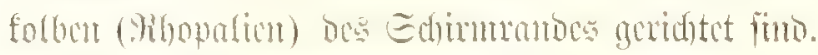

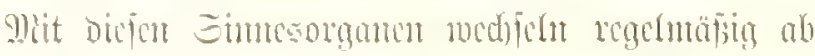

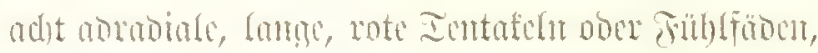

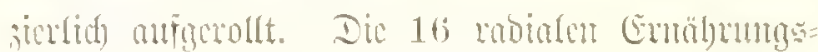

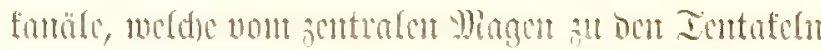

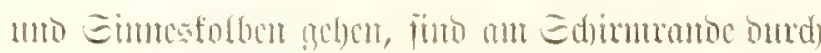

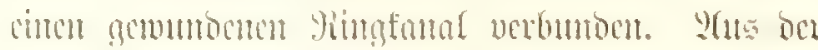
fonfancu unteren Ediumflide (Subumbrella) tritt

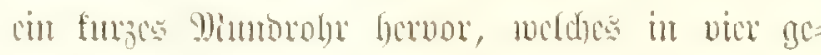

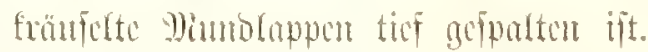

\section{Fig. 4. Chrysara mediterranea (Peron).}

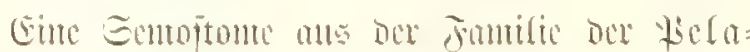
giocu (bon Emmuna); nicumal vexflement. Dio

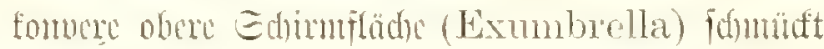
ciu rotbramux Eteru mit 16 breiten Etrablen.

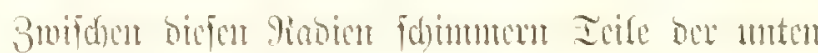

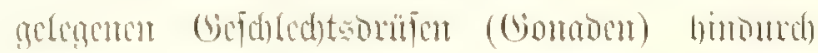

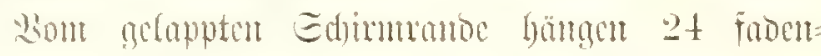
Fönuige Iontatelu berab. Dic vicx fongen roten

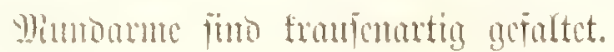



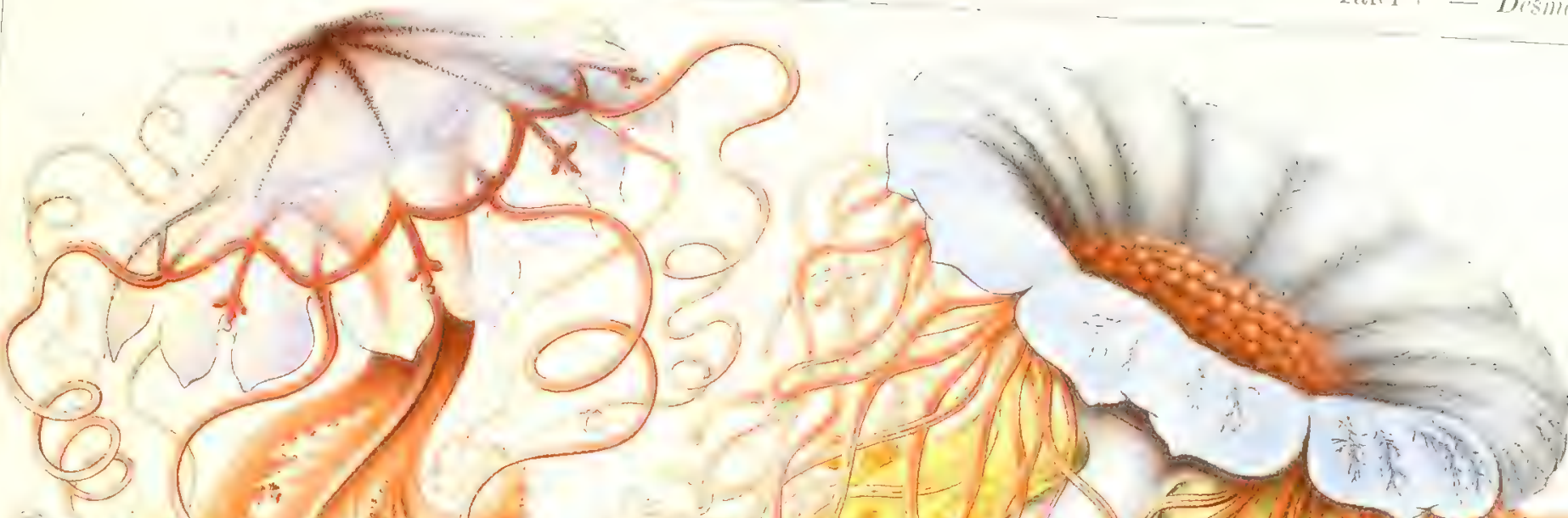

i) $(A)=$
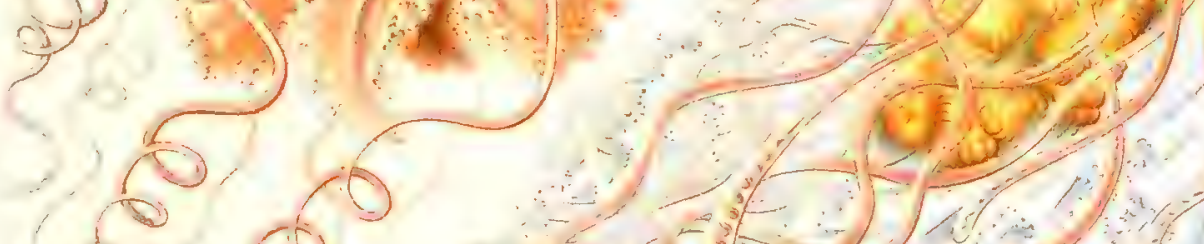

$\frac{1}{4}(0)=(1)$

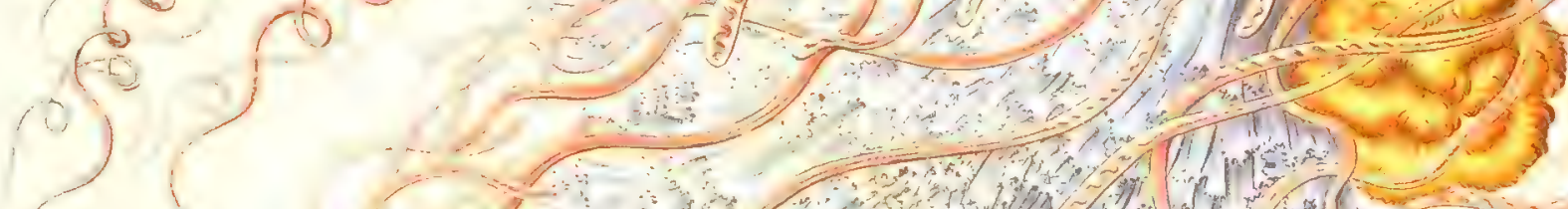

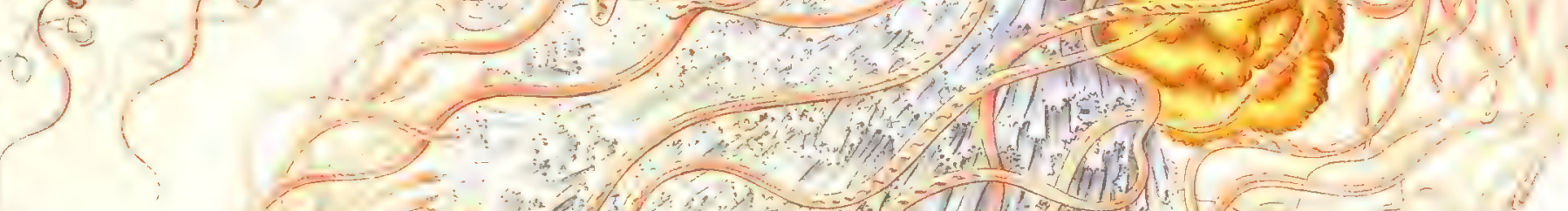

(1)

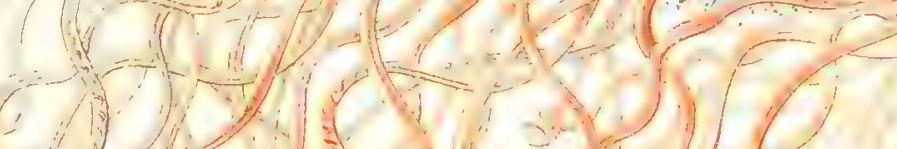

$(1)=(1), 1$

140

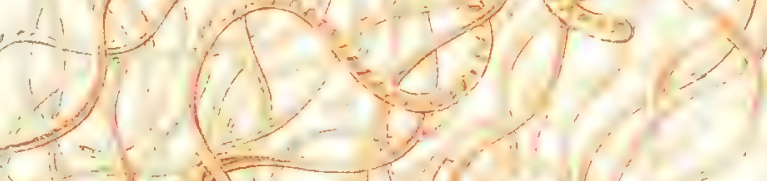

$4=(-1)$

(10) $(1)$

14

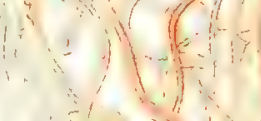

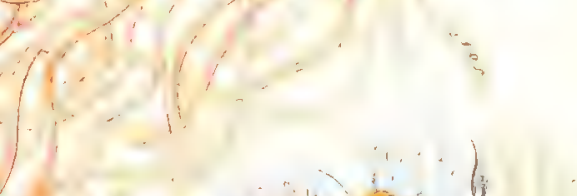

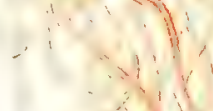

whe
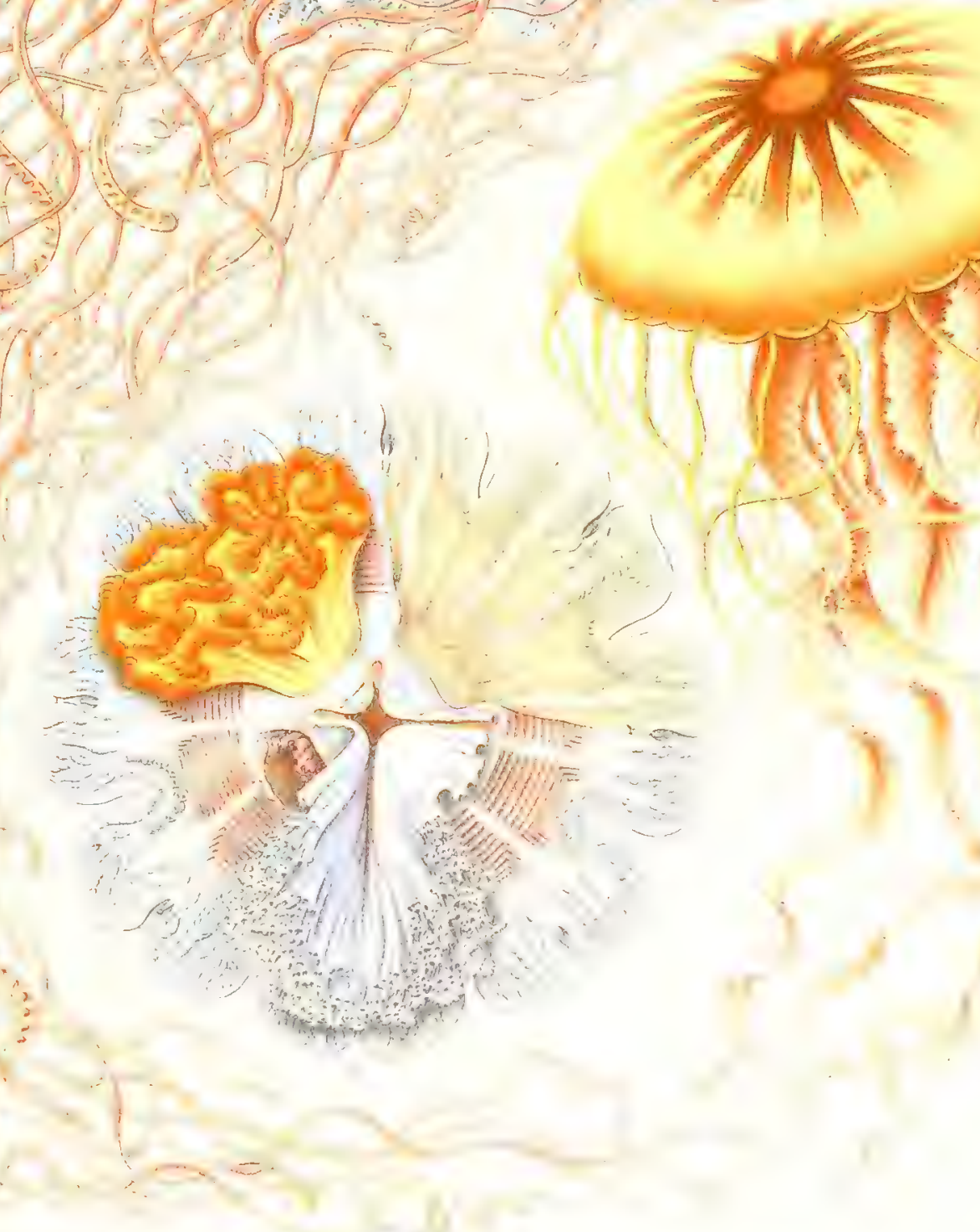

Discomedusae. - stioilionmantin. 



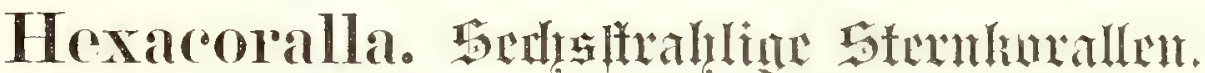

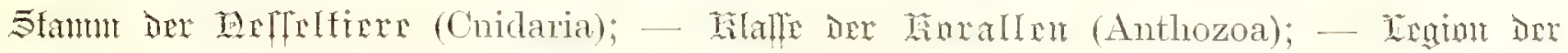

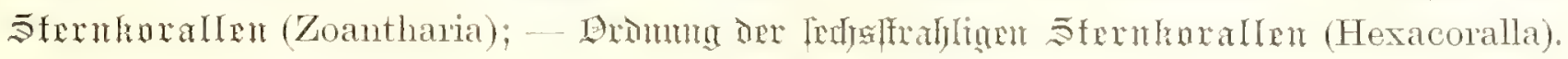

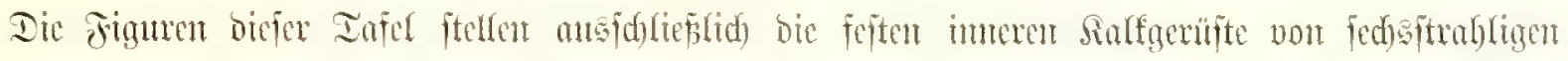

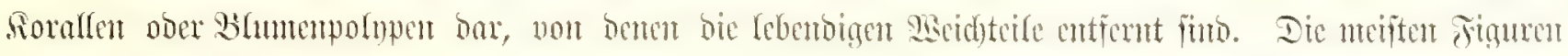

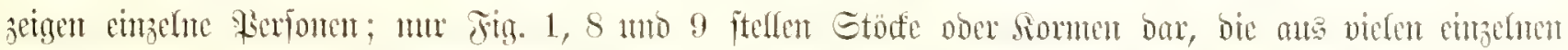

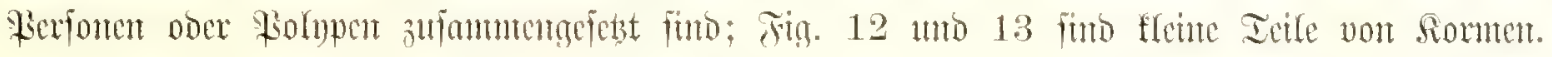

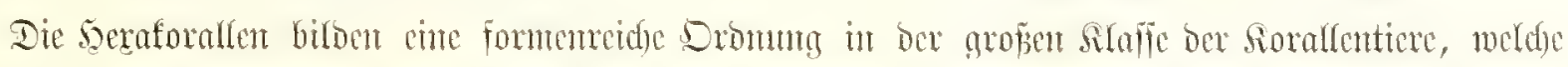

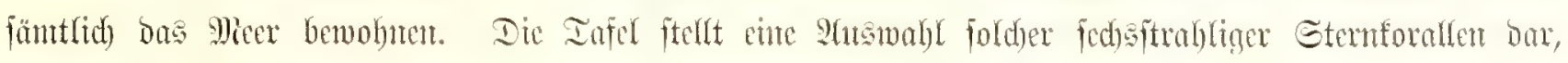

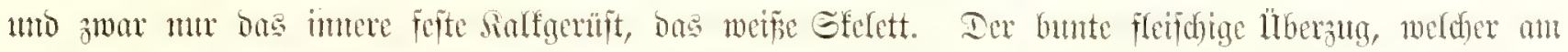
Lebenden Sorallenticere bicfes Efelett bebedt, iit cutfernt.

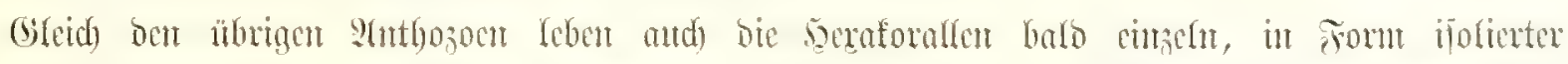

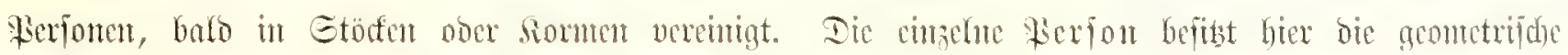

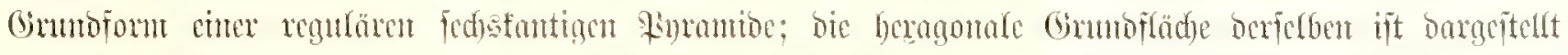

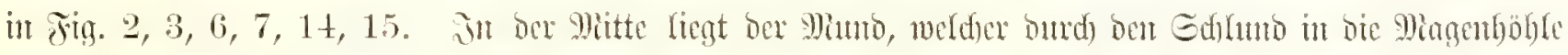

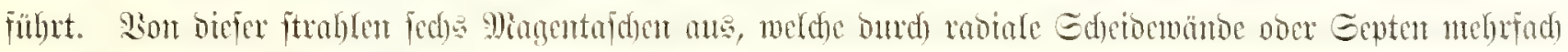

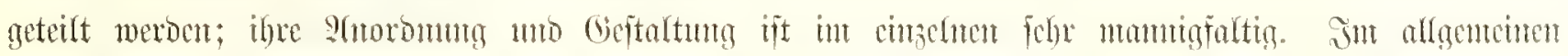

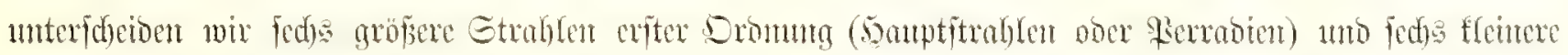

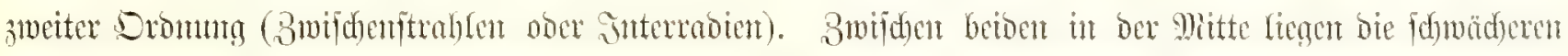

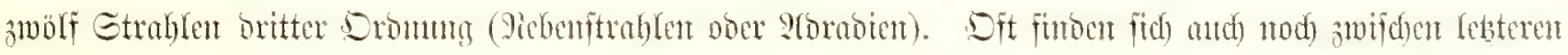

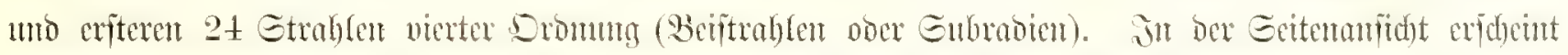

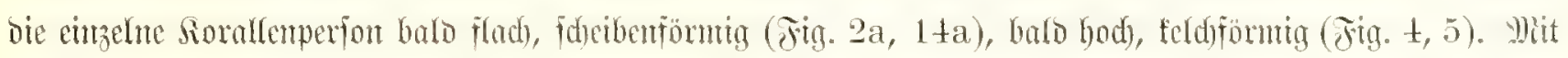

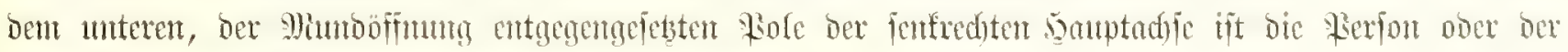

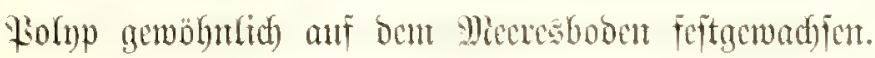

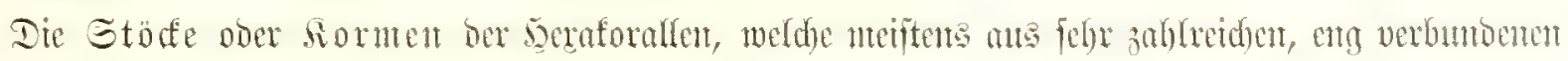

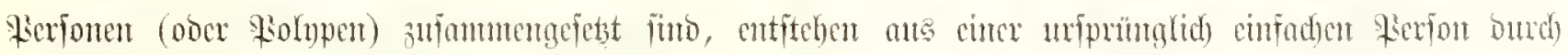

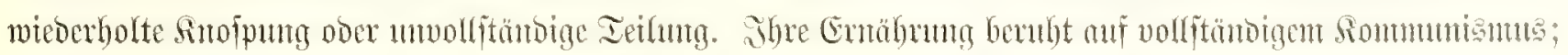

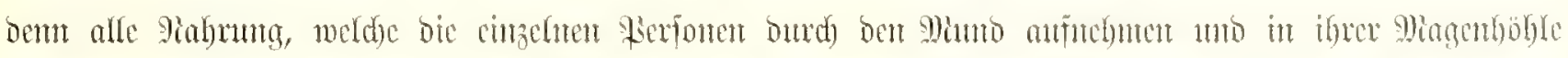

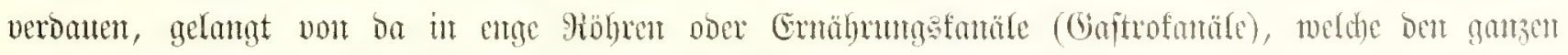

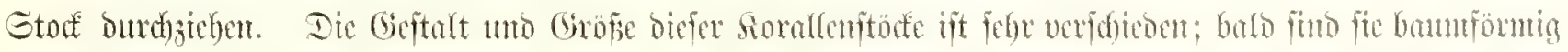

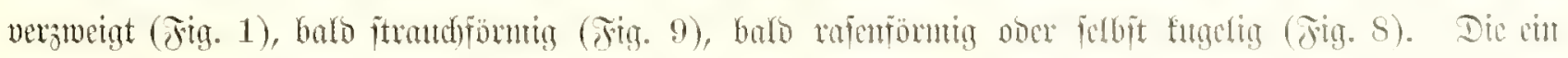

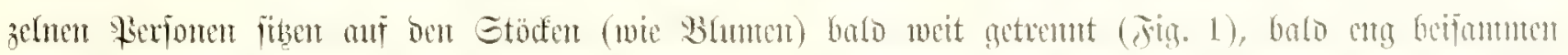

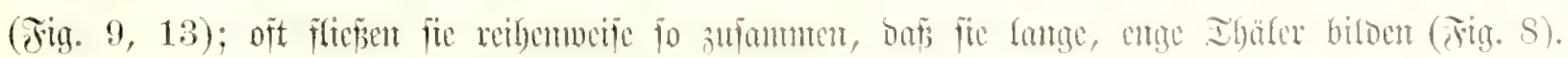

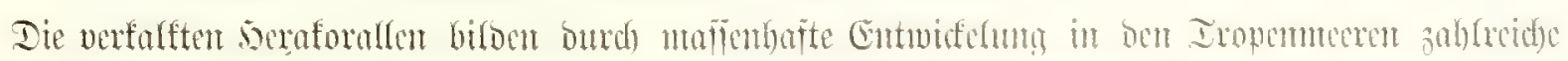

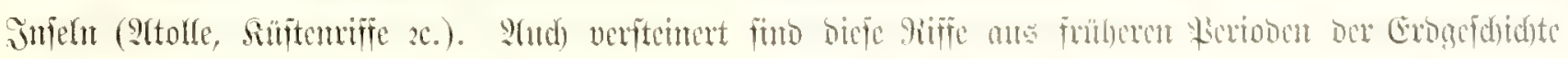

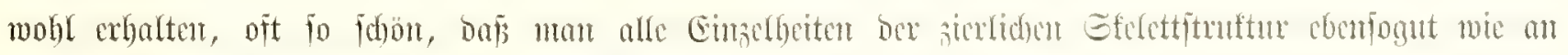

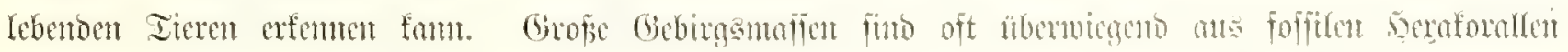

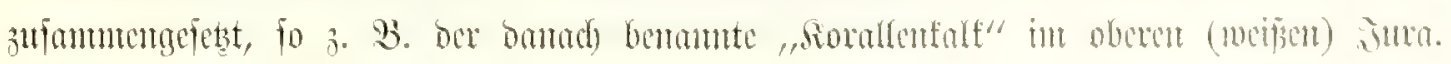


Tign. 1. Lophohelia prolifera (Pelles).

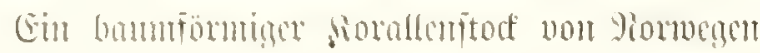

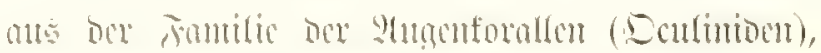

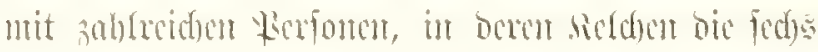

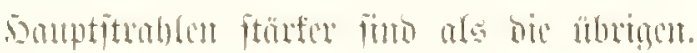

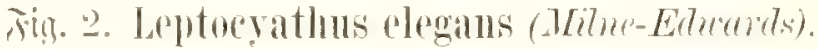

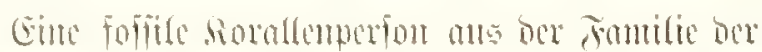

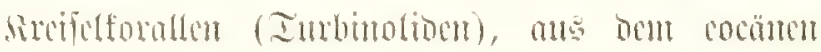

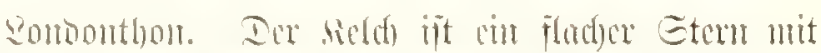
imolf gleid) ftorten somptituhlem.

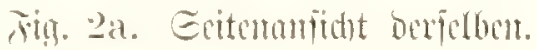

Fing. 3. Cyathina eylindriea (Mitne-Educards).

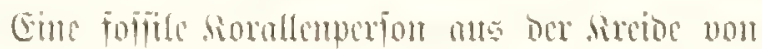

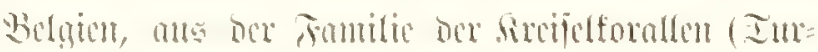

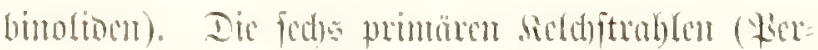

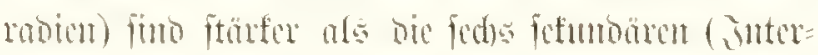
rabiat) atmo bicfe länger als bie zmöf tertiörem

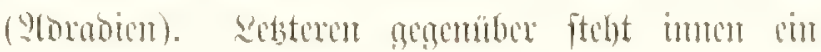
strans von subolf

Fig. t. Balanophyllia floridana (Pourtules).

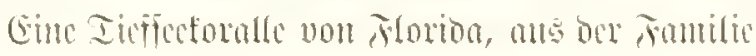

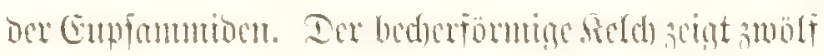
flügeffömign voripringende somptitrablen.

Fing. 5. Rhizotrochus fragilis (Pmetales).

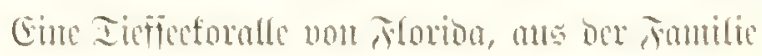

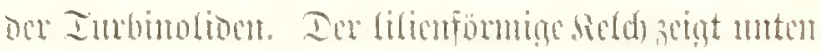

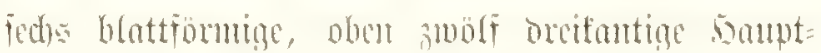

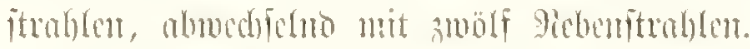

sin. 6. Stephanophyllia alegans (atheEtherds).

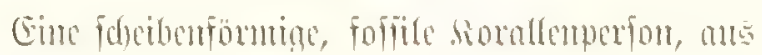

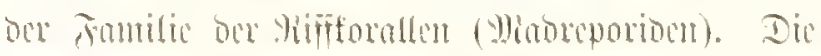

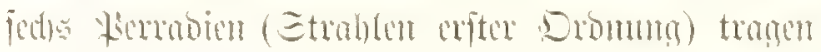

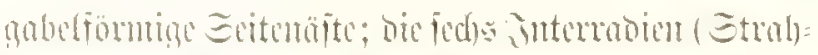

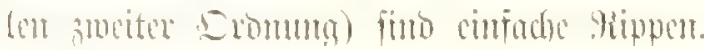

Fin. 7. Astrocyathes paradoxus (Poneteles).

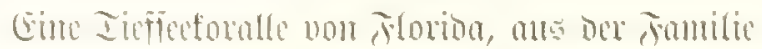

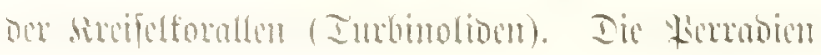

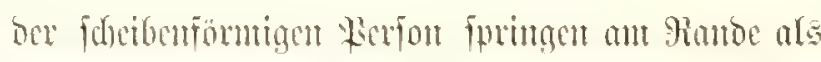

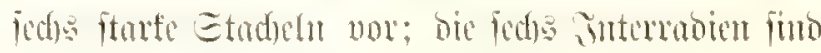

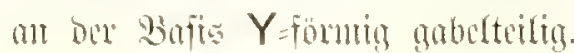

Fig. S. Maeandrima filograma (Lamarch).

Ein fugediger storallentost ats oer Fantilie

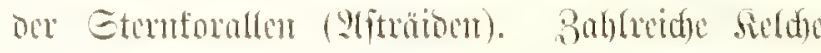

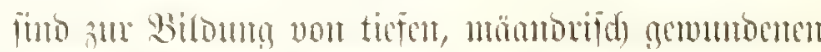

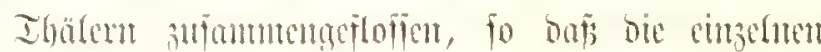

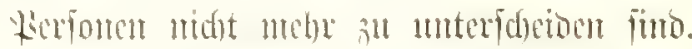

Fing. 9. Ladrepora fruticosa (Brooki).

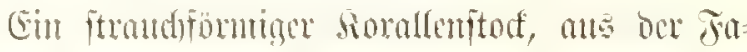

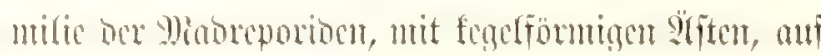

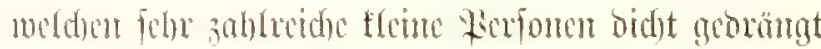

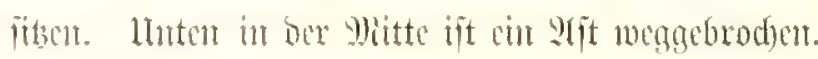

Fing. 10. Flabellum anstrale (Moseley).

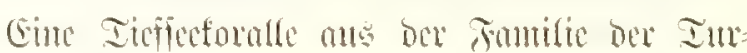
binolions, mit lamger ghumbinalte.

Tig. 11. Flabellum alabastrum (Moseley).

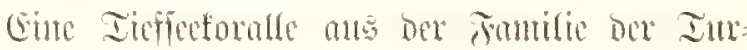
binolion, mit lontaer Mimnojpalte.

Tig. 12. Thammastraea arachnoides arineEidurards).

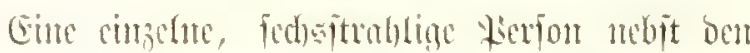
murusenom Etüfen ber benad)barten Wierjonen

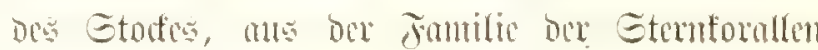

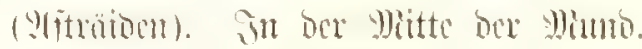

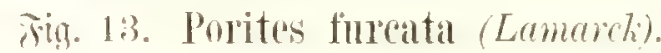

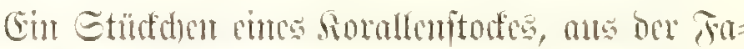
milie dex fiorenforallen (Poritida). Whan fiegt

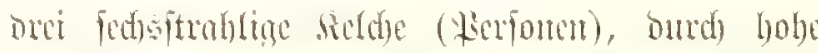
Fed stontige Habmen cingerapit umo getrement.

Fig. 14. Stephanophyllia complicata (Noseley).

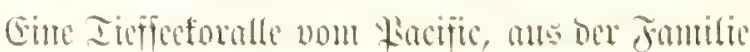
ocr Bififtorallen (Mabreporion).

Fing. 1 ta. Esitenamidet Dexfllen.

rig. 15. Leptopenus discus (Moseley).

sime Iisffectoralle vom 米acific, ans ber Famific

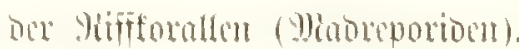




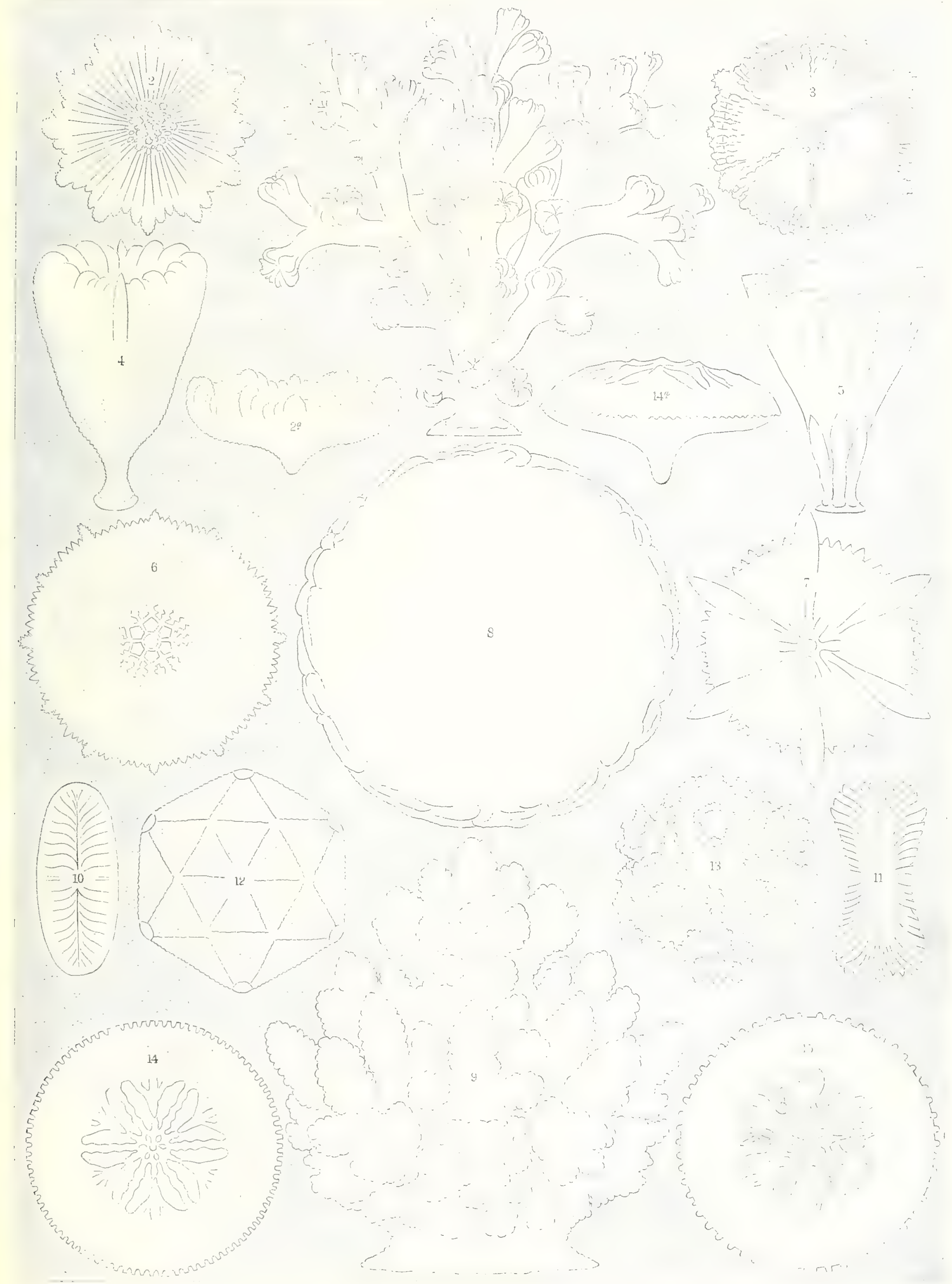





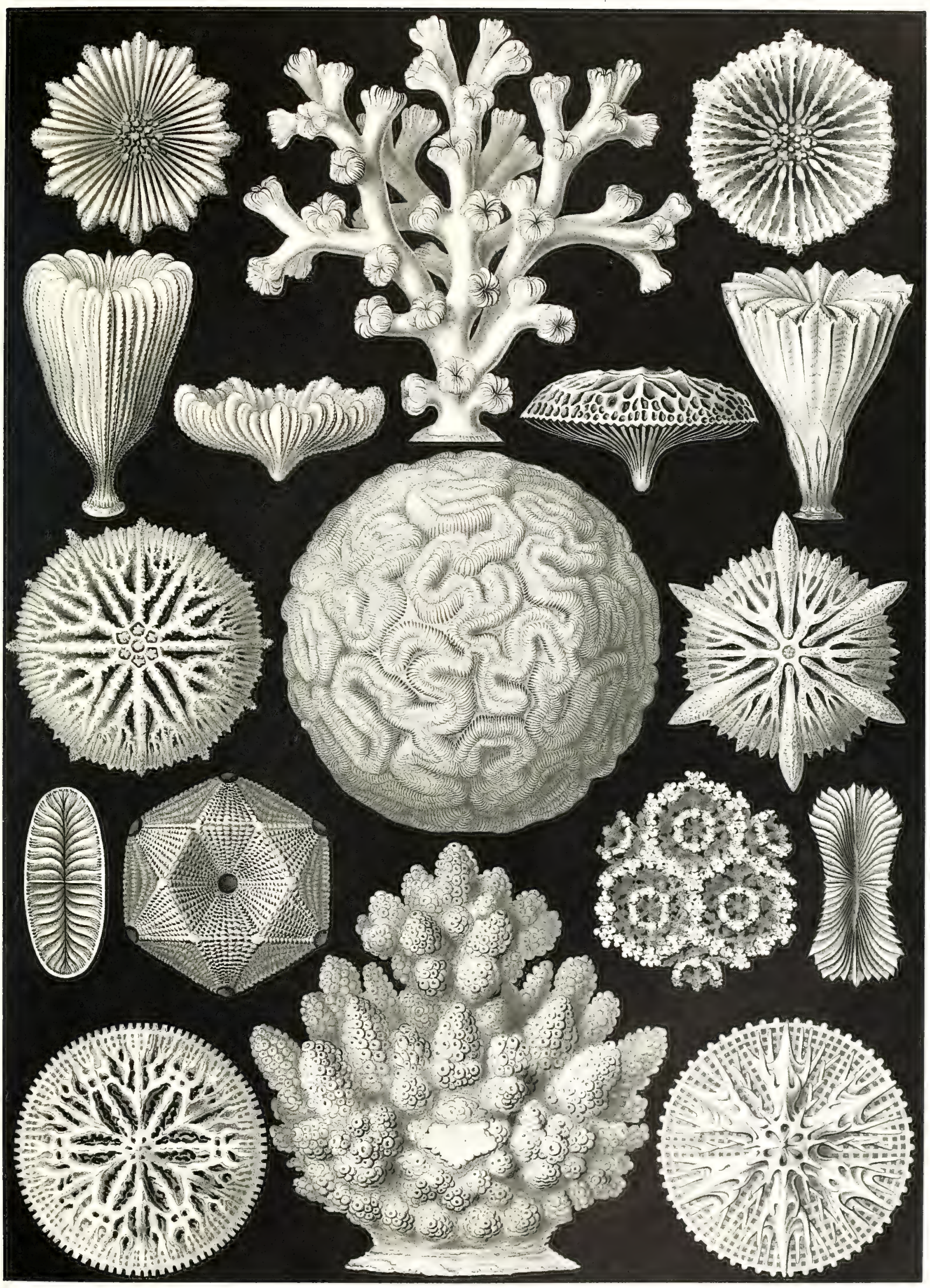

Hexacoralla. 



\section{Ophiodea. 5uthumenteme.}

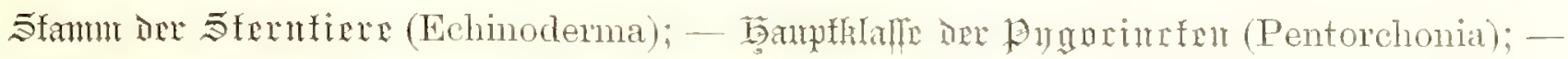

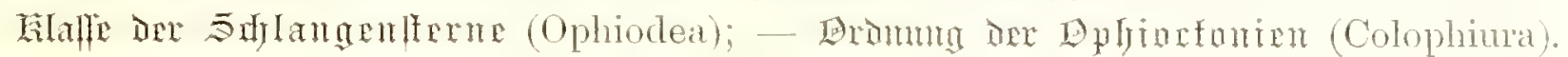

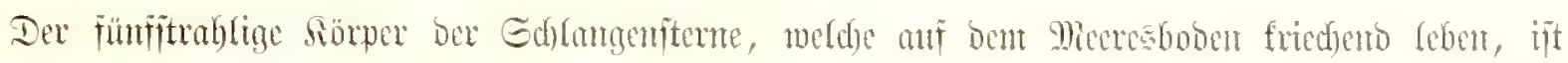

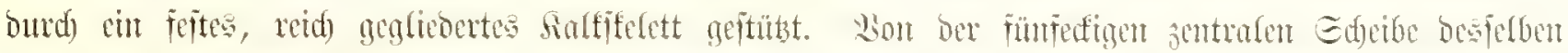

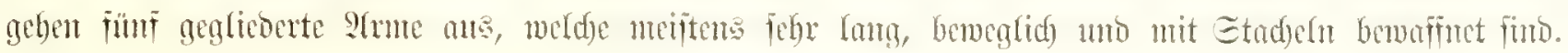

Sig. 1. Ophiothrix capillaris (Lymani).

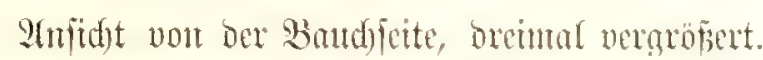

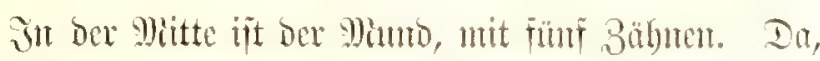
wo die fünf Strnte von bex zentralen Edjeibe $a b=$

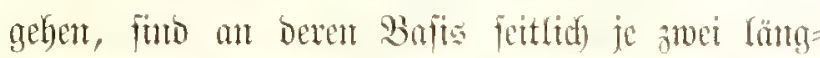

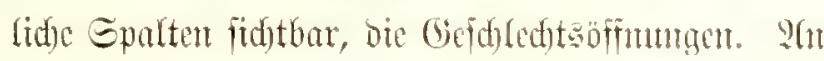

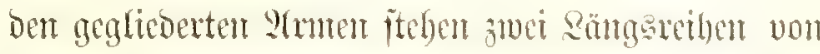

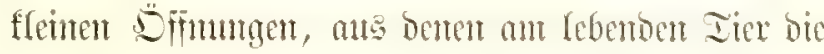

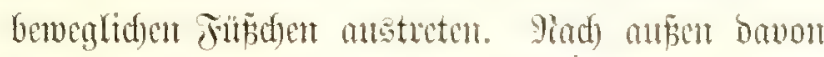

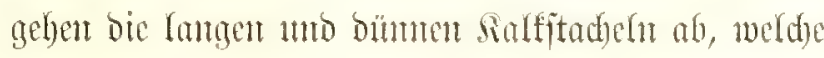
beroglid) uno fein gezalunt finto; fie bienen fowohs jum Edhube als zur Drtäbewegung. Der gröpte Ietl ber fangen : vame ift abgebrodyent.

\section{Fig. 2. Ophiotholia supplicans (Lymenu).}

Y(mild)t des jentralent Gdeetbentetles, non ber

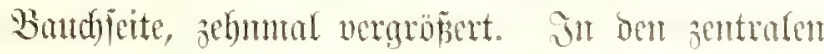
Munto ragen fünf jpite (internbiafe) Bübne bincin, Deren breite bretextige Bafts fäd)ecfönmig gertppt itr.

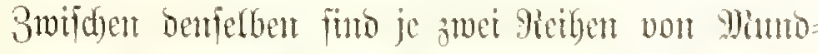

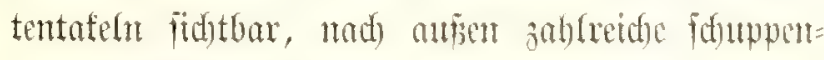
förmige Miumbapillen.

\section{Fing. 3. Ophiocoma rosula ( Link).}

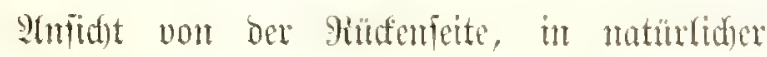
Gröbe. Die zentrale Gdjeibe zeingt füm (perrobialc)

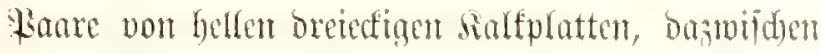
bunfle (interrabiafe) gieifen von fleinen Stadeftr.

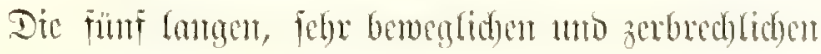

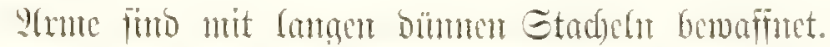
Das Ticr wirft fie bet ber Berithrumen feidst ab.

\section{Fig. t. Astroschema brachiatum (Lyman).}

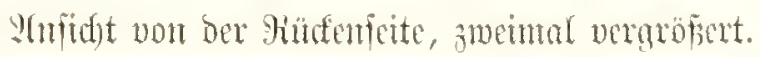

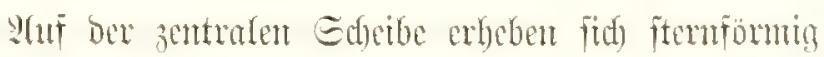

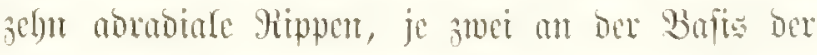

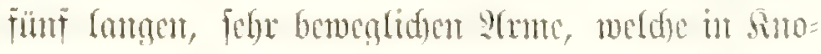
ten veriddintugen finto.

\section{Fig. 5. Astroschema horridum (Lyman).}

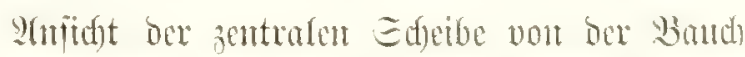

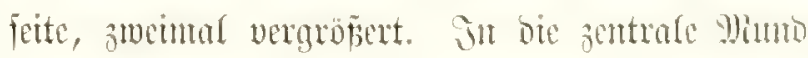

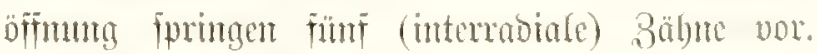
Bwifd)en benfelbent geben bic fïnf lantgent (perra

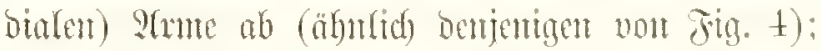

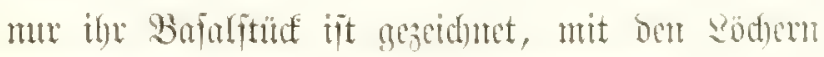

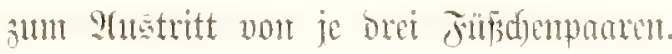

\section{Fin. 6. Astroschema l'ubrum (Lyman).}

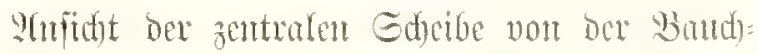

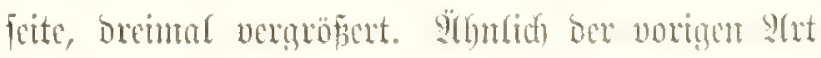

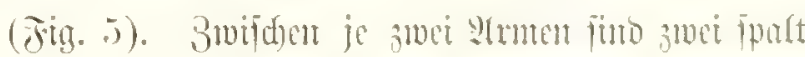

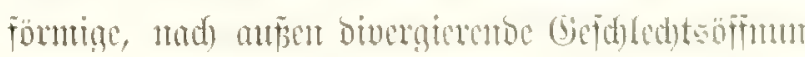
gent fiththor.

Jing. 7. Ophiocreas oedipus (Lyman).

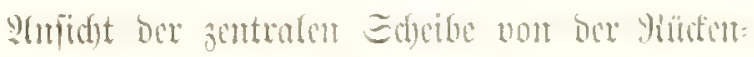

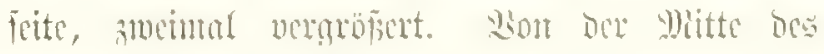

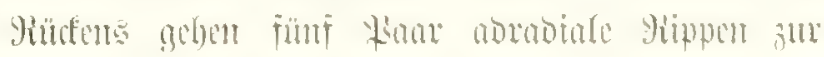
Bafic ber fün perrabialen Strme. 
rin. 8. Pluteus paradoxus (Johomes Mhiller).

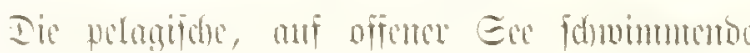

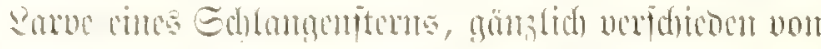

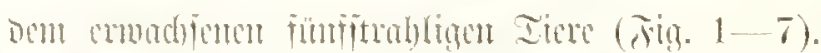

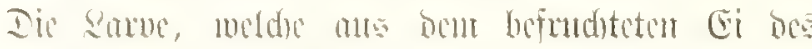

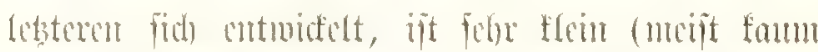
1 mme arofi) unto folmument anther mittels feinos

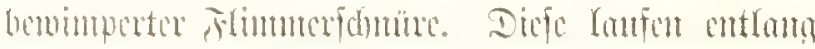

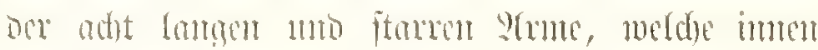

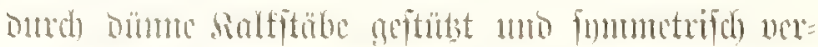

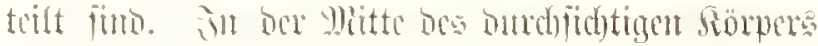

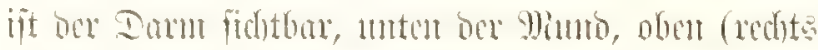

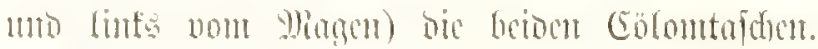

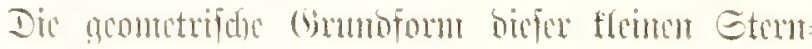

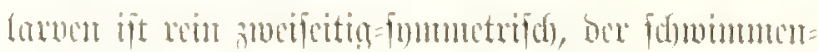

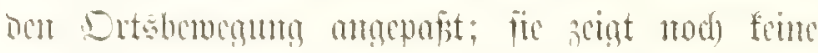

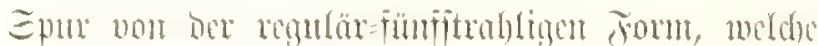

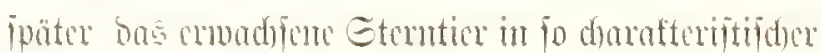

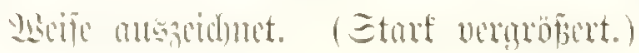

Trig. 9. Pluteus paradoxus (Johames Mither).

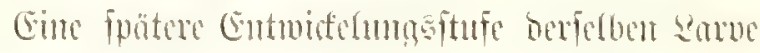

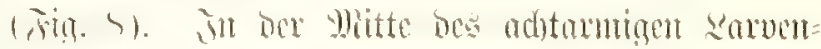

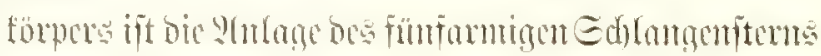

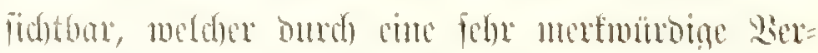

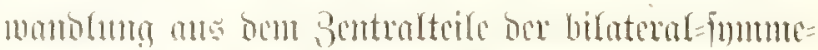

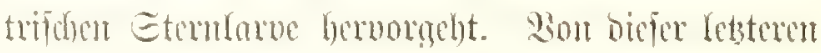

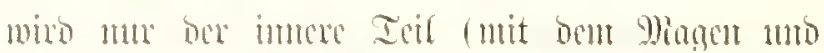

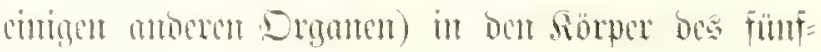

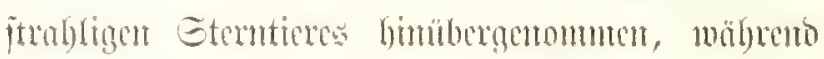
ber anfere Iefl (sic fangen Sarvename mit des

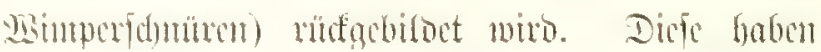

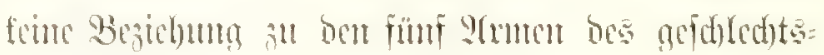
revien Gterntieres, metde fich felbitünoin non ben

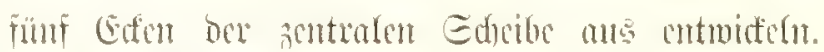

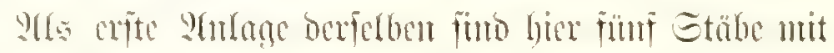

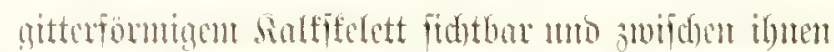

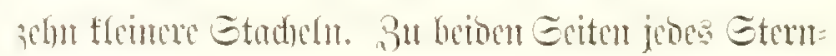

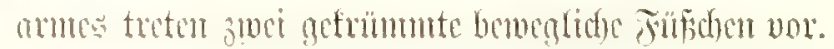


Ophiodea. 



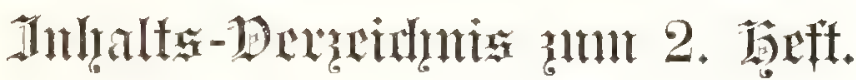

Tafel 11. Heliodiscus. 1trticre ane ber Rlafie orkabiolarien(Eegionder Snunellarien).

Iafel 12. Miliola. Huticre ats ber Sitafie Der Ifalamophoren (Segion ber Efora: mintent).

Iafel 13. Dinobryon. Inticte an der Sant flafle der sufuprien (staffe ber slagel. latert).

Iafel 14. Peridininm. Lrpilanzen ans bex Sauptfafie der sllgettedt (silaffe ber Mafti= gotent).

Tafel 15. Zonaria. Thalluspflanzen ans bent

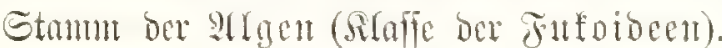

Iafel 16. Pegantha. Neffelticre ans der Silaffe ber Sirapeboten (Dromm ber garfo= ucoujen).

Iafel 17. Porpema. Seffeltice am bor Slafie ber Giplonophoren (Sromm ber Disto= untem).

Iafel 18. Linantha. Mefieltiere me der Silaile

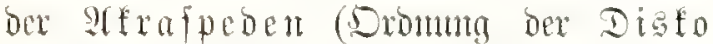
ménjen).

Tafel 19. Pennatula. Sicfiertiere me der Sifafe ber Soralfen (Drommtg ber Dftoforallen).

Iafer 20. Pentacrinus. Stemtere a ber Silafle dex Sirinoiden (Drommg ber Pen= tafritten). 



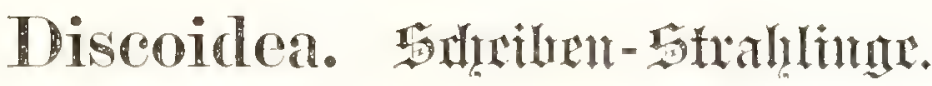

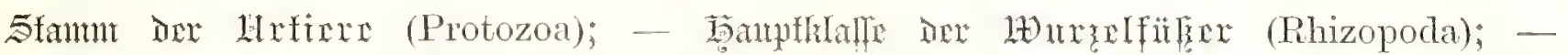

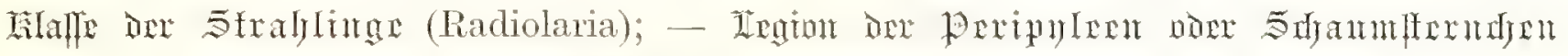

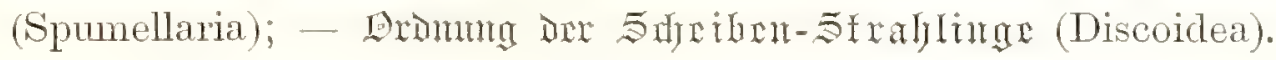

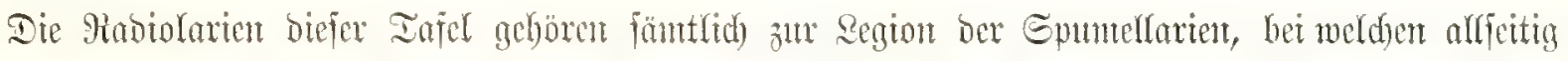

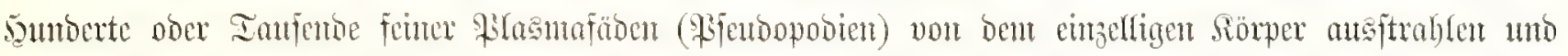

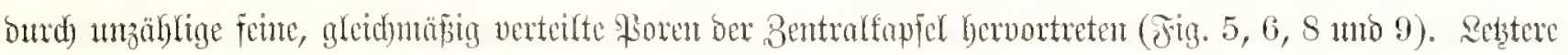

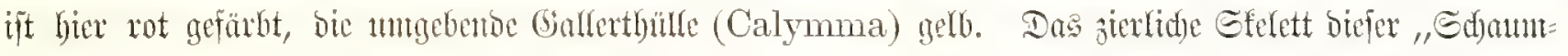

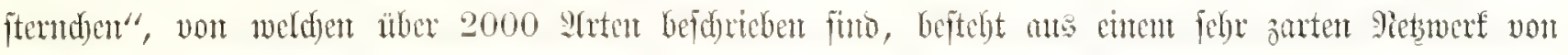

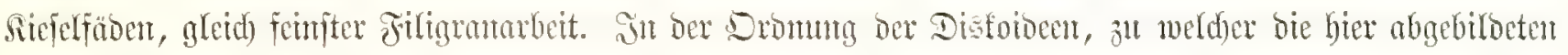

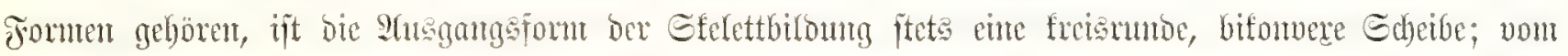

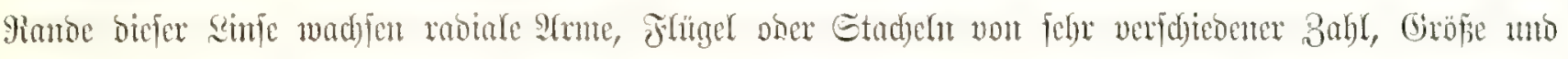

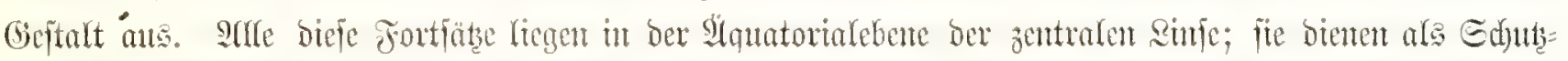

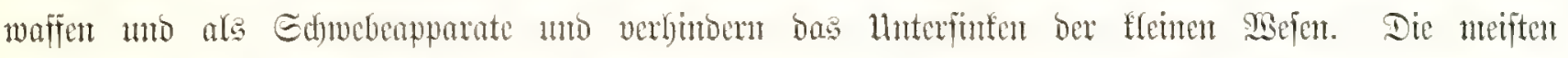

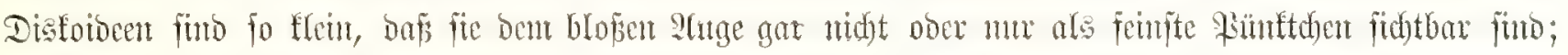

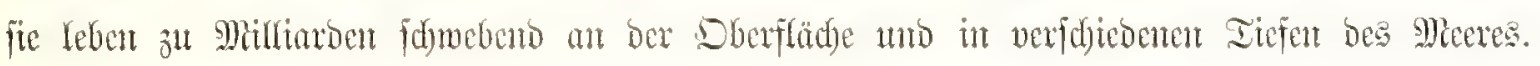

Jig. 1. Histiastrum Boseanum (Haeckel).

Hamilie onx Porodiscida.

Edyeibe frenzförming, mit vier freuzitämbigen

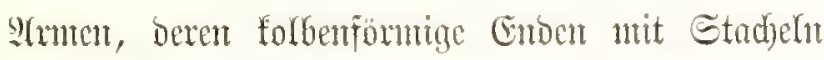

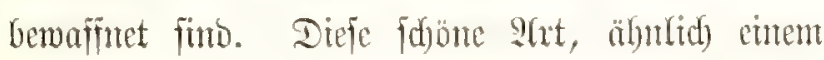

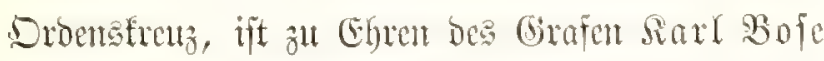

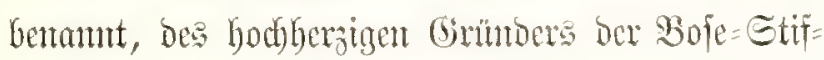
tuntg an ber Hniverfituăt Şent.

テ̛ંg. 2. Stephanastrum quadratum (Haeckel). Familie Der Porodiscida.

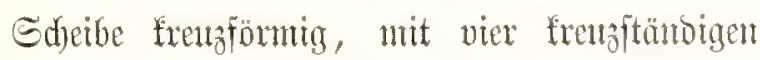

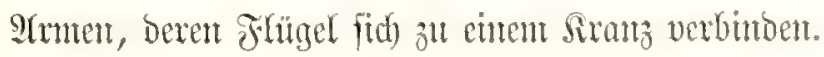

\section{Fig. 3. Dicranastrum furcatum (Hacckel).}

Fantilie dex Porodiscida.

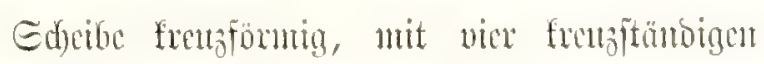
Struten, bie anť̃en gabelipaltiog finto.
Fig. 4. Rhopalastrum trispinosum (Haeckel). Fantilie Dex Porodiscida.

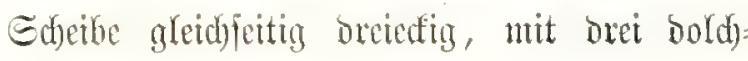

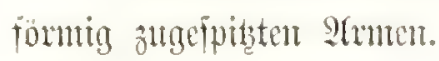

Fig. 5. Chitonastrum lyra (Hacclel). Familic ine Porodiscida.

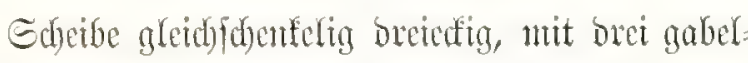

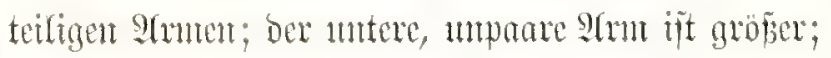
ifm gegentiber jtebt zowifden ben beioen paarigen

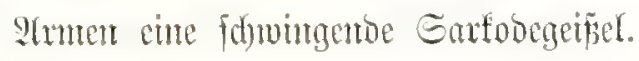

\section{Jig. 6. Enchitonia carcinns (Haeckel).}

Familib ief Porodiscida.

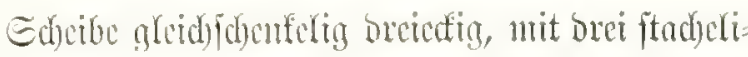

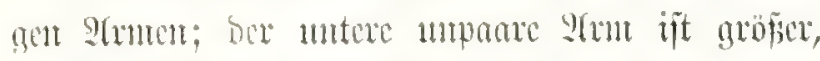

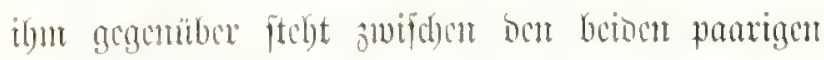
Strmen cine beneglide Garfobegeriser. 
Jig. 7. Myelastrum dodecaceros (Hackel). Finnilie one Porodiscida.

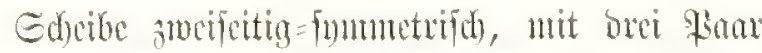
Frïgetu; rote Bentralfapfel mit joülf sappeu.

テig. S. Myelastrum papilio (Haeckel). Hamilie one Porodiscida.

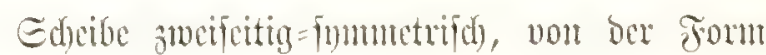

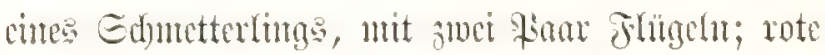
Bentralfapid mit vier sappen.

Fig. 9. Pentinastrum asteriseus (Hacekel).

Fantlie one Porodiscida.

Ed)eibe regulür fümffrtablig, mit fünt gleid)en, ant Ento boldaförnigen S(rutu, bie durd) eine Edjuimmbant von Filfigramert verbunden fims.
Jig. 10. Itexinastrum geryonidum (Haeckel). Familis one Porodiscida.

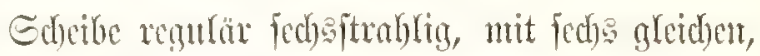

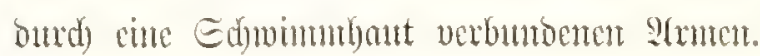

Fig. 11. Heliodrymus dendrocychus (Haeckel). Familie iner Phacodiscida.

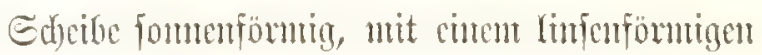

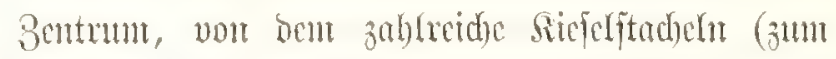
Icil veräitclt) angitrahlen. Dic Dumfelrote Sutgel in ber Mitte ift ber sem ber Belle.

Jig. 12. Holiodiscus glyphodon (Haeckel). Familie ine Phacodiscida.

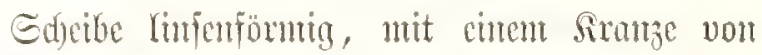
adjt gefurdeter, glcide verteiltent gianojitad)etn. 


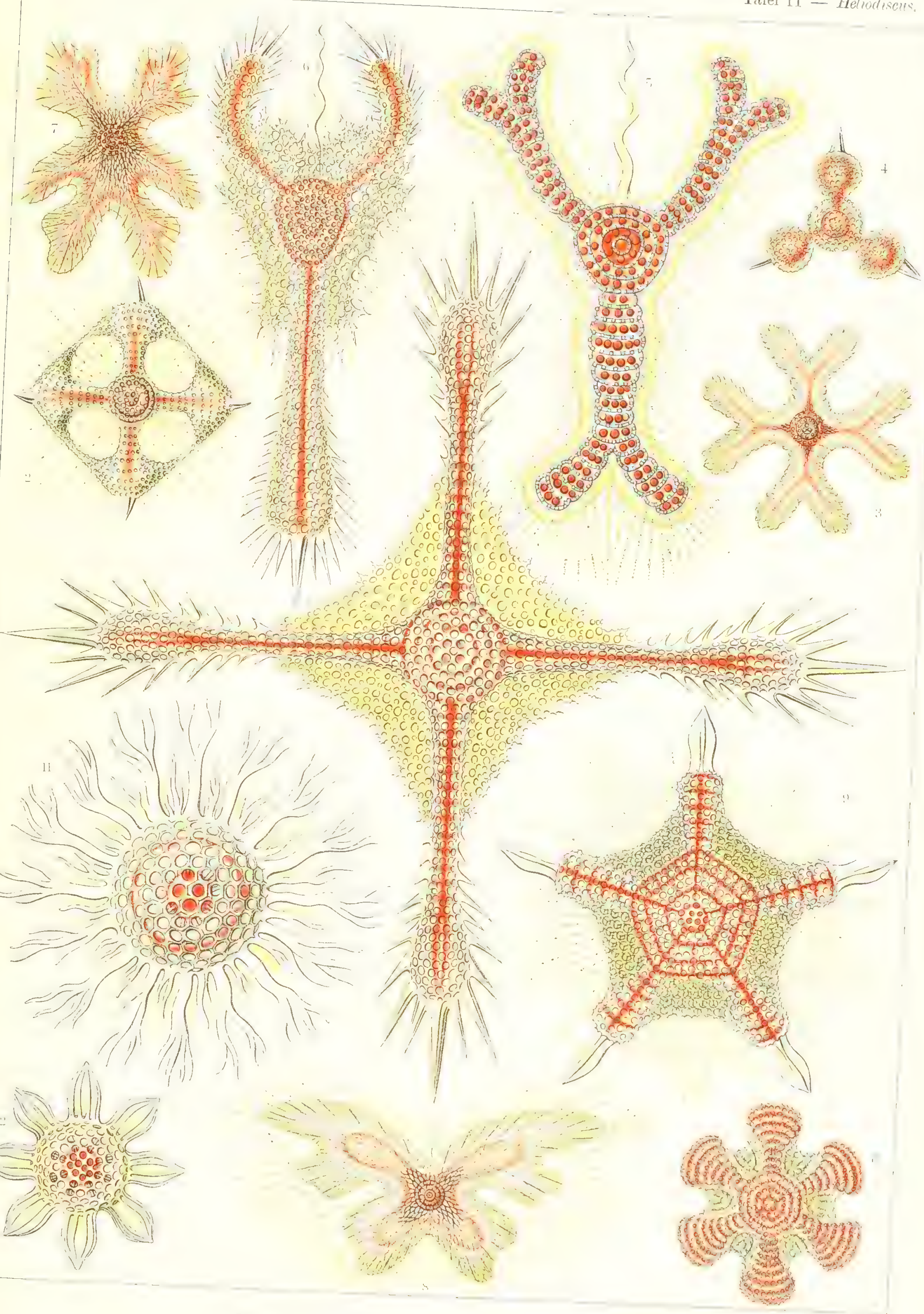

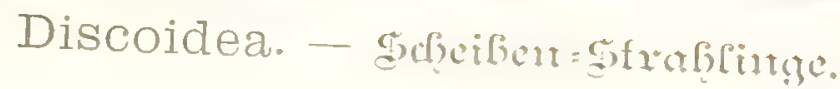





\section{Thalamophora. Tiamutulturn.}

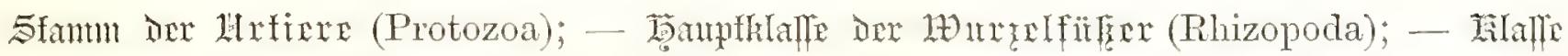

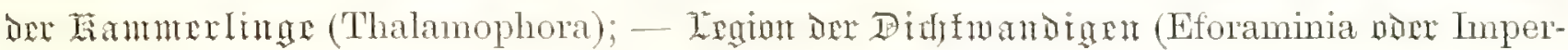
forata); - Familie orr Miliolida.

Die Sinmerlintge (Thalamophora), weldhe anf biefer Taffel bargejtellt fints, gehören fämt=

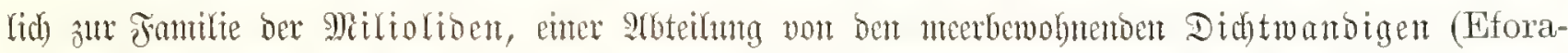
minia); fie unterfdetoen firh von ber anderen Region ber Silnfle, ben Siebwandigen (Foraminifera,

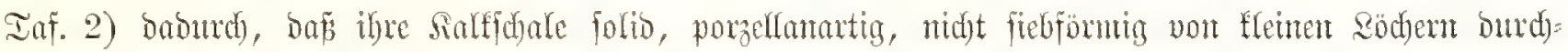

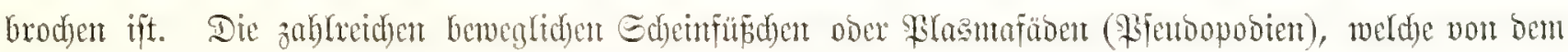

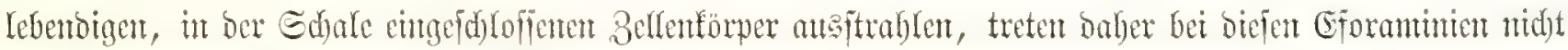

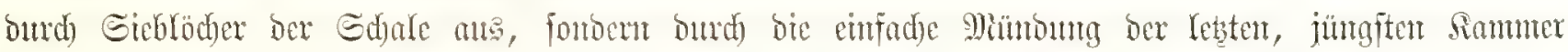

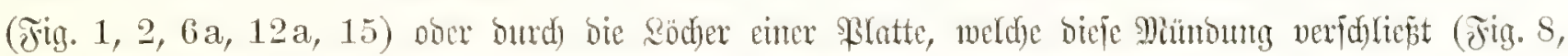

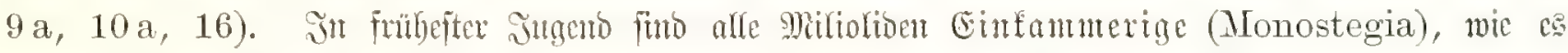

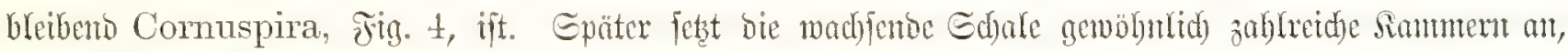

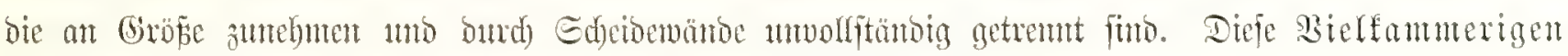

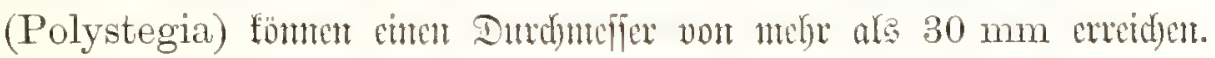

Fig. 1. Miliola parkeri (Brady).

Die Edjate hat $1 \mathrm{~mm}$ Durchuneffer, beftegt

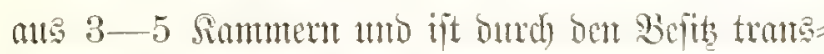

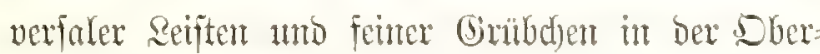
fläd)e anegezeiduntet.

\section{Jig. 2. Miliola reticnlata (Lamarcli).}

Dic Edale hat $2 \mathrm{~mm}$ Durdumefier, bejteft aus

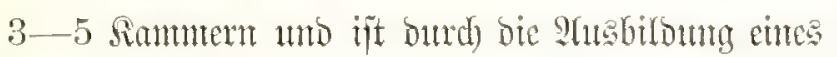

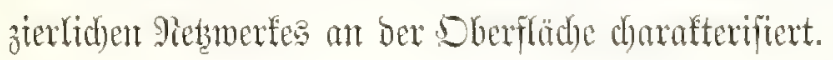

\section{Fin. 3. Miliola striolata (Reuss).}

Die Eringe hat $1,5 \mathrm{~mm}$ Durdemefier, bejtelyt

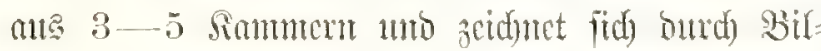

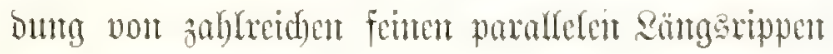
an ber Dberflädye ats?

Fig. 4. Cormuspira planorbis (Max Schultze).

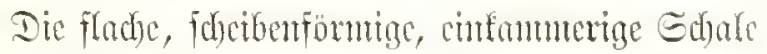
bat 3-4 mm Durdinefijer umb befteht aus cince

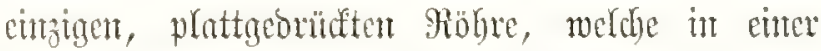
Ebene fpiralig aufgerollt ijt; ihre siseite nimmt gegen bie Miunbuty hin jut.

\section{Jig. 5. Articulina sagra (d'Orbigny).}

Die Gdale ift $1 \mathrm{~mm}$ lamg uno ans $7-9$ Simmment żufanmengefert, beren Dberfläd)e feime Rängatippen zetgt. Dic exjter 3-5 Simmem

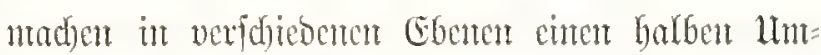
gang (wie bet Miliola, Jig. 1-3); bie folgent= Den 2-4 liegen in einer Steje fintereinanoer uno finto ermeitert.

\section{Jig. 6. Spiroloculina nitida (d"Orbigny).}

Die flodise Edhate bat $1 \mathrm{~mm}$ Durdynefier umb

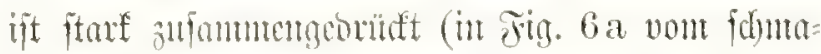

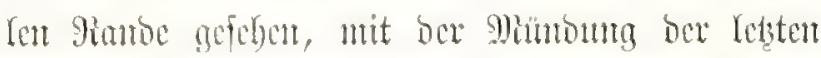
Sentmer). Die Eberflät) iit teifwcife gutbig. Dic 9 Sanmerst funo in cinter Ebene fpiration anfigerollt;

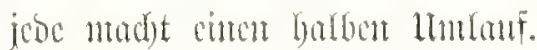


sig. 万. Alreolina melo (a'Orbigny)

Dic Edyate ift metonenformig, von $1 \mathrm{~mm}$ Durdyntfier uno von febr vervisfertem Sammerbat,

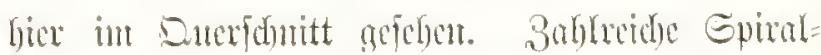
röben, welde in viele sianment abgeteift funo,

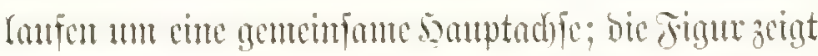

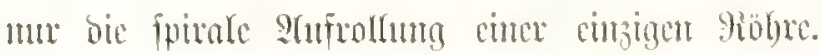

\section{Fing. S. Peneroplis planata (1.ontfort).}

Dic fladhe Edhale ijt fäd)erförmig, nour $1 \mathrm{~mm}$

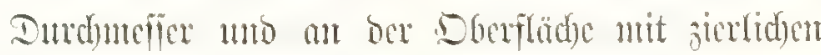
paralleten Mippen gezeidynet. Dic zahtheid)en Sian= ment, weldse in einer ebene fpiralig anfgerollt fimb,

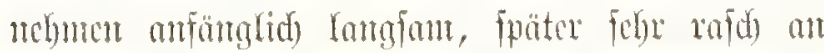

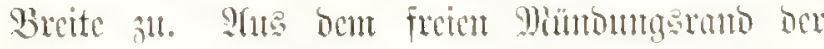

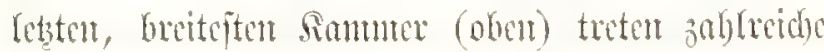

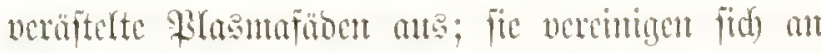

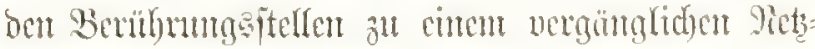

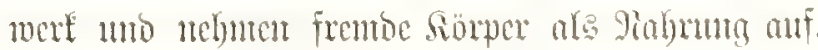

\section{Fig. 9. Intuerima cilcinata (Brady).}

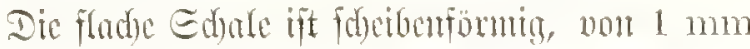

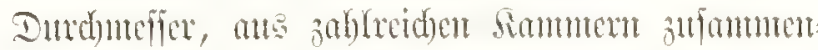

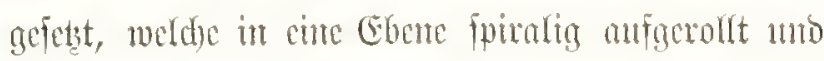

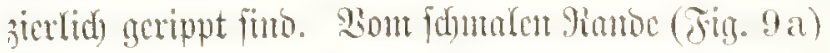
ficht man bie juhfreiden shiumbutgestodyer in ber 然anto Der jüngitent (Iebsten) Stanmer.

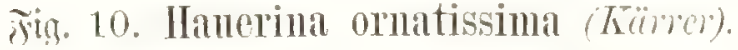

Dic fladoc Edare ift limfonfömia, non $1 \mathrm{~mm}$ Durdmenter, ähntlidy ber vorkergehenoen gebiloct.

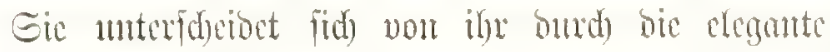

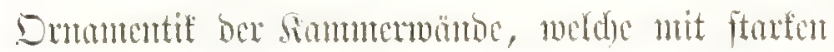

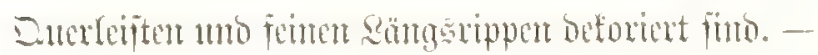
10 a Rambanfidut (unit Miümomon).

Fin. 11. Tertebralina mucromata (n'Obigmy).

Dir Edyale (säntae $1 \mathrm{~mm}$ ) hat untut ben Ban

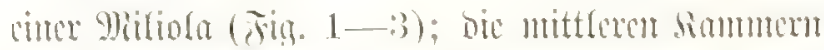

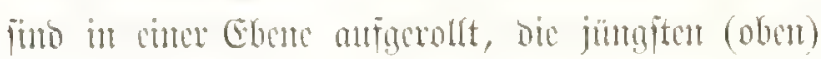

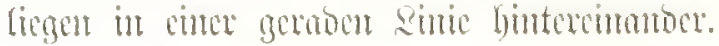

\section{Fig. 12. Vertebralina insignis (Brady).}

Die Guare (non $1 \mathrm{~mm}$ Durdumeffer) i i ähn= ride wie bic vorige getout, aber burde Gribedent ber

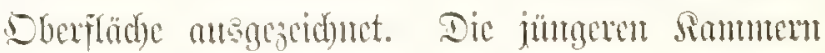

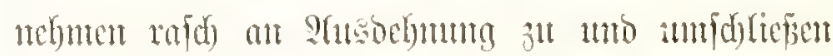

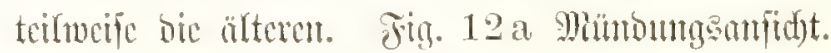

\section{Fig. 13. Vertebralina catena (Haeckel).}

Die Gdyale ijt 2 mm Iontg unto im ältepten Teil

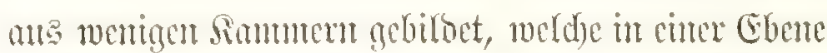
ipiral anfgerollt funs; bic jüntgeren Sammern, in ciner Reibe bintercinamor Viegento, betoen cine Siette.

\section{Fig. 14. Vertebralina furcata (Hacckel).}

Die Gdyale ift gegen $2 \mathrm{~mm}$ fantg uno äbulid ber vorigen gebifoct; aber in ber Ilitte begimnt fie

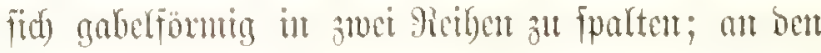
jïmgiten Simment ift bie Gabclteifung vollftündig.

\section{Fig. 15. Biloculina comata (Brady).}

Dic Edhate ift vierfanmerig, ähnlid) Miltiola

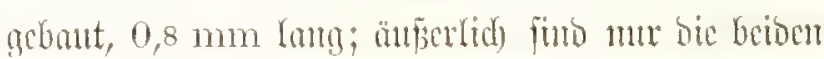

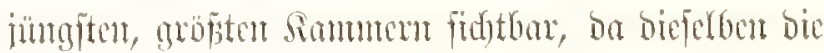

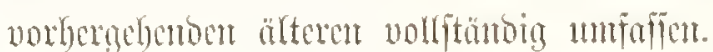

\section{Fin. 16. Orbiculina admea (Lamarch).}

Dis anfanmengeoridffe Edfale ift nantiroio, von

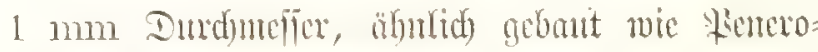
plis (Jig. S); man fitht fie vom Bambe ber Sd)unt=

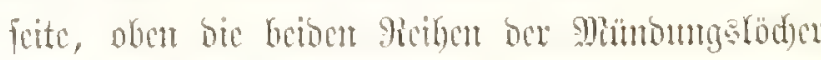
in bex jüngyten Edectomento, unten cunige altere

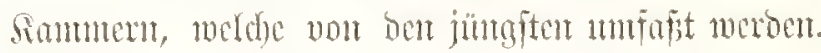

\section{Fig. 17. Orbitolites laciniata (Brady).}

Die fretimune Edhate exreidnt $25-30 \mathrm{~mm}$ Durdumefier uno hat bie Gejtalt ciner bifen Edyeibe, Deren Giano mellenfibuming gefaltet ijt. Eic bejteht

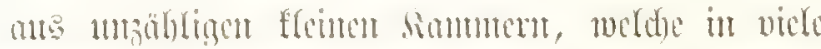

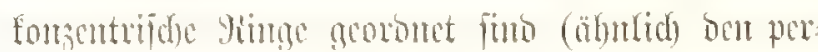
Foraten 9ummuliter); mu bie älteften simmor:

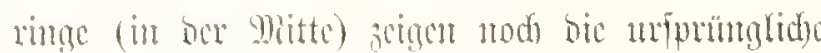

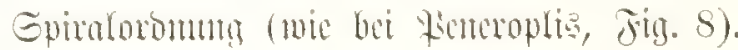



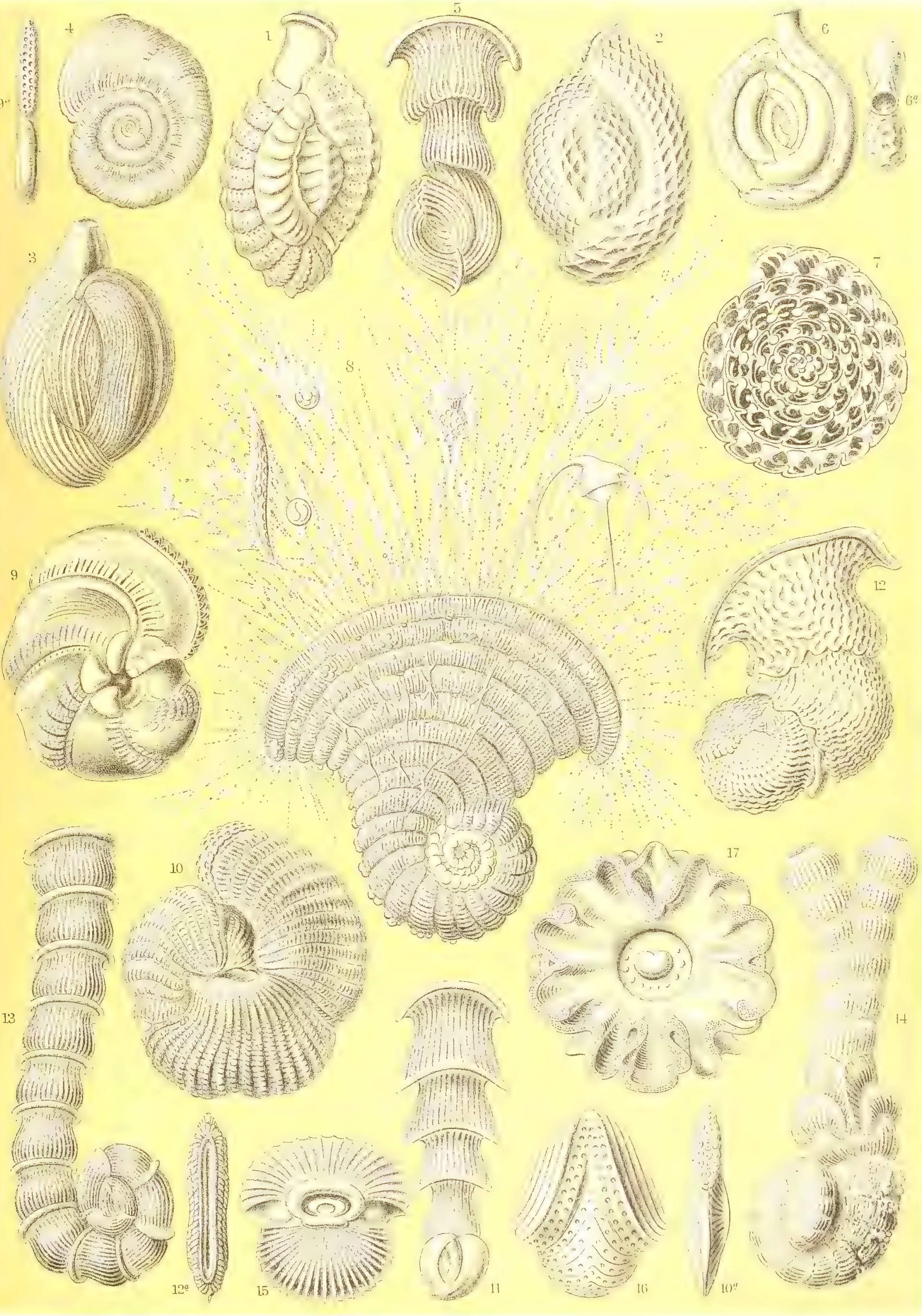

Talamophora. - Escontntertiurge. 



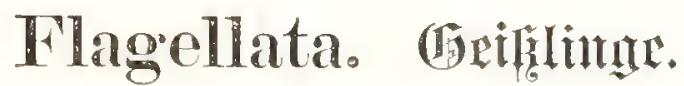

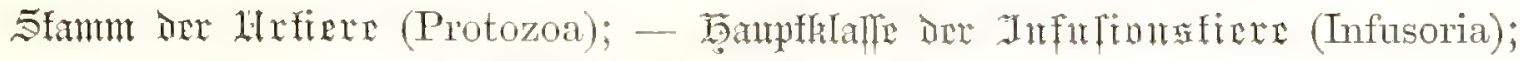

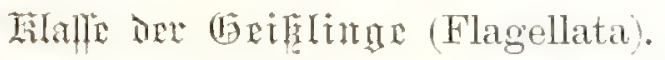

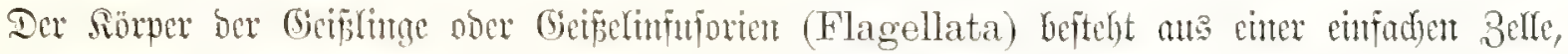

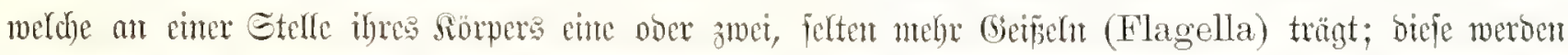

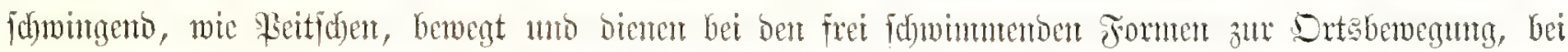

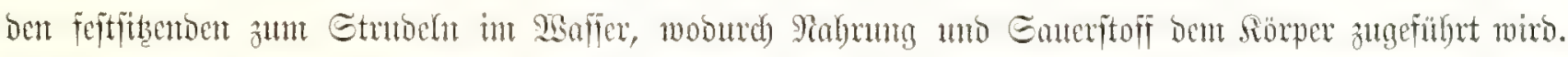

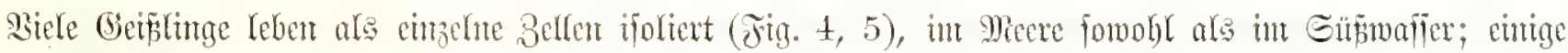

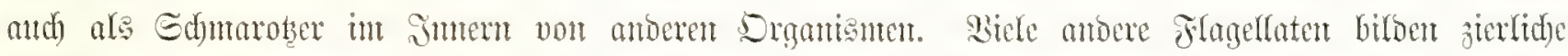

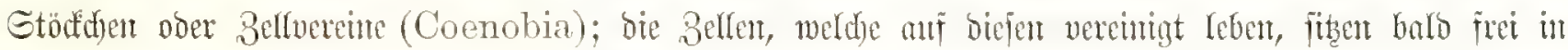
Gruppen auf ben Emoen von veräftelten Etielen (Jig. 1-3), balo wohnen fie in Giobren ober in bedjer=

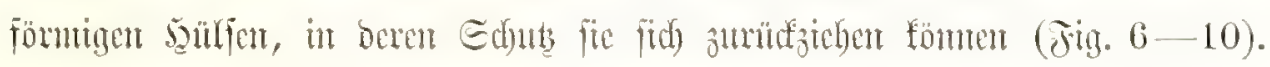

Figr. 1. Anthophysa vegetans (Stein).

Cin meides unt biegfantes, viet nerzwetgtes

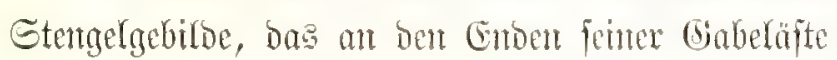
fungelige Bellvereine (Eörobient) trägt. Diefe beftehen

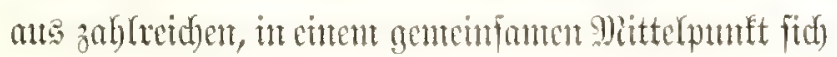
berülyrentoen Beflent, vont denten jebe cine Geiped trägt.

\section{Fig. 2. Cephalothamnium cyclopum (Stein).}

Ein fteifer breiteiliger Etengel trögt an oent Enton feiter Sifte bre Galbfugelige Befluercine (Cönobien);

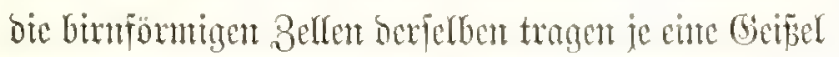
mo beriblyen fidy an dex gemeinfanten Bafis.

\section{Fitg. 3. Codonocladinm candelabrum (Haeckel).}

Ift ber Epiţe cines bümen, fpirafig gebogenten Stengels fteht eime Dofbe mit mebrexen $(4-8)$

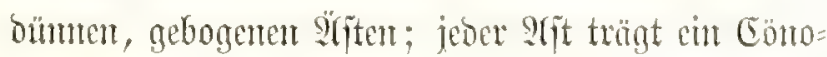
bium, das aus melyeren (3-9) an ber Bafte vereinigten Beffen allammengefest iit. Der bem= förnige Seib jeber Befle trägt oben einen bümen

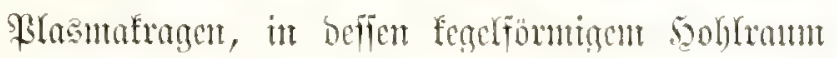

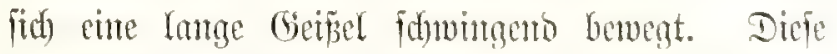

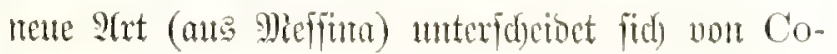

donocladium umbellatum burch bic gebogenen Stiele und bie gröpere Babl ber Beffen in ben doldomförunigen Cönobien.

zig. t. Trichomonas intestinalis (Dujardm).

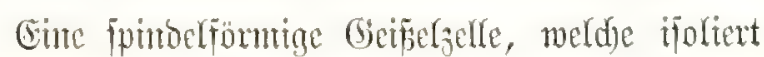
in groper Dienge als siarafit in Darmfantafe vieler

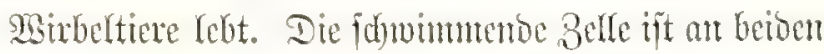

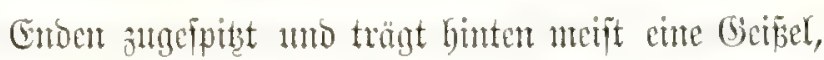
vorst 2-4 (meift 3) Geip̃eln. Ein fdywingentes

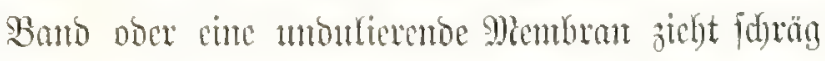
über Den Siorper.

\section{Fing. 5. Tetramitus rostratus (Perty).}

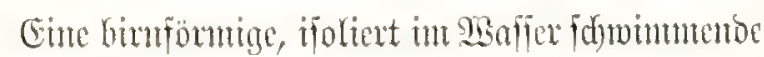

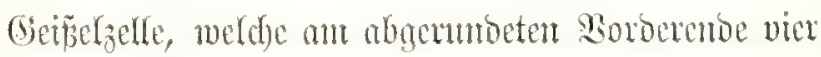

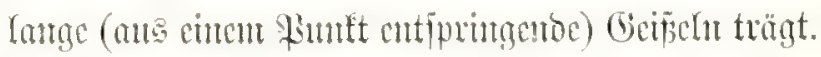

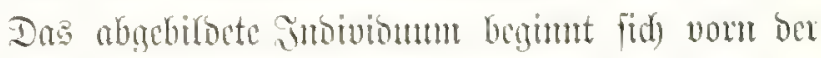

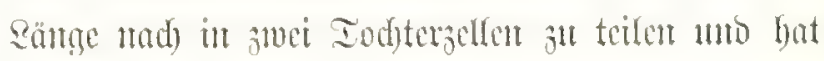
bereits ad)t Geipelu nebildoct.

Fin. 6. Rhipidodendron splendidum (Stem).

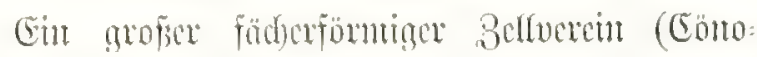

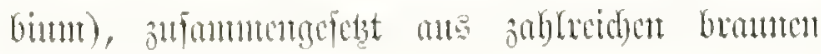




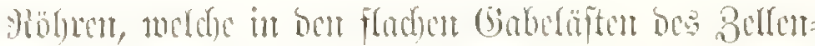

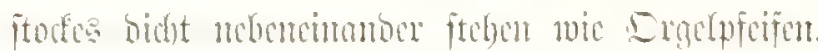

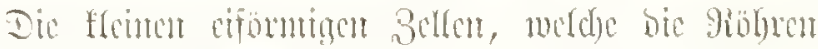

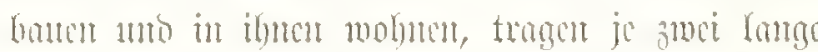

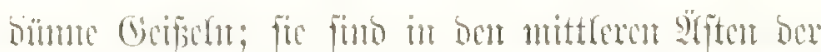

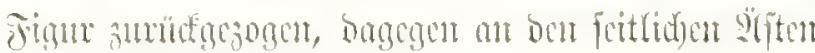
teitweife lecroorgetreten.

\section{Jig. 7. Codonosiga botrytis (Stem).}

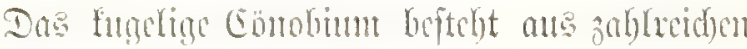
bimformigen Setten, welde in Mittelpunft ber Sungel vercingat uno anf cincm bünmen, geraben

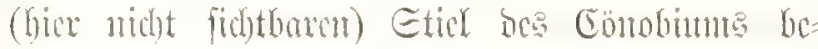

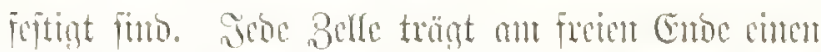

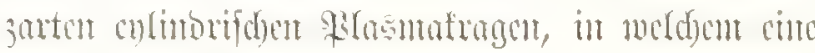
fange Gerised foldumingt.

\section{Fin. S. Phalansterium digitatum (Stein).}

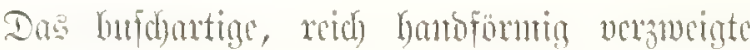

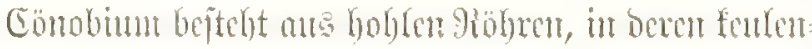

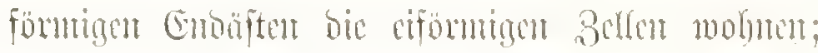

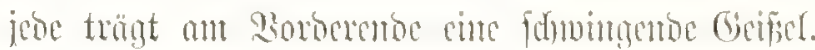

Fin. 9. Dinobryoul sertularia (Ehrenberg).

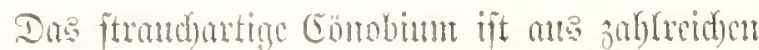

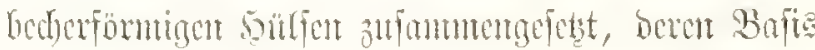
foumabeläbulidy angcipiat ift; bic bafalen Epitan

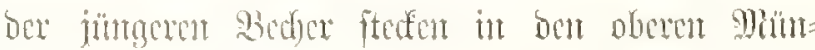

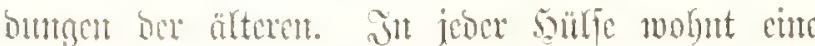
fdolonfe ciförmitge Belfe, weldye oben cine grofie und cine fleine Ginipel trägt.

\section{Tirs. 10. Poteriodendron petiolatum (Stein).}

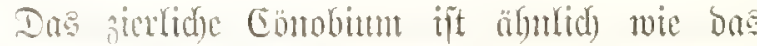

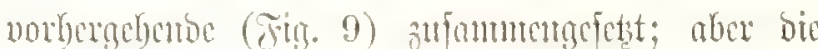

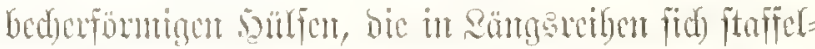

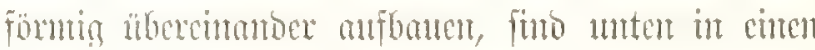
fciurn, bümen Etiet ansegrogen. Stm Sorderento

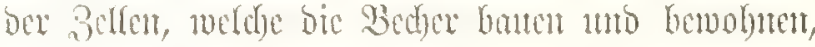
ftelit atben der Geifel cin furzer Rlasmafragen.

Fing. 11. Uvella glancoma (Ethenberg).

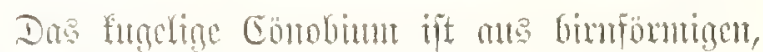

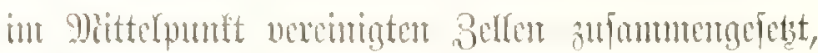

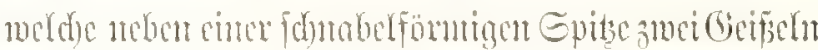

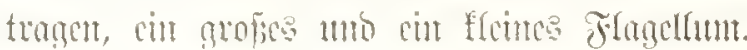



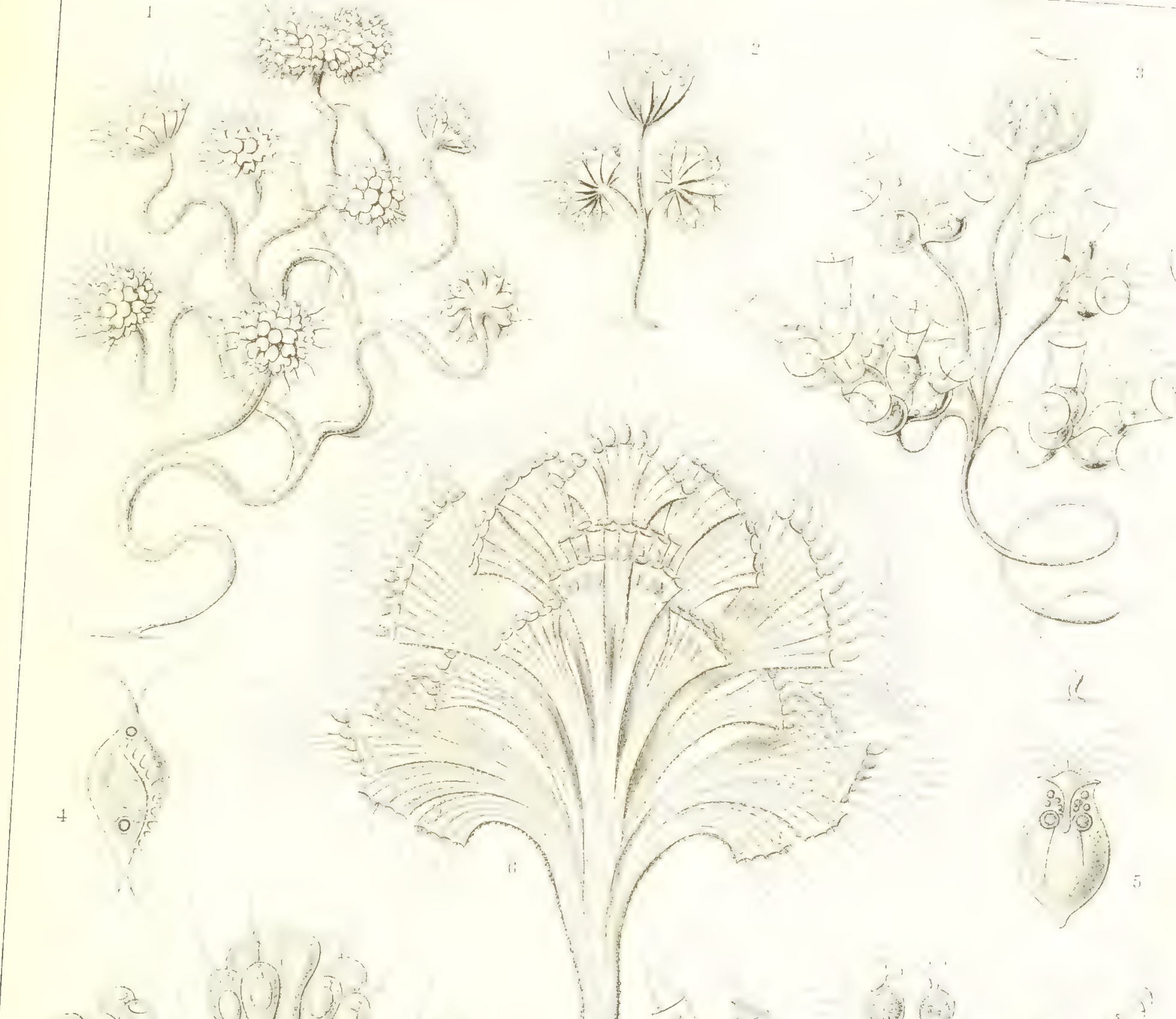

$\left.27^{2}\right) 91 / 2$

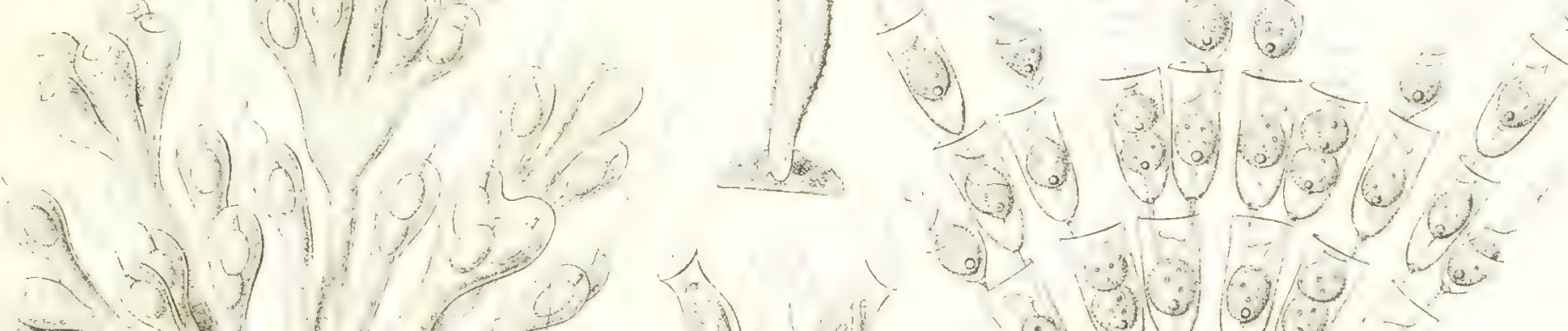
-19 a $y$
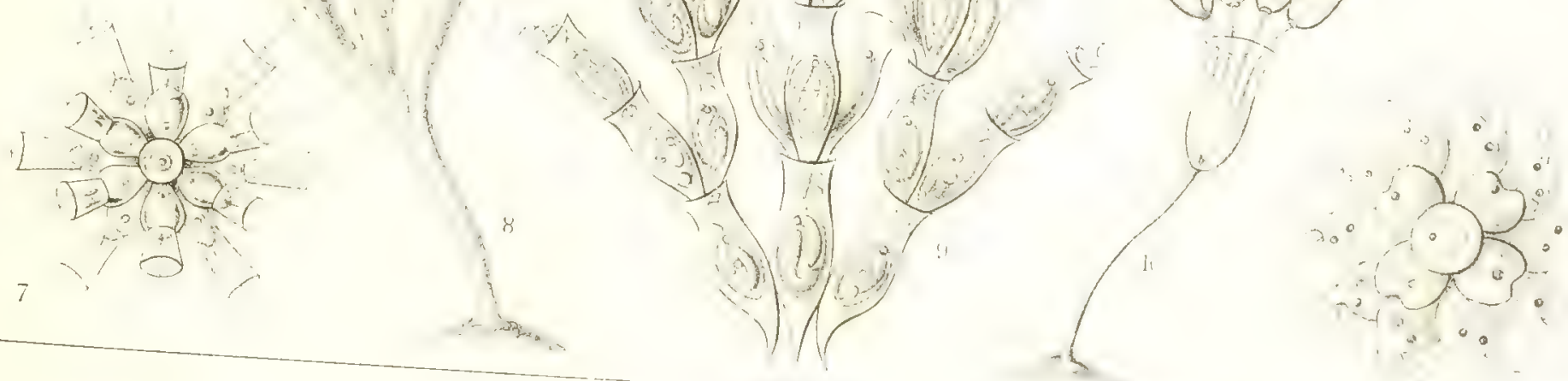

Flagellata. - (sibilimege. 



\section{Peridinea. (oret}

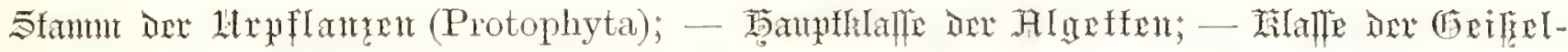

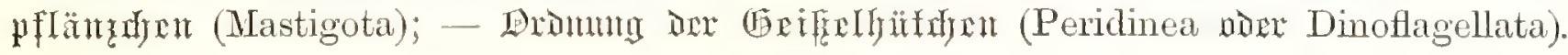

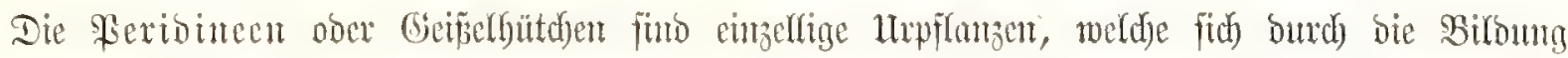

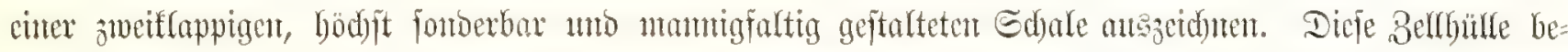

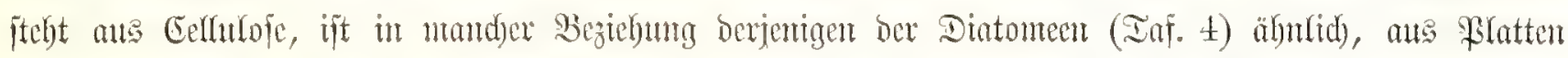

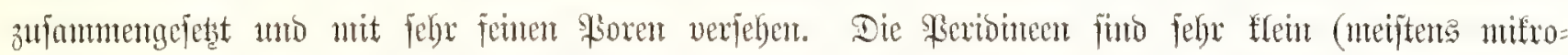

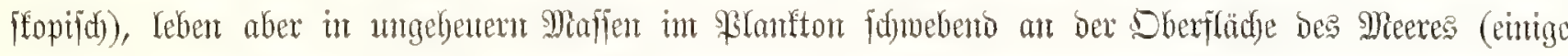

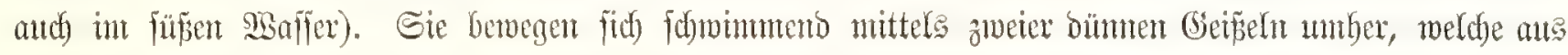

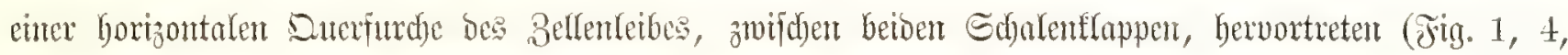

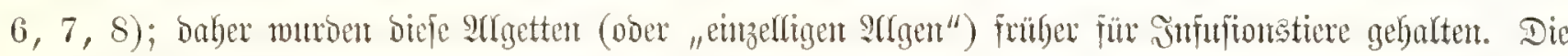

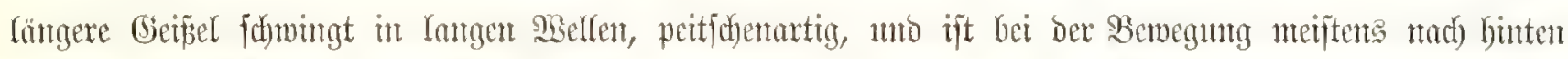

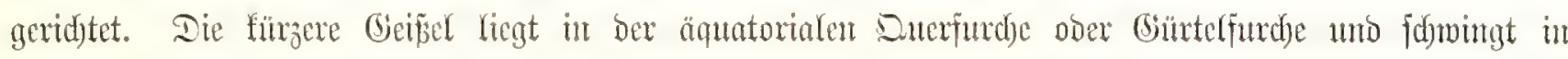

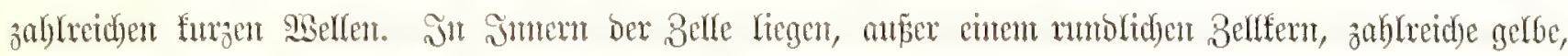

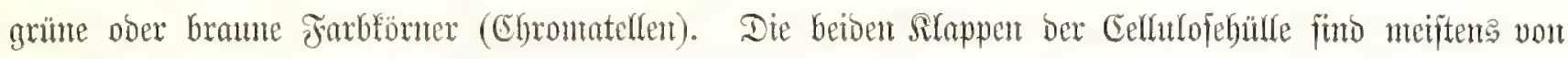

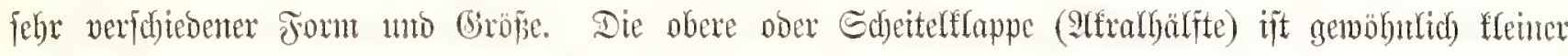

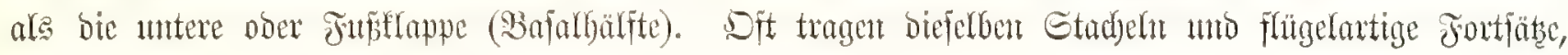
weldye teils als Sdyutwaffen, tetrs als Sdywebeapparate bienten.

\section{Jig. 1. Ceratium tripos (Nitsch).}

Die getäfelte Suale beftebt aus zwei febr um= gleid)en Silappen; bie untere (in ber Jigur nad) oben gefebrte) Junfflappe trägt żei Iange, gefrümmte

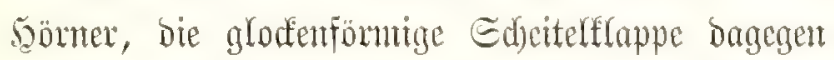
cin lantges (tadt) unten geridytetes) gerabes 5orn.

\section{Fig. 2. Ornithocereus magnifieus (Stein).}

Die gefornte Edjate lyat bie Geptalt cines reid) verzierten Mitterbetms; obent trägt fie cinen fent:

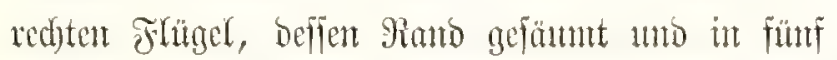
Baffen angezogen ijt; ex wiro ausgeppant butrd

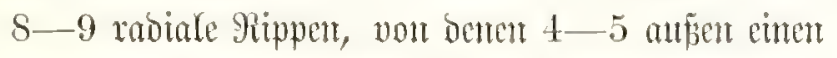
fpongiöfen Bapfen tragen. Dic untere Münonng Des Selme i i te von einem breiten, boppelter, tridjter=

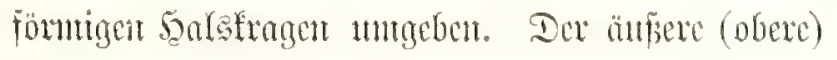

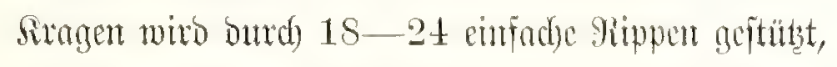
bet inmere (untere) Sragen burd) 10-12 Bippen,

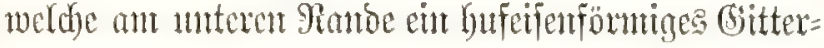
blatt tragen. Der Manm żwijuen beibent Siragent ijt bie ferde ategcolgnte Duterfurdje.

\section{Fing. 3. Ceratocorys lorrida (Stein).}

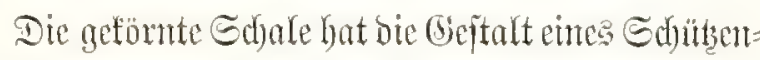

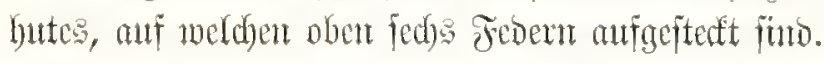
Die Greite Sirempe untent trägt feine ftrahlige Fippen unto ift an ber linfent Seite tief cungeferbt. Die Sheitelflappe (unten an Sutt) ijt fitant reoujiert.

\section{Fig. t. Goniodoma acuminatum (Stein).}

Die Edyate ijt cutfernt; man fieldt mur ben

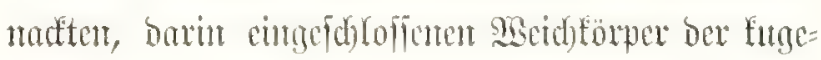
Legen Belle. Die obere balffe berfelfent ift von ber

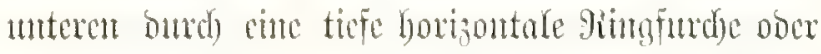

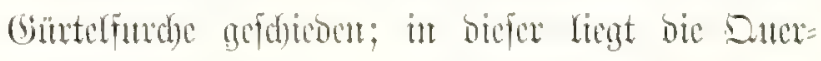

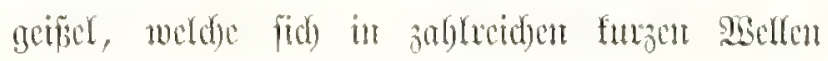


berwegt. Sinfe gebt an ocr slitte ocr äquatorialen

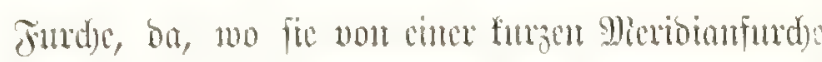

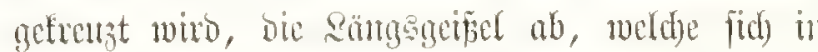

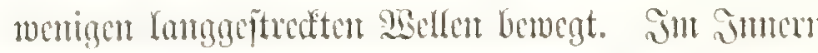

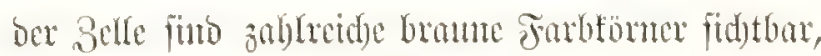

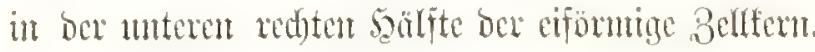

\section{Jig. 5. Dinophysis hommenculus (Stein).}

Dic getönte Gdale bat bie Gejtalt cimes Simm= merbern in Fraú (ohne Sopf), von oer linfen Ecite gefelden. Shen erbebt fich ciu fteifer, worn offerter Etchfragen oock Sopftridutex. Danuter fteht cin fdmölerex salafxagen, ber fid vorn auf ber Bruft

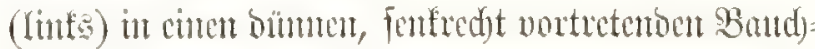
Flügel fortfert. Der gewölbte Siülen (red)ts) ver

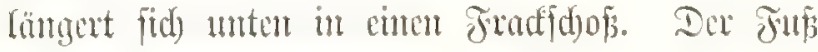
Fpist fid anten fegelfömnig ôt.

\section{Jig. 6. Dinophysis sphaerica (Stein).}

Die fugelige, gefounte Edjale trägt oben cum breiten, vorn offenen Stebfragen ober Siopftriduter, baxuntex cinen fdomälexen salsfragen. Bwifden beioen Sirangen ift in ber Situgfurdje bic wellen=

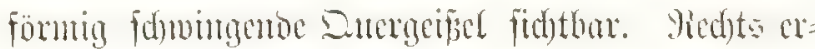
bebt fid) auf ber Bruft cul breiter, meteörmig ge aberter Bandffligel, ang bem anten bie fdomingenoe

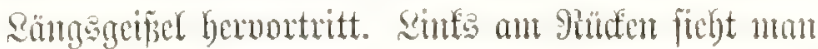
ben cifönmigen 3ellem.

\section{Fig. 7. Ceratium cornutum (Claparède).}

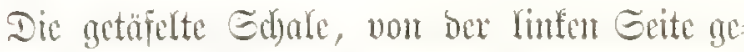

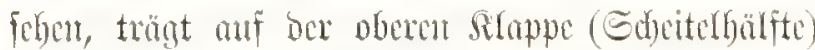
cin fodicf abgeftutsteg Stimborm; anf ber unteren

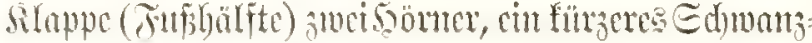

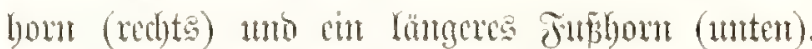

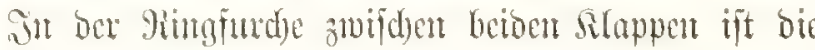

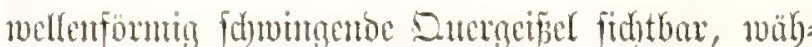
reno unten bie gröbere sänggegeipel vortritt.

\section{Sio. 8. Ceratium macroceros (Schrank).}

Die getäfelte Gdyale, von ber redjten Seite ge=

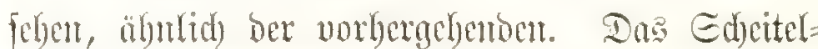
Gourn (anf ber oberen Sllappe) ijt länger; bie untere Silappe trägt hier brei särner (linf Edywanthorm,

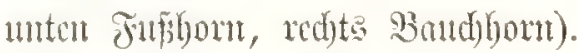

\section{Fig. 9. Pyrgidium pyriforme (Haecket).}

Die cifönnige, gefounte Edhale gleidyt einer Fund, beren funzer Gtid unten von chen linfert= förntigen Siragen itutgeben ift.

\section{Fig. 10. Peridinium divergens (Ehrenberg).}

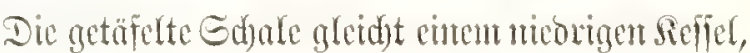

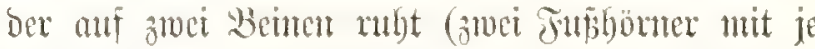
cinent Bahn). Der fegelfömige Dedfel (bie Ed)eitel= flappc) trägt oben cinten Sitopf́.

\section{Jig. 11. Histioneis remora (Stein).}

Dic gefönte Edale, von der linfen Eeite ge= feben. Die fleine Edycitelflappe (nad) unten ge=

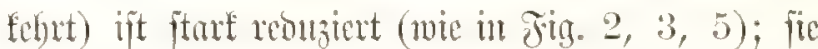
trägt cincen fd)fonten lyohen Sopftrid)ter (immeren Siragen). Die balbfugelige Funftlappe trägt binten

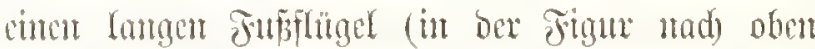

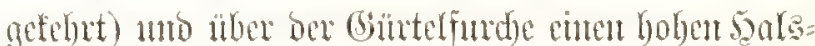
fragen, weldyer in zmei Scitenflappen ge्palten ijt. 


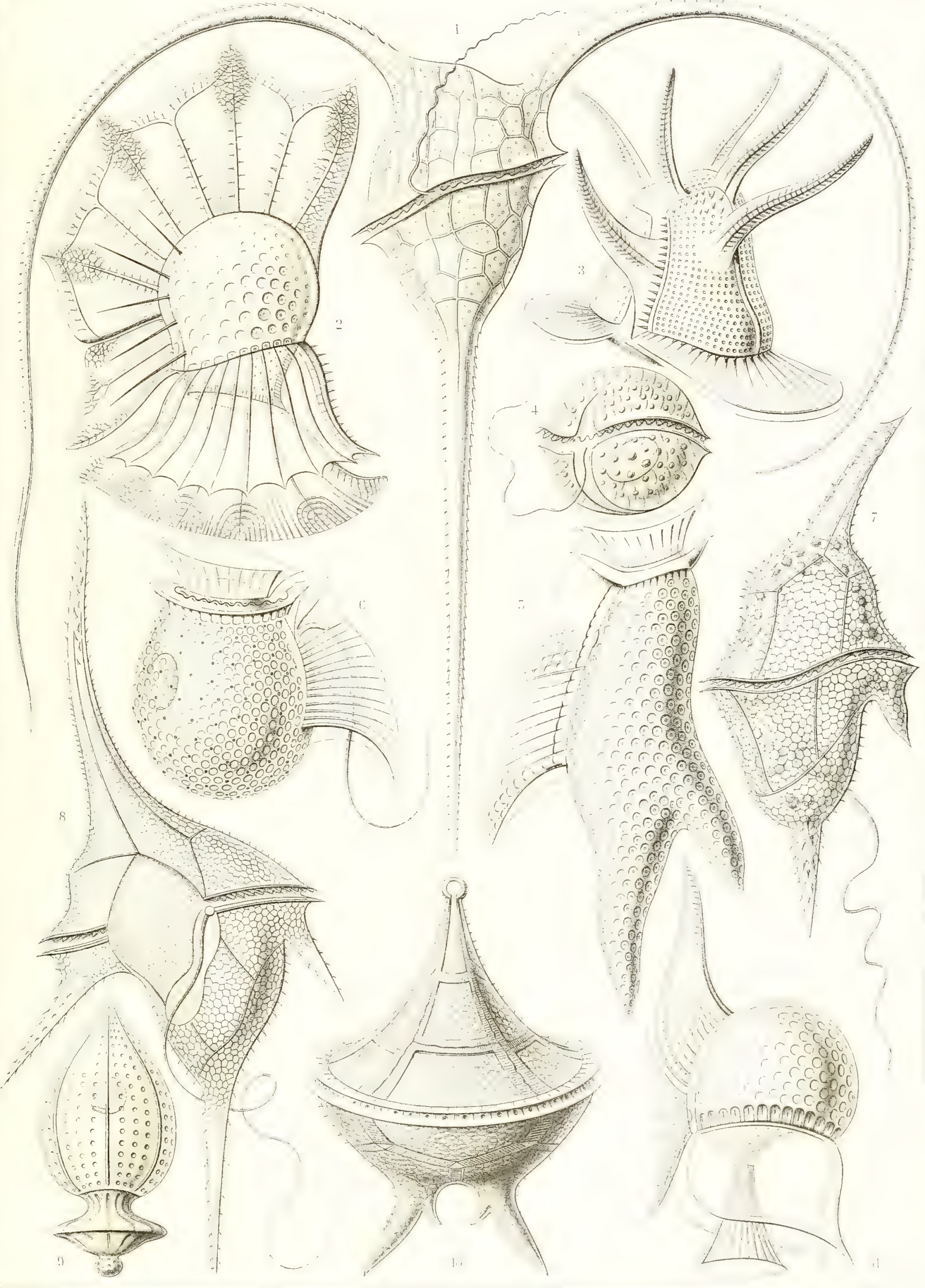

Peridinea. - Seibelliütdicn. 



\section{Fucoideae. firamntanter.}

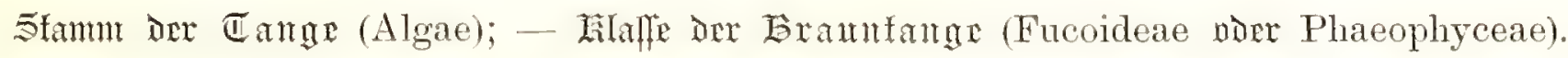

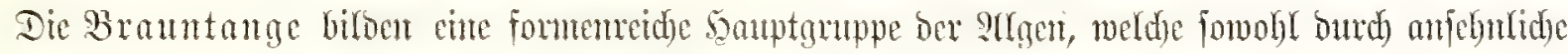

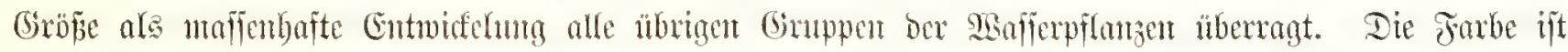

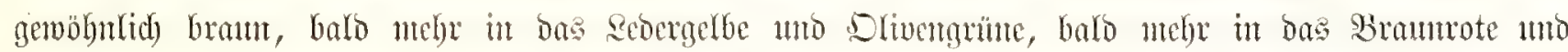

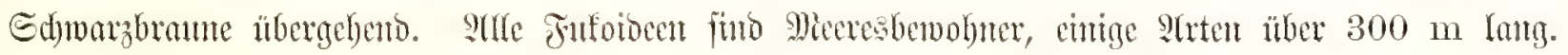

Fig. 1. Nereocystis Lütkeana (1/ertens).

Familie Dex Taminariaren noer Bläfferfamgr.

Der einfadye unto fegr bünne Etengel trägt ant oberen Ento eine gropse birnfömnige Edjummblate unb oberbalf berfelben cine Sirone von jumatent uno fehr lantgen Blättern. Der Etengel wiro über $100 \mathrm{~m}$ lang. (Roropacififder Djean.)

Frig. 2. Cutleria multifila (Grey).

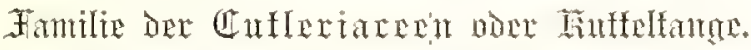

Der fädherfömntige Spró ijt micocrbalt gabet= förming geteilt; bie slffe dümuäutig, blattfömnig, wellentrönnig gebogen umo teifweife fpirafig gebrebt.

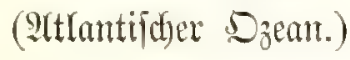

Fig. 3. Cystosira erica (Necceri).

Famtlie one Fufaren nox Blafmfange.

Der Stamm bes Iflallus ift unten burd) eine

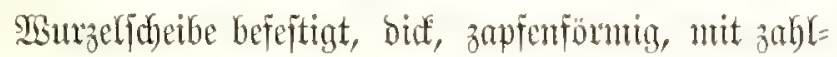
reichen, eiförmigen, ftadjeligen Sinorren bidst bejeţt. Ex trägt viele fadenfönomige, allfeitig verzonetgte

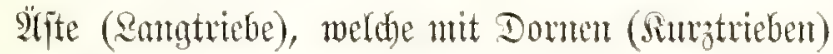
bidit bejeţt finto. (Mittelnteer.)

Fig. t. Thalassophyllum clathrus (Postels).

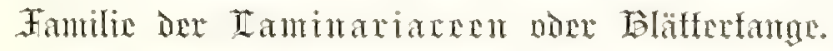

Der ftattlidje Thallus ift unten burd) fafern auf bent Meeresboben befoitigt. Die sifte Des verzweigten Stengels jpalten fid oben umo biloen breite B̉(ätter, weld)e tütenfönnig eingerollt

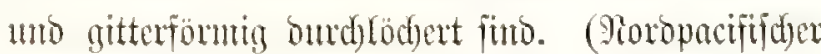
Dicutt.)

Fig. 5. Scaberia Agardlii (Greville).

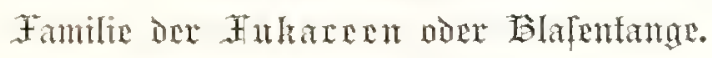

Der Mittelgrope Sproj ijt unten ourd) eime

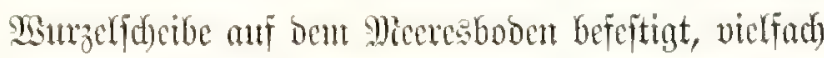
verzmetgt. Der Stanm uno bie Sangtriebe finto

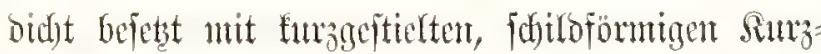

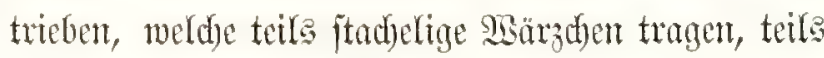
in Blafen verwandelt fitto. (9Tujtralien.)

Fig. 6. Zonaria pavonia (Agardh).

Familie Der Dirfunotaren noer Fädferfange.

Der füderförmige Thallus ift verzoneigt, bie blattfönmigen Sifite flad) ansgebreitet, mit butfeln fonzentrifonen Streifen gezeidunt, an freien Soroer=

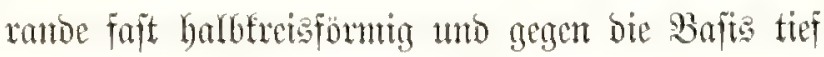
ftrahfeñ̈̈rmig eingejunitten. (Mittelnteer.)

Jitg. 7. Turbinaria gracilis (Sonder).

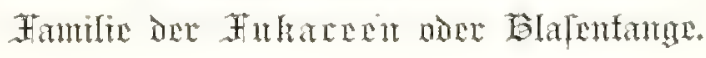

Der bufdoförmige Thalfus ift affection reidy ver-

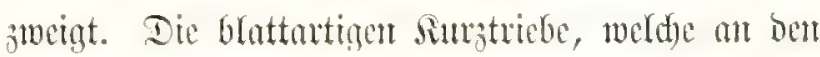
Seiten ber fabenförmigen \&angtriebe aufituen, finto fojiroförntig, breifeitig, ant Rande ftemförming gezülynt; ifre fegefförmigen Stiele füro blafentartig

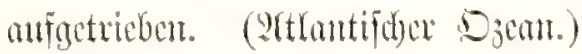





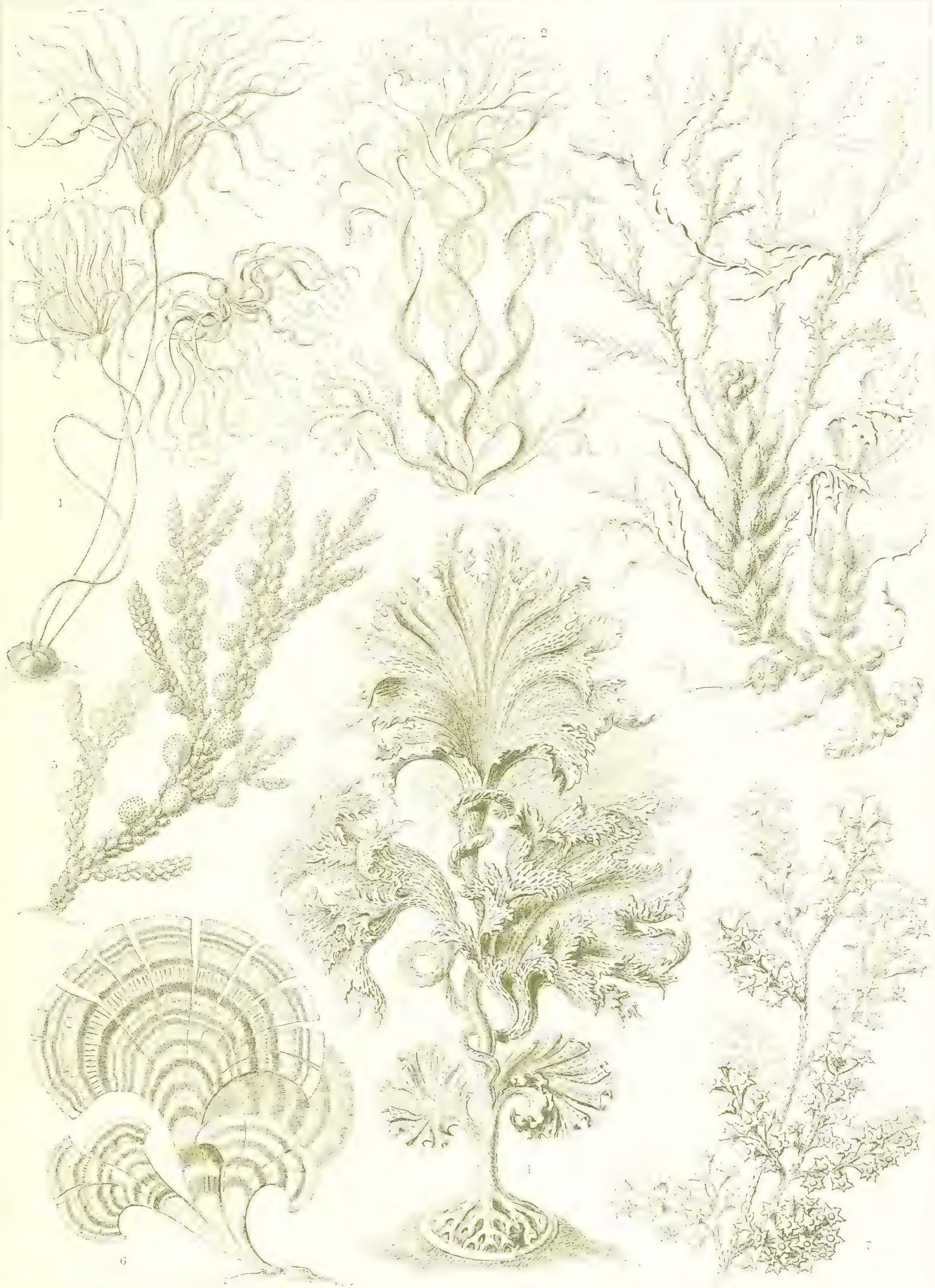

Fucoideae. - כૈrantufurtuge. 



\section{Narcomedusae. 5ramnumallen.}

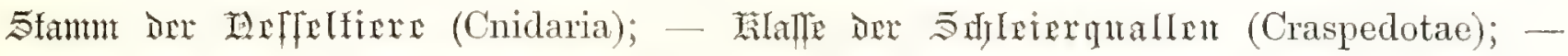

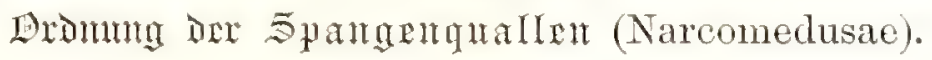

Die Spangenquafren (Narcomedusae) bifben ente eigentünlidje Sronung in ber Rifaffe

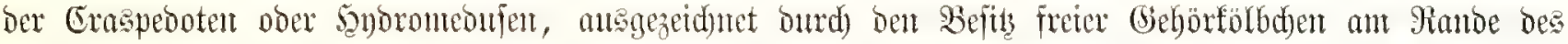

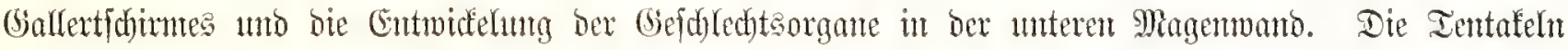

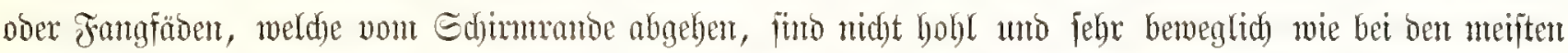

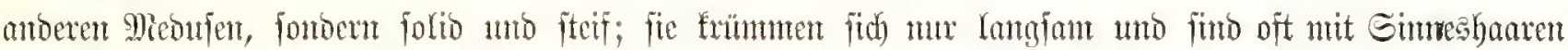

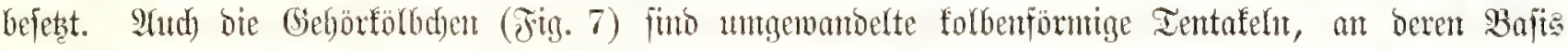

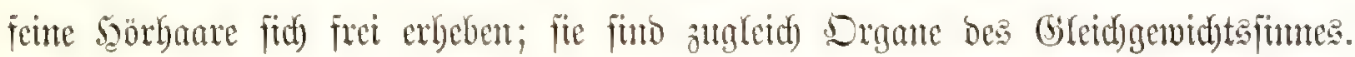

Fig. 1 u. 2. Pegantha pantheon (Haeckel). Familte dex frenantlyident.

Fig. 1. Seitemanfidat der झ̈coufe. Der galler= tige Sörper hat bie Gejtalt eines Diabems unto ijt burch eine hortzontale Bintrifurde in cine obere, faft balbfingefige Edfimtinje uno einen unteren, ge= lappten Sdjimffranz geteilt. Ifue ber Pingäurdje cutfpringen bie 16 fdulanfen, geglieberten, foliben Ientafeln, weldye $S=$ förntig gefrümmt umo mady oben

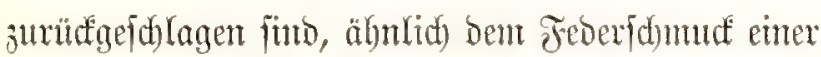
Sinbianerfrone. Der Exfinmfranz ift in 16 ei= förnnige rappen geteilt, weldye unten burd) eimen

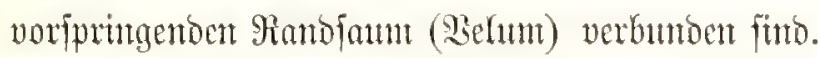
Unten fiebt man etwas in bie Sdjumbaghe Ginein umb exbliaft ben unteren Teil von eintigen (bläı=

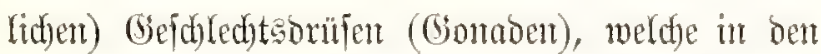
fonfaven Sitiden an ber Immenfeite Der Rappen verborgen liegen.

Jig. 2. Ein einzelner Ed)inulappen berfelben

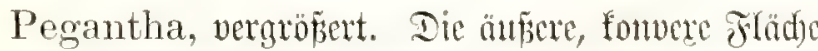

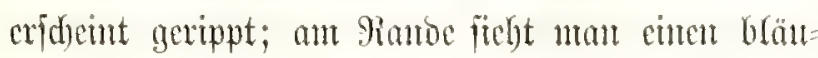

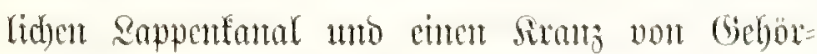
förbdyen (von ähntidyer Billomng wie Jing. 7).

\section{Fig. 3. Aeginura myosura (Haeckel). Familix Dex Ḧhintion.}

Untere Sinfidst Der Miedufe, Derent (Salfertfdirm in Der Seitenamfidat fajt halbefugeling gemölbt ift (ährtlid) Fig. 5). Jut ber Mitte ber Edjumbähle

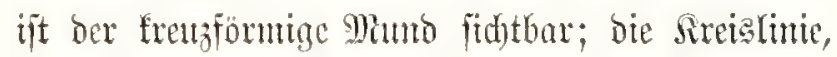
weldye berfelfen umibt, ift ber immere, frei vor=

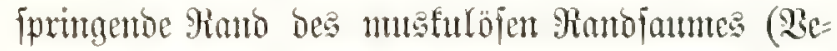

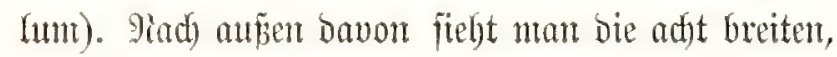
ttad) innen eingefd)lagenen Fantolappen bes Sdjirmes,

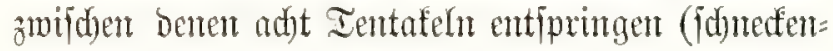
förmig ờlanmengerollt). In jedem sappen liegen

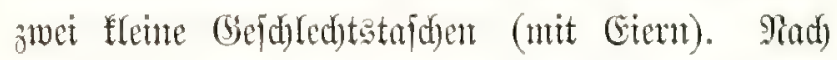
inten vou bent (GGatten) Giantofantal ber anppent

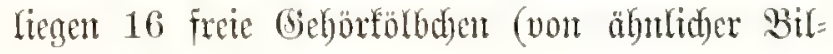
bumg wic Fig. 7).

Fig. t. Solmaris Godeffroyi (Haeckel). Familix ine Snlmarioen.

ltntere Sarfidgt ber Micoule (äbntid) wie Fig. 3). Dex vievedige Minto ijt vout cimem adjtlappigen Ge=

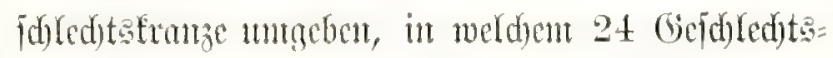
brifien ober Gontaben tabial voriptingen (je bret an jeocm Sirantappent). Pad) aupen bavon fiebt man 


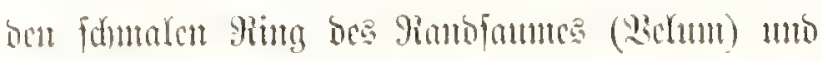

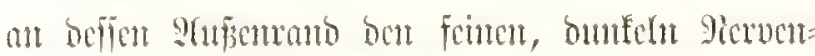

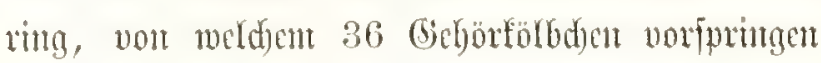

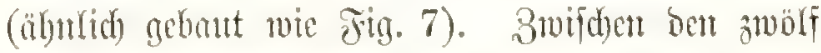
vorgewolbten Fand Lappen bes Ed) Gmes liegen ampen suölf cingerollte Ientafeln.

\section{Jig. 5-7. Cunarcha aeginoides (Hacckel).

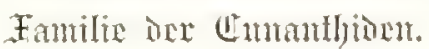

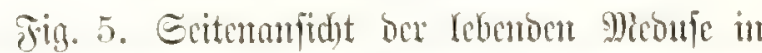
Ed)minmberocgung. Eine ticfe Simgfindye tremt bic gallertige, balbfugelige Edjumlinfe (oben) von Dent vicuteifigen Edyumfranz (unten). 9(115 ber

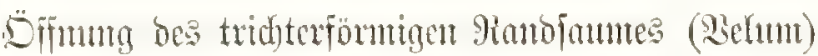

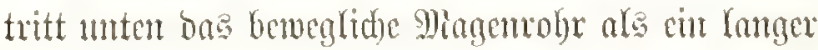
Priffel vor, an beflen Cnoc fid) bex vierefige Mano

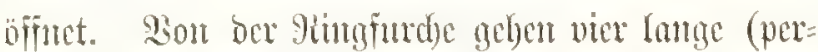
robinle) Ientafeln ab, beren folbenförntige Enocn Inten nit Gimmesharen befut finto. Seon ber viel Bandappen bes Edjumframzes (zwijd)en ic 3̧wei Fangfäben) entbält zmei Ciertajchen mo jeigt unterbatb berjelben cinen blamen Ganbfanal mo Dré Geböröbracu.

Fig. 6. 2nfted berfelben Meoufe won oben.

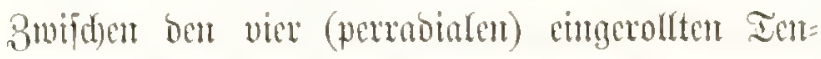
tafeln fpringen bie vier (interrabialen) Rappen bes Edjirmfranges weit vor; jeber trägt am Bambe brei

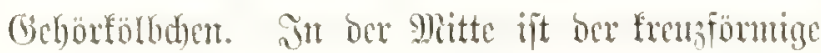

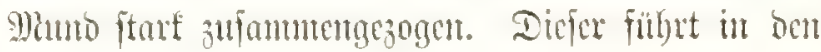

(bläulidyen) Mragen, yon soclden viex Baar Rabial= Eanäle uno viex Ram Rappentajden abgeben.

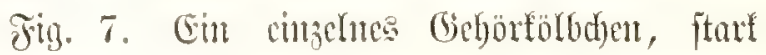

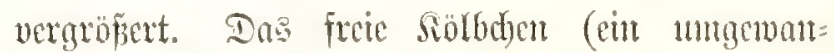
belter Ientafen cntbält oben in Enoteile cinen Dtolitben (soorftein) uno ijt untugbent von zartent

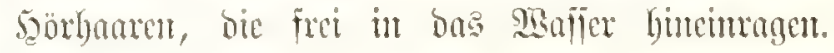
Jit bent barunter gefegencu Teil Des Gdjum= rantoes fiebt man cin Etüd bes Ringfanate uno (unten) eine börpange, untgeben von cinent halb= monofönuigen \$signtentpolfíter.

\section{Fig. 8. Cunantha primigenia (Hackel). Familic ine Curnanthơnen.}

Geitenumidgt ber fduminmenoen Diedufe, äluntid) wie Jig. 5. Gic unterjdeioet fid von biefer batpt

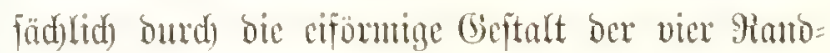
lappen des Gdimnfranzes, von benen jeber mu cin cintige Gebörfolbdent trägt.

\section{Jig. 9. Cunoctantha discoidalis (Hacekel). Fanilie one cumantliton.}

Pufidgt ber Medufe vou oben (wie fig. 6). Die Glate, adytitrablige Stojette ift ber Magen, und in ber Mitte desidben liegt ber fretsumbe Mumo. Son ben Enoen ber adjt Miagentafden geben adyt folioe, gebogene Ientafeln ab (perrabial). 3mijeden ifnent felhen adjt ciförnige Ranolappen, jeber mit

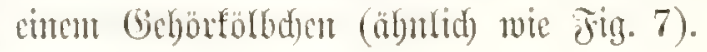



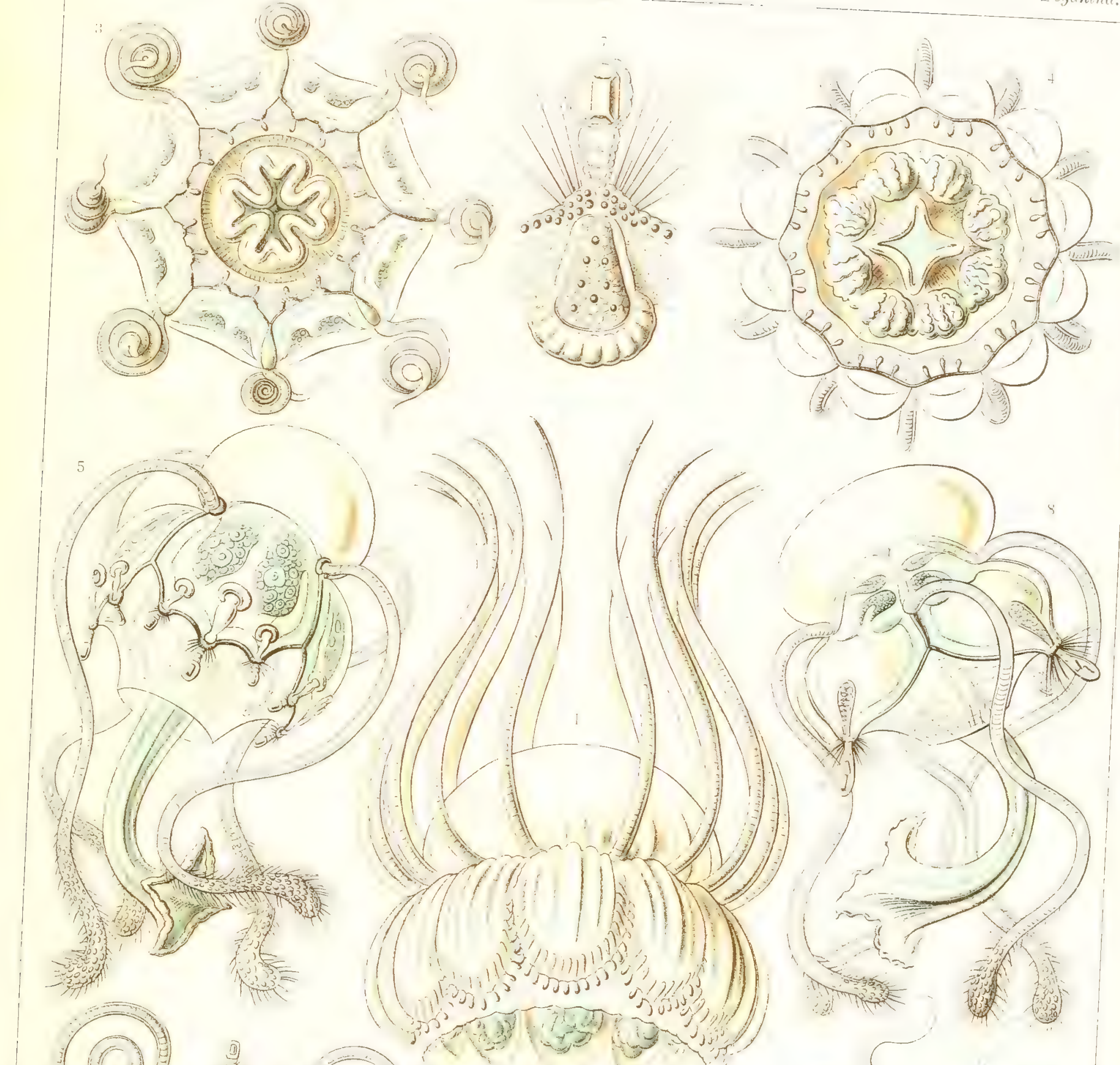



\title{
Siphonophorae. Statatinuallent.
}

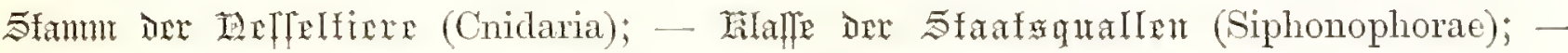

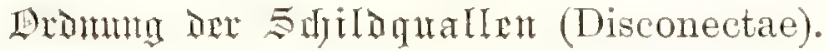

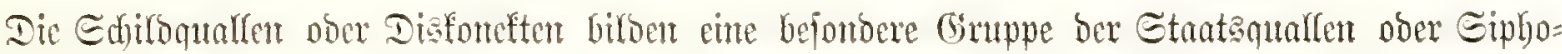

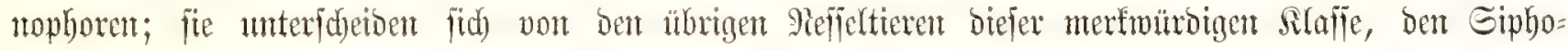

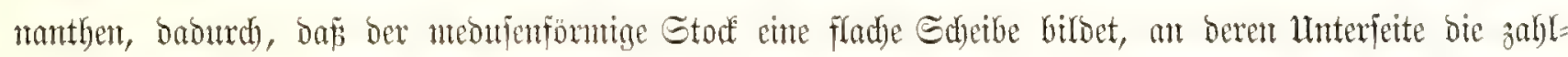

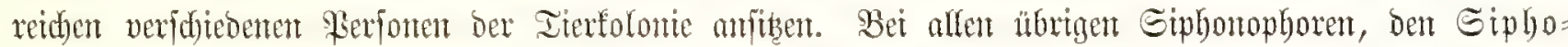
nanthen (jo aud) bei ben auf Iafel 7 abgebildeten Enjtonteften) wirb bex jentrale Stanm bes Bormus, ats weldhent bie vielgejtaltigen, burd) Arbeitsteilung bifferenzierten Eimzeltiere hervorfproffen,

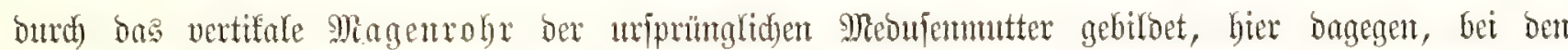

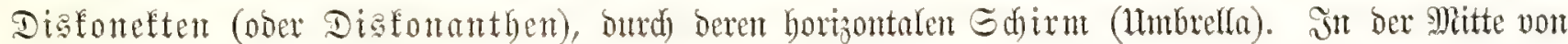

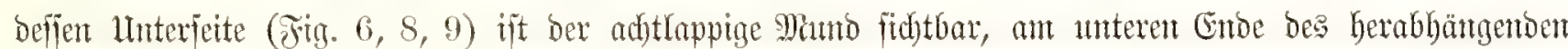

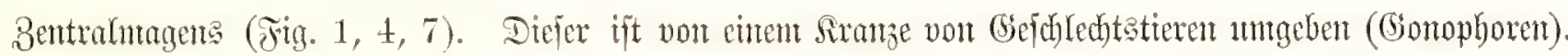

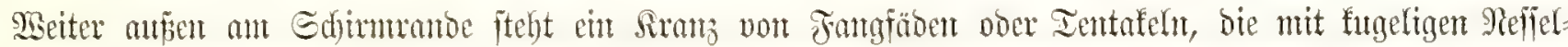

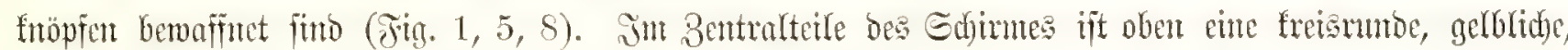
mit suft gefüllte Schminmblaje eingefd) foffen (Jig. 3 unto 5).

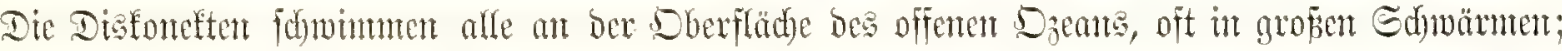

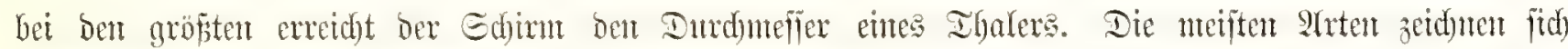

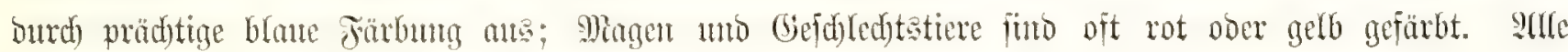

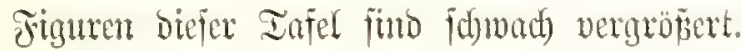

Fig. 1-4. Porpema medusa (Haeckel). Familix Dex Boxpition.

Jig. 1. Der gambe Tieritor vou ber Grite gefehen. Der Edjim (oben) hat bie Gejtalt cimes

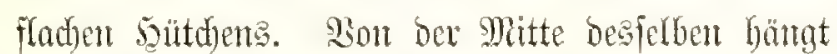
Der rübenförntige brante Magen des \$nuttertieres Gerab, Deffen adytjtrabliger roter Miunto fid) unten ansbreitet. Den mittlexen Teil umtgütet cin Sirntz von zahtreidyen, Grauen, bewegliden Tentafert.

Fity. 2. Die Grumpe von (Gejd) fedytetieren, welde unten franzfönmig bon Bentralntagen untgibt.

Fig. 3. Ednommublafe, weldye in Bentralteite

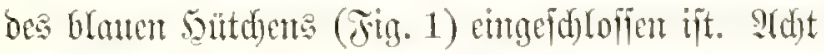

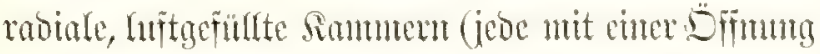

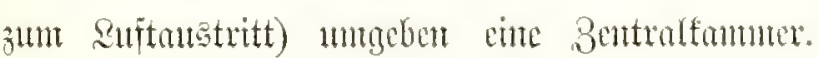

Fig. 4. Ecttentanfidyt bes Stodes Fin. 1 nad Entfermung ber zahtreetden blanten Ientafeln; man jiebt bie ferberfigent Felber, anf benen fie ange= feffen Gaben. Unterbalb ijt ber Siram der roten (Gejd)led)tetiere fidstbor, weldje ben rïbenförmigen Bentralmagen umtgebem.

\section{Jig. 5. Porpalia prunella (Haeckel).} Familic Dex Forpifion.

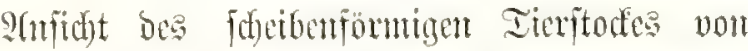

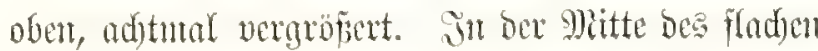
branent Sdjumes fojmmert bie gelbe, mit suft gefüllte Sdywinmblafe ourd). S(ut Ranoe ftehen zahle

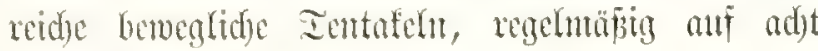
Büntod verterilt. 
Jig. 6 4. 7. Discalia medusina (Haeckel).

Familie one Disfalion.

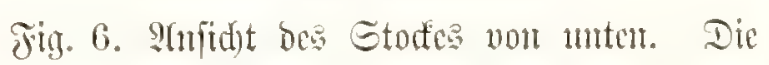
zentrale adstlappige Miundöffmung ift vost adjt roten

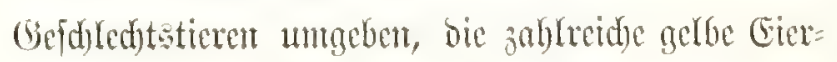
gloufen tragen. Mit ben adjt Giandlappen bes Edfinmes, weldye mit blanen sautoriffen gefüumt

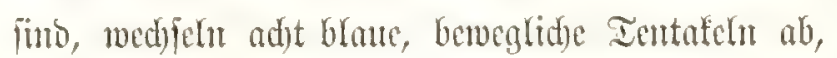

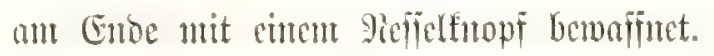

Jig. 7. Exitenamidut besiflben Etodes, nit verfïrsten Ientafeln; in ber Mitte ber fange Bentral= magen, unten ber geöffnete Miuno.

\section{Jig. S-12. Disconalia gastroblasta (Haeckel). Familic Der Diskaliden.}

Fig. S. Infiut bes Stodfes vou untent. In ber Mitte ijt ber adjtrappige \$luno geöfmet, unt=

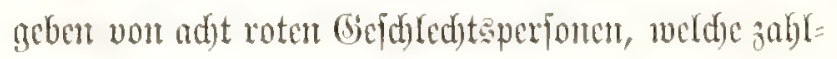
reidye gerbe Eiergloden tragen. Giad) anjen bavon fteben adst ftrablige Bünocl von bramen Ientafelu,

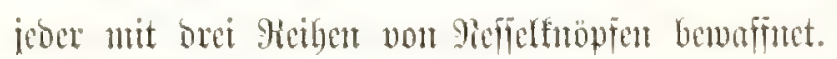
Die interen Ientafeln finto ftarf jufanmentyezogen.
Fig. 9. Ceine junge Rarve von Disconalia, ähnlid) gebitbet wic Discalia (Jig. 6). Der jent=

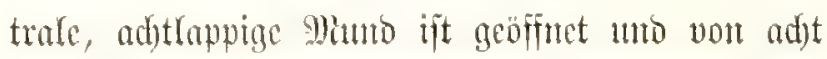

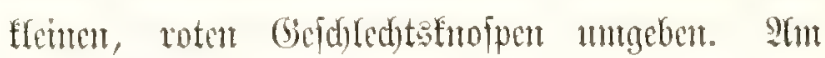
Sdjumranoe, weldyer einen Sanm von blauten saut= brifien trägt, ftchen jwijd)en adft Gandolappen add Ientafeln, mit je vier Piefielfnöpfen.

Fing. 10. 5yorizontalfduntt burd) ben oberen Ietl bes Gdirmes (linfe sälfite); in ber \$litte bic braune Bentralorijie, untgeben von roten Rabial= fantâten; an adjthappigen Hande cin Siranz von bfouten sautorififen.

Fig. 11. Socizontalfanitt burd) ben unteren

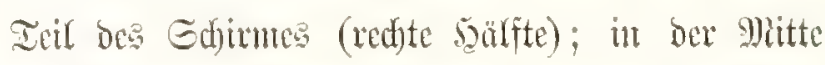
bie sabjle des Bentralmagens, umgeben von ber

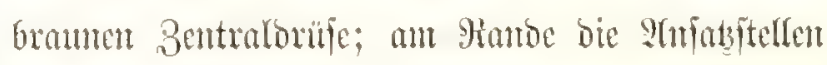
ber abgefdunittenen Ientafelnt.

Jig. 12. Ein cinselnes rotes (bicidyled)teticr

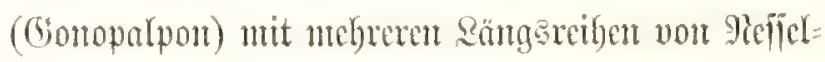
Enoten bewaffnet; unten ein Sirumb von medujen= F̈̈migen Eicugloden (Gionophoren). Diefe löfen

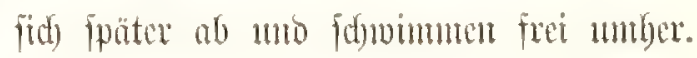




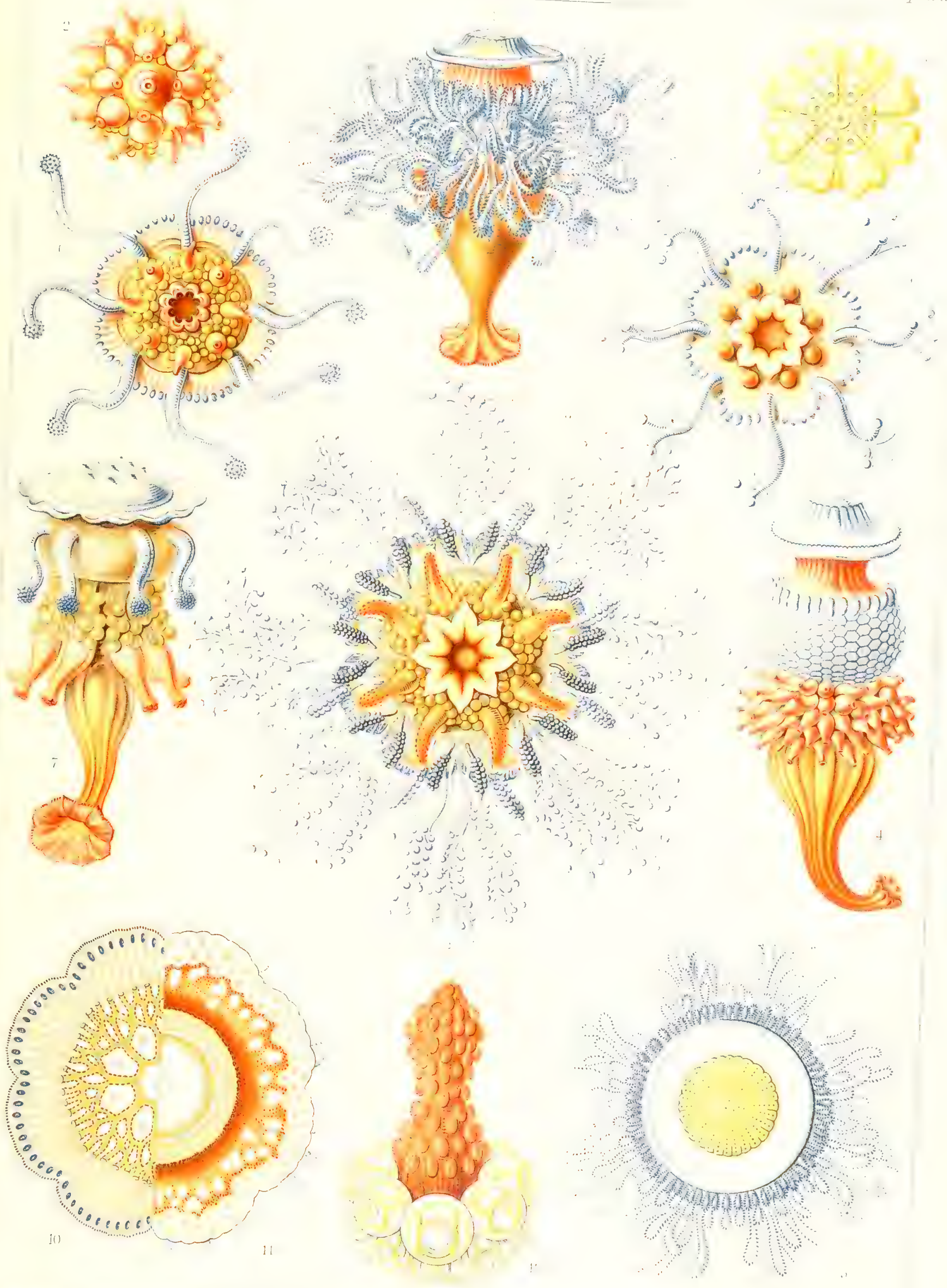

Siphonophorae. - Stcratsomaltert. 



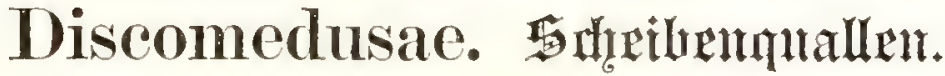

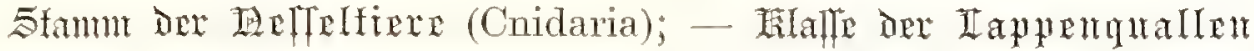

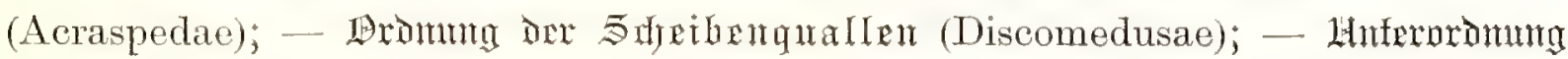 \\ Dex Rofrmituigen (Cannostomae).
}

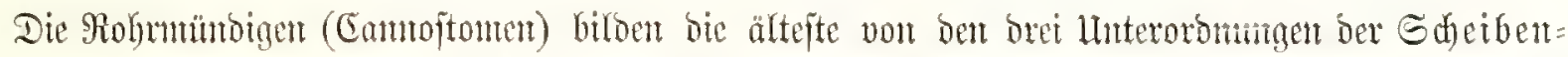

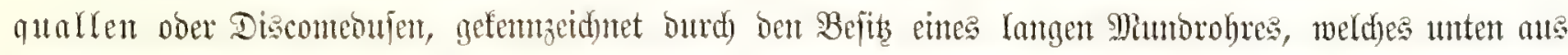

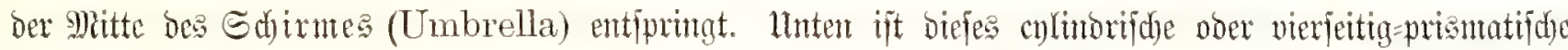
Munbrohr in vier furze, oft gefräufelte aappen gepalten, weldye bie vierefige Mumböfjumn untgeben.

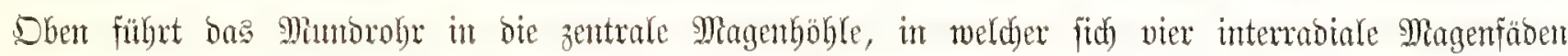

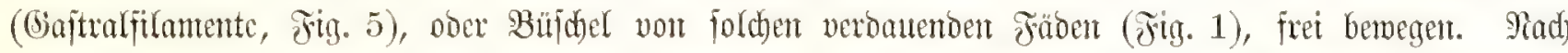

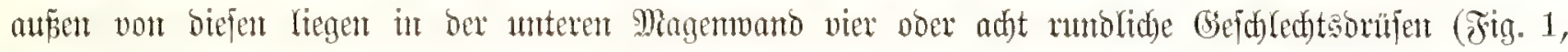

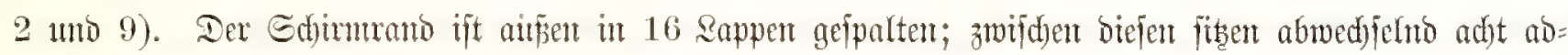

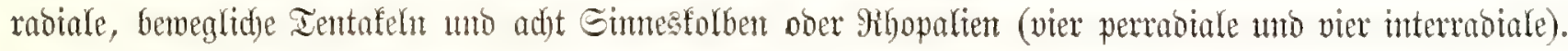

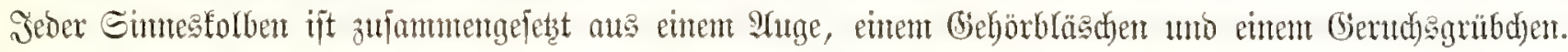

Jig. 1, 2. Linantha Iunulata (Haeckel).

Fig. 1. Untere SGrfidit ber Meduje, melde rubig nut ausgebreitetent Tentafeln an ber Wherfläde bee

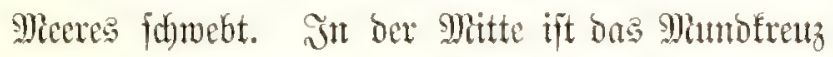

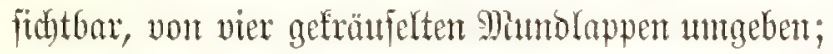
biefe liegent in bent Strablen eriter Dromm (per=

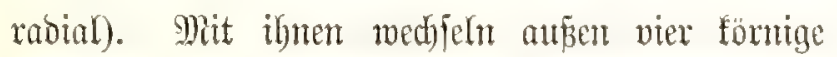
Eierftöfe (Ovaria) ab, in ben Etrahlen zmeiter Dronung (interrabial); an der Simenfeite jebes Dvarume liegt ein Büldgel von Kleinen Magent=

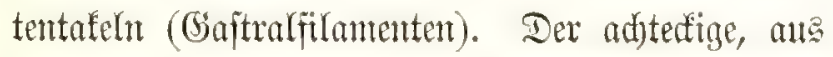
parallelen Fajern zutfammengefeste ßing an ifrer

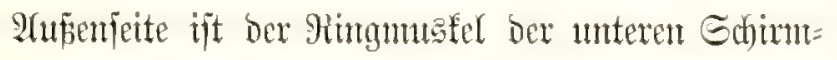
fläd)e (Subumbrella). গad a añen bavon wiro der

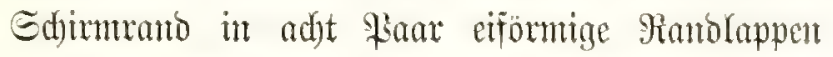
gefpaltert, von benen jeover zowei żterlidy) veräftelte Zappentafd)en enthält, getremnt burch cine futbrabiale Rappenfpantge. 3wiforen bent Bandolappen fitzen ab= wedjelno adjt Simtestolbert unto adde noradiale Tenttafeln (in ben Etrablen britter Dromung).
Jig. 2. Geitenamidut berjelben Meouje. Aut der Mitte ber unteren Sdjimflädje hängt dos Munbrohe hetab, weldes unter in bie vier Mundo= lappen gefpalten ift.

żig. 3-5. Palephyra primigenia (Haeckel).

Drei verjdjiebene Atnfidten ber Medule, im Moten Meere, 1873 ntad bem Rebent gezetdunet. Fitg. 3 fret

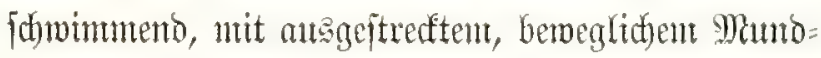
rohr; Die vier gefräufelten Rappent ber \$anooffinung

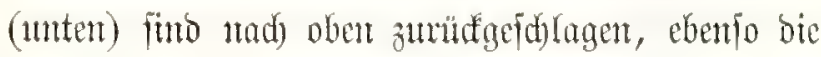
adjt abrabiaten Ientafeln ant Edjummande. Fig. 4 langfant unterfütfento, mit verfürztem, geraoem Mumb=

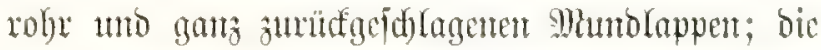

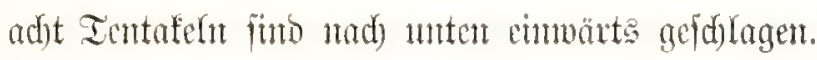

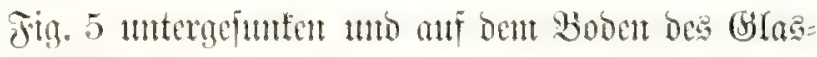

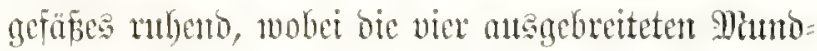

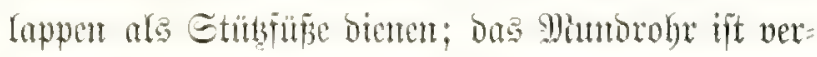
fürazt, die adgt Ientafeln futro bafenförmig gefrümmt. 
Fig. 6. Zonephylal zonaria (Hacekel).

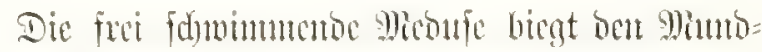

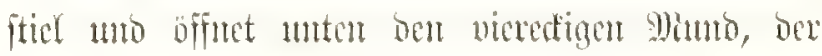
midyt in sappen mengezonen ift. Bwifdent ben 16 Gandoloppen bes Edjumes (meld)ent an ber oberen fonveren Eduirmfläd)e 16 feine Masialrippen ent= ipred)ent) fitzen adyt Ientafelu mo adjt Simmestolben.

\section{Fin. 7. Strobila monodisea (Hacekel).}

Sugenb३uț gepebt ans einer gloctentönmigen \$olnpenanme (Seyphostoma, oben) unt ciner fnofpenden 9icoufen= idfeibe (Ephyra, unten). SBei ben meiften Disco=

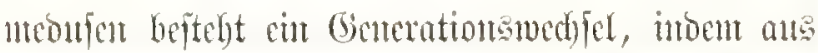

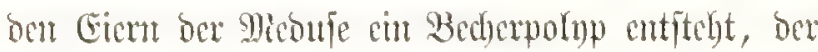
fid) feitiest. Dicjes glodenföminge Gcuplyoitoma (mit vier interrabialen Magenteiften) arjengt burd Sinojpung gerwöhntid) jufhlretde Meoujent, bic fitu abröjent. Sin bent abgebillocten Falle ijt exít cinte

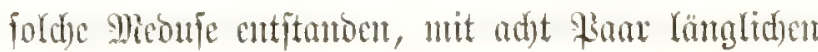
Hanolapper.

\section{Fin. S. Namplanta Challengeri (Hueckel).}

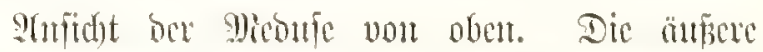
Edirmiflude (Exmmbrella) ijt ourd) cine tiefe

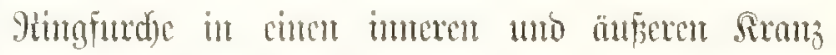
gefondert. Der imere Sirans ift in 16 gleidye Feldoer geteilt. Die 16 sisulfte bes äuperen Surnzes füro ungleid); adjt fdumälcre, primsipafe (nit Simes= folben), wedffedr regetmäñig ab mit adjt breiteren (abrabialent), weldac gebogene Ientafeldt tragen.

Fig. 9. Atolla Wyvillei (Haeckel).

SGufidyt ber Miedufe von unten. Dic zentrale, vierertige Mannobffunng ijt non vier Barfentajden

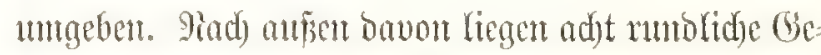

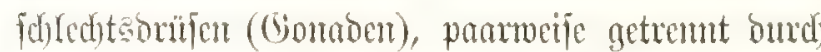
rabiale Misfertu. S(n Rande der unteren Gdirmfläd)e (Subumbrella) fint jwe ringförmuige §ranz=

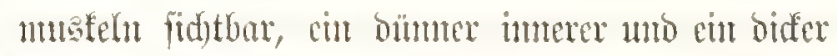
än

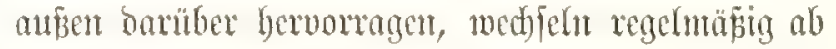
mit bümun, fadenfönnigen Ientafeln. 

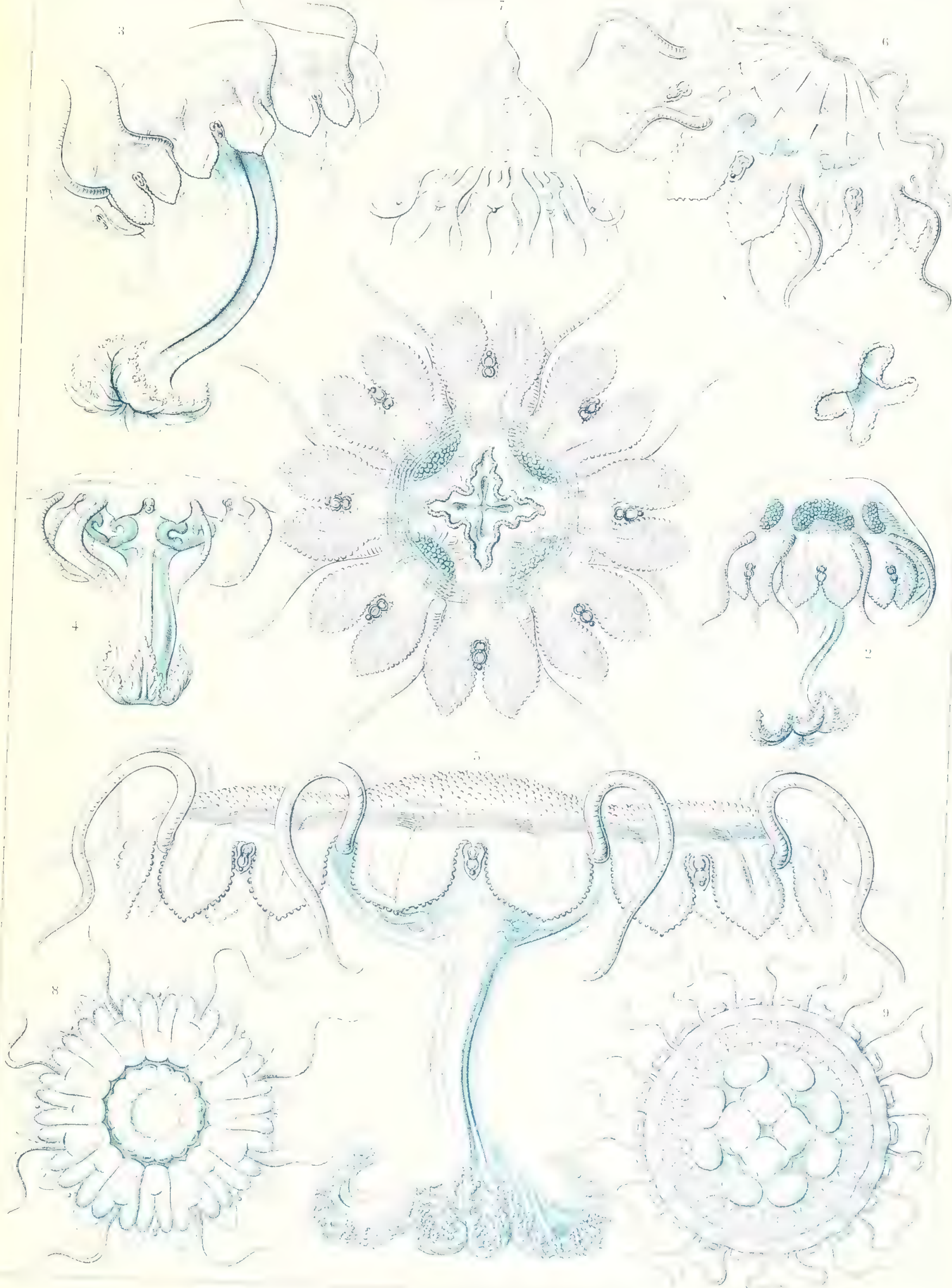

Discomedusae. - Scheibencutaflent. 



\section{Pennatulida. Fonerkmallut.}

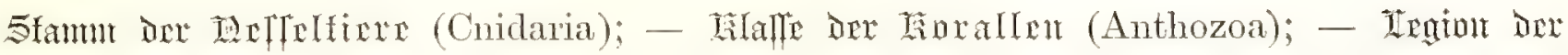

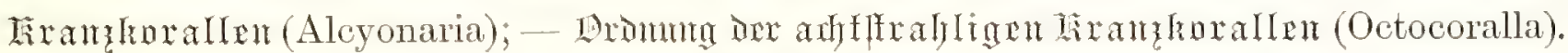

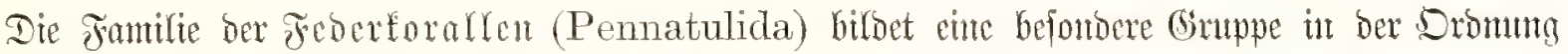

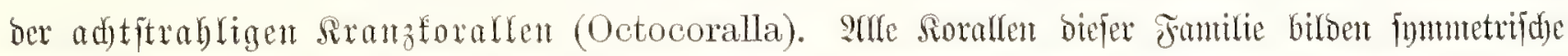

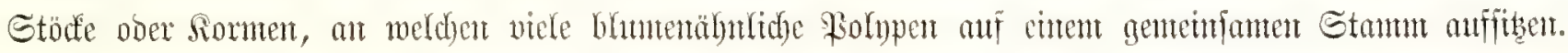

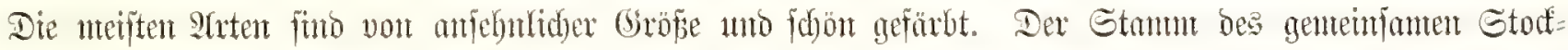

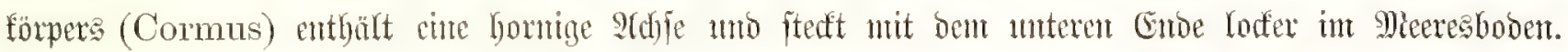

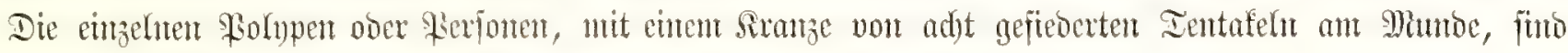

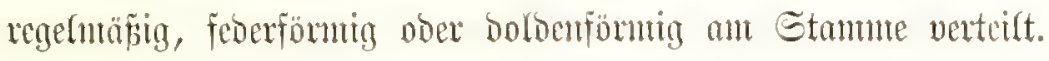

Jig. 1. Umbellula encrimus (Limné).

Der Yange Gtanm biefer, "Dofbenforalle" (fegr verfleimert in Fig. 1a) trägt eine forjumförmige,

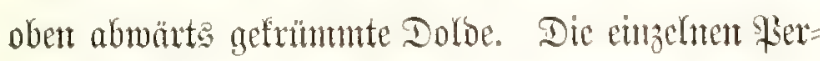
foncu (Folypent), weldye oben in ntebrfad)em Sirange vereinigt anfitient, tragen ad)t bfattförmige, gefiederte Fillbfer ober Tentafern, wie bei alfen amberen Dfto= forallen. Farbe ofiwengelf.

\section{Fig. 2. Stylatula Finmareliica (Sars).}

Ein Fehr langer, rutenförmiger, gefieberter $\Omega_{0}=$ rallemitoci, imen mit einem hormantigen, biegjanten

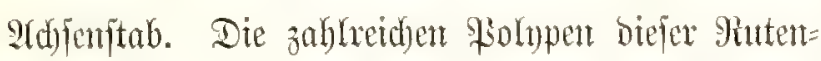

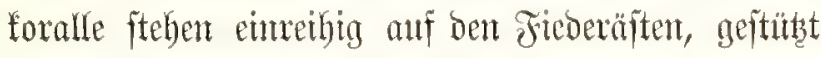
Durd) cine fanmmiörmige Pratte.

\section{Fig. 3. Virgularia Lenckarti (Richiardi).}

Ein Fieberait (Cormidium) von eincr ßutten=

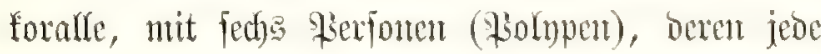

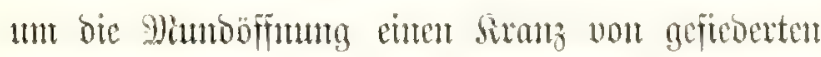
Ientafeln trägt. Sint muteren Teile ber Solnopen fielyt man bic ad)t Mingenteiften ( fdimmern.

\section{Fig. 4. Renilla reniformis (Pallas).}

Der Rorallemitod biejer, "siterentforalle" hat bic Gejtalt cimes nierenförmigen Blattes, Deflen obere

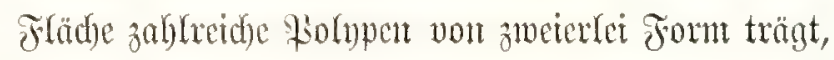

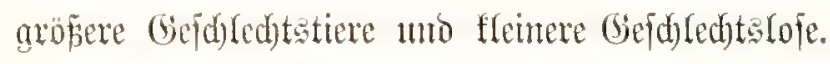
Der Mano jeoes Polypen ift von einem adtitrab= ltgen Fullhferfiant umtgeben. Der gebogene Stiel bes Blattes ift unten antgefdumollen und jteft lodfer in Mecres fdranm. Farbe rot ooer violett.

\section{Fig. 5. Renilla reniformis (Pallas).}

Die ältefite (aus bent cit entitantbent) Perfon ober ber printäre Mutterpolnp - Der Sierentoralfe

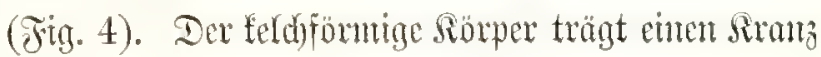
von adit gefiederten Ientafeln.

\section{Fig. 6. Renilla reniformis (Pallas).}

Cin jumner Etoff ber Gierentoralle. Der Mintter= polyp (Fig. 5) bat burd) Sinofpung einen Siranz you

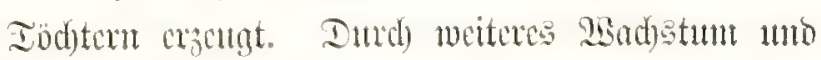

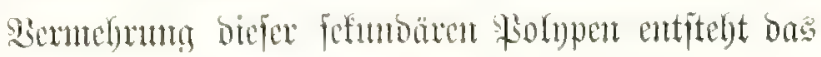

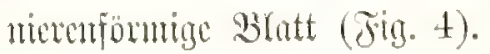


Jig. 7. Stylatula elegans (Dana).

Etiñf von ber Groer eimer giutenforalle (äbn(id) Fin. 2).

Fin. S. Stylatula Kinbergii (Kölliker).

Etüf yon bor Feber cincr Siutenforalle (äfnt= (id) Fig. 2).

Fig. 9. Virgularia glacialis (Sars).

Gtür von der Feder einer Mutenforalfe (äbn= (idi) Fing. 2).

\section{Fìg. 10. Virgularia Rumphii (Kölliker).}

Stüf von ber Froce cimer Muttenforalle (äbn= (id) Fig. 2).

\section{Jin. 11. Virgularia mirabilis (Lamarek).}

Etür vout ber Feder cincr Pintenforalle (äh)t= (id) Jitg. 2).

Jig. 12. Pemnatula spinosa (Ellis).

Der gantze Stox eimer Eecfeder, deren Stiel (ver=

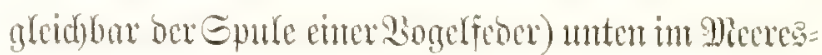

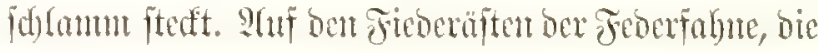
mit cuter gicige won Salfitadyeln bewafjuet find, fitzen in Peiben bic fleinen Perfonen, von berfelben Bit=

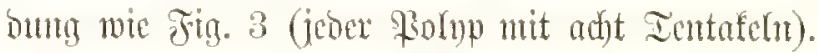

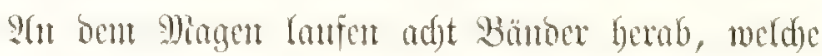

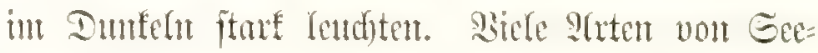
fcocen füto präd)tig gefärbt: rot, violett, blant. 


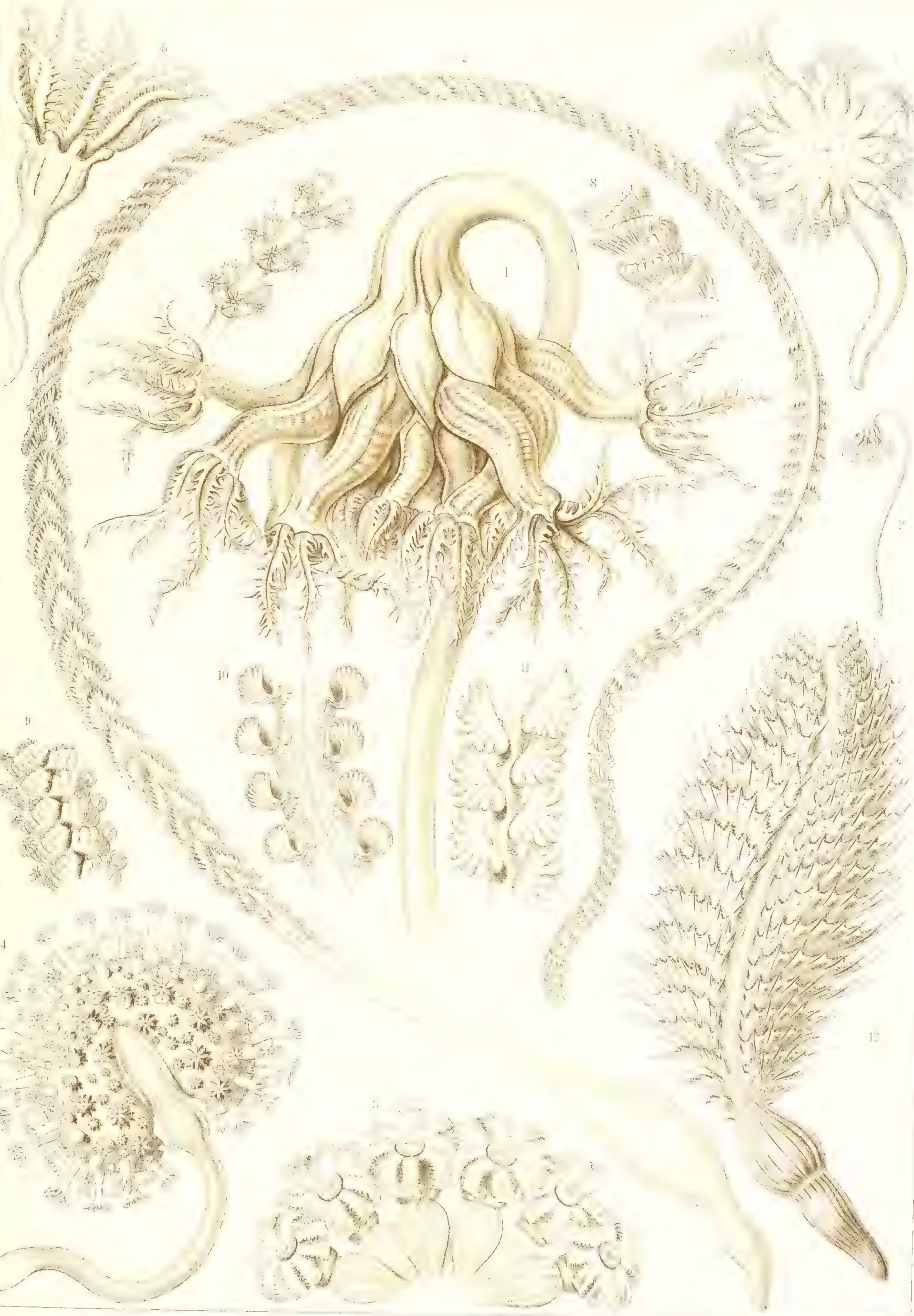

Pennatulida. - Soserforctlient. 

Eafel 20. - Pentacrinus.

\section{Crinoidea. palnumftemer.}

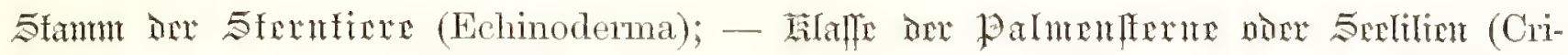

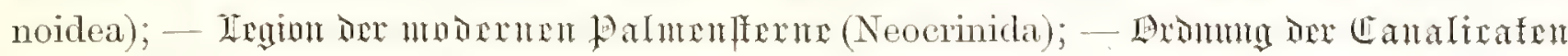

(Pentacrinacea).

Dic Sirafie ber Salntenfterne ober Geelilien (Crinoidea) unterfdectoet fid von ben übrigen

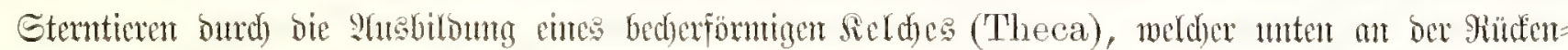

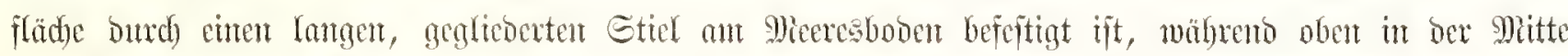

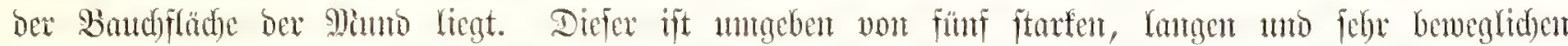

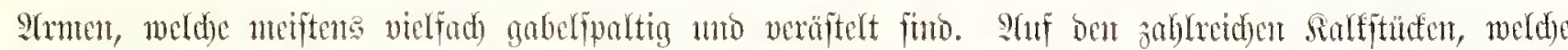

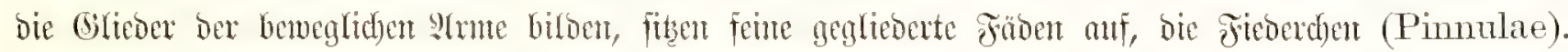

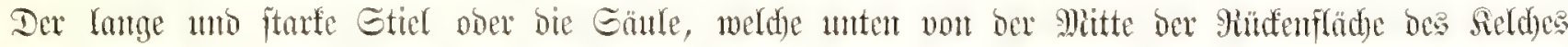

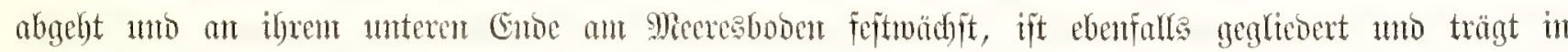

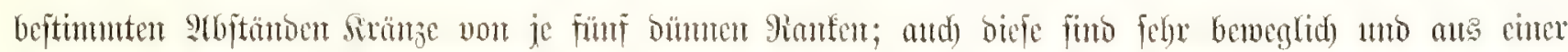

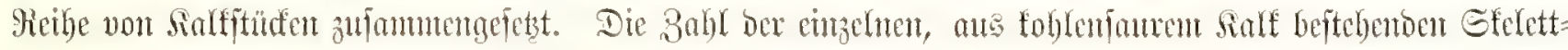

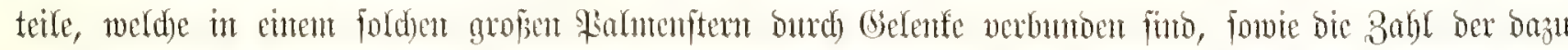

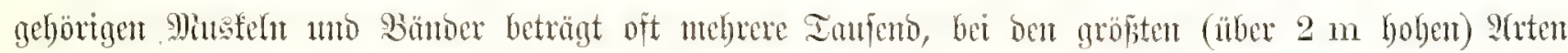

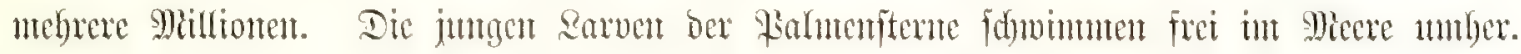

\section{Fig. 1. Metacrinus angulatus (Carpenter).}

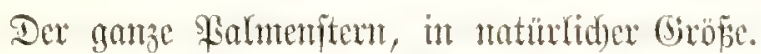
Die fünf mädtigen Irme, weldbe von Seld)e ab= gehen, funt jobon an ber safis in zebn geteilt uno weiterbin viclfad) gaberfpartig veräftelt. Dex untere Teil Des langen Sticks ijt weggelafient.

\section{Fig. 2. Pentacrinus Maclearanus} (Wyoille Thomson).

Der Seld des Salmemitems, mit bem oberen

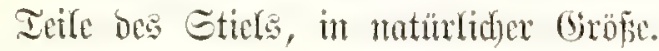

\section{Fig. 3. Pentacrinus Wyville-Thomsonii (Jeffreys).}

Dex Sieldy des Sinturenterns, mit bem oberen Ieile des Gticle, in natürliduer (Gröfic.
Fig. 4-6. Pentacrinus Wyville-Thomsonii (Jeffreys).

Drei Stietglicoer, von ber Gelentfläd)e gefeben,

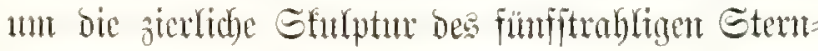
bifloes ză zeigen.

Fig. 7 u. S. Metacrimus angulatus (Carpenter).

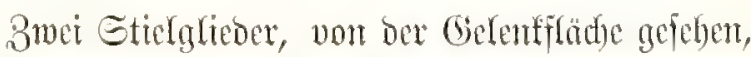
un bie veridficome Sfufptur besfümfittrahligen Stern= bifbes öl zeigen. - Die Stielglicoer zeidunett fith

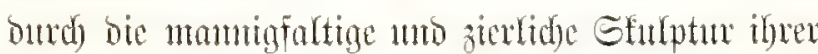

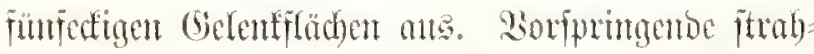

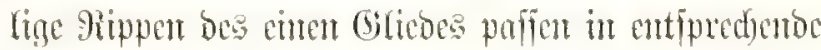

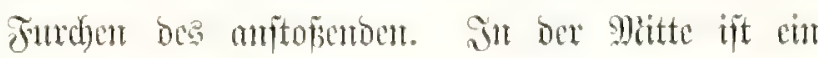

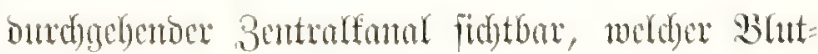

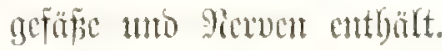





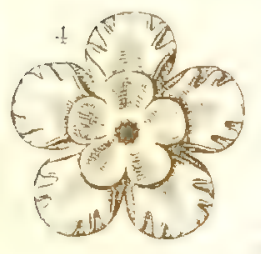

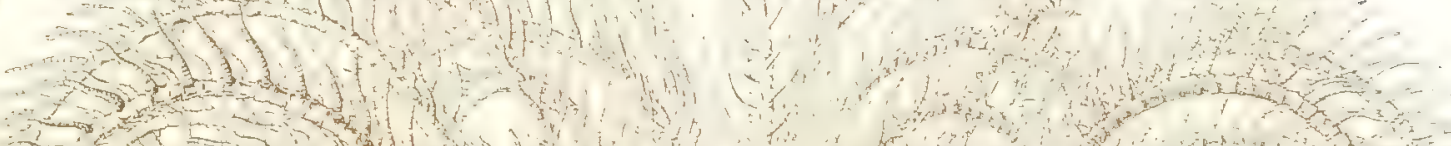
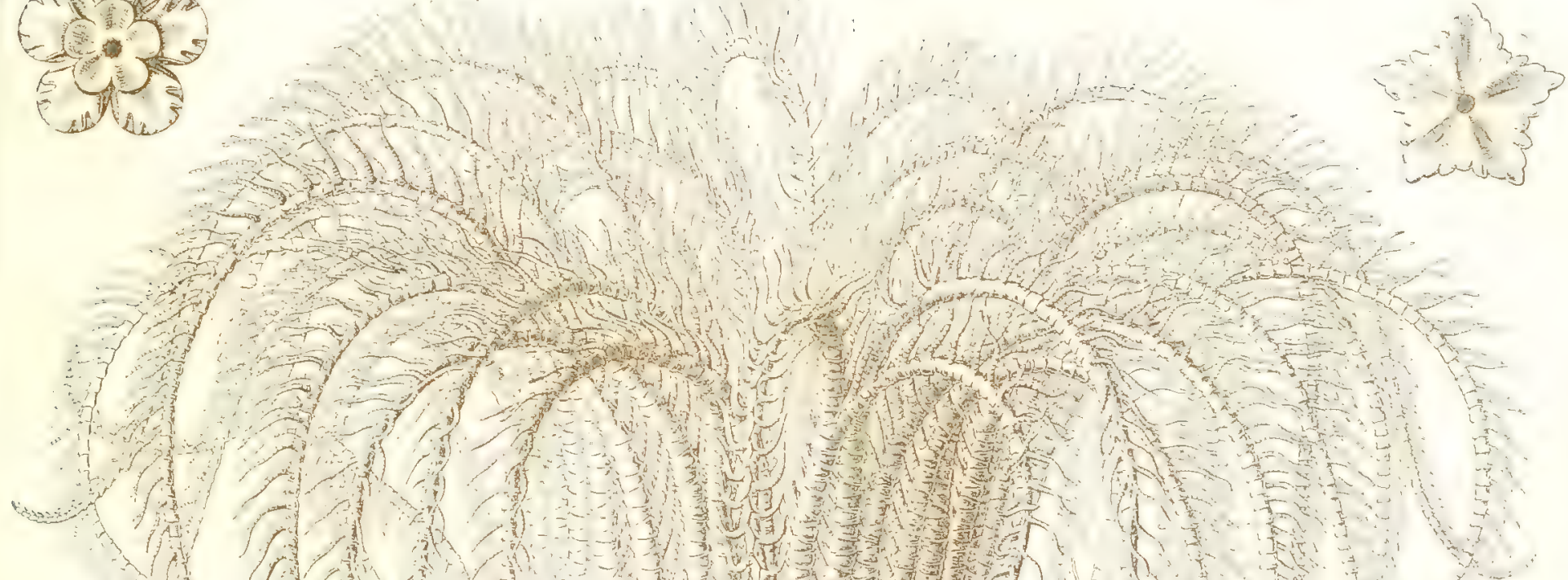

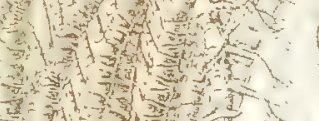

$(1)=2+1$

An
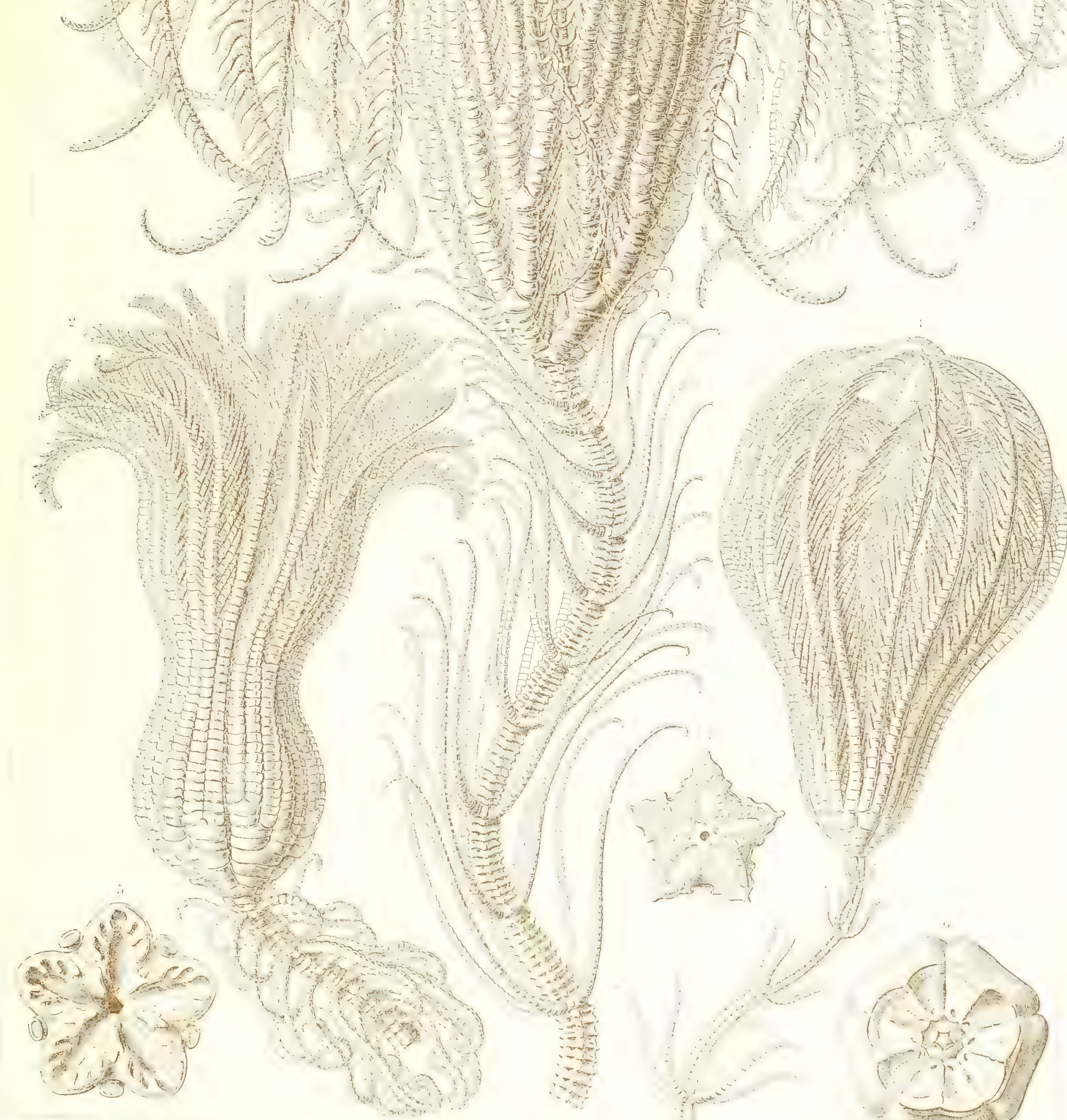



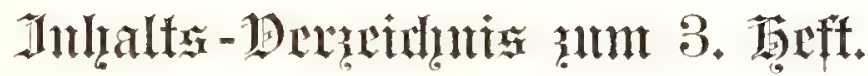

Iafel 21. Xiphacantha. Untiere ans ber Silafie ber Mabiolarien (Region ber Affantharien).

Iafel 22. Elaphospyris. 1hrtiue aus ber Silaffe ber Madiolarien (Eegion ber Maffel= laxien).

Iafel 23. Cristatella. MBmmtiere as ber sifalfe ber Mioosticre ober Bryozocu (Oro= mug ber Strumirbler).

Iafel 24. Stamastrum. Ltrpflomzen me ber

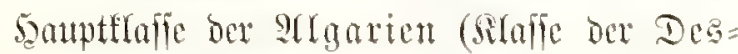
mibiacen ober Sosmarien).

Iafer 25. Diphasia. Teffelticre aus ber Silaffe ber Sabropolypen (Oromm oer Reigen= polrpen oder Eertularien).
Iafer 26. Carmaris. Reffeltiere ans ber Mraffe der Edheierquallen ober Sraspedoten (Dromutg der Iradjomedufen).

Iafel 27. Hormiphora. Reflectiere ate der Silafie ber Siammamalfen ober Sitenophoren (Segion ber Samnoftenien).

Tafel 28. Toreuma. Meflertiere ane ber Araffe der Afraspeden (Drommy der Diafome= bufen).

Iafel 29. Cyathophyllum. Reflelticre aue ber Silaffe der Sorallen (Sromm ber Ietra= forallent.

Iafel 30. Clypeaster. Sterntiere anz der Slaffe ber Echiniden (Drommg ber Rly)= peaftronient). 



\section{Acanthometra. 5tathelltualitume.}

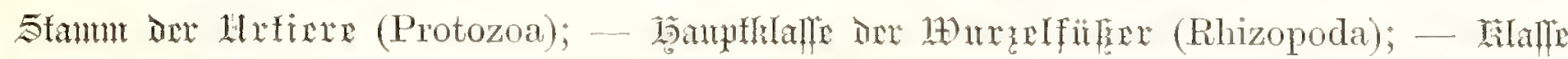

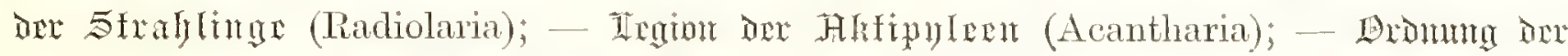
Starfelfualinge (Acanthometra).

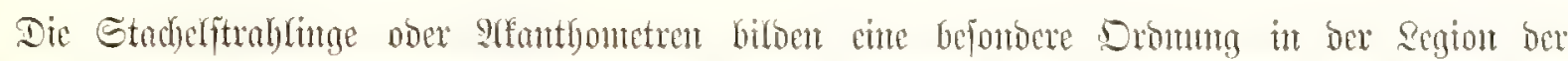

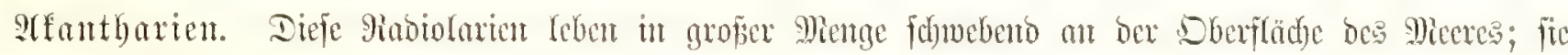

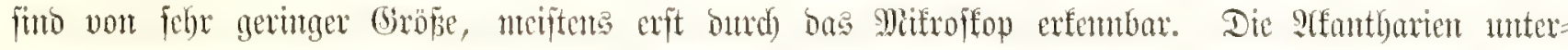

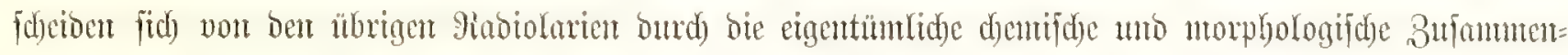

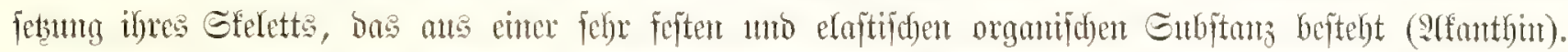

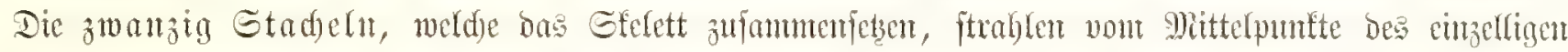

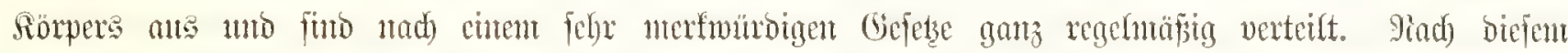

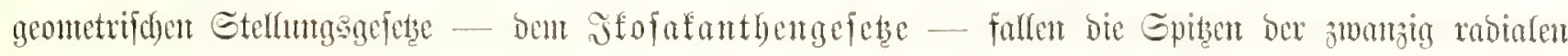

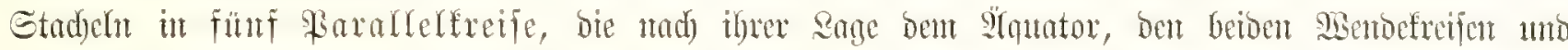

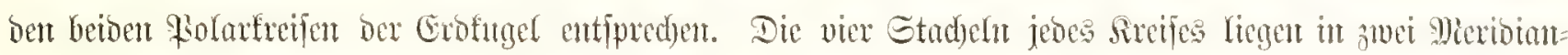

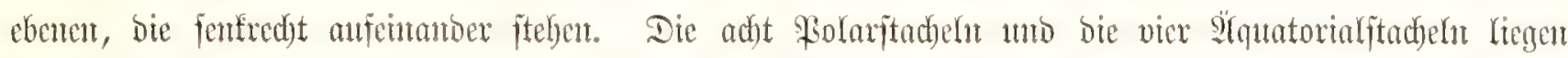

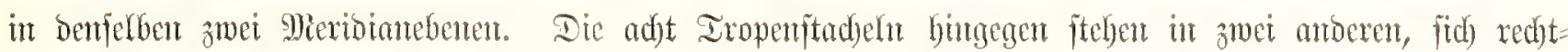

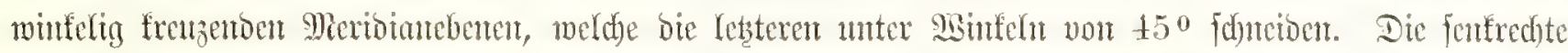

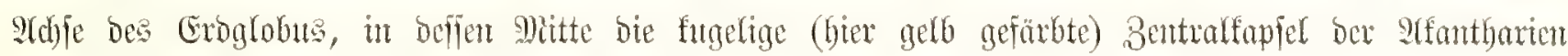

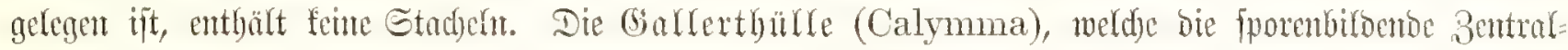

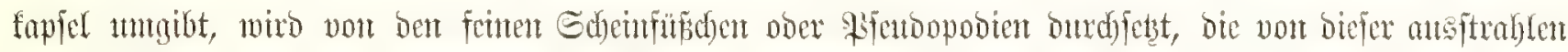

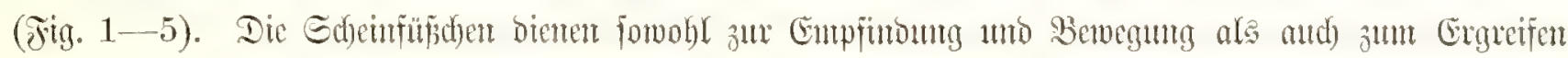

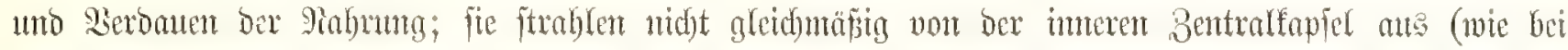

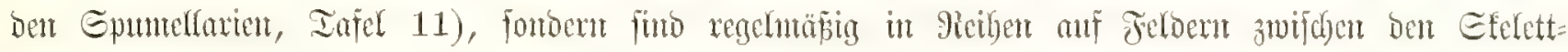
ftad)ch verteilt; bicje Yetzeteren biench als Gdjuțwaffent uno Sdjwebapparate.

Jig. 1. Xiphacantha ciliata (Hackel).

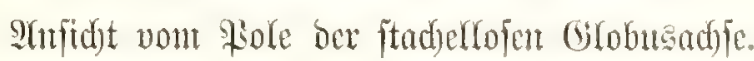
Mian fieht in ber \$itte bie fingelige gelbe Bentrul= fapjel, immerbalb berferben bie vierfantigen Bafal

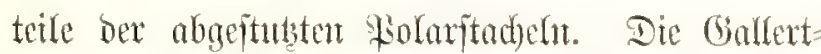

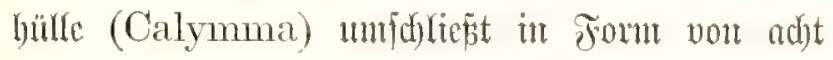

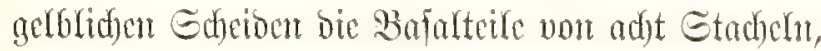

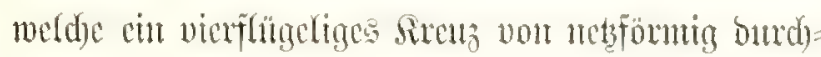
brodyenen Blättent trangen. Dic betoen vertiffaten Into bie beioen horizontalen Stadyedu liegent in ber S̈antotorbene. Die vier antoren (biagnualen)

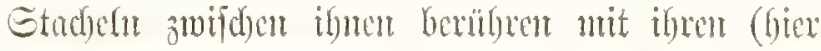

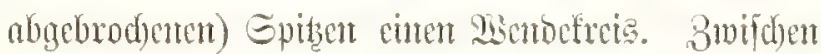

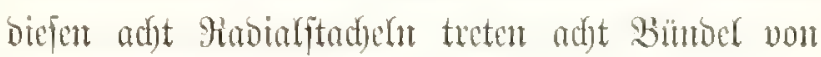
fenten Edheiminisd)en nox:

\section{sig. 2. Xiphacantha spintulosa (Hecekel).}

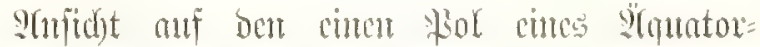

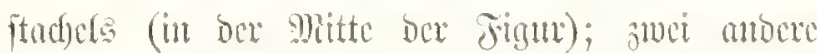

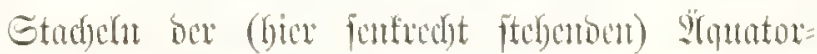

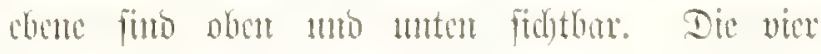

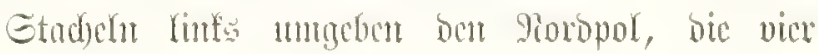




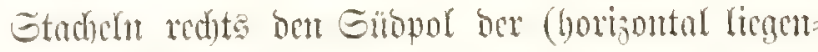
sen) ftaderfojert sauptudffe. Sison ben vier biagonal

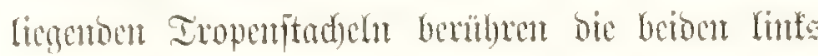

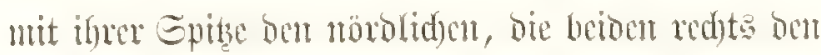

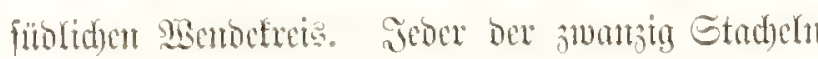
trägt vier Sirenge von vier bornigen Duerjortjäzent.

\section{Fig. 3. Stauracantha quadrifurea (Haeckel).}

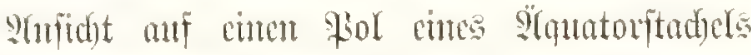
(in ber 将itte Der Finurr); zwei ambere Etad)eh Der (biex magered)t ftebenoen) Silnuatorebene fino

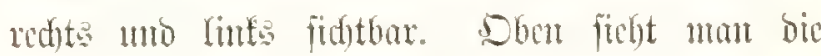
vicr Gtad)efn bes nörofidyen, unten bie vier Etadedn

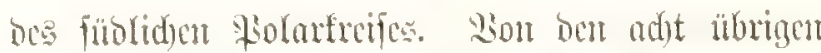
(biagonalen) Stadyedn geljören bie vier oberen bem

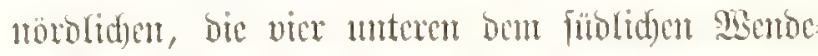

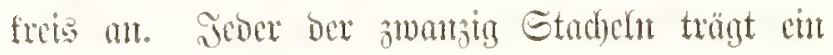

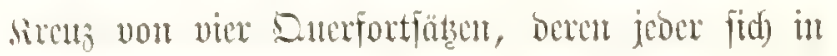
addst Gabeläfte fpaltet.

\section{Fig. 4. Pristacantha polyodon (Haeckel).}

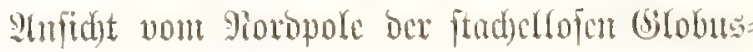

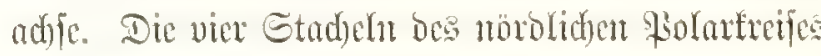

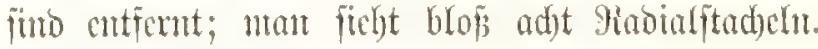
Dic beiben fenfredeten uno bie betoen wagered)ten Etadyeln liegen in der Sitntatorebente. Die vice anberen (biagonaten) Etad)eln berithren mit ifren Episzen ocn nöroliden

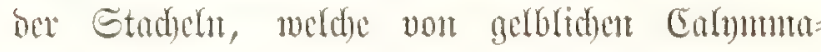
fdectoen unthüllt fimb, billoen vier frensitünotge

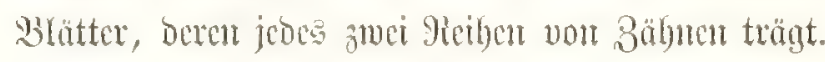

\section{Jig. 5. Lithoptera dodecaptera (Hucckel).}

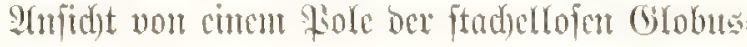
adjfe. Sin ber Mlitte bic gelbe Bentralfapiel, wetde bice nid)t fungelig (mie in Sitg. 1-t), fortocur freng= förmig, viextappig ift. Die vier grofisen Etadhdu, von bentu jeber chrn (bitterfluged mit orei gethen

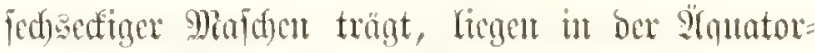

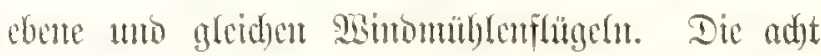
(Dingonalen) Iropenftad)e(n tragen cuten fleiteren Gitterflingel mit me einer Gicihe von Miafden. Dir adjt flemen, cinfaden Folaritad)eln, von benen mu bie vier oberen in ber mitte fidstbar fino, tragent feine Duterfortfätze.

Jin. 6. Acantholonehe peripolaris (Haeckel).

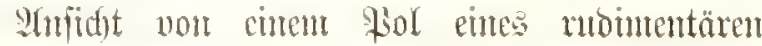

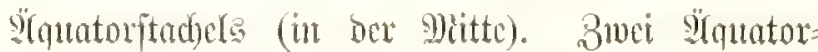

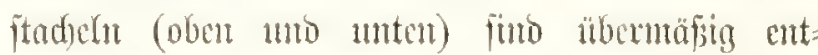

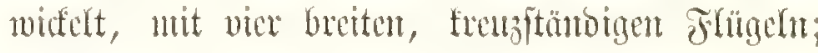
bic betoen antoeren find rüfigebiloct, ebento aud

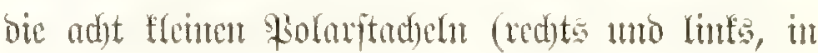

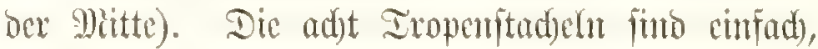
Gomiföming geftünmet, an ber Bafts geflügelt. Die

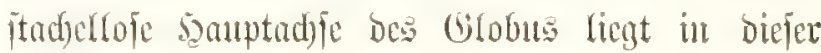
gitgur wageredt.

\section{Fin. 7. Acantholonche favosa (Haeckel).}

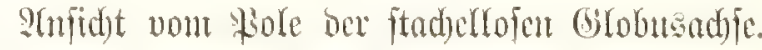

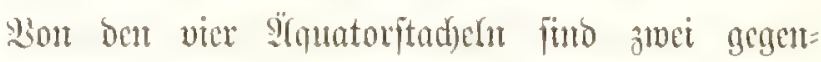

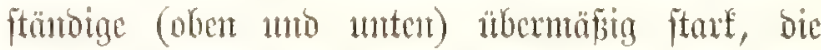
betoen anderen (red)te und lints) rnointentär. Die

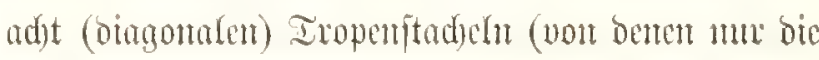
vier oberen fidstbar) find viel teincr; bie $\$$ solax= ftadyeln (in ber Mitte) fino gans verfïmmert. Der

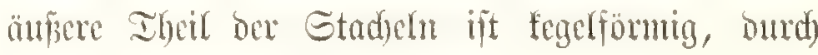
natbige Grïbden atogezeidunt. 


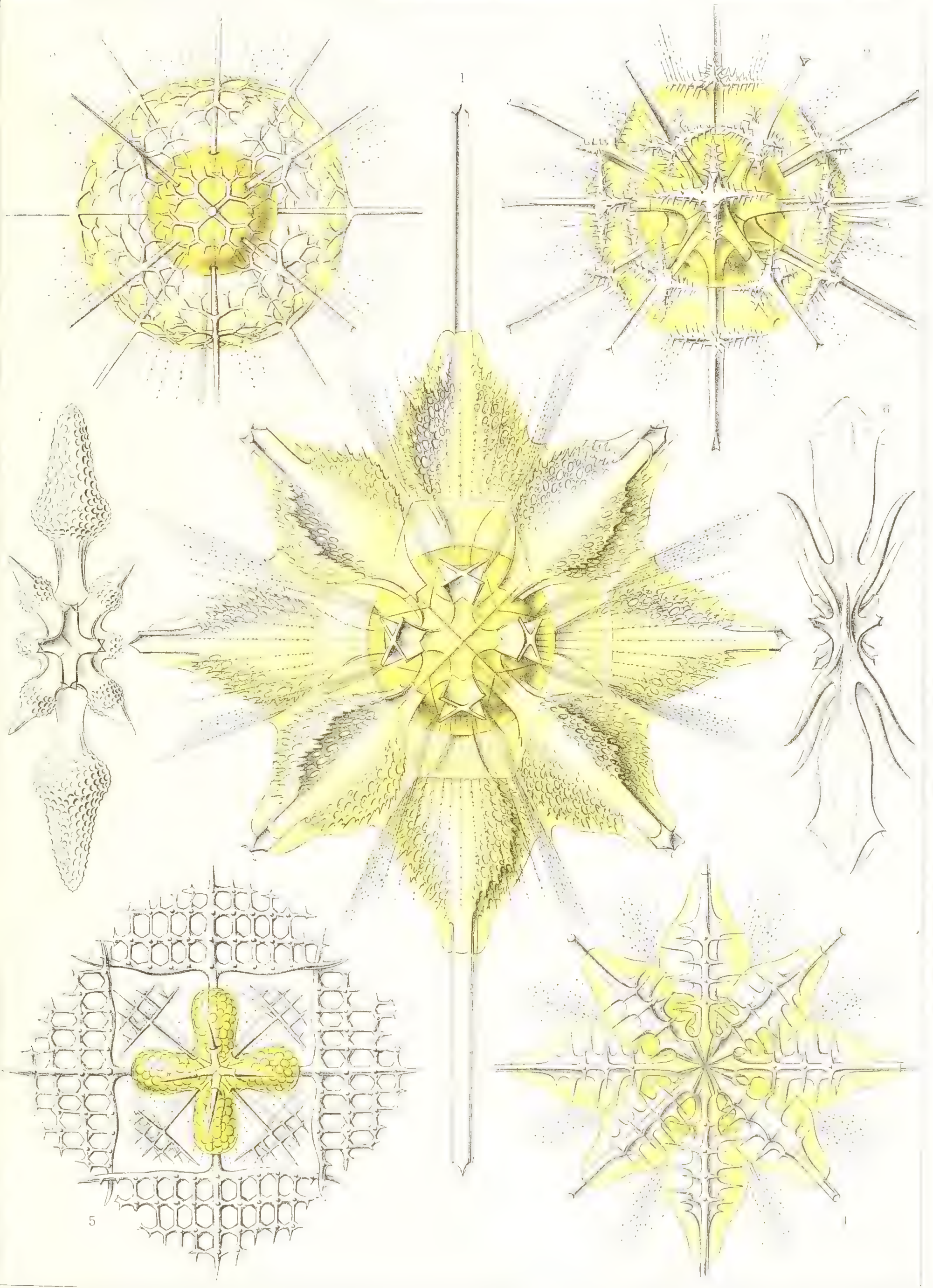





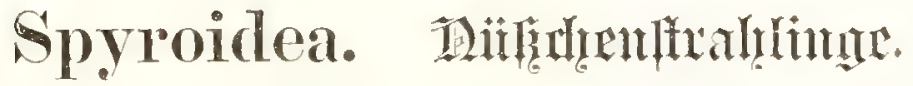

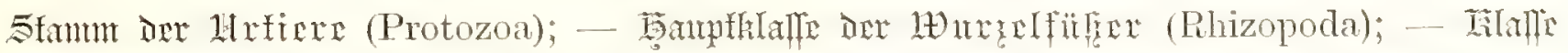

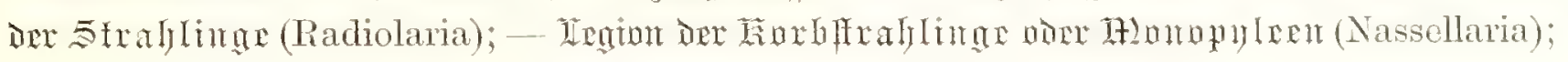

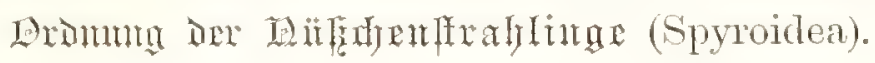

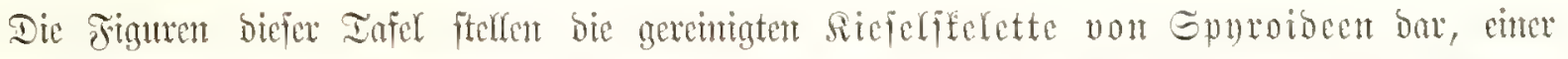

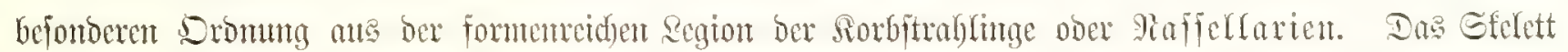

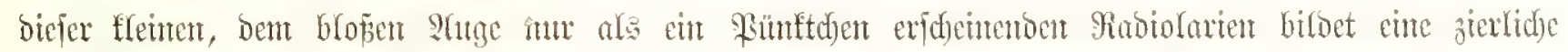

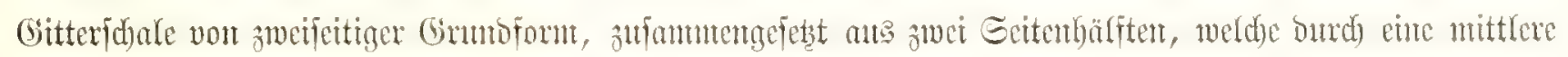

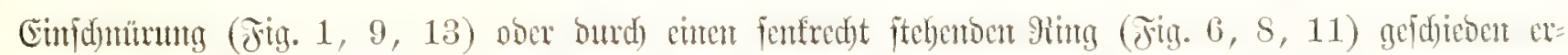

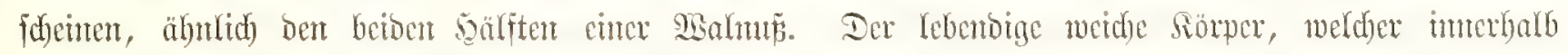

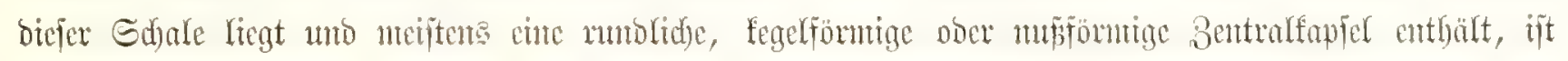

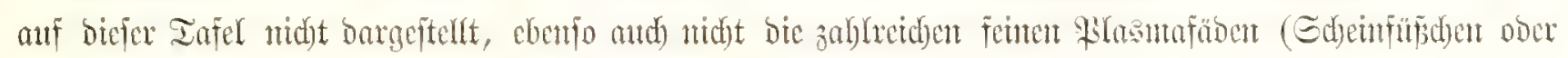
Prendopobien), welde vont benfelben ansftraflen (bgl. Iafel 11 unt 21).

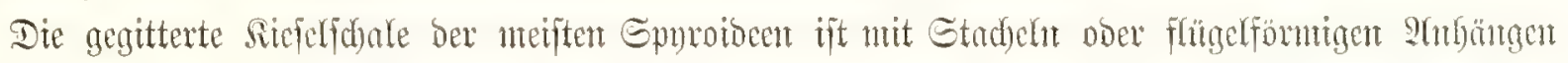

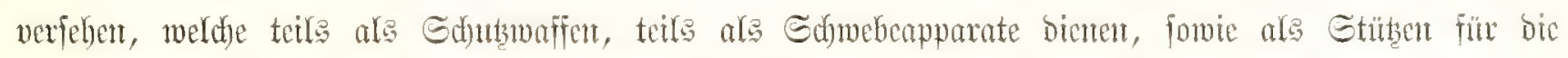

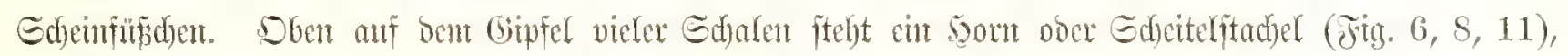

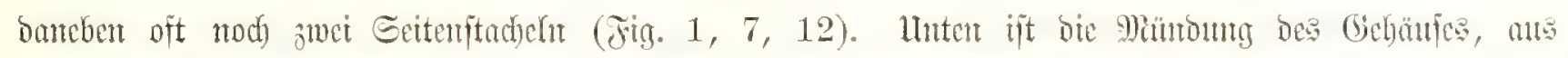

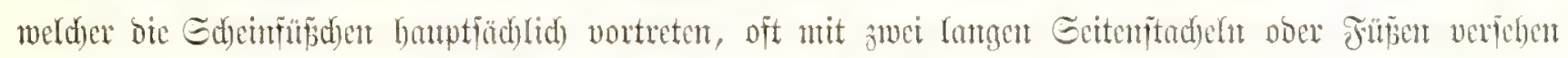

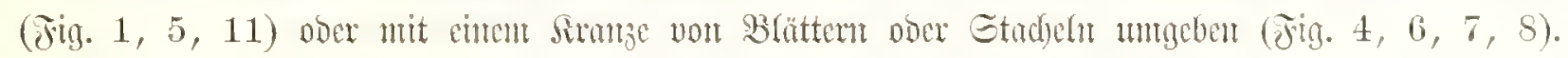

Fig. 1. Triceraspyris gazella (Hacclel).

Edjale oben mit orei soonem, unten mit brei Trǚnt.

Fig. 2. Clathrospyris pyramidalis (Haeckel).

Sdate oben mit curm Edjeitelfons, unten mit

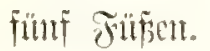

Fig. 3. Pylospyris camariensis (Haeckel).

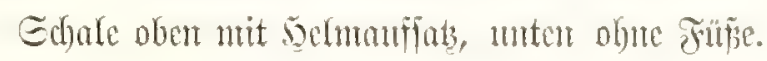

Fig. 4. Anthospyris mammillata (Haeckel).

Gdfale oben mit brei sobumen, unten nit cirrem Sirans vou blattförmigen Jiñen.
Fig. 5. Dendrospyris polyrrhiza (Haeckel).

Sdake oben mit cinem Edeitelforn, mutur mit

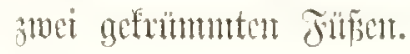

Fig. 6. Sepalospyris pagoda (Hacekel).

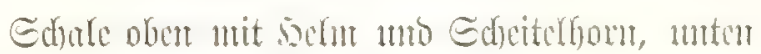

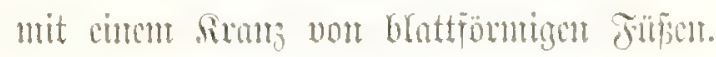

Jig. 7. Elaphospyris cervicornis (Hacekel).

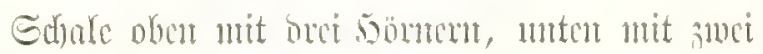

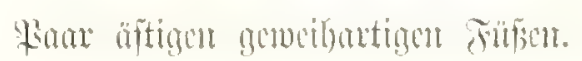


gitg. 8. Tholospyris cmpola (Haeckel).

Edyale oben mit cinem Ed) citurforn, unten mit Drei geweihartigen Fünen.

Jig. 9. Dictyospyris stalactites (Haerlet).

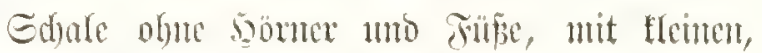
italaftitenälymlidyen Sinorren beoest.

Jig. 10. Dictyospyris anthophora (Haeckel).

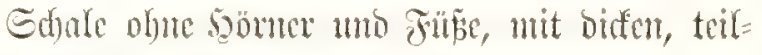
weije gefpaltenen Sinorren bedeft.
Fig. 11. Dorcadospyris dinoceras (Hacekel).

Edyale oben mit cimem Sdyettellon, unten mit

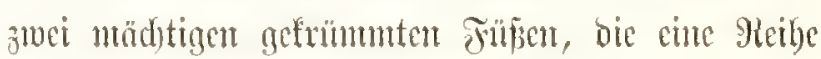
von dornigen Etadhetr tragen.

Fig. 12. Triceraspyris damaecornis (Haeckel).

Sdyale oben mit bret syömen, unten mit zmei Saan ätigen grǚen (von oben gefehen).

Fig. 13. Ceratospyris Strasburgeri (Haeckel).

Ed)ale ftad)elig, mit zaglreid)en geflügclten sör=

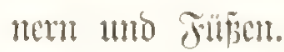




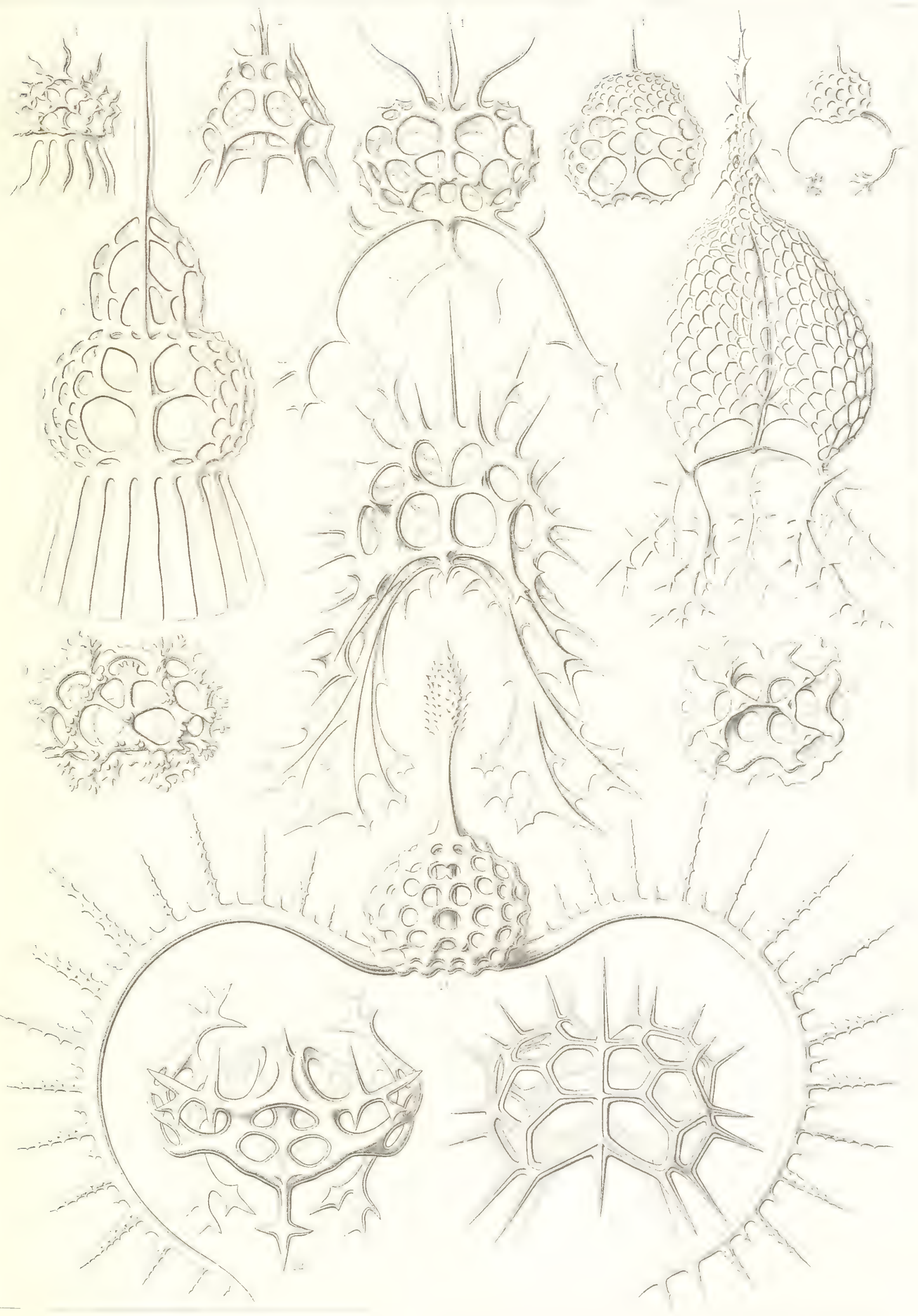

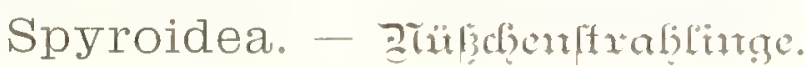





\section{Bryozoa. 14twothtivere.}

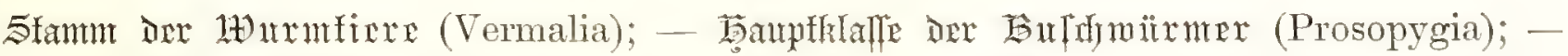

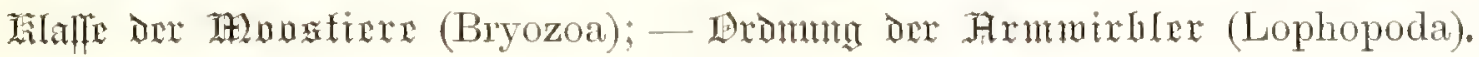

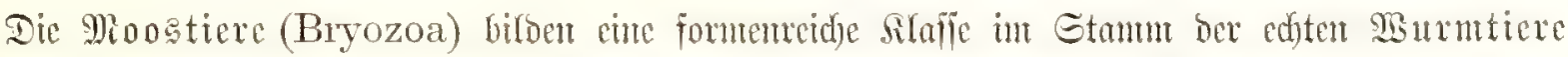

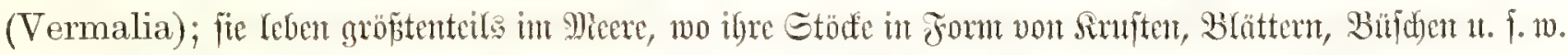

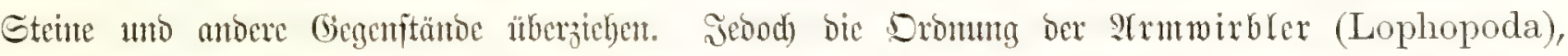

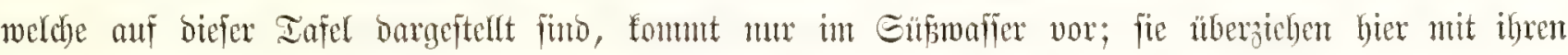

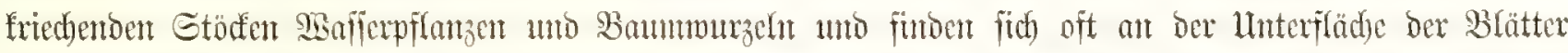

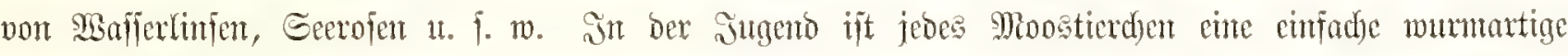

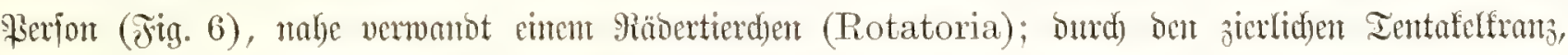

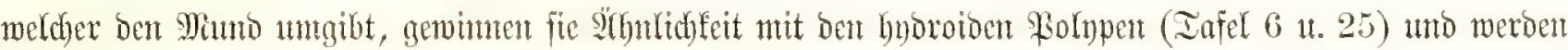

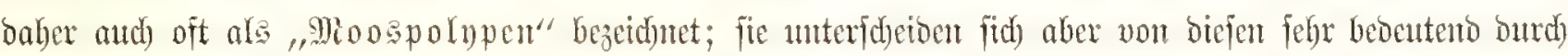

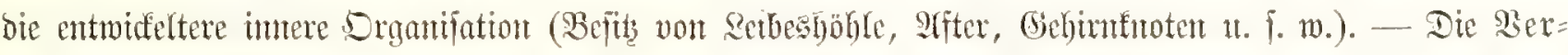

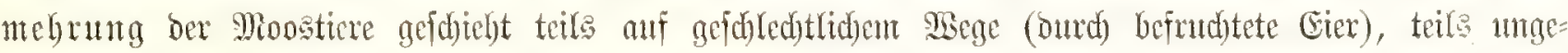

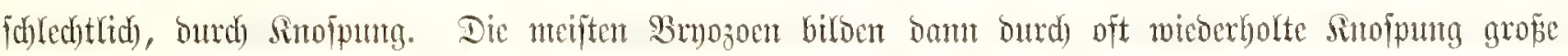

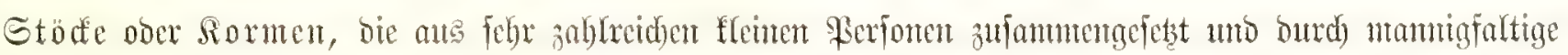

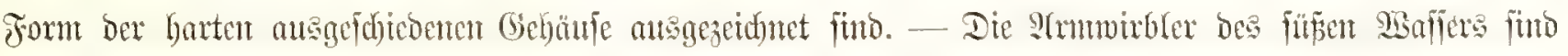

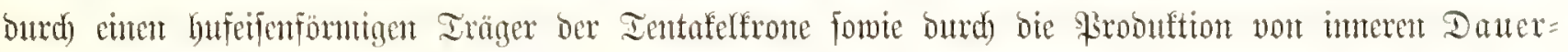

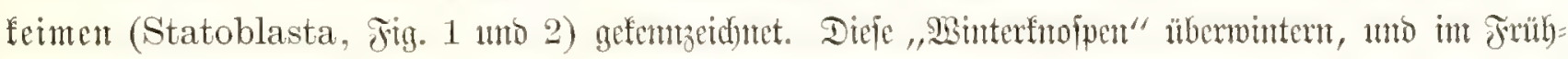

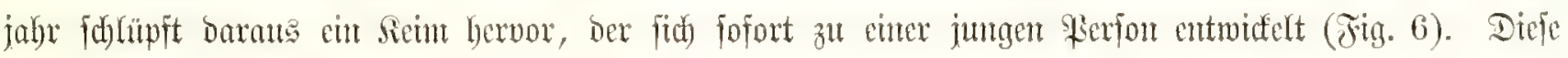

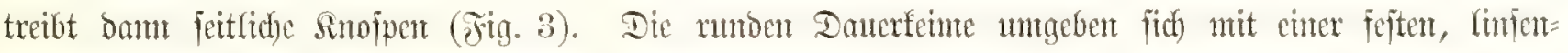

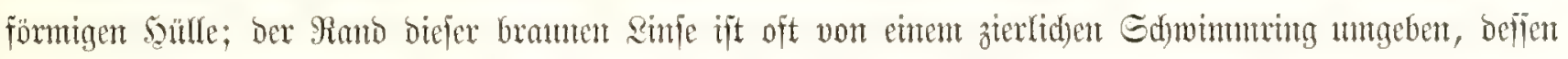

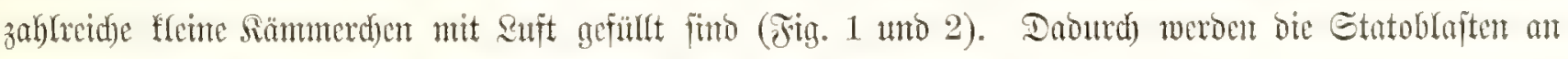

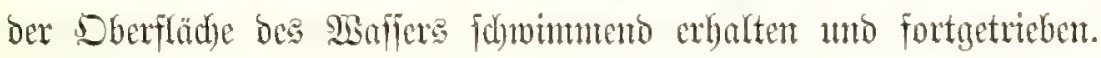

\section{Fig. 1-5. Cristatella mucedo (Cuvier).}

Fig. 1. Ein unreifer Dauerfeim (Etato= blaft), ein viełzelliger linfenförmiger Siörper, ber

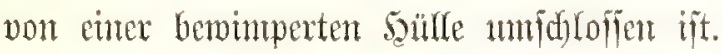

Fig. 2. Ein reifer Dauterfeim (Statoblajt). Der imere (braunc) viclzellige Sörper ijt von ciner

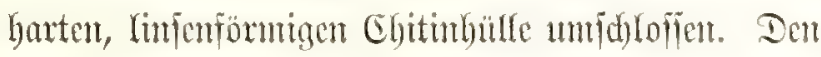
Rano ber bifonnexen zinfe untgibt cin jitulidyer

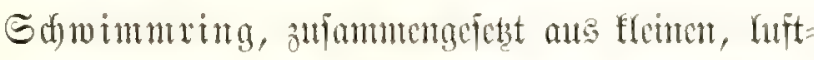

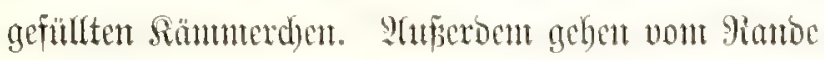
ber Eimfe viele ftrablenfömmige Etadyetn ab, bie ant

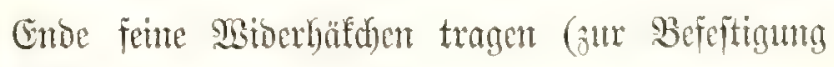
an siafferpf(anzent).

Fig. 3. Ein junges Etörduen (Cormidium), meldes frei umberiduwintut uno aus bret Sicrfonten

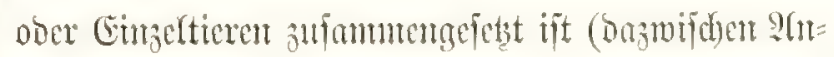
fagen von juei weiteren Ferfonem). Die mittlere

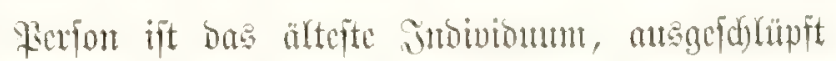

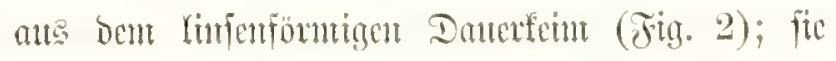

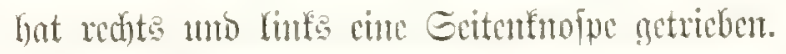

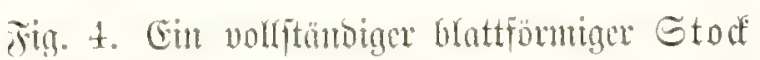
(Cormus), fird fret ill siaffer bemegent, fiduwad) 


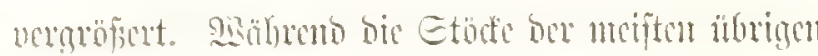

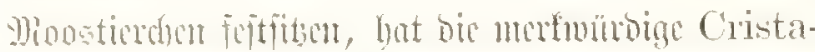

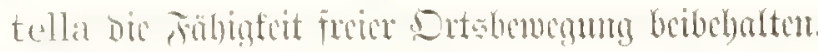

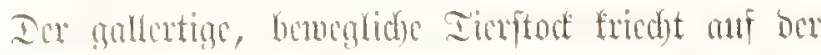

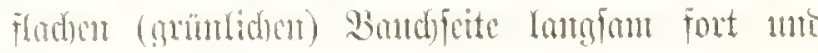

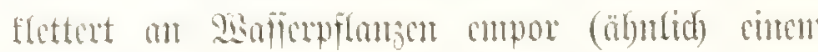

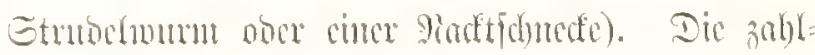

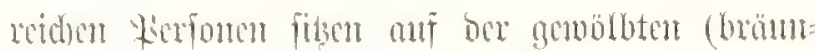

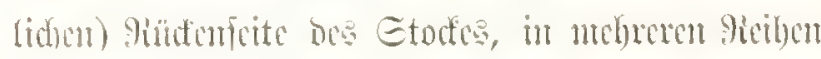

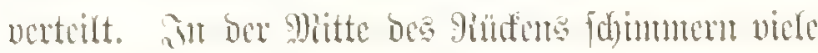

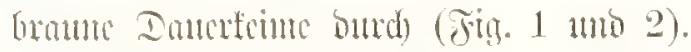

Fitg. 5. Encridunte Dund) ben blattömigen

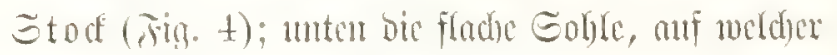

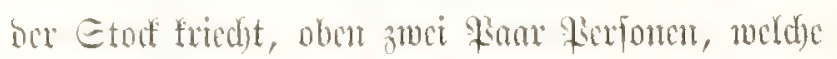

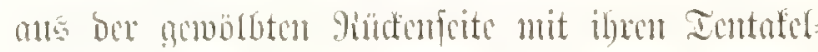

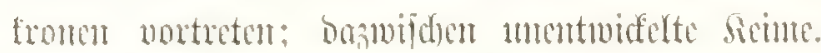

\section{Firs. 6-S. Plumatella repens (Lamarck).}

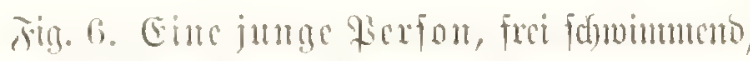

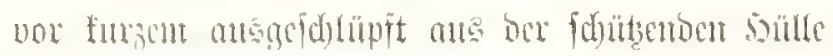
bes Dancrfum (Etatoblaften); bic beibon (brat

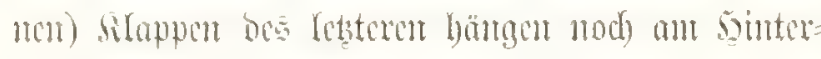
cube bes Iicrden mo zeigen ant Ranto ben zict-

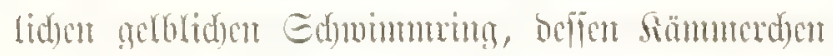

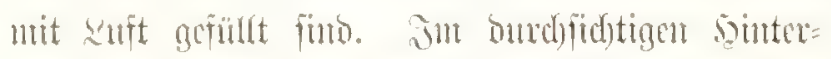
leibe ber Finfon ficht ntan in ber slitte ben fpin=

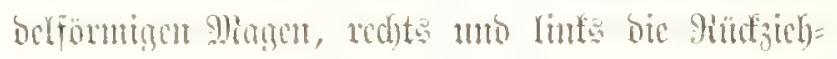

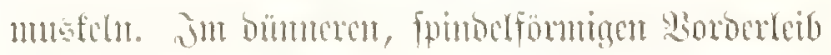

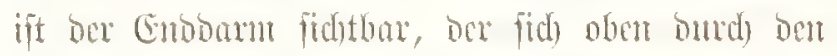

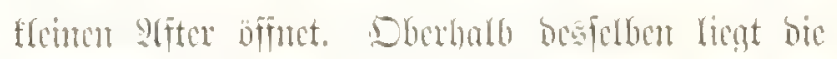

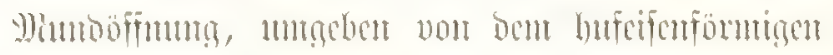
Tentafchträger (Lophophor); af bicjen fitst cume
Sironte von 60-90 zarten, bewegliden, mit Flint=

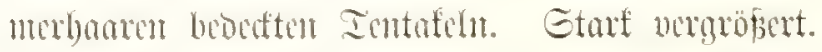

Fig. 7. Ein junger Etod, nit menigen sijten,

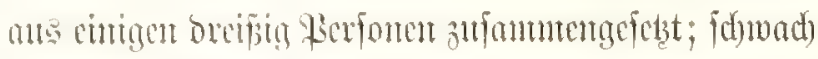

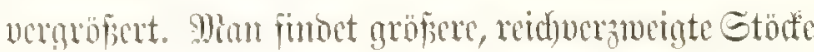
oft anf bex unteren S3lattiad)e non Ecerofen friedyento.

Jig. 8. Ein Gtüfducu bes Etodes Jig. T, ftärfer vergröpert; man fiebt bie Ientafeltronen be fünf Picrionen von verifficomen Eeiten.

Jig. 9. Aleyonella flabellum (Tan Beneden).

Ein junger Stox́ mit jumet inmmetrifd ver= tethen Sauptïften, an beren jeocm zelun Perfonen fiticu; fdunad) vergröpert.

Jig. 10-12. Lophopus erystallinus (Dumortier).

Jitn. 10. Ein junger Etod, ans fün łer=

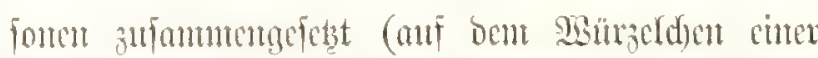

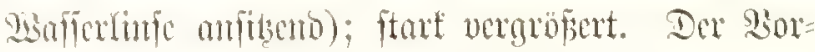

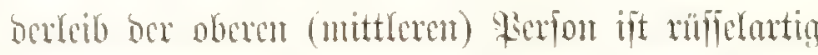
voryeftulfpt, von bex reduten Erite gefolest. Dic Iontaferfrone ijt an bicfer uno an ben beiden be= nad)barten Pierjonen frei entfaltet, an ben beiben

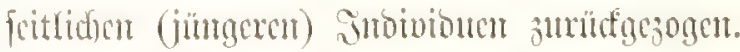

Fig. 11. Einc junge Sinofpe, nod) midht ge=

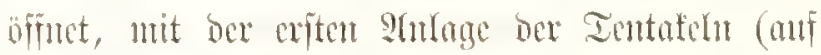

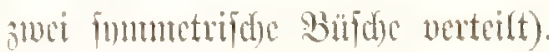

Tig. 12. Einc ülteve Snolpe, nod) nidjt ge= öpunt. Die Inntufeln funo längex abs in Fig. 11 mo bereits fonmetrifd anf bic beibon afme bes bufeifufönntign Ientafelträgers (Lophophor) ver=

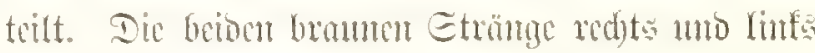
furo Siutsichnustu. 



\section{Desmidiea. Bivitimite.}

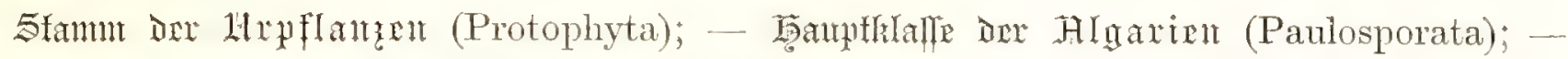

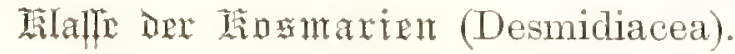

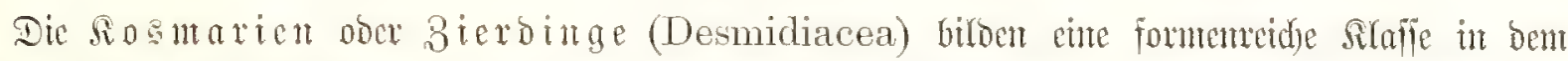

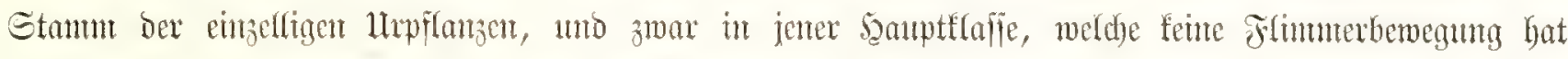

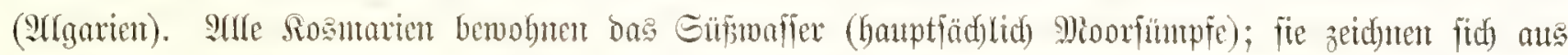

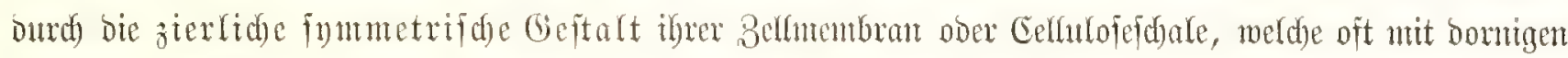

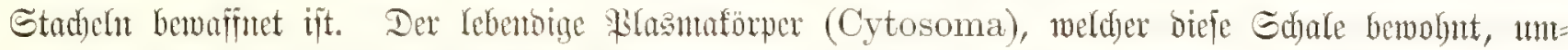

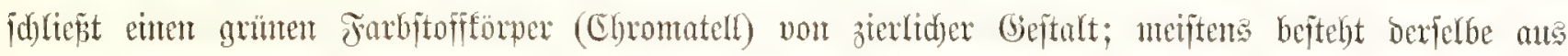

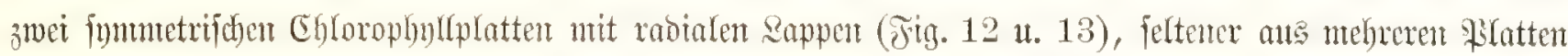

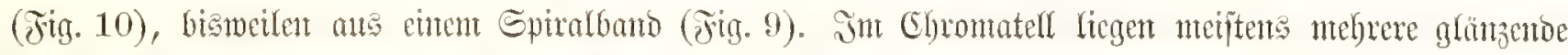

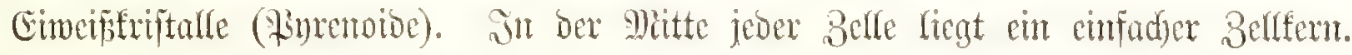

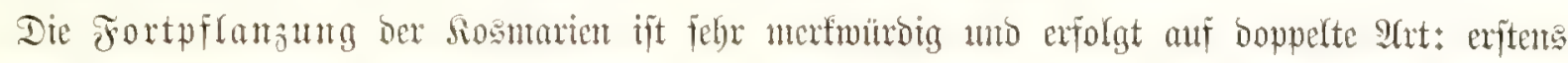

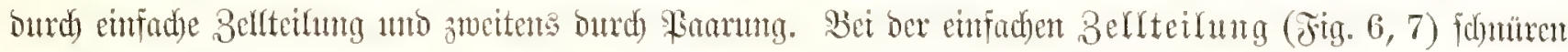

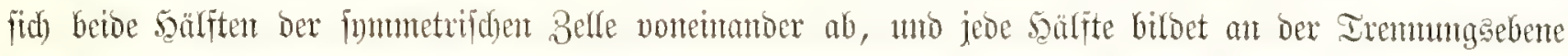

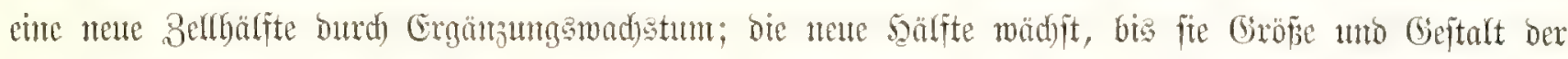

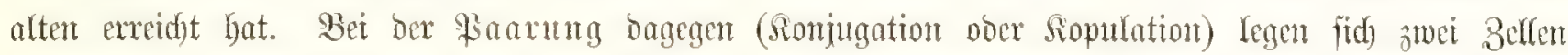

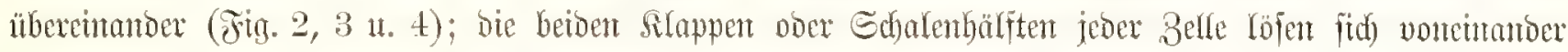

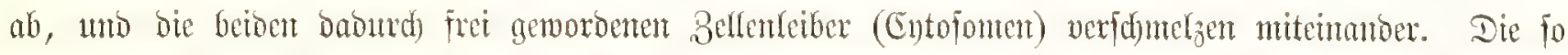

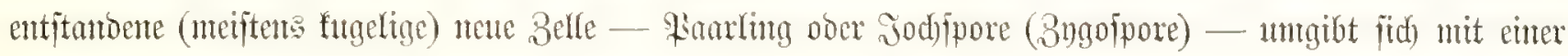

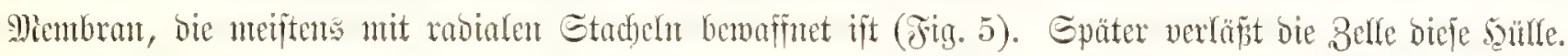

Jig. 1. Staurastrum furcatum (Brebisson).

Eine regelmäpätg breteftige Sosmarie, nit gabcl teiligen Stad)eln bewafinet. Sn ber Mitte ber Belfern.

\section{Fig. 2. Staurastrum vestitum (Brébisson).}

3mei regelmäpang breieditge Sosmarien, meld)e

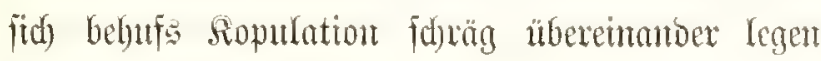
(vgl. Fig. 3,4 u. 5 ).

\section{jig. 3. Staurastrum aculeatum (Ehenbery).}

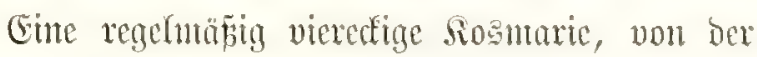
Geitalt cines quabratifden Sofatiflons, mit Etadjech beicent.
Jig. 3a. Frontanfid)t (non ber formulen

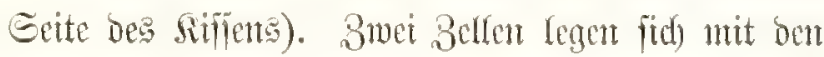
gewölbten breiten Geiten bebufs Siopulation über= einanoer.

Jig. 3b. Endonfid)t (vont ber breitent Geite

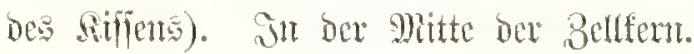

\section{Jig. t. Stamrastrum paradoxmm (Meyen).}

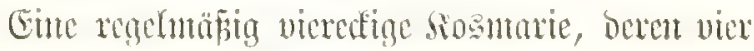

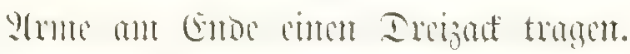

Fig. ta. Froutanfid)t (von ber fodmaten

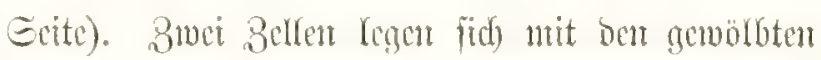
breitur Eciten hehnfs sopulation übereinanoes. 
Fin. 4b. Ens anfidnt (un ber Griton Erito).

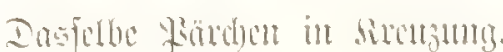

Sig. 5. Staulastrum spinosum (Bribisson).

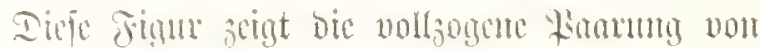

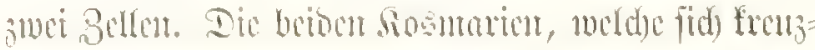

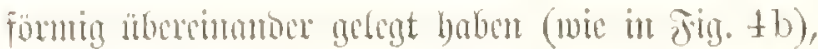

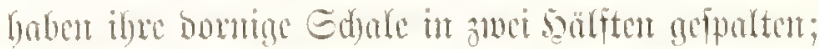

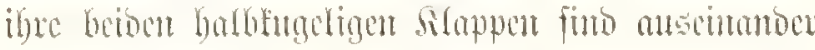
getreten (linte obere nuto red)te untere Sllappe ge=

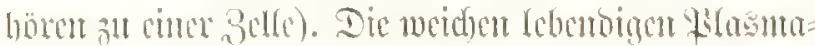

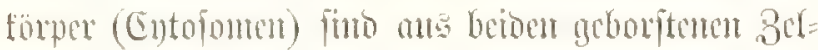

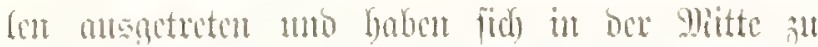

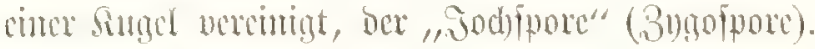

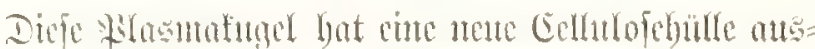

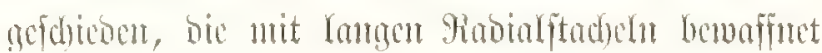
ift; Focr Etadhel trägt an Enbe cinen Dreizad mit orei gablfpaltigan Enobafon.

Fig. 6. Mierasterias denticulata (Brébisson).

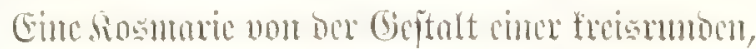

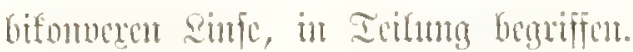

\section{Fion. 7. Micrasterias trigemina (Hackel).}

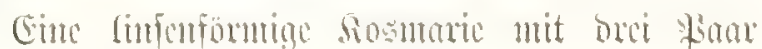

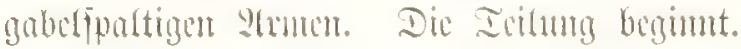

Tin. S. Micrasterias melitensis (Ehrenberg).

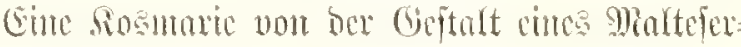
truss, mit oxe tian mebrpaltigen ?trmen.

Sig. 9. Spirotaenia condensata (Brébisson).

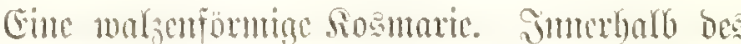

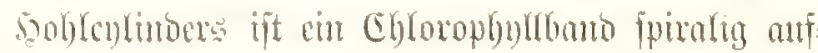
gerollt.

Fin. 10. Closterium costatum (Corcla).

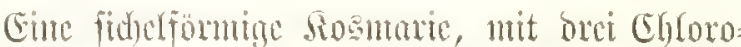

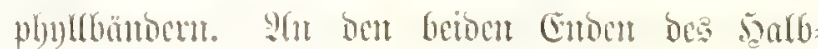
Jnondes liegt cin belfes, fugcliges Bläsdu, in bent fid) fome (bipstriftalle jitterno benocgen.

\section{Fig. 11. Enastrum pecten (Eherenberg).}

Eime fommformige Sosmorie, mit fects Finar Ftumpiost gionolonpent.

Jig. 12. Luastrum agalma (Haeclicl).

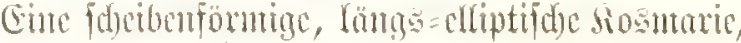
mit ad)t Sinar merbipaltigen Hamolappen.

Fin. 13. Euastrum apiculatum (Ehrenberg).

Eime focibenformige, ancr=etliptidac sosmaric, mit smöl Fina melorpartigan gimolappent. 


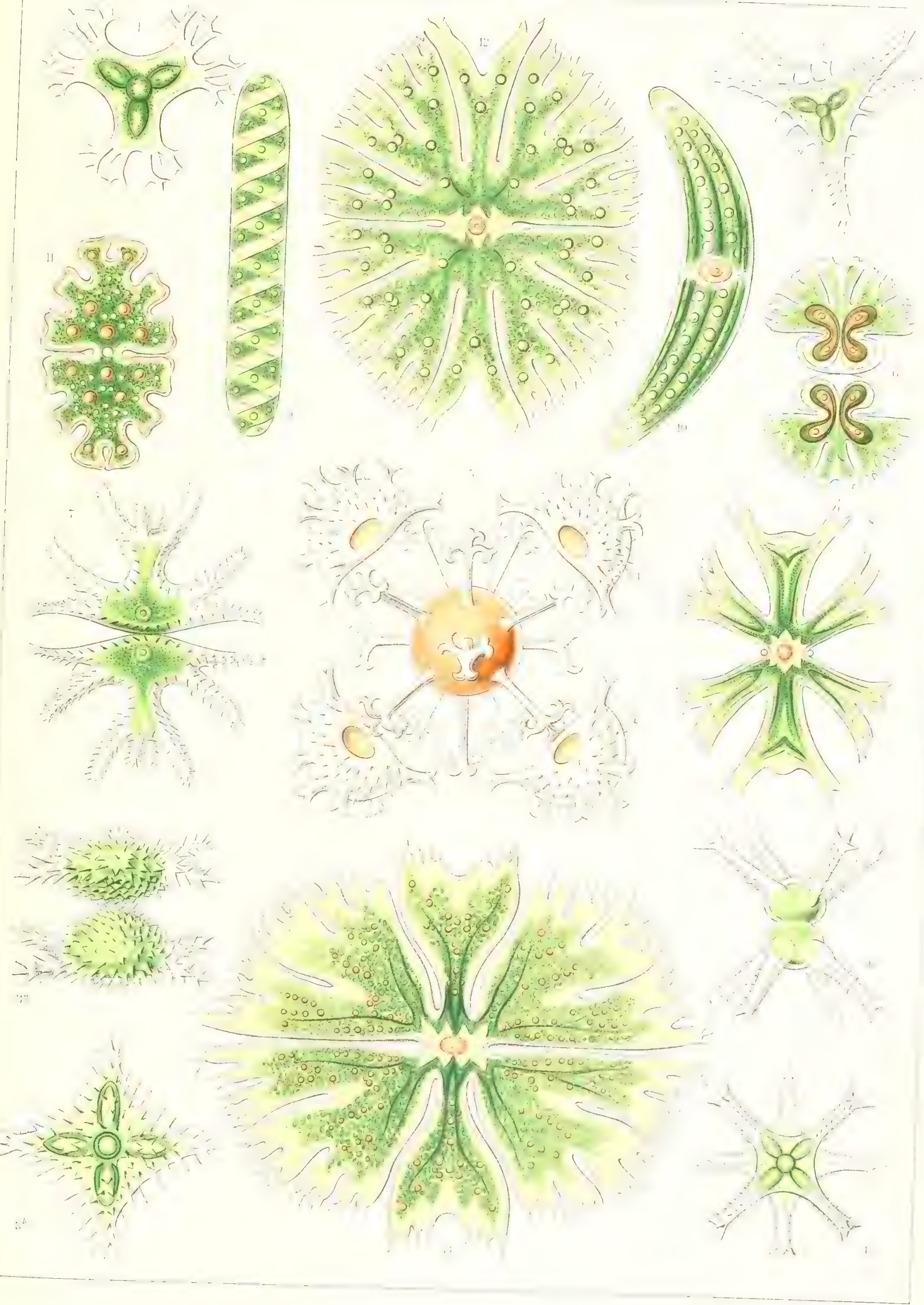

Desmidiea. - Biersimuse. 



\section{Sertulariae。 Thitrumutunut.}

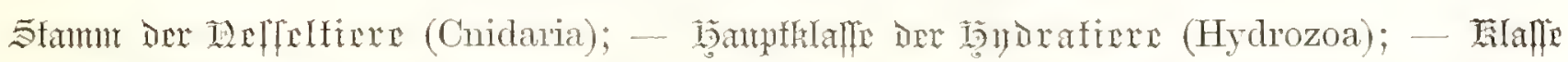

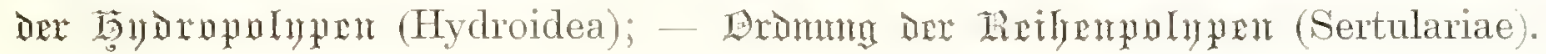

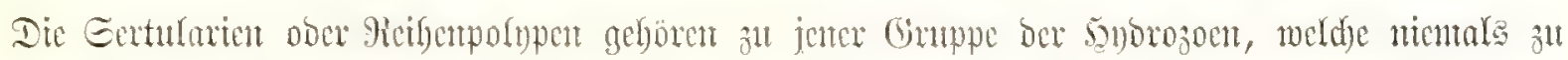

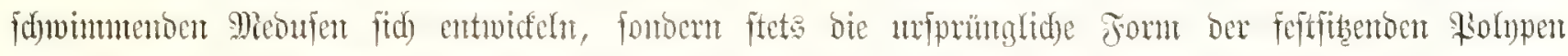

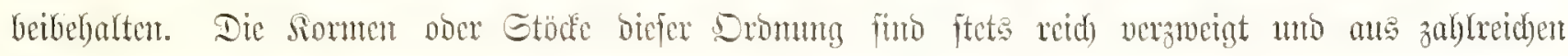

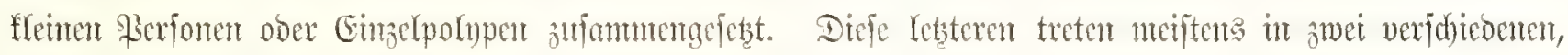

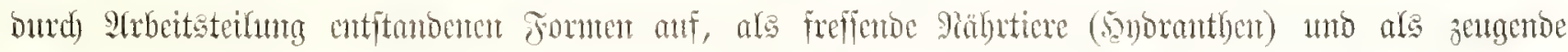

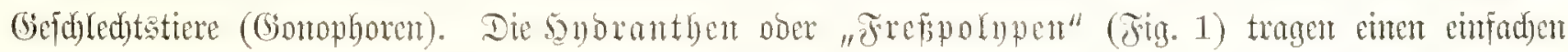

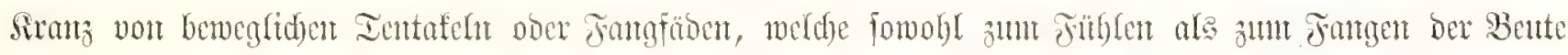

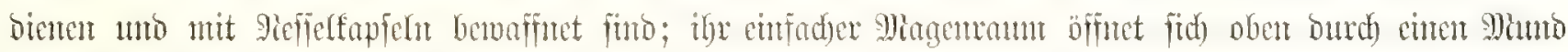

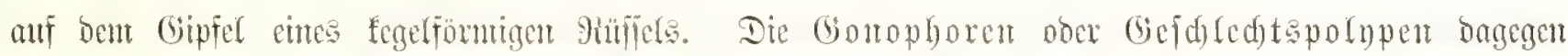

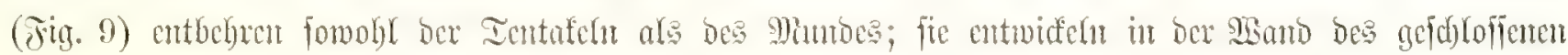

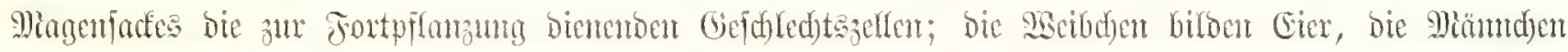

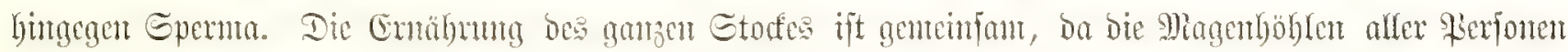

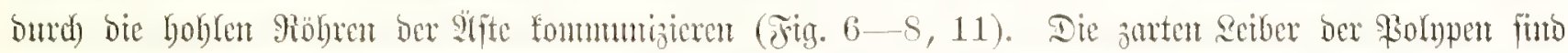

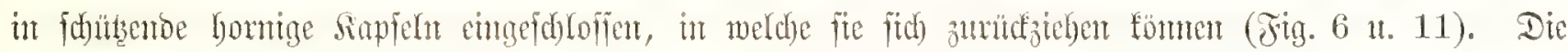

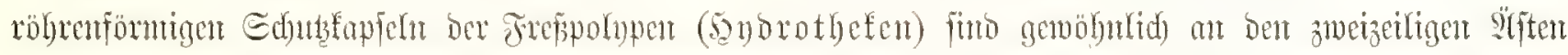

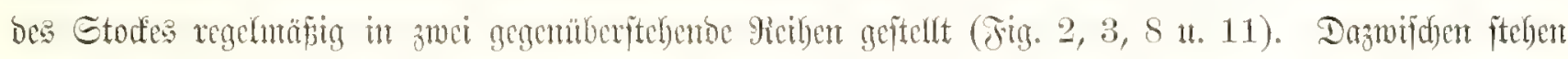

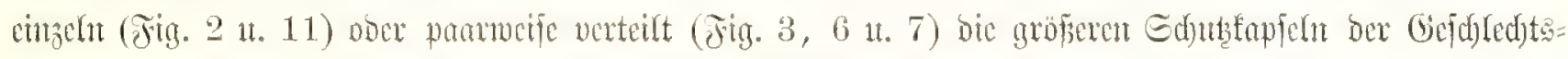

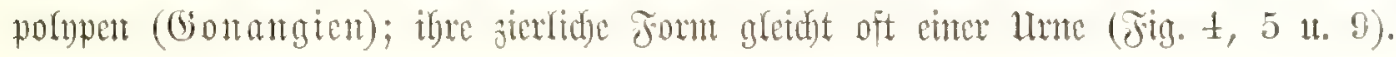

Fig. 1. Diphasia pinaster (L. Agussiz).

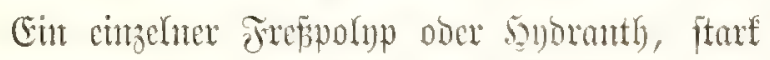

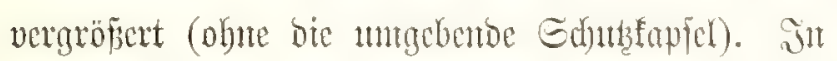
ber Mlitte ift ber eiförmitge Siorper ber Sterfon von Dem cinfachen Ientafelfranz 1 tungürtet; oben offintet fith ber Matmo auf oce Spite bes fegelfömnigent Mitifieres.

\section{Fig. 2. Diphasia pinaster (L. Agassiz).}

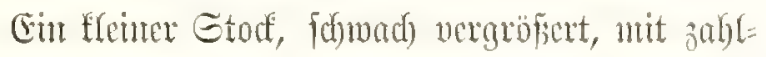
reid)en Geitengucigen, anf benten bic bubrotbefen

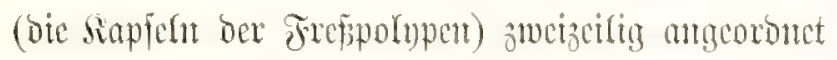

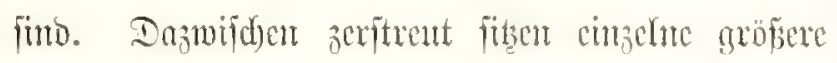

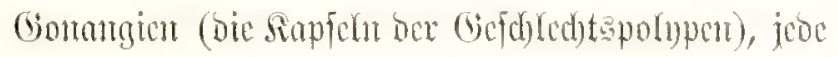
mit vier Bäfnen (vergl. Jig. 8).

\section{Fig. 3. Synthecium elegans (Allman).}

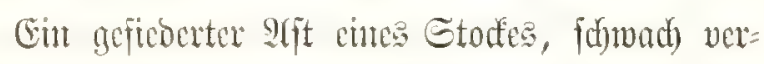

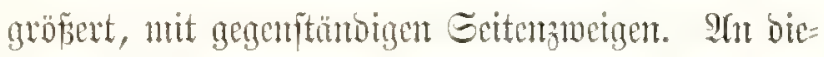

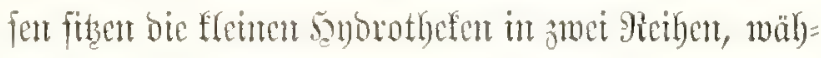
tent an ber Bafie troes Scitenaftes ein paar gröpere,

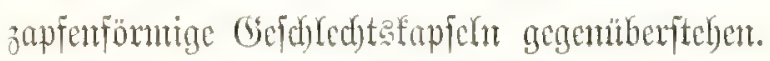

Fing. 4. Idlia pristis (Lamouroux).

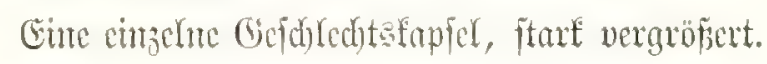

Jitg. 5. Thuiaria quadridens (Allman).

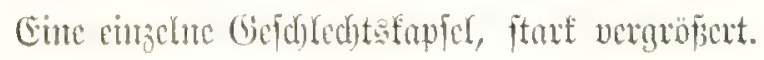

Jig. 6. Synthecium campylocarpum (Allman).

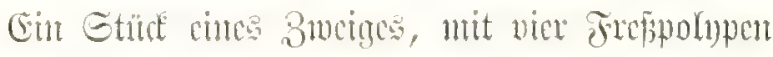

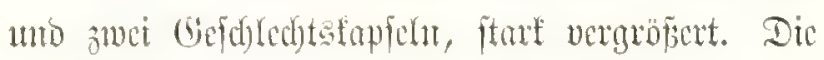




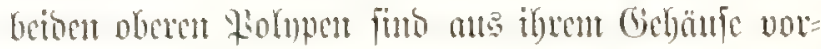

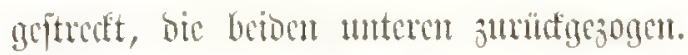

\section{Fin. 7. Desmoscyplius acanthocarpus} (Allman).

Ein Gtüf cims Buciges, mit bre Gricbern

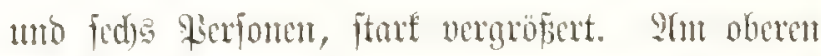

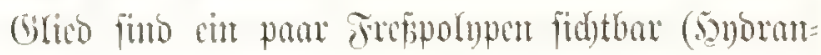
thent), ant mittleren Grlico cin paar lecre Siapfelts

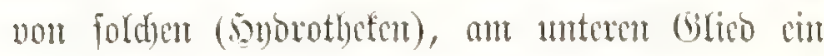
par leere Gefdededstapleln (Gonangien).

Jitg. 8. Diphasia pinaster (L. Agassiz).

Ein Gtür cincs 3weiges von bem in Fig. 2 abgebilocten Etod, ftanf nergröpert. Jyin fiebt bie

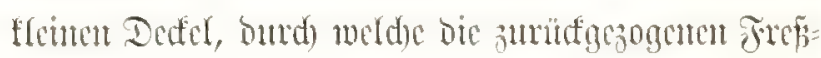

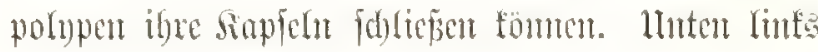

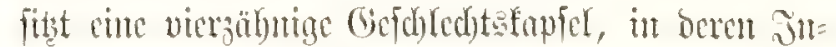

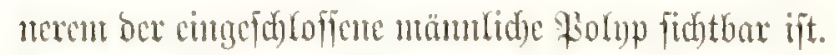

Fig. 9. Eusertularia exserta (Allman).

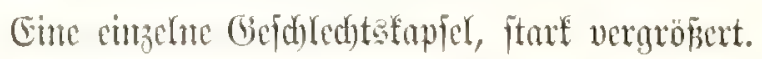

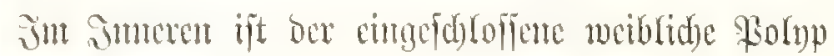
fidetbar:

Jì. 10. Dynamena argentea (Fleming).

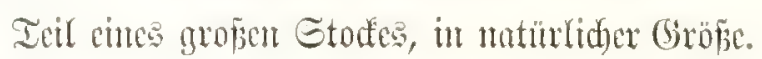

\section{Fig. 11. Thecocladium flabellum (Allmon).}

Cin Etür cimes slites, ftarf vergröpert. Der

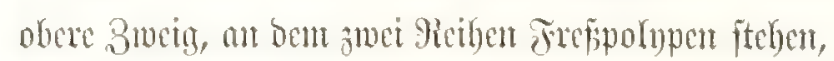
läuft oben in cime Gionfe ans; ant unteren 8 weige

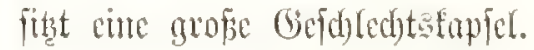




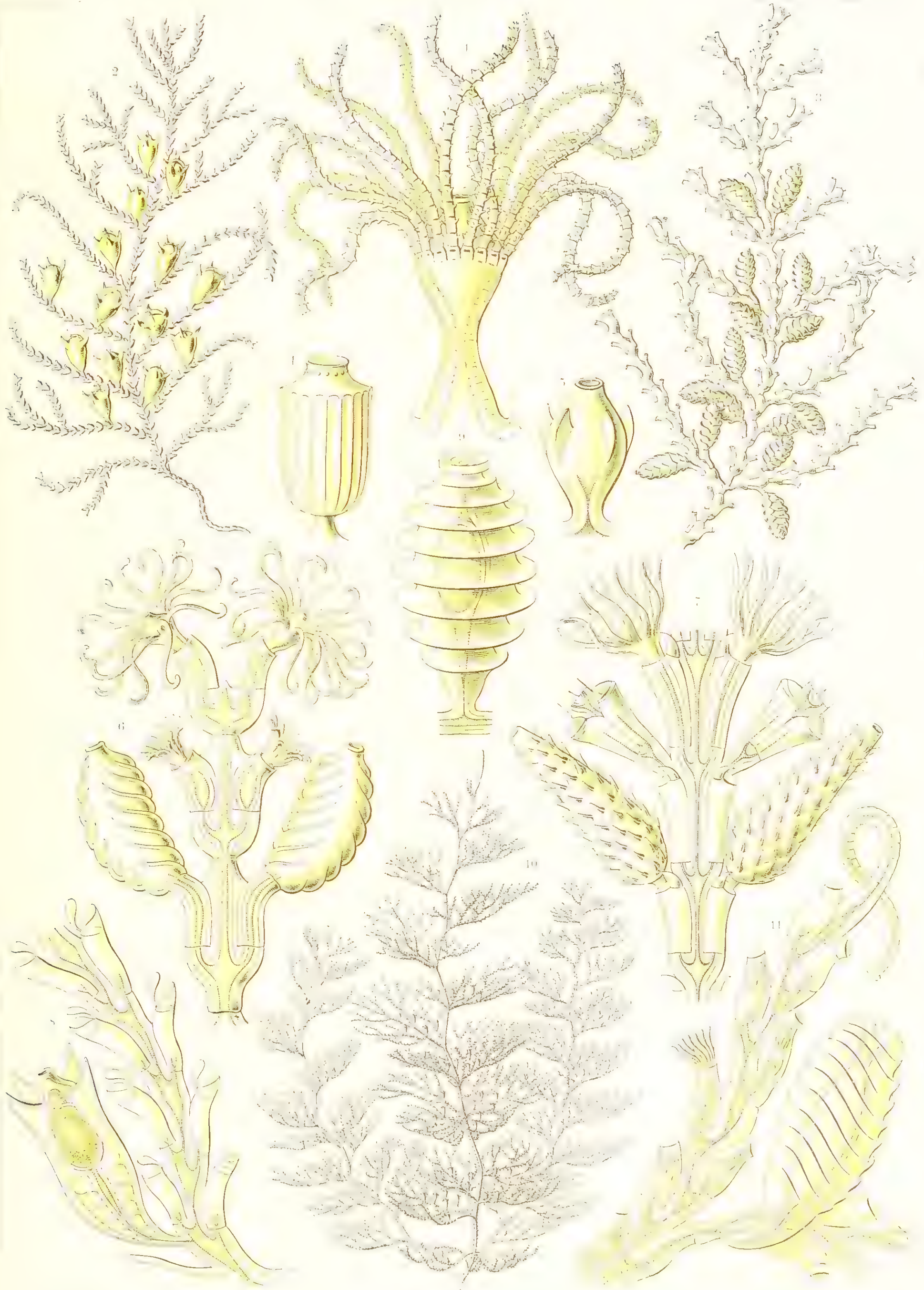

Sertulariae. - Dicibertrolinter. 



\section{Trachomedusac. Tuthentuallent.}

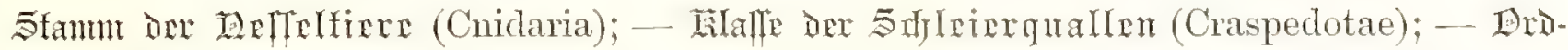

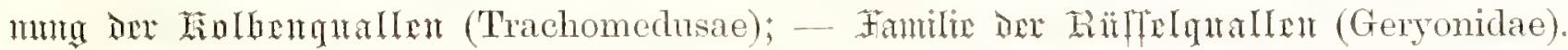

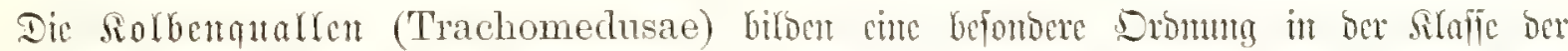

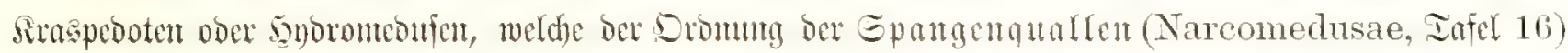

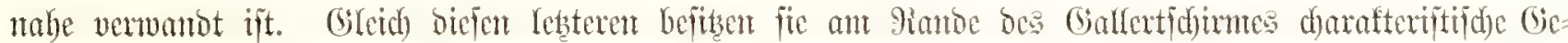

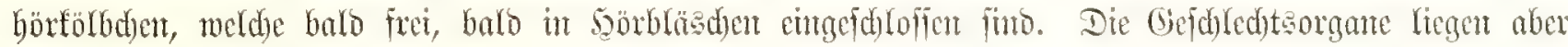
bei ben Solbenquaflen nidft in ber unteren Magenwants (woie bei beat Epantgettqualfen, Iafel 16), font=

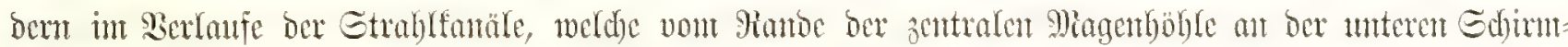

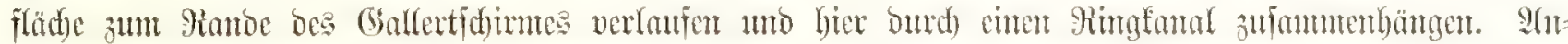

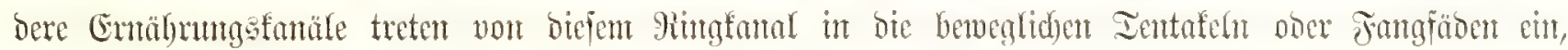

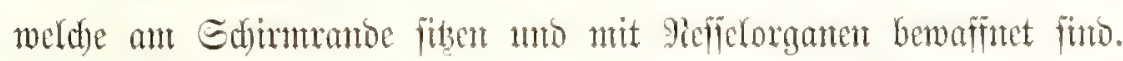

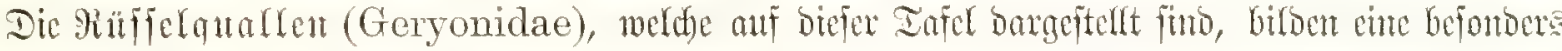

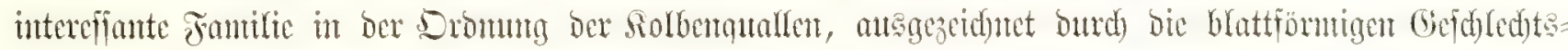

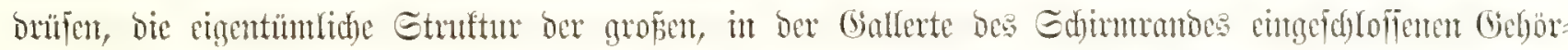

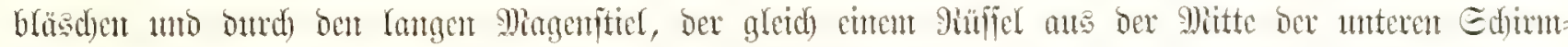

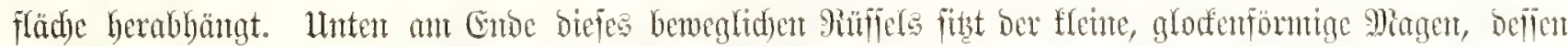

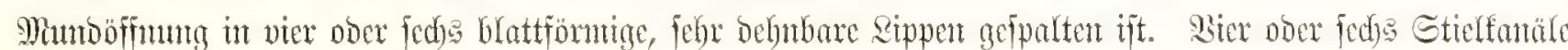

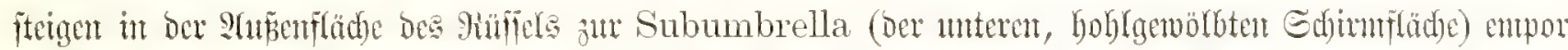

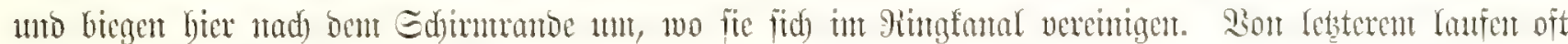

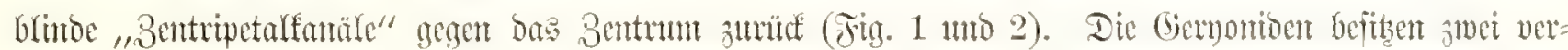

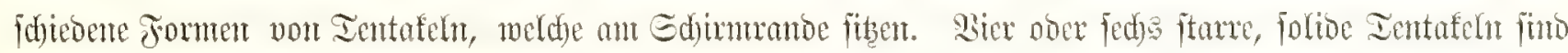

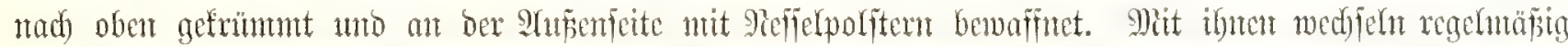

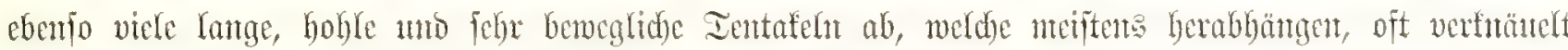
unb mit vielen Mefieltringen perfidemurartig ungeben fino.

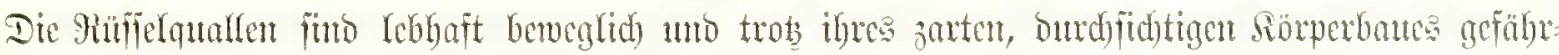

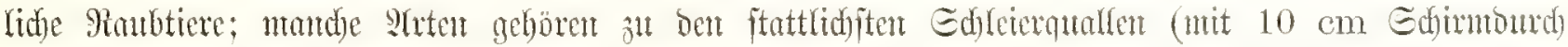

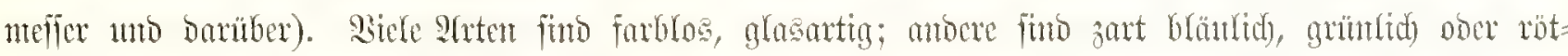

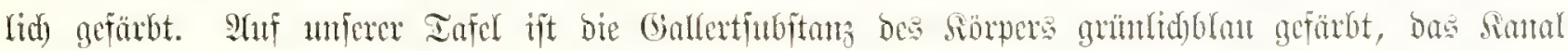

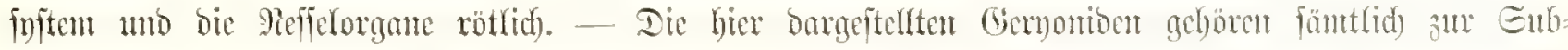

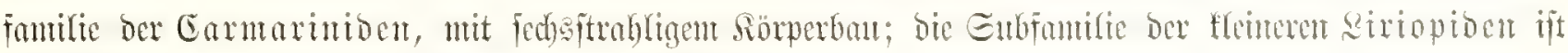
vierfituhlig gebant wie bie meiftent üfrigen Miesuren.

Jig. 1-3. Carmaris Giltschi (Haeckel).

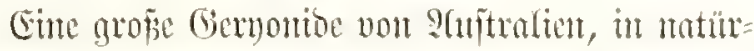

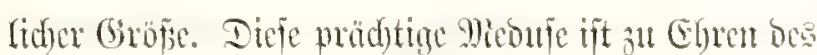

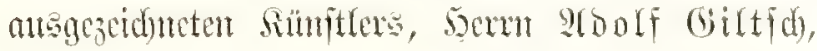

benant, beffen felturent Tafent anto bolfonmentem

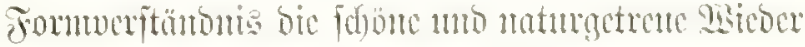

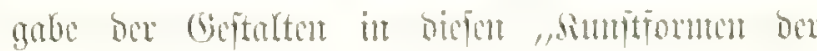
Fiatu" su banten ijt. 


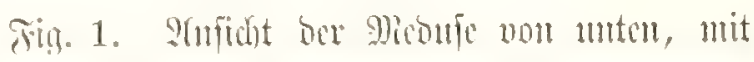

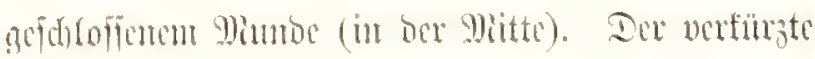

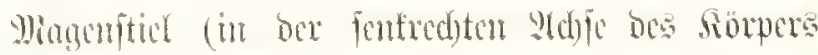

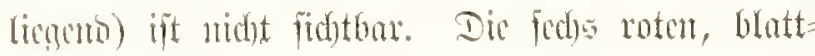

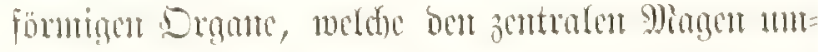

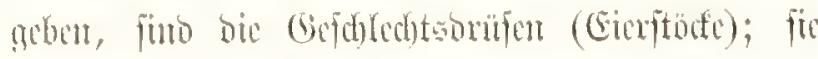

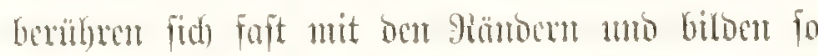
rine fechaftrablige Rojette. Buijuen bicfen feds Gomaben fund 66 brime Bentripetalfanale fidstbar,

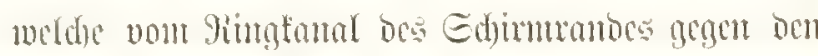

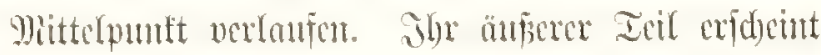

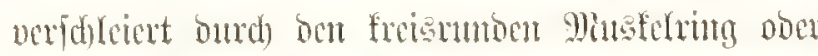
Edfrice (Velum), wercher vom Exhimmande bort= sontal nad) inten vorfpringt. Der Edjumano

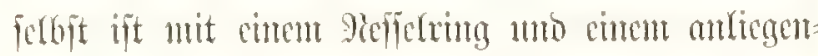

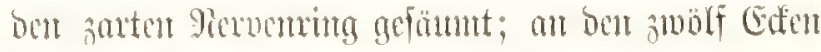

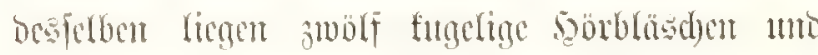
chenio vide Ientufeln; von bicken funo bie fedts

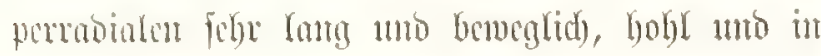

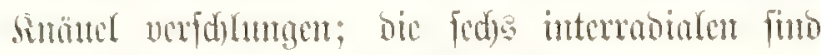
ftcif, folio, boxnförmitg gctrinumt.

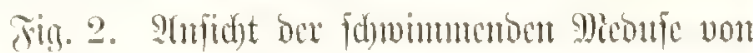
ber Grite Imb ctwas vont anten. Dex Kange Dingen

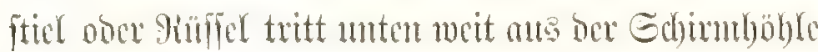

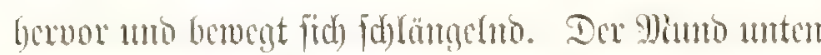

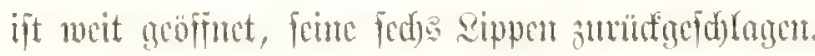

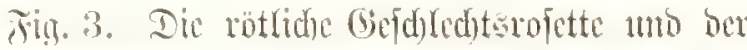

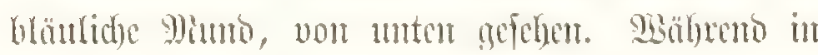
Fig. 1 ber Miagen ftarf 3nfammengezogen ift mo bie fed) Sippen bex Mintobffmung nad) immen gefd) lagen

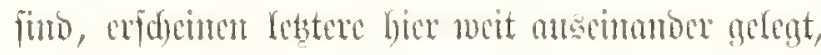
als fed perrabiale, gefrände blatter.

\section{Fig. t-6. Carmarina histata (Haectel).}

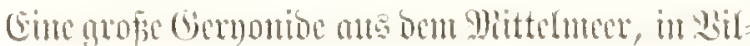

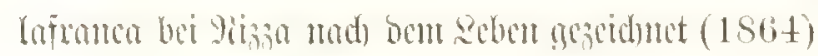

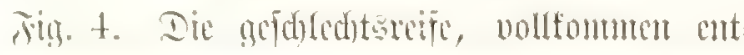

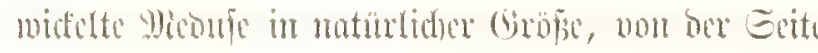

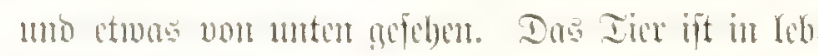

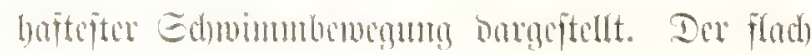

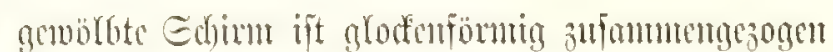

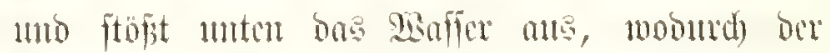
Sd)wintuming (Velum) unten vorgetrieben wird. Dex Mingenfitic ift ftarf gefrimme; ate ben weit

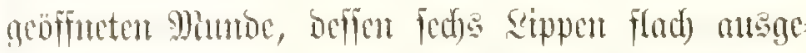
Greitet finto, tritt bic fpuloclformige Bumge bervor. Die fed)s perfidmufoumigen langen Ientafeln be megen fich wummtömmig.

Fig. 5. Ciut jugentolide saroc von pelfe cin Fad)en Rörperban, vergröpert. Der Maganftiel ift nod) nidit cutwidelt. Ier fleme Wiagen fitst oben

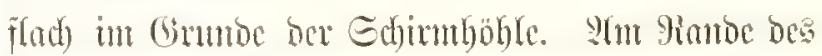
Edjume jiben zmölf furze sarvententafeln, fects fleme prinutue (mit comen Teffelfnopf), nad) oben

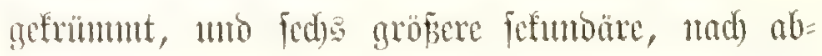
wärts gefd)lagen. Die fedfe langen tertiören Ien= tafeln bce reifen Iieres (Fig. 4) Fehlen nod).

Fig. 6. Cinc ältere saxve mit 18 Ientafeln, von ber Geite umb ctwas von unten gejeben, ver=

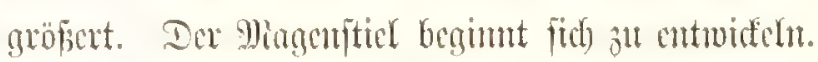
Epäter fallen bei ber Sermomofung bie fod) flemten

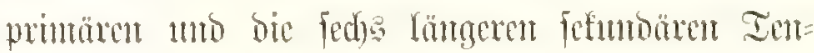
tafeln (meldie nad) oben gejd)lagen fimo) ab, umo

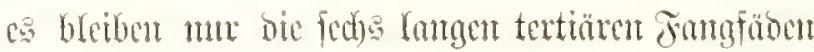
ïbrig, welde gẹd) änget herabbängen (Jig. t).

\section{Jig. 7. Geryones elephas (Hacctiel).}

Gine grofic Gernonioe ans Gilbafrita, von ber Grite 1 tur etmas vont obert acjebat. Dar Guim

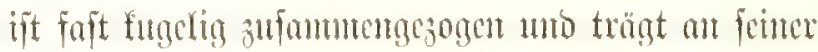
Interfeite fods breite, blattfömige Gonoben (Cies=

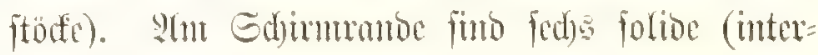
rabiale) Ientafeln bornfömig anfroäte getrünmet,

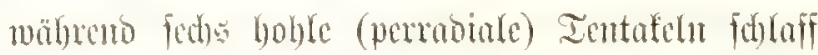

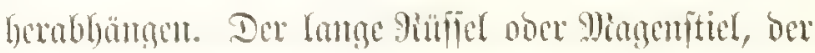
unten me ber Edimboble hervortritt, ift iphatio geträmmt, ber glofferformige \$lagen an femem Imteren Enoc flad) ansgebretet, fo bajs in ber

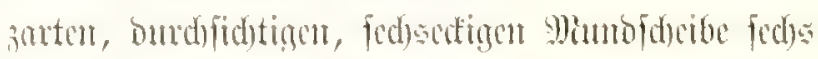

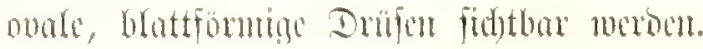




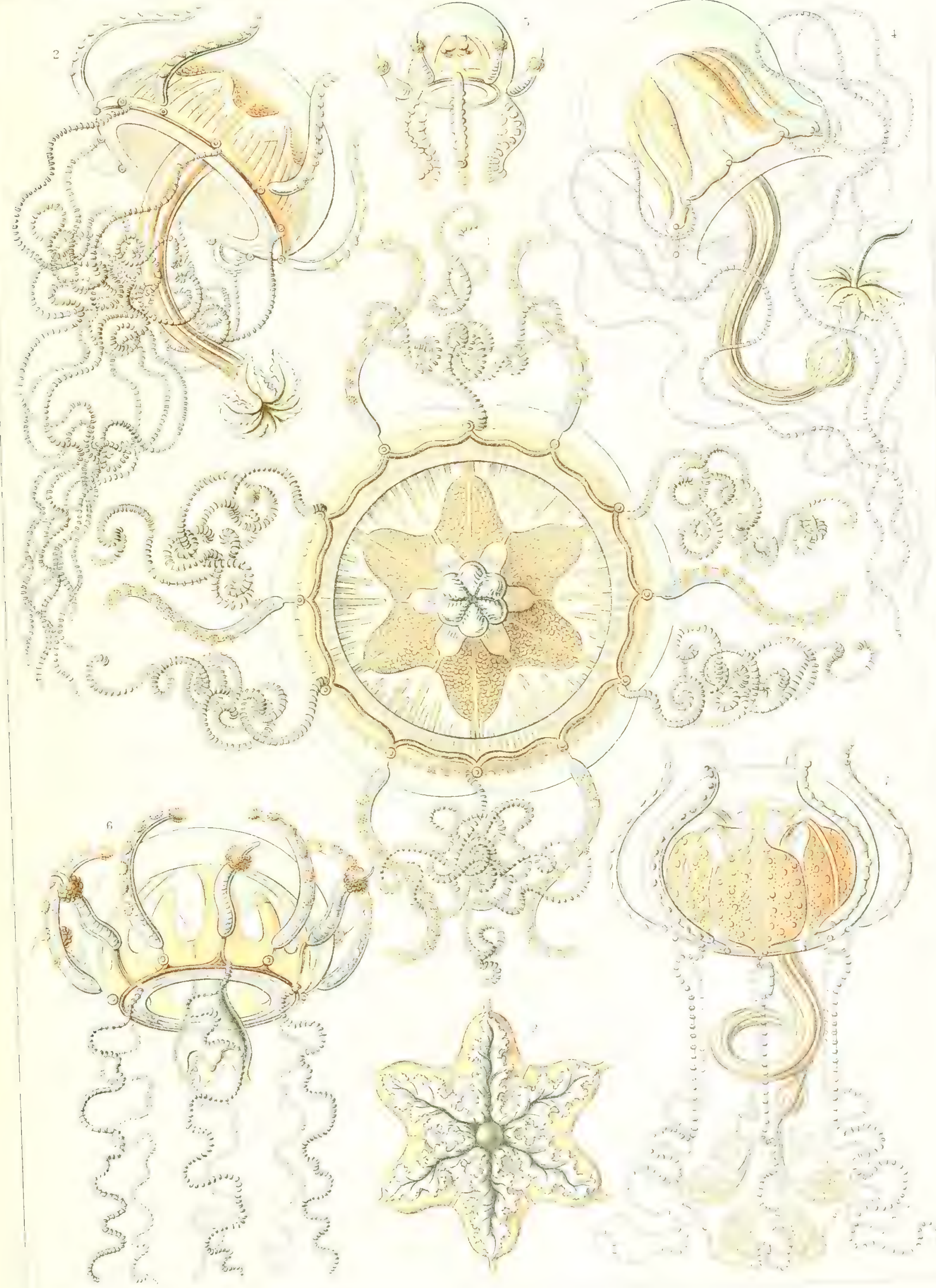

Trachomedusae. - Sirolberrotallent. 



\section{Ctenophorae。 Hammutallur.}

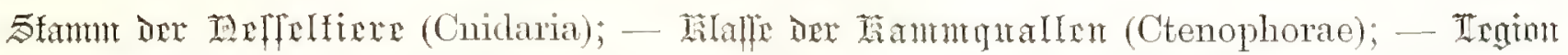

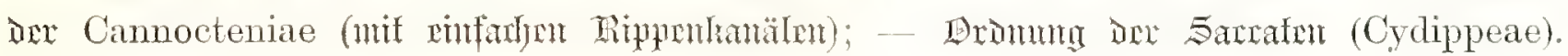

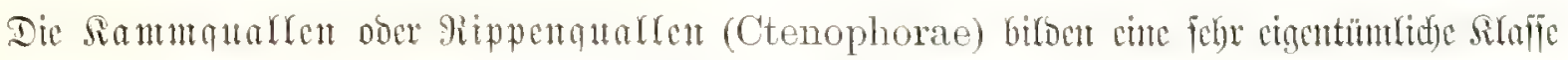

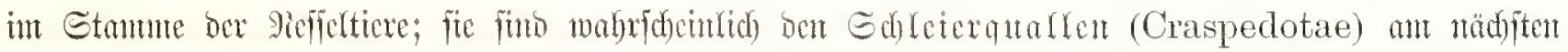

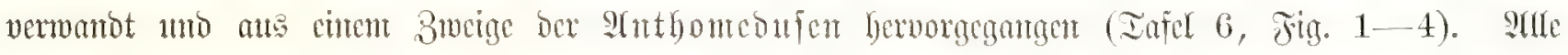

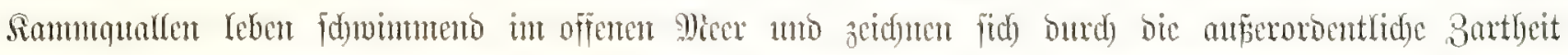

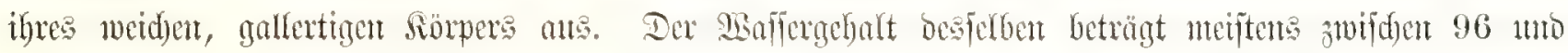

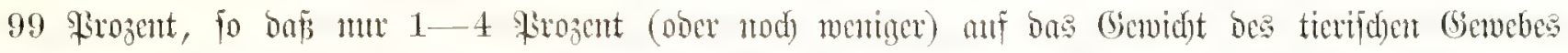
fommen. Dabei ijt ber glasartige fiörper meiftens vollfoumuten burdjutd)tig, fo bajs man bie intere

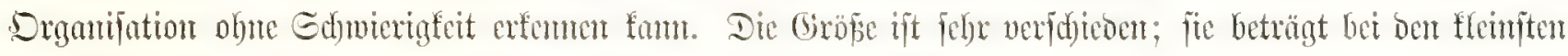
Arten mur wentige Milllimeter, bet ben gröpten über cinen Dieter.

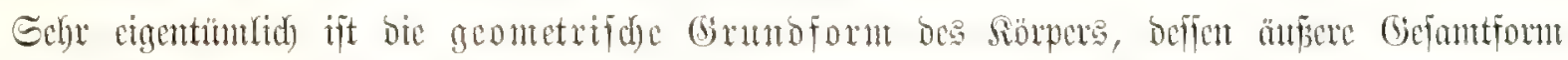

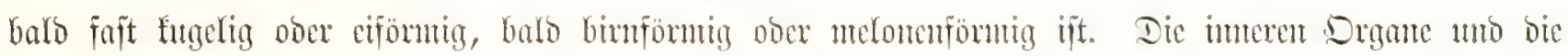

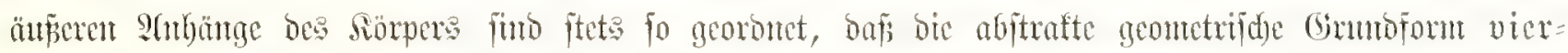

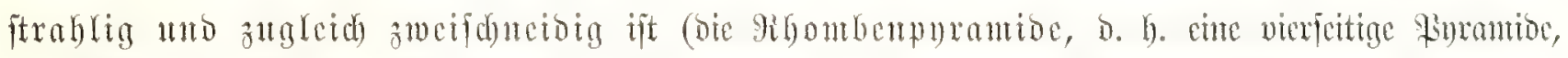

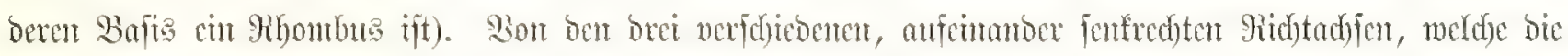

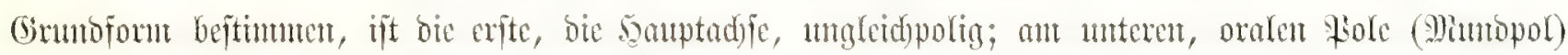

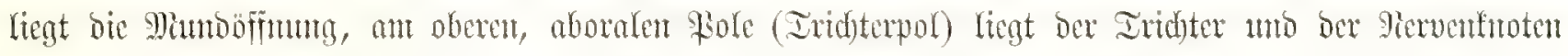

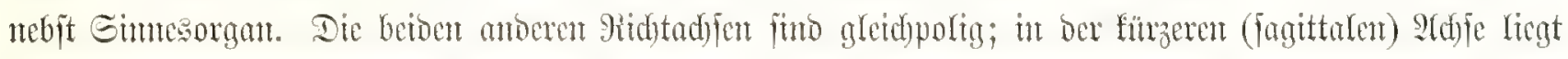

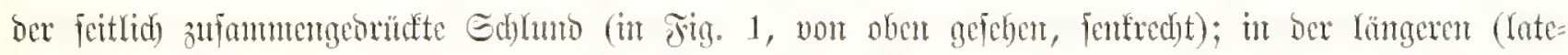

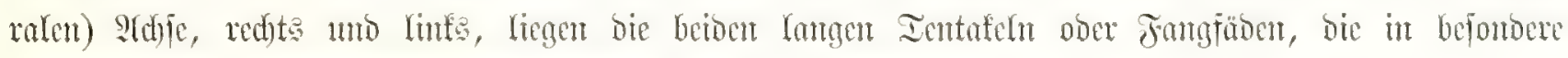

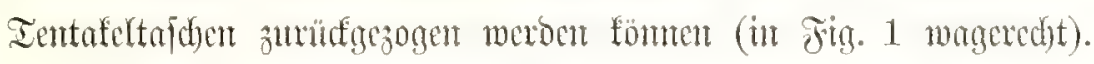

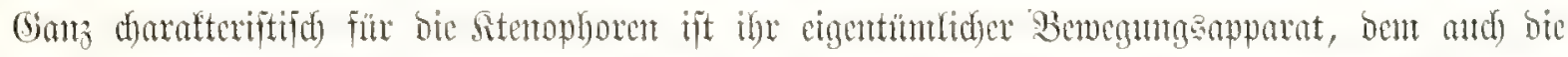
Silofie ifren gianten verounft. Derfelbe befteht ans a d) abrabialen

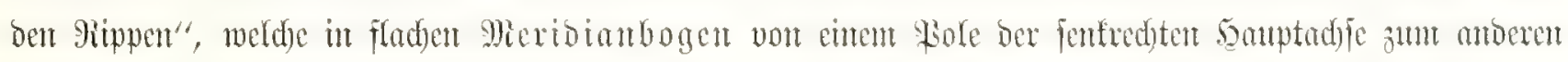

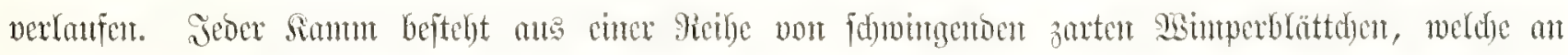

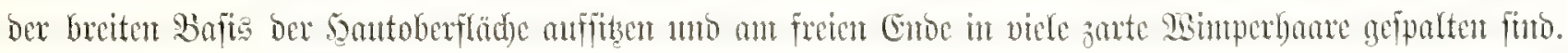

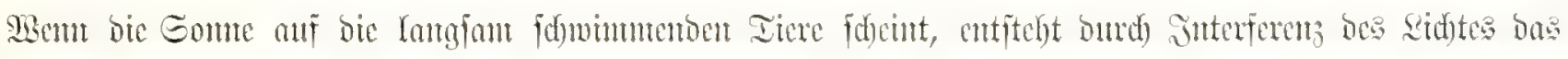

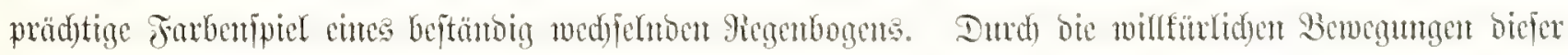

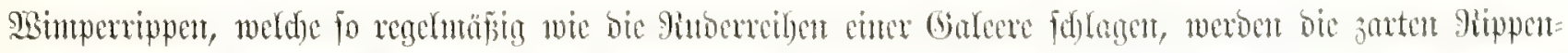
quallen Langiant gheitento in Micer menthergetrieben.

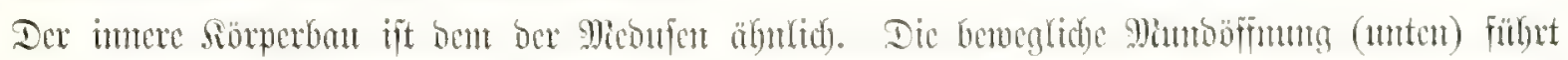

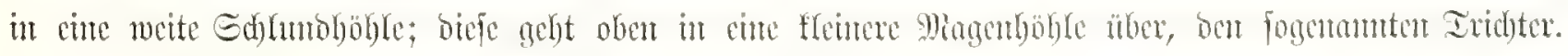

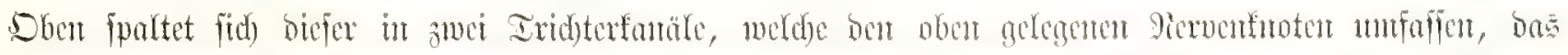

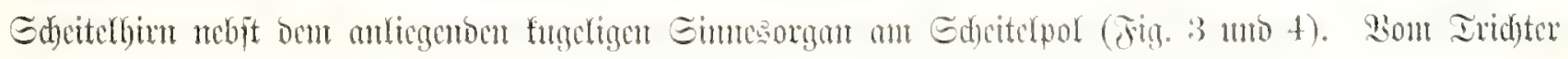




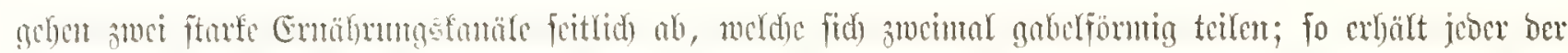

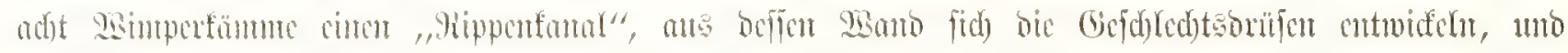

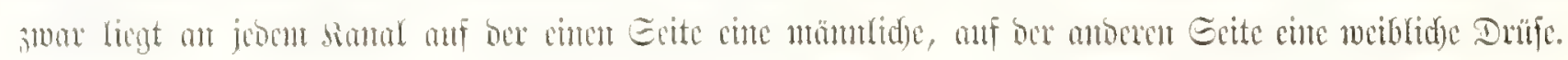

Ting. 1, 2. IIacekelia rubra ( Victor Cams, 1862).

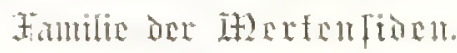

Diefi sicrtide Sitcrophore, in Micfinto (Yo=

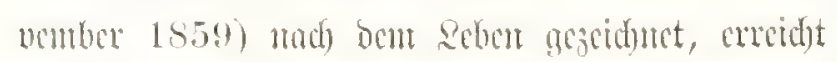
mu 6-S mm siorpertänge; fic jeidhnet jid burd)

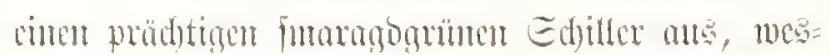
butb fie fpöter (1580) Euchlora rubra gentumt

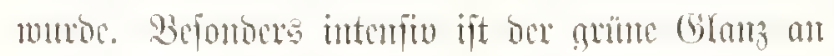

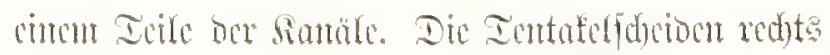
uno linf: fins präd)tig orange noce butrot gefürbt.

Tig. 1. S(mifid)t vout oben, non Iriduterpol,

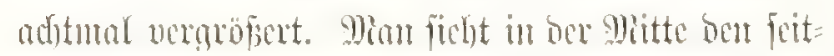

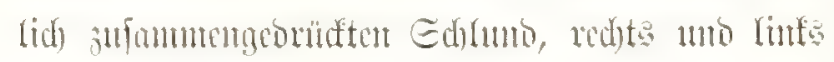
bic betben cimfadyen Fantgäben (ans ifren Injd)en vortetemo), Dnjwifden bie adjt ssimperrippen.

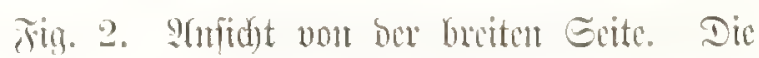

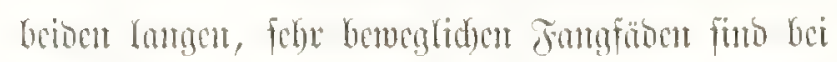
Hacelielia cinfad), wäbrento fie bet allen antocen

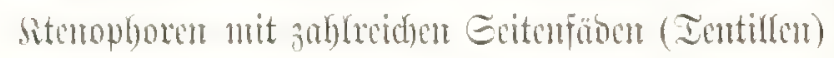
befobt finto. 9fud) ijt Haeckelia (cime ber why $f_{0}=$

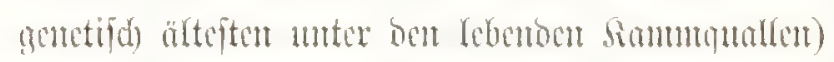
Die eimige Gattung, weldye feine Yateralen Ed) Gumb=

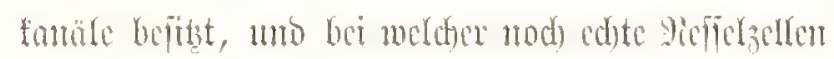

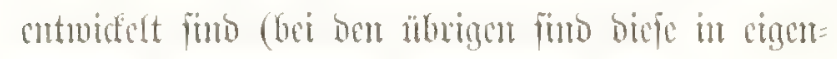
tümliche "Greifallen" nerwambelt).

\section{Trig. 3. Ilormiphora foliosal (Hacekel).

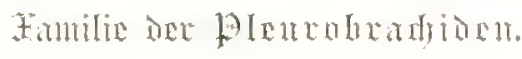

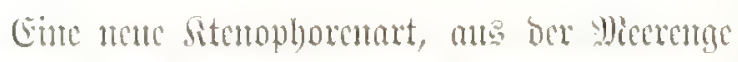

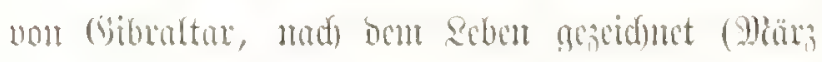

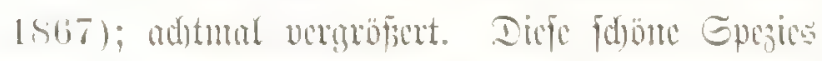

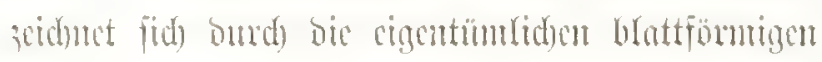

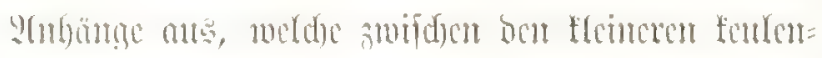

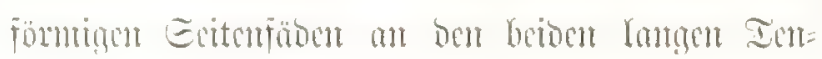

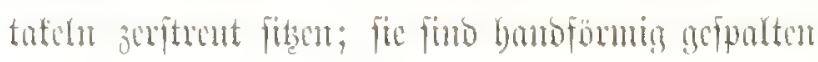

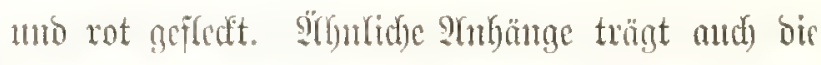
fanturifde Hormiphora palmata (Chm). In

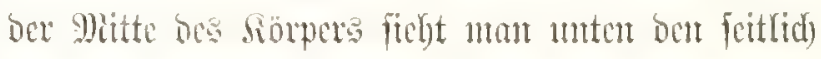

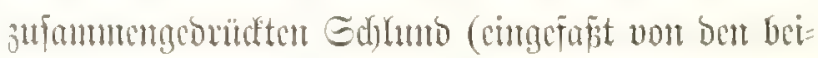
but Geflunbfantäl(on), oben ben Irid)ter unt bie beiben Iriduterfantäle, weld)e bas Gimesorgan an Gdeitelpol umfaifert.

\section{Jig. t. Callianira bialata (Delle Chiaje). Familix one}

Strfidet vou ber breiten Eeite, fdumad) ver=

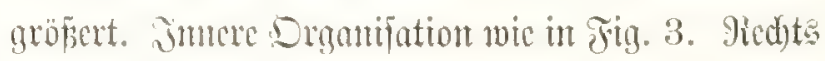

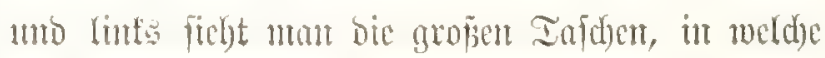

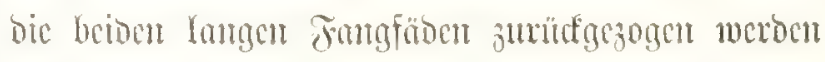

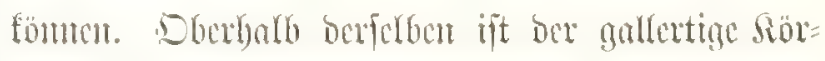

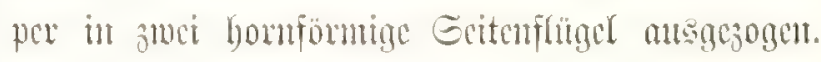

\section{Fig. 5. Tinerfe cyanea (Chun).}

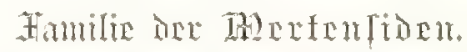

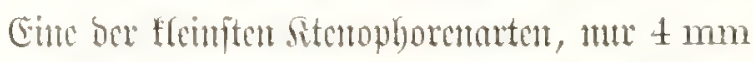

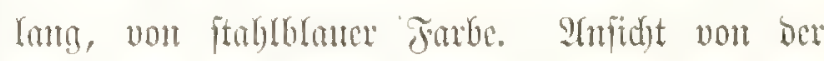

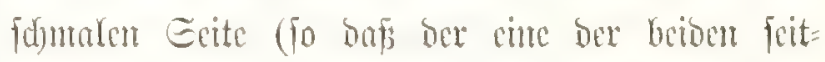
liden Ientafeln in ber Slitte vorn fidbtome ijt, ber andere hinten).

\section{Fig. 6. Lampetia pancerina (Chun).}

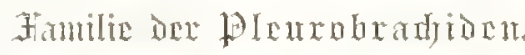

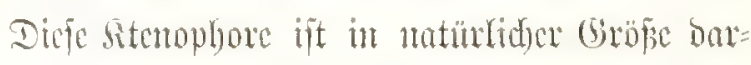
gefterit, ben Mumb nad) oben, Dem Iriduterpol nad unten (ungetelynt wic bic Stellung in Fig. 2-5). Das jarte, glocterfournnige Tiel hängt ant bor Sber=

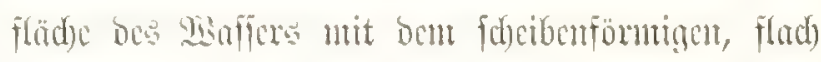

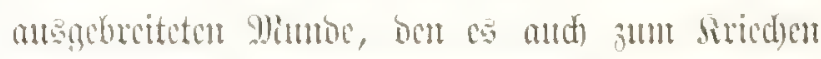

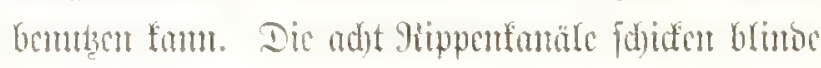
Fortfätse in bie sarte Mumbhant. Die beiben Kangen

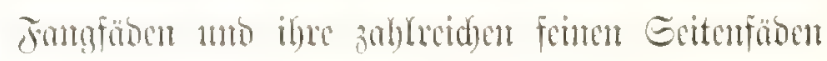

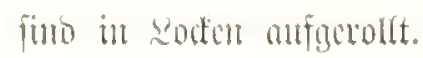




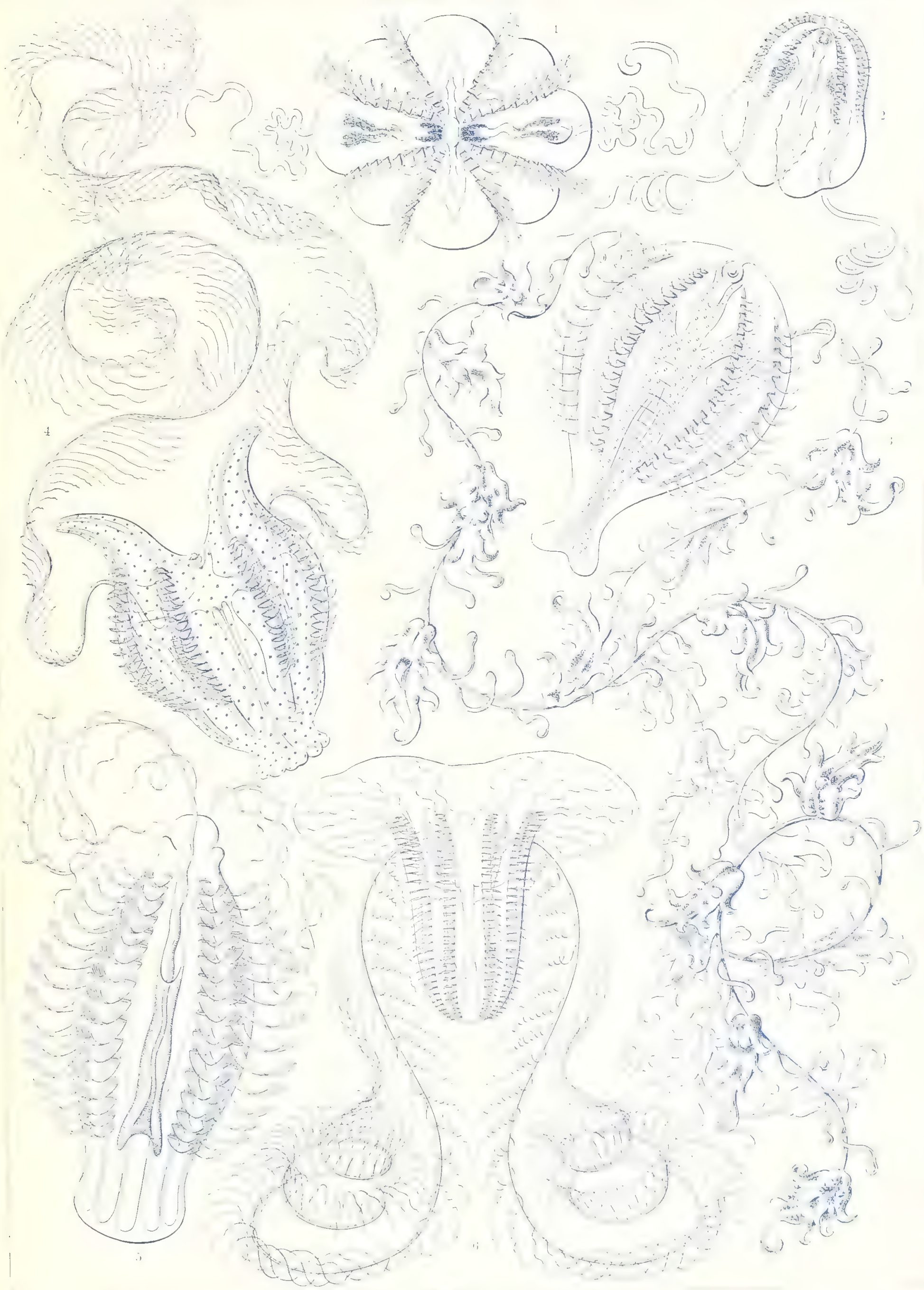





\title{
Discomedusae. Futhethmuthen.
}

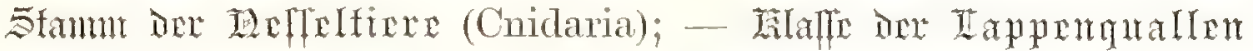

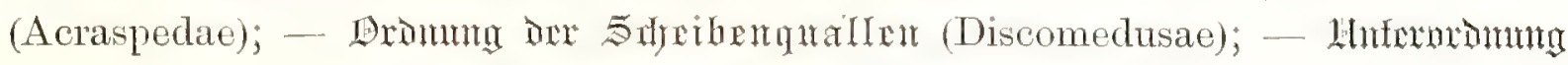 \\ der Lt)
}

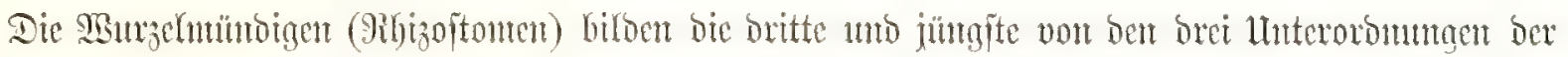

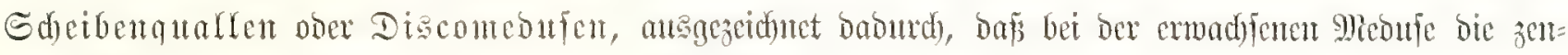

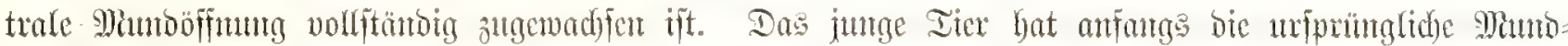

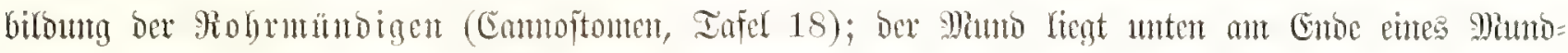

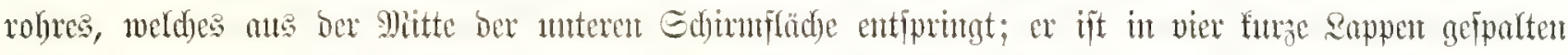

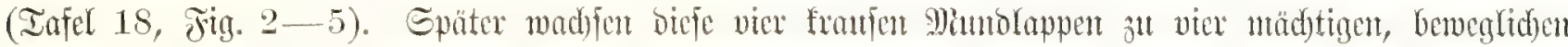

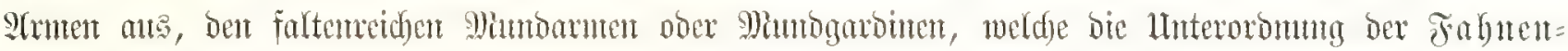

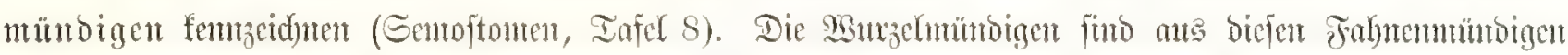

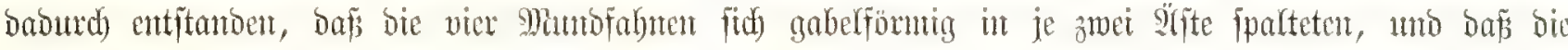

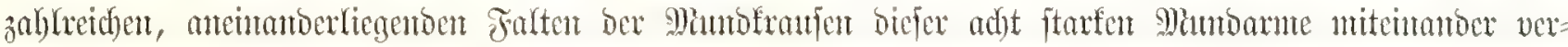

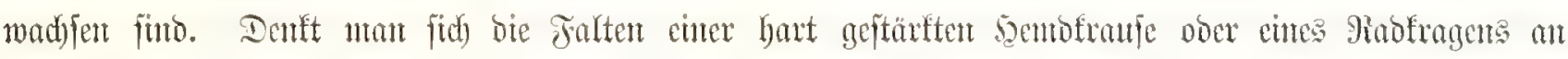

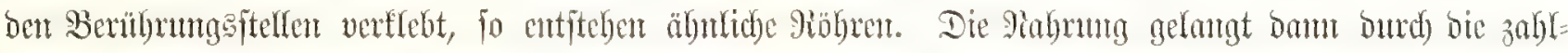

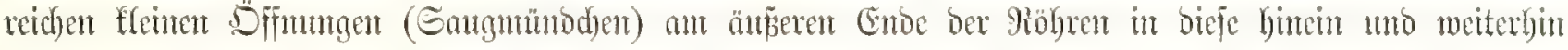

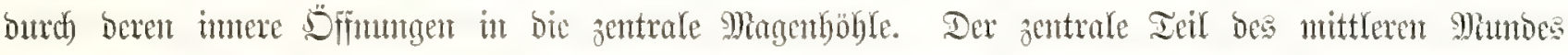

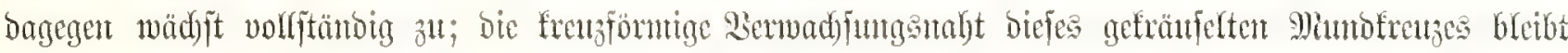

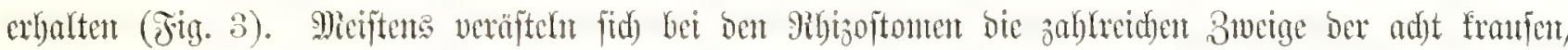

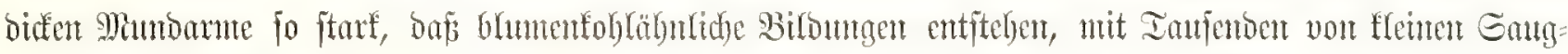

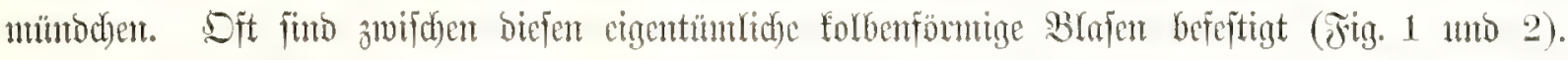

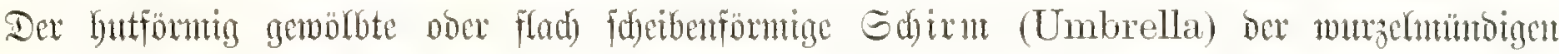

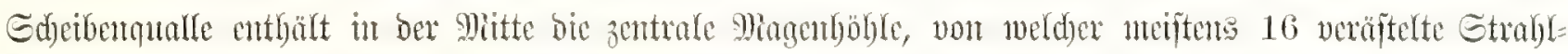

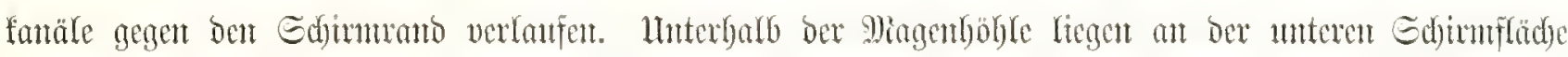

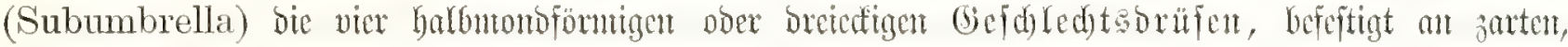
faltigen Bänbern (Gonades, Fig. 4). Bwifden ifnten bitrot bor untere Bamm Der Mingenföhre cun

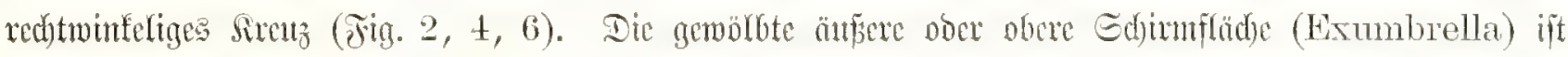

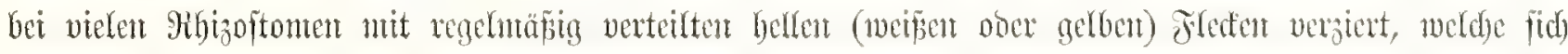

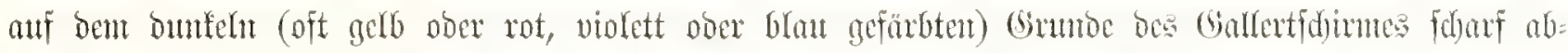

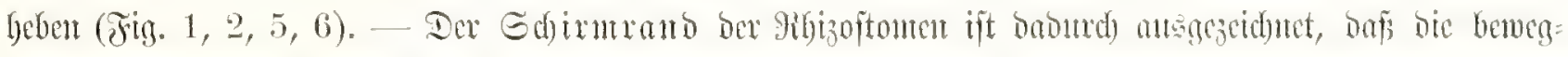

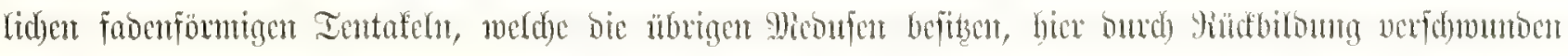

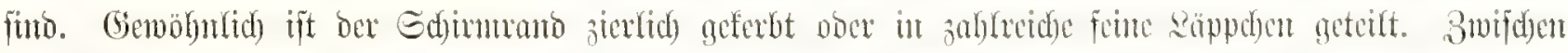

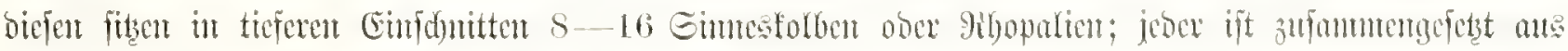

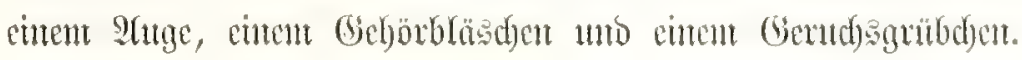


Fig. 1. t. Toreuma bellagemma (Hueckel).

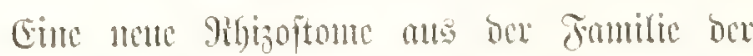

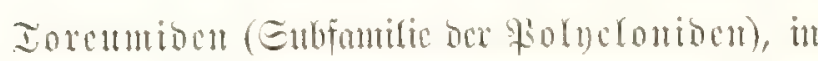
Berligemuna mif Eenfon (im Iojentber 1881) ntad)

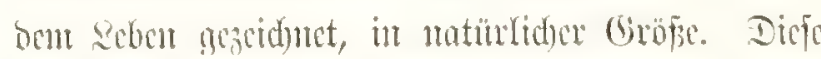

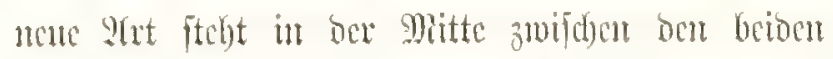
antoren (ebenfalle in Subifd)en Djen vorfoument ber) P(rten ow Gatturg Toreuma (T. theophila แmi T. thamnostoma).

Fia. 1. Stufidut ber ganzen Micoufe vout ber

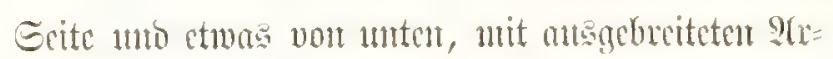

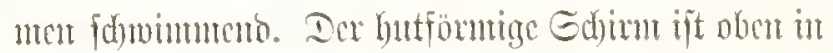

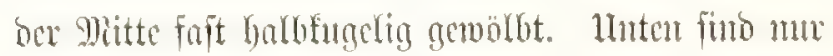

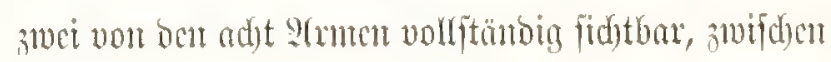

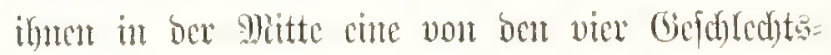

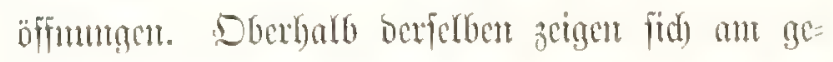

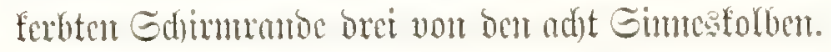

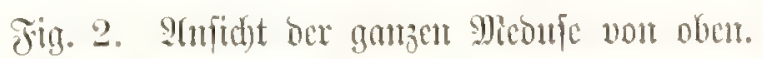

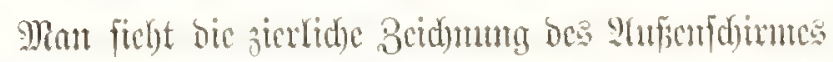
(Exumbrella), bylle Flcden auf dunfelm Grunbe. Sn ber Mitte fdimntern bie vier Edjenfel bes (Ges=

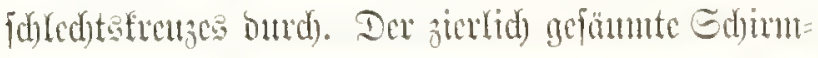

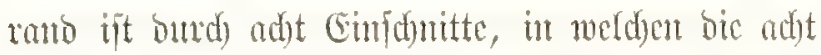
Gimmestolben fitzen, in bogenfömuige Rappen getcilt.

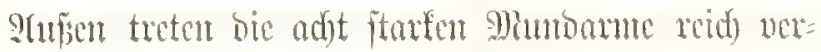
äftelt hervor, mit feuten Emtgframfon uno folben=

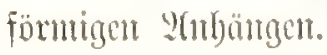

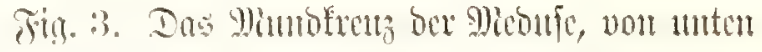
gefelyen. Dis vier Bajalftidfe ber Mumbarme funo pramocife nerbuntont; fie teilen fid) guberjpaltig. Die

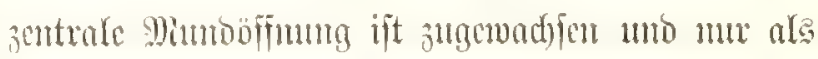
feine Siabt crfeumbar, cbenfo beren Fortfetburg auf

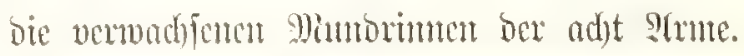

Fig. 4. Das Gefdredytefurutz ber Micome, won obent nefehen. Die Defte der jentralen Miagenböhle ift weggenommen, fo ba man bie vier interrabialen

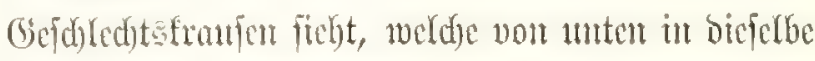
bincimagen. Seoc Sranfe beftelyt aus cinem gefalte=

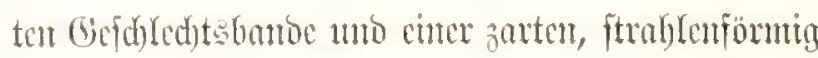

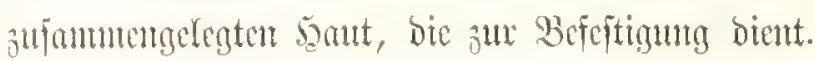

\section{Fig. 5. Toreuma thamnostoma (Haeckel).}

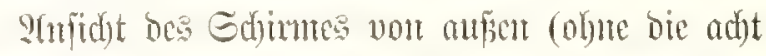
Sfrute), in Galfer natürlid)er (Gröfic. Mlan fieht bic bumte Beid)nung bicfer : S(rt, nit ftrah) gejtellten bellen Fleften (ad)t gropien, 16--48 mitt= Iexut uto vieten f(ciulerent).

Fig. 6. Cassiopeja cyclobalia (Leo Schultze).

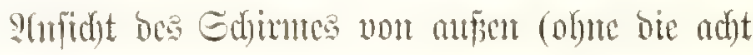

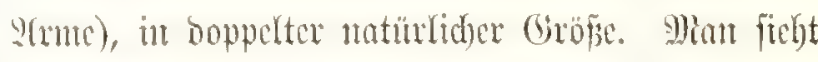

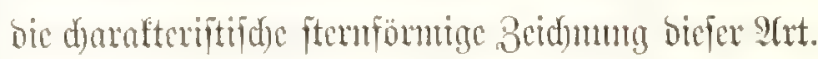

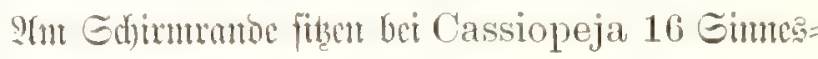
forben (bei Toreuma mu adjt). 


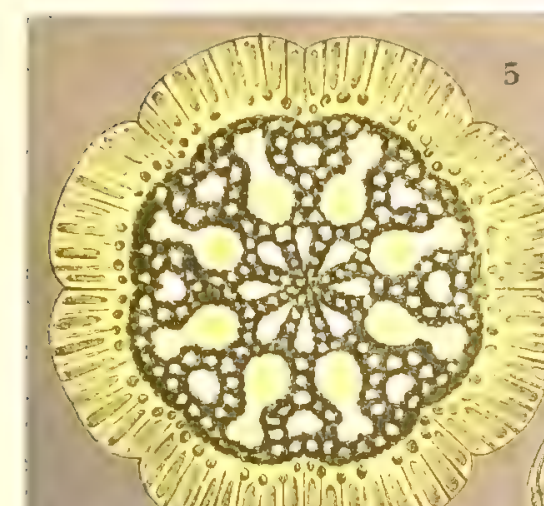

(1)

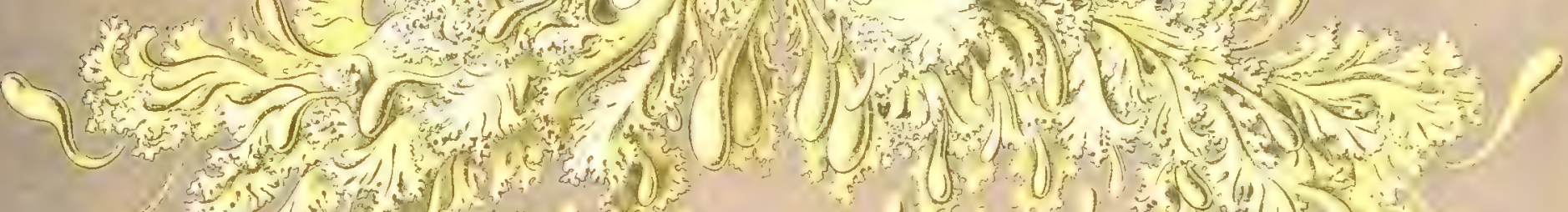

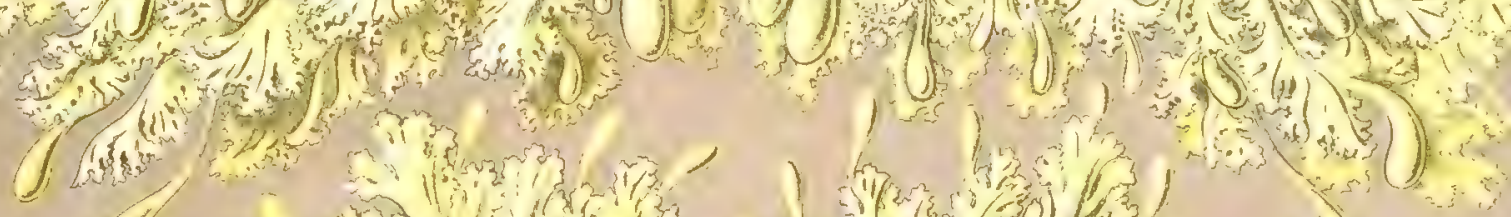

$$
\text { - 1) }
$$

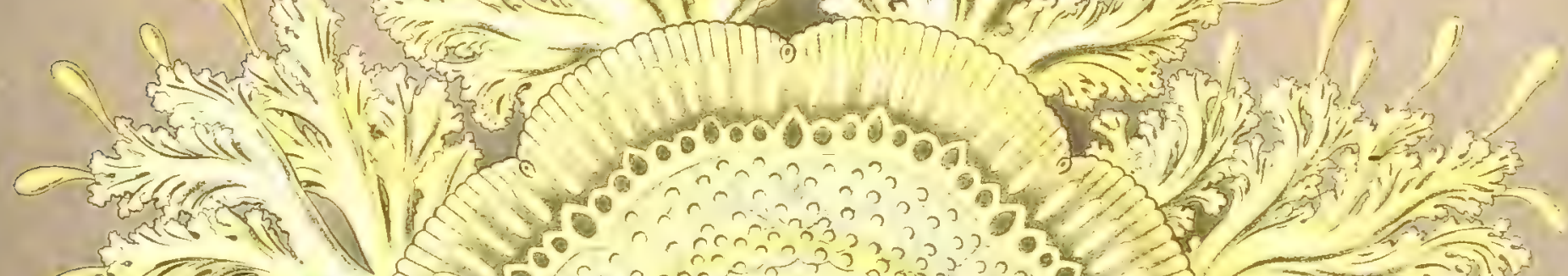

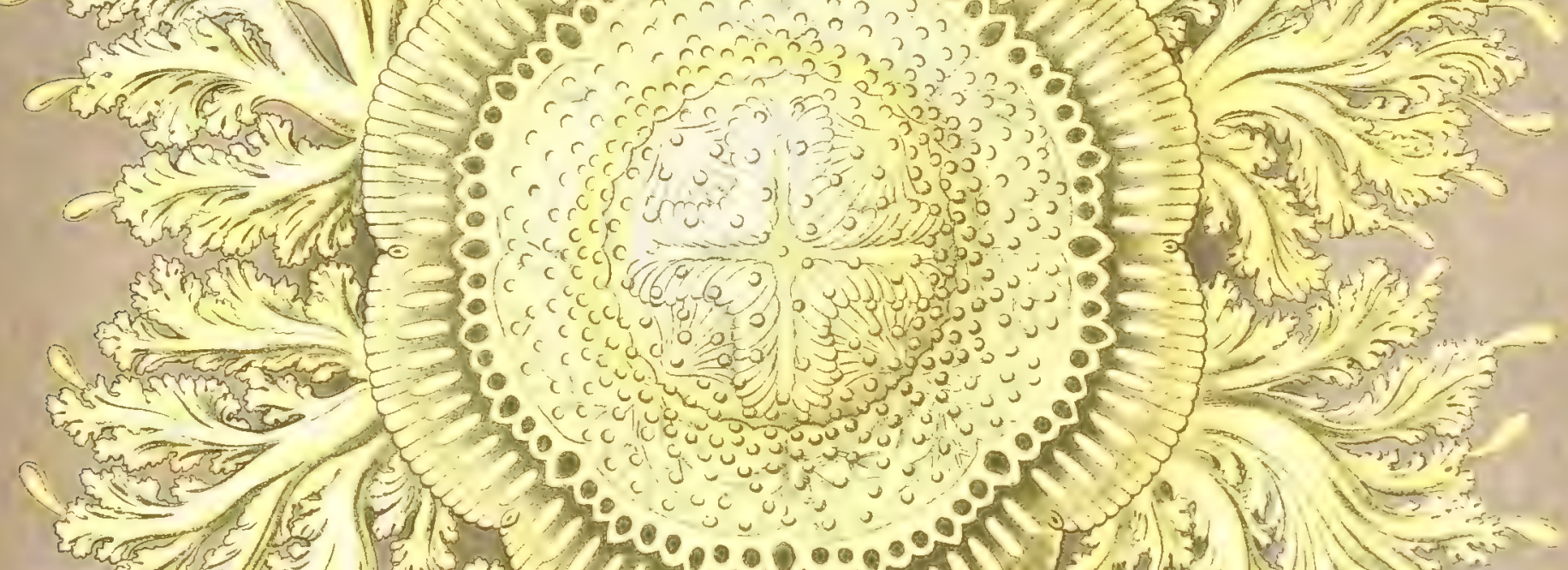

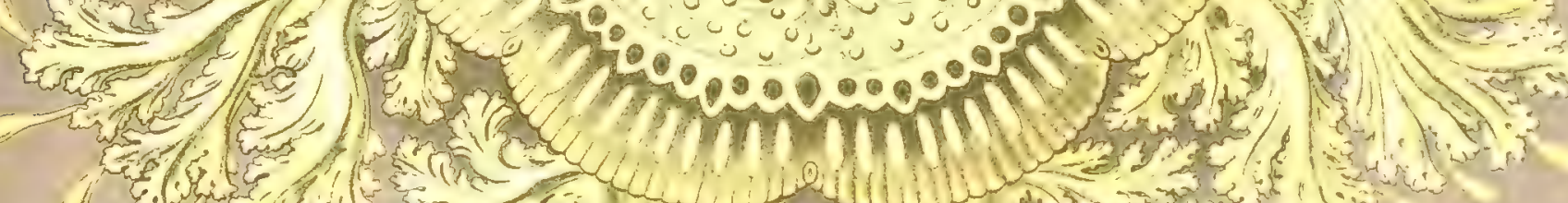

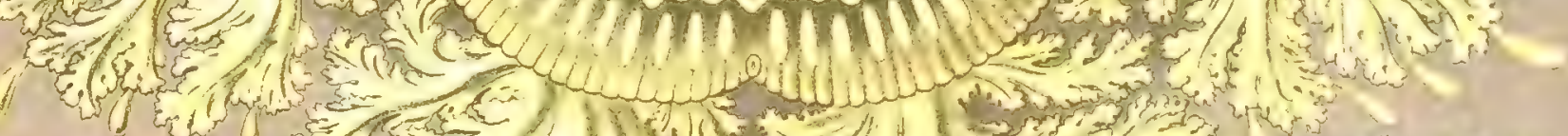

1 (1) (19-1)

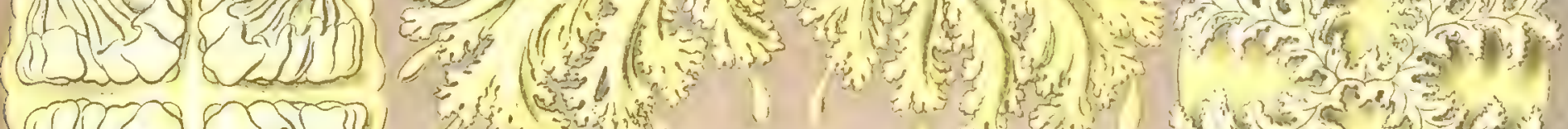
(190) 



\section{Tetracoralla. Biwlfral!line stankwallen.}

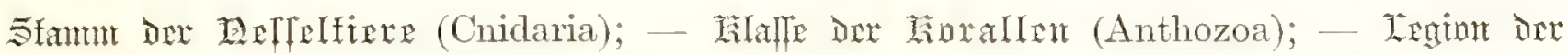

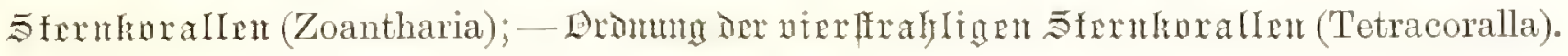

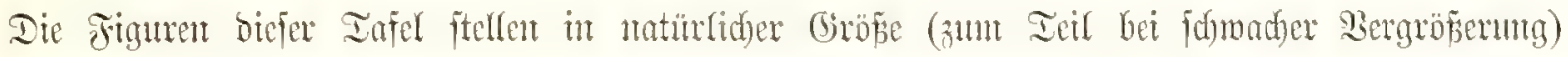

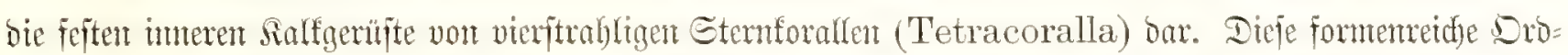

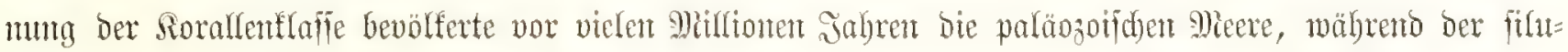

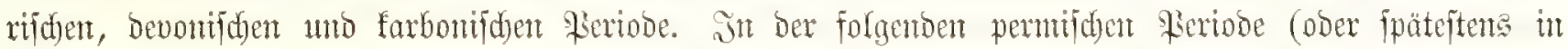

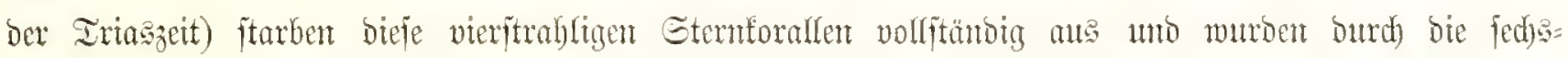

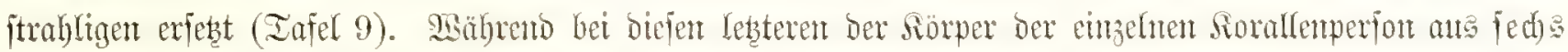

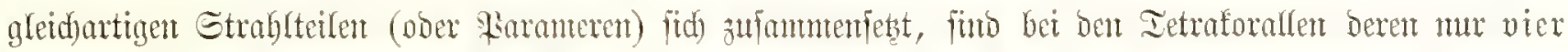

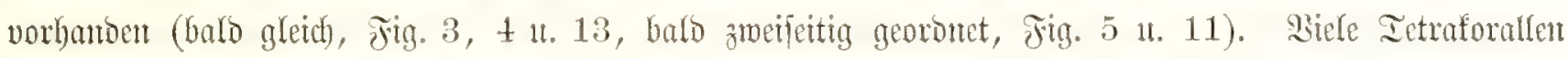

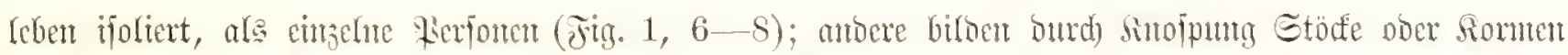

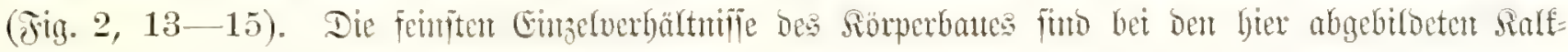

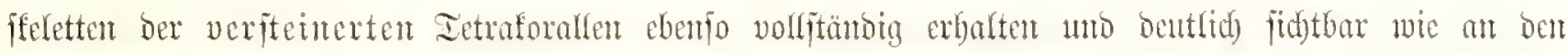

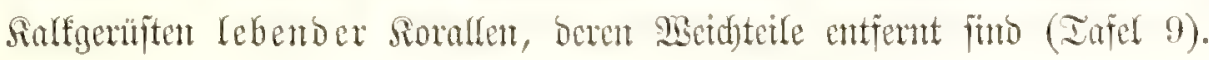

Fig. 1. Omphyma turbinata (Mitne Edwards).

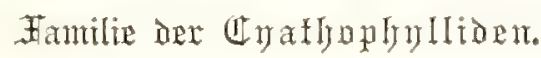

Cinte foffitle serfon ats dem fiturifden Balf= fteitr. Der bedferförmige Riorper ift untent burds Sisurzeln befejtigt. Shent feét man in bie fegel= Förnige Munthögle Gimeitr.

\section{Fin. 2.Cyathophyllum Narmini (Milne Edwards).

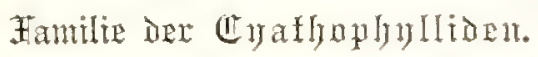

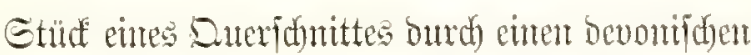

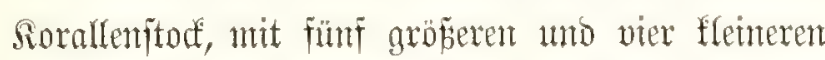

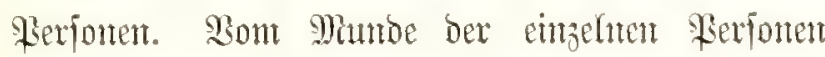
gehen zahlreide Stemteiften jtrahlenföming m.

\section{Fig. 3. Pachyphyllum devoniense (Milne Edwards).}

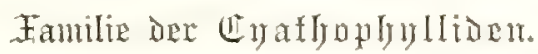

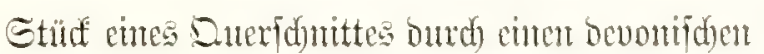

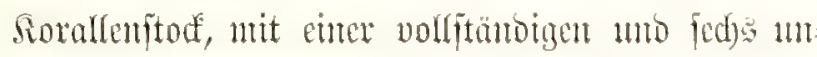
volfintünigent \&exponten.

\section{Fig. 4. Goniophyllum pyramidale (Bilne Edwards).}

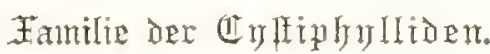

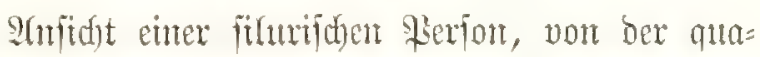

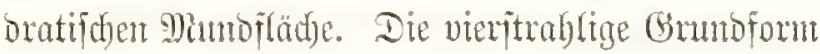
tritt Deutfide vor.

\section{Fitg. 5. Henophyllum tennimargimum (1Tilne Eduards).}

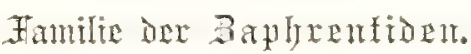

Stnifidet einer farbonifd)en \$erfon (aus ber Stein=

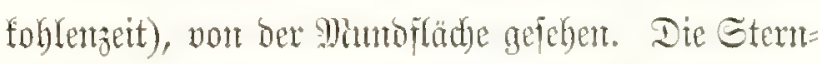
Keiften bes vieritrohligent Rörpers fund bier ftart zmeifeitig georonet, ơll betom Eeiten einter jagittalen Mittelebent.

Jig. 6. Zaphrentis cornicula (Lesueur). Familis der Japjentionu.

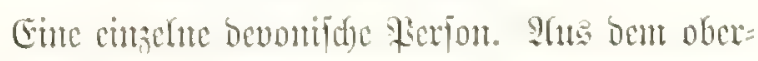
ften Teife ber sidd)want ift bie vorbere Sälfte bes

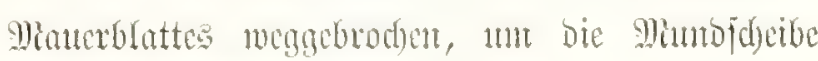

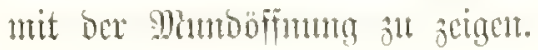


rig. 7. ('yathophyllum expansum (d'Obrigny).

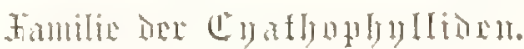

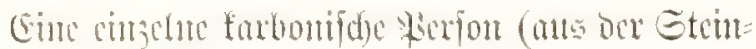

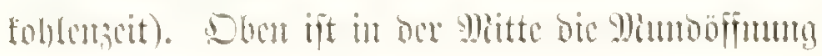

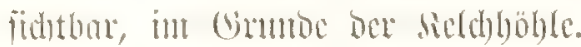

sig. 8. (yathaxonia cynodon (Rafinesque).

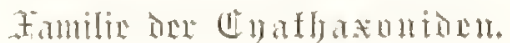

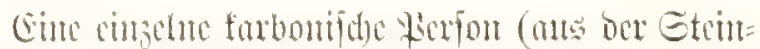

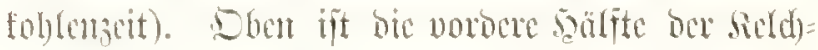
wanto meggebrodten, um die fegelfömige Eünte (columella) jut zergen, weldye fid) aus bem Grumbe Dow dingen crbebt.

\section{Giv. 9. Lithostrotion irregulare (Mitue Edwords).}

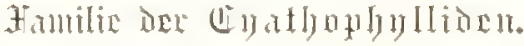

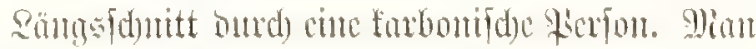

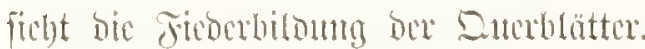

Jig. 10. Alveolites Battersbyi (Milne Educerds).

Familie sec anolifiost.

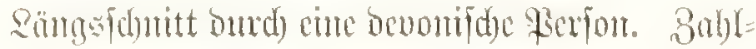
reide Duerblätter ober Boben funo zwifden Den

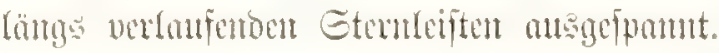

\section{Jig. 11. Hadrophyllum multiradiatum} (Witne Edwards).

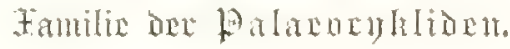

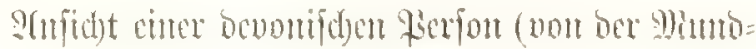

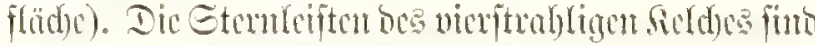
sumcifcitio georonet, mic bei Menophyllum, Jing. 5.

\section{Jitg. 12. Clisiophyllum turbinatum} (Jomes Thomson).

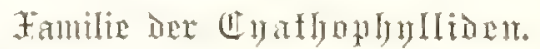

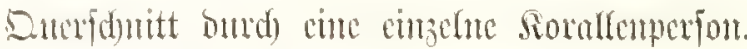
Dis Stemteifen funo fpiral gewumon.

\section{Jig. 13. Acervularia ananas (Scheceigger).}

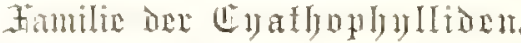

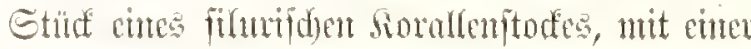

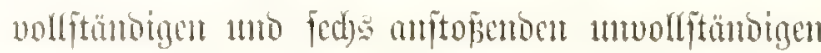
Lierfonetr.

\section{Fig. 14. Syliongoplyyllum organum (1Filne Edwards).}

Famtilie bet

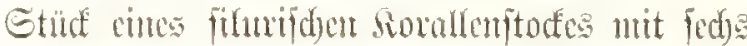

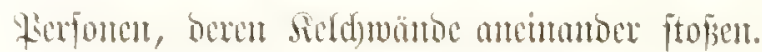

Jig. 15. Cyathophyllum articulatum (Milne Edwards).

Fimilie dex (1)

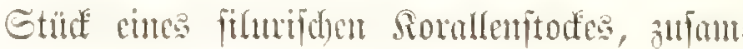

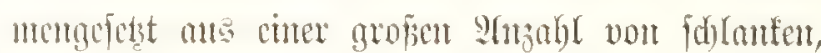
geglicoerten Serfonen; viele jumge Inbiviouen wad)=

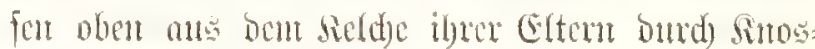
punty bervor. 


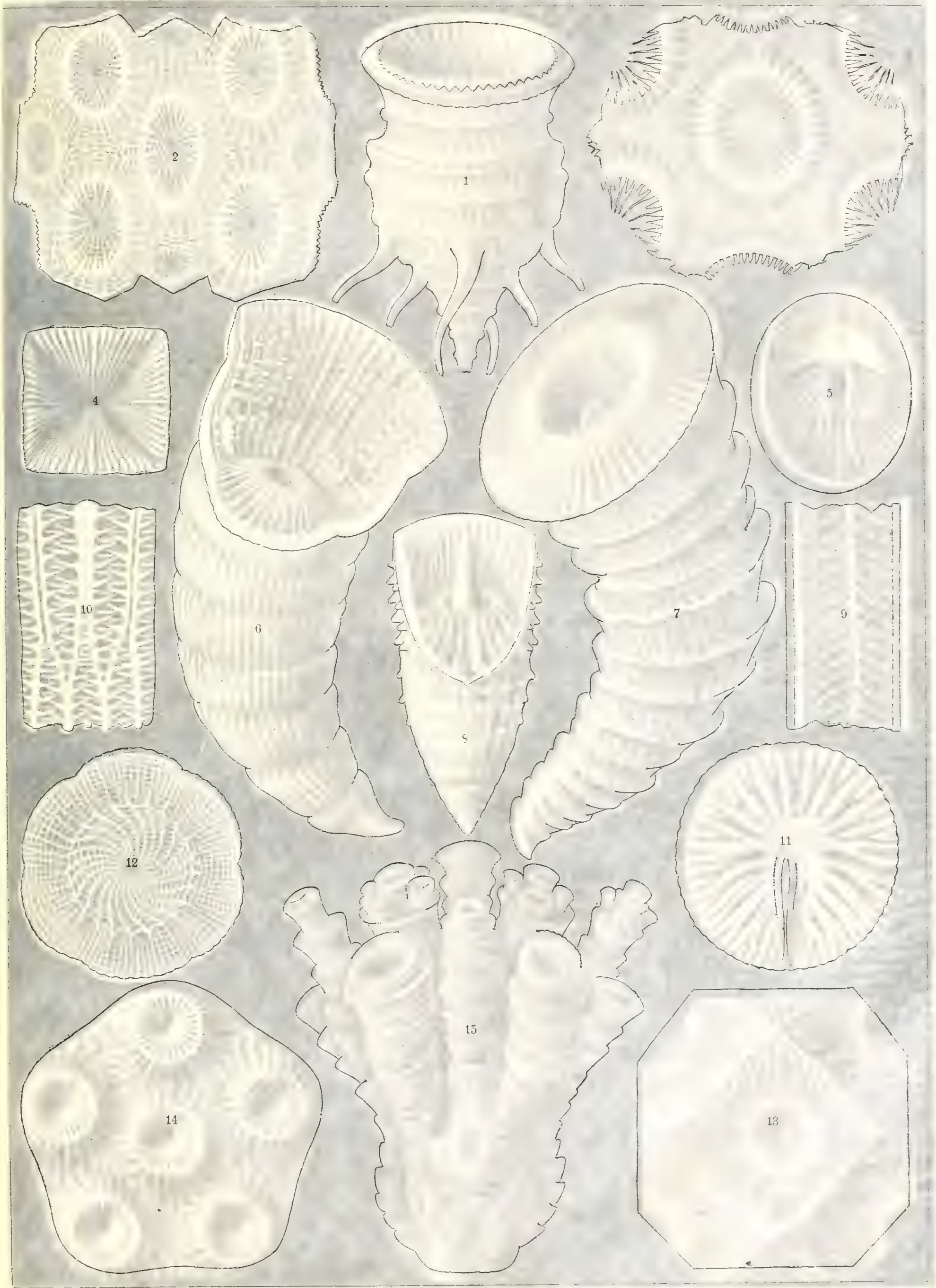


$=-$

112

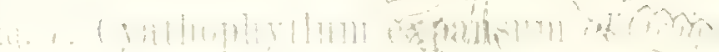

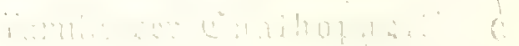

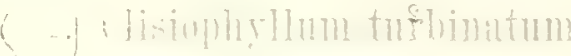

I. Thum Thomsoni

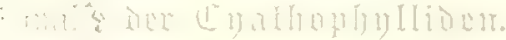

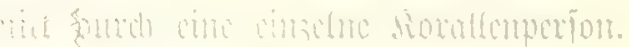

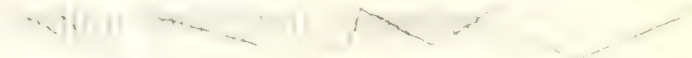

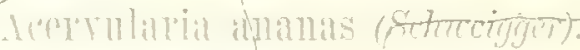

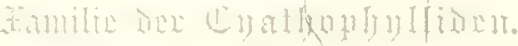

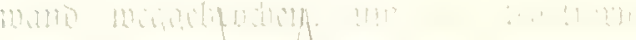

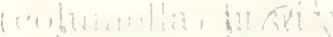

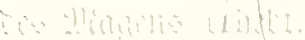
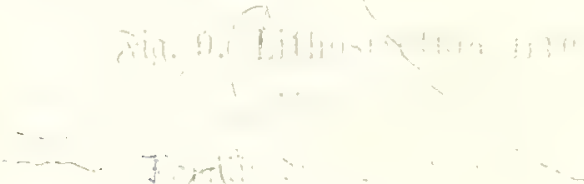

Yit

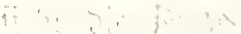

in 111,13

thitin -1

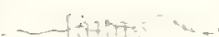

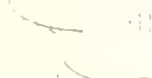

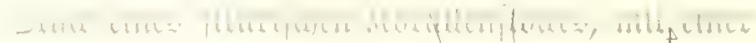

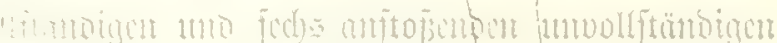
:19.3011.

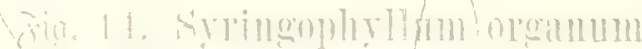

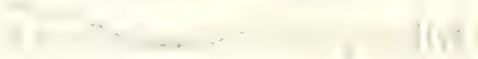

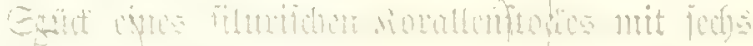

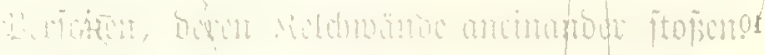

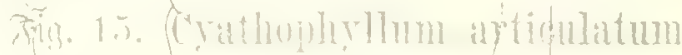
(Milne Ederede).

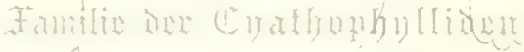

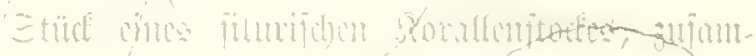

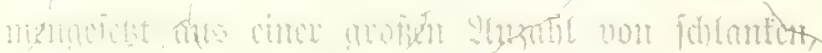

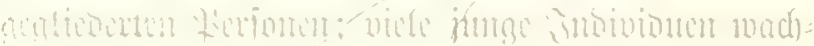

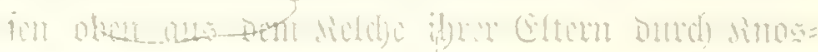




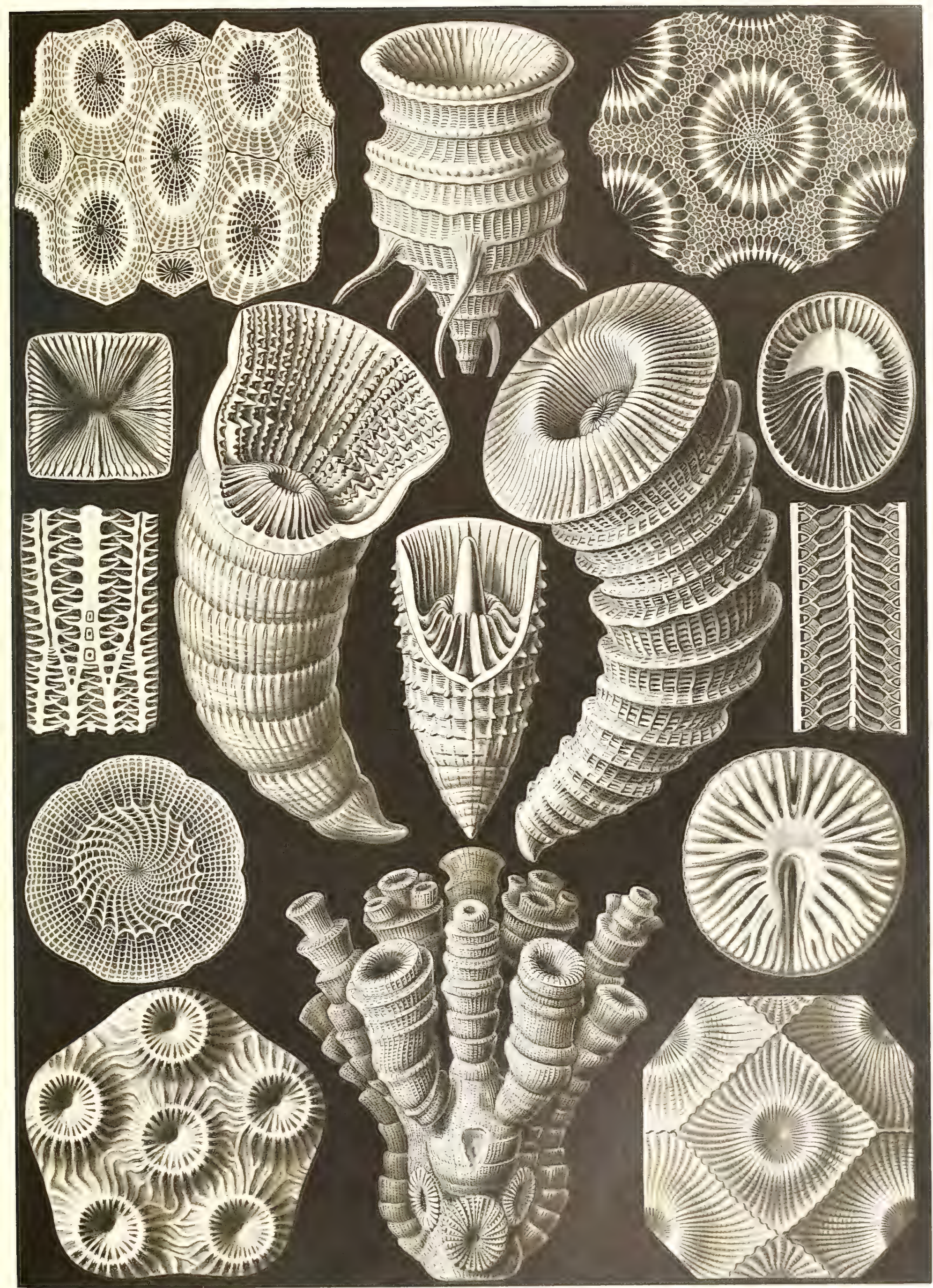

Tetracoralla. - Jierlftaflige Sterurlioxalfent. 



\section{Echinidea. Inthlterute.}

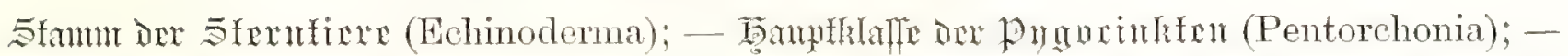

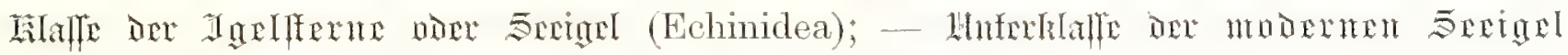

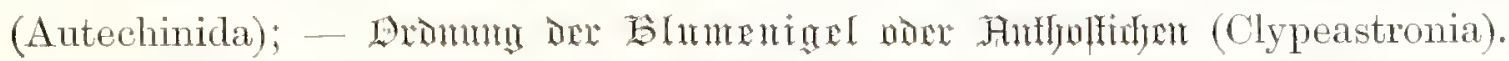

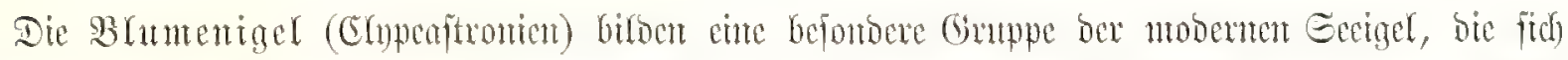

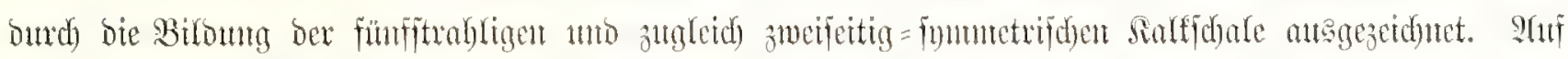

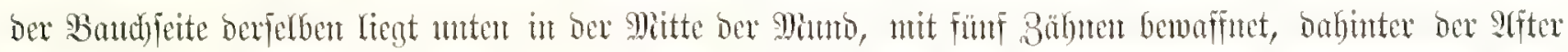

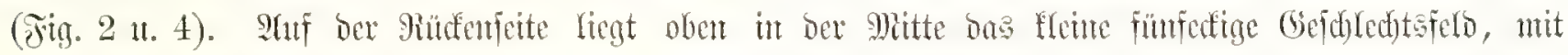
fünf feinen (Gefd)

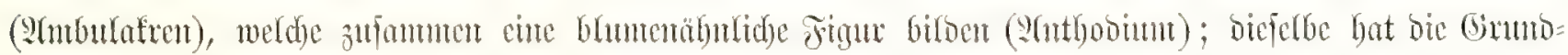

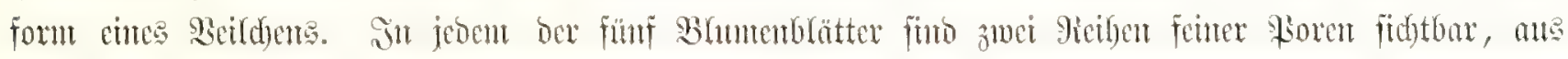

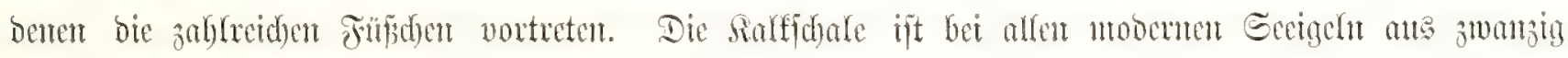

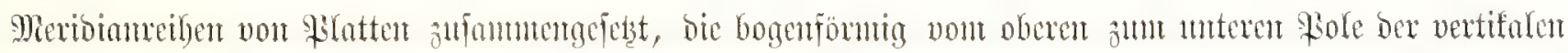

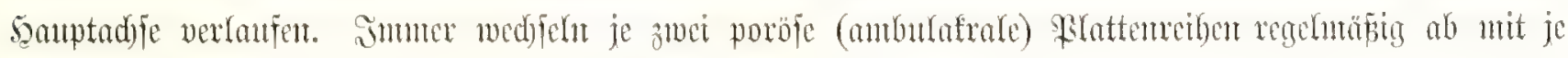

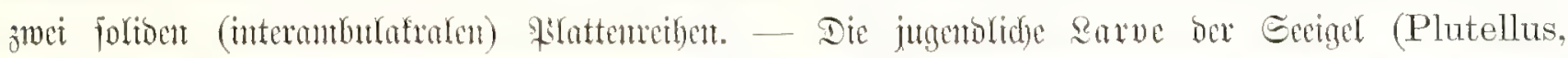

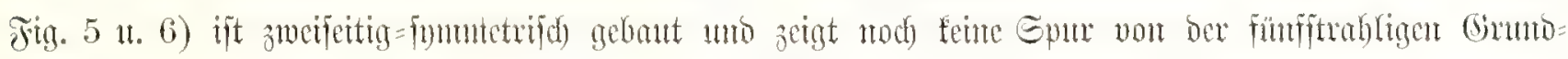

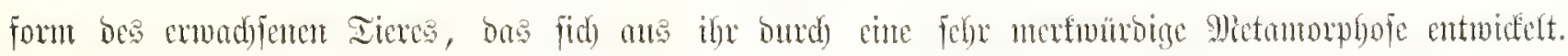

Fig. 1 it. 2. Clypeaster rosaceus (Lamarch).

Áamilie oer cistupaftriont.

Dex rofenfarbige Edyiloiger, wout oen Sutillent,

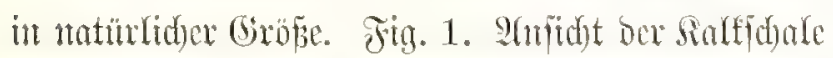
von der Siüufenfeite, mad) Entfernung ber Stad)ehr.

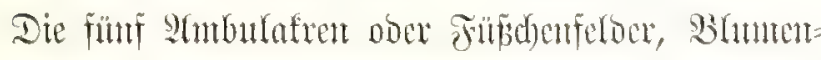

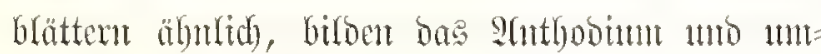
geben bas fleme zentrale Gejdyledstafelo, mit fiun Feiment Sifmungen.

Jign. 2. Die obere (borfale) Särfte ber Sialf-

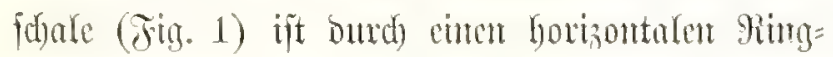

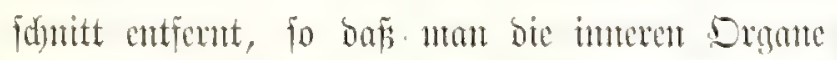

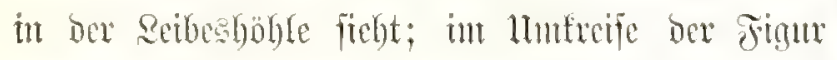

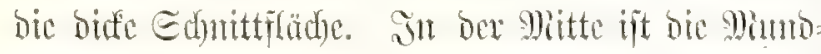

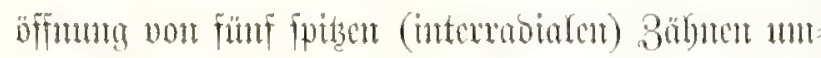

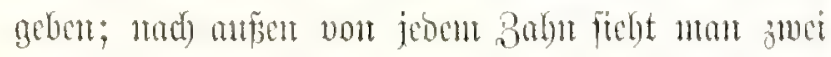
(buntele) Sturifelgruben. Die Bübne meroen bem
Sianen Durd) bie fräftigen Simumbsfeln bemegt,

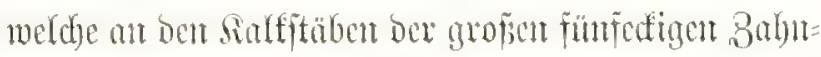
pyrantioe befejtigt fint (ber fogenumten, "sateme Des Arriftoteles"). Der fümflappige Siramb, weldyer

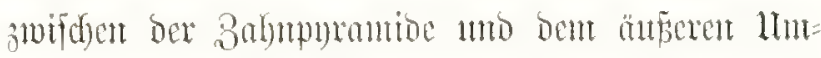
freife ber Edyale lient, wirb ourd) bie fünf tranbigen,

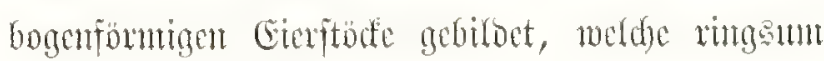

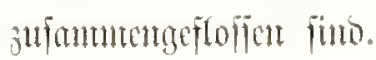

\section{Jing. 3 u. 4. Encope emarginata (Leske).}

$$
\text { trantic ine smufullion. }
$$

Der ofiventurine serbiget, won Sraftlien, in

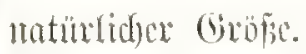

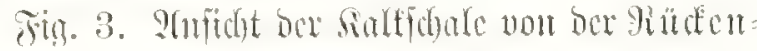
feite, mad) Entfomm ber Gtadych. Dic füm

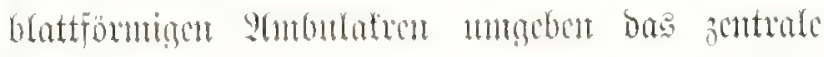

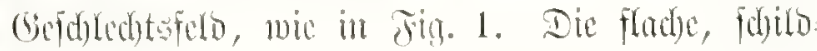


förmitge Salfichale bor Gattumg Encope ift vor an

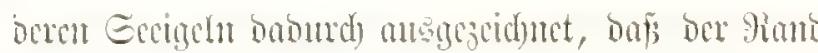
fïmf perrobiale eimfonitte befizt. Son ber Mitte

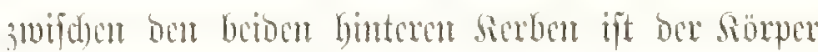

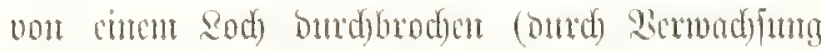

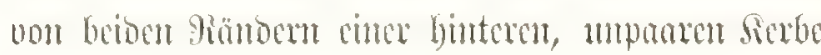
cutifuntom).

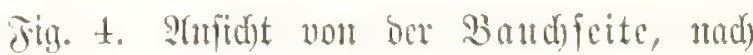
Entfermung ber Etadjeln. Son ben jentral gelegenen Mimbe gehen fünf gabelfpaltige uno ver aiftelte Eubueftorem nocr : Smbutafralfurden aus,

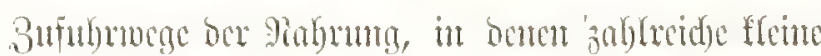

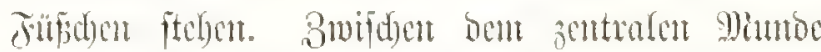

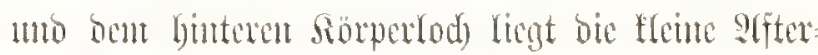

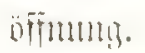

Jitg. 5-9. Eehinocyamus pusillus (Niitler). 等amilie one eringeaftrion.

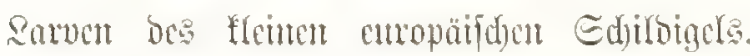
Diefe fimf Figuren find ftarf vergröfert anto ftellen

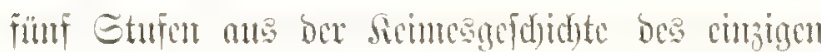
Elypeajtronicn bax, welder bie curopäifduen Micere bewolnut.

Fig. 5. Die jumge Rarve (Plutellus Echinocyami), tS Gtunben alt, $m$ 1/4 $\mathrm{mm}$ lonț, 250 mal vernröpiert. Dic beioen fteifen 9 (rme fino

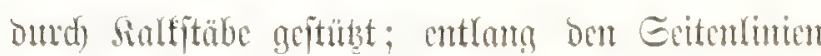

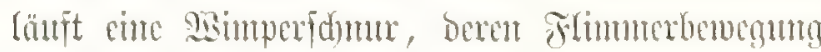
jum Edwwintmen bient. Snt bor 将itte ijt ber cin fadje (getbe) Darm der sarve fidtbar, oben ber

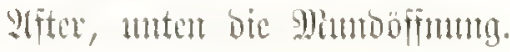

Sig. 6. Cinte ülterc Plutellus-šarve, 10 Iage

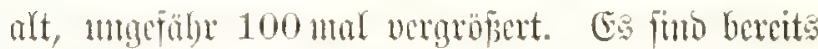

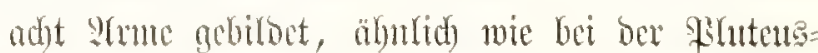
lave vou Ophiothrix ( Iafal 10, Fig. 8). Itm Darm (in ber Mitte ber Jigur) funt bre 9 (b)

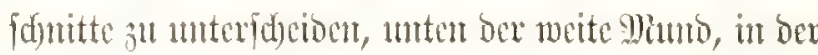
Witte ber Mingen, obent ber Enboarm mit ben SIfter.

Sig. 7. Der jumge Eccigel, meldjer fid durd Sicrwantumg ane bor \$ilutellusharve (gig. 6) entmoifelt loat, 45 Iage alt, ftart vergröpert, von

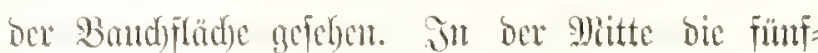

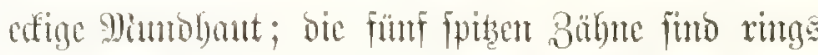
mu biefe angelegt (mit je brei Sinlfitütert). Die Ed)alenanlage bifose cinen Srans von gitterförntigen Siarfplattent. Biad) anisen bavon fiebt ntan bie fünf

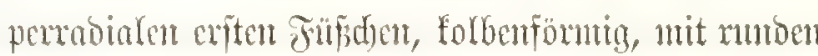
Emufdeiben; ongwifden fümf interrabiafe Etadjet gruppen.

Fig. S. Das Miuntofelo cittes etwas älteren Exetgels, 50 Iage alt, $200 \mathrm{mal}$ vergröpert, von

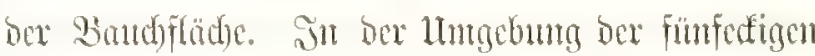

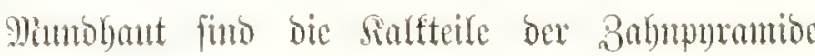
meiter entwiffert. Dic fünf vorfuringenton Sialf=

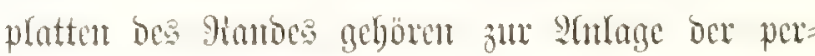
rabialen PGnbulafrem.

Fig. 9. Ein jumger Serigel, 60 Inge alt,

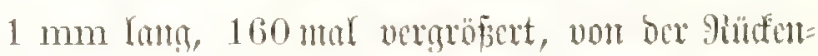
fläd)e gejehen. Das salfifelett ift jtürter cutwidfelt, fowohl bic (Gitterplatten, welde bie Ed)alenanlage bitocm, als bie lamuen, funmetrifa) angeorbuten bewegliden Etadidn. 


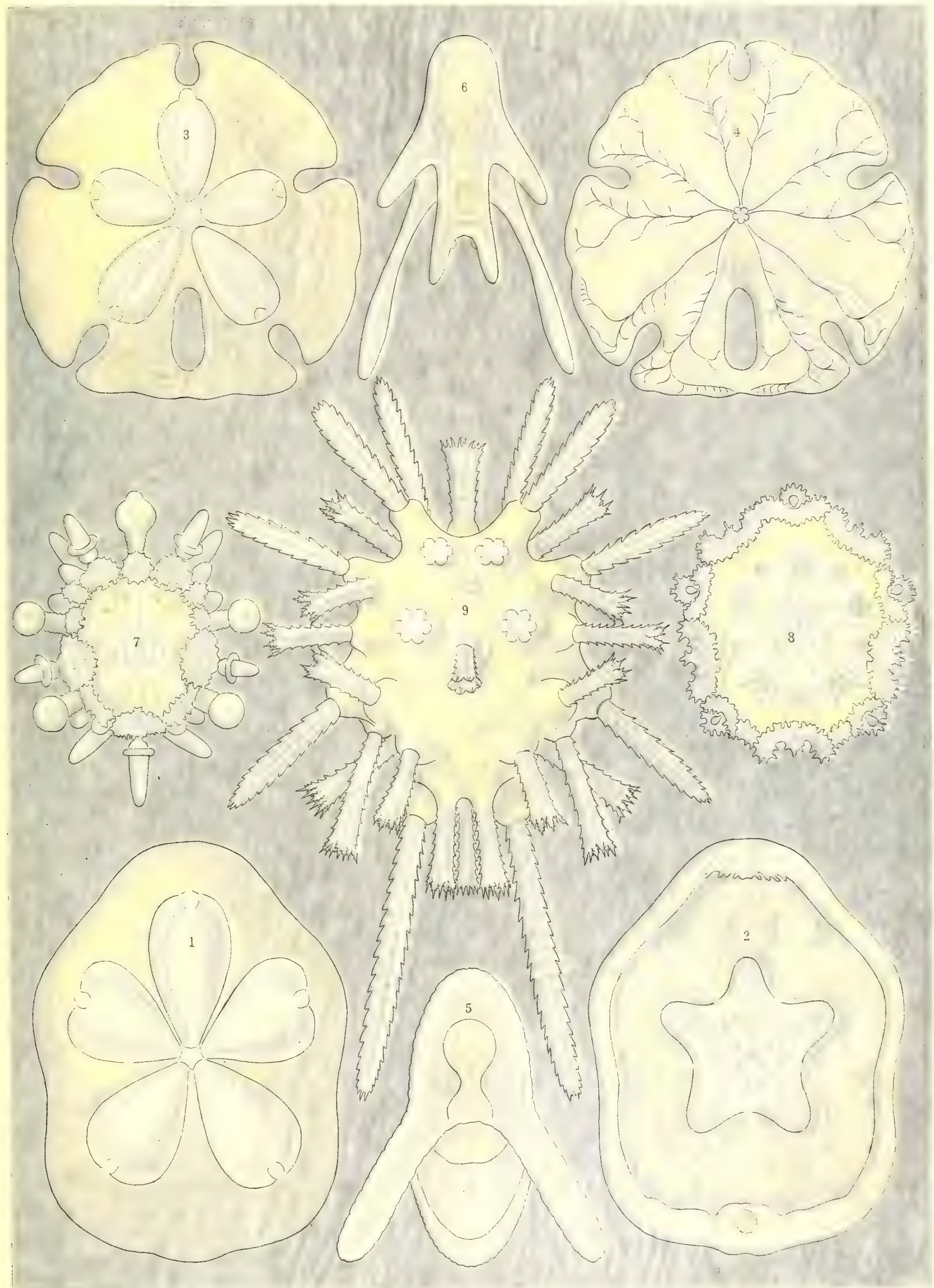




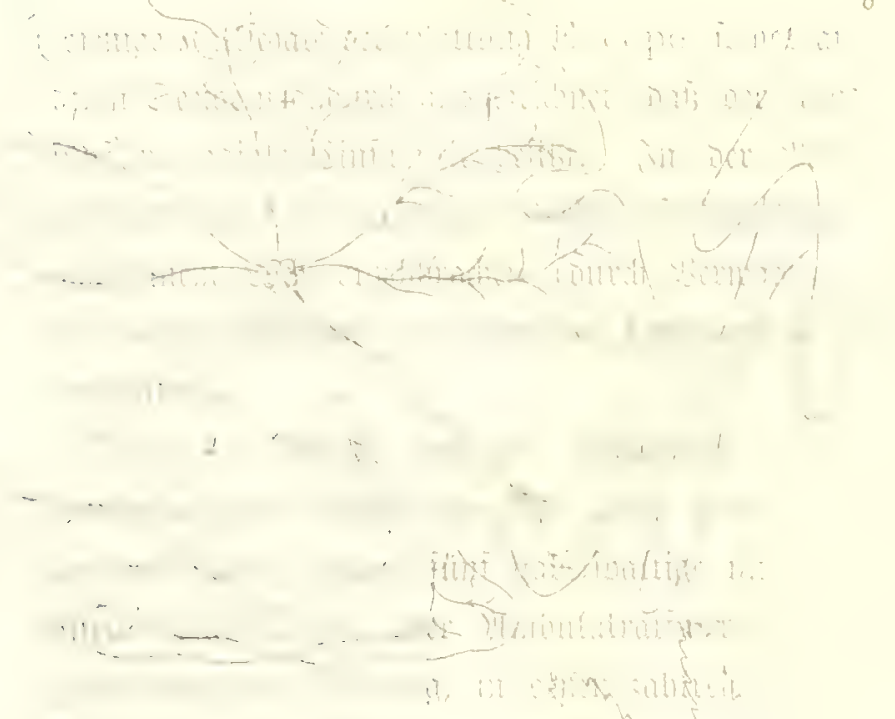

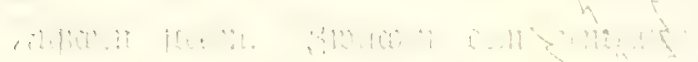

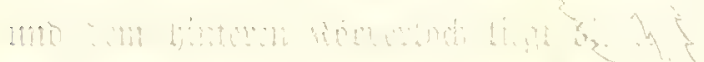

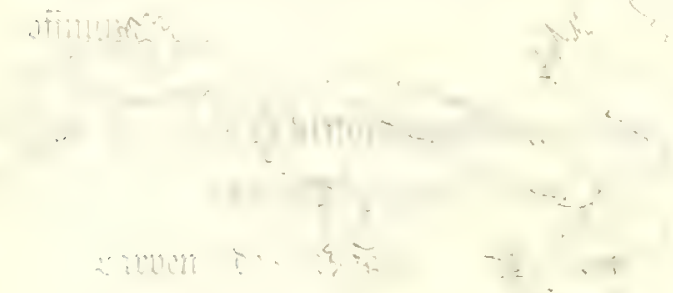

Ente if

Fini†

(s) 


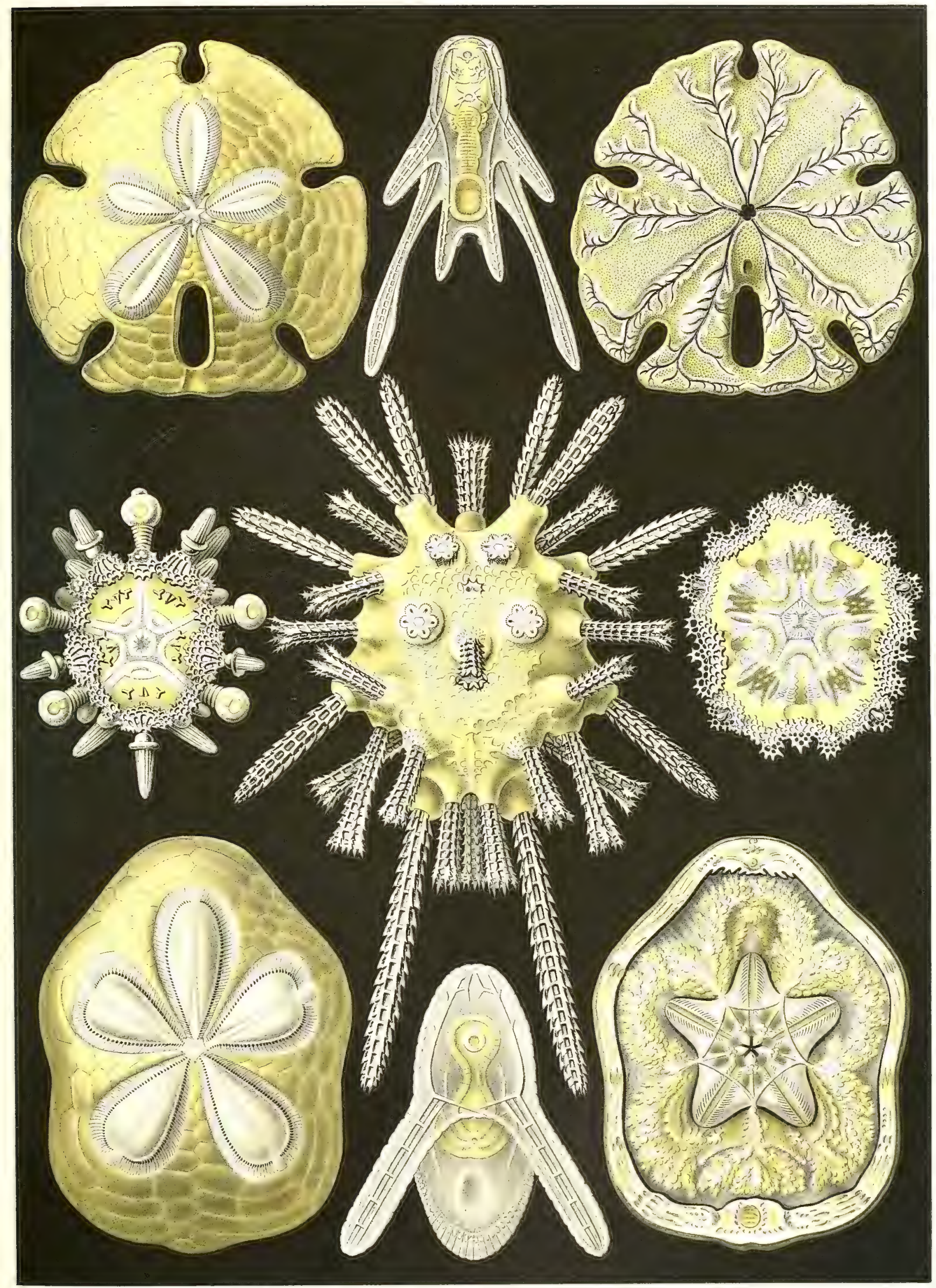





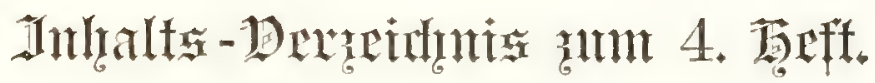

Iafel 31. Calocyclas. Itutiere ane ber Rlafie Der Madiolarten (Region Der Mafferfarien, Dromm ber (Eyrtotideen).

Iafer 32. Pedalion. 13mmtiene ans ber Grafle ber Mäberticre ober Gotatorien.

Iafel 33. Flustra. Minuticue an der Silaffe ber 9loostiene ober Bryozoen (Region ber Siramzirbler oder Steluatopobent).

Iafel 34. Pediastrum. Itrpflanzen aus dor

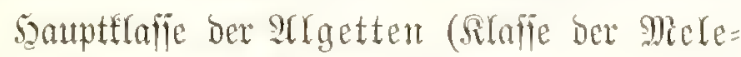
thatien ober Coenobiotica).

Tafel 35. Farrea. Riebertiere mis bem Stamm der Spongien ober Sdymanmtiere (תrafie ber Siejclfdwämtnte, Silicispongiae; Dró=

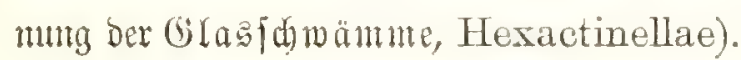

Iafel 36. Aequorea. Reffeltiere an ber Silajp ber Sdyeicrquallet ober Sirapeboten (Srbmug ber Icptomedufen).

Iafel 37. Discolabe. Meffeltiere me bor Silaffe Der Gtantaquallen ober Giphonophoren (Dromung der Silgujonecten).

Iafel 35. Periphylla. Acfifticue ans ber Sifafic ber Atraspeden (Drbung ber Siscome= D)

Iafel 39. Gorgonia. Jieffertiere ans ber fifafie ber Soralfen (Drommtg Der Dftoforallen, Familie ber Rimbentorallen ober Gorgo= nitoen).

Iafel 40. Asterias. Gtemtiere am bor Rrafle

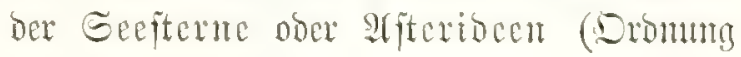
ber Colafteriont). 



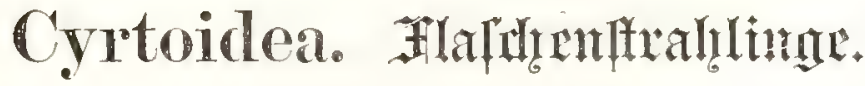

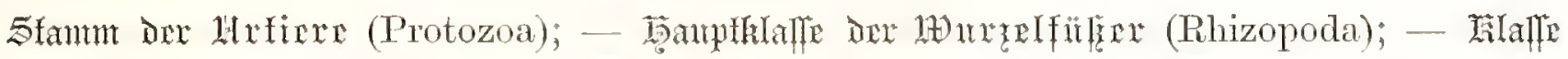

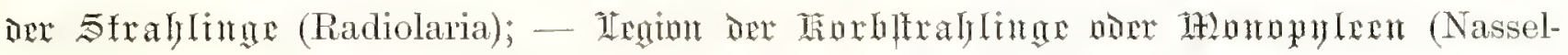

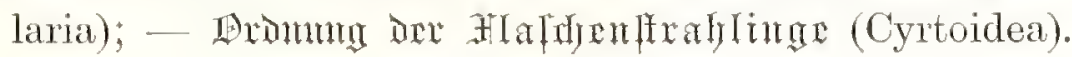

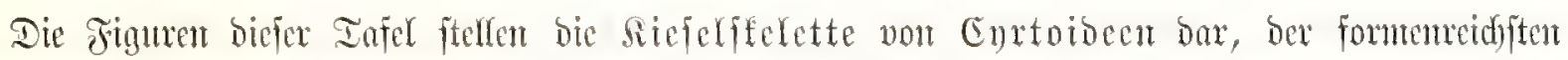

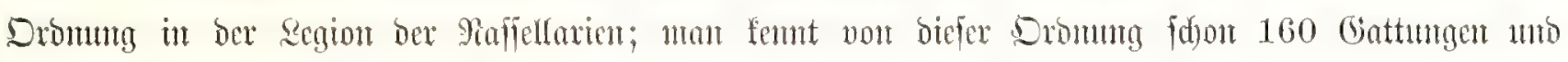

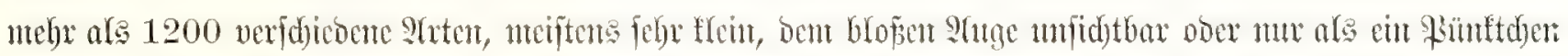

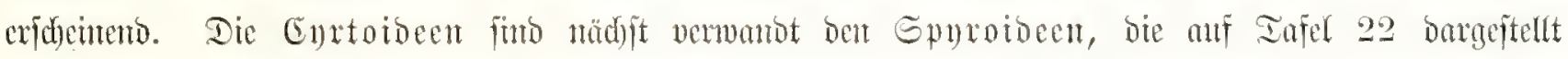

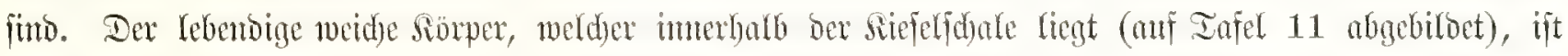

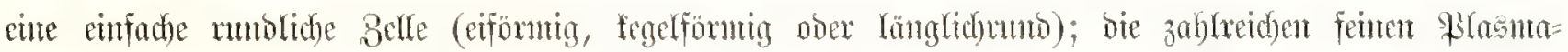

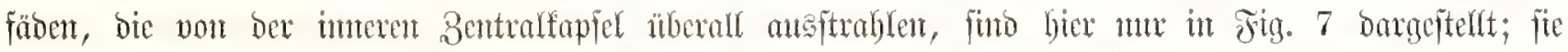

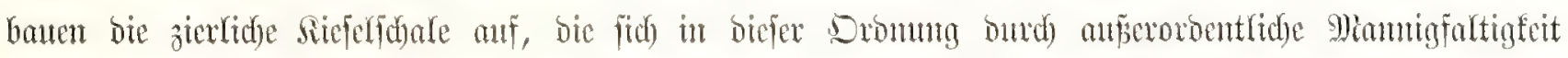

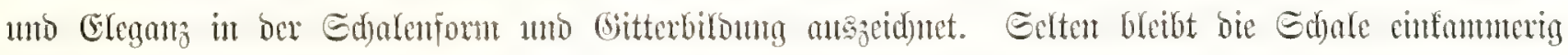

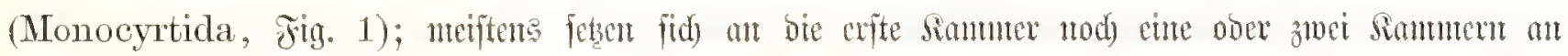
(Bmeifanmerige, Dicyrtida, Fin 2, 3; - Dreifmunerige, Tricyrtida, Jig. t-8). Damm miro bie

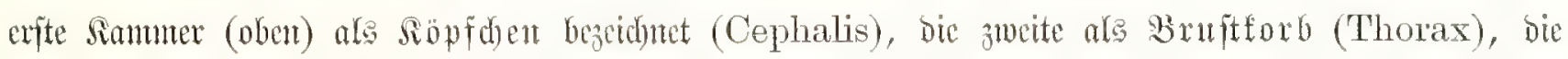

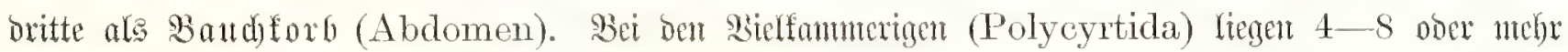

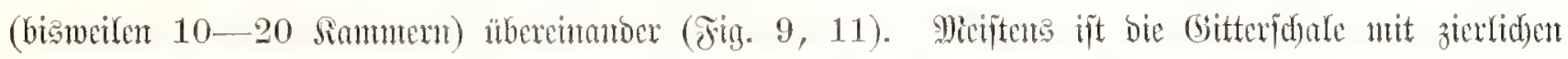

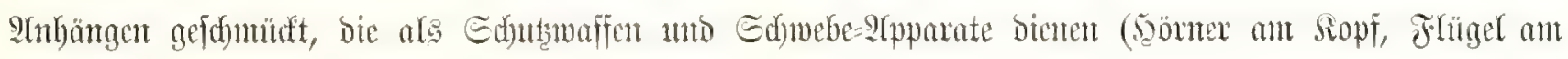
Brufttorb, Fuife am Bautdforbi).

Jig. 1. Cyrtophormis spiralis (Haeckel).

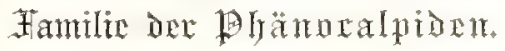

\$ergröperung 400. Edhale cinfonmucrig, mit einfad)er Miündurg; gezälynte Spiralrippen zwifden Den Foremreiben.

Fig. 2. Clathrocanium reginae (Haeckel).

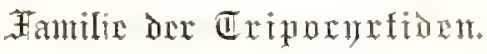

S3ergröfienming 600. Sdyale zmeifanmerig; arfte Sammer ("Siopfdhen") mit cinem Edyeitelforn; zocite

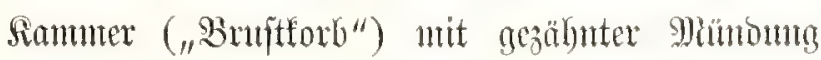
unto mit bret rabialen Rippent, zwifdyen benen brei

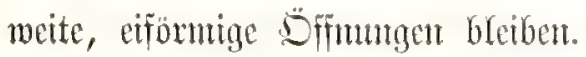

Fig. 3. Anthocyrtium campanula (Hacckel).

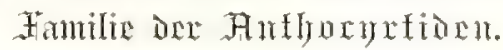

Bergröp̧enunty 400. Edjale zmeifanmmerig;

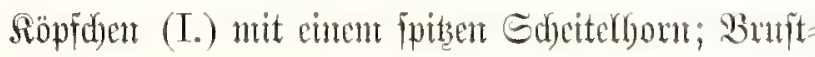

forb (II.) glodemfömig, an ber 羽iundung mit éntem Sirnı von vielent Bäbsten.

Jig. 4. Pterocorys rhinoceros (Haeckel).

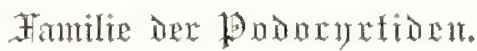

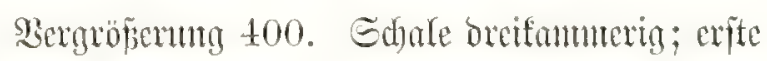

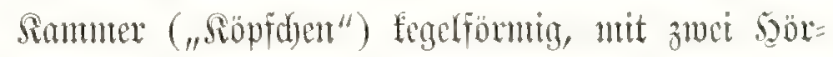
nern; jweite Sinmer ("Brujtforb") breifertig= pmramional, mit orei antgefpitsten Fringeh; oritte

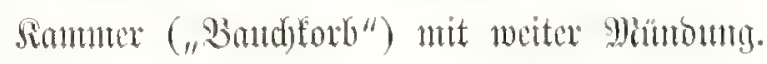

Fig. 5. Tithornithium falco (Hacekel). tamilie Den fononerfion.

Sergröficumg to0. Edhate breifonmerig; Röpfdyen mit Sdycitelforn; Brufterb faft furgelig,

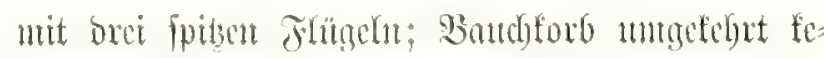
gefförmig, muten gefdalofict. 


\section{Jig. 6. Alacorys Bismarckii (Haecket).}

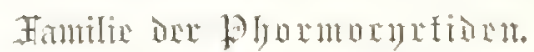

Burgröferma 200. Edule orcitummerig;

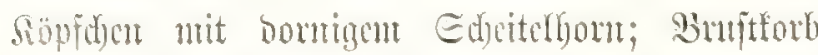

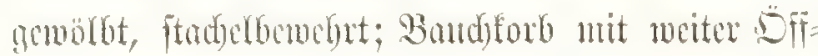

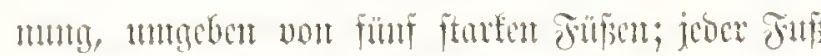

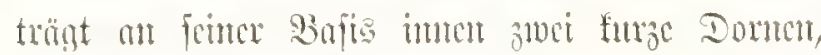

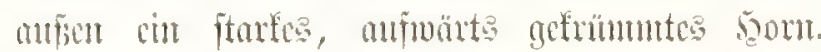

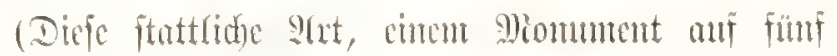

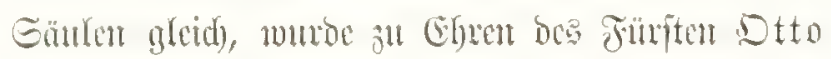

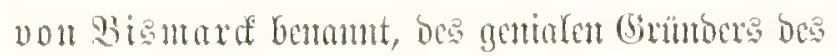

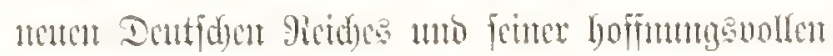
Solonialmad)t. (Ex wurbe als proftifder Semer

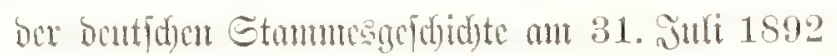
in Jena zum criten Doftor ber Siburogenie honoris causa emamt.)

\section{Jig. 7. Caloevelas monmmentum (Hacekel).}

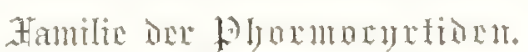

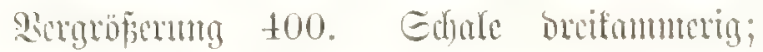
Siopfocen mit cintent ftarfen breifantigen Edycited: boun; Bsutfterb glodenfömin, nit vielen Kangen

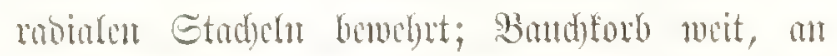

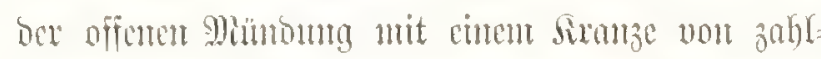

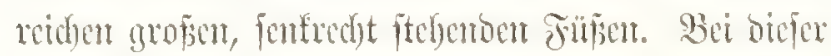

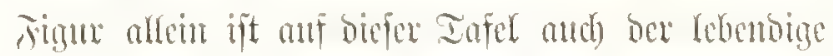

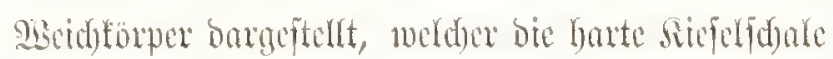
anfbant. 羿on ber fegelförntigen Bentrulfapfer, bie

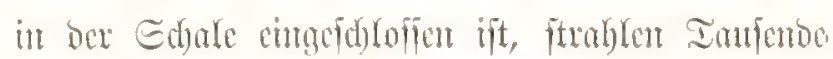

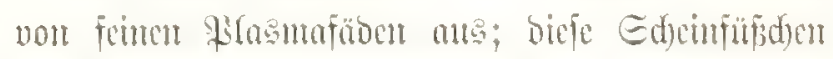

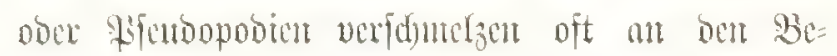
rifhrumgepunften; fie bicuen fowoht jum Bewegen

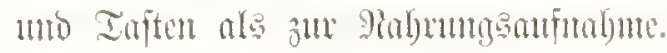

Fig. S. Pterocanium trilobum (Hacckel).

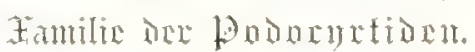

Sergroperntuy 300. Edjare orcifunmerig;

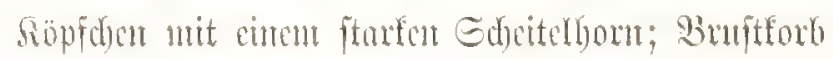
orcifantiy=purantion, ftadelig; Bandforb in bret mrobe sappen gejpalten, juiflyen benen bre lantge

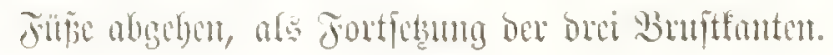

\section{Fig. 9. Stichophaena Ritteriana (Haeckel).}

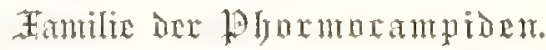

Sergröficunt 400. Edjafe vielfammerig, $\mathfrak{k}=$

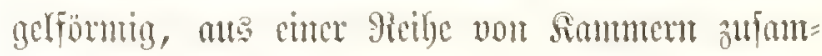

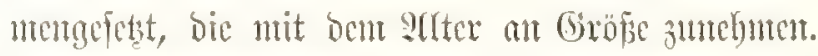

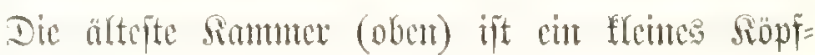
d)en mit cintem Edyitelfon; bie jüngfte 1 mo leste Simuner (unten) ift fobr grop, ballonföbunig, fajt futgelig aufgetricben. Sluf biefer fitgel verfaufen

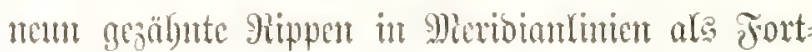
fothung von matn voripringentoen Flitgelut bes mitt=

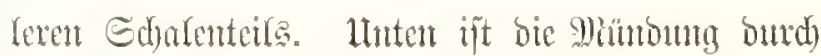

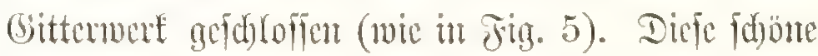

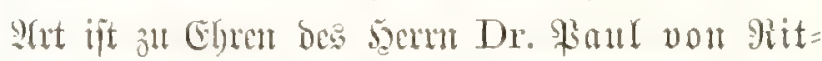
tex in Bafal bentamt, ber in Jahre 1886 an ber

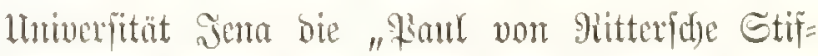
tuntg für plyylogenctifat)e Boologie" grümbcte uno

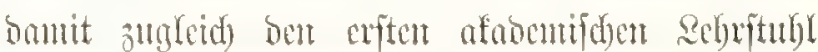

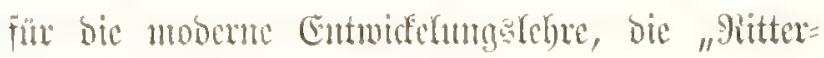

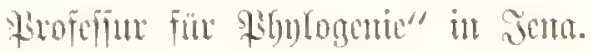

\section{Fin. 10. Dietyocodon Ammasethe (Haeckel).

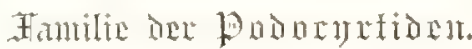

Sicrgribscumg 400. Edhate drifammerig; Sïpfdar mit cincm ftarfen Edyeitelform; Burntforb

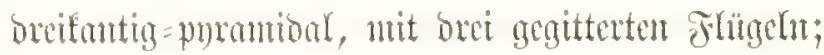
Bandfforb mit brei Giltrtedn vont gropen Gitter=

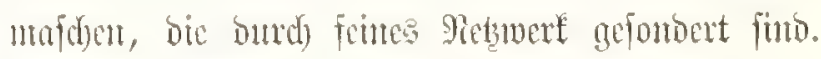
Mitmbung unten mit cinem Siranze von nem bret=

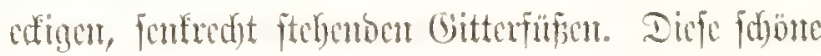
Shet ijt bem Geoüdytuis vou Stuna saedel, ge= boxue Sethe, gewionet (geb. 1835, geft. 1864).

\section{Fin. 11. Artopilimm elegans (Haeckel). Familix ine Sfidnention.}

Burgröferumg 200. Edfate vierfammerig, oret=

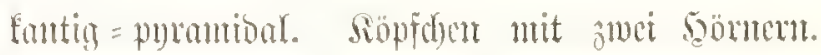

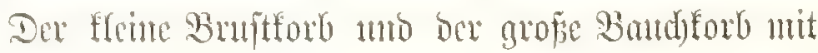
brei granten Sianten, bie an Beginn ber vierten

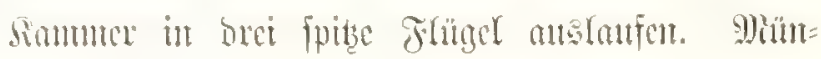
bumg zadfig, mit men forferdaten Bälynen. 


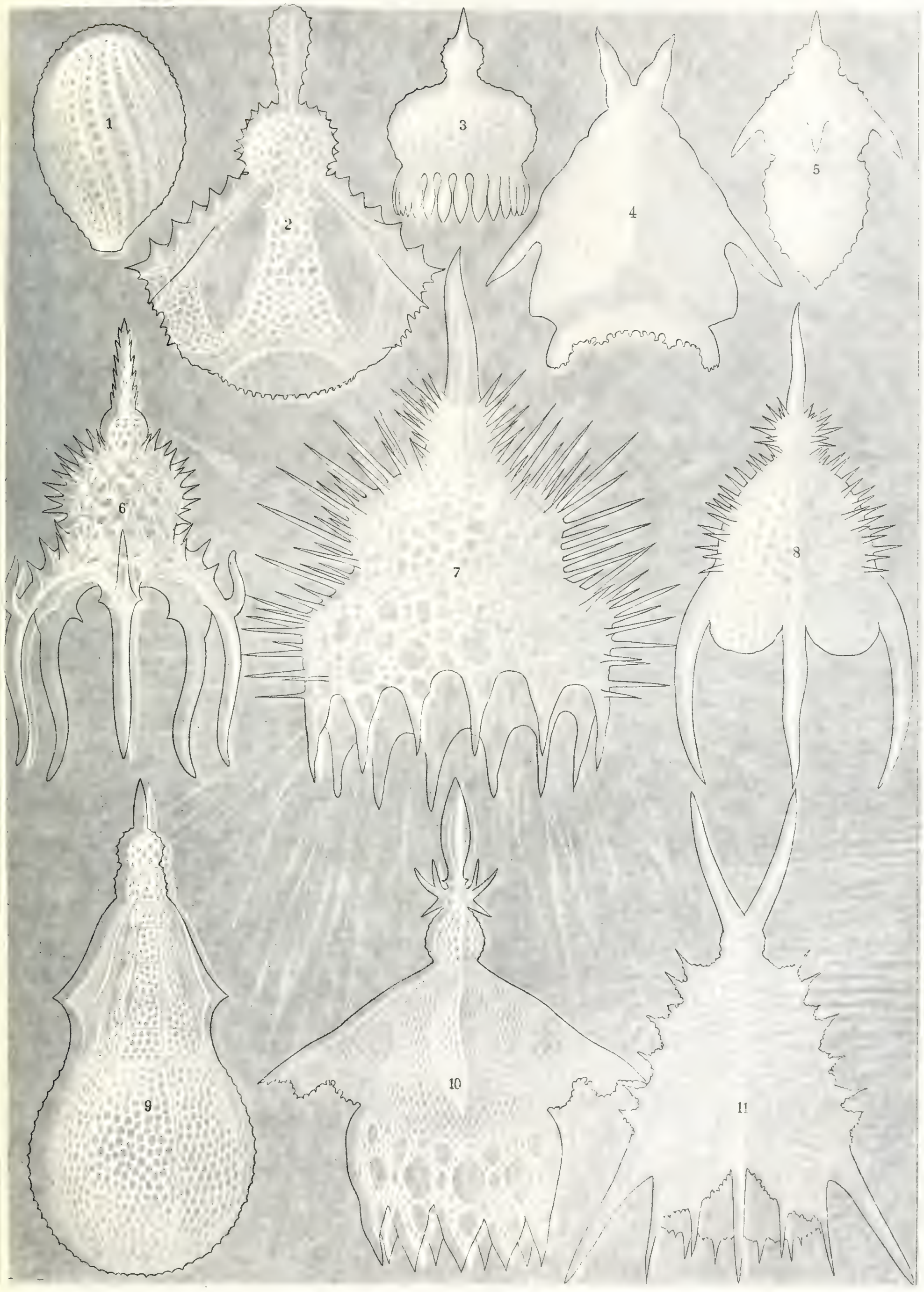




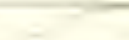

$\therefore \ldots$

$\therefore ?$
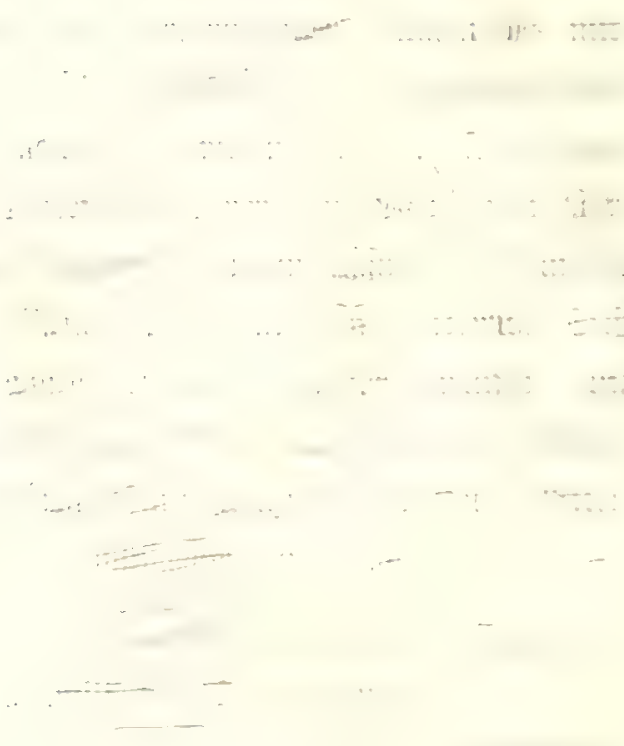


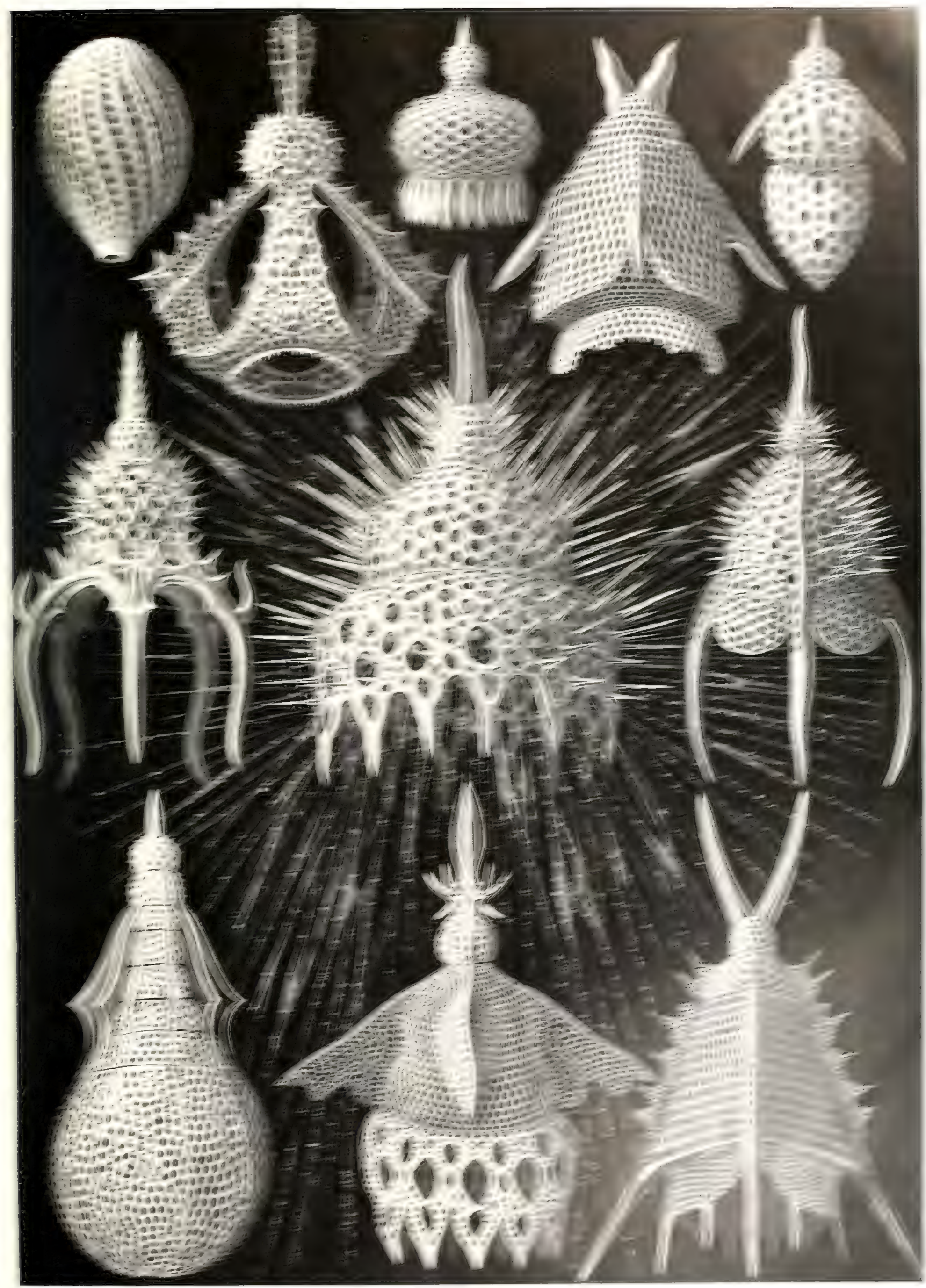





\title{
Rotatoria. Rämertiere.
}

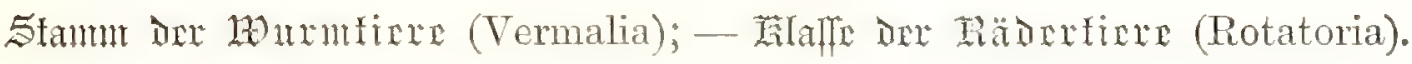

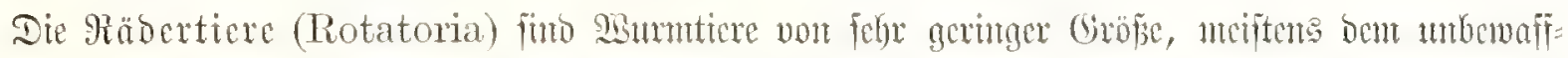

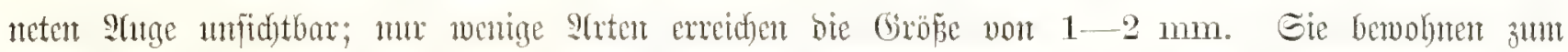

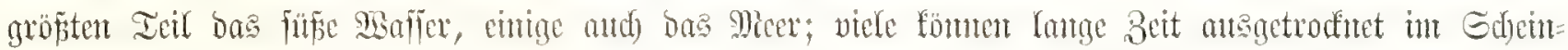

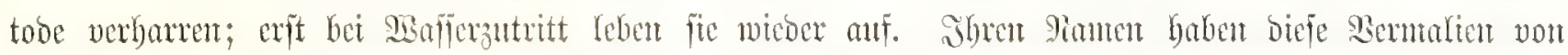

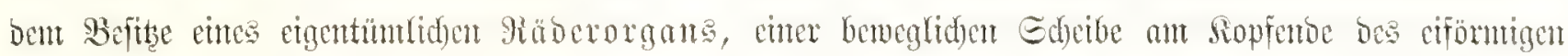

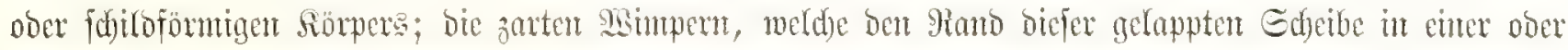

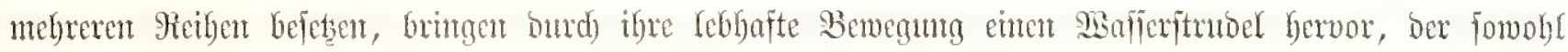

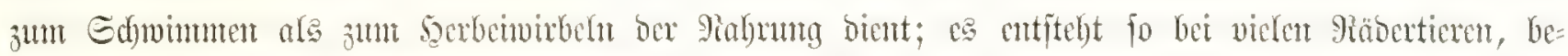

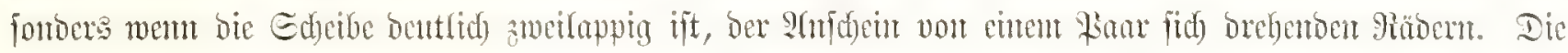
meiften gäborticre fdominnten fo fret int

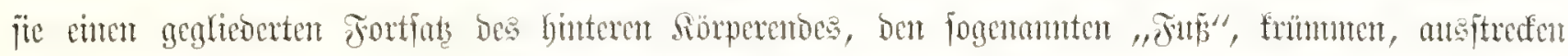

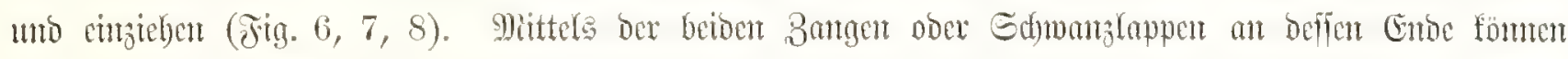

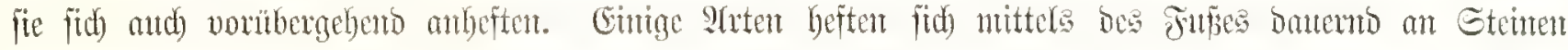

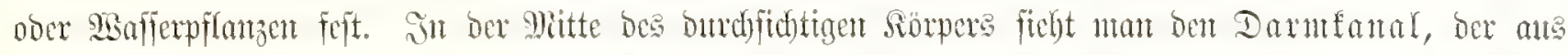

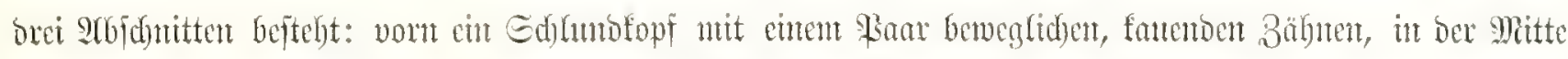

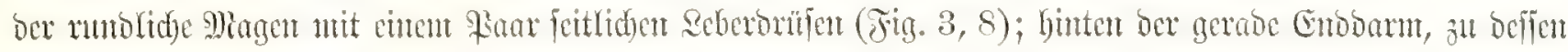

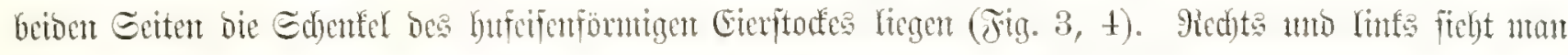

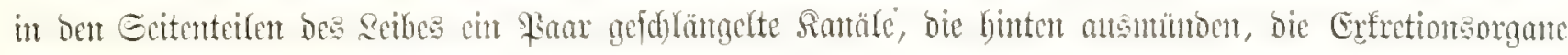

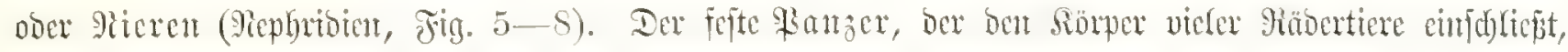

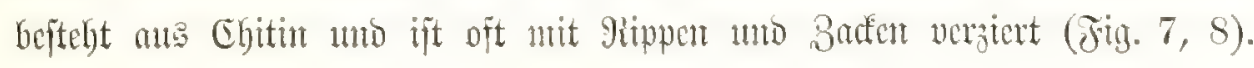

\section{Jig. 1. Pedalion mirum (Hudson).}

Fantilie ox Sxirfopoden.

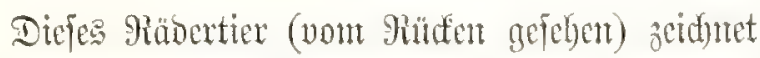

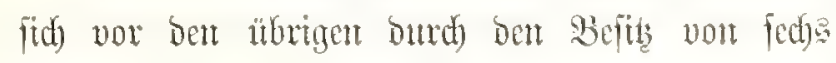
boriftentragentoen, beinartigen Ifubängen aus, bie

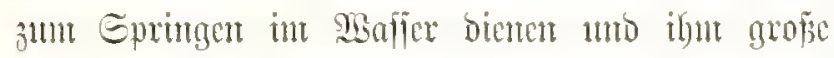

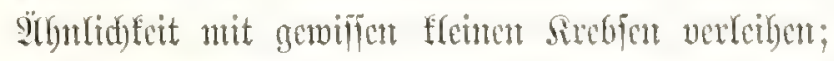

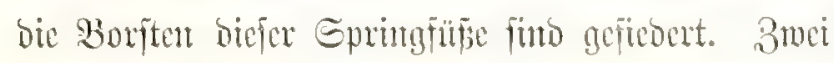

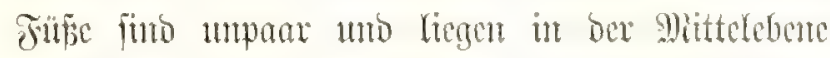

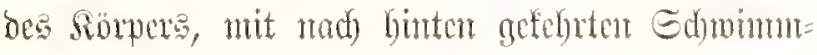
borften (ein flemterer Fur oben ali bent giüfent,

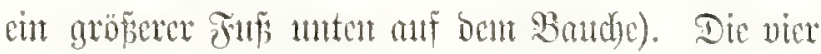

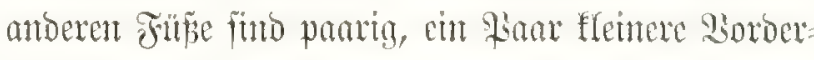

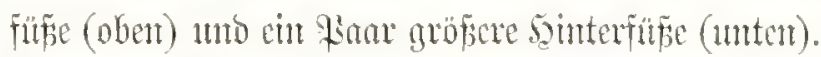

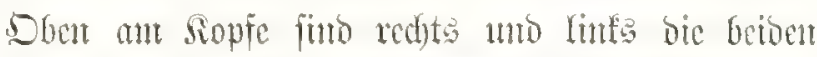

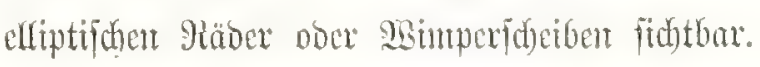

Jitg. 2. Lacinularia socialis (Etwenberg). Familis Dex Lffizafioner.

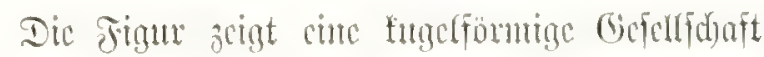

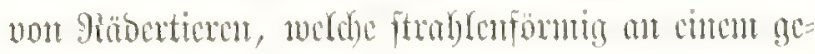

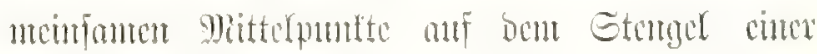
sisfferpflange amfirizen. 



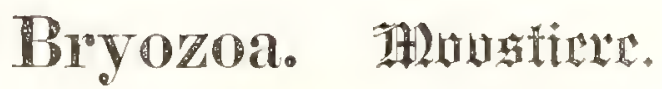

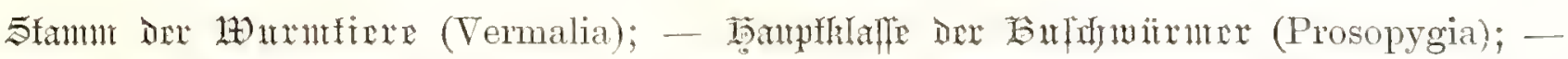

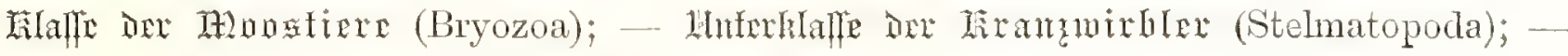

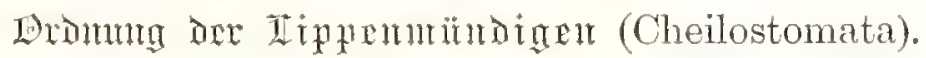

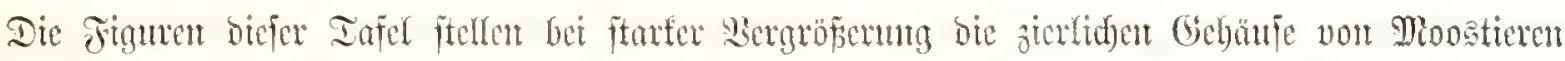

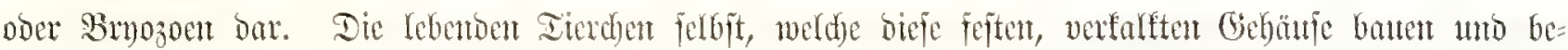

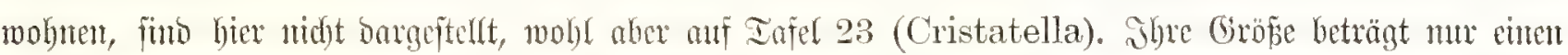

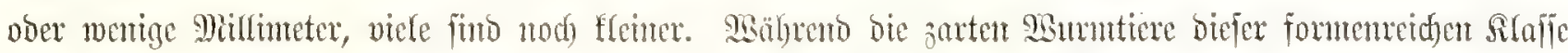

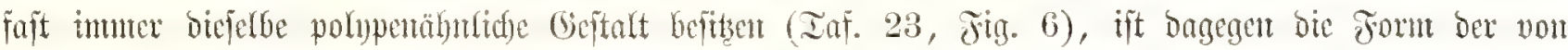

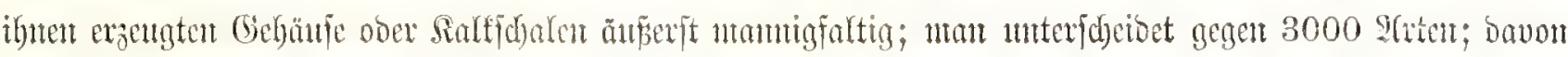

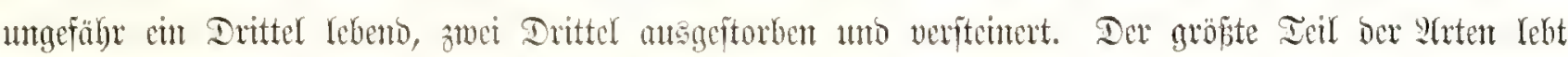
int Mieere, unr fegr wentige int füpen sisner.

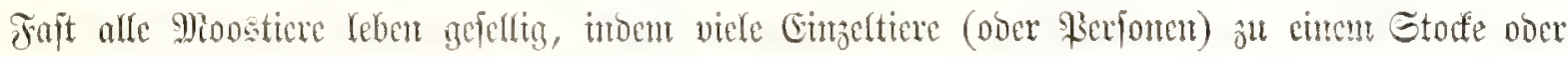

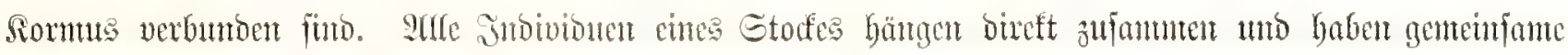

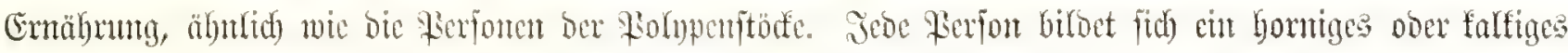

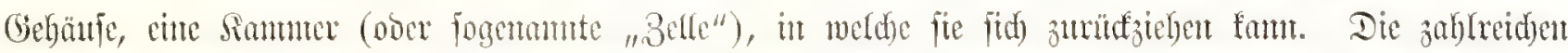

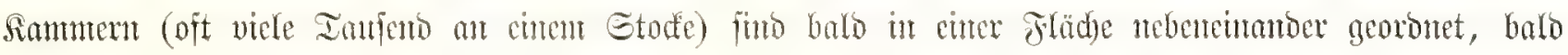

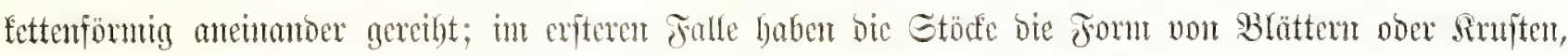

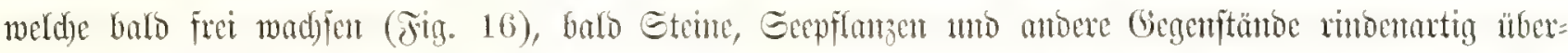

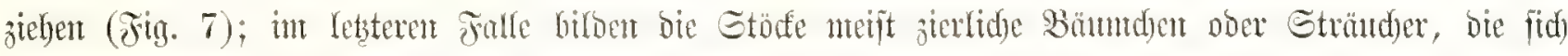

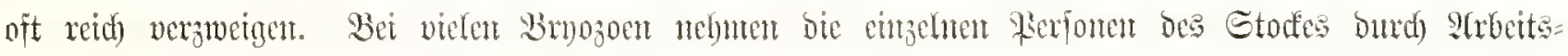

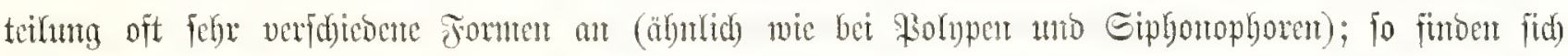

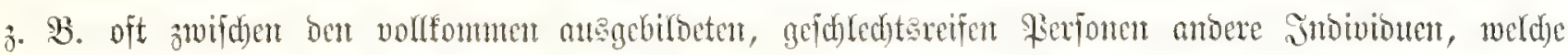

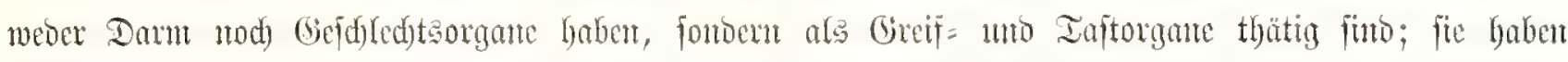

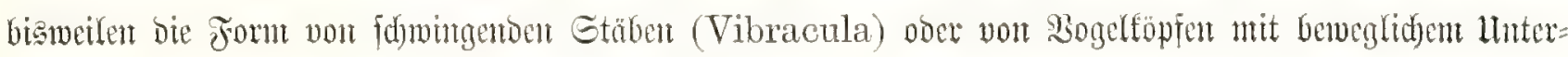
fdumabel (Avicularia, Fig. 6, 14 uto 15).

Fig. 1. Lepralia spinifera (Johnston).

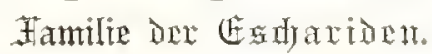

Sieben bentabbarte Sianment (nur bie żmei mittleren vollitäntoig).

Fig. 2. Cribrilina punctata (Hassall).

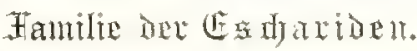

Cinte cingefte Sanmer.

Jing. 3. Umbonnla verrucosa (Hinctis).

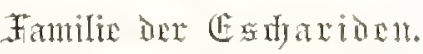

Cine einzelne fiammer.
Fig. 4. Cribrilina radiata (Smitt).

Familie one 近的少arion.

Cine cinticlne Simmur.

Fitg. 5. Lepralia alata (Busk).

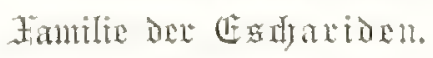

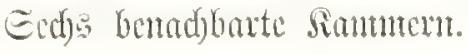

Sing. 6. Bugula flabellata (Busk).

Familix be birellation.

Gedjs benadibante Sianment. 


\section{Sin. T. Cupularia stellata (Bushi).}

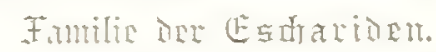

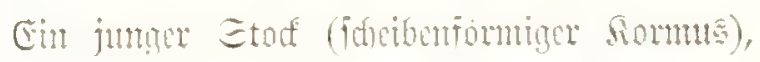

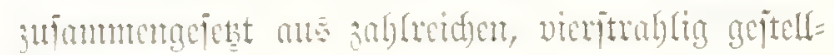
tent hiommterst.

Jiog. S. Farciminaria aculeata (Buski).

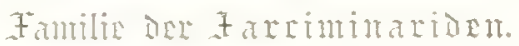

Eime Gruppe bon summerm (die oret oberen vollitünotg).

Jig. 9. Lmbonula reticulata (Hincks).

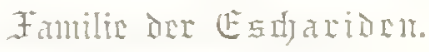

Eine cinsclte sianmer.

jotg. 10. Cribrilina costata (Busk).

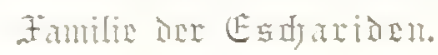

Eitue cimblne hammer.

Trig. 11. Smittia Landsbororii (Hinctes).

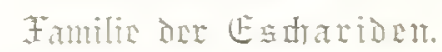

eine eimgelue hommer.

Jìn. 12. Smittia reticulata (Hinctis).

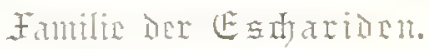

Eine cimblne sommer.

jig. 13. Lepralia ammulata (Tohnston). Famitic Der E E E

Cine eingelne hammer.

Jig. 1t. Diachoris magellanica (Busti).

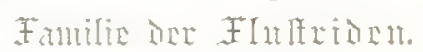

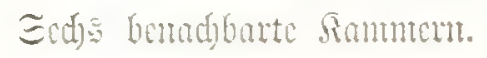

Jig. 15. Diachoris crotali (Busti).

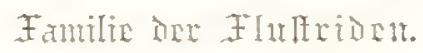

Sed bomadibarte Sanment.

Fin. 16. Flustra Gayi (Sarigny).

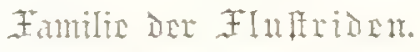

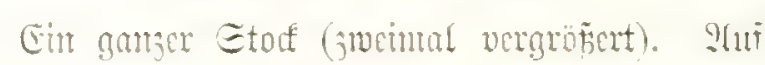

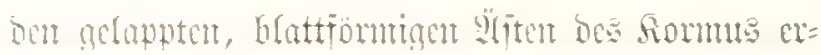

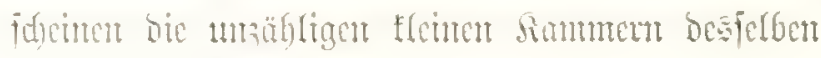
als fleme Rumfte.

Jig. 17. Flustra Garii (Sarigny). Familie Dre FInfution。

Ireizebu cintsetne fummern vout bem Etodf Jing. 16, jtarf vergrö̌nert.

Jig. 1s. Schizoporella hyalima (Hinchs).

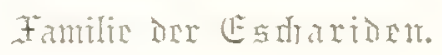

Trei benadiborte sammen.

Jig. 19. Lepralia rariolosa (Johnston).

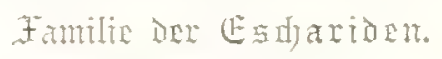

Eine entrelte simmer.

Fig. 20. (horizopora Bronguiartii (Audoum).

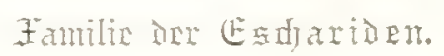

Erei benadbarte sammem.

Jig. 21. Flustra Lragoi (Savigny).

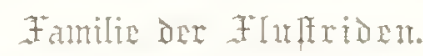

Eiste Gruppe vont 17 Sianmem. 


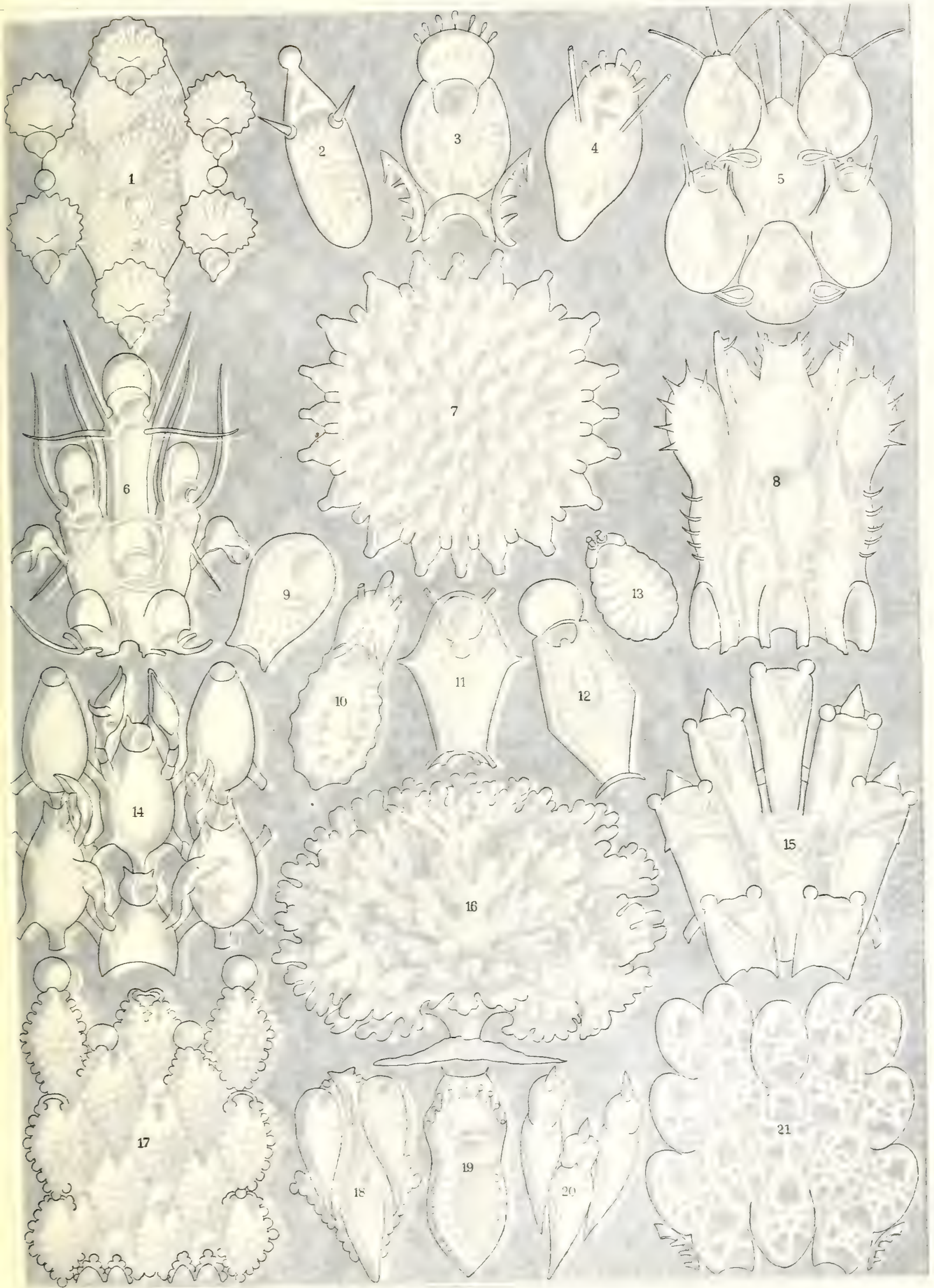




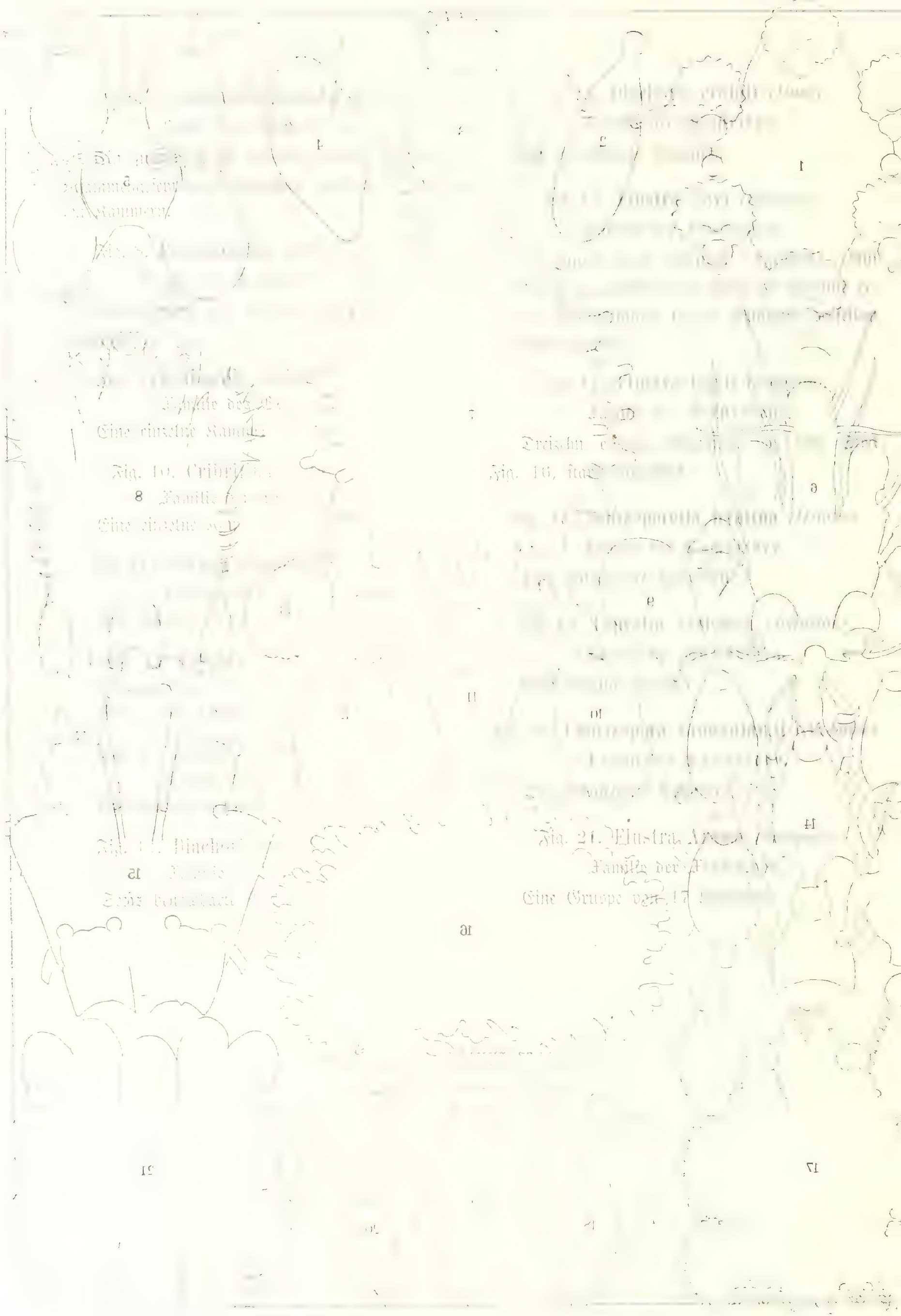




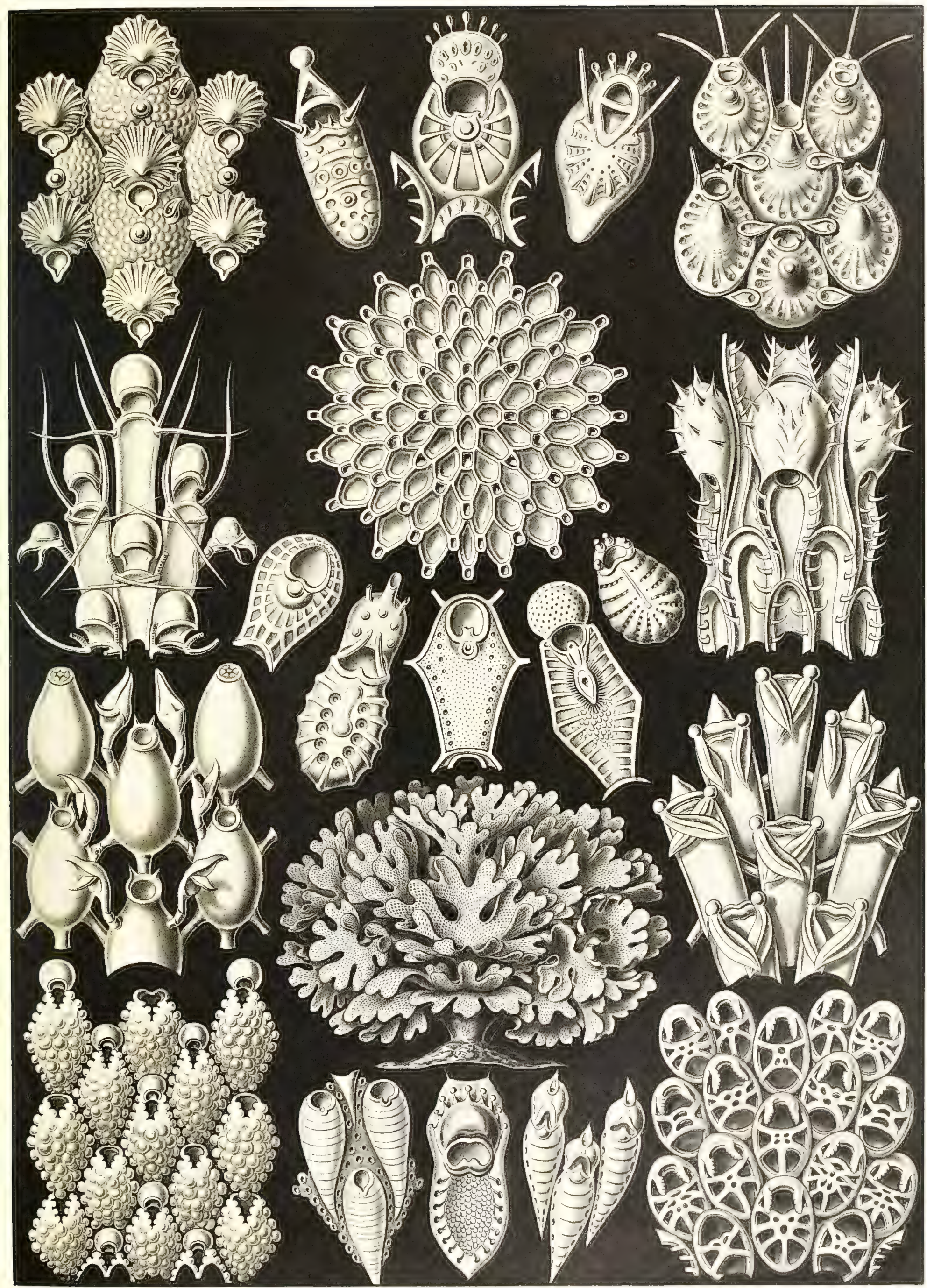





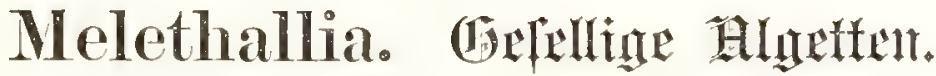

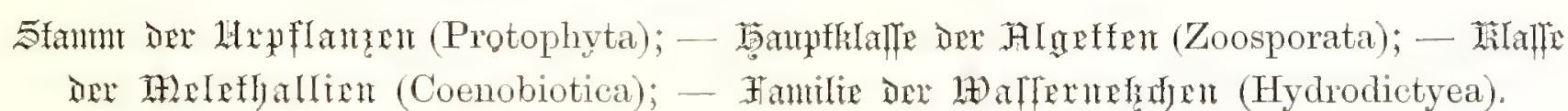

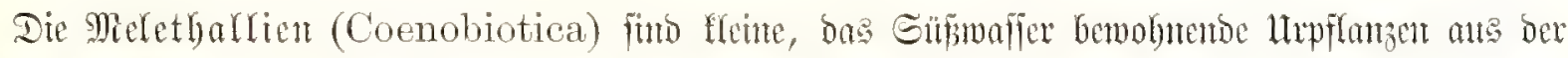

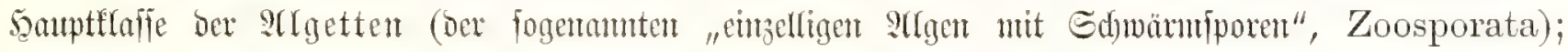

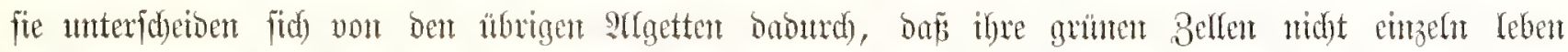

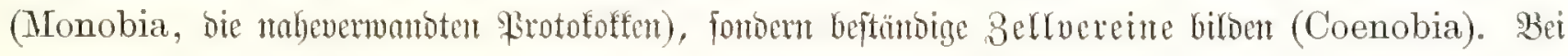

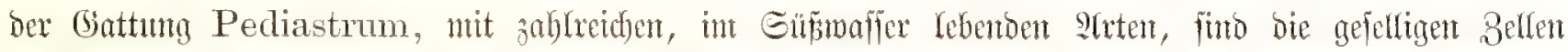

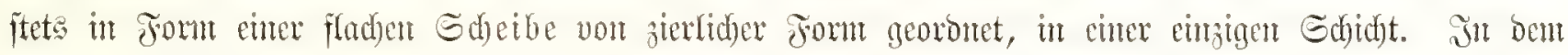

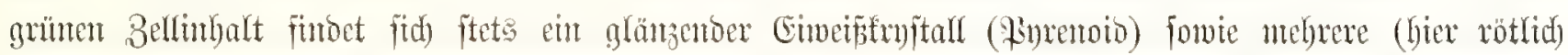

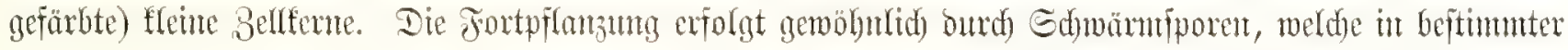
Baht $(4,8,16,32)$ in eincr Belle entïtehen; bant fpringt ant einer Stelle bie Bellwano auf, uno aus

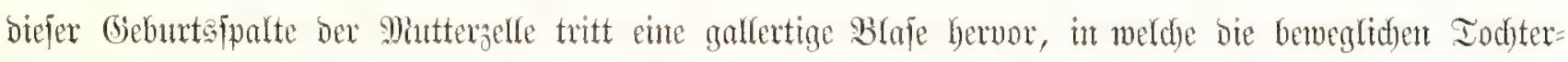

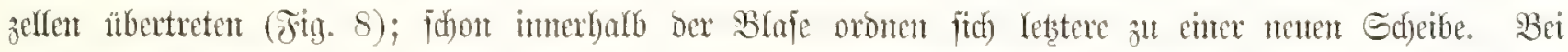

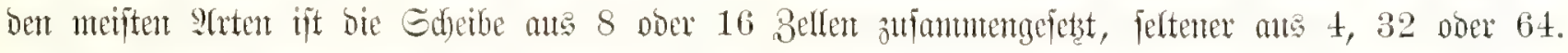

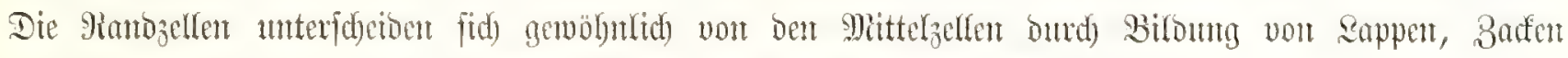

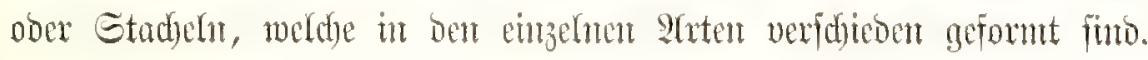

\section{Fig. 1. Pediastrum tetras (Ehrenberg).}

Die Sdyeibe befteht ans vier gleiden, int Sirenz

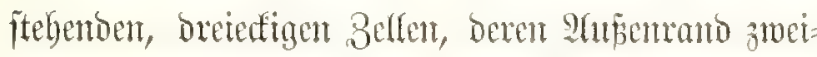
lappin und vierjpitzig ijt. Seode Belfe enthält ein

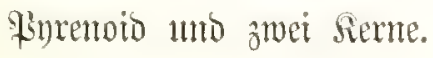

\section{Fig. 2. Pediastrum rotula (Kützing).}

Die Edjeibe ift aus adjt zweifappigen Bellen zulfammengefetst; bie Mittelzedfe enthält fümf Sierne, bie fieben Rantojellen je fectses sume.

\section{Fin. 3. Pediastrum granulatum (Kützing).}

Die Edeibe beftert ats adjt Belfer, won berren

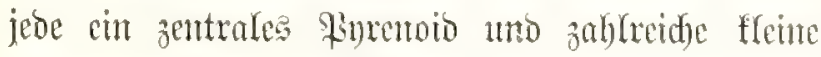

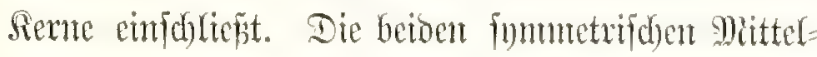
zellen fint trapezoio, ohne Fortfätze. Die fedfo

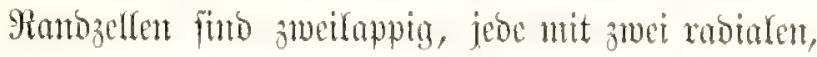
förnig raullyen siolben bewaffnet.

\section{Fin. t. Pediastrum octonnm (Haeckel).}

Die Edyeibe befteht ans adyt gleidyen, flafdent=

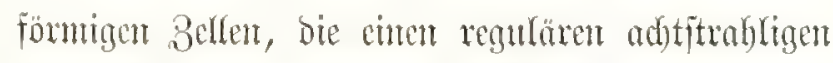

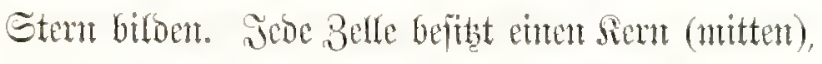

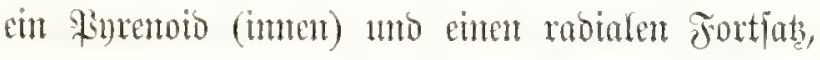
gleid) einem glafdenthats (anjem).

\section{Fig. 5. Peliastrum cruciatum (Haeckel).}

Die Gdabe bejteht ats vier gleidyen, im sirens ftehenon juct appigen Bellen; jede Belfe enthält

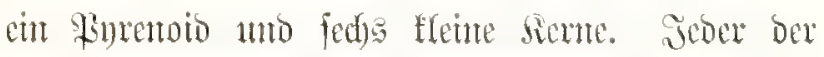

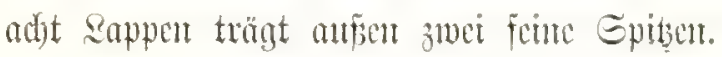

\section{Fig. 6. Pediastrum selenaea (Kützing).}

Die Gderbe beftedt an 16 Betfer, wetche bie

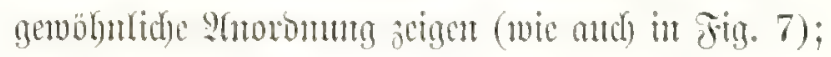
cime zentrale Dittelzelfe ift von fumf äbultidyent ungeben, unb biefe pout cincm firange von zebt 
jweilappigen Siandocllen. Sede Belle enthält eit zent=

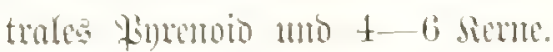

\section{Jin. 7. Pediastrum pertusum (Kütring).}

Die Edeche befteht at 16 Bellen, in berfelben ?turomung wie Sitg. 6, mu burd) grofiere 3 wifden=

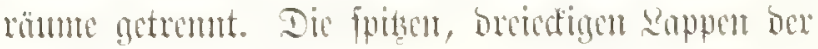

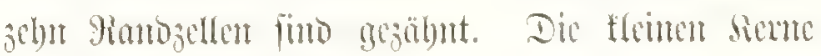

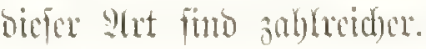

\section{Jig. 8. Pediastrum elegans (Haeckel).}

Dic Educibe beftedt ans 32 3ellen; cine zent=

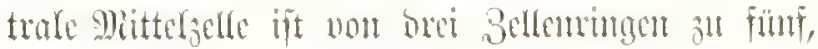

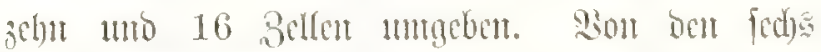

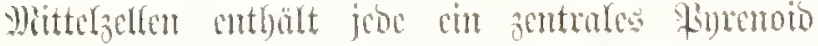

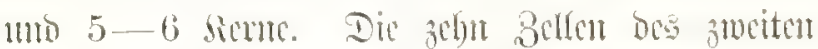

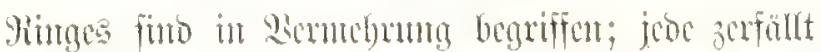
Dutrd) Ietlung in $8-16$ Bellen. Dis 16 3ellen

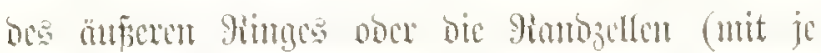
vier jpitzen, gezäbnten 9ianoloppen) zecigen ben (Ge=

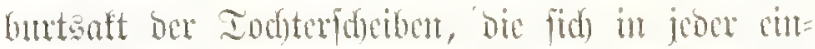

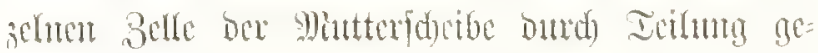

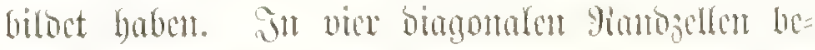

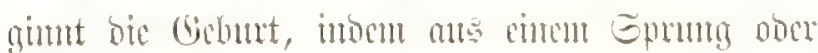

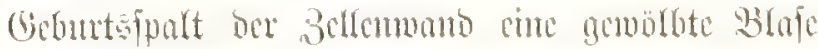
vortritt. Sn vier moeren, zmifden jenen liegentom Rimbselfen ift bie Geburt weiter vorigedoritten; bie vier jungen Tod)terfdeiben (beren 16 beneglide $3 \mathrm{ct}=$

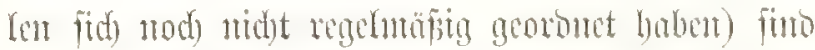

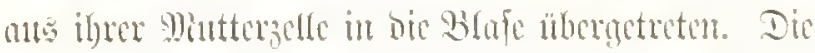

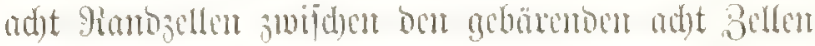

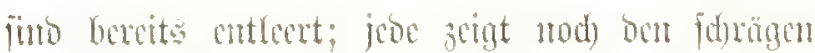
Sprung der Bellenwano, ma weldyent bic gethormen Iodyterifuciben angetreten furo.

\section{Fin. 9. Pediastrum lunatum (Haectel).}

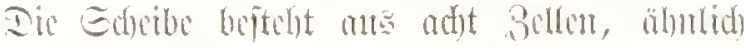

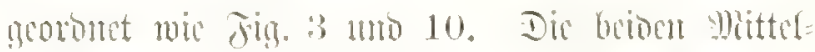

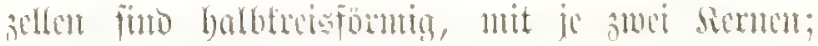

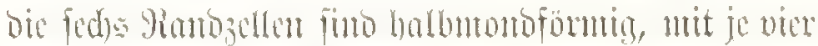

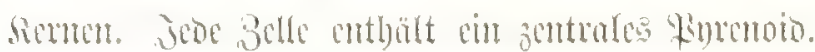

Jit. 10. Pediastrum furcatum (Haecket).

Dic Edrethe bejtelyt ans adyt Bellen, ähulid groronet wie Jits. 3 umo 9. Die beiden syittel-

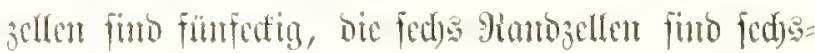
ectig, anjis gathelteifig.

\section{Fia. 11. Pediastrmm Braunii (Haeckel).}

Dic elliptifde Gdreibe bejteht ans 8 pentago-

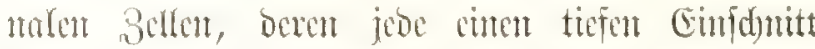
jeigt. Dic fedje Romballen fimo mit je vier zarten Eniden bemaffmet. Diefe :Irt ift mad) ocm fein=

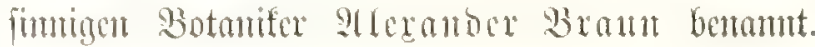

\section{Fin. 12. Pediastrum ellipticum (Elwenberg).}

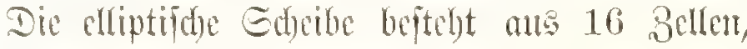
von benten jeoe cin Sinrenoio und vier Sieme ent=

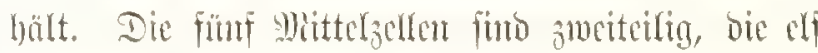

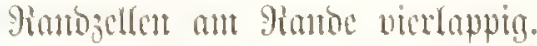

\section{Fin. 13. Pediastrum Darwinii (Haeckel).}

Die bimformige Ed)eibe ijt befateral mo beiteht

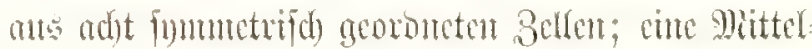

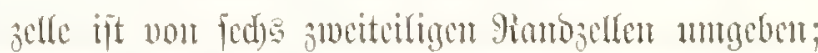

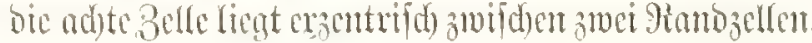

\section{jign. 1t. Pediastrum trochiscus (Haeckel).}

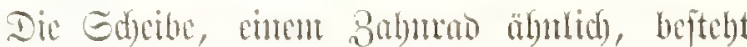

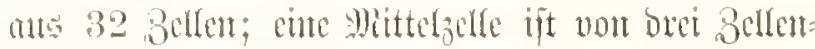
rimgen untuben; ber arfe (immere) Ging ift ans Fïn, ber jueite (uittlere) ams zelbu mo ber britte

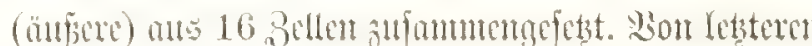

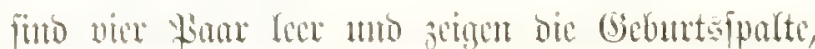

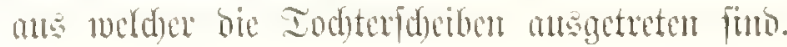

\section{jin. 15. Pediastrum solare (Haeckel).}

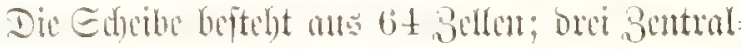

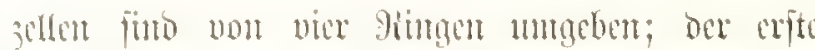
Jime enthält 7 , ber sweite 13 , ber britte 18 mo ber vierte 23 Bellen. Jese Belle enthält cin til

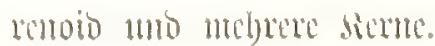




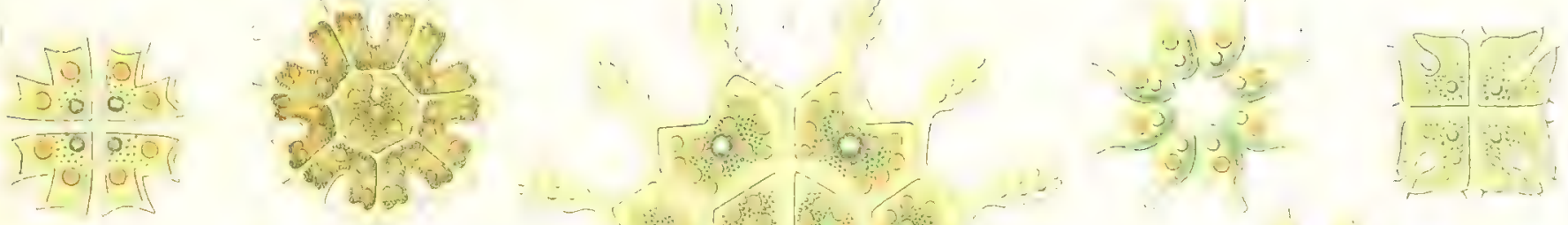

o 000
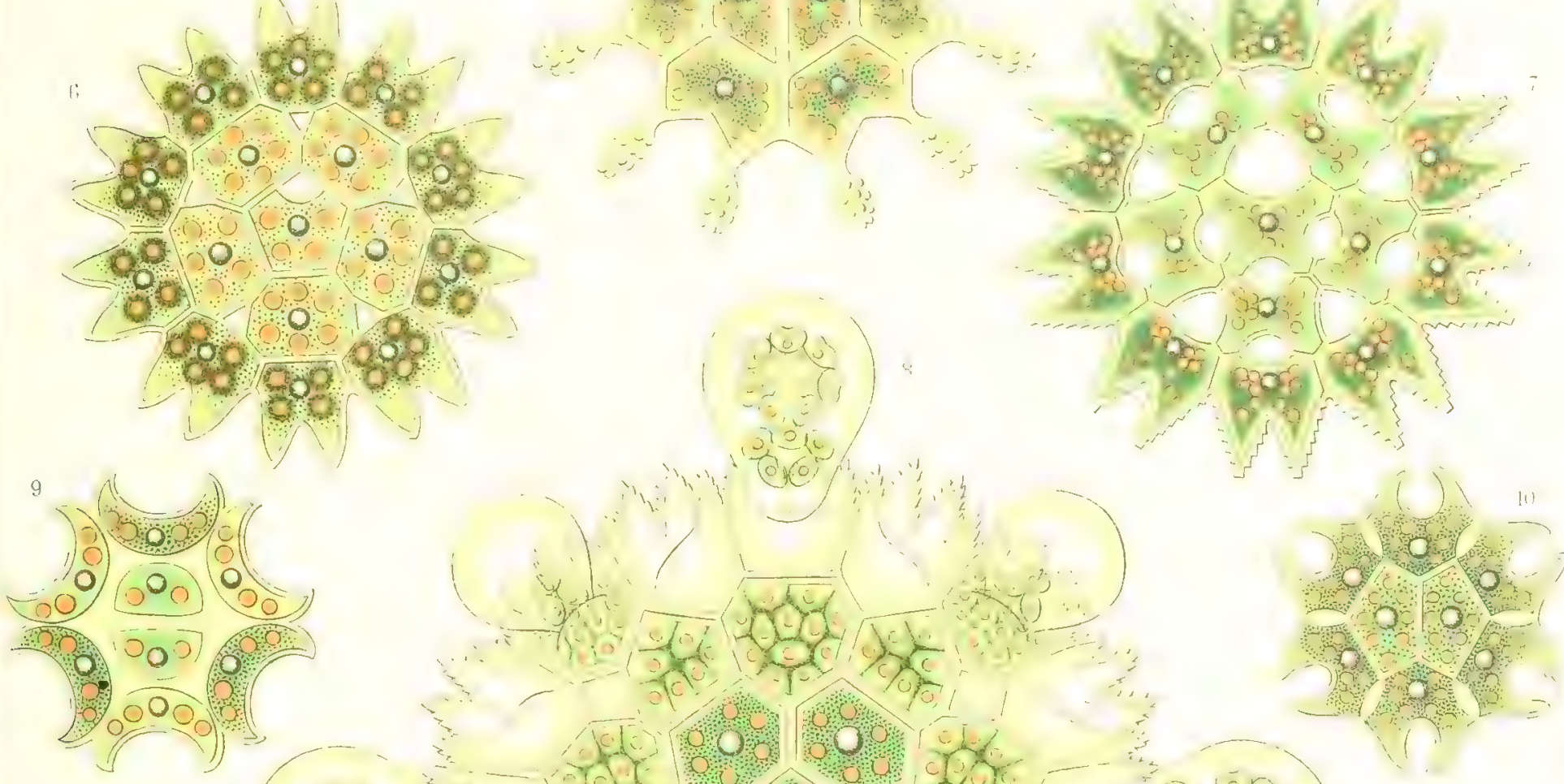

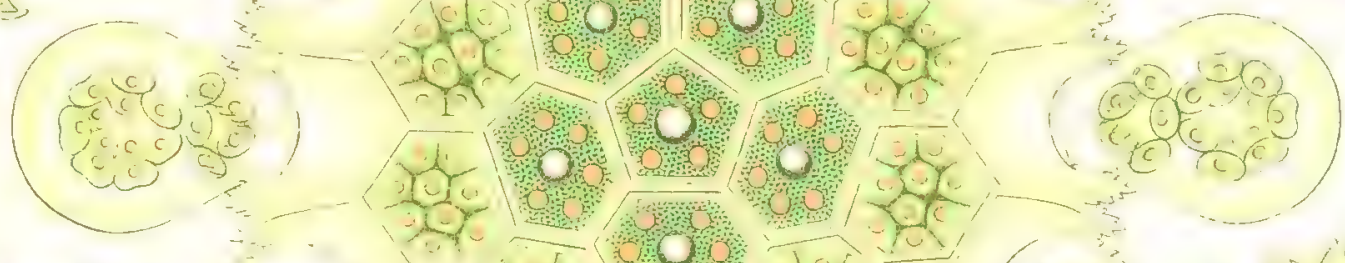
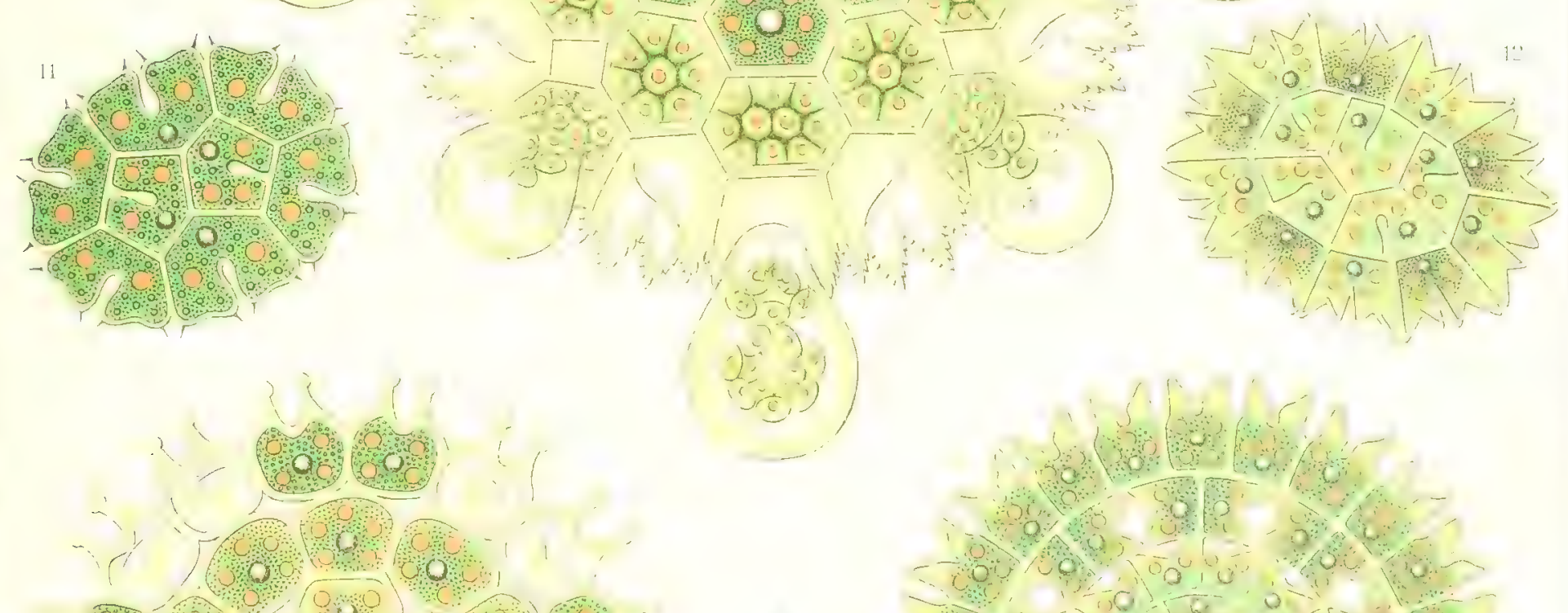

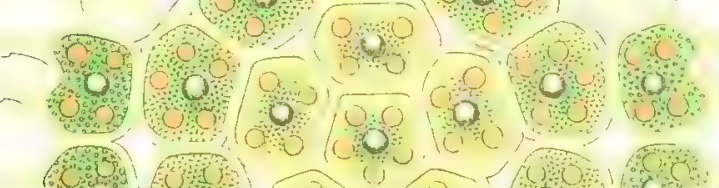
mol 0 oper $80 d$

$$
\begin{aligned}
& \text { 3. 0, } 000,000 \\
& \text { 10 } 0000 \\
& 0010
\end{aligned}
$$

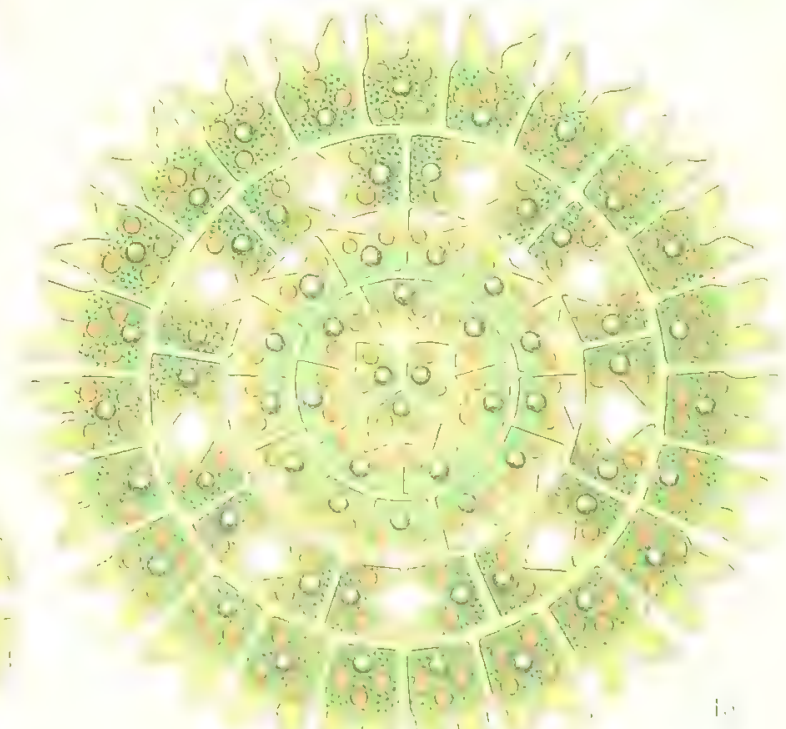


. 


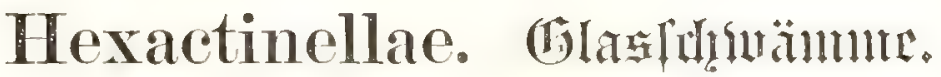

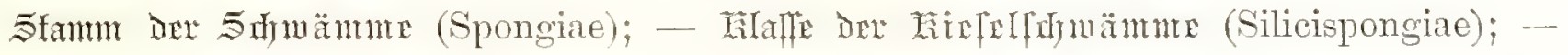

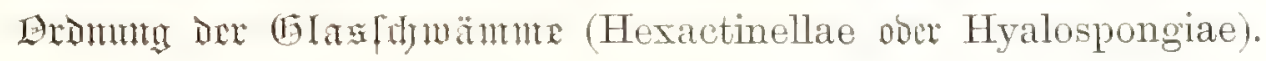

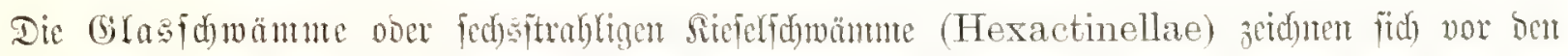

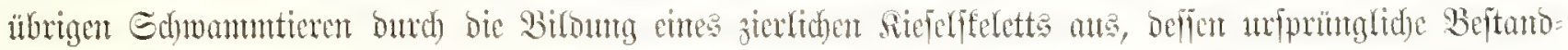

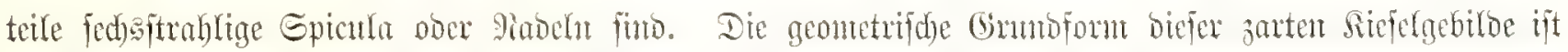

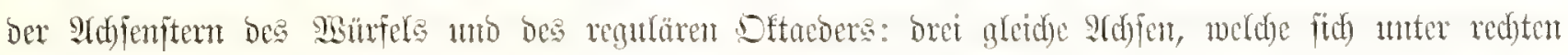

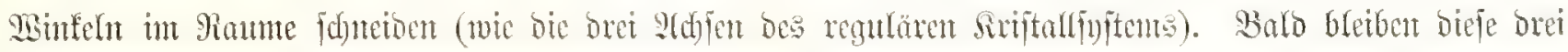

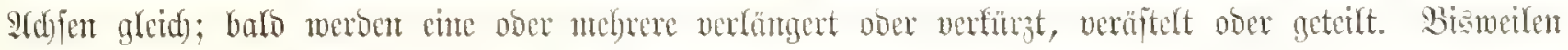

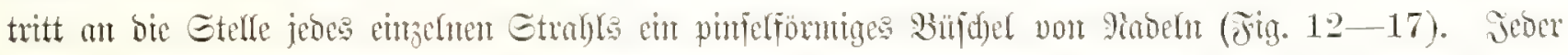

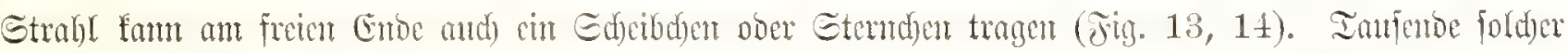

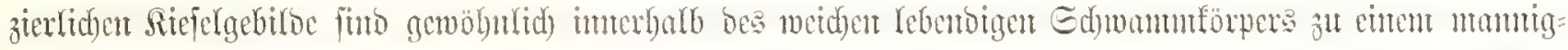

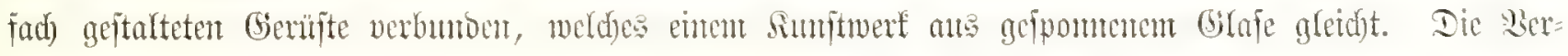

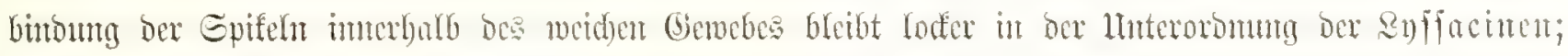

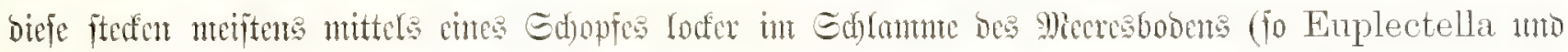

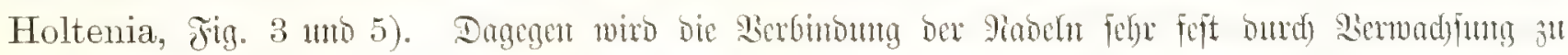

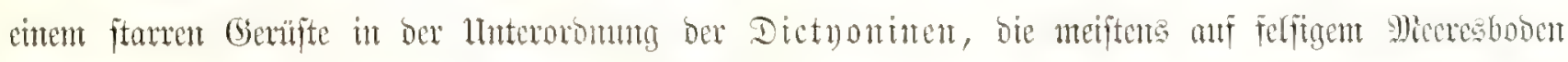

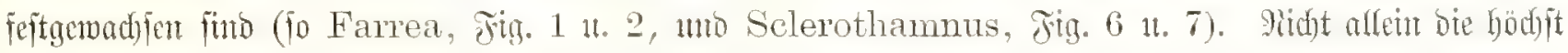

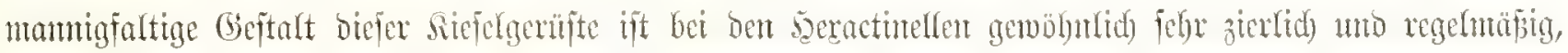

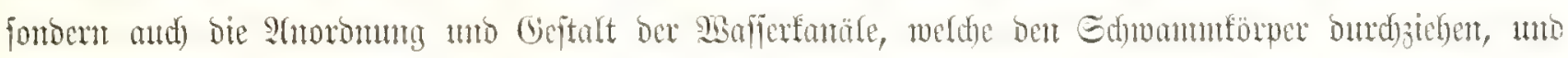

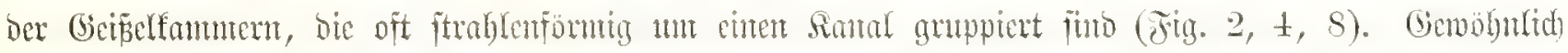

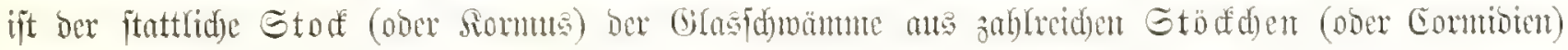

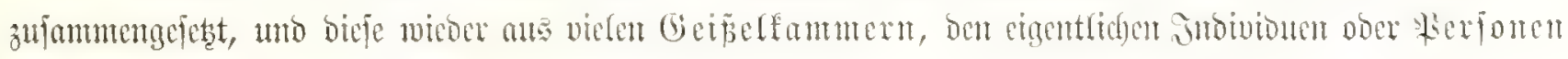
oce Sdinanmes.

\section{Jig. 1. Farrea Haeckelii (F. E. Schulze).}

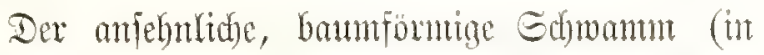

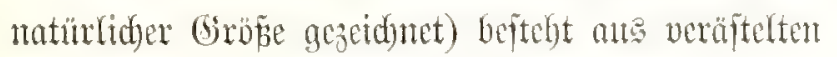
Goblent Möhren, deren büme, aber fejte gigand ein

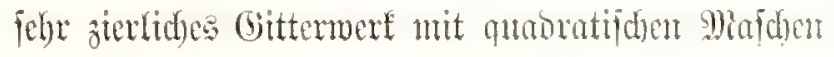
zeigt. Dumd bie Feinen Foren der Dberfläd)e ftrönt

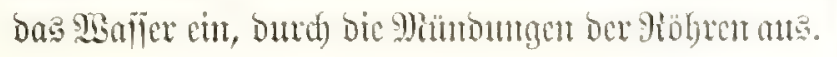

\section{J̃ig. 2. Farrea Haeckelii (F. E. Schulze).}

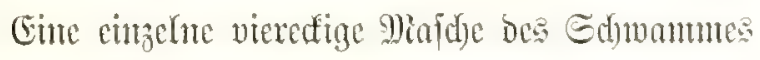

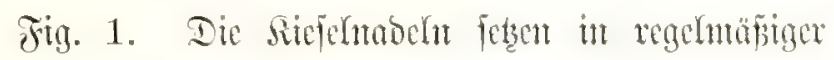
Anoromung ein boppeltes Gittemver anfanmen; bic

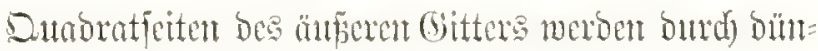

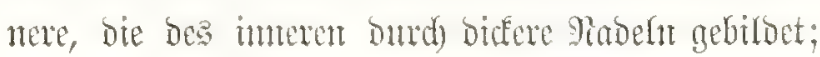

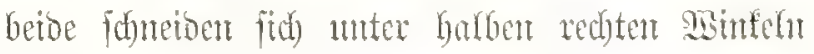

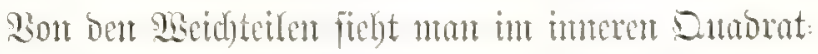

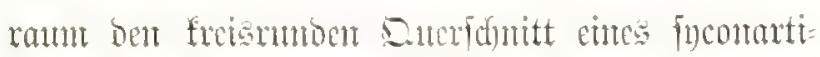

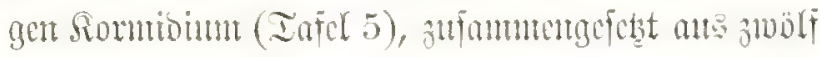

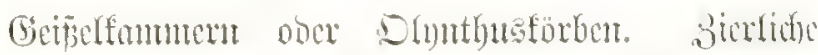

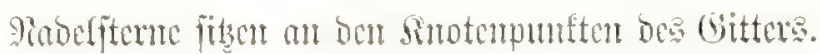

gin. 3. Euplectella aspergillum (Owen).

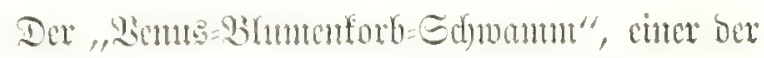

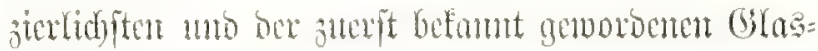


fod) wämme (un cin Drittel verffeitert). Ein ziter= lid)er Epirnlfanm länt am bic bünn cylimbrifden sourpers, beffen ohere B̈fmung (Os-

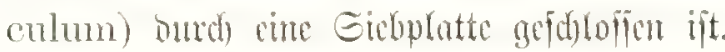

\section{Fig. 4. Euplectella aspergillum (Oxen).}

Ein Etüd der än Sin ben nier (Exten bes Dutabates, weldes burd)

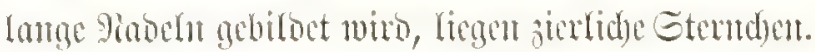

\section{Jig. 5. Holtenia crateromorpha (Hyoille} Thom:on).

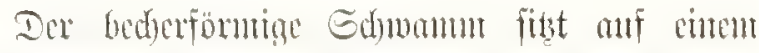
langen Eticl, ber burd) cinten firgigen Bufid) von

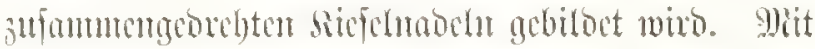

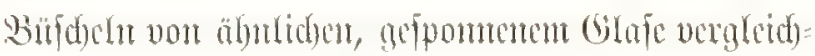

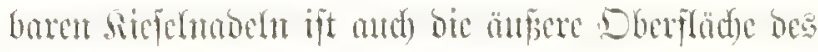

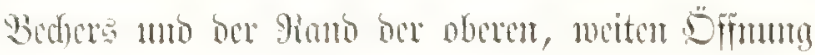
(Osenlum) beoctt. Das zierfid)e Gittermert ber

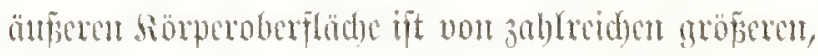

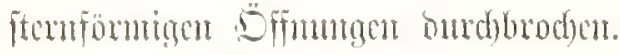

\section{Fig. 6. Selerothammus spiralis (1Lershall).}

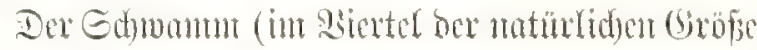

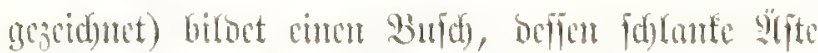

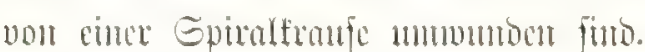

Jin. 7. Sclerothammus spiralis (1Fershell).

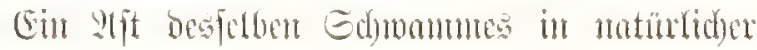
Grober.

Fig. S. Polyopogon amadu (Wyrille Thomson).

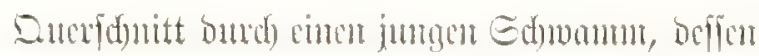

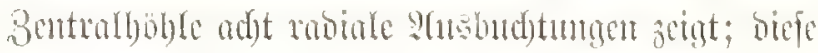

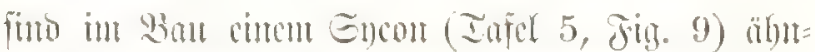

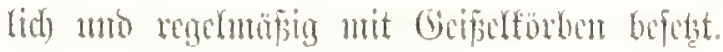

jig. 9. Pheronema rhaphanus (Franz Eithard Schulze).

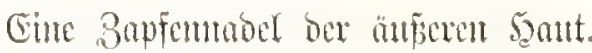

Fin. 10. IIyalonema indicum (Franz Eilhard S(hulve).

Ein Stuphiotsens oder cin sieferftab, welded an betoen Entoen enten Gtent trägt.

Jig. 11. Ilyalonema conns (F. E. Schulze). Eir Stmphiotschs, äbutid) Jing. 10.

Jin. 12. Regadrella phoenix (Oskar Schmidt).

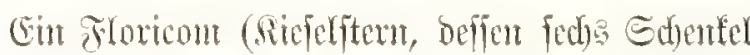

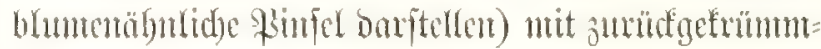
ten B̊mumenblättent.

Fig. 13. Saccocalyx pedunculata (Franz Eithard Schulze).

Cin Discoheraiter, Etern mit fpiralia georehten Emojtralyen, bic cime fleme Edyeibe tragen.

Fig. 14. Crateromorpha Meyeri (Gray).

(Ein Discoherniter, Etem mit fects Sinfedr.

Jig. 15. Hyaloslylus dives (Franz Eilhard Sthul:e).

Ein Sarrofter, Gtem mit Piohrfolben.

Fig. 16. Polylophns philippinensis (Gray).

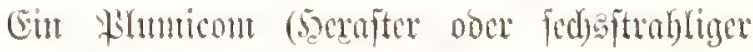
Siefelftern mit fed s geoerbuifden).

Fing. 17. Styloealyx tenera (Franz Eithard Schulve).

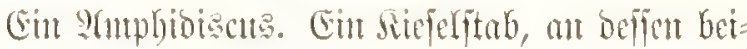

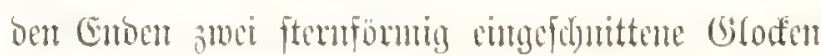
cimanoer gegemberitelou. 

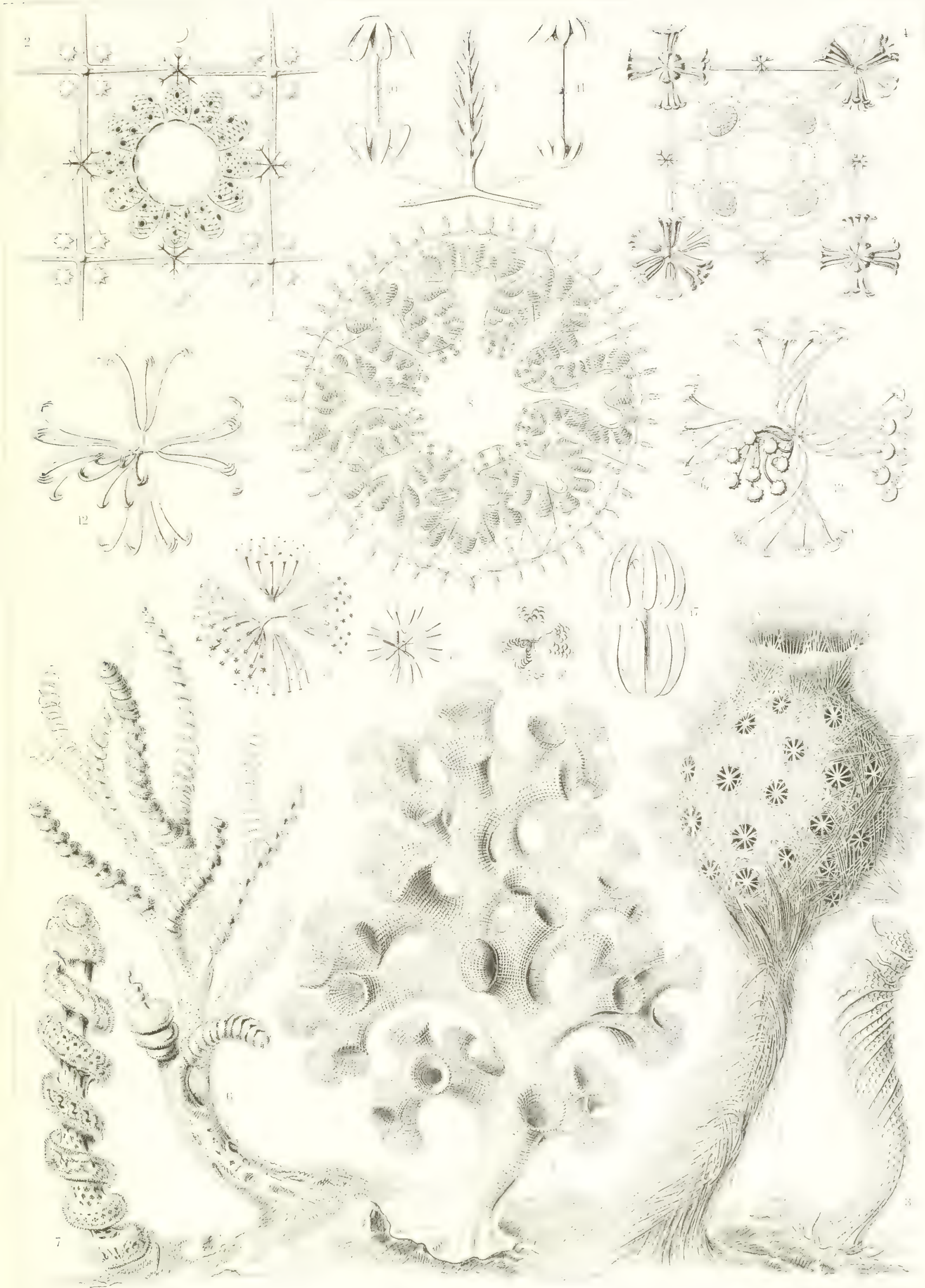

Hexactinellae. - (s)lasidinämmt 



\section{Leptomedusae. Ialfumuallur.}

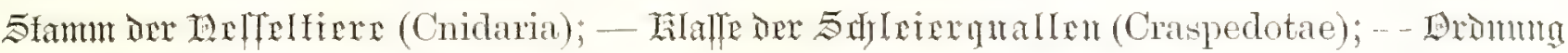

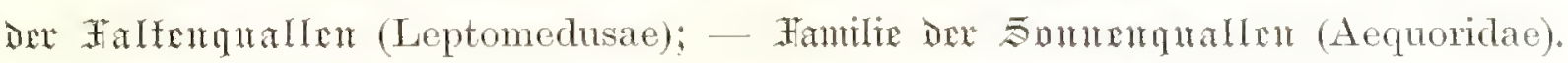

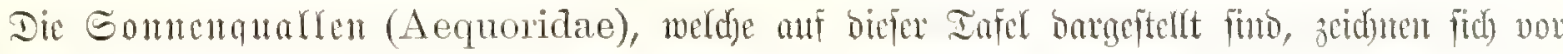

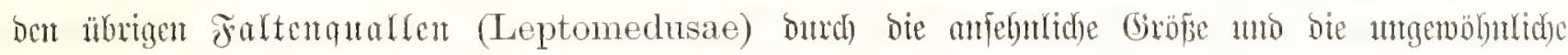

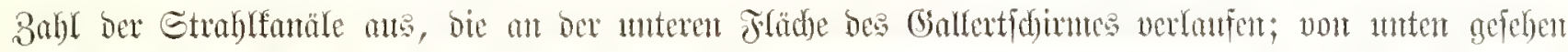

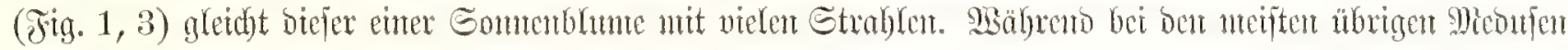

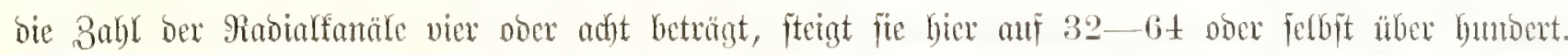

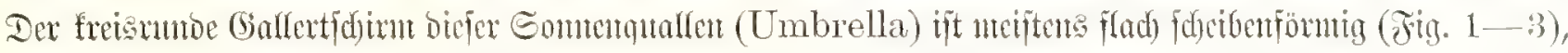

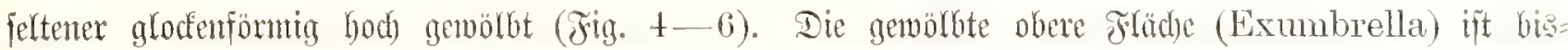

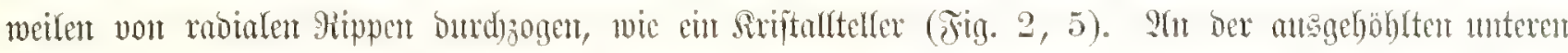

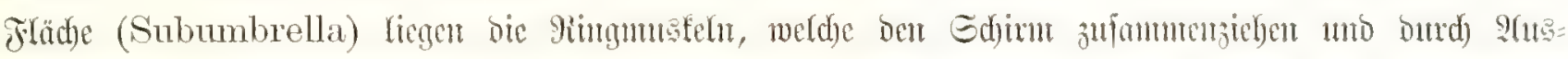

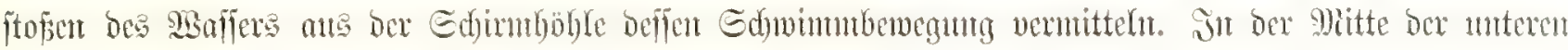

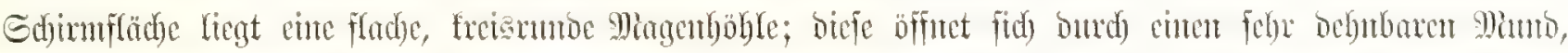

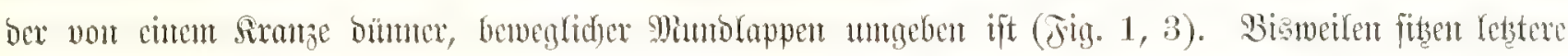

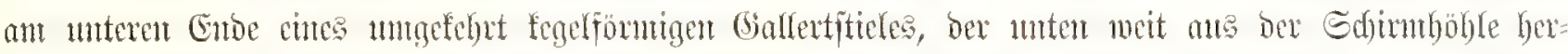

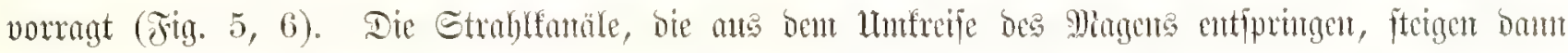

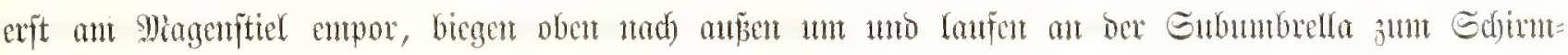

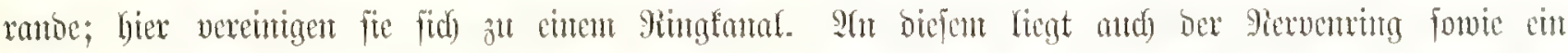

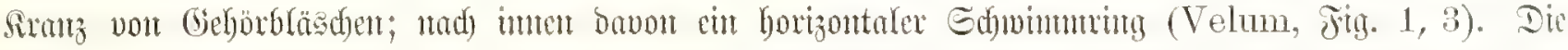

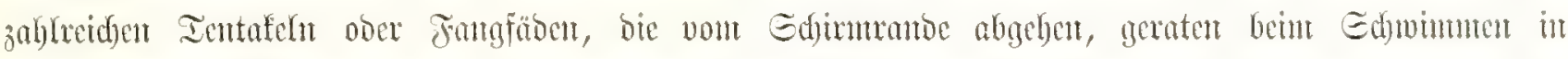

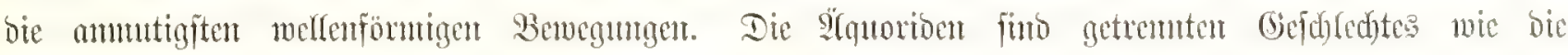

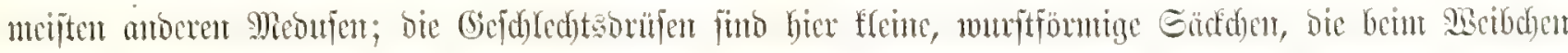

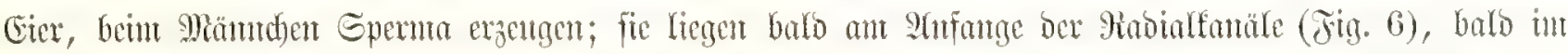

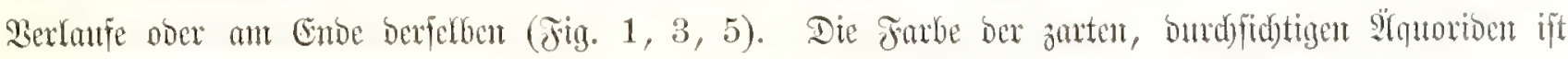
meifteng bräulid) ober lidet rötlid).

\section{Fig. 1. Ae(unorea discus (Haeckel).}

Ifts bem Mittelmeer, in natünlicher Gröñe, von unten gefeber. Dex geoffinte zentrole Minto ift von cinem Sranze łurzer sippenfranfen untgeben uno fülynt in eine fladje Maggentyöhle, won beren

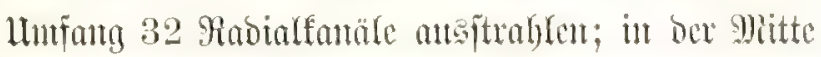

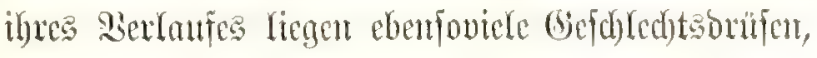
an Ranbe furze Fangfäben. Pad) imen fpringt

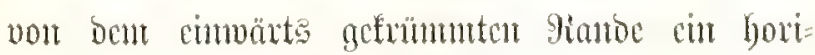
zontater \$iugketring vor (Velum).
Fig. 2 แ. 3. Zygocanna diplocoutus (Haeckel).

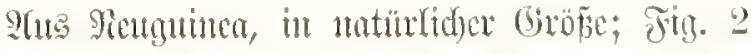
von ber Geite, Fitg. 3 vou unten gefelyent. Dor

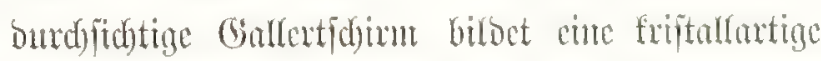
Edretbe, beren flad) gewöblote obere gläd)e von

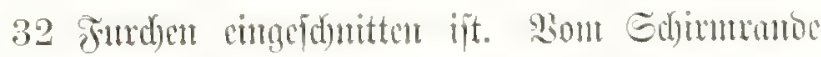

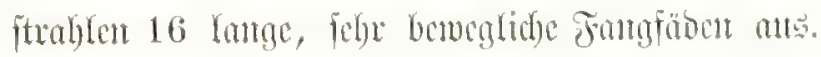

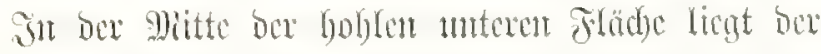

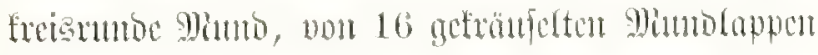

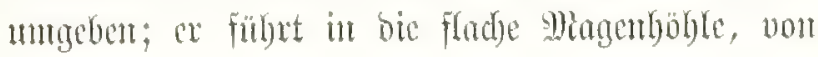


beren Shato 16 gabelpartige Robialfanäle ams

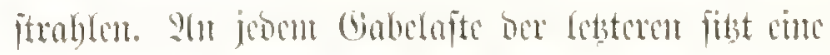

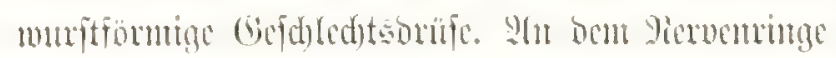

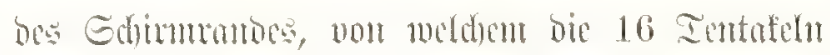

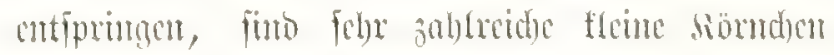
fid)tbar (beborbläsd)en); nad) innen bavon cin fretis= rumber, horizontafer Minsteling (Velum).

\section{Fig. t. Polyeanma germanica (Haeckel).}

Son selgolano, in matulider Gröbe, non oex

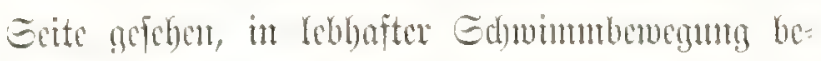
griffer. Der flad aewölbte Gallertfdion ift fart

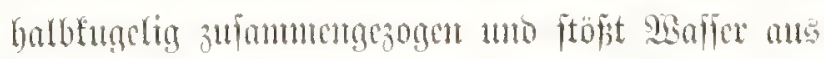
ber unteres Edrimböble ats. Inturd miro ber

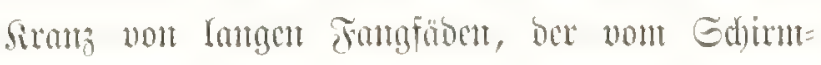

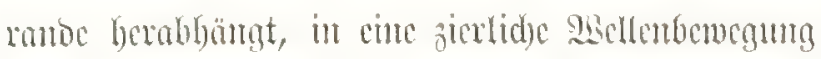

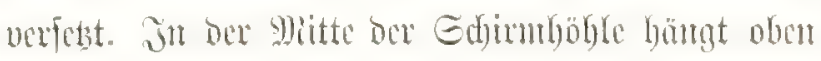
ber Miagen bexab, von beffen Iturfecife $50 \ldots-70$ Rabialfunäle maftrablen. Die Ringmusten an

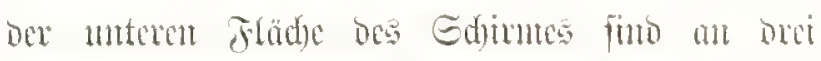
Stelfen befonots ftork zufummengezogat.

\section{Fig. 5. Zygocannula diplocontus (Haecked).}

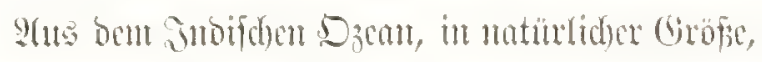
von ber Erite geflyen. Iex hod)gewöbte Gallert=

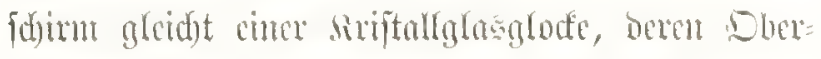

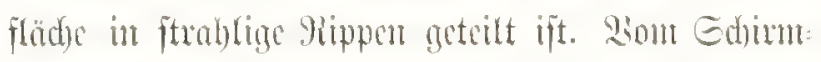

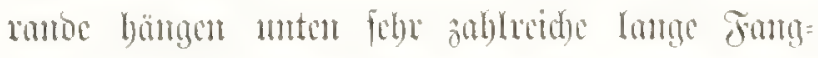
fäben berab. Sn ber Mitte bex Gdjumbohle fint ber untgefebrt fegelförmige Gallertiticl bes Magene, Der in 16 lange, gefräufelte, mellenfoumig bemegte Mimolappen gejpalten ift. 3ahlreide Babialfamale gehen von singen mfrwärts, biegen oben in ber

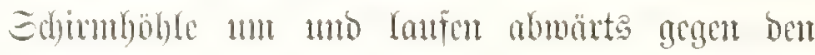

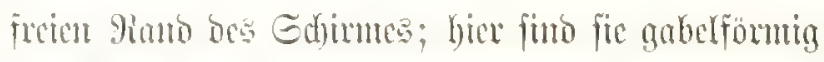
gejpalten, umb jeocr Giabelajt trägt cine faltige

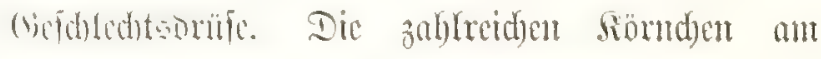

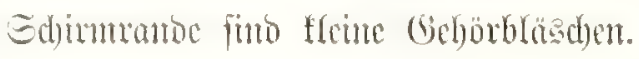

\section{Jig. 6. Orehistoma elegans (Haeckel).}

sealle von unten, ball von ber Geite gejeben,

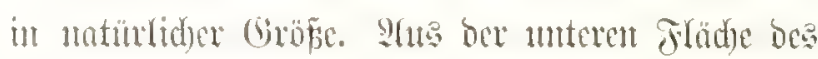

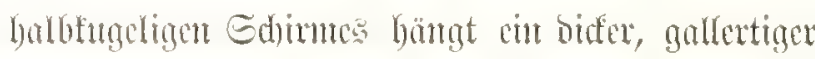

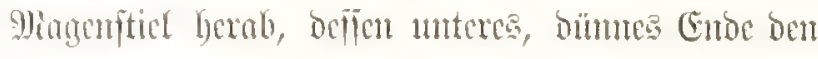
Slagent trïgt; biefer ift faft bis am Grumbe in 32 Cange, düme, bandförnige 93umolappen geipalten, bic fide fräutfelnto bemegar. Gleid) oberbalb

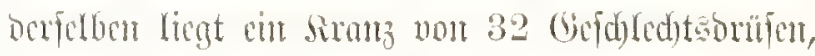
an Begimue oce aufifteigenoen Robialfanäle; oben

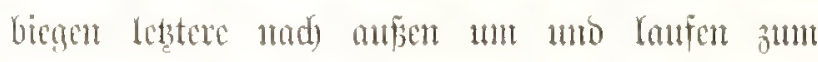

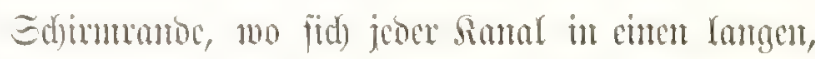
beweglident Fangfabent fortfocst. Diefe efcrante neuc

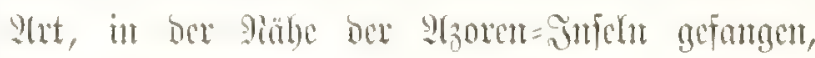
unterfdecioet fid von ber verwanten Orehistoma Steenstrupii ber : (nutillen burd) ben fdulanteren

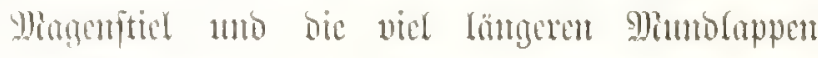
4nto Tentafelit. 


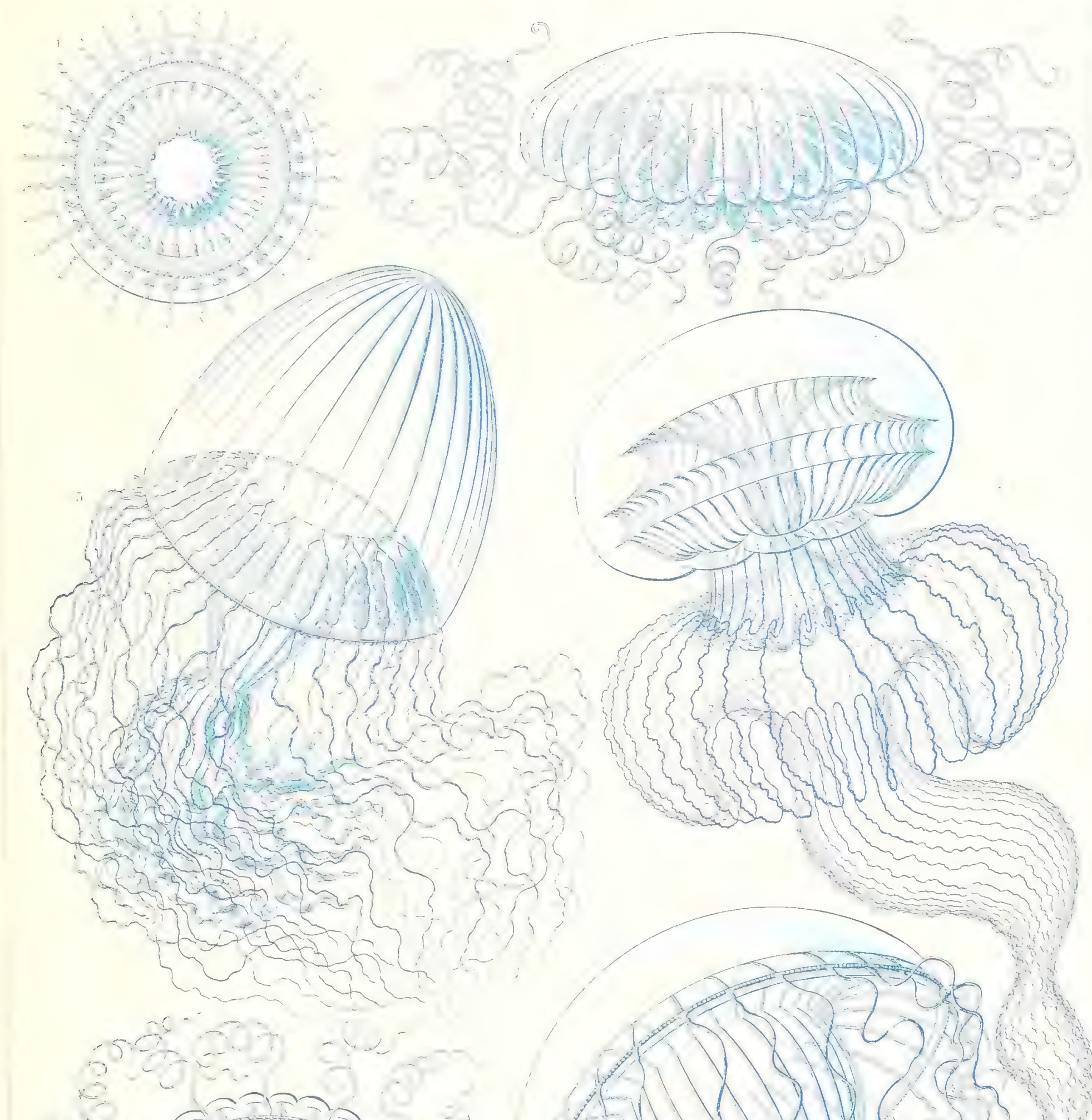

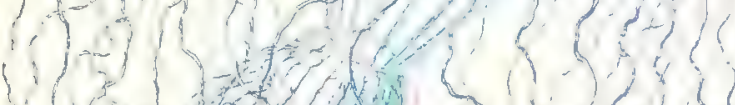

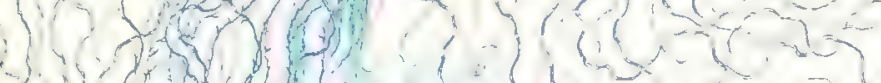

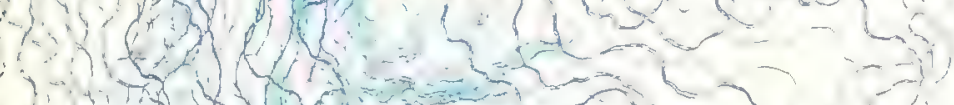

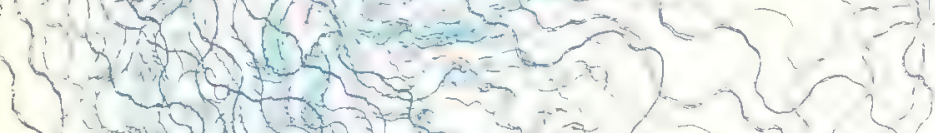

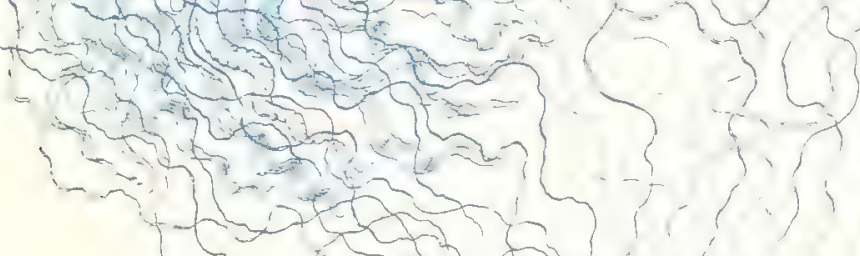

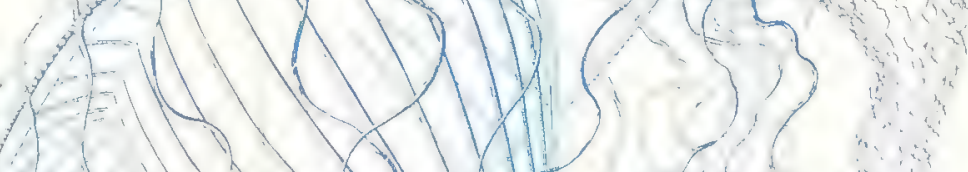
50 (n)

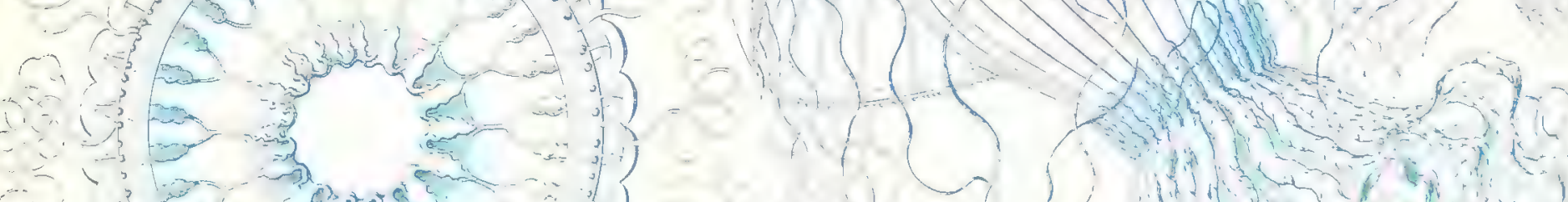

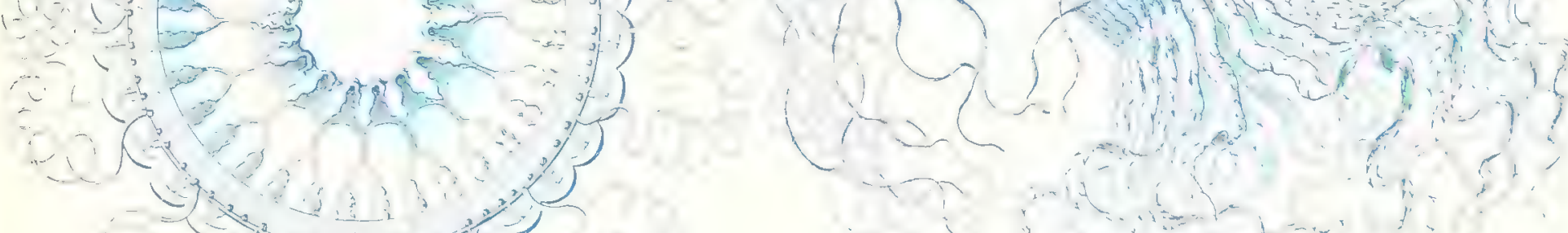
enceros

Leptomedusae. - Siraltentquallent. 



\section{Siphonophorae. 5tataniluallit.}

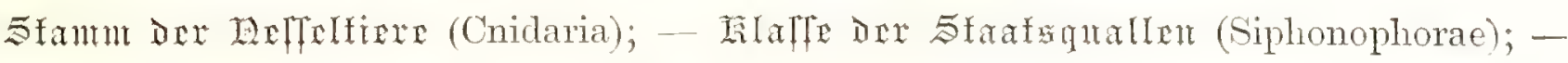

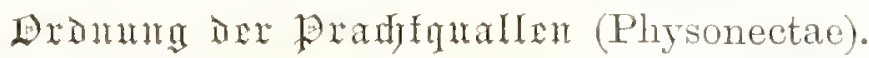

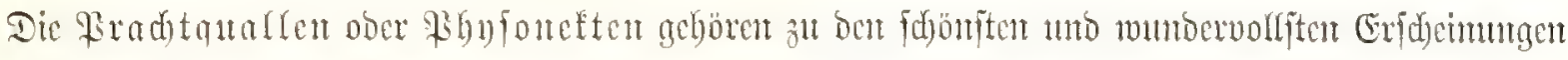

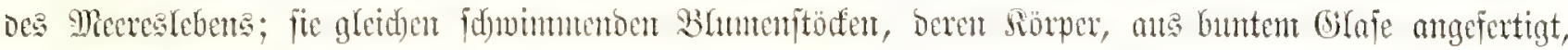

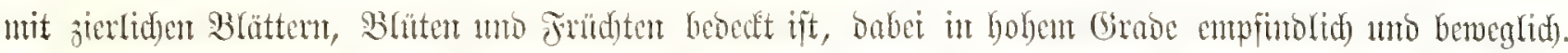

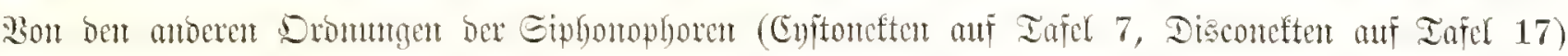

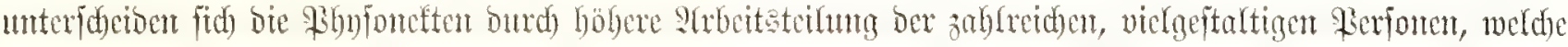

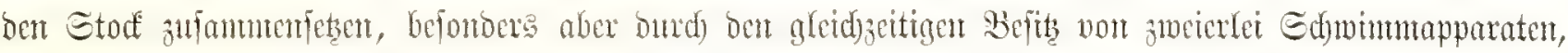

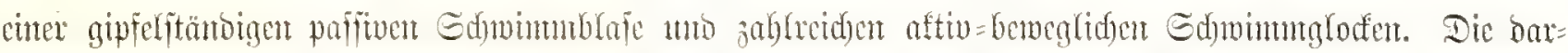

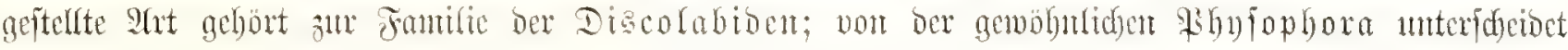

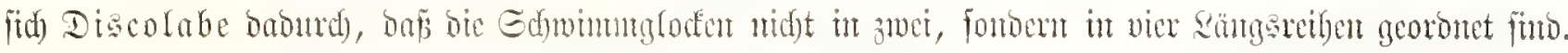

Fig. 1 -5. Discolabe quadrigata (Heeckel).

Dieje prad)tuolle Eiphonophore ift in Fig. 1 vollftändoig bargeftellt, wic fie in Desenther 1881 im Snoifaten Dicant gefangen uno in Belfigenma nad) bent sebon gejeidnet 1 murbe (in boppelter

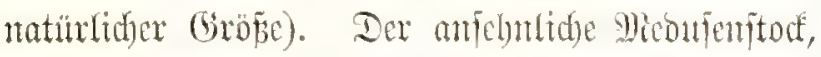
ber aus mebreren taufento. Cinzeltieren, mednfen= artigen Perjonen, zulammengefebt ijt, gleicht einent bInnengeidumüten Iafelanfiabs ober cinem bunten

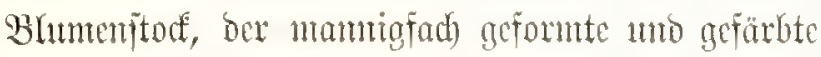
Blätter, Bhütent unt Früdyte trägt. Der folmin= mento Sibrper bes ganzent Stodes ober Sionme bes

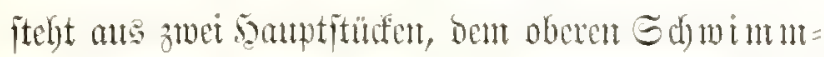

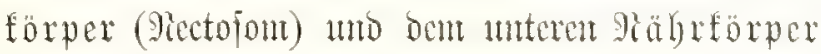
(Siphofom).

Der Sd) winm fürper (Nectosoma) trägt oben an ber Epitse des jentralen Etanmes (obcr

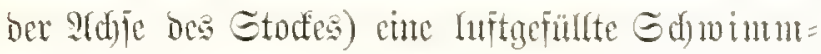
blafe (Pnenmatophora), einten bubroftatifuen

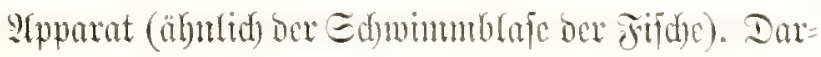
unter folgt eime vierfeitig=pmrantionfe Edywimmiäule,

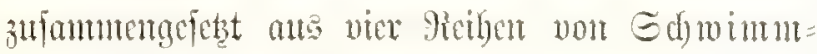
gloden (Nectophora); bas funo Miednen bhe
Magen uno Minto, bie blop be Slufgabe haben, Durch ifyre regelutäpigent Bufanmenziefuntgent bent ganzen Stodf fduminment fortahewegen. Sine einzelne Edhwinmglodfe, won ber bxeiten Seite gefehen (ntit ifren vier gemundenen Ernährungafanäten), ijt in Jitg. 3 bargeftellt; - Fin. 2 zeigh bie $29 n=$

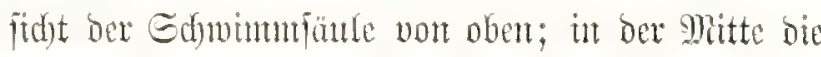
fideitelftänbige Sonwinmblafe, untgeben von ben vier Fieiben ber freuzftänbigen Edjwinnmgloffen.

Der Piäbreärpex (Siphosoma) begimnt bei biejer Ifrt mit eunent breiten Srantze von fajlantgenfömuigent Salponen ober Tajtem (Iaftpolnpent),

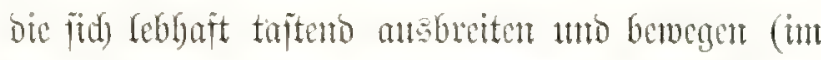
zeben foür rojemot gefürbt); aus ber Bajte jedes Iafters erbebt fidf cin Langer, febr beweglidyer

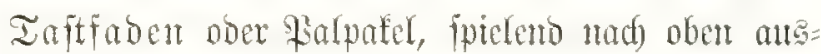
scitrect. Lutter bem Edyutze ber Iafterfrome fitist jutäd)f̆ cin Siranz von tranbenförmingen Siörpen,

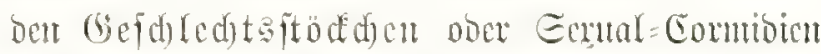
(Gonodendra). Gebe Tranbe beftelst ans cimem

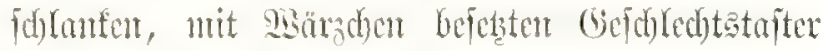
(Gonopalpon), aus eince oberen meibliden Tratbe

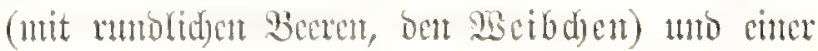




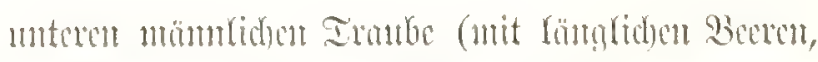

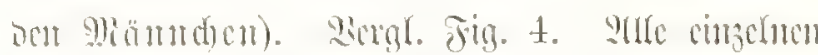

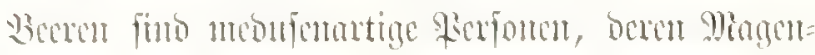

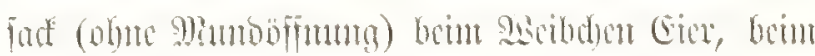

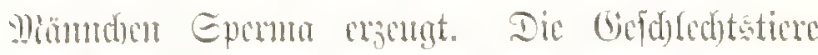

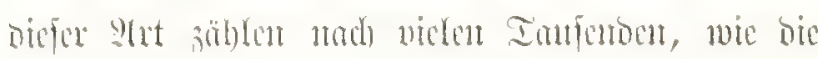

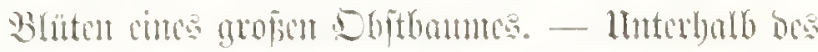

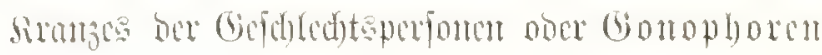

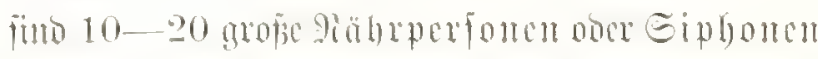
fidsthar (and) "Gangroburen" oder "Truppohpen",

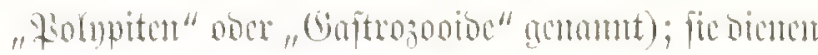

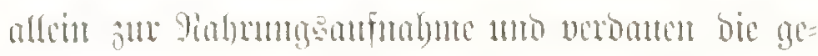

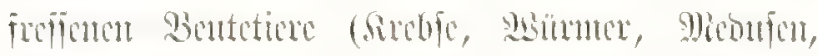

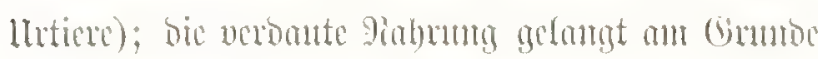
ber Eiphonten in bic bohte gebre bes gentimfanten

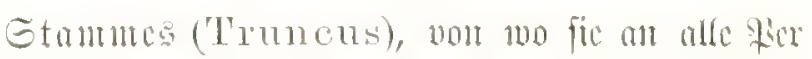

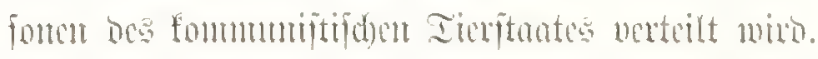
Dir Giphonen finto gelle gefürbt, fohr bemeglide),

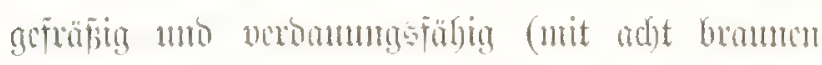

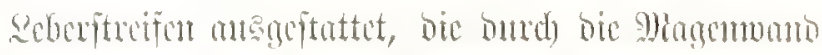

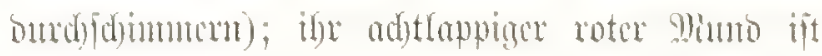

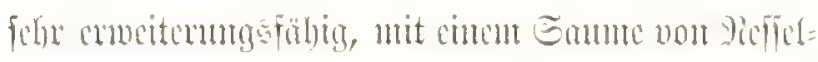

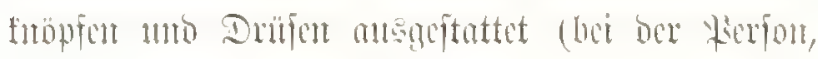

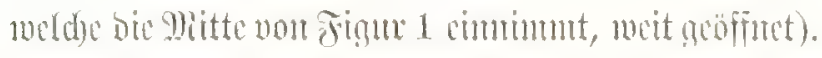

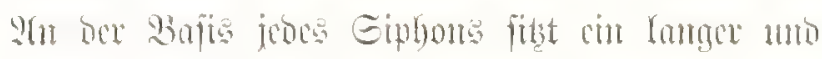
itarfer Fongfabout ober Ientafed, befest mit cimer

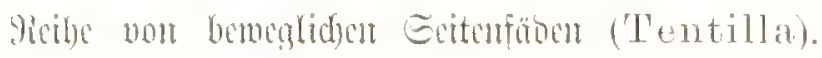

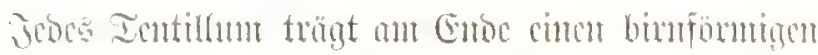

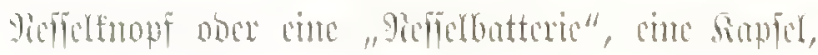

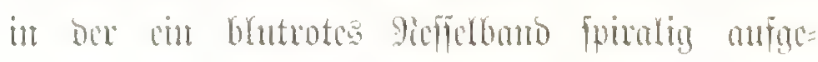

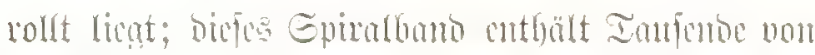

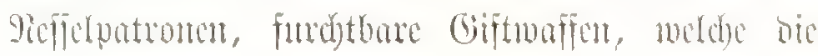

Soutetiere töten. Das Eptel ber Kangen Ientafelu

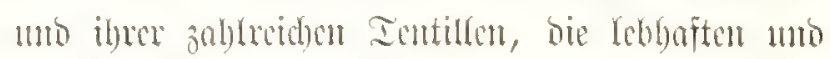

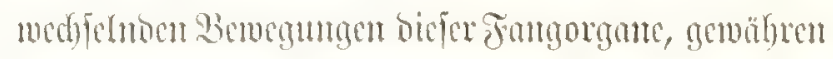

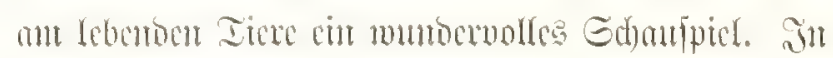
Titg. 1 i it ber Ientatelfufd) fpiralig aufgerollt und

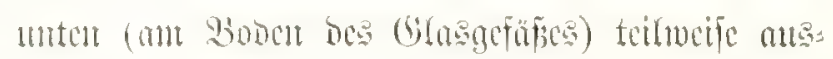

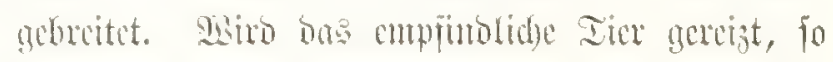

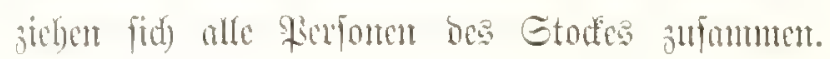

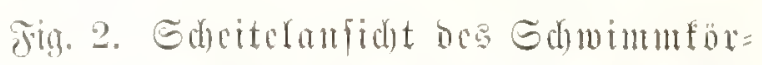

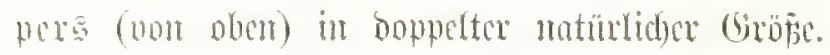
Die fresumbe Edmummelafe (Wimmutophore) in

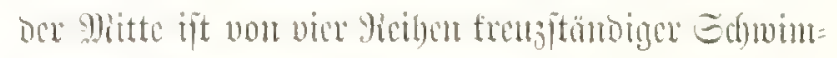

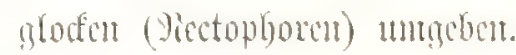

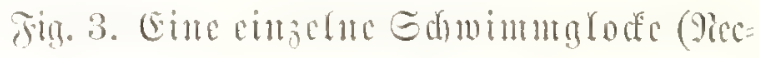
tophore), von ber breiten Geite griphen, fünfmal ver=

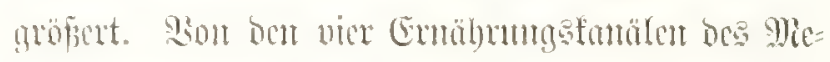

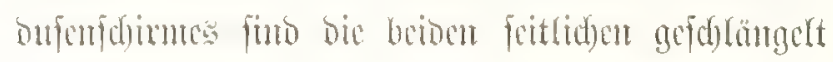
uno vich lämence als bie betben mittleren.

Sig. $t$ mo 5. Der Stanm ('T'uncus),

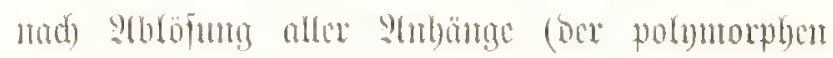

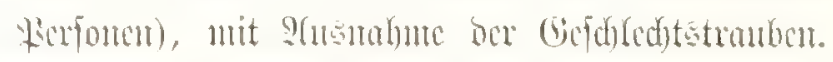

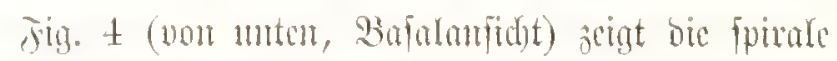

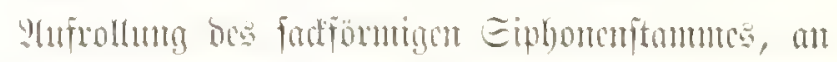

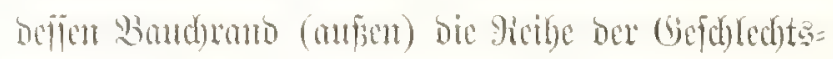

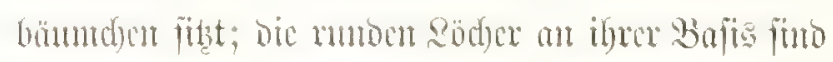
Die Strfatiftelen ber abgeloften Eiphonen. Fig. 5

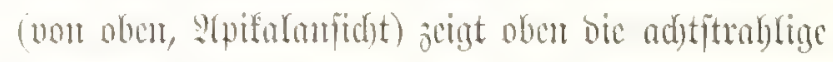

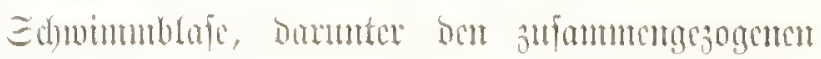
Etomm des Edjummuforpers. Dic viereffigen

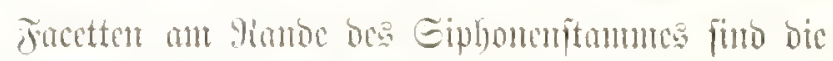

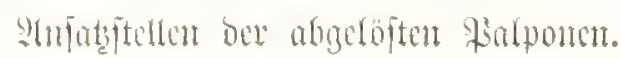




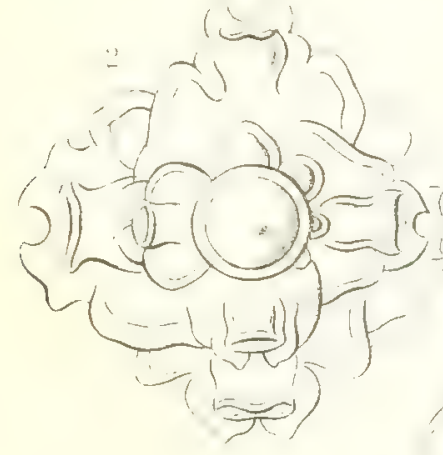

1)
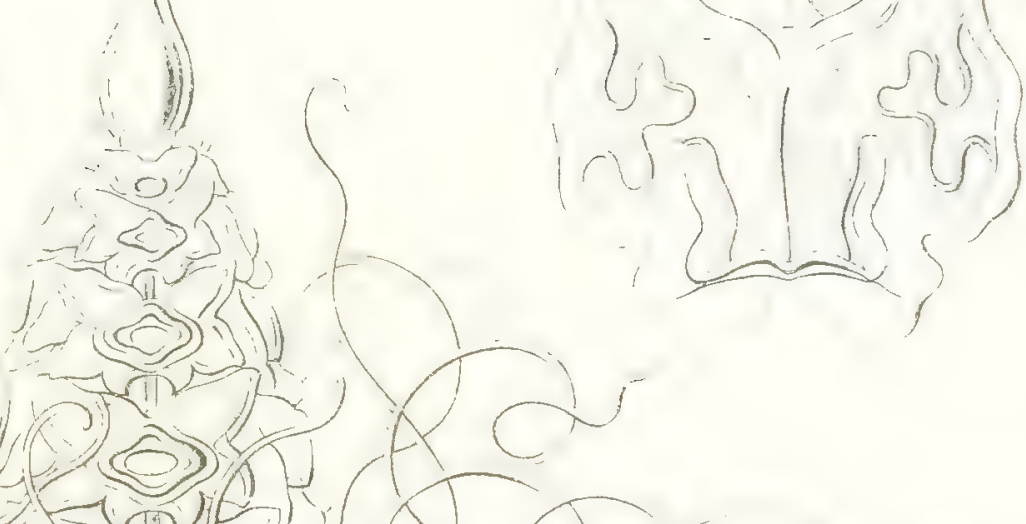

$=4$

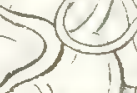

)

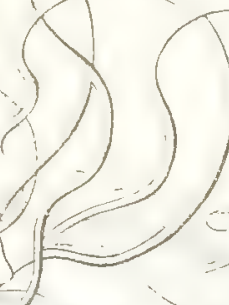

(1)
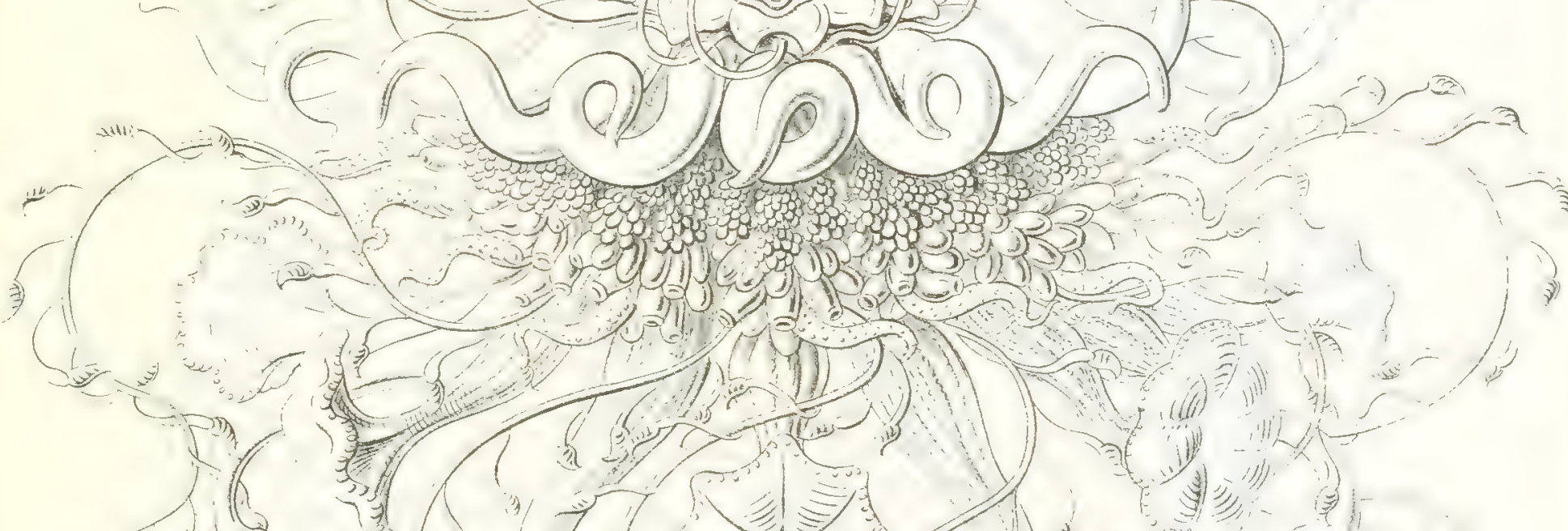

(19.3.

$(3+2)$ (3)

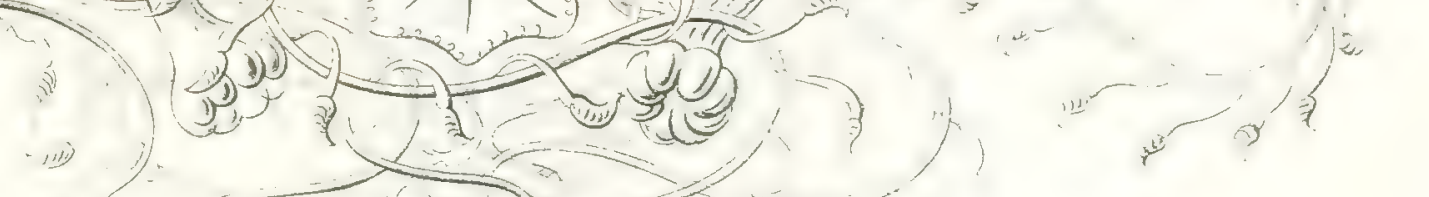

$+40-2$

nos

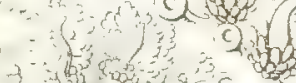

(os

in 13

3y

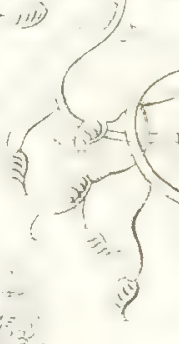

$+2$
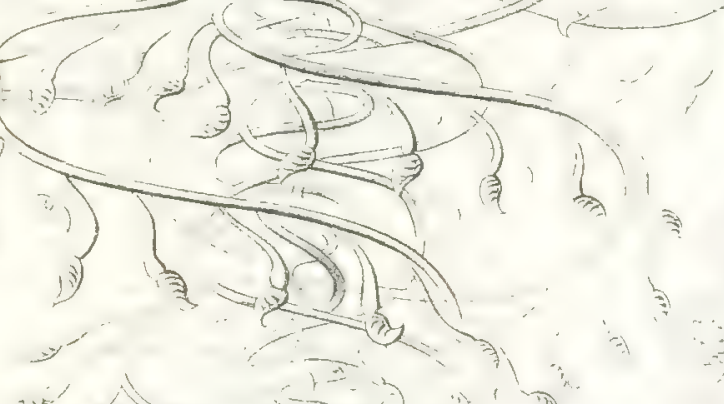

(1)
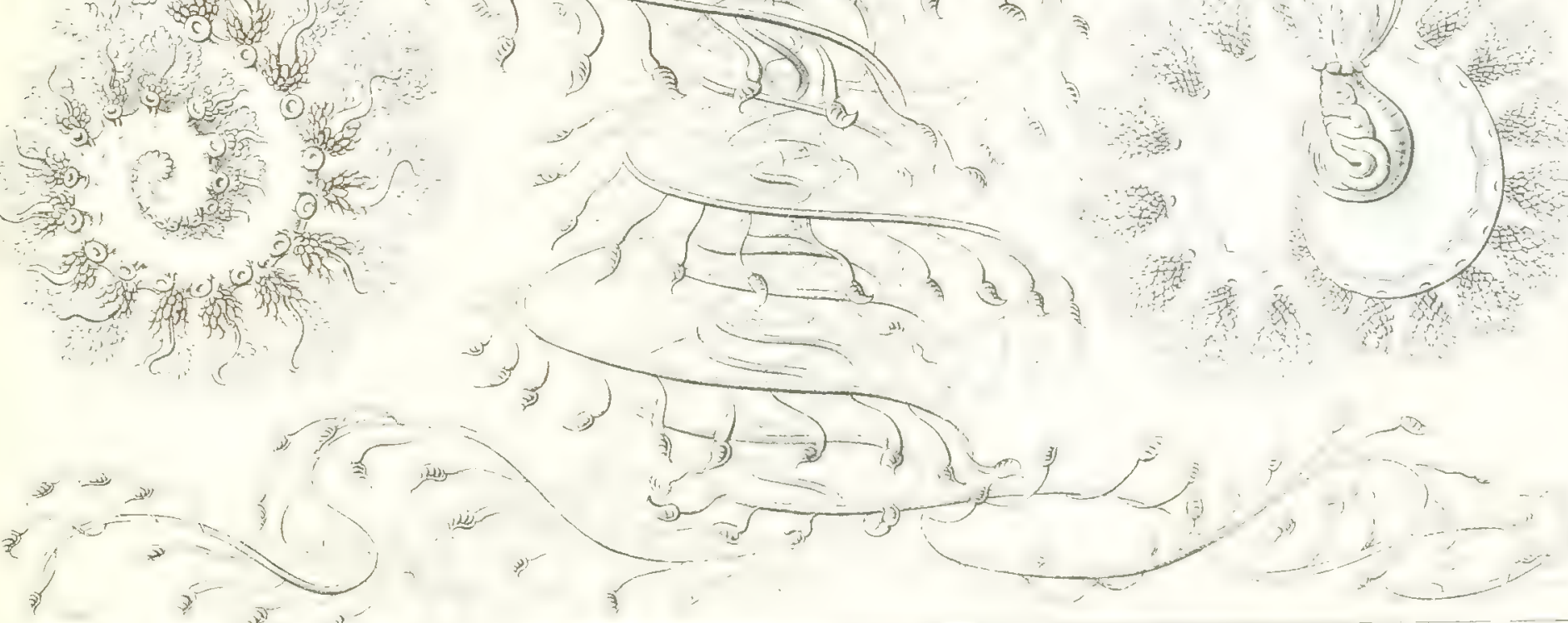

Siphonophorae. - Sfatafsitallert. 



\section{Peromedusae. Talithenmallum.}

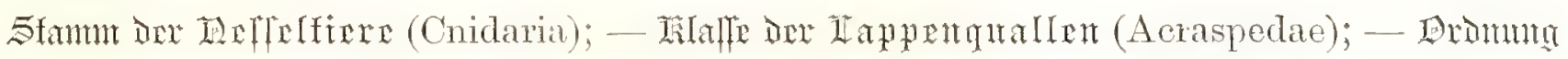

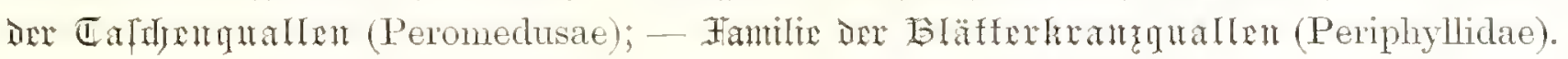

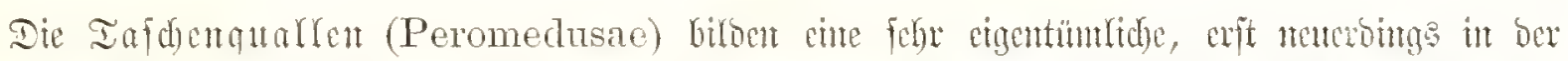

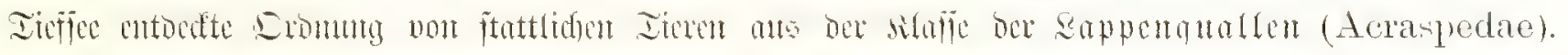

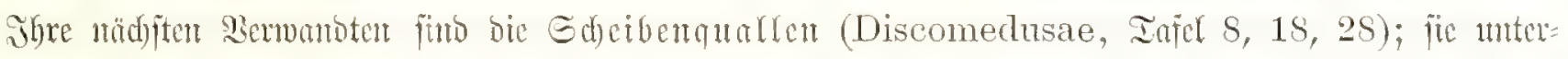

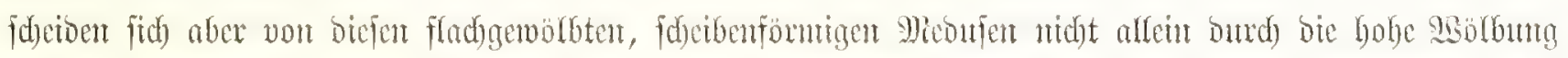

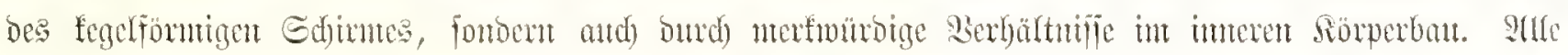

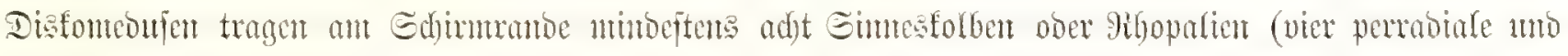

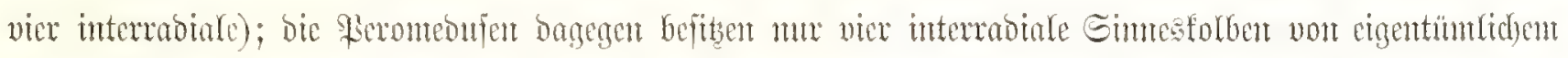

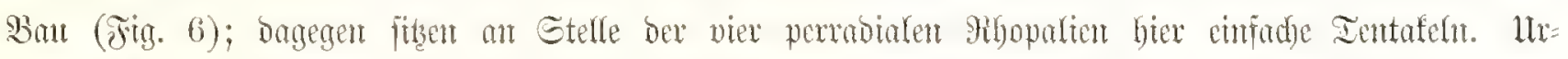

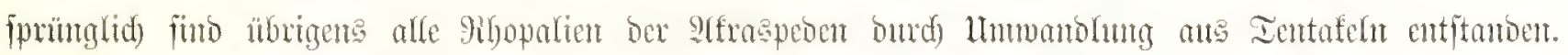

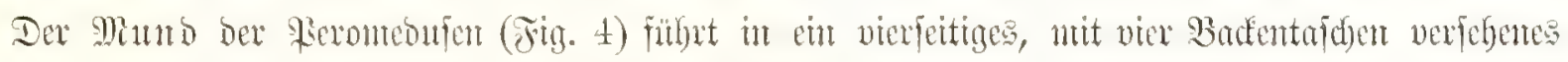

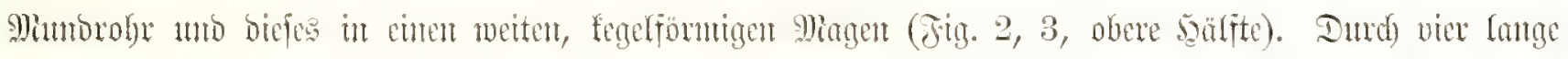

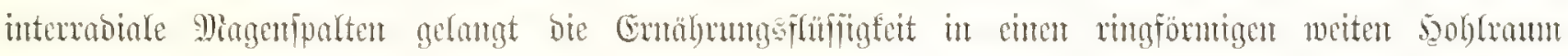

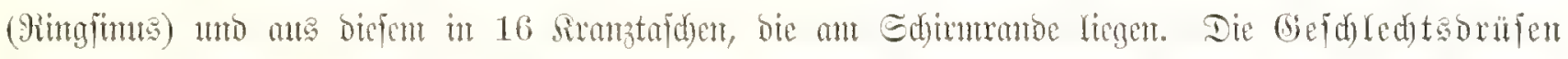

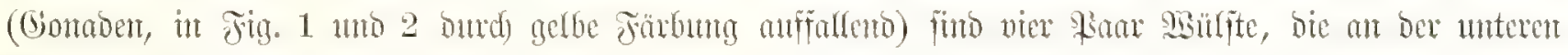

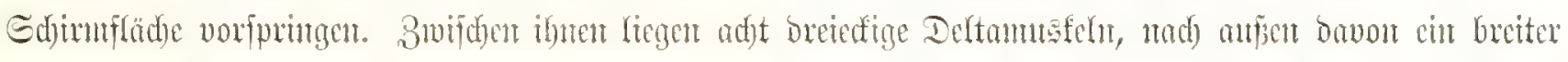

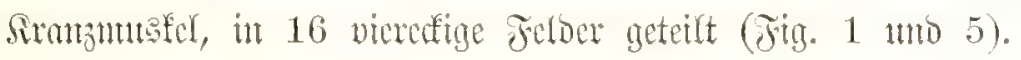

\section{Fig. 1-2. Periphylla mirabilis. (Haeckel).}

Cine grofse Ferommonfe, an bex Ditfiute von Penjectano in 6600 Fur Tiefe von ber Ehallenger= Expedition gefangent (Sd)irn $16 \mathrm{~cm}$ hod), $12 \mathrm{~cm}$ breit).

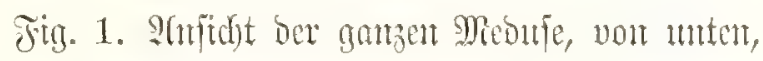
in orei Biertel natiurfider Gröpe. Die Mitte Der

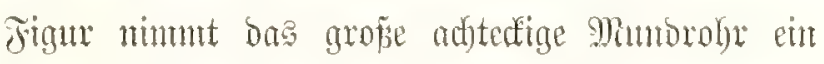
(Jig. 4). Dex mulftige Munoranto i etr etwas cin=

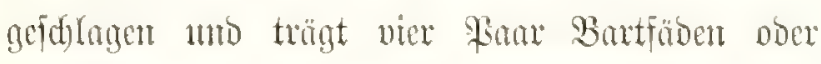
Draljifantente. Die Dunfle, trid)terförntige 5äble,

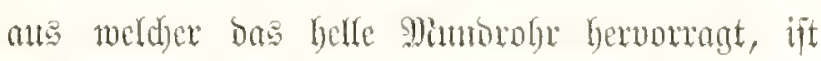
die ticfe Edyinurgoble, ifre Innterfläd)e (Subumbrella) ift rotfiducolett gefürot und grofitentcils

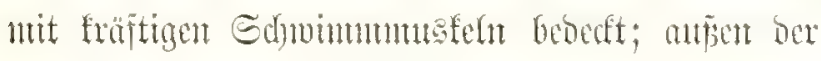
breite Sirmzun

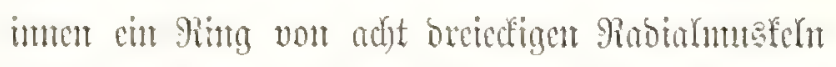

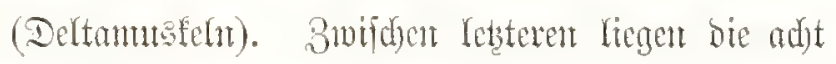

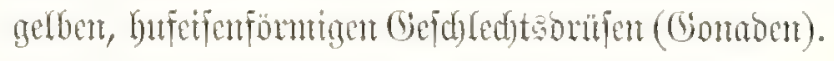

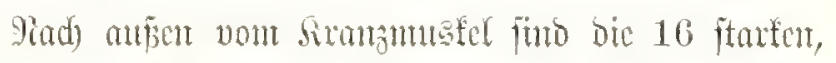

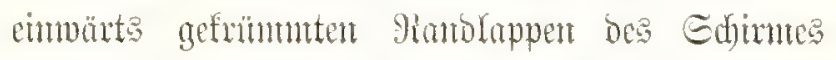

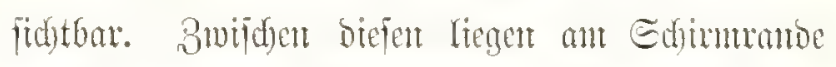
vier intemabiale Eimmesforben (biagonal) unb 12 ftarfe Fangfäben oder Ientafefn (vicx perrabiale und acjt abrabiale).

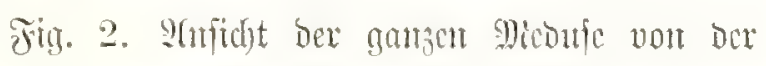
Scite. Der hole, fegelfoumige Edyint ift burd ente

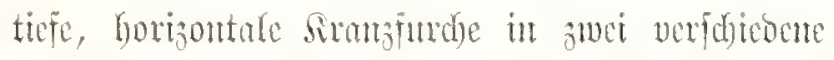

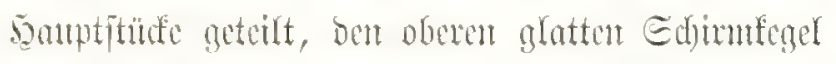
und Den interes, in 16 Fetocr getcilten Sdjim frang. Durch bie sisanto ber menteren sälfte bes

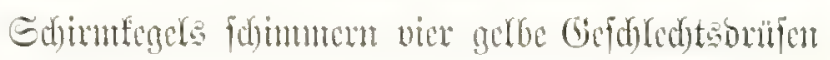




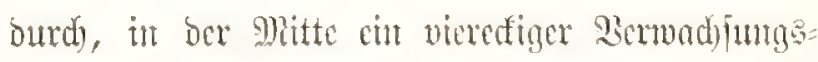
fnoten (Cathamma). Dur Edirntronts scigt in

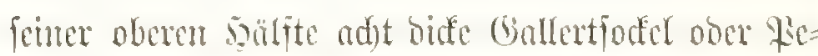
balicn, in bex unteren sölfte 16 fdumälexe Rano. lappen. Bwifisen biefent fitsen in jebent Dunoranten bes Edhinmanos orci ftarte, cimoürts anfgerollte Ientafeln uno in ber slitte zwifden ibuen cin Eimterfolbent.

\section{Jig. 3. Periphylla Peronii (Hacekel).}

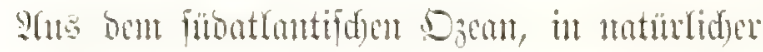

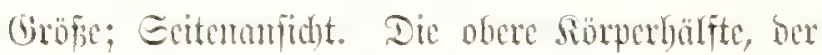

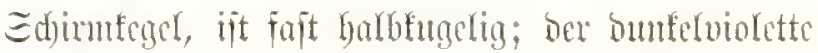
Bentralmagen fdrmmert burdy bic biffe, blänlidbe Gollertmanto bes Edimes burth. Die nutere

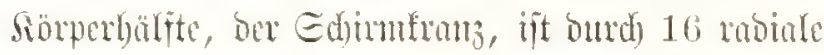
Eimfduntte in ebenfoviele Ranoloppen geteilt. 3wi=

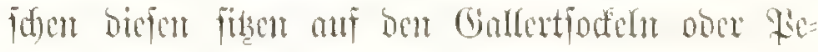
balter 12 ftarte aufgerollte Fanganme (je brei in jebem Duabranten) no vier interabiale Gimes: folben. llutert tritt aus ber Eduimtgoble ber breite, gerblidue, ancit geofinte slumb heruor.

Fig. 4. Periphylla hyacinthina (Steenstrup).

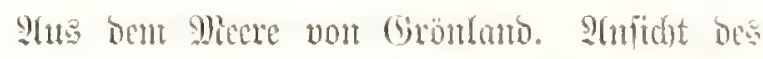

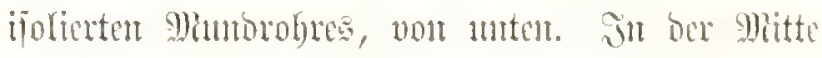

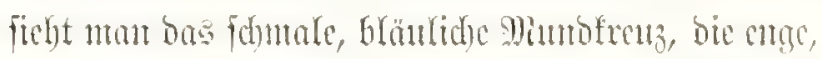
frensfömuge S̈finmug, weldye in ben Mingen fïlyrt.
Yad) aufen vou ben viex pertabialea Gduenteln bes Mantefrenzes legen viex T=förmige Badentajden, getrent burd) vict interrabiale gelbe Miunofäulen.

\section{Fin. 5-7. Periphylla mirabilis (Haeckel).}

Fin. 5. Sueridurtt ourd bie slitte des aior= pers, mit fdentatifder Projeftion ber verifhiedenen Drgane. Sn ber Mitte bas Mimbfrenz, zunifuen beffen vice Edifufch adjt Gaftralfifamente fidtbar fund (untre Diagententafeln). Dam folgt ein Rrans

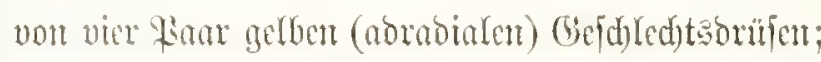

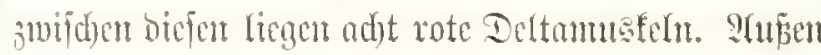
ift cin Silans won 16 gelben Miagentafden und von 16 branen 年ontien in Duexfdutt fidtbar.

Fig. 6. Ein cindurer Simtestolben (Rhopalium), ftart vergröpert. Der obere, fdutülere Ieil bicps Gimmeänpers enthält un ber söhle cince Detichuppe cin fugeliges Gebörbläsdyen, bas mit Suiftallen gefullt it. 8 beion Geiter bes=

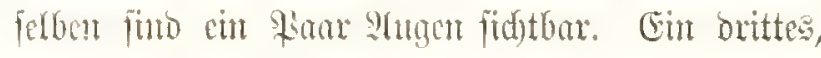
untarase Suge (nit gelbex Einfe, untgeben von cuen violetten Sifgnentrung) licgt in breiteren un= teren Ieil des gihopalim, ber von cintent fragen= fönnigen branmen Signnentpolfter mit zwei biffen Edjenfen mufafit wiro.

Fig. 7. Duterdantt burdh ben Mugked einer

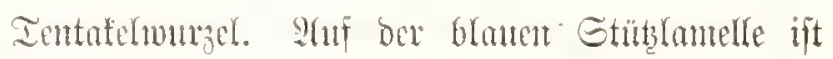
der sisurgetum sfel in jierlid)e Fulten gelegt. 

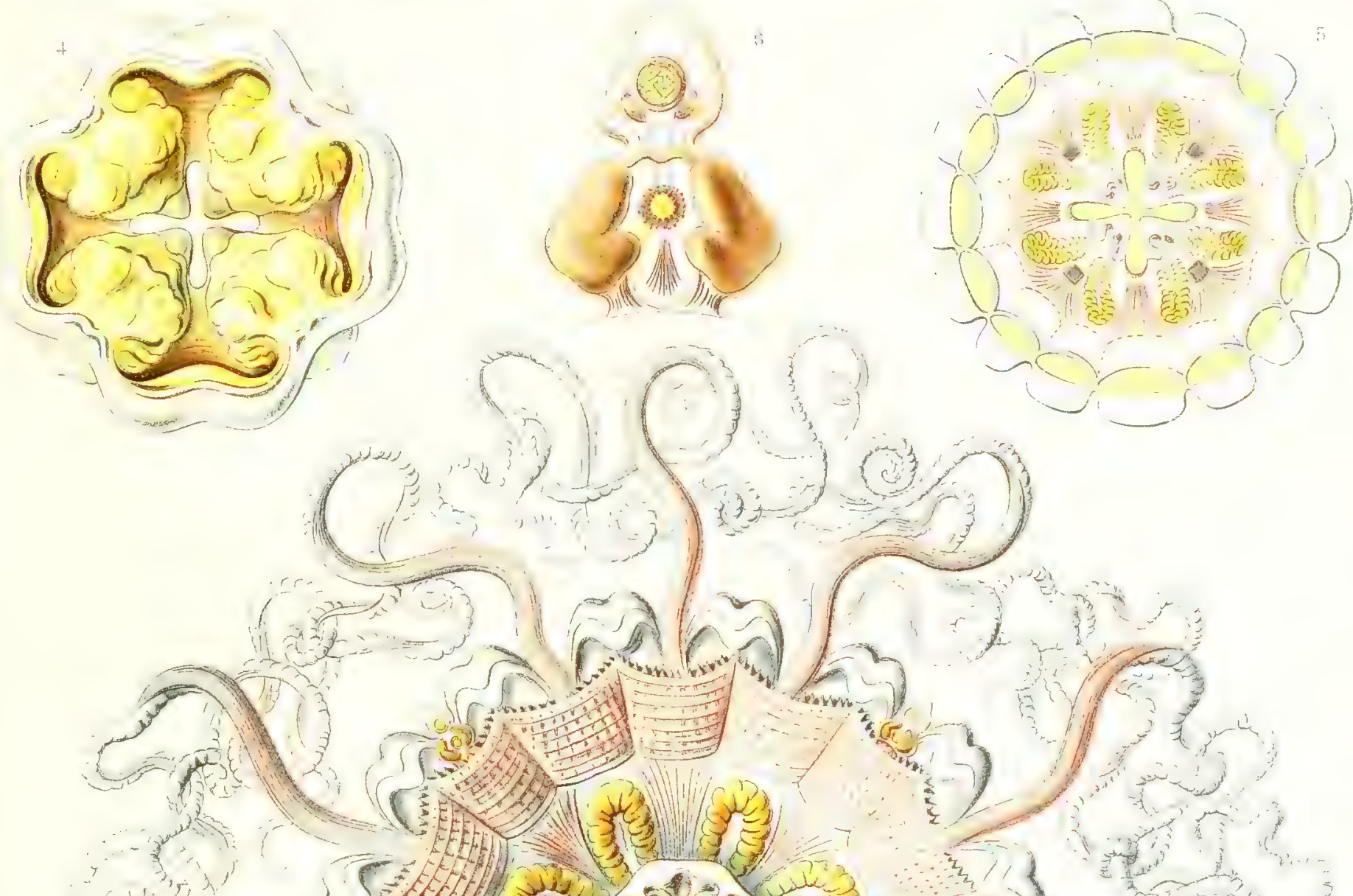

-

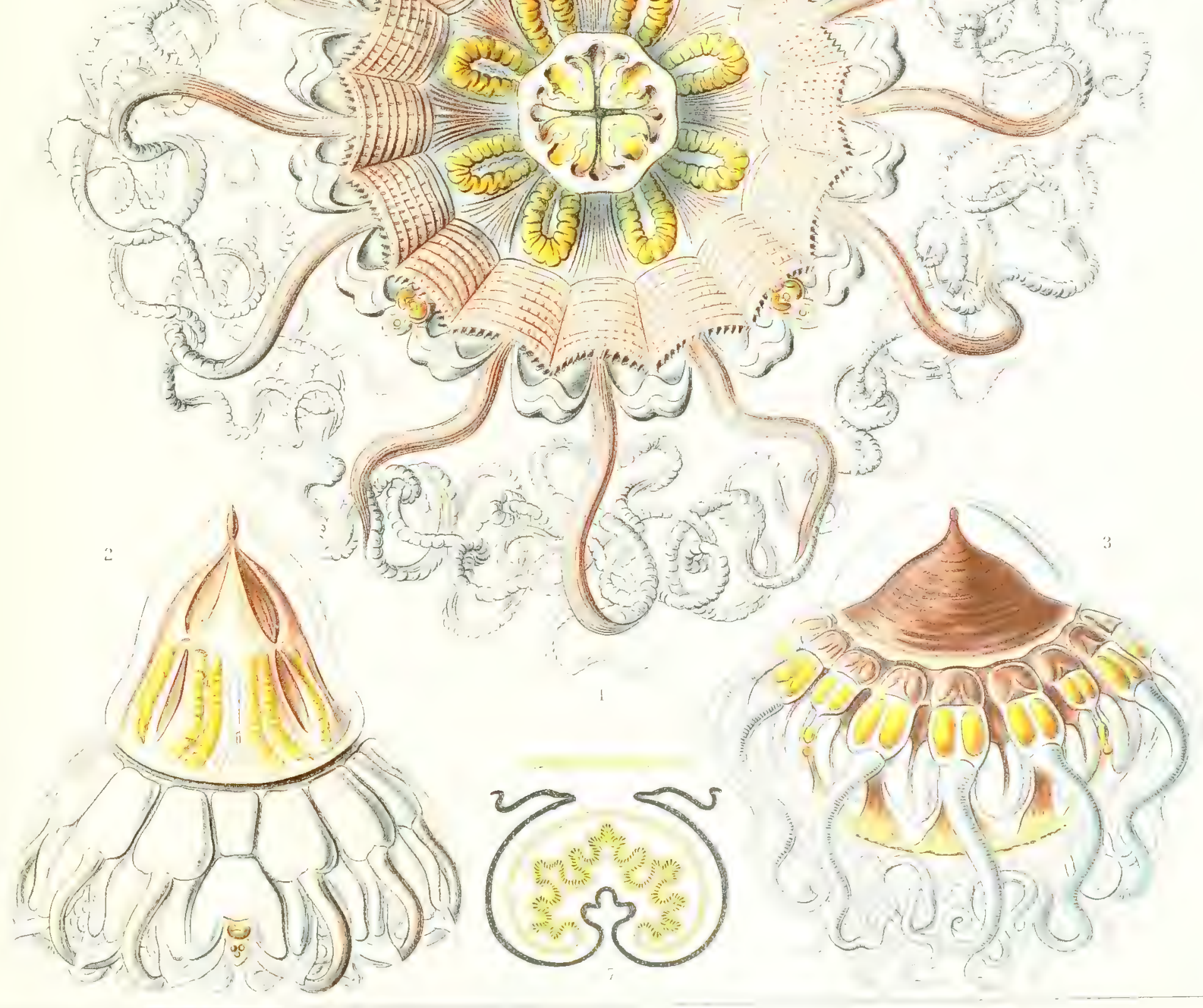

Peromedusae. बaldientritallent. 



\section{Gorgonida. Dimmenthuratlen.}

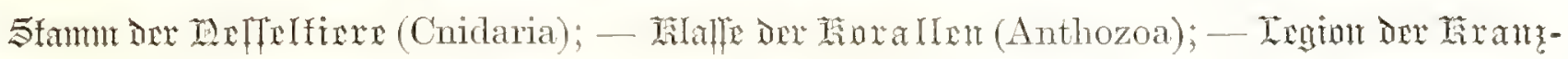

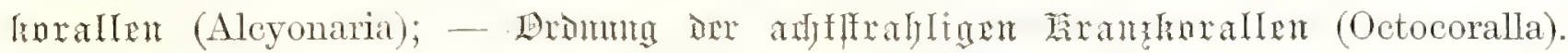

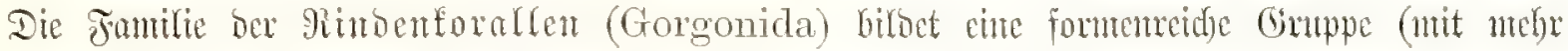

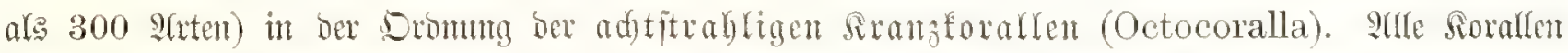

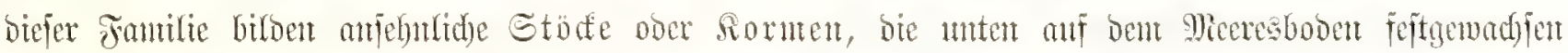

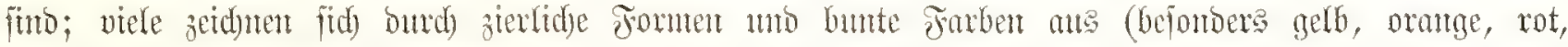

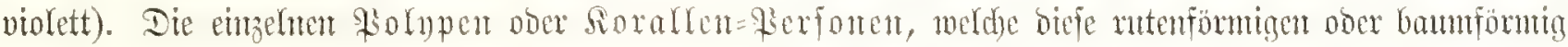

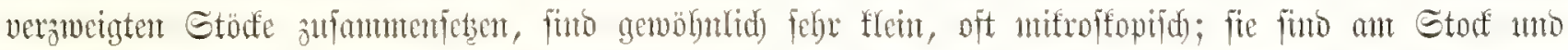

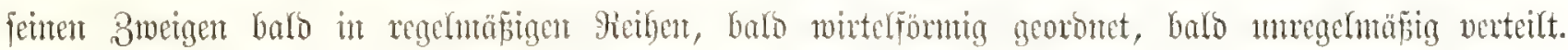

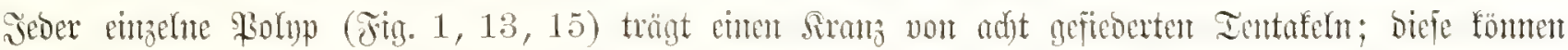

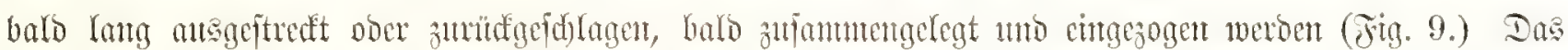

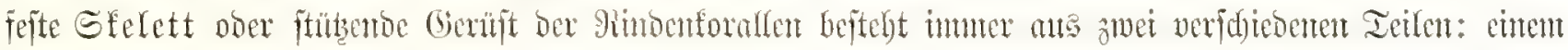

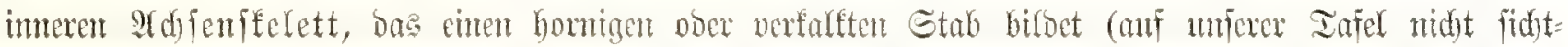

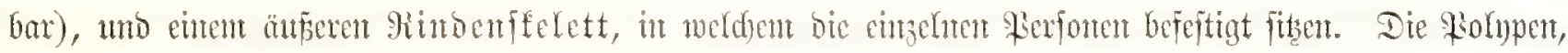

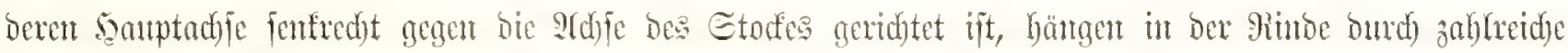

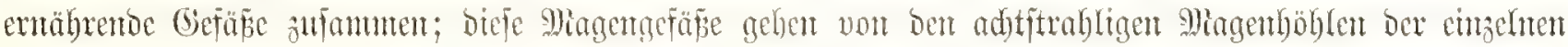

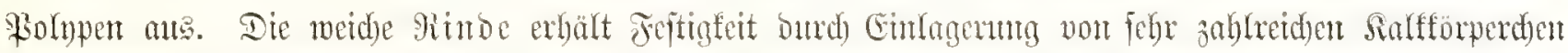

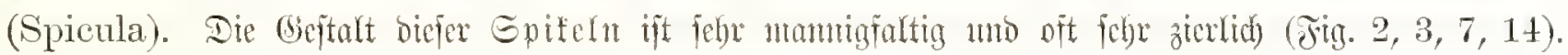

Fitg. 1. Gorgonia verrucosa (Pallas).

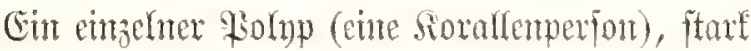
vergrö̌̃ert, mit angeftrecten adyt Fomgamen; von biejen gefiederten Tentafeln furo vier nad) obert,

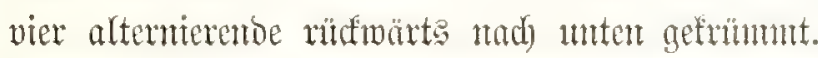
Sm burdjictutigen Reib ift imtren ber flafdenförntige

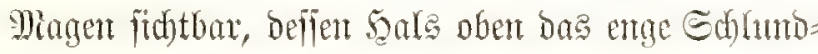
wohn bifoet. Unten ift die Bafis bes bhumenfömnigen Solupen von einent nitedrigen feldförmigen Fortfats

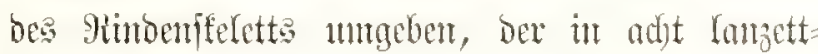
förmige, bornige Blätter gejpaltent ift.

\section{Fig. 2. Platycaulos Danielsseni (Perceval Wright).}

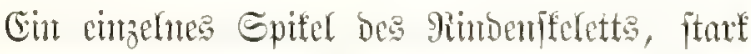

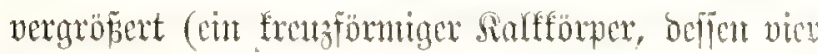
Edjenfel ein âthrenbifidel tragent).

\section{Jig. 3. Euplexamra parciclados (Perceval Wright).}

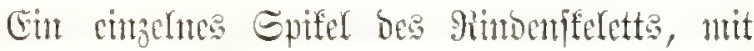

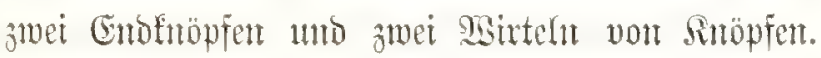

Jitg. t. Primnoella biserialis (Perceral Wright).

3wet sistel von dem fangen, rutenförmigen

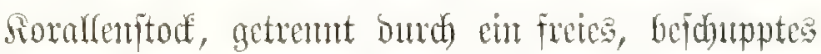

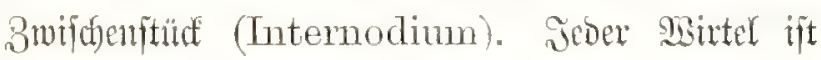

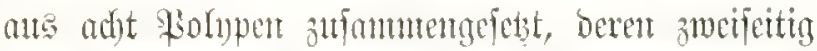

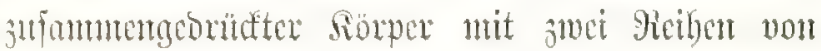
verfalftent Edhutpon gepanjert ijt.

Jig. 5. Primnoella Murrayi (Percecal Wright).

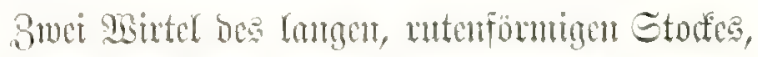

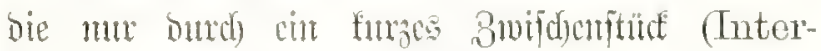
nodium) getrent finto. Soll jebent sisited ftelen 


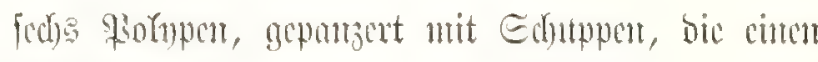
Dorn tragut.

\section{Jiu. 6. Stemella spinosa (Pereral Tright).}

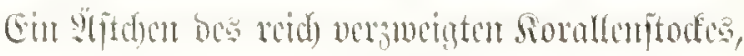

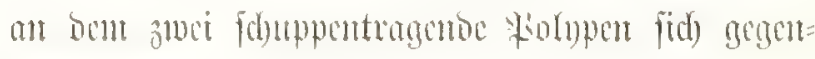
itberitelour.

\section{Jign. 万. Juncella juncea (Pullas).}

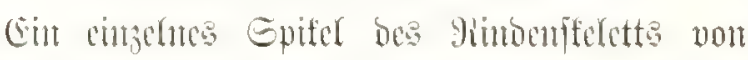
ber Form cinte biden falfitubes, ber an beiben Enocn cinct bornigen 胃iorgantern trägt.

\section{Fig. S. Calyptrophora japonica (Graly).}

Drei Ssintel vou ben lamgat, mutenförnigen

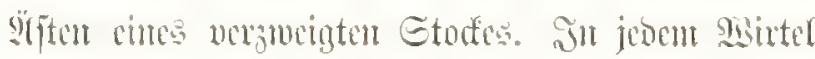
ftehen bre, wer ober fünf Folupen, gededt burd)

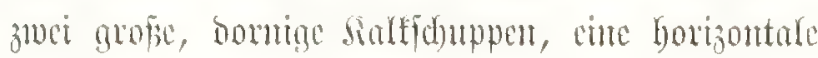
and cine vertifule. Der Sinlus, ber burde bife

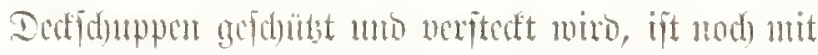
cincut me adst Epifeln gebilocten Deded verfeben.

\section{Fing. 9. (Gorgonia verrucosa (Palles).}

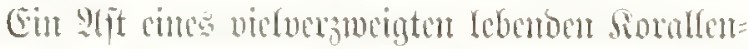

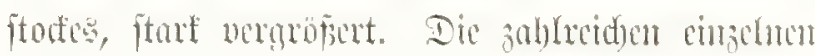
Wolupen, oocr bic Sirjomen bes sormus, futo in

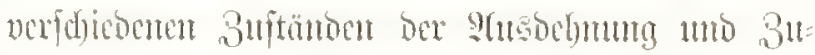

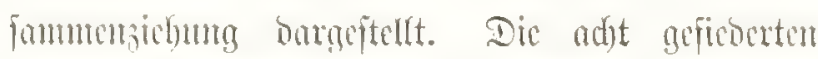

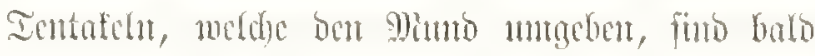

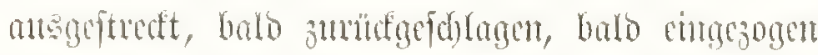
(Farbe neränocrlid): weifs, getb, orange, rot).

\section{Jig. 10. Leanthogorgia longiflora}

$$
\text { (I'erceval Wright). }
$$

Cin arft bes verzucigten forallentodes, ock mit Dormen beoneft ift. Dev blunenformige Folup

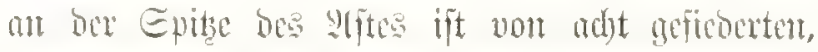

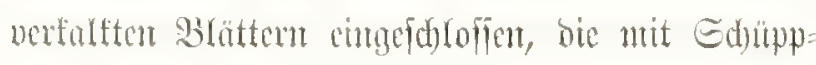
d)en benedef fimo.

\section{Jịg. 11. Primnoella Anstralasiae (Gray).}

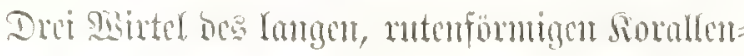

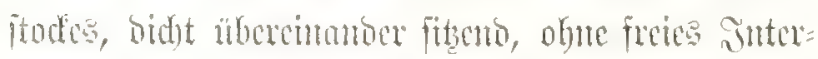

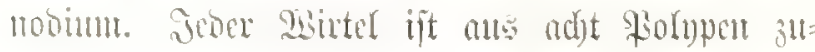

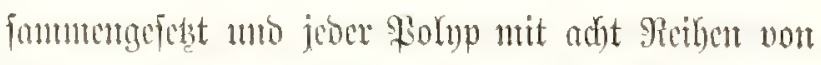

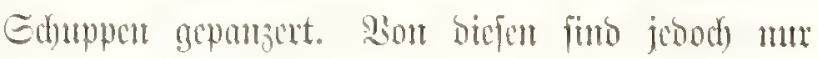

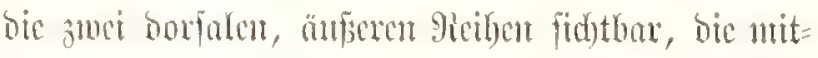
cinamber altemieren. Die jedje ffemeren gieiben liegert barmuter verifert.

\section{Fig. 12. Calypterinus Almani (Terceral Wright).}

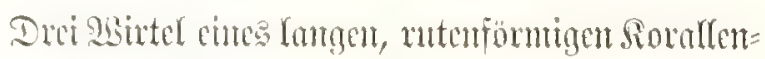
ftocke, getremt butrd) furze Snternobien. In jebem

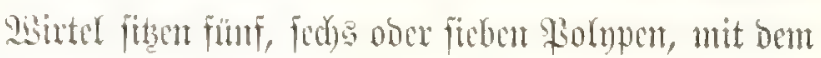

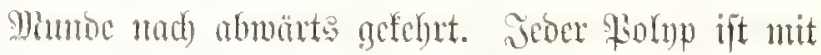

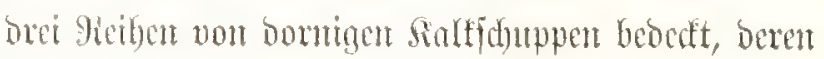
obcrite (bajale) cint horizontares G(t)ubead) bildot.

\section{Jity. 13. Paramuricea spimosa (Kölliker).}

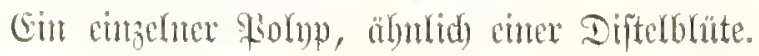
Unter an ber Safte ift ber feldförmige Sïrper wour ener Dontmfrome unneben. Dbon ift bie

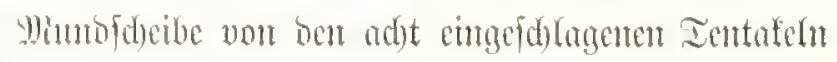
bebalt, bie nit Kogentönmigen Epifern belegt fimb.

\section{Fing. 1t. Juncea barbalensis (Duchassaing).}

Ein cingehes Epifel des gimbenffeletts, von

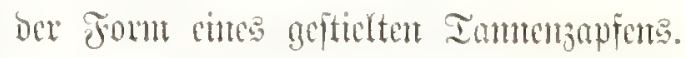

\section{Fig. 15. Anthomuricea argentea (Percecul Wright).}

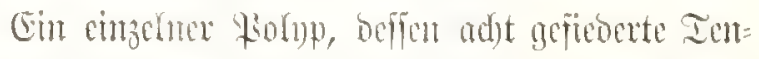

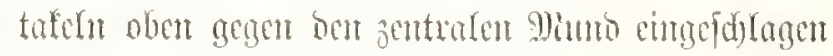

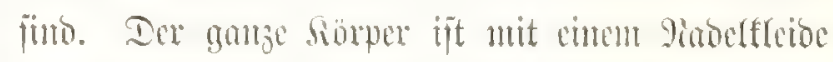

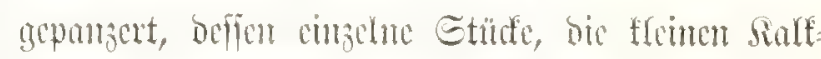
Mabeh ober Epifen, in ad)t aefteroerten Doppelreiben eng ancinantor gelagert finto.

\section{Fig. 16. Calyptrophora Wyvillei} (Perceval Wright).

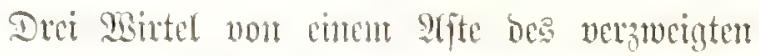

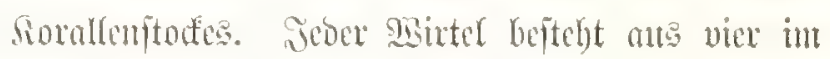

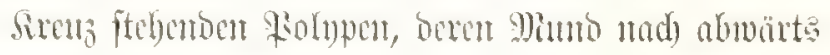

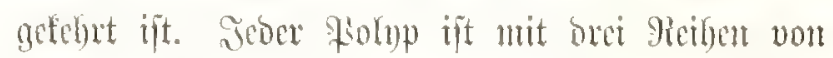
Ed)uppen gepanzert; bie oberiften (bafaren) finto

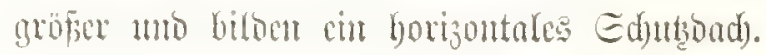




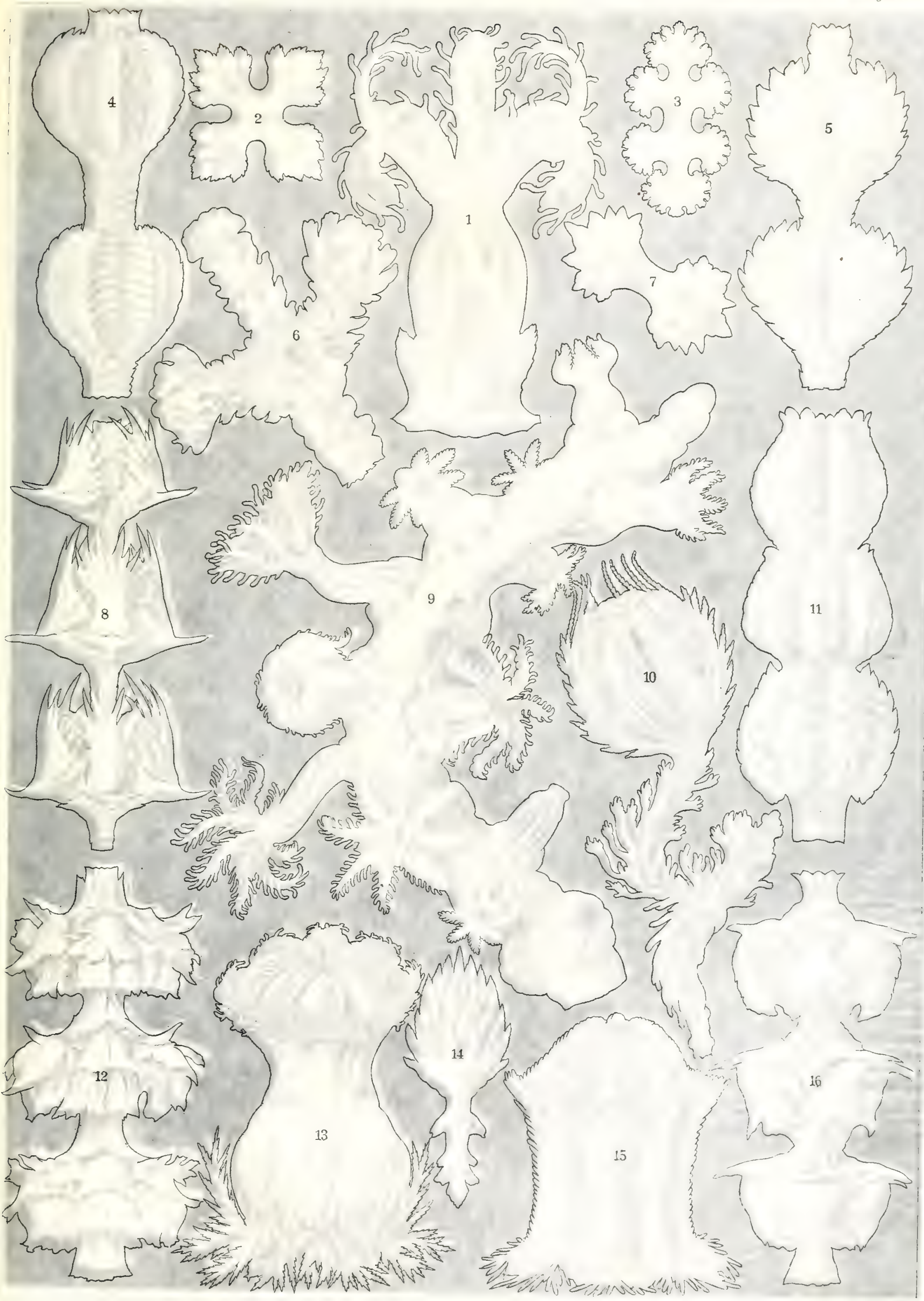




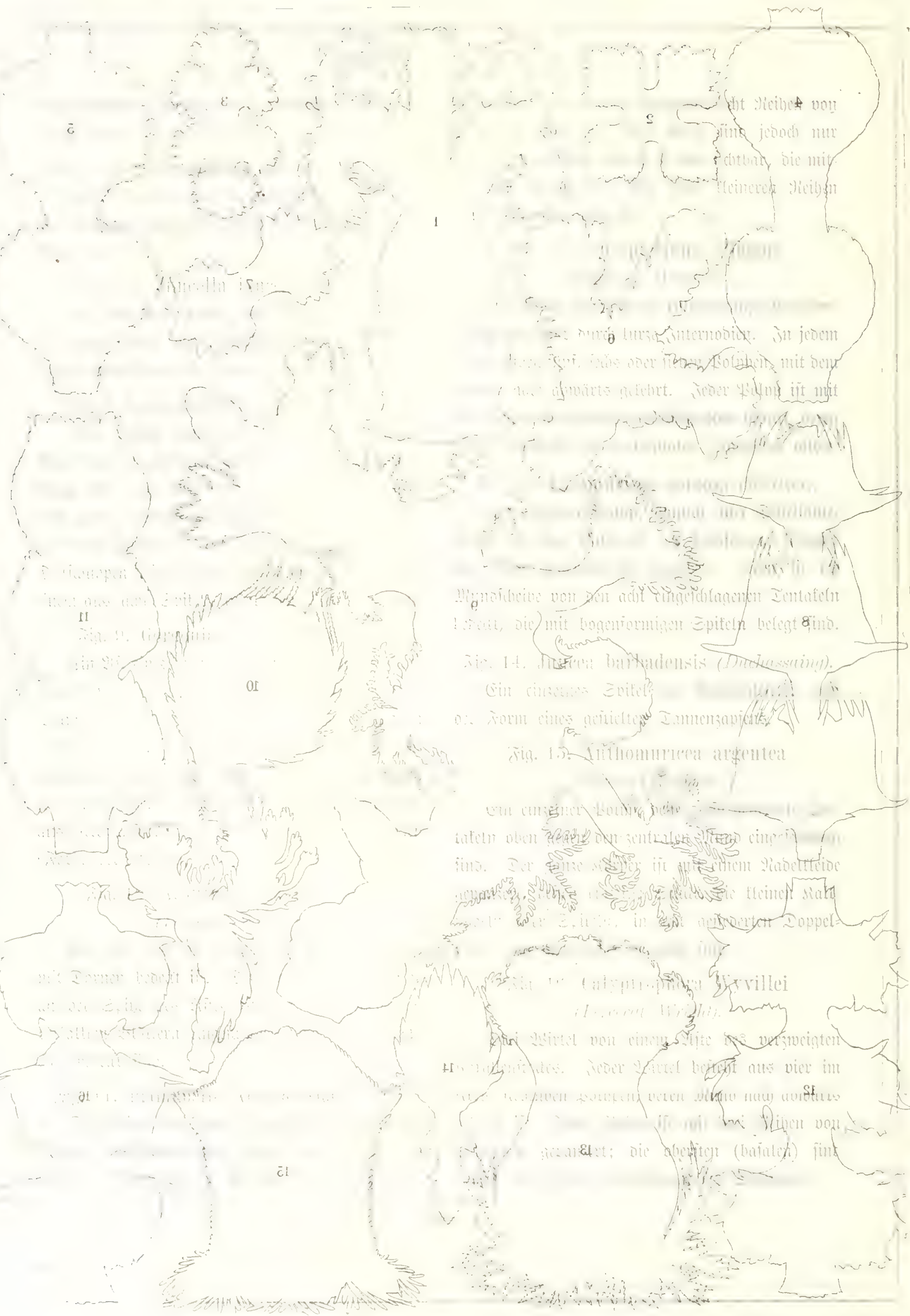





\section{Asteridea. $\mathfrak{g e k l t \mathfrak { u n t }}$}

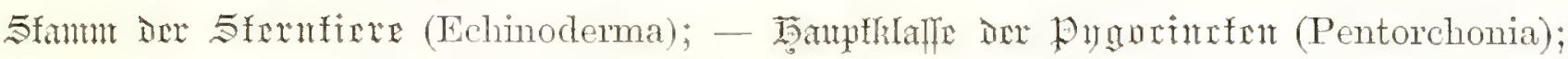

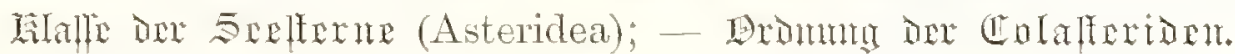

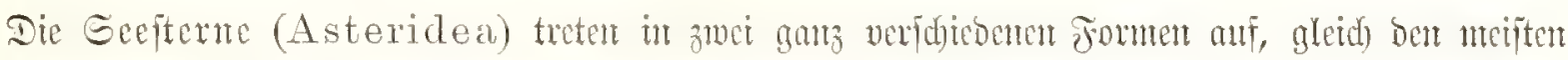
anberen Stemtierent. Das mmeife juntge Iirx, die Stemfarve (Astrolarva, Fig. 2-4) ift jefr

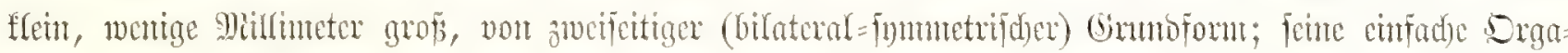

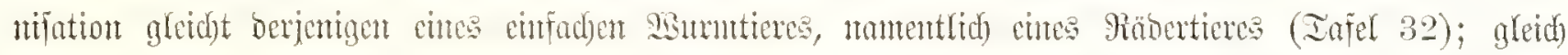

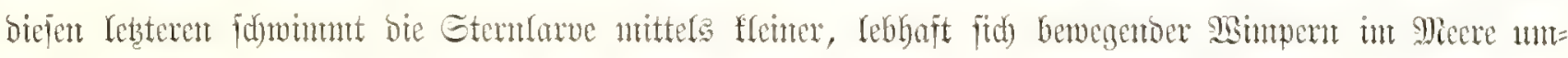

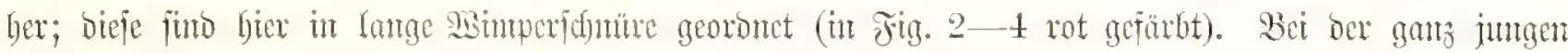

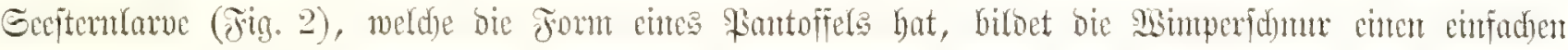

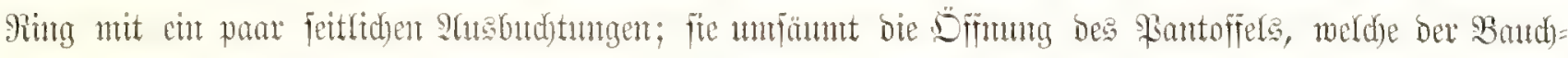

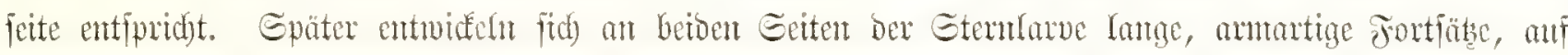

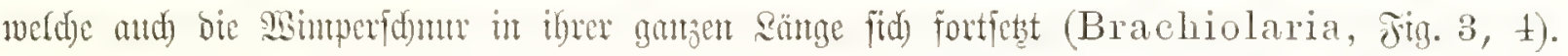

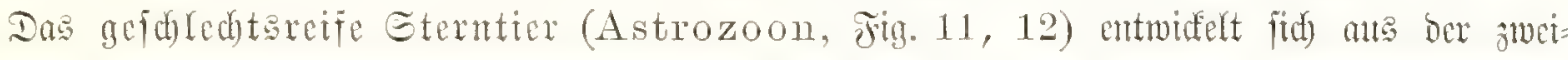

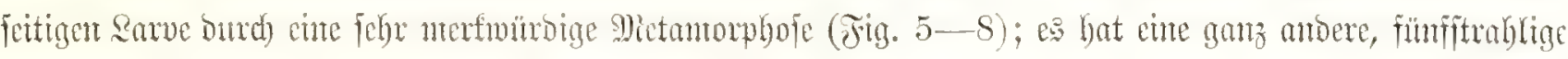

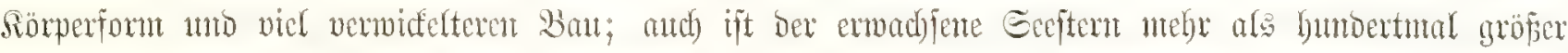

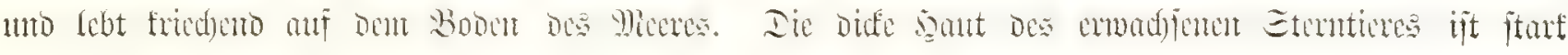

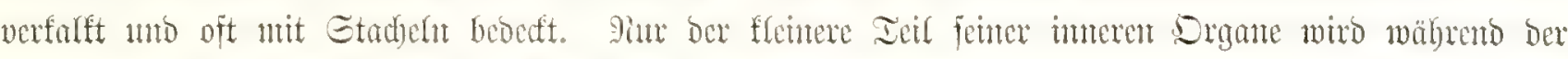

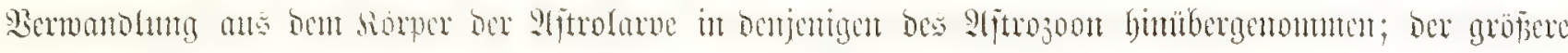

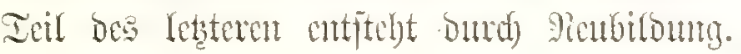

Fig. 1. Asterias rubens (Limé).

Der gewöbultidye rote Eerftern ber curopäifdon

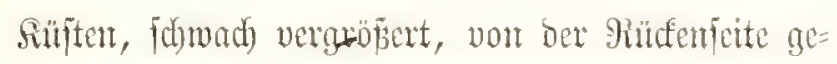
jehent; bas junge Tier ift ntod) stidjt antegewadjent unto

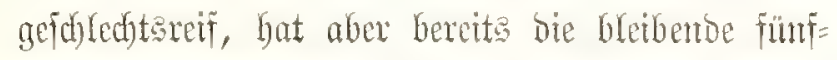

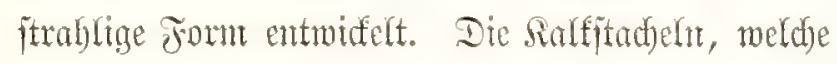

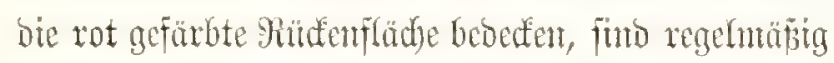

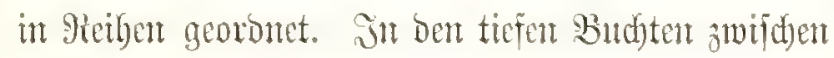

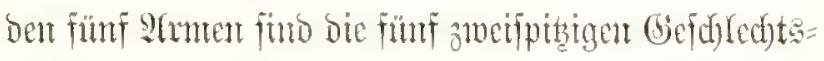

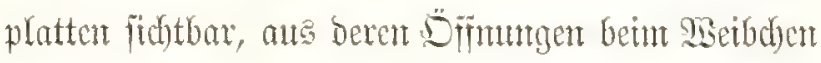

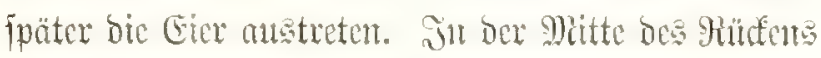

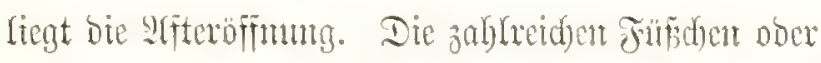

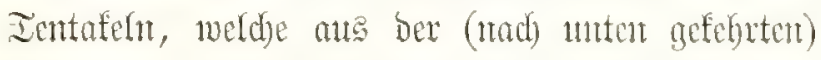

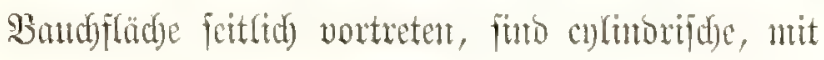

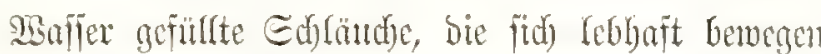

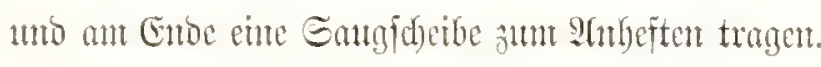

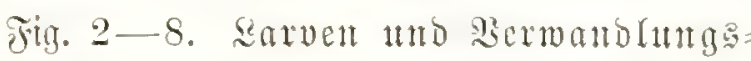
fitfen eines nabe vermanten Seefterns; Me:

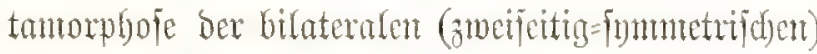
Slftrofarve in bas pentarabiale (Fümittrablig ge=

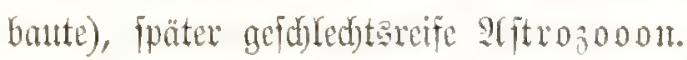

Fitg. 2. Die jugentidye zmeifeitige Ravwe, bie

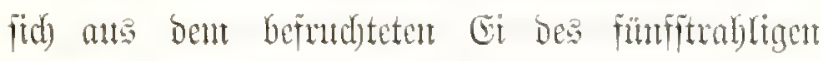
Eccitems entwifelt hat (Scaphularia). Dic Bandfeite ber partofferfounnigen Sarve ift von sim-

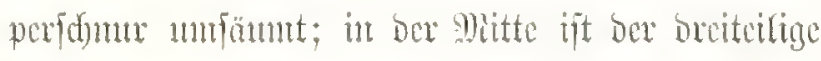

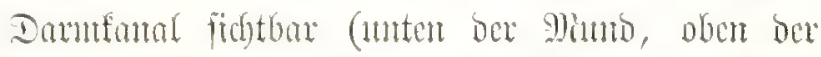
Iffer, in ber Mitte bajwifthen ber Mangent). 
Fin. 3). Cime ältere anve (Bipimmaria), von

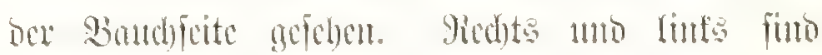

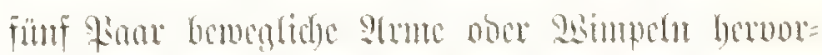

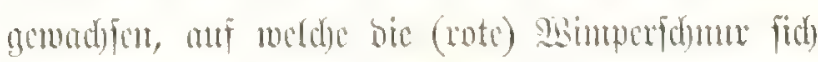
fortfert; jwet finor liegen unten ant Mlanoe, brei

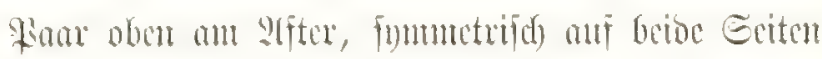

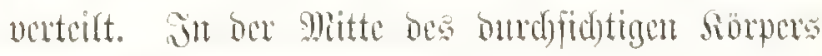

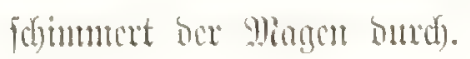

Fig. 4. Eine weiter mtwitelte sarve (Brachiolaria), wne ber redten Gite gefoldon; ber

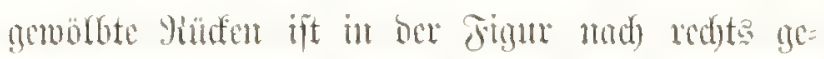

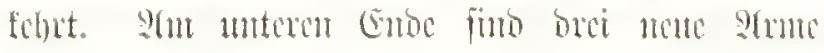

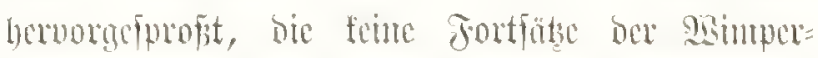

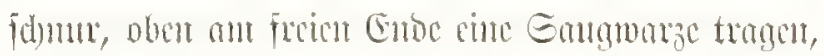

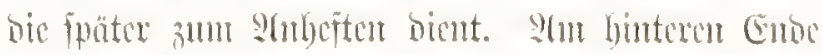

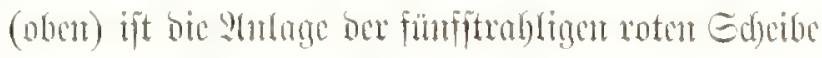

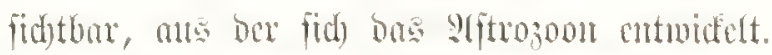

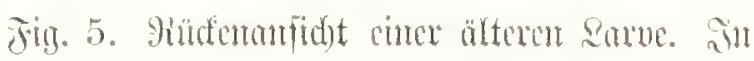

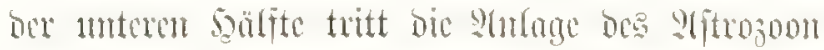

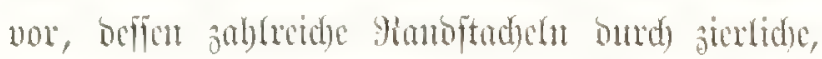

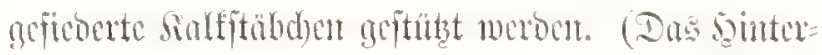

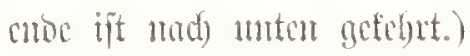

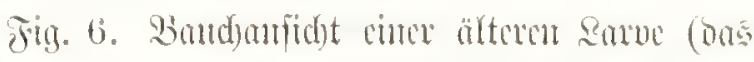
Sintereme ift mad) unten geferent). Son ber oferen

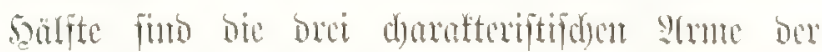
Brachiolaria fidftbar, die ant Emo Gang

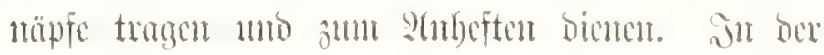

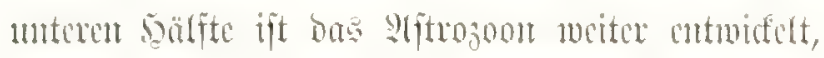

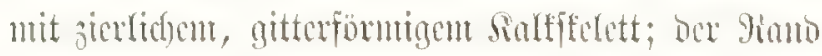

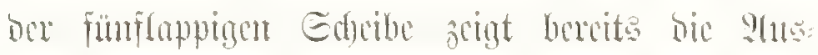

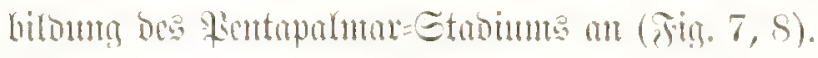

Fig. 7 mo S. Fientapatmar=Stabium be

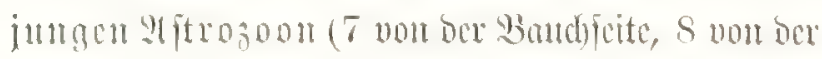

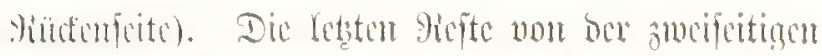

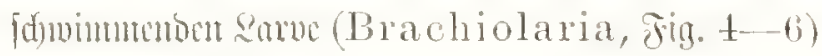

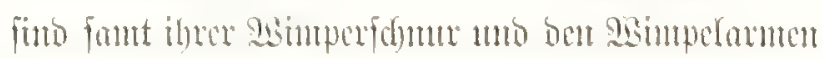

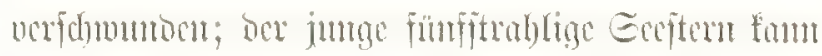

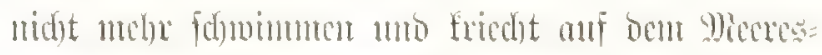

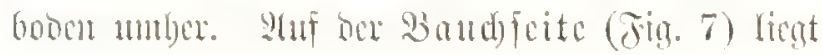

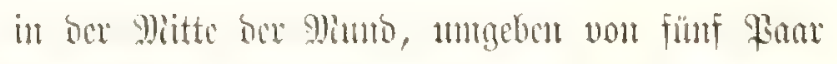
Emufüidyen. Sind anen bovon frebt man bae

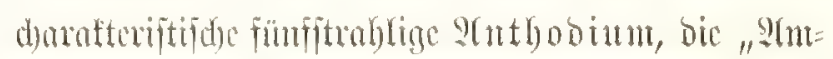

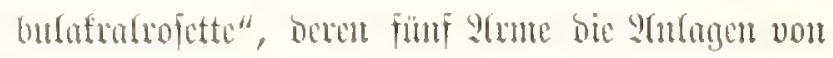
je fünf

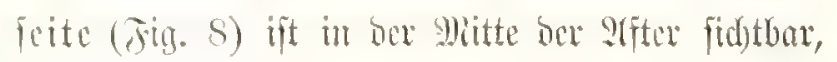
umgehen non fünf Stadjelgruppen. Diefes "Renta=

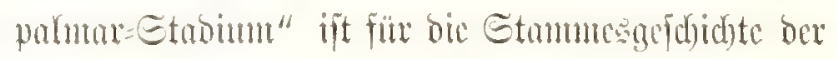
Etcruticue befontons widtig, weil as in abnlid)er

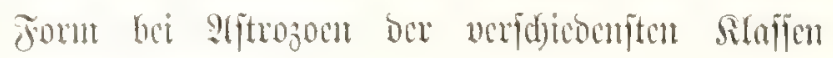
misortelut.

\section{Jin. 9 mo 11. Iymenaster echimulatus}

$$
\text { (Percy Sladen). }
$$

Cin auftralifd)er Ecciten (ane 12,000 Jun

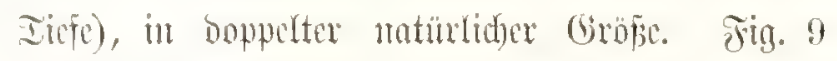

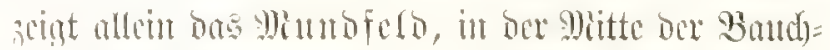

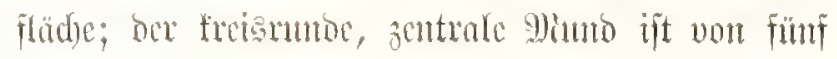
bemeglident Etad)efgruppent untgebor. Fig. 11 zarigt

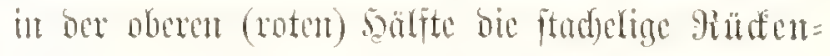

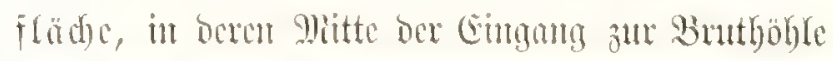

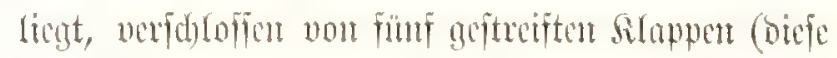
mo bie folgento Gattung von Iieffeefternen tragen ibre junge Brut währento ber Entwiffelung in ber

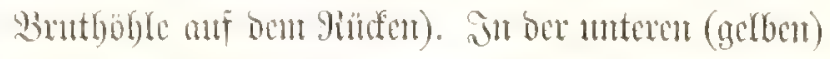
Sälfte von Fig. 11 ficht man anf bor Baudafläd)e

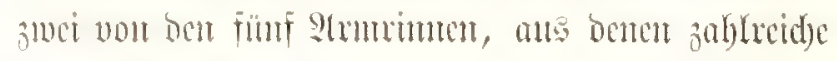
Jüboun vortreten.

\section{Jig. 10 uno 12. Pteraster stellifer (Percy Sladen).}

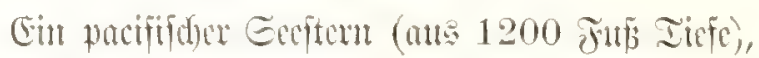

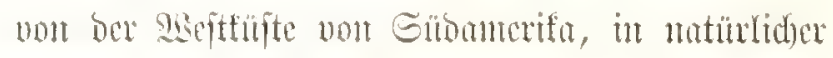

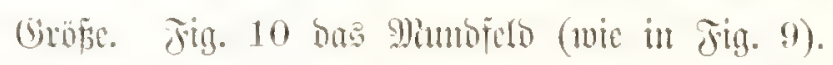

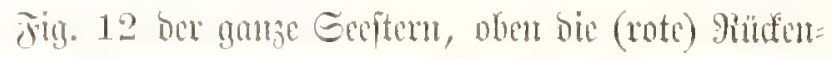
Feite, untem bic (gethe) Bandf)jeite (wie in Fig. 11).

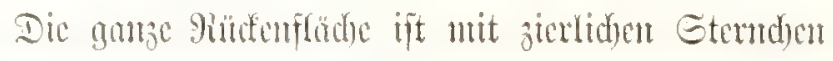

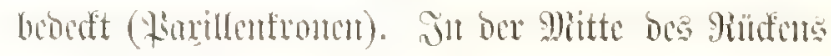

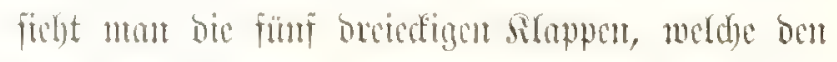

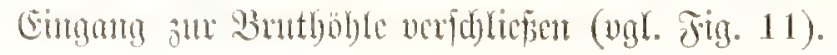




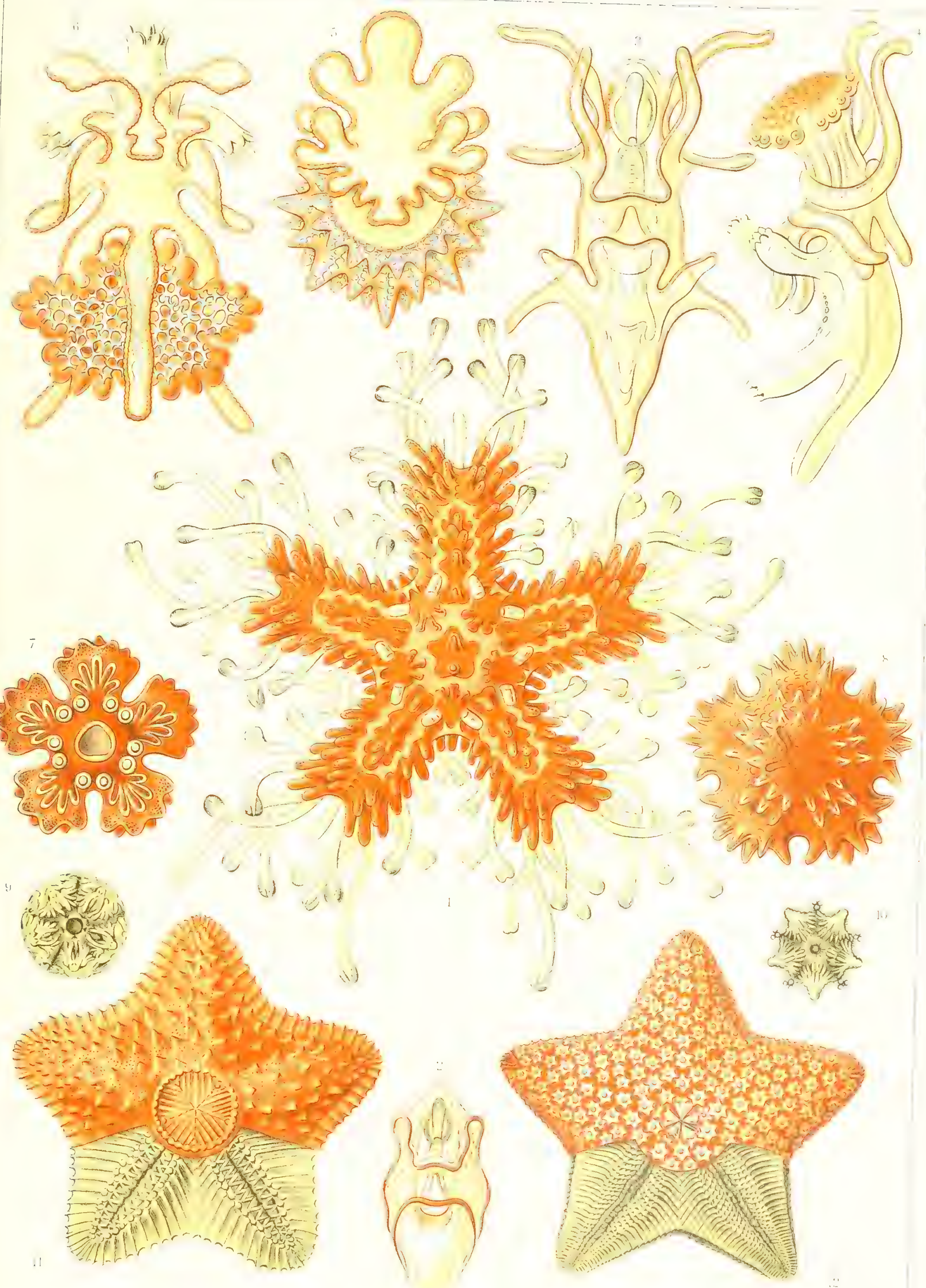





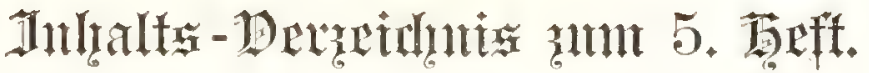

Iafel 41. Dorataspis. Hrtiere aus ber Alafic ber Rabiolarien (Region Der Stantharien, Sornumg der alfanthophrafen).

Tafel 42. Ostracion. SBirberticre ans ber Silafic bex Fifd) (Interflaffe ber Sinod)enfifdic, Teleostei; Srommg ber Gdunoblfifide, Plectognathi; Interfanilie Dex Soffer= fifd)c, Ostraciontes).

Tafel 43. Acolis. Metdytere an bet Silaffe ber Sd)neten ober Gafteropoben (Srommg ber Sadftener, Nudibranchia).

Tafel 44. Ammonites. Macidtiere ans ber Slaffe der Rrafen doex Cephalopoden (Fa milte bex Ammonghörnex, Ammonitida).

Iafel 45. Campannlina. Seffieltiere aus der Silaffe der Syoropolypen (Drommg ocr Girofenpolypen ooser Sampanartent).
Iafel 46. Gemmaria. Feffeltiere ate ber Slaffe ber Soleieraualen oocr frappeboten (Dobmug ber şrumenquarren, Anthomedusae).

Tafel 47. Limulus. Gificoertiere ane ber saupt= flafie der Siruftentiere, Crustacea (Silofie ber Gofirstiere, Aspidonia).

Tafel 45. Lucernaria. Reflettiere aus ber Sifafie ber anpenquarken oder Afraspeben (Dro= mutg oer Bedferquarlen, Stauromedusae).

Iafel 49. Heliactis. Refleltive aus ber Rafle ber Rorallen, Anthozoa (Srommg der

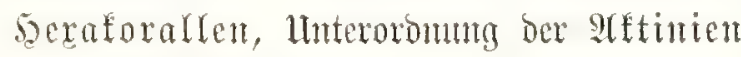
ober Germentonen).

Tafel 50. Sporadipus. Stentiere aus der Sifafle der Geegurten (Thuroidea ooer Holothuriae). 



\section{Acanthophracta. Hom}

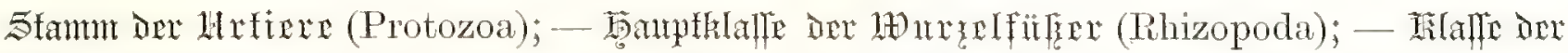

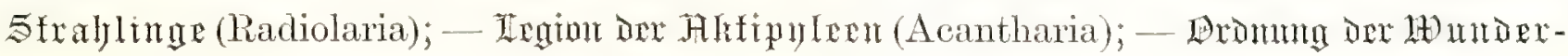
ftraffinge (Acanthophracta).

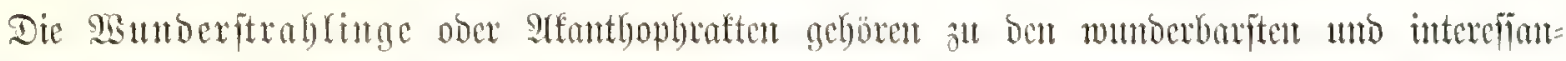

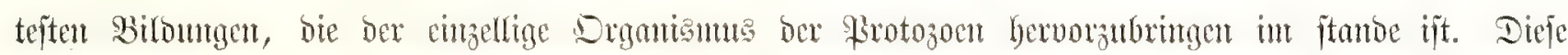

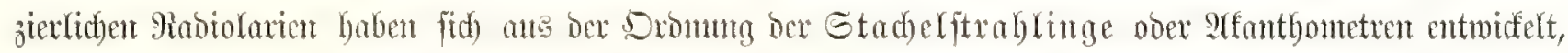

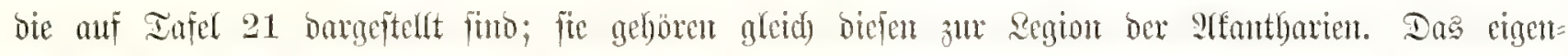

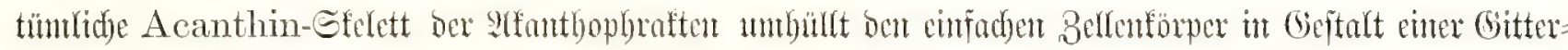

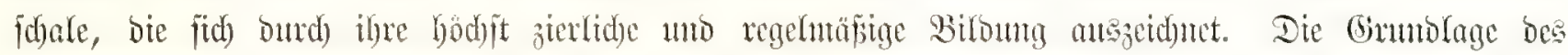

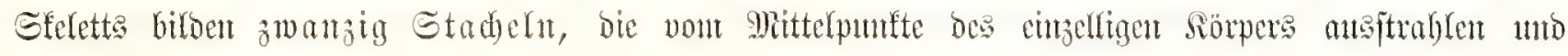

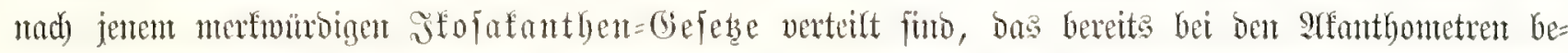

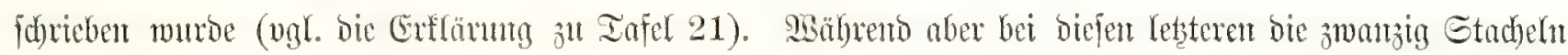

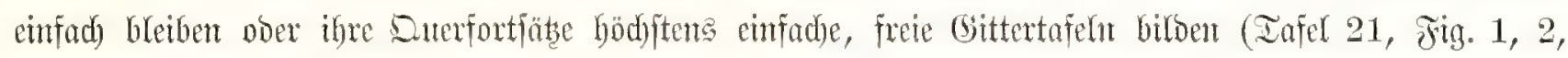

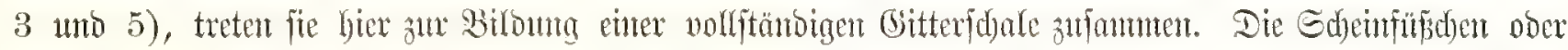

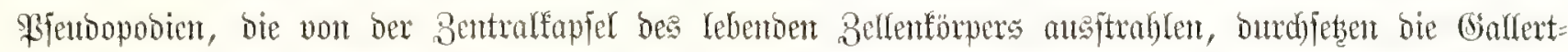

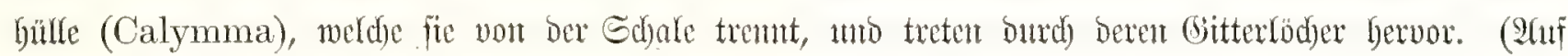
umferex Iafel 41 finto mur bie gereinigten Efelette bargeftellt, nidgt der siscidförper.)

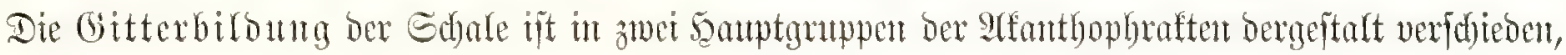

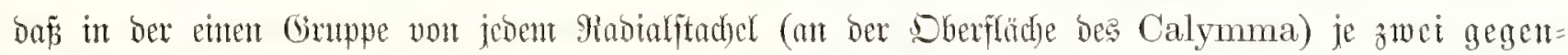

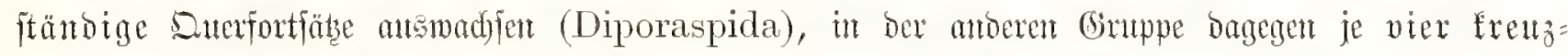

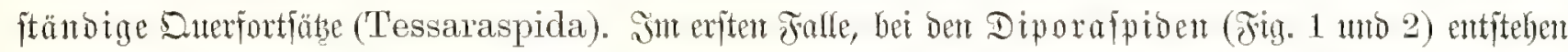

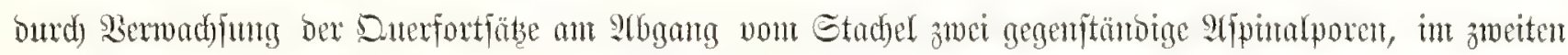

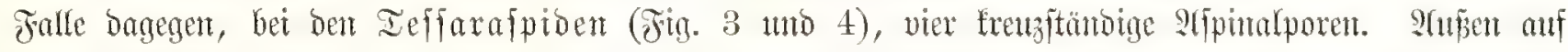

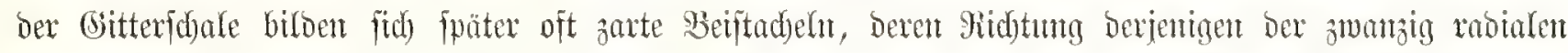

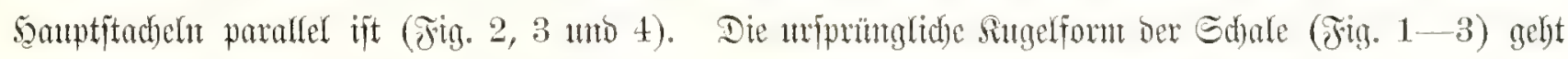

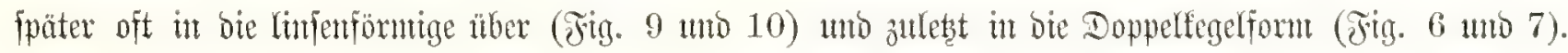

Fig. 1. Dorataspis typica (Hacekel).

Solaramitut ber fingeligen Edjale. In bor Mitte ber Figur ijt ber Sofarpone fidtbar, um=

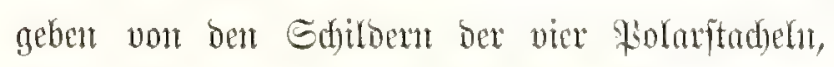
berent jeber einen Siragen mit zuci arjpitalporen

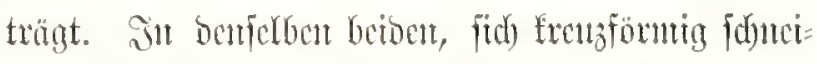

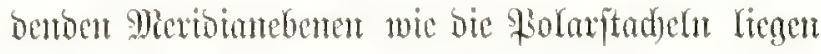

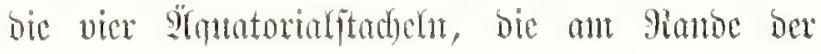

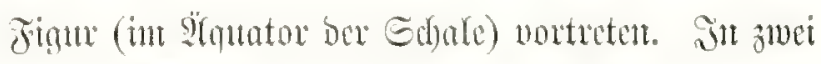
antoren \$icriotantebentu, weldye bie erferen unter 
Mintfeln von 45 Grab bingonal founcioen, Yiegen

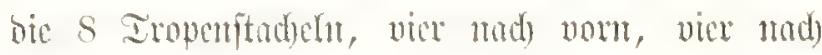
hinten geridgtet. Int jeber Sinht, bie jue ancinander=

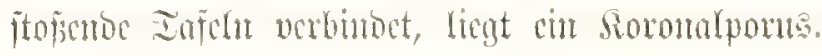

\section{Jig. 2. Diporaspis nephropora (Hacckel).}

Slontatmialanfidet ber fundigen Echale. Sin ber

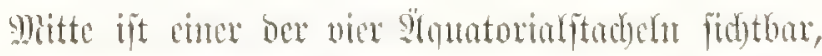

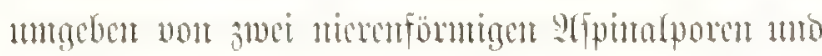

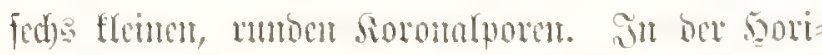

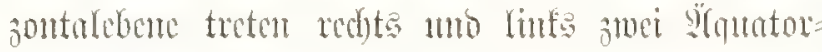

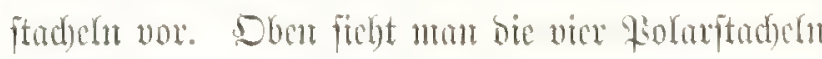

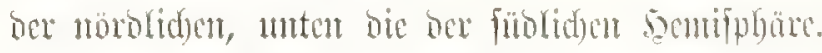

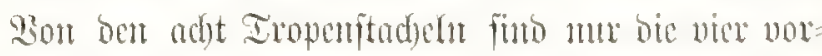
Deren, bell Cendetemben fidethar. Dic Dberfläd) ber

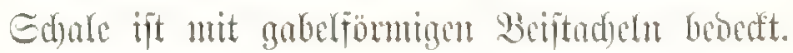

\section{jig. 3. Lychnaspis miranda (Hacckel).}

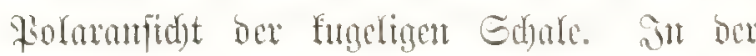

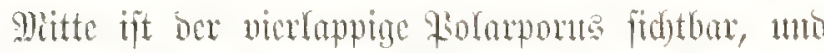
in biefent bas Bentumt ber Sunge, in bent bie 20

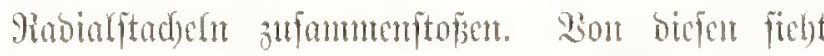
men 16: Die vier ägutatorialen tmo bic bier vor: Deren polaren, àmifdent biefen bie adjt Iropenftadyedn (bitugotal, vier vordere unto vier hintere). Bahlretde, zidfandforming grbogene Beiftadyeln Laufen paralled ben 20 somptitad)etn, anf beren Gittertafeln fie fids

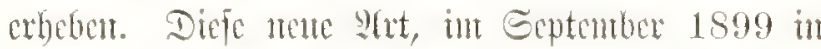

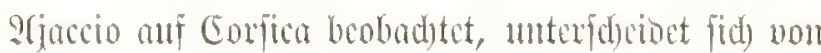
ben verwanten S(ren ber Gattung burde bie vier

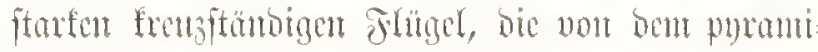

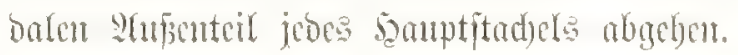

\section{jig. t. Lyehmaspis polyancistra (Haeckel).}

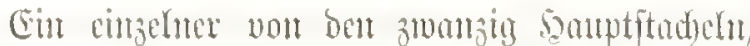

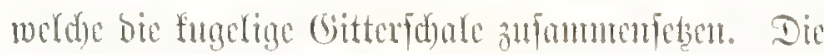
vier frewjitümbigen Buerportjübe, bic von bor Mitte

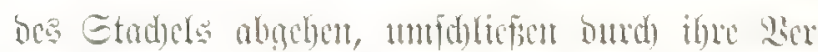

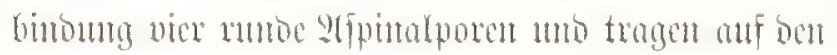

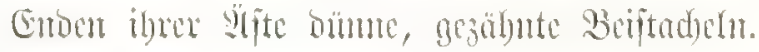

\section{Tign. 5. Echinaspis echinoides (Haeckel).}

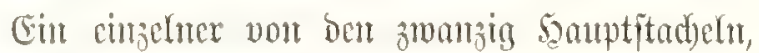

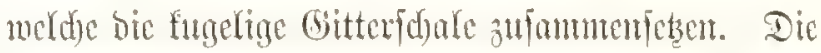
vier frenzitüntoigen Duterfortfübe, bic von ber Mitte

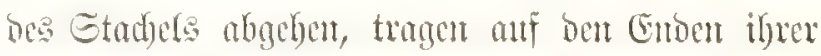

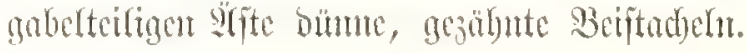

\section{Fin. 6. Diplocolpus costatatus (Haeckel).}

Die Edrale biefer Ginttung weidst an meijten non ber urprinngliden Stmmmform ab; von oen 20 Mabialftadyeln, weldye bie cigentlidye Gitteridyale zut= fammenferen (in ber Mitte ber Figur), fund 18 noi=

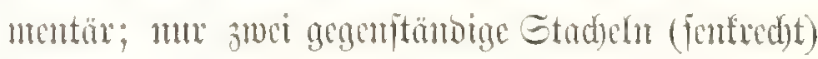

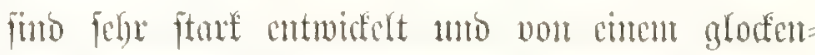
förmigen Sirngen mit gezühuten Rano untgeben.

\section{Fing. 7. Diploconus hexilphyllus (Haeckel).}

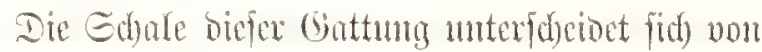

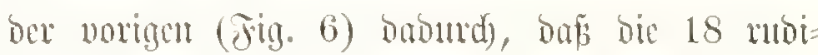
mentüru Rabialfadycln nod) änperlid vortreten.

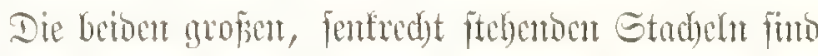

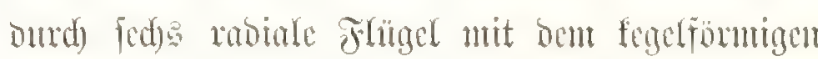

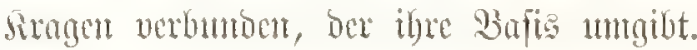

\section{Jig. 8. Icosaspis elegans (Haeckel).}

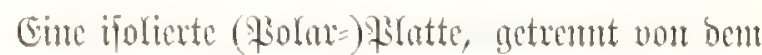
Berbande ber 20 (bitterplatten (äfultid) mie Jign. 3).

\section{Fin. 9. Hexaconus serratus (Haeckel).}

Die limfonfömige Gitteridgale ift am 20 gia

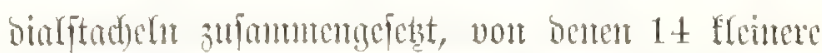

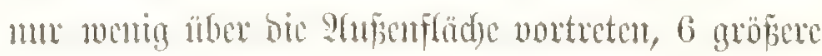
von ftarfen, gezälnten Edheiben untgeben finto.

\section{Fig. 10. Hexacolpus nivalis (Haeckel).}

Die limfenföminge Gitterfdale iit an $20 \Re a=$ bialftad)ch ăfanmmengefest, von bemen 1 t flemere

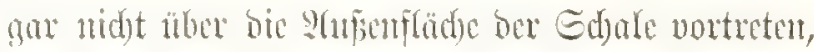
fect) gröfere (ant simfemrande) von fturfent, geripptent Etadelidactoen mafdarofien furo. 


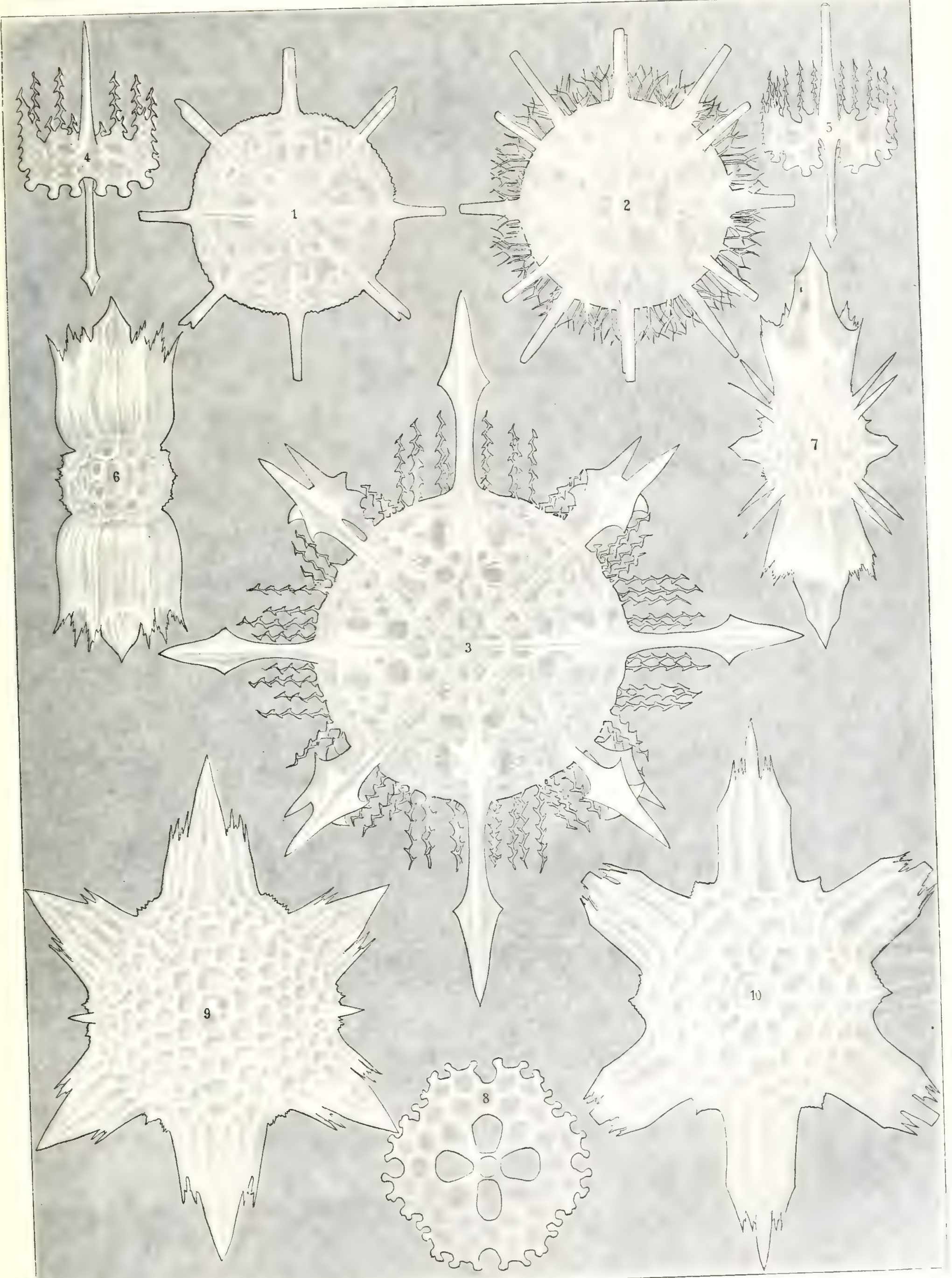




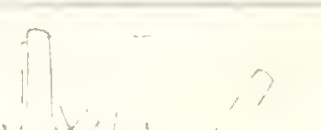

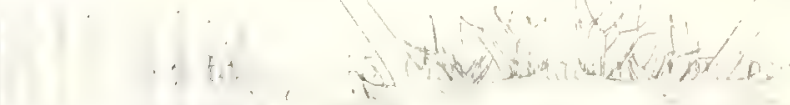
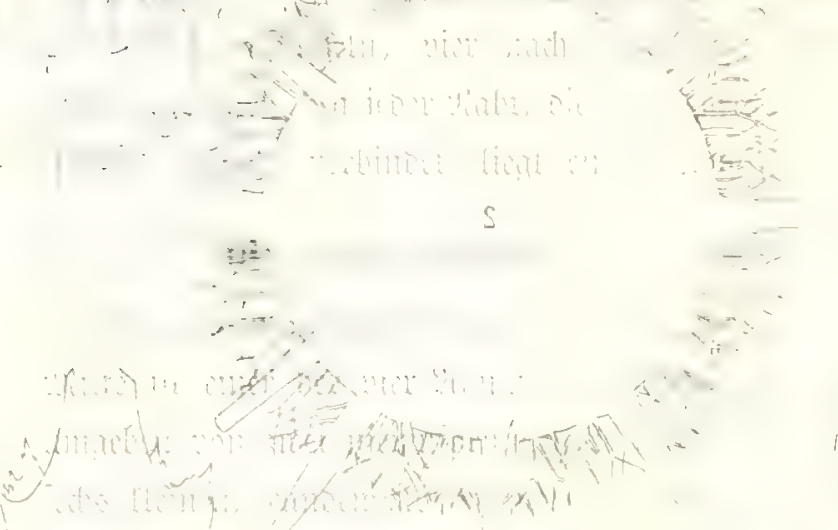

(c) and

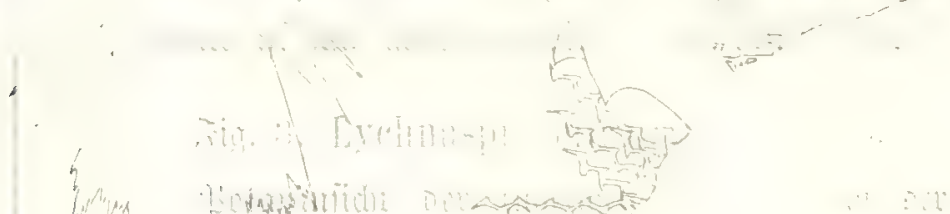

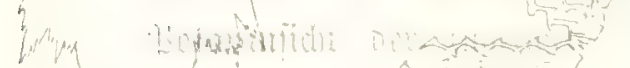

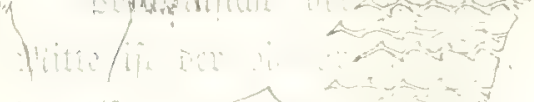

ary a

$\therefore-$ 


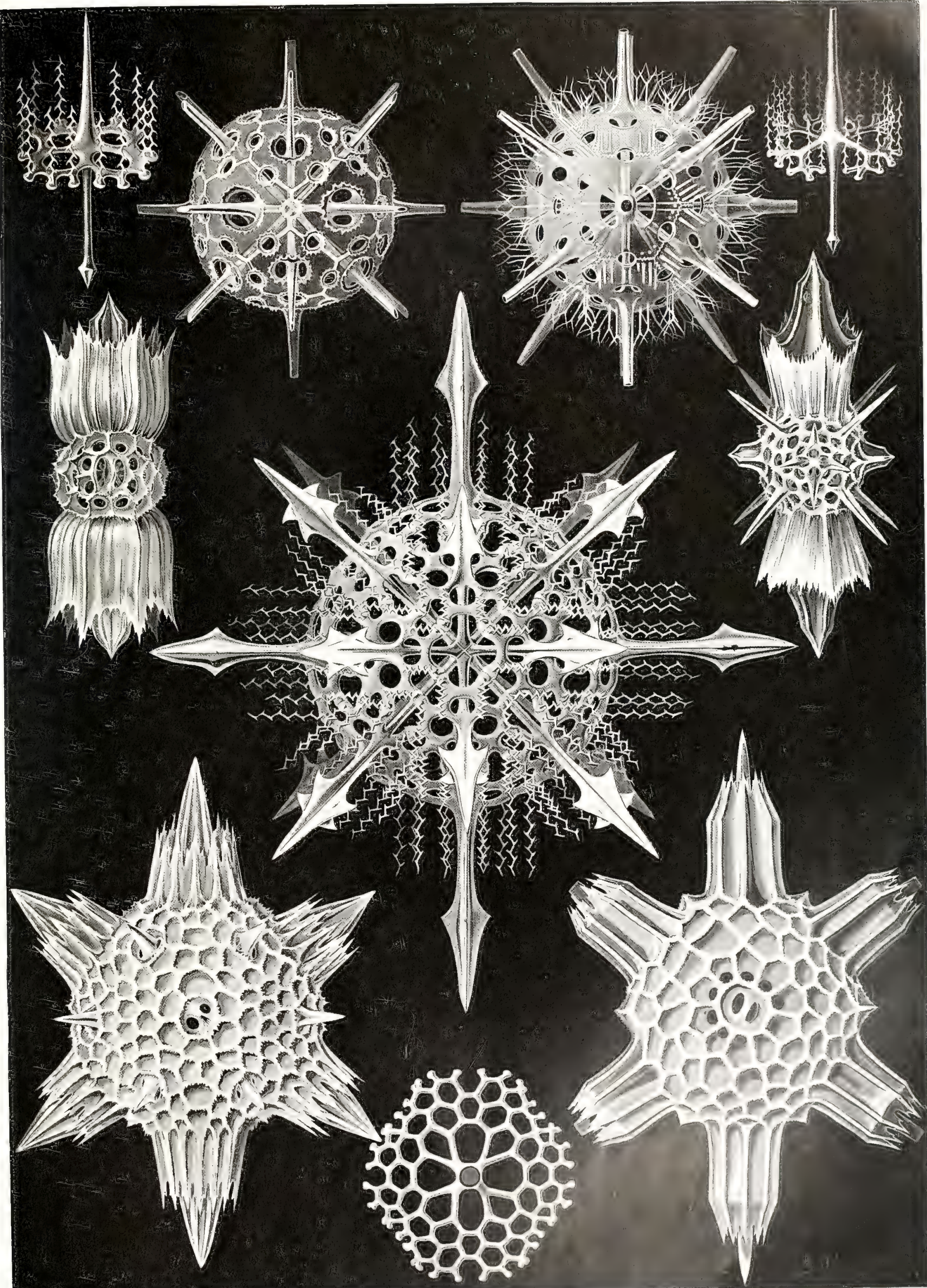

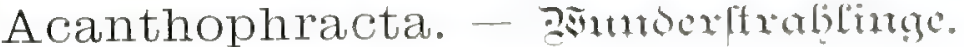





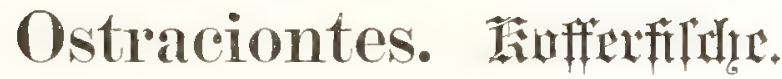

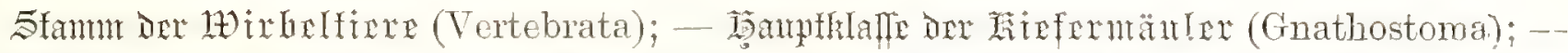

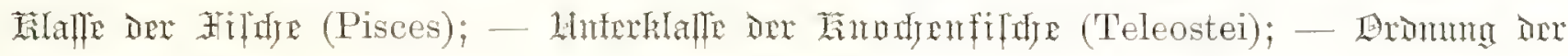

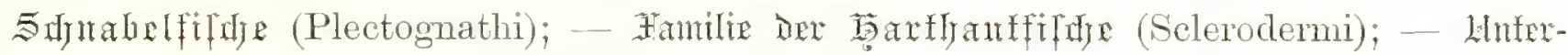

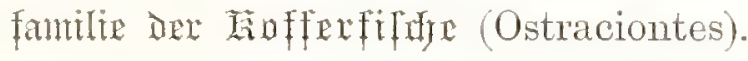

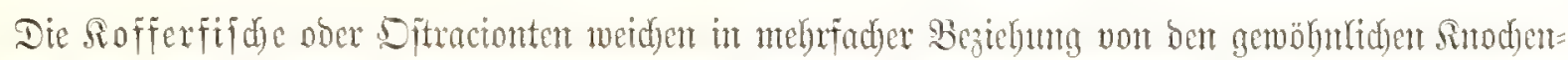

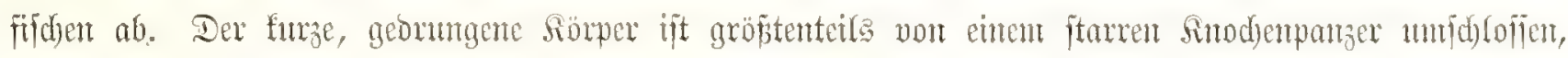

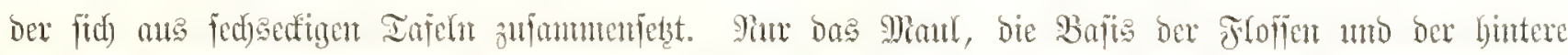

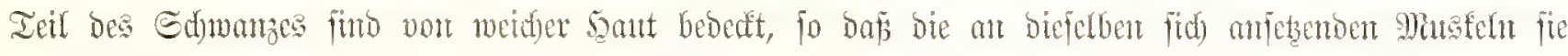

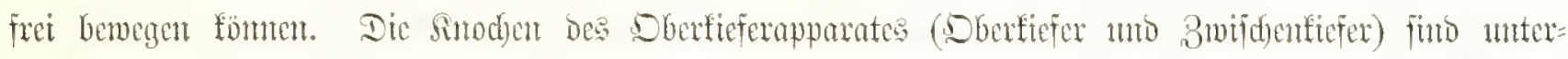

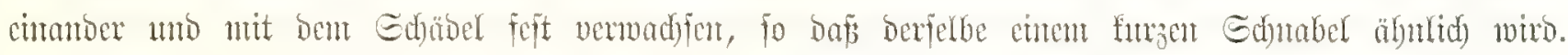

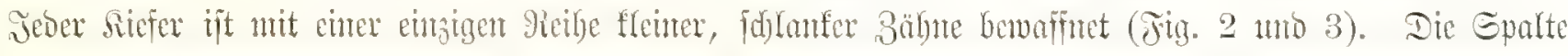

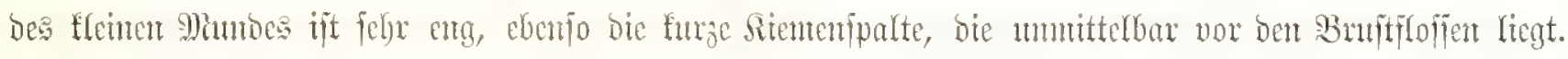

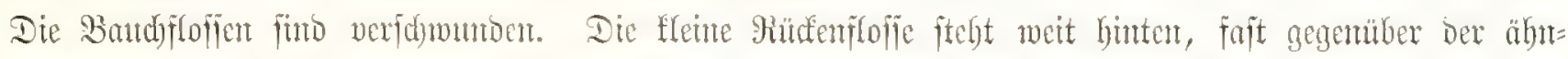

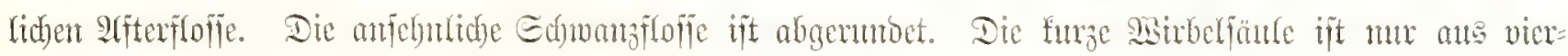

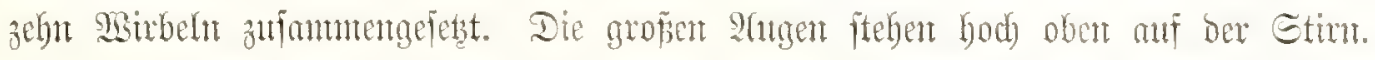

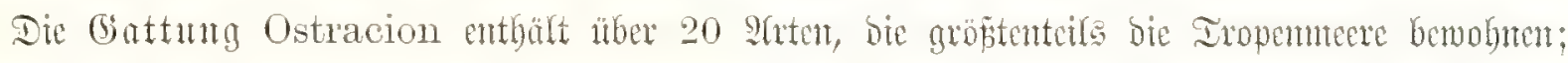

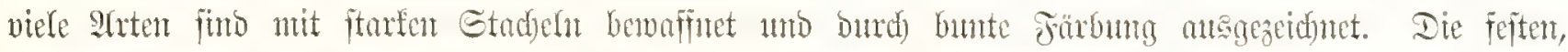

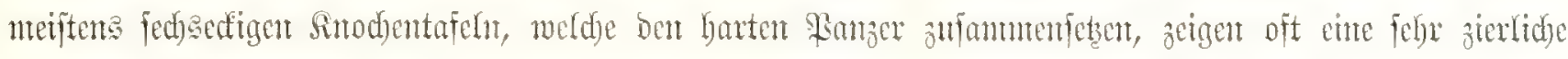

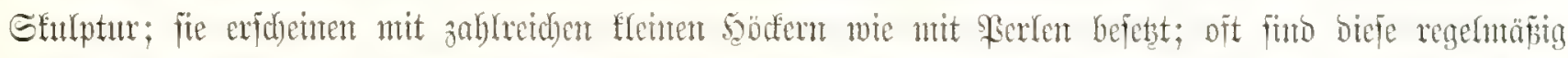

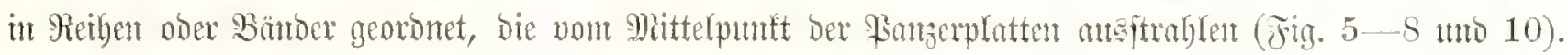

そrig. 1-5. 0stracion cormutus (Limé).

Der gehörnte Sofferfifd. Fitg. 1 vou ber Riüdemfeite; Fig. 2 von vorn, von ber Mimbofete

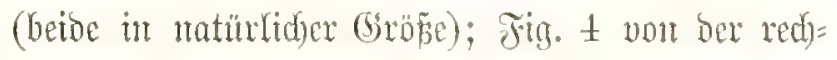
ten Ecite (verf(einert). Jig. 3 Der Mints, vort vorn, geöffnet (vergröfiert). Fig. 5 cime fed) escefitige

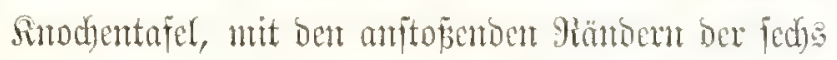

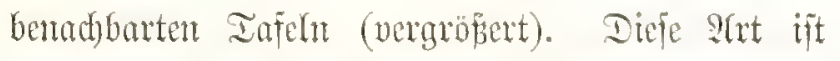
Durde) vier ftarfe, fajt gorizontal abjtefento gönter atsgejeidynet, won bettent bas obere Pant (utber Dent

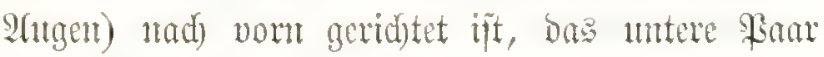

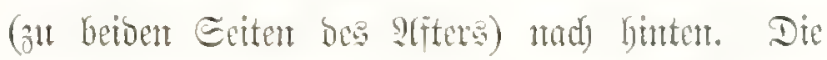

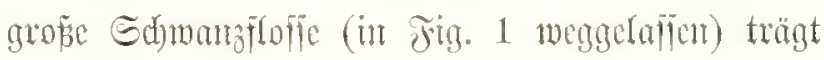
zablreidye situgenffete.

Fin. 6-S. Ostracion quadricornis (Limé).

Dex vierbarmige sofferfifd). Fig. 6 von Dex linfent Geite; Fig. 7 mo 8 jwe cingelne Sirtodyen= 


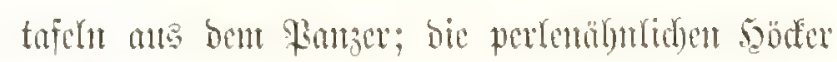
ber Sberfläde finto ftrablemforming in siciben ge oronet, bie von Mittefpunft angelfen. Die vien

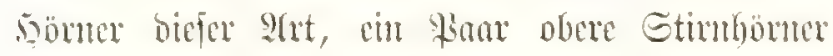

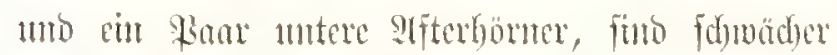
als biejenigen ber norbergebentom strt.

\section{Fig. 9. Ostracion auritus (Shaw).}

Der geobrte sofferfifd (uon ber rediten

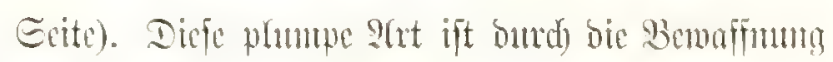
mit jwolf gropen, rüdmärts gerid)teten sörnern

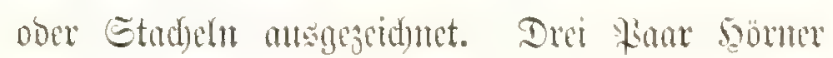

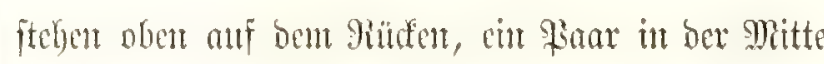

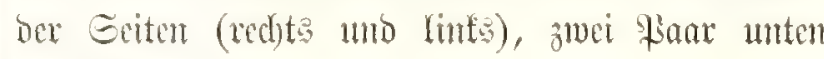
ant Bandje.

Fing. 10. Ostracion turritus (Swainson).

Der geturunte Sofferfifd) (von der linfent Ecite, vertfeinert). Diefe fondoerbare $\mathfrak{A}$ (nt trägt auf ben Bürfen, oberhalb der paralfeten Seitenf́nten, einren fegerförnigen Budfel, beffen Gipjel ein ftarker

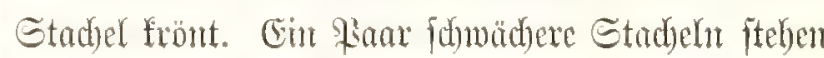

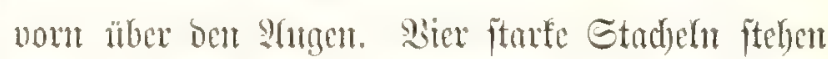
bintercinmol anf ber Bautd)fante uno finto nach binten gerid)tet. 


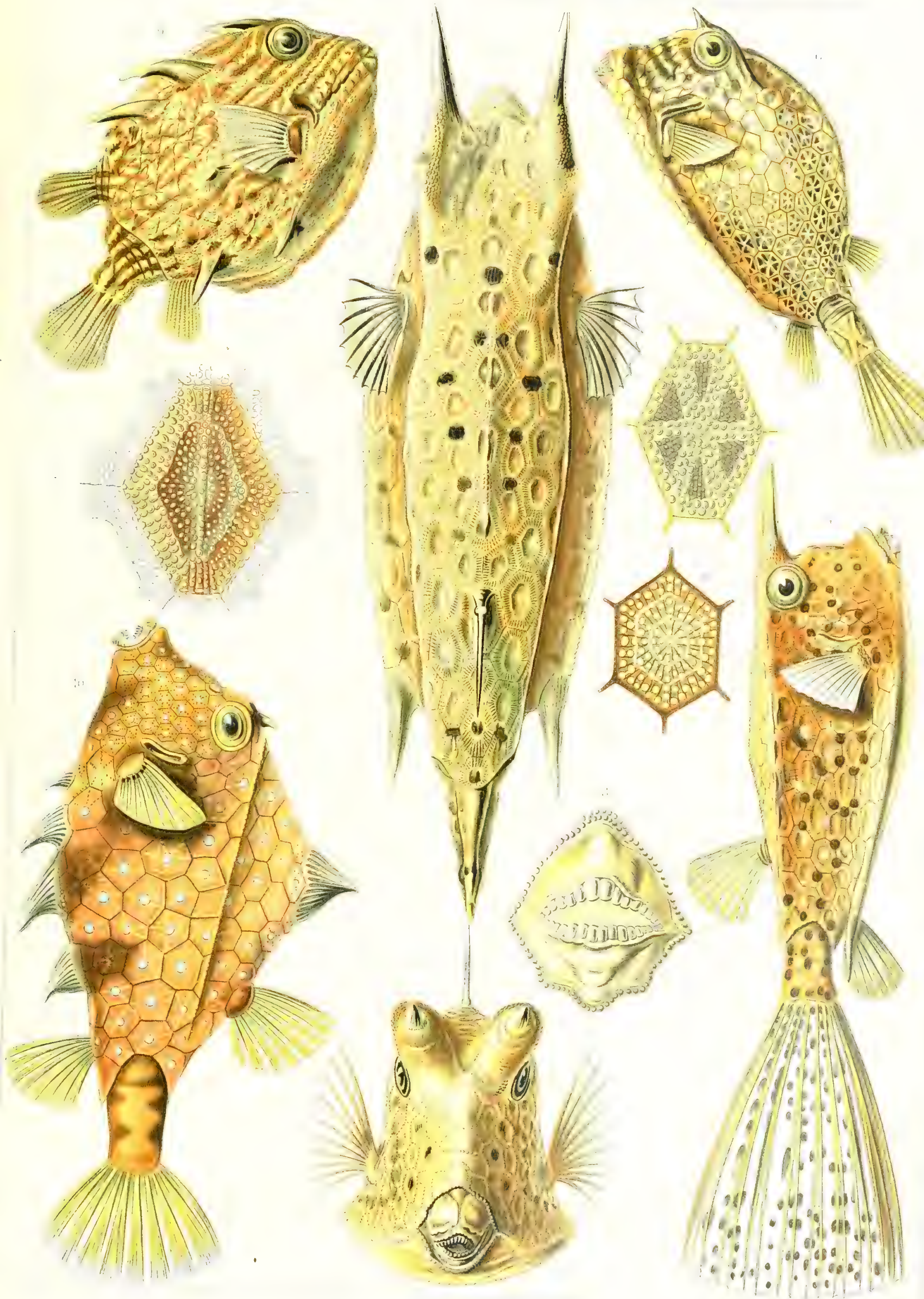

Ostraciontes. - sofferfilite. 



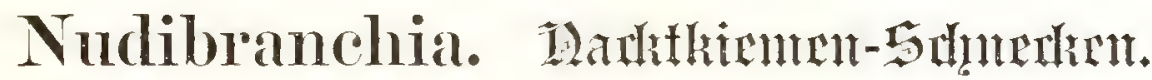

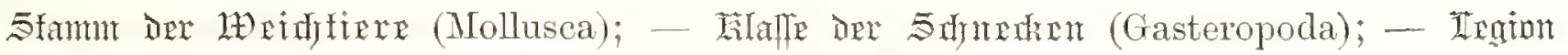

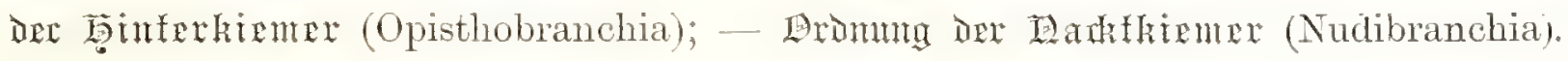

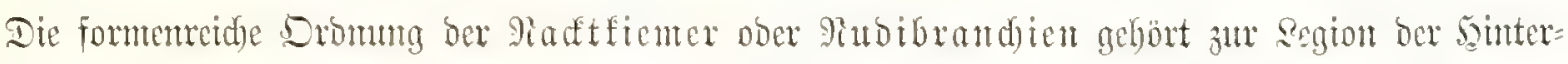

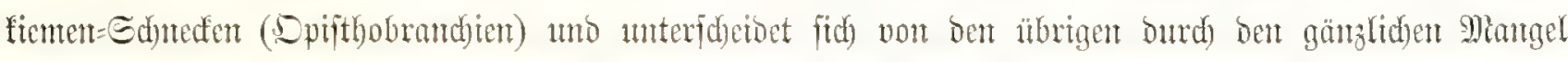

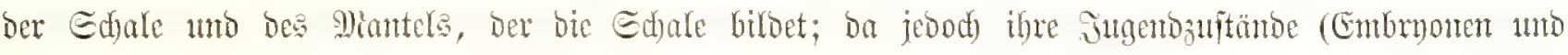

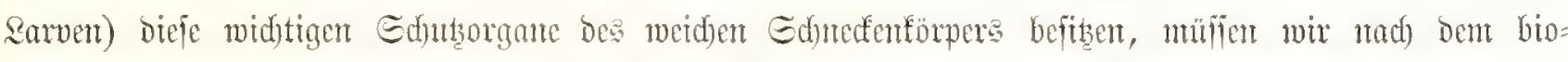

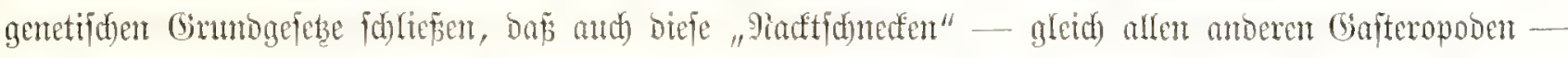

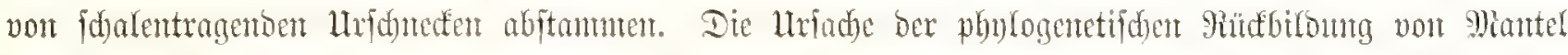

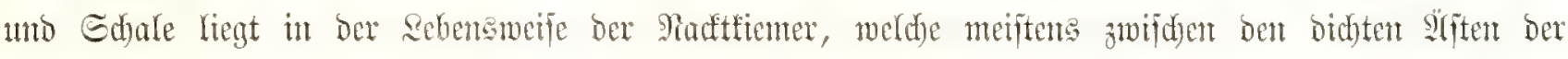

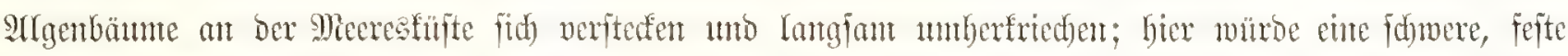

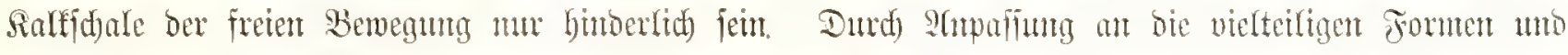

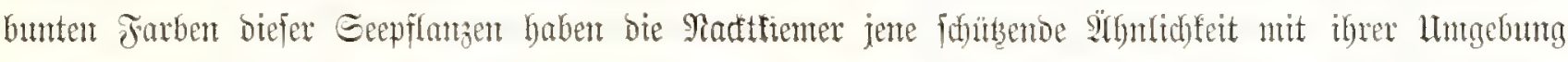

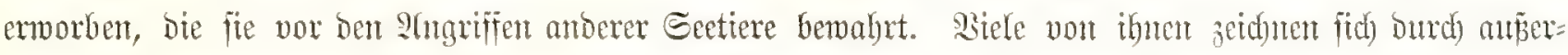

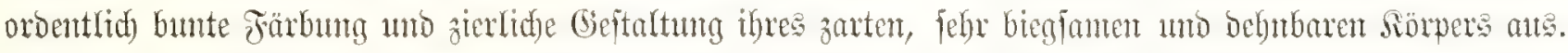

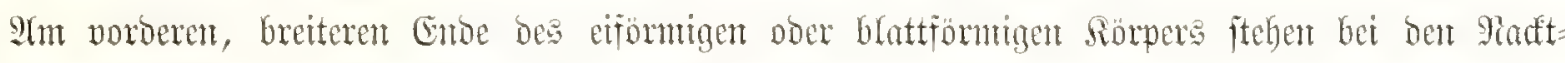

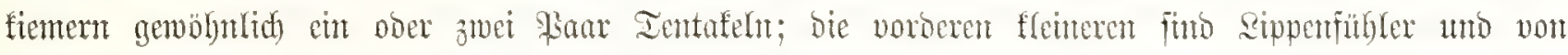

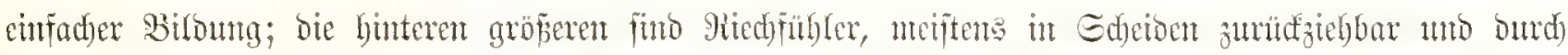

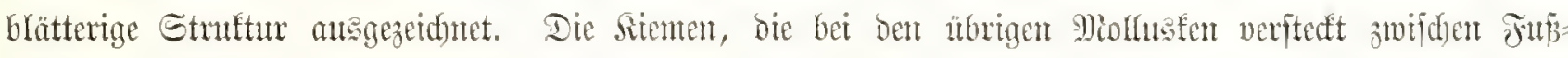

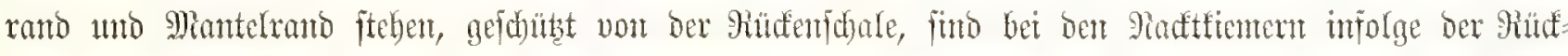

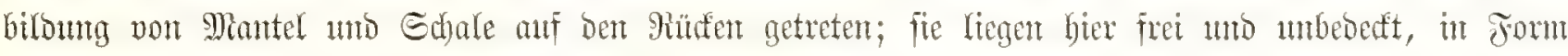

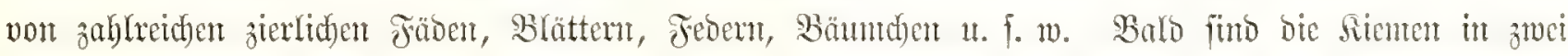

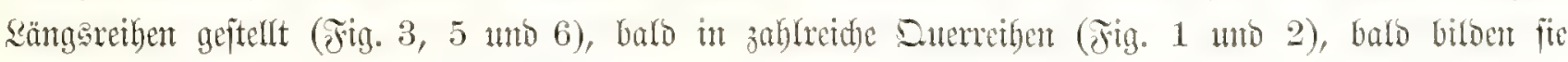

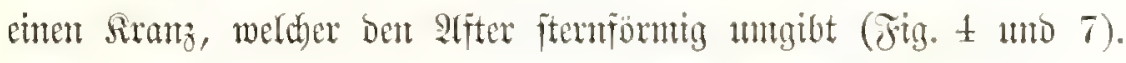

\section{Fig. 1. Ilermaea bifida (Lovén).}

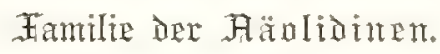

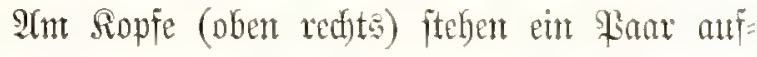
gerollte Tentafelts oder Riedffühlex uno Dabinter

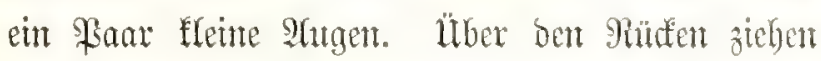

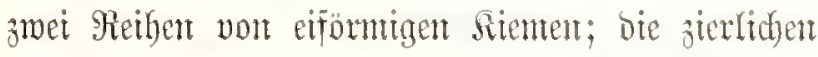
roten, gefiederten Giefäpae, Die von ben Gecioen Mangen=

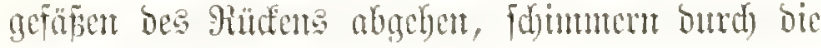

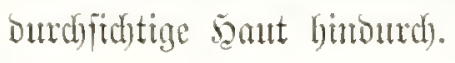

\section{Fig. 2. Aeolis coronata (Forbes).}

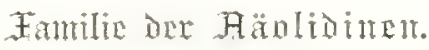

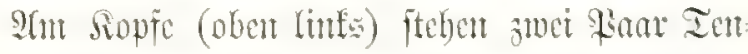
tafecht, vont bencu bie vorberen (Rippenfithler) cinfad), 


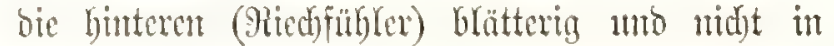

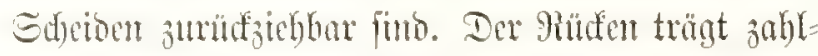
reidye rote, fabenförmige Siemen, bie buifdectmeife mif jwei Rängeriben und fedjs bis adjt Duex= reifen werteilt finto.

\section{Fig. 3. Dendronotus arborescens (Alder).}

Familie Dex Denornutioner.

Ifn Sopfe (oben linfor) ftelyt vorn auf oer Etim cin Siranz von adjt baumförnigen 9ebenfüblern

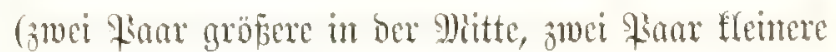

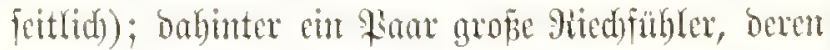
oberes Stüt fentenformin, nit einer Rethe von

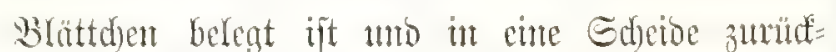
gezogen werben fant, bie cisten Siratr von baum=

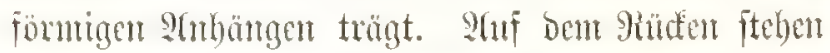
zwei Яeihen von baumförmigen Sitemen, Deren Gröpe vont vorn mad binten abnimunt.

\section{Fig. 4. Idalia elegans (Lenckart).}

Familir Der Doridinen.

Stm Siopfe (unten linfsis) ftehen vorn ein Sianor Dünte Etimfüflex, bahinter ein Soan ftürfere Sited =

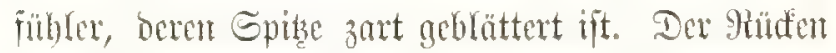
trüngt brei Räng šreiben von Mantelfäben (cime nitt= leve unparae und zwet feitlidfe paarige) und linten

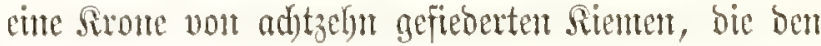
Sifter ungeber.

\section{Fin. 5. Doto coronata (Lovén).}

Familie der Dofuniden.

Sam Sopfe (oben redita) ftehen ein Saar cin

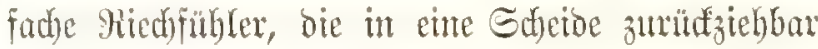

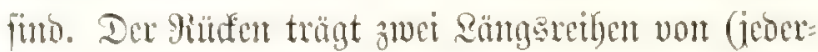
feits fünf) gropen, fentenfïrmtgen Sientenblajen, bie mit fungeriörmigen $9 \mathrm{sarzen} \mathrm{bejest} \mathrm{finto.}$

\section{Fig. 6. Tritonia Hombergii (Cuvier). Familie one Uxifontaden.}

SIn Sionfe (oben linfs) ftehen ein sian gezalfte Etimlappen; bahinter ein Faar cnlinbrijd)e, gezähnte Jühlex, bie in eine Ed)cioe zurüfigezogen werven fömen. Der Kintefen ijt mit zowei Keiben von ge= ftederten Siemen gejdunünt.

\section{Fig. 7. Ancula eristata (Loven). Familie der Baridinen.}

Stm Sopfe (oben linfs) ftehen cin 秥an fumbe

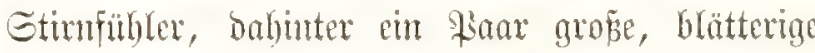
Sitedfüblex, bie an ifrer safis zomei fügerförmige Fortjäbe tragen. SUlf ber Mlitte bes giudfens liegt der sfftex, umgeben vou einer jiertiden Rienten= frome, bie ans brei feocrförntigen, boppelt gefieder=

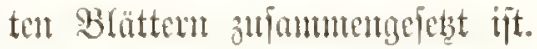




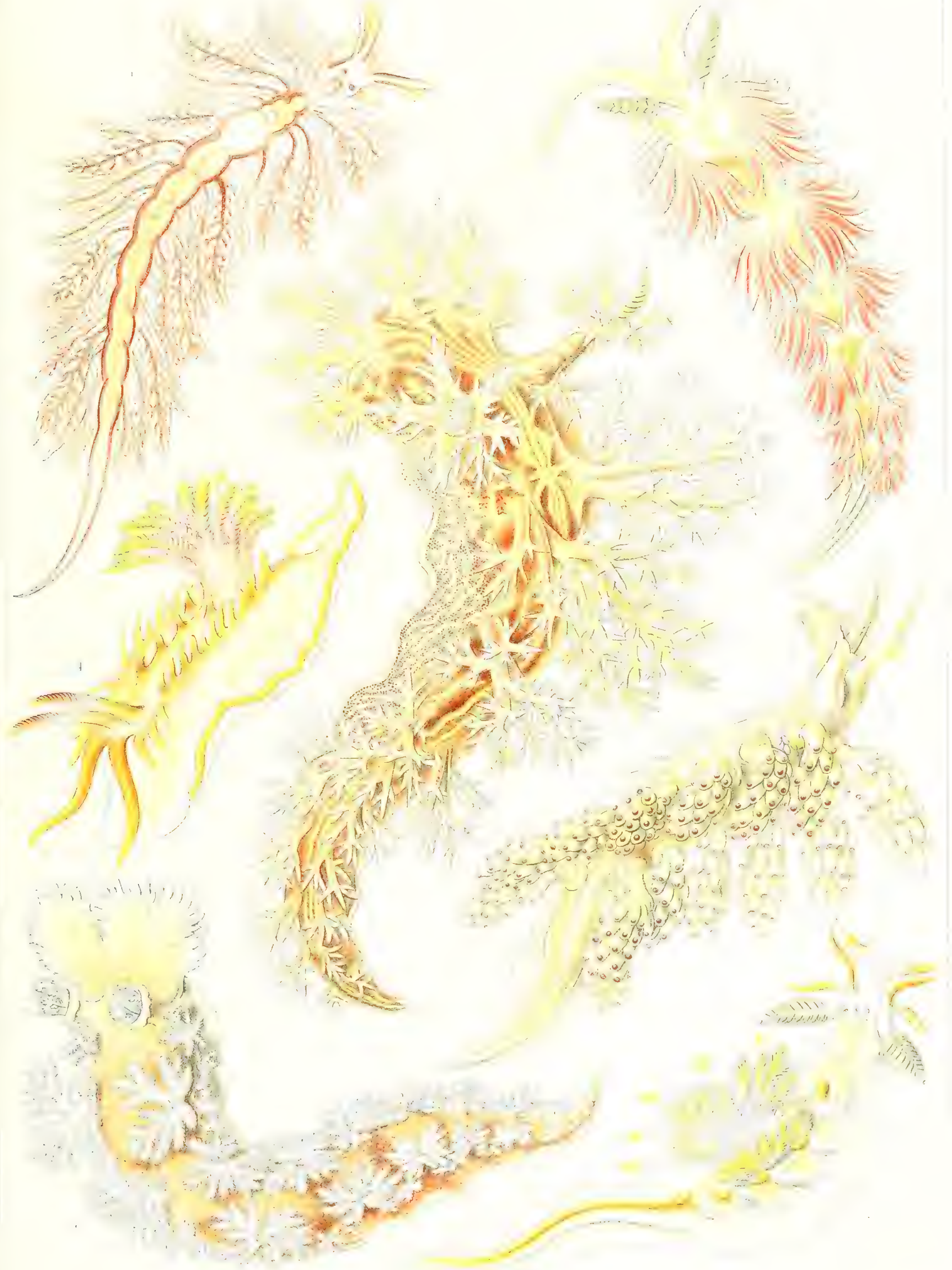

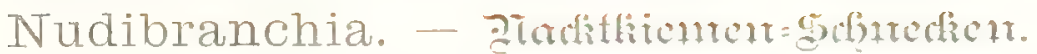


.

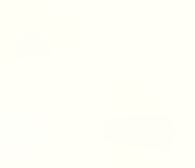

(2)

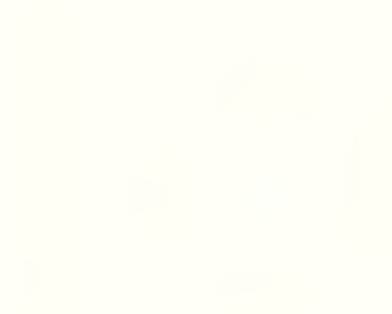

(

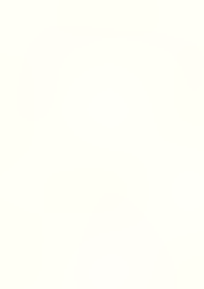

(

. 


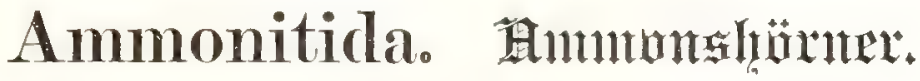

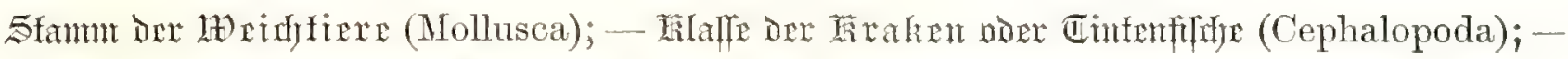

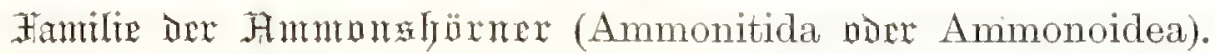

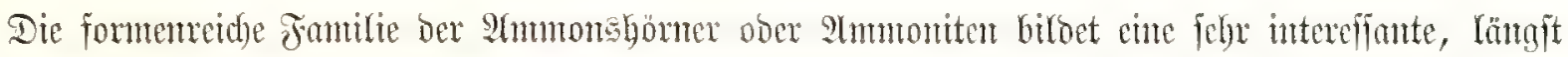

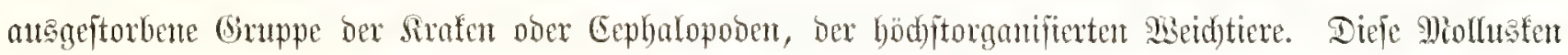

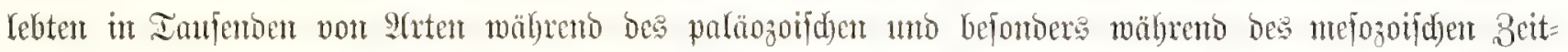

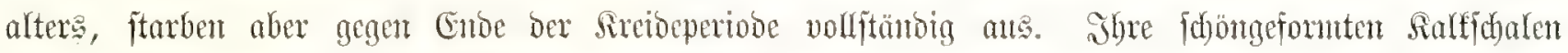

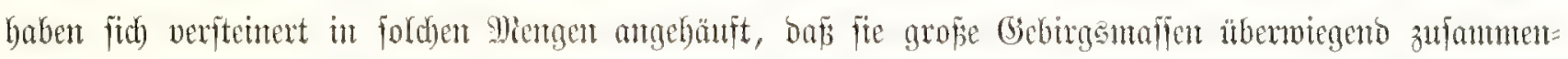

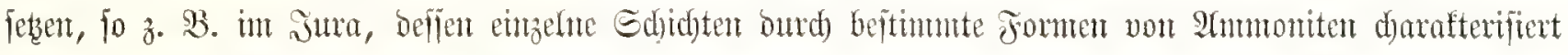

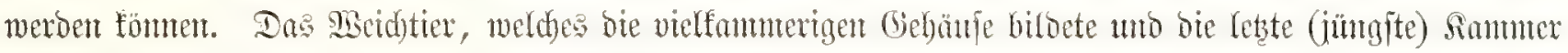

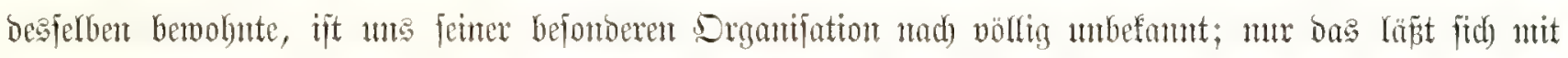

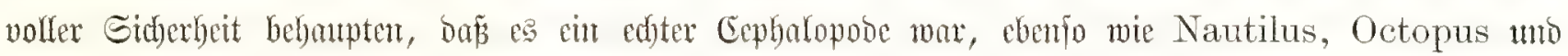

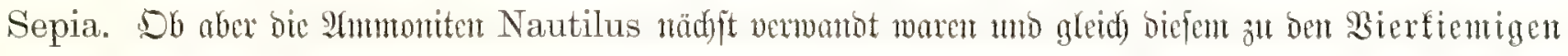
(Tetrabranchia) gehörten, ober viefmelyr zu ben 3 weifiemigen (Dibranchia), wie Spirula, Sepia

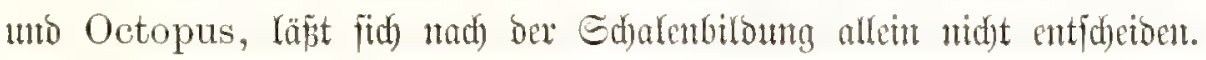

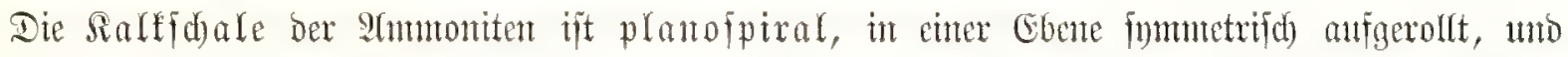

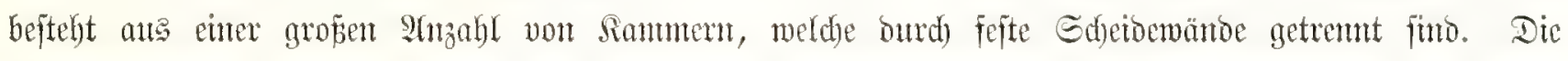
Sanment waren mit Sefft gefüllt, wie es bei ben hente nod) lebentoen vierfiemigen Nautilus uno żmé=

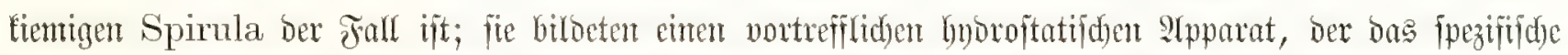

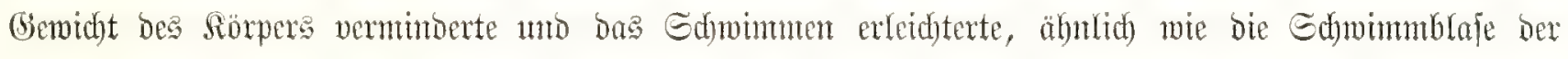

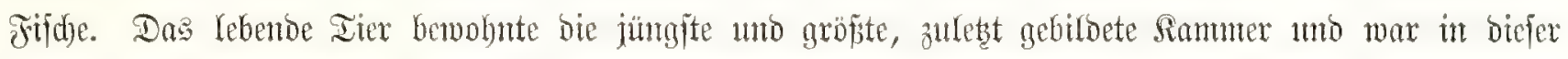

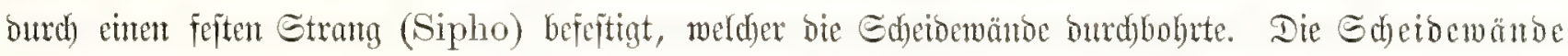

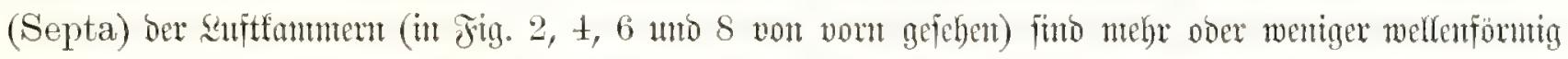

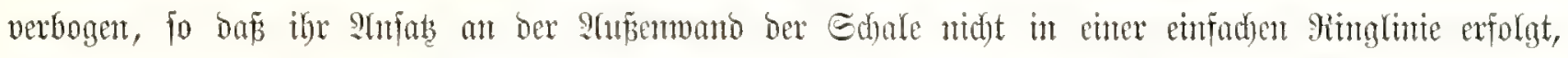

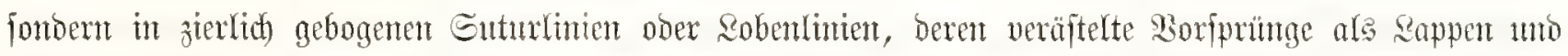

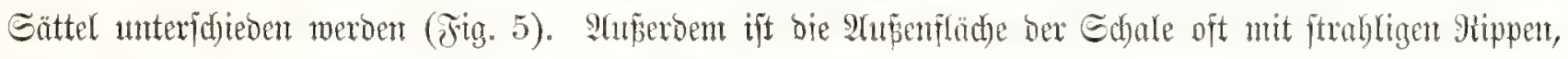
Reiften, Sauten, Stadjeln u. F. w. verziert.

Jig. 1, 2. Ammonites (Cardioceras) cordatus (Quenstedt).

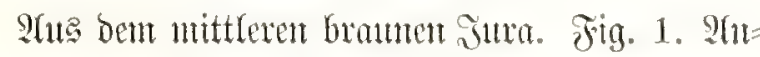

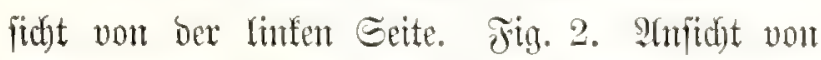
ber Bandjecte. Sben ift in ber Edalemmünomng die jüngite Simmerideciocwanto fidstbar.
Fig. 3, 4. Ammonites (Schioenbachia) Coupei (Brogniart).

Stus Der mittleren (Cenoman=) Siretoe. Fig. 3.

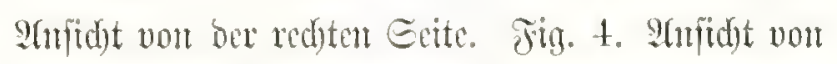

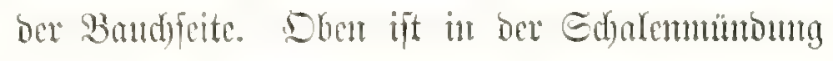
bie jüngite Sanmerfderibemano fidetbar. 
Fig. 5, 6. Ammonites (Ptychites) opulentus (Hojsisovich).

YHe ber alpinen Irias. Fin. 5. Itmitut von ber linfen Ecite. Fig. 6. Shufidet vout ber Baud feite. Sben ift in bex Edjalemmuntomg bie jüngite

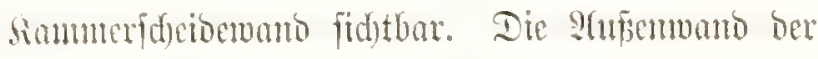

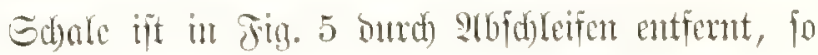

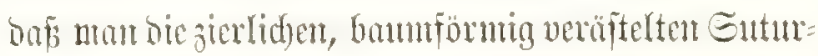

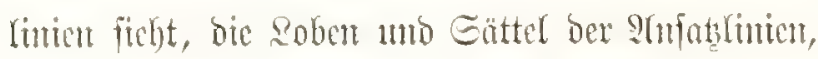
burd) welde bie Edycibowämbe ber sufttanmen an ber Imtmonto oer Edjale befeftigt finto.

Jig. 7: Ammonites (ormatus) mammillaris (Schlotheim).

Itus bor unterent Sireioe (Gault). Suffidft von ber redten Geite.
Fig. S. Ammonites (planulatus) carernosus (Quenstedt).

SHts Der oberen (weipen) Sireioc. Frontalfantitt

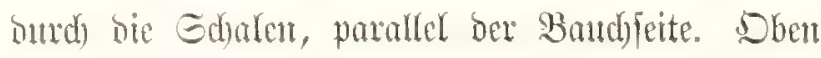

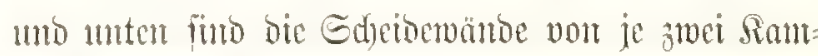
mern fid)tbar, bajwifiden ber imere soblraum von mtchreren lungängen ber Gdjate.

Fig. 9. Ammonites (amalthens) rotula (Schlotheim).

Sus bent unteren (fd)warzent) Suma. STrfidet von bor linten Geite.

Jig. 10. Ammonites (stephanoceras) Humphryi (Sowerby).

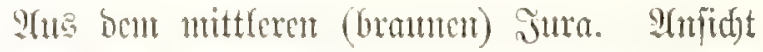
von Der red)ten Erite. 


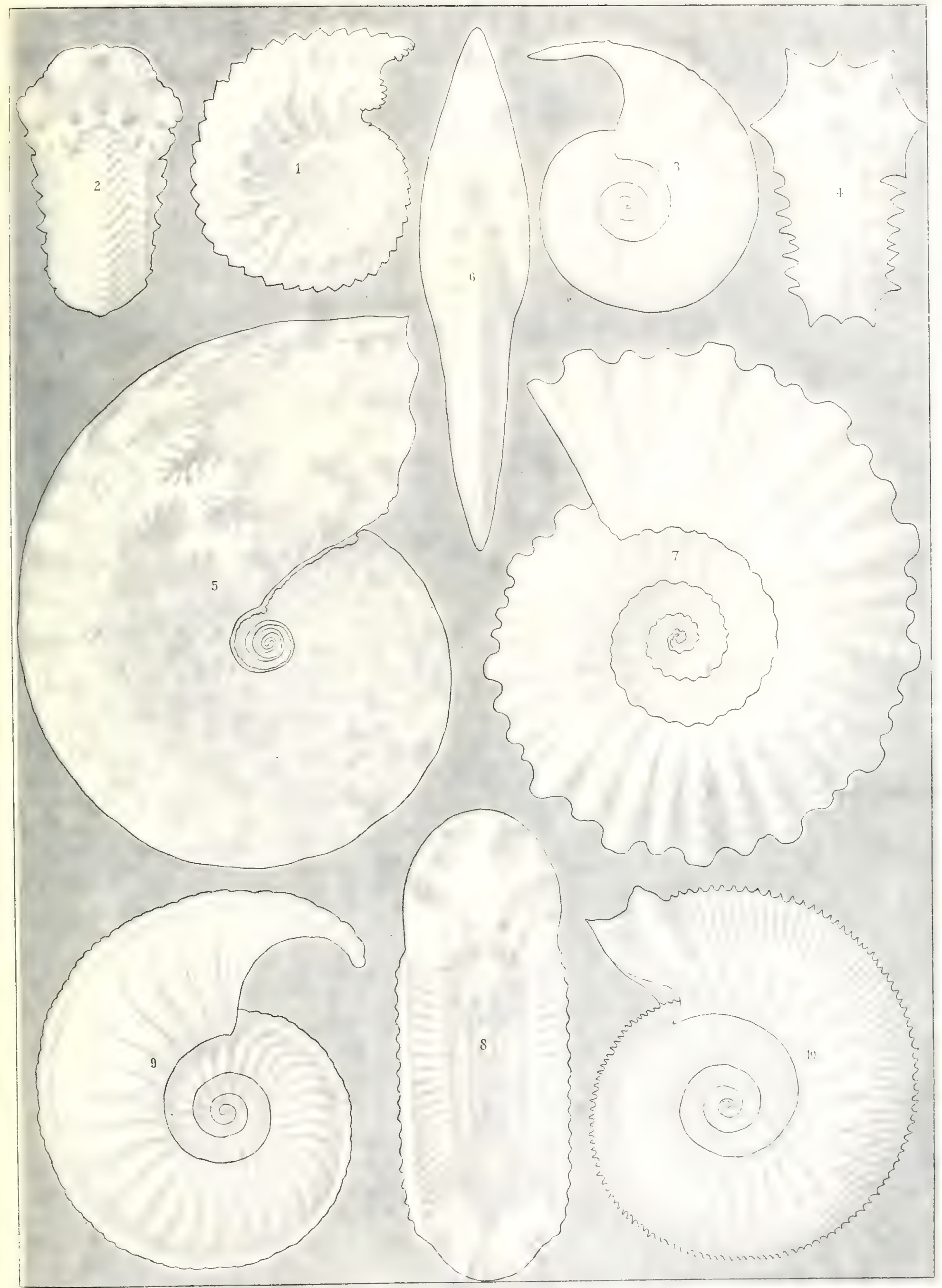



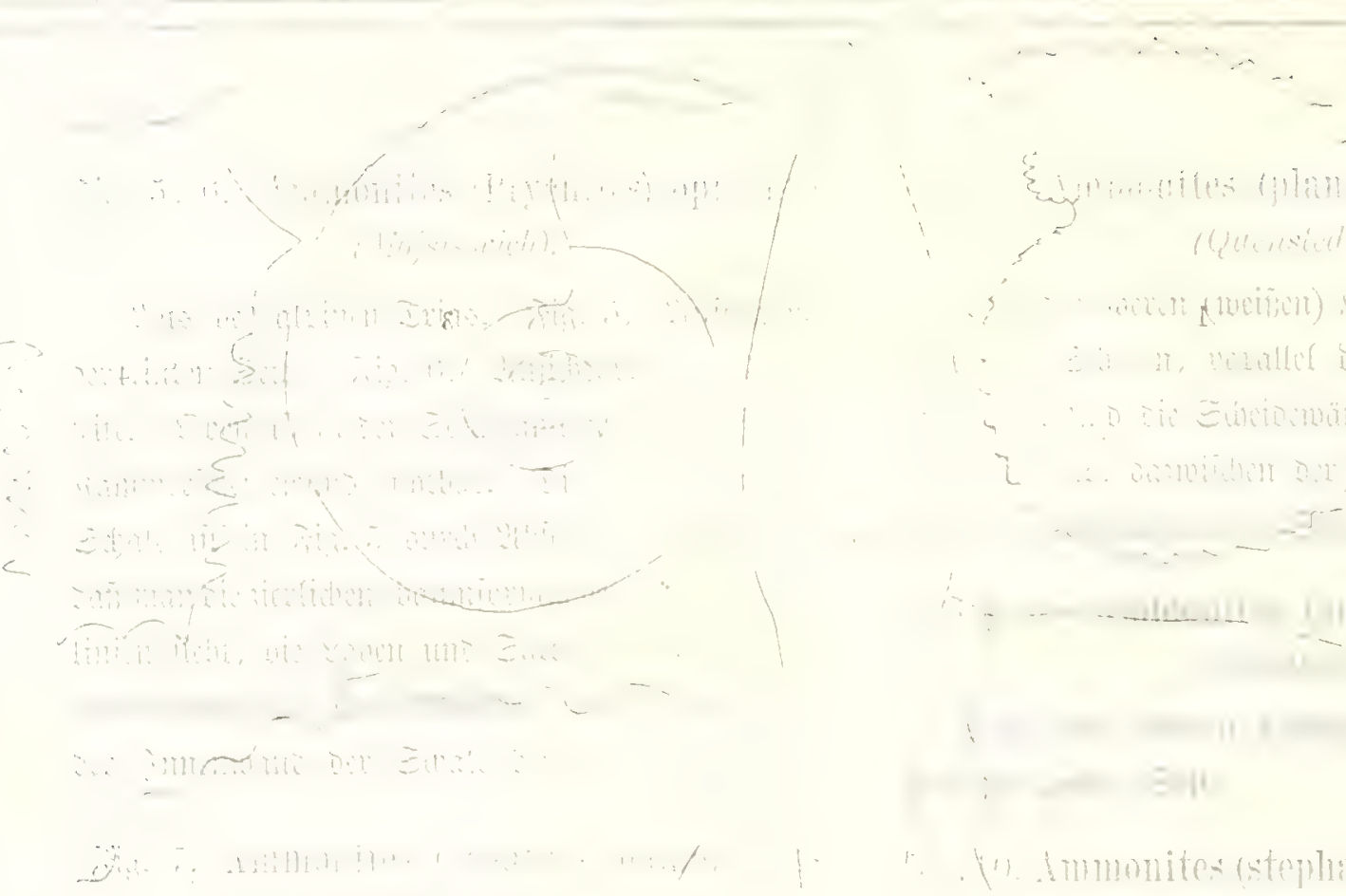

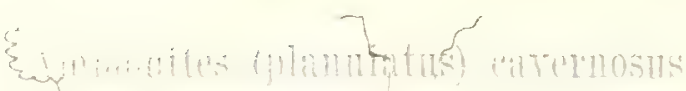
(Yuteriatl) $\{$ \}

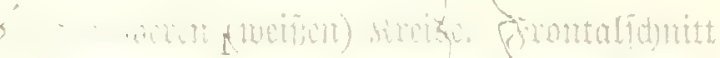

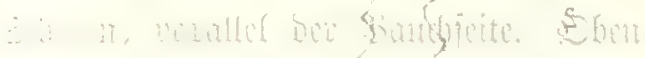

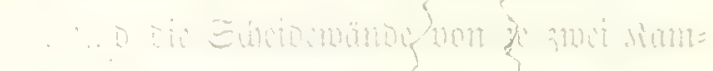

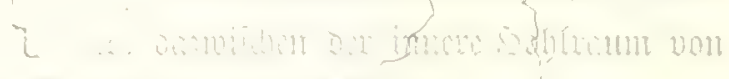

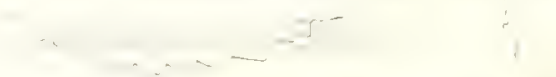

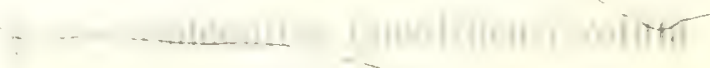

: 11 t 311

(1) Immonites (stephlanocerns) IInmulney

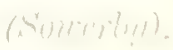

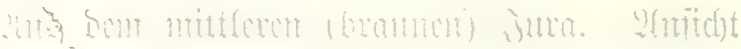

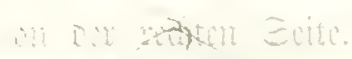




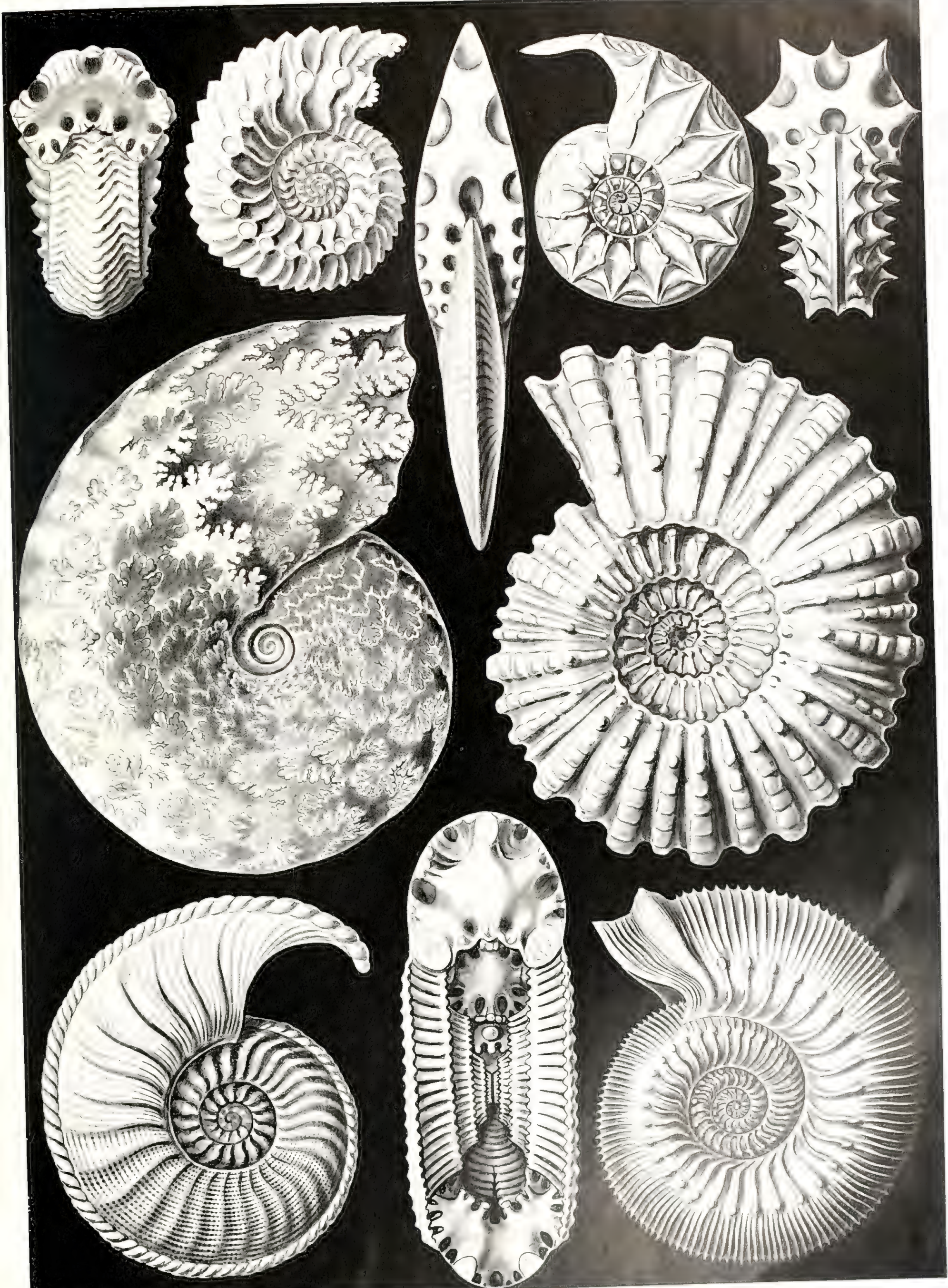

Ammonitida. 



\section{Campanariae. (oformenturument.}

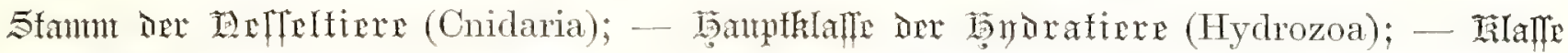

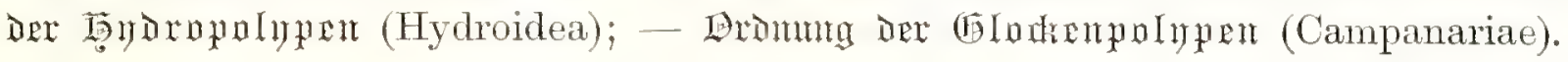

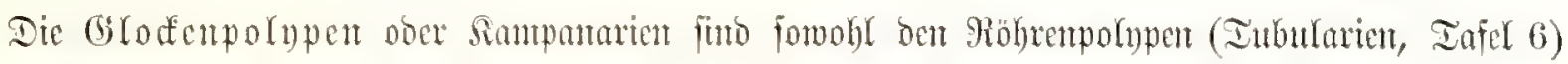

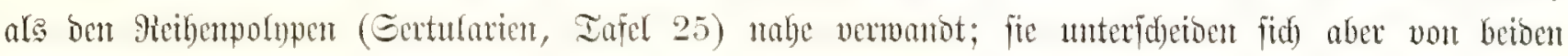

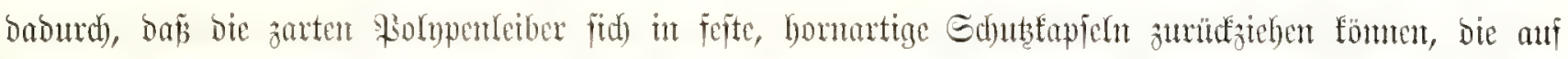

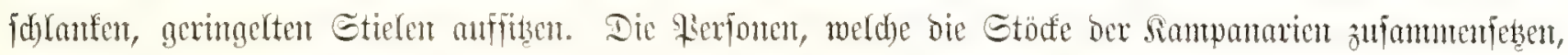

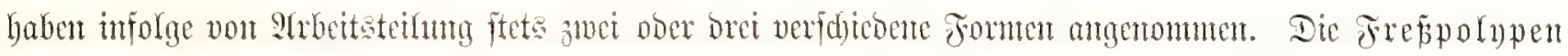

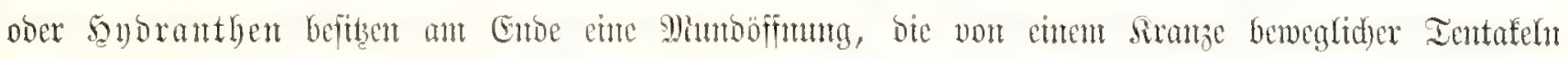

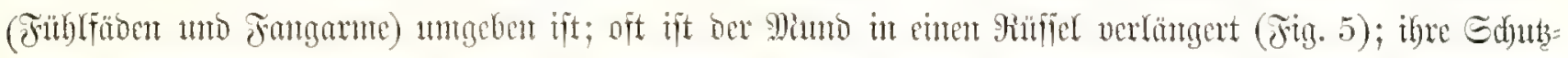

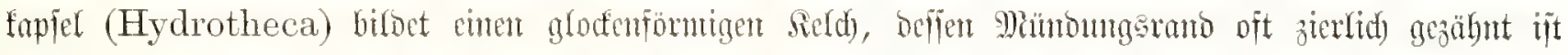

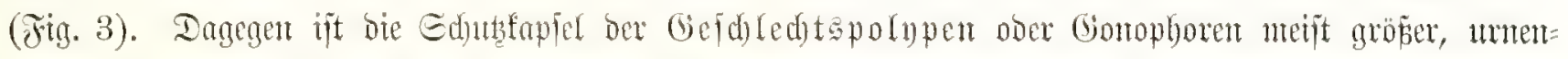

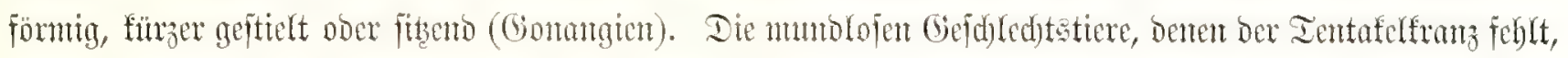

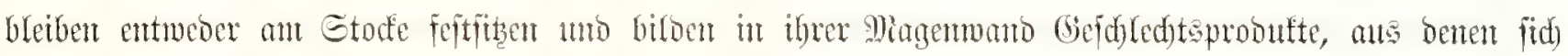

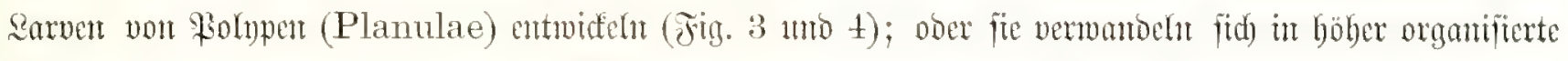

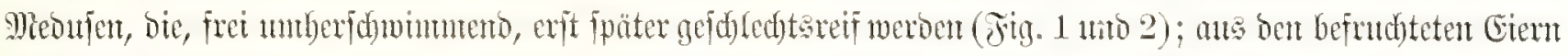

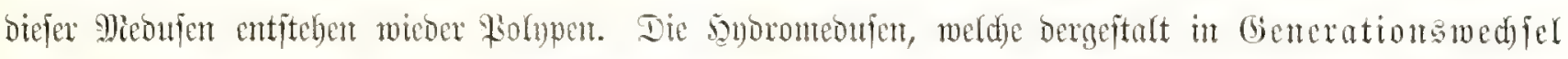

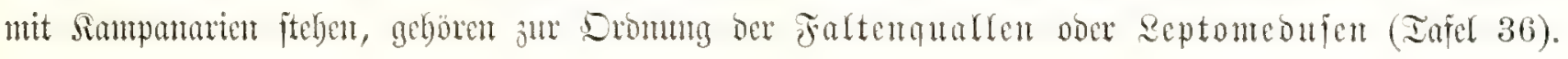

Fig. 1. Campanulima pimnata (Hueckel).

Der Stod biefer menen Simmantaric (von ber

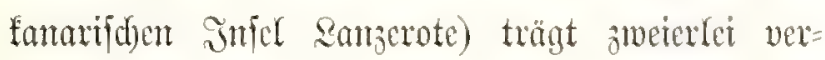
fifiedene 界erfonen: Die fleineren Freppolypen uno

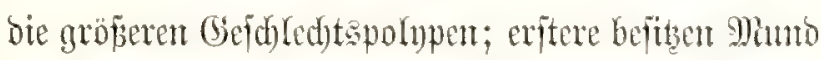

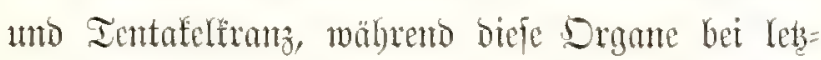

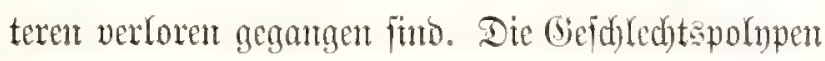
verwandeltr fïd) fpäter in frete Medufen, beren Sdjum

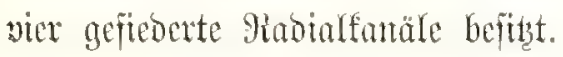

Jig. 2. Campanulina tenuis (Van Beneden).

Der Stodf biefer fimmantatie zeigt int oberen

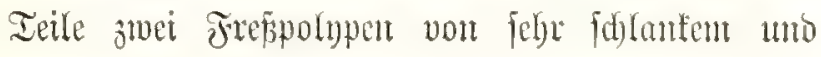

zantem Sörperbau (z̧wija)en beiben cine Snoppe),

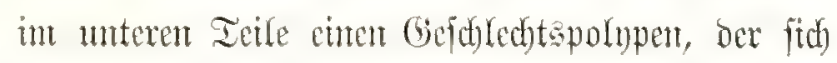

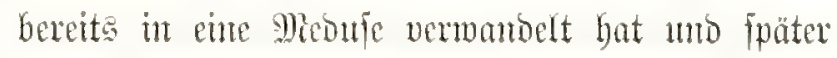
ablọ̈t (nnit vier einfad)en Rabialfanälen, bie an

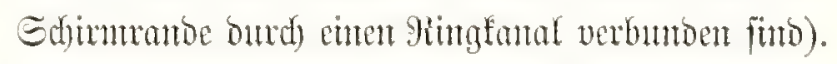
Unten in Grumbe ber Edjumthögle fitst bei ber Me

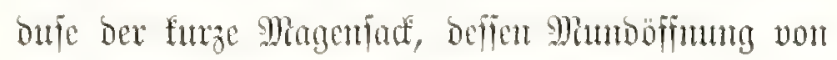

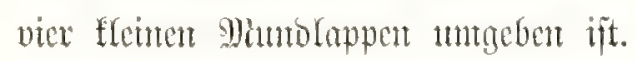

jotg. 3. Campanularia ptychoeyathus (Allman).

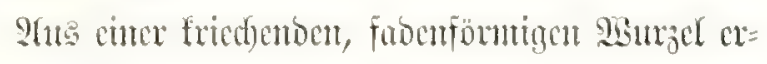

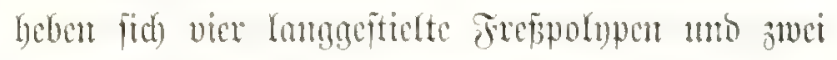

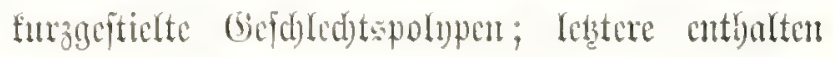


mebrere medufoibe Seime uno entfehren ber Mumb= öffumn uno bes Ientafelfranzes ber exferen. Diefe

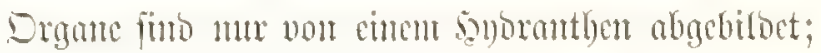

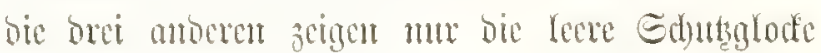
(Hydrotheca).

\section{Tig. t. Opereularella lacerata (Hincks).}

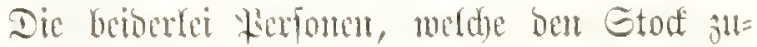

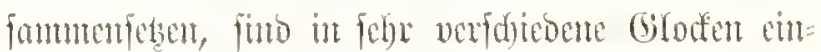

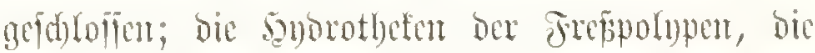
Minto ano Ientafelfumb tragen, find forlante,

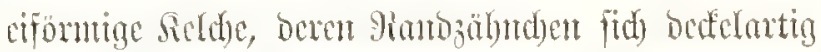

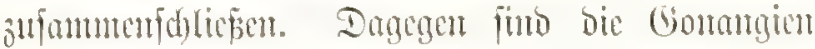

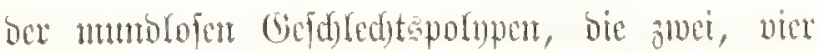

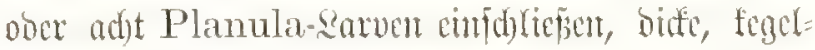

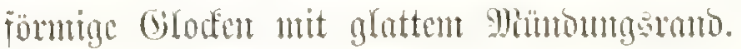

\section{Fig. 5. Ophiodes mirabilis (Hincks).}

Der fownad) verameigte Stod trägt brei ver:

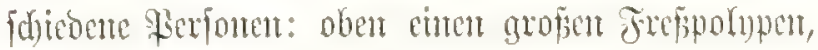
beffen Tentatelfrons cunen eiförnigen Giuffel un= gibt (ourd) che forafe Eimfdumm vom Mangen

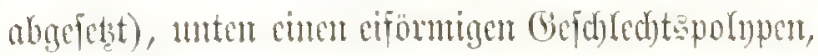
boflent unthuttlentoer Serdy geringelt ijt, anperdent brei

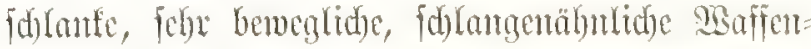

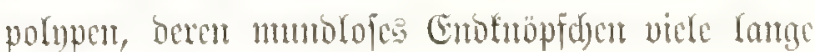
Refferfä́den entfentoet.
Fig. 6. Iypanthea hemisphaeriea (Allman).

Stus Dem fried)enden

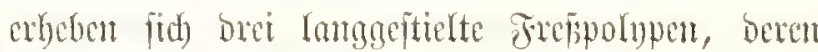
Sörper mit M)umb mo Imentufelfrant in bie halb=

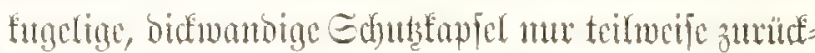
gezogen werbon foum; zall beiben Geiten fithen zwei

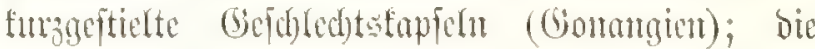
cif̈orntigen, Munblofen (Gejd)led)tspolypen in biejen

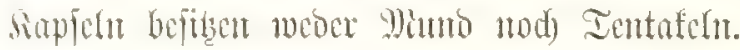

\section{Jig. 7. Obelaria genieulata (Hacckel).}

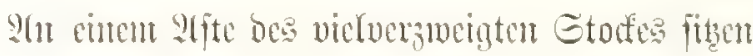
mebrese Freppolypen, vou bencen bre ben Tentafed= frans zesigen, Dex Den Miund untgibt. Iiefer unten

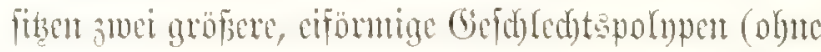
Munto uno Ientafeln); jeber von bicjen erzengt in

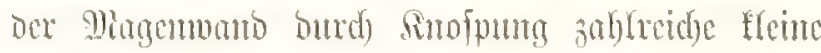

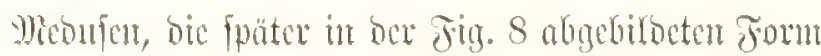
fret weroch.

\section{Fing. S. Obelia lucifera (Haeckel).}

Dic flente Micoufe, bic fid) in bost Gejd) fapfeln von Obelaria geniculata (Fig. 7 ) cntwidelt bat, jeigt ant Edhintrande enten Sirans vou

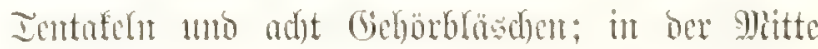
Diunt anto Bjagen, untgeben von vier Eicriftöffen. 


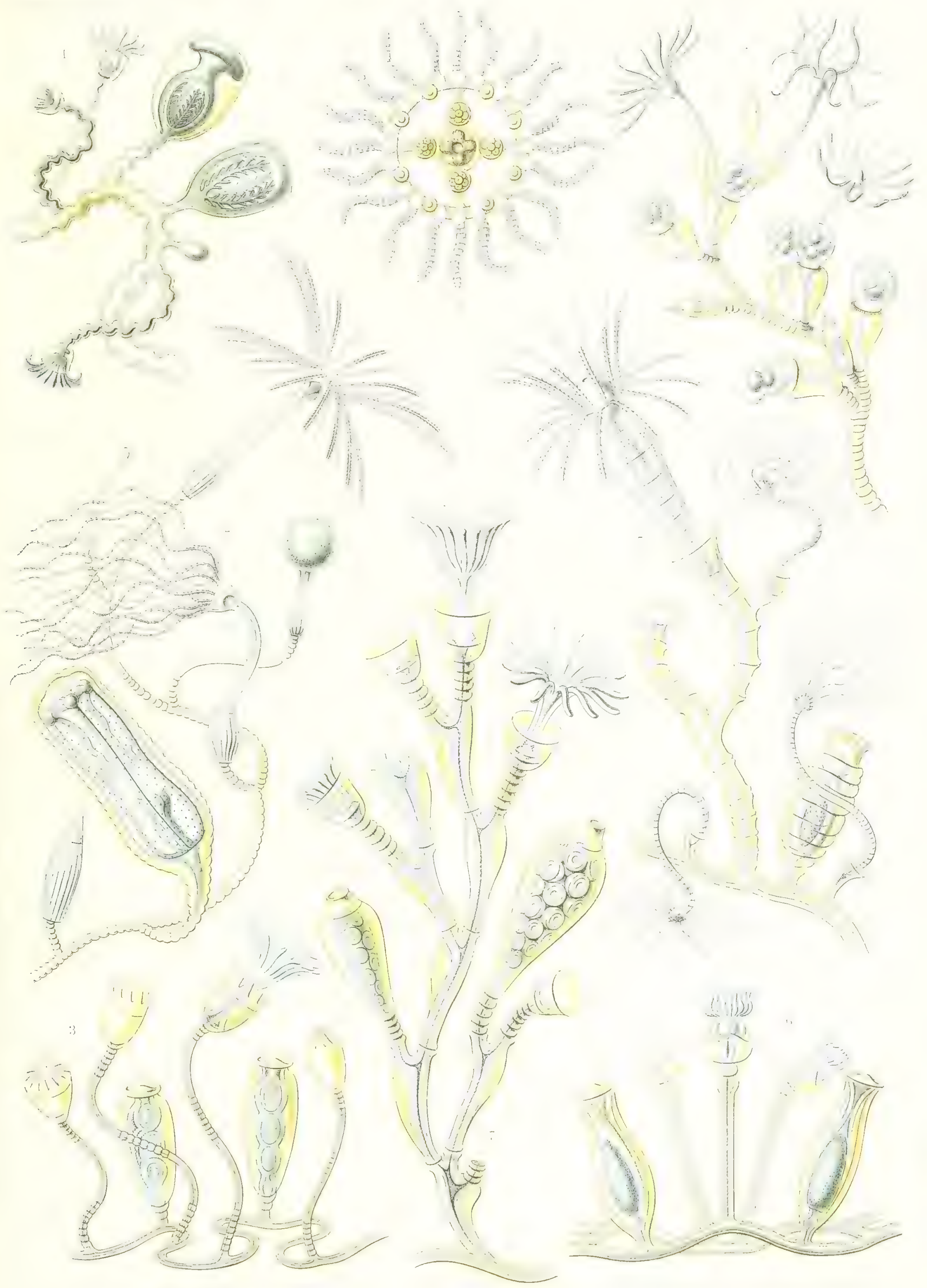

Campanariae. - silodiertpolipert. 



\section{Anthomedusae. Balummunuallen.}

Stanm onx I I Dromung Dex Dhuntentualfen (Anthomedusae).

Die Blumenquaflen (Anthomedusae) unterfdheiden fid) von ben übrigen brei Sromungen

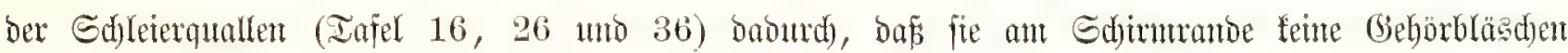

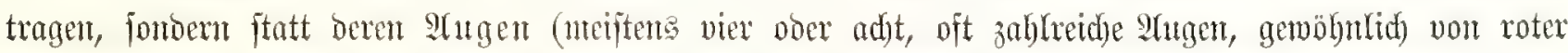

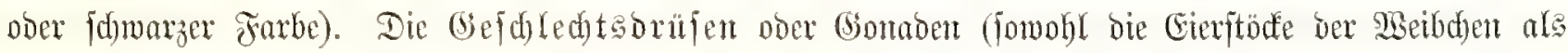

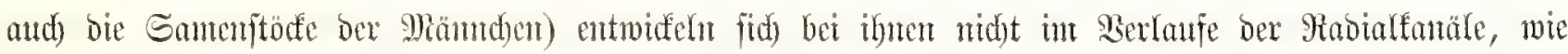

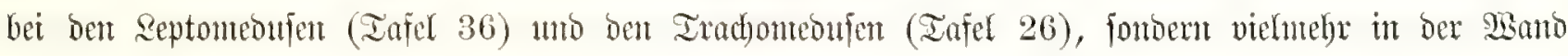

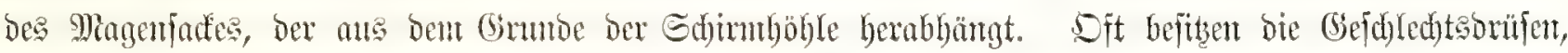

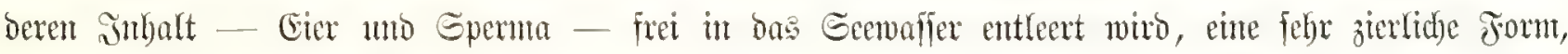

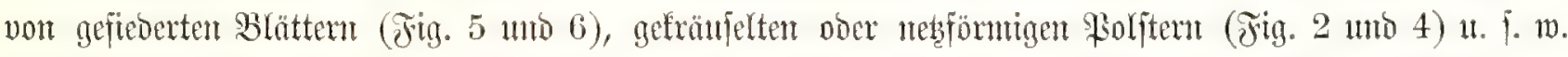

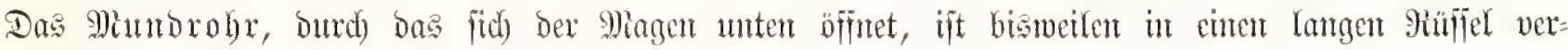

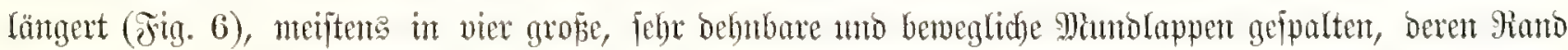

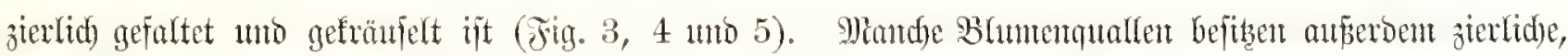
einfache ober veräftelte Muntogrifiel, bie an freien Endoe Meffelftöpfe tragen; Gald entipringen biefelben

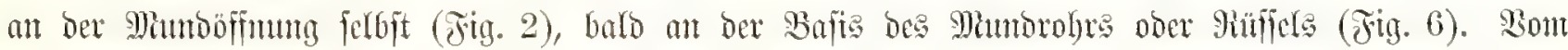
Ranbe bes glodenförmigen Sdjumes (Umbrella) entipringen urfprünglid) vier Ientafefr ober Fanganme,

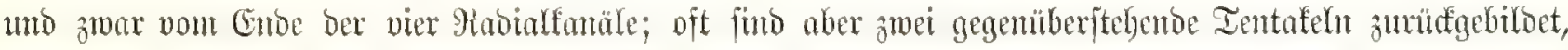

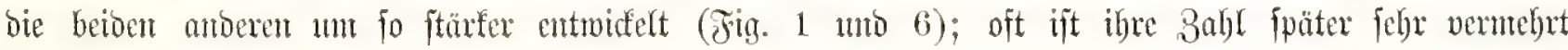
(अig. 2 und 3).

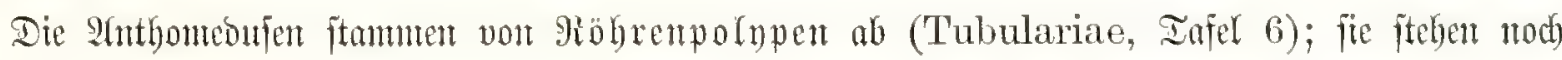

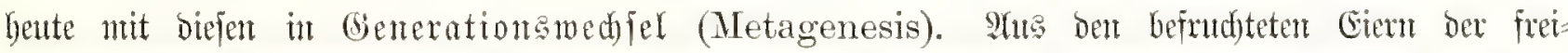

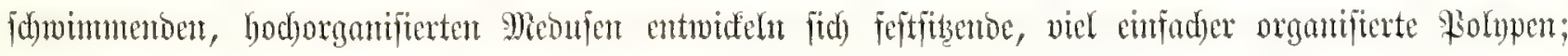
biefe erzenten burd) Sunopuntra wieder Miedufen.

Fig. 1. Gemmaria sagittaria (Haeckel).

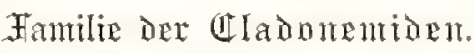

Geitenamidut der Miesuje, 20mal vergröpert.

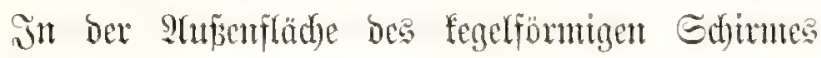
(Exumbrella) vertaufen vier freuzftämbige Meffel=

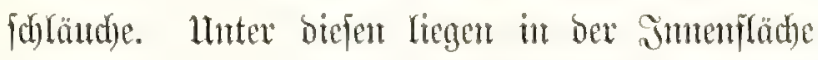
(Subumbrella) vier fojmale Miabialfantäle, bie fid ant Gdimmanbe in cinen gitugfant veremigen, oben aber in ben ciförntigen Magen cimmümoen.

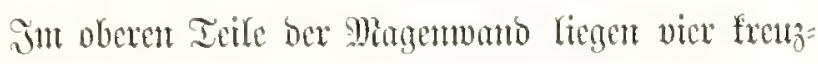
ftänbige (Gejd)

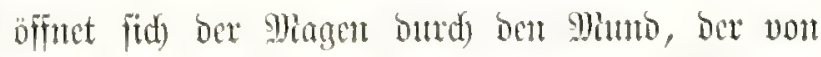
vier gefräuffelten Mimblappen umtgeben ift. SIm Sdjumrande fiben vier Ientafelt, von benen zwei 


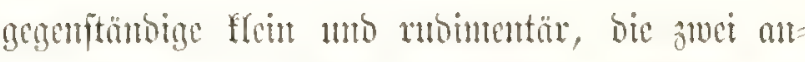

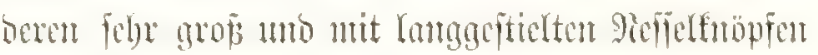
bewafinct jino.

\section{Jid. 2. Rathkea fasciculata (Haeckel).}

Familic one latarneliorm.

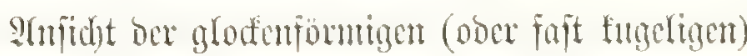
Meome vou ober, viemal vergrö̈ert. SMint fiebt

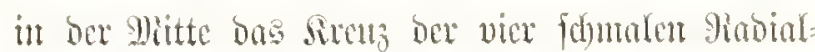
famäle, barumter bie viex rotem, faltigen (Gefdeled)t

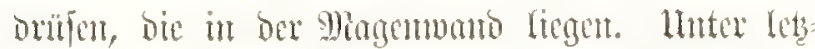
teren treten aupien bic gabelteifigen Emoäftdent Der

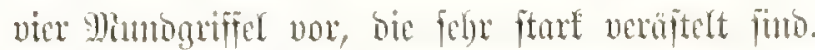
Die adteffige Finum, weld)e biefe Miumogrifiel umgibt, ift burd Minsferentzichungen ber Subumbrella beoningt. Die zalhlreiden Ientafelu, bie anjent unter bou Eduimuramo nortreten, fino gefräufelt umb auf ad)t Bünod ant Fianoe verteilt; itber jebent Bünod fibet ein :luge.

Fin. 3 und 4. Tiara pileata (L. Agassiz).

Familie one Tiarion.

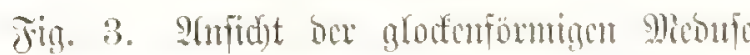
von unten, breimal vergröfert. Stan ftest in ber Mitte bie viex grofien, roten Mimblappen, bie ben

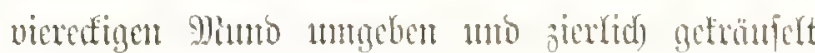

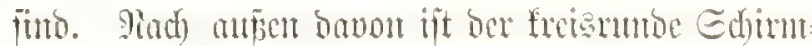
ranto fidfthar, imen feit Ditufetritg (Velum),

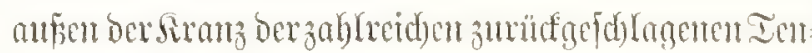

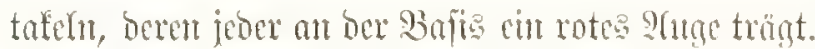

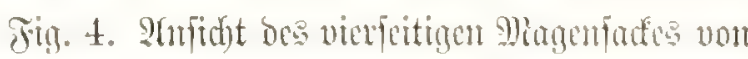
Der Grite; itt femer 18 and liegen bie metänmia

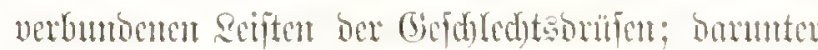
bie vier aropien, roten Matmblappen, Beren giänoer itarf gefaltet anto getrüulelt finto.
Jig. 5. Stomotoca pterophylla (Haeckel).

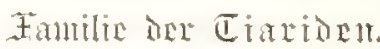

Penfidst bes vienfeitigen, faft futgeligent Magen=

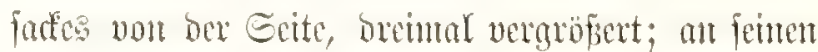

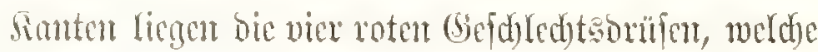
bie Form won siterfiden, Doppelt gefiederten Blät= teru Gaben; barunter bie grofisen, gefrüufleten Mumb= lappen, วแtritufgejd) Logen.

\section{Jig. 6. Thamnostylus dinema (Hacckel).

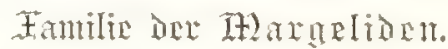

Eeitenunfidyt ber Micoufe (ctwas vou unten),

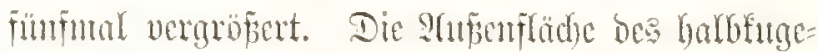

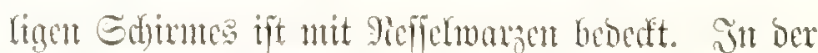
Mitte ber Simenfläd) hängt ber vierfetitige Magen=

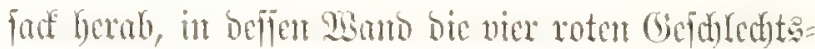

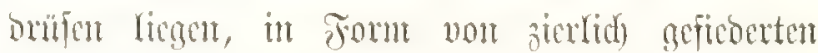

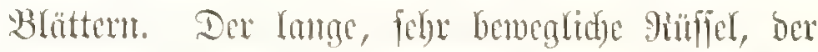
unten vour Mingen herubfängt (wic ocr Silöppel

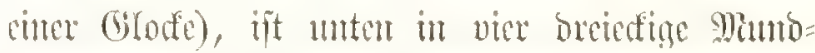
lappen gepralten, oben an ber Bafte wou vier fehr grofien, roten Mambgriffelu amgeben, bic fehr ftarf

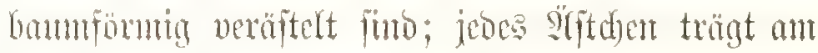

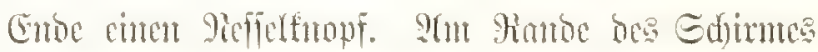

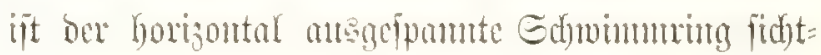

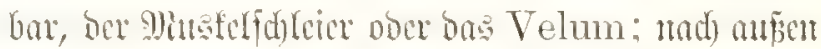
cin roter Sieffelring, ber ben Berveming beaft. Son ben unfurüngliden vier Ientafern, die an Enoe

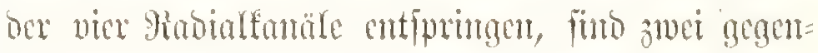

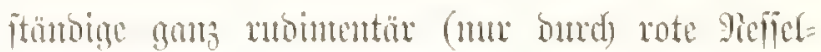
frröpfe amgebeutet); bic beioen anderen fino 1 an fo

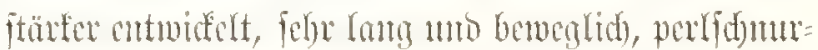

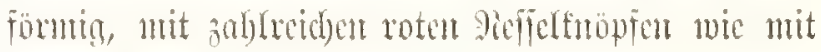
将ren befert. 


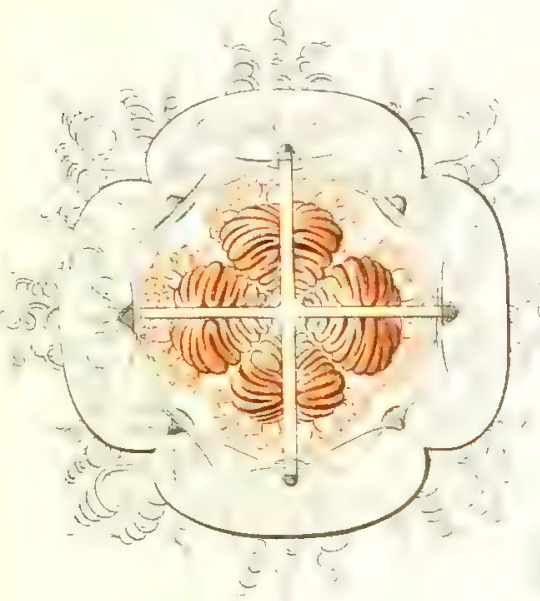

(3)

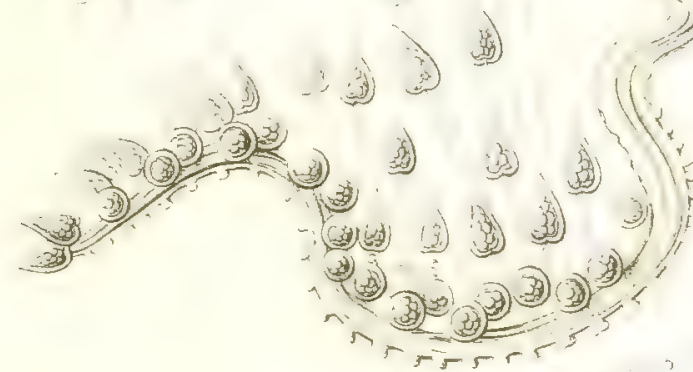

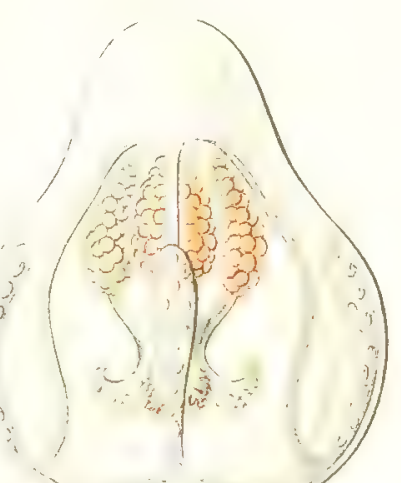

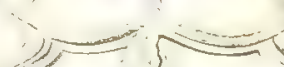

(i)

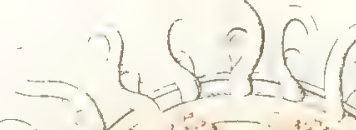

匀)

(3)

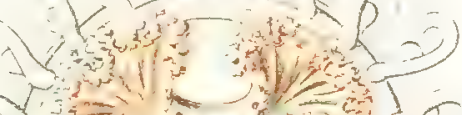

$\rightarrow P^{2}$ (

$\frac{1}{2}+10$

(3) -1$)$ $+4 e^{2}$

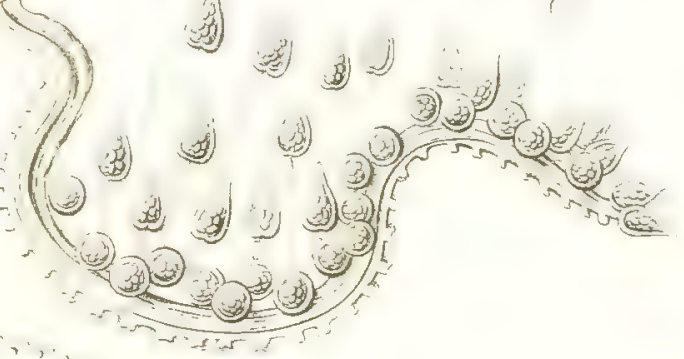

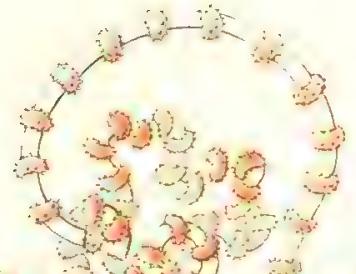

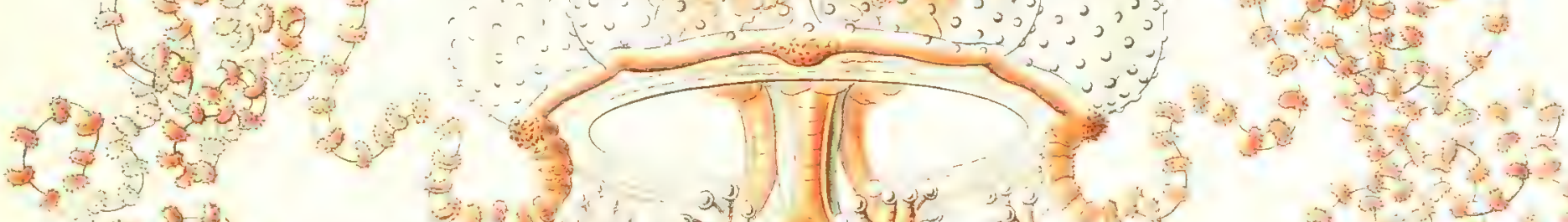

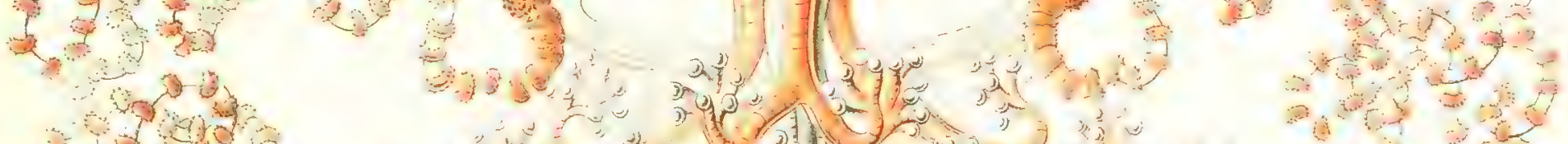

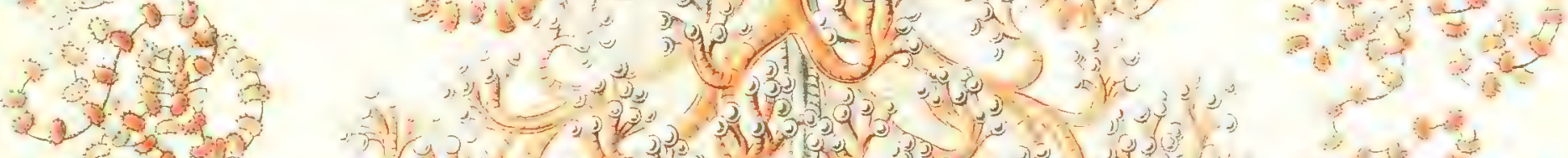

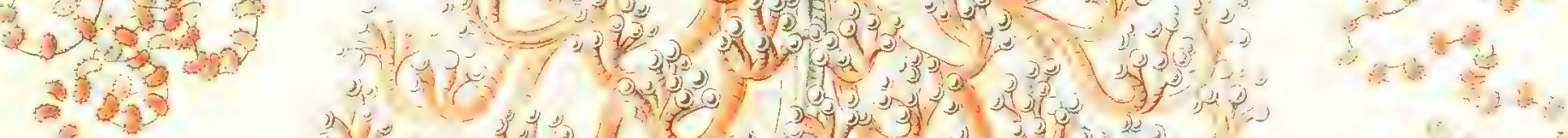

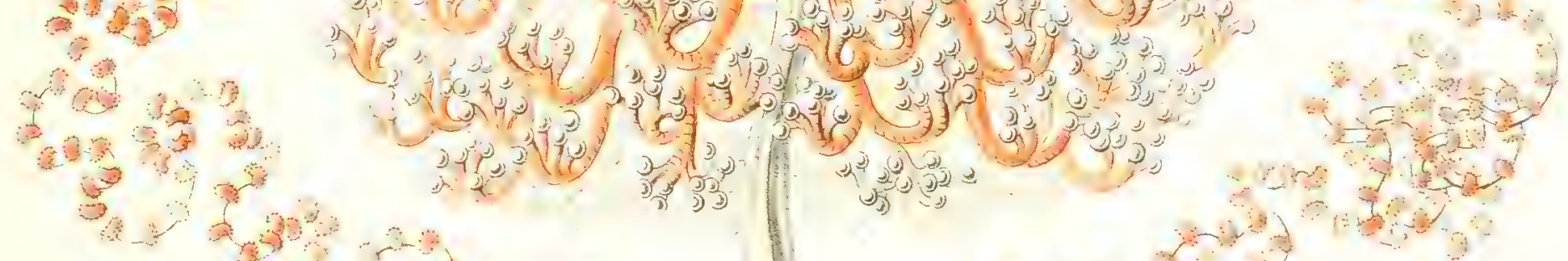

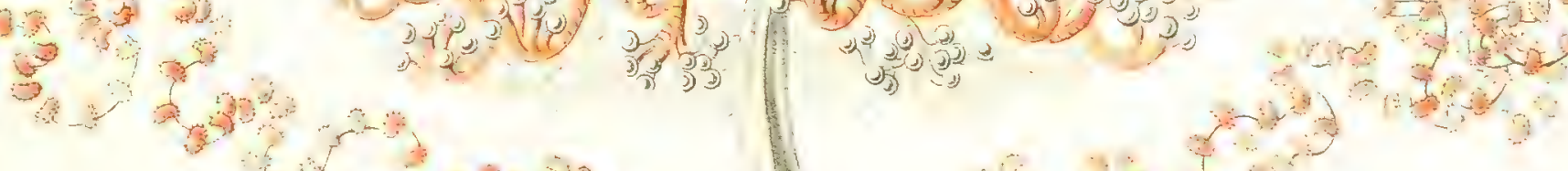
in

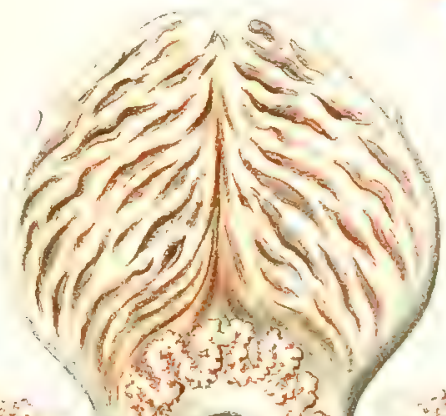

16. $\mathrm{C}(\mathrm{C}$ (19.

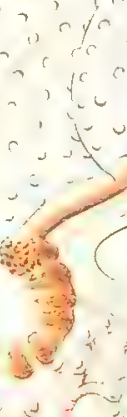

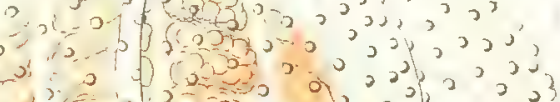
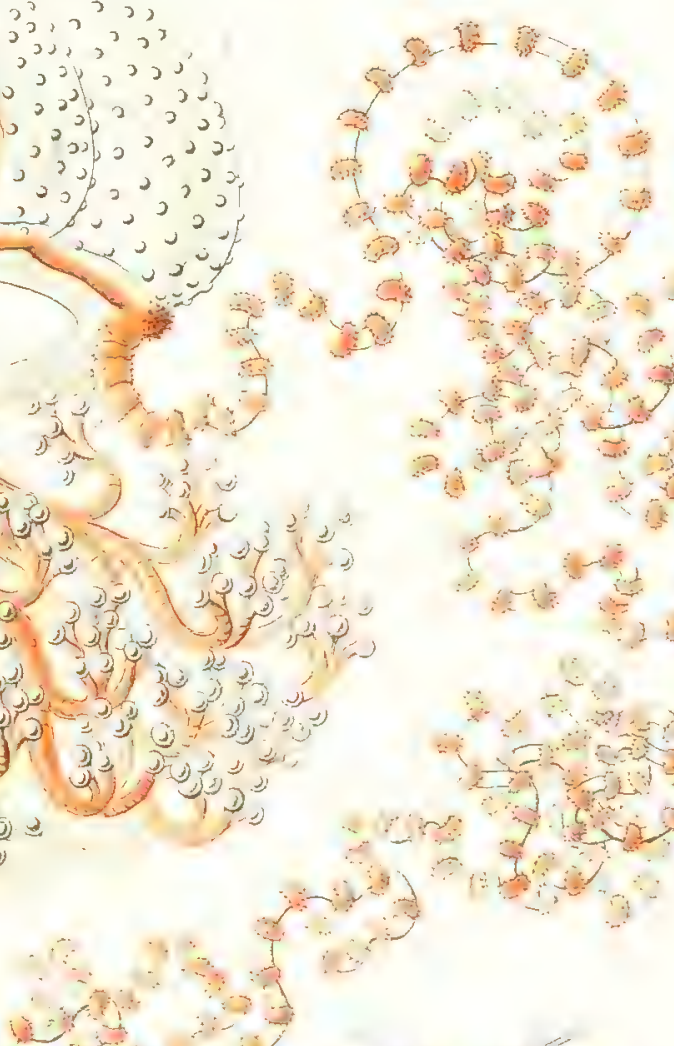

8 as 3 an

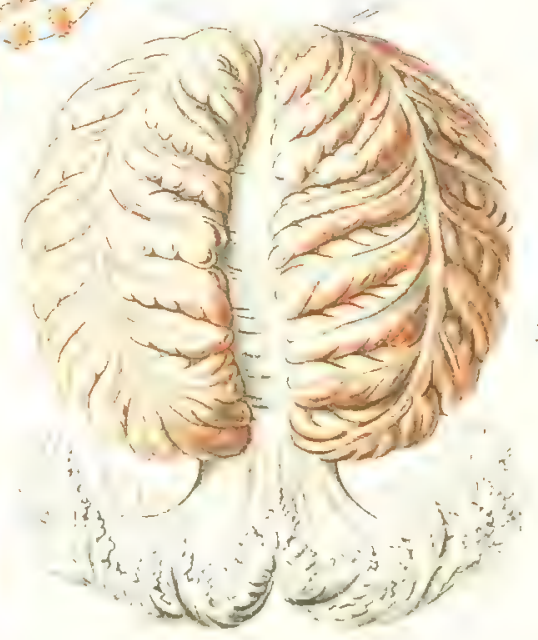

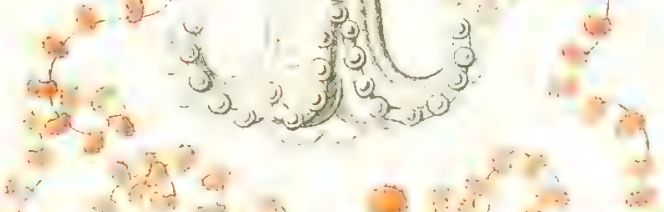

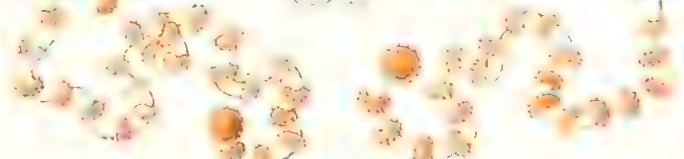





\section{Aspidonia. Strtilitiver.}

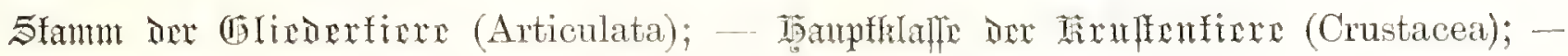

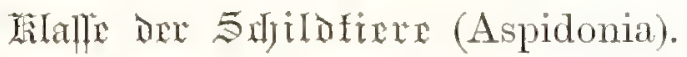

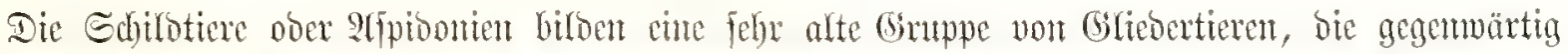

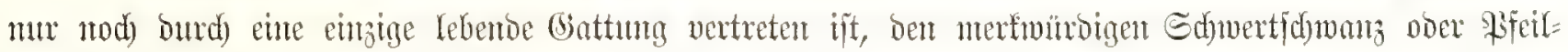

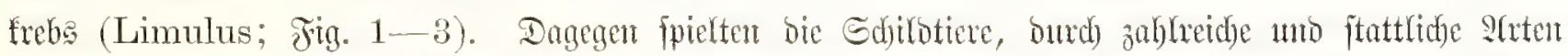

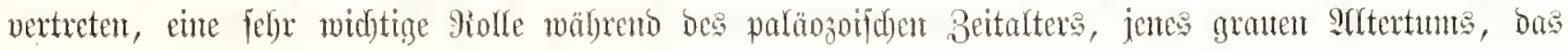

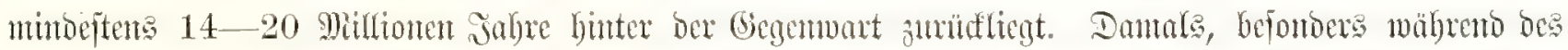

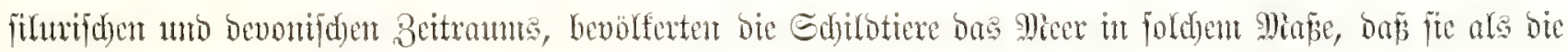

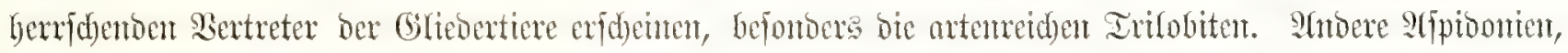

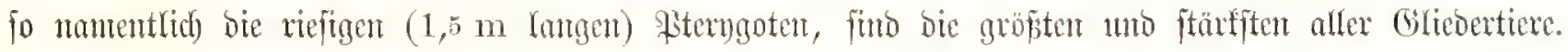

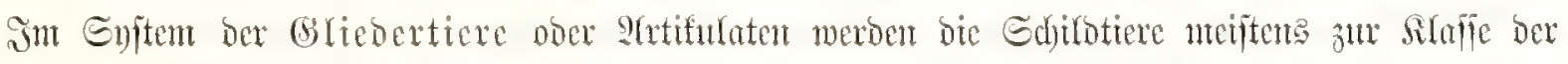

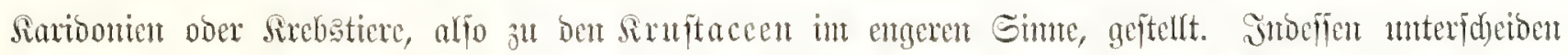

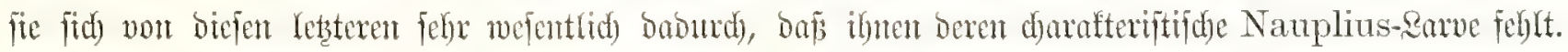

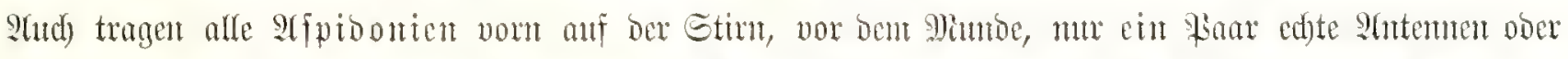

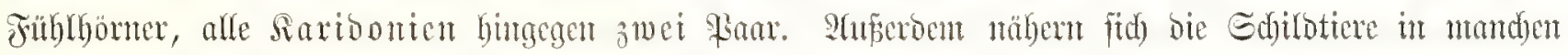

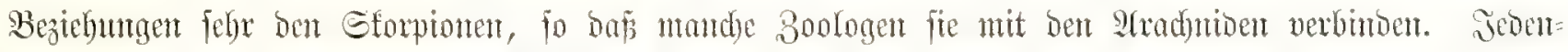

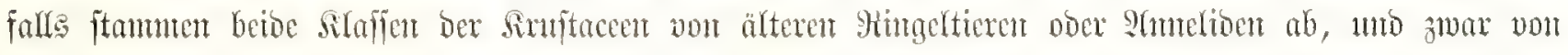

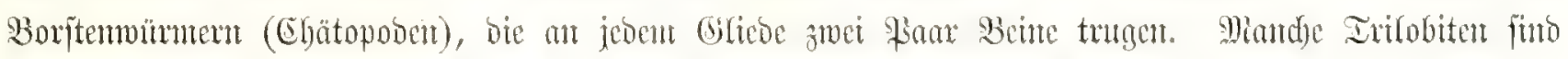

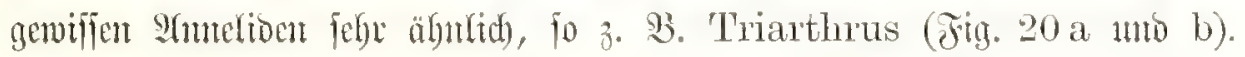

\section{Fig. 1-3. Limulus moluccanus (Clusins).}

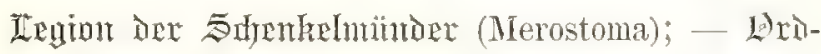

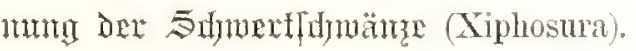

Die einzige heute nod) Iebentio Gattung ans ber Rlaife der Edhirdiere (mit wenigen Sraten, in Den wärmeren M(eeren).

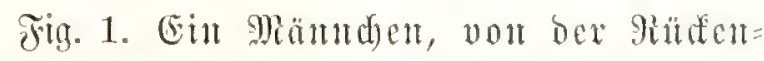
feite gejeben, ein Drittel natürider Gröpe. Der

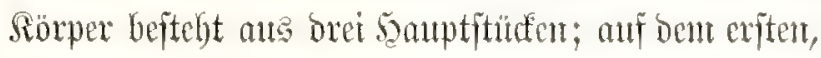

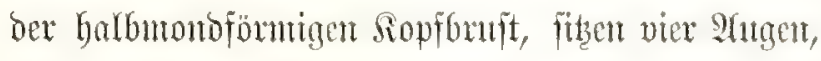
vorn cin Fan fleine cinfadye, weiter bintent cin Saar grofie zufammengefetite stugen; ons zweite,

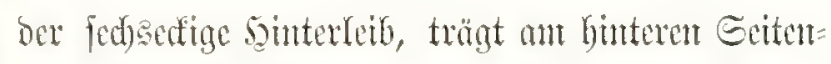
ranoe fedjs sian Eeitenitadyedr; Das britte, bemeg=

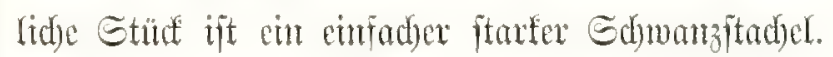

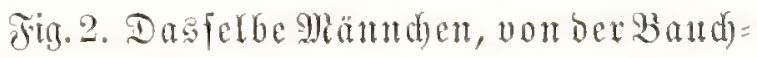

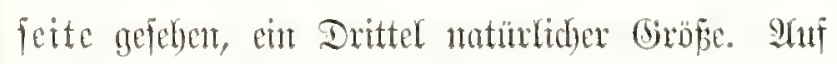
Der Unterfeite liegen unter Den grö̌en Siopfbruft=

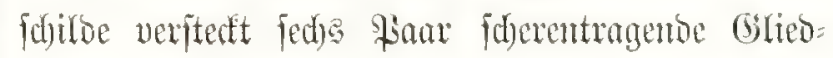

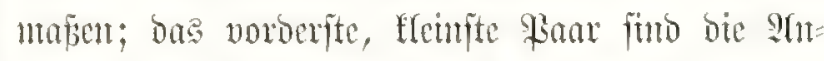
temten ober Fuhblgäner (vor dem Mlumbe getegent);

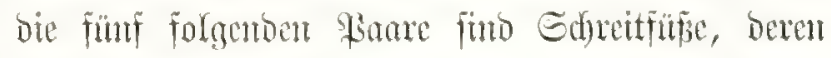
Bafalghieber sum Siunen bicnen. Itnter bent fect) s:

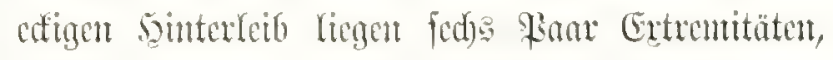

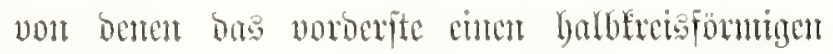


Situmentodel bifoct mo bie folgenoen fünf \&an Sicmenfupie bebedt.

Jig. 3. Sarve bes Limulus. Die jugend= lidfen sarven ber Ed)wertfdwänze Gaben nod) feiten

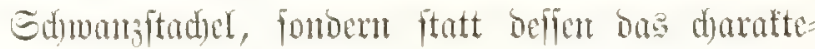
riftifbe Echnangidilo (Pygidium) Der Iriboliten (Jig. 6, 9, 17 แ. F. w.). Sic werben baher mit

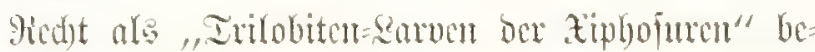

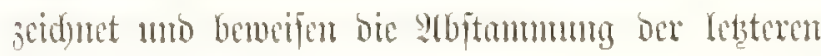
non Iribbiten.

\section{Jig. 4. Eurypterus lischeri (Eichacald)}

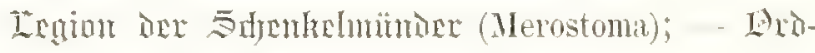
mun ox⿺ Riefwkxbị (Gigantostraca).

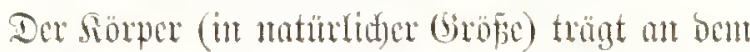

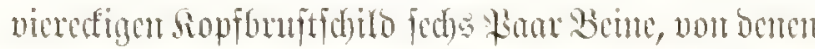
bas vorberite, dic sutemen, bick nidyt fidjtbar, bes letste mit emer jtarten Edyere bewaijnet ift; worn

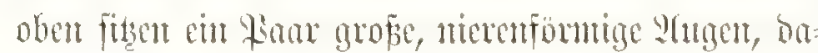
zwifben ein Pan freme Punftangen. Dex lange Sinterleín beftebt an zwolf Gificoern mo cincm Edmoanjitadel.

Jin. 5. Pterygotus anglicus (Agassiz).

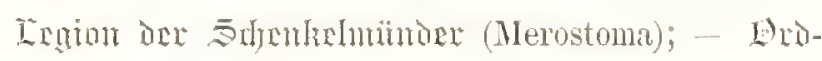
mang ber Litclenturble (Gigantostraca).

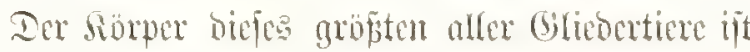

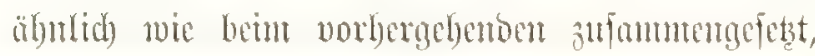
mixo aber zelute bis smolfmal fo grop $(1,5 \mathrm{~m}$ lamg $)$. Das crjte Bemmar, die Gutemen (bei bet norigen Let fehr flem unb unter bon Sopf veritedt), ift hiex lang mid folant, mit cincr Edyere bewafnet.

Jig. 6-21. Trilobita ober Palaeades.

Irginu ine Dreifeilfreble (Trilobita), verftenert.

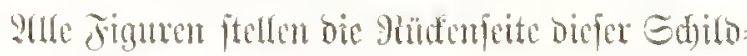

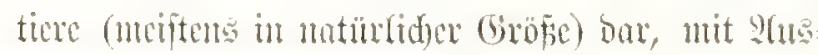

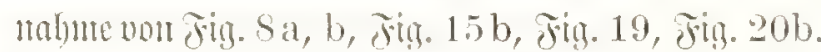
Jhren Peumen bat bie artemecide Segion ber Irilo.

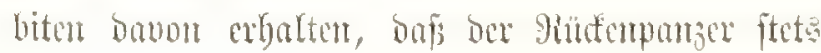

burd) smei parallele Sänngifudent int brei Felber geteilt ift, cin mpanes Mittelfelo (Epindel ober Rhachis) แmb jwei paarige Ecitenfeloer (Pleurae).

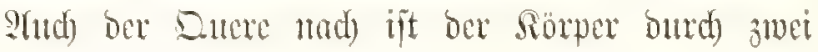
parallele Tramonerfalfurd)en in brei Stüfe geteilt: Siopf, Riumpi un Gdumanj. Der Sopf (Caput) ift bex becitcite Ieil, oft balfontonoformig uno binten in swe lange Eeitentbönex atsgezogen; cr trägt

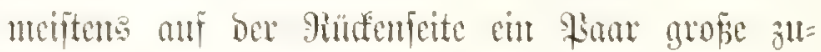
fommengejete S(ugen. Der Mumpf (Thorax) ijt

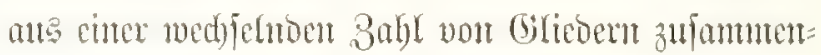
gefelst. Der Sdywanz (Pygidium) beịtelnt meijtens

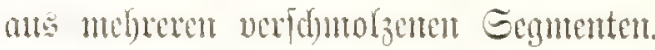

Fin. 6. Trinuclens Goldfussi (Barrande).

Fig. 7. Deiphon Forbesi (Burrande).

Jin. 8. Phacops latifions (Bronn).

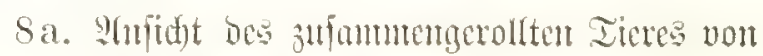
nort, Sb von ber linfen Erite.

Fin. 9. Dalmania punctata (Barrande).

Jin. 10. Ampyx Rouaulti (Barande).

Jig. 11. Paradoxides bohemicus (Boeck).

jing. 12. Cheirurus insignis (Beyrich).

Jig. 13. Lcilaspis Dufresnoyi (Burrande)

Jig. 1t. Megalaspis extenuatus (Angelin).

Jig. 15. Harpes ungula (Sternberg).

15 a vout güufen, 15 b von ber red)ten Geite.

Jig. 16. Agnostus pisiformis (Lime).

Jig. 17. Lichas palmata (Burande).

Jig. 1s. Hydrocephalus saturnoides (Barr.).

Jig. 19. Sphaerexochus mirus (Beyrich).

E(nfict) von ber lintur Erite.

Fitg. 20. Triarthrus Becki (Beechov).

$20 \mathrm{a}$. 9(nfid)t notr bet Siüfenfeite; 20b. STtt= fidst von ber Bandjaite. Dicje Irtlobituform ge=

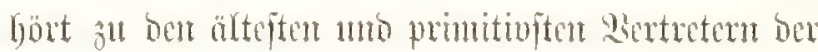

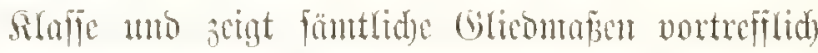

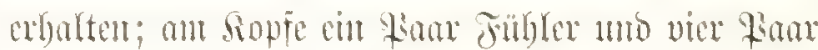

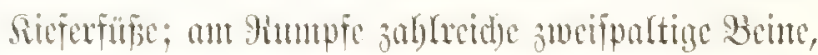
beren binterex slft fammförmige Sienten trägt. 


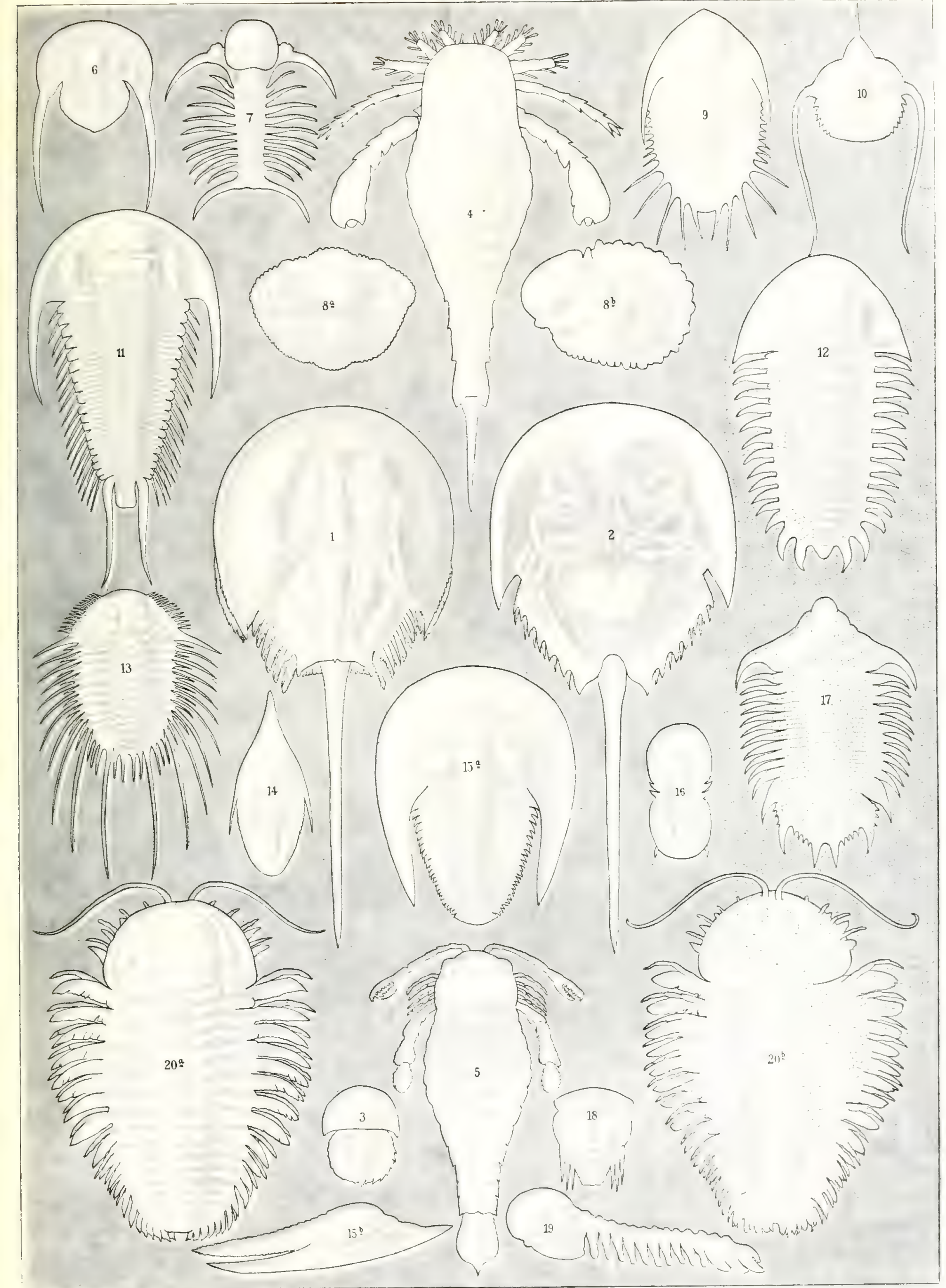





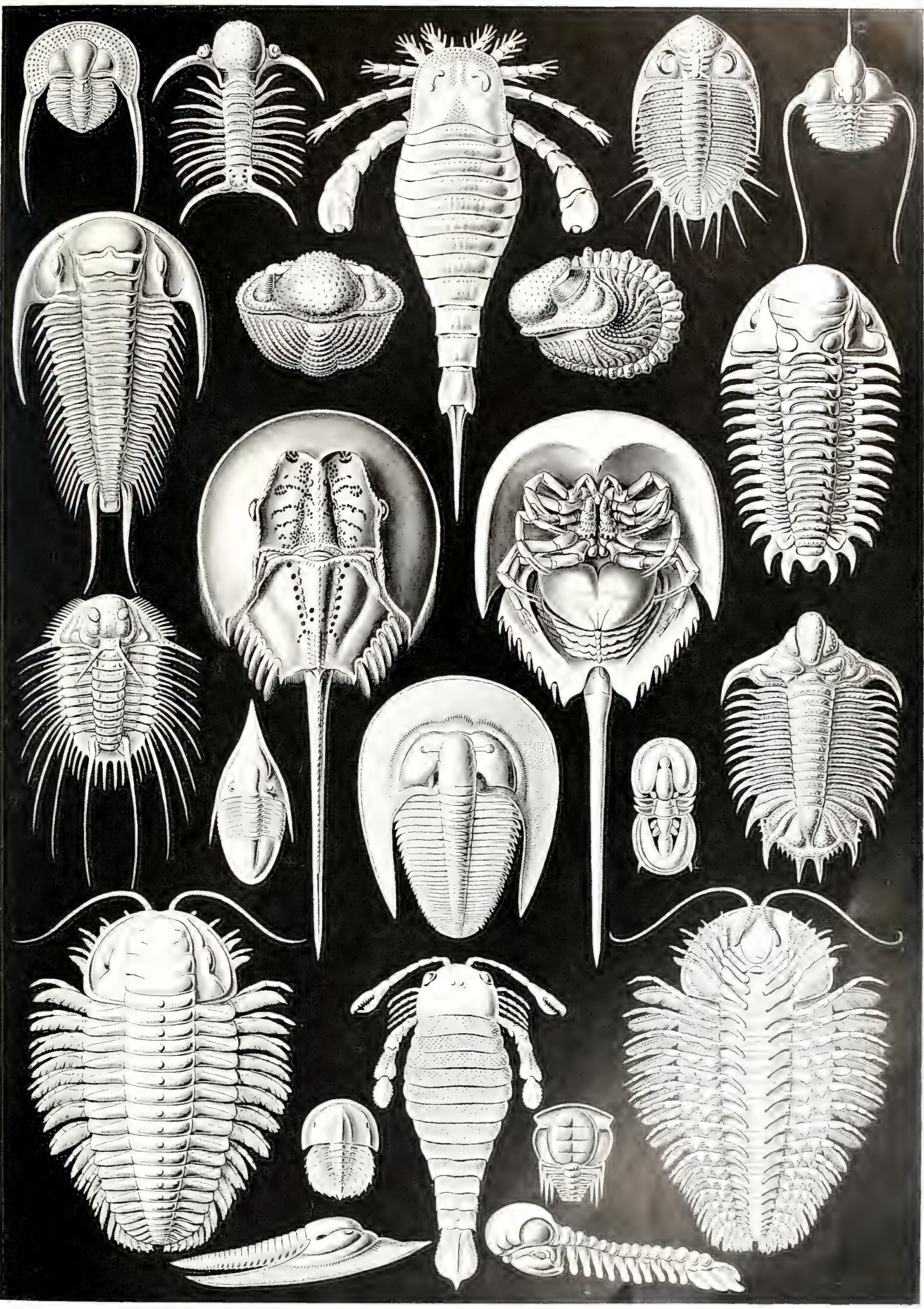

Aspidonia. 



\title{
Stauromedusae. berthermaller.
}

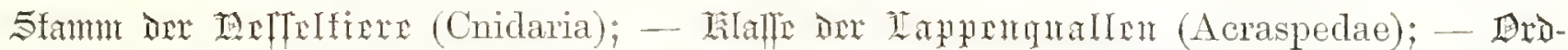 \\ mug ont bedrexuallen (Stauromedusae).
}

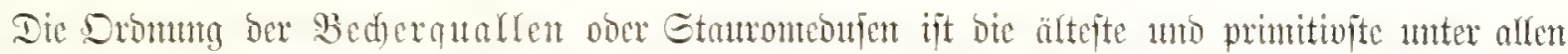

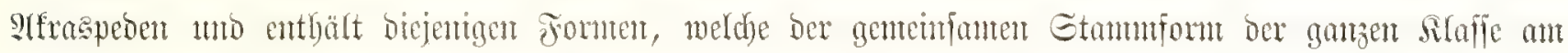

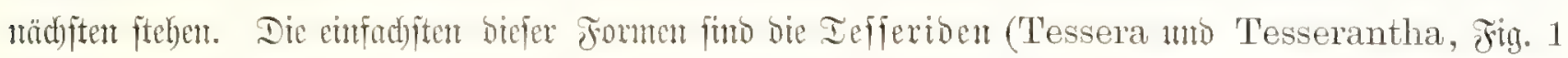
unt 2); ifre Srganifation meid)t mu menig von Derjentigen des Scyphostoma ab, jenter Scuphopolypen=

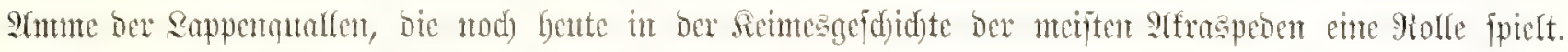

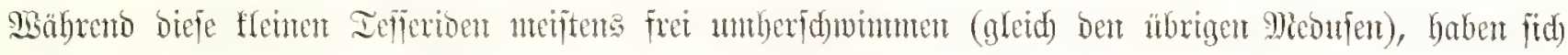

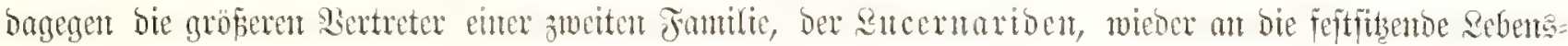

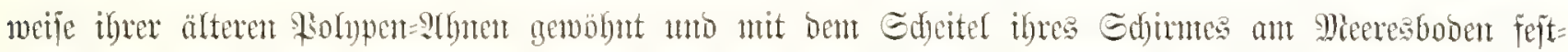

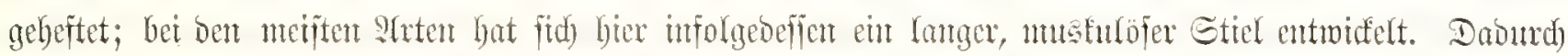

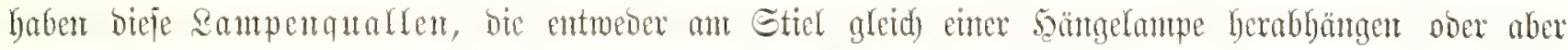

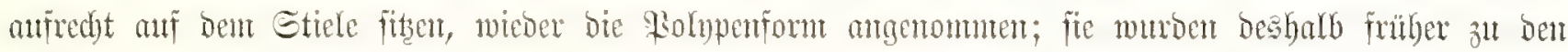

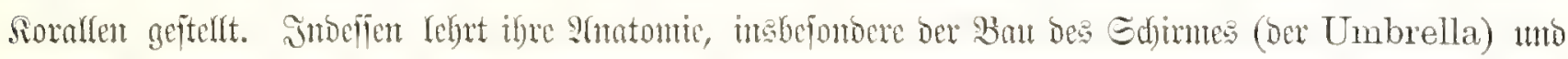

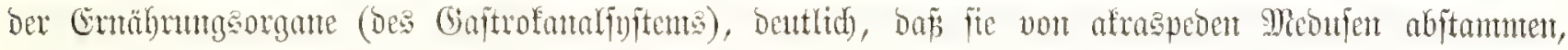

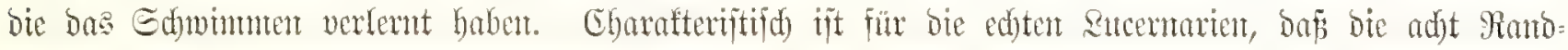

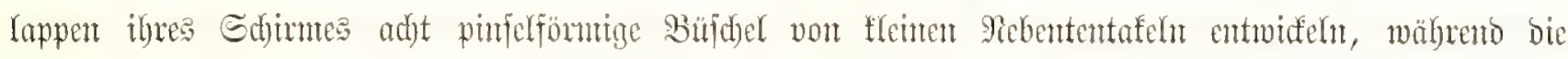

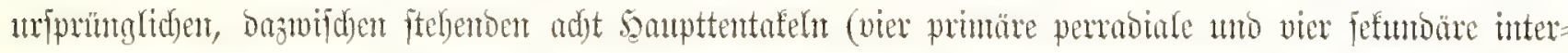

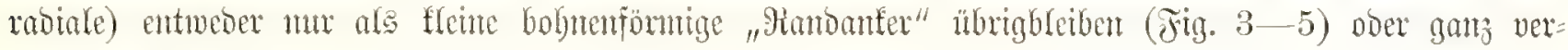
ichuinden (Fig. 7).

Fig. 1, 2. Tesserantha connectens (Hackel).

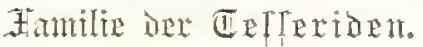

Fig. 1. Arnfidst ber frei formimmenoen Becherqualle vout ber Seite, jefmmal vergröperert; die 16

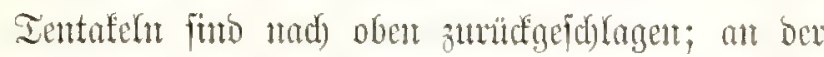

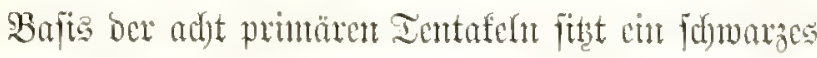

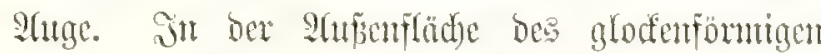
Edjumes (Exumbrella) vertaufen 16 Meffetripnen (ad)t ftärtere perrabiale mo adjt fdjwäd)ere inter: rabiafe). Unten aus der Gdjimmbähle hängt bas vierfantige Miagemrohr herab.

Jig. 2. 9trfitut berfelben Bed)erquafle vont unten.

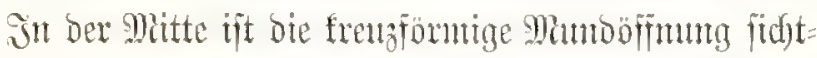
bar, unngeben vou vier zierlid) gcträufferten 9 Muno=

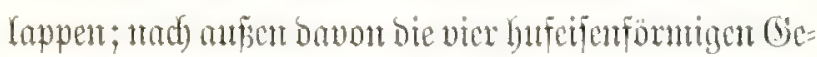

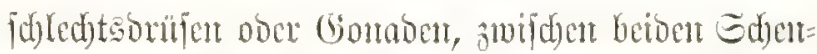

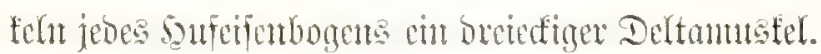

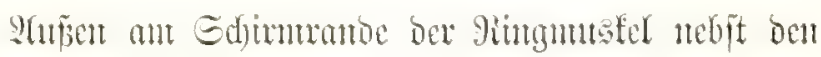
SUnfäben ber Ientafertu. 
Fin. 3-5. Haliclystus auricula (Clark).

Fantic ber cuermation.

Fig. 5. Sunfitit ber sampentualle wout ber Exite; ber fleifdige Etiel, ber vour Gdyettel Des ulodenforntign Edjumes (Umbrella) entipringt, ift

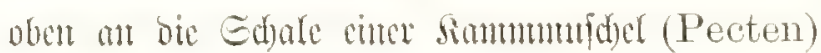
ungefuftet. Der Edjirntrano (untent) ijt in acht orecerfige gionolappen getcilt, bic cin pinfelförmiges

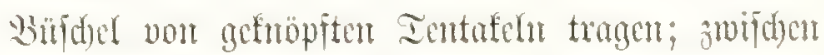

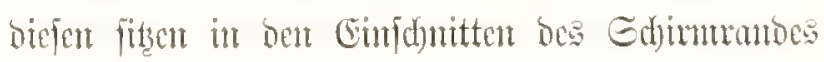
bie ad)t "Mantounfer", bie untgebirocten litberrejte

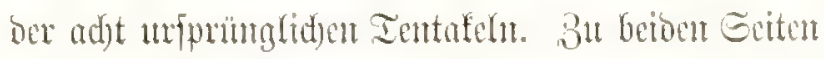
ber numfuldojen Mingentcifte (Tüntole), bie jid) in ber Mitte ber Figne von Etier herabsient, liegen

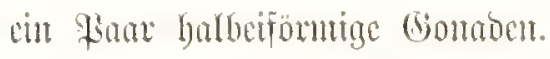

Jig. 4. Dicfelbe Sampenqualle (Jig. 3) mit

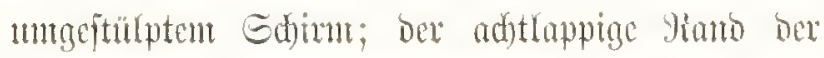

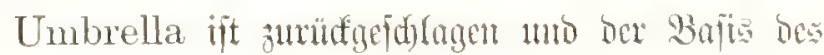
Gtiels gentäbert; in ber 9litte tritt unten ber vier= fantige Siliffel frei vor.

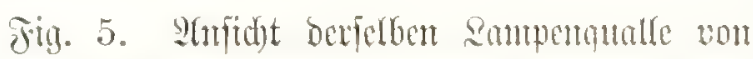
nnten; it ber Mlitte bas Mimntrents. Dic vier bia= gonalen Eeiften (Iöniolen) fino die interrabialen

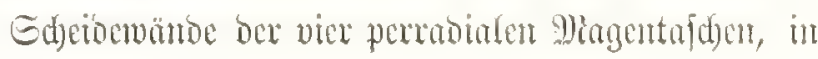

beren unterer \$Bmo bic vier Paan Gionaben (Gie=

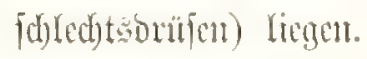

\section{Sig. 6. Lucermaria bathyphila (Haeckel). Hamilie ine Irrexuarion.}

Duerfonitt burd) ben Etiel cinex Eantengualle, Deren sibrperform in wejentlidjent ber in Fig. $3-5$

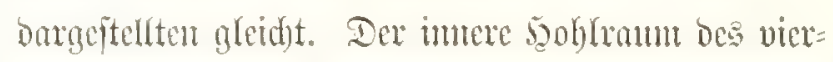

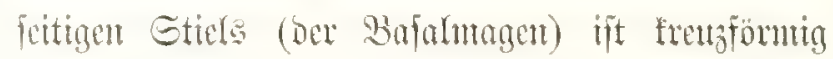
แno wiro buth vier vorfpringenoe Rüngeleiften (Iüntolent) in vier Iafdent getcilt. Die Musfel= bänocr, bie ber sänge nad) in ben Iäniolen ver=

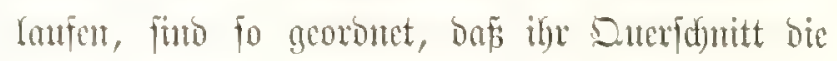

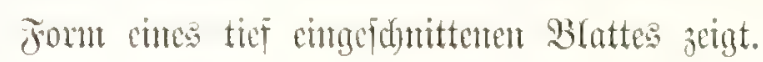

jig. 7. Lucermaria pyramidalis (Haeckel).

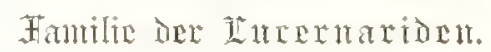

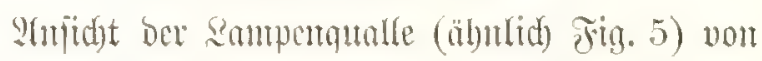
unten. Mian fielgt in ber Mitte bas Muntufrens uno

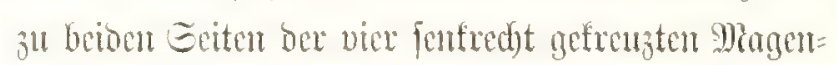

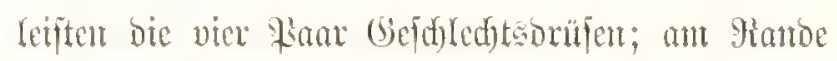
Die adjt panrweife genäherten Ranblappen, jwifdyen

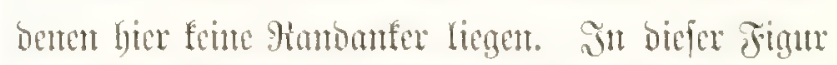
fteben bie Perrabion (Etrahlen erjter Dromung) biagontal, bagegen in Jin. 5 bie Etrablent ameiter Dronme (bic Suterrabien). 


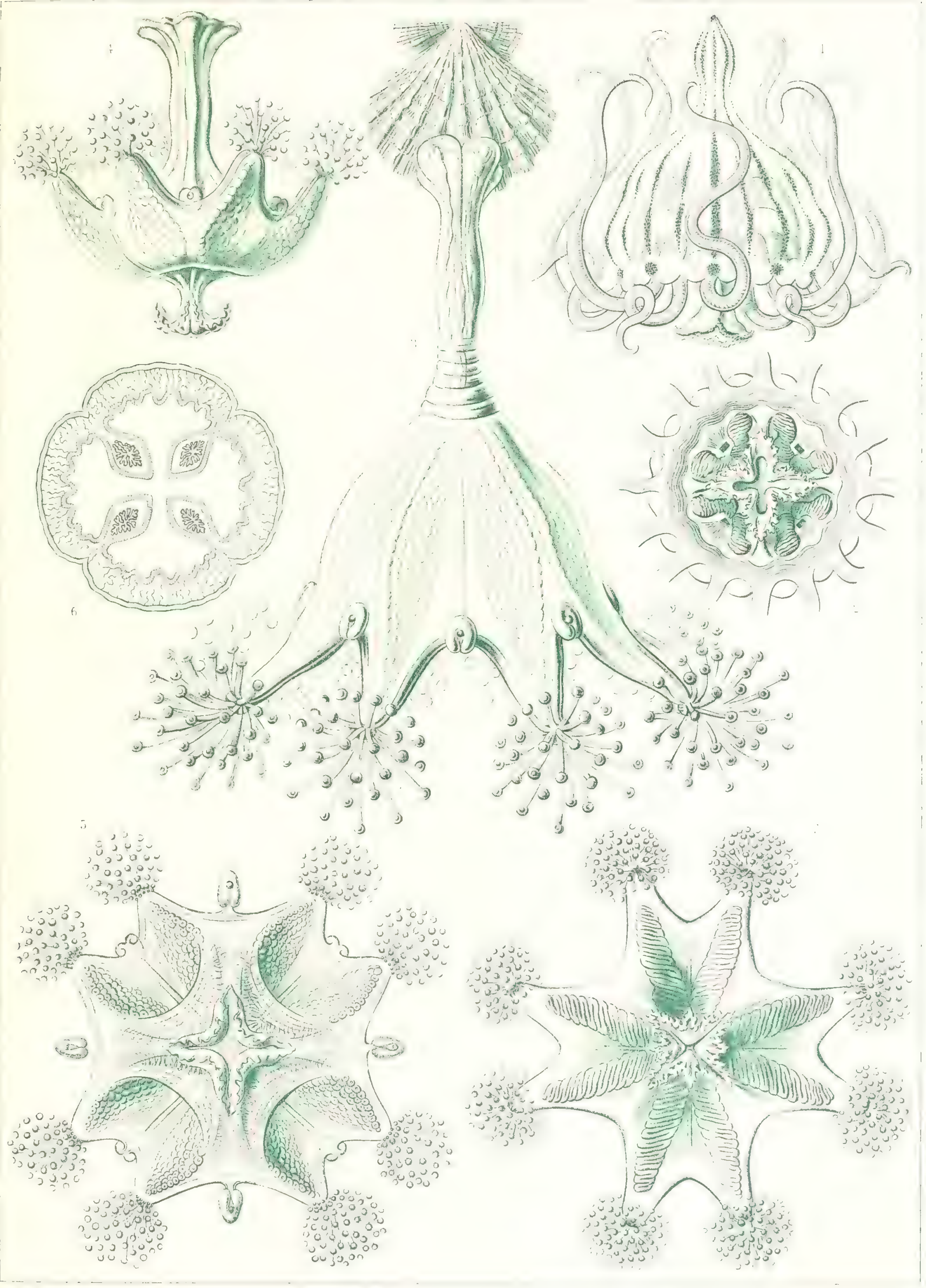

Stauromedusae. Isediercutallent. 



\section{Actiniae. מoventmument.}

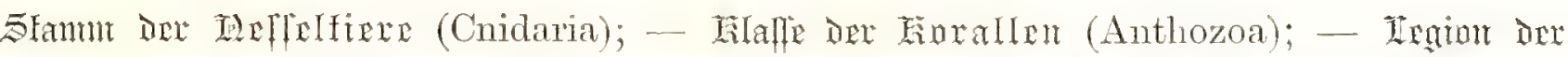

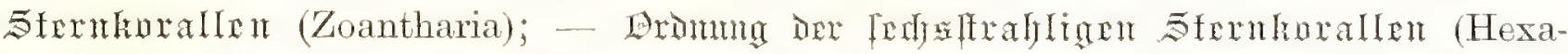

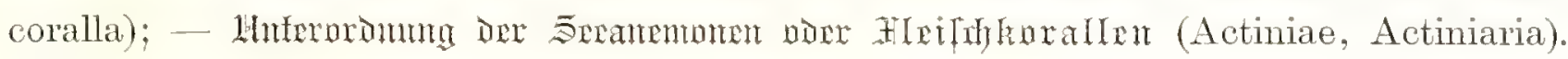

Die Germemonen ober Ffeifdforalfen unterfdycioen fid) von ben übrigen Etemforalfen Durd

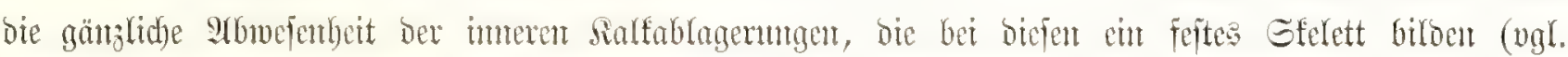
Iafel 9, 5eraforallen; Iafel 29, Ietraforallen). Der ganze Sürper der Siorallenperjon, bie bei den

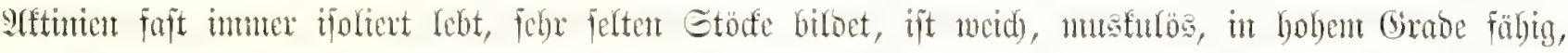

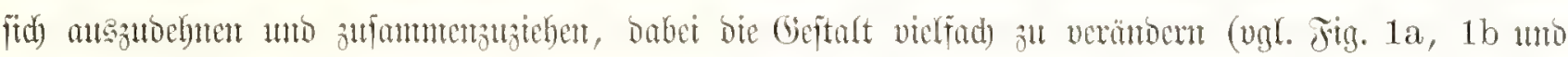

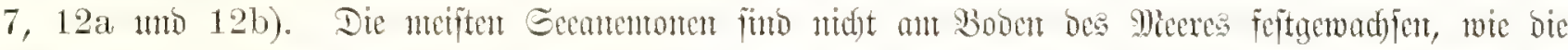

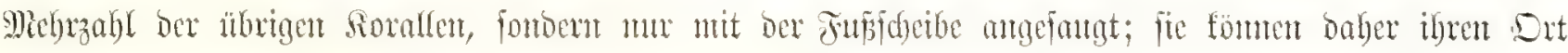

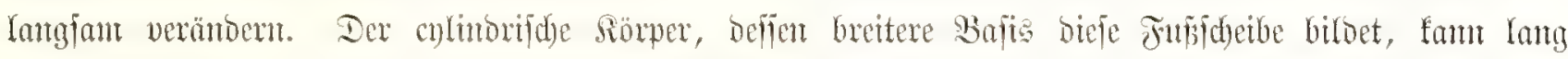

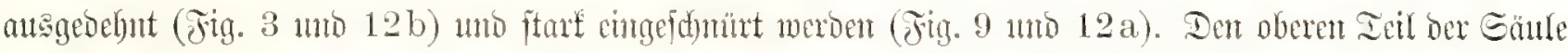

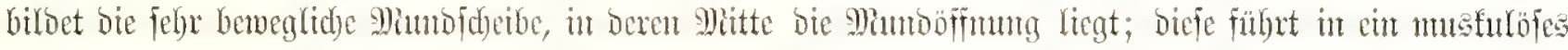

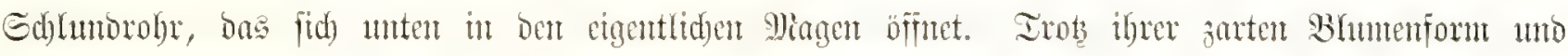

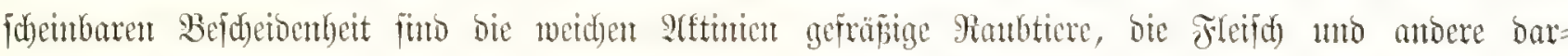

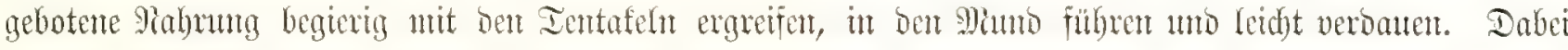

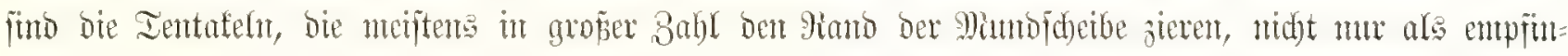

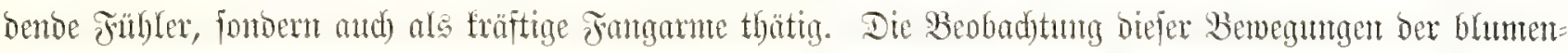

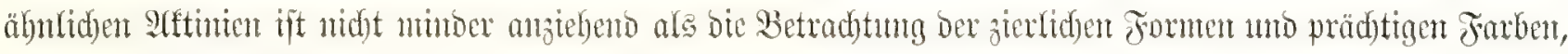

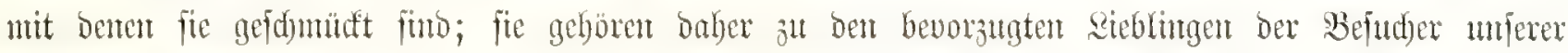
mobernen $\mathfrak{A q u a r i e n .}$

Fin. 1. Heliactis bellis (Thompson).

Fig. 1a. Stnitd)t won oben, mit bent Strablen= framb ber atsgebreiteten Fangame; ber Duexipalt in ber Mitte ift ber Mutur. Die Darunter ftebernoe

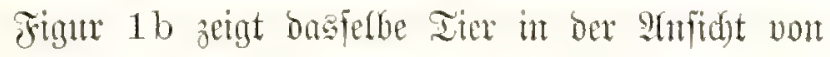
ber Geite, mit z̆lfammengez̧ogenent Ientafeftr.

Fig. 2. Mlesacmaea stellata (Andres).

Son ben 36 Fantgarment biefer Sirt fund die

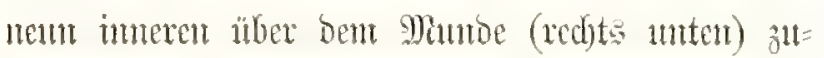
fanmentelegt, bic 27 übrigen in fieben Büntbel ver=

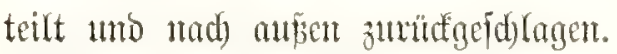

\section{Jitg. 3. Liptasia Couchii (Gosse).}

Die Iantgent Fantgarme befintoen fid in lebhafter,

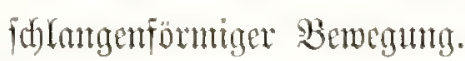

\section{Fig. t. Cylista impatiens (Dana).}

Der Rourper ijt an ber Bafis anfgetrieben, gegen

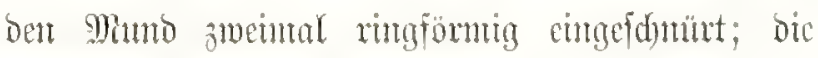
Ientafeler finto zufammentgęogent.

\section{Fig. 5. Bunodles thallia (Gosse).}

Dor hatbefugelige siörper und bic fangarme finb jtarf́ zullammengezogen. 
Fin. 6. Netridium praetextum (Couthouy).

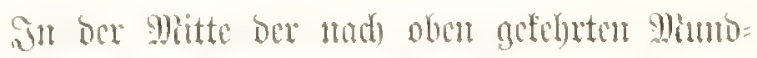
ideibe tritt ber sippeming vor. Die Fonganme

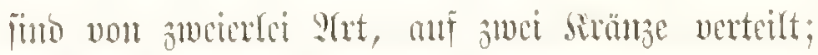
bic Ientafeln bo imteren Sirutzes fund cinfad),

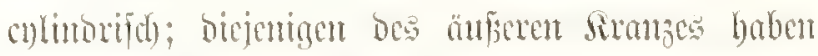
bic Form von gefräufelten mo gelappten Blättent.

\section{fig. 7. Heliactis troglodytes (Thompson).}

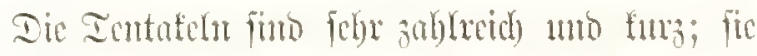

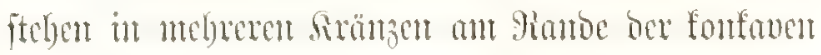

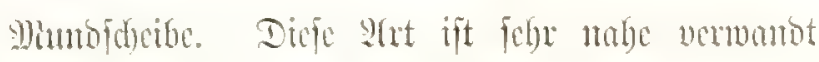
ocr in Fign 1 abgebilontent Enezies.

\section{Fin. 8. Anthea cereus (Gosse).}

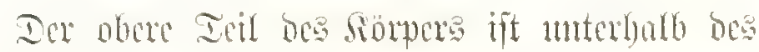
Ed)luntos fturf anjanmmagagon, fo bon ber untere

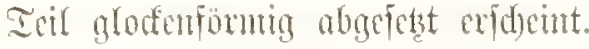

Fin. 9. Aiptasia undata (Blurtens).

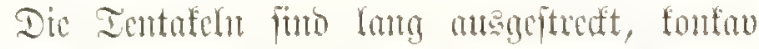

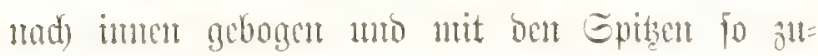
fantmengelegt, bafis fie cine Sirome bildont.

Jitg. 10. Aiptasia diaphana (Andres).

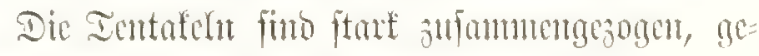
rabe, beutlid) in zunci sirüme geftellt.

Fig. 11. Bunodes monilifera (Duna).

Die aerinachten Ientafern funo in reblafter, fa)fangentöntmiger Bewegung. Der untere Tetl bes

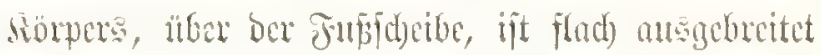

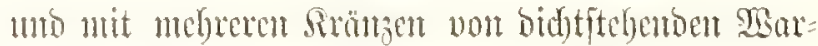

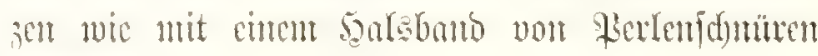
geid)untutut.

\section{Jin. 12. Corynactis viridis (Allman).}

Der Sörper it it Fitgur 12a glodenfionntig jufanmentyezogen, in Figur $12 \mathrm{~b}$ lang culintorijd) angedefint; bie jahtretden Ientafeln, bie on Ende

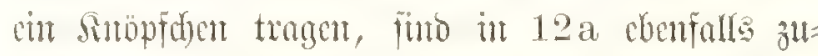

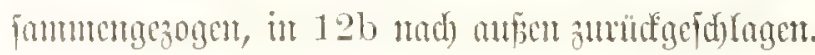

\section{Jig. 13. Metridium concinnatum (Duna).}

Dic grope simofdceibe, in deren Mitte das vorgeftülpte Edylumorolyr ringförmig vortritt, ift

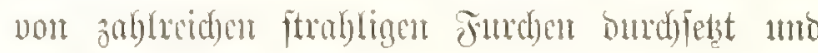
ant Fanbe in fods grofe, nube soppen geteilt, anf benten bie jablreid)en fpitien Ientafeln in Fect)s

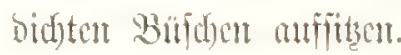

\section{Fing. 1t. Sagartia chrysosplenium (Gosse).}

SUlf ben glotenförmigen Siörper verlouffen Räng

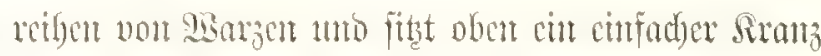
non furzen, Difen, cip̈rmigen Ientafern.

\section{Jign. 15. Actinoloba diantluss (Blainville).}

Der glatte, culnorifde siörper ift unten burd)

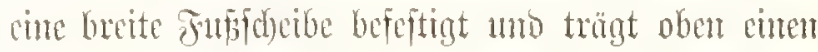

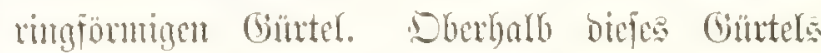

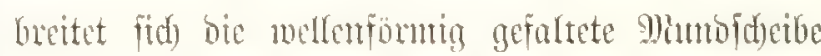

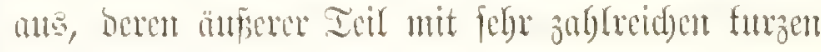
Ientafelut beoceft ift. 


\section{1}

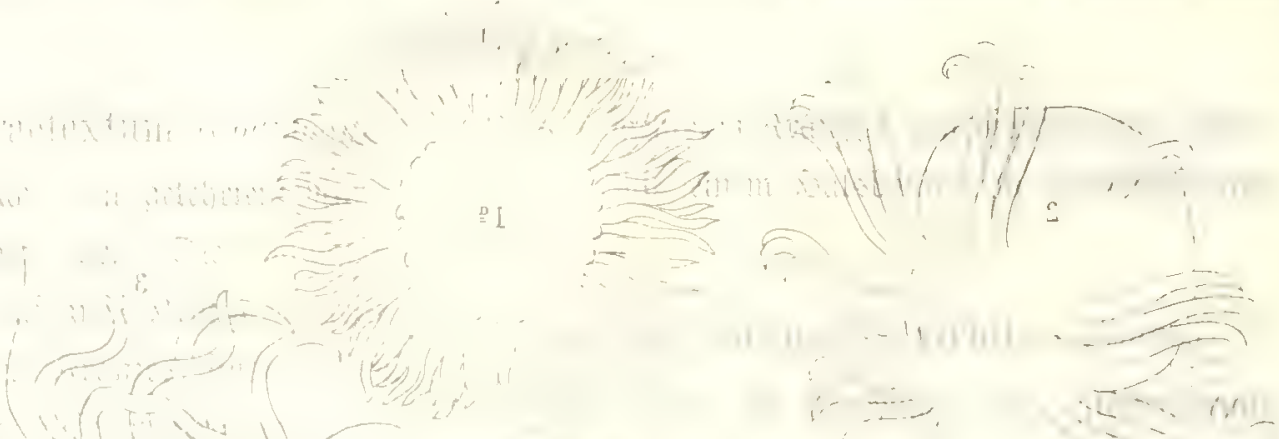

i.

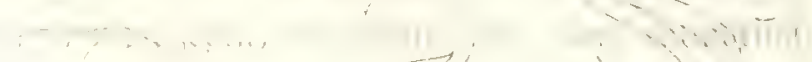

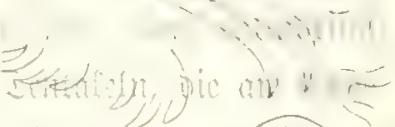

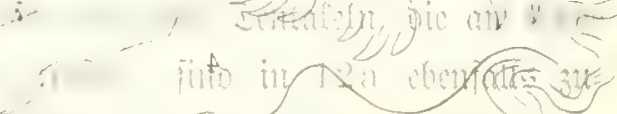

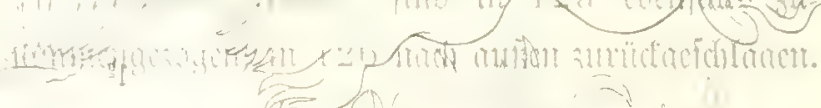

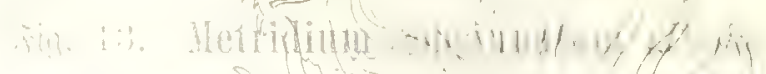

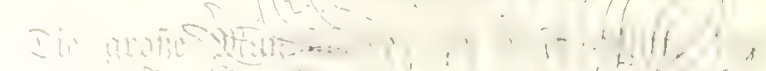

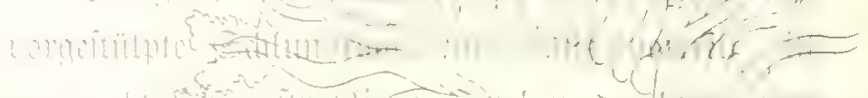

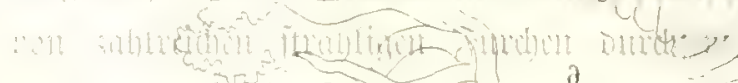
$\therefore$. Sumbe

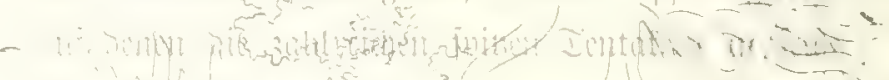
Afintil

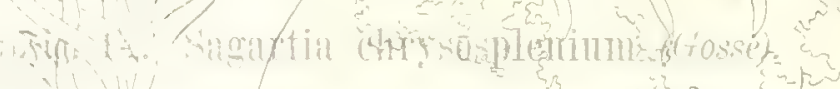

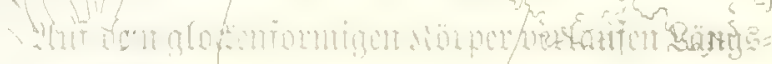

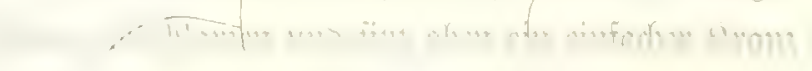

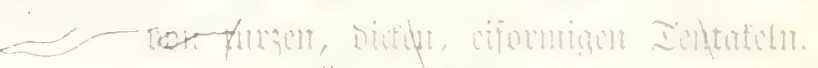

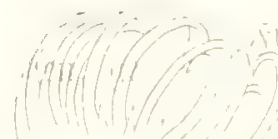

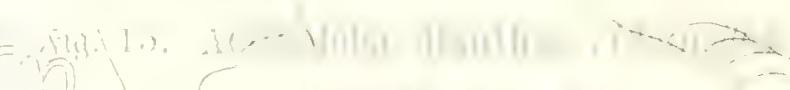

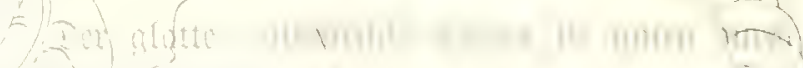

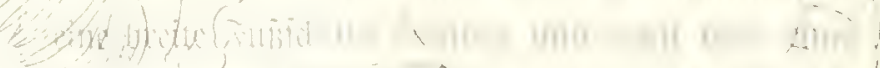

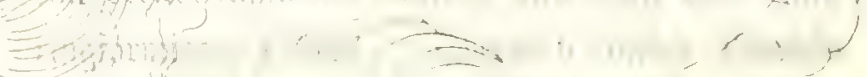

Ftitet

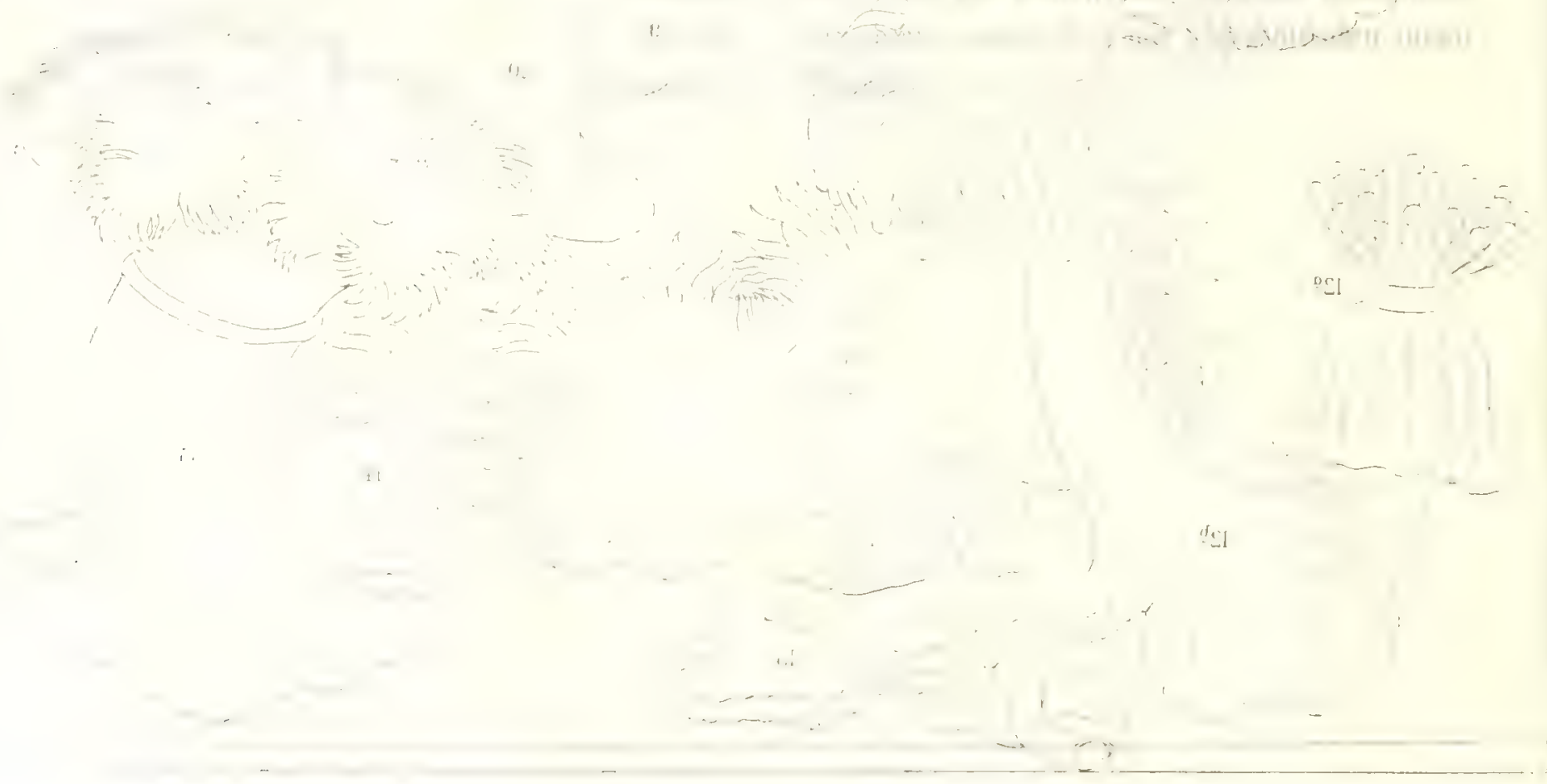




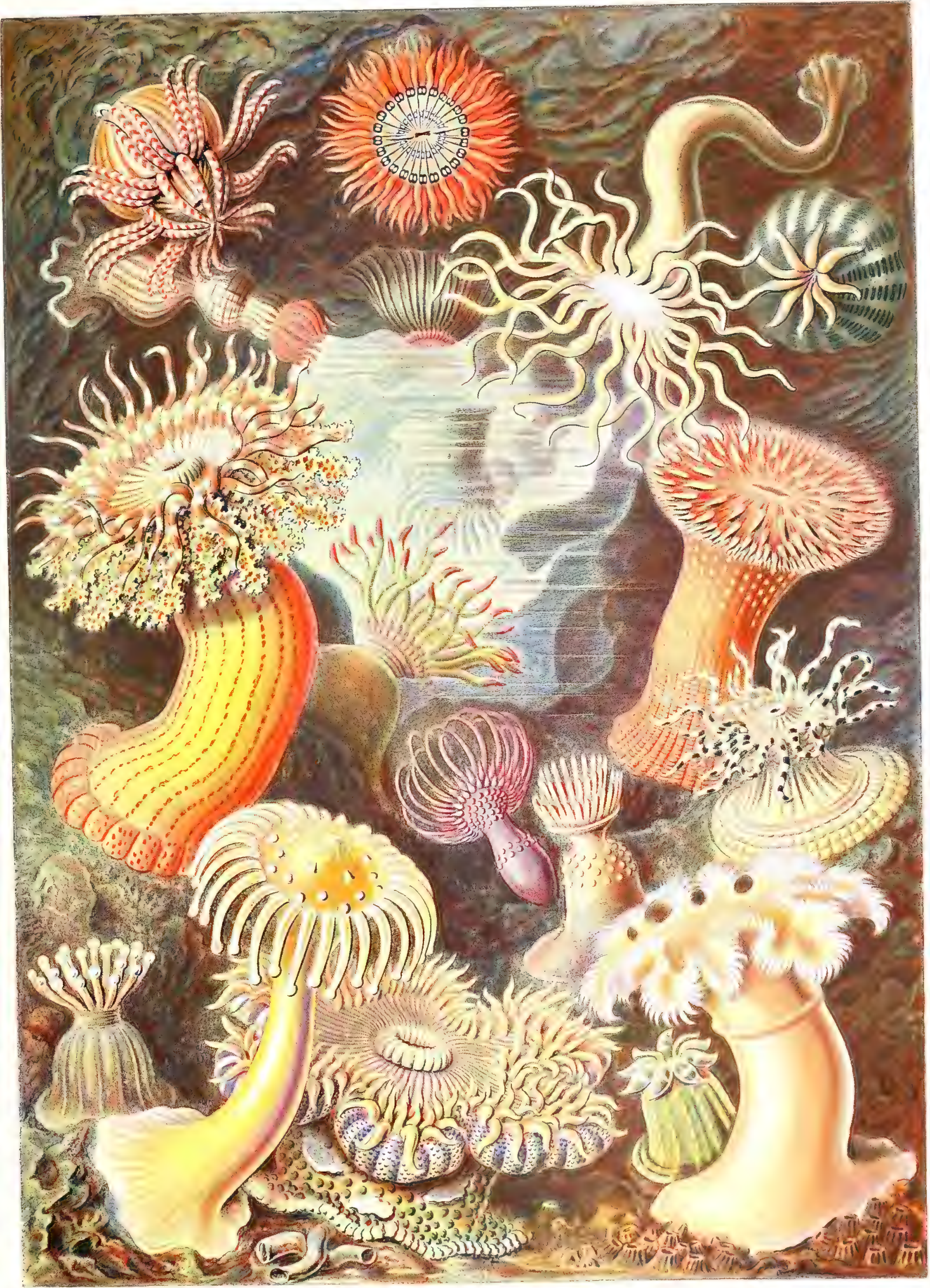

Actiniae. 



\section{Thuroidea. (bumkutume.}

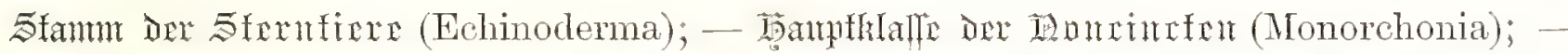

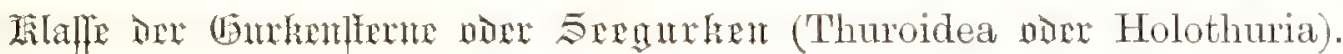

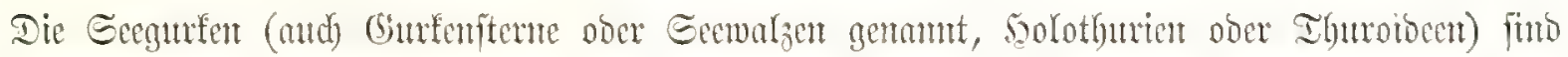

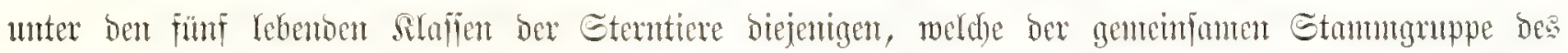

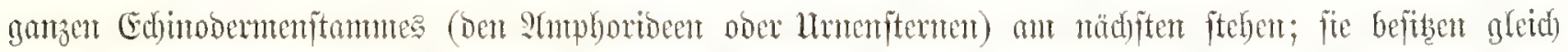

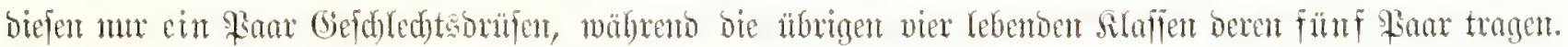
S(tud) än

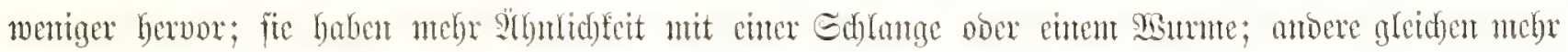

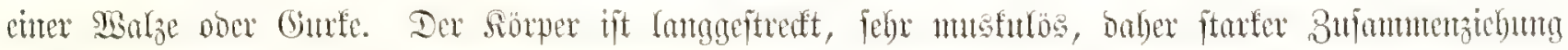

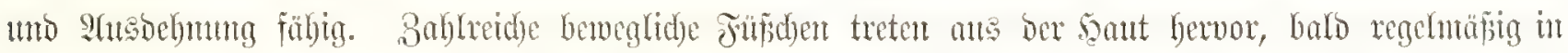

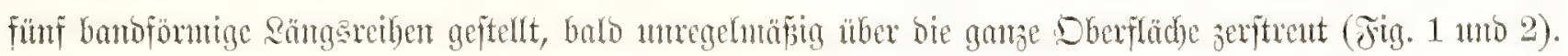

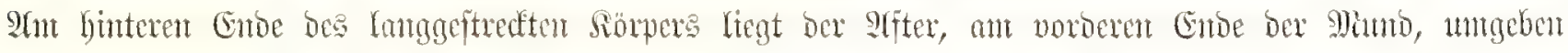

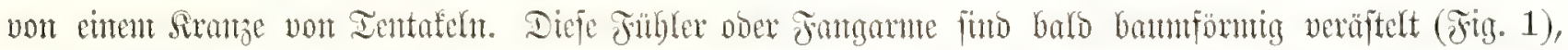

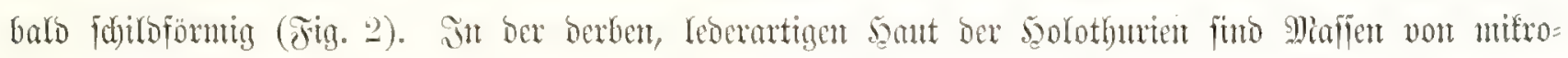

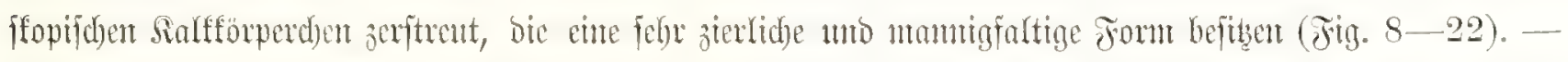

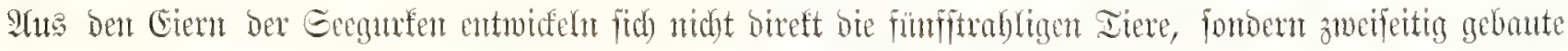

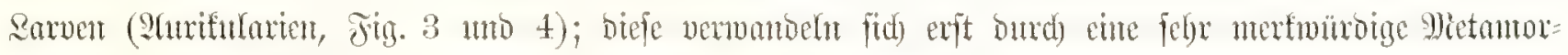

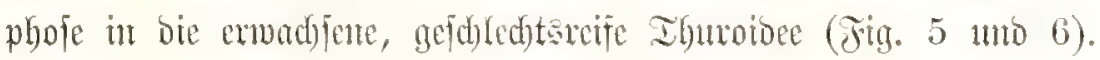

Fig. 1. Phyllophorns mina (Grube).

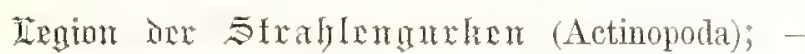
IDromma Der baumfüiflex (Dendrochirota).

Der gefrimmte, walzenförmige Sörper biejer

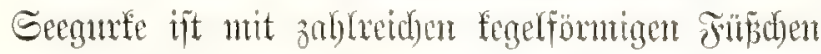

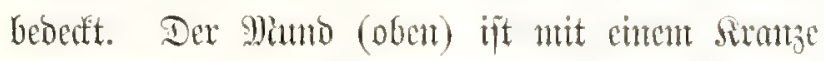

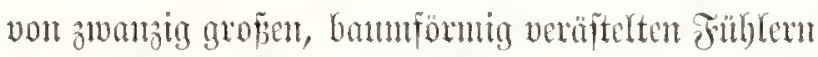
umgeben, deren Enoüftd)en ein gezadtes säppdyen

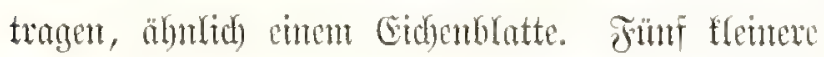
Füblex funo in eincm interen Sirnto georonet, fünf́ zelht gröp̃ere in cincut äuperen Siranz.
Fig. 2. Sporadipus botellus (Selenka).

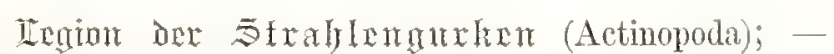

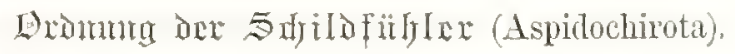

Der gefrümmte, fdufaugenförmitge Sörper Dicfer Seegurfe ift gelb gefärbt, nit braumen, ftemförntigen

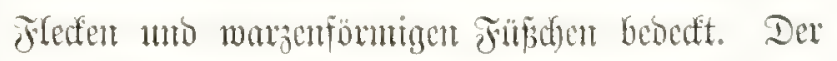

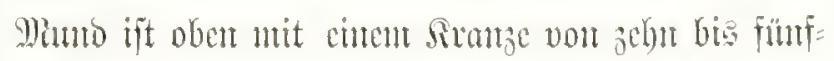

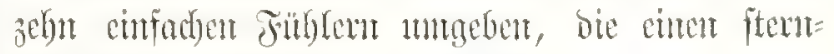
fömuig cingefdnittenen Erhito tragen. Diefe Solo=

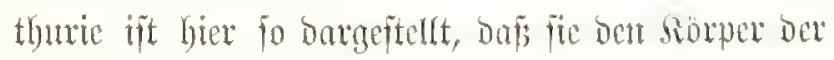
vorigen Sfrt gleid) ciner Edyrange munumbet. 


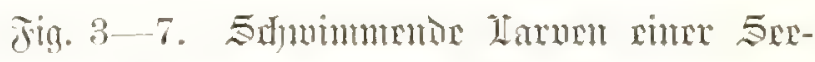
anture (Synapta digitata), ftant vergröficet.

Fin. 3. 3weifcitige sarve (Auricularia),

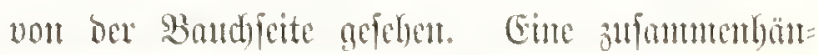

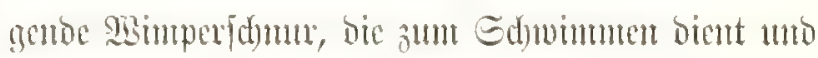

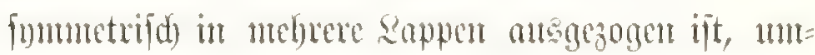
fümut ben Bandrano bes pantoffelförmigen Sörpers;

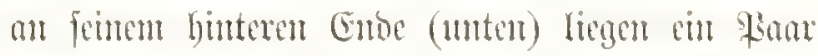

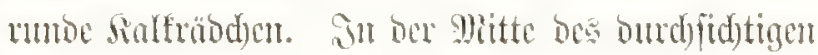
Siörpers fojumert ber Darntanal burd).

Jig. 4. Dieferbe zocifatige Earne (Auricularia), weiter entwifelt. Dic gimperidyme ijt verlängert uno ftörfer gebogen. S'ont Mlagen baben

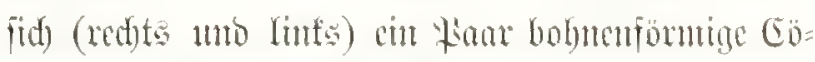

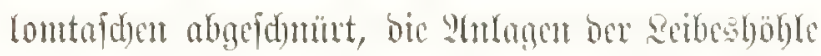
(Coeloma). Stom vorberen Ende ber linten Cö: comtafde (in ber Jigu redte oben) hat fid) eim

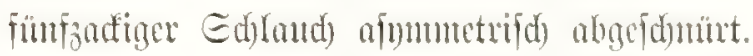

Jig. 5. Tomentiormige zarue (Doliolaria), ans ber âmeifeitigen pantoffelförmigent sarve

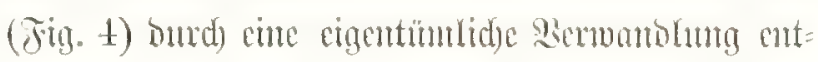
wiffelt. Slu bie Etelle Dex anfanmenthängentom Disimperfontr fint 5 getremte simpergürted ges treten. Der \$luno (oben) ift vou 5 Ientafech umftellt.

Jig. 6. Eine ältere tomutufurmige \&arue,

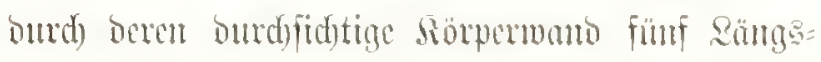

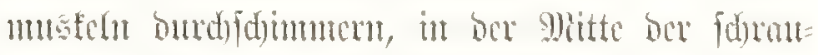
Genförmig gemutuone Dornt. Sinten (monten) füto

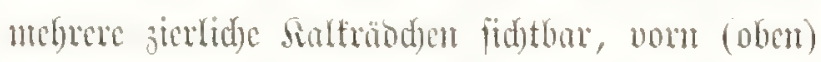
veräftelte Salfitäbdyen, bie einen Ming unn bie Bafis be fimfitrobligen Futhletfrange biloen.

Fig. 7. Dueridnitt burd) ben vorberen Ieir bex tomenfömigen arave, fric. 5. Das fiunfedtige Mambfoild (in ber Mitte) ift von bem Yervenuing untgeben, beffen verbidte 5 Eafen bie

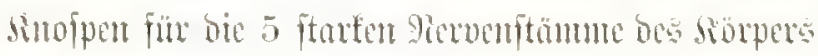
ansenben. Bmifden Den Iesteren bie vimgfömnigen Ducriduntte ber fümf boblen \&rimür= Ientafeln.
Fig. S-22. Sinlfërperdien aus ber 5 ant von Gecgurfen, ftart vergröpert. Diefe mifro= ffopifden Sulffïrperd)en liegen z̆ Mkillionen in ber leocrartigen saut ber 5olothuren cingebettet 1 mio

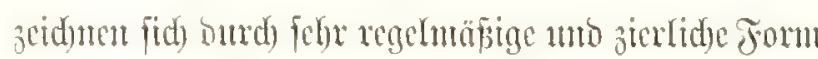

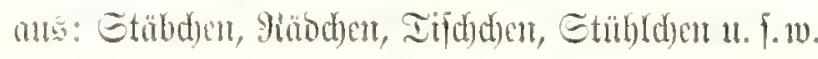

Jig. 8. Stichopus Murxayi (Theel).

Jin. 9. Myriotrochus Rinkii (Steenstrup).

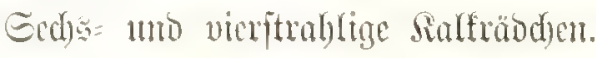

Fig. 10. Candina coriacea (Hutton).

Doppeträbdyen, anjen vier, imten adyt Speiden.

Fin. 11. Paclopatides aspera (Theel).

Jümfitrabliger Salfförper. Ein vertifaler Stab fteldt in ber Mitte cince horizontalen Gtabfrenzes.

Jig. 12. Elpidia rigida (Theel).

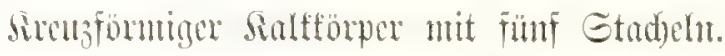

Fig. 13. Symapta aculeata (Theel).

Fig. 14. Symapta glabra (Semper).

Sarterförmige sinftörper.

Jig. 15. Colochinus inormatus (Marenweller). Sinfförper non Geftalt eines Doppedringe

Jig. 16. Stichopus Moebii (Semper).

Gegitterte Iifdoplatte cimes quabratioden Sialf=

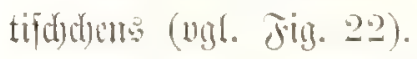

Sig. 17 uno 18. Clirodota venusta (Semon).

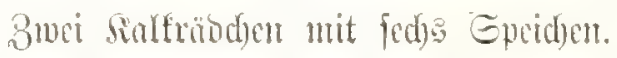

Fing. 19. Cucumaria crucifera (Semper). sirenförntiger sialfförper.

Jig. 20. Thelenota atra (Jacger).

Stublförniger sialfforper.

Jig. 21. Arbacia pustulosa (Semon).

Eedfistrabliger sialfförper von Beftalt cimes Gittertifdes mit brei gubelteifigen Beinen.

Jin. 22. Stichopus Moebii (Semper).

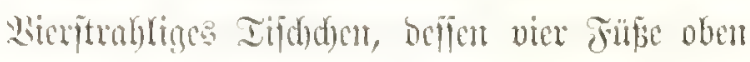

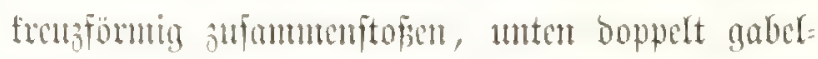

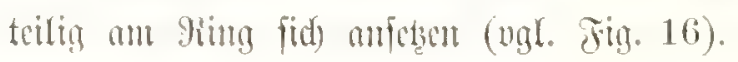




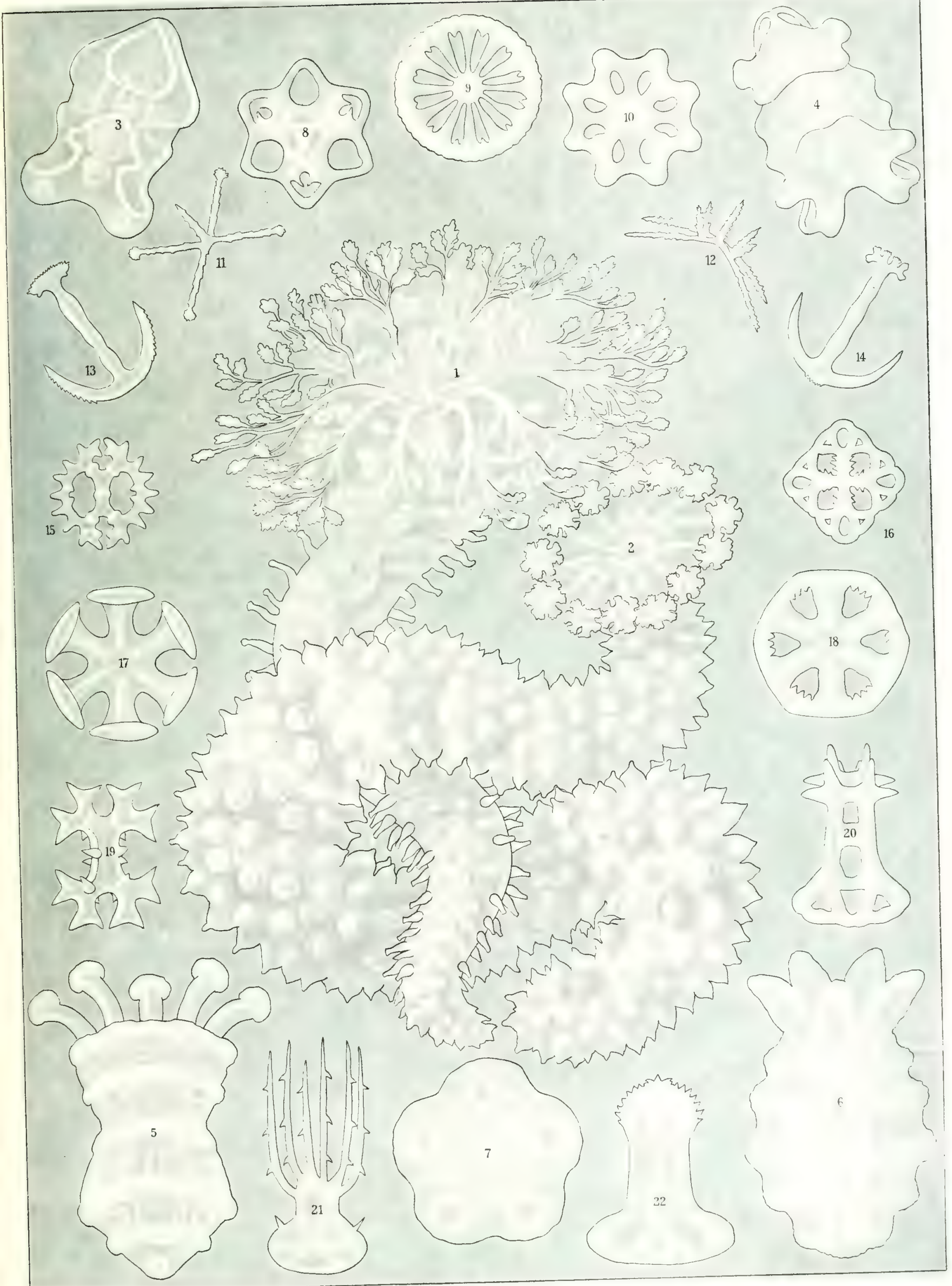




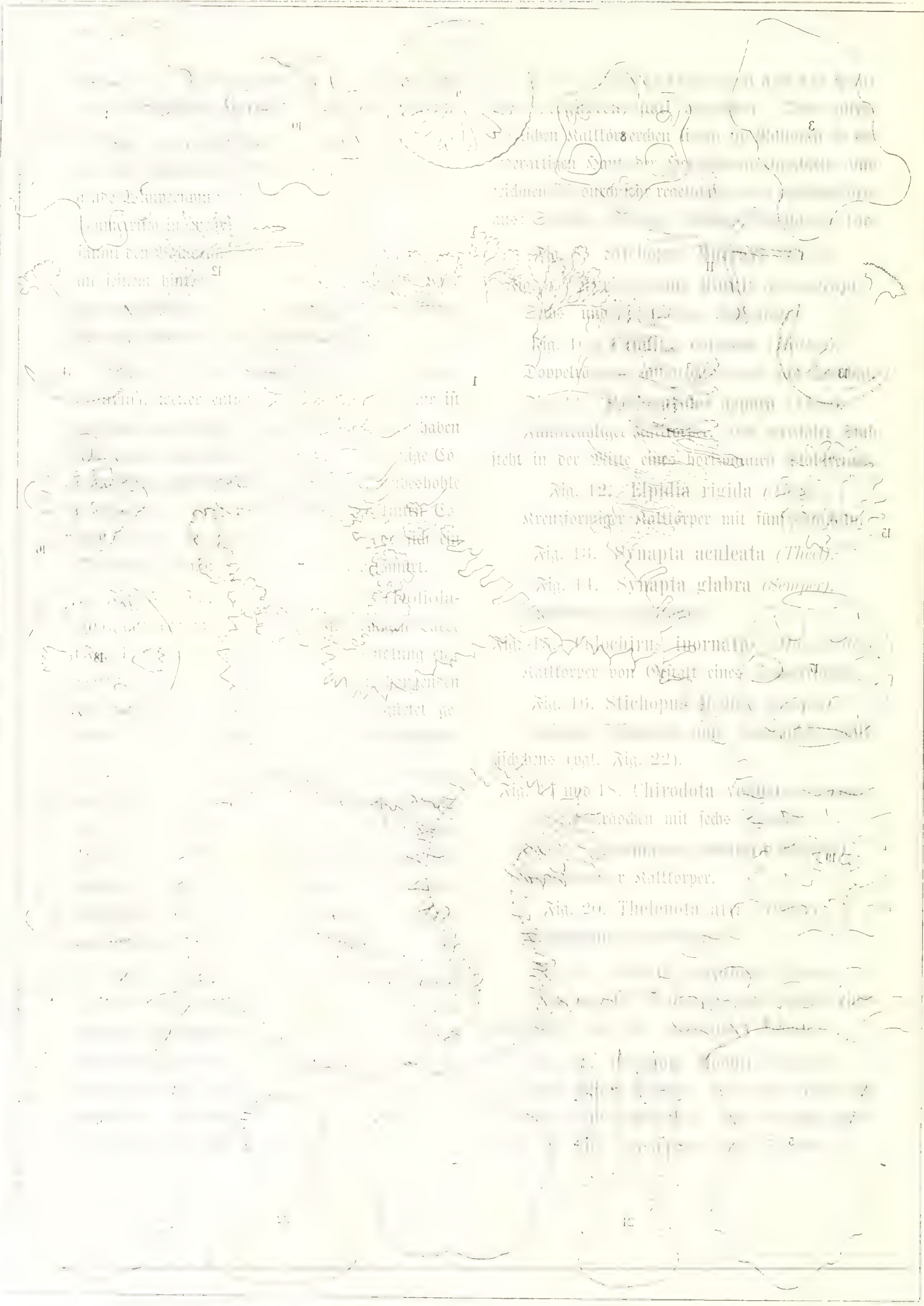




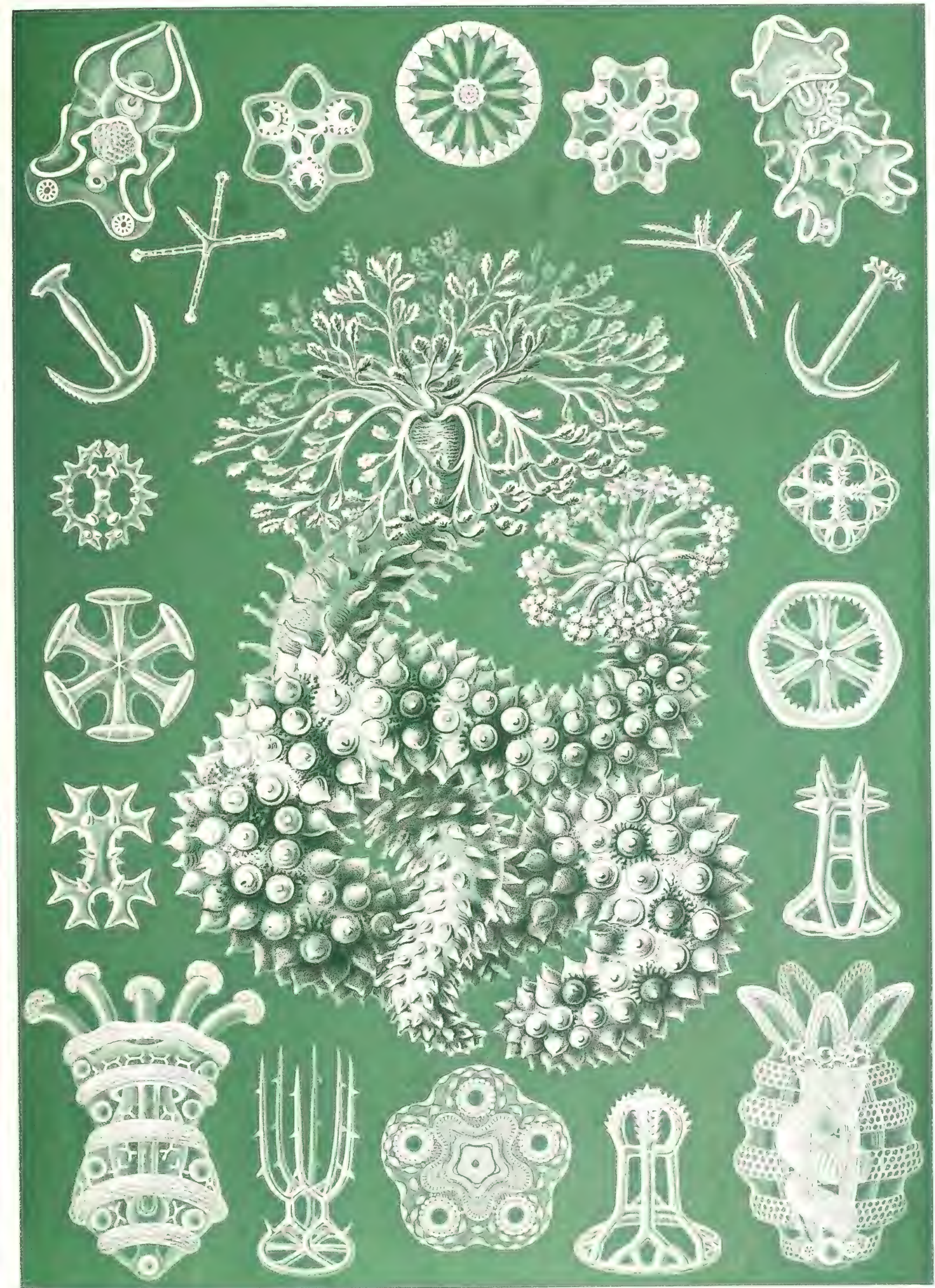

Thuroidea. - sintichltexte. 



\section{Kunifíormen der Matur.}

Von

Prof. Dr. Ernit Haeckel.

20

Zweite Sammlung.

Fünizig Jlluifrationstafeln mit beictreibendem $\tau$ ext.

Cथल

Leipzig und Wien.

Derlag des Bibliographilcten Jnifituts. 



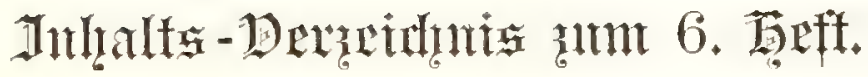

Iafel 51. Collosphaera. Urticre aus der Rlafie Der Madiolarien, Dromm ber Seretus: Strahlinge (Polycyttaria).

Iafel 52. Platycerium. Famplanzen ats der Siaffe ber zanbfarme (Filicinae), Fantlie bcr Tupfelfarme (Polypodiaceae).

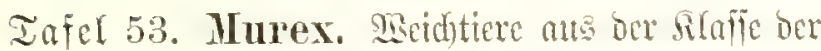
Sdyeden ober (Safteropoben, Dromm ber Ranmfiemer (Ctenobranchia).

Tafel 54. Oetopus. Isedutiere aus ber Rlafie der Sirafen oocr Cephalopoden, Segion der Iridster=\{rafen (Gamochonia).

Iafel 55. Cytherea. Meidyticre aus der Slaffe ber mujdelst ober atcephaten (3weiftap=

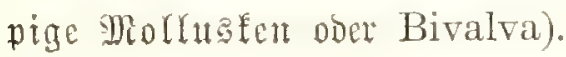

Iafel 56. Calanus. G6lieoertiere aus ber 5aupt= Elafie Der Arufterticre (Crustacea), Dro = murg ocr Muberfrebje (Copepoda).

Iafel 57. Lepas. Ghfeberticre aus ber 5aupt= flaffe ber Sirntentiere (Crustacea), Dro= mng ber Ranfenfrebje (Cirripedia).

Tafel 58. Alucita. Gifiebertere aus ber Silafie ber Serbtieve (Insecta), Sromtung ber Sdimetterlinge (Lepidoptera).

Tafel 59. Strobalia. Selifeltiere aus ber filaffe ber Stantaguallen doer Siphonophoren, Srommg oer Rigyjonecten.

Tafel 60. Cidaris. Etentiere ans ber Slaffe Der Geeiget oder ethintident, Dromurg ber Cionronien. 



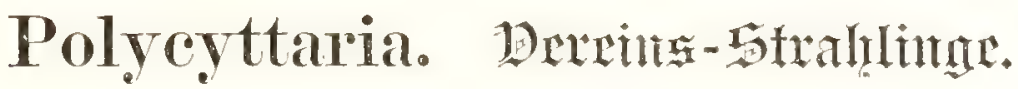

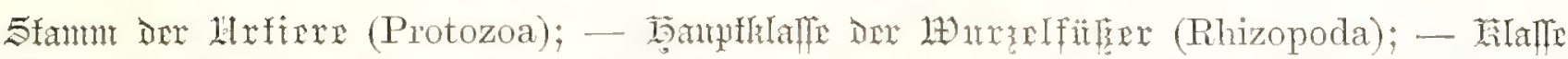

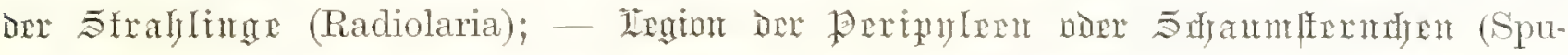

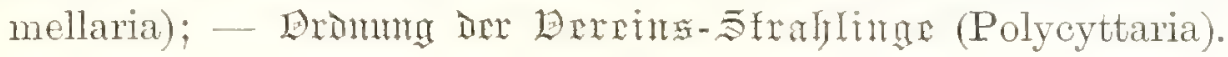

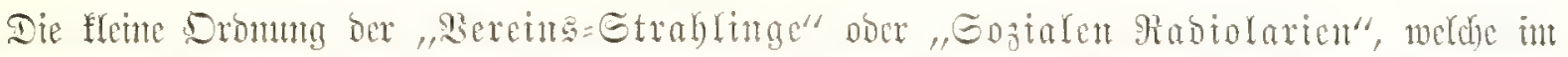

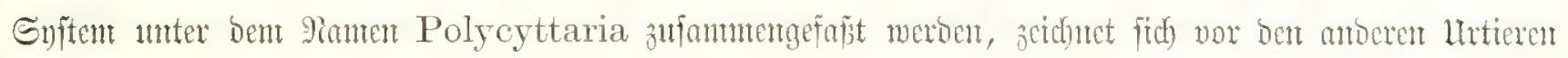

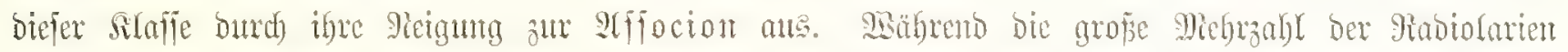

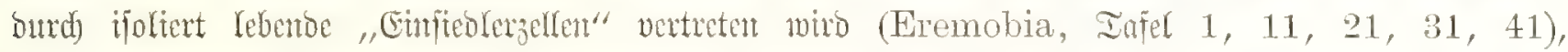

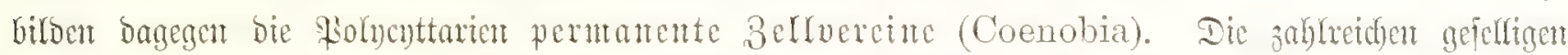

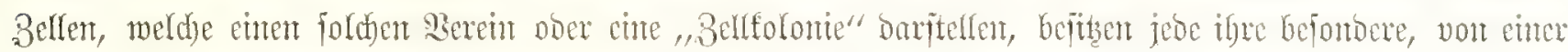

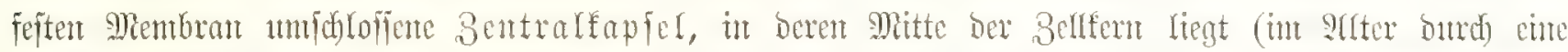

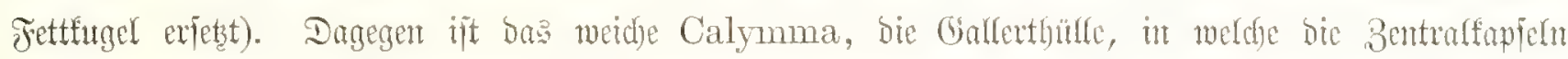

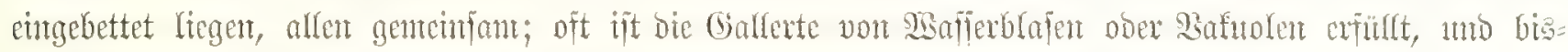

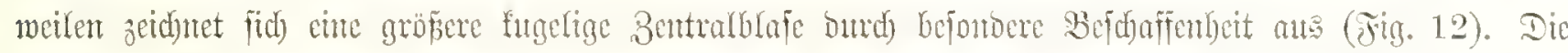

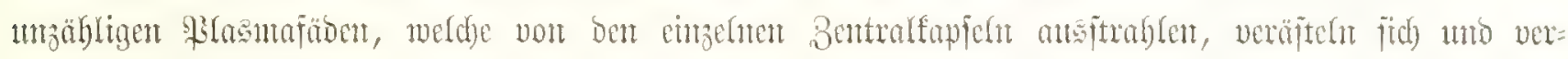

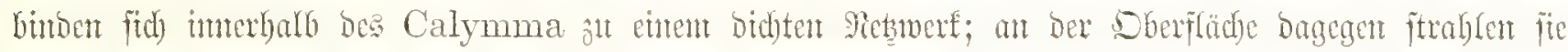

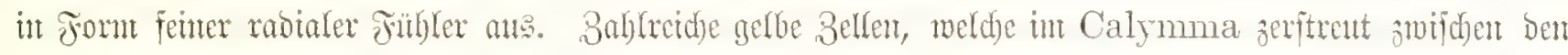

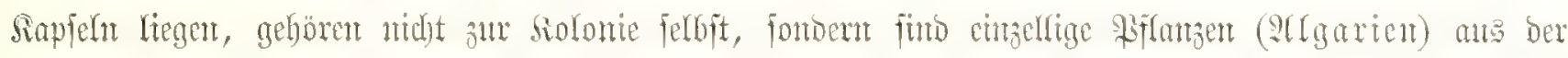

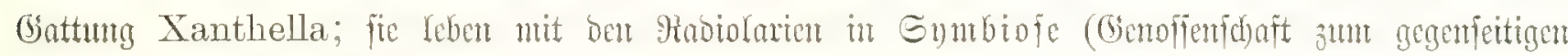
ß̊rtetl; Fitg. 2, 10, 11, 12).

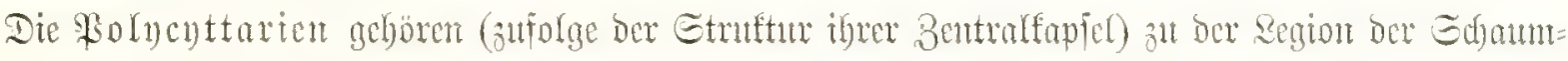

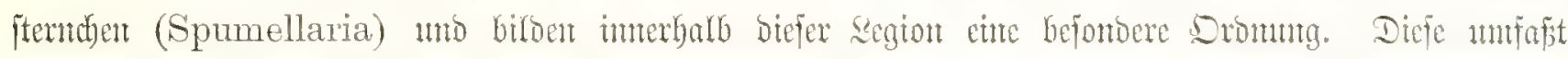

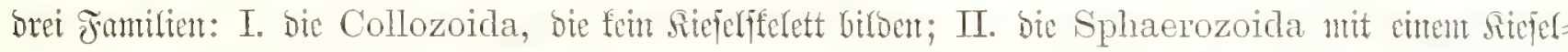

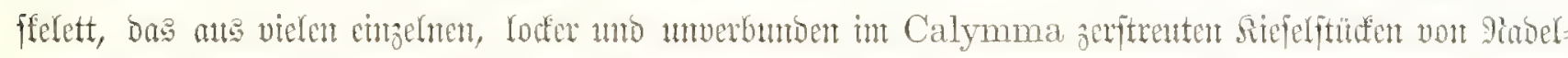

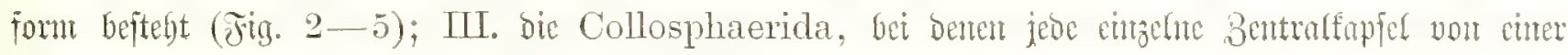

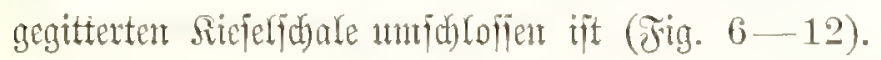

Fig. 1. Collosphaera primordialis (Hackiel).

Ein ringförmiges Cönobiun int ratürlider

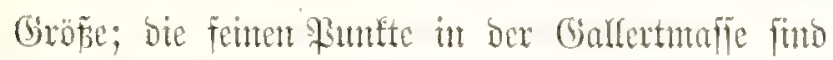
bie eingeltum Bentralfapjeln.

\section{Fitg. 2. Thalassoxanthium medusinum (Haeckel).}

Ein einzelnes, cinzelliges Tier, julammengefetst aus ber blauen Bentralfapiel uno deren gelblidjer

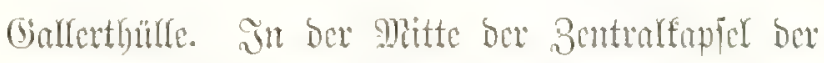
futgelige Belffern, mit vident Sicrntörperden; bie

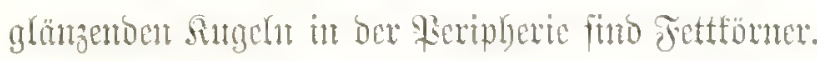
Bablredde getbe sörnet int Calymma fino font

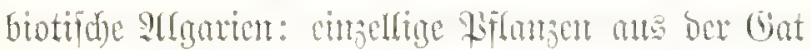
tunt Xanthella. Cume änere fountsente Dornen=

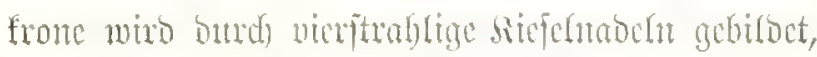
oeren gefrummete Edyentel dounig futb. 
Sig. 3. Sphacrozoum orodimare (Huectel).

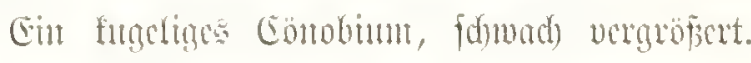
Dic benten Bentralfapich ber Einzeltim, melde

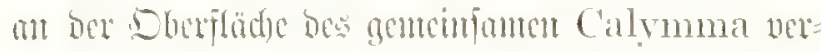
teift liegen, fimb linfenfäming umo cutbalten cure

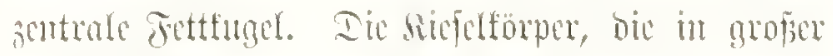
3oble in Calymma jerftrent funt, tragen an betoen Solen me Etabe je orci Ednenfed.

Fig. t. Thalassoxanthinm cervicorne (Haecket).

Ein cinzelnet, breiftrafliger Siefelförper, befien

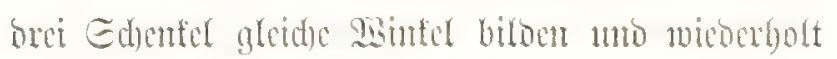
gabeförmuig verïitelt fimb.

Fig. 5. Sphaerozoum spinosissimmm (Hacket).

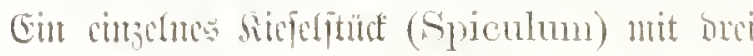
Divergenten Edyenteln an jeom folde be wittel

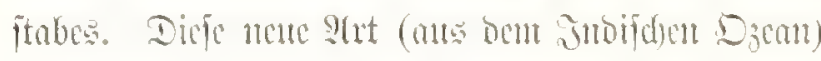

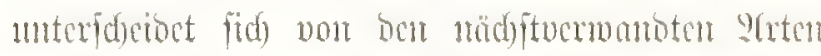
Dor Gattung (S. armatum uno S. punctatum)

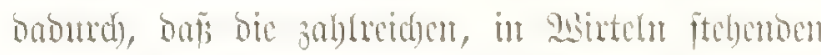

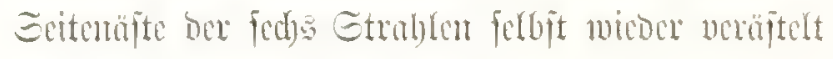
unto mit Donnen bejest funo.

jig. 6. Coronosphinera diadema (Hacthel).

ein cingelnes, cingelliges Iier, bofien blate

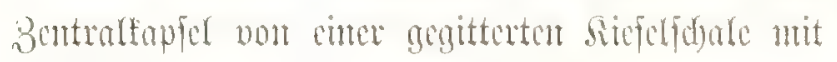

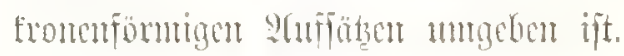

jig. 7. Trypanosphaera trepanata (Huccket).

Eime cingelne Belle, mungeben von ber fingeligen

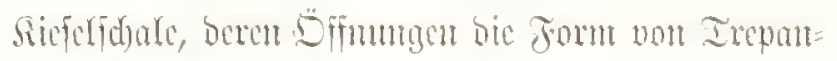
tronten tranger.

Fig. 8. Acrosphnera inflata (Hecket).

Eine cinzeltue Belle, tungebat von bor fingerigat

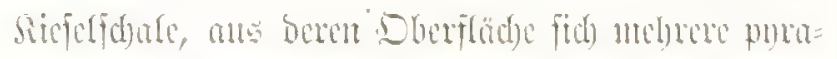

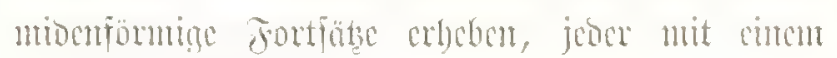
rabialen (sipipelftad)ct.
Fing. O. Nazosphlaera lagotis (Haectiel).

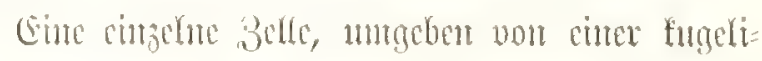
gen Sichelforde, ans deren Dberfläd)e fide vide

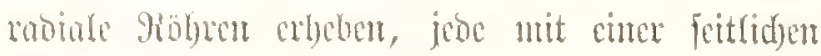

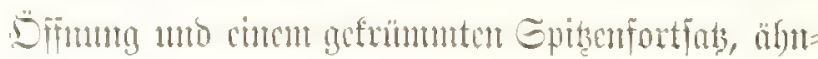
(id) eimen safonobs.

\section{Jig. 10. ('aminosphaera dendrophora (Itaeckel).}

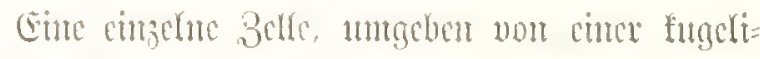

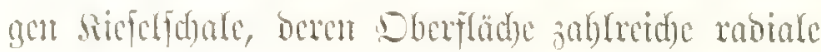

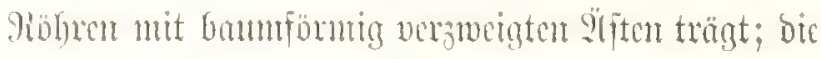

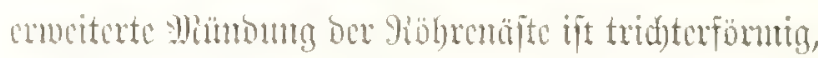

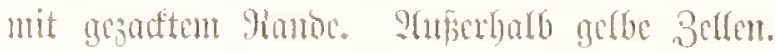

Firg. 11. Coronosphaera calycina (Hacckel).

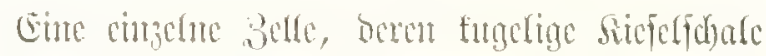

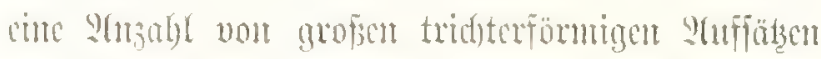

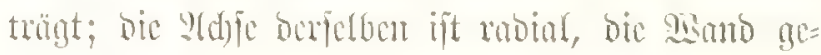

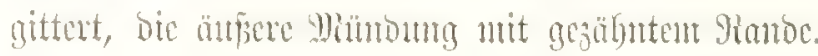

Jig. 12. Solenosphata familiaris (Hackel).

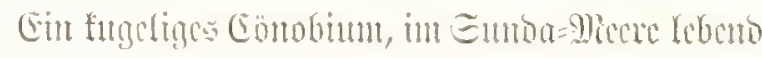

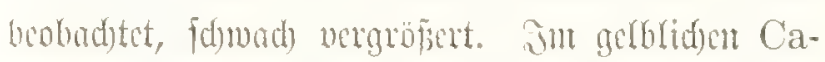

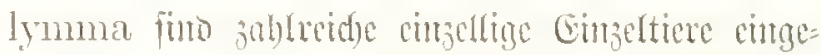

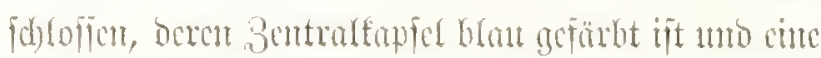

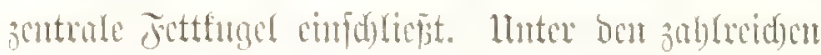

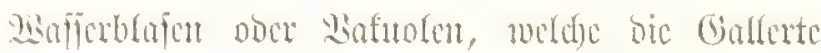
jwifd) ben singetuen Butlen erfüllen, zeid)net fith

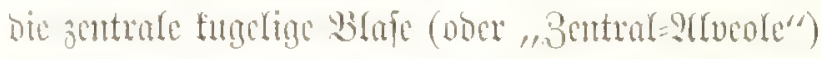
Durd) einte verbiffte

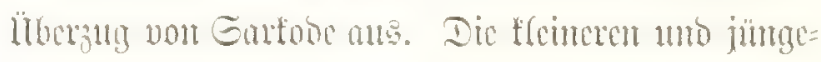
ren 3ellen (im Surneren bes Conobimm) füro nod)

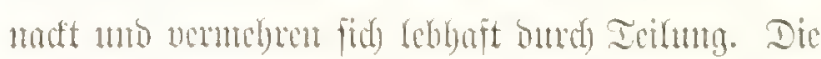
gröperen uno älteren Bellen (an Der Dberflädye)

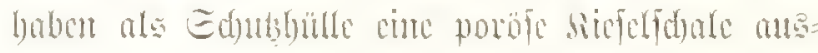

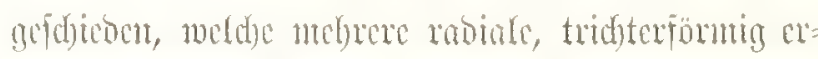

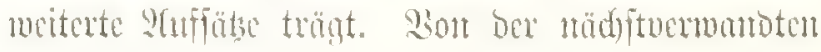
Sulenosphaera cornucopiae (Haeckei) unter=

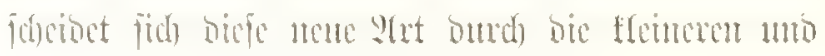
regehmäpigen toren ber Gitterfdure. 

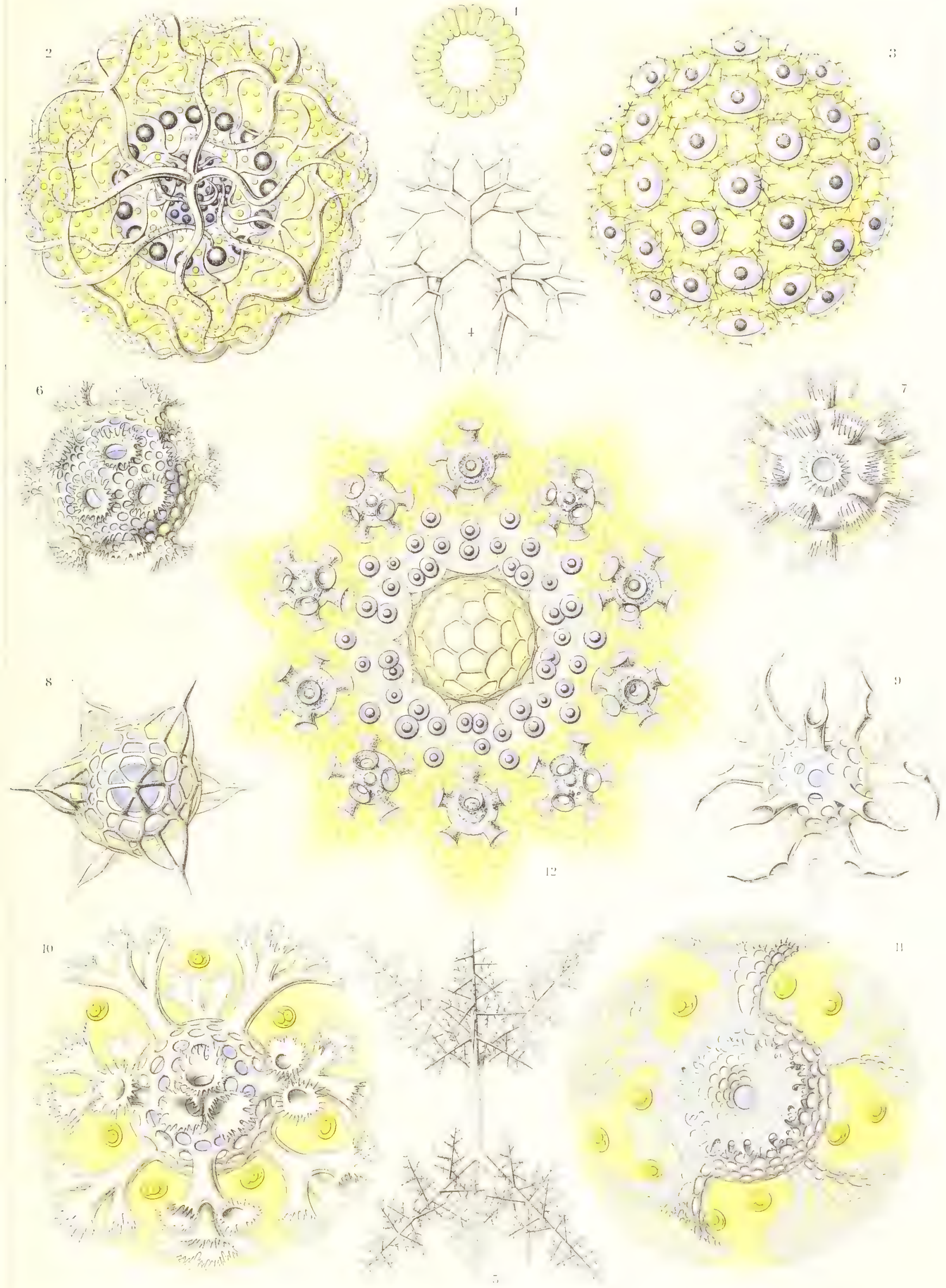

Polycyttaria. Tiexirs=strablinge. 

Tafel 52. - Platycerium.

\section{Filicinae. Taullaume.}

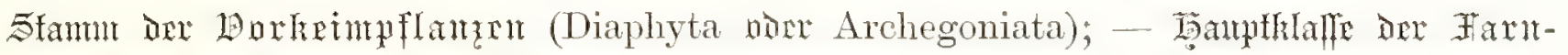

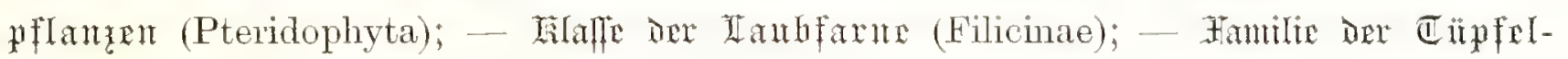
fante (Polypodiaceae).

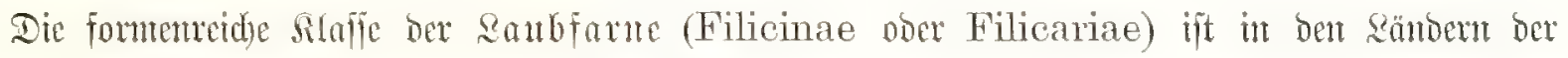

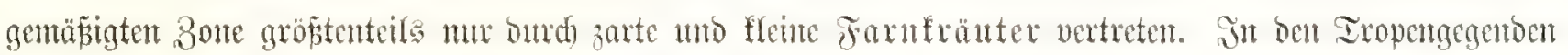

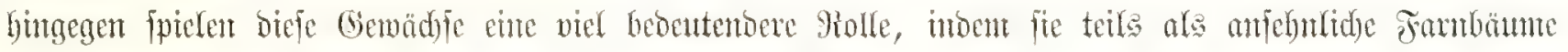

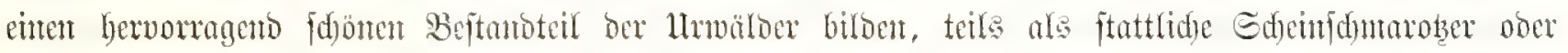

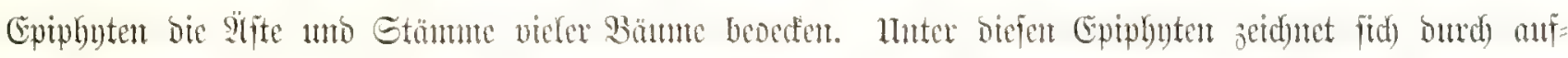

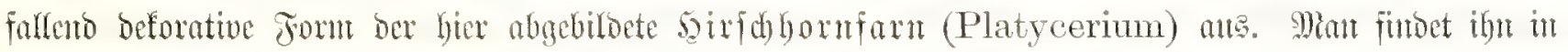

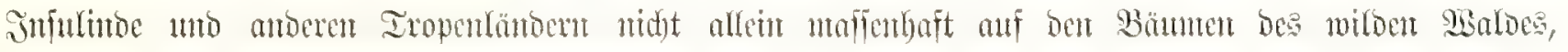
fontoen aut) als Bierpflantze in bent Gärten.

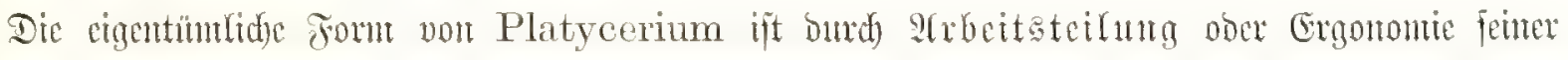

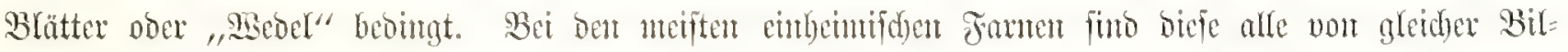

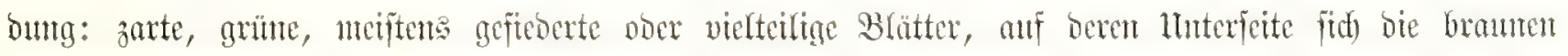

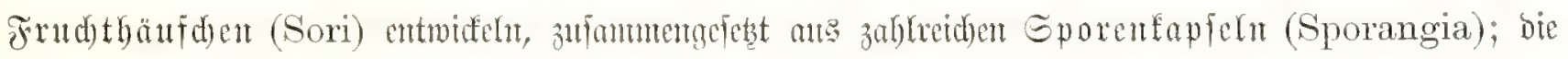

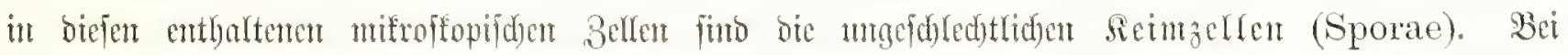
Platycerium Gingegen, wie bei cintgen anoeren Fanmen, entwifelt bie Fiflambe jwei ober felbit brei

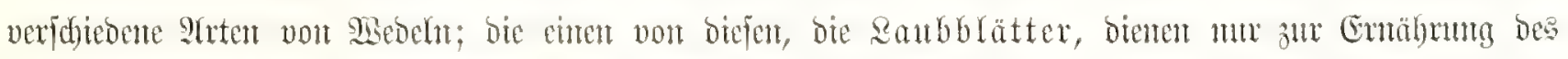

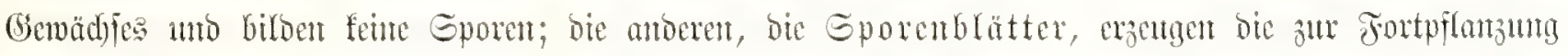

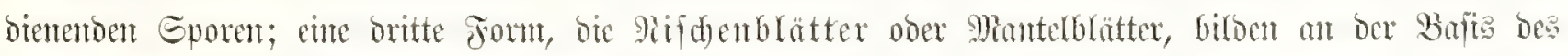

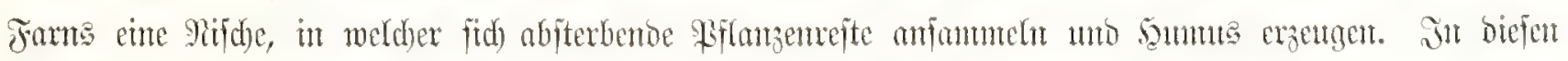

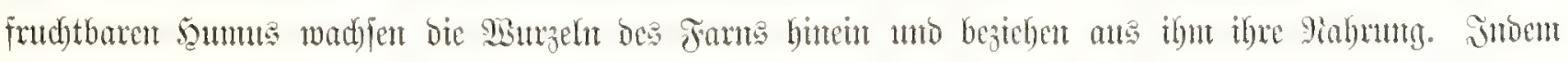

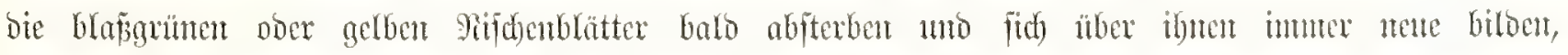

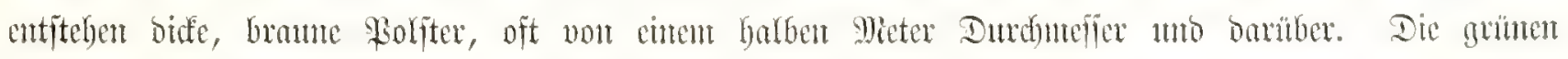

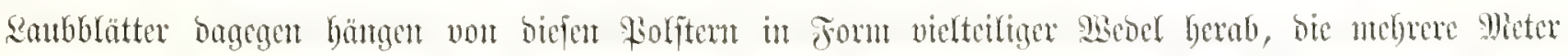

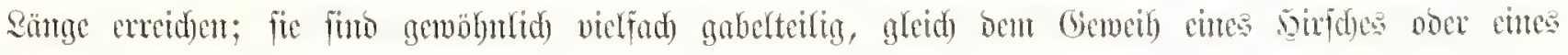

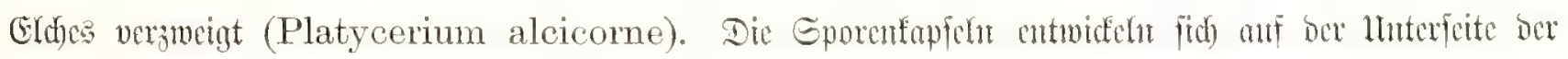

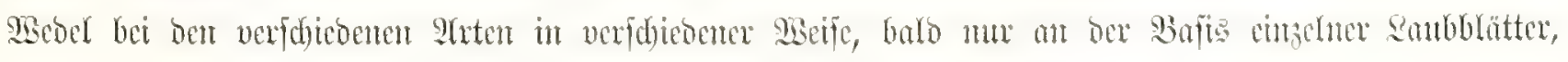

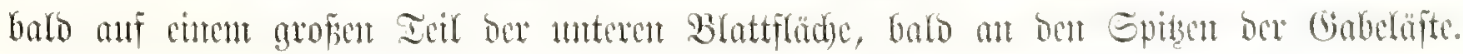


Jig. 1-4. Platycerium grande (Hooker).

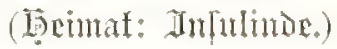

Fin. 1: Eim junger Etodf in $1 / 8$ ber matür= lichen Gröpe. Die biffe, Grame Sinnlfe in der Mlitte

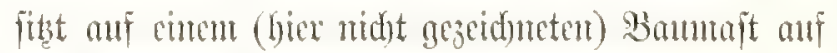
uno wiro burd viefe abgeitorbene gifidenblättex gebildost, bie wie bic Edyaten cinter Bwicber über=

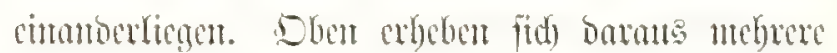
vielteilinge, fäd)erförmige, bellgrüne Miantelbrätter, dic feine Eporen birbent. Inten längen Mtehrere ounfelgrün, gencibörmige Sporenbrätter herab,

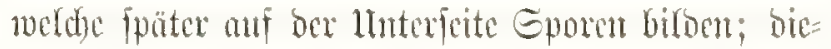
felben werben bom viel länger, oft mebrere slicter

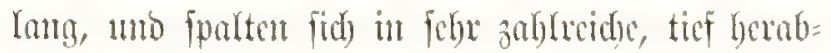
hängeno Gabeläfte.

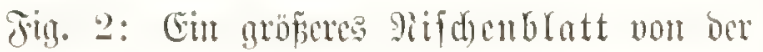
Form cutce itarl gerippten Fönder.

Fig. 3: Eim gröperes Mifugenblatt von ber Form cimer simutilusighate.
Fig. 4: Ein gröficres Rif(d) enblatt von ber Form eince Füllforms.

Jig. 5, 6. Platycerium stemmaria (Beanvais).

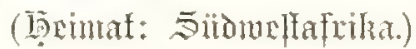

Der flente Etorf, Den Fitg. 5 แnto 6 von 3 wei verfdjèonen Seiten zeigen, trä̈gt mur wenige Blät= tex; bie aufrecten, nad) oben gefebrten fimb bie

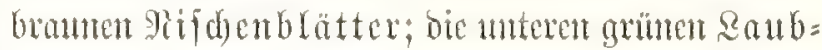
bratter bifoen fpäter an ber Innterfeite Eporen.

\section{Fig. 7. Platycerium Hilli (1/oore).}

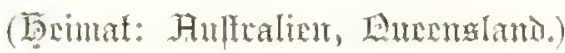

Der fleine Gtorf trägt unten wentige gelbe, mufderförnige siifodenbratter, oben cinige auf= redote, grüne, hanoförmig gelappte saubbrätter; an ber Interergete ifrer Epizen bitoen fid fpäter bic Epmren. 


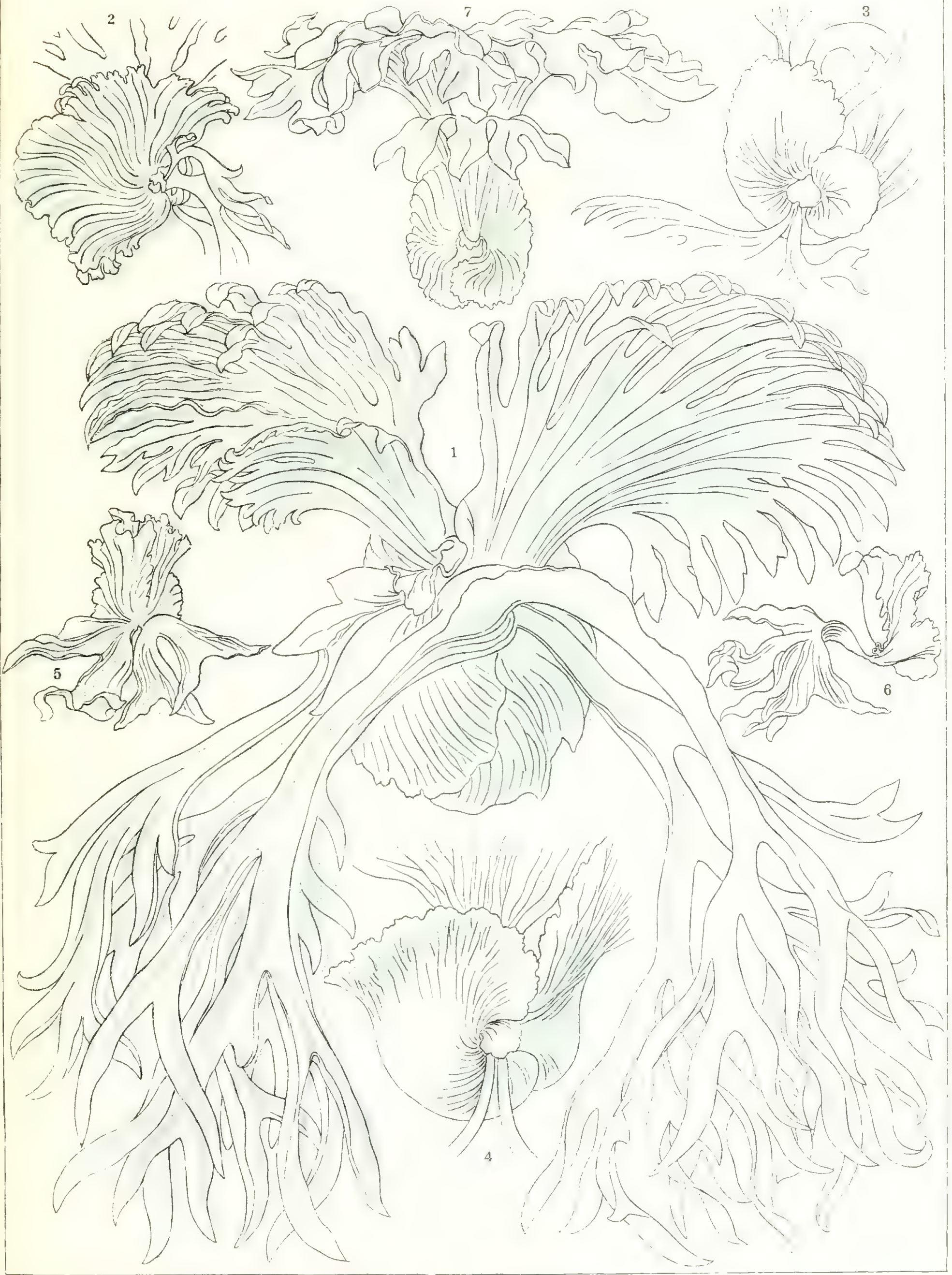




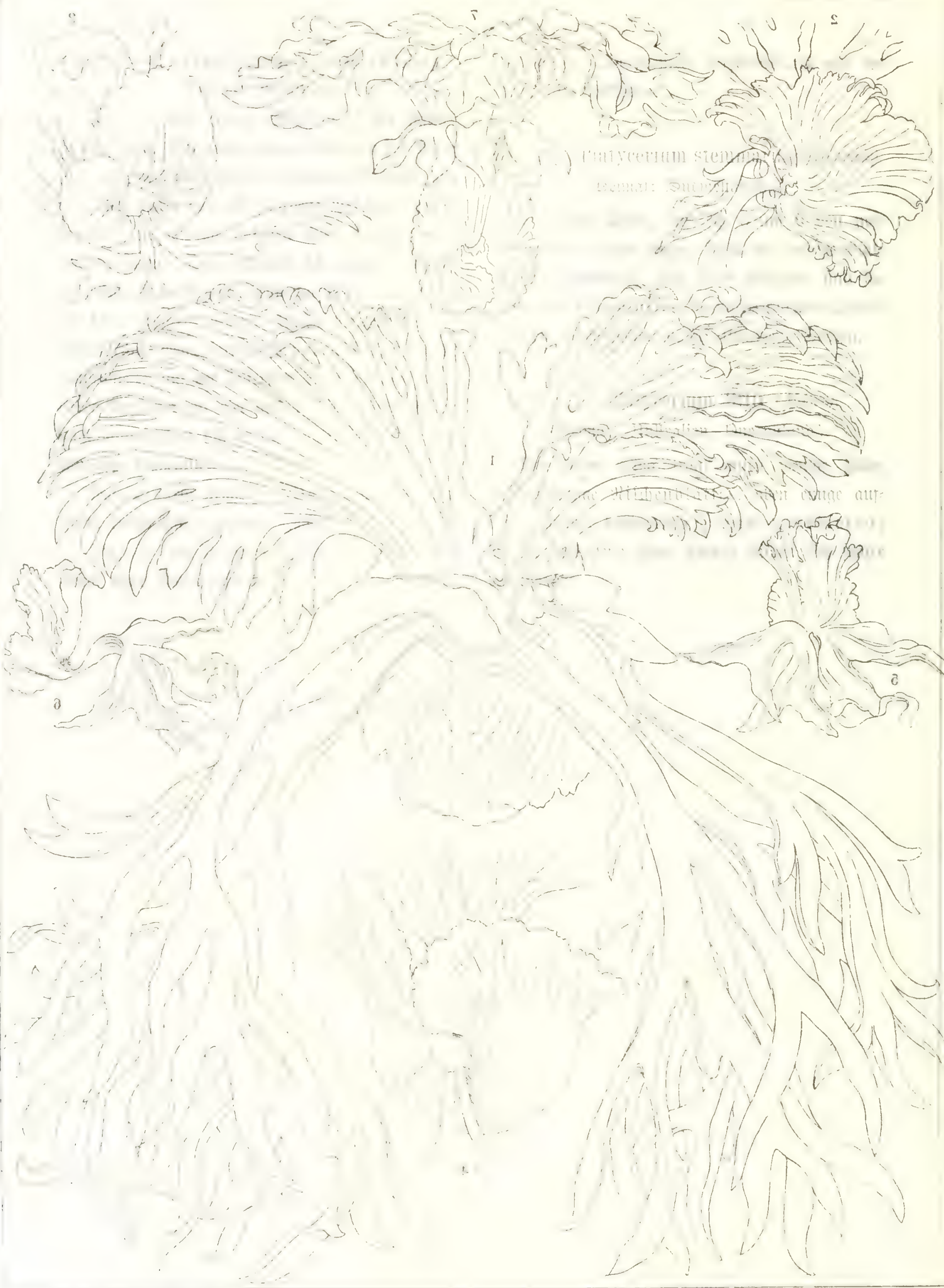




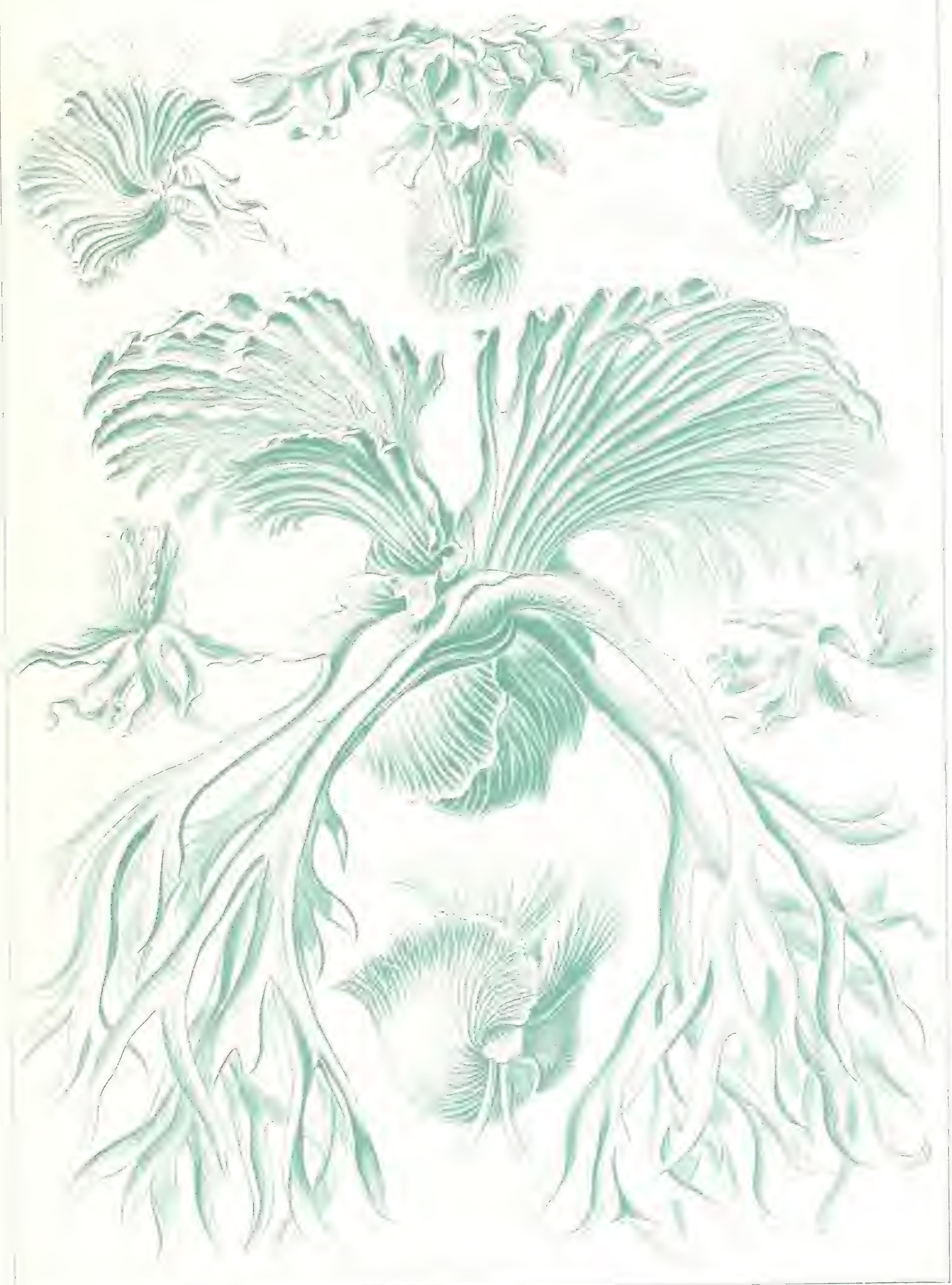

Filicinae. - Sorbtaxne. 



\section{Ctenobranchia. Finnuthienten-}

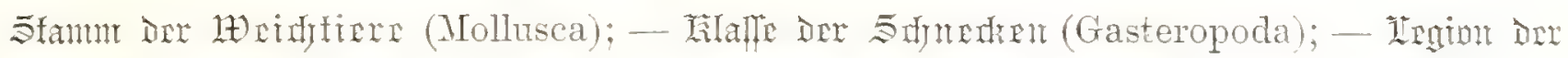
Barberkienter (Prosobranchia); - Bromm Der Fammirmer (Ctenobranchia).

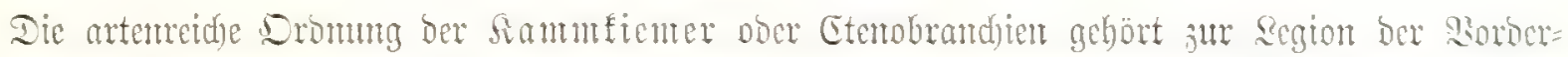

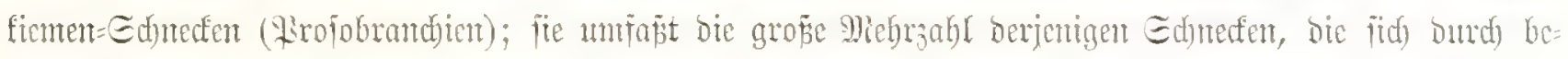

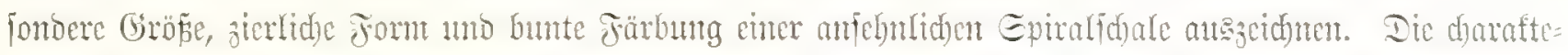

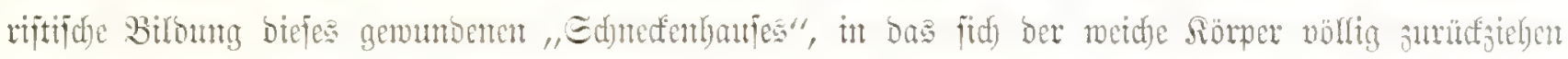

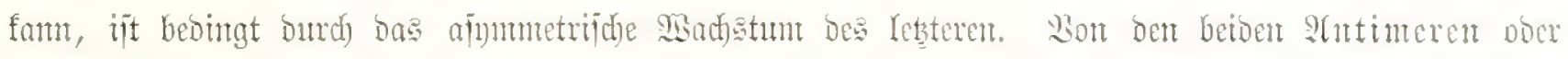

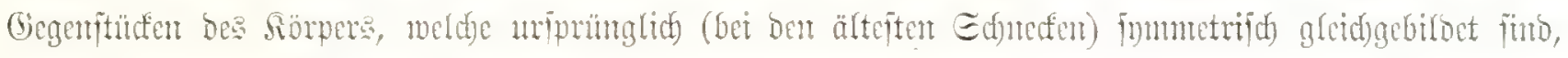

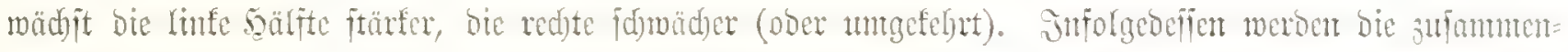

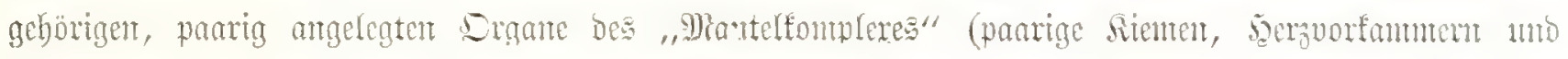

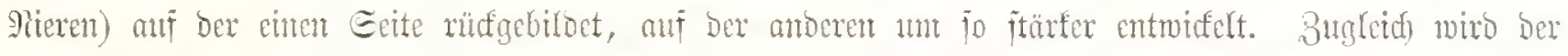

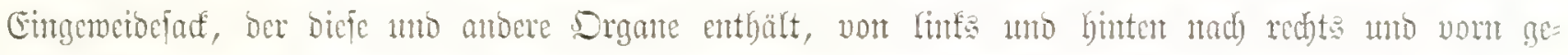

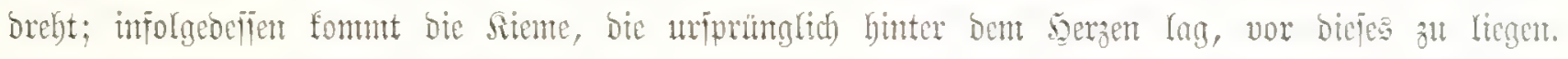
Bei reiterent afyumetriffon 羿ad)

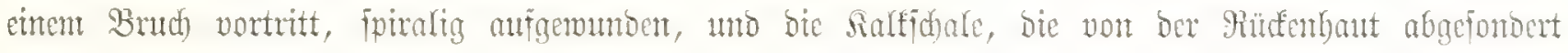
wirb, nimmt bie form einter aujiteigenton

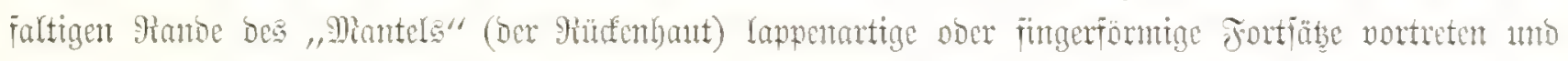

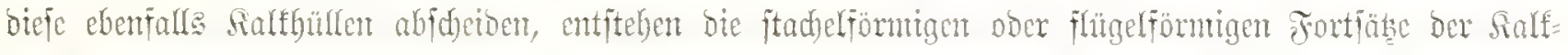

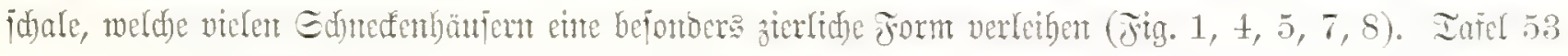

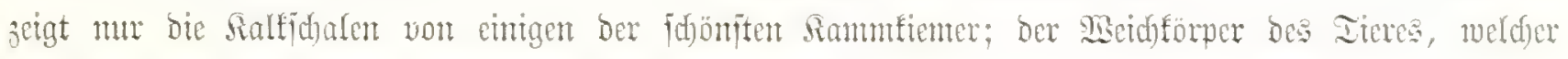
Den 5ohlaum ber Edjale ausiüllt, ift nidjt bargejtellt.

Fitg. 1. Calcar triumphans (Philippi).

Die "trimmpierento Epormfdneté, ans Ja=

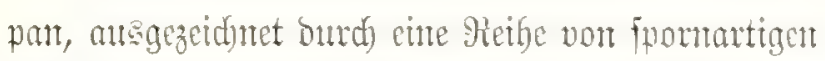
Stadjeln an ber Bajts ber Edyale; Irmintat von ber Spitae bes Gefäufes.

Jig. 2. Comts imperialis (Lime').

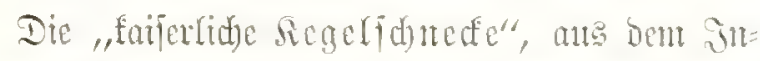
bifden Dzean. Die Echale ijt untgetefrt fegel=

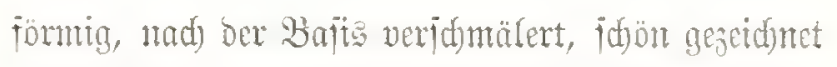
uno gefärbt. Ier obere Fano ber simountgen trägt cine Areige von fegelförnigen söfdem; bie lange un

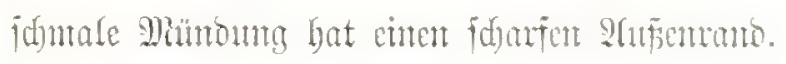

jig. 3. Harpa ventricosa (Lamarch).

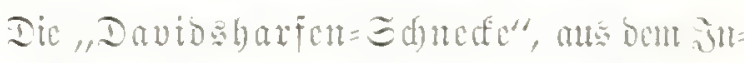

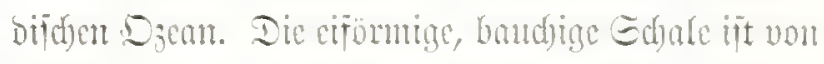
belfer sifafarbe, mit breiten brannen uno jajunten 
woifien Dutbunou. Dic purpurroten Rängsrippen,

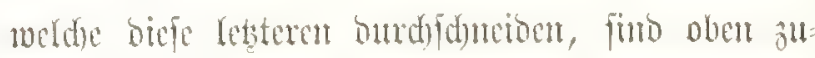
gefpizt mo unter bex Epitse mit cimem ftarten feget= förntigen Babur bewaffuet.

Jig. 4. Mnrex tennispinus (Lamarck).

Dic, Doppel= Spinncutopf=Sdyede", ans bent Junfficn Dzean. Die grame Edale trägt bre famm ralleten Gtudeln.

Fig. 5. Nurex inflatus (Lamarck).

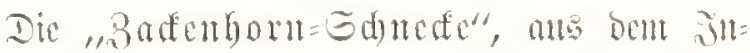

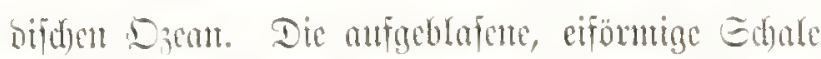
ift quex gefurdet anto gerippt, weifs mo braun ge=

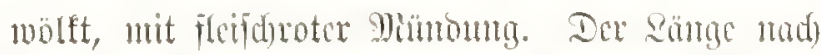

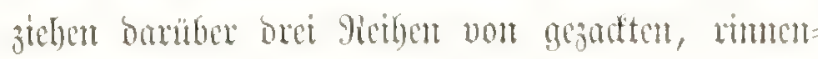
förmigen, zmüafgebogenen Domen.
Jig. 6. Fusus longicauda (Lamarck).

Die "langröbrige Epindelfdunede", ats bem Jubijuen Dican. Die vorbere 13 mo ber Guale ift entfent, un bie sentrale Epunod (Columella)

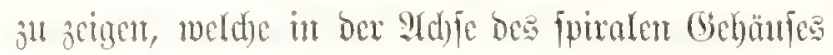

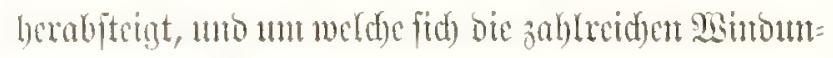

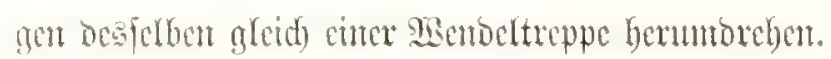
Fig. 7, 8. Astralium imperiale (Chemnitz).

Die "fniferlide Eternfdutefie", aus giculese fanb. Fig. 7 Itufidut von unten, Fig. 8 von obert. Won unten fiebt man in ben tiefen siabel (Um-

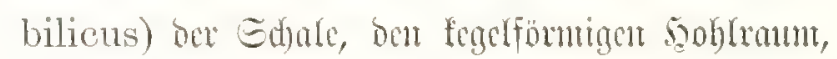

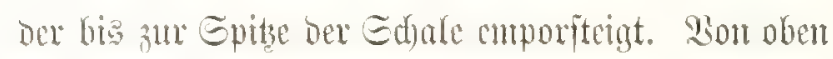
ficht man bie Meithe ber jierlid)ent oreiedfigen Blätter ober Flthgel, welde fächerartig gerippt füto uno läutge bes unteren Fantos jock sisnoung in regedmäpigen vafitünocn jtebcr. 


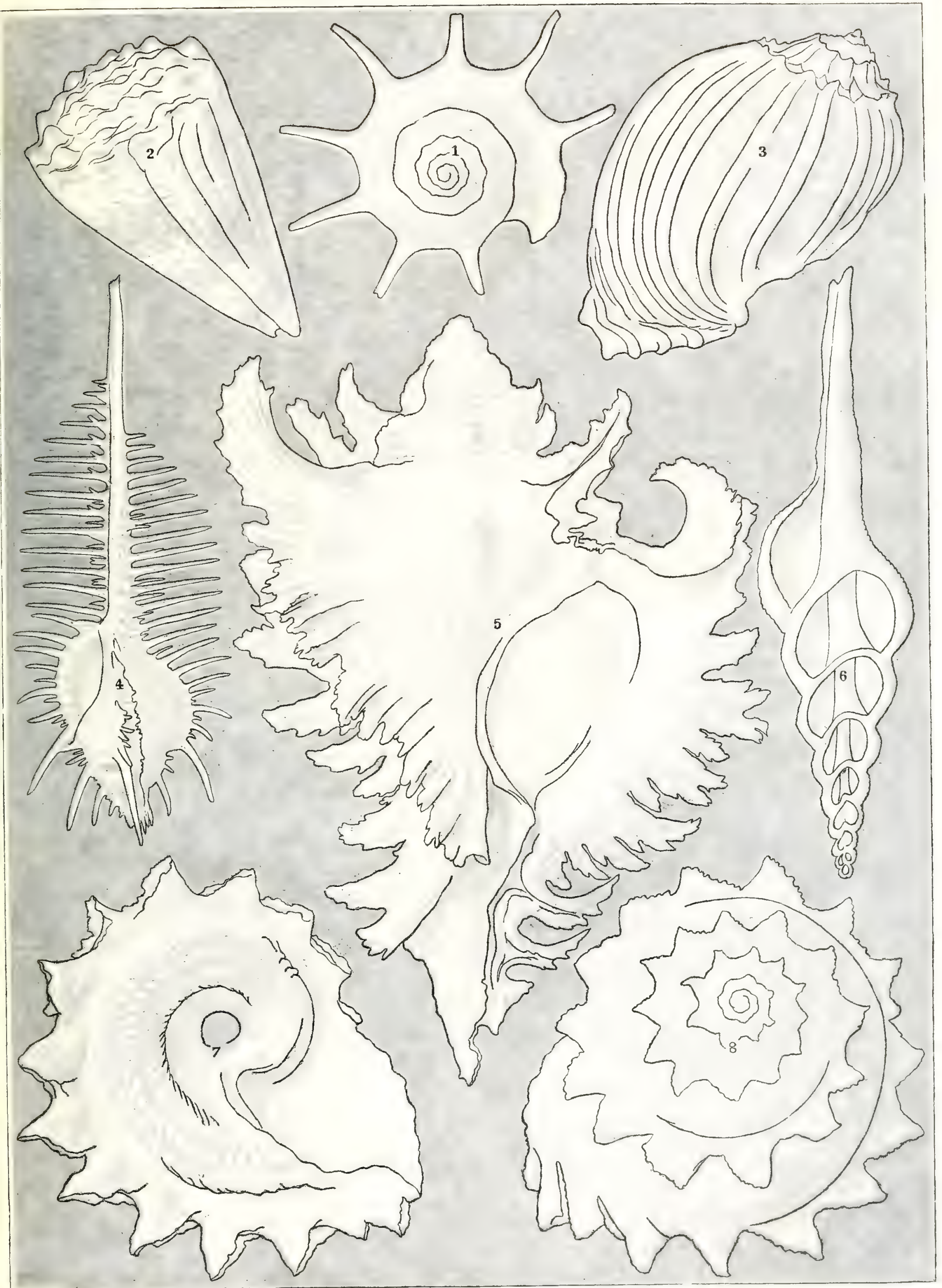




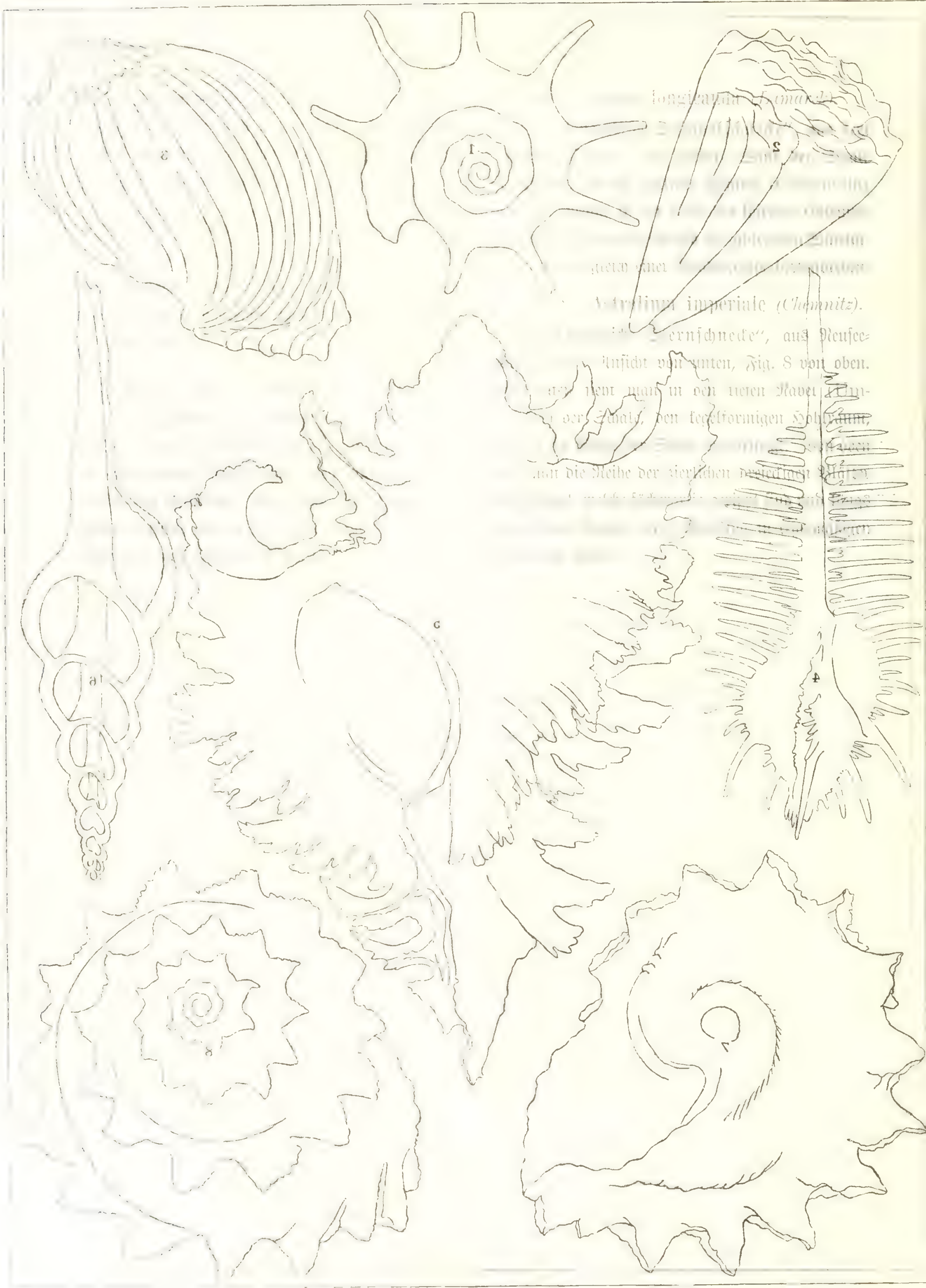




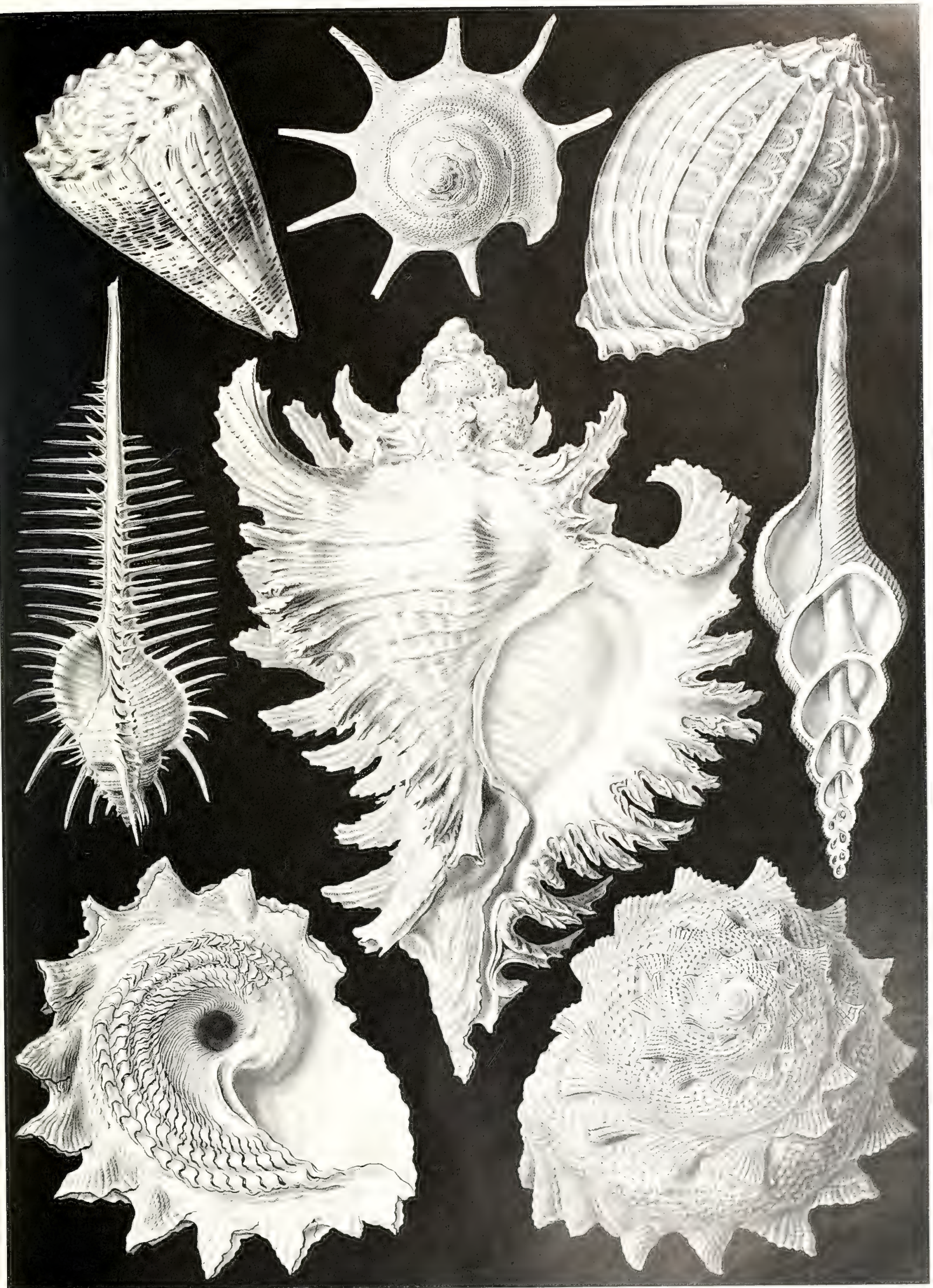

Prosobranchia. - Boxdertitentent=Edintedient. 



\section{Gamochonia. Trutgtexhatuen.}

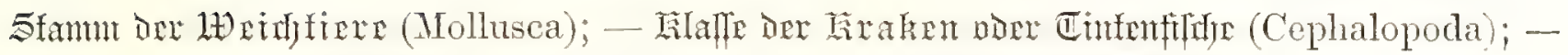

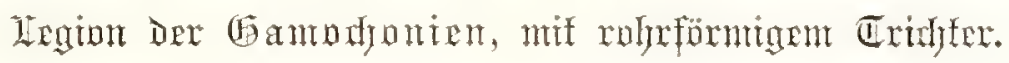

Die Srafen ober "Iintenfifide", weldye auf biejer Iafel abgebiloct fün, gebören an ber jünge

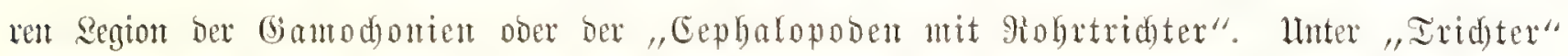

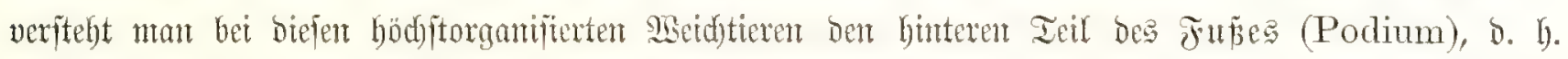

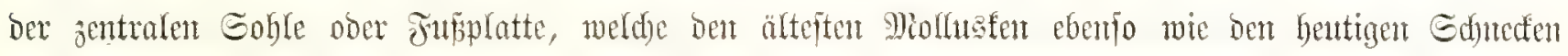

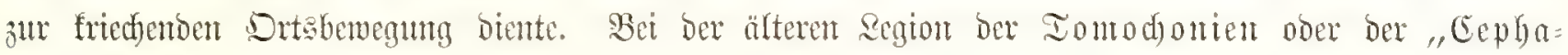

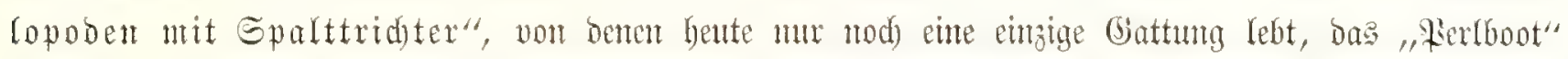

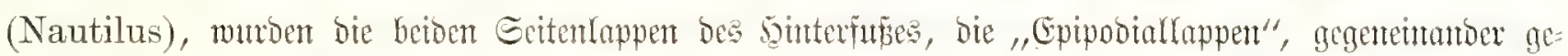

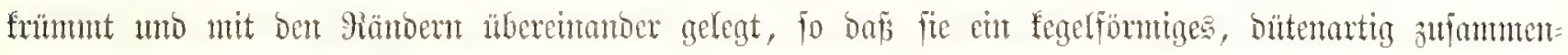

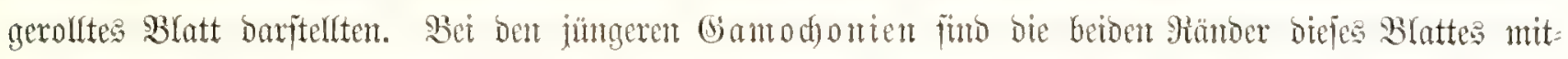

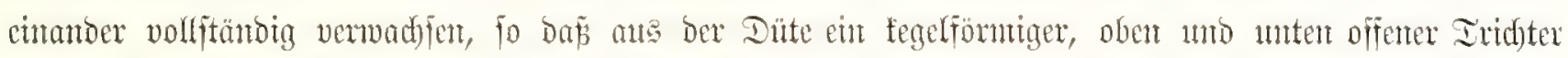

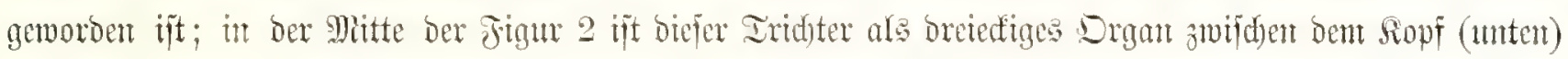

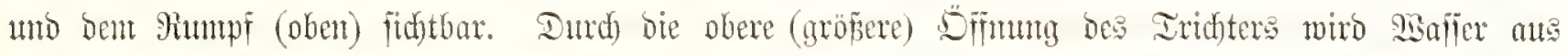

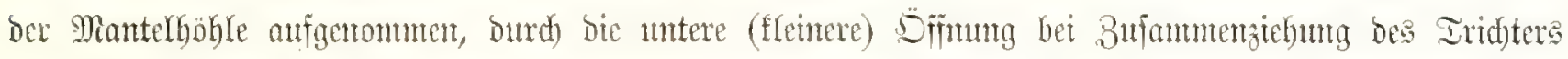

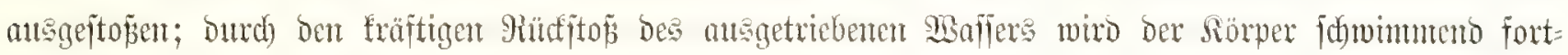

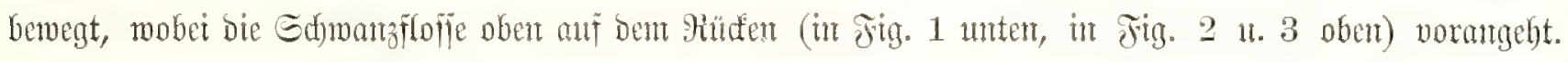

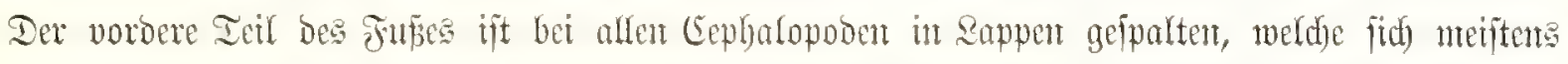

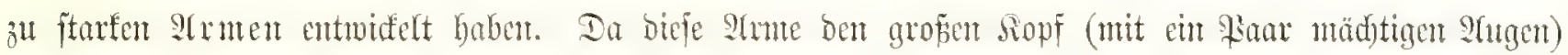

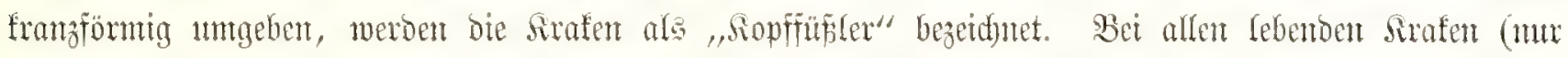

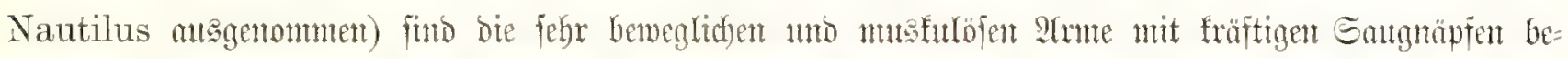

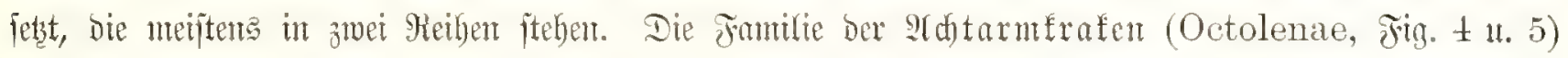

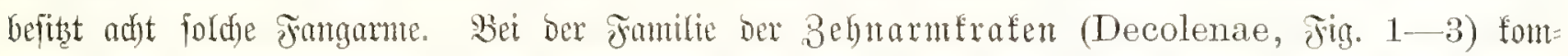

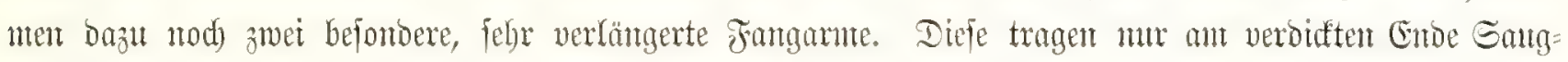

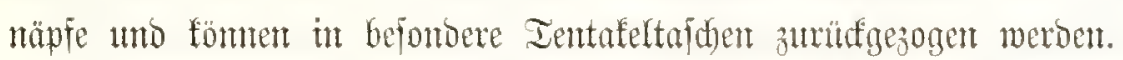

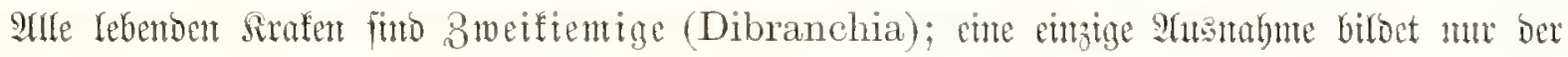

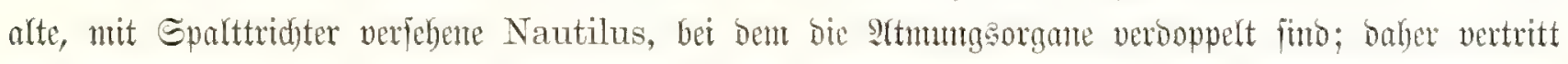
er bie bejonbere Gruppe ber Sierfiemigen (Tetrabranchia). Die anfefmlidye, nit sufffanmen ge=

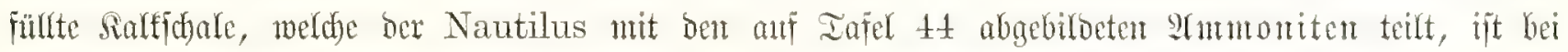

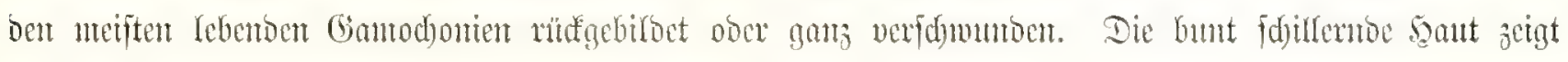

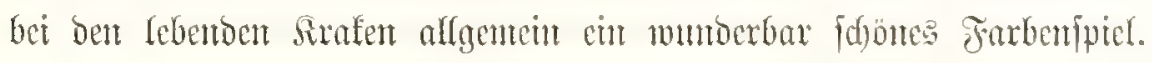


Fia. 1. Chirotenthis Veranyi (Finusac).

Familir Der Bafjuarmbratro (Decolenae).

Ior shopf (stad) oben gefebret) trägt cint fant

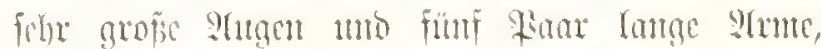

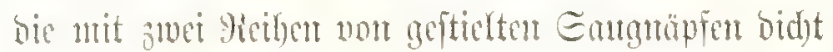

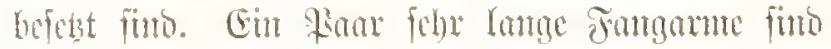

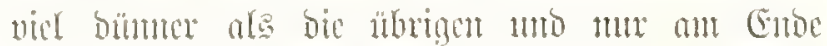
mit cincr ftarfon Eangplatte bewaffnet; fie fömen in cure befontoere Iafd) zutütgezogen weroen. Der

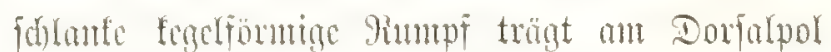

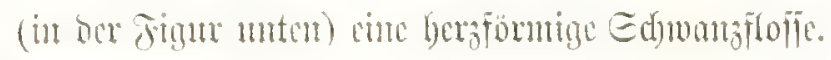
(Mittimert.)

\section{Fin. 2. Ilistiotenthis Rüppellii (Terany).}

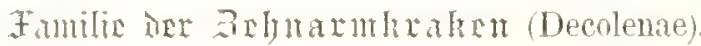

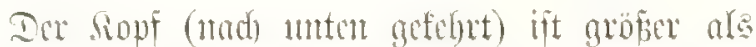

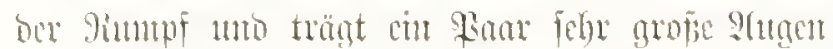

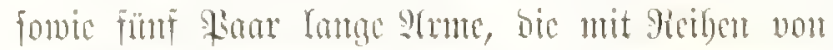

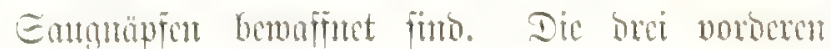

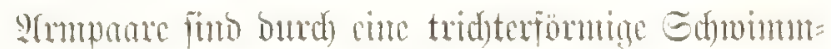

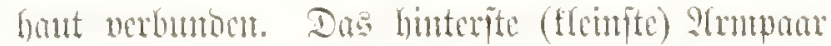
iit fret. Die betoent fehr longen, viel bünueren

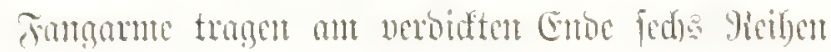

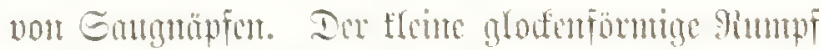
trägt oben am Inrfalpol cine breite boraformige Sd)wanjtofie. (9hittelmect.)
Tig. 3. Pinnoctopus cordiformis (Gaimard). Familic one Anfarmbraken (Octolenae).

Der Sopf (trad) unten geferbrt) trägt viex Raar

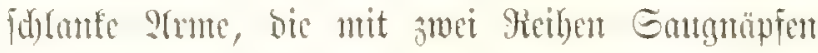
befetet und am Grumbe burd) cine Edbummbant nerbumben finto. Der eiförmige Simmpf ift oben am Dorfalpol in feiner ganzen Sareite vou ciner herz=

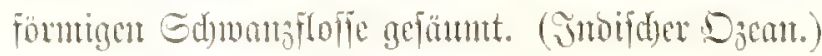

Fig. 4. Octopus vulgaris (Lamarck).

Familie Dex Ady axmkrakn (Octolenae).

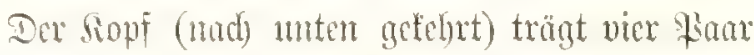

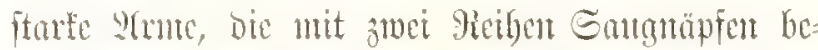
jetst turo ant Grunto buth cine Edhwintmbant ver=

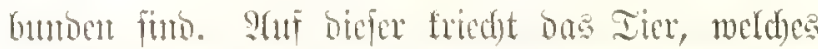

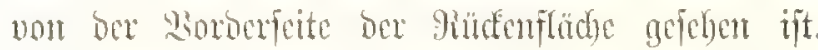

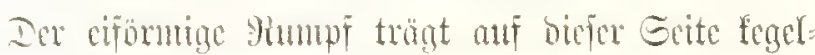

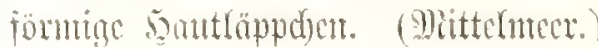

Fin. 5. Oetopus granulatus (Lamareli).

Familie on Bdyfarmbraken (Octolenae).

Der Sopf (tad) obeat gefelyrt) trägt adyt foldr ftarfe Shume, bic mit juet gieihen von gropien Gang:

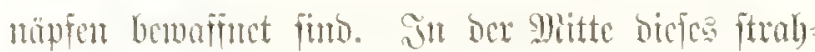

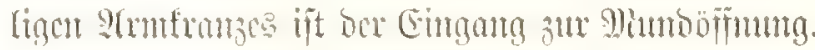
Der biffe ciförming Gump (in ber Fign unten) ijt mit viefen founen Sönndyen hebert. 


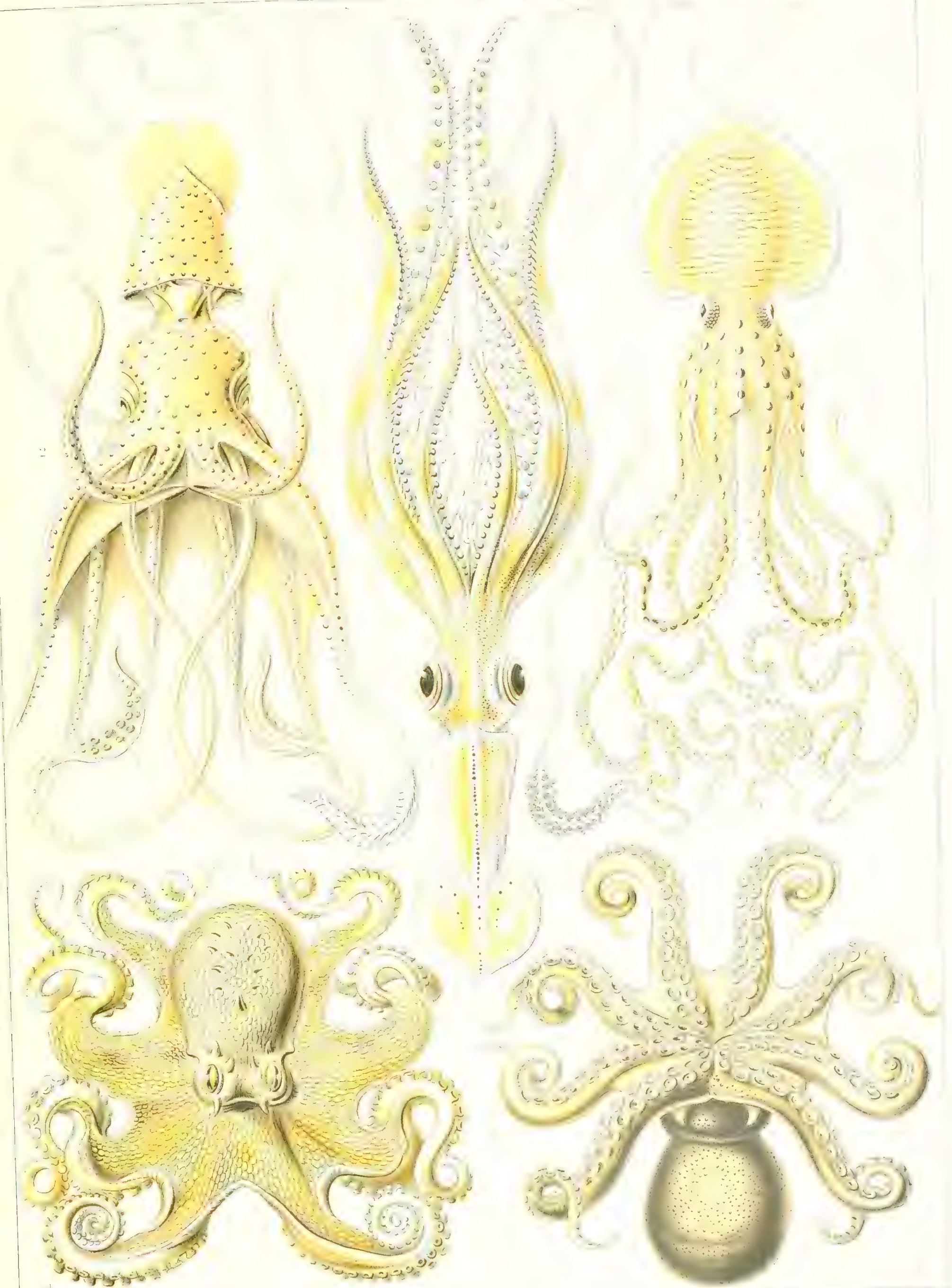

Gamochonia. - Eridflextirctient. 



\section{Acephala. Matrftrutit.}

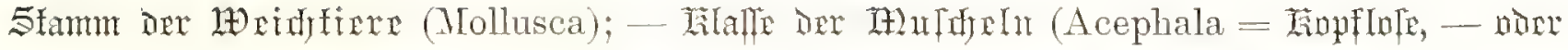

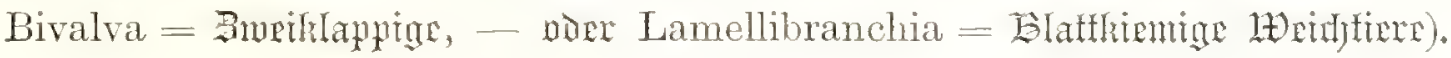

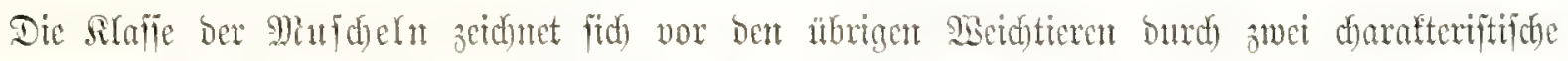

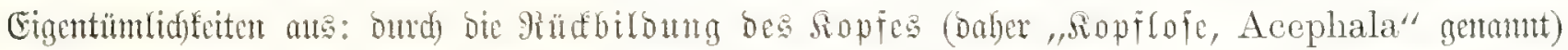

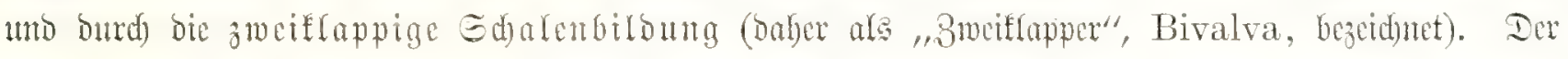

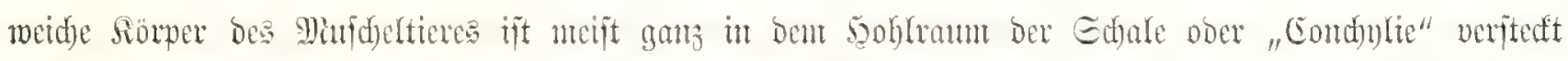

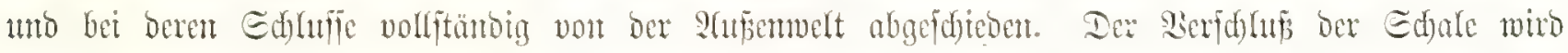

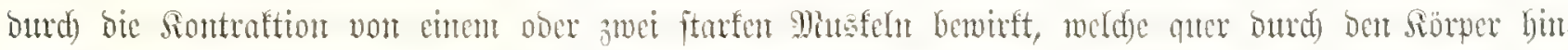

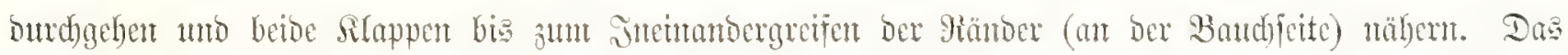

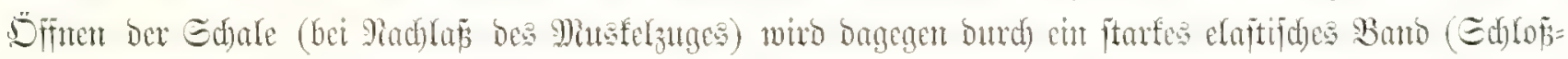

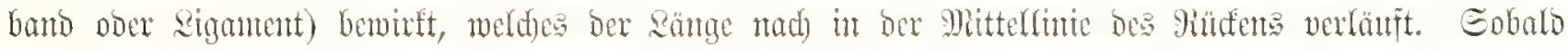

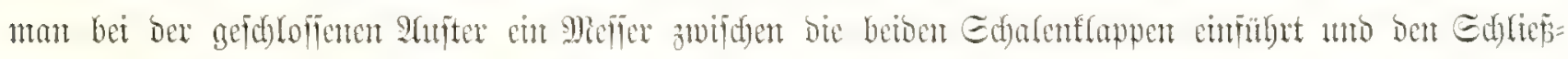

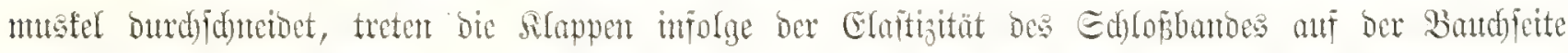

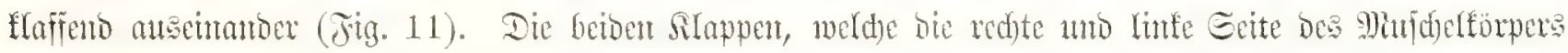

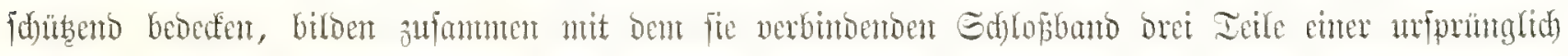

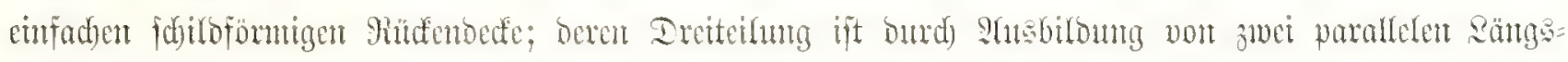
furde)en entitandont.

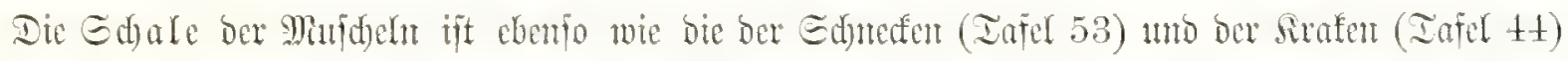

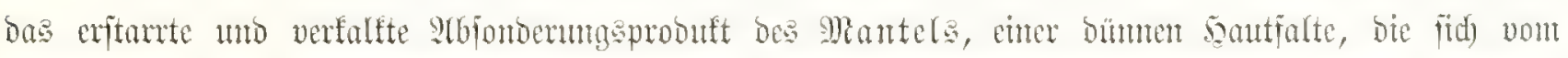

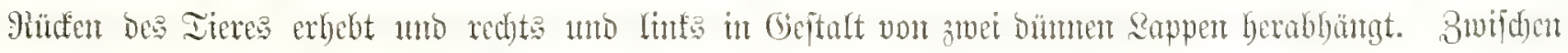

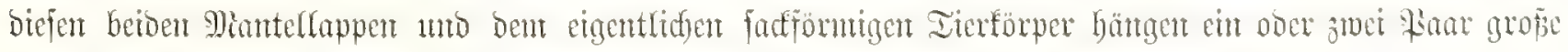

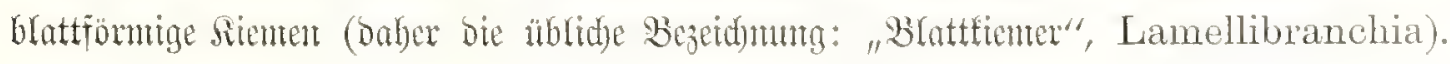

Fig. 1-3. Cytherea Dione (Lumarch). Familie dex Bemanutiteln (Venerida).

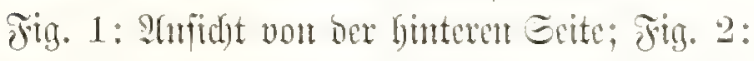

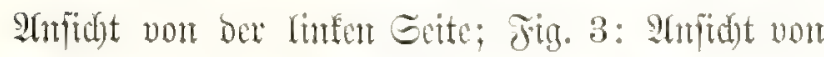
Der vorberen mo bberen Geite. Die Gdhale ber

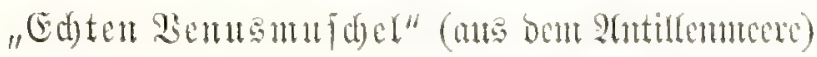

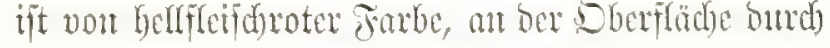

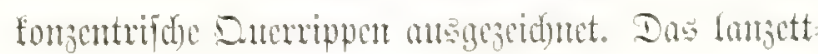

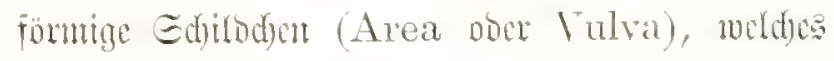

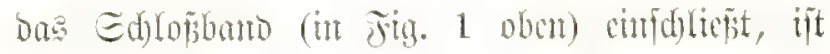
purpurrot uno von cinem sirange gefrinumter Sta dhclit geild)ütist. 


\section{Fin. 4 11. 5. Cardium aculeatum (Timi).}

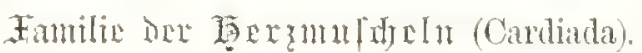

Fig. 4: Saridot von ber redsten Eeite; Jig. 5: Stufid)t von ber hinteren Ecitc. Dir Edhale biejer

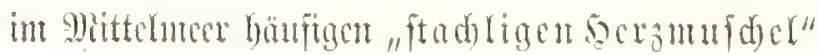
ift von rötlidgactber Furbe mo burd) vorfpringettoe

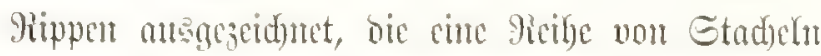
tragen; bic Kippen. ftrablen von ben fogenamten

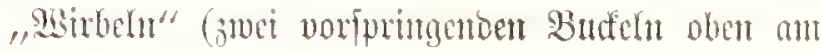

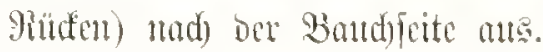

Fig. 6-9. Hemicardium cardissa (Timé).

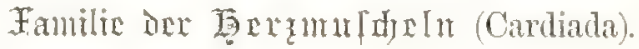

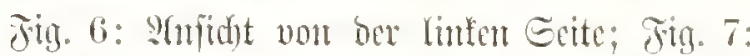

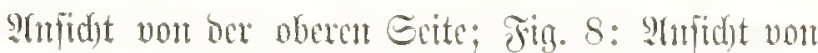
bor vorberen Eeite; Jig. 9: S(nfidut von ber hin=

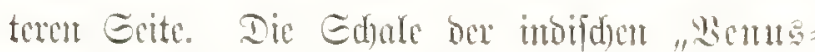
berzmufdel" ijt heraförmig, wost wetiser Farbe,

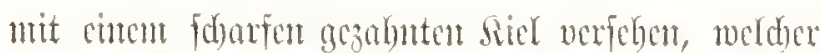

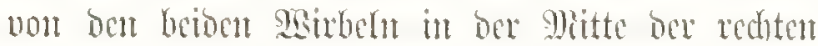
umb \inten Slappe gegen bie Bandbyeite borabläuft, utro mit forzacutrifden gefönten Bogemippen, meldye bent side parallet fanfor.
Jig. 10-13. 'l'ridaena squamosa (Lamerck).

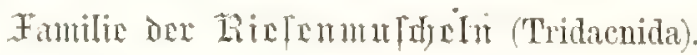

Dic "fduppige Ricienum

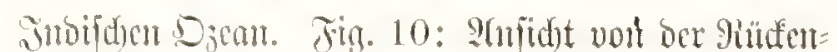

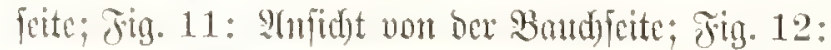

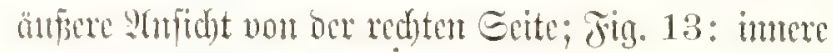

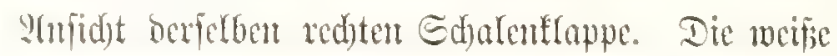
Edyate int an ber Salpenfläd)e mellenförmig gebogen umb vou ftarfen gippen burdyzogen, weldye von ben Wirbefu gegen ben freien Edfalemmo ansigtrahlen. YH jooer Mippe erhebt fid eime Meibe von brattförmi= gen Ed)uppen, bic wie soblyiegel übereinander liegen.

\section{Fig. 14. Ilippopus maculatus (Lamarck).}

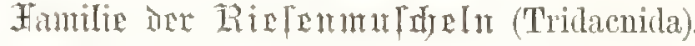

Dic "rotgefleate Biferdebufmufdel", aus

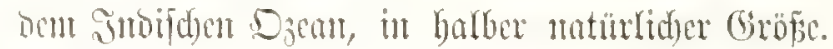

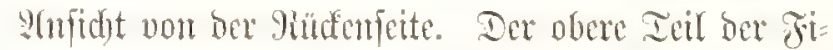

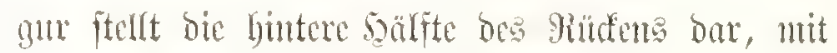

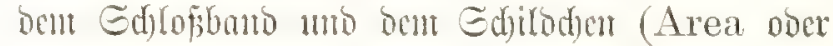
Vulva); ber untere Ieil ber Figur jeigt bic vor=

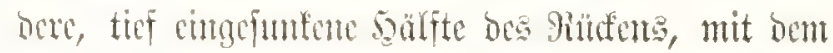
Dofram ooer Feloden (Lumula). 


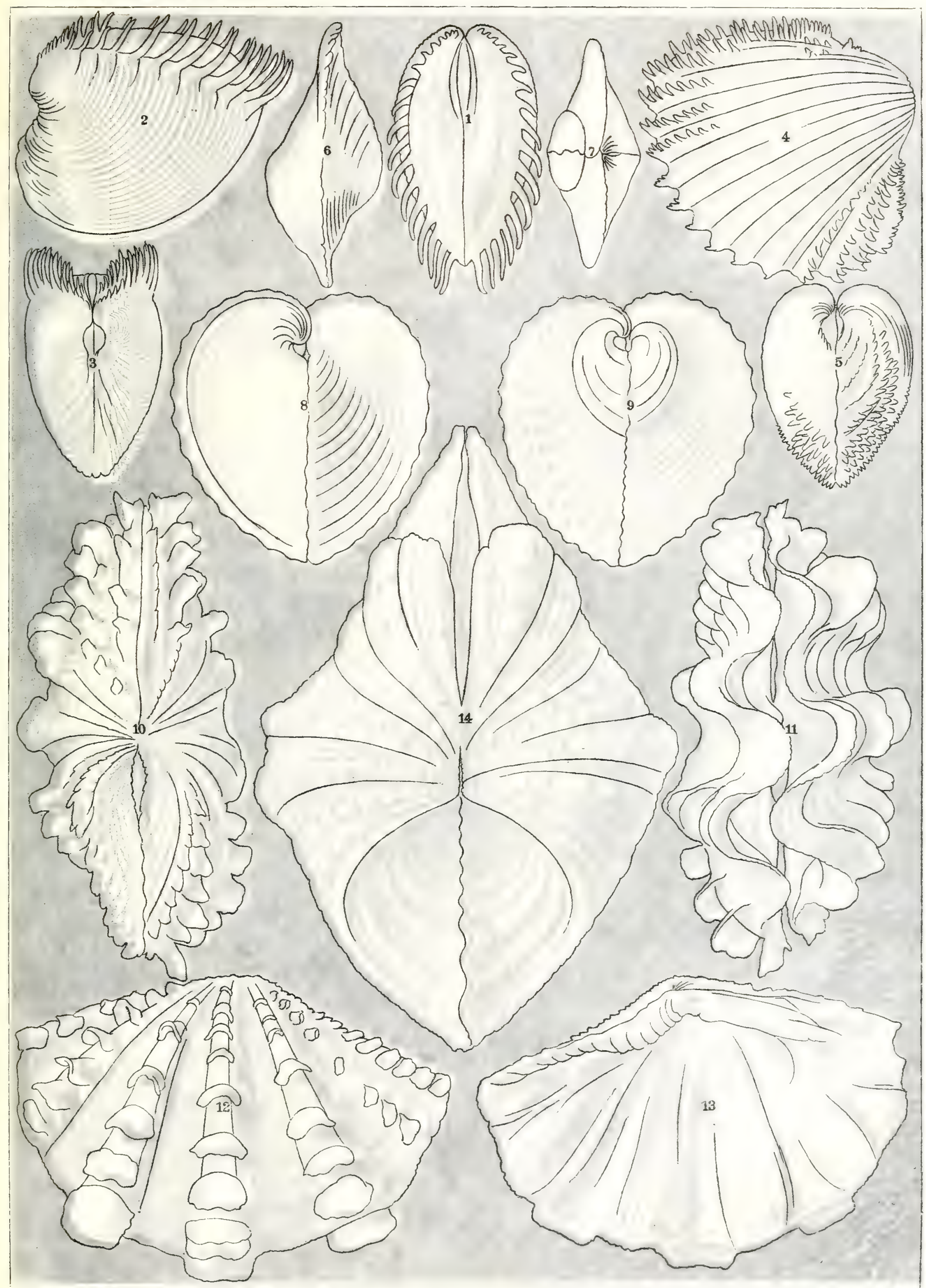


-

-

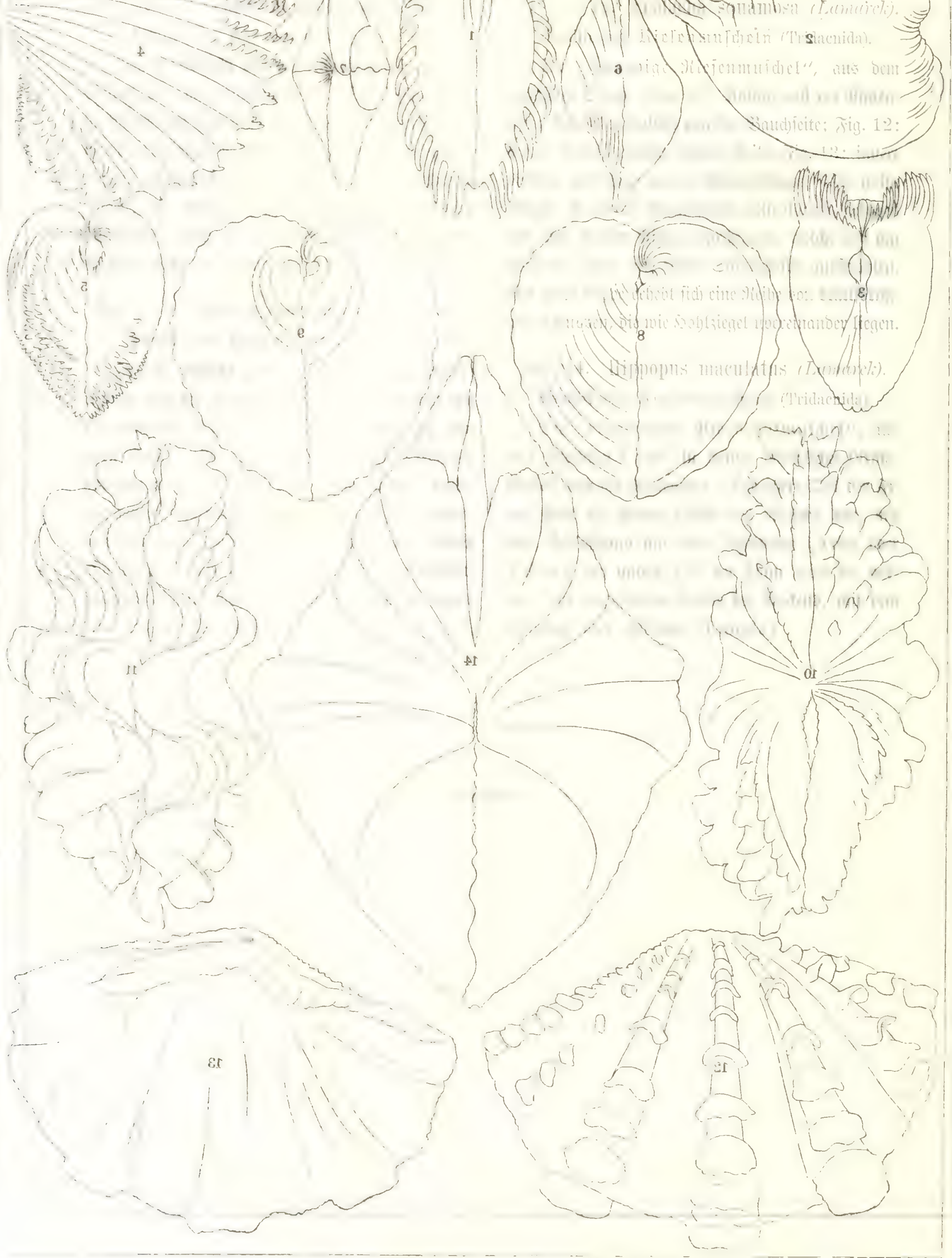




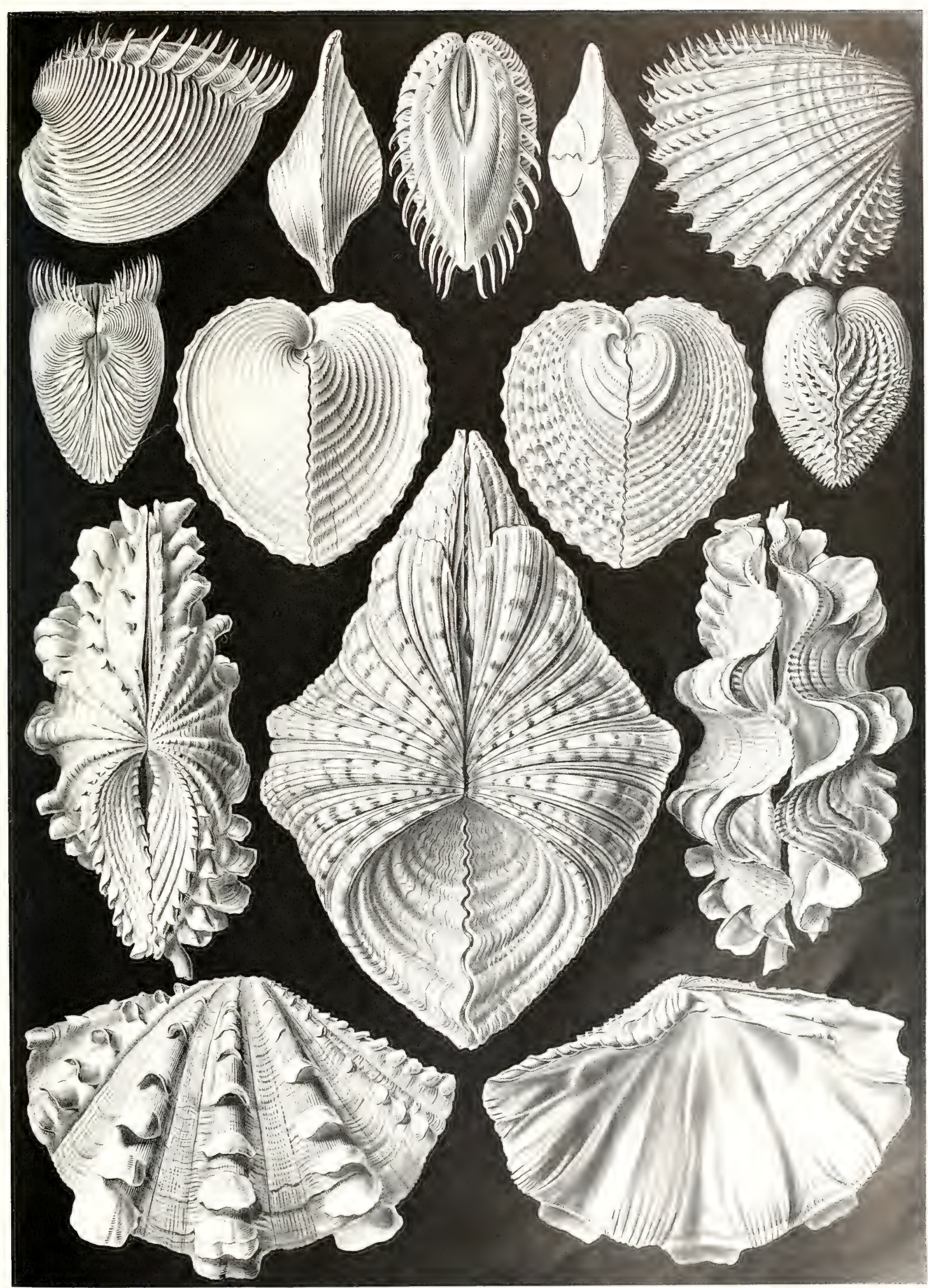

Acephala. - Zâtuldedir. 



\section{Copepoda. Rumeruedre.}

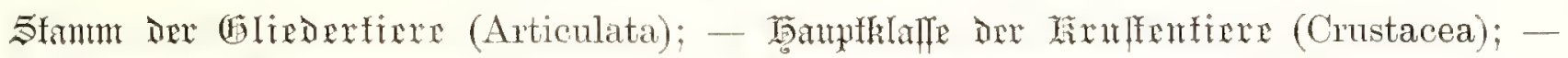

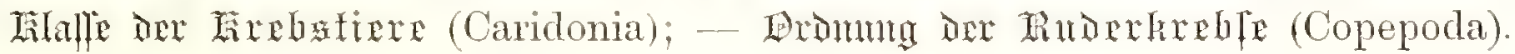

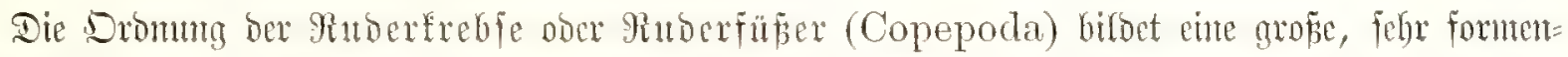

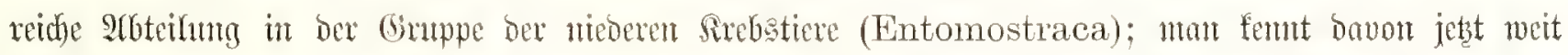

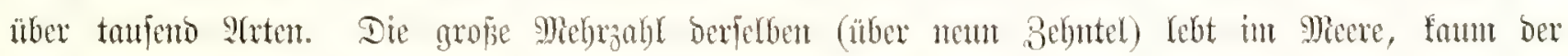

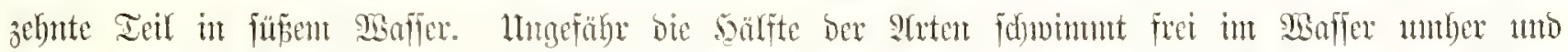

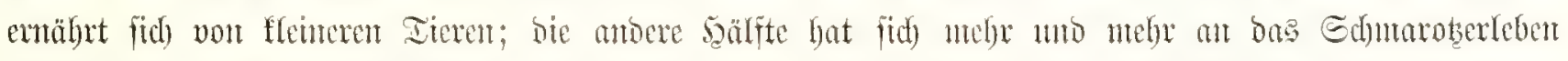

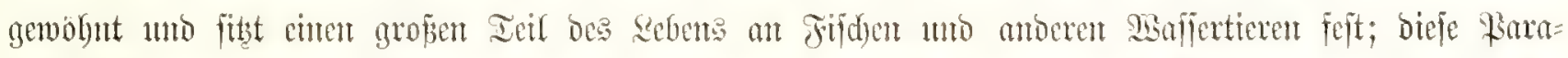

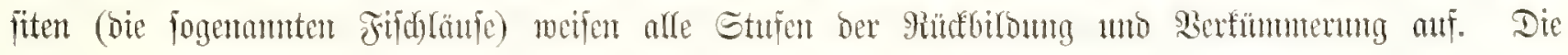

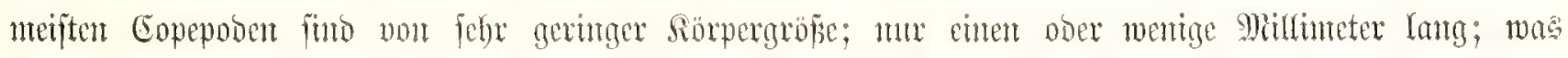

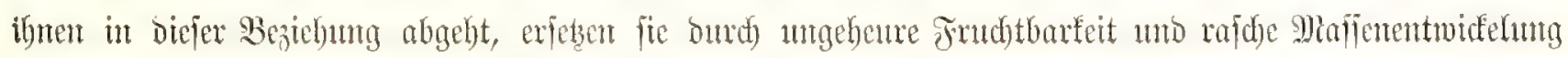

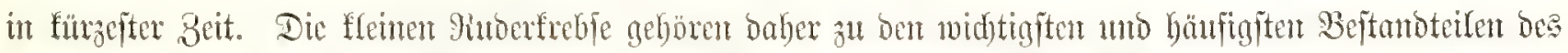

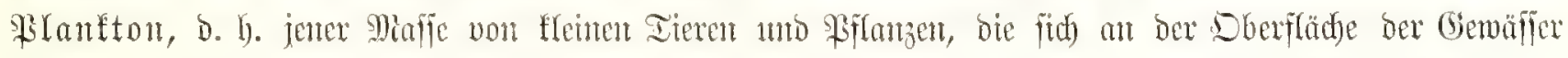

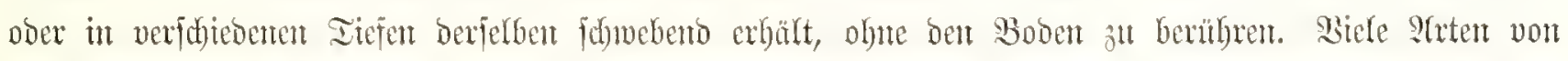

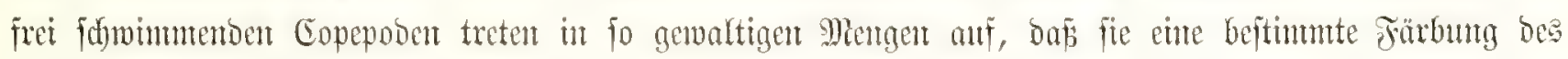

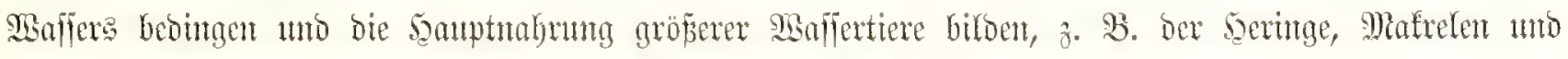

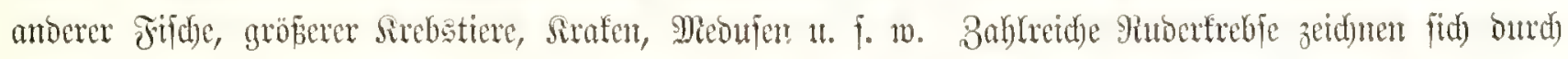

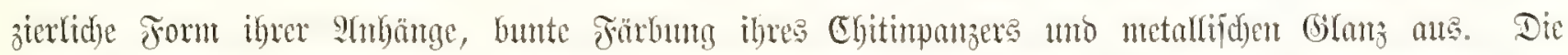
Beine umo Edhwanzborften funo oft gefiebert ober mit żterfiduen, Gunten, feoerfoumigen SInfängen ge=

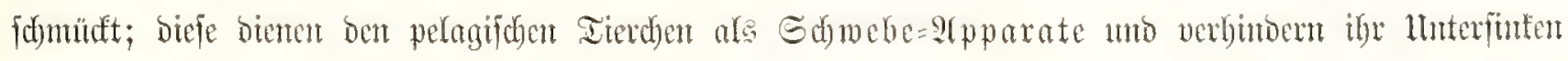
im sisafier.

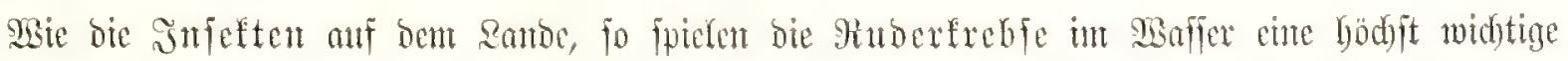

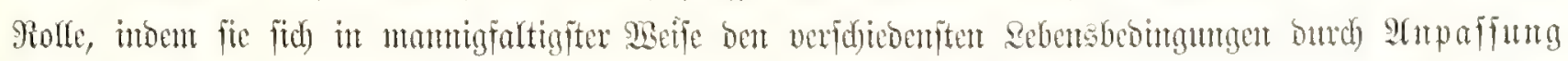
Fügen; und wie bie crfteren, fo bewahren and) bie lesteteren (trobs ber gröpten Miamnigfaltigfeit ber fpe=

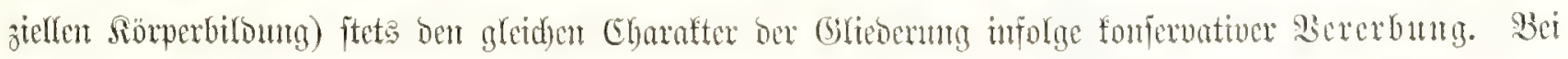

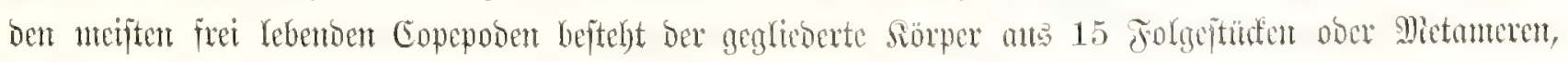

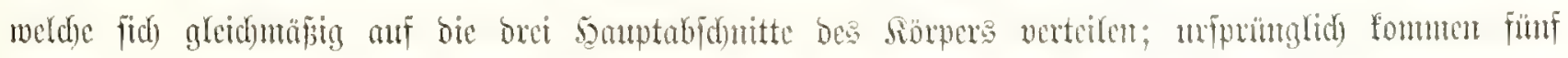

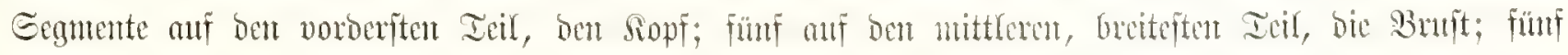

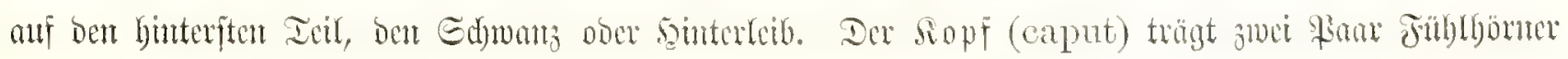




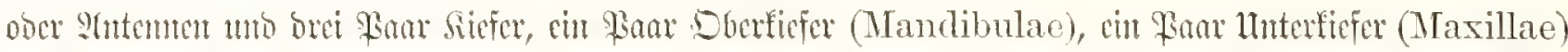

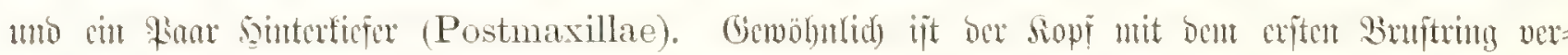

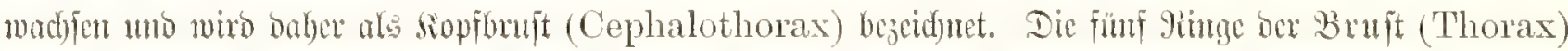

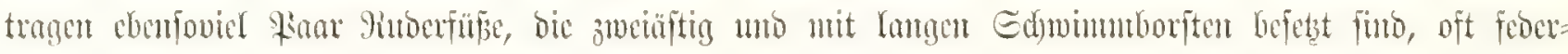

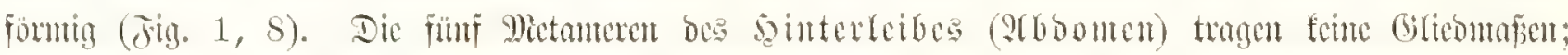

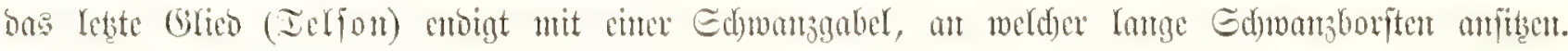
Y) biefe fömten bie Form non jierfiden bunten Febern baben (Jig. 1, S). Die sgetbdyen tragen ge=

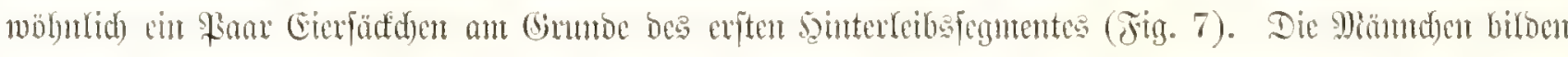

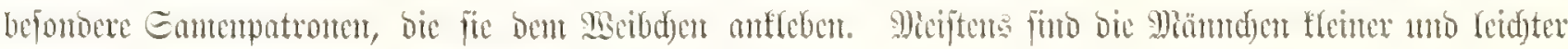
beweglide als bie berberen siscibden.

Stle sigumen biefer Iafel füb ftant vergröfert.

Jig. 1. Calanus pavo (Dana). 刃ämud)ent.

Jig. 2. Clytemnestra scutellata (Dana). macibct)en.

Jig. 3. Oncaea venusta (Philippi).

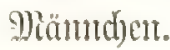

Ggig. 4. Gryptopontius thorelli(Giesbrecht). 照eibdyen.
Jig. 5. Acontiophorus scutatus (Brady). Mscibder.

Fig. 6. Corycaens renustus (Dana). 然eibchen.

Jig. 7. Sapphirina Darwinii (Haeckel). 留eibchen.

Jig. 8. Angaptilus filigerus (Giesbrecht). 刃iämndyon. 


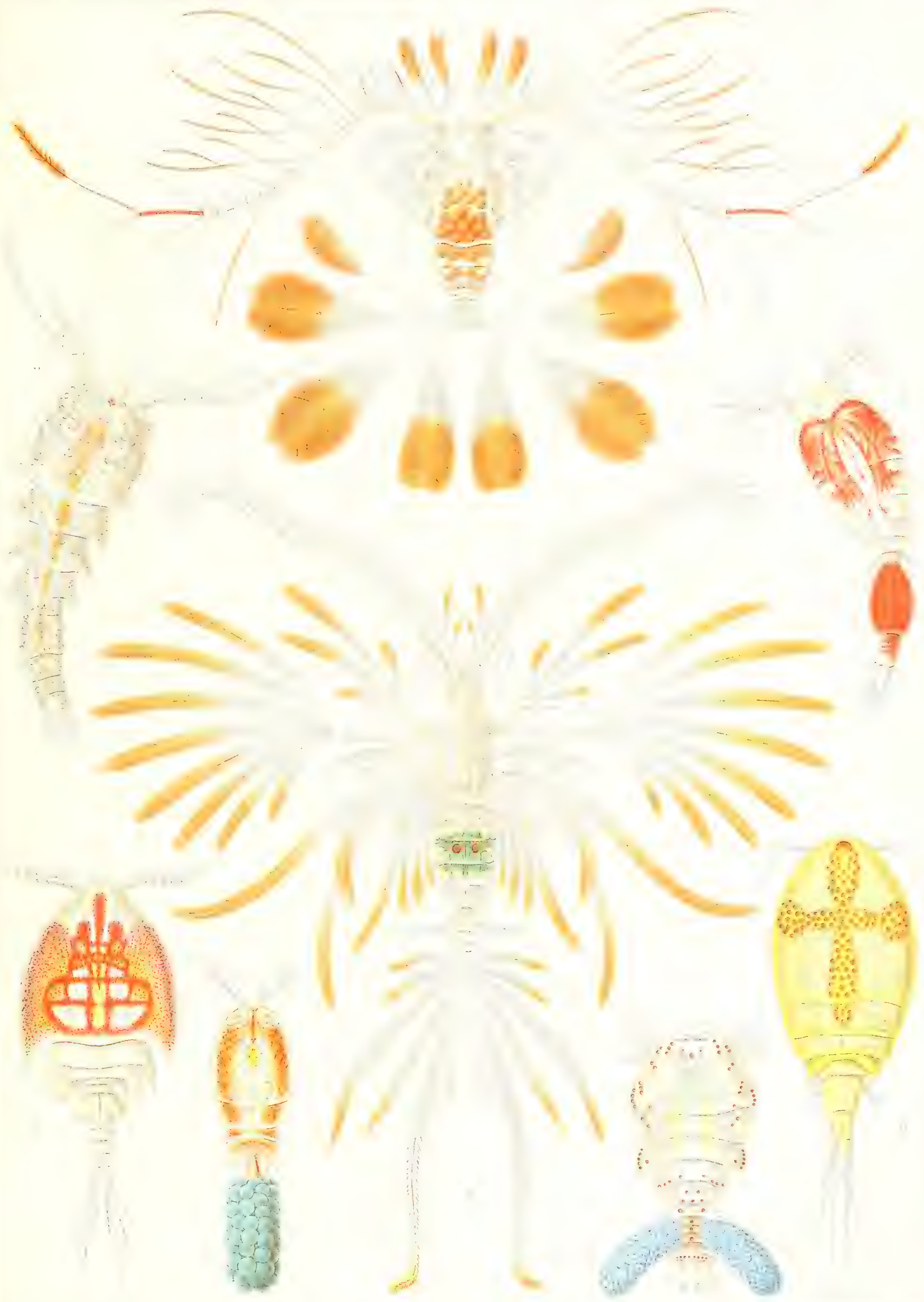

Copepoda. - Zintserfireble. 



\section{Cirripedia. Ramkentmertre.}

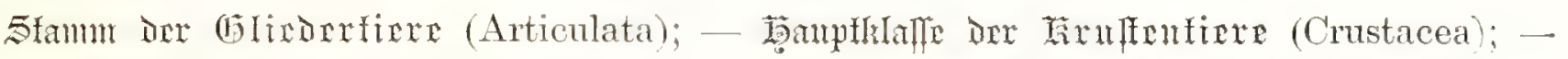

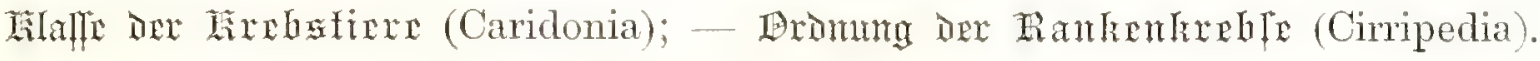

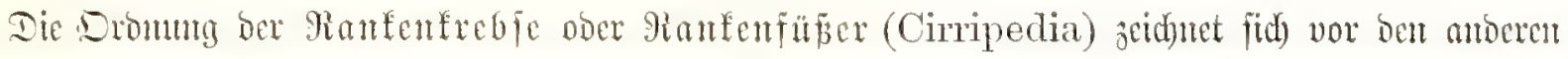

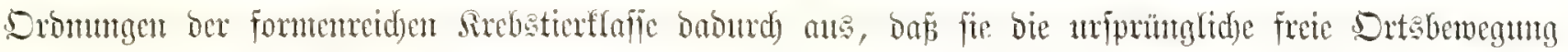

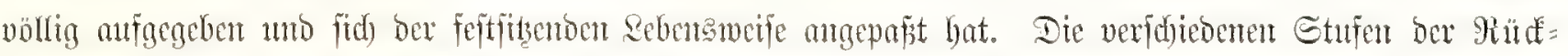

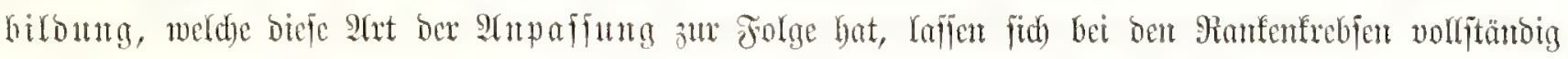

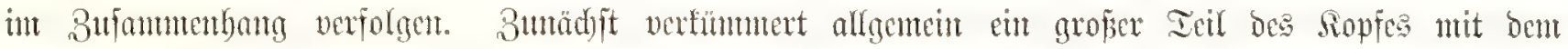

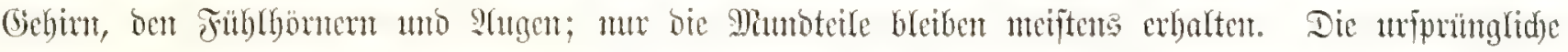

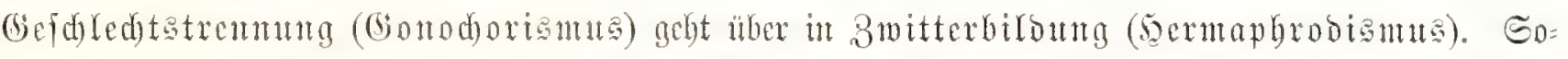

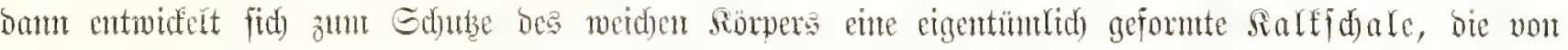

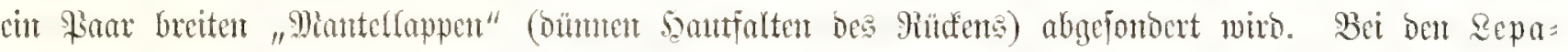

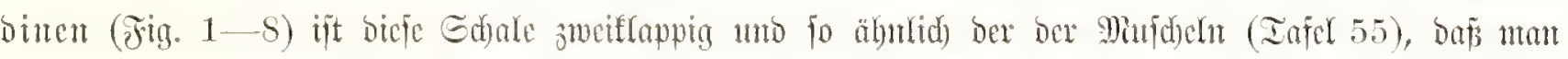
Dic Repabinten frither ăt biefer Silajle von

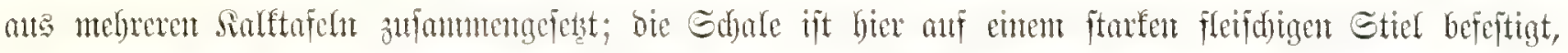

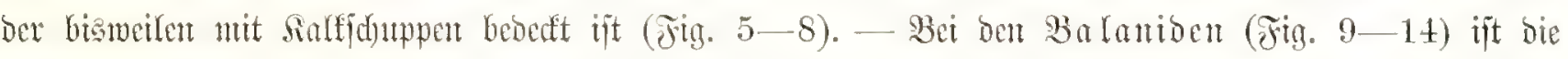

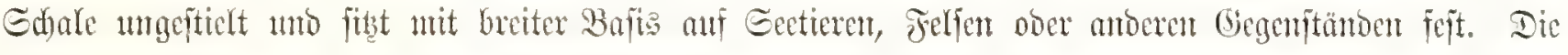

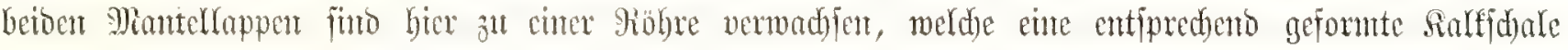

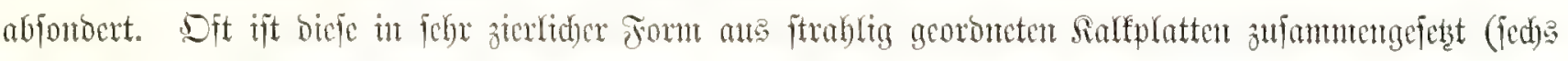

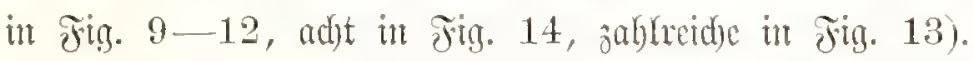

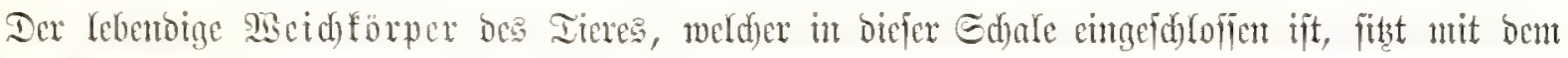

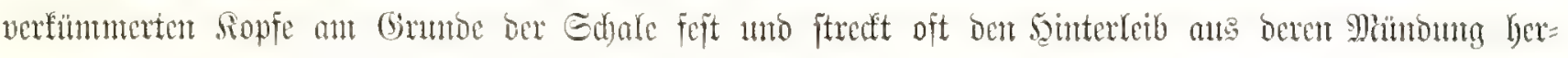

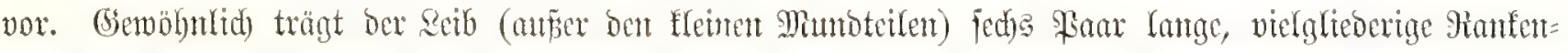
fü

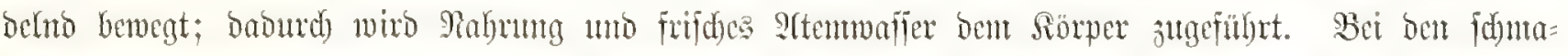

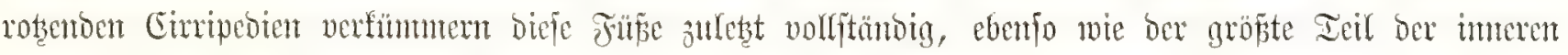

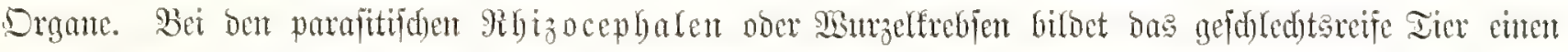

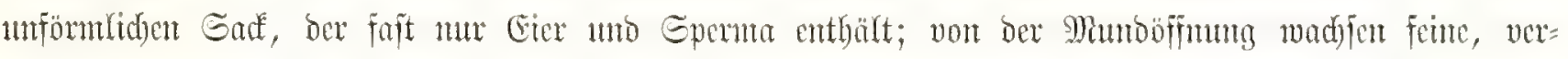

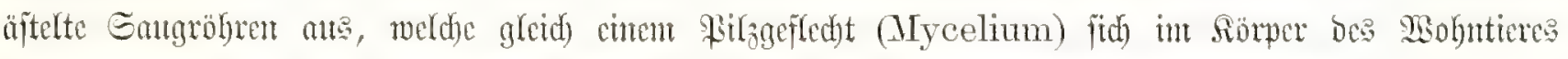

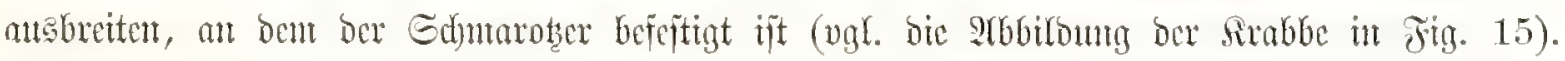

Fig. 1, 2. Lepas anatifera (Linné).

Fig. 1: Dne Tier ift in ber jomeiflappigen Sdare

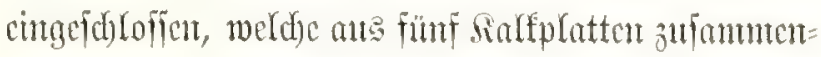
gefert unto anf eintem quergerungelten Stiel befejtigt

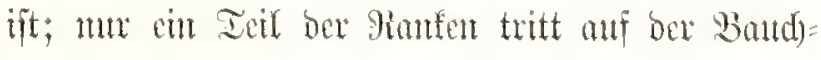
frite vor. Shrjidyt won ber wechten Geite.
Fitg. 2: Dic linfe Edjalentlappe ijt cutfent,

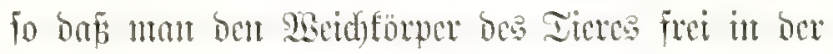

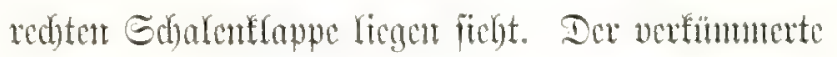
Sopf ift nad) untert geridstet uno ant oberen entoe

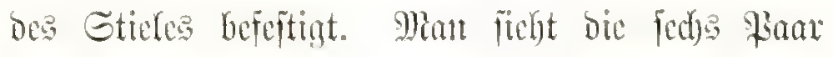
Gebanten Rautenfifife. SGufidst vout limks. 
Fign.: Conchoderma aluritum (Olfers).

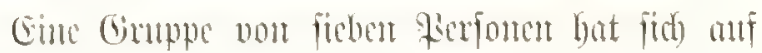
bor toten Eshate cincr Coronula diadema (sig. $9,10)$ andeferst. Dic mittlere Ferjon (untert), anf

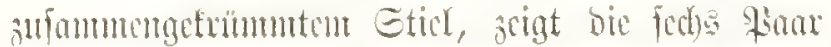

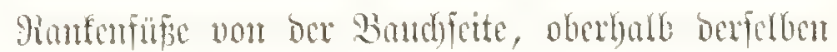

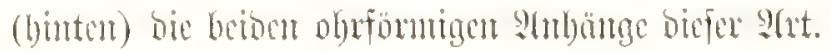

Fig. 4. Pentalasmis vitrea (Leach).

Dos Iide ift me ber Gable genommen mo vou ber Bandfipete gefehen; oben ift ber biffe, fugelige siopi ant oberften Eticlente befejtigt. Bwifacm ben beioen punftierten, harbmonofömnigen Bement= briffent (bie bent sitt jun Befoftigung liefern) ift ber

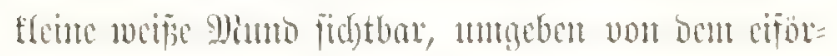

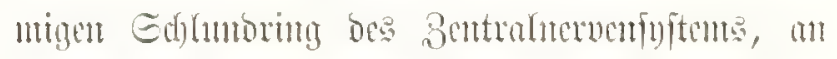
welden fid bie siette bes Bandfuntare binten an=

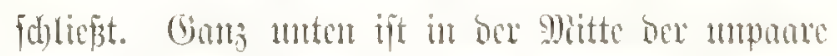

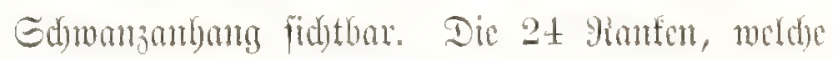

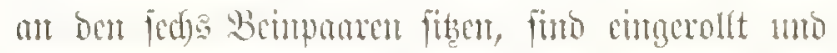
mit Borften befetst; bas vorberfete Bempar ift ftïter uno von ben zweiten burdy eine Rüfe getrent.

Jig. 5, 6. Sealpellum eximium (Hoek).

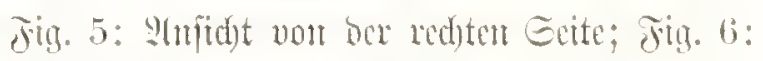

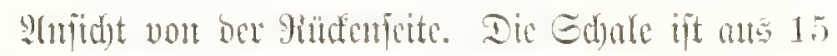

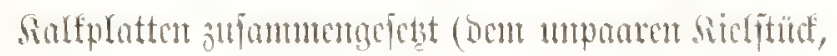
Carina, oben anf bent Jiüden, unb fieben Plaax

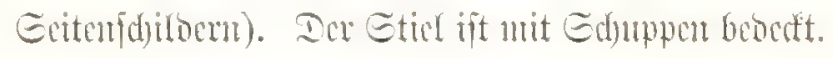

Fig. 7, 8. Scalpellum vitreum (Hock).

Fig. 7: 9lutid)t vout ber linfen Gcite; Jig. S:

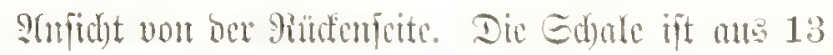

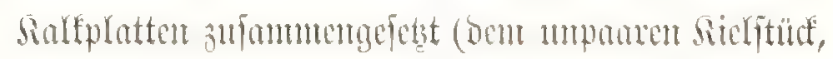

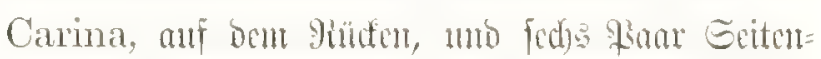

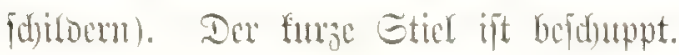

Fitg. :, 10. Coronnla diadema (Tamarek).

Fin. 9: Irnfidat ber Gdale vou ber oberen,

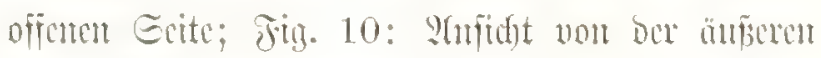

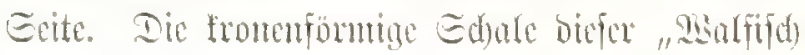

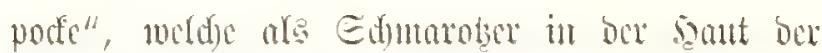

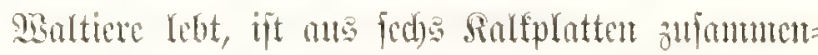

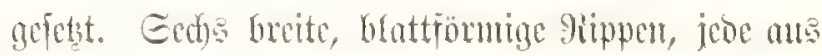

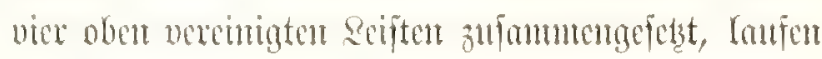
nom oberen simbe bex fodjectigen Gdyalcuminoung bogenförming gegen beren Bafts.

\section{Fign. 11. Corounla reginae (Damin).}

Suftedt ber Edhafe vou ber oberen, offenen Eeite. Die Fedrs Gippen, welde von ben fects Eefen ber oberen Gdhatemtünoung ausgeben, finto fäd)erförmitig uno breiter afe bat ber vorigen Tret.

\section{Fig. 12. (hthamalus antennatus (Damoin).}

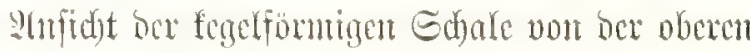
offencn Eente. Die fed fö fäd)erförmnigen Sarffpratten,

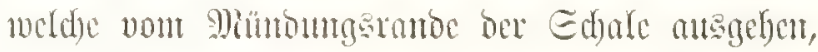

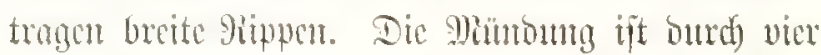
orciectige Ieferfitüfe gefdroflent.

Fig. 13. Catophragmus polymerus (Danvin).

Shrifdet oer Edhale vou ber oferen Eente. Die

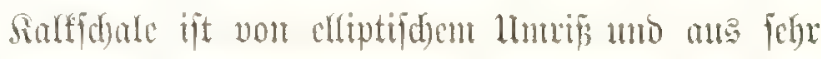

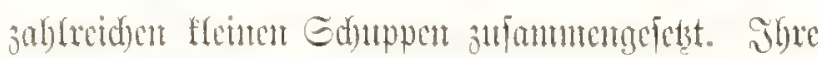
obere Niünoming, welde burdi) vier breieftige sialf=

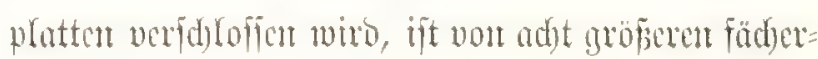
förntigen Iafeltr umtgebert.

Jig. 14. Octomeris angulosa (Soucrby).

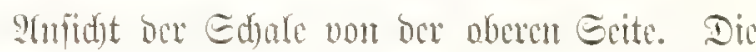

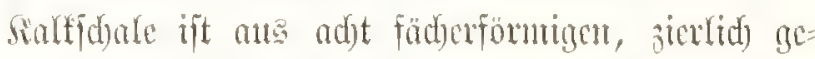

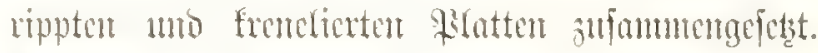

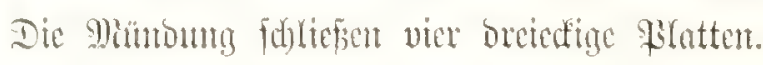

\section{Fin. 15. Sacenlina carcini (Thompson).}

Die Jigur fiellt in maturlid)er (Grope bie Bantd)feite cincr gewöbuliden sirabbe bar (Careinus maenas, Leach). Das ganbe Fleifod ift von ben murzefformig veräftelten Gangröbren ber parapiti= Fojen Sacculina burdjzogen, beren quer=ciförmiger Jneiper seib unten anf ber Bandjeite bes furjen Edwounges ber sirabbe befeptigt ift. 


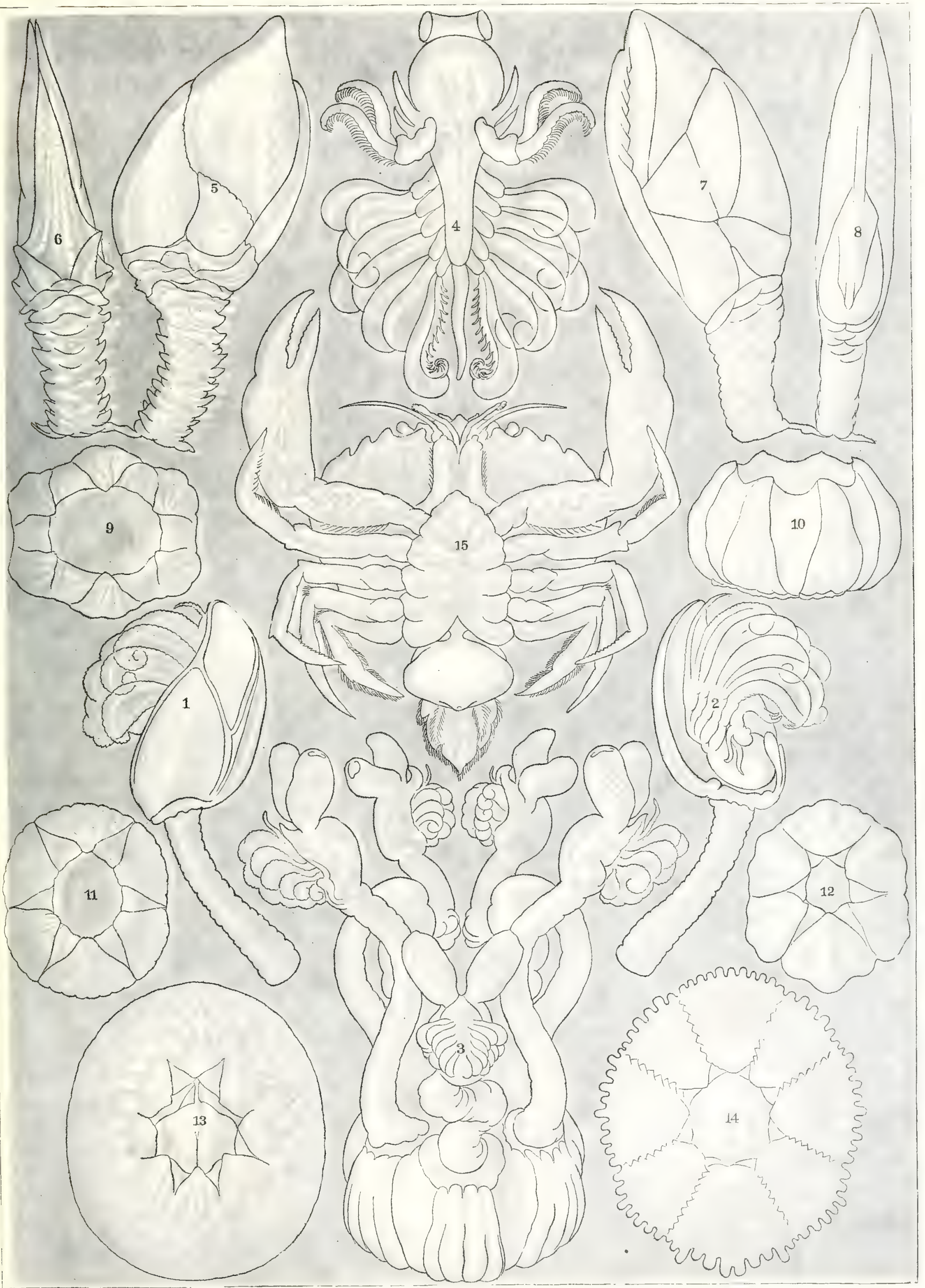




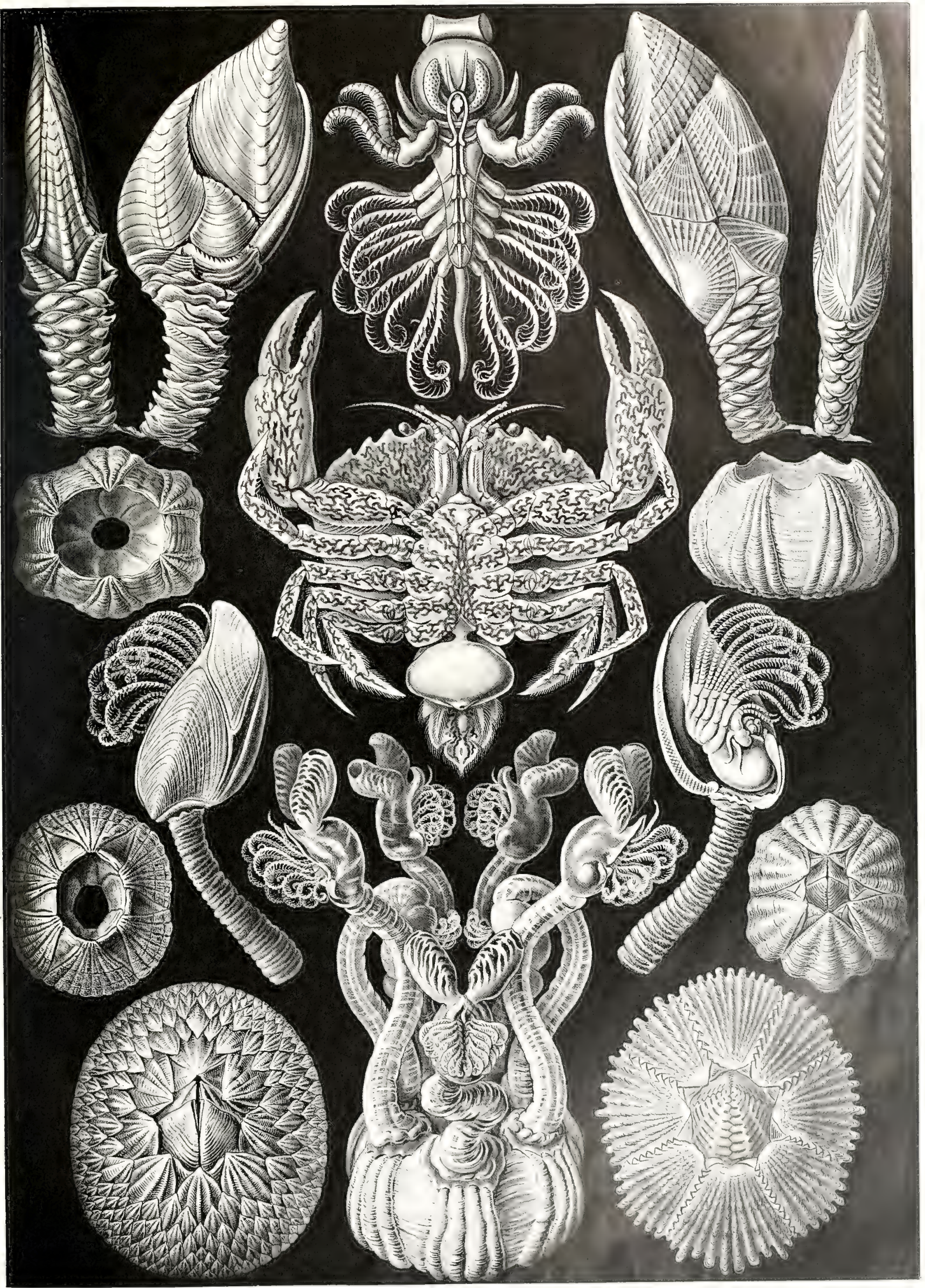

Cirripedia. - Bimulientireble. 



\section{Tineida. H2wtten.}

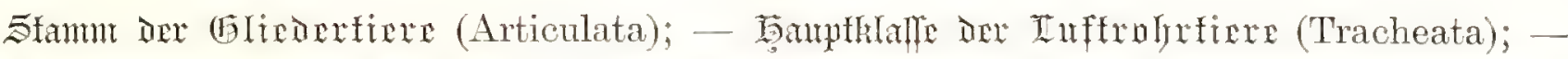

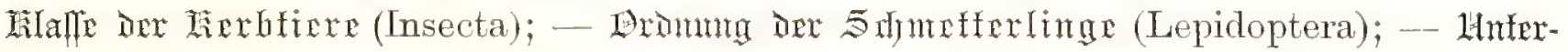

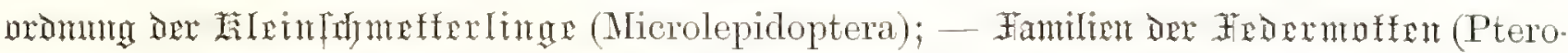

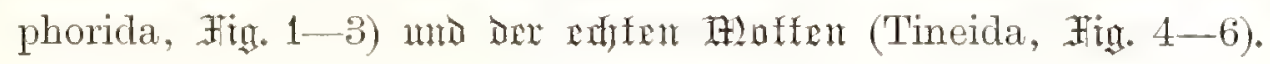

Die Fantifint bar Motten (Tineida) unto ber Federmotten (Pterophorida) enthalten bie

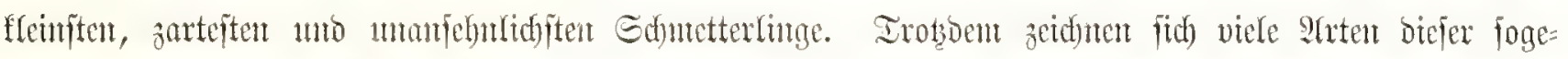

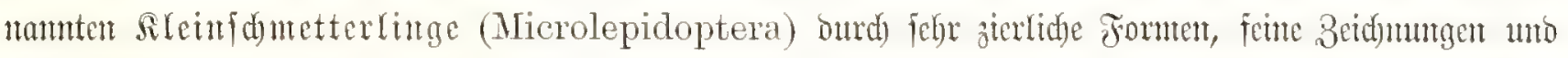

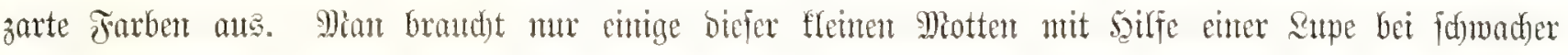

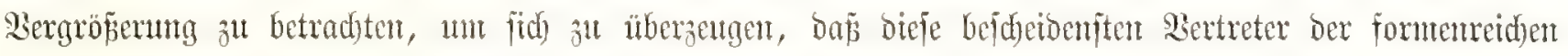

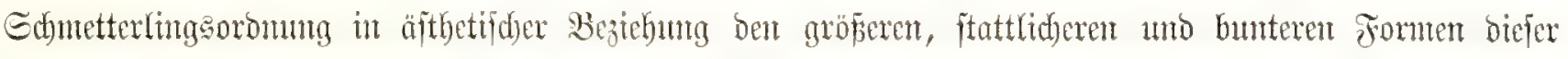

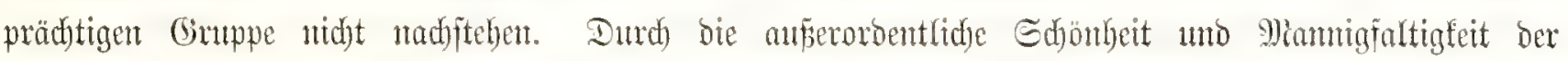

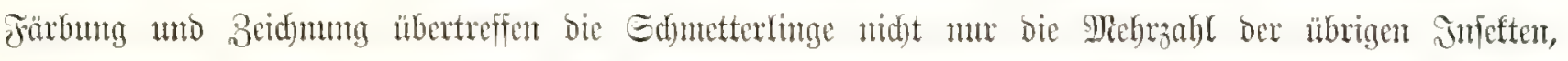

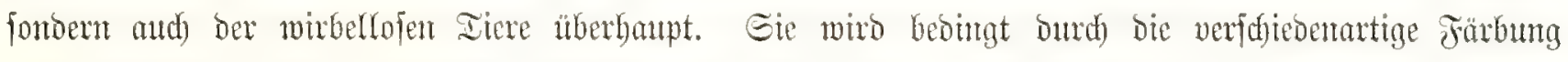

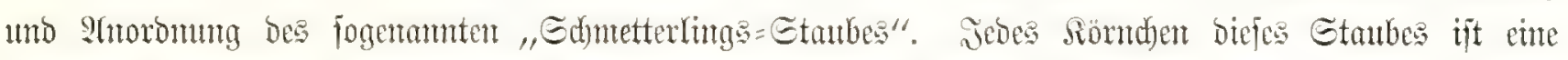

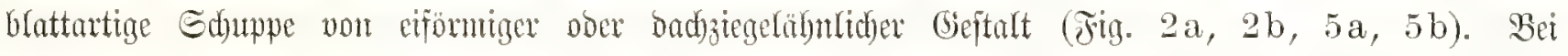

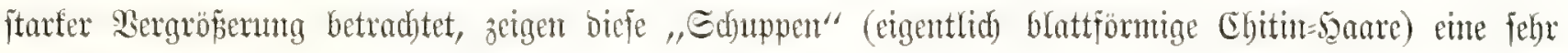
feine Streifitng.

Die gewöhnlidyen Miotten (Tineida, Fig. 4-6) befrtien żoei Faar ungeteilte Flügel, gleid)

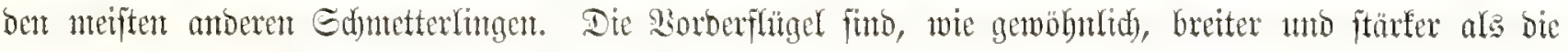

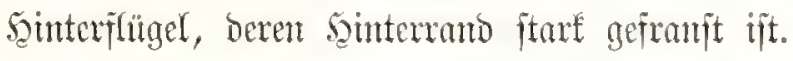

Dagegen zeidmen fid bie Federmotten ober Federgeiften (Pterophorida, Fig. 1-3) vor

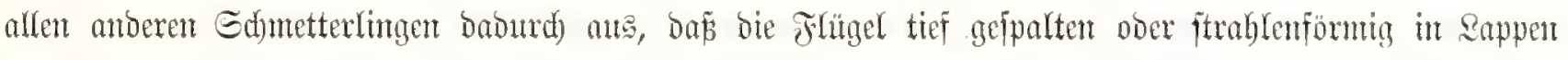
geteilt unt bie sappen foocrartig gefranjt funt. Bei ber Gattumg Pterophorus (Fig. 2, 3) finto bie Sorderflügel zmeifpalttg, bie Sainterflügel breiteilig; in ber Fube werbent bie Flügel zufammengetegt umo

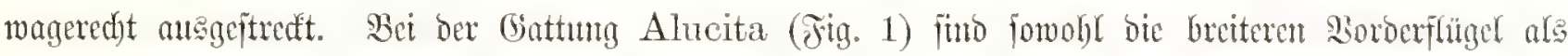

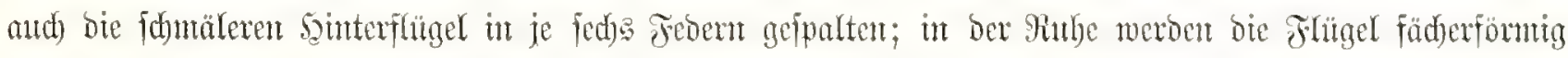

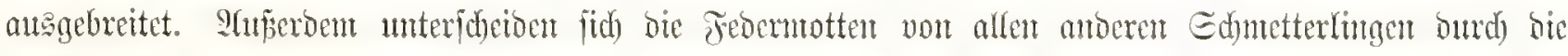

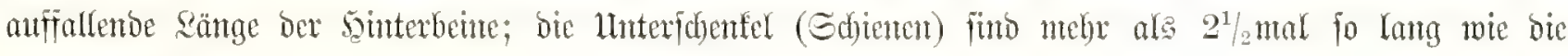
Dheridjenfel. 
Fing. 1. Alncita hexalactyla (Timé).

(二 Omeodes hexadactyla, Spuler.)

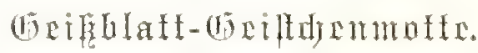

$15 \mathrm{~mm}$ breit, 8mal nexnröfert. Familie bex Pterophorida.

Subfamilie Dex Alucitida.

Die Miotte ijt bram gefürbt, mit getben ober grancu zirfăfförmigen Duerbindon. Sic trägt 24 jierlide Feoem, ba fowobl bie lärgeten Sorocr= flüget als and bie kinzeren binterflüget in je feds geficoerte Strahten gepalten finto.

\section{jign. 2. Pterophorus pentadactylus (Limné). \\ (- Aciptilia pentadactyla, Hübner.) 5d) \\ $30 \mathrm{~mm}$ hreif, bmal nerorübret. \\ Famtilie one Pterophorida. \\ Subfamilix one Aciptilida.}

Dic ganze Miotte ijt fohnecweip. Die lömgeren Sorberflügel find zweifpaltig, die furzeren sinter= flinger breiteilig. Die foinen langen Framen ber

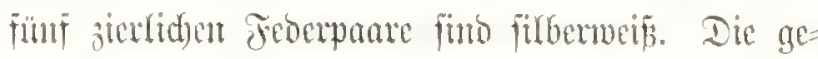
meinfe Sirt unter ben cinbeimifoen Feocmottent.

Jig. 2a unb 2b. Einzelne Gduppen, ftarf ver= gröpicert.

Fitg. 3. Pterophorus rhododactylus (Limé).

(= Cnaemidophorus rhododactylus, Wallengren.)

Roten- Feormofte.

$24 \mathrm{~mm} \mathrm{breif,} 5$ mal vergeälect.

Famtic ine Pterophorida.

Subfamilis one Aciptilida.

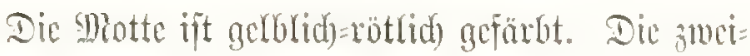

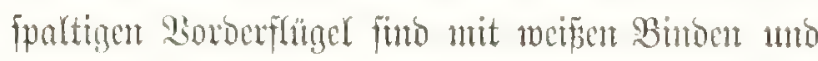
Gritenfleften geziert, mit einer branten Duterbinto umb Gaumlinie. Dic breiteiltigen sainterflüget funo ftarf bewismert utro tragen nor ber Epitze cinen bramen glext.
Jig. t. Lithocolletis populifolia (Treitschke).

(- Gracilaria populifolia, Zeller.)

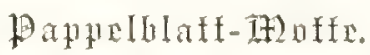

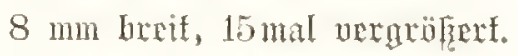

Familir one Tineida.

Subfamilie bre Lithocolletida.

Die Miotte ijt bräuntich gefürbt. Die Sorber=

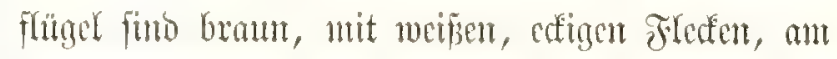
seinterranto lantg geframit. Die sinterffingel finto felgr fd)mal, braungrau, mit fangen gelben sime pern bidst bejekct.

\section{Jin. 5. Plutella xylostella (Zeller).}

(- Cerostoma xylostella, Latrille.)

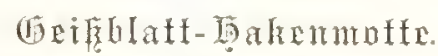

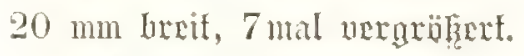
Hamilie ber Tineida. Subfamilie dex Plutellida.

Dic Miotte ijt bräunlich) gefärbt. Die Sororoer= flügel funo barfenförmig, an ber Epitze hafenartig gefriunnt, braum, am gefraniten sinterranoe gelb. Die Yänglidd=eiförmigen Şinterfflugel fint rötlid) jutber= grau, mit fangen simmern bejetzt.

Fig. 5a uno 5b. Eimalne Sduppen, ftarf ver= gröp̄ert.

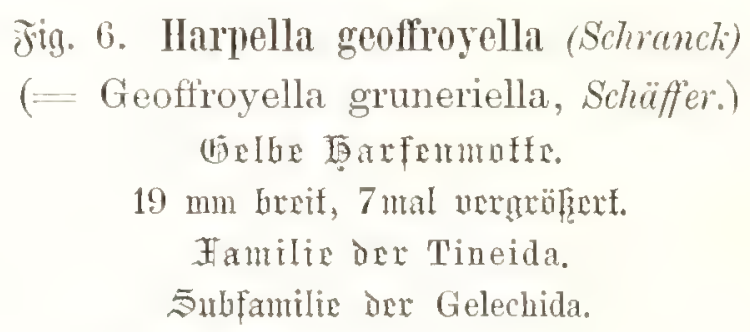

Jig. 6. Harpella geoffroyella (Schrenck)

(- Geoffroyella gruneriella, Schäffer.)

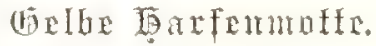

$19 \mathrm{~mm}$ breit, $7 \mathrm{mal}$ merunoügert.

Familie ber Tineida.

Subfamilie bne Gelechida.

Die Miotte ift gelblid) gefürbt. Die Sorocr-

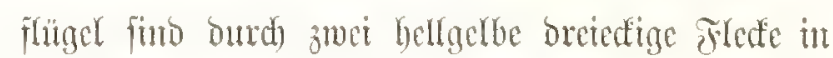
zwei Felocr geteilt. Das Sumenfelo ijt oferergelb, mifent jumtbram, mit grumilbemen, fdjwars ge ränoerten Striden verăiert. Das : Yht5enfelo ift gelb= Graut mit fowarzbranuten Streifen und ganto. Die seintecflügel futro lang bewintpert unto braungrau. 


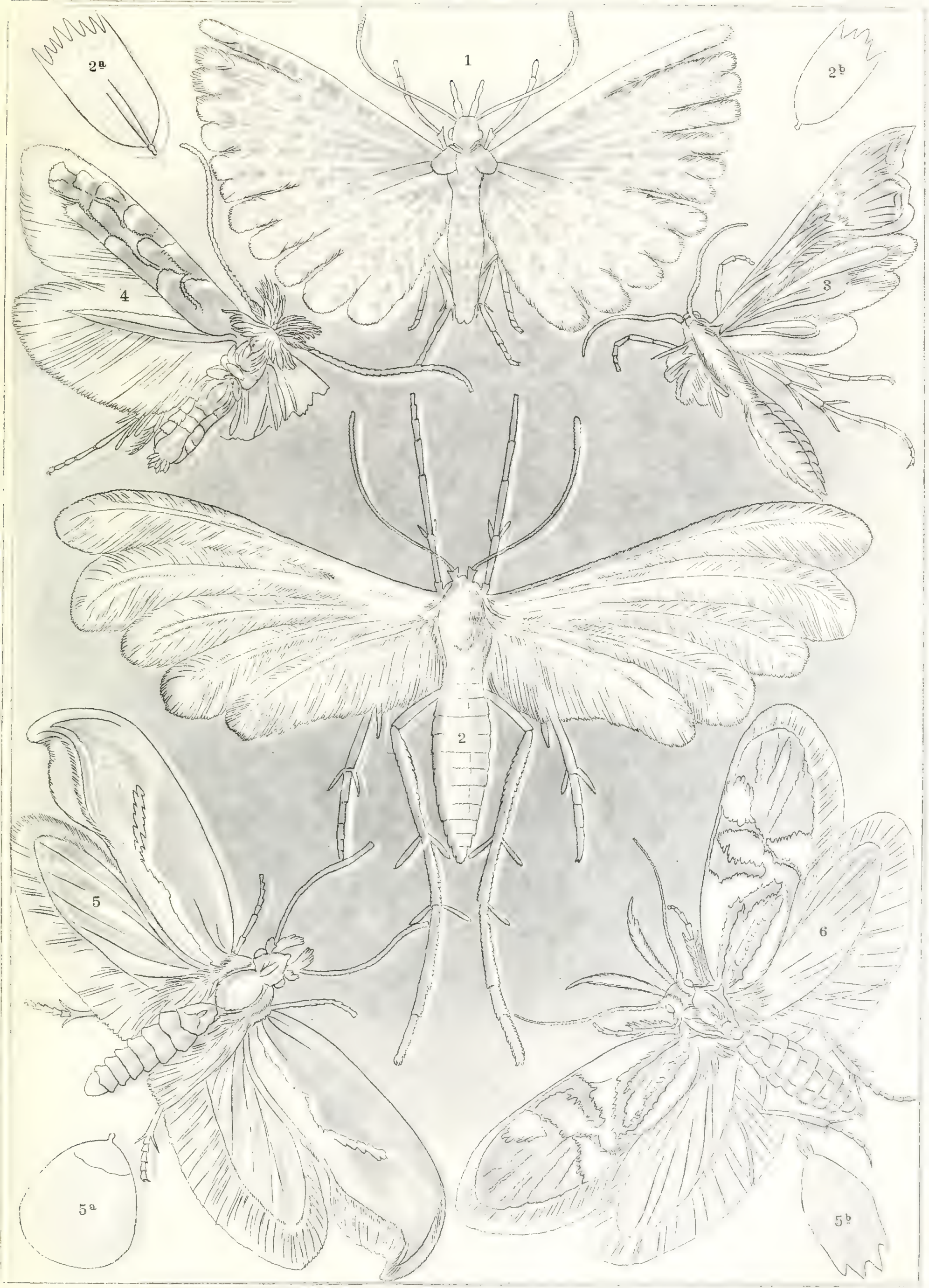



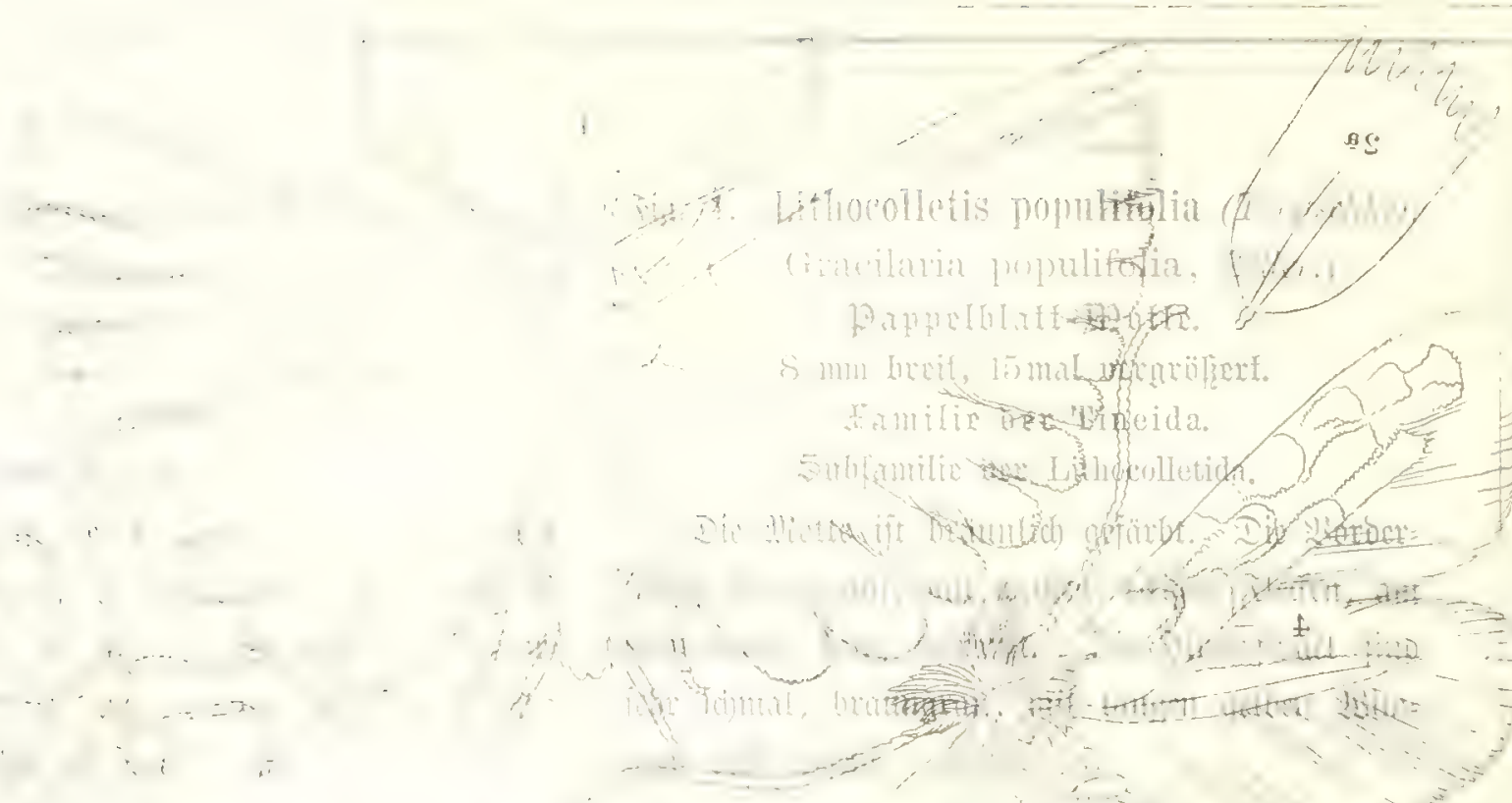

Lethocolletis popmlivitia (t) fyang

(imalaria pupulifolia,

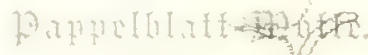

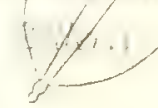

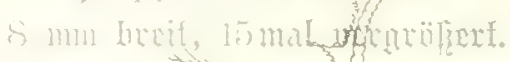

x.mitir textheida.

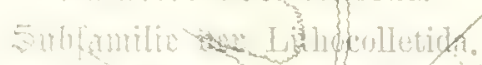

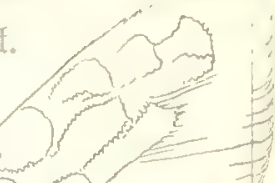

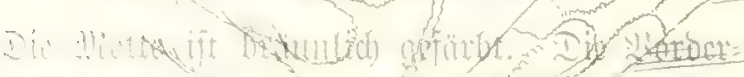

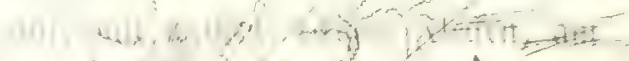

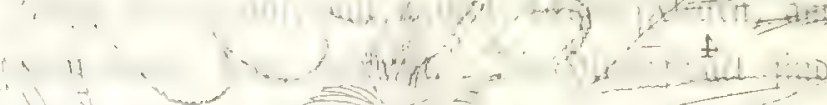

in

.

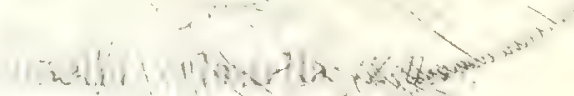

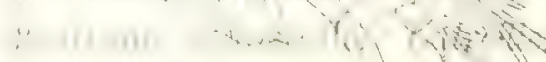

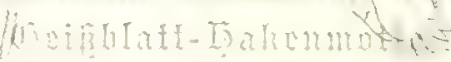

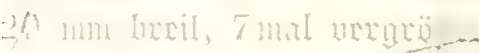

familir opy tex

that....

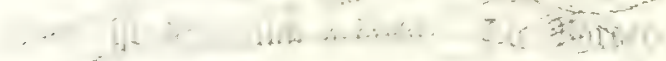

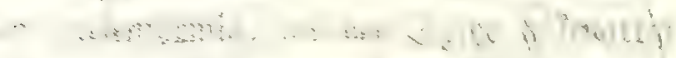

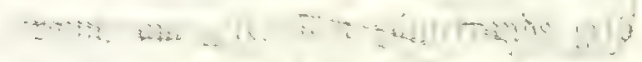

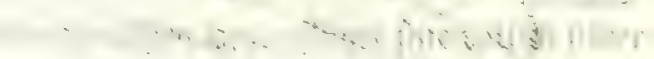

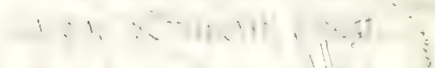

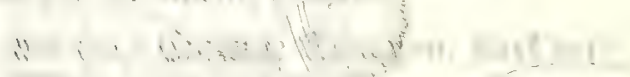

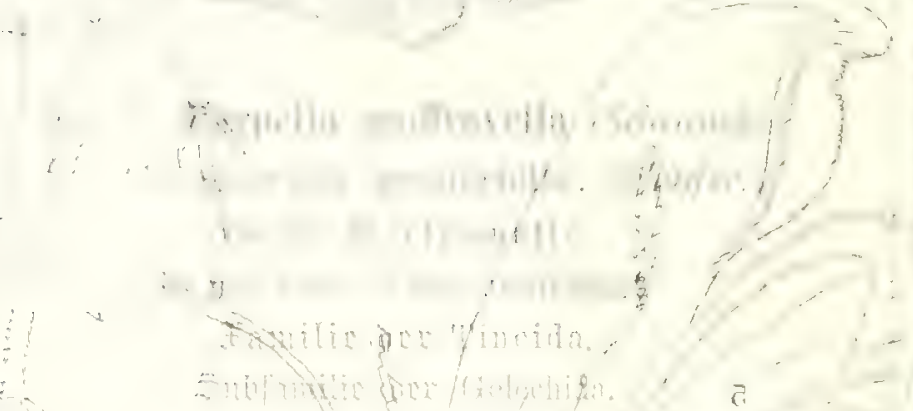

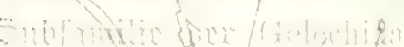

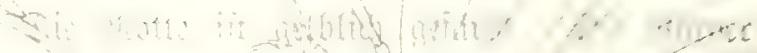

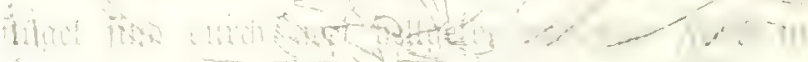

$\therefore$ Muta mole

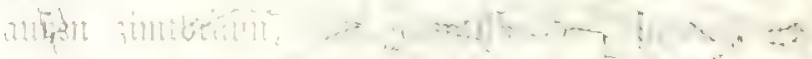

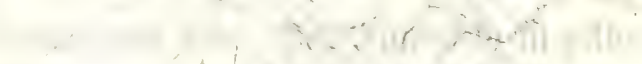

ano. 


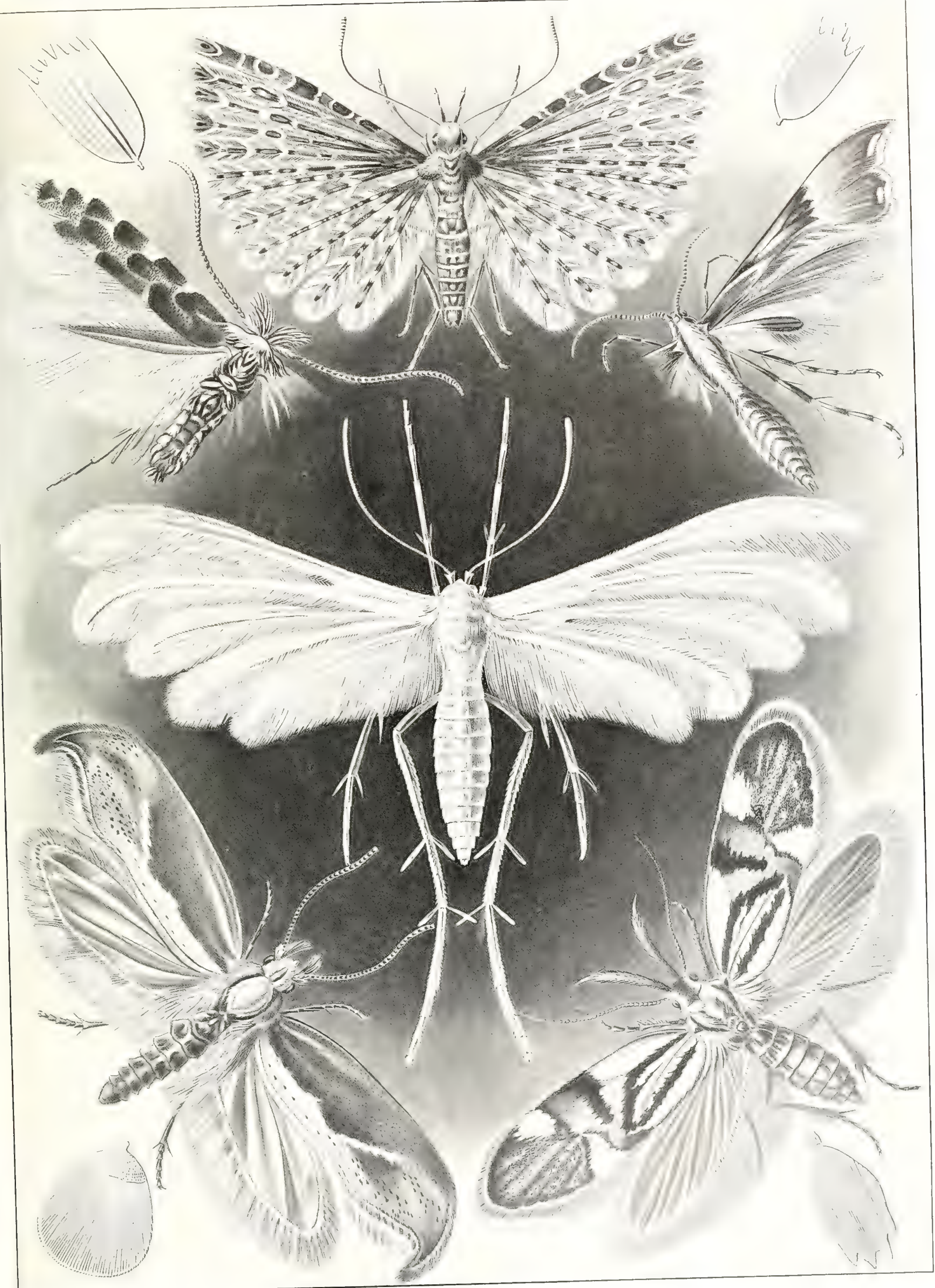

Tineida. 징ten. 

Tafel 59. - Strobalia.

\section{Siphonophorae. Staaftatiallent.}

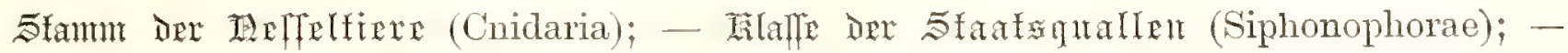
Bromma Der pradyfguallen (Physonectae).

Jig. 1-9. Strobalia cupola (Haeckel).

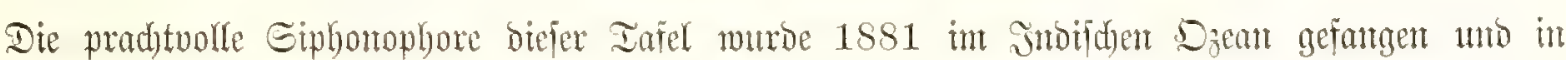

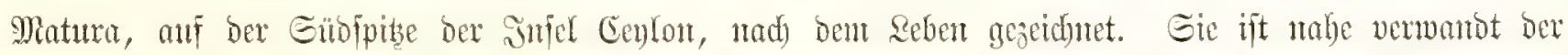
eutropäifden Forskalia, forvie andy der auf Iafel 37 abgebttoeten Discolabe quadrigata. Der gantze

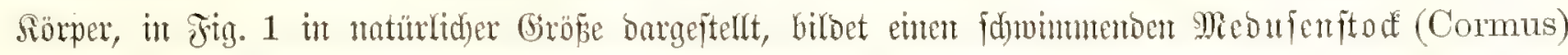

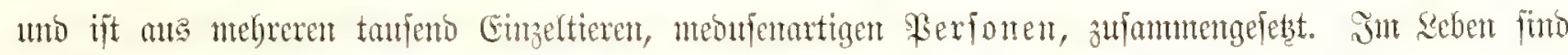

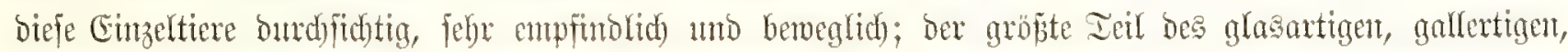

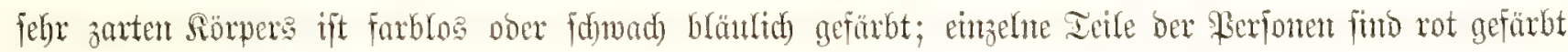

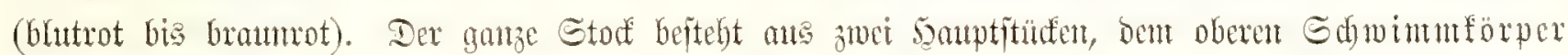

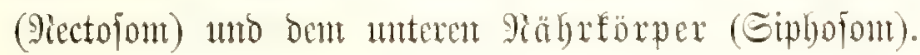

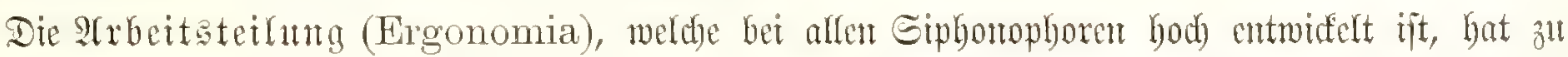
Der auffälligen Formipaltung (Polymorphismus) der vielen Ferfonen gerührt, melde bieje mert=

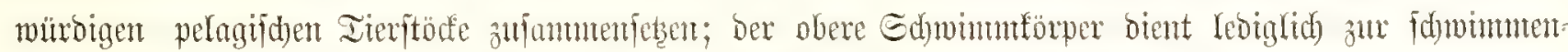

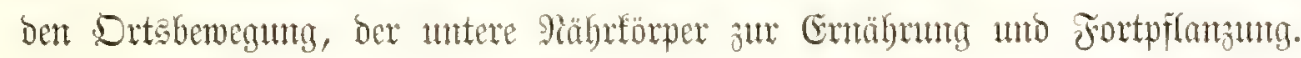

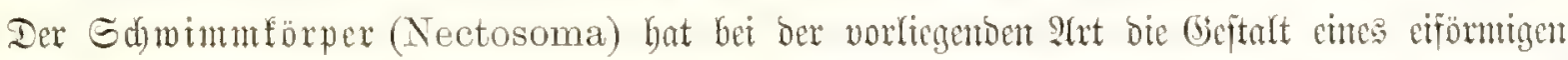

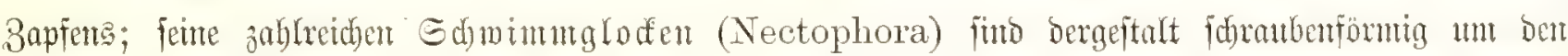

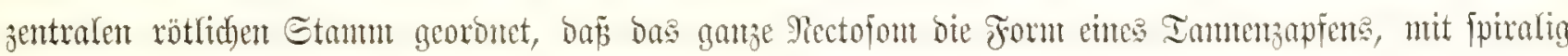

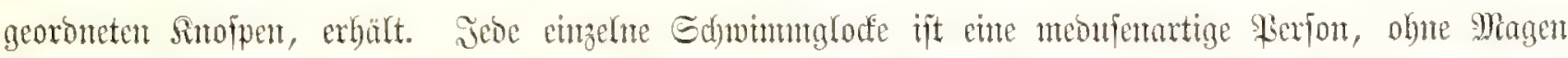

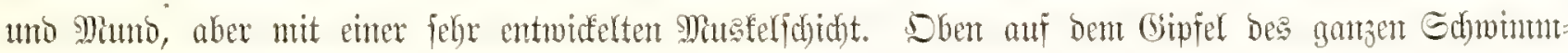

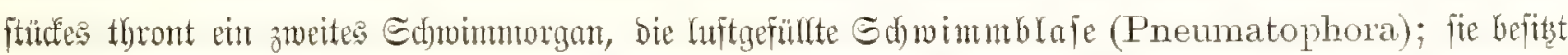

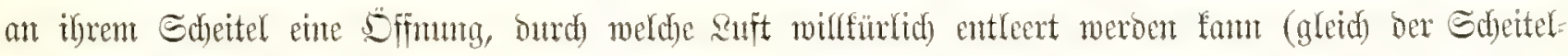

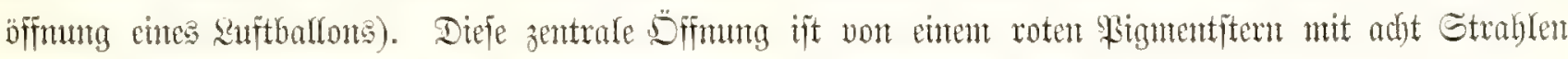

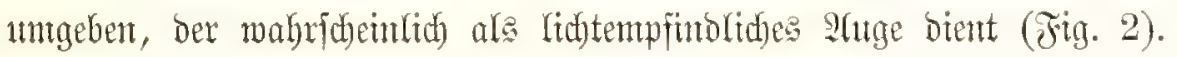

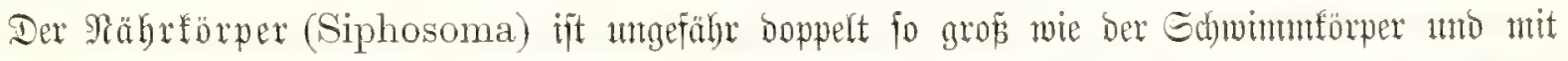

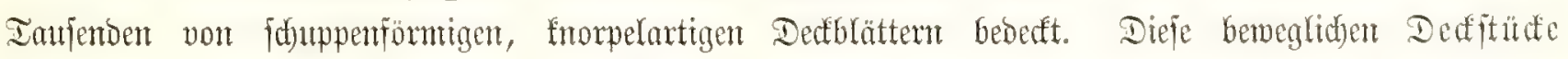

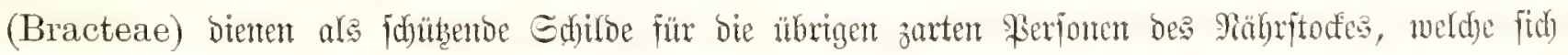

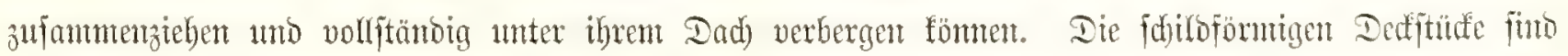

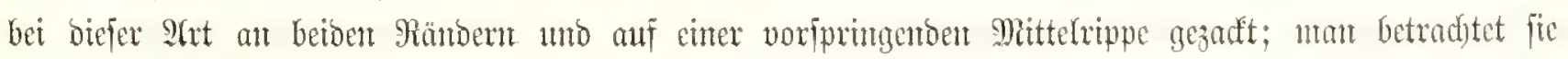

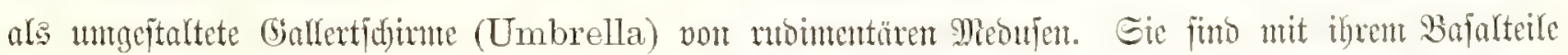

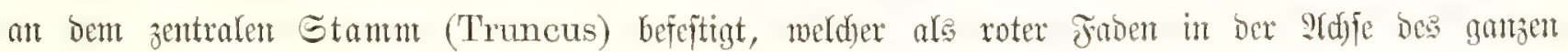
Stodes verfäuft. Ebenfo funb an ben Stamm aud) bie übrigen Ferfonen bes gähreförpers angebeftet; bicfe

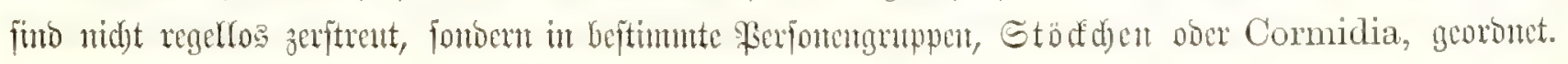




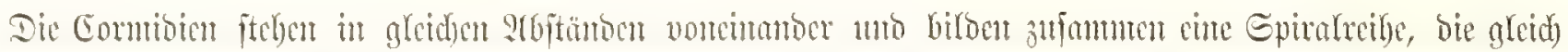

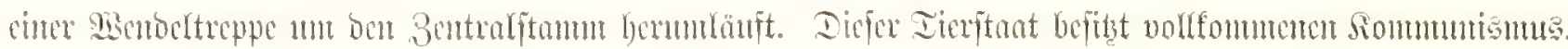

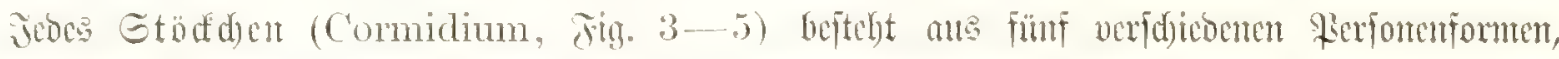

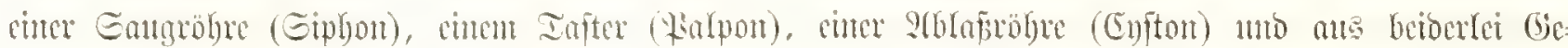

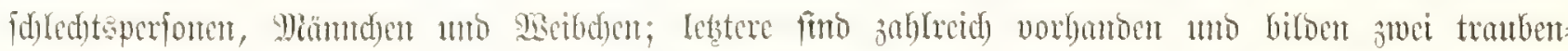

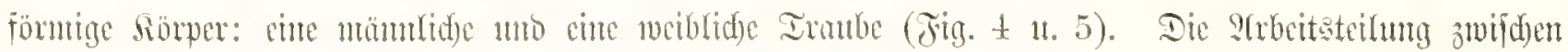

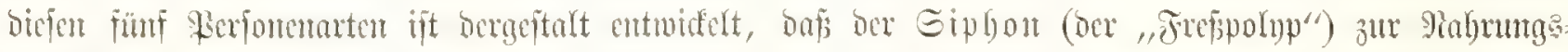

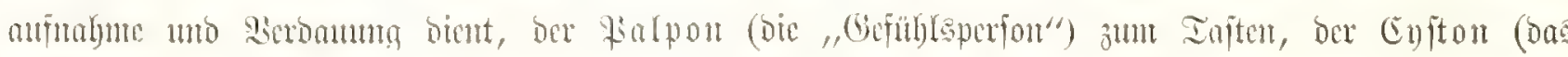

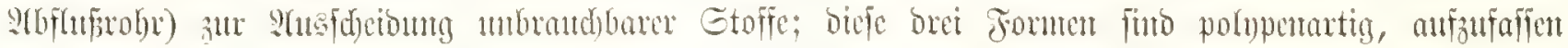

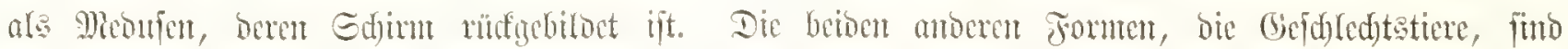

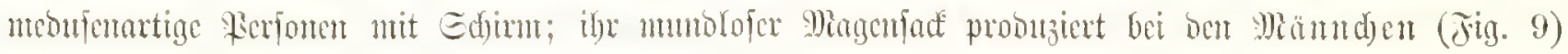

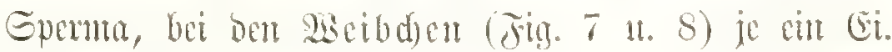

Jign. 1. Dur ganze Gtodf (Cormus) in ma= tür(id)er Gröñe, frei füminmmono.

Fig. 2. Dir Gdummblaje (Pnemmatophora), oben vont Edyeited gefden; in ber \$litte Dic Edeiteloffmm, bas ruftlod).

Jign. 3. Ein Gtödd) (Cormidium) mit

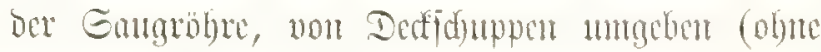
bie anberen, in Sig. 4 bargejtellten werfonent). Dis polupenurtige Gaugrobre (Eiphon) beftcht ans vier Icilen: 1) bem büumen Gtiel (oben), 2) bem fugeligen Grumbunagen, 3) bem weiten Mangen (nit adst roter Reberftreifen) uno t) Dem giulfel, Der

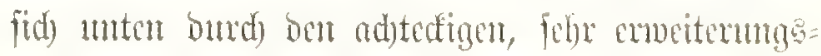

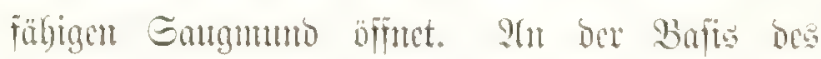

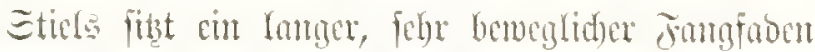
(Ientafel) mo an bicfom in gleiden Yhitünocn viele furaze rote Geitufäben (Ientillen).

Jig. 4. Cin Etöddgen (Cormidium), আ bem bie Eangröhre entfent ift. Unter ben fófils=

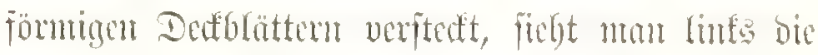

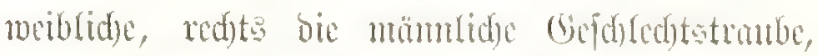

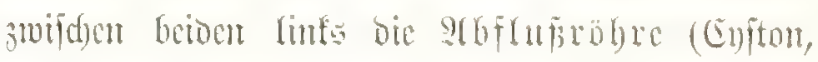
mit roter, fegelförmiger Mlünommg), redots ben fa)ranten, fpinderförmigen Iafter (Rialwon).
Jig. 5. Cü Gtö̊ducn (Cormidium), von

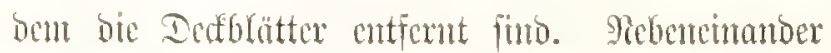
finto ant Stanm angebeftet: rinfes bie suciblidje, red)ts bie mämulidye Gefd) redotstraube (betoe aus

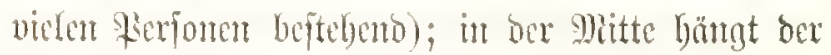
grobe Siphon (mit eingezogenen add sippen an

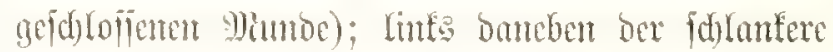
Confton (mit rotem ifter), reduts dor Palpon.

Fig. 6. Gin Seitenfaben des Tentafete (Tentillum), mit ber roten Meffelbatterie, bie in Geitalt eims Spirallandes gewumben ift; fie ent= hält Iaufento gittiger seffelfapfeln; untent an Enoe cin bümer Gnbfadent. Etark vergrösert.

Jig. 7 1. 8. Cune weiblid)e fierfon (Grynophora); cine glodéfröormige Miconfe mit cintem

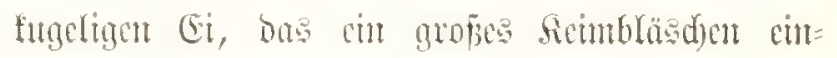

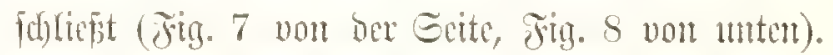
Stu unteren Enoe der vier Strablfantäle, bie in

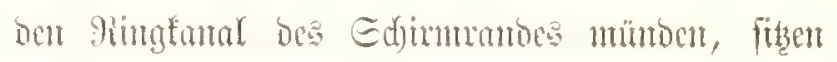

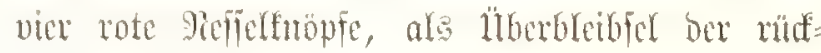
gebilocten Ientateln.

Jig. 9. Eine mämlide 壮erfou (Androphora); eine verfunmerte sicoufe, beren groper tolbenïormiger Mingenfarf Eperma erzengt. 


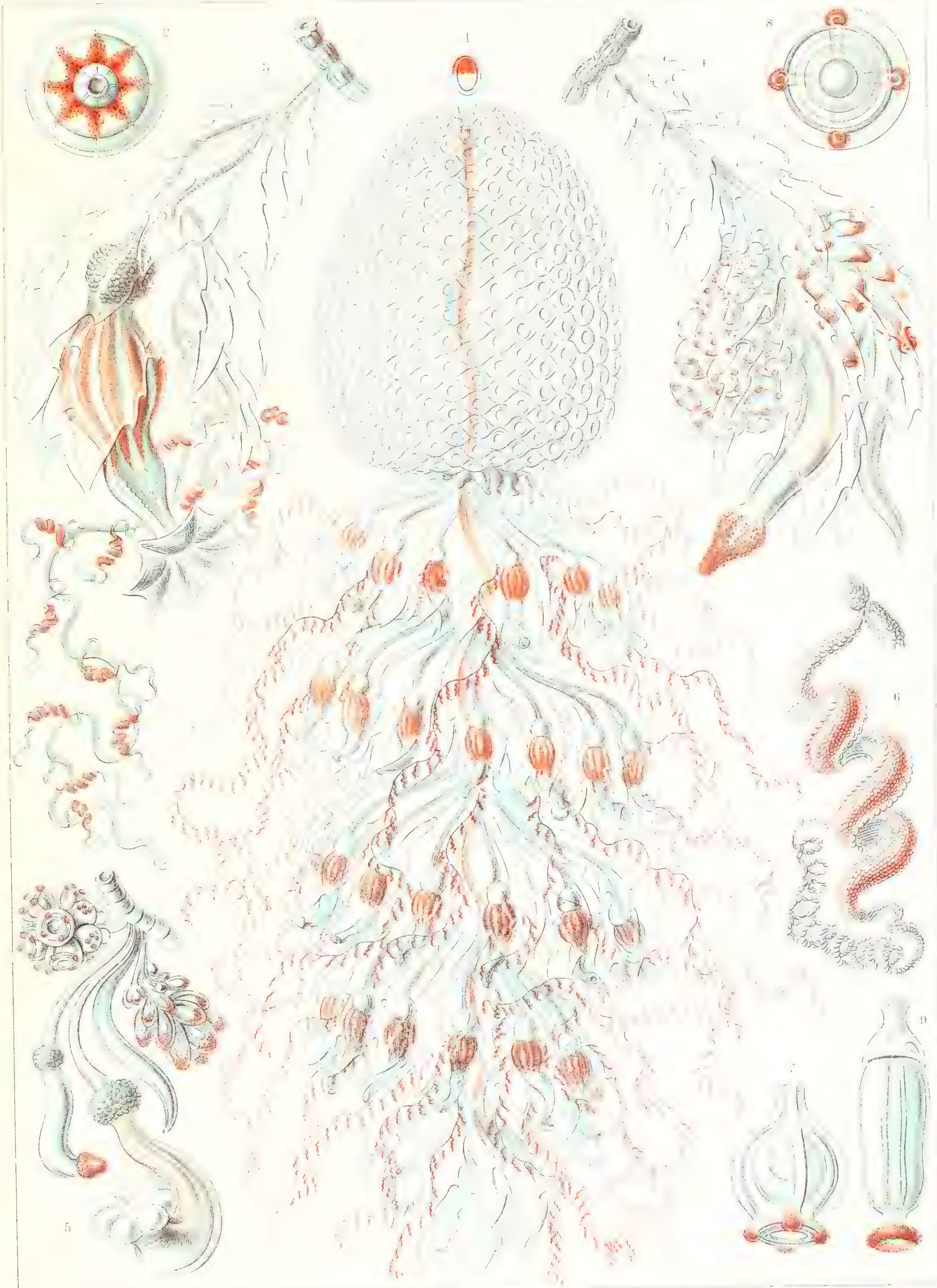

Siphonophorae. - Stardsqutallent. 


\section{Echinidea. Intherme.}

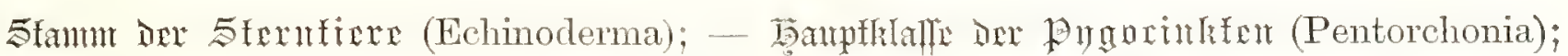

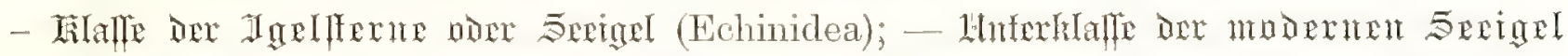

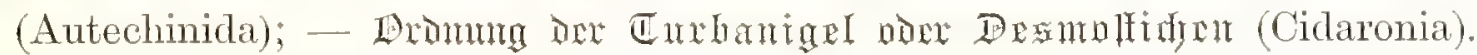

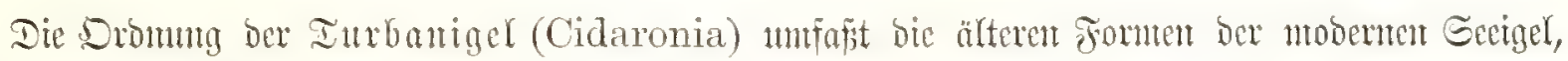

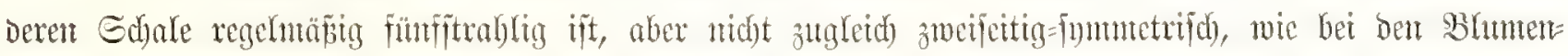

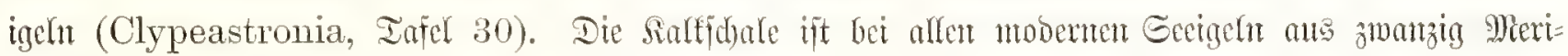

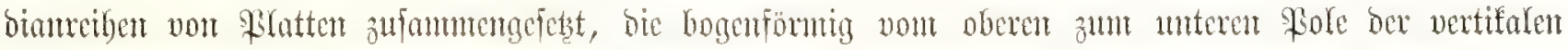

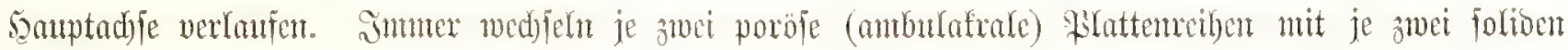

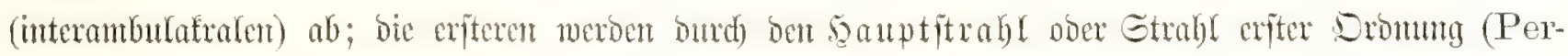
radius) getremnt, bie Iebeterent burd) Den 3 wifdenftrahl ober Strahd zweiter Dromung (Interradius).

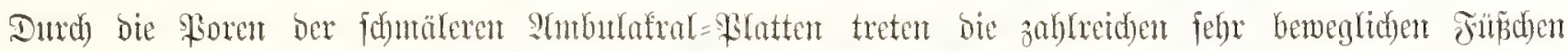

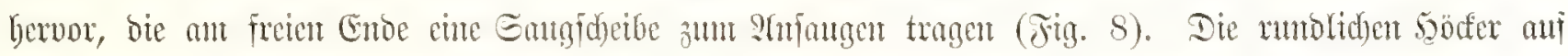

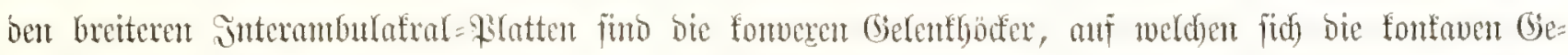

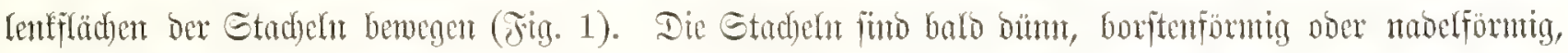

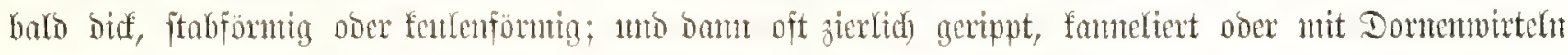

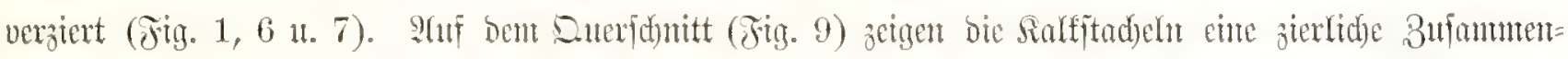

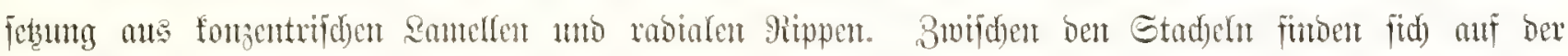

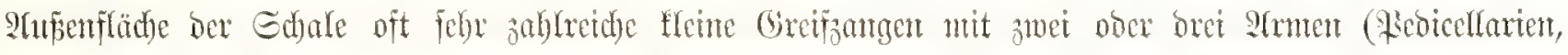

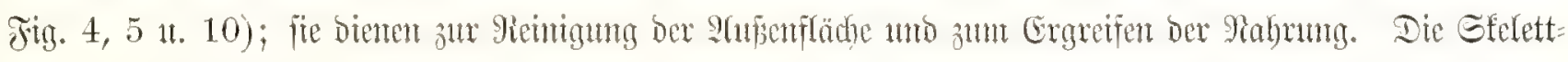

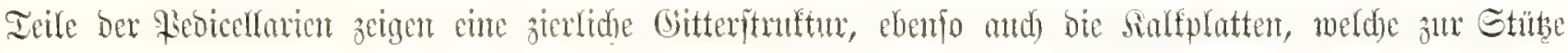

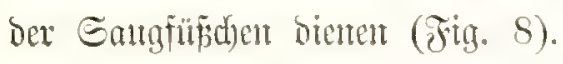

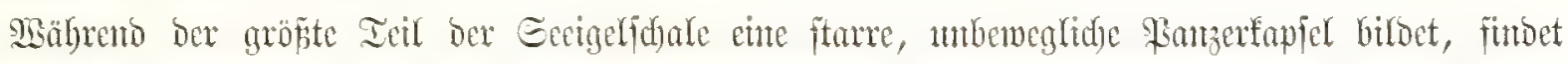

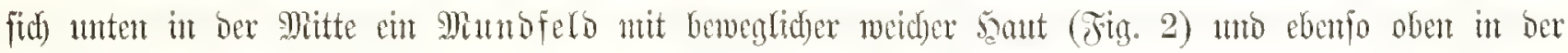

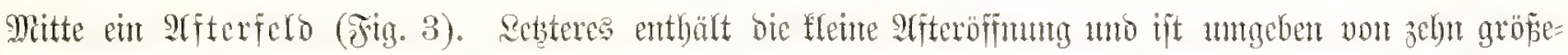

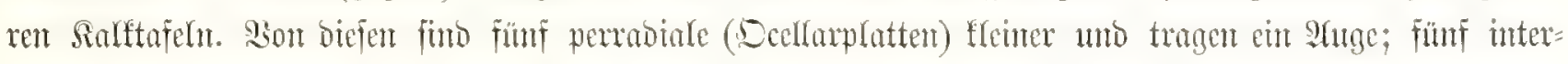

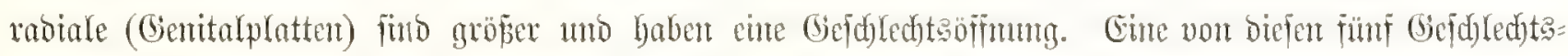
platten (in Fig. 3 bie untere) ift gröfer als bie vier anderen; fie ftelft eint poröfes Sieb bar unb bient

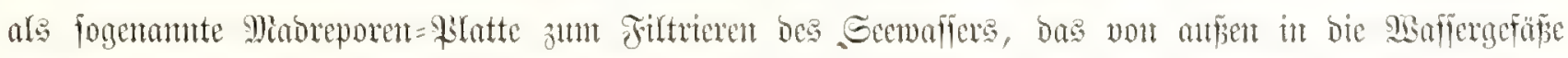

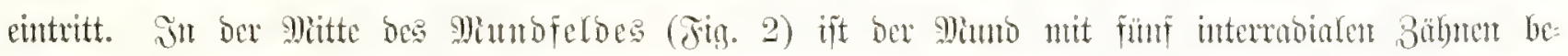

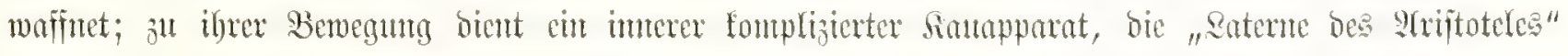

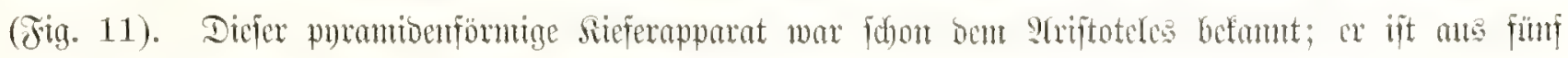

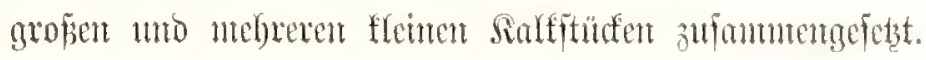


Fig. 1. Cidaris tribuloïles (Lamarch).

Familic ine Cidarida.

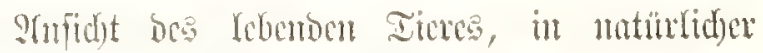

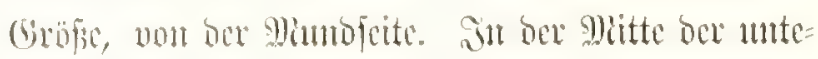
ren (uentralent ooder oratent) Geite fund bie fünf

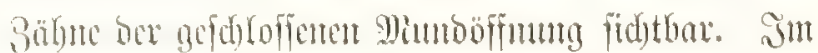
Itmente bor getäferten salfidale treten samberte

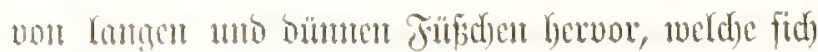
lebraft frumment bewegen ano ant freten Enoe mit

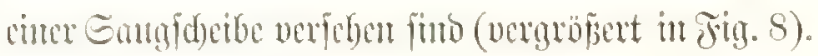

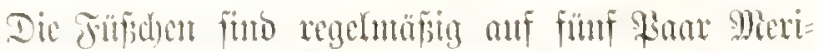

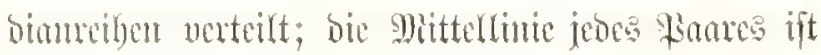
ber Etrabl arfer Sromung (S.mptitrabl oder Per-

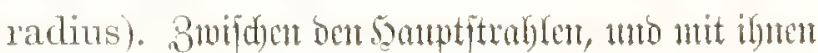

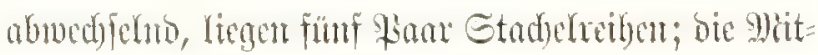

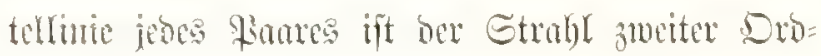
ung (Bmifdenftrobl ober Interradius). Dic biffen

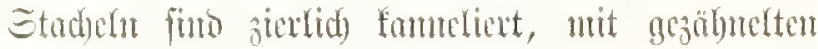

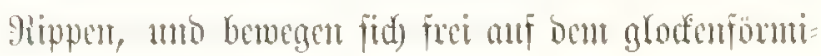
gen gefurd)ten Eodfer.

\section{Jig. 2. 4. 3. Cidaris baculosa (Tamarck).} Hamilix ine Cidarida.

Fig. 2: Das Mimofero ber Gd)ale (Mittel=

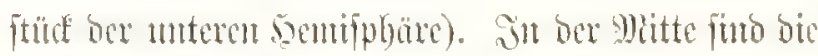

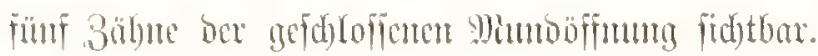

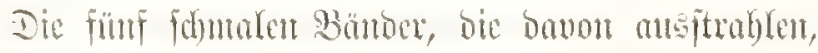
futs bie perrobiufen Ambulacra (bic Pilattemreifon

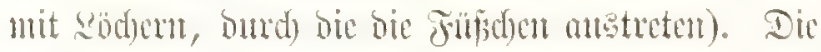

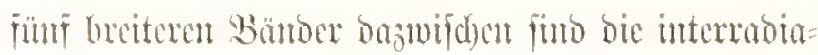
lent Interambulacra, bie Sifattemeihen mit gro=

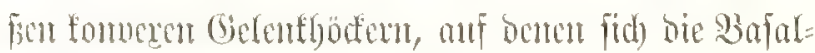
moen ber Stadyeln bewoegen.

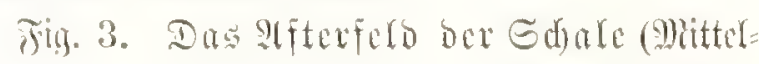

ftülf ber oberen Semifphäre). Die Nrfteröffum in ber Mitte bes Edjeitelfeldoes, ift von melyeren flei=

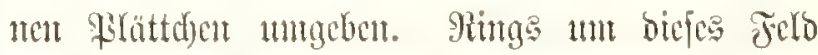
liegt ent Sirunz von zellu gröperen Iafeht, beren

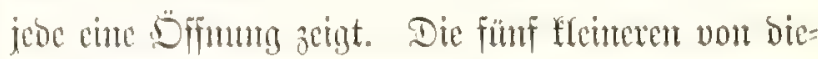
fen Tafeln funo die perrabialen Deerrarplatten, bie ent stuge tragen. Die fünf gröferen Iafjelt find bie interrabialen Gentalplatten, bie cime

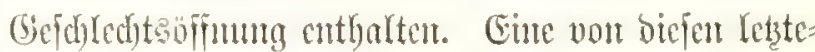
ren (unten in ber Mittc) ijt gröperer und bient ala 1,9labreporempfatte" zum Filtricren bes Scemaficus,

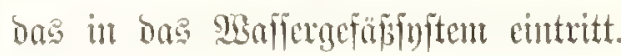

Frg. 4. Dorocidaris papillata (Agassiz).

Eine breiarmige Gretizange (Pebicellarie).

Fig. 5. Strongylocentrus $111($ lus (Agassiz).

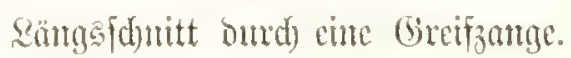

Fig. 6. Phyllacanthus anmulifera (Agassiz).

(Ein cunzelmex Etadjel, fammelicet mo mit vielen 玉isirteln von Dornen verzicrt.

Fin. 7. Phyllacanthus baculosa (Agassiz).

Ein cunzelner Etadel, mit mehreren paralleten

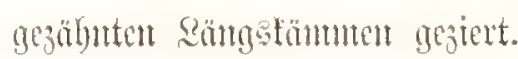

Fig. 8. Psammechinms miliaris (Agassiz).

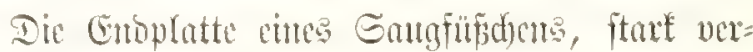
größert, geftürist bund) Fünf gegitterte Salfplatten Fig. 9. Centrostephanus longispinns (Peters).

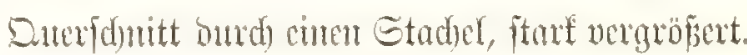
Fig. 10 1. 11. Sphaerechinus esculentus (Desor).

Fig. 10. Eine bretannige Greifange (Pedicel-

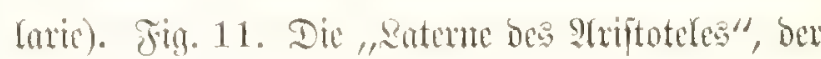
intere Sumapparat, ber obent bie fünf Bülyme trägt. 


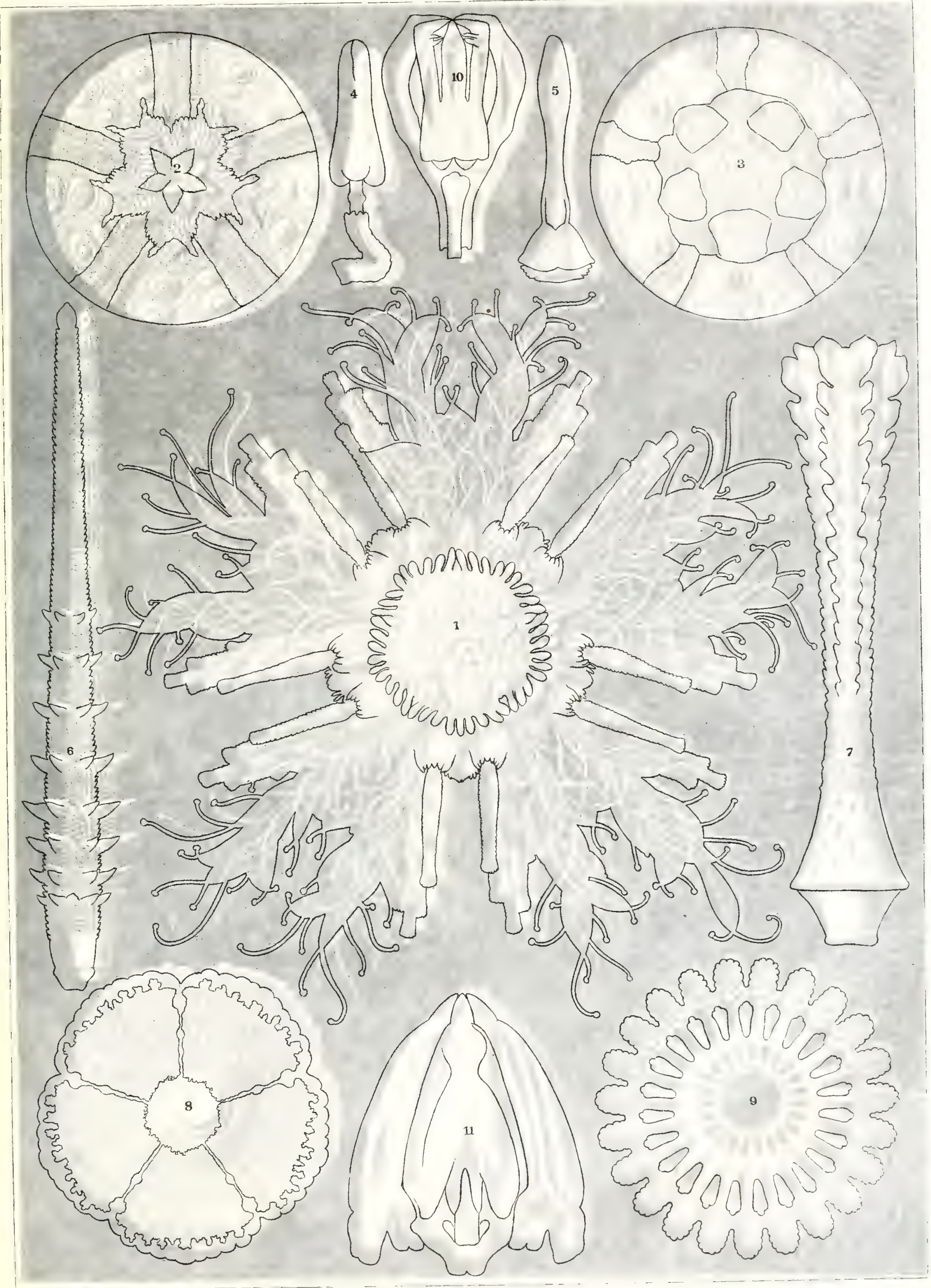



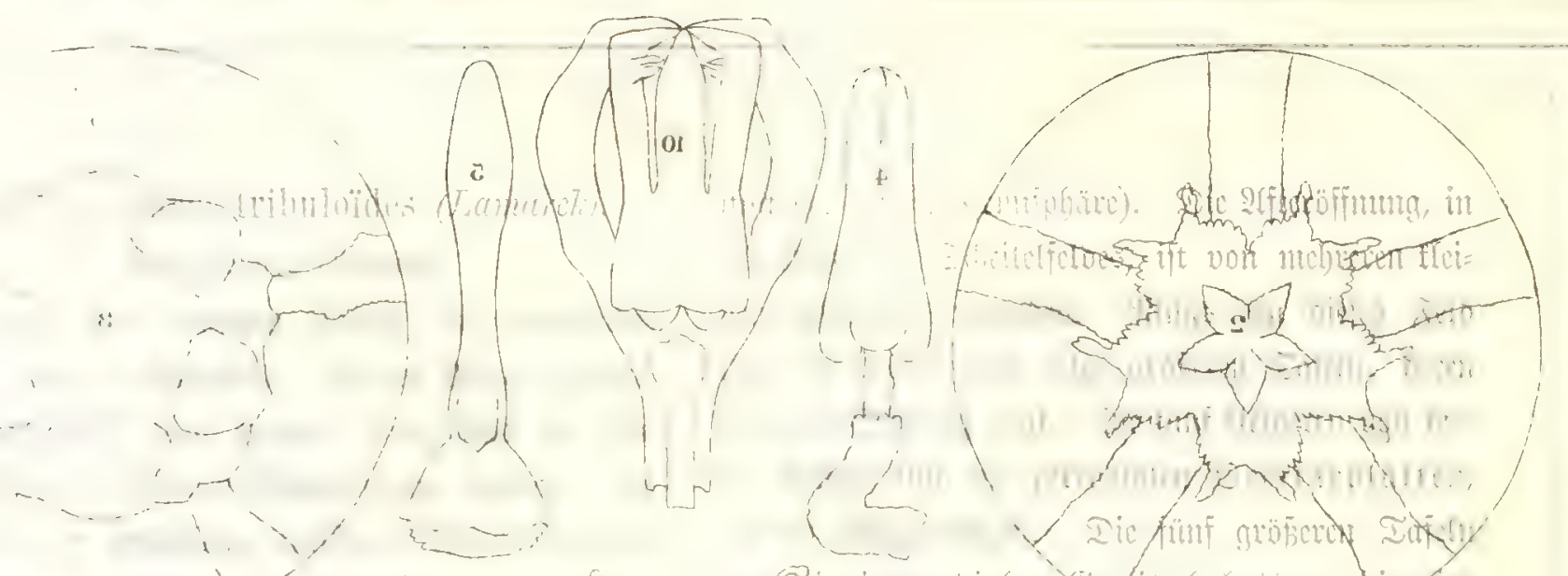

W. mment Gimane thr: an:

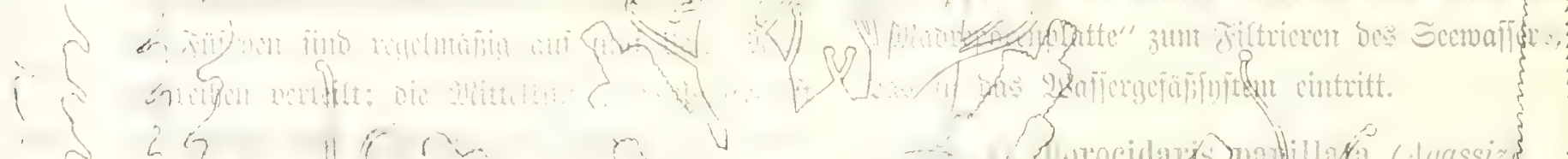
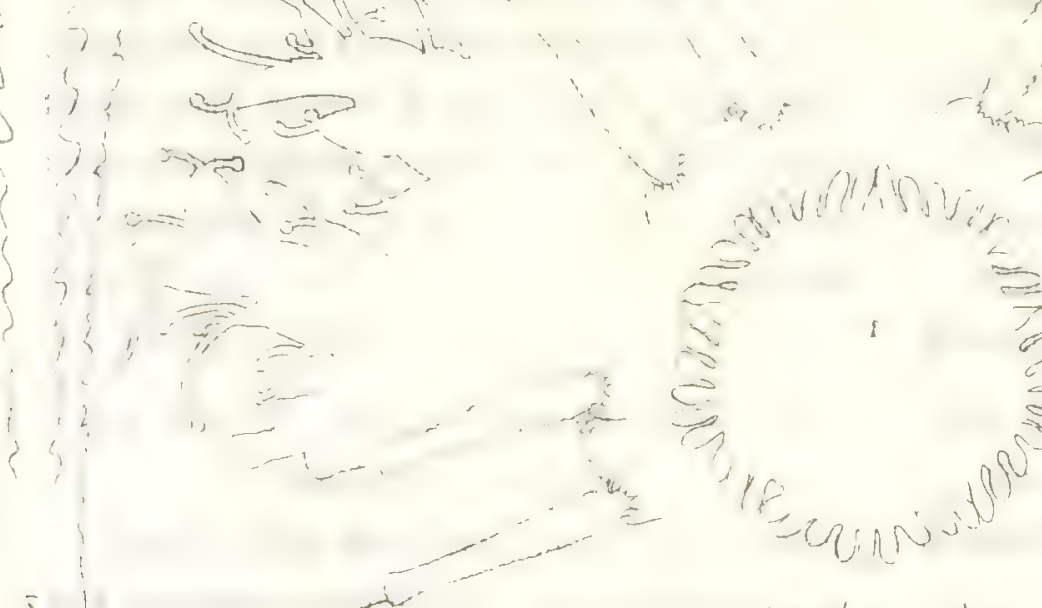


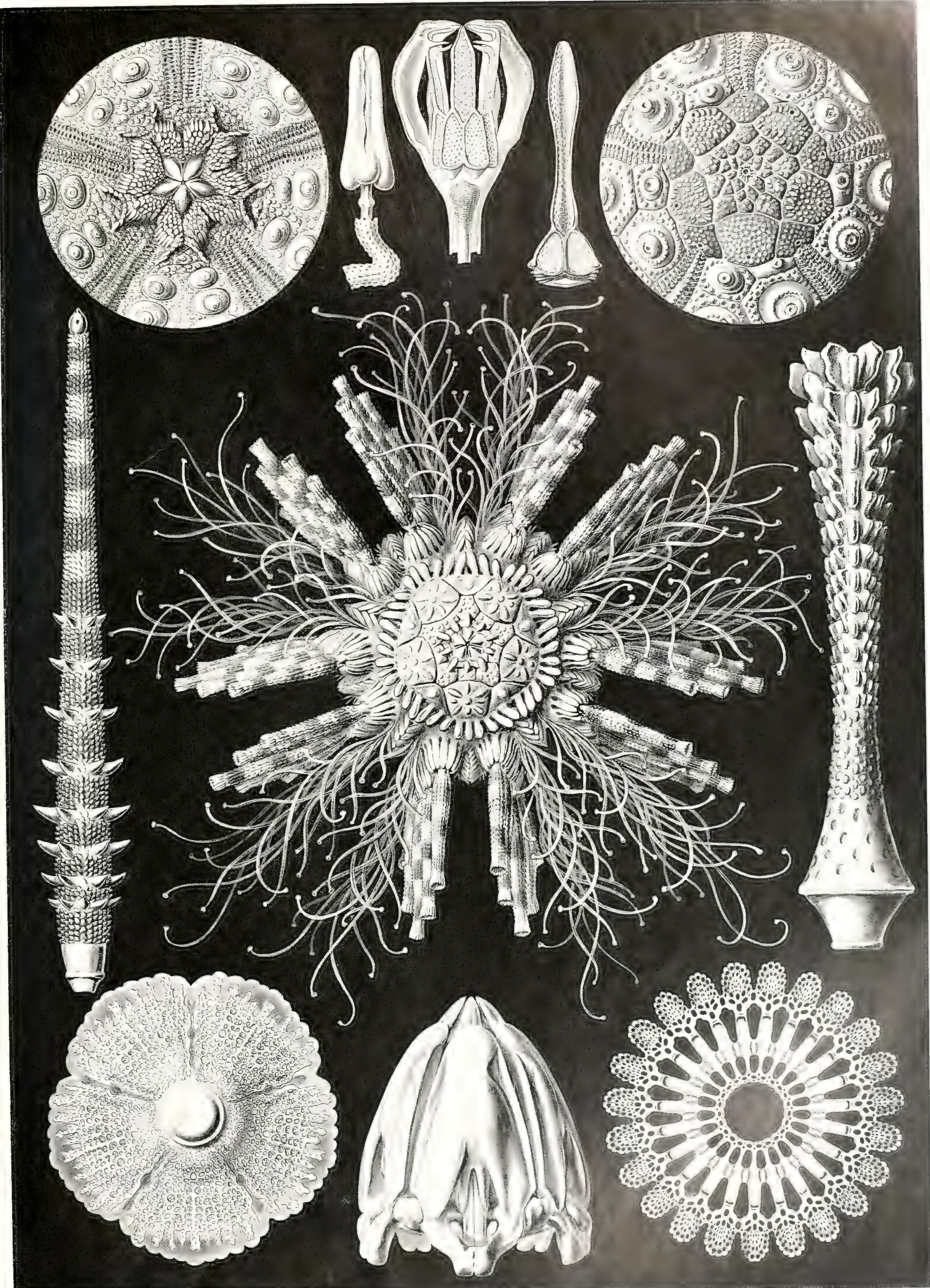

Echinidea. - Jgelternte. 



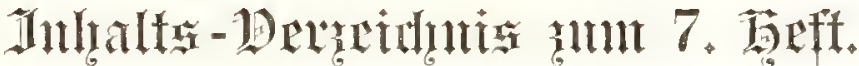

Tafel 61. Auloguaphis. Itrtiere me ber Silofie oer Fabiolarien (Eegind der shäobarien).

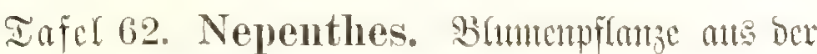
Samptffafie der stugiofpermen (sifalle der Difotuleent).

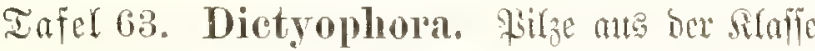
ber Sdyammpilze (Basimycetes), Renion ber Satobafioter.

Iafer 6t. Canlerpa. Mrpffonzen aus ber 5ampt= fiaffe ber argatten (stafje ber Giphonten).

Iafel 65. Delesseria. Iffgen ats ber Sifafle der Rotalgen (Floriocen ober Rgodo= physect).

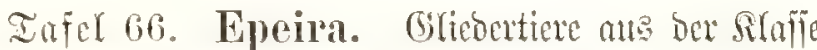
ber Gpinnentiere (Arachnida).

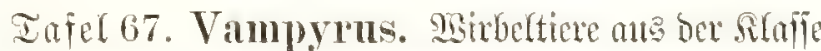
ber Găngetiere, Interflaffe der : Blazenta= lien(Srommgoer jelcoertiere, Chiroptera).

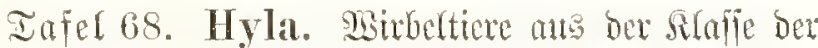
Anturbien, senion ber Fröjde (Batrachia oder Anura).

Iafel 69. Turbinaria. Teffelticre an dex Slaffe ber Soralfen (Dromm ber seraforallem).

Iafel 70. Astropliyton. Stemtiere mes ber Sitafie ber Dphiodeen, Dromm der Enrua= fonien (Cladophiura). 



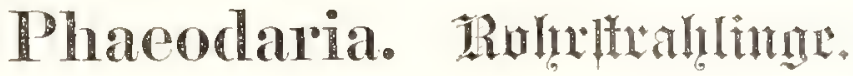

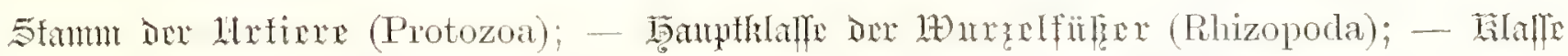

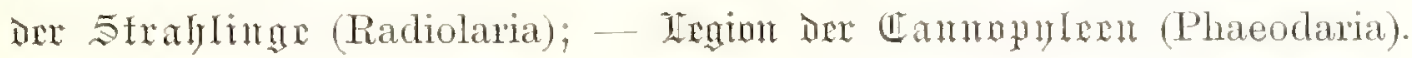

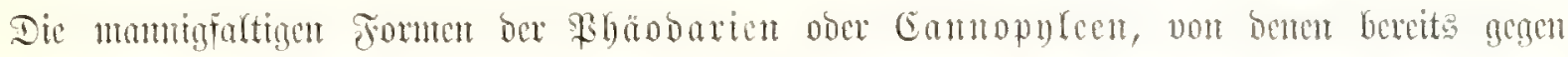

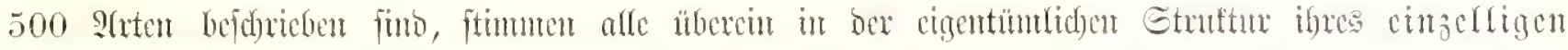

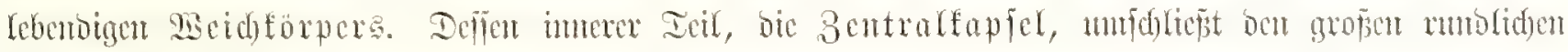

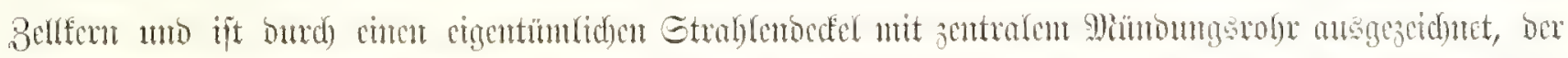

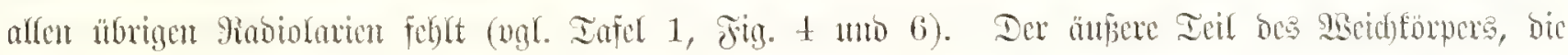

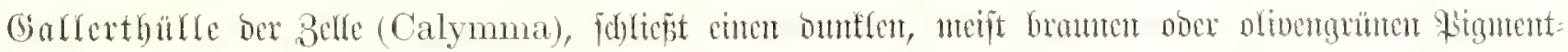

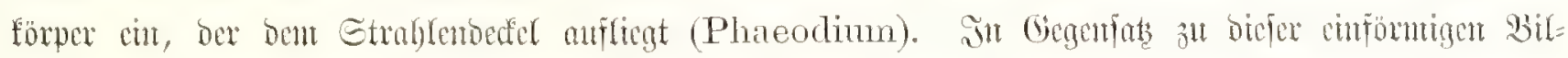

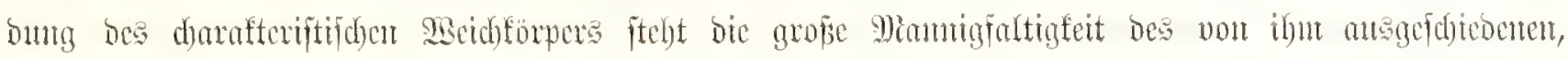

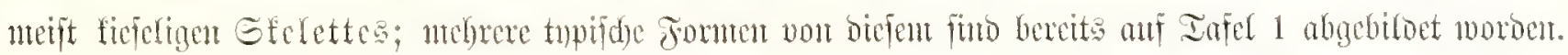

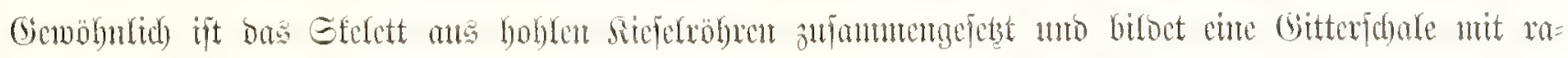

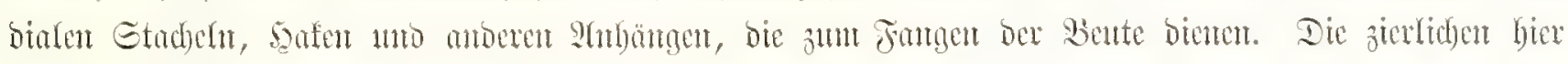

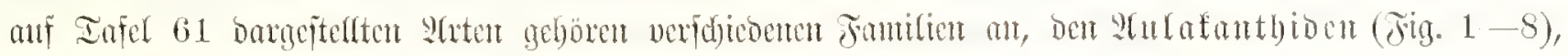

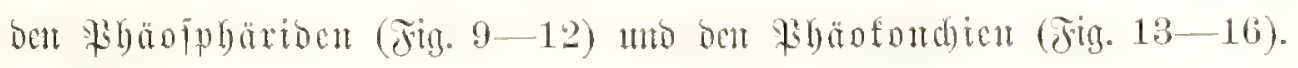

\section{Fig. 1 -8. Aulacanthida.

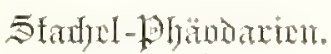

Rhönobarien, berent Eletett ans jablreidyen cint

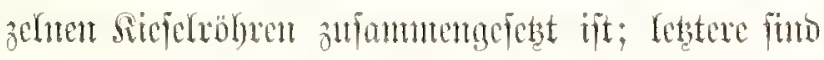
Ftrahlig gegen Den Mittelpunft ber funetigen Bent

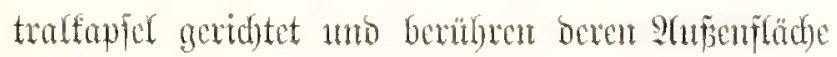

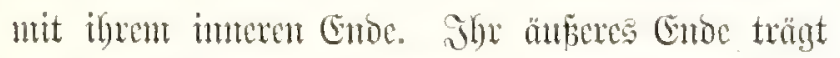
meiftens Etadyefn, sgiocrlyaten ooer Sirünge von

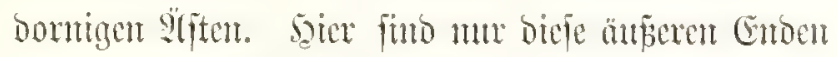

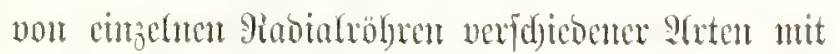
ibren Enousten bargefterlt.

Jig. 1. Aulographis candelabrum (Haeckel).

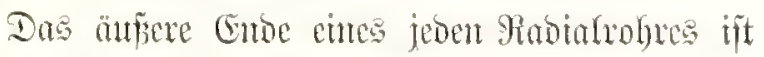

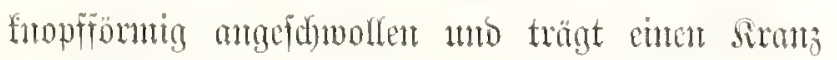
von 6 -9 gefrïmmten hohten Cundiften, bie mit

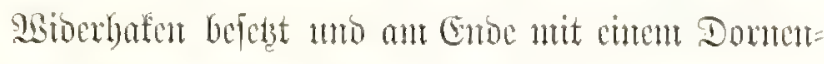
ftern (Spathilla) getrönt finto.

\section{Jing. 2. Aulographis pulvinata (Hacekcl).}

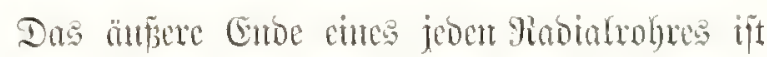

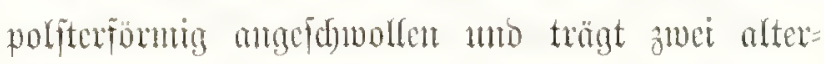
nerende Siränze vout gernom, rabial bivergierenden Entoäften; jeoer Enoaft zeigt jwet gegenftänoige feit=

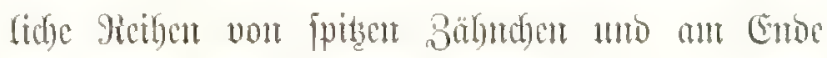
curnen Domenifen (Spathilla).

Fig. 3. Aulograplis verticillata (Haeckel).

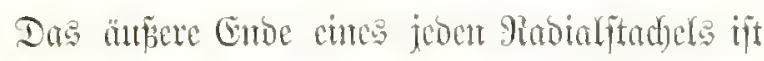

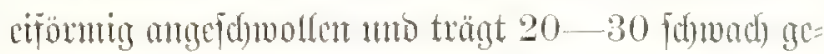

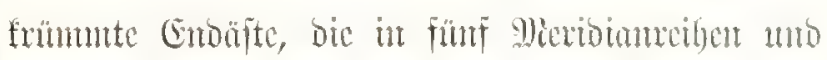

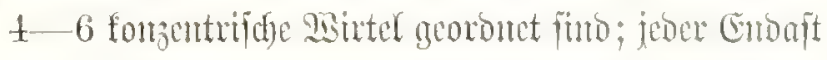
trägt zwei gegenfitünoige feitlide Feibent non bafor uno ane estoce cinen Dornemftem (Spathilla).

Fig. 4. Aulographis asteriscus (Hacckel).

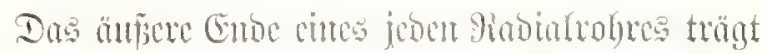
eimen Siranz yon 6-9 geroben, gefröntent Ëroüjten. 


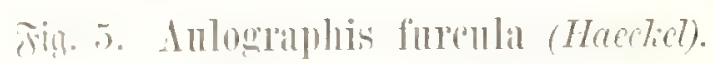

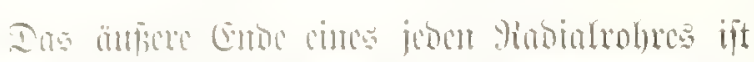

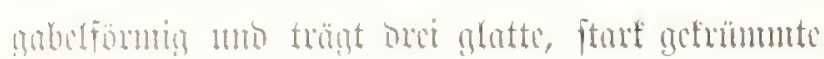

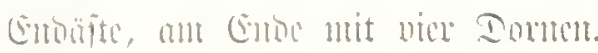

\section{Fing. 6. Anlographis triglochin (Hacckel).}

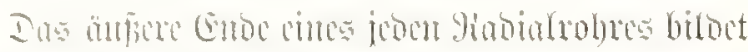

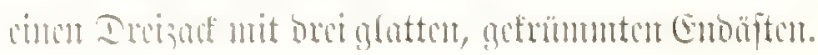

\section{Jig. 7. Aulographis bovicormis (IIaceliel).}

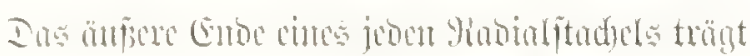

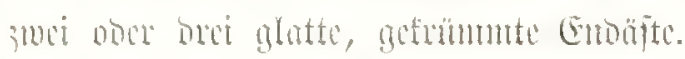

Şig. S. Anlographlis ancolata (Hacekel).

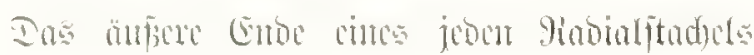

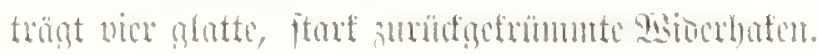

\section{Jin. 9-12. Phacosphaeria.

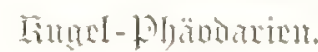

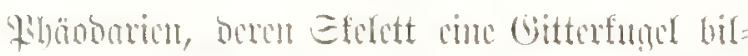

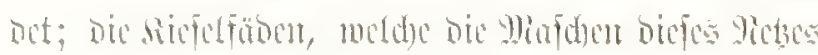

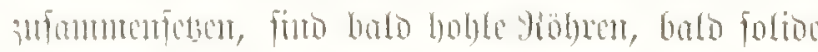

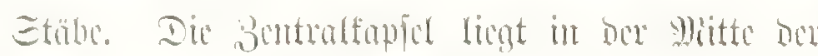
(Gittertuge, won ihr burd) bie (Gallerthülle getrement.

\section{Fing. 4, 10. Silgenoseclla stellata (Hackel)}

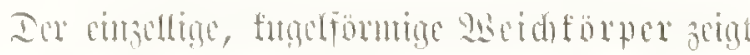

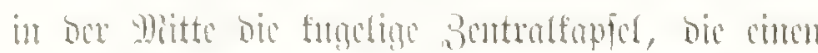

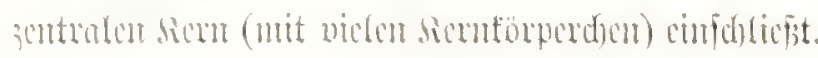

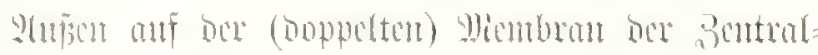

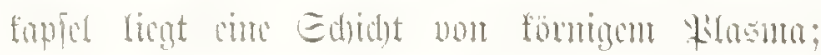

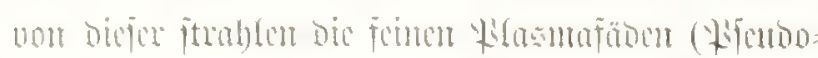

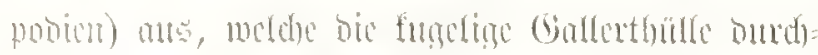

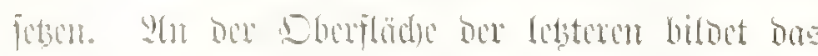

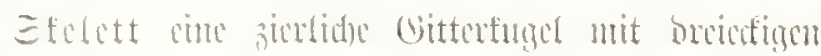

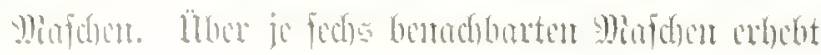

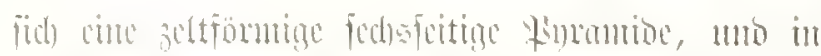

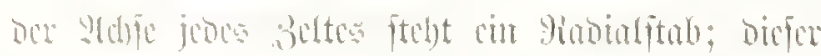

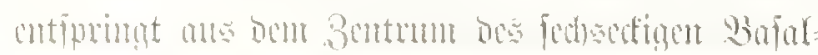

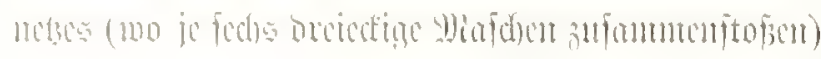

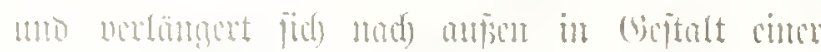

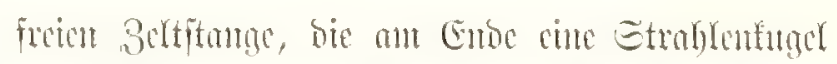
trägt. Soner Enoaft bor lesteren ijt mit cinten Domenteru gefrout. - Jig. 10. Dic Etrahlen=

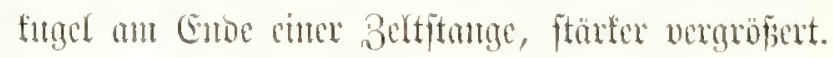

Fiu. 11. Sagenosecna ormata (Haeckel).

Cime Brtfiturac, bie ftatt cinter Etrablenfugd

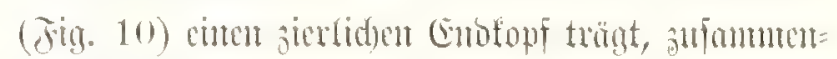

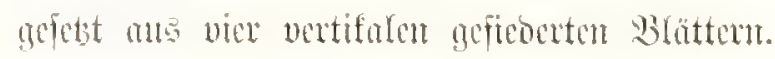

\section{Sig. 12. Auloscena mirabilis (Hacekel).}

Eine Beltitange mit bivergenten Enoâtes, bie an Enoc cimen Dorntuitem (Spathilla) tragen.

\section{Jig. 13-16. Phacoconchia.

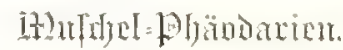

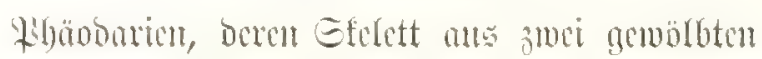

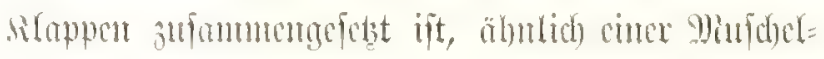

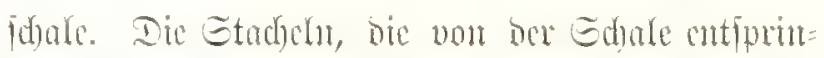

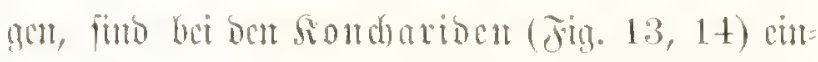

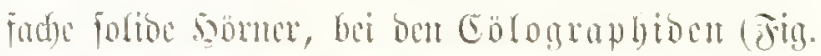

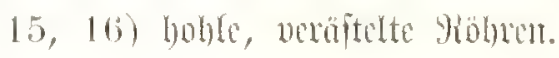

Sing. 13. Conchoceras cormutum (Hueckel).

Die zuciffoppluge Gitterforale trägt an binteren

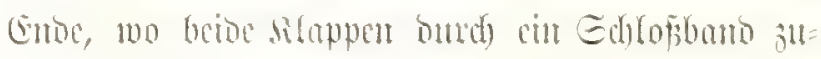

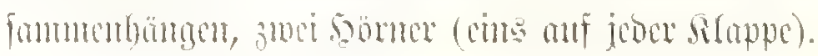

Sig. 1t. Conchonia quadricornis (Haeckel).

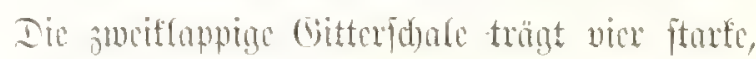

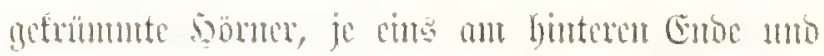

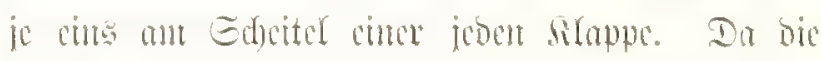

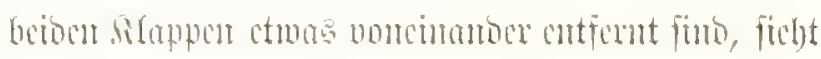

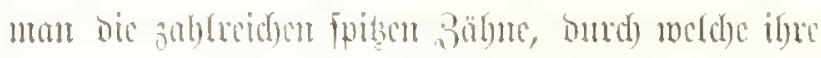

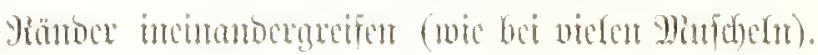

Jig. 15. Coelographis regina (Haecket).

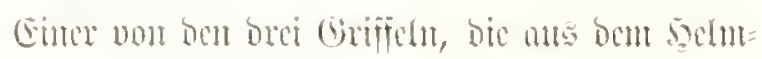

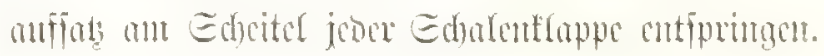

Jis. 16. Coelospathis ancorata (Hackel).

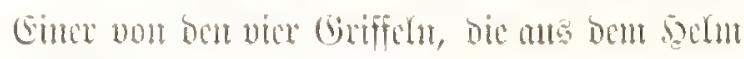
anfats ant Ed)eited joor Edalenflappe antipringen. 


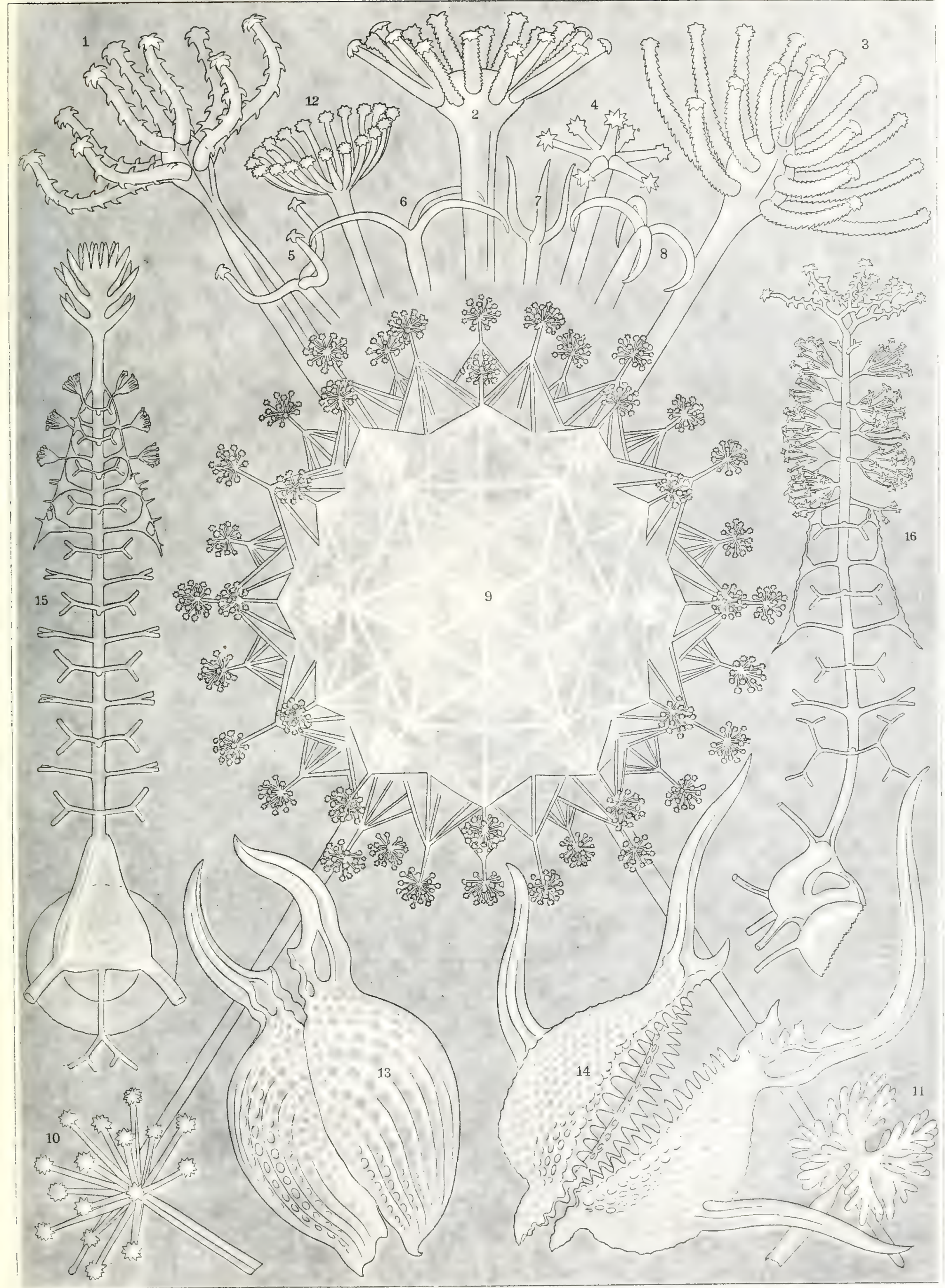





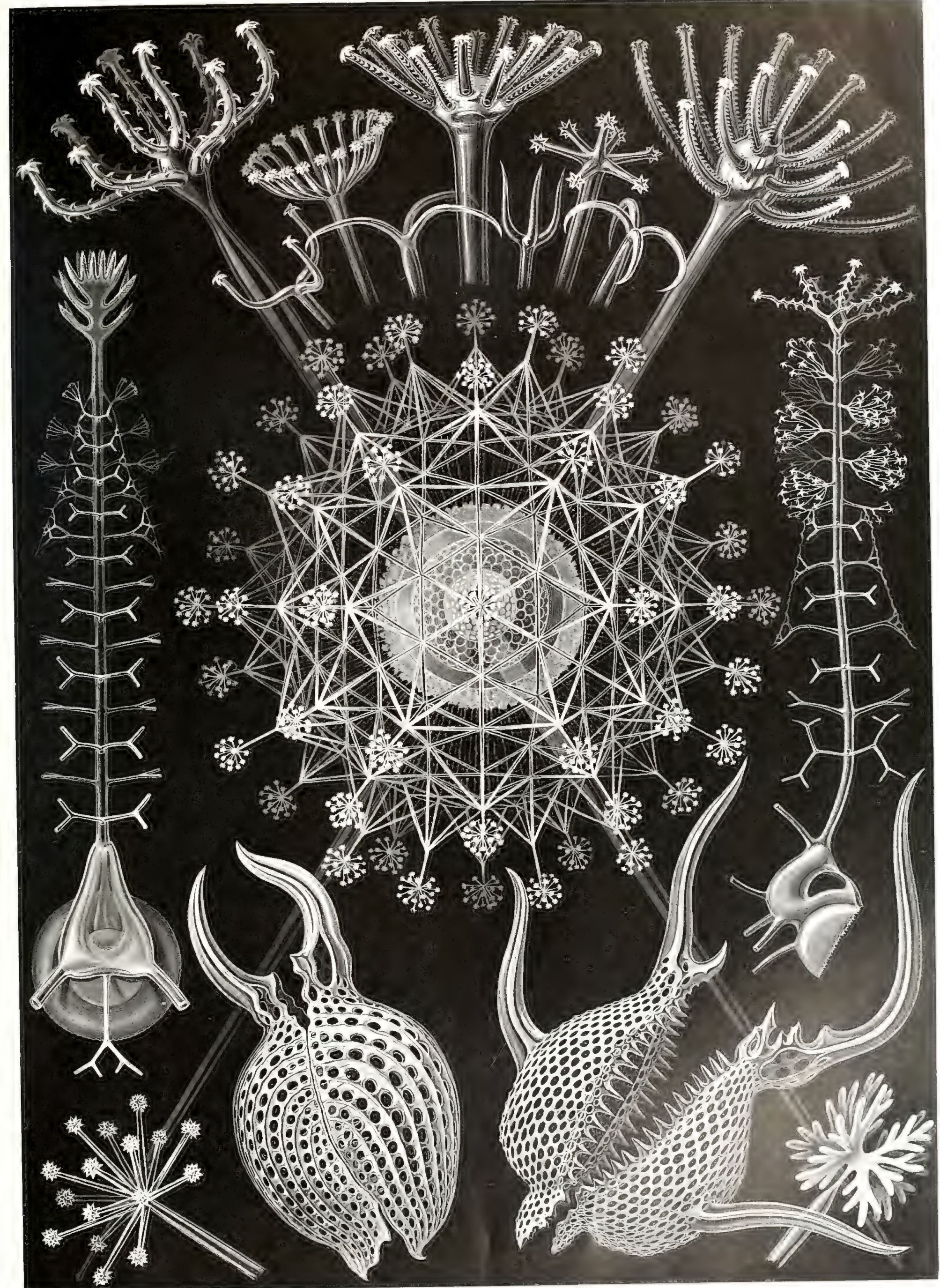





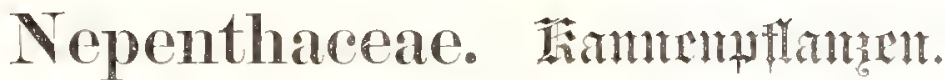

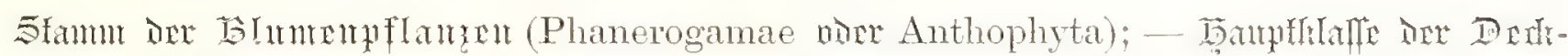

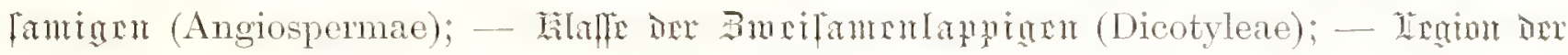

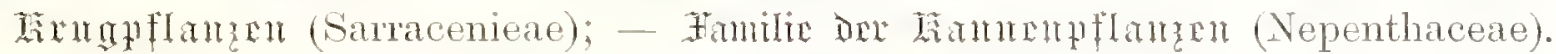

Jepenthes melamphora (Reinuard).

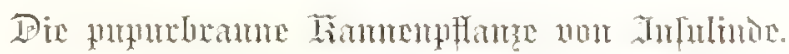

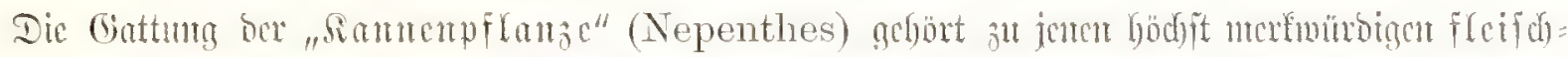

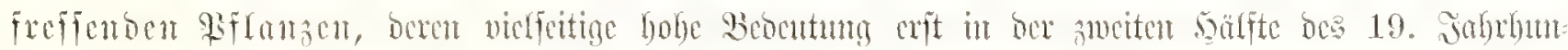

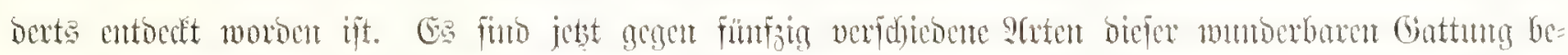

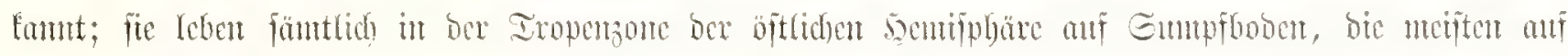

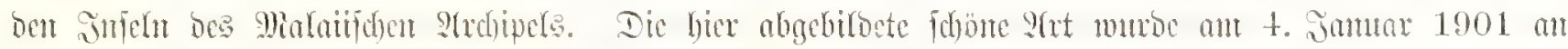

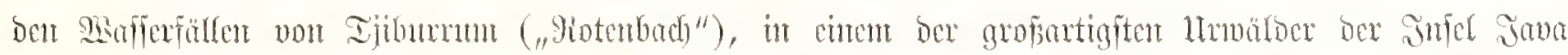

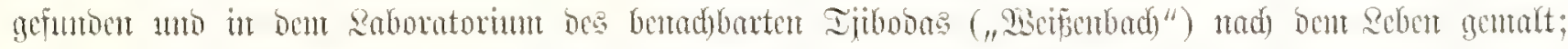

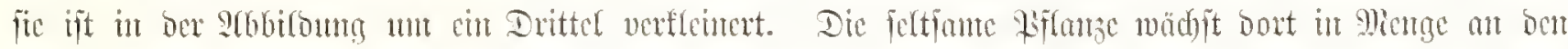

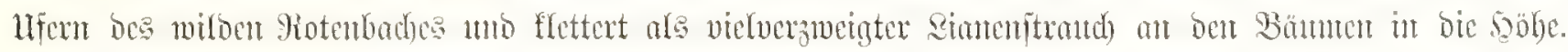

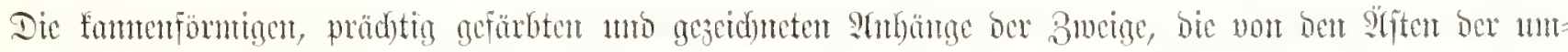

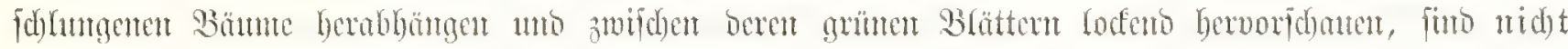

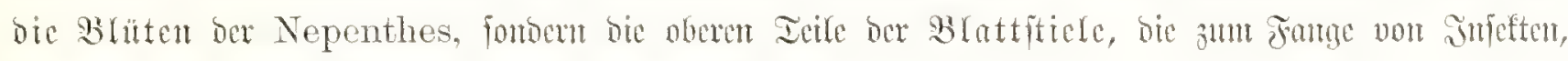
Spinten unto anocren feemen Tieren cingeridatet finto.

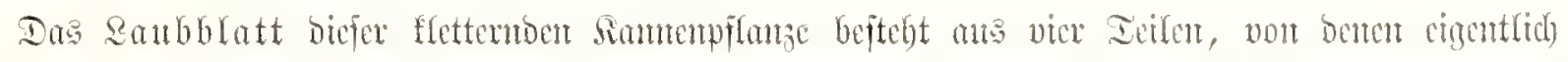

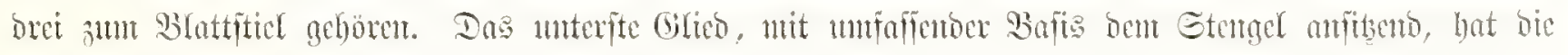

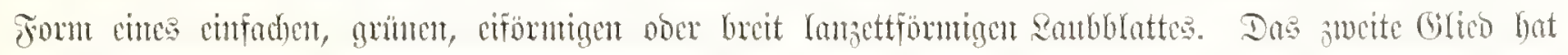

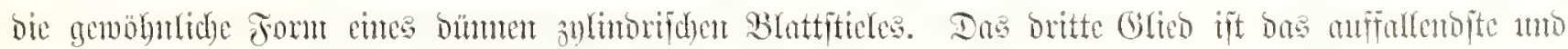

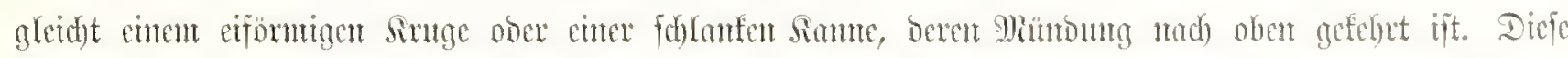
Deffinurg wiro gejd)

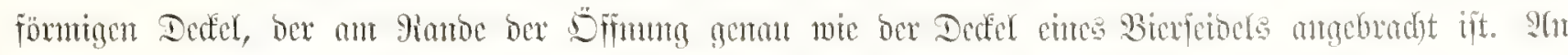

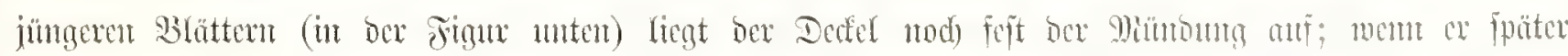

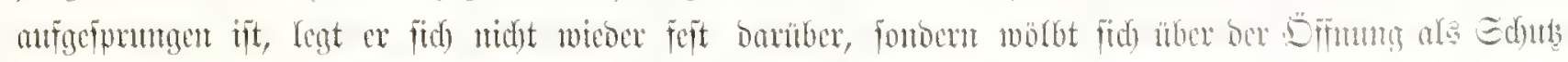

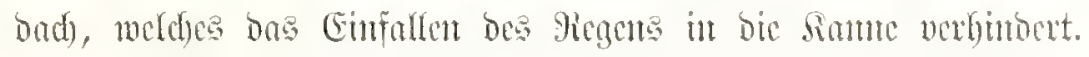

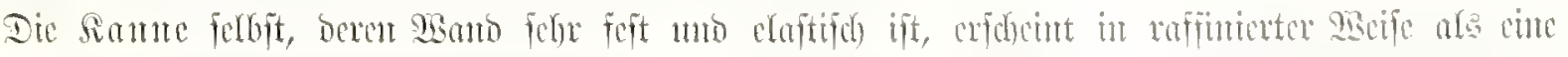

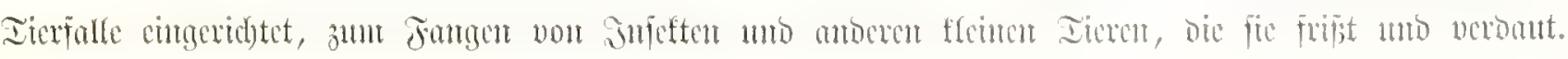




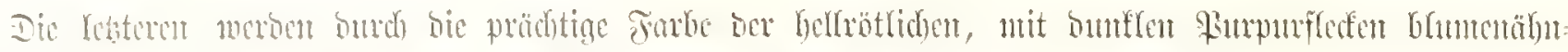

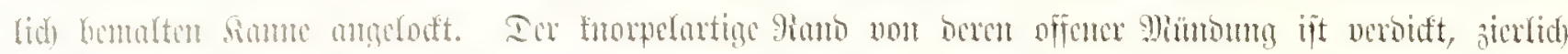

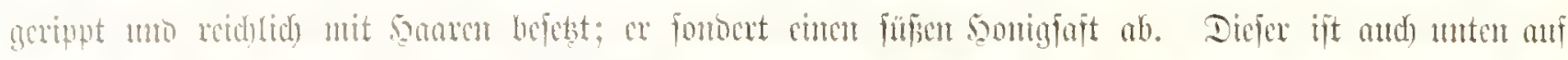

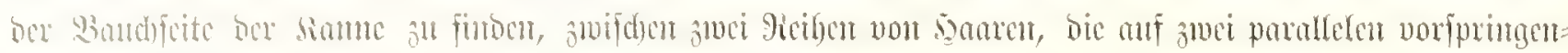

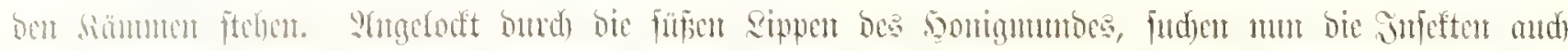

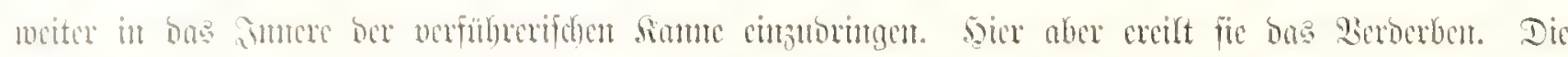

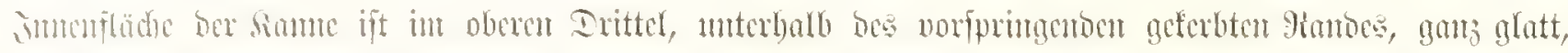

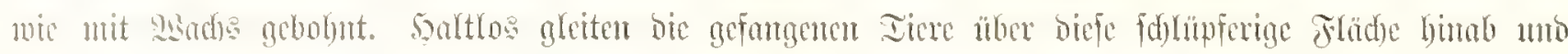

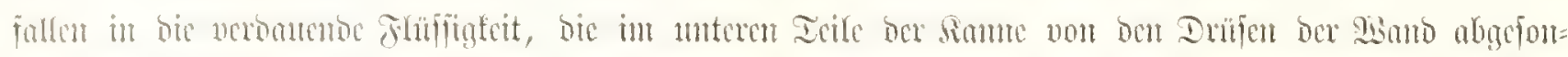

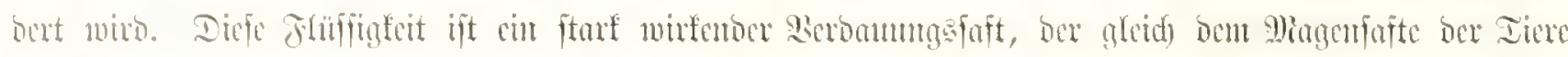

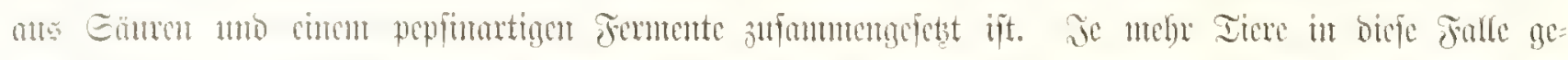

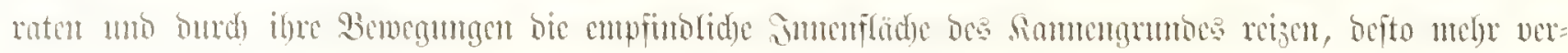

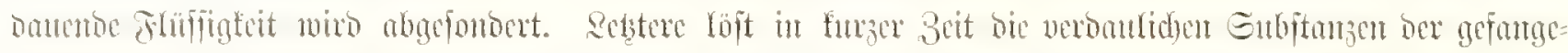

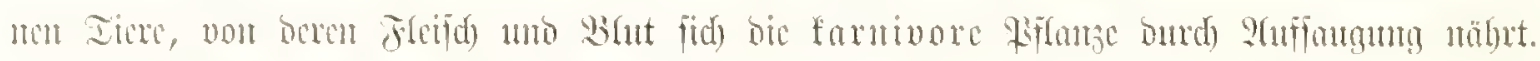

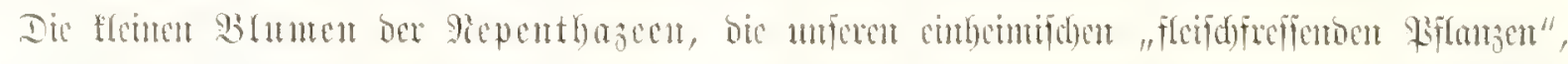

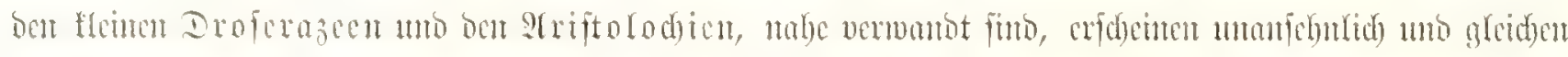

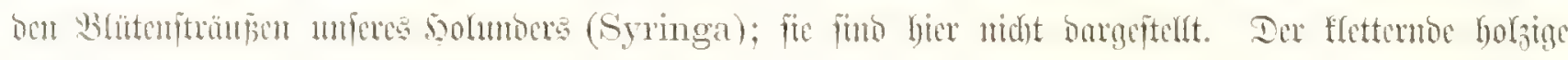

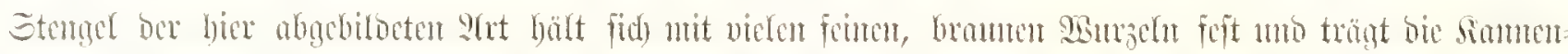

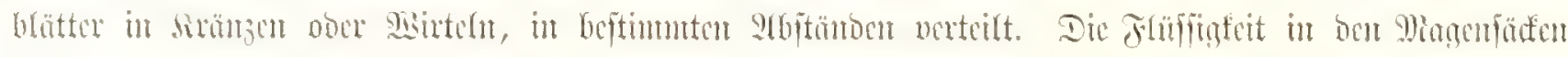

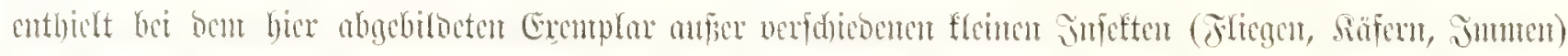

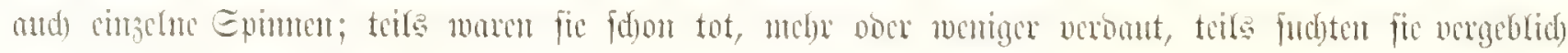
ats bor fotle bermushttommen. 


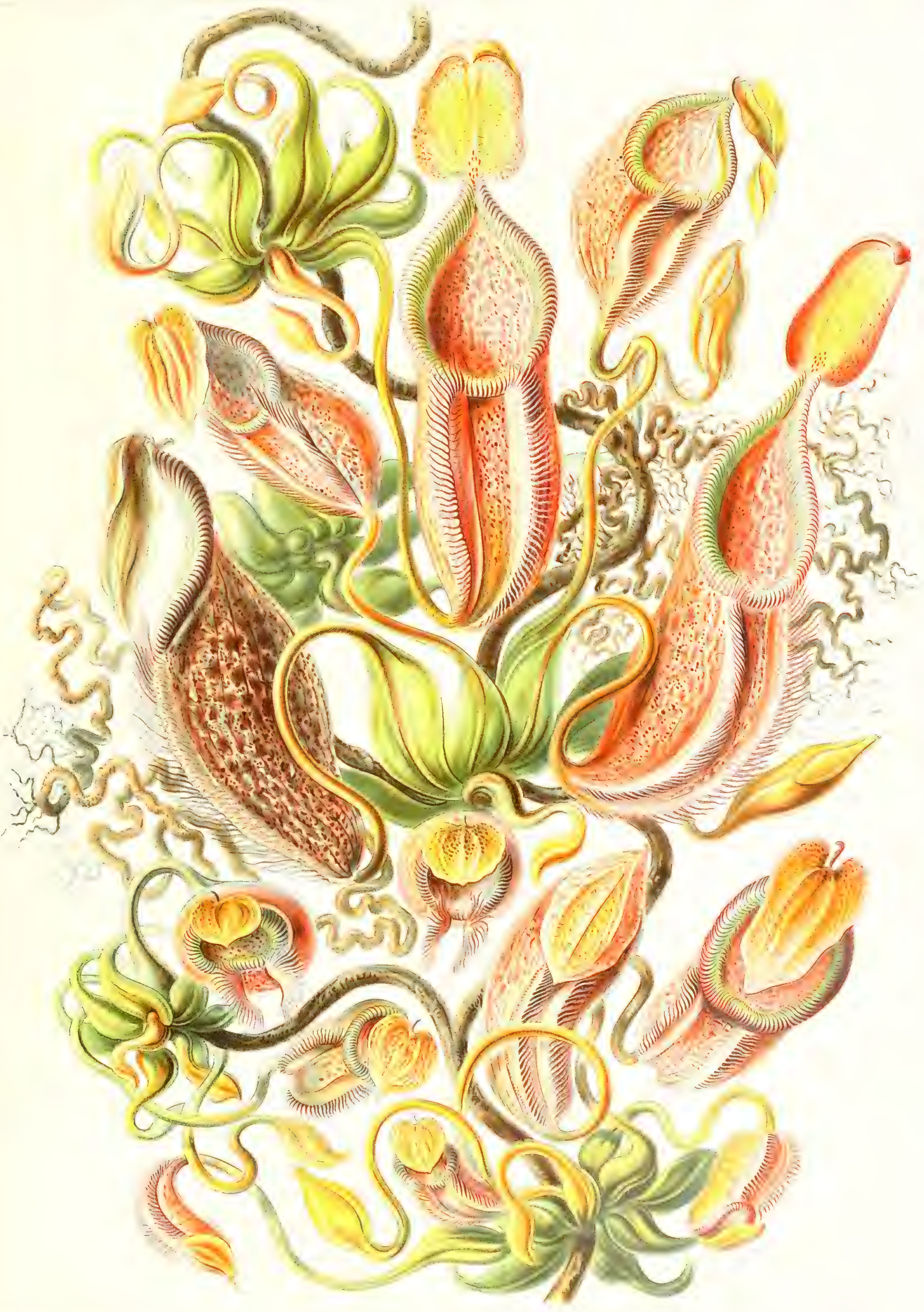

Nepenthaceae. - Emantentliangert. 



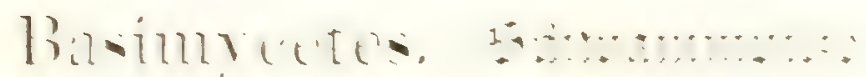

$\Xi \therefore \quad \therefore \because$

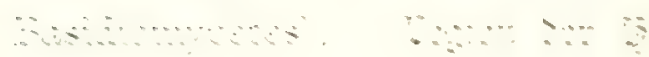

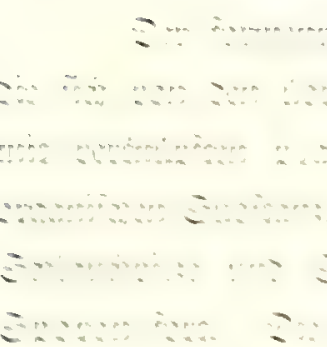

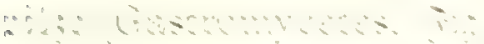

$3:$

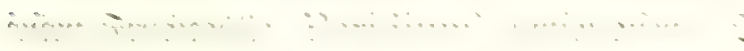

n.m.n.

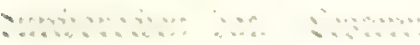

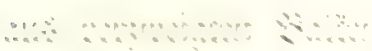

$\because$ ?

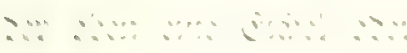

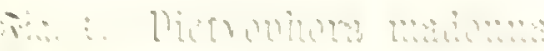

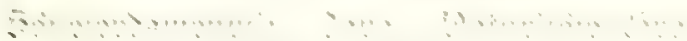

$\therefore \quad \therefore \quad \therefore \quad \ldots+\ldots+\cdots \cdot$

>n

…"

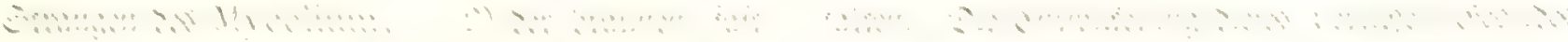

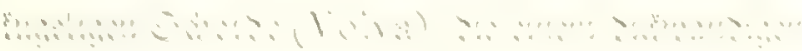

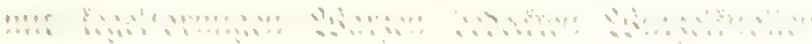

An

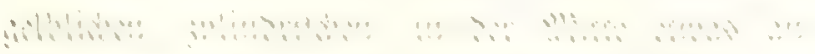
s.'s

(1) B.?.

$\therefore \ldots \therefore \quad \therefore \quad \therefore \quad \therefore$ i.

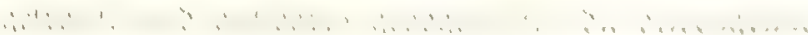

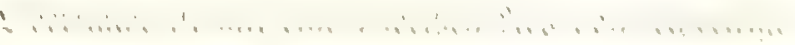

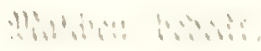

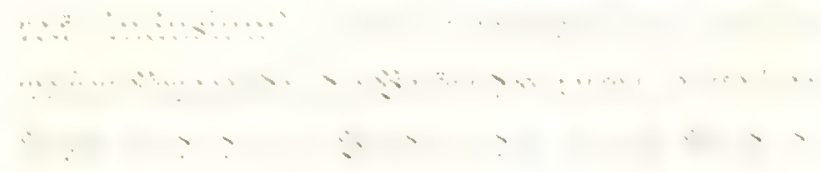

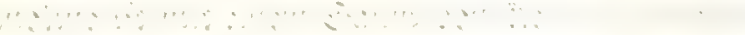

(….........

a........
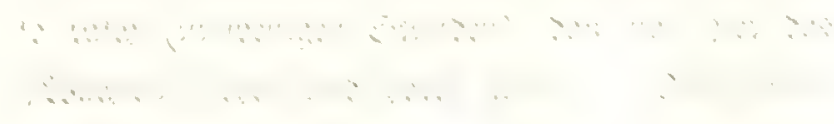

16. 
Fir. 2.. Phallus impulicus (Lime).

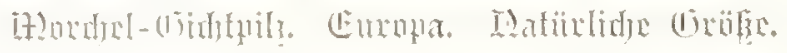

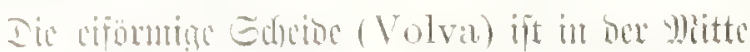

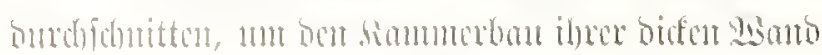

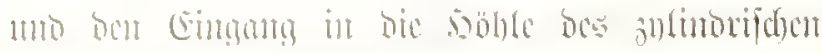

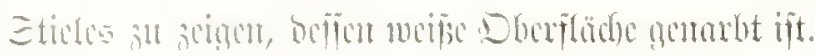

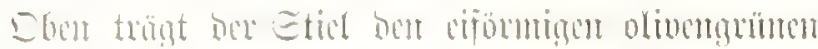

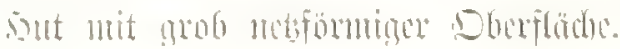

\section{Fing. :3. Aseroi lubra (Billudive).}

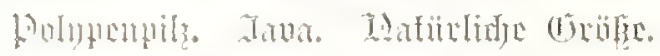

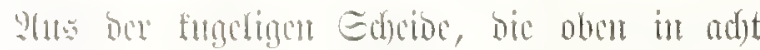

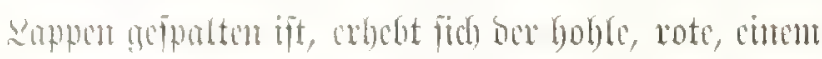

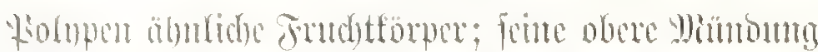

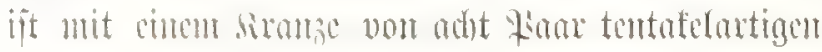

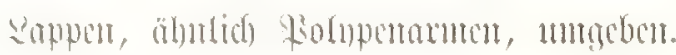

\section{Fin. t. (lathrus cancellatus (Toumefort).}

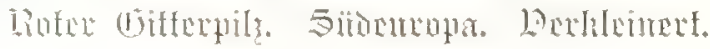

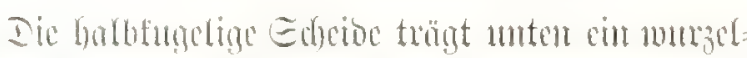

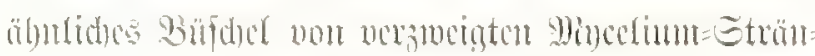

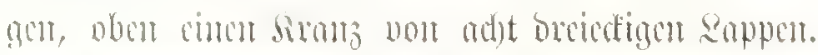

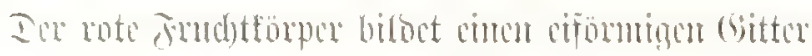

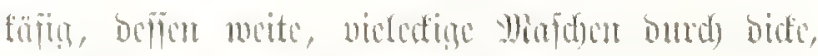
quergetaltete balfen getrement finto.

Tign. 5. Clathrella erispa (E. Fischer).

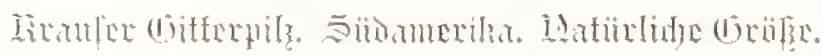

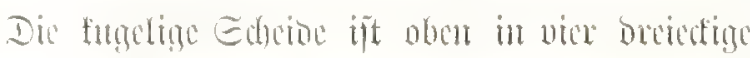

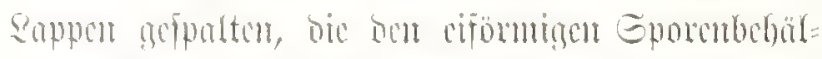

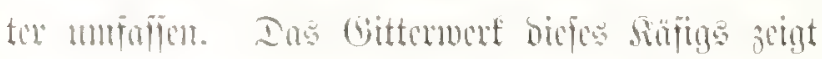

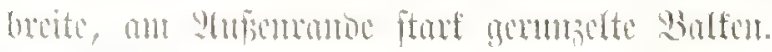

Fing. (i. Clathrella pusilla (E. Fischer).

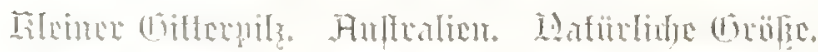

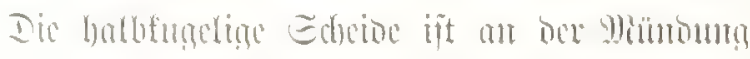

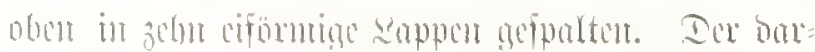

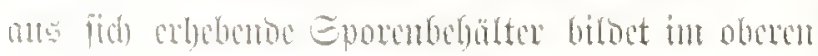

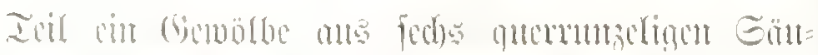

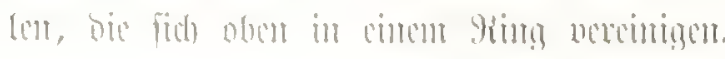

Jig. 7. Calathisens sepia (1Contague).

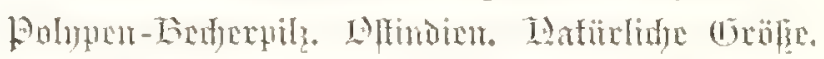

Der Fututtörper hat bie Gejtalt cinte Bedets,

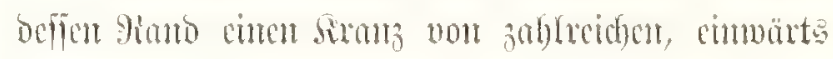
gefrimunten Folupentarmen trägt, untent bie fungelige Edyetoo billoct.

Jiţ. S. Simblum sphaerocephalum (Klotsch).

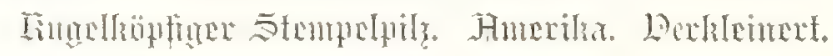

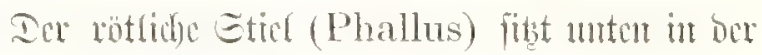

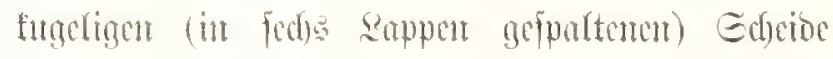
(Volva) umo trägt oben cincm gitterfämnigen Frudut= förper (Receptaculum), at befient gerutgelten Barfen imm bie Eporemnafic antiont.

Fing. 9. Anthurus borealis (Burton).

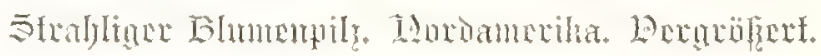

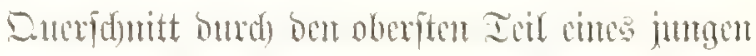

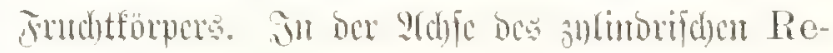
ceptaculum, bas onjemigen won Phallus (Fig. T)

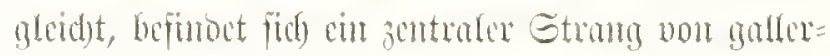

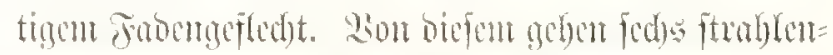

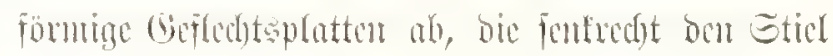

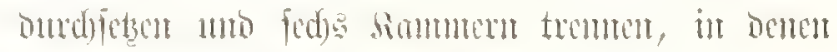
dic Grormunafic (Gleba) licgt.

Tin. 10. Geaster multifidus aricheli).

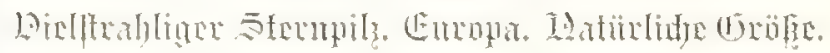

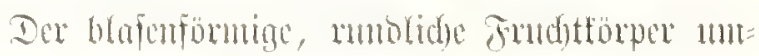

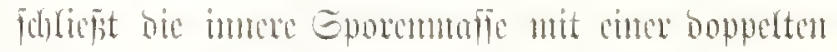

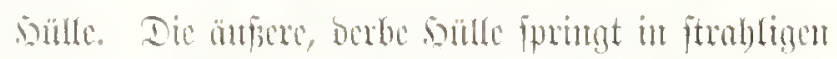

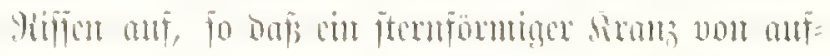
gerollen soppen entitelyt. Die immere sinlle itt sart.

Tin. 11. Copruuus comatus (lleiller).

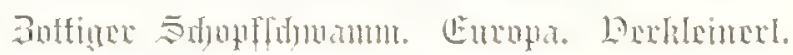

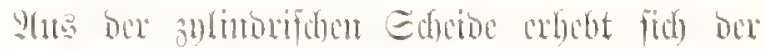

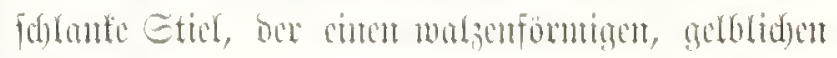

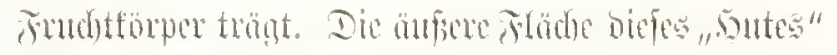
ijt mit 3otten booseft. 



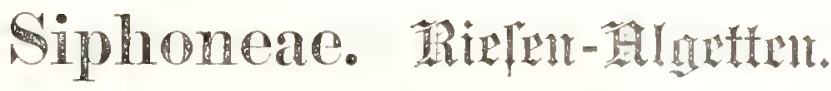

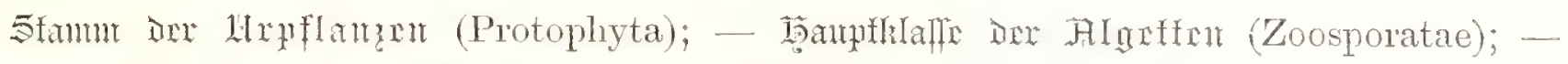

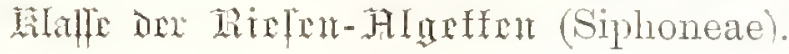

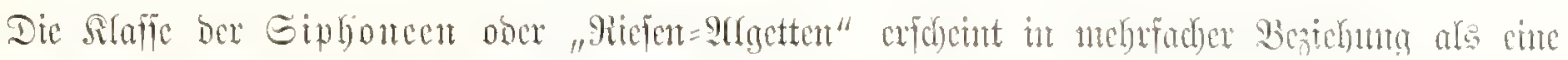

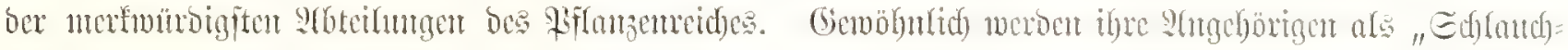

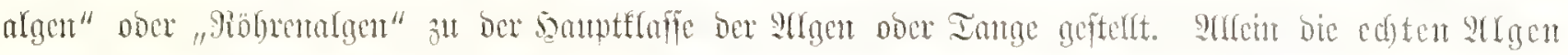

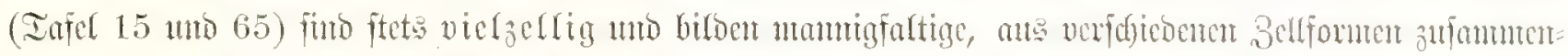

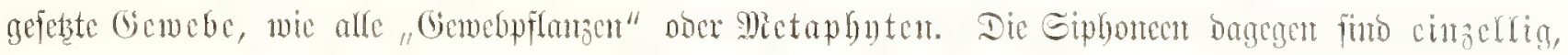

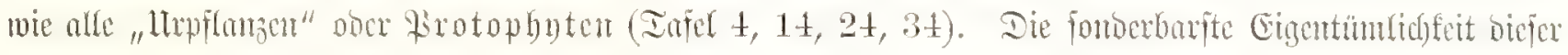

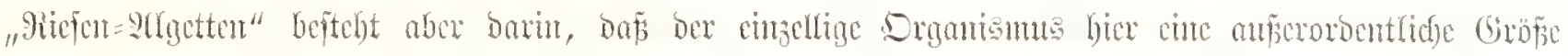

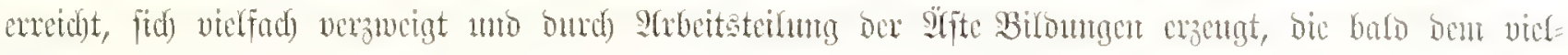

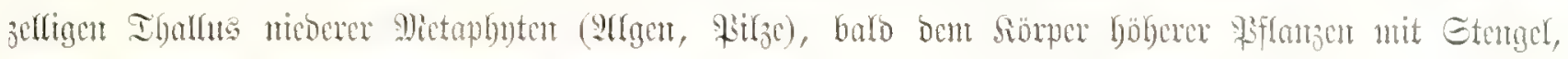

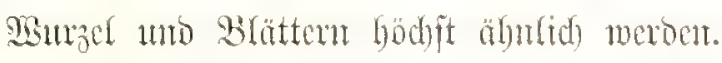

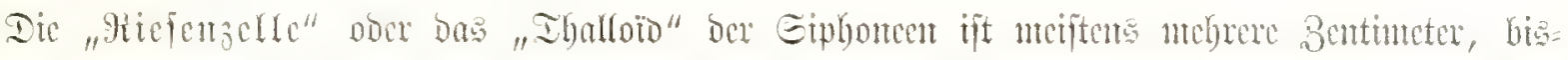

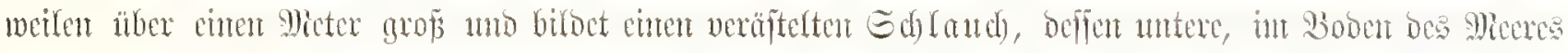

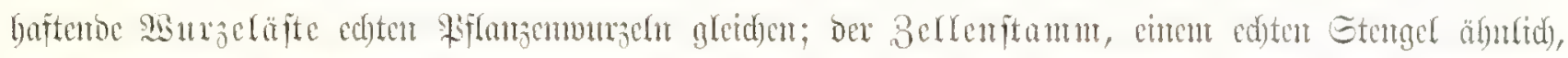

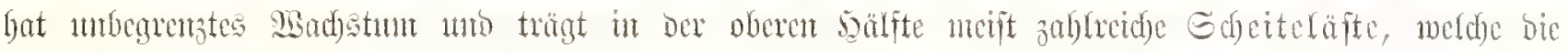

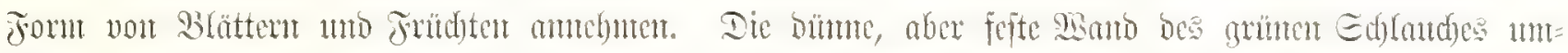

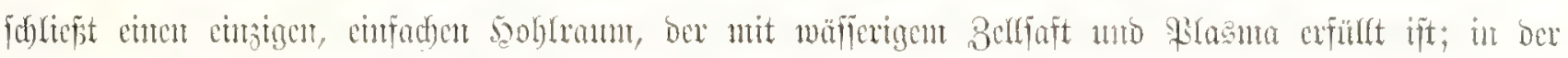

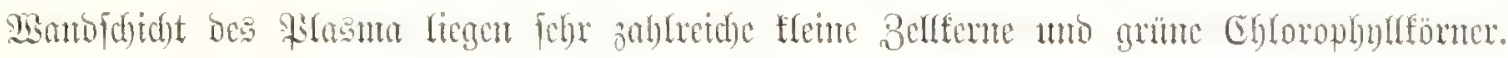

Dic Fantic bue Canferpazen (Jig. 1-6) wirb mm buth) bie cutzige Gattung Canlempa

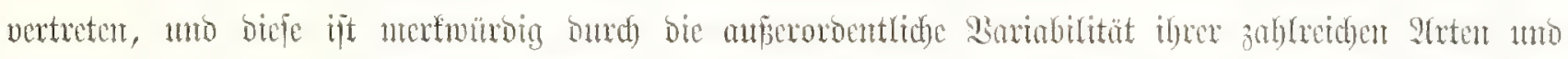

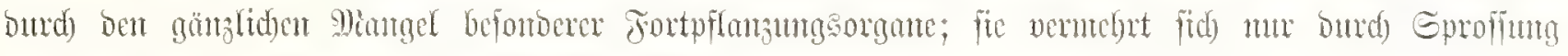

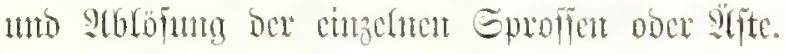

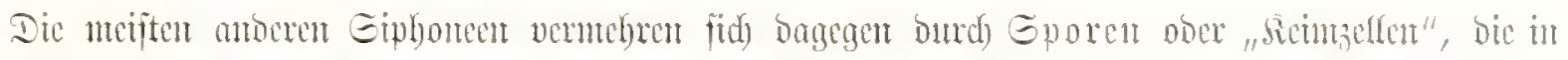

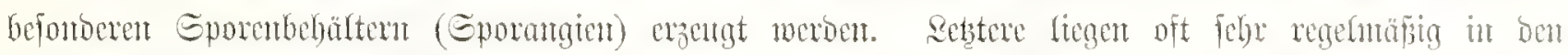

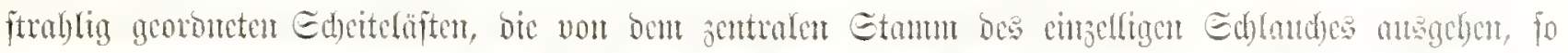
bei ben Dafulfaden (Jig. 8-11).

gig. 1. Canlerpa lacemosa (Agardh).

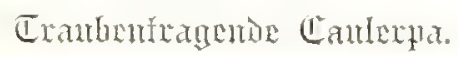

Thu bon sionallenbänfen des gioten Miceres.

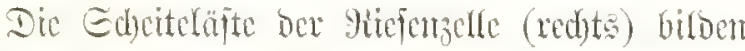

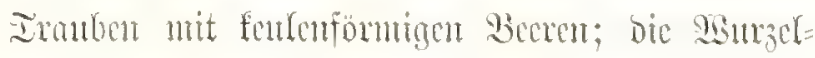

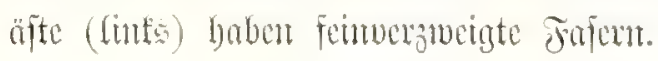

\section{Fin. 2. Canlerpa uvifera (Ayurdh).

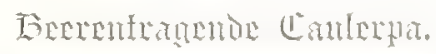

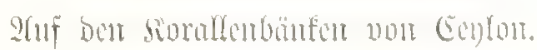

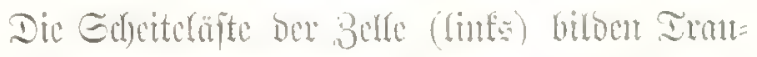

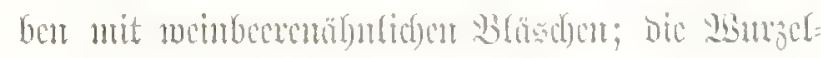

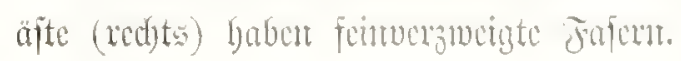




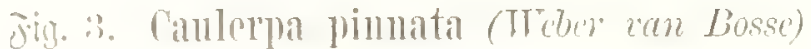

\section{(i)firomerte catertis.}

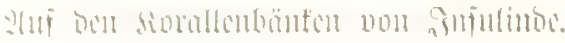

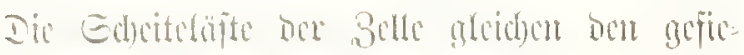

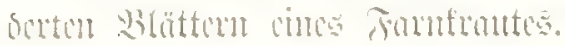

Ting. t. Caulerpa peltata (Tamouroux).

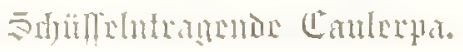

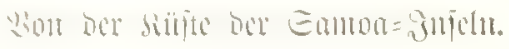

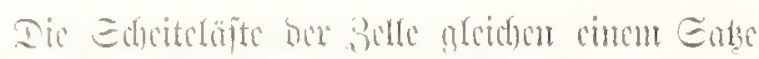

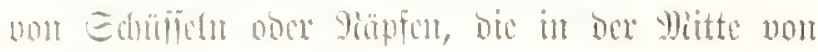

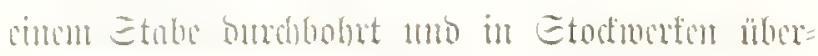
cintunocr grovonet fins.

Jig. 5. Canlerpa paspaloildes (Harey).

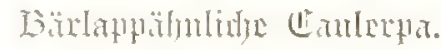

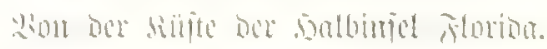

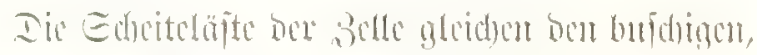

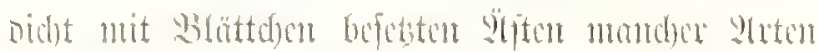
nour Bürr(app (Lycopordinm).

Sìn. 6. Canlerpa macrodisca (Decrisme).

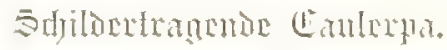

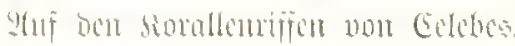

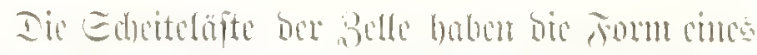

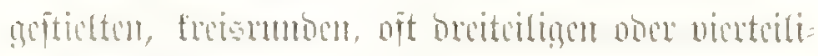

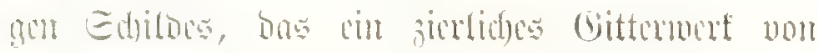
Mippen tringt.

\section{Gign. 7. Struvea plumosa (someter).}

fromerämine Baloniazer.

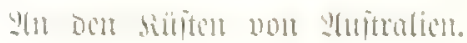

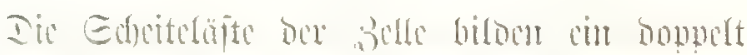

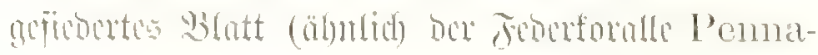
tula, Infol 19, Jig. 12). Dic Jitederifte fumb

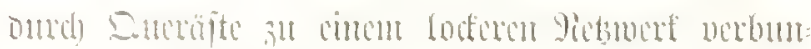

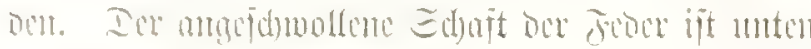

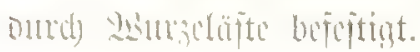

Jin. 8, 9. Teomeris Kelleri (Cramer).

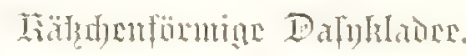

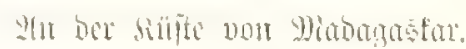

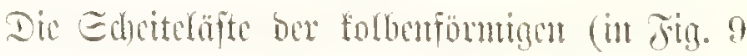

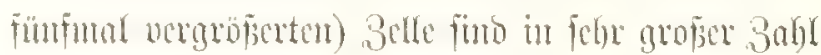

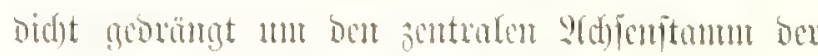
Belle gruppiert (wie bet allen Dajuffaben). Die

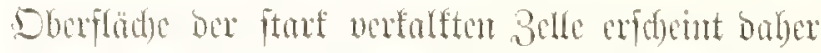
jertid) facettient mo bebanet (Jiug. 9). 9uf bem

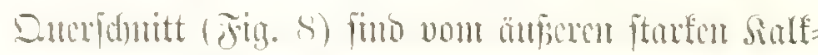

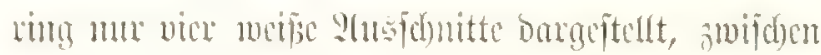

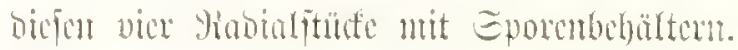

Fin. 10. Netabularia mediterranea (Lam.).

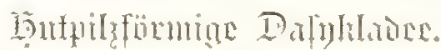

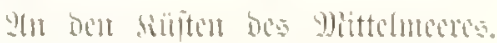

Dir Edreiteläte ber lomggeitelem, verfarftem

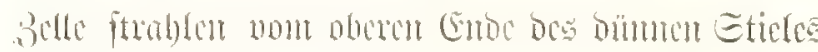

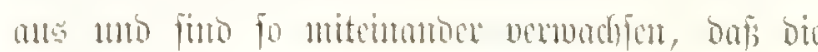

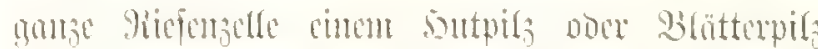

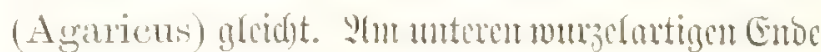

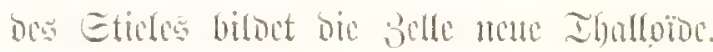

Fig. 11. Bornetella capitata (Atgerdh).

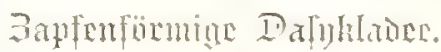

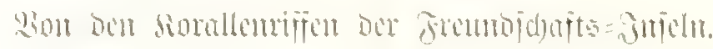

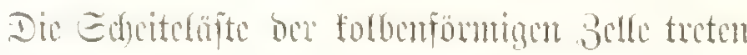

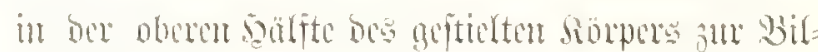

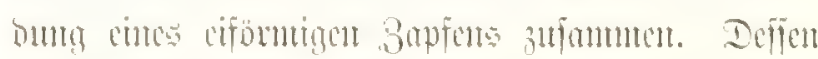

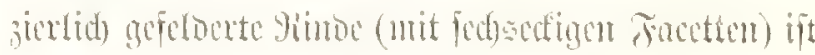

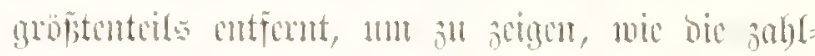

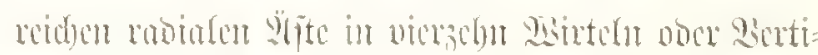

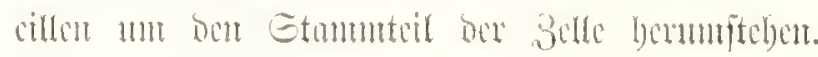
Won joon

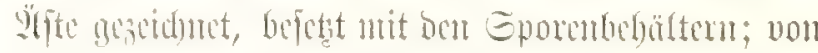

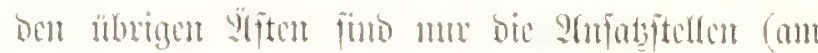
jentrolon Etmumteil bor 3olle) fidstbas. 


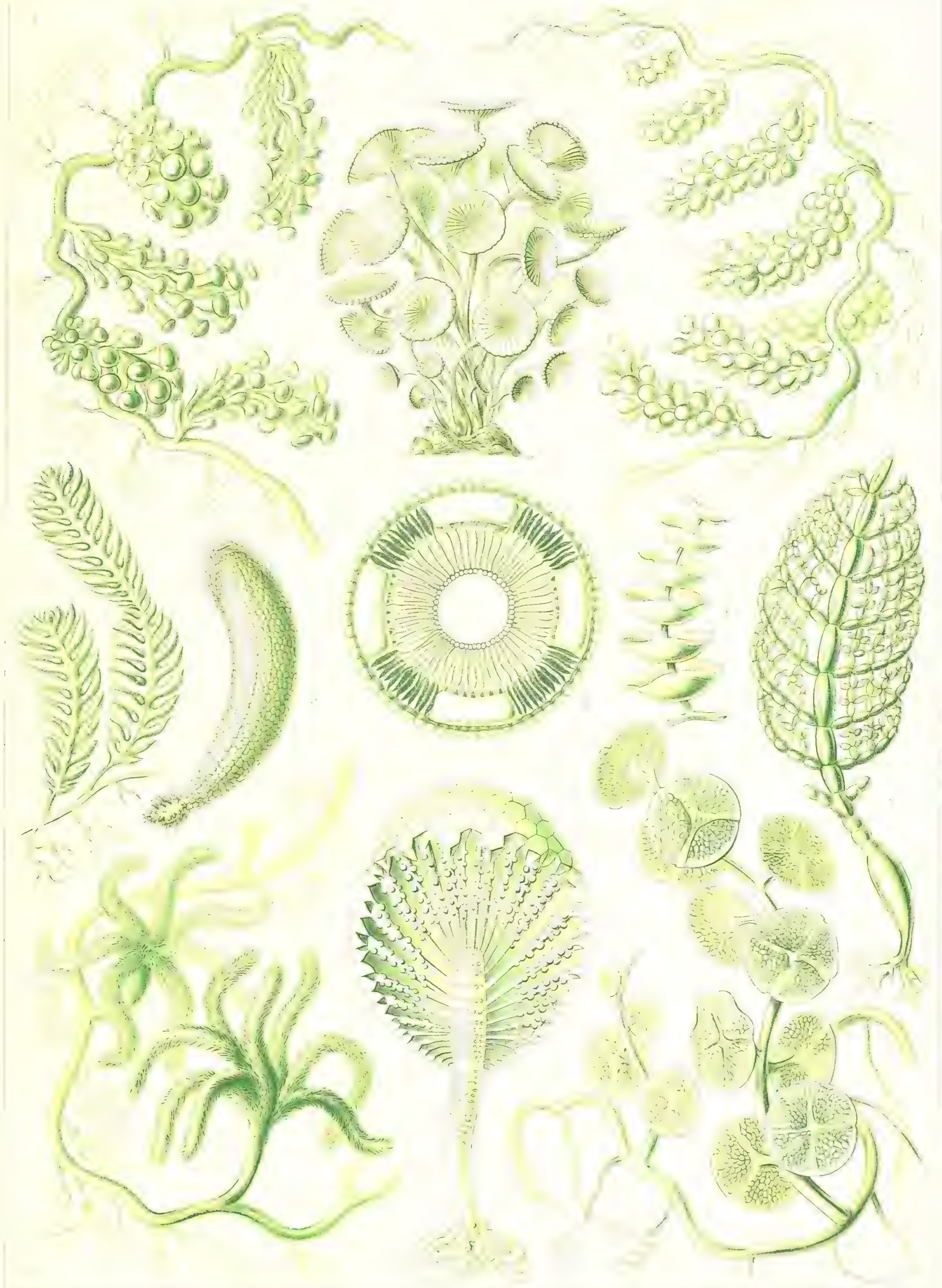

Siphoneae. - Jikelent = Mlig̣effert. 



\section{Florideae. Rutalnen.}

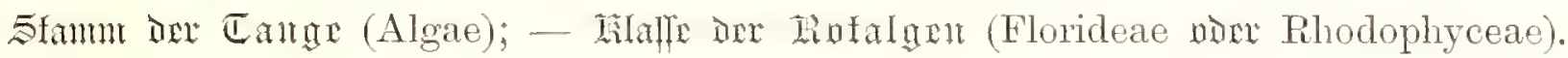

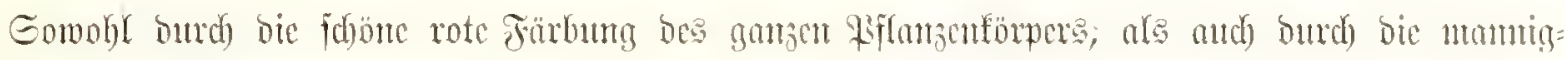

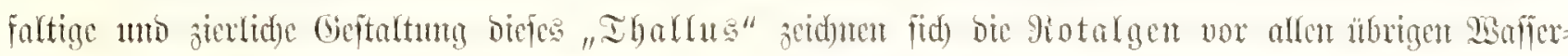

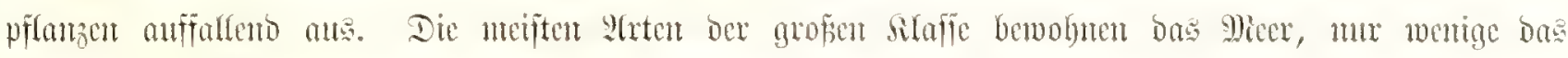

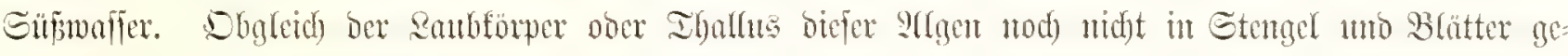

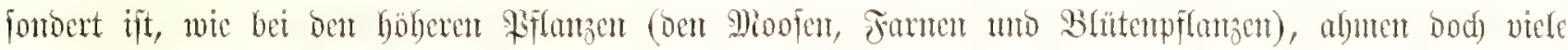

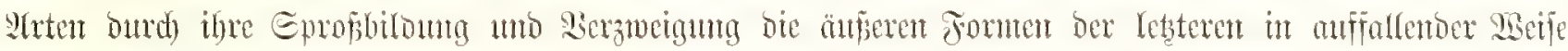

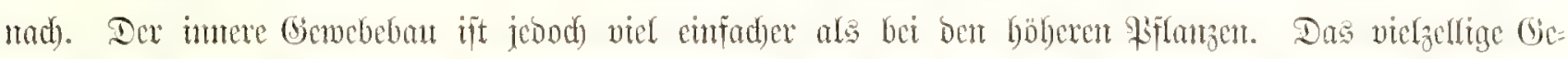

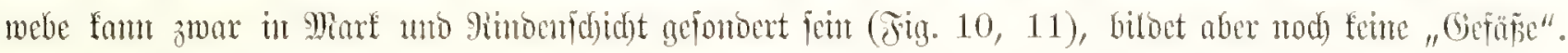

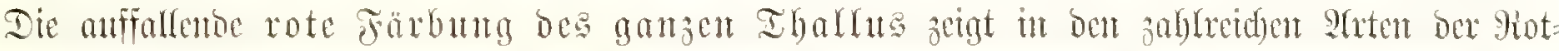

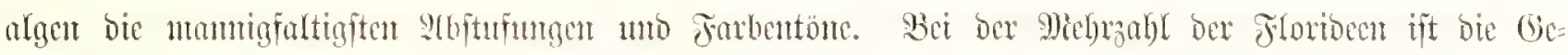

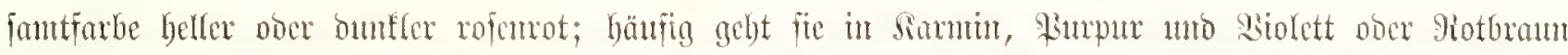

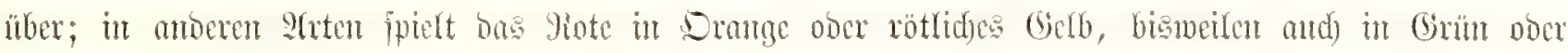

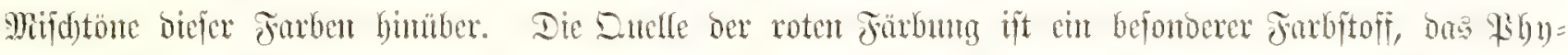

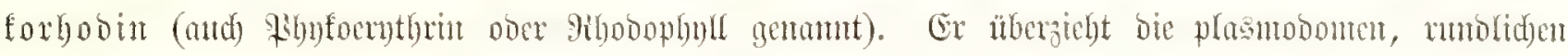

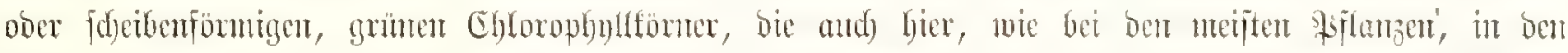

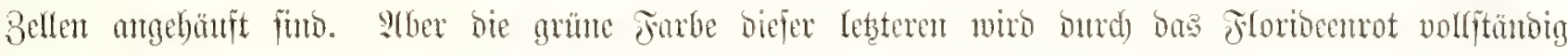

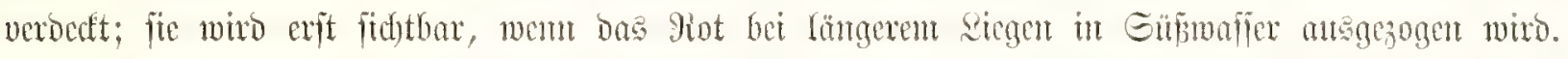

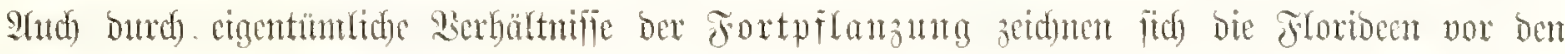

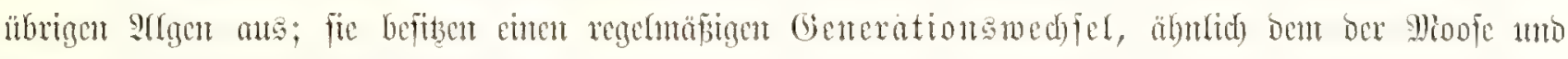

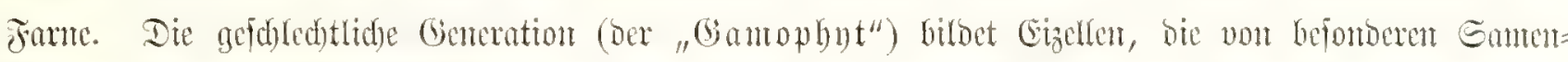

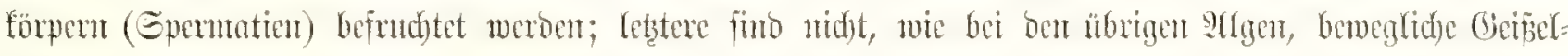

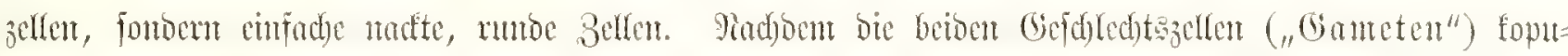

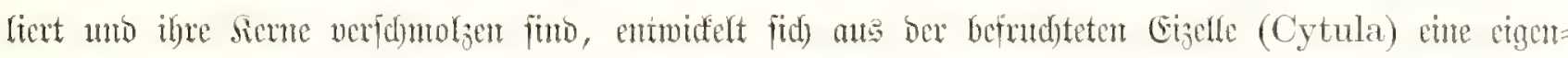

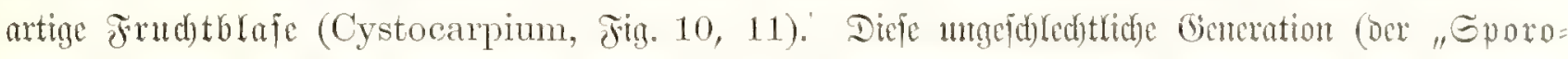

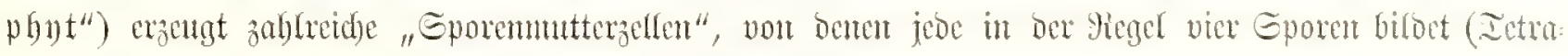

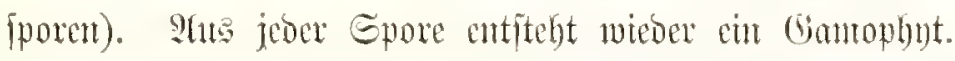

Jig. 1. Chondrus crispus (Limé).

Fomilie oex (1)inatiment.

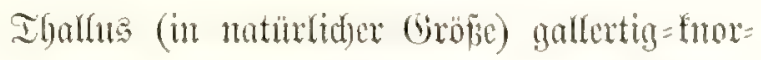
pelig, mit vicfen, wicoerbolt gabelteiligen Sijten. Diefe Irt liciert getrofinet das offizinelle "Ear=

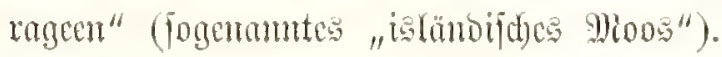

Fig. 2. Lmansia glomerata (Agardh).

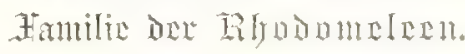

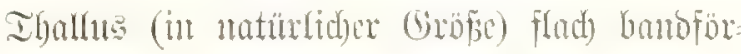
mig, mit alternierenom Eeituriproffon, bic ant Giunoe

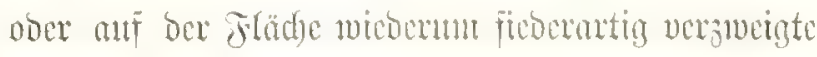
gicbemproffen juciter unb britter Dobmung tragen. 
jitu. 3. Constantinea rosamarima (Postels).

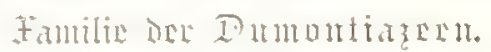

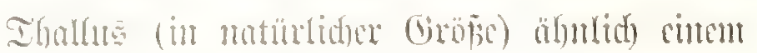

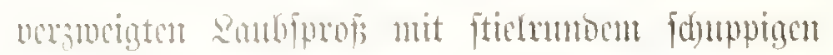

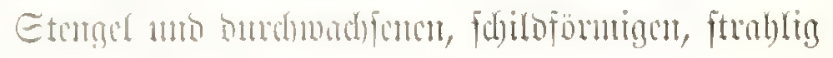
mejurtiten Bilutterit.

\section{Jitg. t. Ptilota serrata (Kütuing).}

tamile one teramiazent

Ihalfus (in maturlided Grofe) auperft reid) berancigt, mit viden foocrartigen siften, bie wie

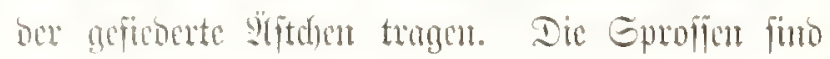
abrgeplattet, smeifontecioin.

Jig. J. Ptilota densa (Agardh).

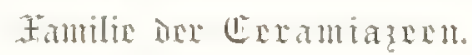

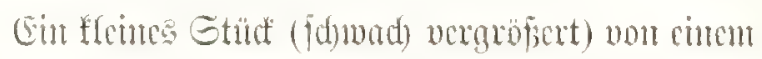
Ecitmberge bes viefverzweigten gefiederten Ihallus,

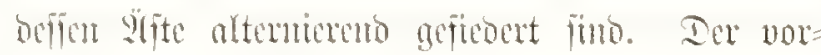
bore, fontave grand ocr sifte ijt glatt, bex hin tere, formere gimb halb geficoert. Geocm Jienerafte

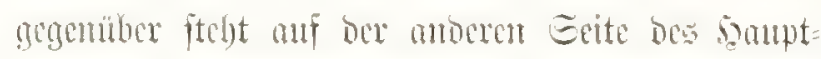
njte ein Epormainträger, ein verfintster fondt=

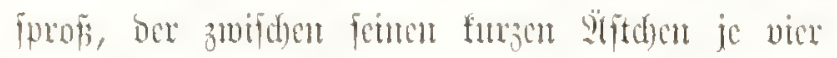
Eporangicn trägt.

jig. 6. Rissonella relruenlosa (Agarmh).

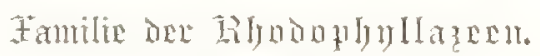

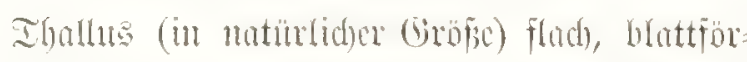

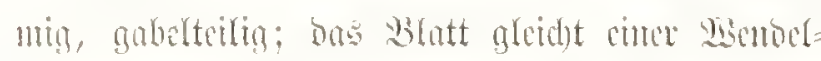

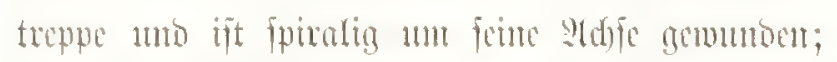

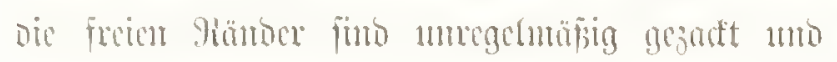
gewimpert.

\section{Fig. 7. Delesseria involvens (Harey).} Familie der Delefrertaren.

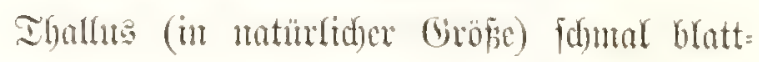

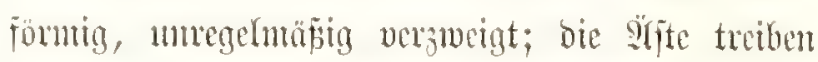

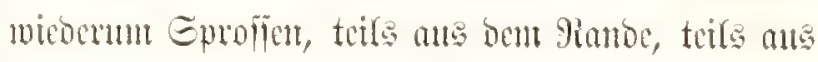
ber Mitterippe bes Blattes. Die Enoen der Eproffen finto sierlidi eingerollt.

Jig. S. Delesseria sanguinca (Limé). Familie der Dreffrriaten。

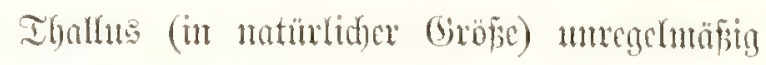
verämeigt; bie Eprofien Kaben bie Gejtalt cines fehr

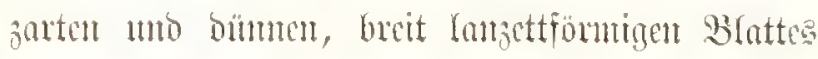

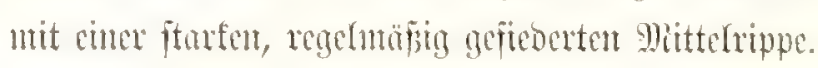

Jig. 9. Temastoma cervicorne (Agardh). Fैamilie ber Isemaftumazert.

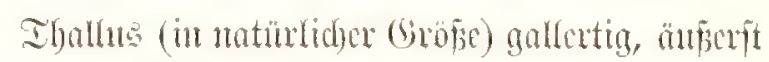
from verzueigt, einem Bblumenfohlfopf ähntid); bie

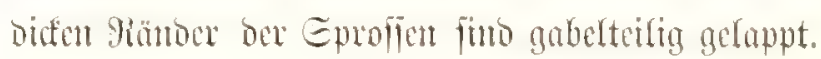

Fig. 10. Solieria chordalis (Agardh).

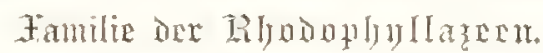

Eutrederer Edynitt burt) cine Frutdotblafe (Cystocarpium), ftarf nergrajert. Dben ift in ber 9litte Der cunge Sintal fidethor, ourd den bie Epo= rent ans ber Eporenfindst austreten.

Jig. 11. Binderella neglecta (Schmitz). familie ine Grliotazen.

Eufred)ter Eduntt bund) cime Fundotblaje (Cystocarpium), ftarf vergrofipert. Im Grumbe ber

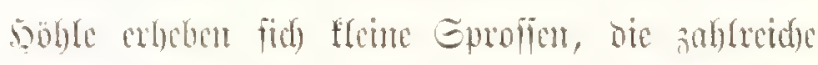

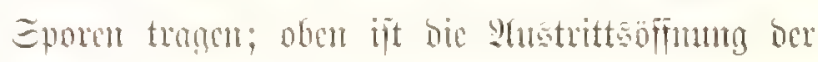
Eprortu. 


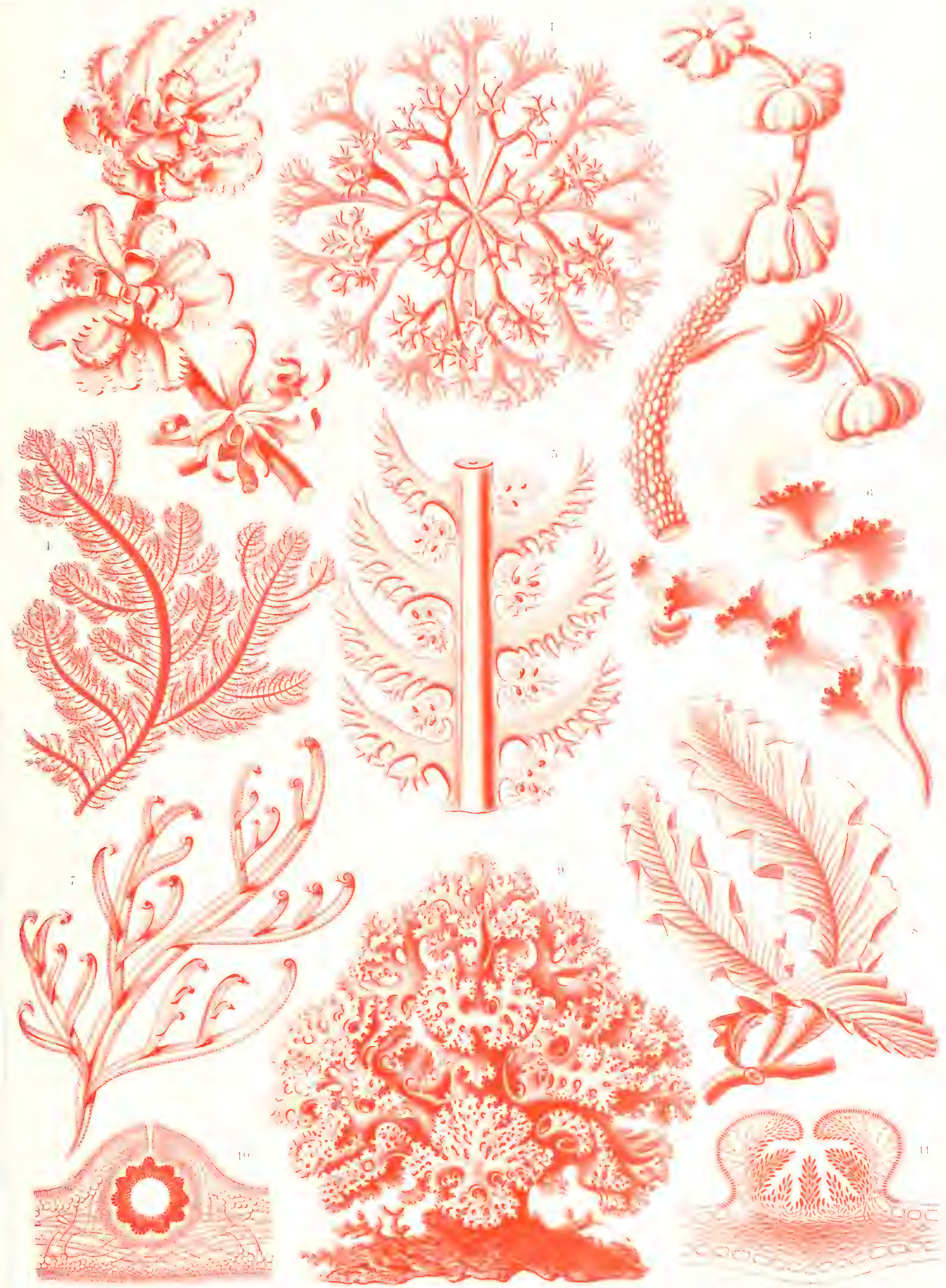

Florideae. - Ziofaliger. 

Tafel 66. - Epeira.

\section{Arachnida. $\mathfrak{g}$ printutitive.}

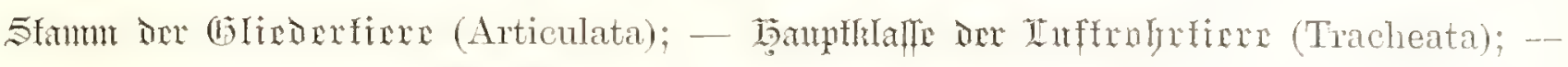
Lalle oev Spimenfiexe (Arachnida).

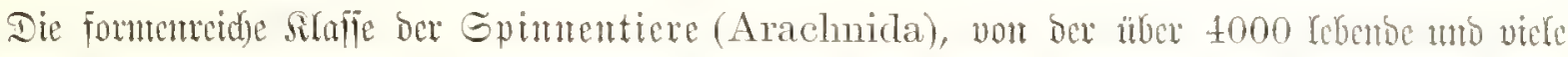

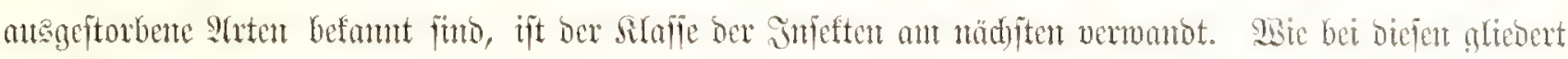

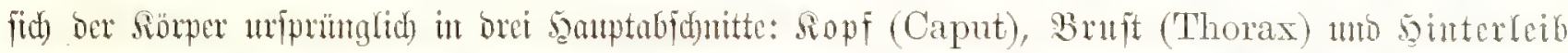

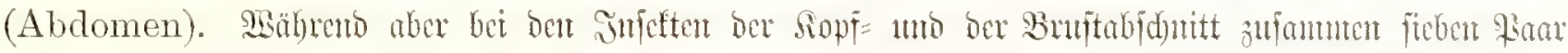

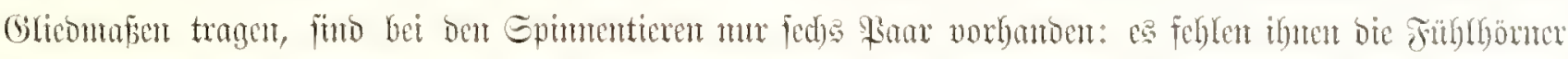

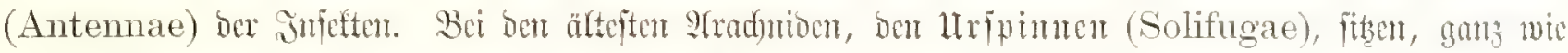

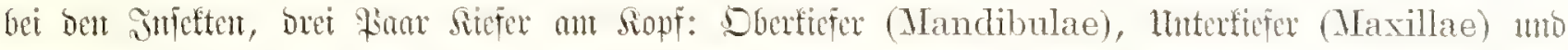

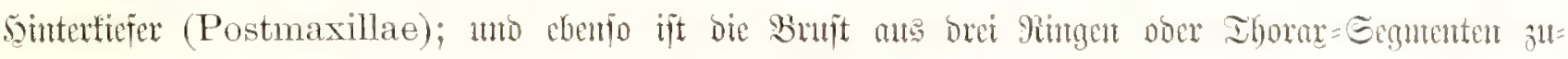

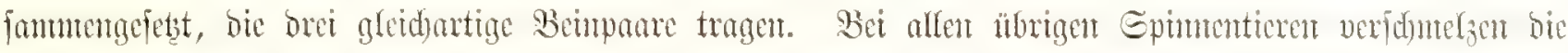

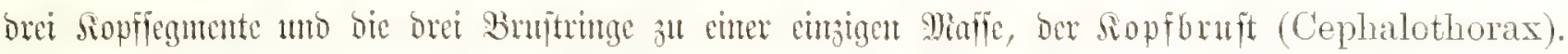

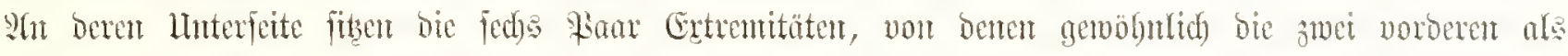

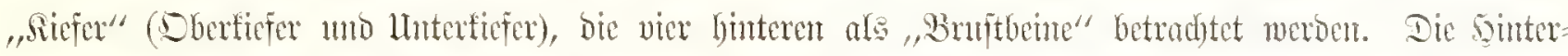

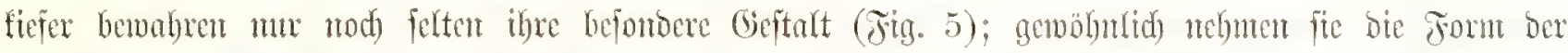

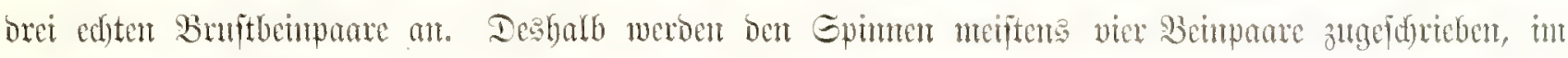

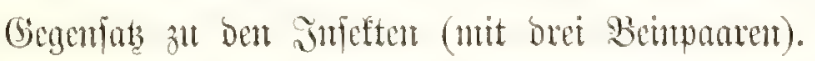

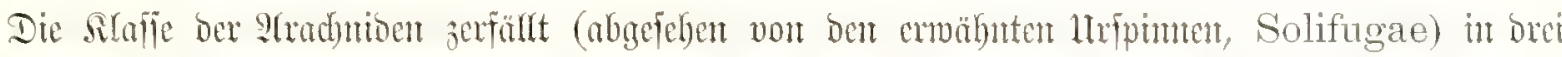

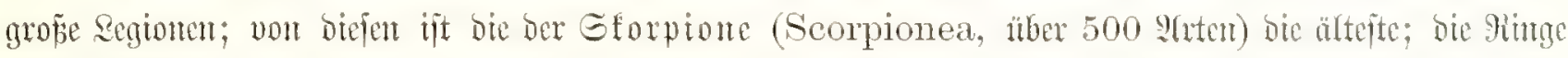

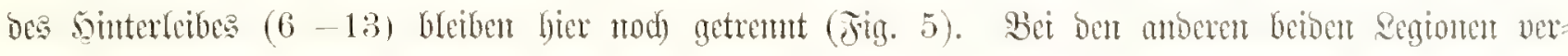

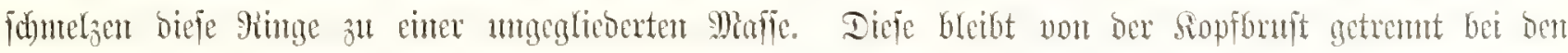

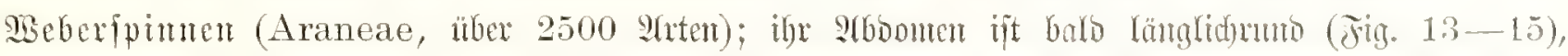

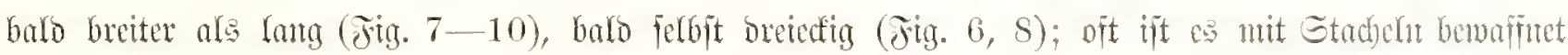

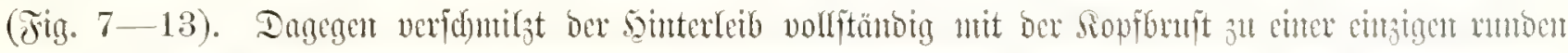

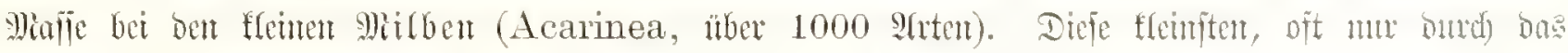

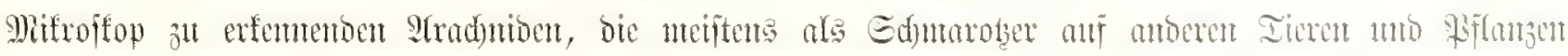

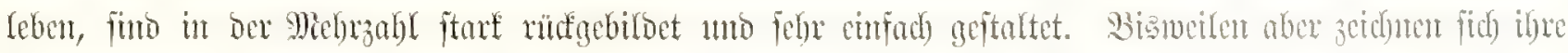

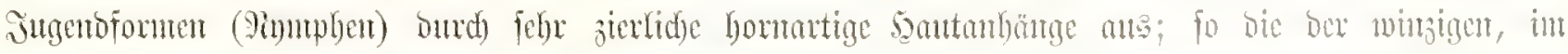
Mroofe lebenton Mronmirben (Oribatidae, Fig. 1-4). 
Tign. 1. Teqeocranus hericius (Mthael).

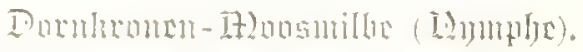

(E)mopa. E) nut vergrofient $(0,60 \mathrm{~mm}$ Imtg).

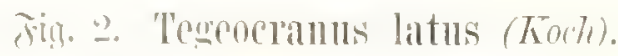

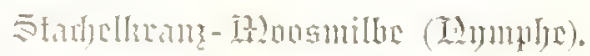

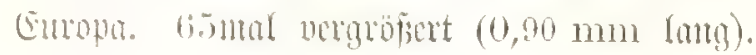

Sity. 3. Tregeocranus cepheiformis (Nicolet).

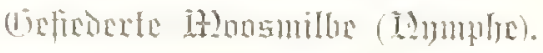

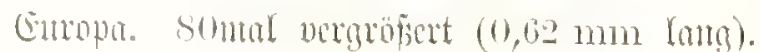

Jig. t. Leiosoma palmicinctum (Mechat).

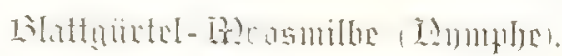

Emropa. Fonutal vergröfert $(1,0 \mathrm{~mm}$ Yang)

Jig. 5. Phrynus reniformis (olicie).

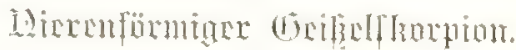

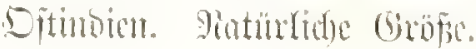

Ting. 6. Mrkys cordiformis atakkenaer).

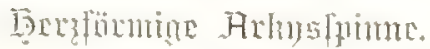

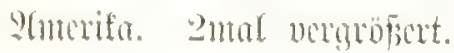

Jin 7. Gasteracantha eancriformis (Latreille).

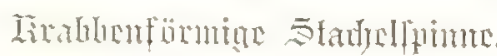

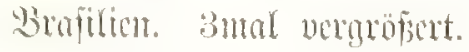

jig. ․ Gasteracantha acrosomoïles (Koch).

Drrietrine stadjelfonme.

Miabagastax. 5mal vergrobert.

Jig. 9. Gasteracantha geminata (Koch).

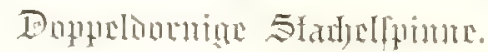

Dftimoien. Butal vergrofipert.

Fin. 10. Gasteracantha arcuata (Koch).

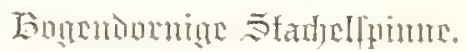

Saba. 2ntal vecuröipert.

Jig. 11. Acrosoma hexacanthum (Hathn).

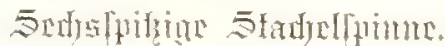

Brafitien. tmal neraropiert.

Ting. 12. Acrosoma spinosmm (Koch).

Didronming stadjellpinur.

Eltomerifa. 2mal verorobisert.

Jitu. 13. Acrosoma bifurcatum (Huhn).

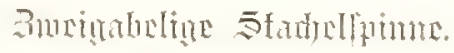

Brafifion. tutal vergroficert.

Jig. 1t. 0xyopes variegatus (Hohm).

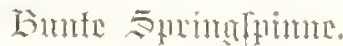

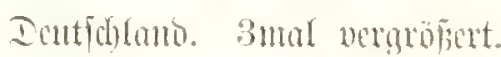

Fing. 15. Epeila diadema (Limne').

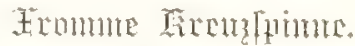

Dentidalano. 3mal vergropert. 


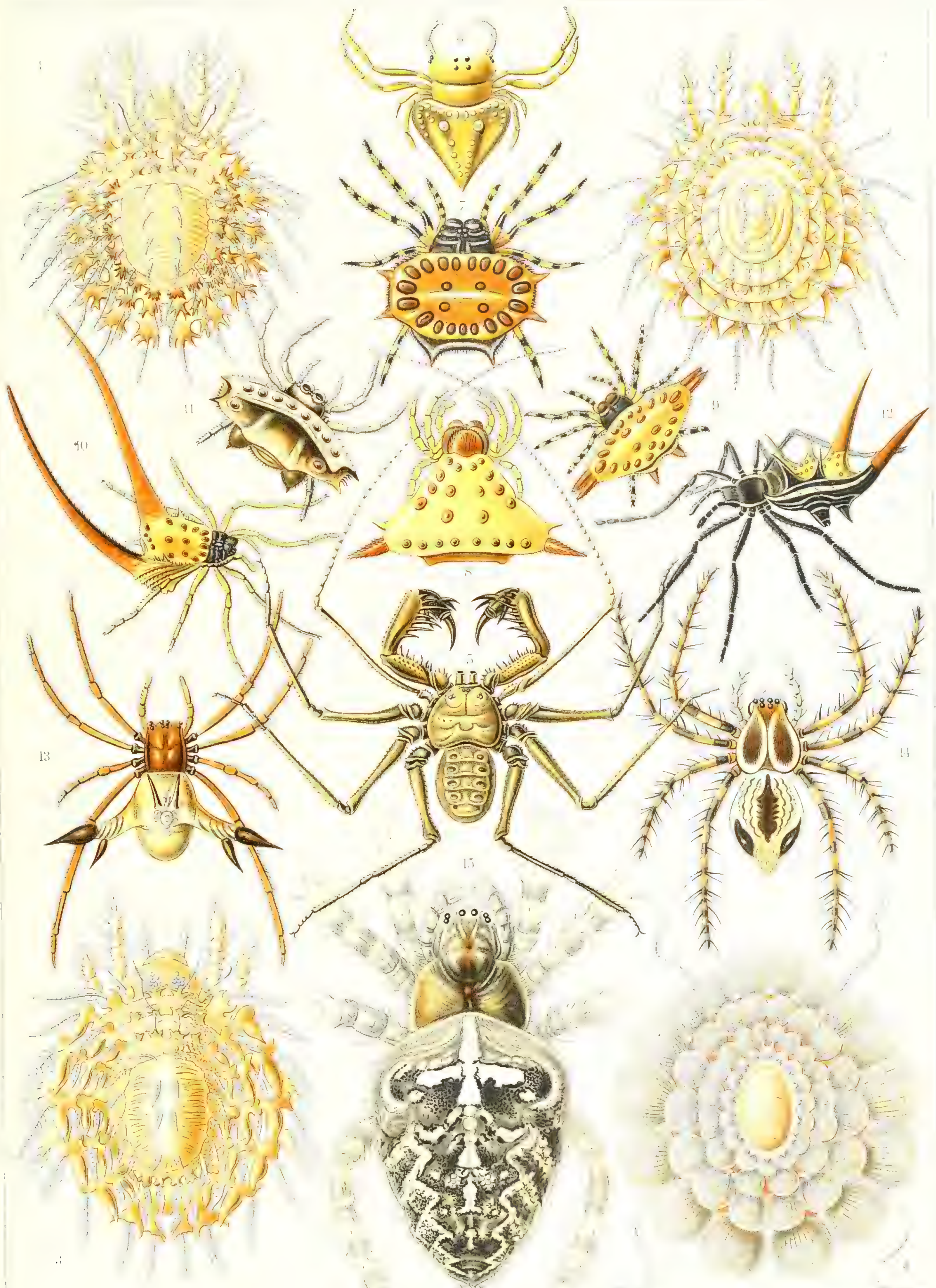

Arachnida. - Spinmentione. 



\section{Chiroptera. flemertime.}

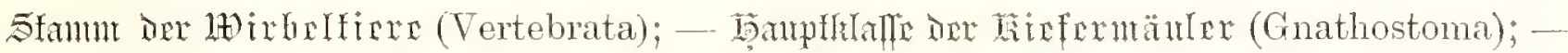

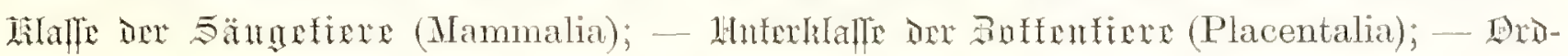
mun Dre Iromefire (Chiroptera).

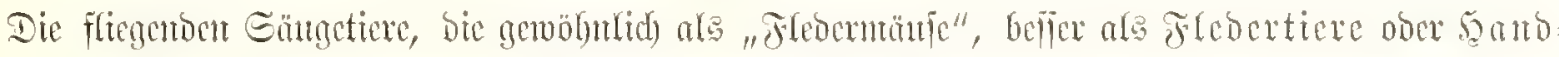

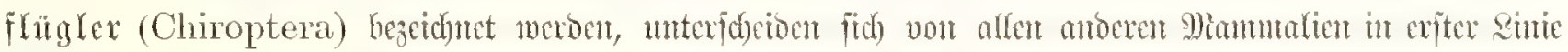

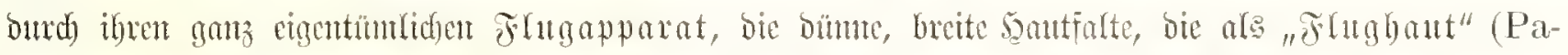

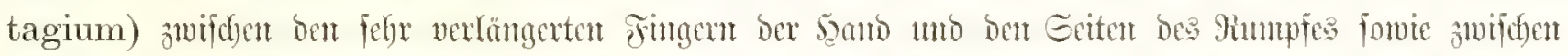

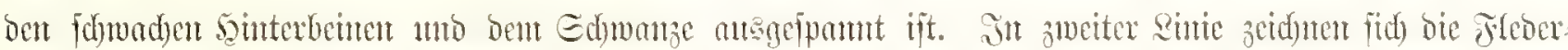

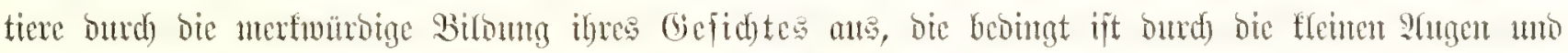

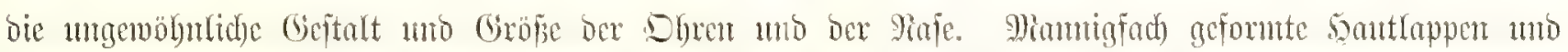

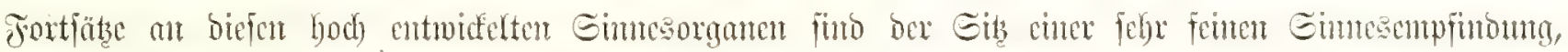

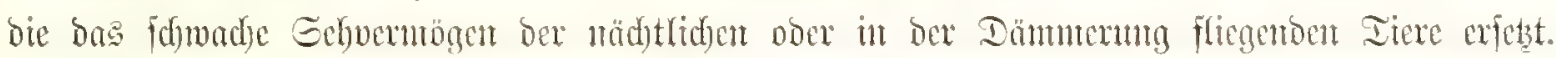

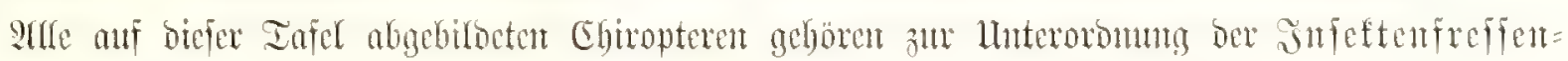

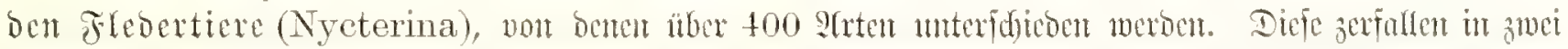

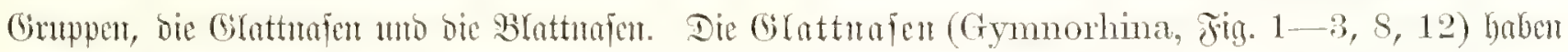

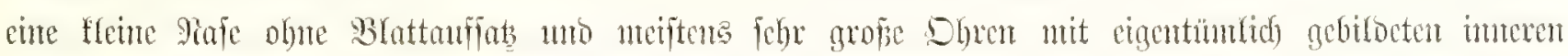

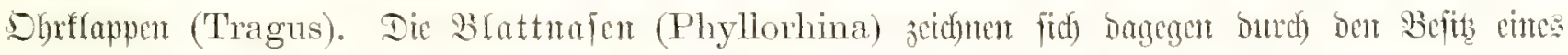

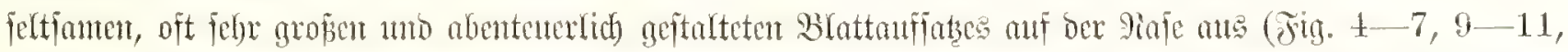

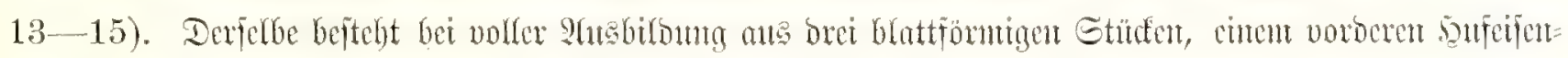

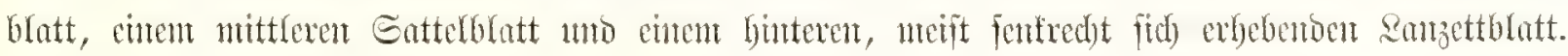

\section{Fig. 1, 2. Plecotus anritus (Geoffroy).}

Die Dhen fino febre grofi, fajt fo lang wie Der Siumpf, büunhäntig. Dic Frgum 1 ift etwas ver= fleitert. In Figut 2 ift ber Sopf berfellen atut

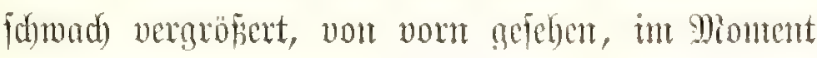

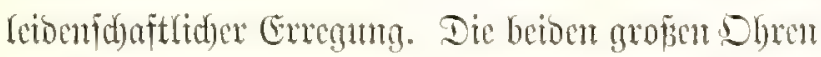
fino atmas madh ber Ecite gelegt uno gegen bie Epitze gefaltet. Die immere Shrflappe ijt Lamzettförntion,

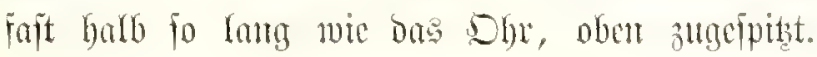

Fin. 3. Nyctopliilus australis (Peters).

Die riejengropien Dhrent funt länger unto breiter als Der Sopf, bümbäntig. Die imnere Drnefoppe
(Tragus) ift cint Drittel fo lang wie bas Dhr, oben abgeruntet, unten ant Bande nit voripringent=

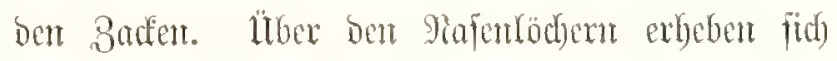
Gintereinanoer zowe fleciue, quergejtellte Blätter.

Fig. 4. Hegaderma trifolimm (Geoffroyy).

Die aropen Shren fitro ant Sumetranto in der

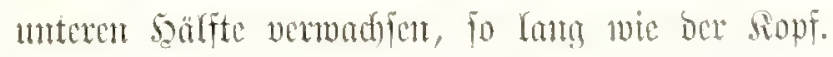
Die imcre Dhrffoppe (Tragus) ijt ajmet Drittel

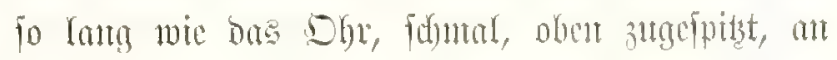

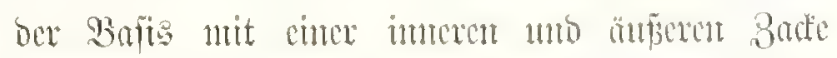

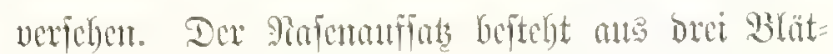

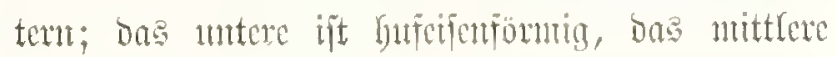
(Gorisontale) mo das obere (vertifale) Geräroutig. 
Fing. 5. Vampyrius auritus (Peters).

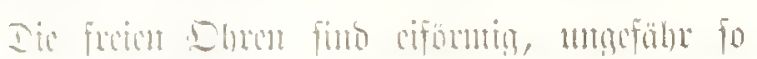

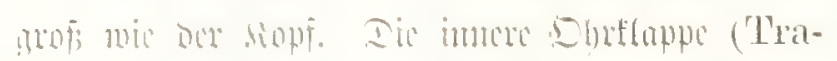

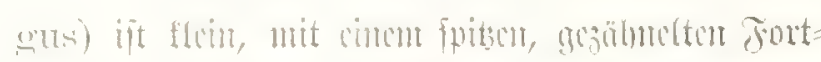

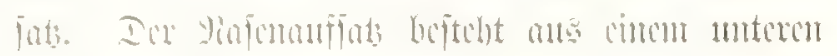

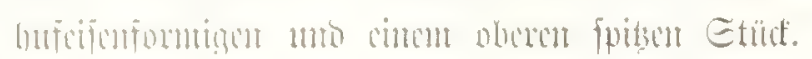

\section{Fing. 15, 7. Lonchordhina aurita (Tomes).}

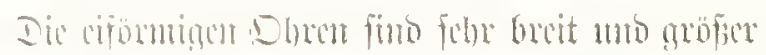
ats ber siopr. Dic immere Dhetloppe (Tragus)

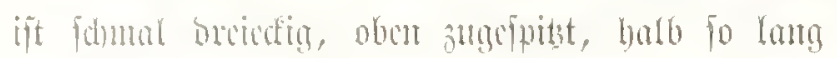

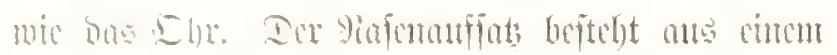

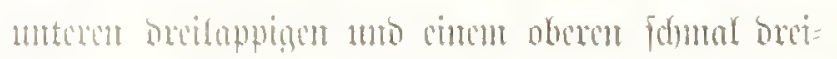

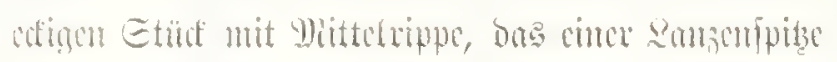

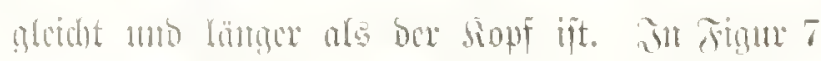
ift ber sionf balb wou bistem, halb vou oce limfor Esite ardent

\section{Jig. s. Taltalus stramineus (Gray).}

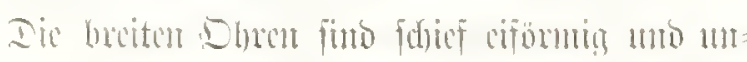

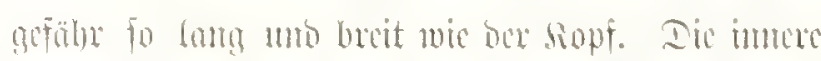
Ebrflope ('Tragus) ijt trein, faft harbmonofor:

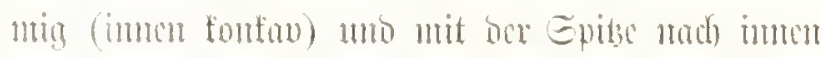

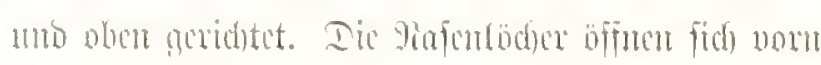

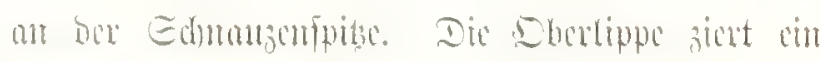
breitur Edmurfort.

\section{Jig. !. Wormopss blainvillei (Peters).}

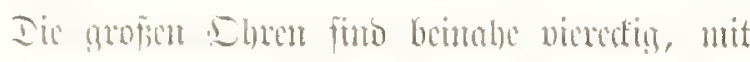

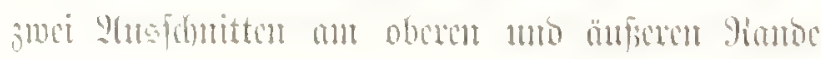

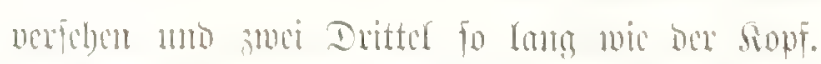

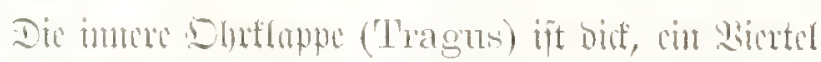

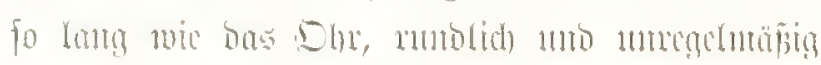

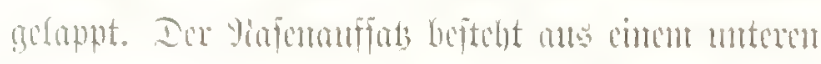

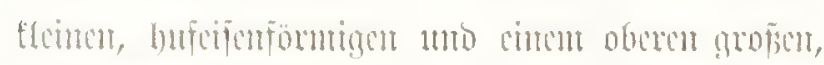

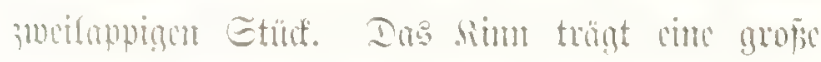

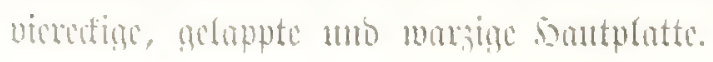

Fitu. 10. Anthops oruatus (Thomess).

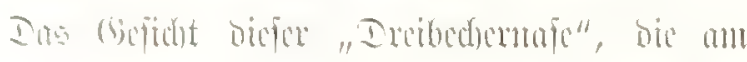

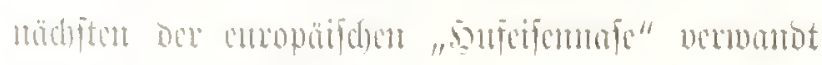

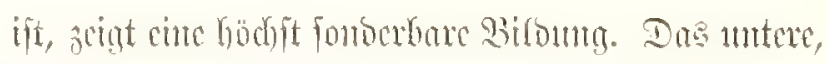

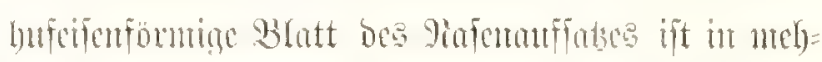

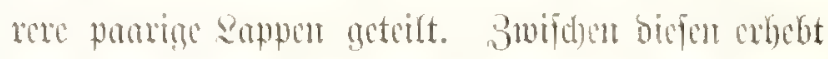

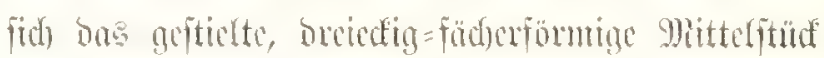
Des oberen vertifulen Bblattes, bas oben ore paralled

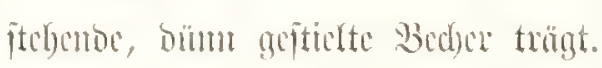

\section{Sig. 11. Phyllostoma hastatum (Pullas).}

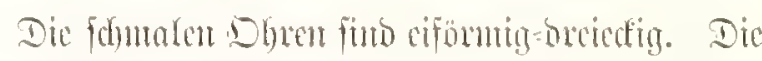

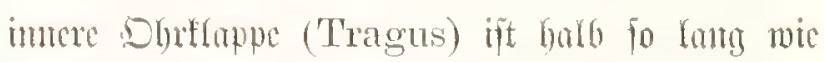

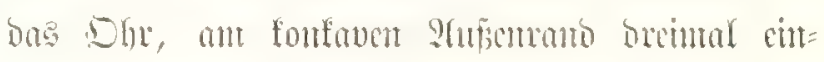

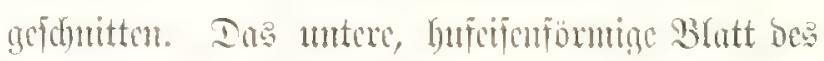

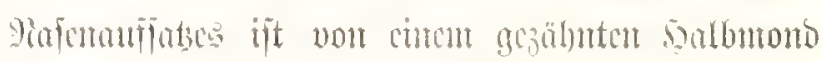

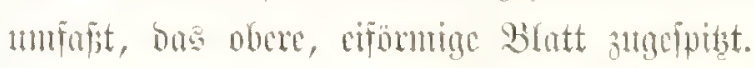

\section{Fin. 12. Furipterus coepuleseens (Tomes).}

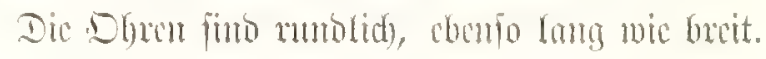

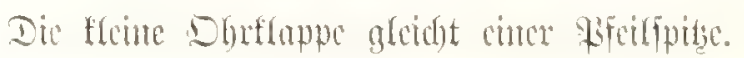

\section{Jig. 13. Rhinolophus equinus (Sctreber).}

Dic orcteffigen Dhren fimo quergeripht und am

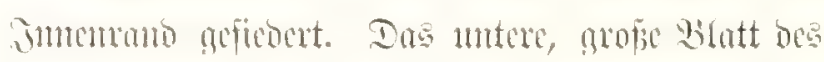

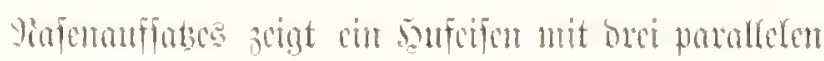
Wograpanen; bas obere, fleme Blatt bilbet cin

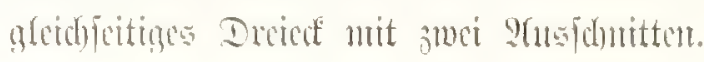

\section{Fig. 1t. Centurio flarigularis (Peters).}

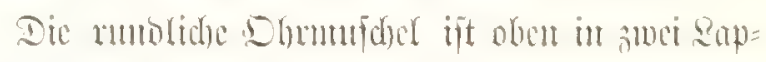
pen geteilt, ebenfo wie unten bie fleme Dhrfloppe

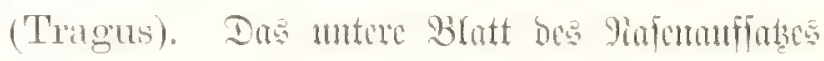

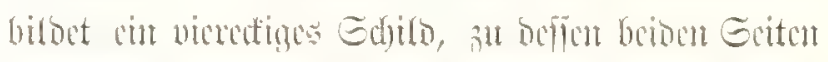

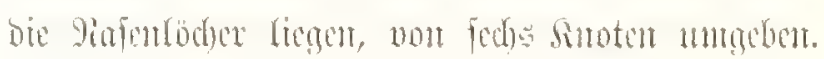
Das obere shatt bifoct cincen storiprumg mit bre

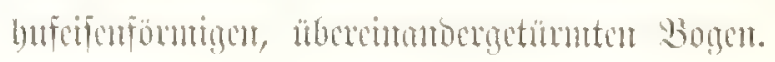

\section{Fig. 15. Vammprous spectrum (Geoffroy).}

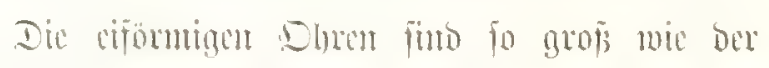

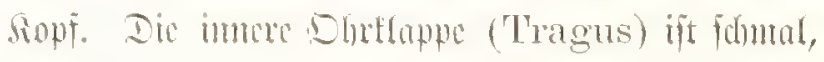

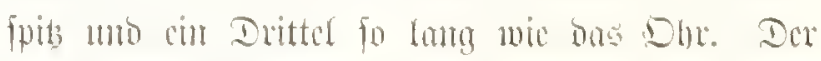

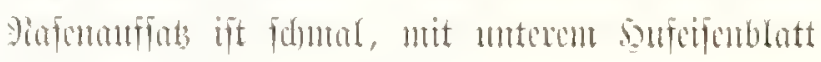

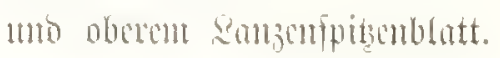

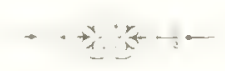



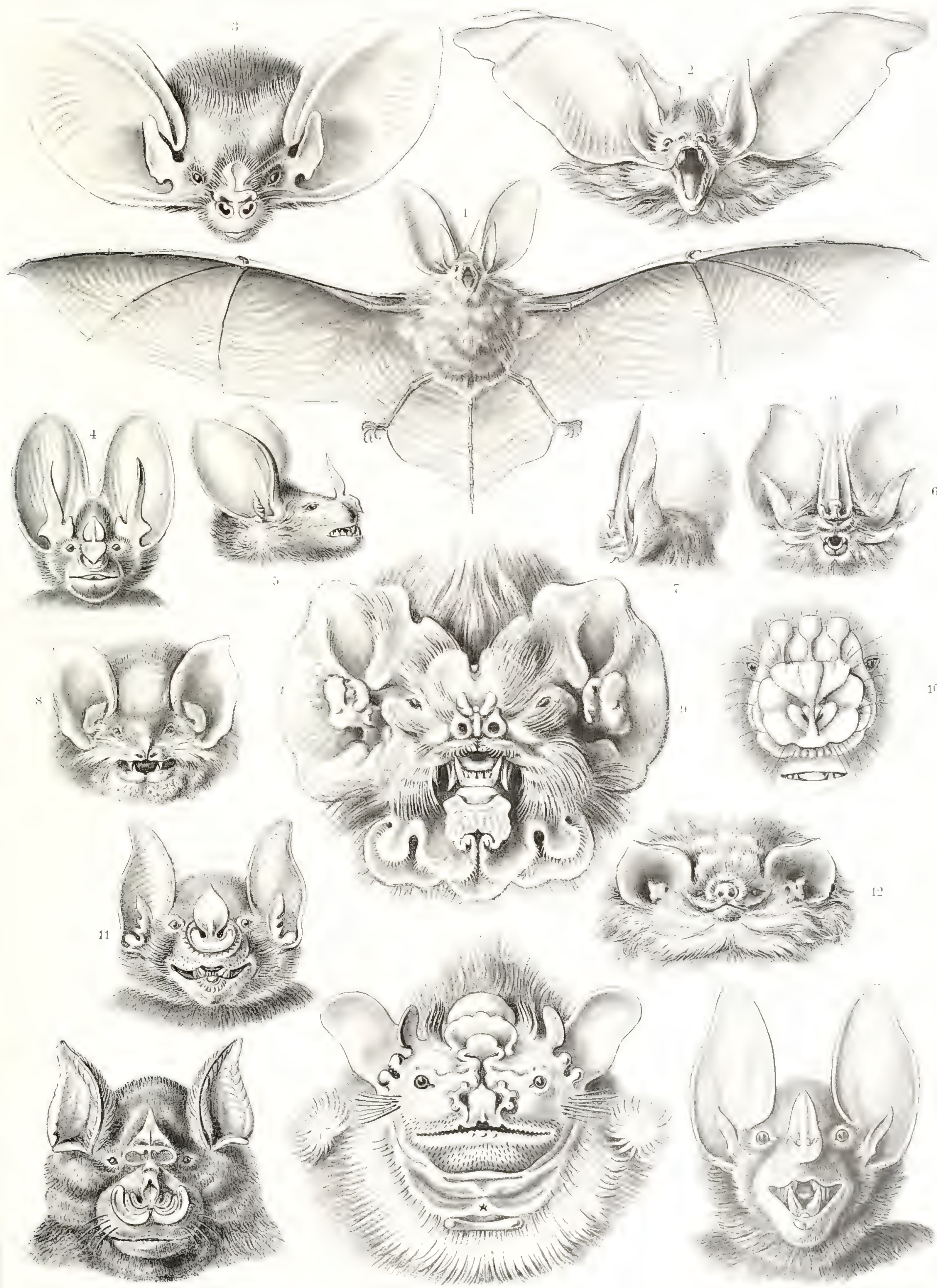

Chiroptera. - Sileortiere. 



\section{Patrachia. Frotrotre.}

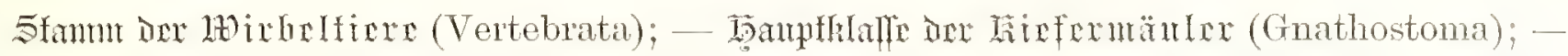

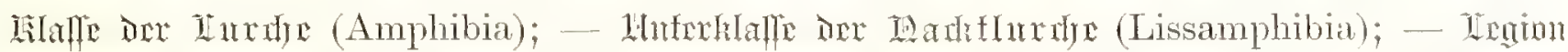

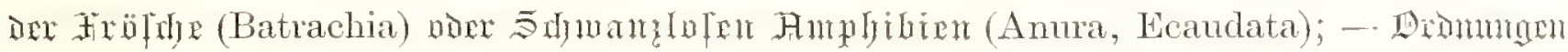

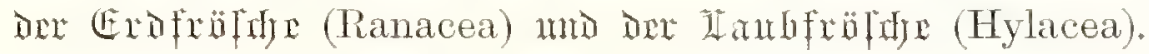

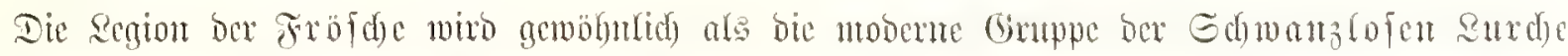

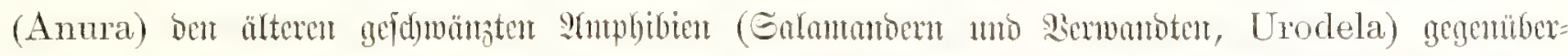

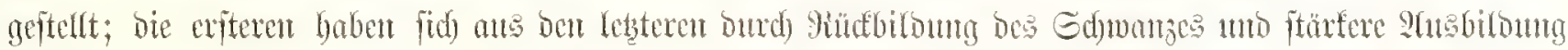

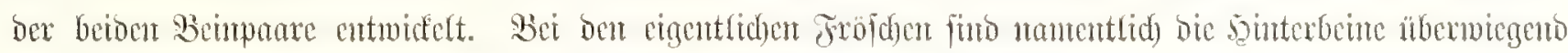

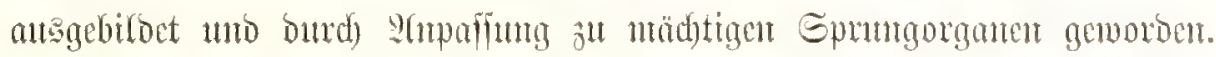

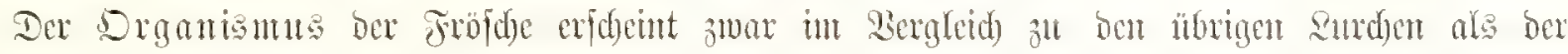

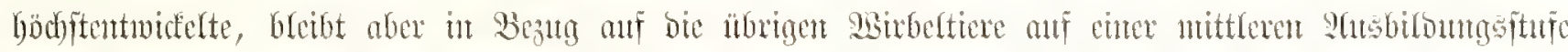

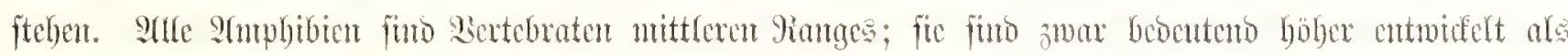

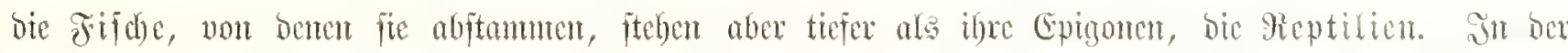

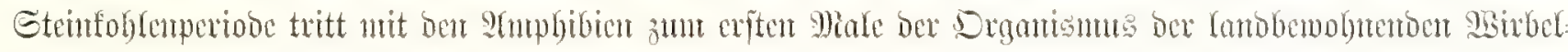

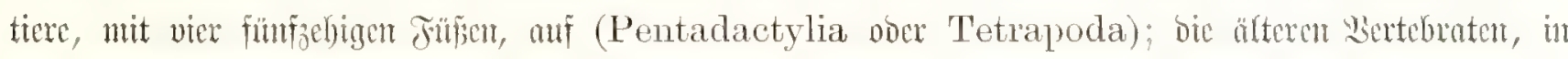

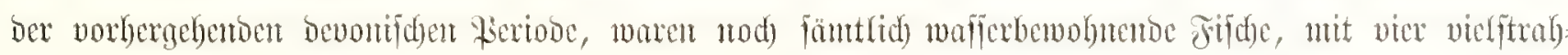

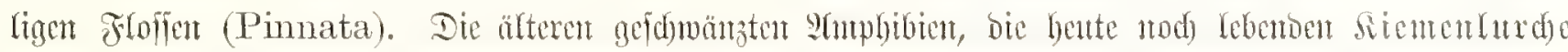

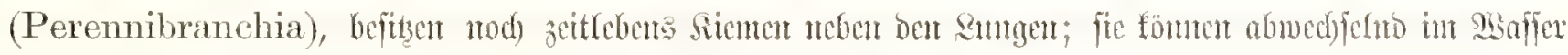
burd) bie Sitemen unto auf bent ambe burd bie sungent atment.

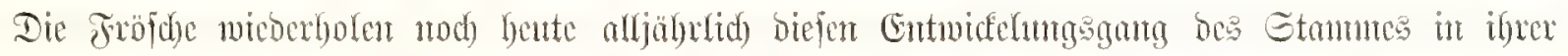

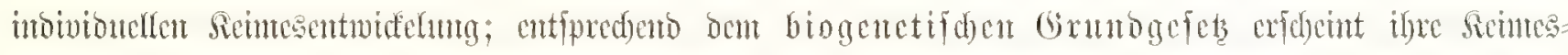

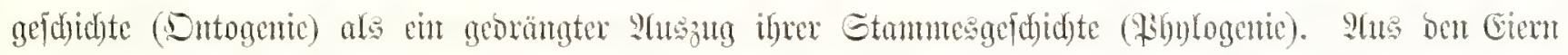

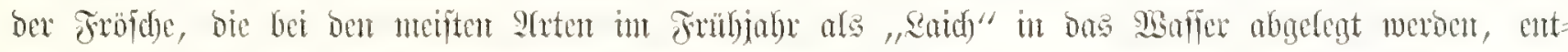

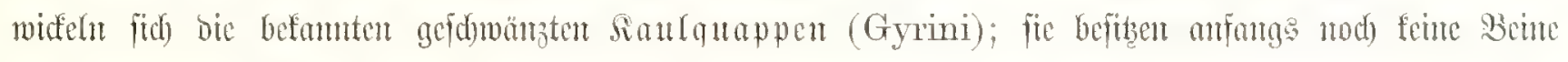

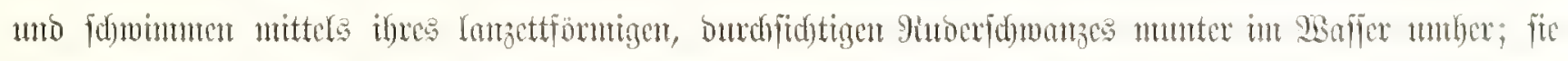

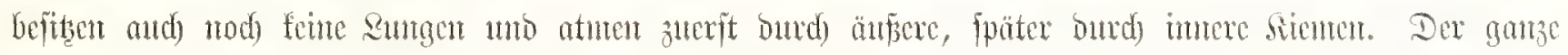

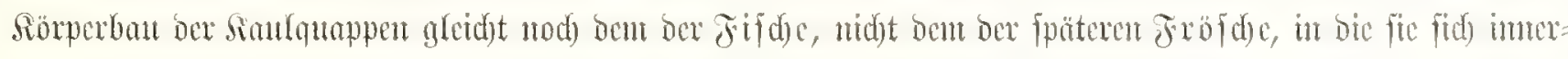

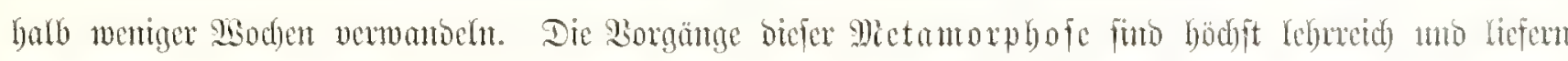

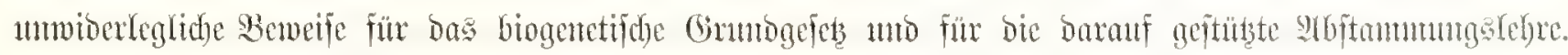

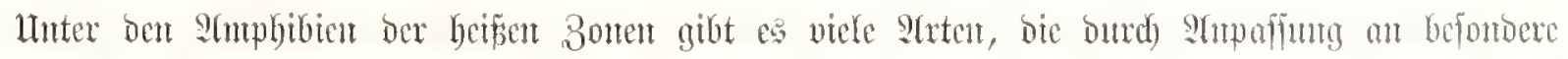

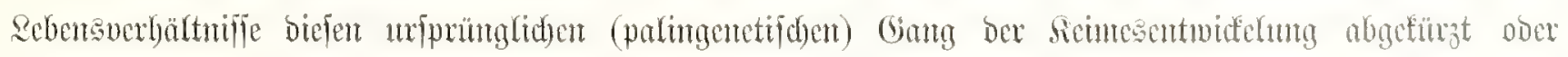

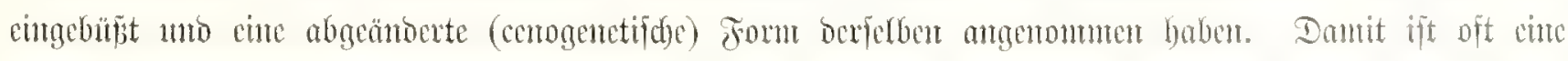

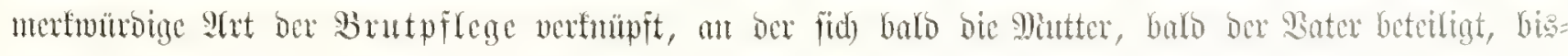

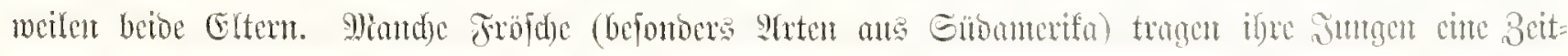

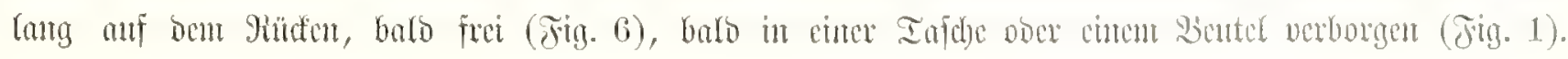


Ting. 1. Totodelphys ovifera (Itimland).

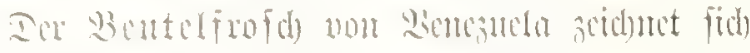

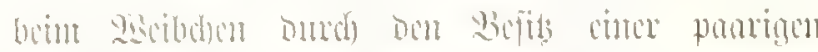

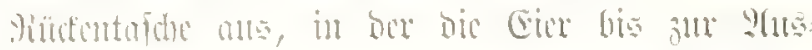

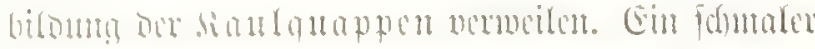

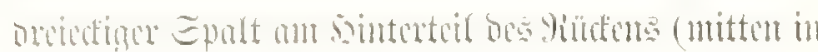

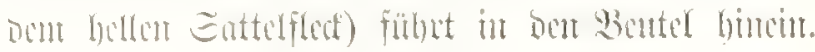

\section{Tirg. ‥ Ilyla merillionalis (Boulenger).}

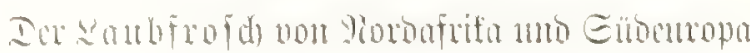

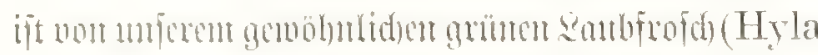

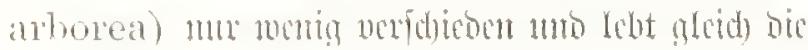
Font anf

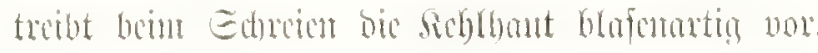

Trig. :3. Hyla tubereulosa (Boulenger).

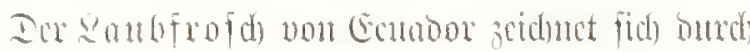

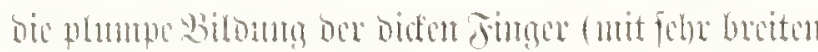

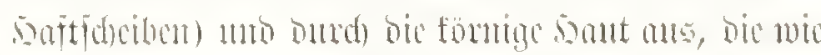
bet ben siroten bidnt mit breifigen Jig. t. Aniphigmathodon (iïntheri (Boutenger).

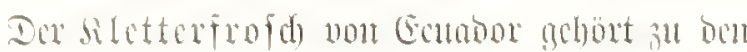

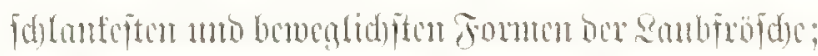

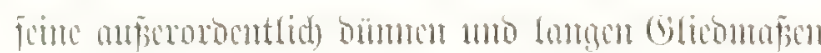

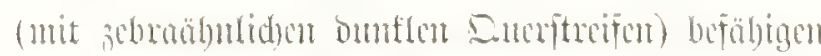

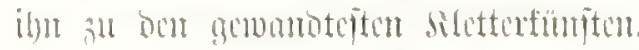

Fin. 5. Lihatcophorus pardalis (Wellece).

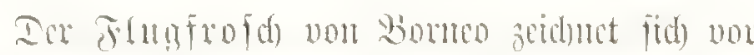

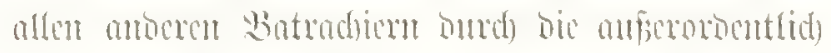

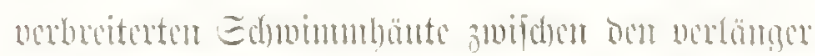

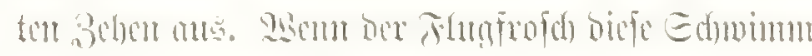

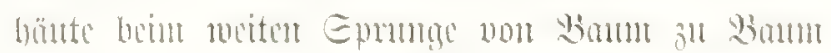

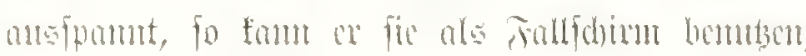
(ii)mlid) mic bie Fingorad)en (1)raconellus) mater

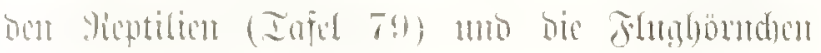
(Iteromys) unter ben Yiandicuen.

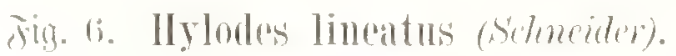

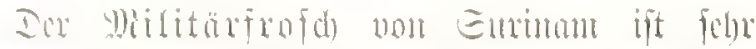

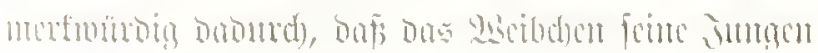

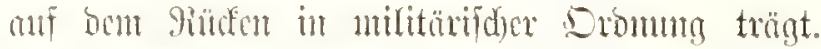

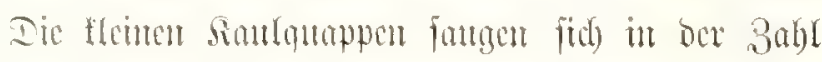
won 12 bis 20 mit ibren Mitmojangnäpfen an zowei

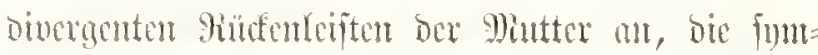

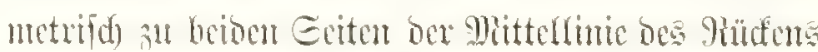

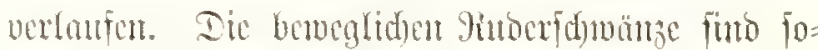
wohl redote als and linfs mad) aufien gerichtet.

\section{Jig. 7. Limmodytes erythraeus (Duméril).}

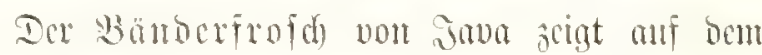

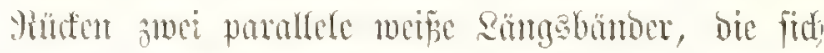

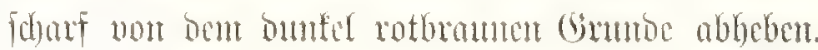
Dex fpringentoe saubfrofd i get gerabe in Begriff, mittels ber vorgeitulpten zweifpaltigen 3unge cim Jinfett zut fangen.

\section{Fing. S. Ceratobatrachus Gïntheri (Boulenger).}

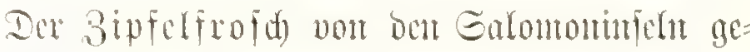

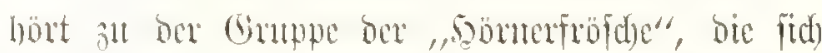

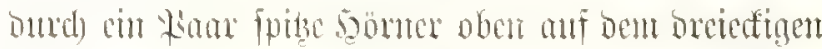

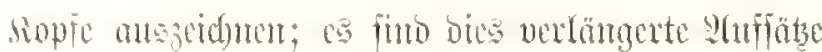
Dex oberent angenlioes. Dic bunte Fäbung ano

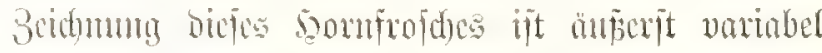
unio oft ber lumgebung muepapt.

\section{Tin. 9. Breviceps mossambicus (Peters).}

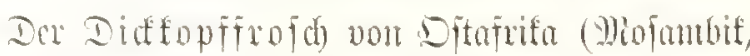
Emmbefi) weidst in der Gejtalt des febr furzen umb bitur siopfers mfrfalleno von allen anberen

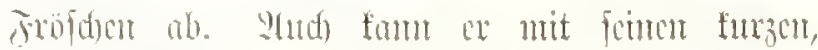

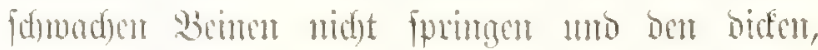

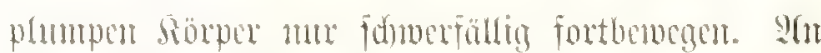

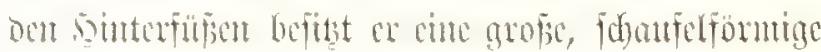

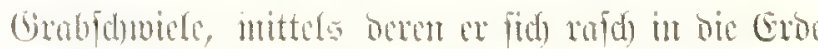

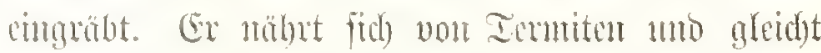

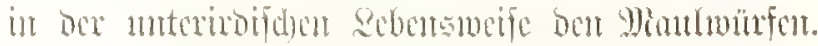

\section{Jig. 10. Rama pipiens (Lime).}

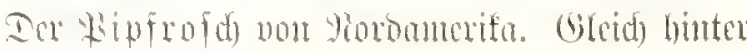

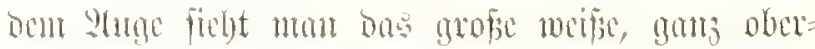
Fläd)(id) gutegent Iron!medfell. 


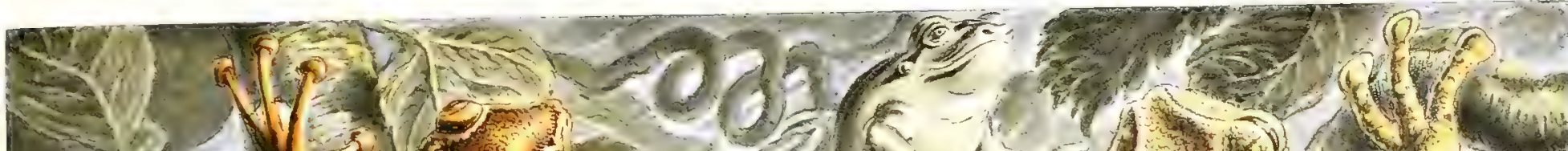

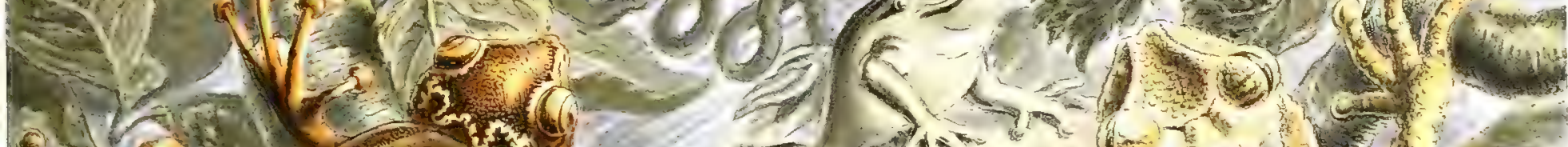

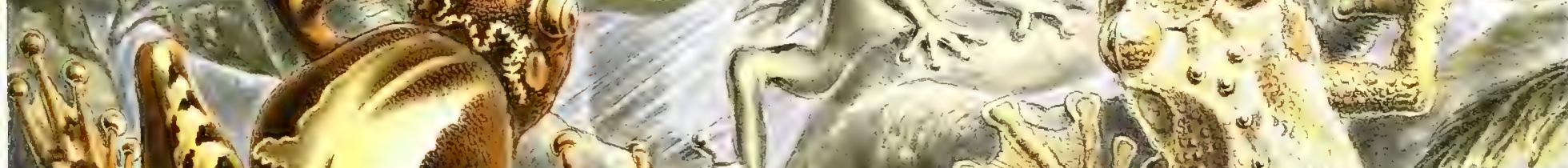

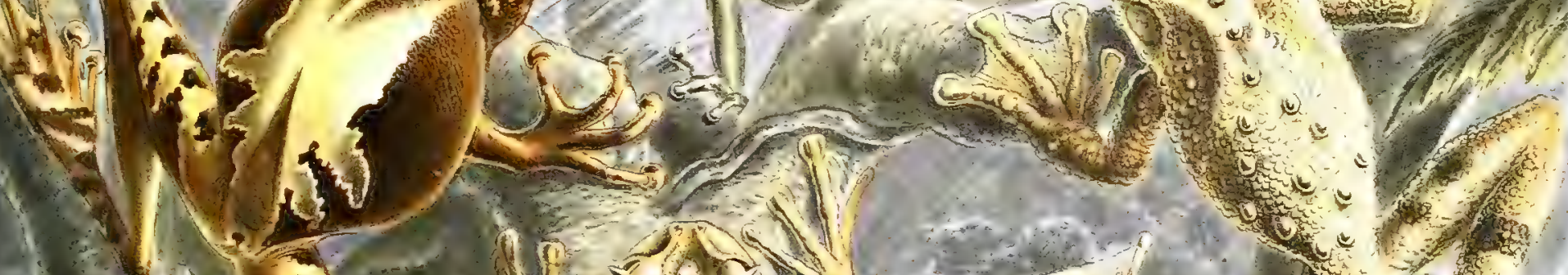

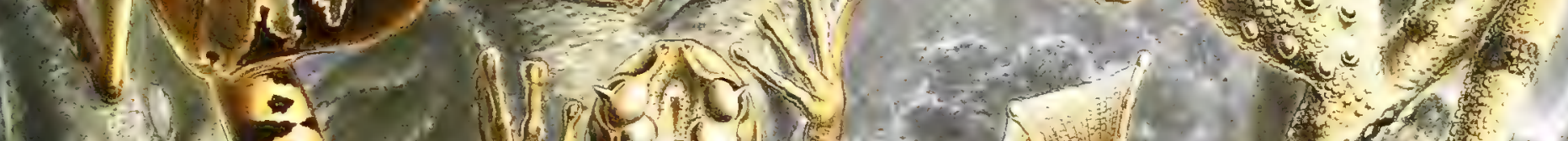
and

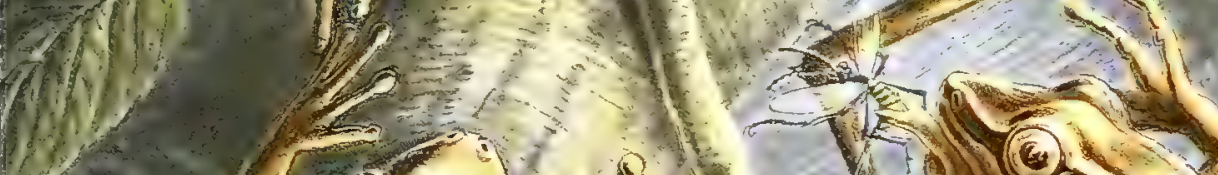
(p, $11 \rightarrow \rightarrow$ ces $4\left(1 / c^{2}\right.$ Batrachia. - Stotidio 



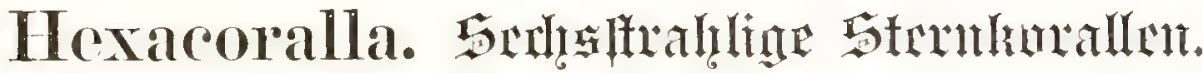

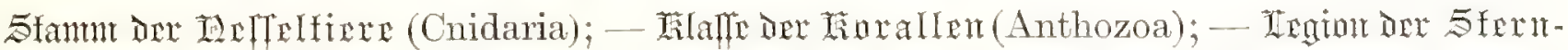

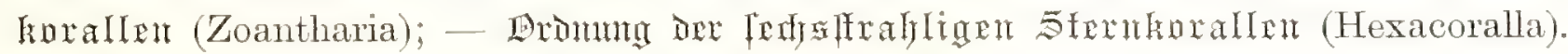

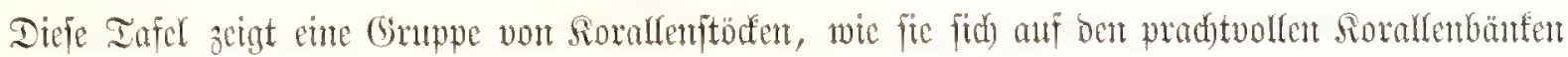

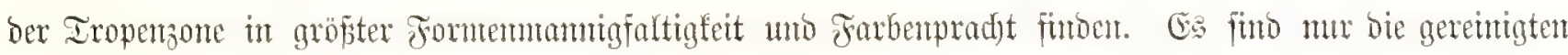

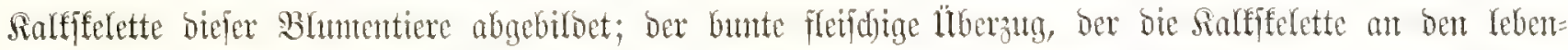

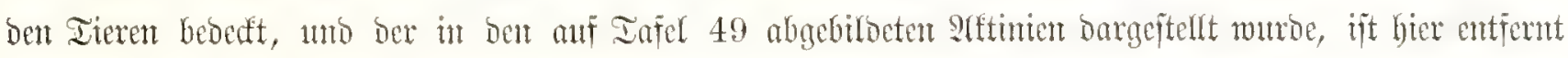

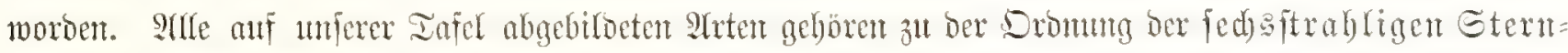
forallen (ebenjo wie bie auf Iafel 9 unb 49 bargeftellten 9 Inthozoen); fie ftanmen von ben indiffen

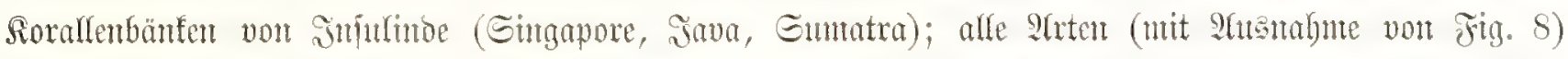

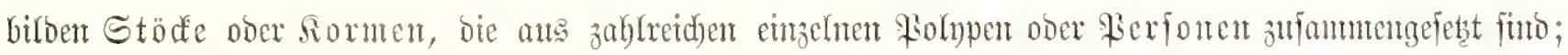

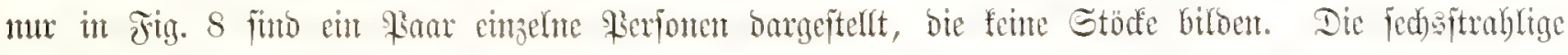

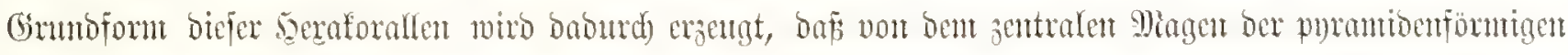

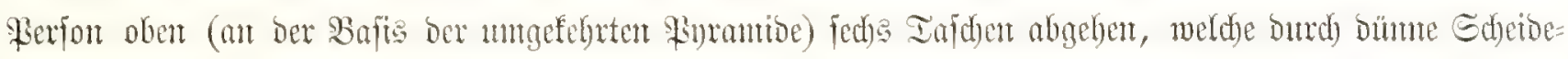

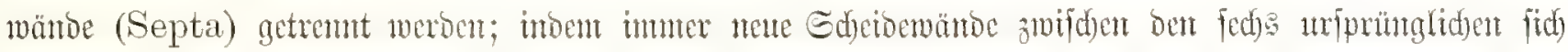

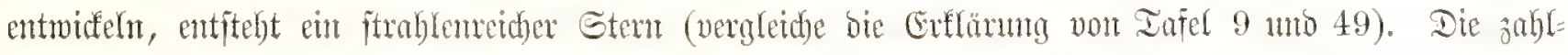

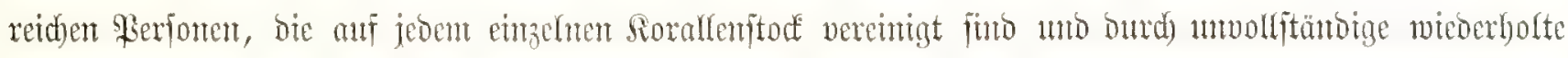

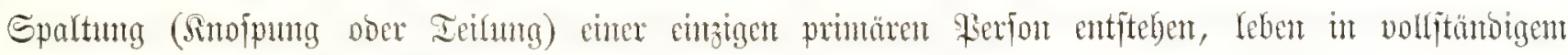

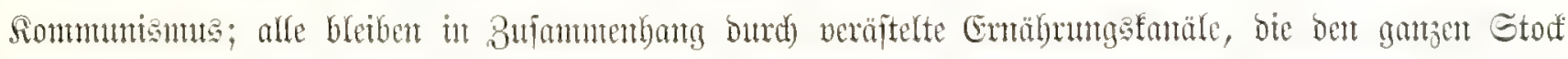

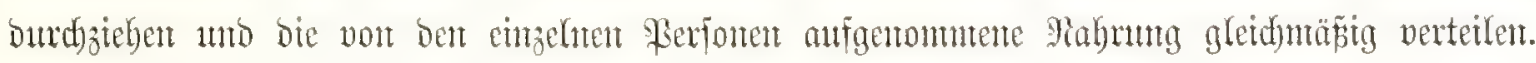

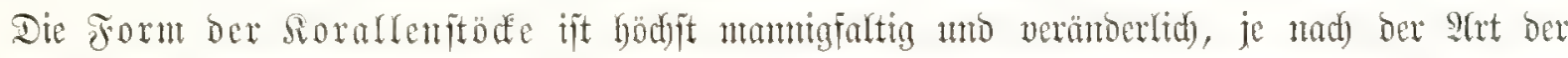

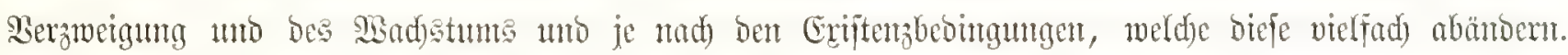

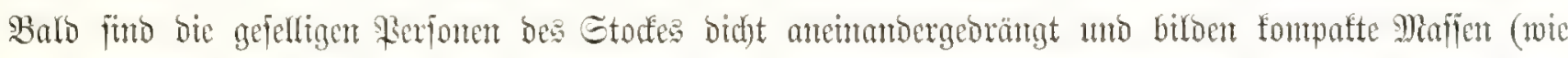

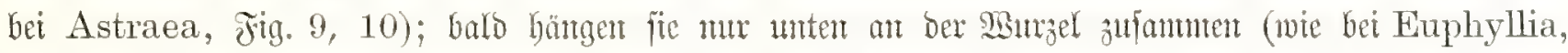

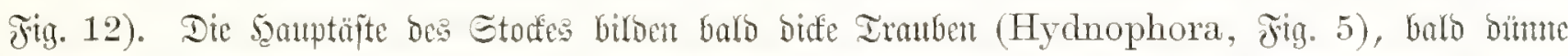
Blätter (Lophoseris, Fig. 3,4). Es gibt viefe Sioralfenarten, bet benent feim Stout bent antoeren

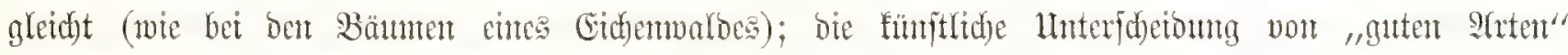

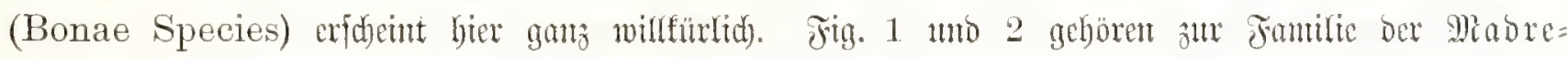

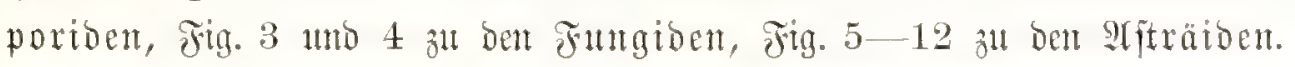

\section{Fig. 1. Turbinaria transformis (Haeckel).}

Dieje tene afrt ber formemetiben Gattung Turbinaria, von Singapore, gefört zu der Speziles= gruppe des hödjit variablen Gemes Turbinaria, bie als Crateriformis befdrieben wirb (Bedjer= form ber Sireifelforalle); untex den fedyzegn befaunten Irten biefes Gubgeme jteft ifo bie Turbinaria undata (Henry Bernard) an nädyften. Sie unter=

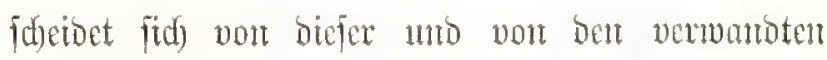

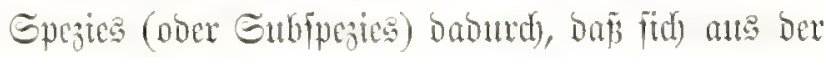

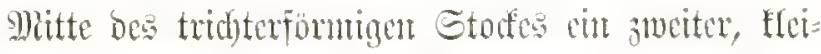

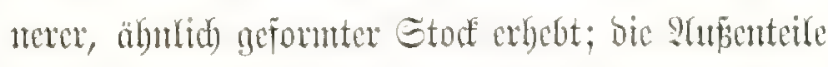
bes bünmwandigen Tridsters finc ftanf wellenförmitg

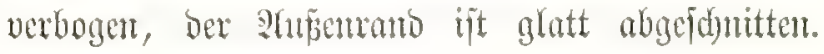


Fig. 2. Turbinaria rolusta (Heny Bemard).

Diefe ?ret vout Thubinaria gedourt foll ber Enciesgrump Foliata. Dic mellenfömig geboge-

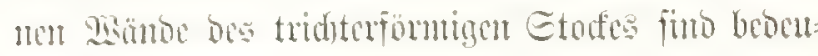

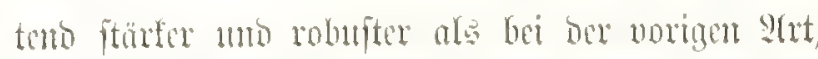

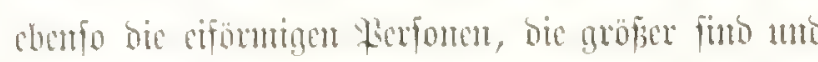

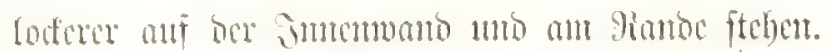

Fig. 3. Lophoseris frondifera (Milne-Eduards).

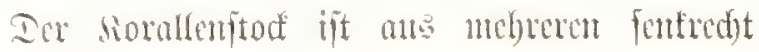

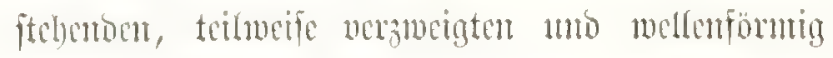
gethogenen Bhattem jufanmengefert; bier Fteben bie

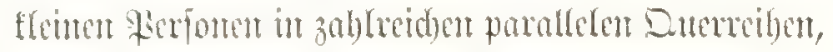
bie butrd wagered)te siänme getremut weroen.

Jign. t. Lophoseris divarieata (Nitne-Eduards).

Diefe S(rt ift ber vorbergeberoen nabe verwontot;

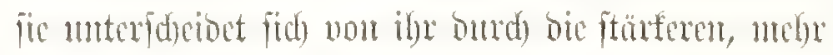
Imrrgelntäfig verbogenu nuto gewumbenen Blättex bes Sorallemitodes, befonbers aber burd anfitetgentoe iturte Mippen, bie won ber Bafte bes Gtofes ans ftrablen und bie hortzontalen siänune frenzen.

\section{jig. 5. Ilydnophora racemosa (Hacckel).}

Diefe neme Strt ber Gattung Hydnophora, vou

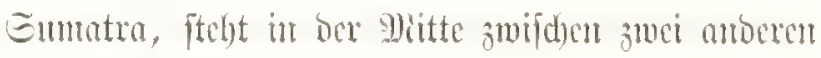
imbifuen Sertent berfelben: H. exesa uno H. lobata.

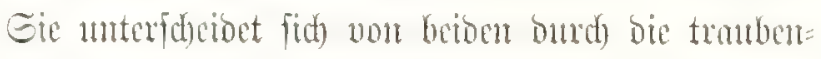

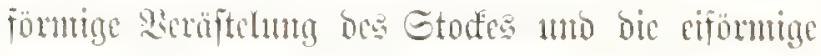
Geftalt ber Perfonen, die bidetgebrängt an Den folbesförming angejd)mollenen Enoäten füben.

\section{sig. 6. Tridacophyllia lactuca (Blaimille).}

Der Sinorallenftod, won bem hier bropi ber vierte Icil bargeftellt ift, bat bie Foum ente rumben Galat= fopfes, beffor bünte franfe Blätter vielfad) gemumben,

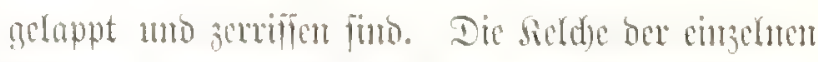

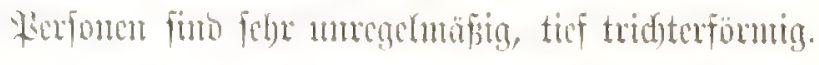

Fig. 7. Manicina crispata (Milne-Eduards).

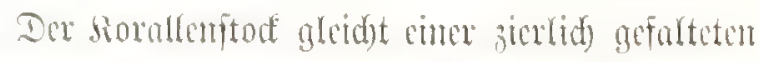

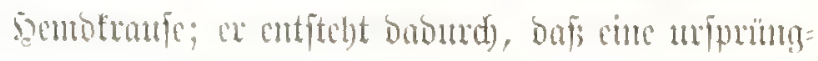

(idi) cinfadje, in ber Jutgento tridftectömige Pierfon (cin jogentamter Seldi) in bie sönge answädjit, tmo

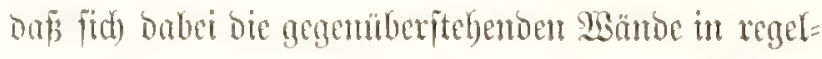
mâfigige Jalten legen; bic imere, vertiefte Fläd)e

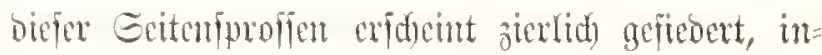
bem bie Septen jut betoen Eciten bes langgejogenten

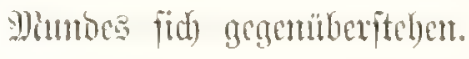

\section{Fig. S. Lithopliyllia lacera (Oken).}

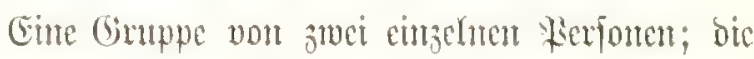
trid)terförmige obere Fläd)e, in beren verticter Mitte bie \$lumböfmung licgt, ift vont ber rabialen

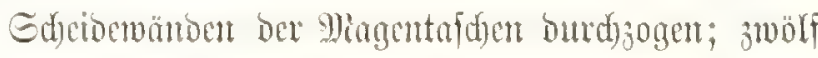

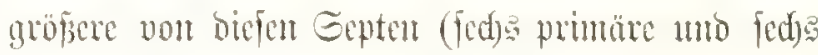
fefmoüre) füto ftärfer als bie librigen; ifre freien Stünoce finto ftarf gezadt.

\section{Fig. 4. Astraea magnifica (Dana).}

Der sorallemitorf (Cormus) ift in mebrere Störfden (Cormidia) geteilt, melde ontrd) tiefe

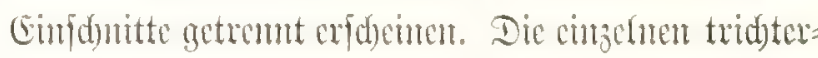

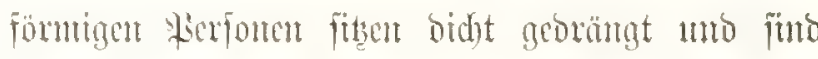
burd) gegenfeitigen Dut umregehmäpig vieledig.

\section{Jig. 10. Astraea expansa (Milne-Edwards).}

Diefe S(rt ijt ähutlid) ber vorigen gebant; aber ber Stout ift Flad) alf bem Bobert als̈gebreitet; bie poln:

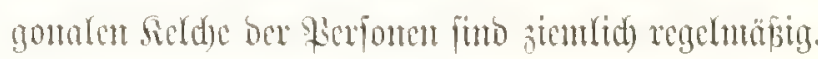

\section{Jivg. 11. Pterogyra laxa (Mlihe-Edwards).}

Der Etorf ijt ats wentigen (uriprünglid) jedfa)

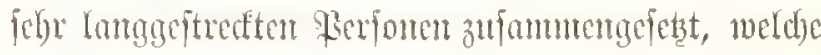
bie form fodmater gepieberter Blätter haben. Die

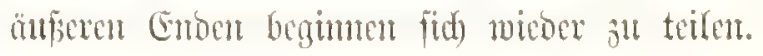

Jig. 12. Euphyllia striata (Milne-Edecards).

Der Siorallenitod, won bent bie Jigur mur ben britten Ieil jeight, ift im limriffe faft futgefig. Die

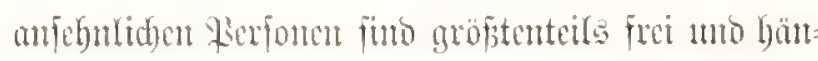

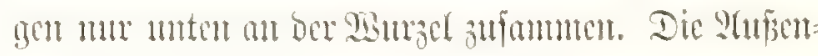

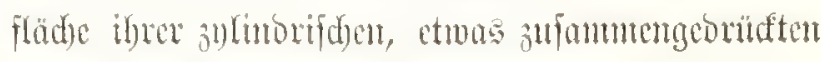
Siclde (oas Mianceblatt) iit Feimgerippt. 


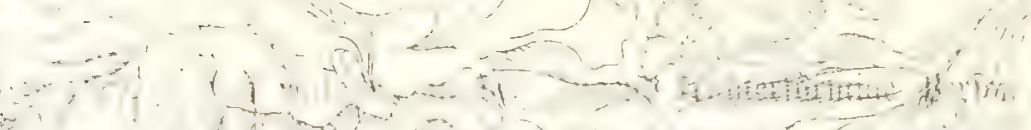
1 (1)

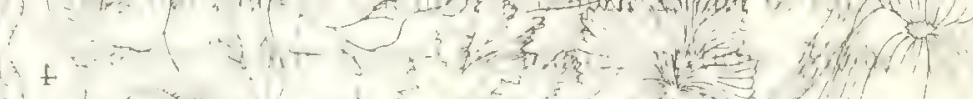

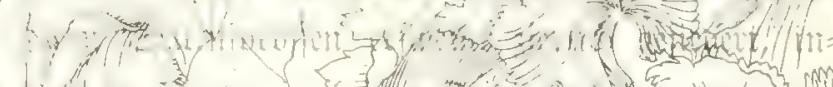
ivit $\quad$ is

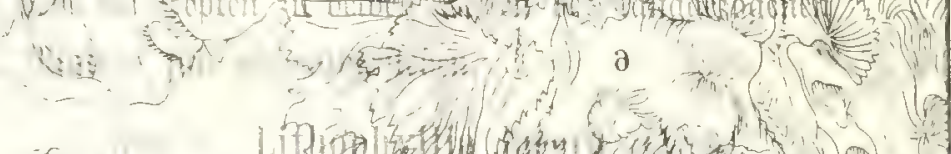

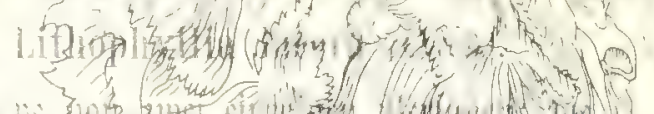
4 $\therefore$ ( m not

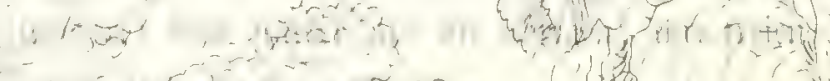
a

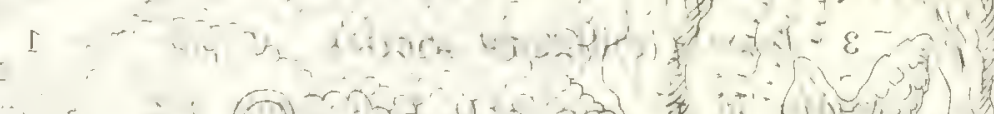
a

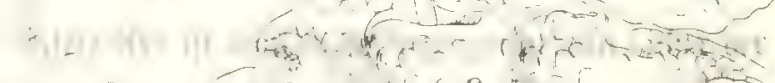

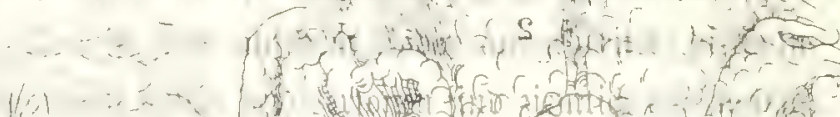

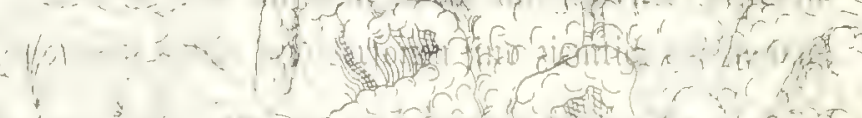

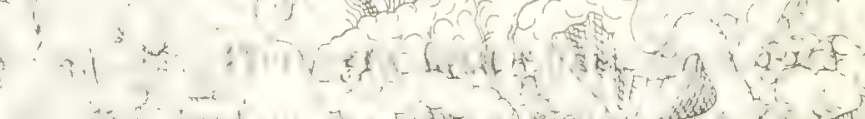

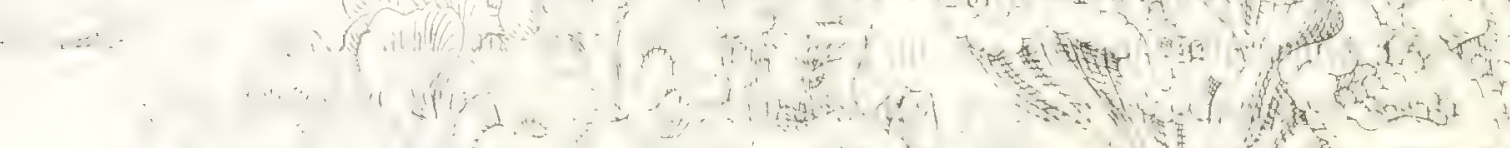
․

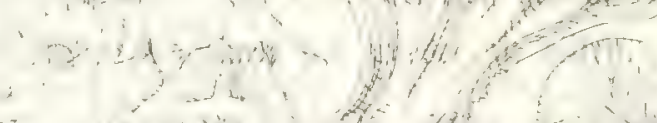
(1)

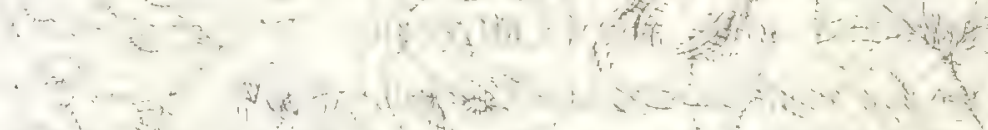

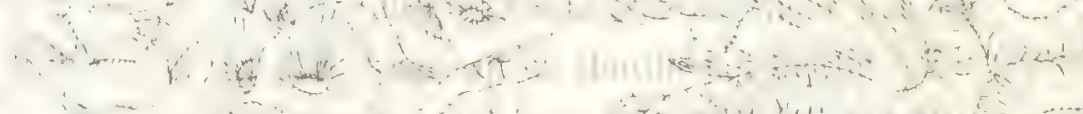

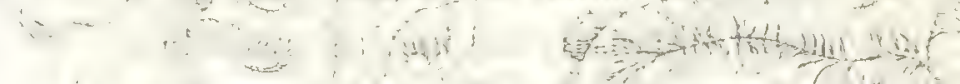
1. $1401+10$

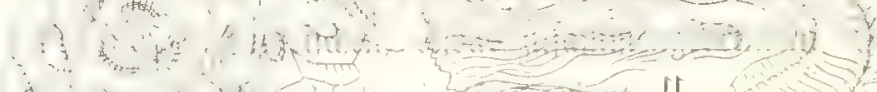
A $91 \mathrm{cos}$ 


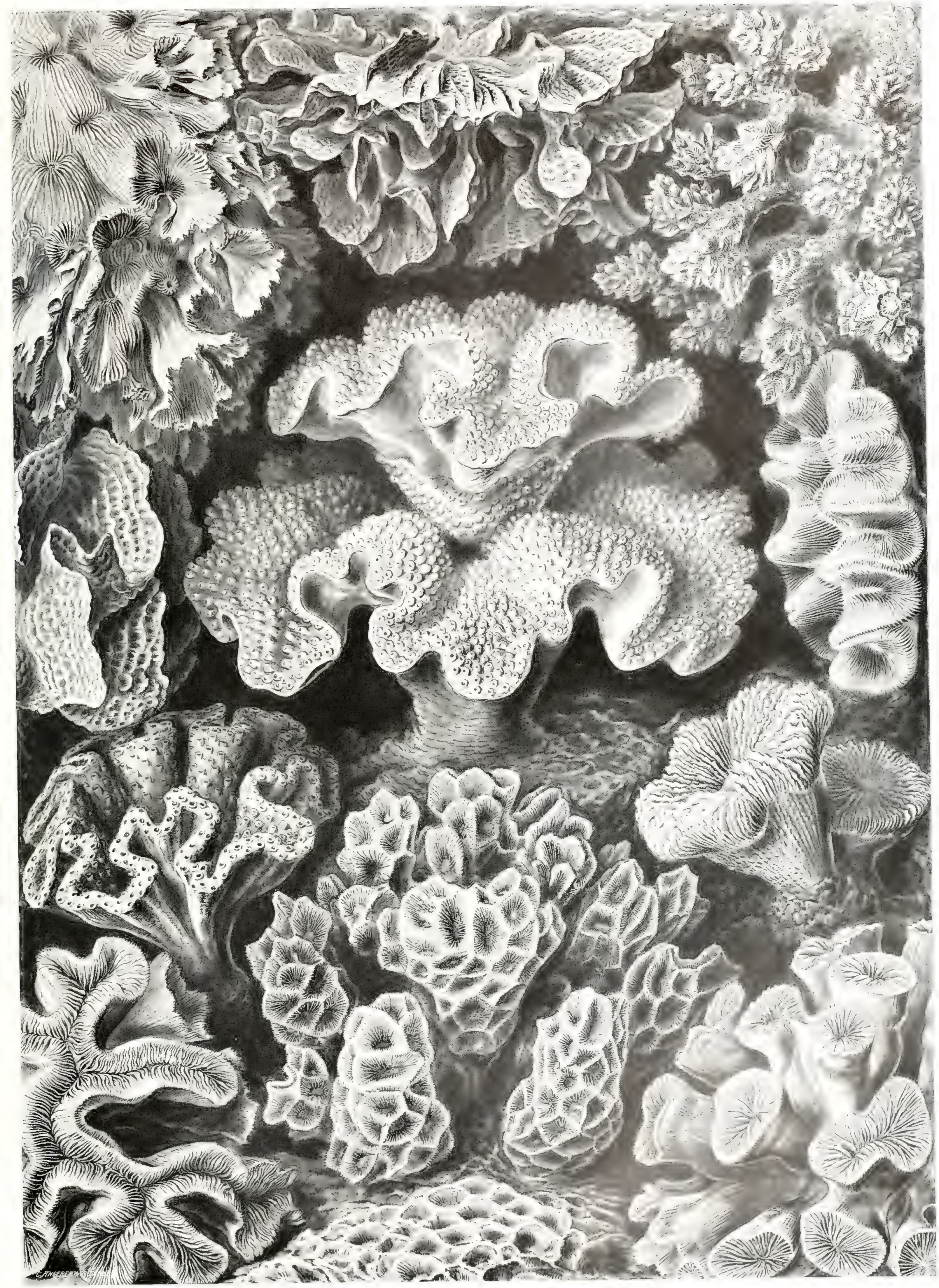

Hexacoralla. 



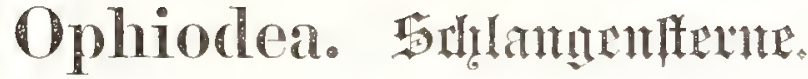

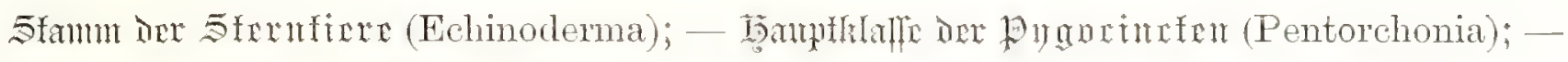

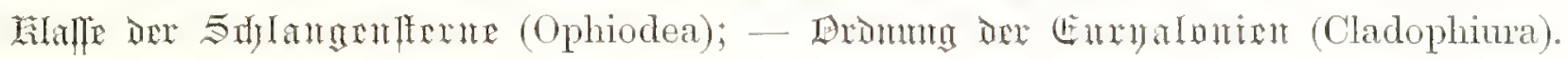

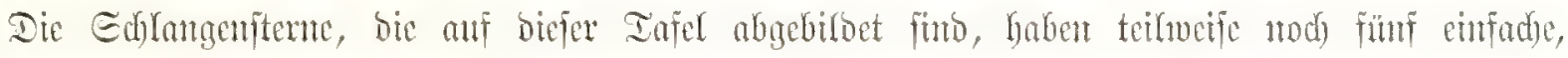

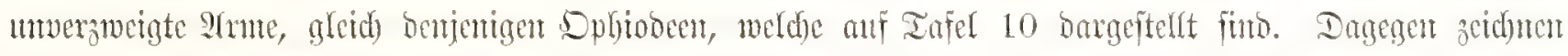

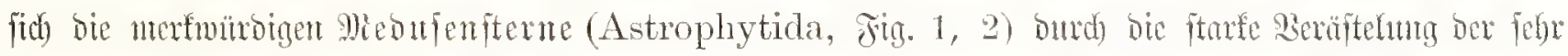

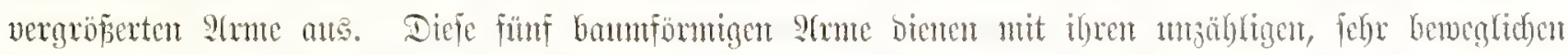

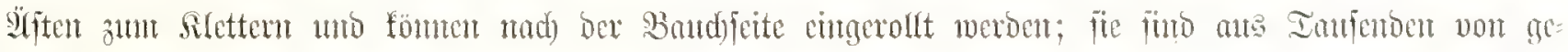

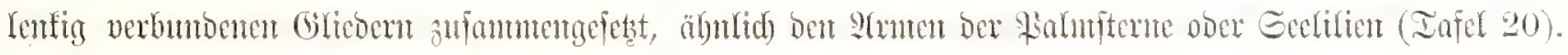

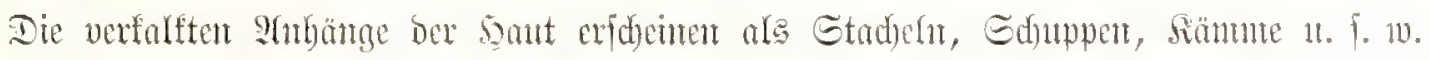

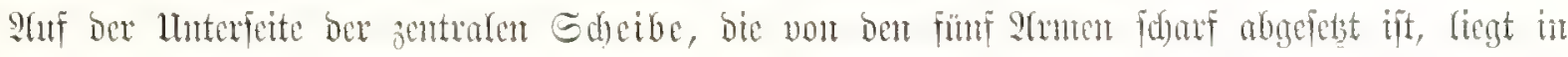

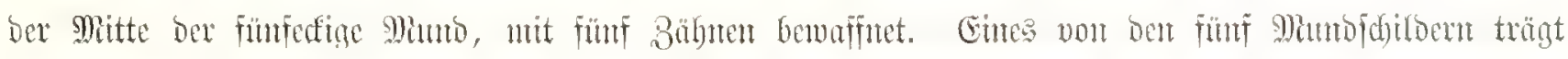

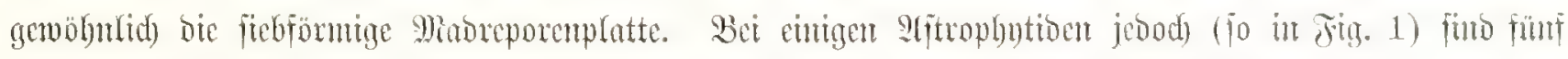

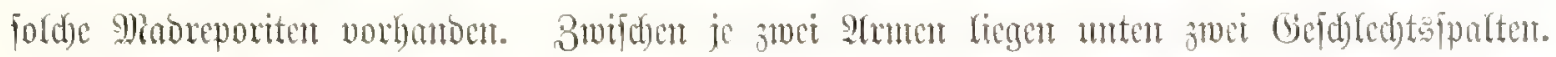

Fig. 1, 2. Astrophyton darwinium (Haeckel).

Fig. 1. Das ganta Sterntier, in natiunfidyer Gröpe, vont unten gefehen, in ber Mitte ber Miunt.

Jig. 2. Der zentrale Teil bes Iieres (bie Sdyeibe), vou oben gefeben. (Sumatra.)

Dicfe neue Srt ber Gattung Astrophyton, ats Dem Subtiden Djean, ftelt unter Den befanten Spejics biefes Gemus ant nädjitent bet betoen int=

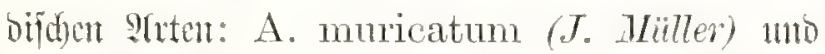
A. Linckii (.T. Muiller). Gie unteridfeibet fid) abcr bon biefen, wie von affen andoren betamnten

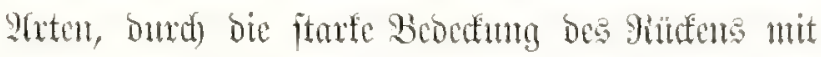

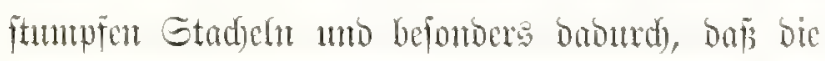

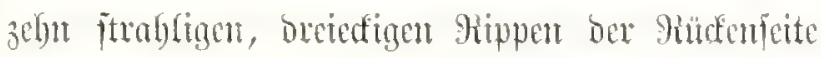
Der Edyeibe wentg vortreter, vicheldx paandife ju

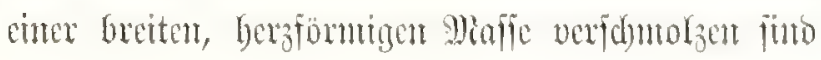

(Jig. 2). Die Etadefn tretert and ant Pante ber Sdyetbe, zwifden ben Strmen, arffarfento vor.

Der sentrale fünffipaltige sumo ift von fünf

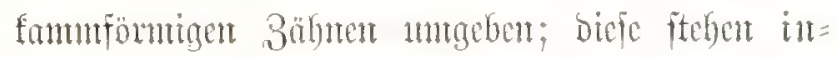
terrabial (in ben Straffentedfen jweiter Dromntg)

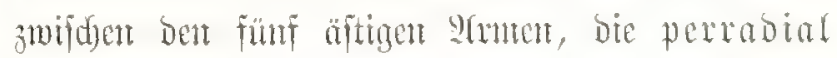

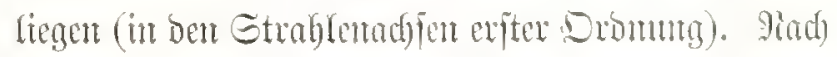

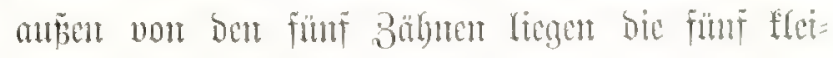

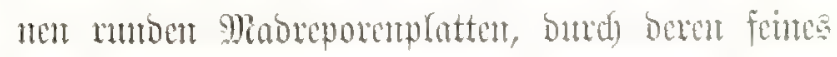

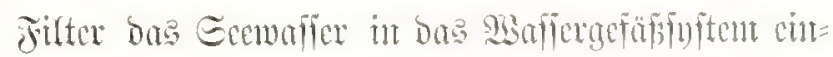

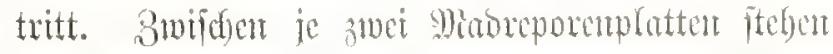

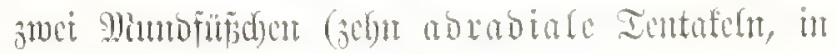
oen Gtrablen britter Drommog). Sult benferben

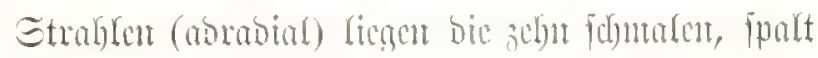

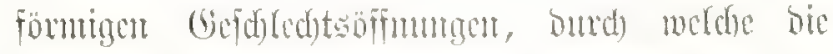

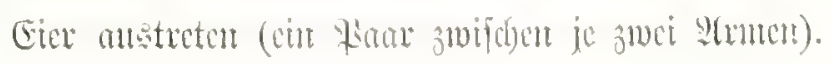




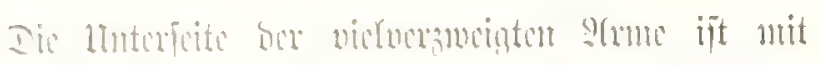

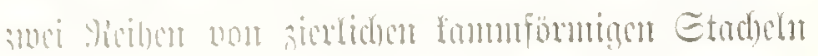

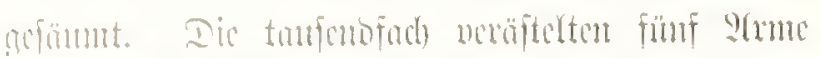

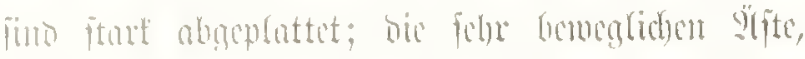

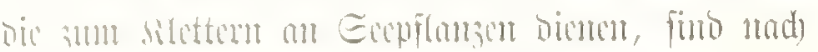

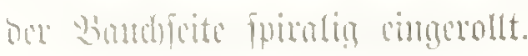

Tin. :3. (ophiopholis japonica (Tyman).

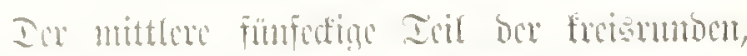

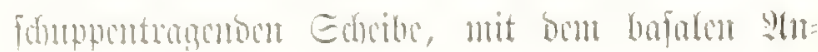

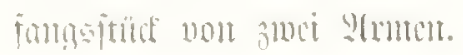

Tim. 4. (tphiotholia supplicans (Lmman).

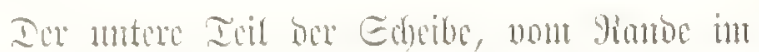

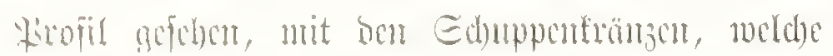
bis bafalteile ber funf strute foubeno magben

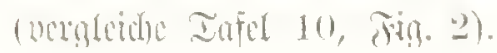

Fing. 5. (ophioholus nimbella (Lyman).

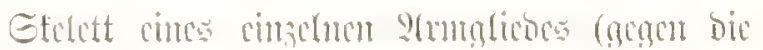

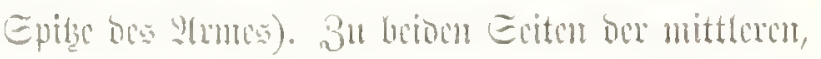

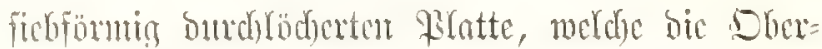

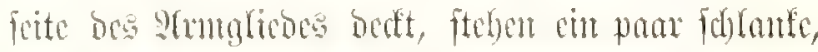
gabelteilige Goitmplatten, bie viele bimme, gefmöpfte

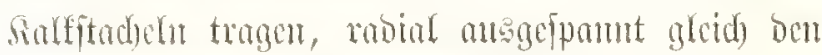
Stäben cuncs Regenfointes.

Jig. 6. Ophioglypha minuta (Lyman).

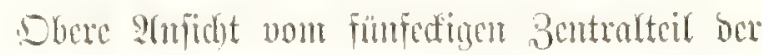
Sdycibe, mblt cincur Etüd bes anyemzentom Kano.

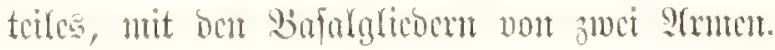

\section{Fin. 7. Ilemipholis cordifera (Lyman).}

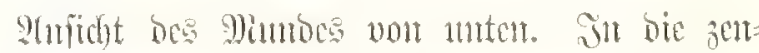

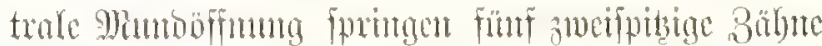
vor, getraget von fünf Lian birnförmigen Sicfern. Bwifden ben lesteren liegen ic zuci fingerföntige

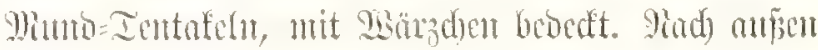

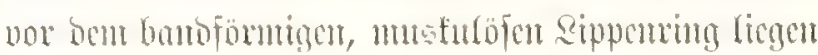
fünfachn Salfulatten: an jeber bex füm Cefon cu

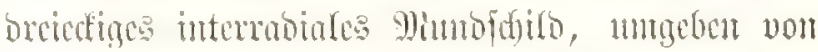

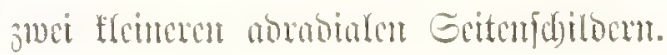



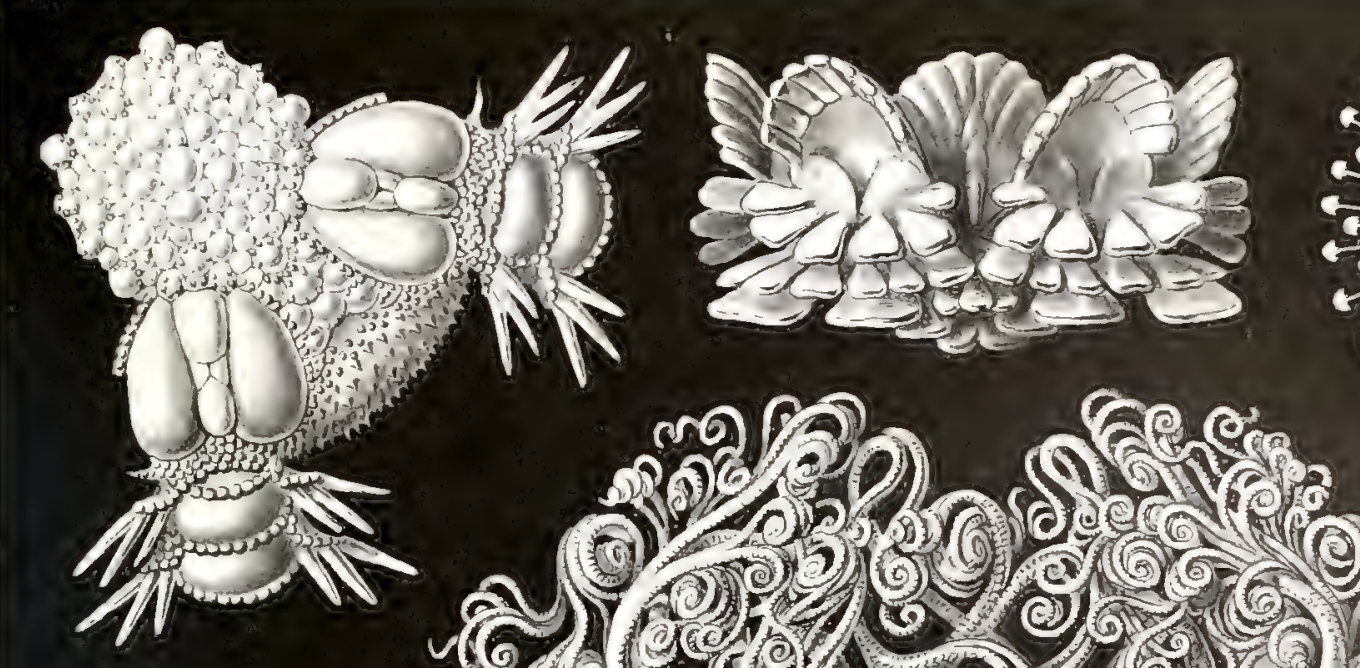

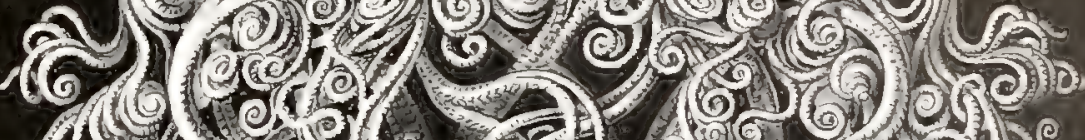

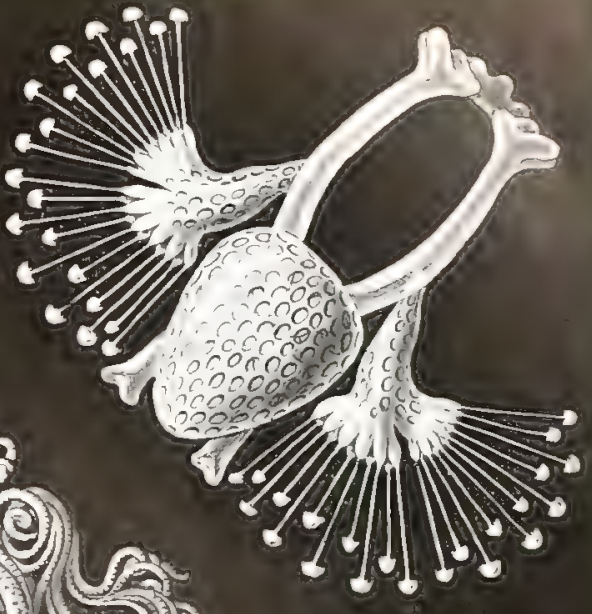

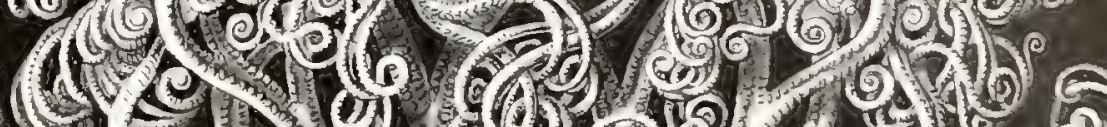

\section{(9) $1(5)$ (8)}

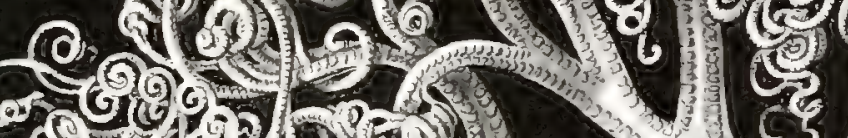

G $(1056)(5)$ calgrole.

(c)

(6) $610 \mathrm{C}$

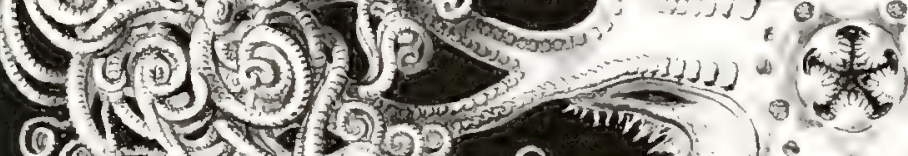
G6.

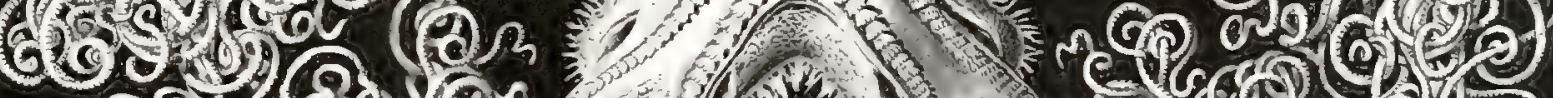
CQ9

ก⿺辶万人?

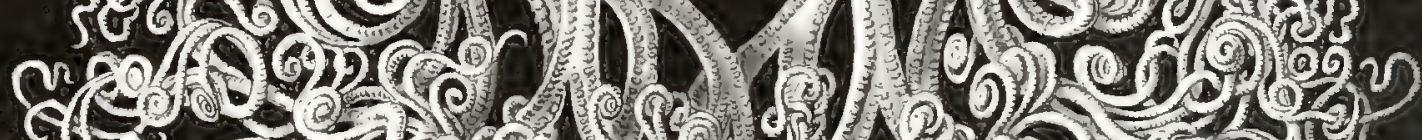

(a) लne

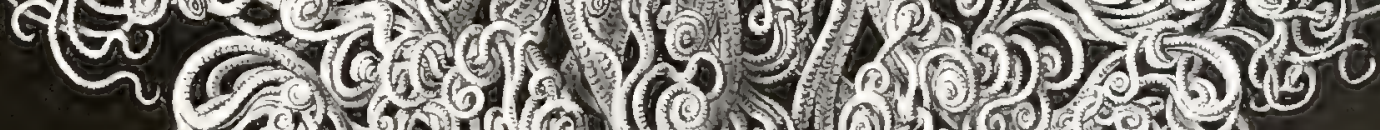

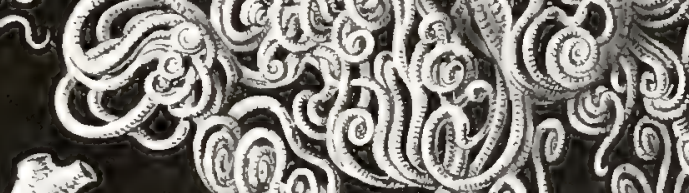

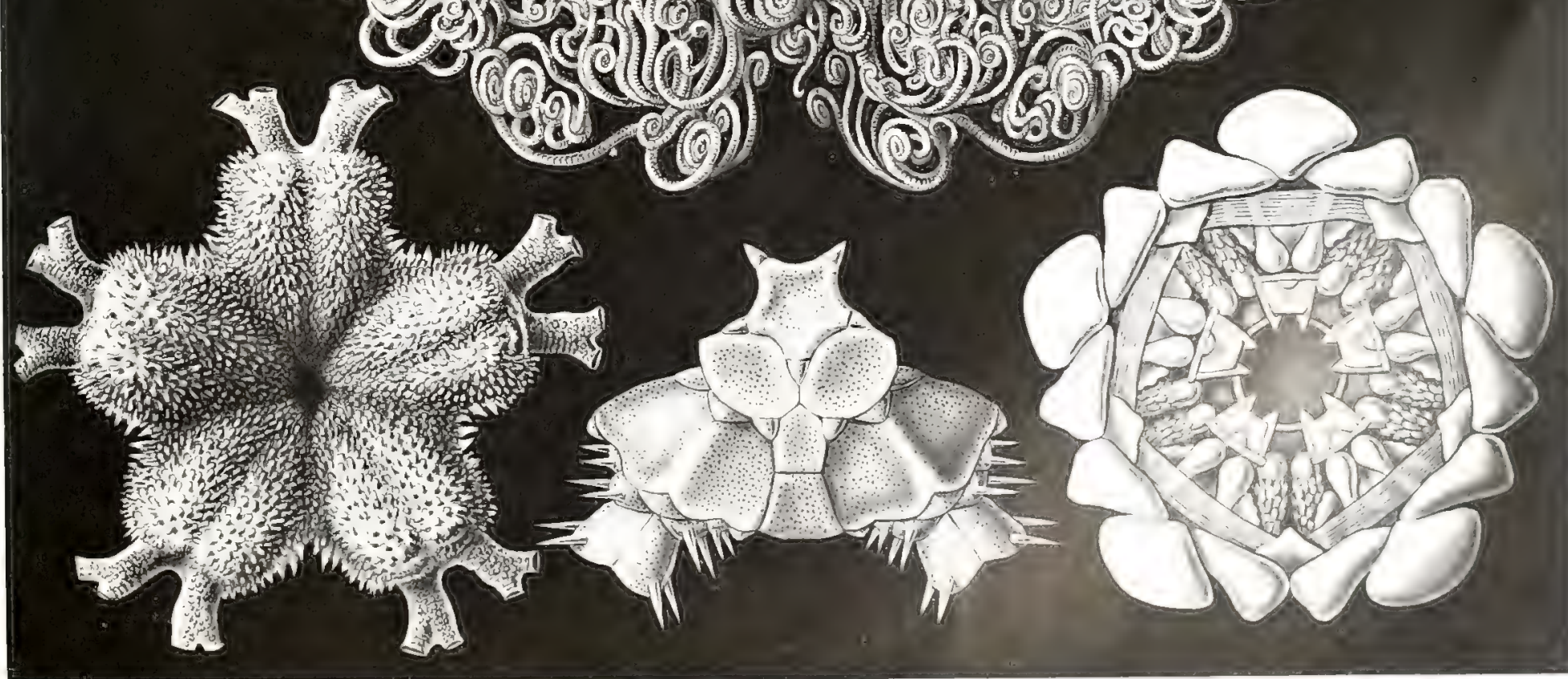

Ophiodea. 



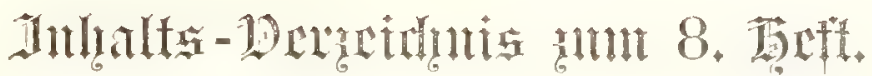

Iafel 71. Tympanidium. Itrtice ans bor

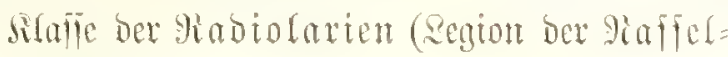
faricul).

Iafel 72. Polytrichum. Mloospfontion an ber Silafie ber ambutopic (IInscinae).

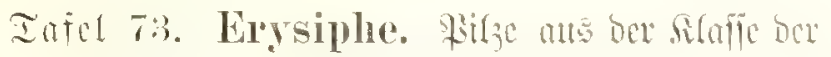

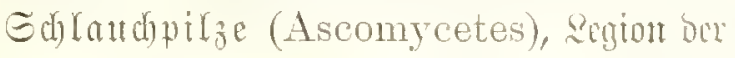
Carpascodii.

Iafel 7 t. Cypripedium. S3นmm Dex Fantilie ber Drediocen (Samptelafie Der

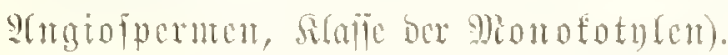

Iafel 75. Diplozoon. 此attenticue (Platodes)

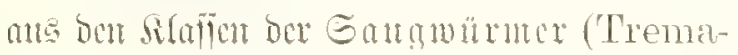
todes) mono ber Bambmurmer (Cestodes).

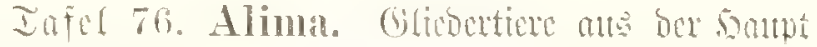
flaffe ber surutenticre (Crustacea), sergion ber sanzerfrobfe (Thoracostraca).

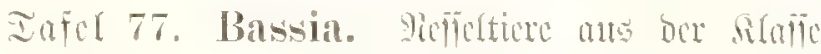
Der Gtantantallen now Giphouphorem,

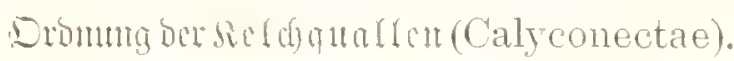

Infel 78. Charybdea. Miffeltime me be

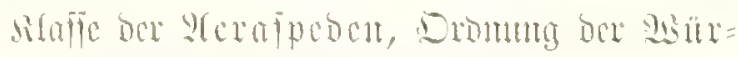
felquallen (Cubomedusae).

Tafol 79. Basiliscus. girbettere an bor

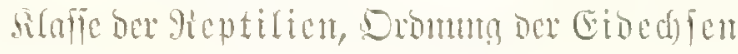
(Lacertilia).

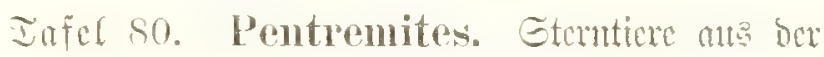

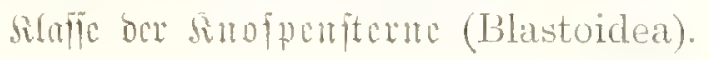





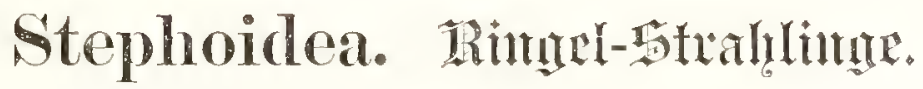

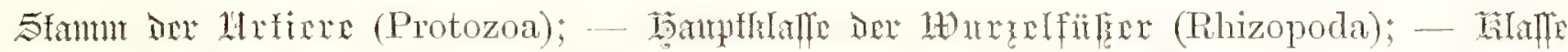

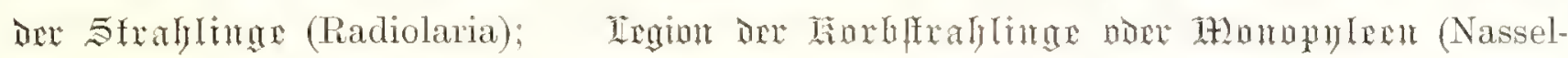

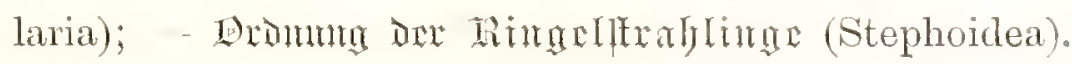

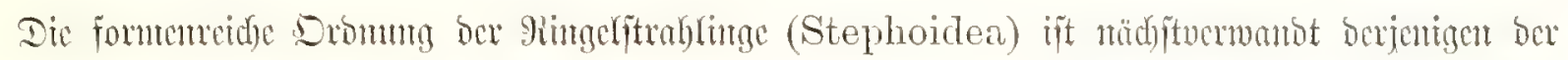

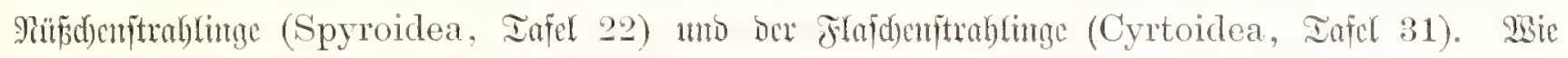

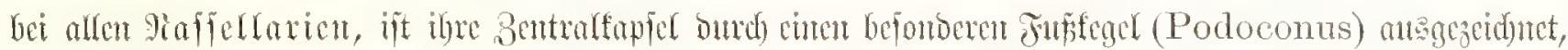

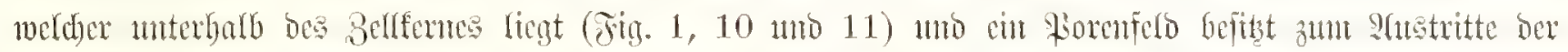

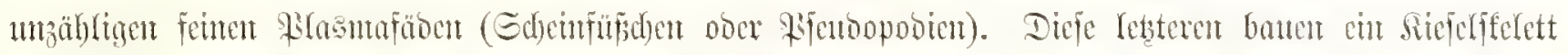

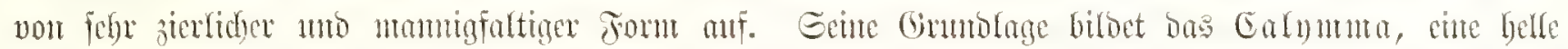

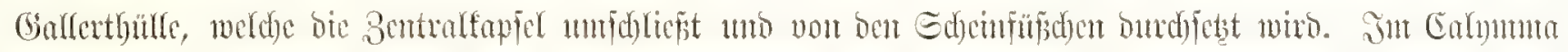

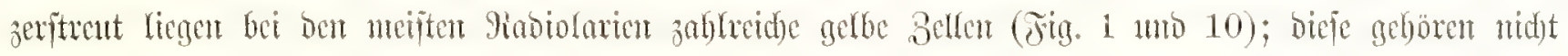

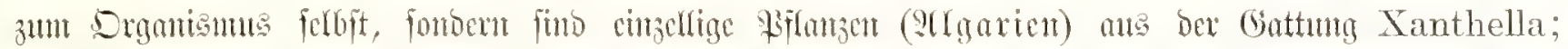

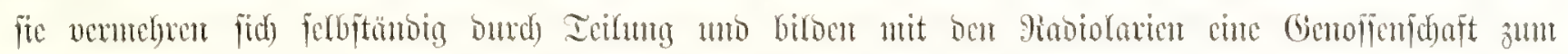
gegenfertigut Sarteil (Eumbioje; vgl. Iafel 51, Jig. 2, 10, 11 und 12).

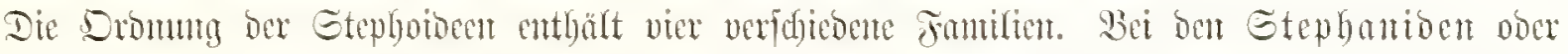

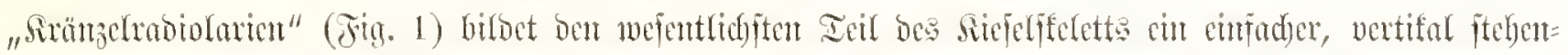

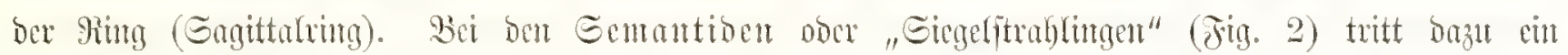

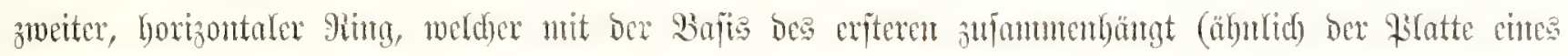

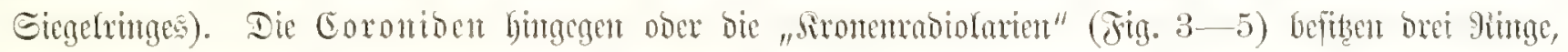

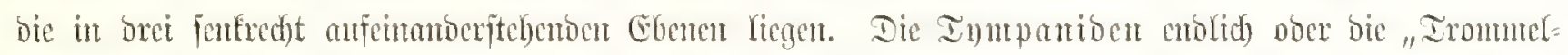

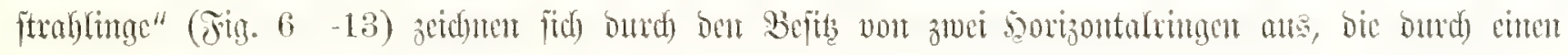
ober mebrere Sertifarringe verbutsen funs.

\section{Fig. 1. Lithoeirens magnifieus (Haeckel).} Familie der sterthantion.

Die eiförntige Bentralfupjed (rot) enthält unten ben Podoconus, oben ben wunfẗ̈̈rnigen Bellferu,

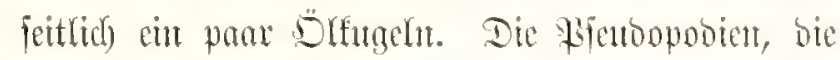

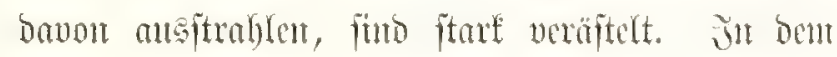
Ealymma zentrent Yiegen zahfreidye getbe Belfen, bic

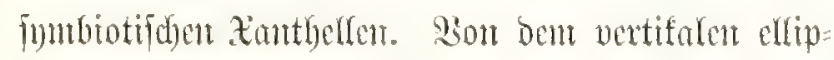

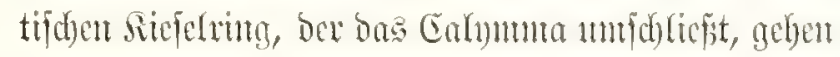
vide gewerbförntig verzuetgte Etadyedr ab.
Jig. 2. Semantis sigillum (Hacekel). Fantilic der Semanfiont.

Das Gfefett beftert ma jwet Sicjefringat, die

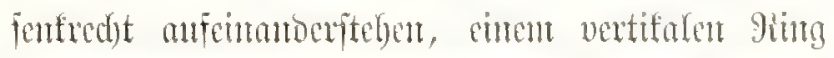
(gleich Fig. 1) unt cintent horizontalen ging (untent).

Jitg. 3. Acanthodesmia corona (Haccket). trantilie der $\mathbb{C}$ ormutiont.

Das fromenälntiche Gfelett beftegt me curm

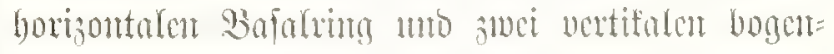
förmigen Epangur, bic fïd) oben fremsatr. 
Sign. +. Tristephanium dimensirum (Hacckel). Familie ine Clommion.

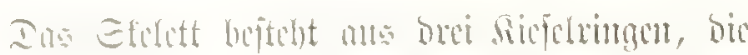

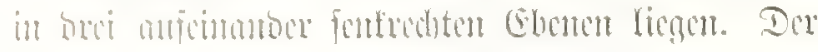

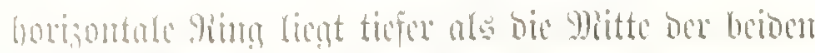

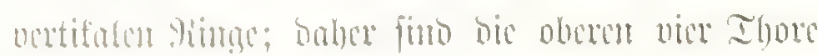
merber als bie bier unteren.

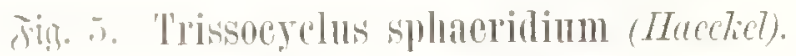
Familie ber curnution.

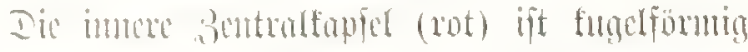

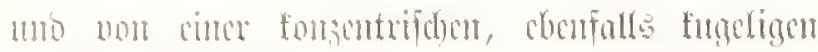

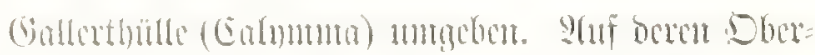

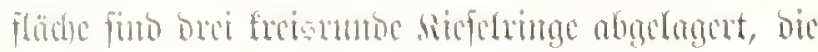

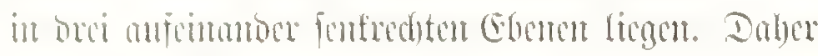

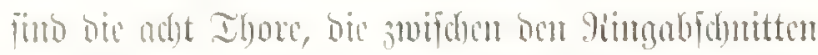

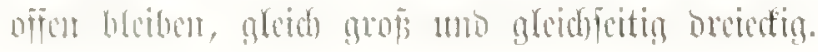

\section{Fig. 6-13. Fomilic dex Imun}

Die Sometic der Irommelftrablinge (Tympamidal unterfortoet fid won ben brei anberen

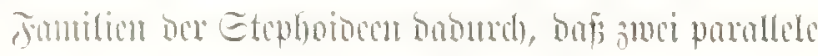
horisontate sieferimge bas Efelett bitom nuic bei

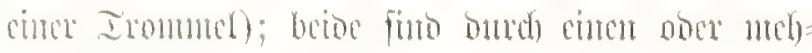

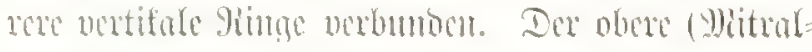

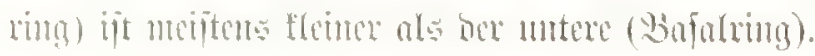

Fin. 19. Octotympanmm cervicorne (Haeckel).

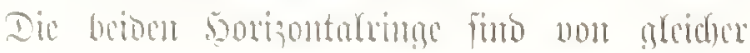

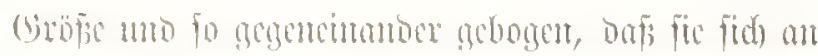

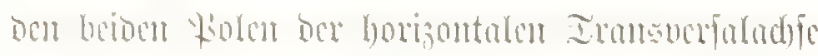

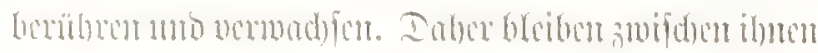

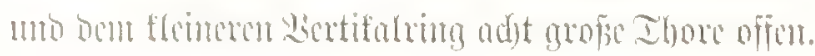

Tịg. †. Hicrocubus zollarius (Hacelal).

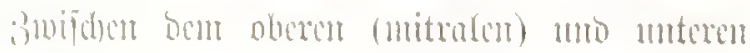

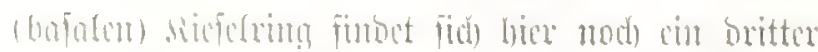

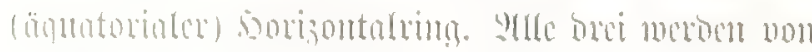

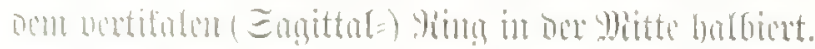

Jitg. 8. Tympaniscus tripodiseus (Haeckel).

Die betoen sonizontatringe finto butrd fedse ver= tifale Eüulen (bic sălften von bre Mieribianningen) verbumon. Der Edyeited trügt oben cinen Gipfel=

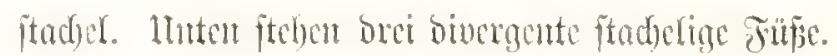

\section{Fing. 9. Trmpaniscus quadrupes (Haeckel).}

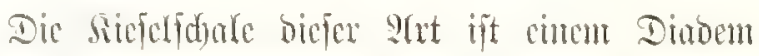

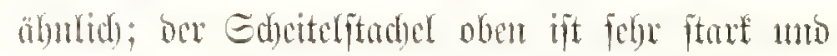
Domig. Str der Bafte vier furze fenfredste guñe.

\section{Jig. 10. Tympanidium foliosum (Haeckel).}

Das siefelffectet ift ans jwe horizontafen utto vice vertifalen Gingen ơllfummentgefert, bic fid) in

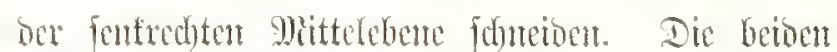

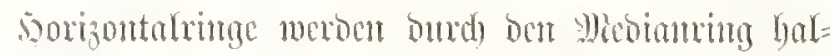
biert. 3wifden ben blattartig verfureiterten Etadyeln

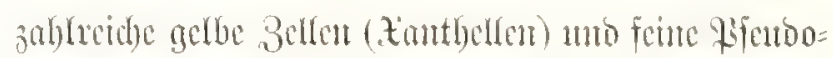

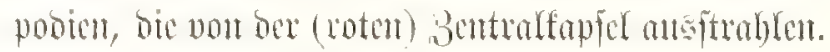

\section{Fig. 11. Lithotympanum tuberosum (Hacekel).}

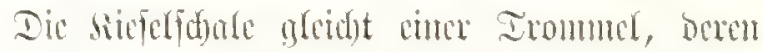
betibe Iromutdiflle burd) cine gewoblete Gitterplatte

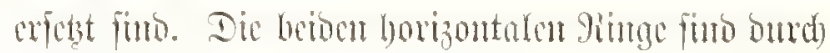
10 bir 12 fontredste parallele Etäbe verbmom.

\section{Jin. 12. ('ireotympanmm octogonium (Haeckel).}

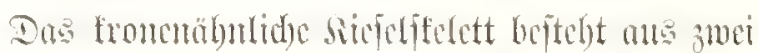
paralleten sporizontalringen, bie burde ad)t Etäbe nerbunton fims. Da ber untere (bofale) Ging boppelt fo grof ift als ber obere (mitrafe), fteigen bie Stäbe

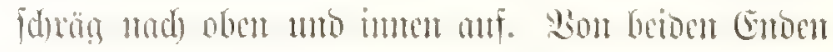
jebes Etaber fpringt cint gezäbnter Dom vor.

\section{Sig. 13. Lithoeubus astragalus (Haeckel).}

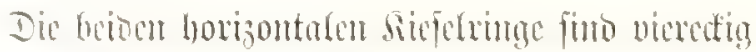

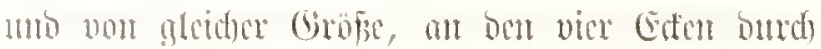

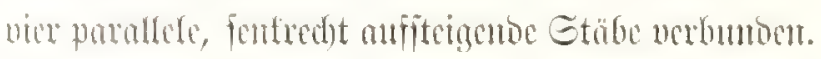

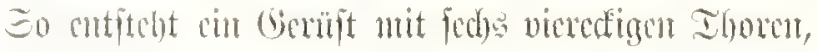

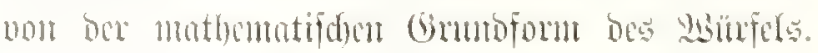

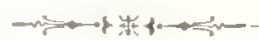





\section{Muscoinae. Taulmumer.}

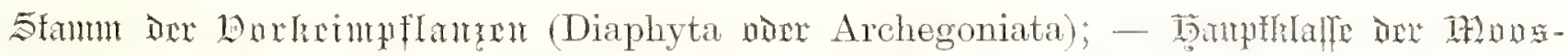

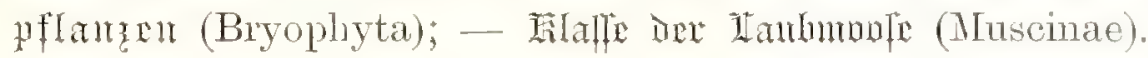

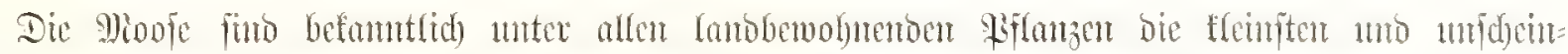

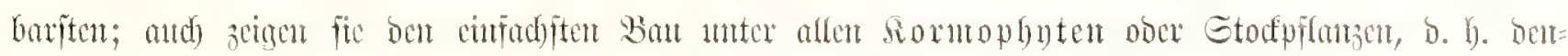

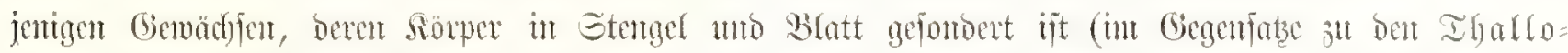

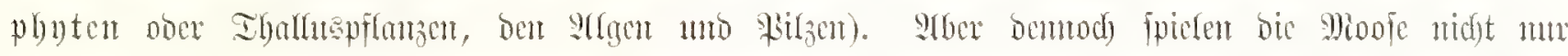

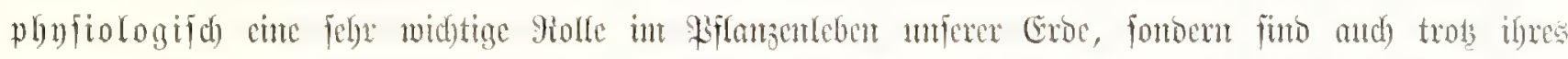

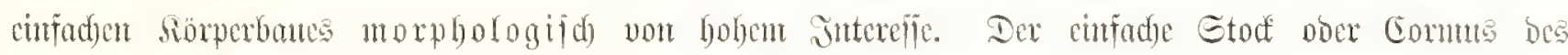

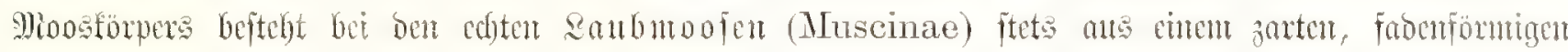

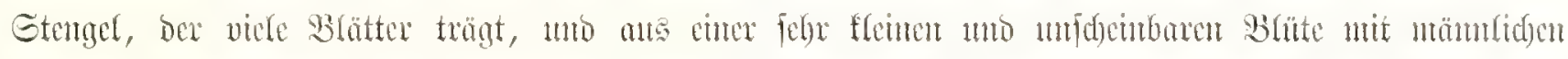

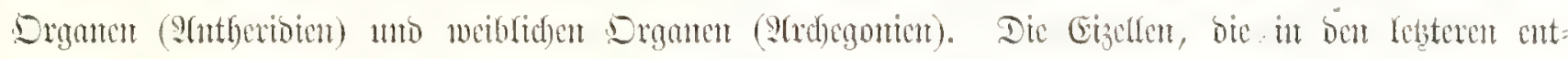

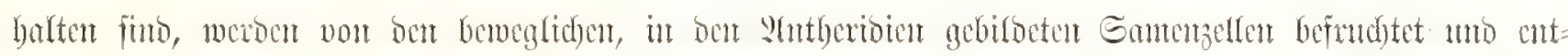

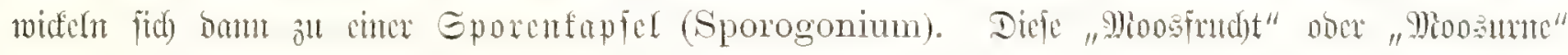

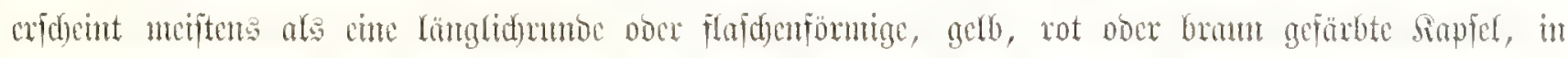

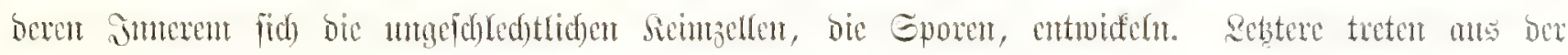

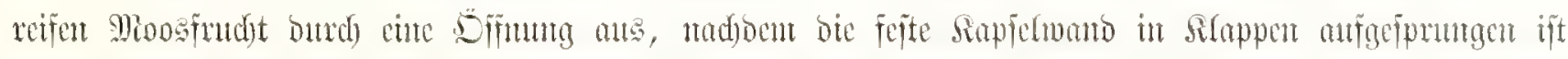

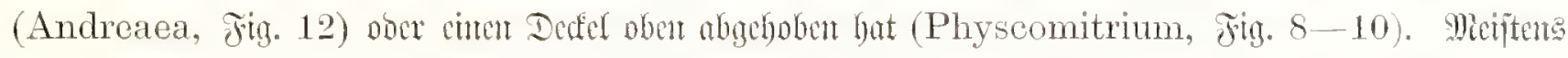

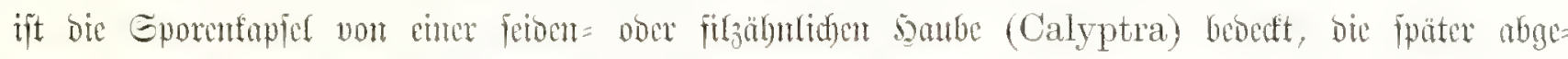
worfen wiro (Polytrichum commune, Fitg. 3, oben redfon).

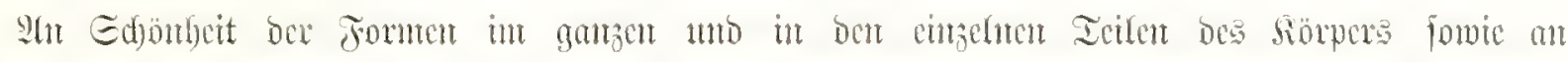

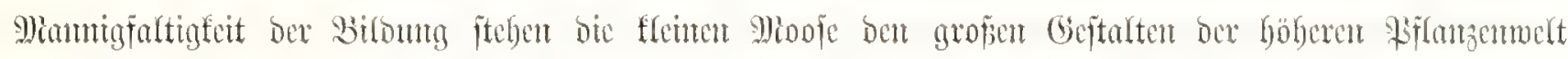

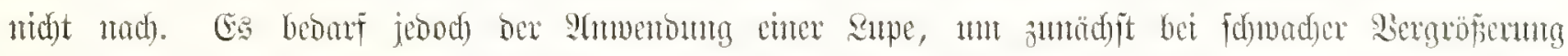

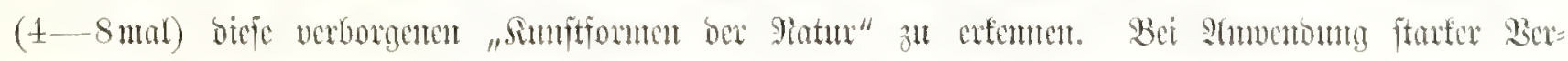

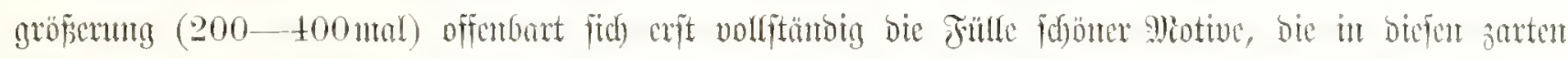

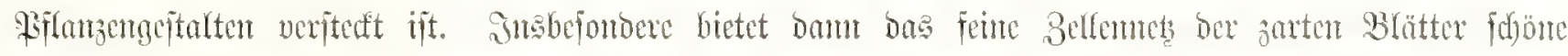

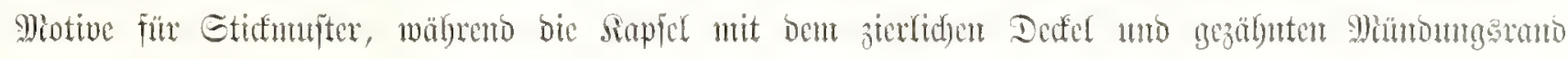
Sorfagent für Utrutent utro Flajden liefert.

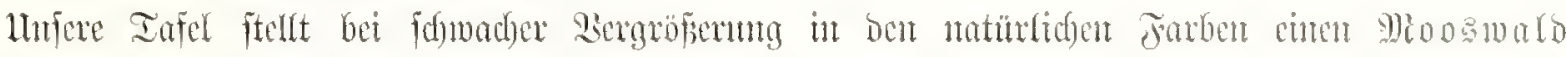

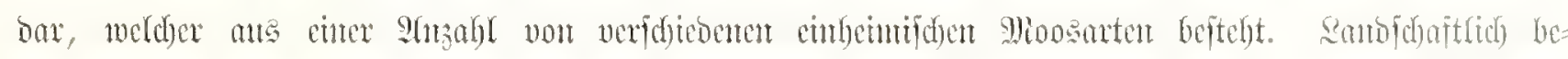

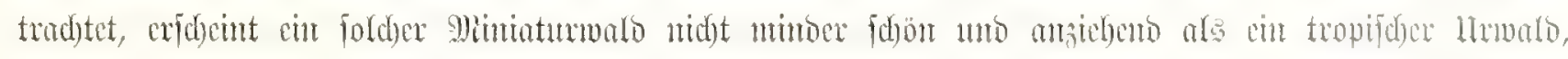

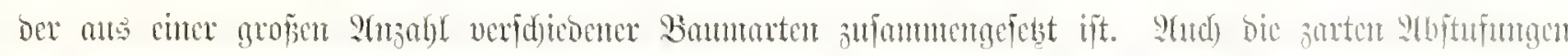

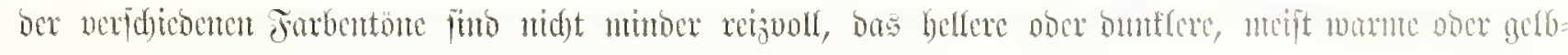

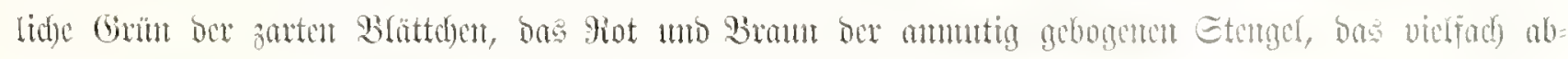

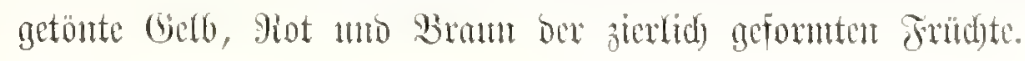




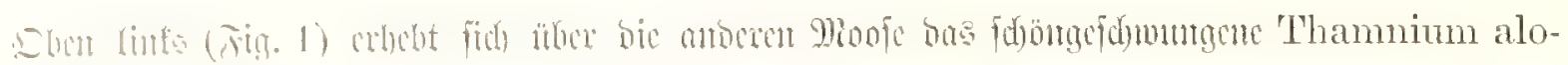

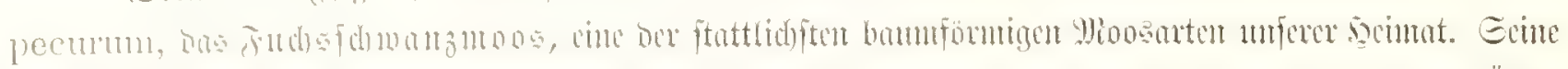

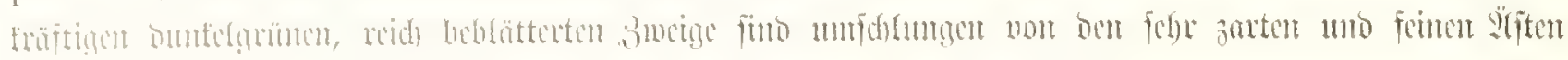

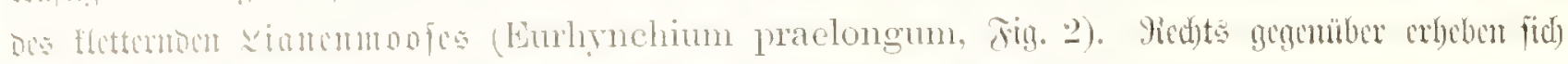

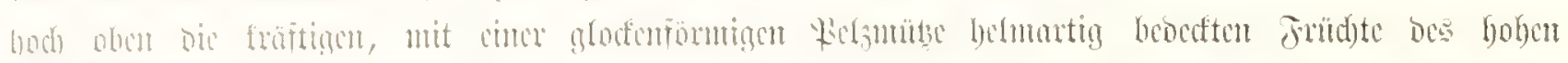

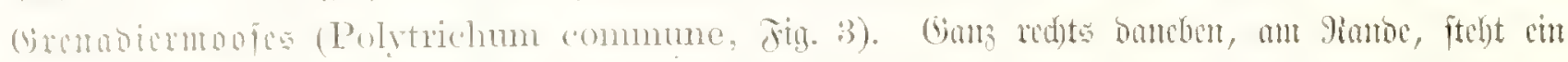

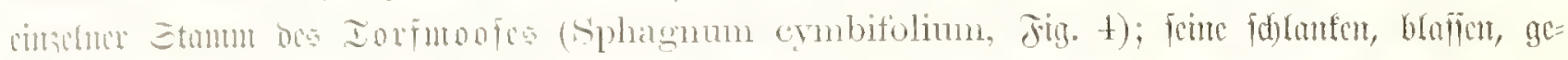

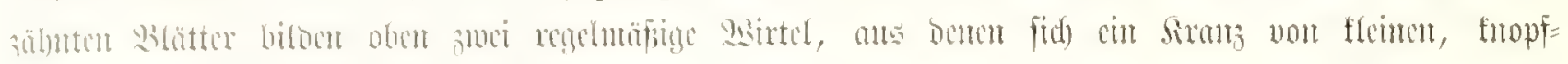

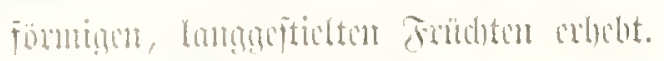

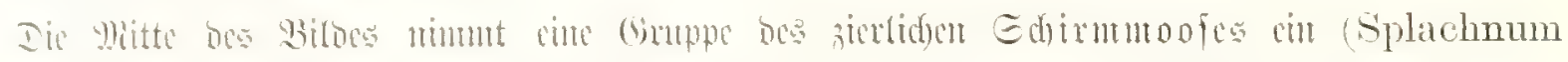

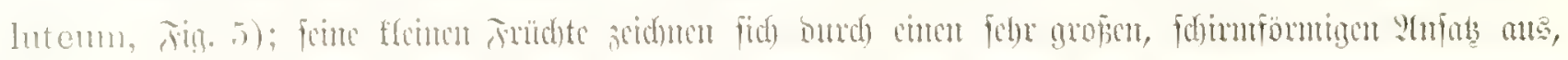

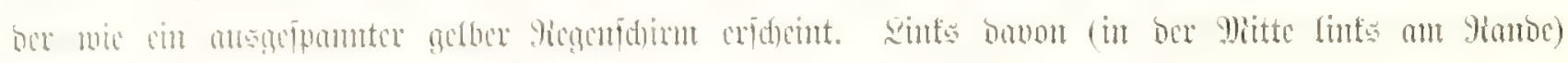

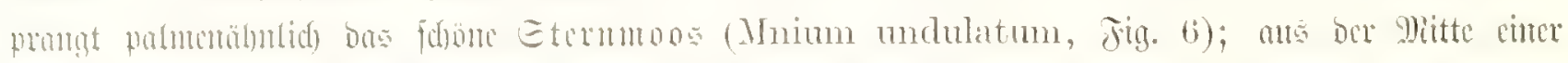

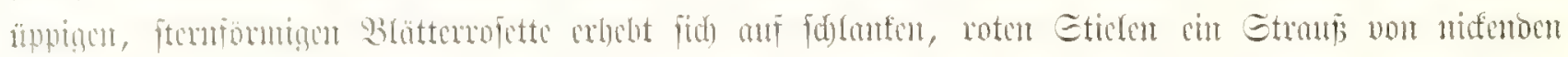

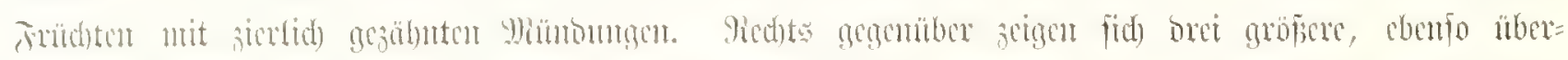

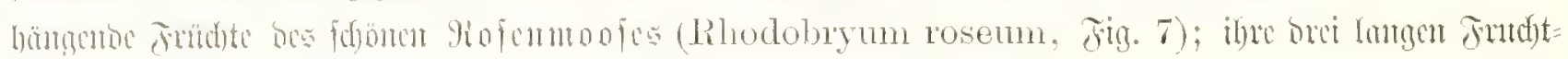

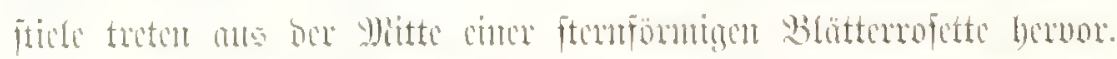

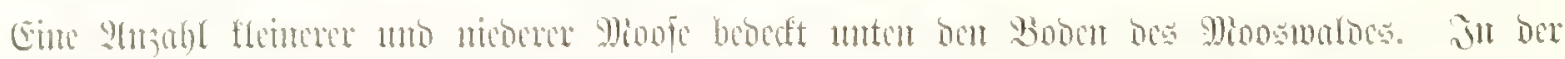
exfe linf

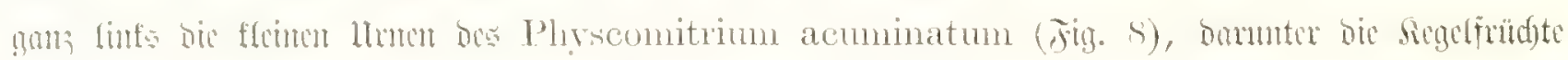

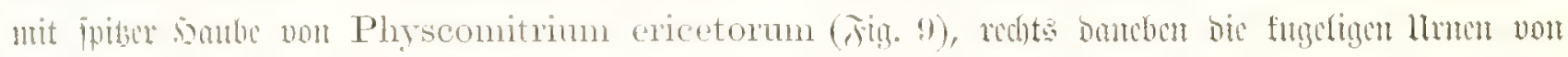

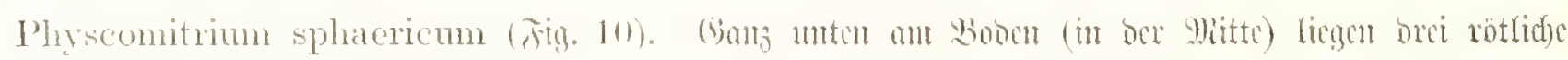

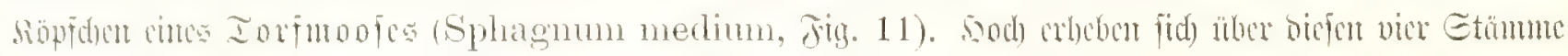

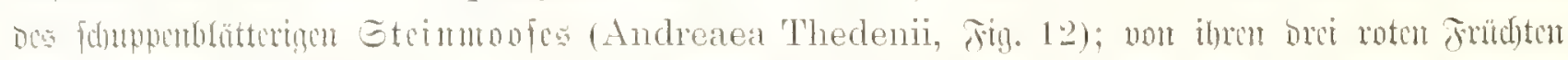

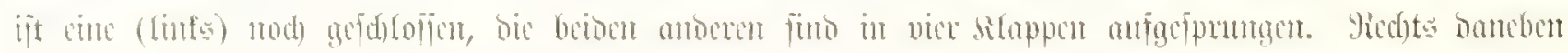

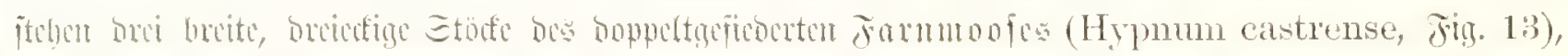

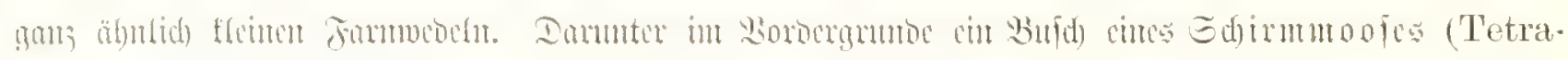

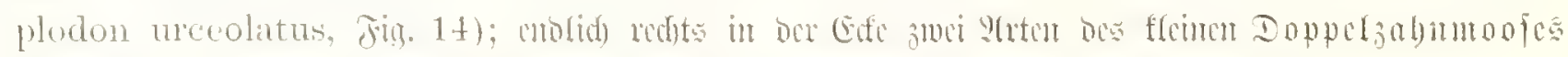

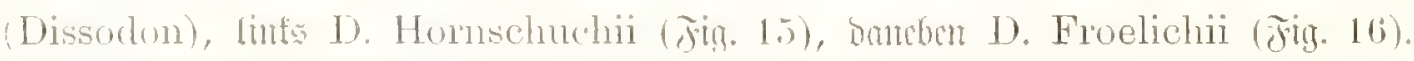

Fit?. 1. Thammium alopecurum (Limo).

Fitg. ㄹ. Eurhynchium pratongum (Timmé).

Fig. 3. Polytrichum commune (Lime').

Tign. t. Sphlagnum eymbifolium (Ehoum).

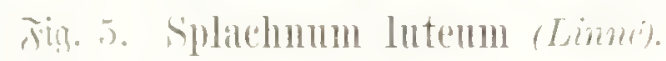

Ting. A. Hnium Indulatum (Hederig).

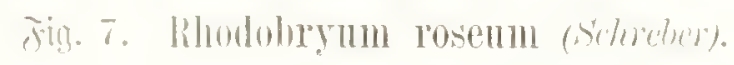

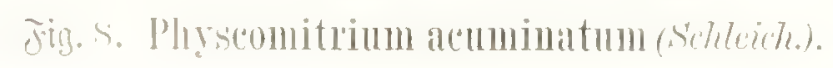

Jig. 9. Physcomitrium ericetorum (Noteris). Jìg. 10. Physeomitrium sphaericum (Schecaeg.). Jing. 11. Splhigilum medium (Limpricht).

Fing. 12. Andreaca Thedenii (Schimper). Fig. 1:3. Hypmum castrense (Limei).

Jig. 1t. Tetraplodon urceolatus (Schimper).

Jigz. 15. Dissodon Hornschnchii (Greville).

Jin. 16. Hissodon Froclichii (Hedecig). 


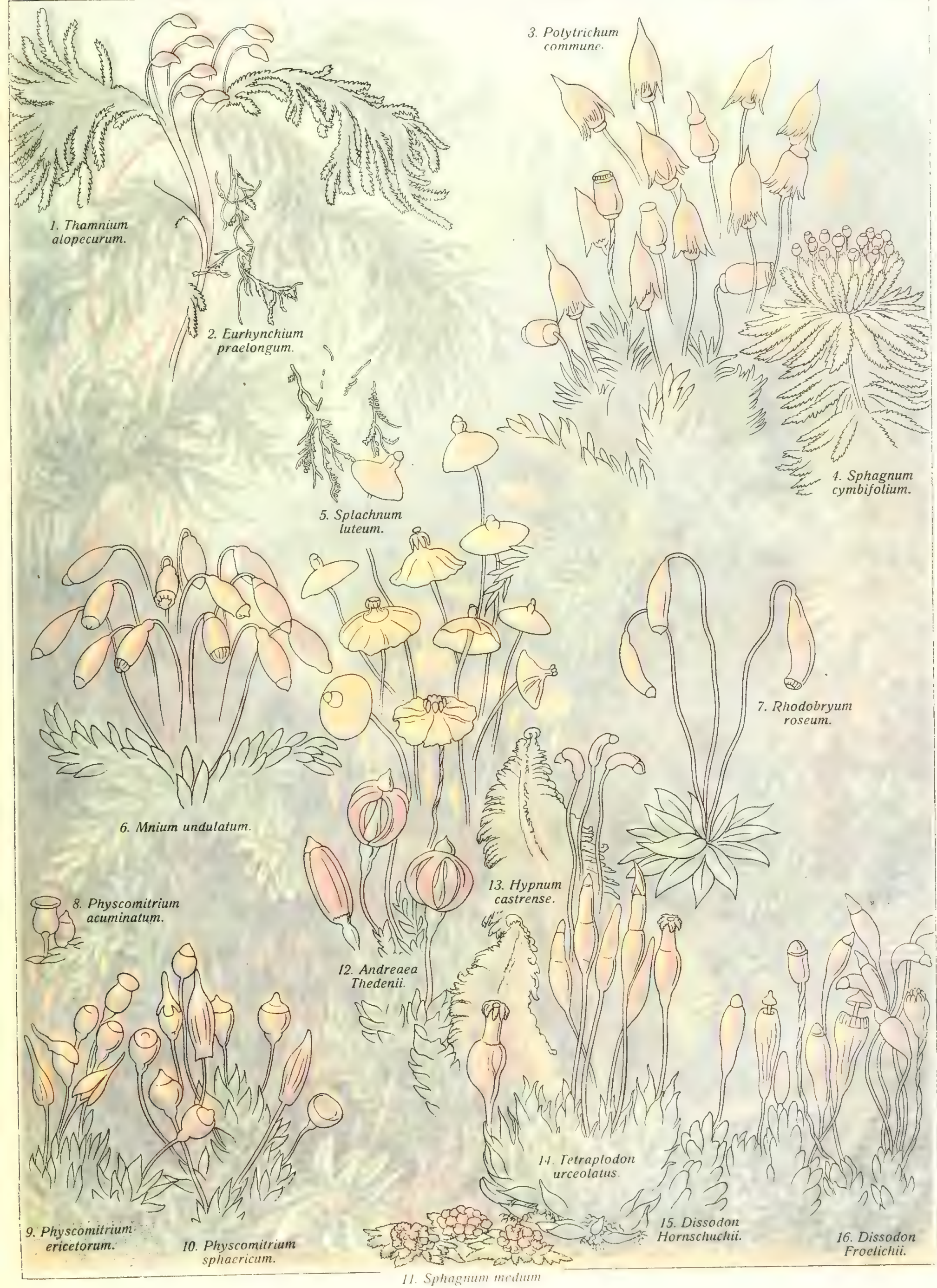




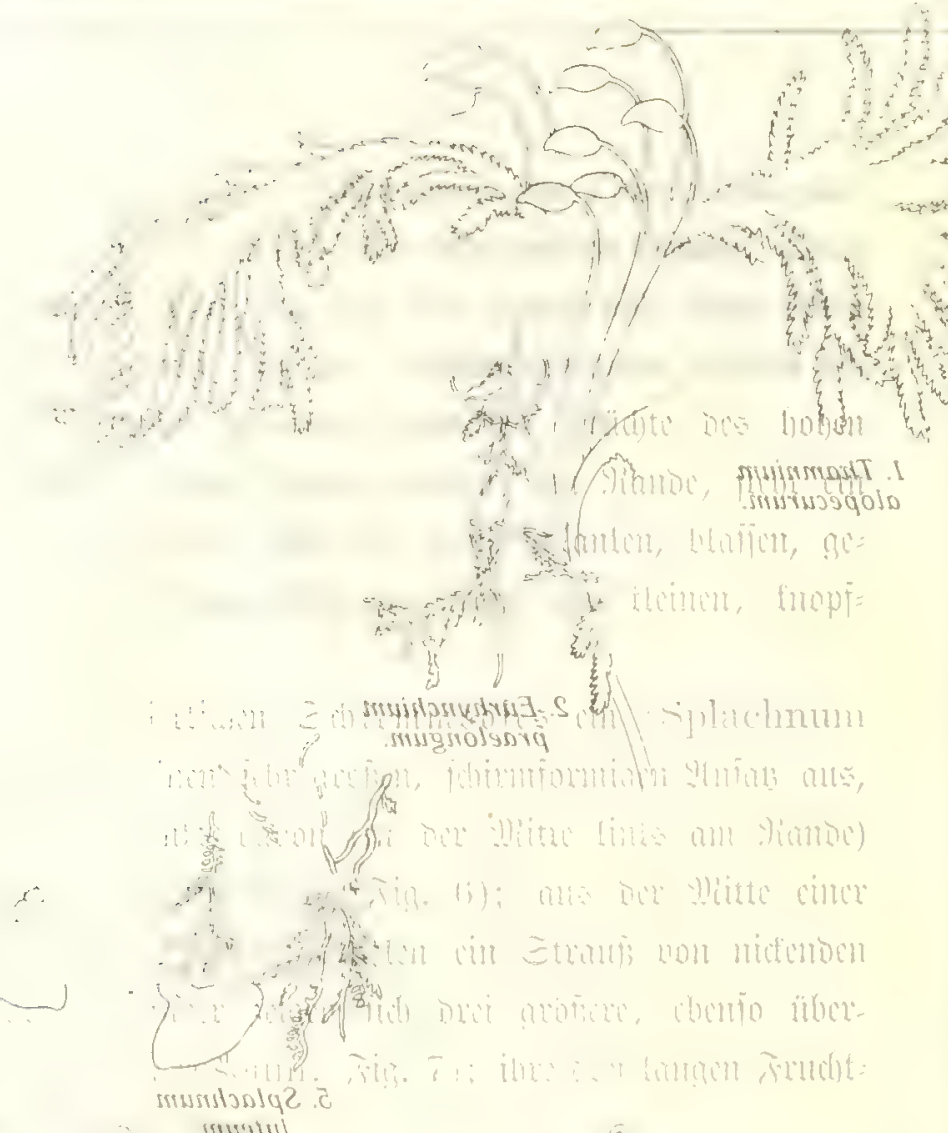

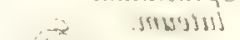




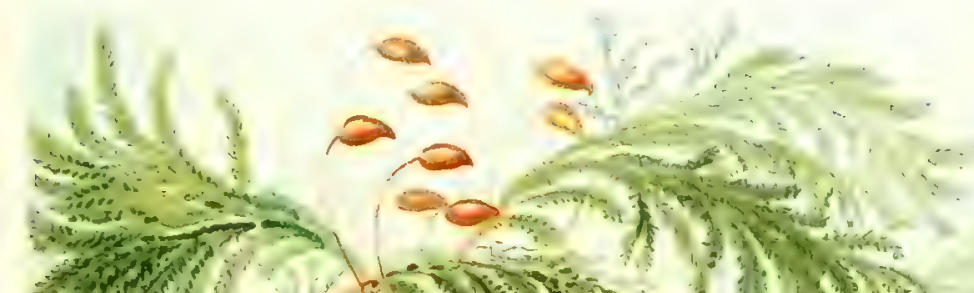

dea.

$$
\text { - } 1000
$$

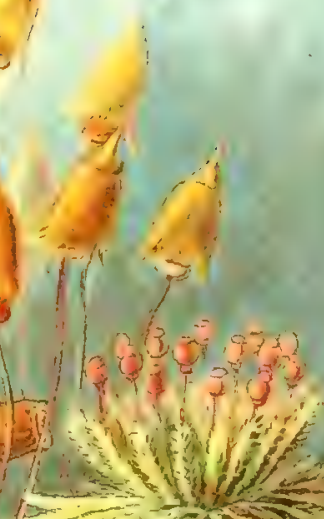

$4 \sqrt{16}$

\section{ind} $y=$

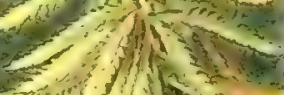

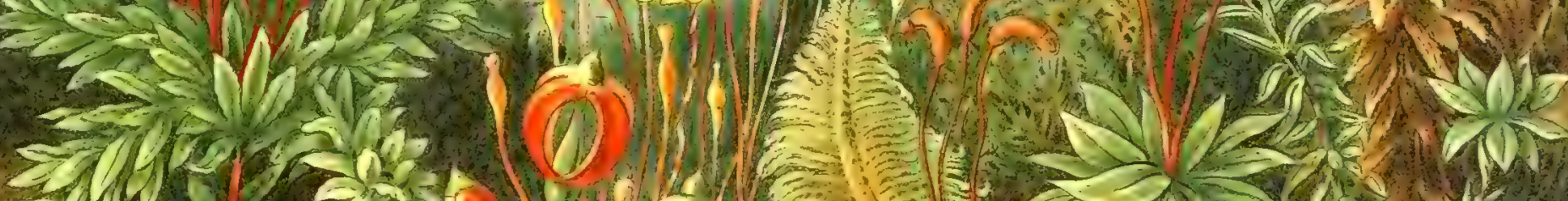

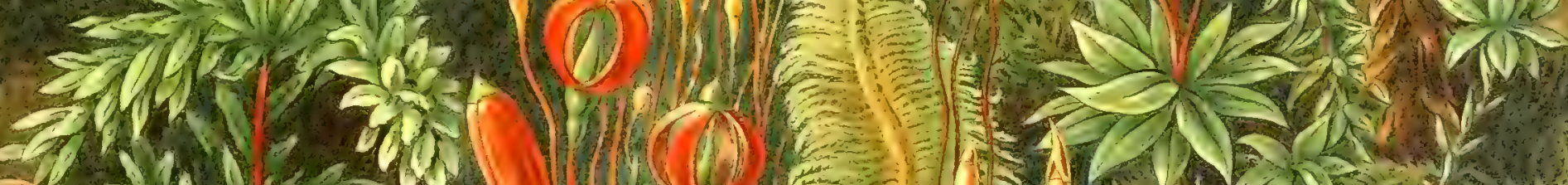
Hon 900 (1) n cobland

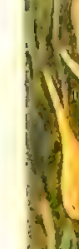

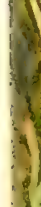

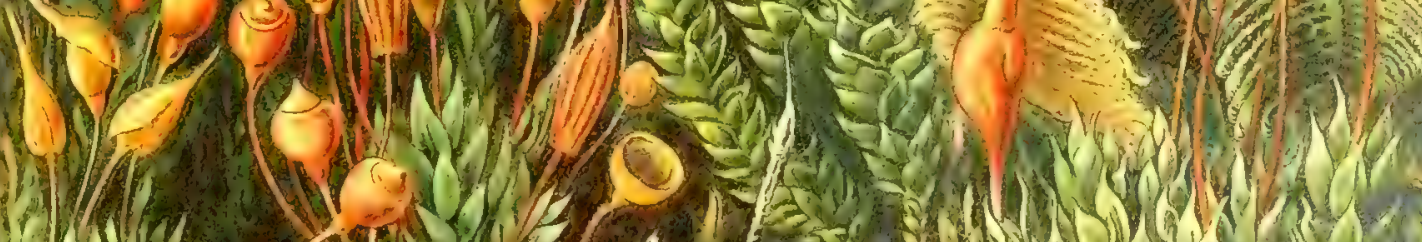

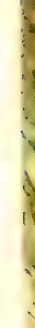

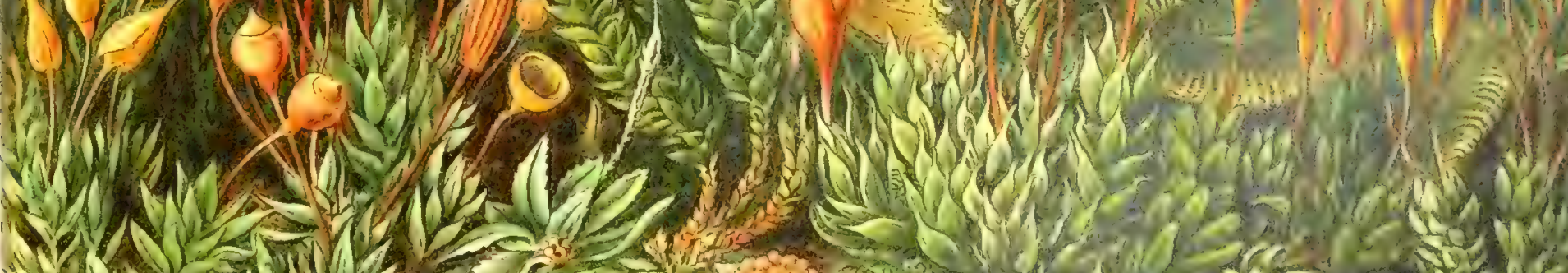

1.1. 140

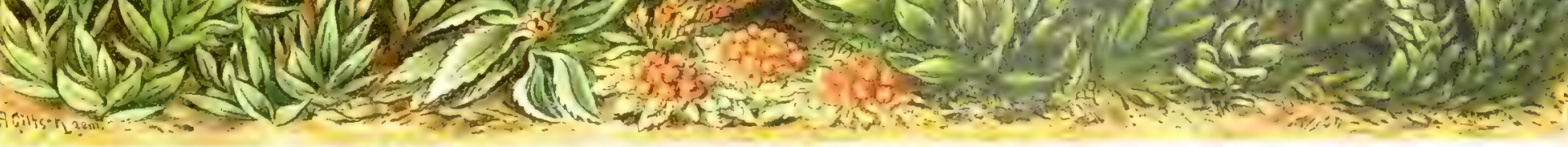





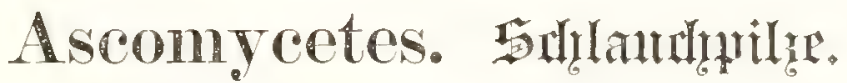

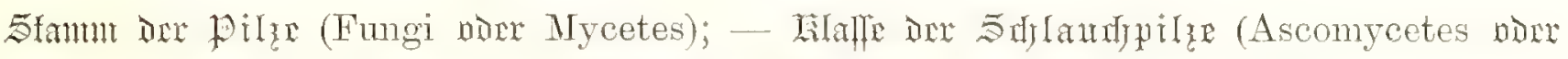

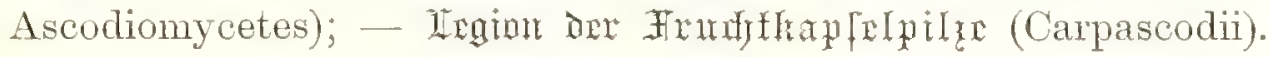

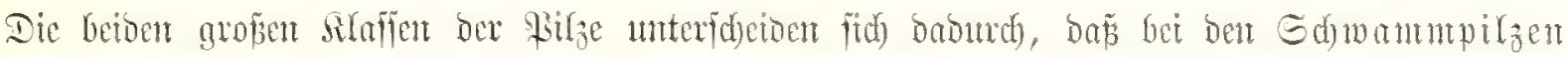

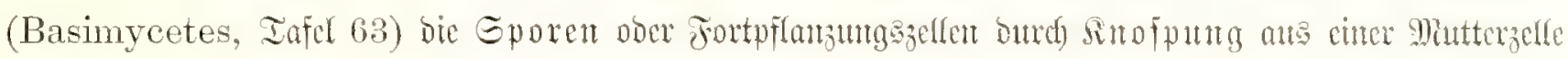

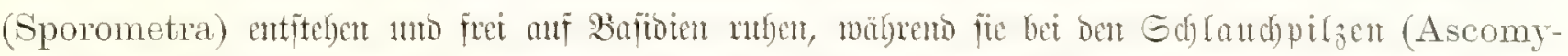

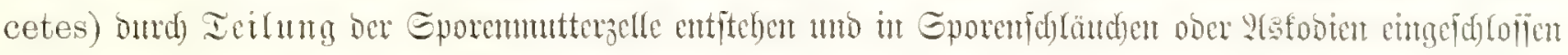

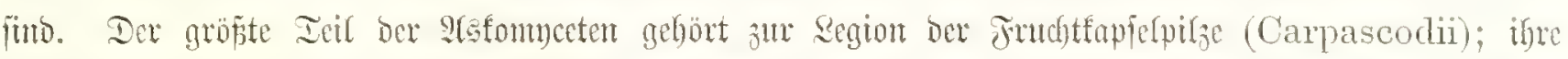

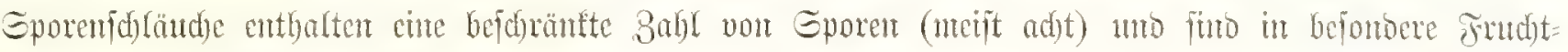

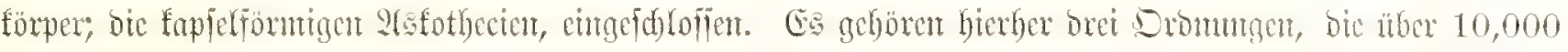

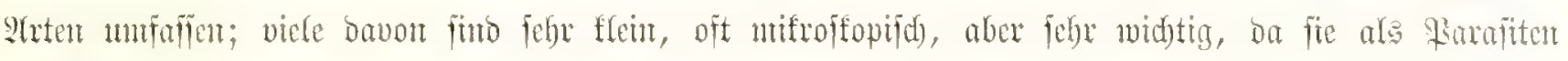
von \$iflanjent veroerblidge Suranfleiten verantafient.

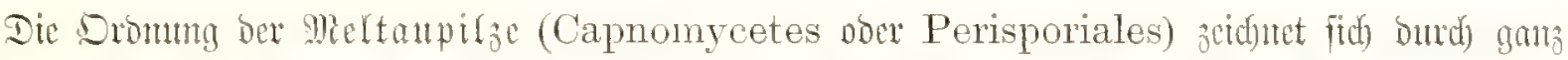

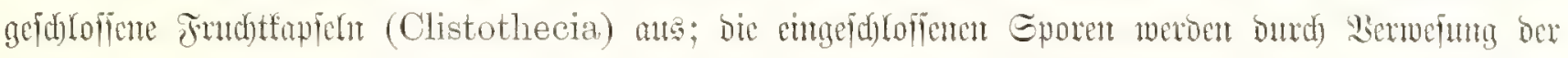

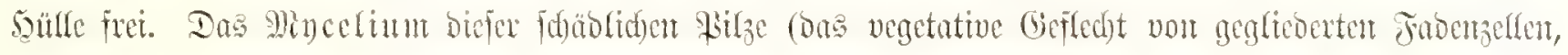

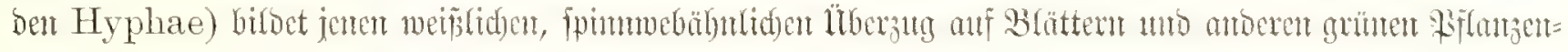

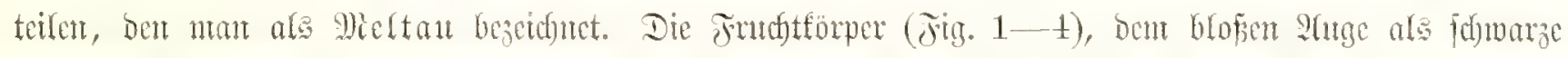

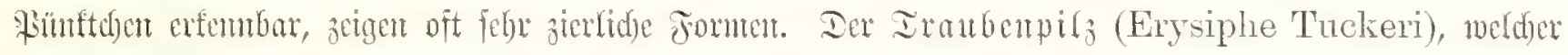

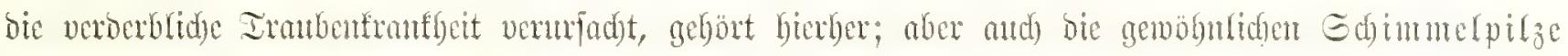
(Penicillium, Eurotium).

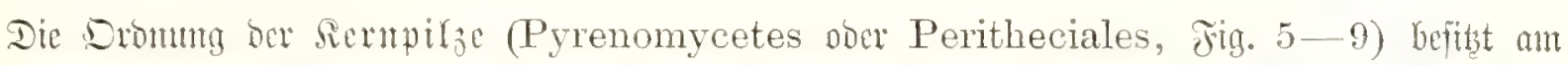

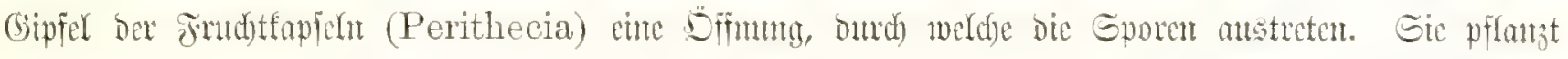

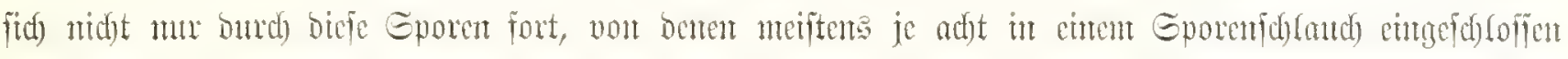

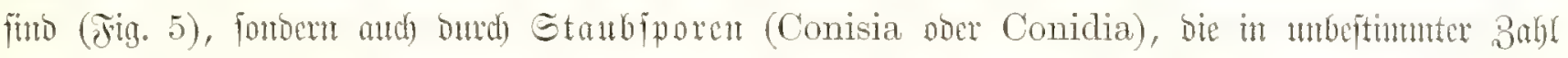

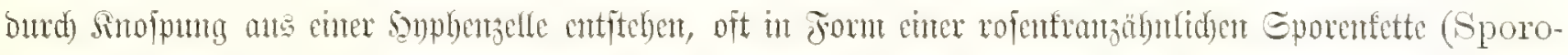

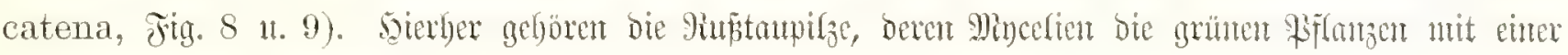

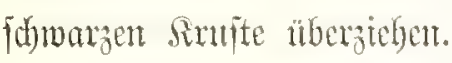

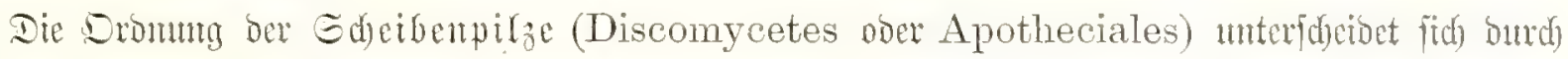

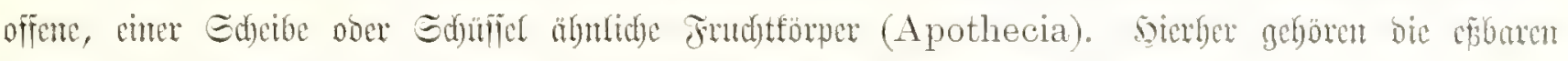
Miordech (Morchella), bic Rordedn (Helvella) mo bic Bedferpifye (Peziza).

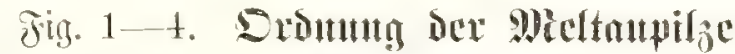

(Capnomycetes odcr Perisporiales).

Fig. 1. Erssiphe Berberidis (De Candolle).

Micltatpily bes Enucronom. Sebt auf ben Blättern von Berberis vulgaris.

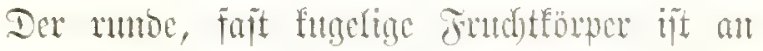
ber Bafis von cinem Sirunze jicrfidjer bane tme geben, die wicoerlyott gabetteilin und geweifartig verjweigt find. Dic Gatturg Erysiphe ift forr reid) an foüblidfun 9 (retent. 
Ting. 2. Erysiplıe Alni (De Cantolle).

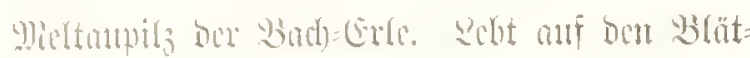
tcum 100 Alnus glutinosa.

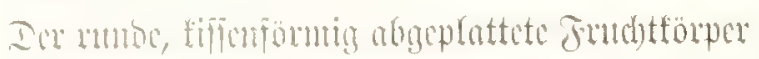

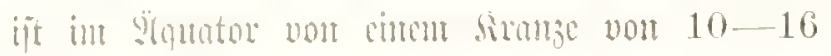

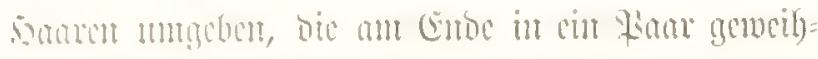

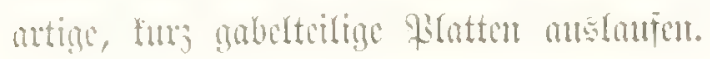

Tin. :3. Erysiphe Salicis (De Candolle).

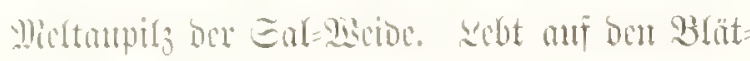
tom von Salix caprea.

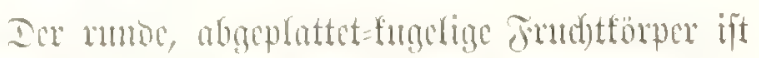

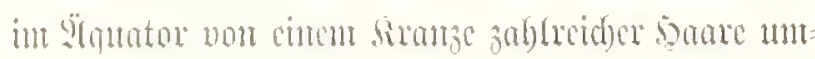

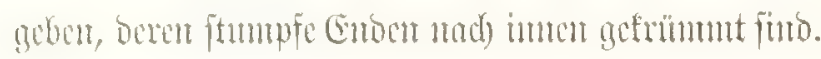

Ting. 4. Erysiphe aceris (De Candolle).

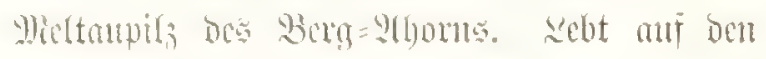
Bhättem non Acel Pseudoplatanus.

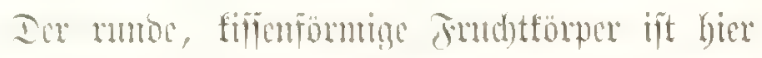

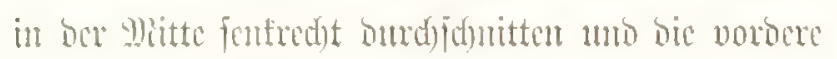

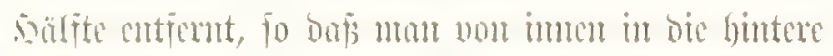

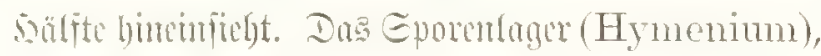

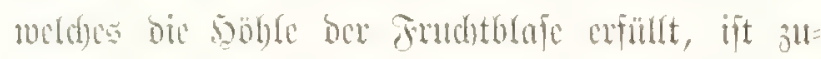

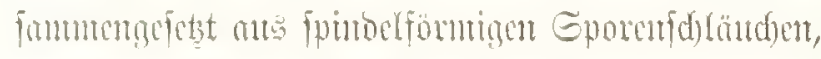
bic je adht Growen enthalten, uno ans gegleberten,

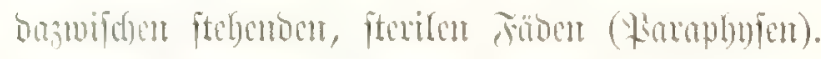

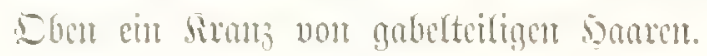

\section{Fig. 5-9. Drommtn dex Sermpilge}

(Pyrenomycetes nidr Peritheciales).

Sitg. 5. Cucurbitaria macrospora (Tulesne).

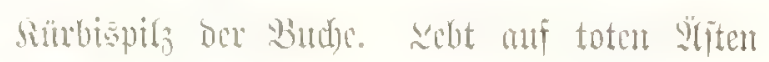
von Fagus silvatica.

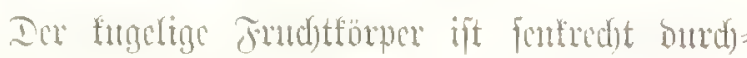

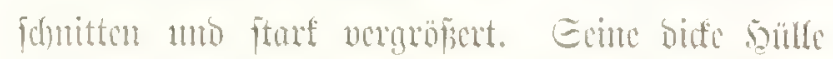

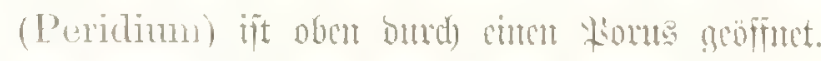

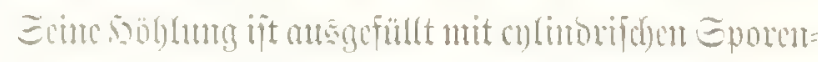

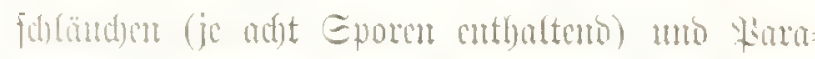

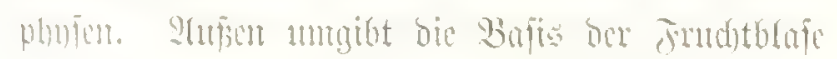

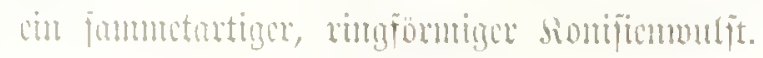

Jig. 6. Ilypomyces chrysospermms (Tulasne).

gilzaparafit anf sedderpilzen. sebt anf bem Frudjtförper be Boletus tomentosus.

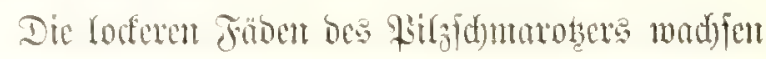

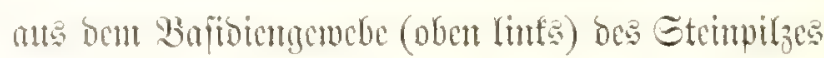
hervor, auf weldem ber Ed)marotzer lebt. Sie tragen

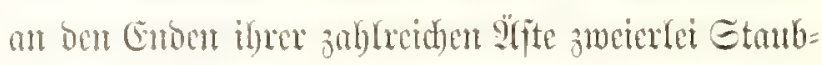
Fporen (Conisia): die gröferer (Macroconisia) finto gologelf unto ftad)elig rauth; bie fleimeren (Microconisia) füno founcewein mo glatt.

\section{Jig. 7. Hypomyces asterophorus (Thlasne).}

Sirzparafit anf Blätterpifzent. Sebr auf bem Fruthtförper von Agaricus-Prtent.

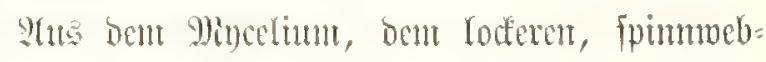
äfnlid)en Fubcugeffed)t, bas ocn vegetativen Siörpex

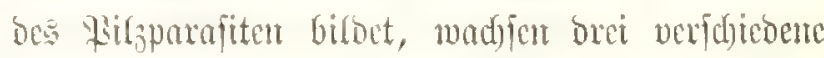
Fortpflanzumgsorgane herwor: 1) bie getäfelten, fu=

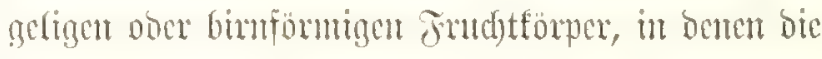
Sporen entjtelen (oben red)ts); 2) bie jarten, ver= äjtelten Fäben, an benen bic gröp̃eren, ftadjeligen Stanbjporen herworfmofpen (Macroconisia, oben (infis); und 3) Yanne, gegficoente Fäbon, bie fid

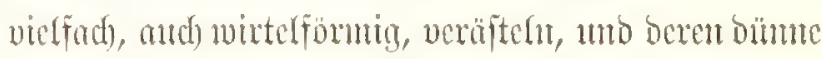
Cmoäte bogenförmitg gefduwungen funb; bic cingehnen

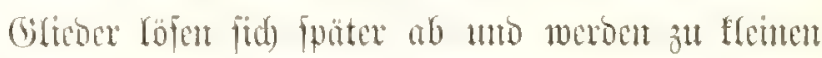
Staubjporem (Microconisia).

\section{Jig. S. Melanconis umbonata (Tulasne).}

Ruñtaupir ber Eidjeminoe. Sebt anf abgeitor= bener Rimbe you Quercus.

Cinc Gruppe von fpunderöorntigen, fantggepticlten Sontifenfrudten (Pyenoconisia); jede foltefit chre Sette von 4-8 Staubfiporen (Conisia) cir.

\section{Jig. 9. Pleospora herbarum (Tulesne)}

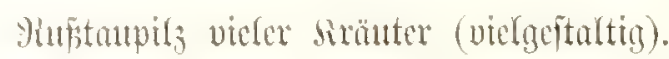

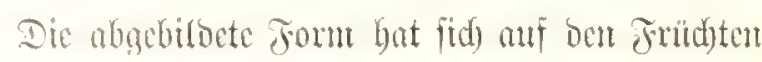
von Cucurbita, bie burd) sisinteripoit jerifort füro,

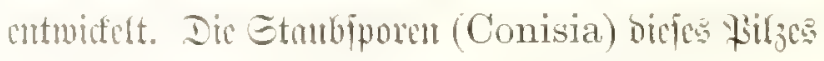

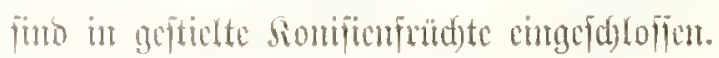




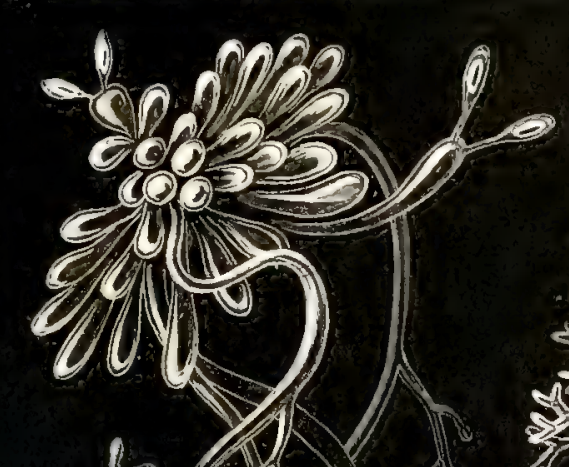

(c) 610

10 N No 2.1 Nol A o $1.1 \times 1)$ (1) 13

(1) $1 \mathrm{~N}^{3} \mathrm{~s}$

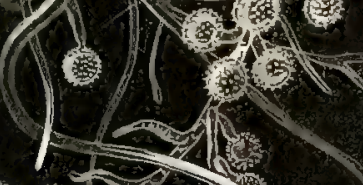

(6)

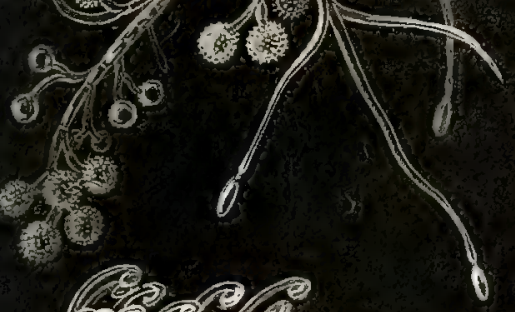

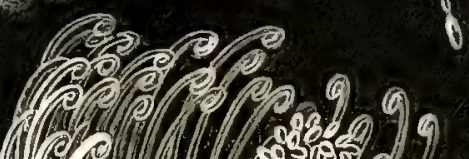
(Nof(p)

- 1 ( ring

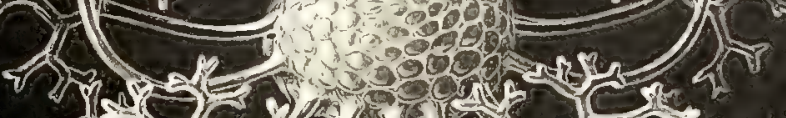
nances

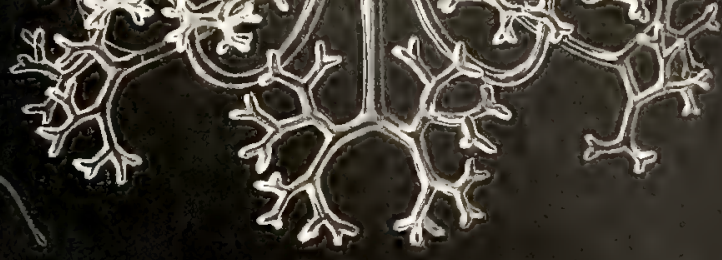

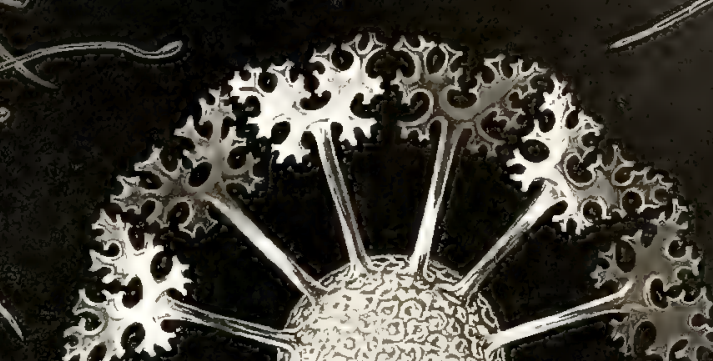
Hen

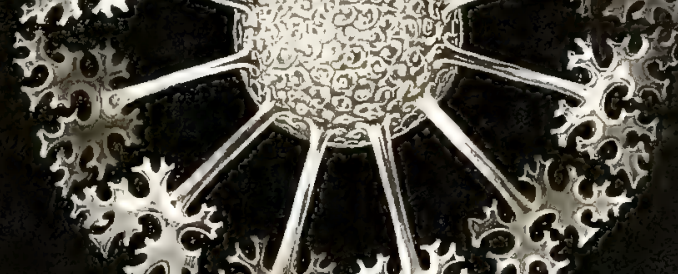

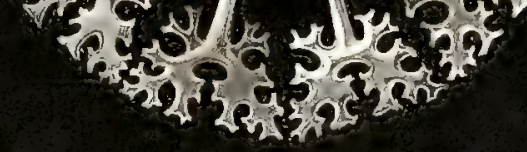

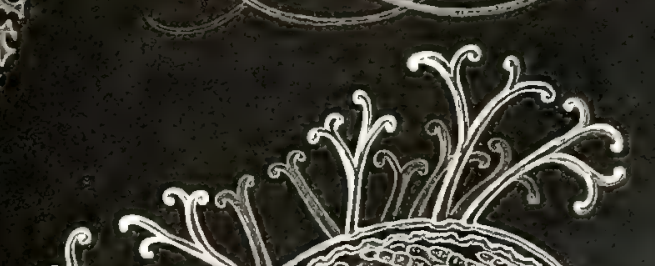

m) 2 s $=-1090$

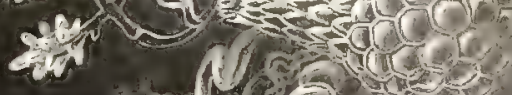
19 8 . (1) (6) a) (P) 23

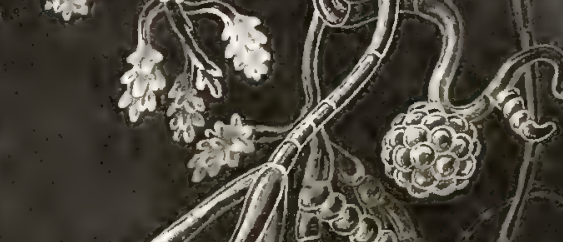

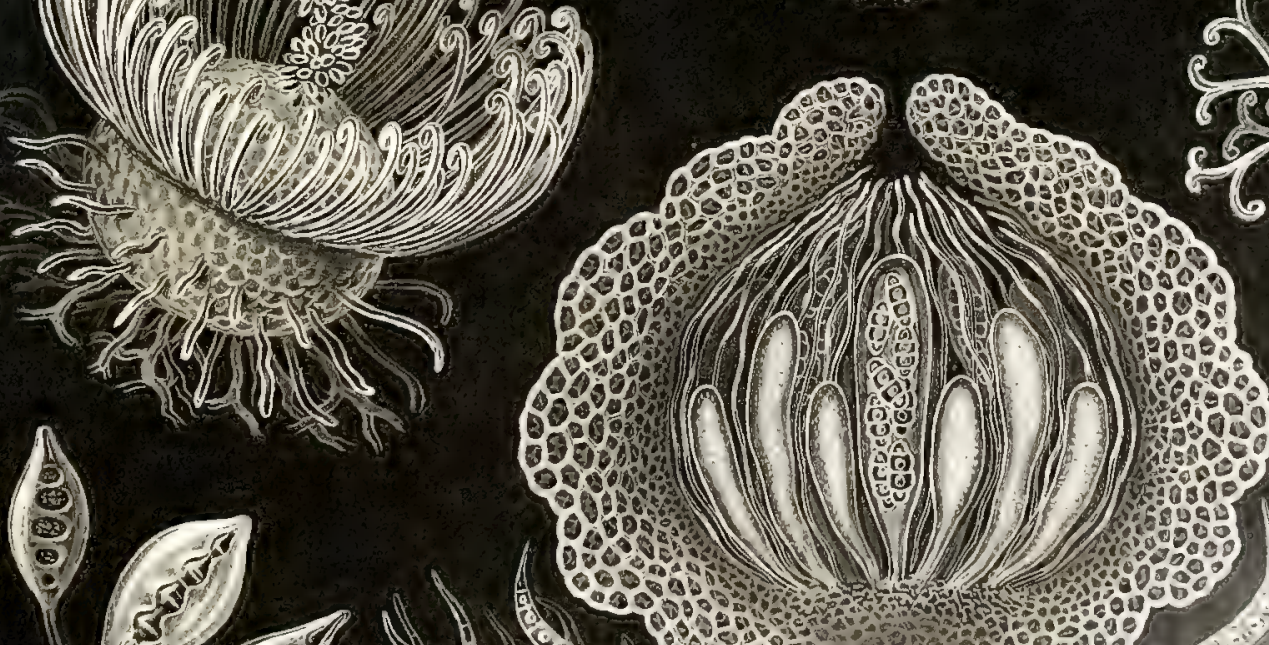

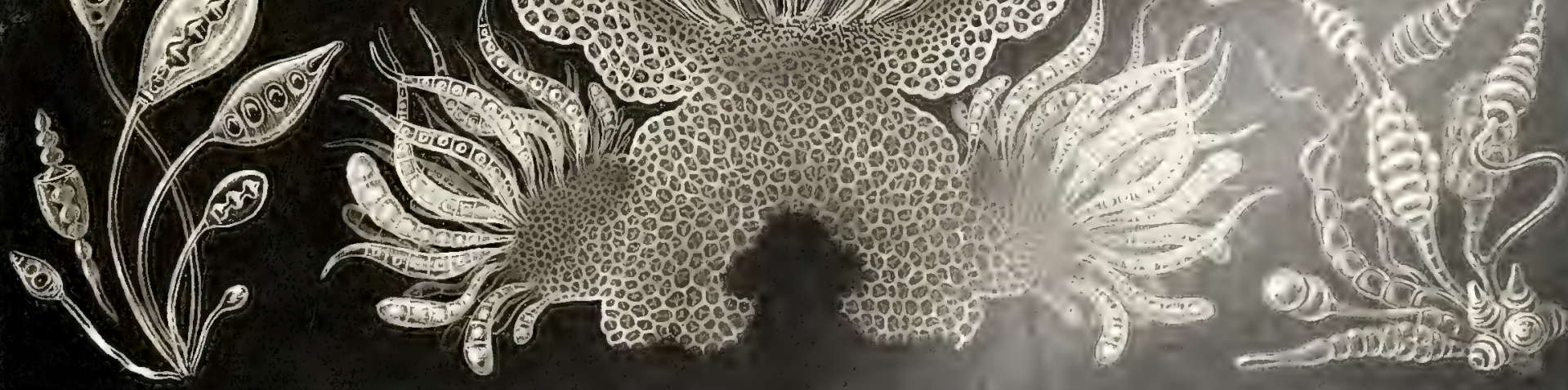





\section{Orchideae. Dumturhmun.}

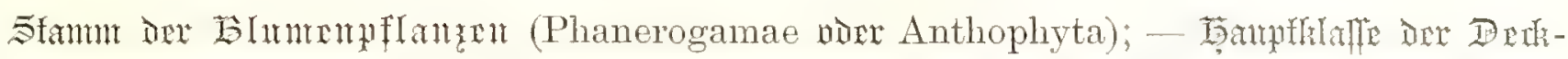

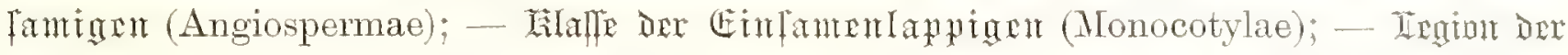

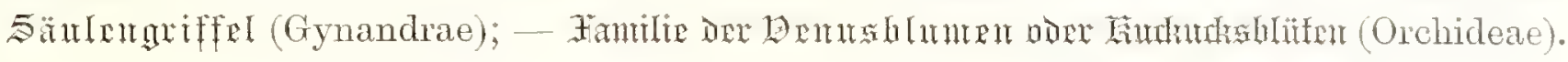

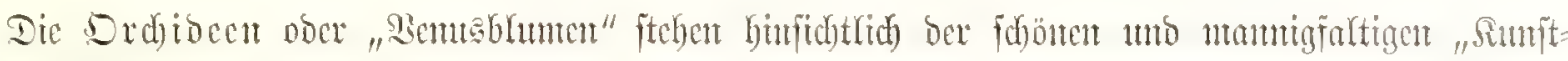

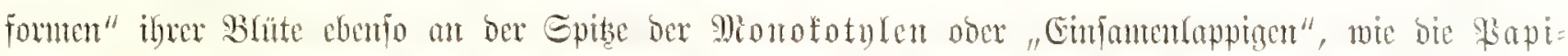

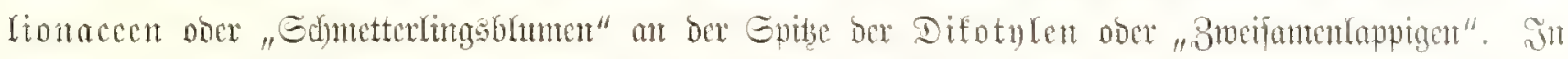

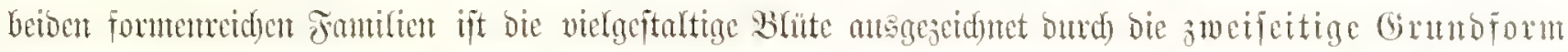

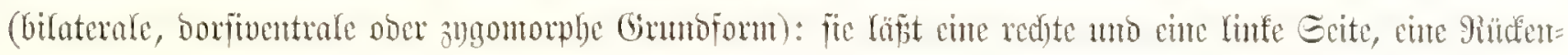

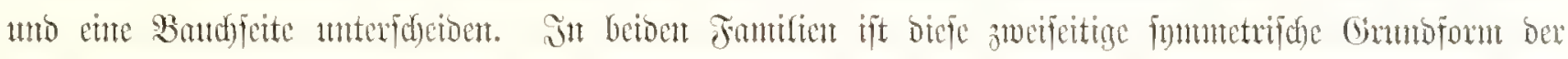

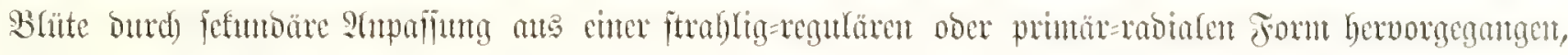

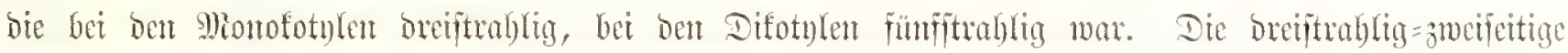

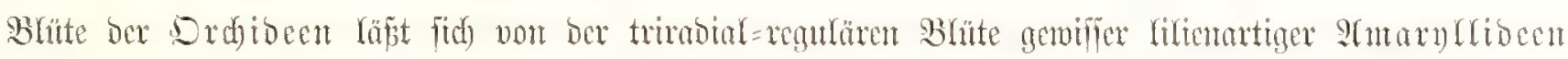

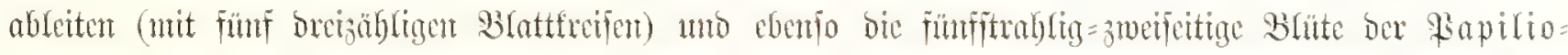

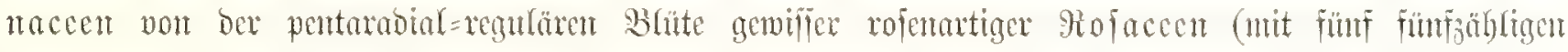

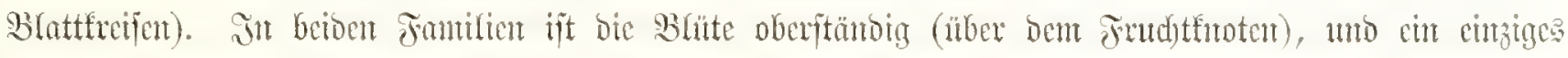

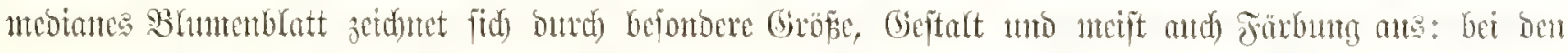

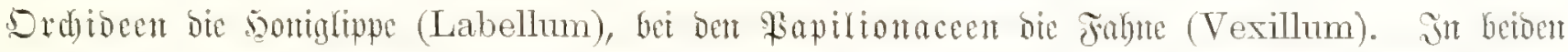

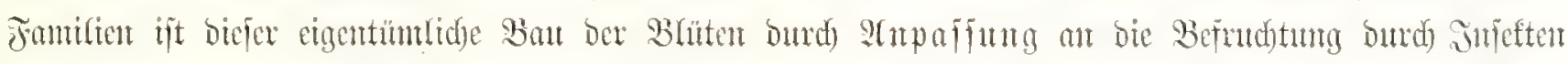

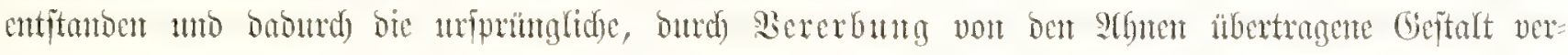

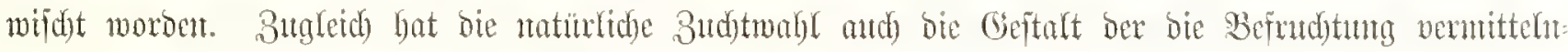

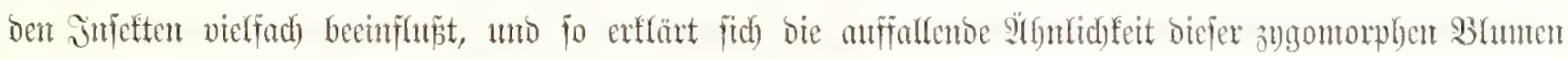
mit Bicnen uno Summefn, Fltegen uno Edymetterfingen.

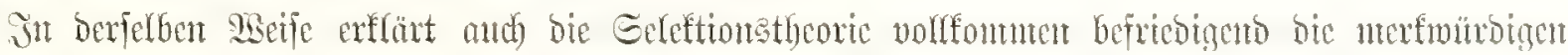

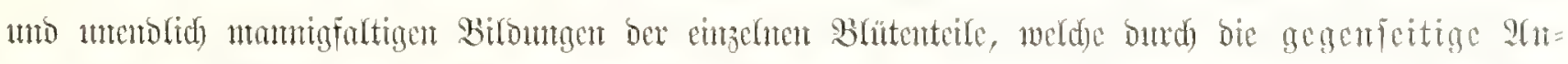

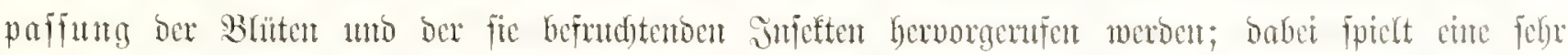

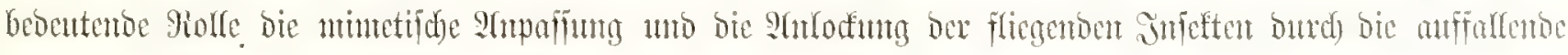

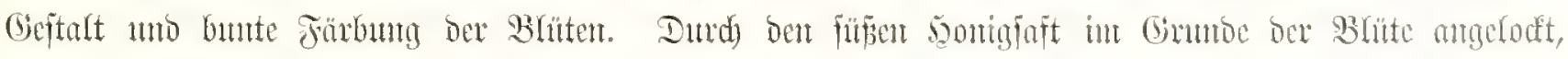

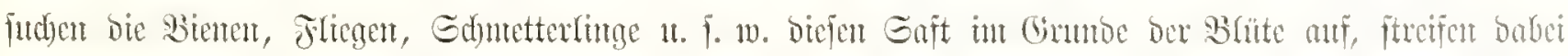

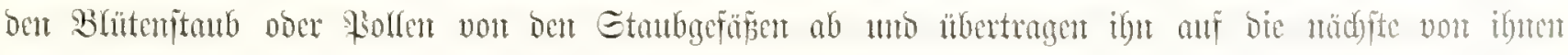

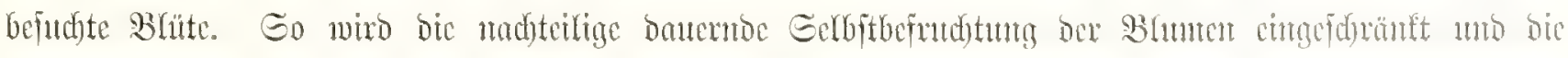

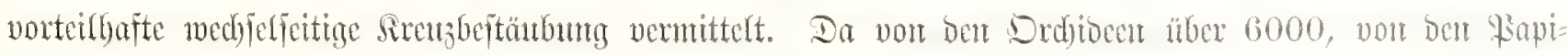

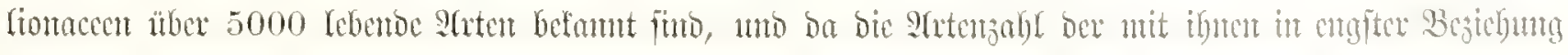

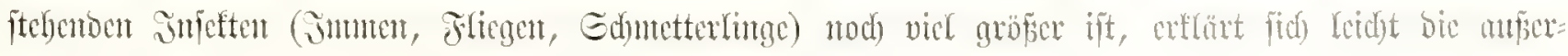

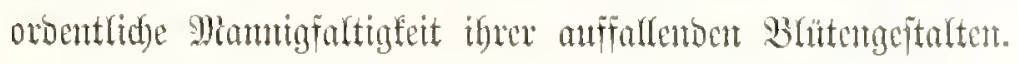




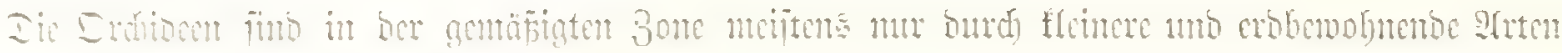

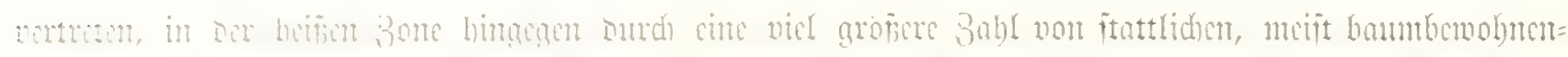

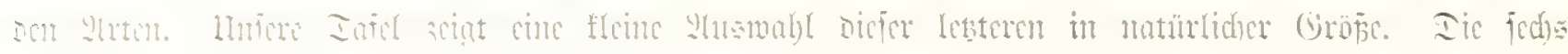

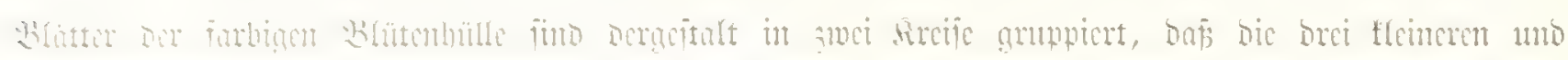
Fomberen

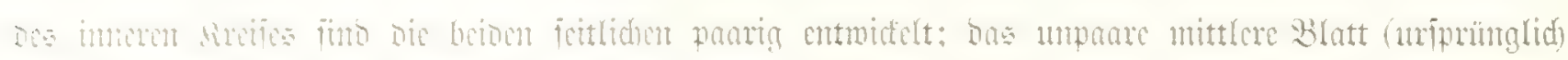

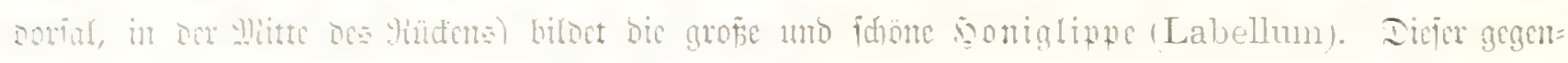

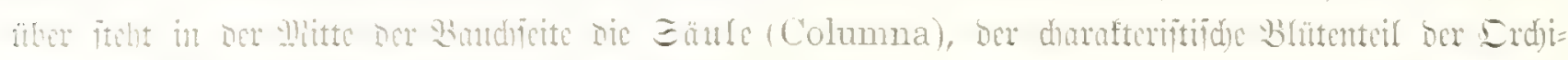

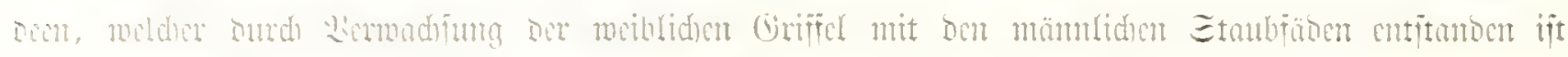

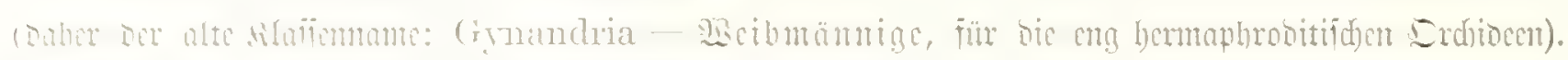

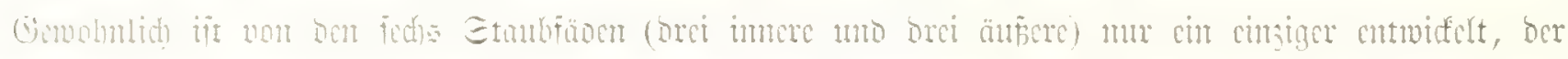

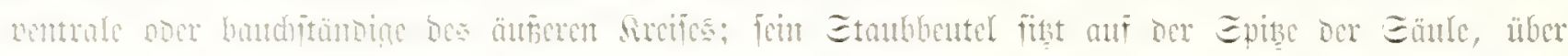

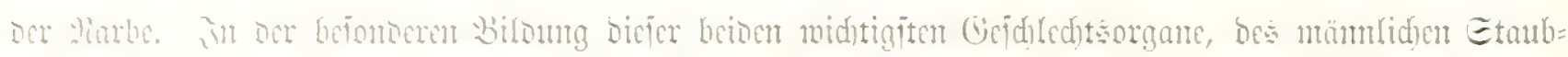

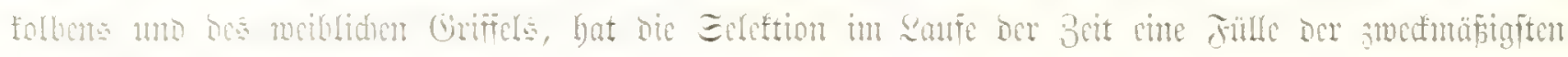
Cimmidumnen munidelt.

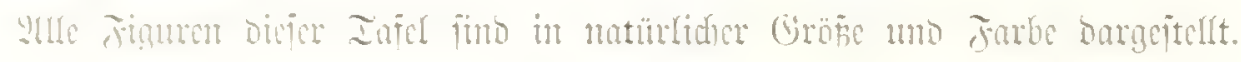

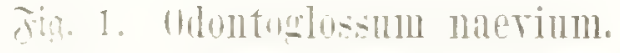

Fin. "2. Oncilium kramerianum.

Fig. Od. Odontoglusim ramosissimum.

ritg. Ł. Gdontoglosim schroederianum.

rig. 5. Cattley ballantiniana.

rig. is. Cattleya mendellii.

Tig. †. Typripedim lemuinieri.

Jig. C. Cattleya ruchellensis.
Jig. A. Cypripedium leeamm.

Jig. 10. Odontoglossum wattianum.

Tig. 11. Cattleya Jabiata.

Fitg. 12. Epidendrum atropurpureum

jig. 1:3. Cypripedium arons.

Jig. 14. Paphinia rugosa.

Jig. 15. Zygopetalum xanthinum.

Jig. 16. Oncidium laxense. 

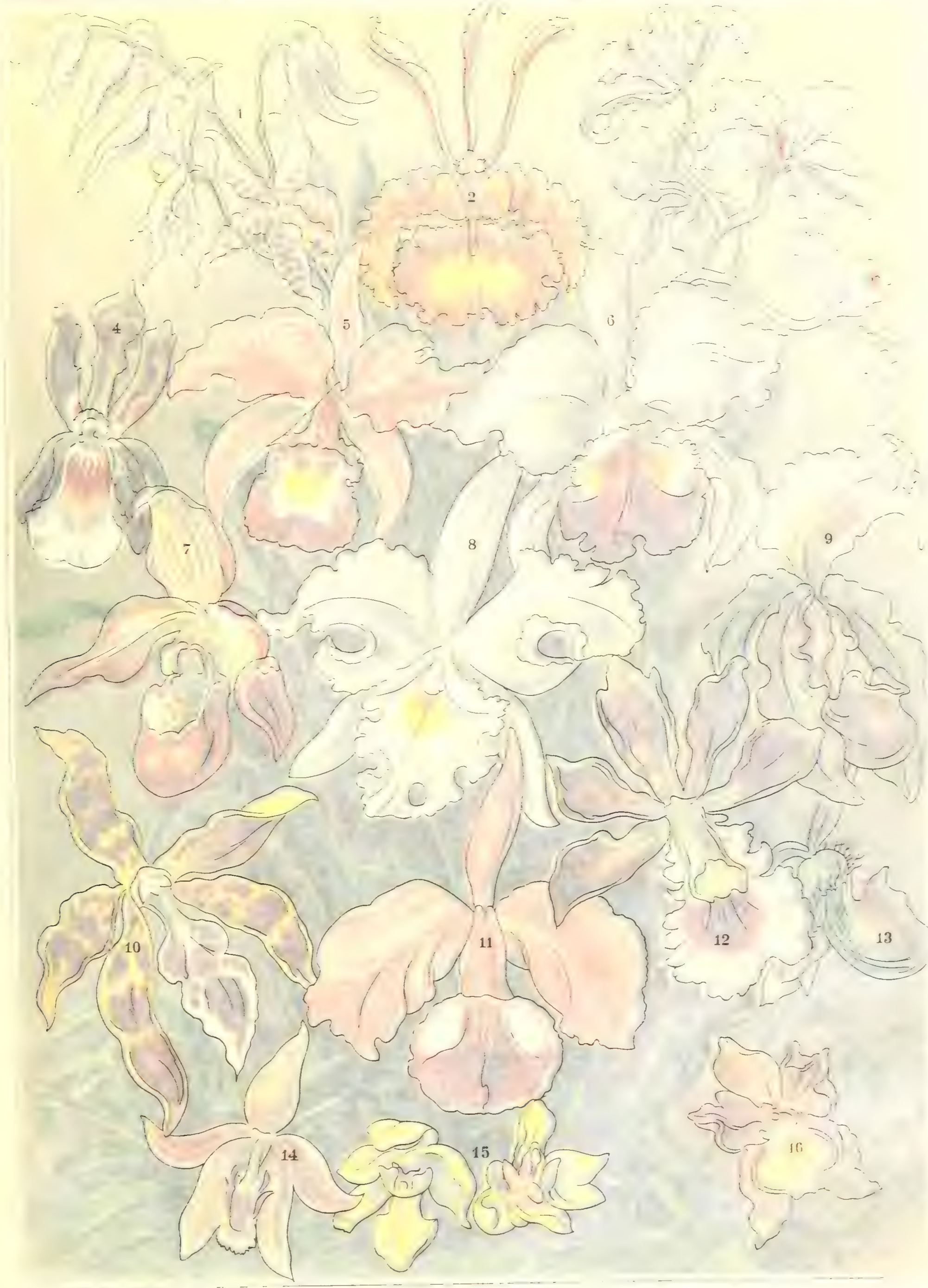


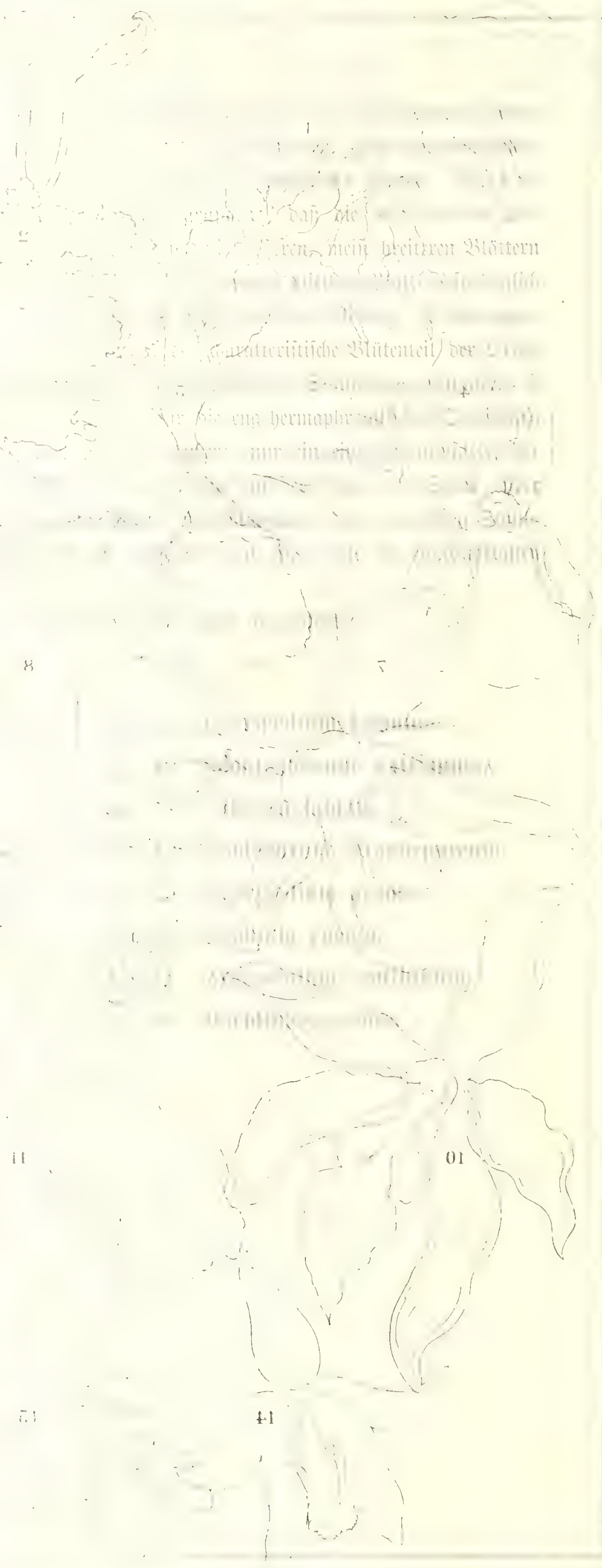




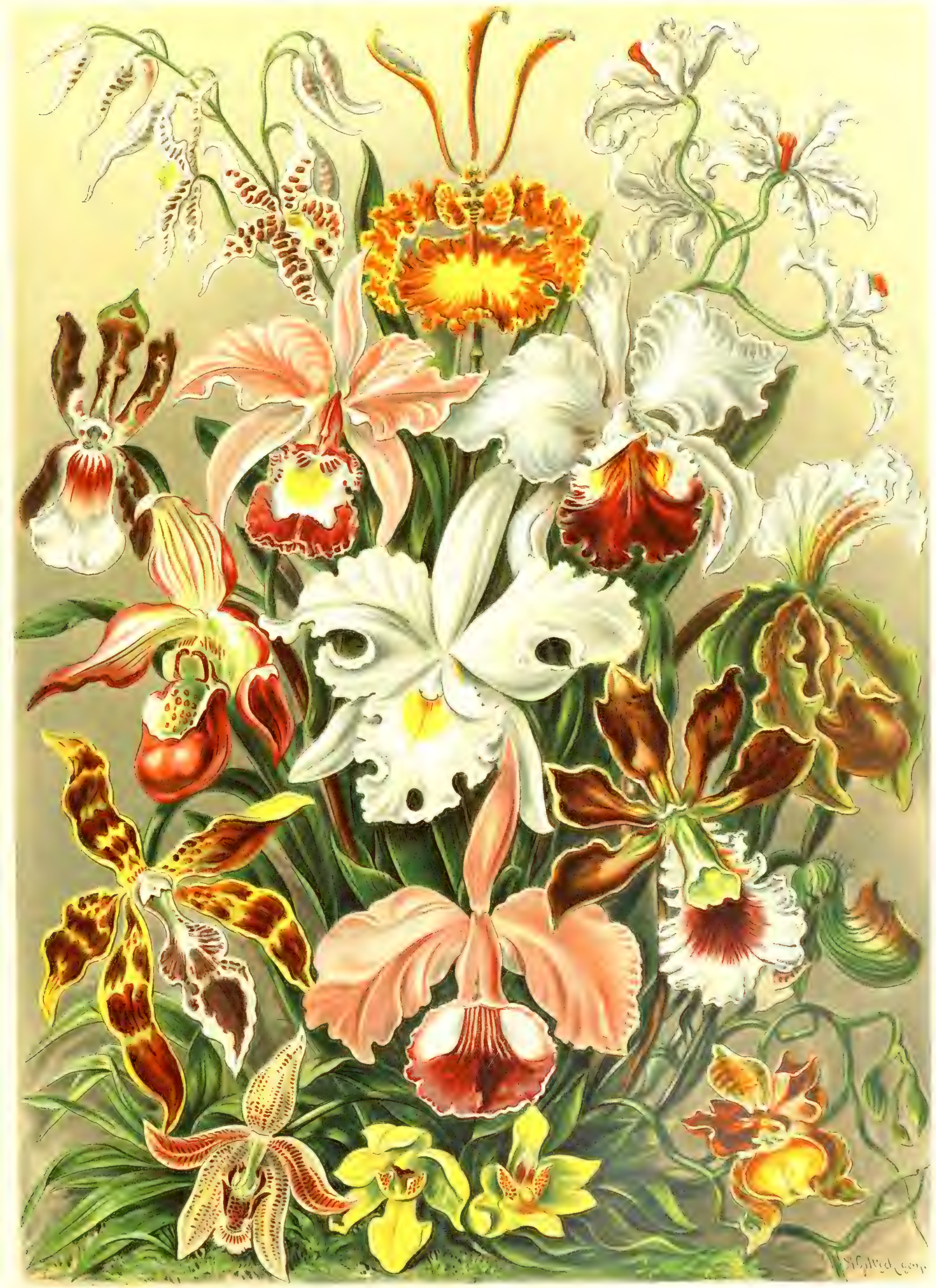

Orchideae.

25entuslitutent. 



\section{Platodes. plaftentiene.}

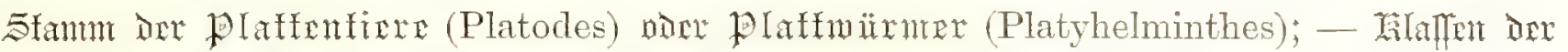
5angmitrmex (Trematodes) mo der Lamomitrurre (Cestodes).

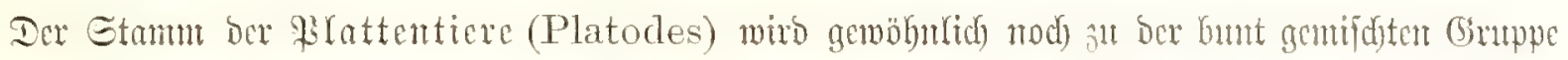

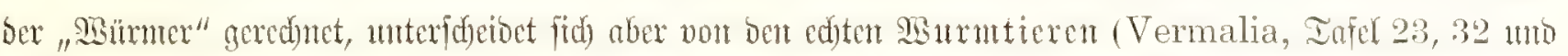

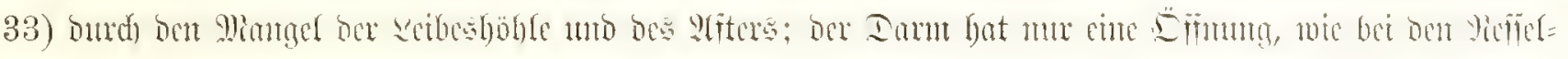

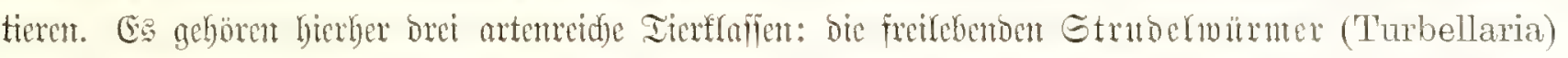

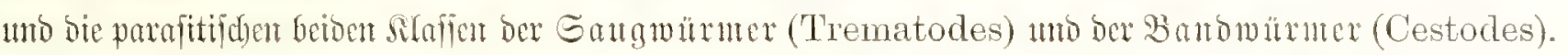

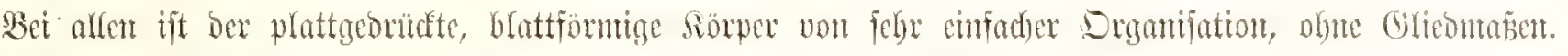

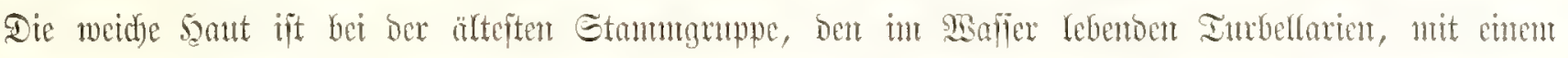

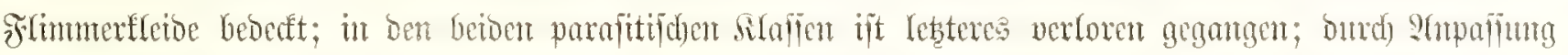

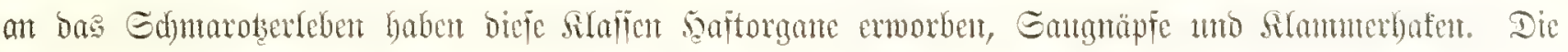

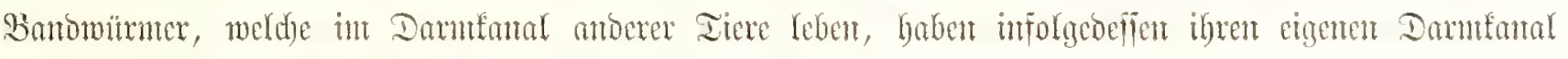

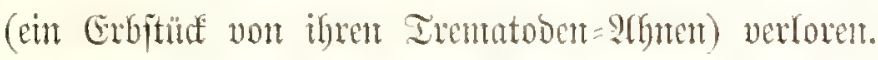

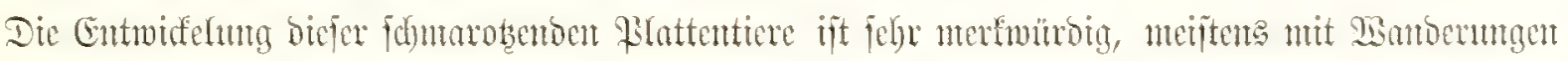

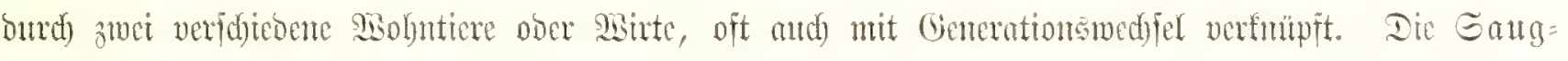

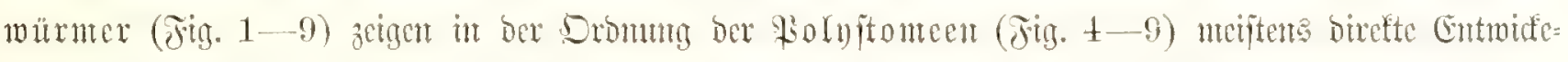

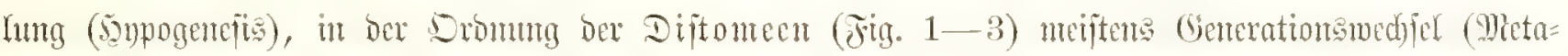

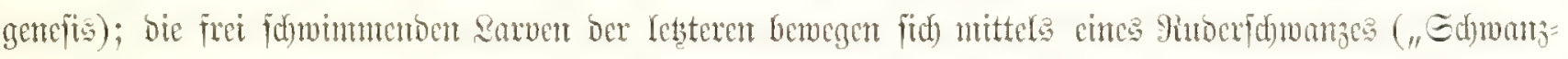

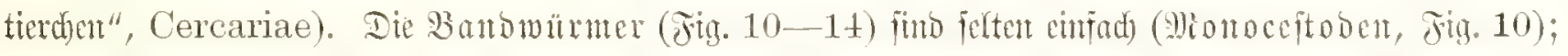

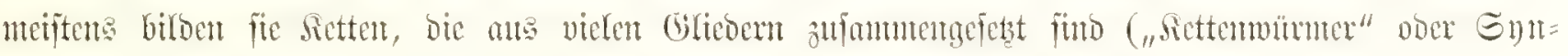
ceftoden, Fitg. 11-1t); jeocs Gifed (Froglottide) entipridyt cimem Mionoceftoden.

\section{Fig. 1. Cerearia dichotoma (Johannes Mritler).}

Freifebento Irentatobenfarve me ber Gat=

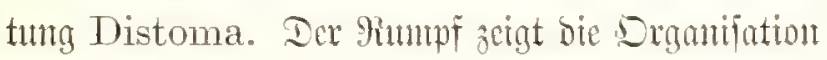

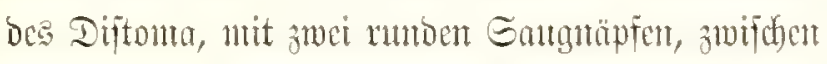
Denen ber (gelbe) Domnfanal, mit zmei Gabeläjten,

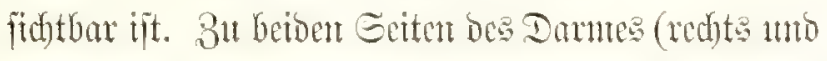

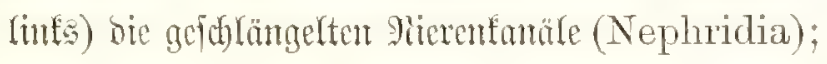
biefe münben in ben żmetarmigen Behälter, weldecr

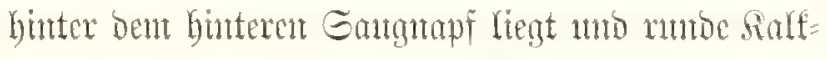

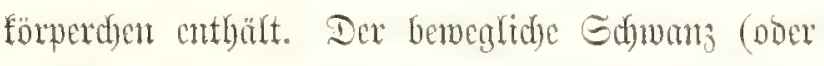
ber hintere förperteil) ijt gabelfualtig.

\section{Fitg. 2. Cercaria spinifera (La Talette).}

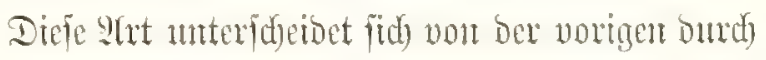
eincm ftadjeligen Salsfragen Ginter Dent vorderent

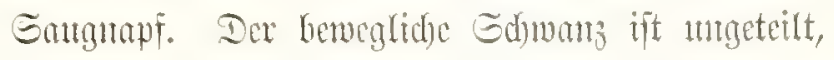
unit cintem bümen, floffenfönntigen bautfoum.

Fing. 3. Cercaria bucephalus (Ercolani).

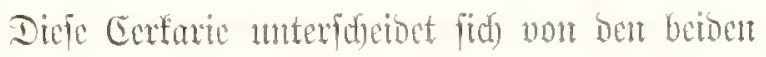

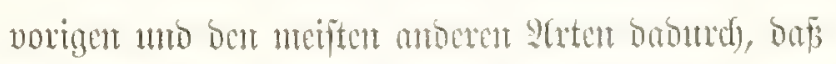

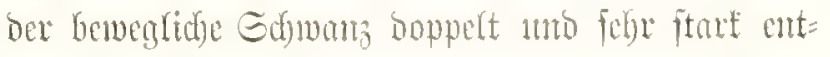

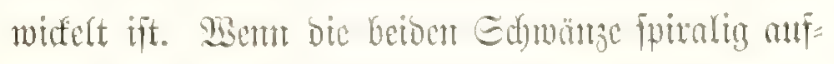

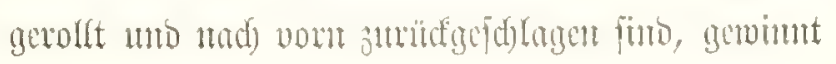




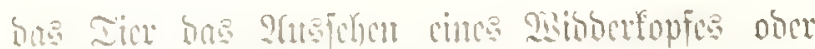

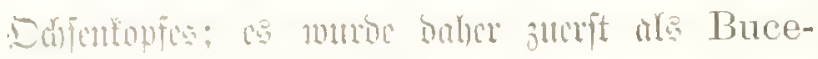
phalus polymorphus (Sichold) beforichen. Der

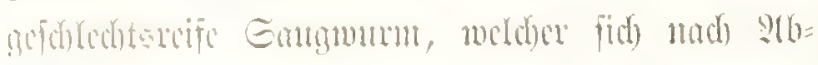

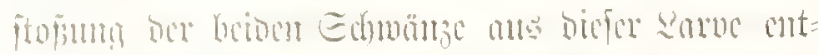

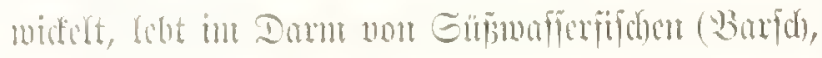

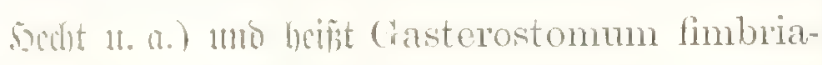

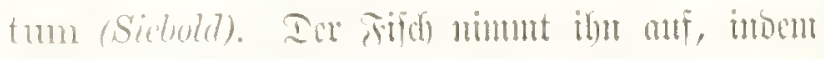

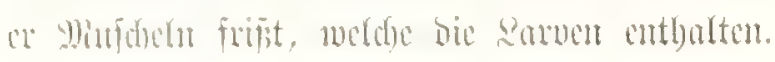

Ting. 4, . P.olystomum integerrimum (Rudolphi).

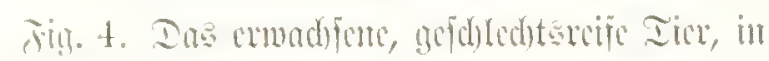

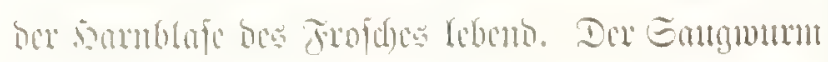

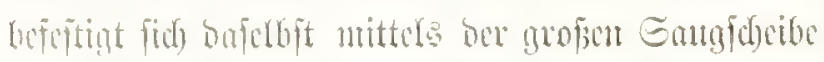

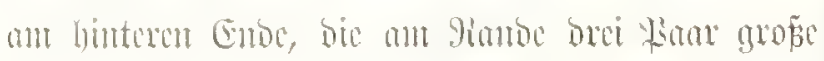

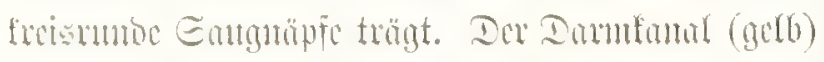

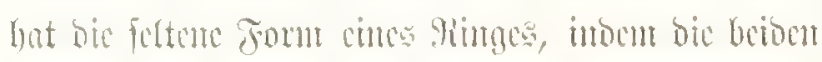

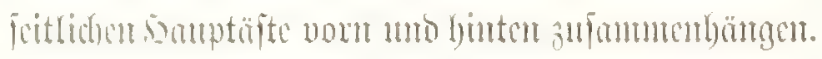

Tig. 5. Dic unteife anvo besfelben Iitres,

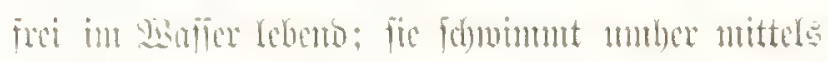

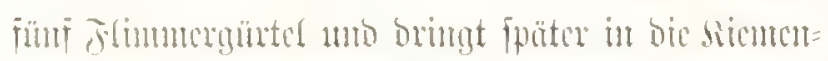

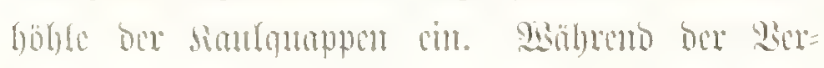

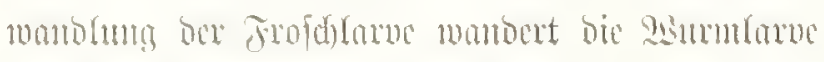

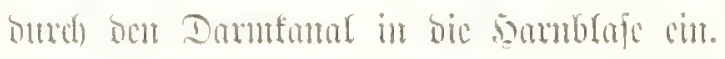

\section{jig. 6. (ivrodactylus elegans (Nortmam).}

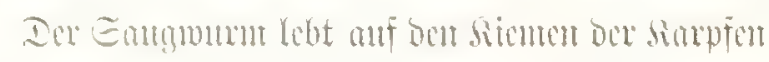

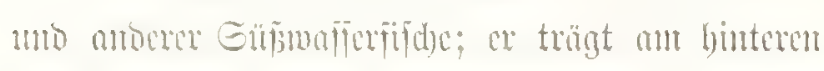

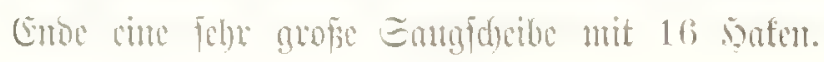

\section{Trig. 万. Diplozoon paradoxum (Nordnann).}

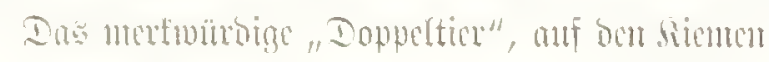

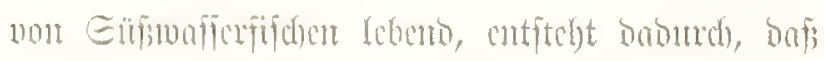

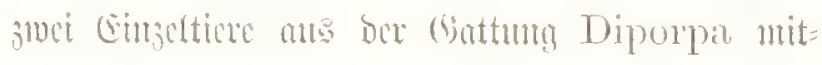

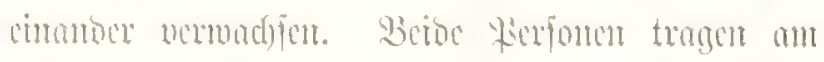

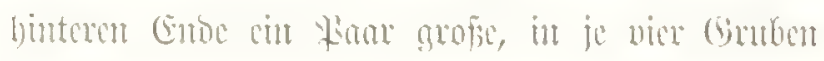
getcilte saftfdecifen uno anferbent in ber yitte cumen

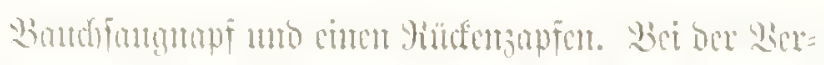

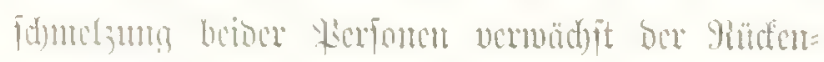

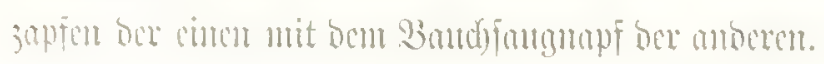

\section{Fig. S. Tristomum coccineum (Curier).}

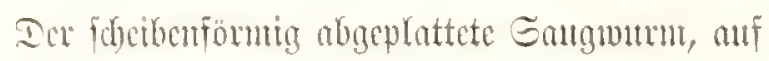
Jifden fommarotzent, ift burd) brei Gamgnäpfe be=

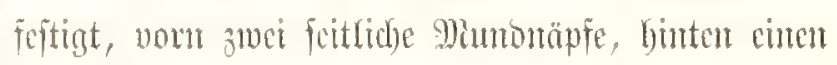
grō̌en rabfönmigen baud)uapf. Der Darm (getb) bifoct cinen breiefigen Ming mit viefen siffen.

\section{Fing. 9. Callicotyle Kroyeri (Diesing).}

20r ben cuifad) gabelteiligen Darm (gelb) ricgt

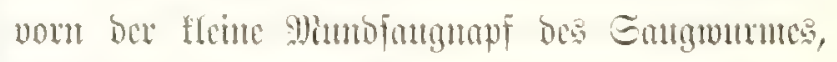
Gintent oor grofie, robfömige Baudjangmapf.

\section{Fin. 10. Caryophyllaeus mutabilis (Rudolphi).}

Dicfer ungegriconte Relfenmunn, int Dame Dor Sarpfen lebent, vertritt bic Ginupe ber cinfachen Bantowitumer (Monocestoda). Dic imteren $D \mathrm{D}=$

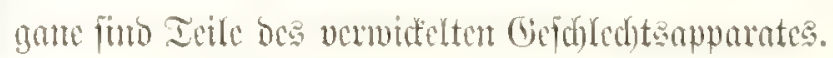

Fin. 11. Tetrarhynchus longicollis (Cuvier).

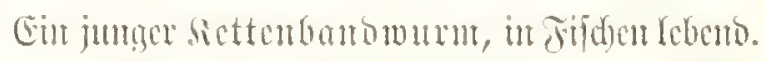

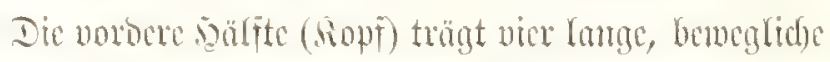

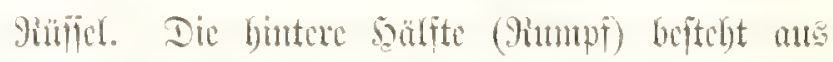

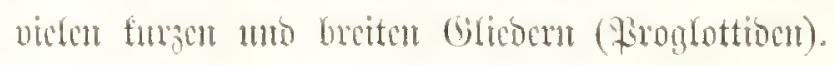

\section{Jig. 12. Phyllobothryon gracile (Van Beneden).}

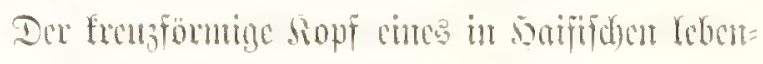
ben settenbanosurnes, mit nier grofien, ge

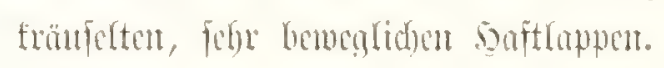

\section{Jin. 13 4. 14. Taenia solinm (Rudolphi).}

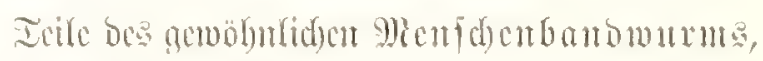

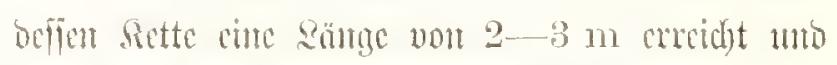
me $800-900$ cunsthent Ghedem bejtelyt.

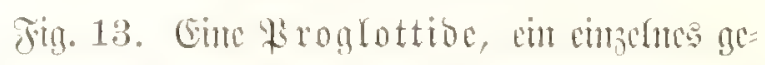

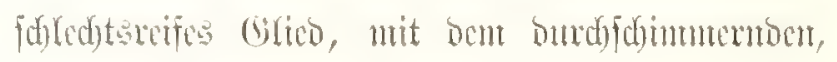
veräfteltem estbebälter (literusis).

Jig. 14. Der Banowurntopf (Scolex), vom

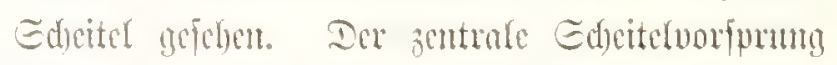
(Rostellum) ift nit cimen sirange von 25-2S

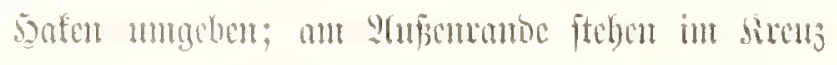
vice grofie numoc Gangnänf. 


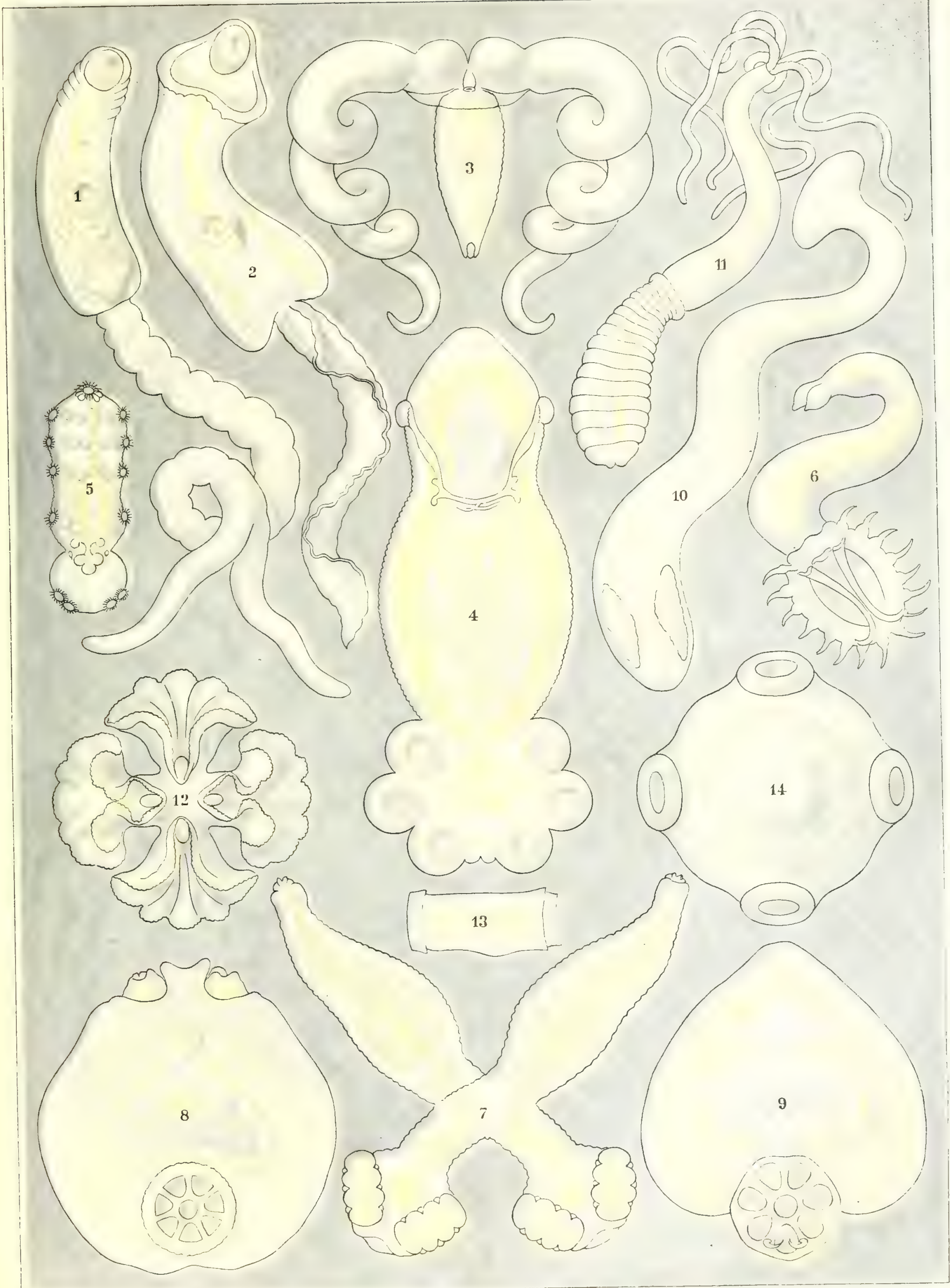





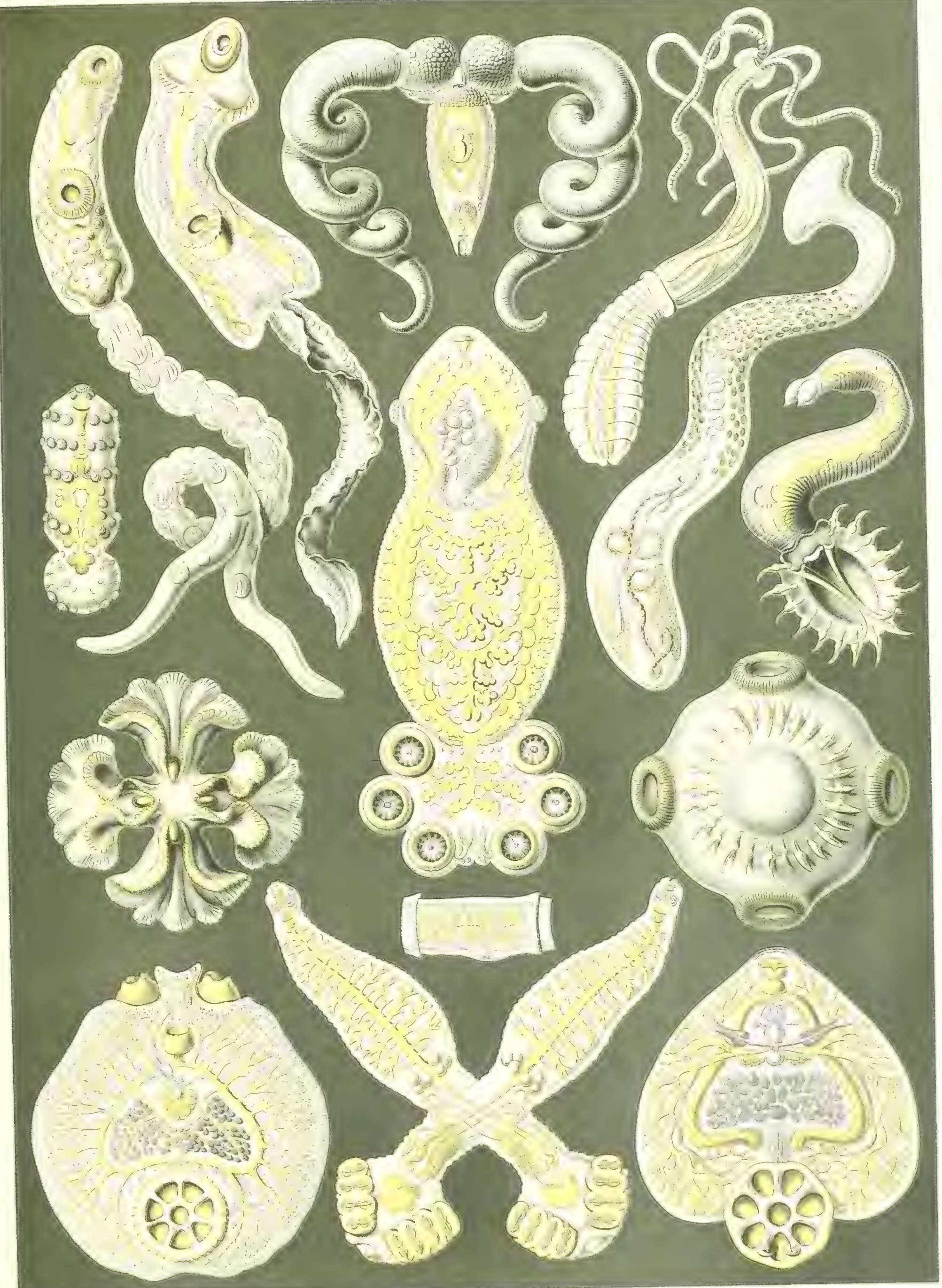

Platodes. aaffentiere. 



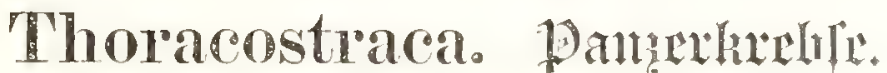

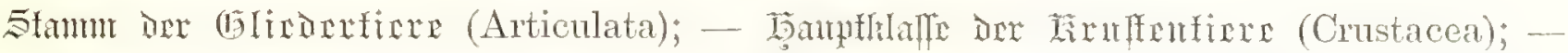

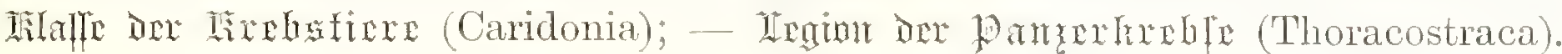

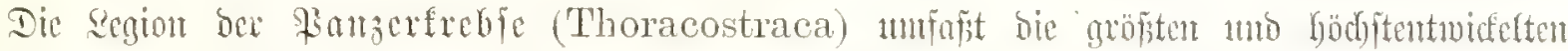

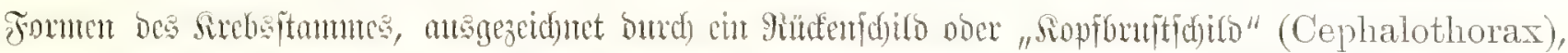

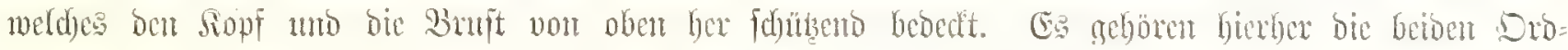

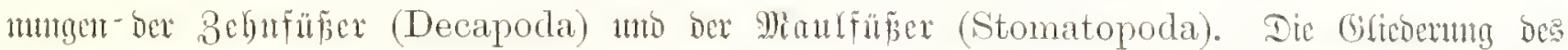

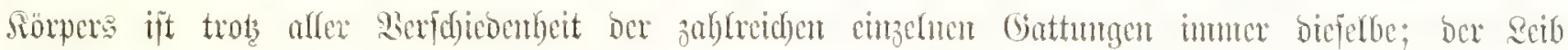

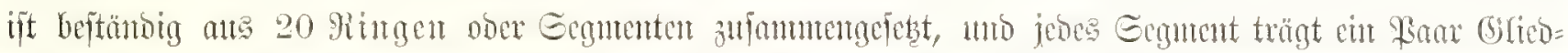

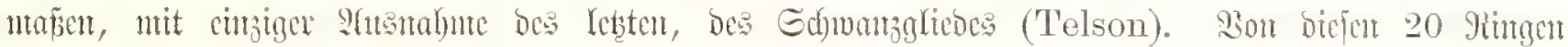

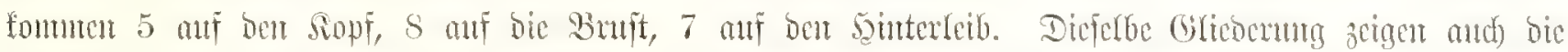

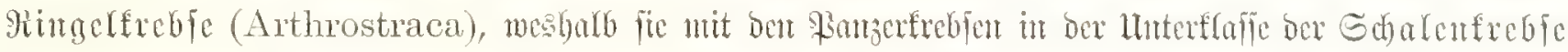

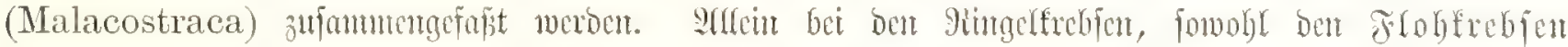

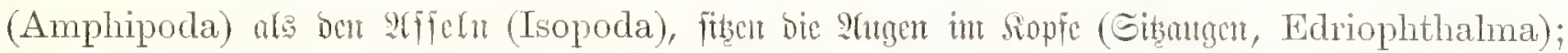

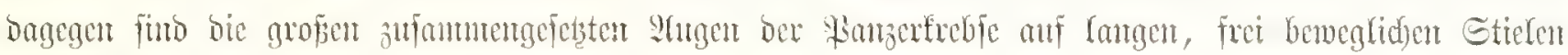
angebradits (Etielargen, Podophthalma).

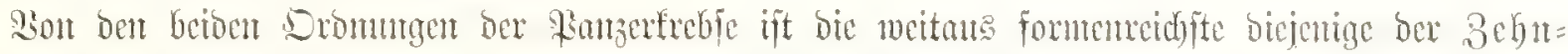

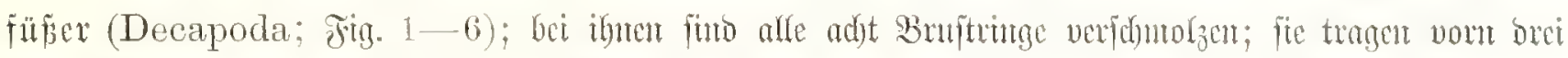

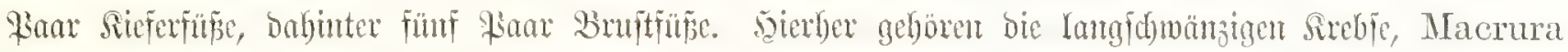

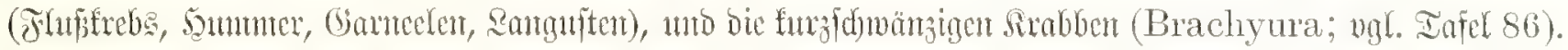

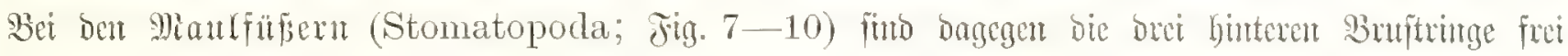

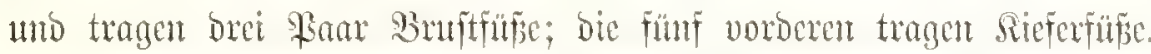

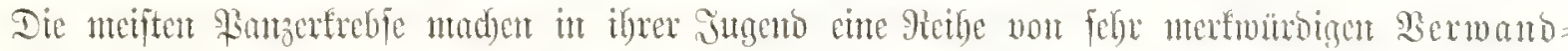

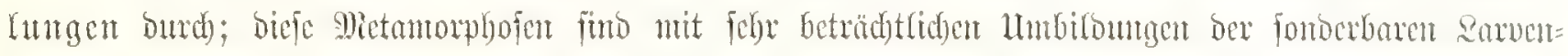

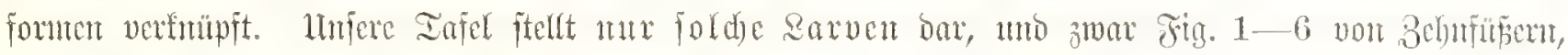

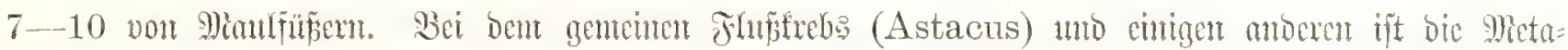

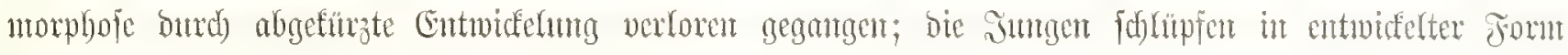
ans bent cit.

Fig. 1. Lucifer typus (Mitne Eduards). Irantite ber (1) axmeden (Caridina).

Gastrula, Sicin bes Iimes in dom bedentury volfent Sutgentioftabiunt, in weldyent ber grodentröntutige

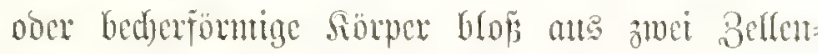
Fichiden beftebt, ben beiben printären Siemblättem.

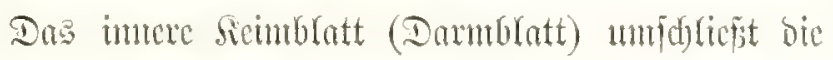

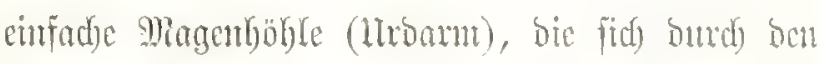

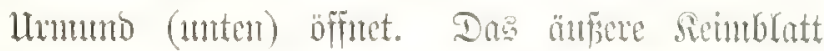

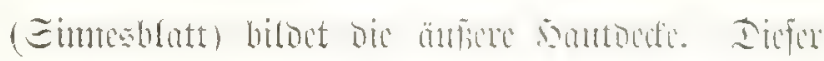
Gastrula-3uftano ift allen Gemebeticen (Meta-

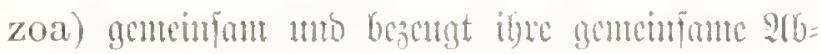
ftommung von chror Gtanmiform (Gastraea); $\mathfrak{c r}$

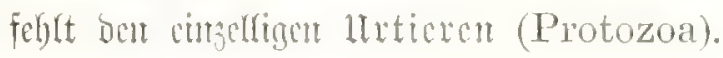




\section{Fin. :. Penaeus Juelleri (Haceliel).

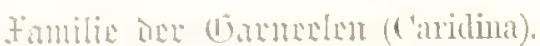

Natuplins, surve bes Eicres in bent beocut

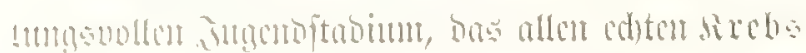

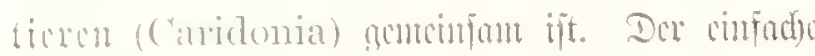

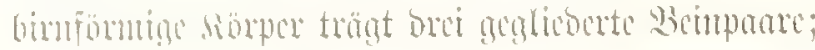

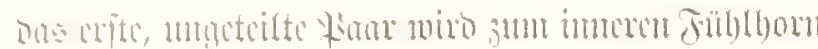

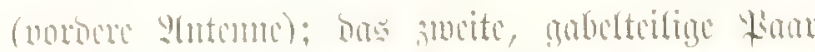

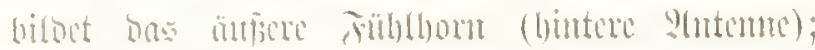

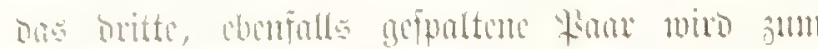
Ebrtictu (Mandibula).

Fin. 3. Mastigopus dorsipinalis (Spenee Bate).

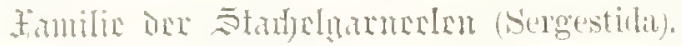

Emu von hergestes temuis (Spente Bate).

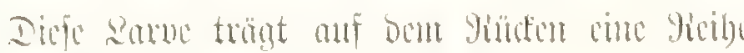
nou sutrummenten Stududn.

Titu. 4. Elaphocaris Dohrnii (Spence Bute).

Fumilie bex Stadfelnameden (Sergestida).

smo von Sergestes elaphocaris (spence Bute).

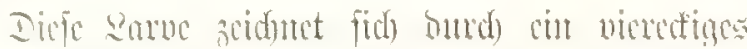

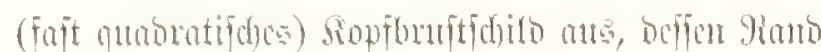
mit neäfteltur Gtadydn bonnfinct ipt.

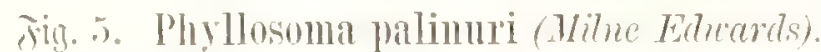
Familie one Lamenuten (Palinuida).

Sarus non Palimurus vulgaris (Latreille).

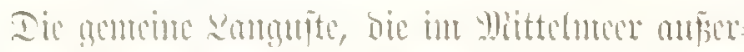

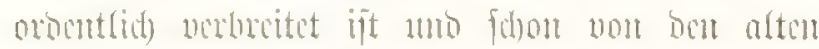

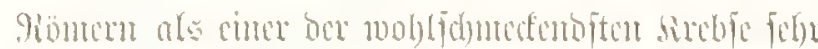

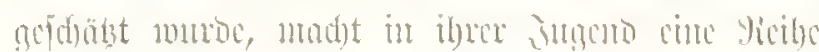

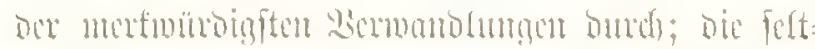

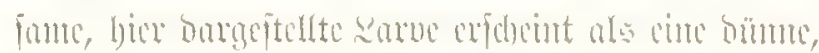

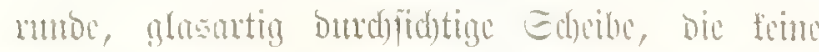

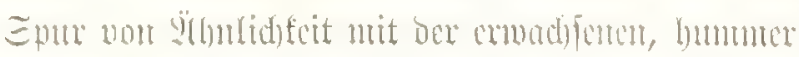

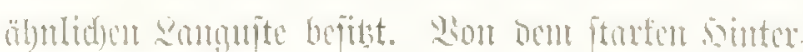

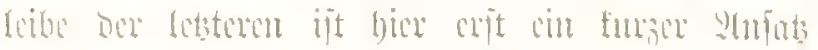

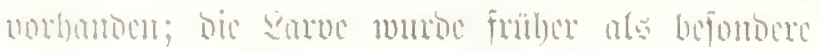
(Gottume, Phyllosoma, befdricbor.

\section{Jig. 6. Zoẹa Carcini (Mitne Edwards).} Familix one Firabuen (Brachyura).

Zoëa-Rarve ber gencincu sirabbe, Carinus Macnas (Leache).

Dic furzafumänigen Defapoden (Brachyura).

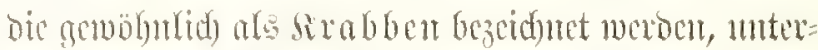

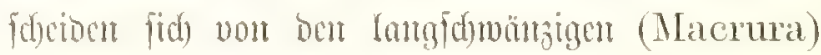

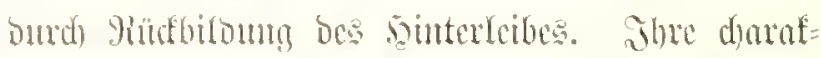
teriftifle 7oëa-save bat cin Paar febr grope

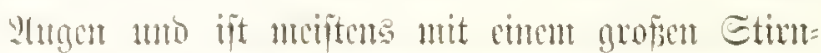

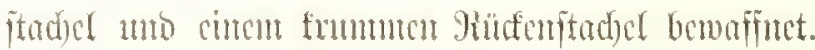

Jig. 7. Gonerichthus chiragia (Brooks).

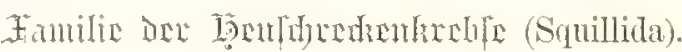

Rarue bes sambidftrofes, Gonodactylus chiragra (Latreille).

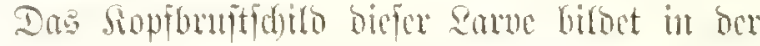

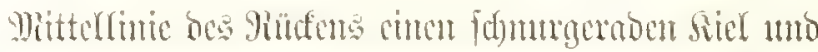
läuft non wno binten in cimen ftarfen Stad)el ats.

Fing. S ano 9. Alima gracilis (Brooks).

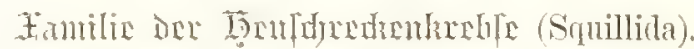

sarven non Squilla gracilis (Brooks).

Dic Rorven von Squilla fumo in ben veriffice

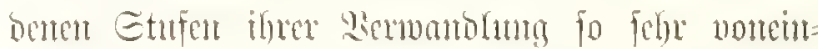

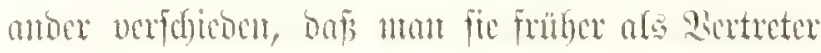

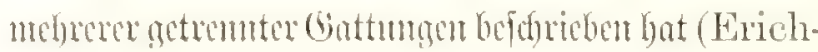
thoïdina, Alima, Erichthus u. f. w.). Der sinterteib, be ber cutwicfelten Squilla febr frout

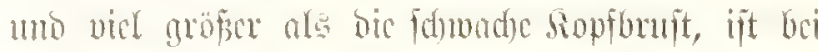
oce jungen Erichthoüdina-sarve nod) unthenenteno.

Fing. 10. Llima bidens (Claus).

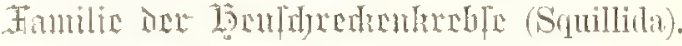

zarve von Squilla mantis (Rondelet).

Dinge abentenerlide sarvenform sedduct fid

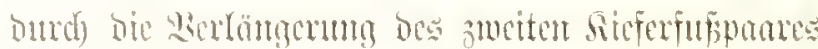

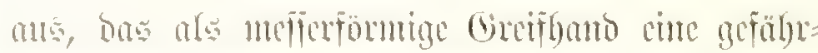

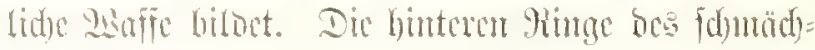

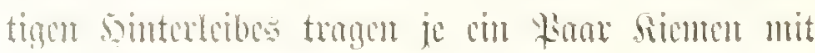
+5 barbgeficonten sifter 


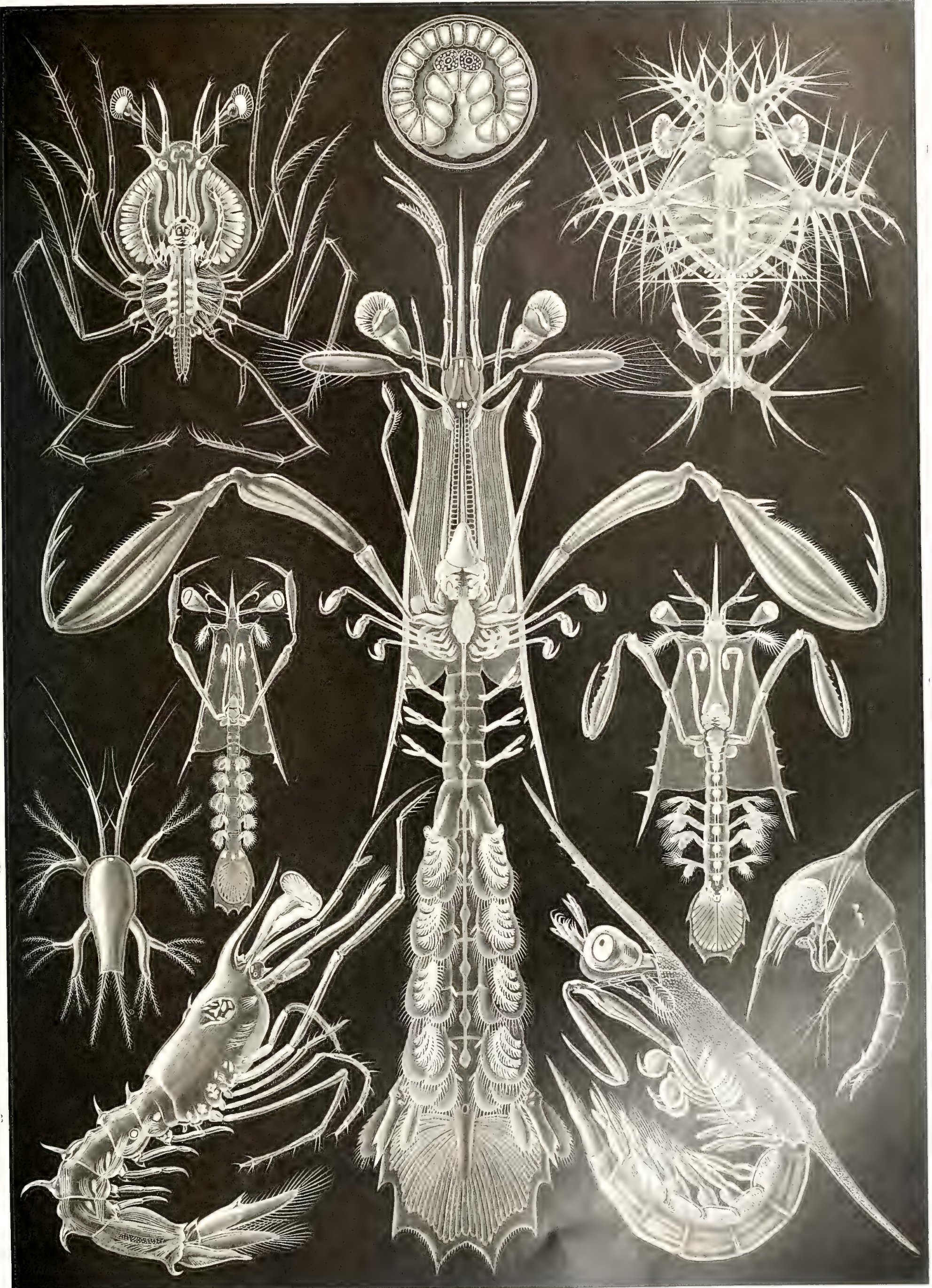

Thoracostraca. - جarserfireble. 



\section{Siphonophorae. Stataxuntallet.}

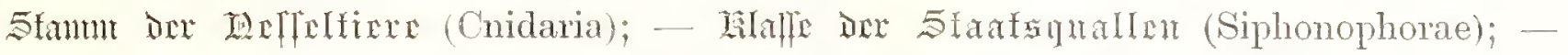
Dromm Dex lieldyquallem (Calyconectae).

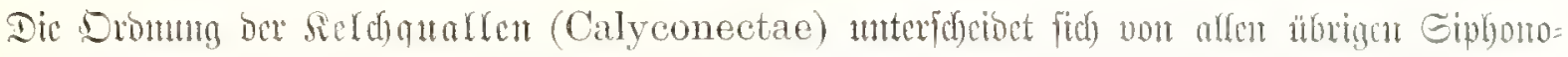

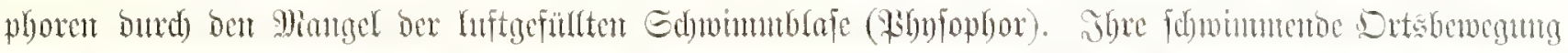

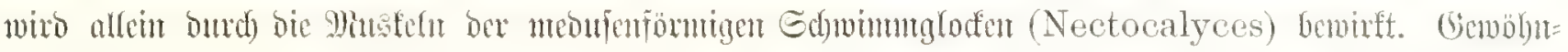

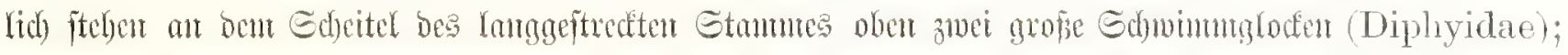

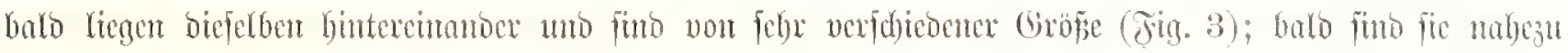

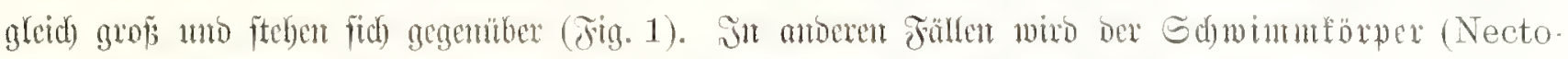

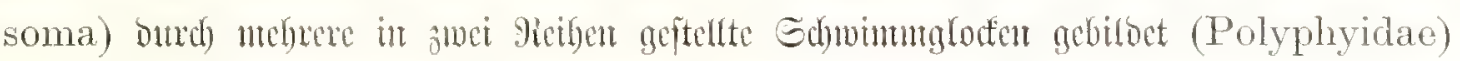

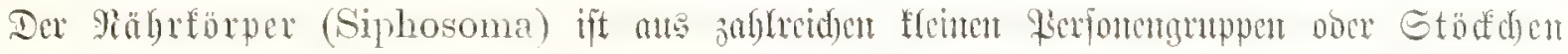

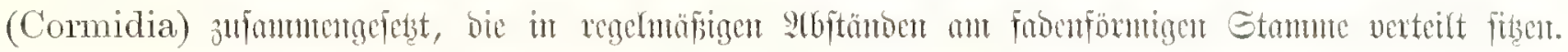

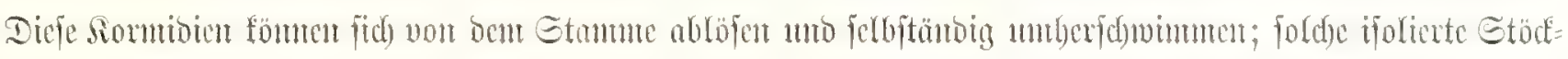

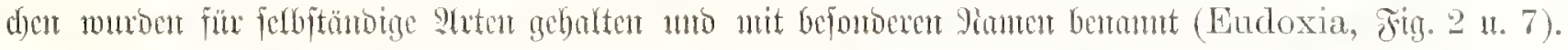

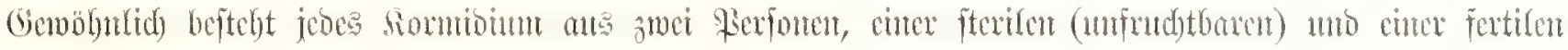

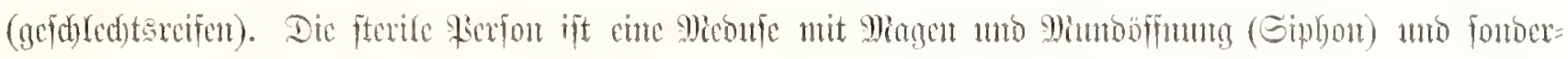

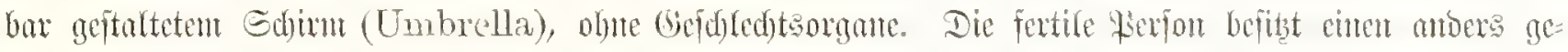

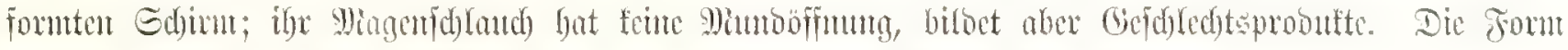

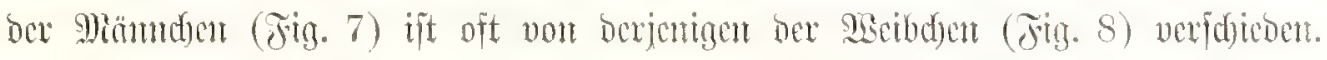

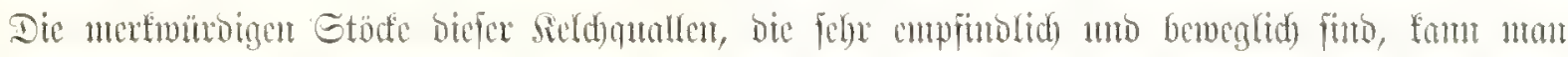

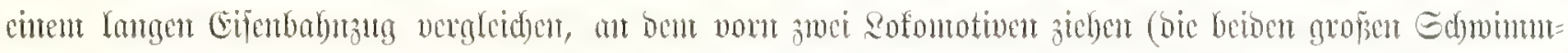

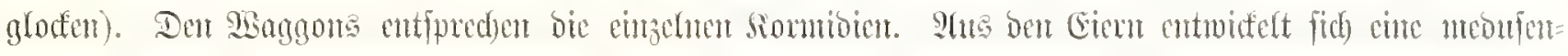

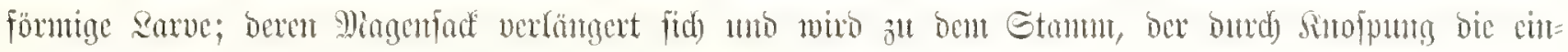

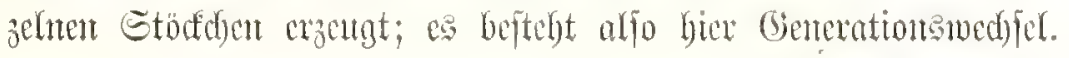

Fig. 1 u. 2. Praya galea (Hacckel).

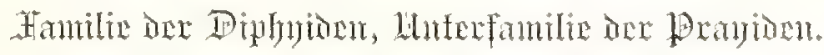

Fig. 1. Der ganze Tieritad (Cormus), von

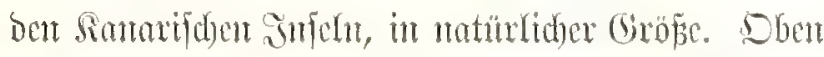

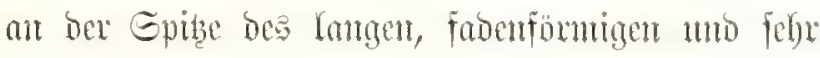
bewegliden Gtanturs fitsen bie betoen gropent

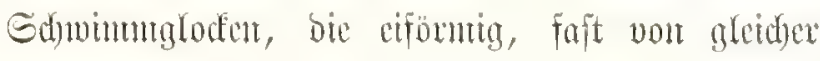

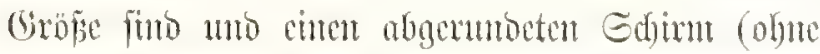

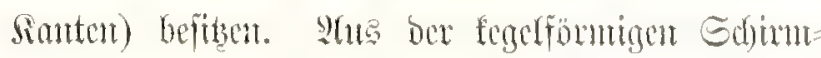

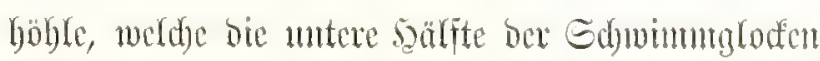

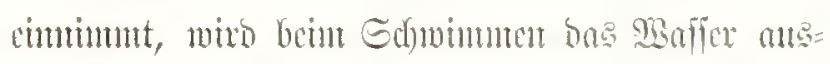

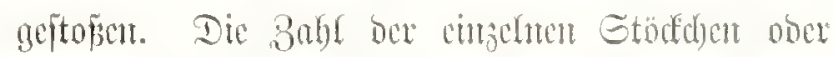

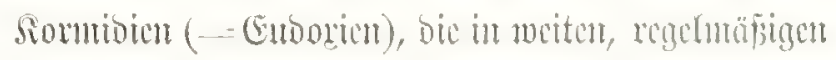
3wifdemtätmen ant Etantme verteilt fitsen, ift bei

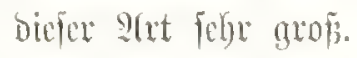

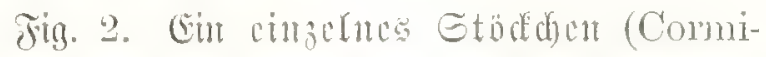
dium) ober cint Eudoxia (bet biefer Yrat als

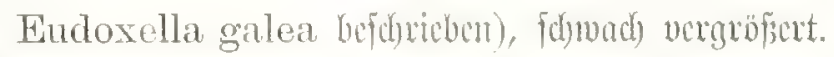

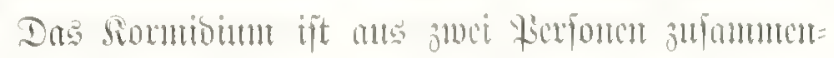
geferet, cince fteriten uno cunce fertilen. Dic fterile 


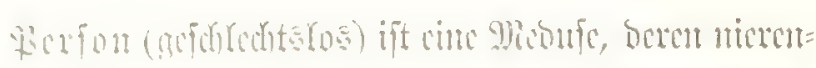

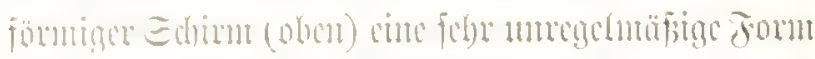

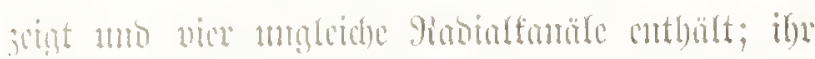

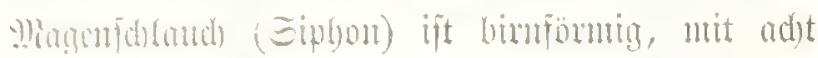

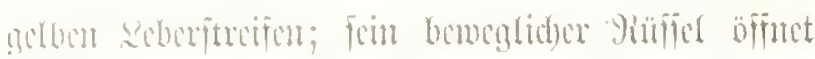

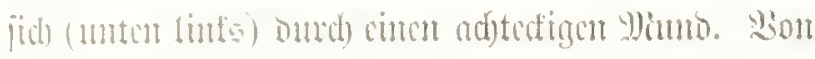

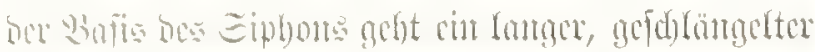

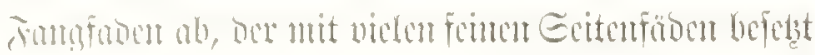

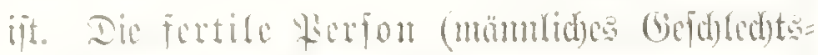

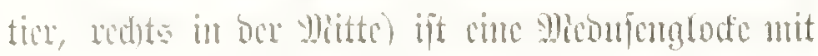

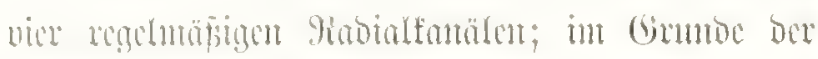

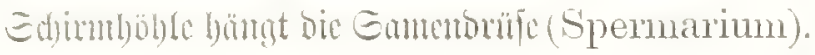

\section{Tiț. 3) - S. Bassia obelisens (Haeckel).}

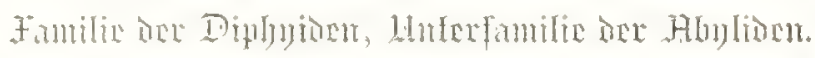

Fing. 3. In ganta Iierfode (Comus), bon

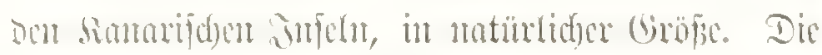

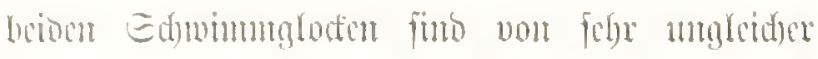

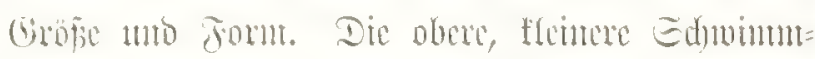

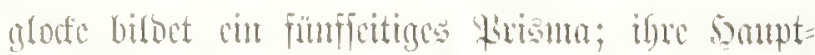

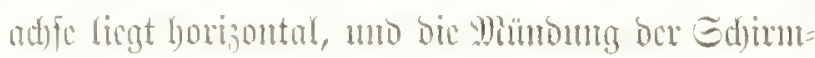

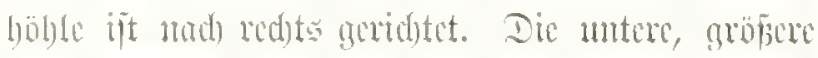
Edhwimnglode bat bie form cines vicreitigen

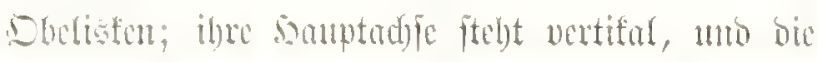

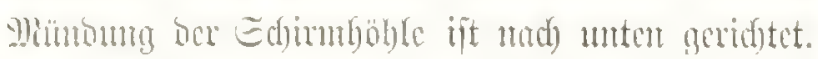

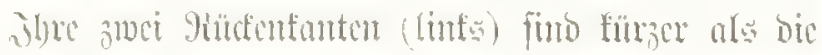

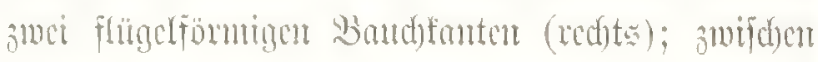
Iesteren tritt unten ber lange, fabenfömmige Gtunm

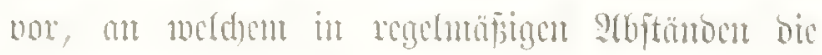
Limpehen sormibion fitsen.

Jig. t. Dic obere Ed)mimmglode core mpi=

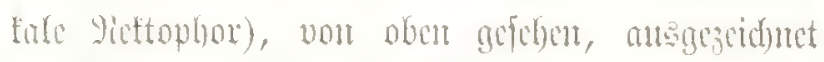

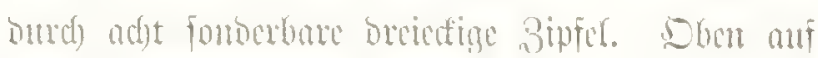

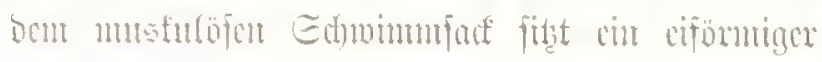

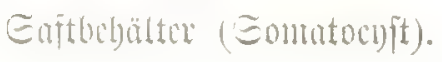

Sig. 5. Die obere Sdywimmglode, won worn gefelen (wou ber Bafalpeite). Jul ber Mlitte

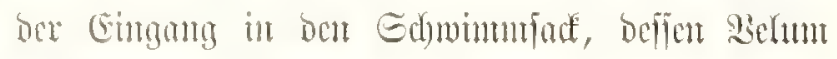
cint freismonder gimgfunt umnibt, von bem vier Fabialtanắc abgeben.

Jig. 6. Dic nutere Gduimmglode (ber

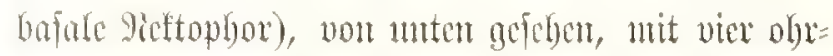
förmigen, breieffigen Bipfeln. Sben fiegt mant in

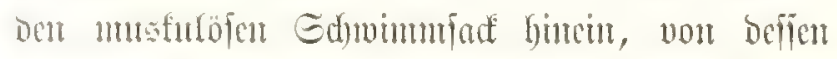
Gimgtanat vicr Tabialfanäle abgeben; unten in ben

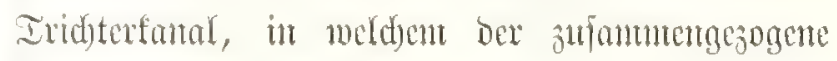
giöfrforper veritect ift.

Jig. 7. Cun cingelute Stöd) (Cormidium) oder cine Eudoxia (bei bicfer $\mathfrak{O}$ (rt als Sphemoïdes obeliscus befduricben), fdhwad) vergröpert.

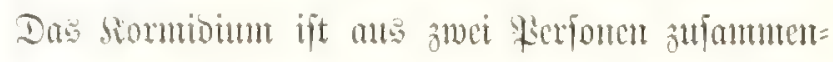

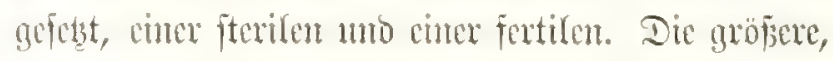

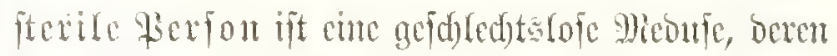
feltfan gefounter Edjum mit vielen gefielfröppen beferst ift uno zowolf orcifantig=puramionale Fortfätse

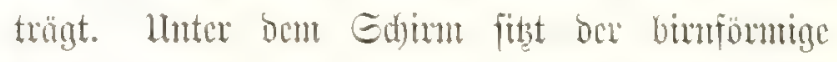

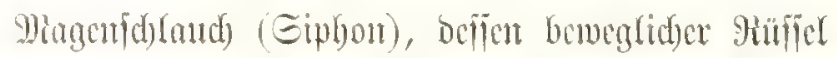
fid) Durd) Den 将iuno bffuct (unten red)t lange Fangfoden, ber von der Bafis bes Giphons angerd, ift mit viefen fenten Geitenfäben befebst. Joser cirzeltre Eeitemfaben trügt cinte bohntenför=

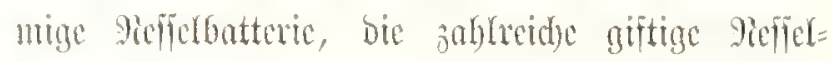
organe cutbätt. Dic fertile Perfon (unüntlides

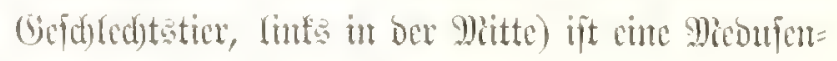
glode mit vicr Bafaripfoln.

Jig. 8. Ein weibliducs Gefdled teticx, ifo= liert. Die Form bes vierfeitig=purmutionten Edjumes ift non ber des mümulidjen (Fig. T) nerfidicocn. J̀n Ginmbe dor Echimurbable hängt der Eicritod (Dvarimu). 


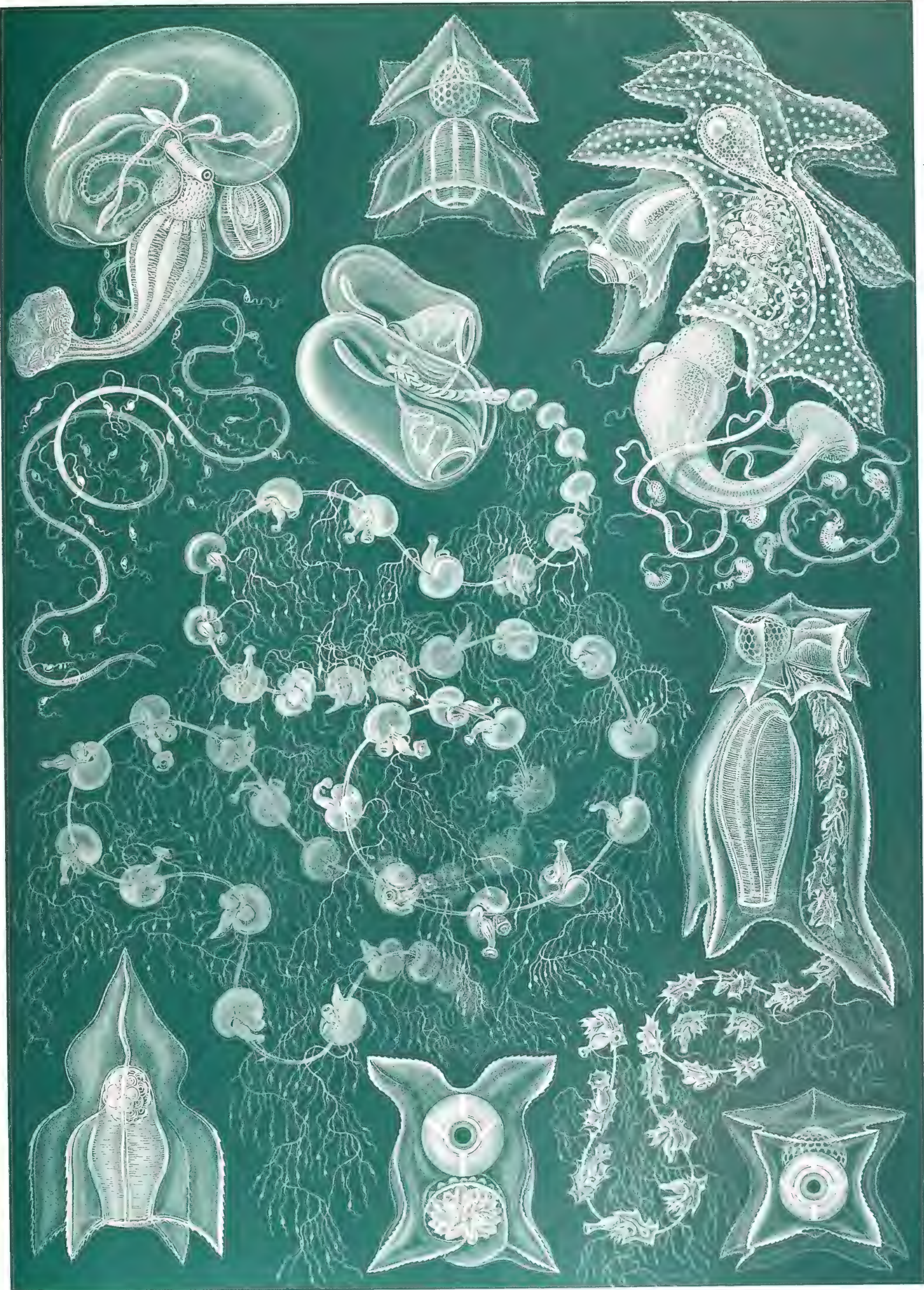

Siphonophorae. Stadsintallert. 



\section{Cubomedusae。 12 infulmallur.}

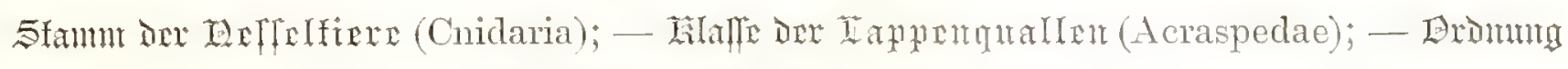

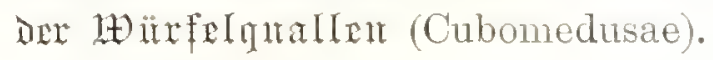

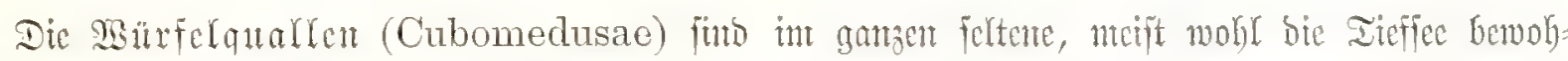

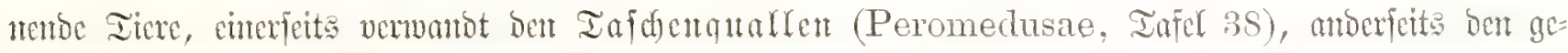

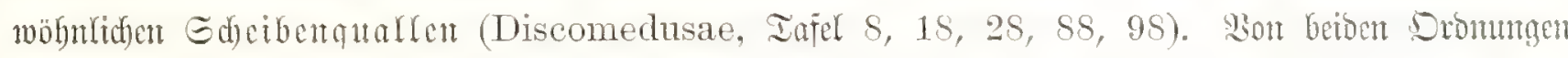

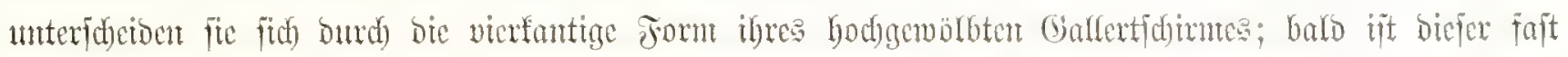

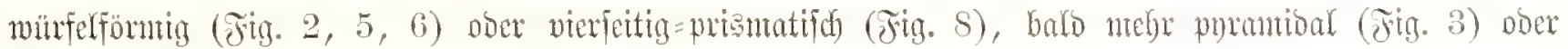

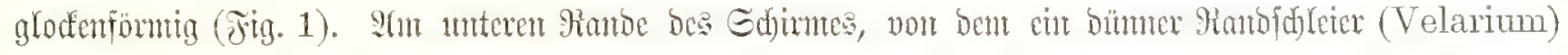

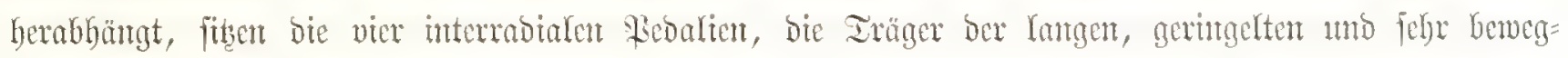

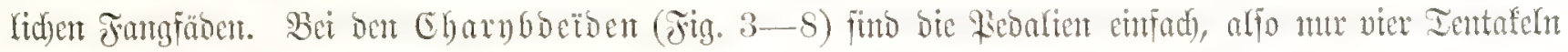

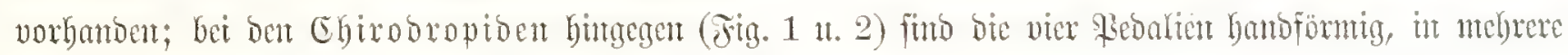

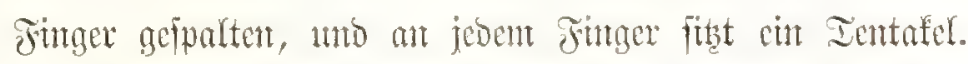

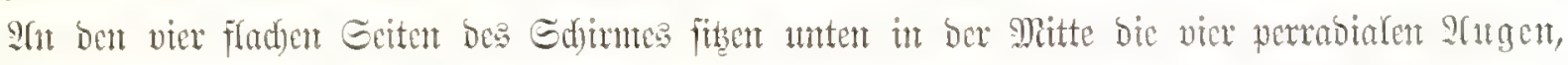

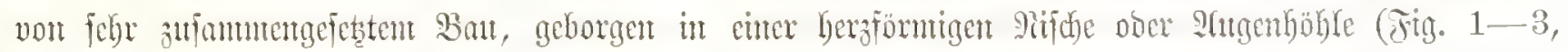

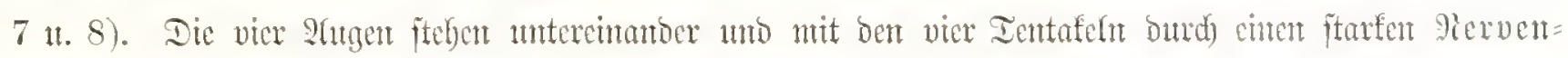

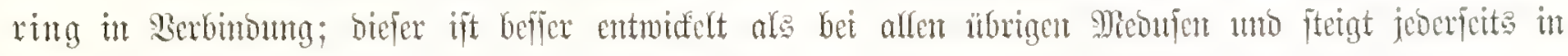

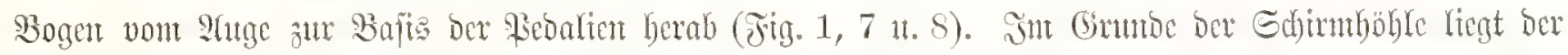

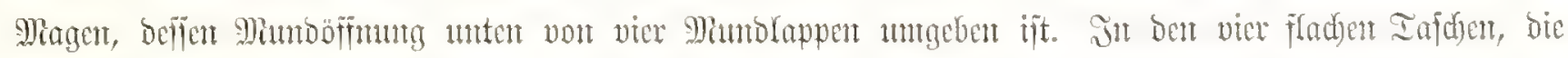

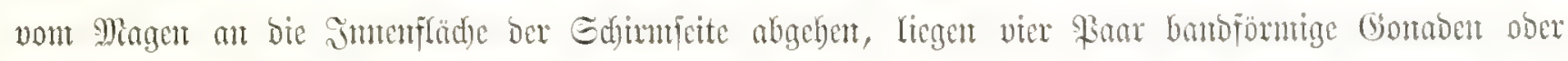

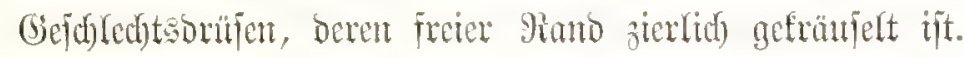

Fig. 1. Chirodropns palmatus (Haeckel). Fantilie dex Chyounoniden.

gisurfelqualle ate bem füblichen attrantifden

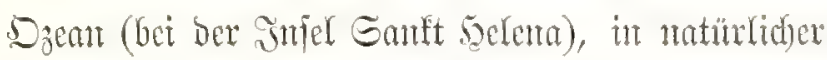

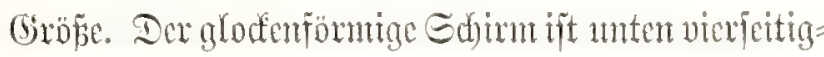
prißmatijo, obent fuppelförmiog gewölbt. Die ftarfen

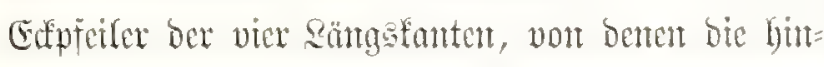

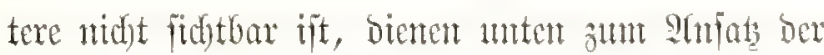
viet mäd)tigen, hantoförntigen Rebaltent, bie fajt po

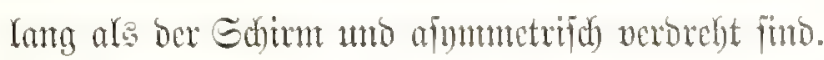
Sebe 5anto ift in 21 lange Galfertfünger gefpaltert, umb jeber Finger trägt cinen feldr langent, geringelten Tentafer. Durdi bie glasartig ourdoffdetige sisto
Des Sdfirmes formmtent bie geftëtt]elten Gontaben

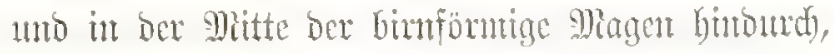

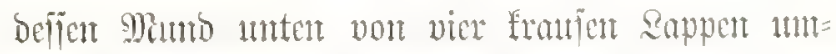
geben ijt. Der breite Hanbid) Jeter (Velarium), ber vom Edhinuranto untent herabgängt, ift von jier= lidyen gefiebertent Santälen bumdyzogen.

Fig. 2. Chiropsalmus quadrigatus (Haectel).

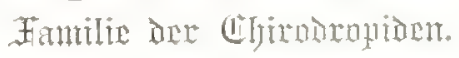

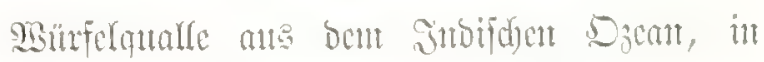

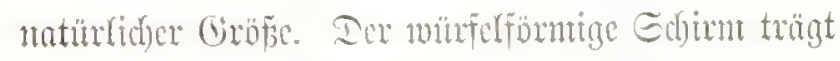

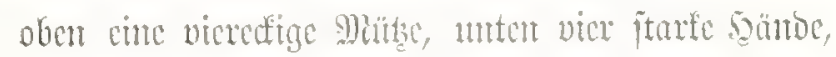

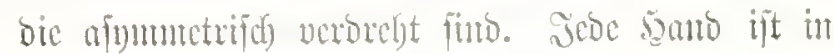




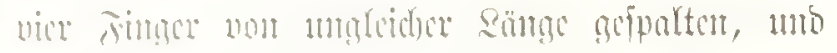

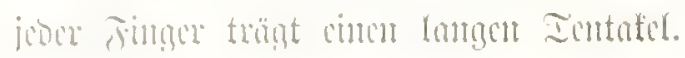

\section{Fing. :3 4. 4. ('harylodea obeliseus (Hacelel).

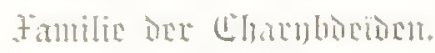

2.

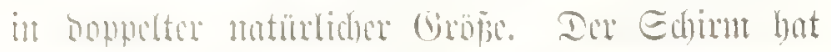

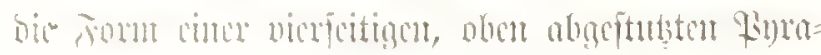

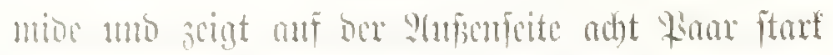
voriprintano süntyalciten. Die nier perrabialen

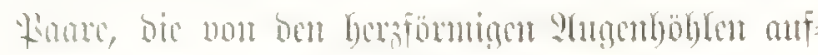

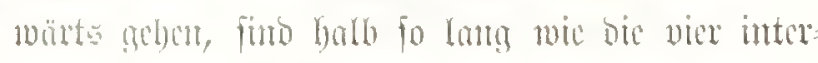

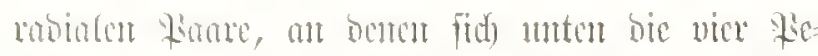

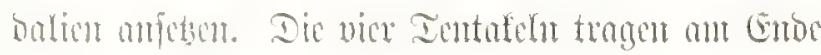
cimen Gieflelfnop

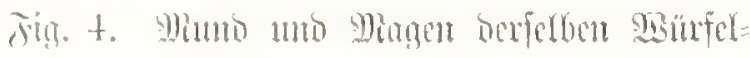
quatle (metd)e in sig. 3 oben in Ginmoe oce Gilode

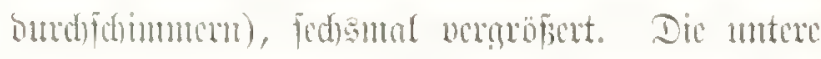

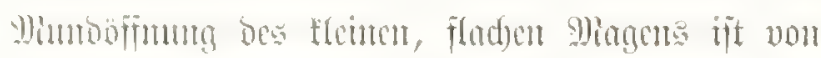

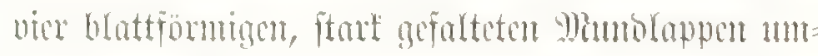

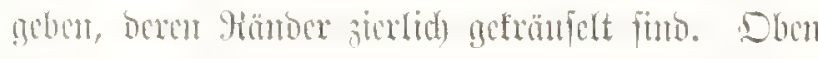

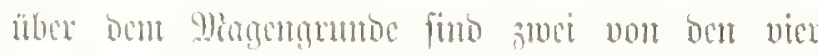

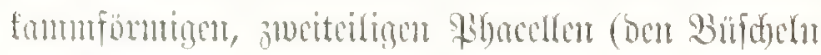

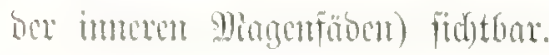

\section{Tig. 5. 4. 6. Charybdea murayana (Haceke).

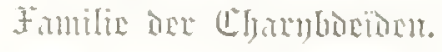

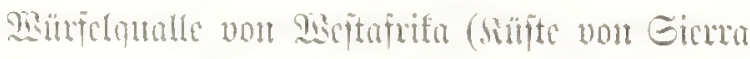

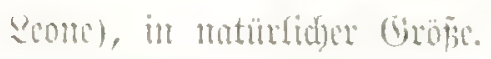

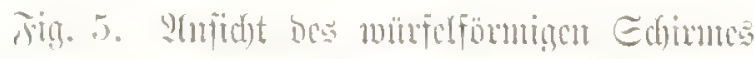

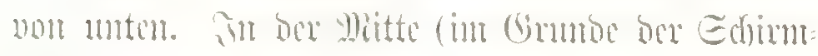

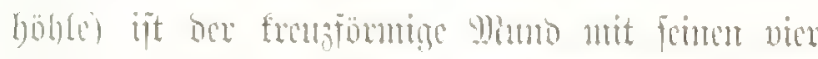

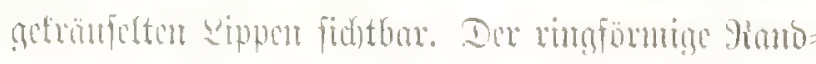

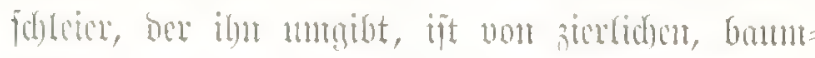

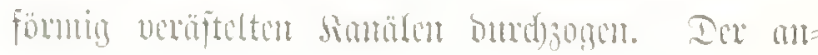

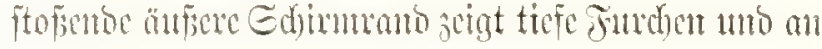

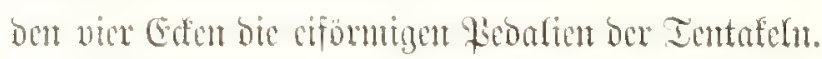

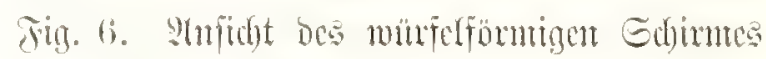
won oben. In ber Mitte (in Grumbe ber Mragen=

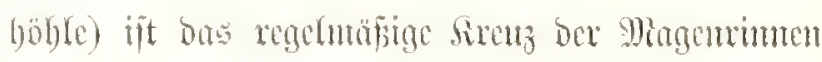

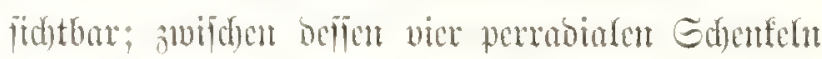

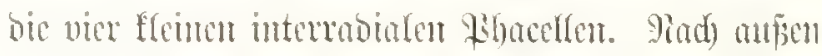
von Kesteren ipringen bie biffen Doppelpfeiter ber Edjimfonten tart vor; an ibrem unteren Endoe die vier SHedalien mit ben Ientafeln.

\section{Fig. 7. Procharybdis tetraptera (Hacekel).

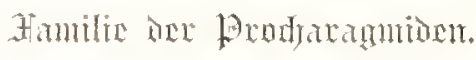

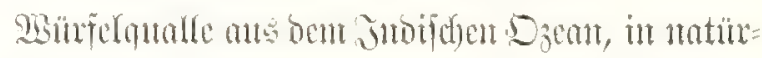

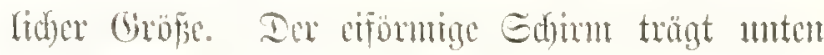
vier mäd)tige, blattfom mige Webalien, von benen bier

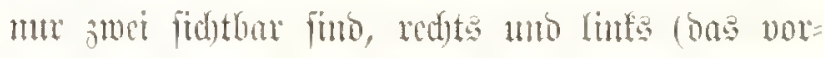

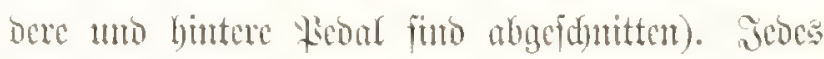

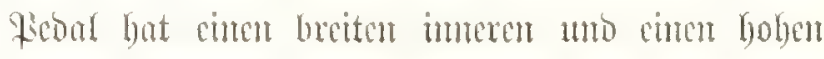

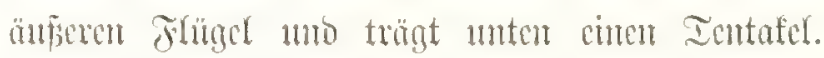

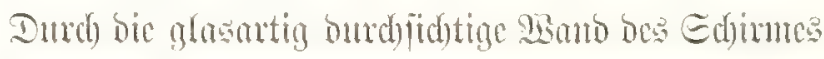
fojimment vice brattfömige Gonabenpane burd) mo ober bie eifoumigen Mintolappen.

\section{Fin. 8. 'Tamoya prismatica (Haeckel).

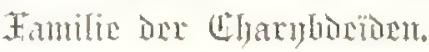

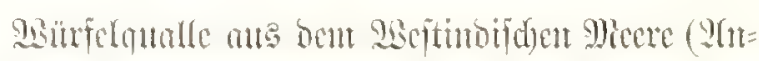

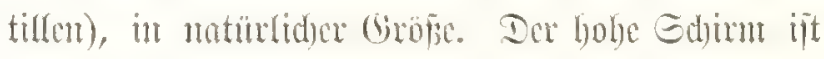
vicrfertig=prismatifd), boppert fo hod) ars breit. Die vier fenfrechten interrabialen Eefpfeifre bes Edimes

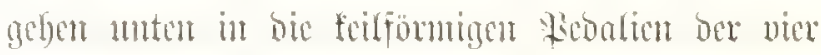
Tentafeln n̈ber. SIt ber Smmenfite ber Edfpfeiler

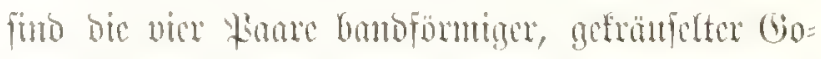

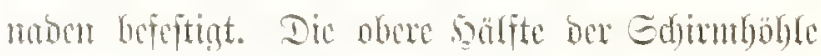
nimmt ber fugetige magen cir, bie untere sälfte dic biex grofien, blattförmigen Mimblappor. 


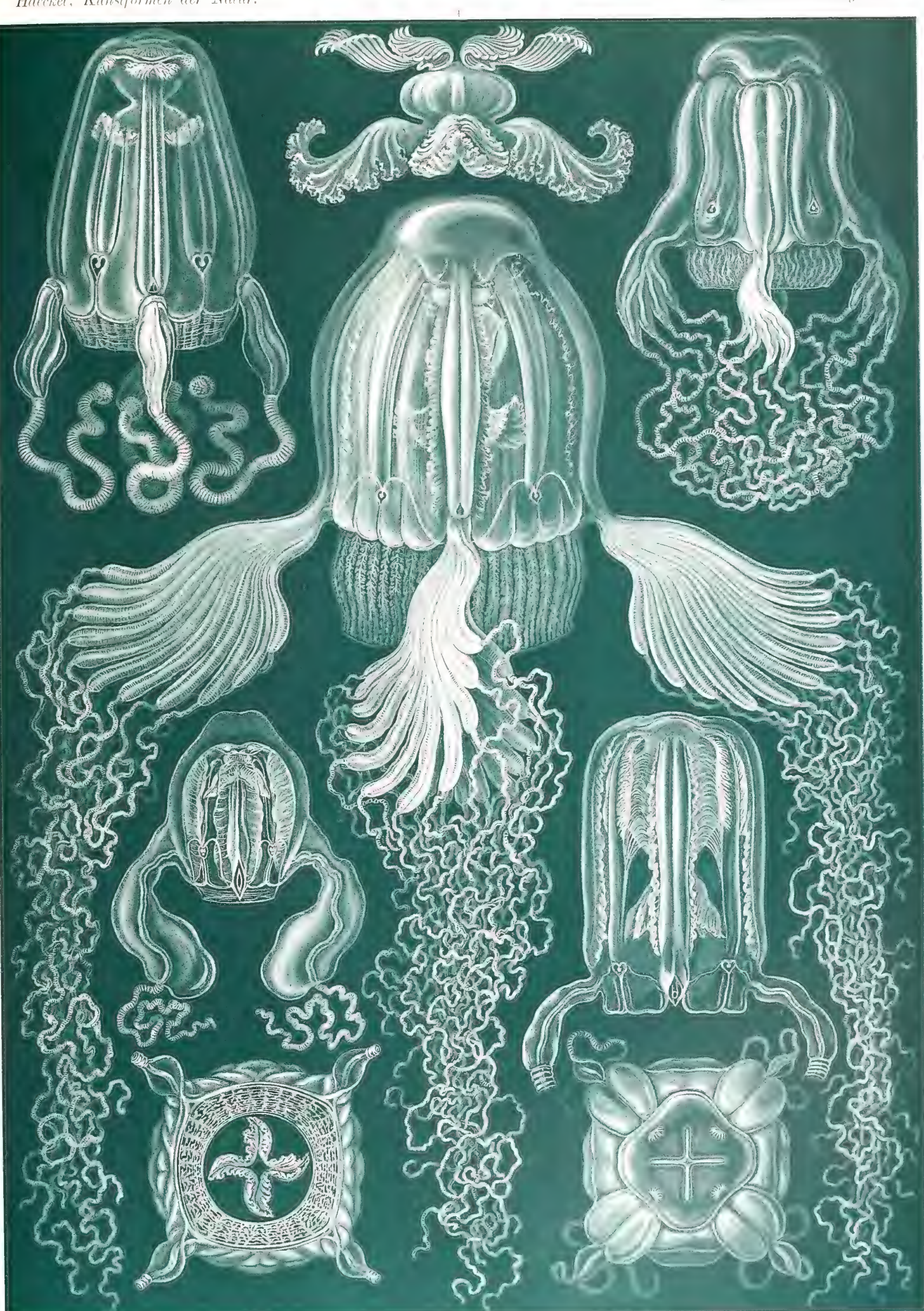





\section{Lacertilia. Eimedrtent.}

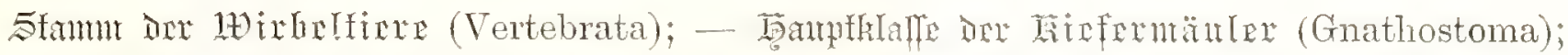

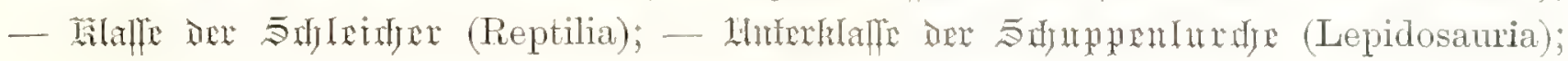
- Dromnty Der eriordffen (Lacertilia).

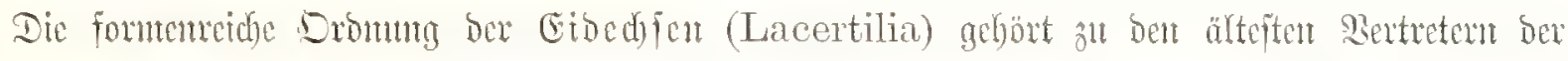

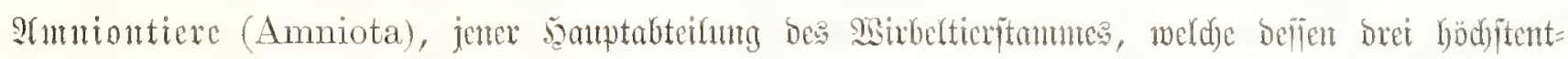

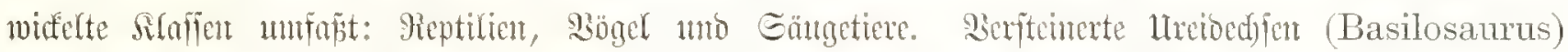

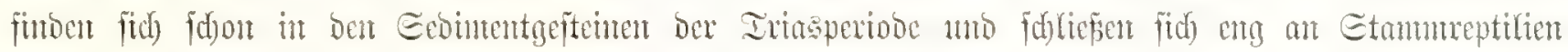

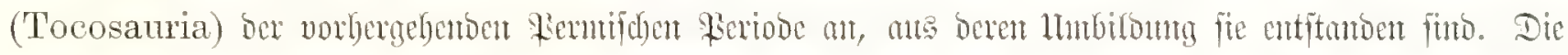

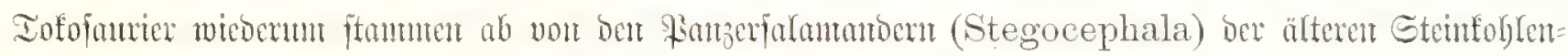

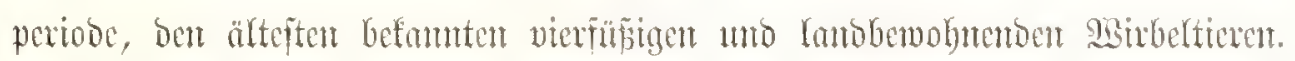

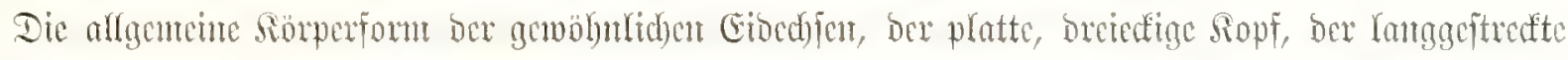

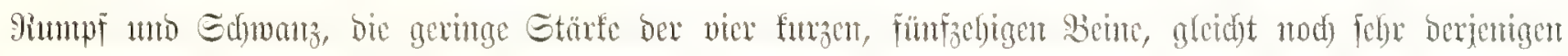

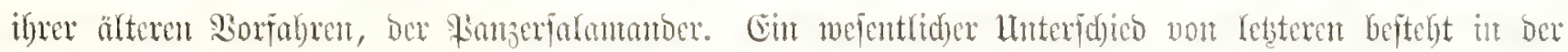

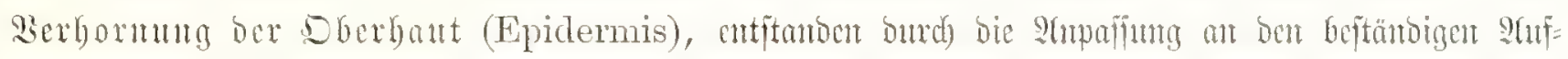

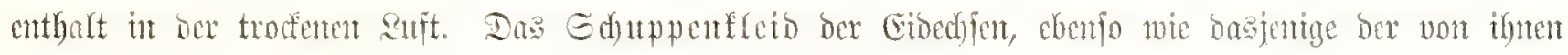

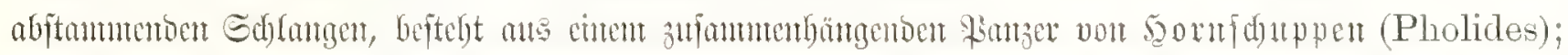

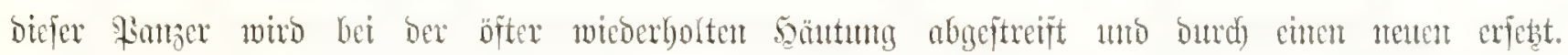

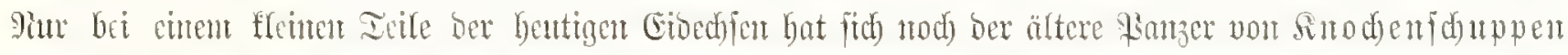

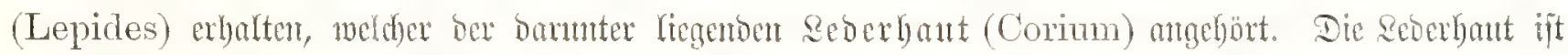

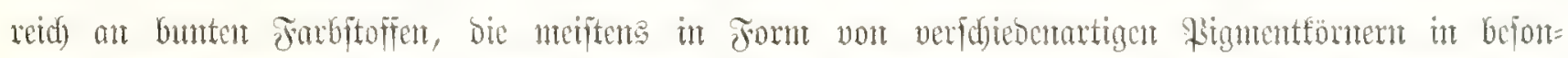

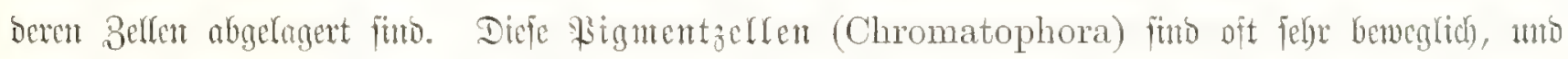

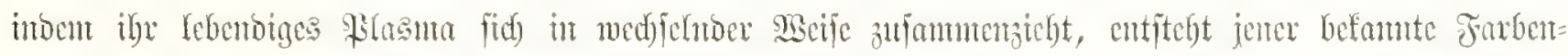

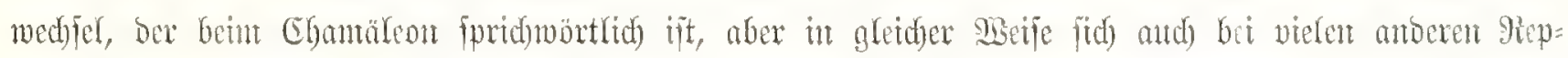

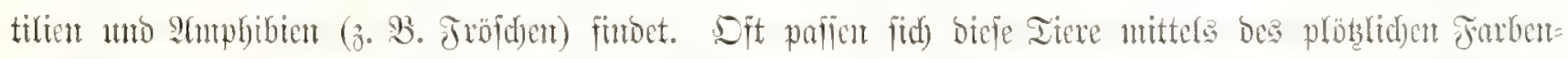

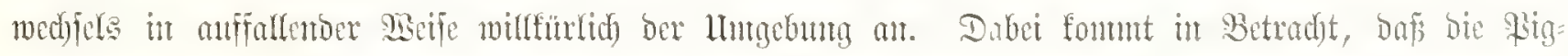

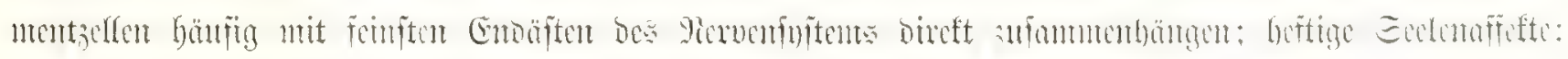

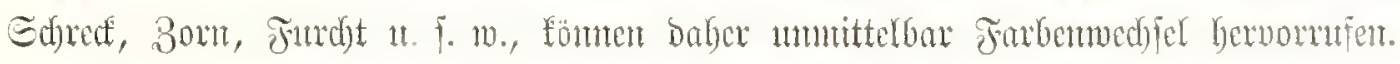

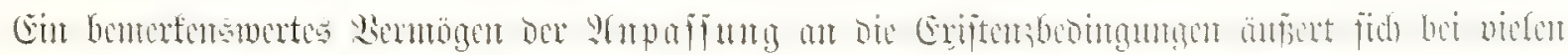

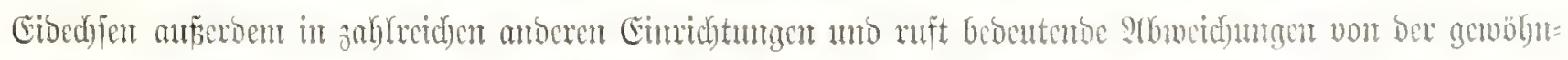

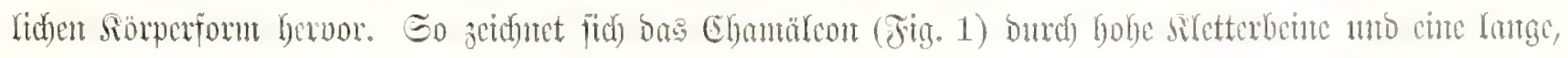

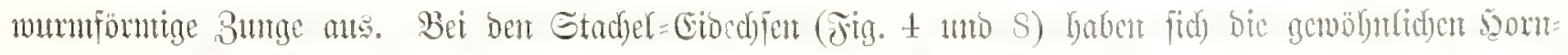

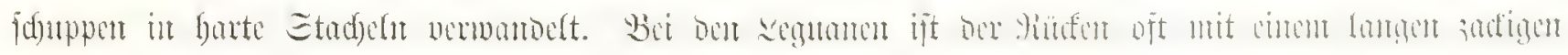

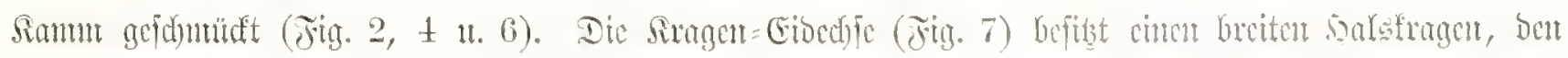

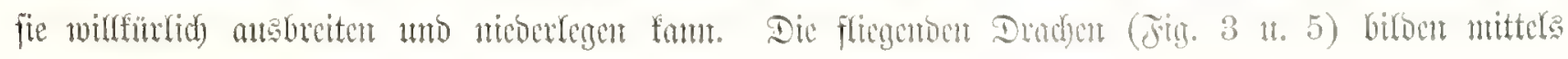




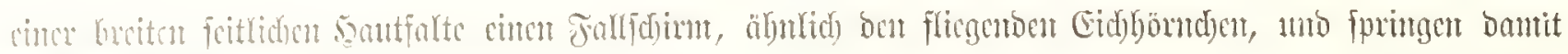
vout

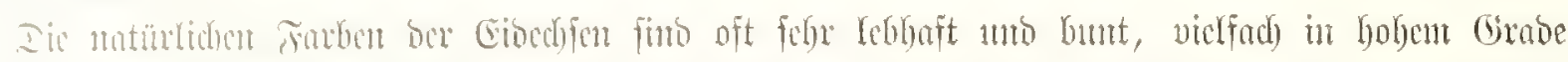

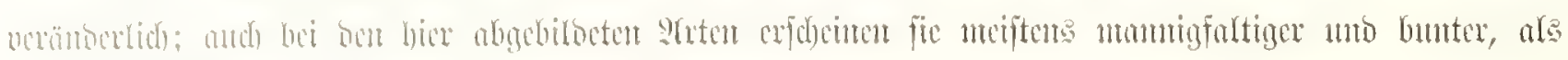

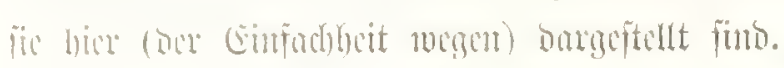

\section{Fing. 1. Chamaeleon montium (Buchholz).}

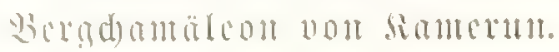

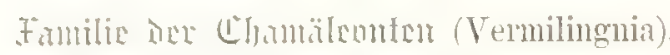

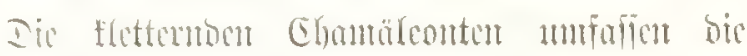

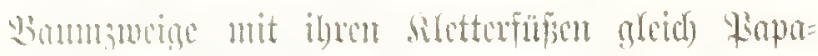

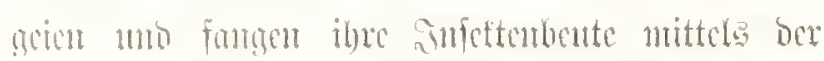

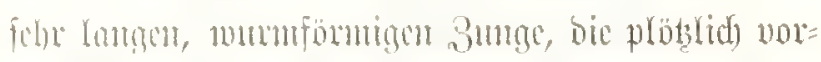

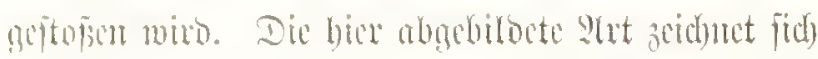

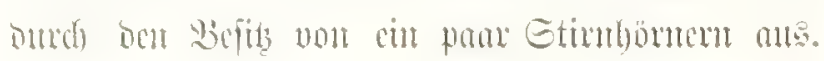

\section{rig. ‥ Lophyrus tigrinus (Dumévil).}

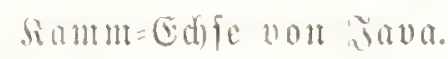

Fantilic one Bamm-.Hummen (Dendrohatae).

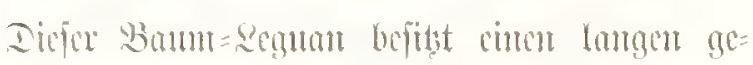

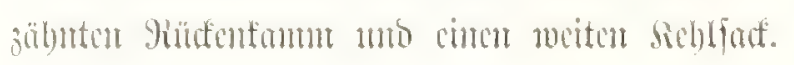

Fig. 3. Iraconellus rolans (Limé).

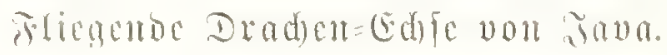

trintie one Gam-Anamen (Dendrobatre).

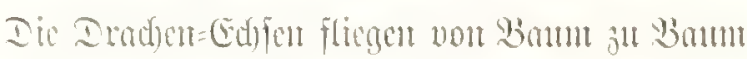
mittes cinter breiten foitliden somtfalte, bic als

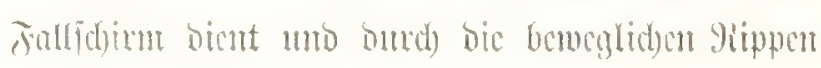
maะgojpanut wiro.

Jig. t. Plirynosoma cornutum (Tiegmamn).

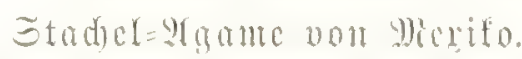

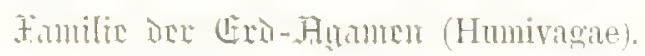

Etntt bu gamöhntidyen Edynpar trägt bicfe Eio.

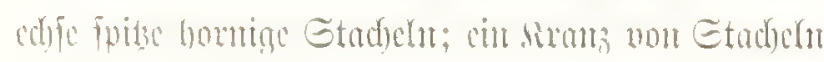
an sintertopf tritt burd) bejombere (Gröpe vor.
Jig. 5. Ptychozoon homalocephalım (Kuhl). Fralten=Gete vou Java.

Familie one (15edrontru (Ascalabotre).

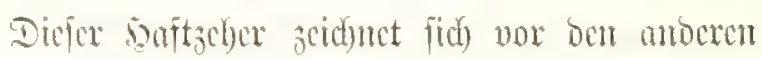
(Gedonen ourd) cin \$ina breite feitfid)e Sautfalten an, bic jwifdy Sorberbecusen uns sinterbeinem

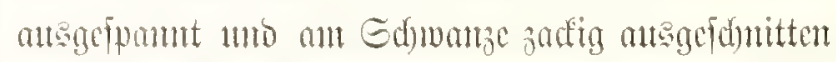

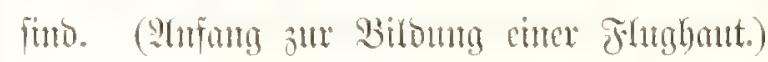

Fin. 6. Basiliseus americamms (Daudin). Bafirisfen=erdie von Gitanand.

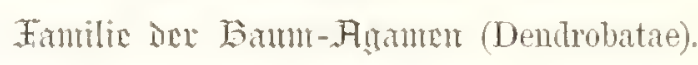

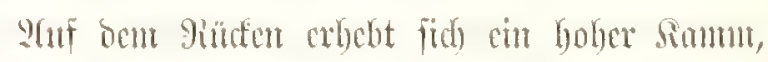

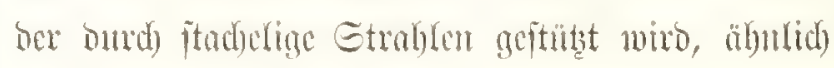

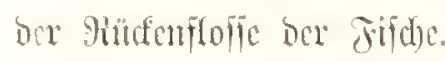

Fig. 7. Chlanydosaurus Kingii (Gray).

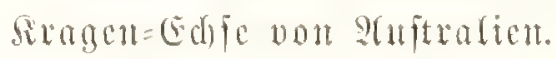

Hamilix Dex Bom-Hummen (Dendrobatae).

Der bals ijt von ciner grofert, ant Panto gezöbuten sautfalte untgeben, bie cintent breiten

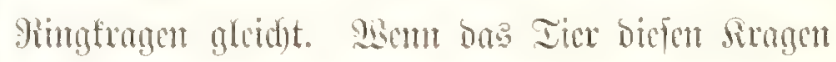

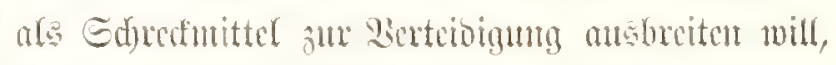

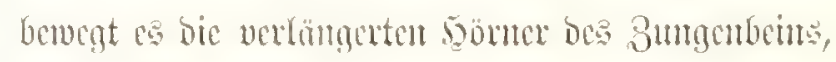
die als Gtittse bienen.

Fig. S. Moloch horridus (Gray).

Etadel=9lolod won Shtftalien.

Frunilin dex (Ext-Humen (Humivagne).

Der ganze Siorper ift mit biffen, fegelförntigen Etad)e(n beoceft, bie fich ats gewöbuliden samt= fdumpert entwidelt babent. 


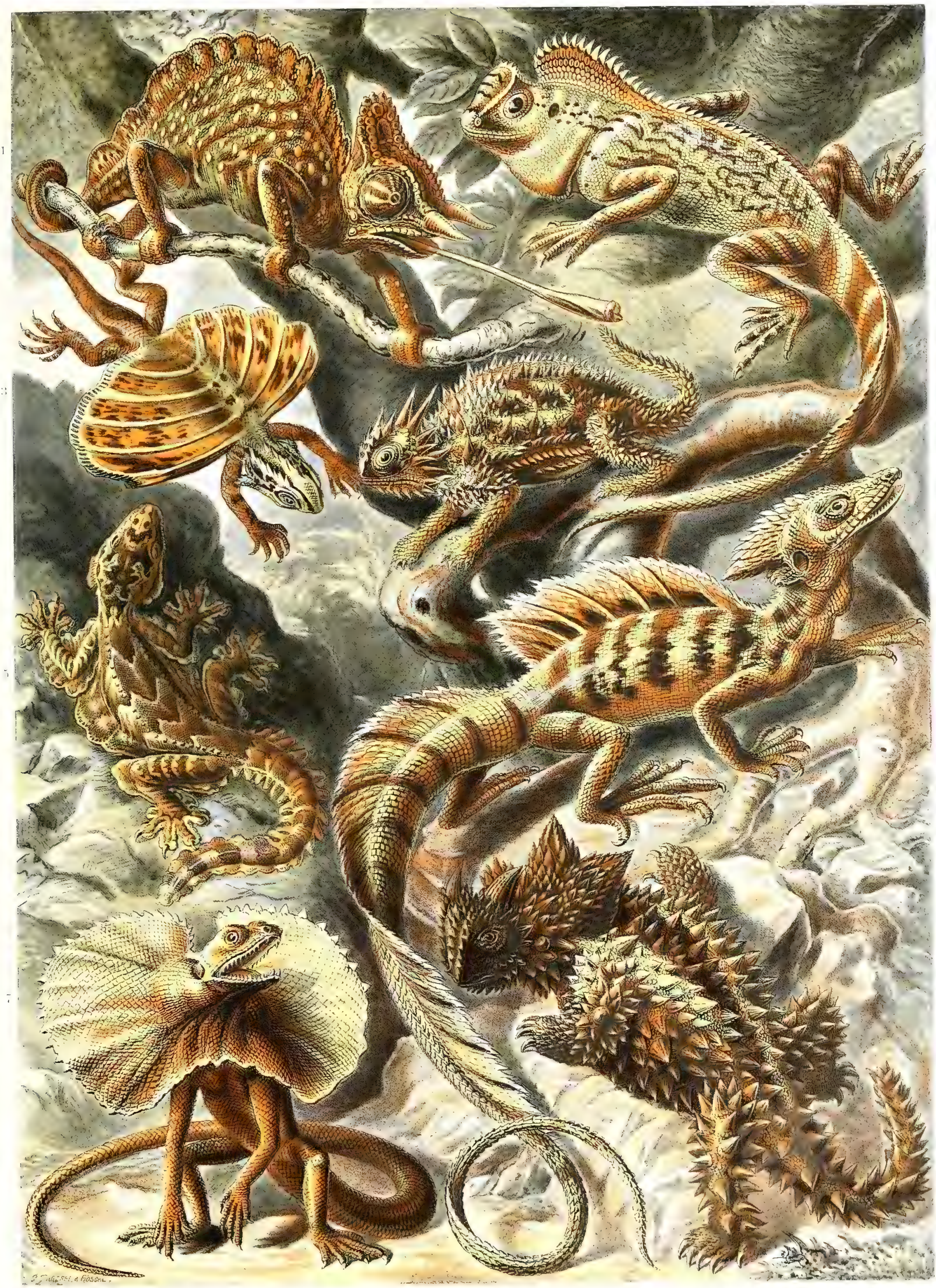

Lacertilia. - ciscodifon. 



\section{Blastoidea. Itrolpenterme.}

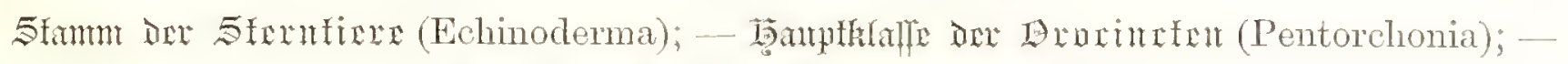

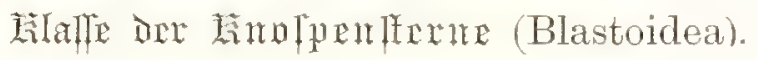

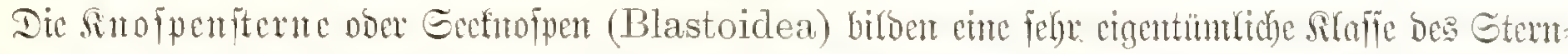

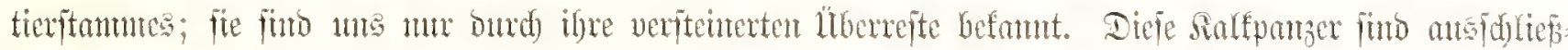

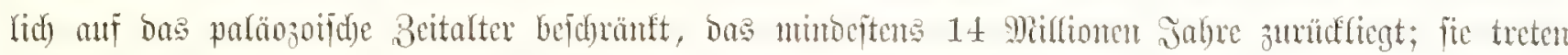

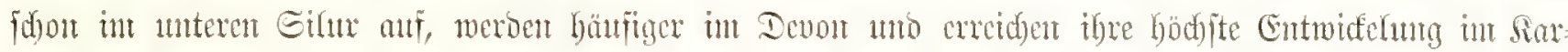

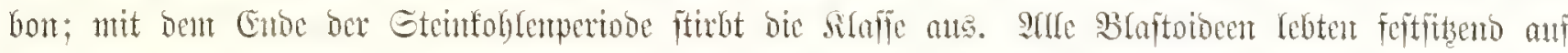

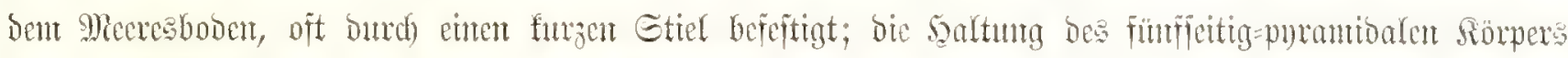
war baher biefelbe wie bet ifrent bireften Sorfahren, ben Beutelfernen (Cystoidea, Iafel 90), tmo bei

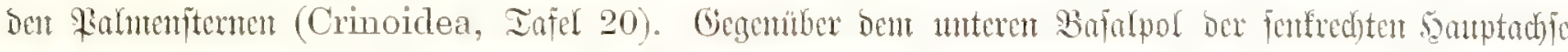

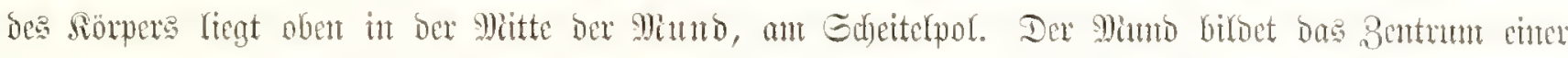

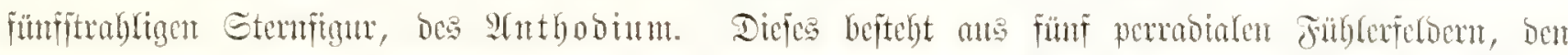

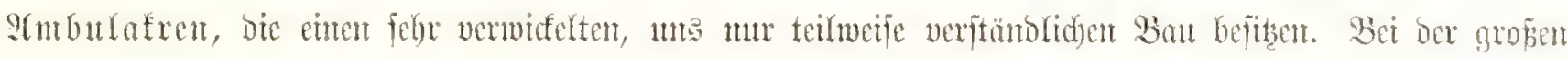

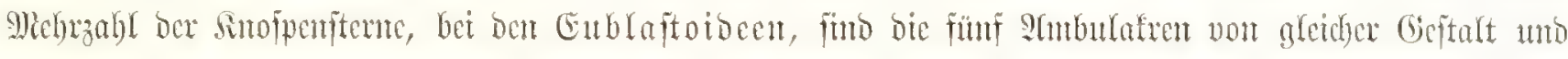

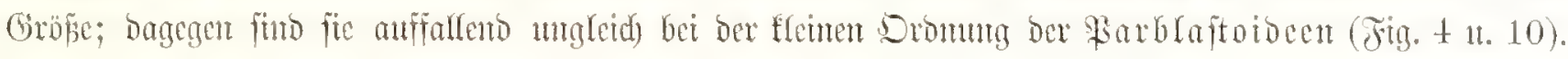

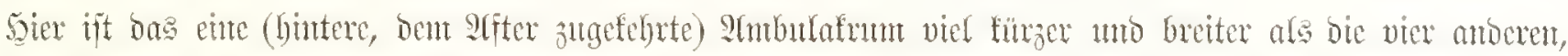

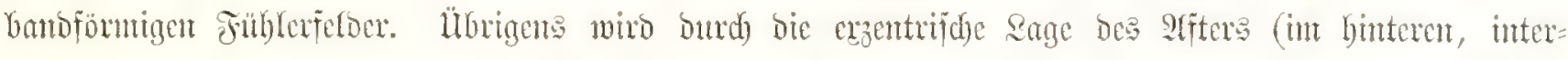

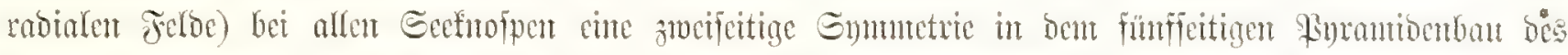

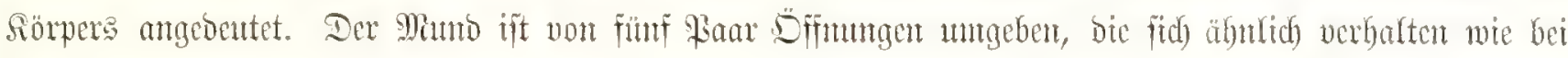
den Ed)langenfternen (Ophiodea, Iafel 10 1t. 70); wahkfdeinlid) bienten fie, wie bé biefen, zut Ent=

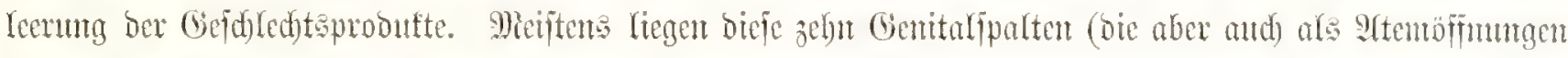

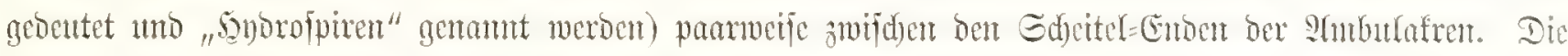

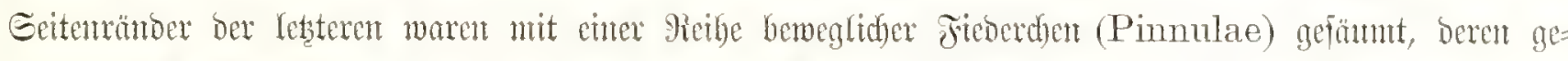

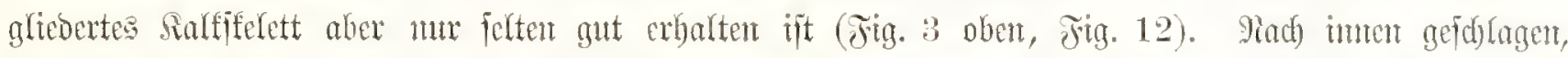

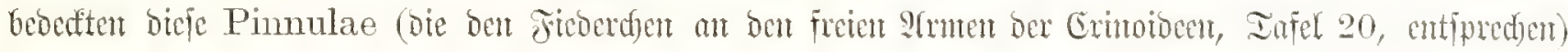

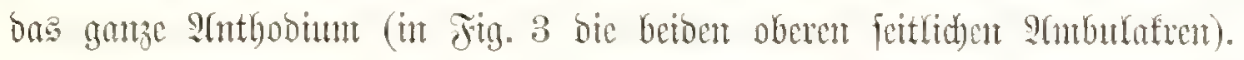

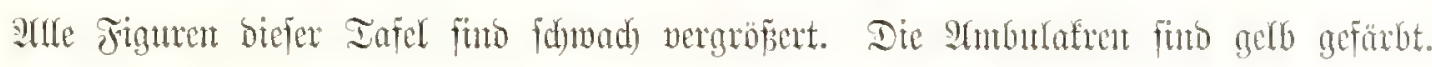

Jig. 1. Pentremites pyriformis (Say).

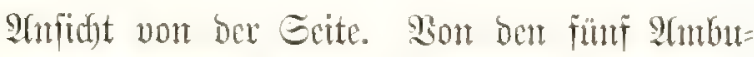

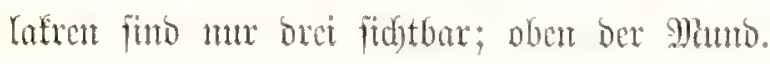

\section{Fig. 2. Pentremites orbiguyauus (Koninck).}

Irridut von Gedsitel; in ber Mlitte Der Minto, oben barüber ber grojie $\mathfrak{a}$ iter.
Fig. 3. Pentremites species (Amold Lang).

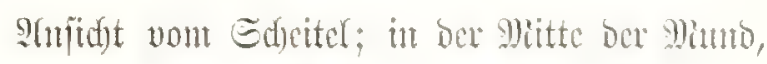

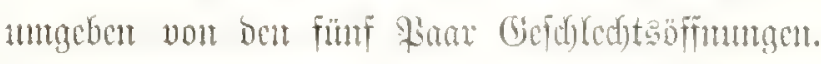

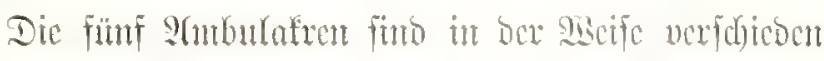
Dargeftellt, Da jo bie Pimnulae (bie geglicocrten

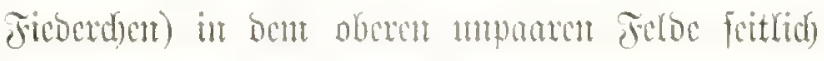

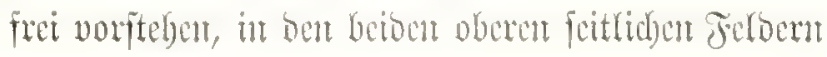




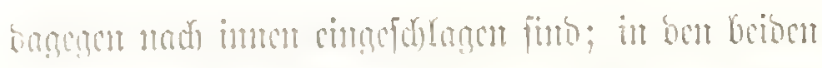

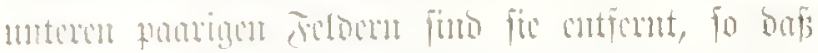

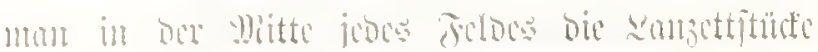

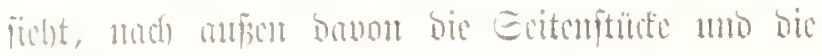

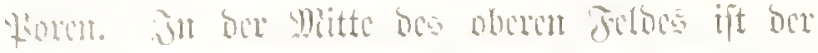

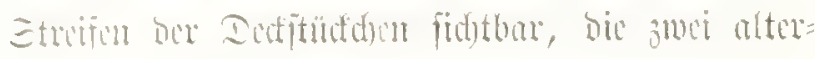
nicrense gichen bifson.

Ting. t. Zygoerinus cruciatus (Bromn).

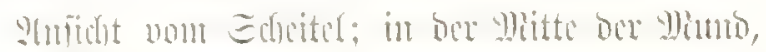

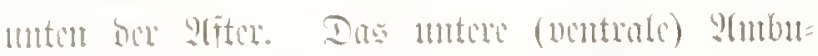

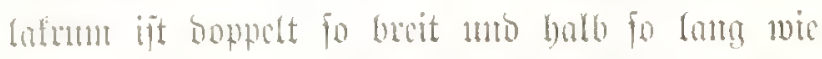

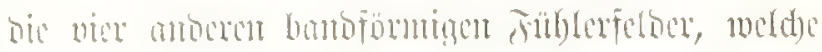

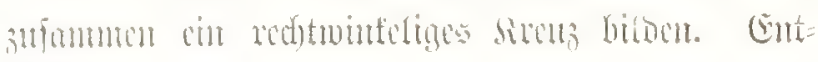

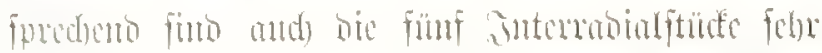

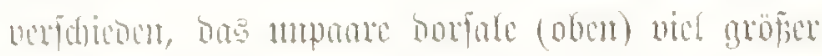

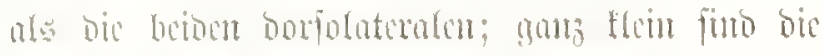
beisen unteren (omtrolateralen) Feloer.

Jig. 5. Orophocrinus stelliformis (Etheritge).

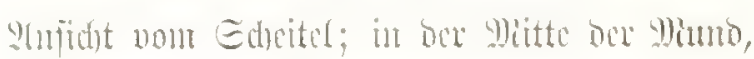

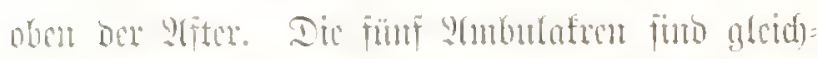

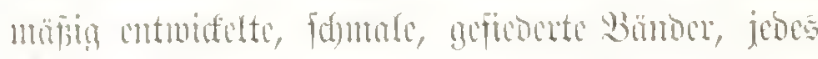

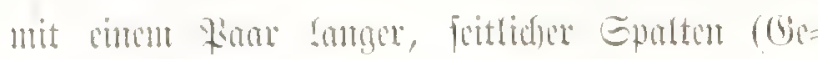

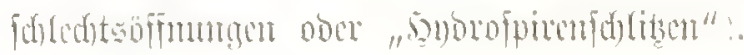

Jig. 6. Phaenoschisma acutum (Etheridge).

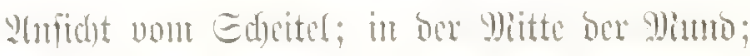

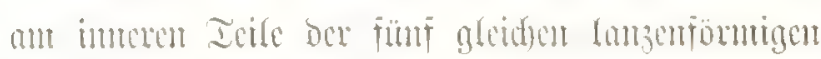

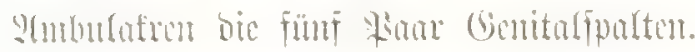

Tin. 7. Elaeacrinus olivanites (Troost).

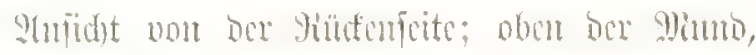

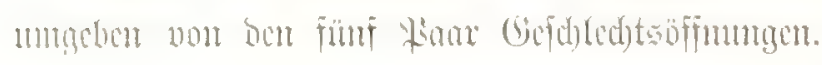

Tin. S. Elaeacrinus Vermenili (Roemer).

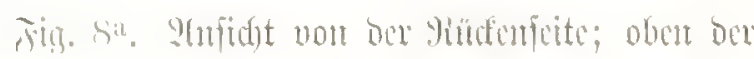

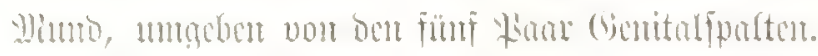

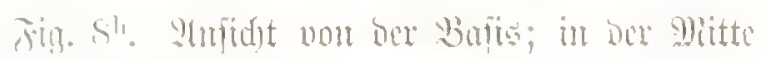

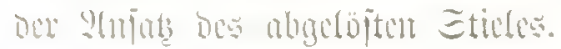

Gign. . Codonaster trilobatus (Buther).

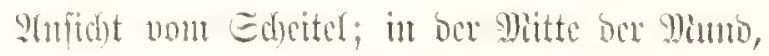

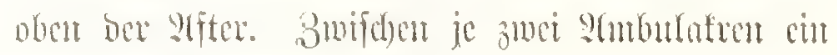

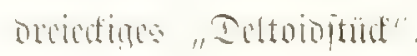

\section{Jig. 10. Eleutherocrinus Cassedayi (Shmard).}

Jig. 10?. S(nfid)t von Edjettel; in ber Mitte ber Mumo. Das untere (ventrale) Stmbufafum ift Doppelt fo breit unb hatb fo laug wie bie vier amoeren

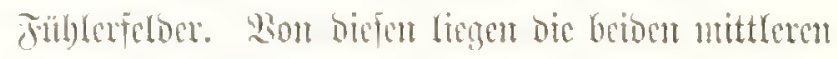
(ventrolaterafen) in cumer Mncribiandene, bic beibon oberen (borjolnternlen) bivergieren gegen ben Siüden.

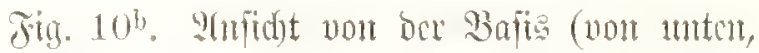
wo bas Iier befeptint war). Miant field, bafs bie Sentrarfeite jicunlid) flad), bic Dorfarfeite Dagegen ftarf gewölot ift.

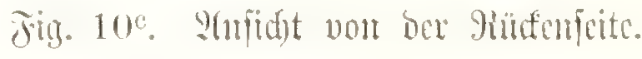

Fig. 11. Asteroblastus stellatus (Fr. Schmirt).

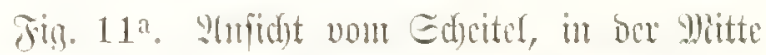

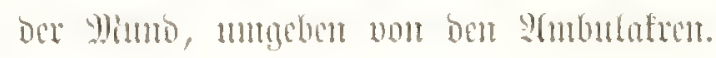

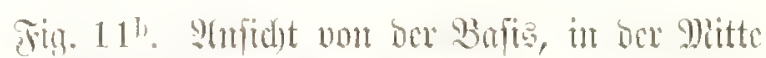

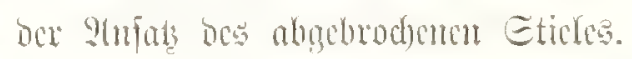

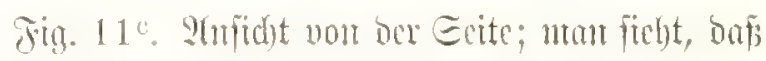

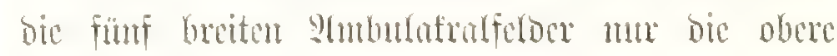

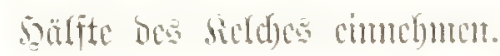

\section{Jig. 12. Asteroblastus Volborthi (Fr. Schmidt).}

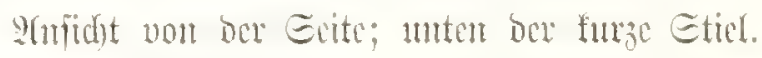

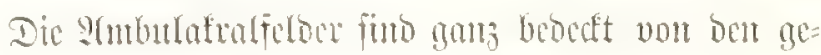
aftoderten bemeglidyen Ficoerdyen (Pimnulae), meldye

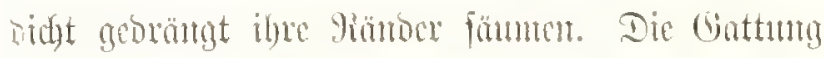
Asteroblastus wuroe früber ju ben Geräpfen ge ftellt (Cystoidea, Infer 90); fic bifloct ben litber= ganty von birfon ju bu Blastoidea mo fum

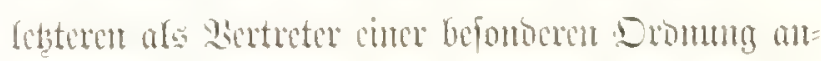
gefdrofien merben: ser wroblaftoben.

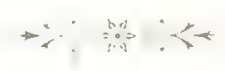





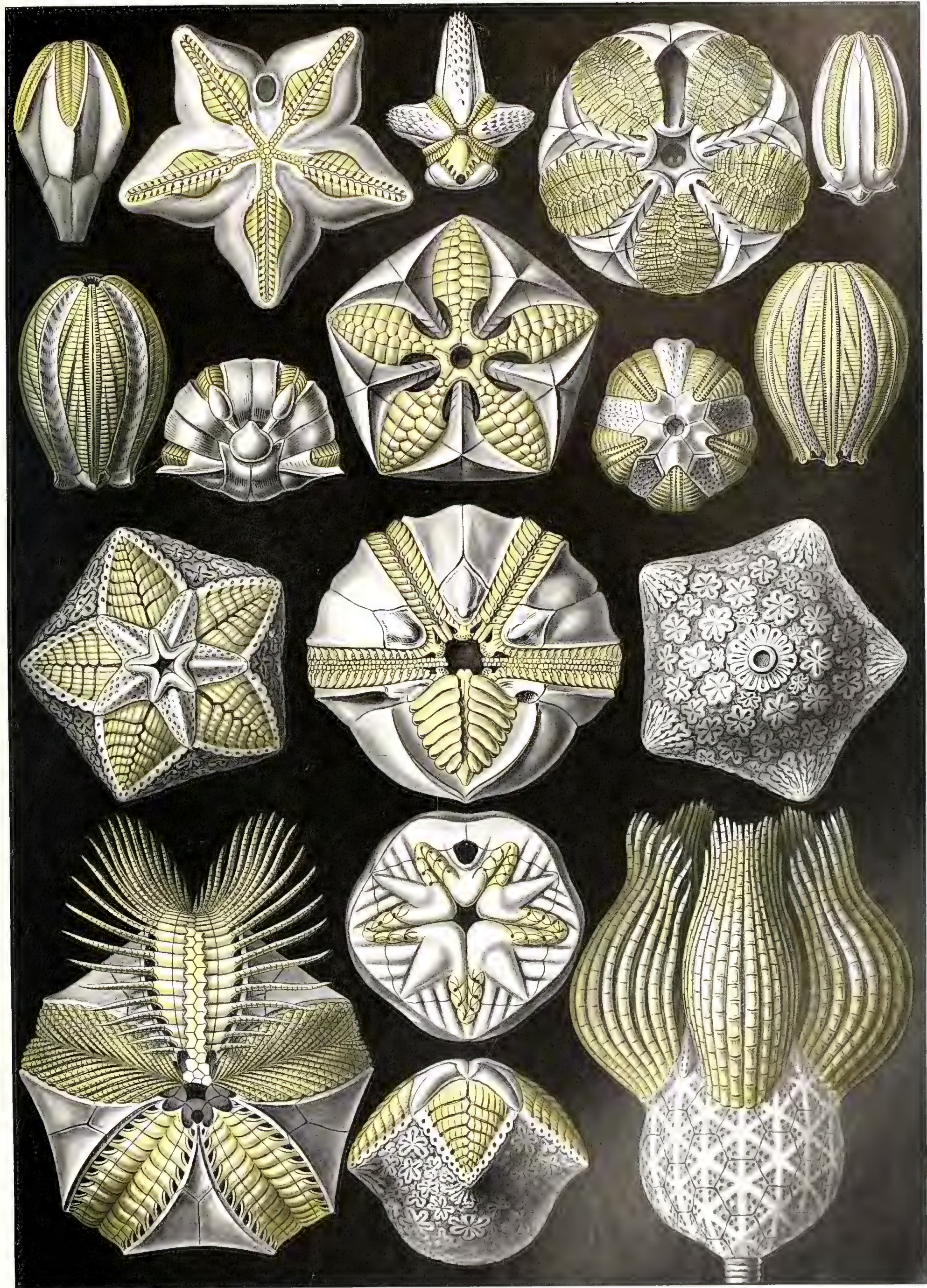

Blastoüdea. - smolpenlertre 



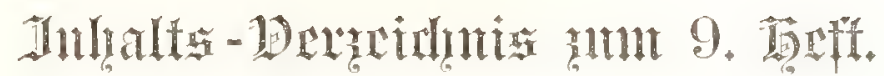

Iafel S1. Lagena. Itrtice an ocr filafic ber fiammertinge (Thalamophora), segion ber Eiebwandigen (Foraminifera).

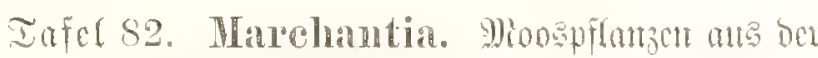
Silofic bet sebermode (Hepaticae).

Iafer 83. Cladonia. Thathepflangen ans ber Rlafic ber Flad)ten (Lichenes).

Iafel St. Navicula. Itupfamgen me bet Sompt= flafle der stgarien, Shaffe ber Diato. nters.

Iafel 85. Cynthia. Minteftiere (Tunicata) an ber Silafic dor Serforiden (Ascidiae).
Infel S6. Hathenope. Gifionertere an ber Batptfaffe bu Sruftenticre (Crustacea),

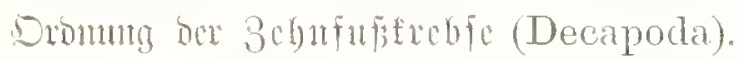

Infel 87. Pegasts. Wbithertere an ber Alafic ocr Fifd) (Pisces), Interfafic ber Stroden= fifde (Teleostei).

Iafel S8. Pilema. Sefferticue ans ber fifafic ber sappontunfen (Acraspedae), Dromtung Det Edeibunaturn (Discomednsae).

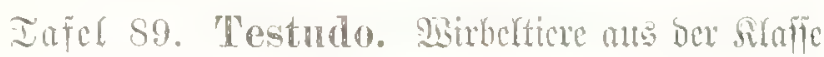
ber Sdy retder (Reptilia), Region ber Gdild = fuóten (Chelonia).

Iafel 90. Callocystis. Etunticre an ocr Slafic ber Beutcliterue (Cystoidea). 



\section{Thalamophora. Hammedintw.}

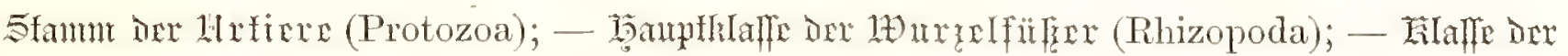

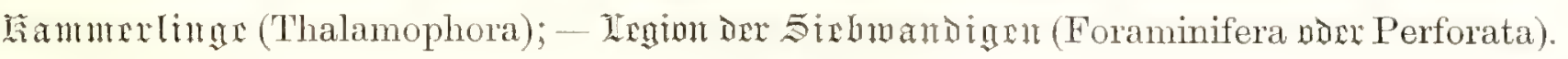

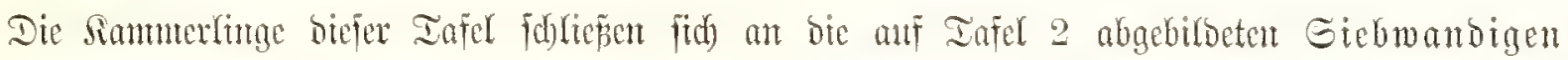

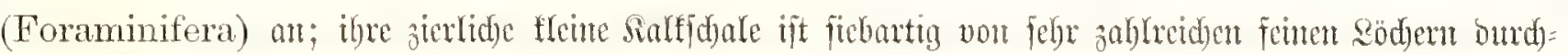

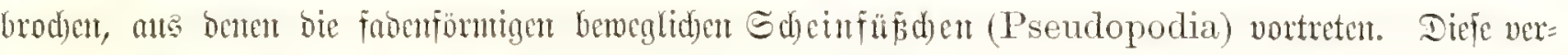

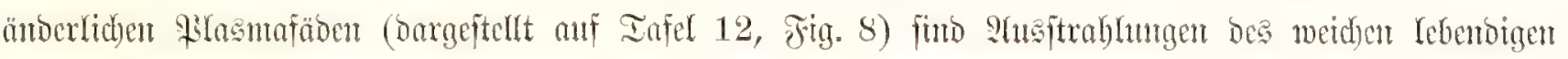

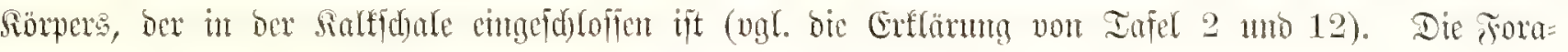
miniferen zerfallen in Einfammerige (Monothalamia, Fig. 1-10) mo 3ielfammerige (Polythalamia, Fig. 11-22); aud bie leteteren fino in ber Jugeno cinfanumerig, Fetsen aber fpäter nete,

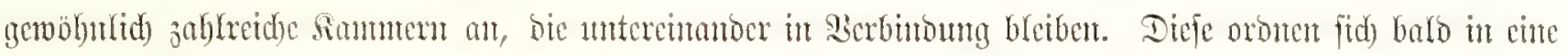

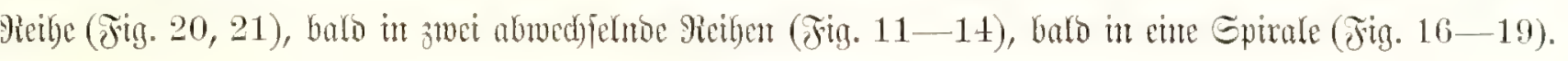

\section{Fitg. 1. Lagena formosa (Schwager).}

Die einfanmerige Edjale ift fla fjenförntig, $1 \mathrm{~mm}$

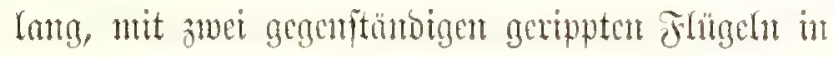
cincer Mcribiantebent.

\section{Fig. 2. Lagena auriculata (Brady).}

Die einfanmerige Edjale, $0,4 \mathrm{~mm}$ lang, ijt von orei gexippten uno gemuntomen Stügeht umgeben.

Fig. 3. Lagena pannosa (1Fillett).

Die einfommerige E(f)afe, $0,3 \mathrm{~mm}$ lantg, greid)t

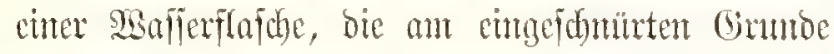

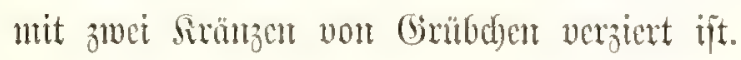

Fig. 4. Lagema tor(quata (Brady).

Die jiertid)e Edafe (Fing. 4 a vont ber Eeite, tb von unten gejeflen) ift $0,6 \mathrm{~mm}$ lang, flafdeen=

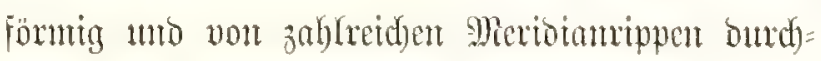
zogen, bie mit Grubdemeifon abwedjedn.

\section{Fig. 5. Lagena squamosa (Brady).}

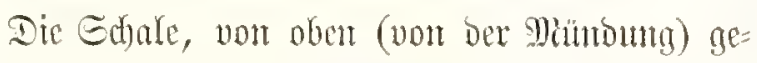
ichen, $1 \mathrm{~mm}$ lang, ijt äburicy ber Lagena alata (Tafel 2, Jitg. 17), limfonförmitg, an Fianbe geflügelt.

\section{Jig. 6. Lagena Milletti (Hacckel).}

Dic flaidfurförntige Edyale (von obent gerehcrt), $0,4 \mathrm{~mm}$ lang, ift äbullid ber Lagena torquata, Fig. 4 , aber vout ad)t Spiralrippent unmwuthen, bie Doppefreifen von Foren tragen (älynlid) L. striatopunctata, Parker). - (9tus SMlulinde.)

Fig. 7. Lagena Walleriana (Joseph Wright).

Die Cimfentötmige Edfate (von oben gefehent), $0,5 \mathrm{~mm}$ lang, ift am Simbe mit eintem breifadyen Flïgel vergiert.

Jig. 8. Lagena castrensis (Schwager).

Die limfenförmige Gedale (von oben gefeben), $0,4 \mathrm{~mm}$ lang, hat grubige Sherfäad)e (wie Fig. t)

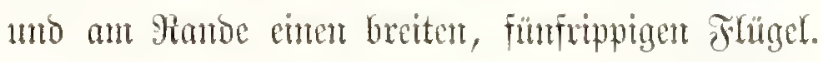

Fig. 9. Lagena semistriata (Villiamson).

Die fegelförmige Sdare, $0,4 \mathrm{~mm}$ landg, hat

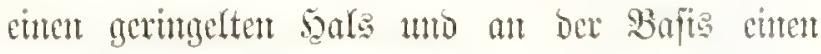
Sitrats von adjt Füfidjert.

\section{Fig. 10. Lagena plumigera (Brady).}

Dic flafdemfönunge Edjalc, $0,6 \mathrm{~mm}$ lang, hat

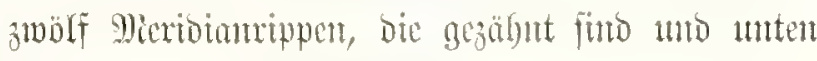
in balbgeffederte Frïgel auslatfen. 
Ging. 11. Bulimina spimulosi (Milliamson).

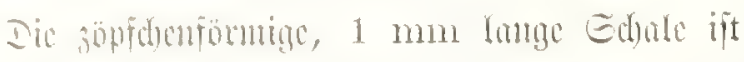

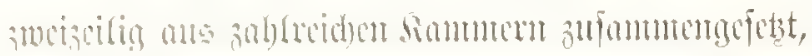

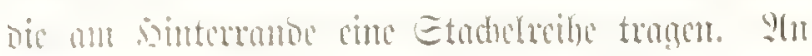

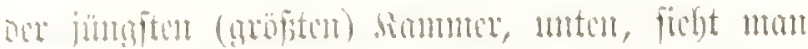

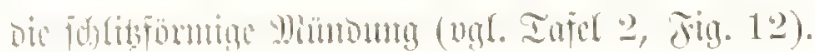

\section{Fing. 12. Bulimina marginata (d Orbigney).}

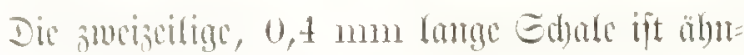
(id) ber vorigen, hat aber an sinterranoe jeber

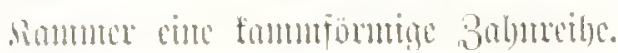

\section{Fig. 1:3. Bolivina Durrandii (Millett).}

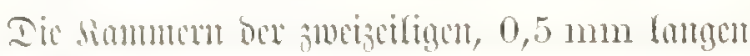

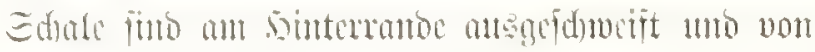

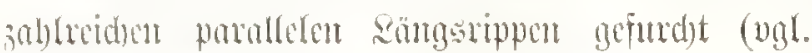
Infid 2 , Tig. 3).

Fig. 1t. Bolivina convallaria (Millett).

Die simuntern ber smeizciligen, $0,5 \mathrm{~mm}$ Yangen Ed)ate furo ablutid derjenigen von Sign. 12, aber Incterer gejtellt, meroriger, glatter wh anf bem viüren ftörfer genölbt.

Sig. 15. Uvigerina porrecta (Brady).

Dic sionnten ber id)tanten, $0,5 \mathrm{mmn}$ lamgen

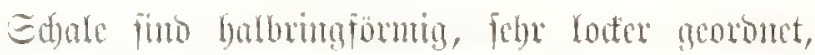
an ber Yupomano mit farfen süngstippen verfehen (ugl. Injel 2, gig. 2).

Fig. 16. Truncatulina ungeriana (dorbigny).

Die flade Epiralfdale, $1001 \mathrm{~mm}$ Ditrd:

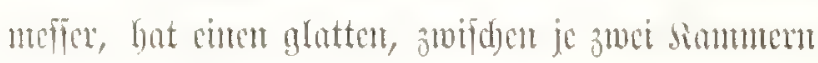
cingeterbten stusemano.

\section{Fign. 17. Rotalia calcar (d'Orbigmy).}

Dic flade Epiralfdale, $0,7 \mathrm{~mm}$ grofs, gleidet

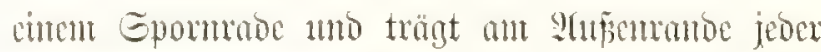
siommer ciment giabialablnt.

\section{Fig. 18. Polystomella imperatrix (Brady).}

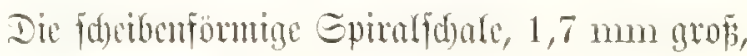

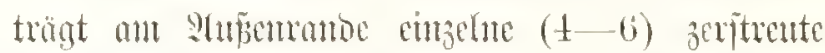

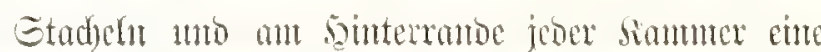
Mithe von Edhliten (ogl. Iafel 2, Jig. 7).

Jig. 19. Cristellaria calcar (Parker).

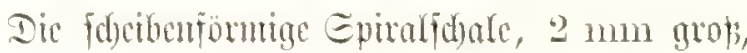
gleidht cinm Epormao unto trägt an ficlfömingon

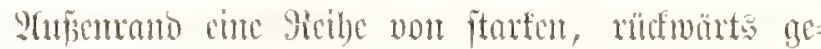
frimmuten Gtadden (ygl. Iafer 2, Jig. $4-6$ ).

Jig. 20. Bifurina Mackinnonii (1tillett).

Dic gerabgeftreffte Sdafe, $0,6 \mathrm{~nm}$ lang, be=

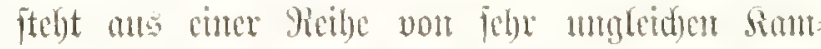
mern, bie fait breciefing finto uno fid) am (embe burd cinen langen, fdumafen Edylits biffnen.

Fin. 21. Lingulima pagoda (1)illett).

Dic germbgeftrefte Edjale, $0,5 \mathrm{~mm}$ lang, be-

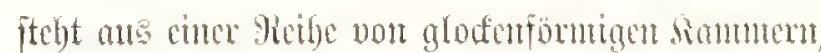

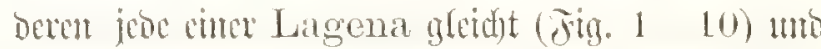

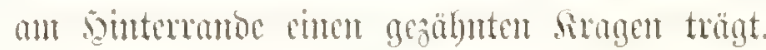

\section{Jig. 22. Mimosima liystrix (Willett).}

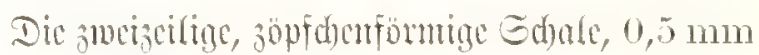

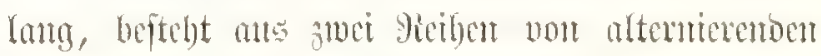

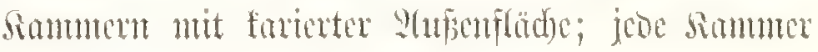
trägt cinter ftarten Etadud. 


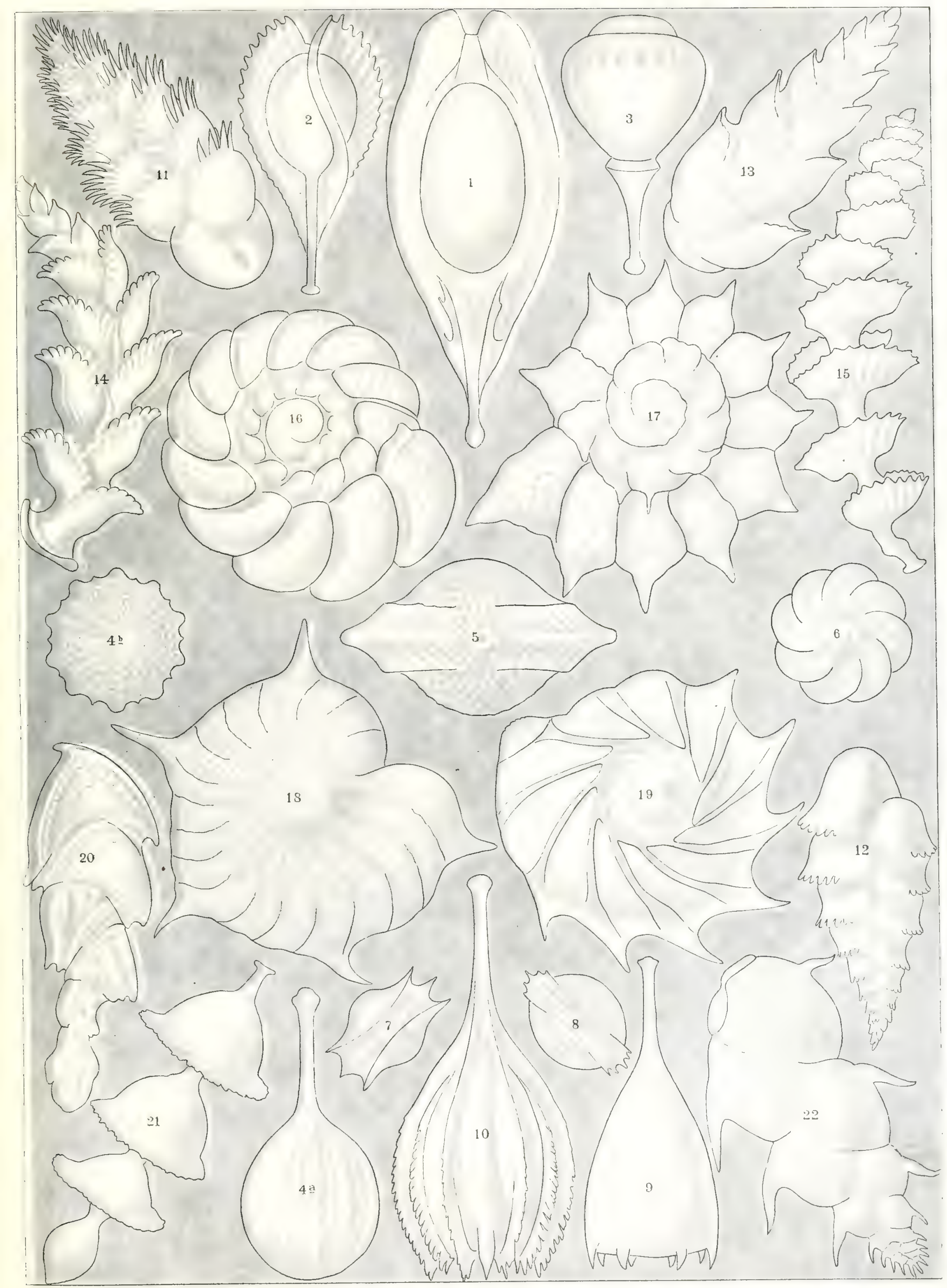





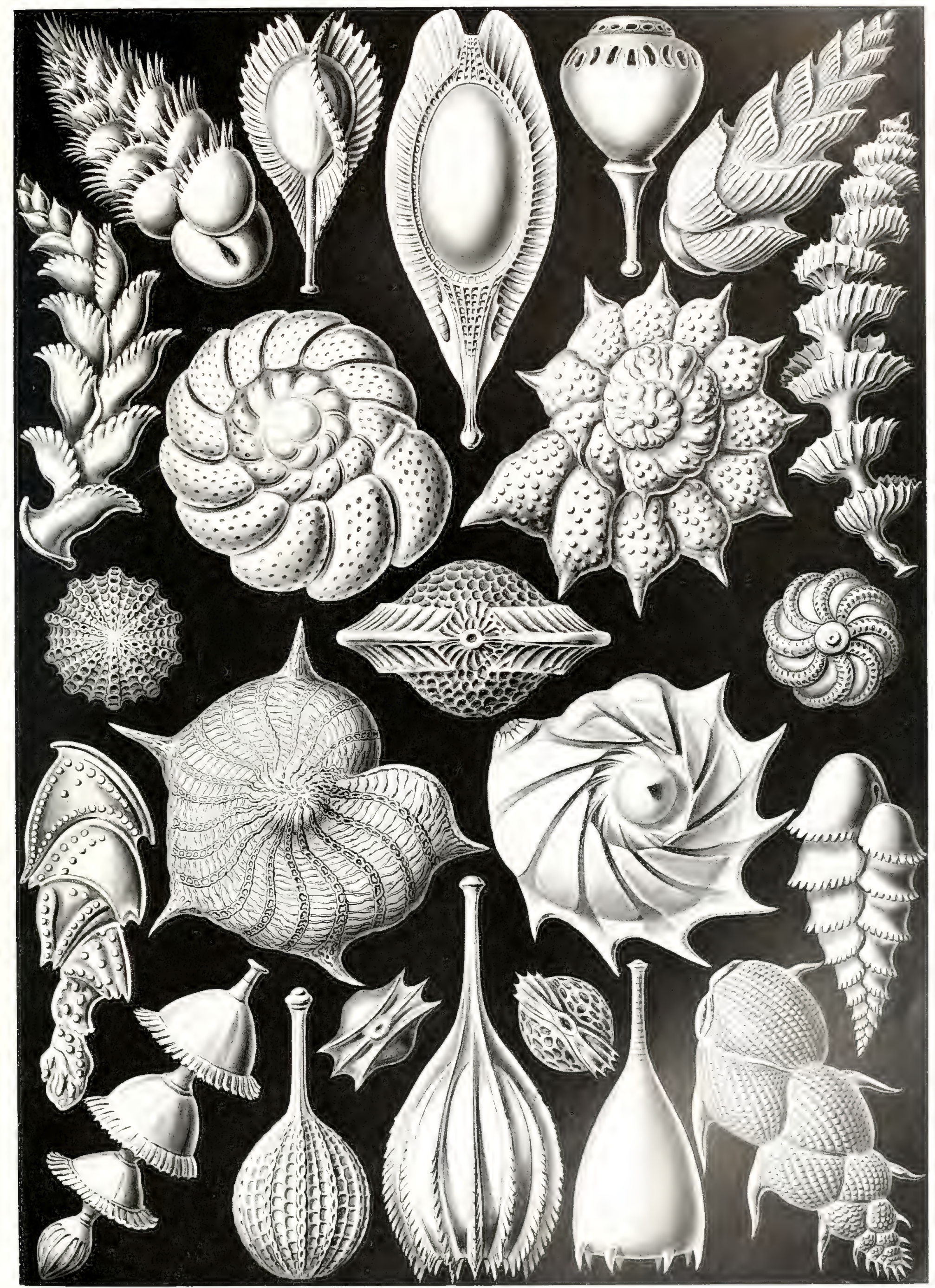

Thalamophora. 



\section{Hepaticae. Telremumie.}

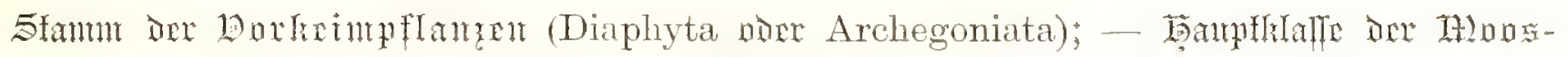
pflamęr (Bryophyta); 一 Tilalfe der Tehermonfe (Hepaticae).

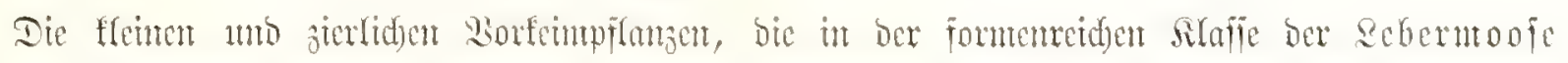

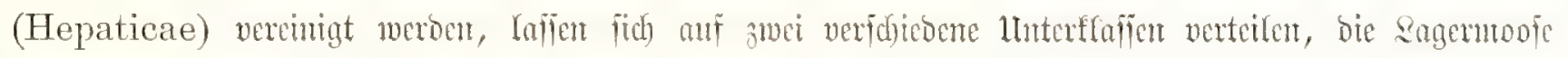

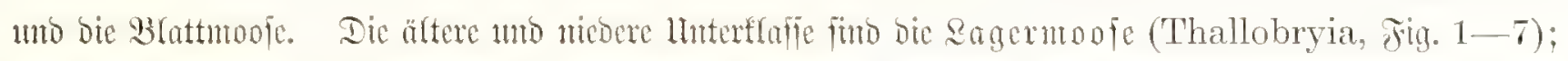

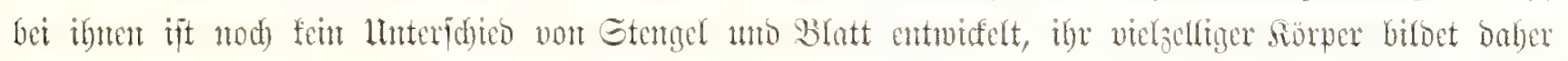

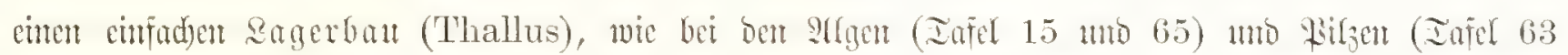

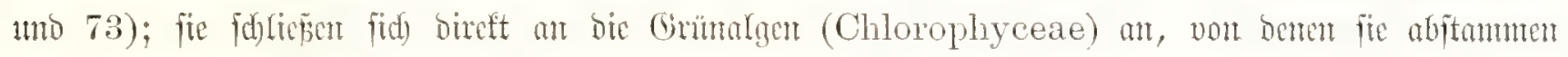

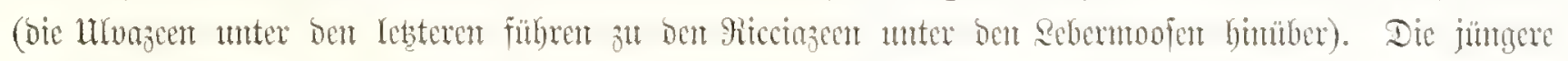

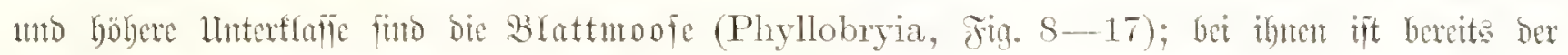

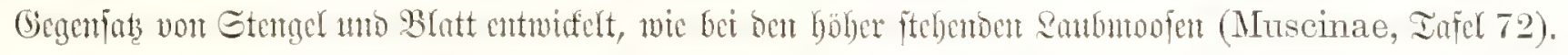

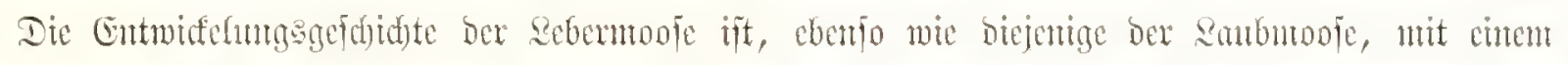

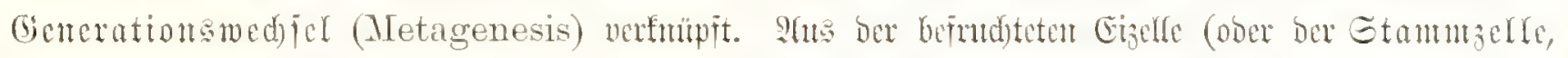

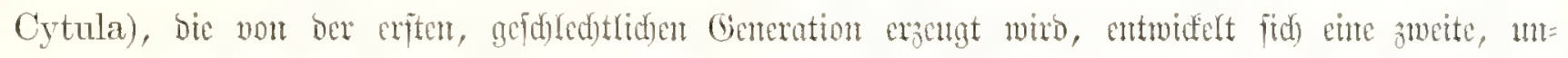

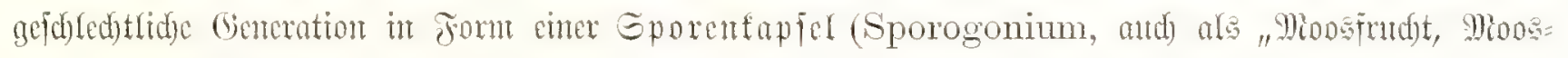

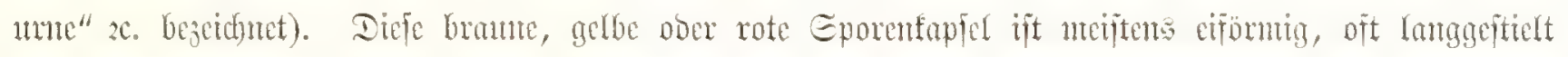

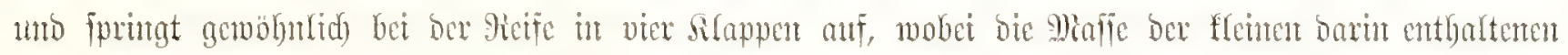

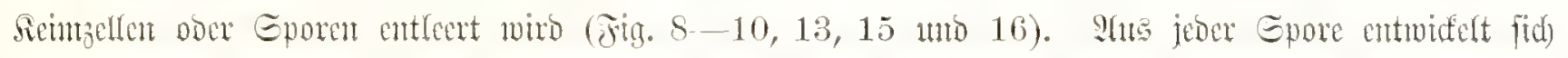

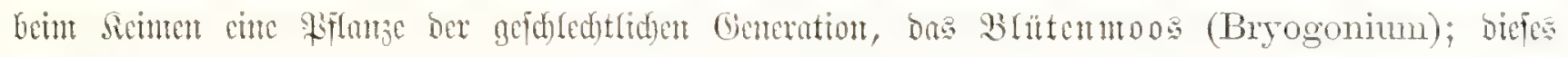

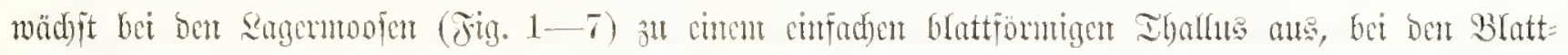

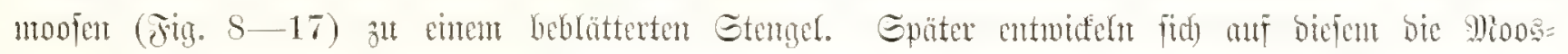

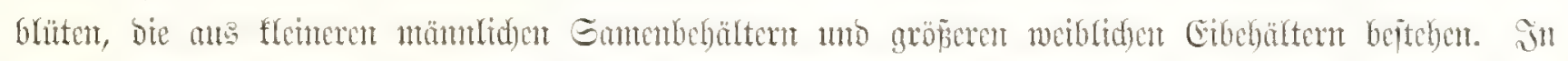

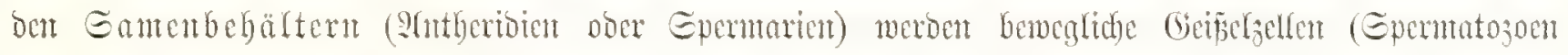

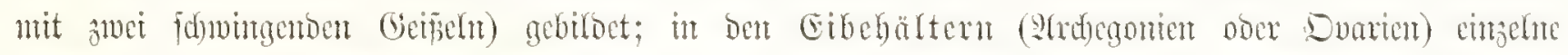

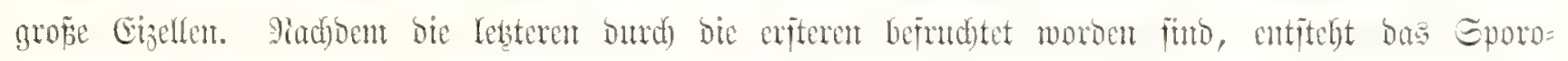

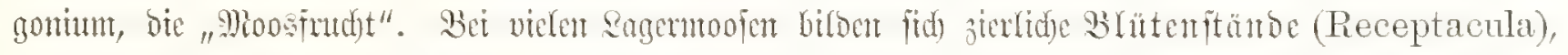

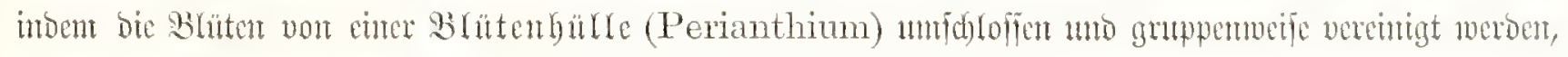

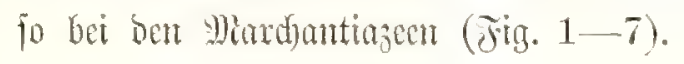

Fig. 1. Narehantia nitida (Lehmann).

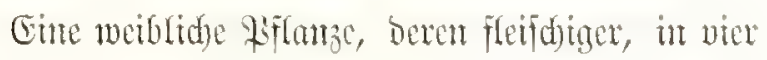
breite, gabelteifige sappen gejpaltener seagerbout (Thallus) frebon gciticlte Blütenitünoc (Recepta-

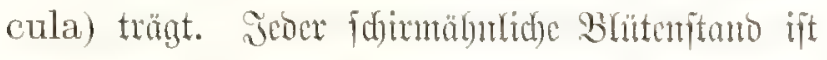

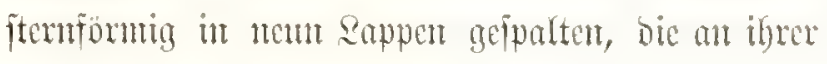
Interfeite bie Eporenfopicht tragent. gig. 2. Marchantia polymorpha (Linné).

Cin cinzefrer weiblid)er Blütentant, vont unten

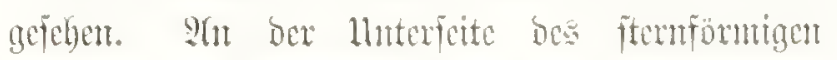

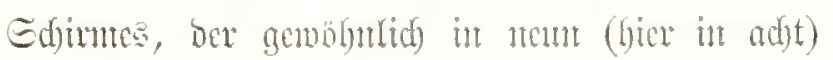

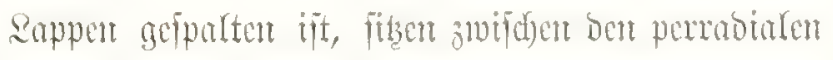
Sappen ebenio viefe interrabiale meiblide Bratent,

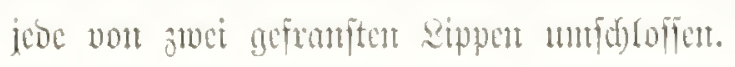


Tin. :3. Fimbriaria marginata (Gottsche).

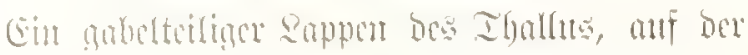
Itnterfeite mit Mismachanden befert, trägt anf

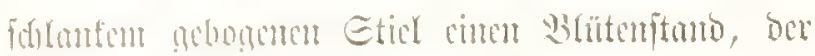

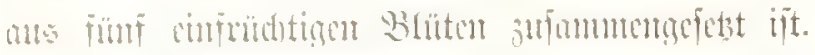

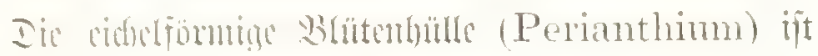

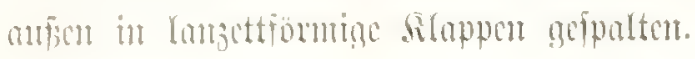

Fing. t. Fimbriaria venosa (Lehmann).

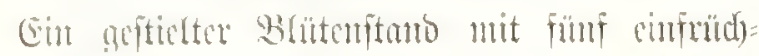
tignen 근ten, mie in Fig. :3.

Fiţ. ․ Fimbriaria cubensis (Gottsche).

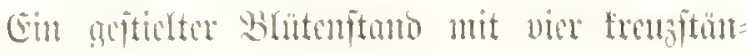

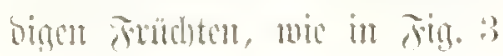

Fin. 6. Fimbriaria samguinea (Lindenberg).

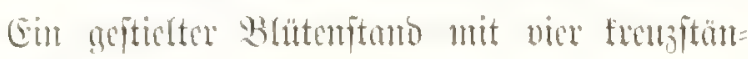
bignen Früthten, wie in Fign.:3.

Fig. 7. Lumularia ernciata (Dumertere).

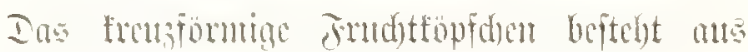

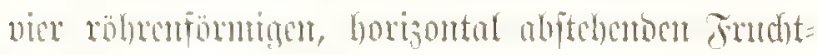
hüllu (

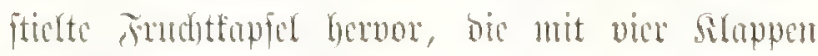

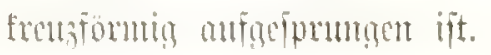

Titg. S. Jungermannia rentricosa (Dickson).

Eim Eprofi, ans beffen sidd obon cine ge itielte, in viex Siloppen amfgefprungene Eporen= fopfel berwortritt.
Jig. 9. Jungermannia conniveus (Dickson).

Ein Etöfden nit vicr freujitünoigen Eproflen.

Fin. 10. Lepidozia reptans (Nees).

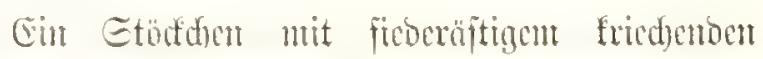
Etengel, mts beflen 9yitte fid cine gefticlte Eporen= fapplet urbetit.

Fin. 11. Jubula Hutelinsiae (Dumortier).

Cin Etüt cines Gprofies, von der Interfeite gejefent.

Jig. 12. Harpalejeunia ancistrodes (Spruce).

Ein Etüt cimes Eprofies, von ber Interfeite acjeber.

sig. 1:3. Scapania mululata (Nees).

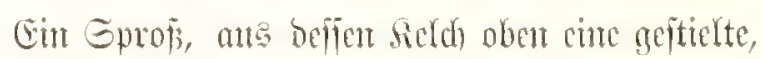
in vier siloppen anfgeiprungene Eporenfapied her: vortritt.

Jig. 14. Scapania subalpina (Dumortier).

ein beblätterter Gproṕ.

Fig. 15. Seapania umbrosa (Nees).

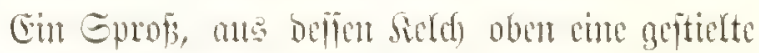
Sporcutapid heruortritt.

Trig. 16. Scapania nemorosa (Nees).

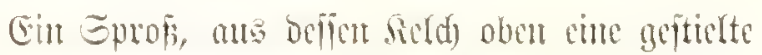
Sporenforted hervortritt.

Fin. 17. Scapania aequiloba (Nees).

Ein behlätterter Emroj, oben mit ben Sield. 


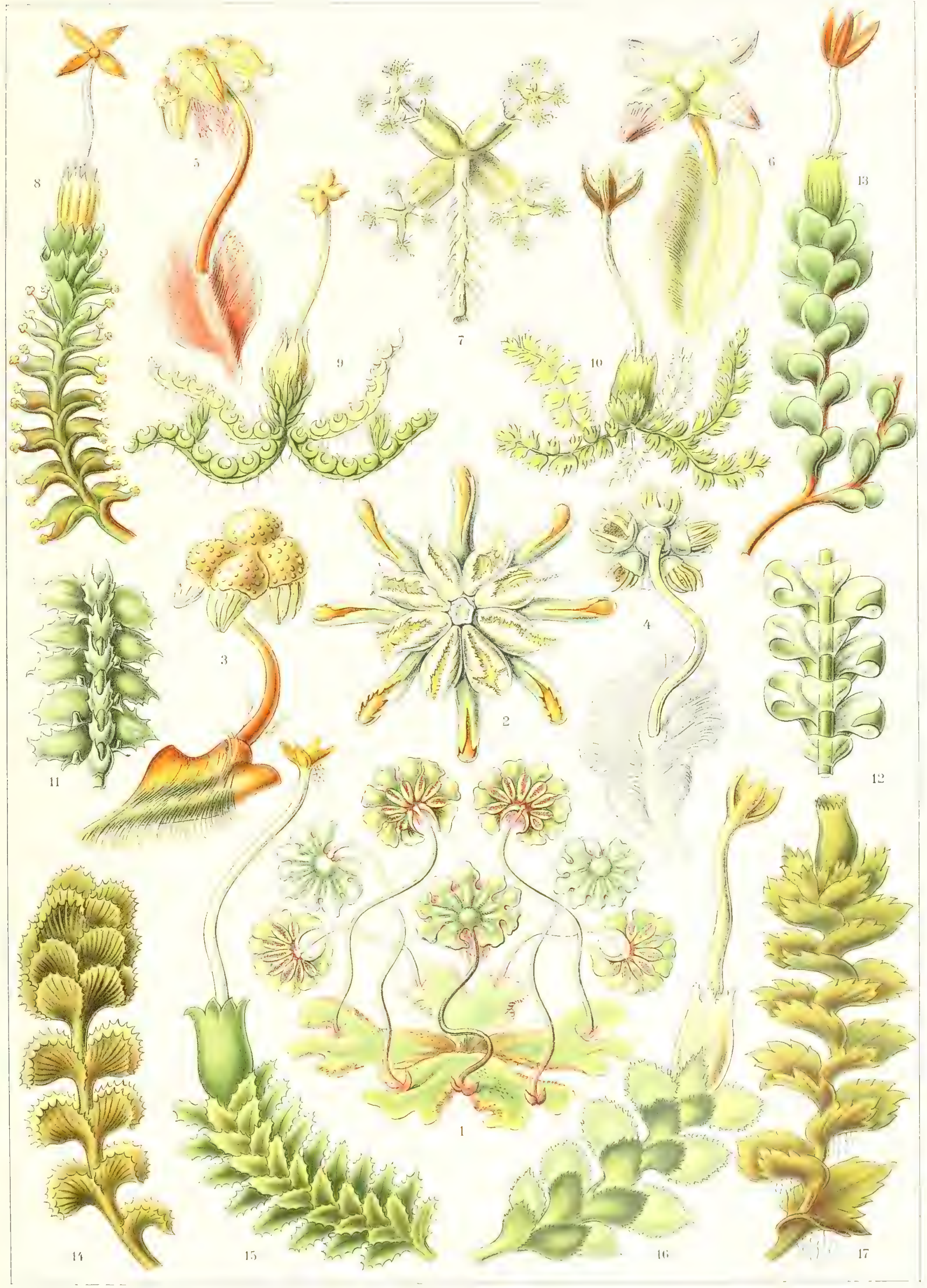

Hepaticae. - solierntoole. 



\section{Lichenes. Itherlitert.}

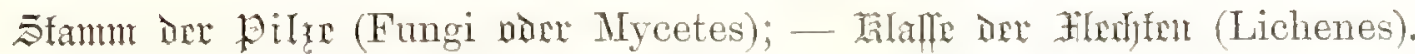

Die formemredde Gruppe ber Fledten (Lichenes) bithet cine ber merfwüroigften Rlaffen bes

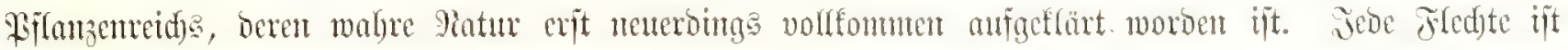

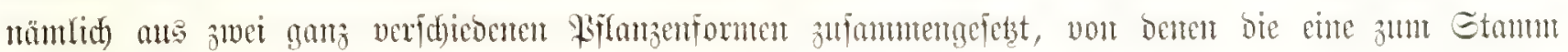

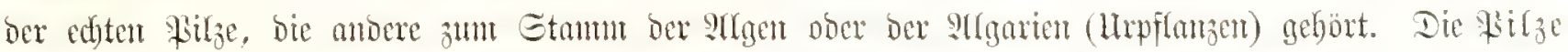

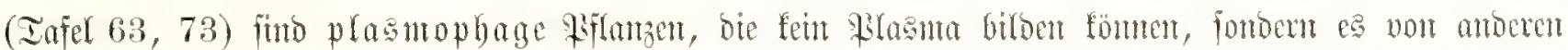

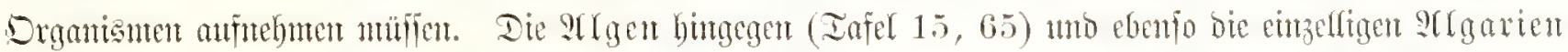

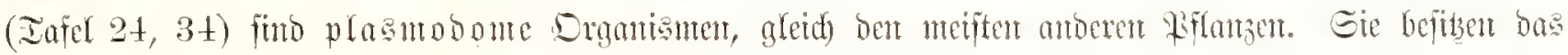

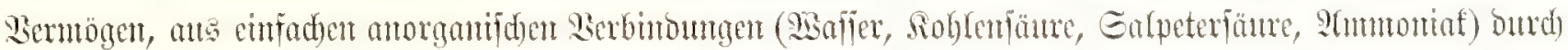

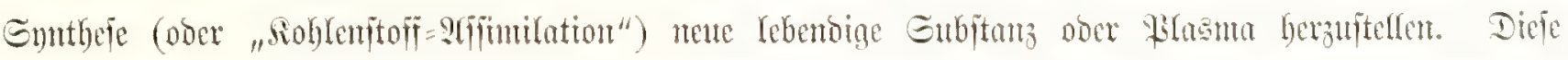

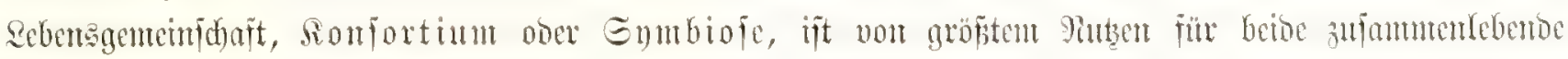

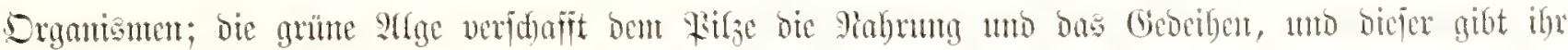

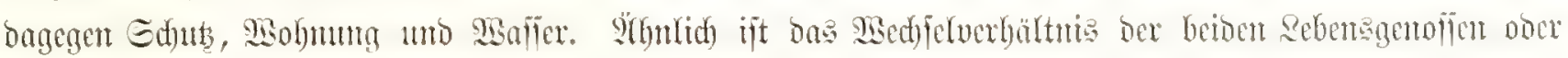

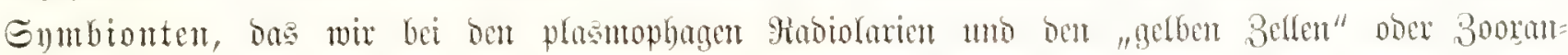

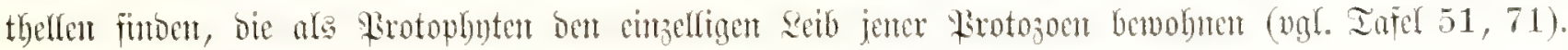

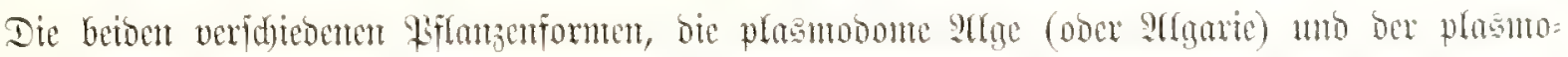

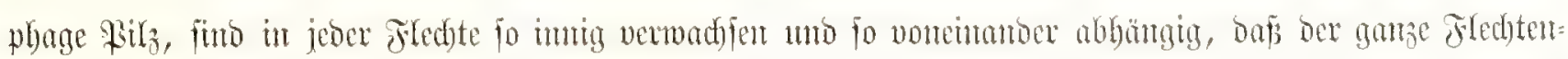

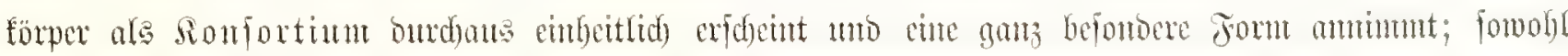

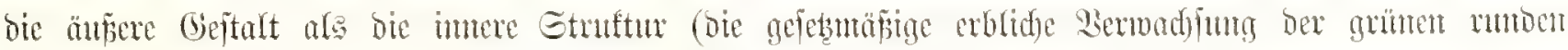

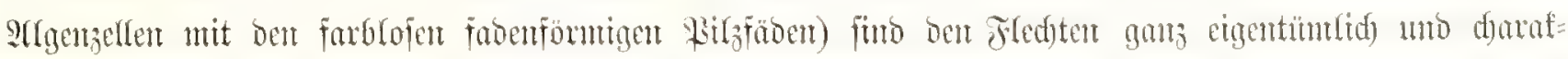

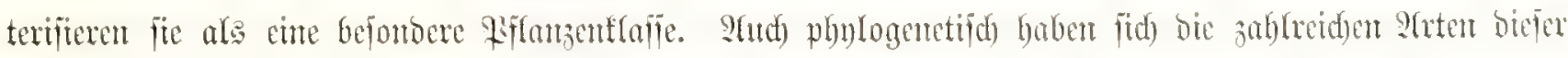

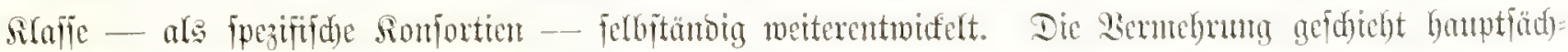

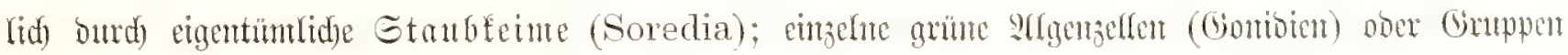

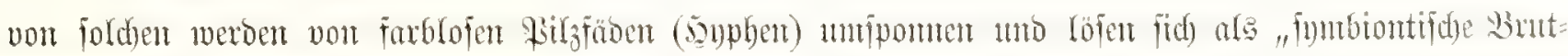

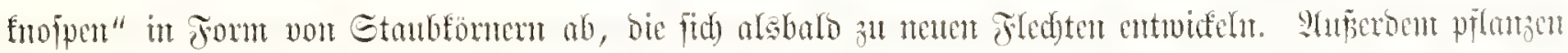

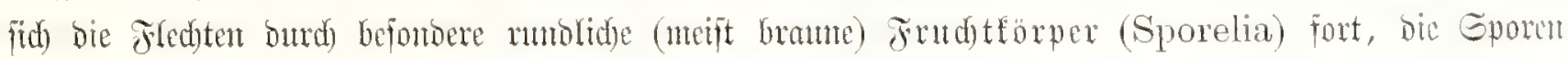

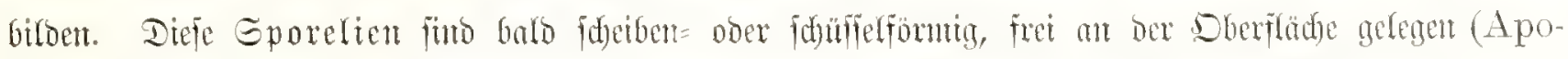

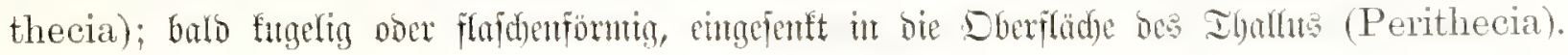

jög. 1. Cladonia retipora (Floerke).

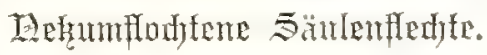
Ratürfidue Gröb̄e.

Der Thalfus biroct einen baumïormig veräjtelten,

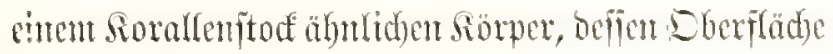

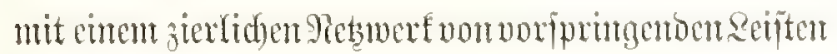

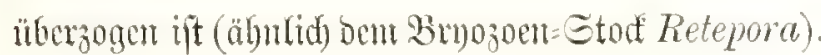

\section{Fig. 2. Cladonia perfoliata (Hooker)

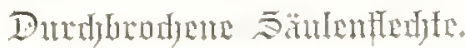 E(t)wad) vergröjert.}

Der Thallus birbet antiftrebaroc actrinumte

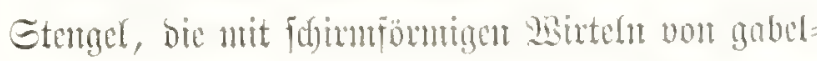

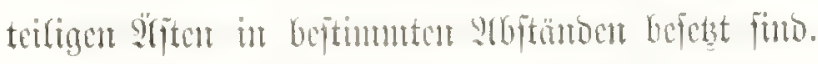

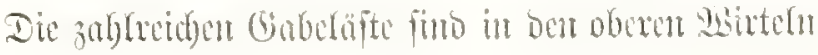




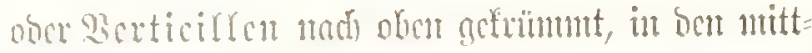

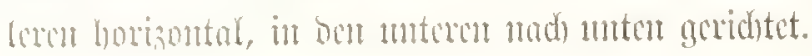

Ting.: Chollonia rerticillata (Achard).

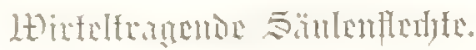

E(b) verutionert.

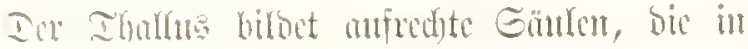

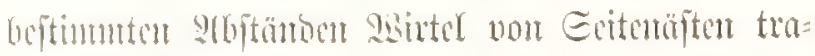

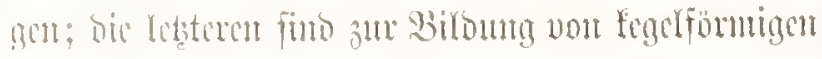

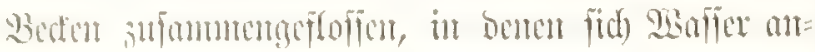

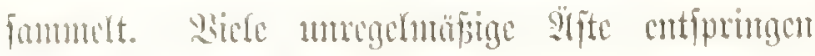
vour Simbe ber Beden.

Jiti. 4. Cladonia sqmamosa (Hoffmam).

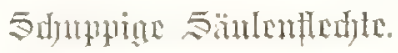

Ed)wach verurofifert.

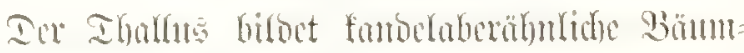
d)en, beren biffe Günte guberformig verzmeigh ift; an ben erroen ber sifte fteben beerenfoumige rot= broune Spotbecien. Die Dberfläd) ber Sifte ift mit abifthemon Edumpen ober battförmigen $\mathfrak{g}=$ frebten säppden beocett.

Fig. 5. Cladonia fimbriata (Fries).

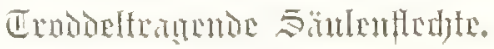
Edmad) verọüfert.

Dor Ifyallus bildot neiftelte Buther, bie an ifrem

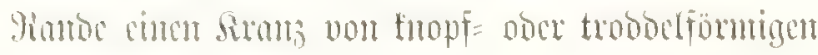
Elpothecion trager.

Jig. 6. Clatonia colnucopiae (Fries).

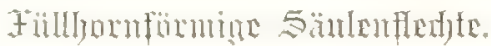

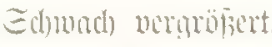

Der Thallu biloct umrgeteldete, cinem Finflgom

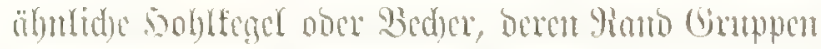
bout fnopffömigen :(potl)ecion trïgt.

\section{Fing. 7. Sticta pulmonaria (Achand).

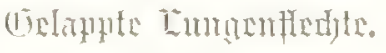 Yiatürlide Grofor.}

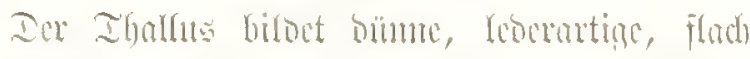

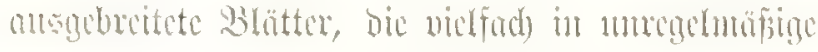

Rappen von verfdjedenter Gröfe geteilt füto. Die Grante Dherfcite ijt grubig, von cinem giedzwerf förnige Sciften burd)zogen; bie getbbrame Unter=

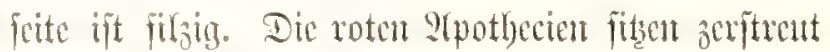
ant Ganto ber sappent.

\section{Jig. S. Parmelia stellaris (Fries).

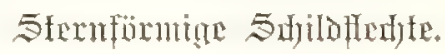 Yiatürliche Grobipe.}

Der Ifallus bifset cimen freisnutben graten Edjils, in ber Mlitte warzin, mit vielen bramen

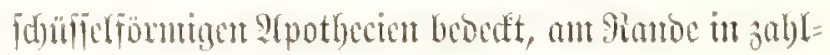
reide jtrablento, vielteifige sappen gefpalten.

\section{Sing. 9. Parmelia olivacea (Achard).

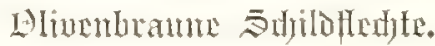 Siationlide Grobe.}

Dor Thallus bitset cinen regetmanfing freis=

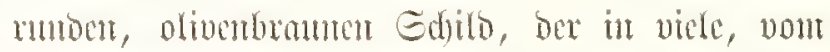
Wittelpumft anstrablente Falten gelegt ift. Der Fand ift in viele fladje, abgerumbete, gefräufflte umo geferbte sappen gejpaltem.

\section{Fin. 10. Parmelia caperata (Acherd).

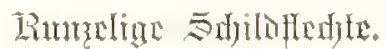 Mintirrlidre Gröfoe.}

Der Ifallus biloct cincu fretirntom ober ellip=

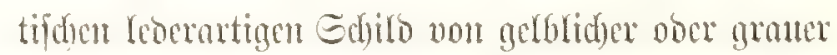

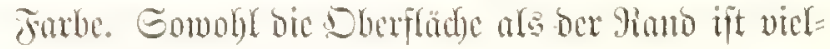
fad) gefaltet uns in unzäblige sappen umb säppdyen

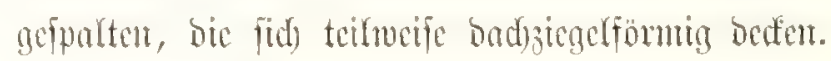

\section{Jig. 11. Hagenia crinalis (Schteicher). Berfalerte Lt)imprefledte. Sintïrtide (Grónge.}

Dex Ifallus bilbet cinent blattförmigen, Yäntg=

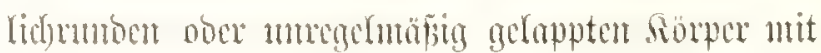
vidfad) veriöteltest 3weigen, beren feinfte sifteden

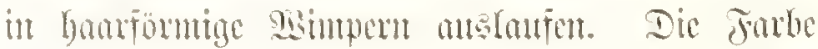

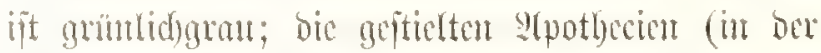

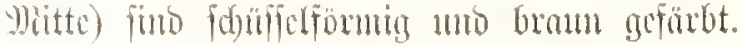




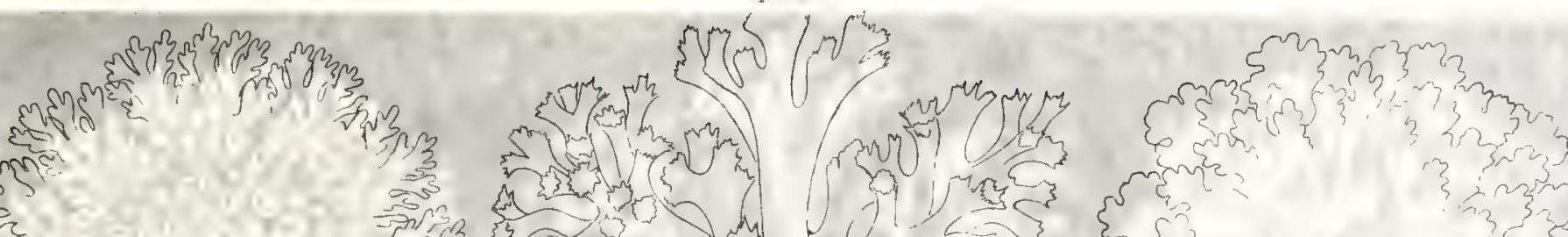

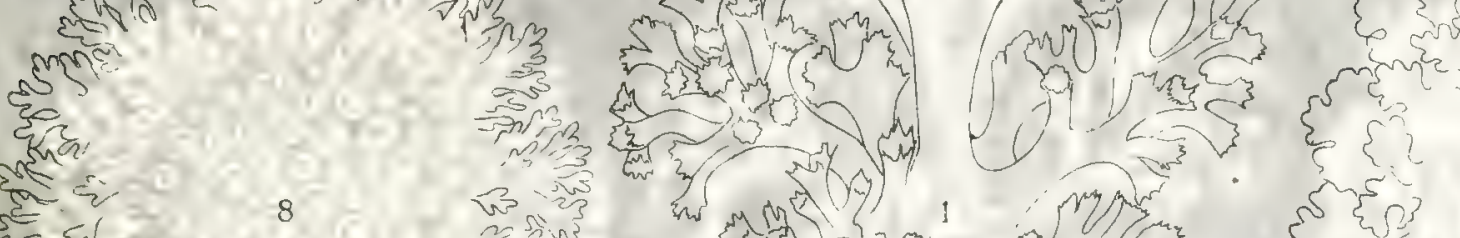

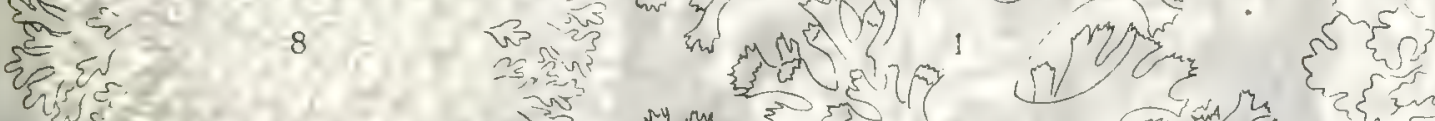

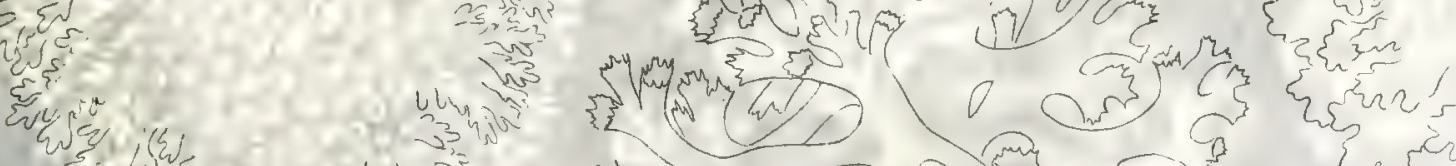

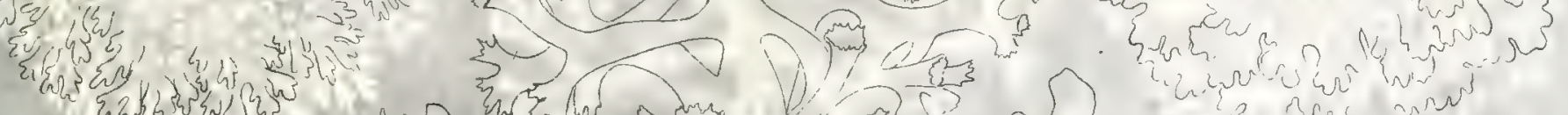
LI

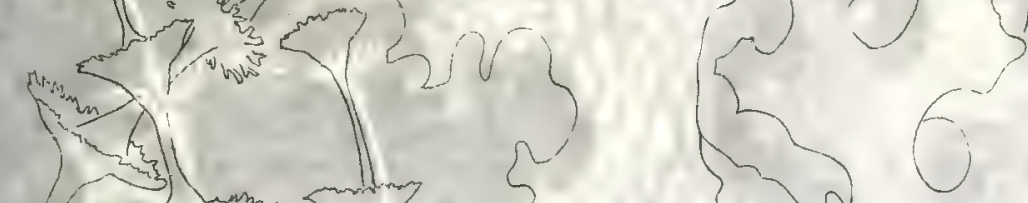

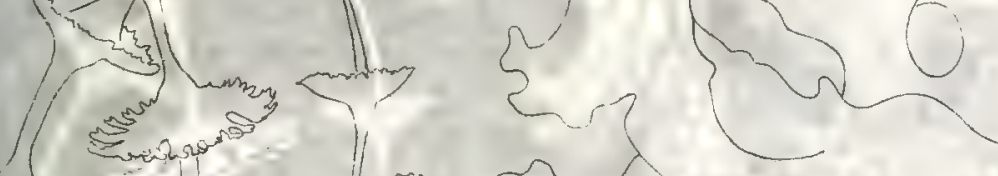

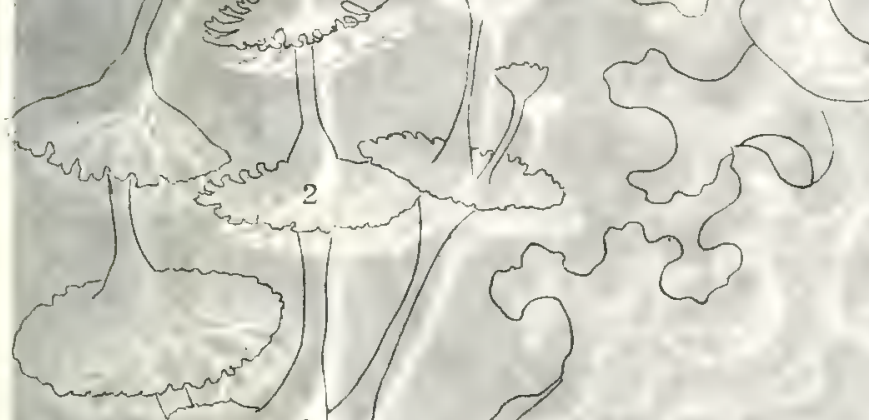

(3)

(3)

(n) $\underbrace{}_{3}$

Fin

.7.

(5)

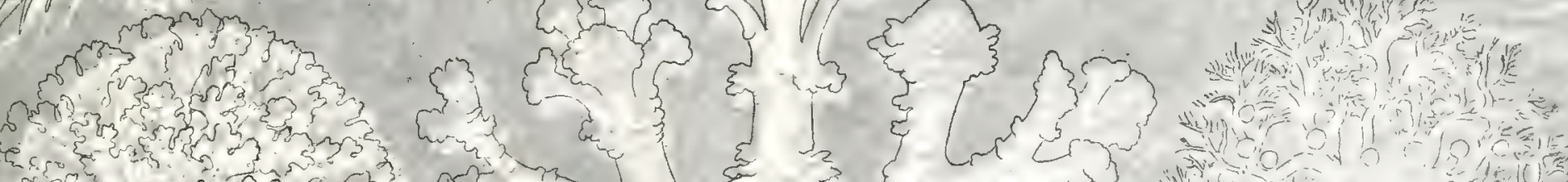

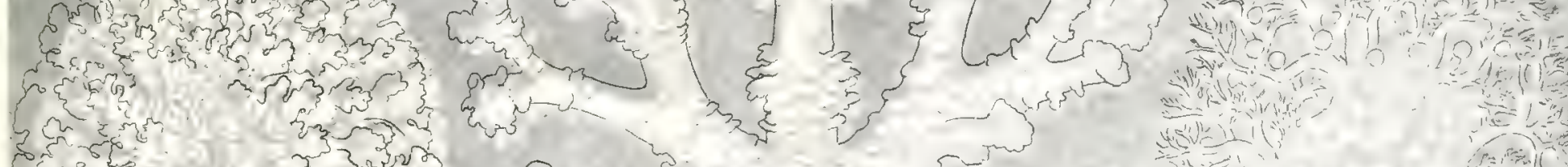

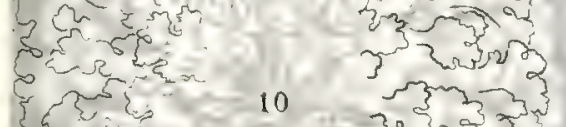

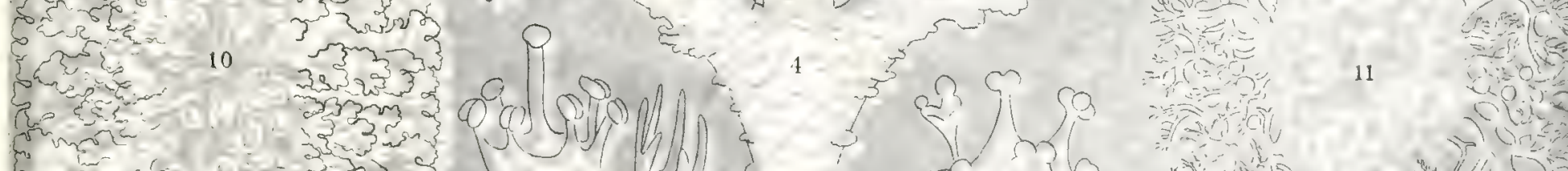

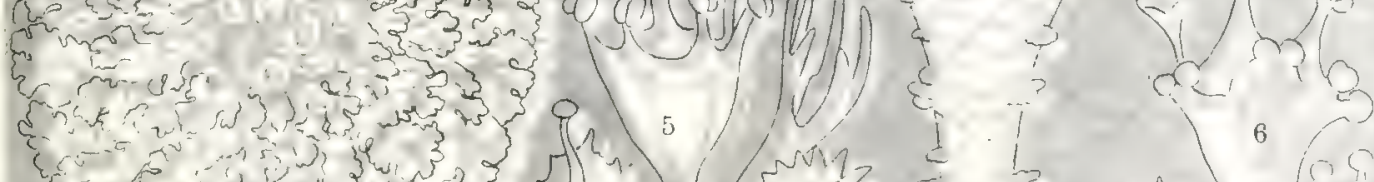

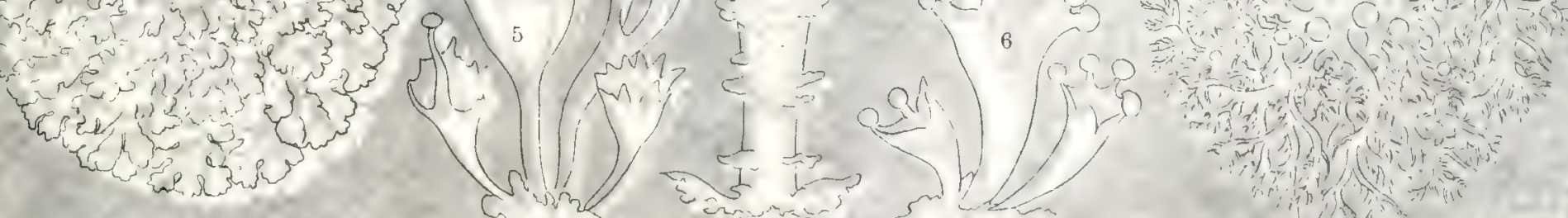




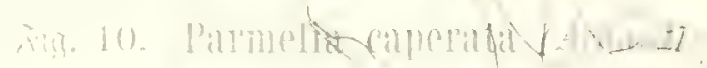

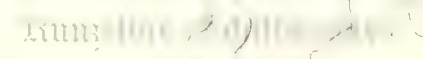

O $, 1, i$

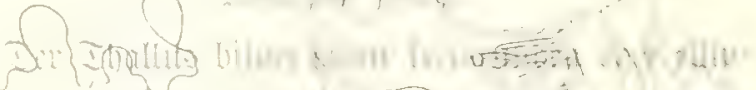

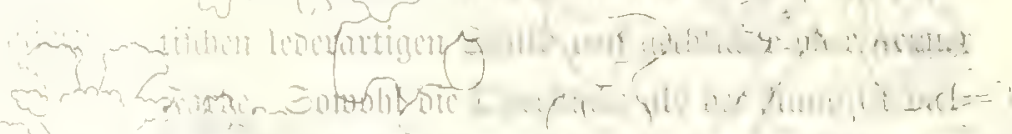

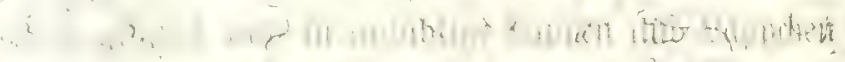

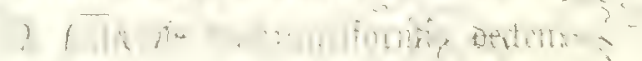
in

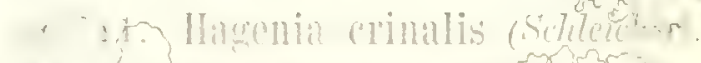

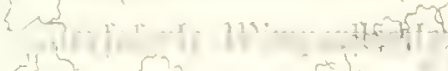

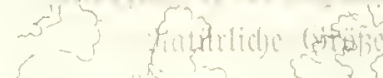

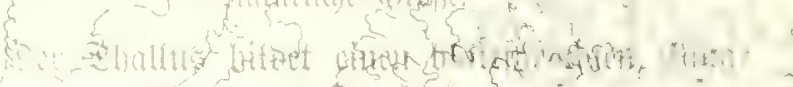

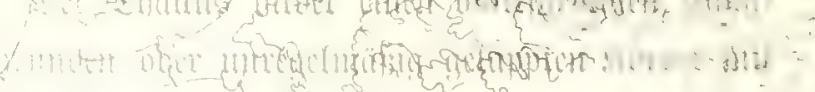
mintcluter

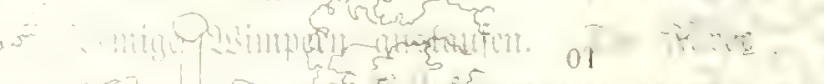
(1) $\therefore \therefore \therefore$

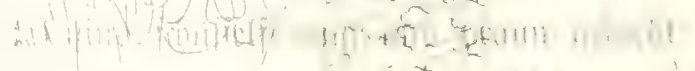

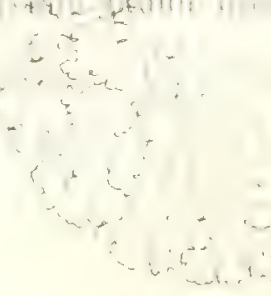




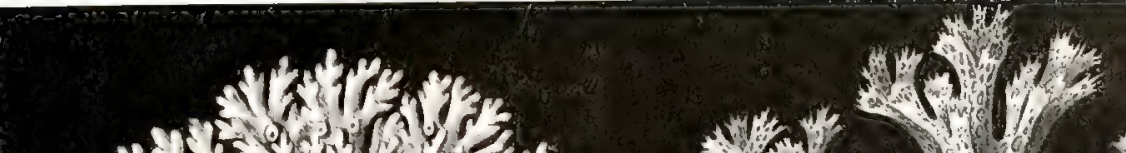

whthe $60 \%, 0$

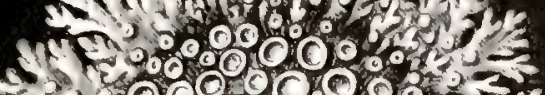

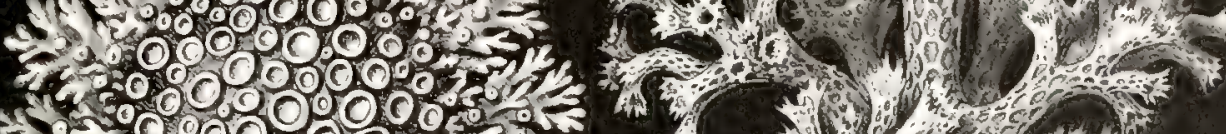
$+40000000005$ $5=12009000909 \mathrm{M}$

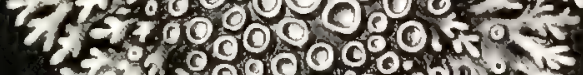
$210.990 .00 \%$

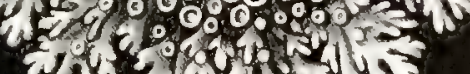

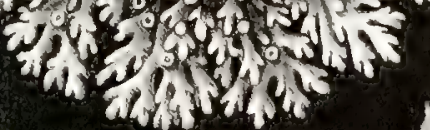

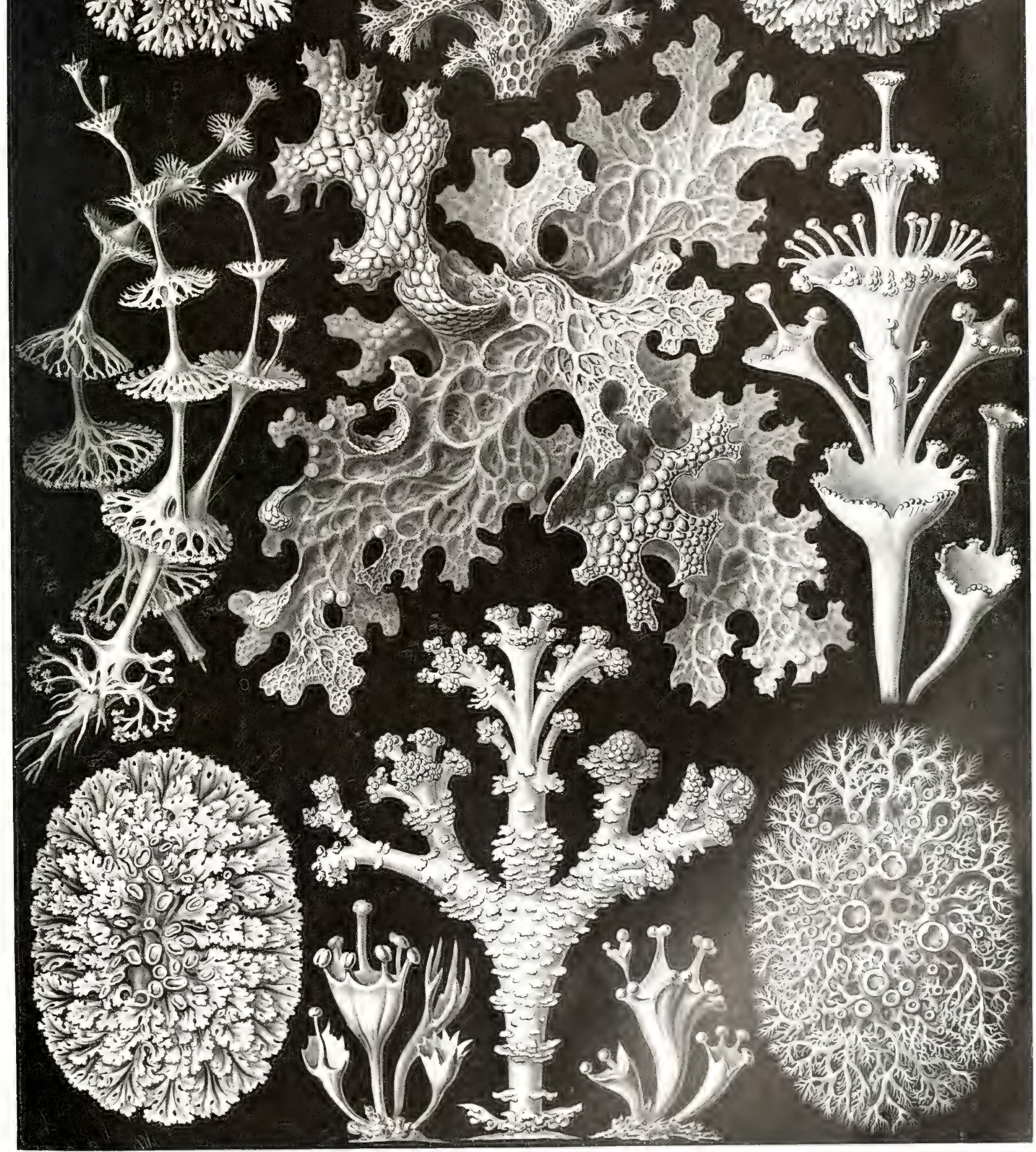

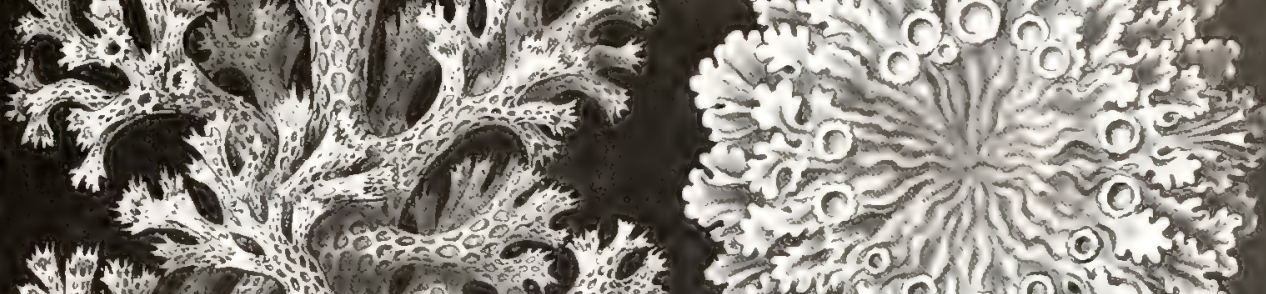

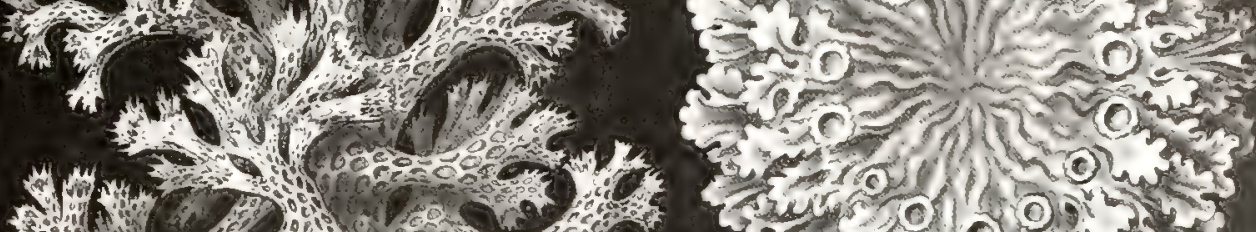
fint?

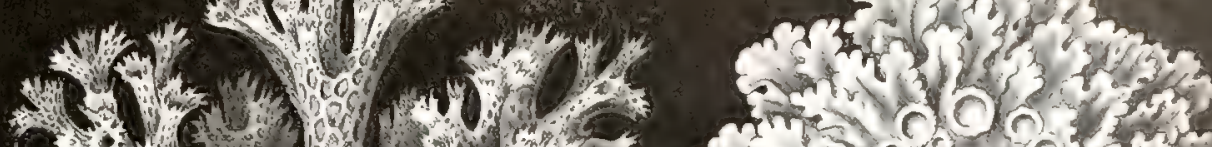

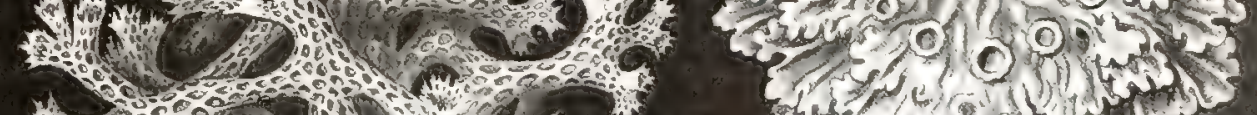

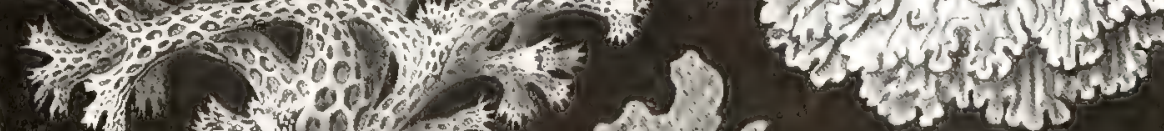
1 



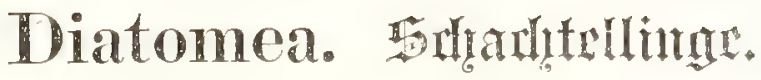

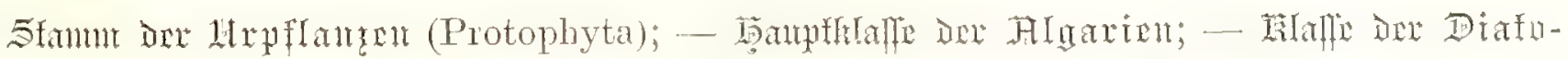

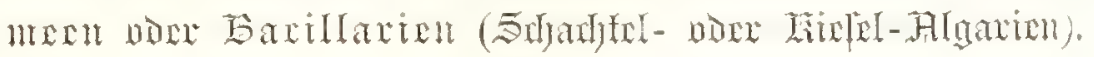

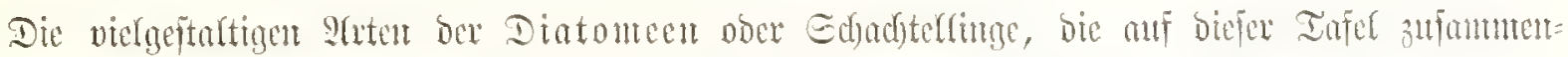

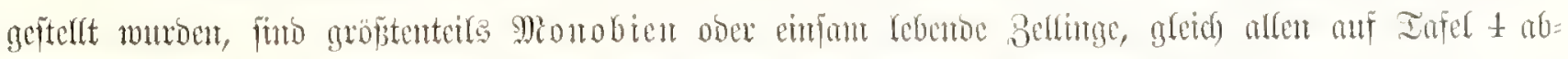

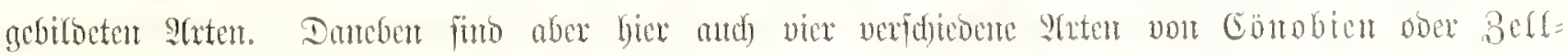

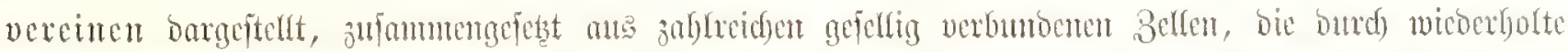

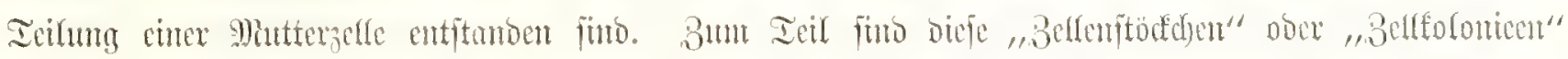

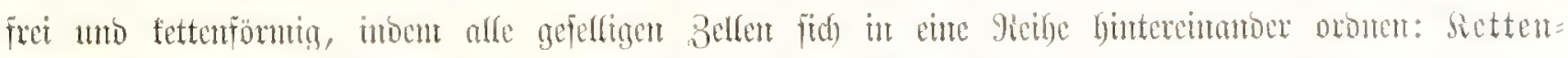

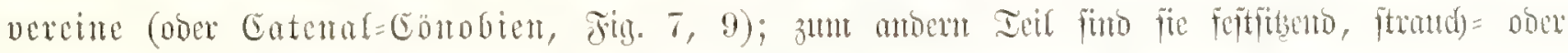

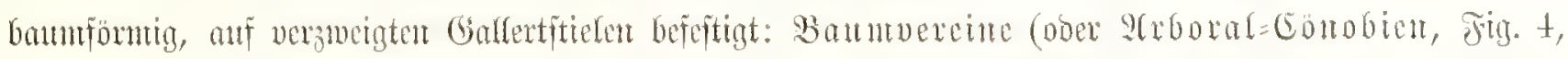

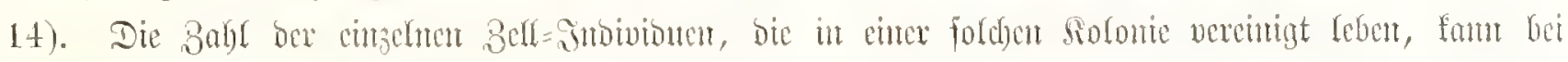
grofien Cöntobent vicle Immento betragent.

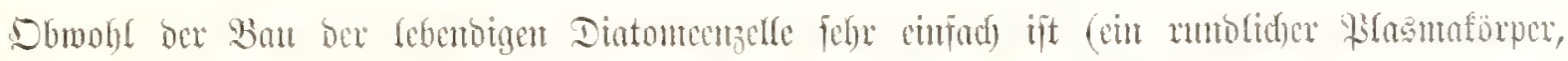

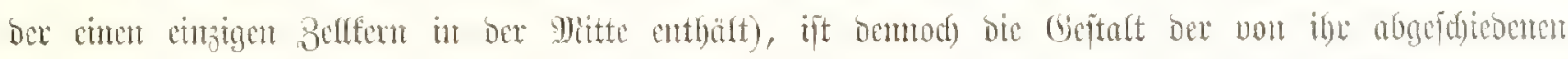

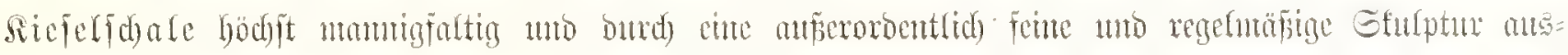

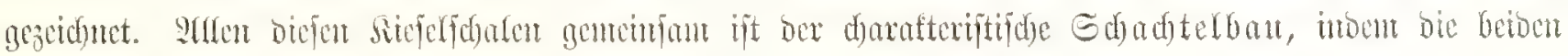

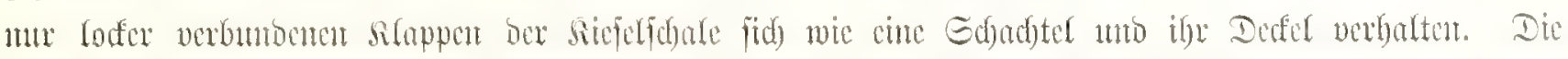

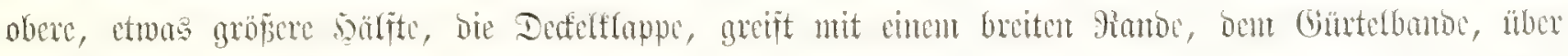

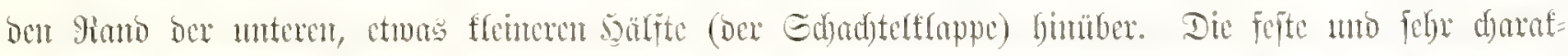

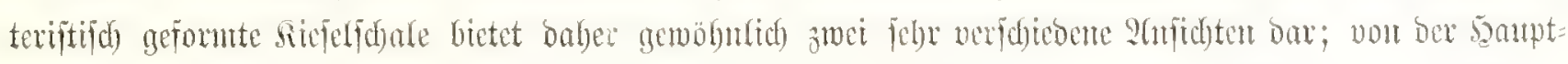

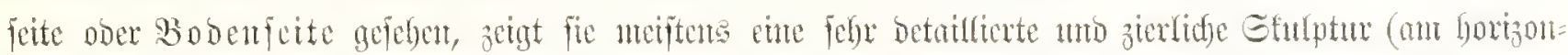

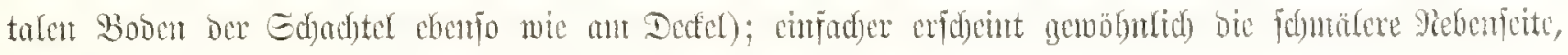

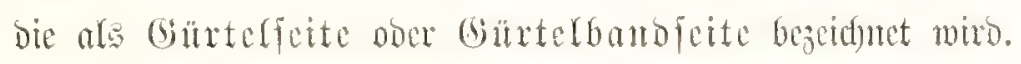

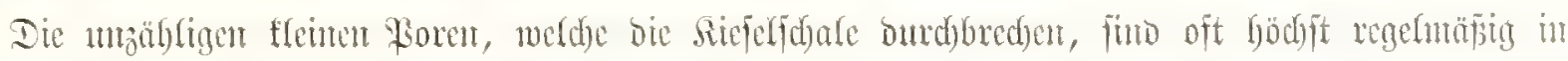

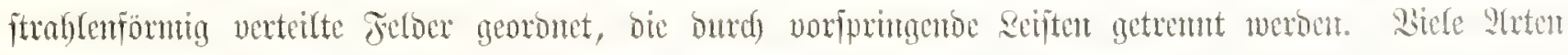

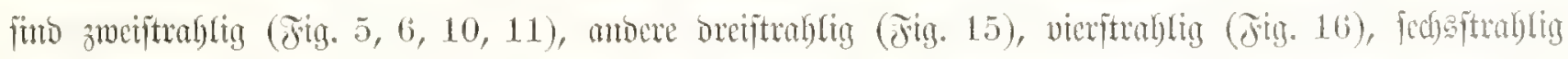

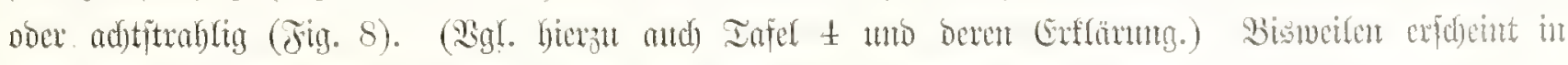

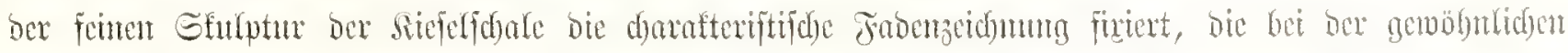

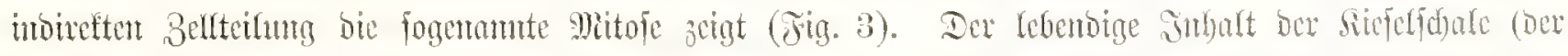

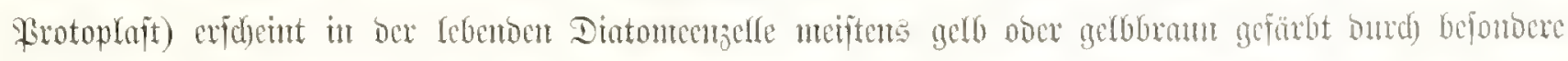

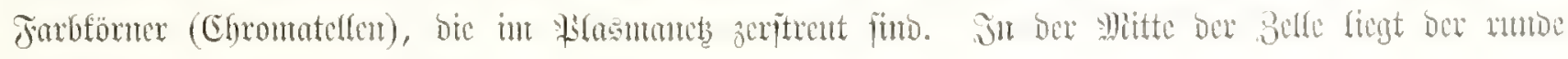
Belferre (Nucleus obu Karyon). 
Tit. 1. Pyrgodiseus armatus (Kitton).

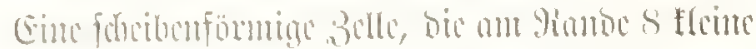

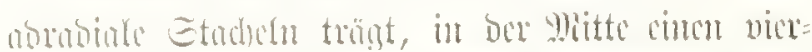

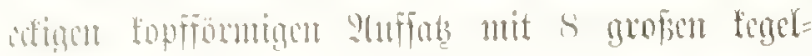
formingen Etadelu (t horizontalen perrobialen mo

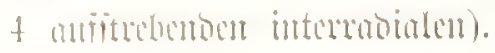

Ting. ‥ Rutilaria monile (Grore).

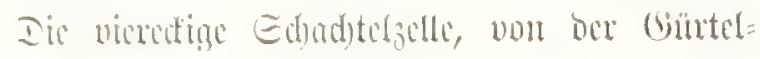
bamblitic geforen.

Ting. :. Aulisens elegans (Bailey).

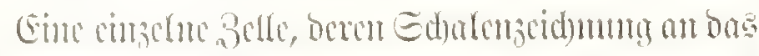

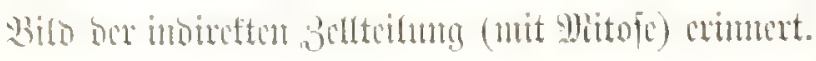

Titz. 4. Cocconema (istula (Ehrenterg).

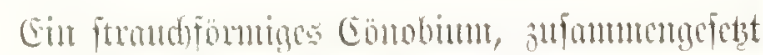

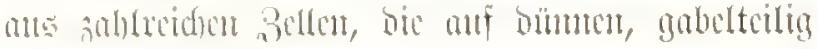
mersmenten Gonlertitidar fitsen.

Jig. 5. Campyloneis (irevillei (W. Smith).

Eine cinsehe Belle mit bilateral=rabiales Etruftum, utit elliptifdem S3obon.

Jiş. 6. Asteromplaalus imbricatus (Wallich).

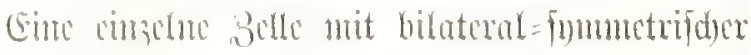

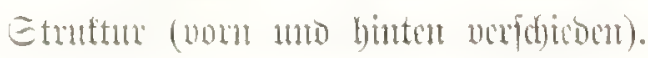

Fin. 7 . Odontella aurita (Lymboyc).

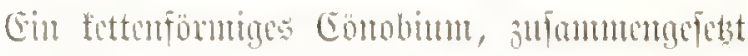

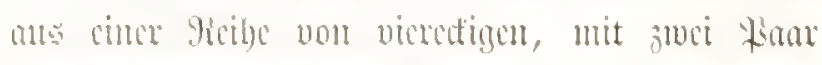

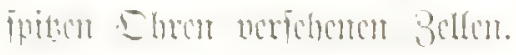

rity. S. Grovea pedalis (Grore).

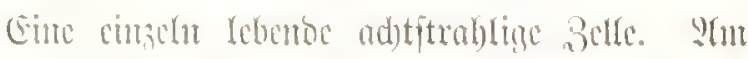

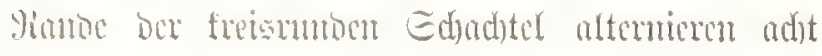
perrabiale breitere mit acht interabialen fdynäleren

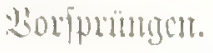

\section{Fing. 9. Biddulphia pulchella (Gray).}

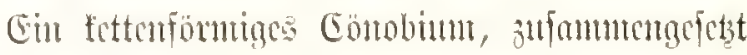

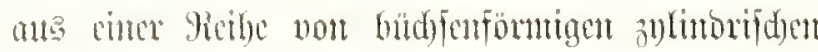

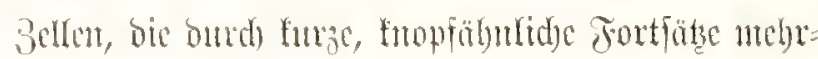
fad) vertnupft fino.

\section{Fing. 10. Navicula bullata (Norman).}

Eine cinzelne fpinodförmige Bdlle.

Fig. 11. Savicula didyma (Greg.).

Eine cingelne geigenföntige 3elle.

Fig. 12. ('ampylodiscus bicruciatus (Greg.).

Eine eitzelne Befle mit einent Doppelfrenz.

Jig. 13. Surirella puleherrima (1leara).

Eine cingelste mucrgeripte 3 elle nit longett: Förmigem Bentralortantent.

\section{Jig. 1t. Liemophora flabellata (Carm.).}

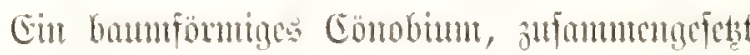
aus fäd)erförmigen (Gruppen von feifförnigen Bellest, bie mif gabelteiligen Gallertfticlen jteben.

Fig. 15. Triceratium Robertsianum (Greville).

Eime eingelme, gleidy)eitig oretedige Belle mit polygnitalen foucttent.

Jin. 16. Gephyria constricta (Greville).

Eine cinzelne lomggeitrente, jumeifaitige Bolle

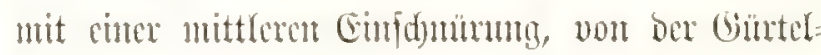
banofaite acfelen.

\section{Jig. 17. Amphithetras elegans (Greville).}

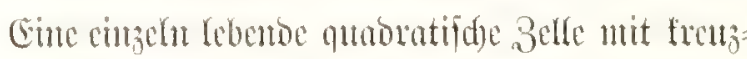
förmiger 3eid)untg uno vierftrahliger Sfulptus. 


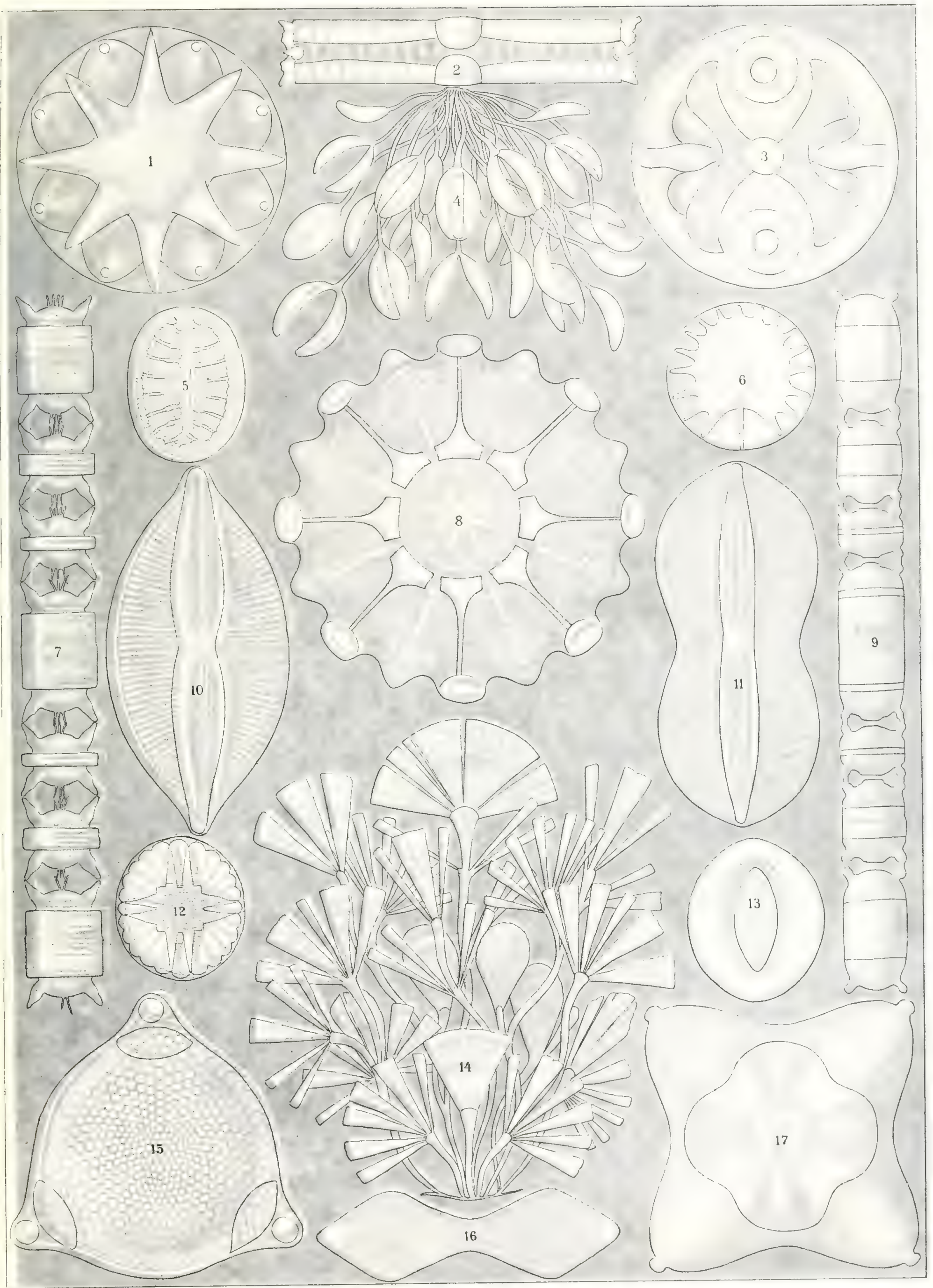




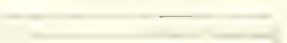

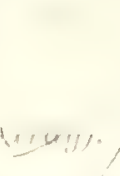

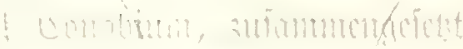

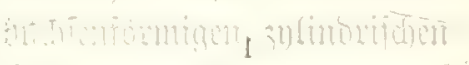

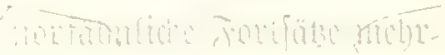

Whititi ine

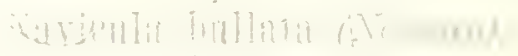

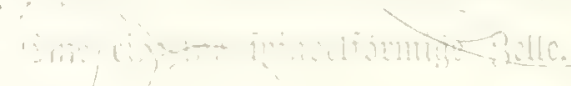

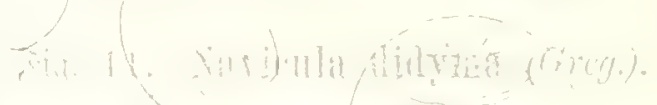

$\because y$ tinsthe dquantom

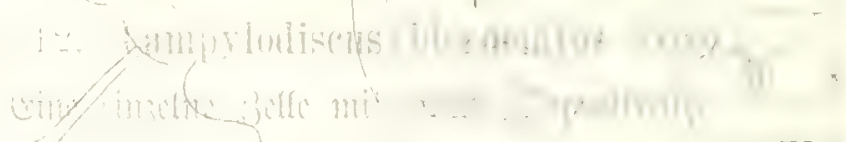

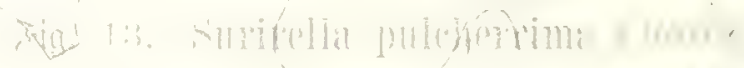

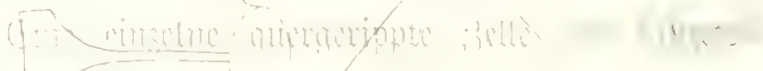

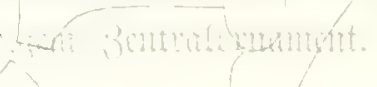

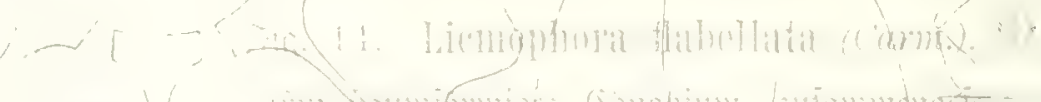

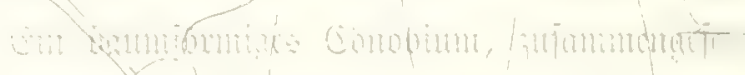

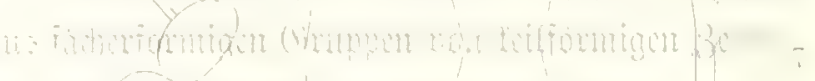

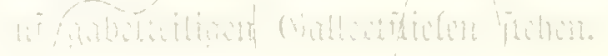

..........

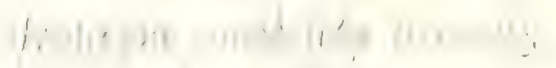

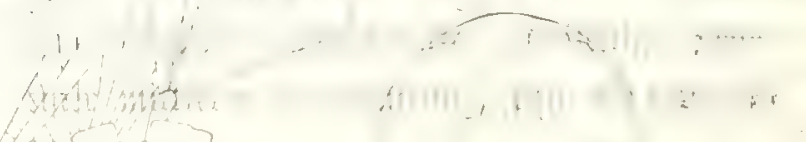

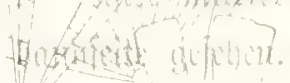

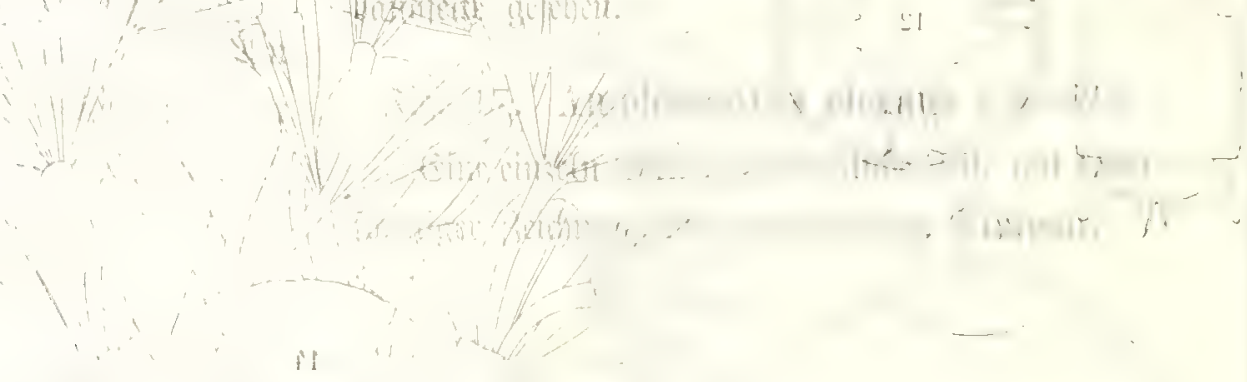

il 


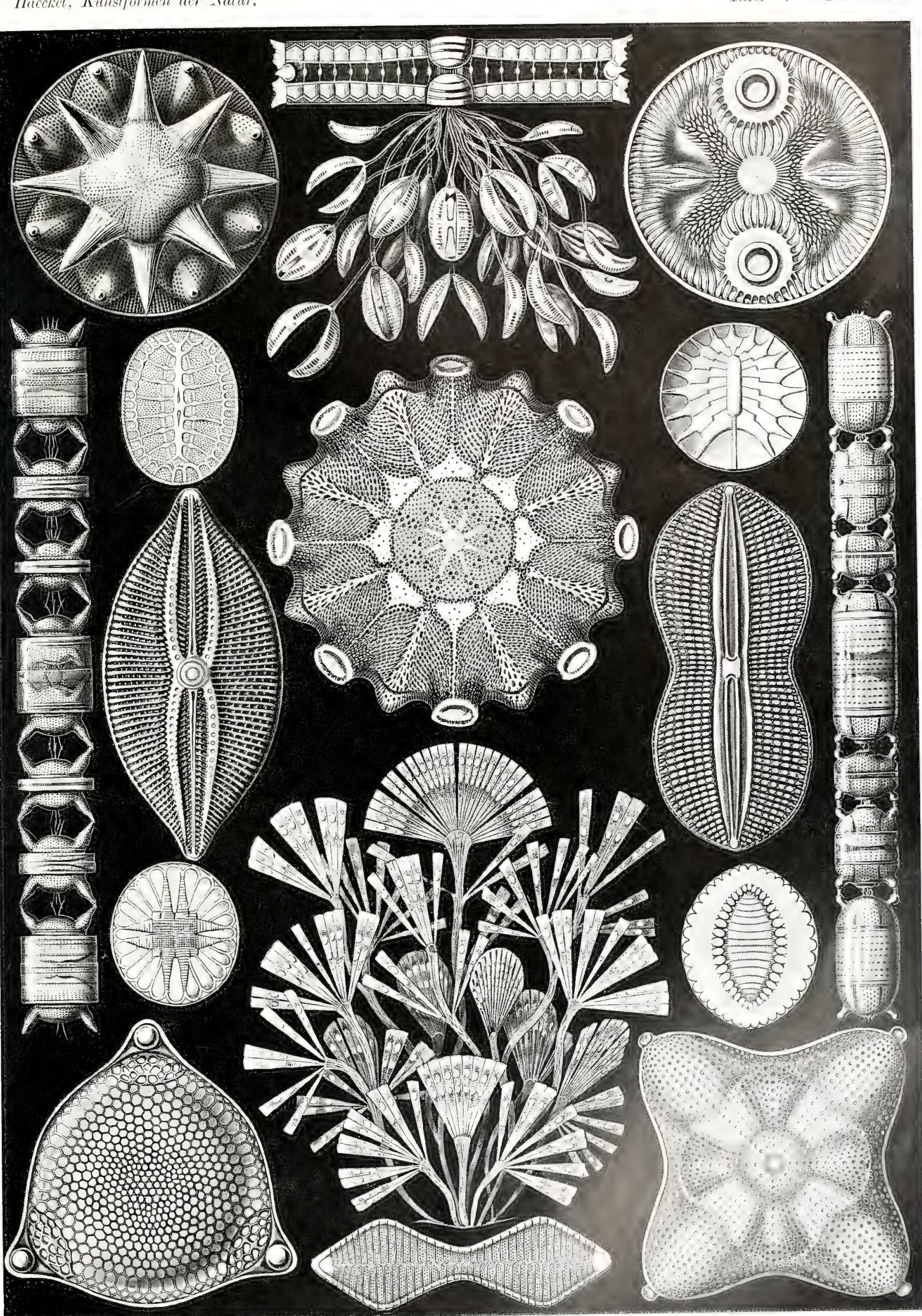

Diatomea. - sdichtellintuge. 


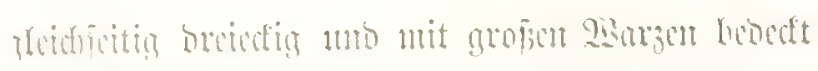

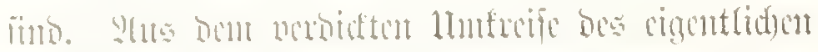

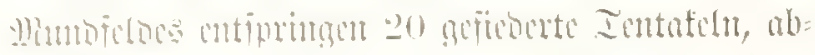

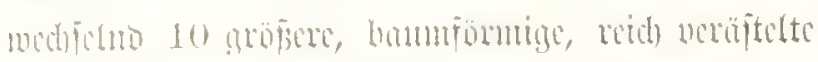

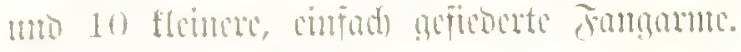

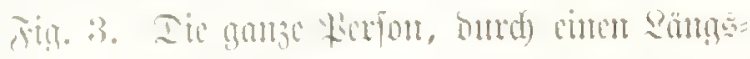

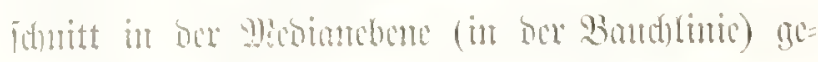

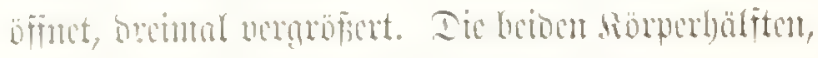

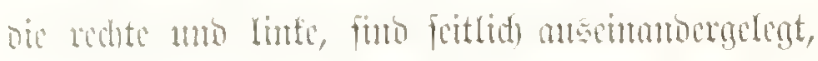

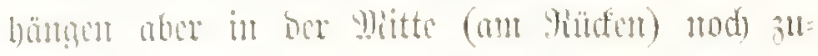

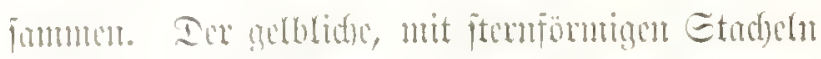
beodfe Whatel ijt inten von ber bünuen weiden

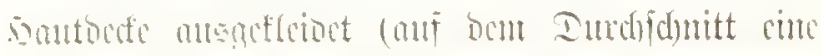
lote suric). Die weite Miantelböble ijt zแm gröpten

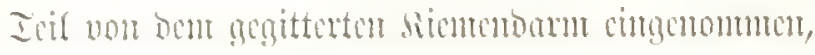
Deflen jumenflathe anf jober Ecite (redts mo lints)

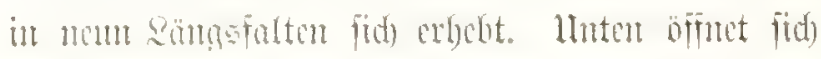
Det hicmenomat in ben flement Dlagen (in ber Witte); oer Iumborn, ber barans cutfpringt, ijt

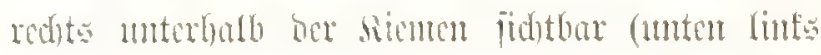

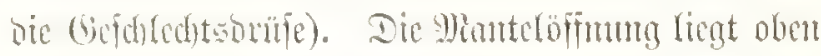

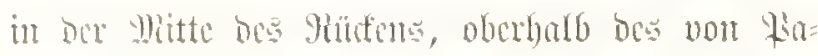

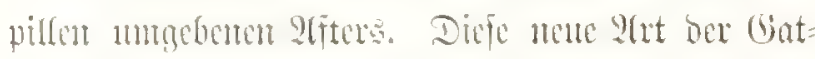
tman Cynthia, von Emmatra, ift mabe vermanot bex curnparifon C. echinata (Lime) uno ber mitra lifden C. spinifera (Herdman); fie unterforetoet

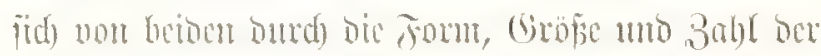
Diantelfadych, ber Icntafeln mo ber sicmenfalter.

Fing. to Molgula tuluulosa (Forbes).

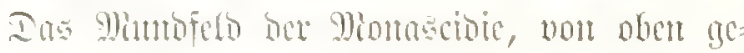

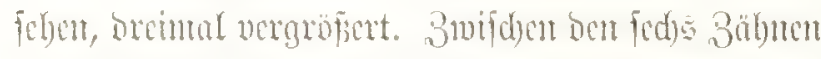

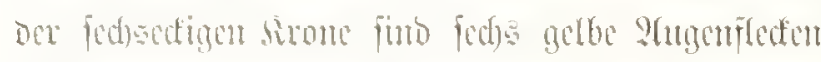

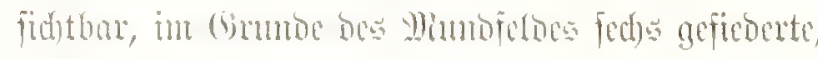
mit ben Epiben and immon ncridntete Iontafeln.

Jig. 5. Fragarium elegans (ciured).

In: tundige, rote, ciner Erobere äbulidhe Etod

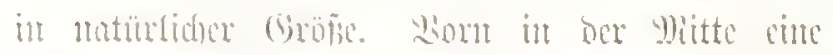

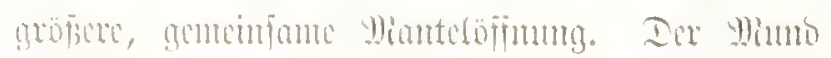

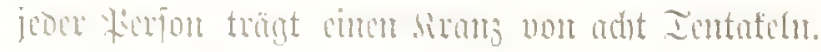

Jig. 6, 7. Polyclinum constellatum (Sarigmy).

Jig. 6. Cin ciförunger Etod, ane melreren

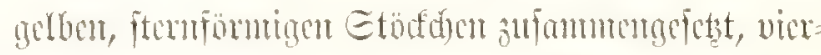
mal vergröpert. Dex gemeimante Mianted ift blau.

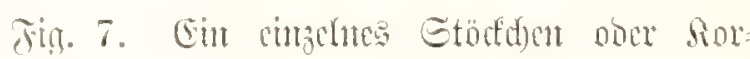

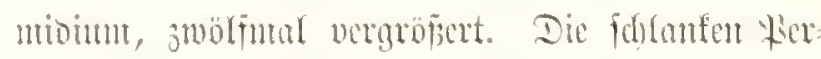

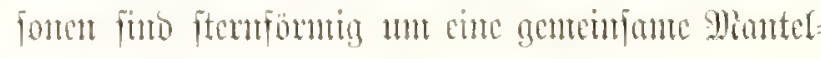
offrmatg (Bentraltionfe) gmppiert.

\section{Fig. S. Synoecum turgens (Phimps).}

Gir Etäf(d)en von fed) Limporm, von oben gefoben, in matimlicher Giröse. Seoe fierfon trïgt

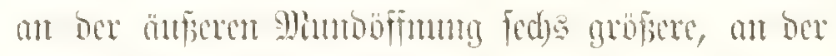

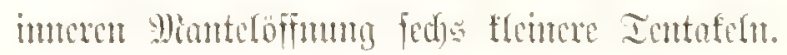

Fig. 9. Botryllus polyeyclus (Sacigny).

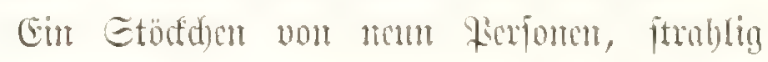
gruppicut un bic gencinfane Dianteloffunrg; Der giuns ift nad) aupen gefeldet. Diefe mo bie for

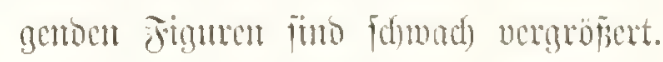

Jig. 10. Botryllus rubigo (Giard).

cin Etöffuen von men frabligen tienjomen.

Fig. 11. Botryllus Jarionis (Giurd).

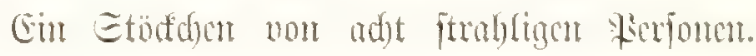

Jin. 12. Botryllus hellebortus (Giard).

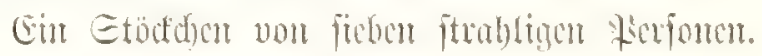

Fig. 13. Polyeyclus cyanens (Drasche).

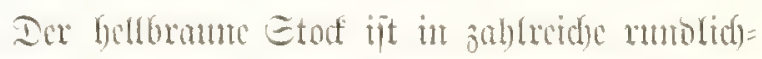

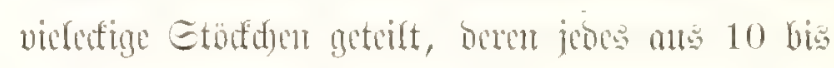

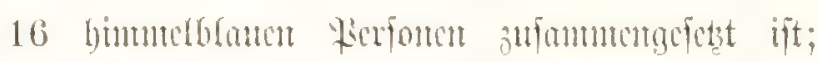

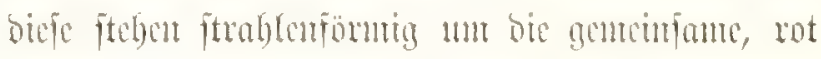

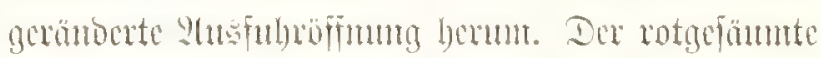

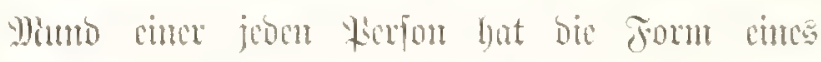

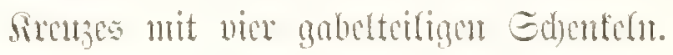

Fig. 1t. Botrylloides purpureus (Drascho).

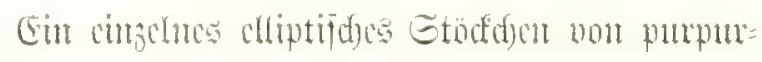

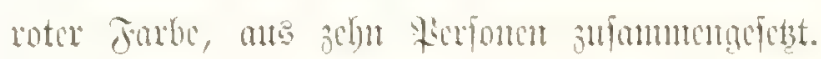

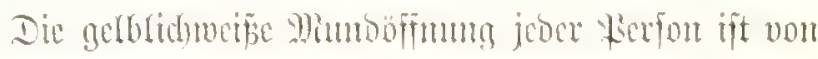

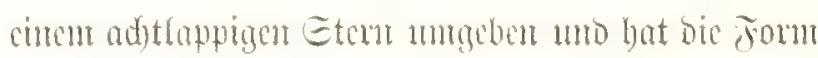

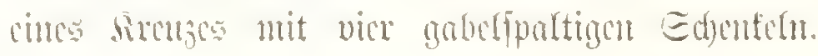




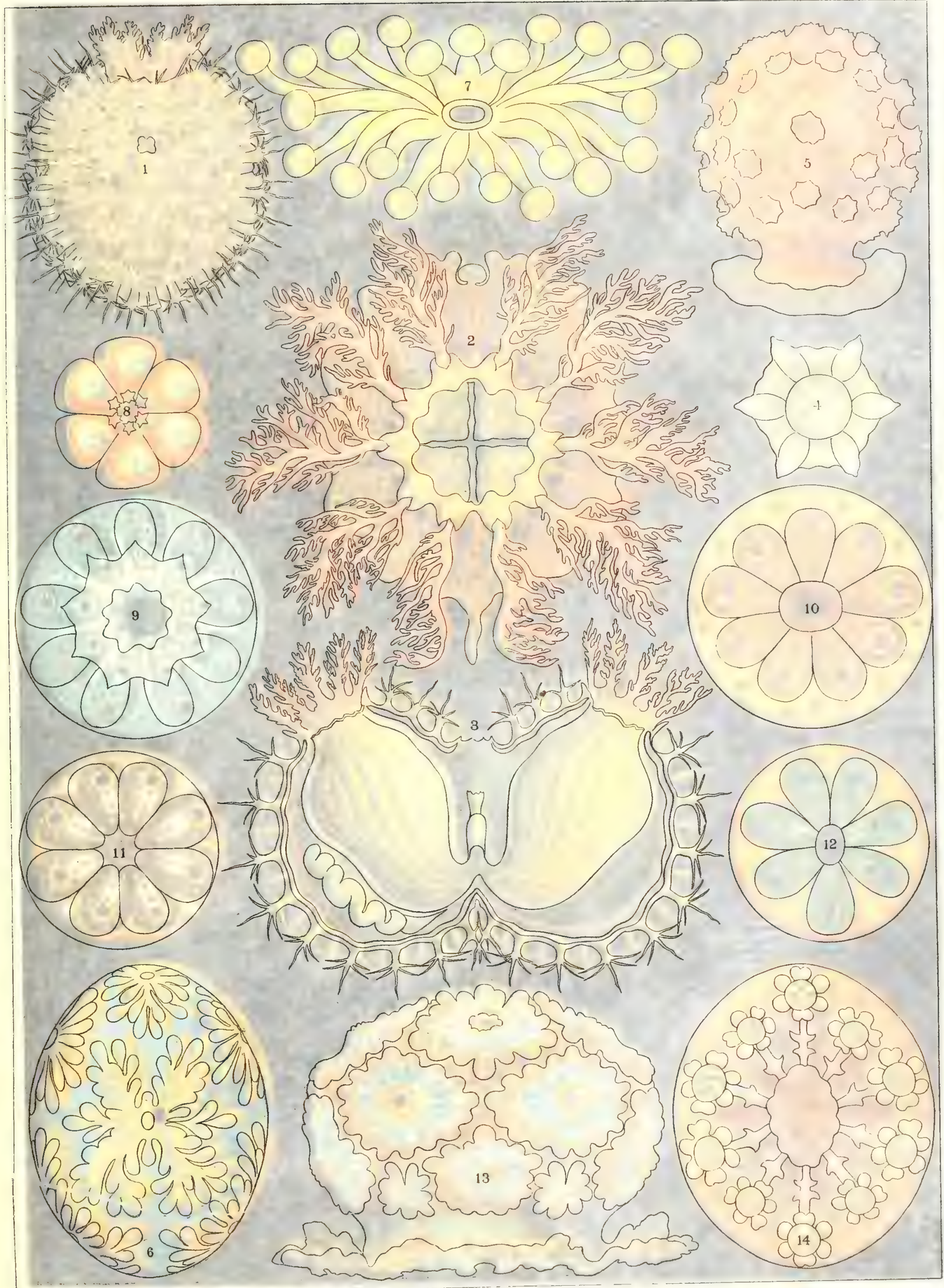




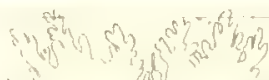
$\therefore$. (atil

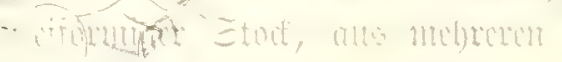

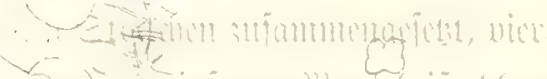

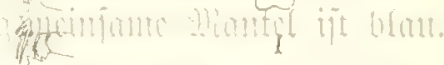

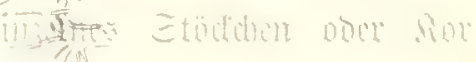

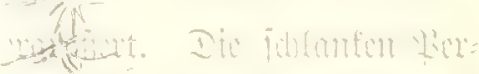
. 


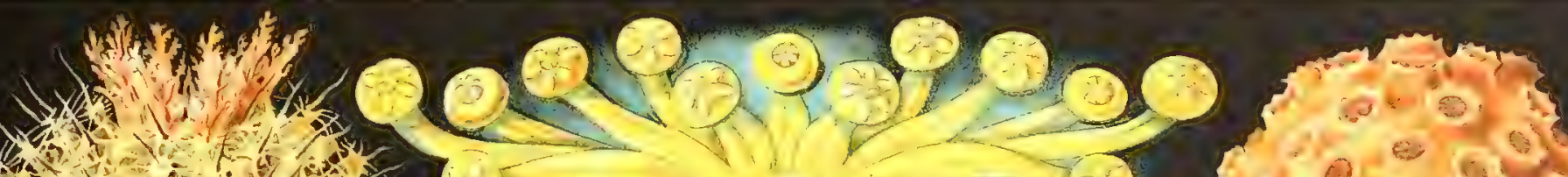

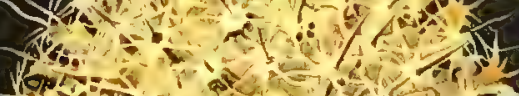

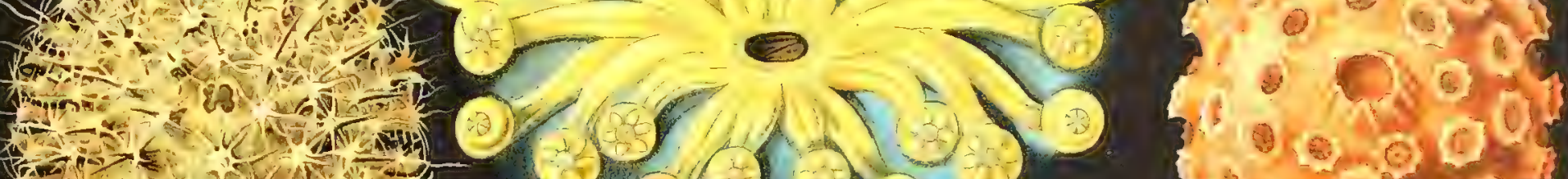
I.

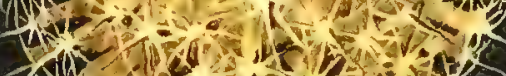
Aar or

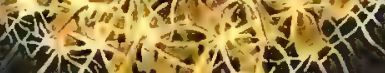
(7)

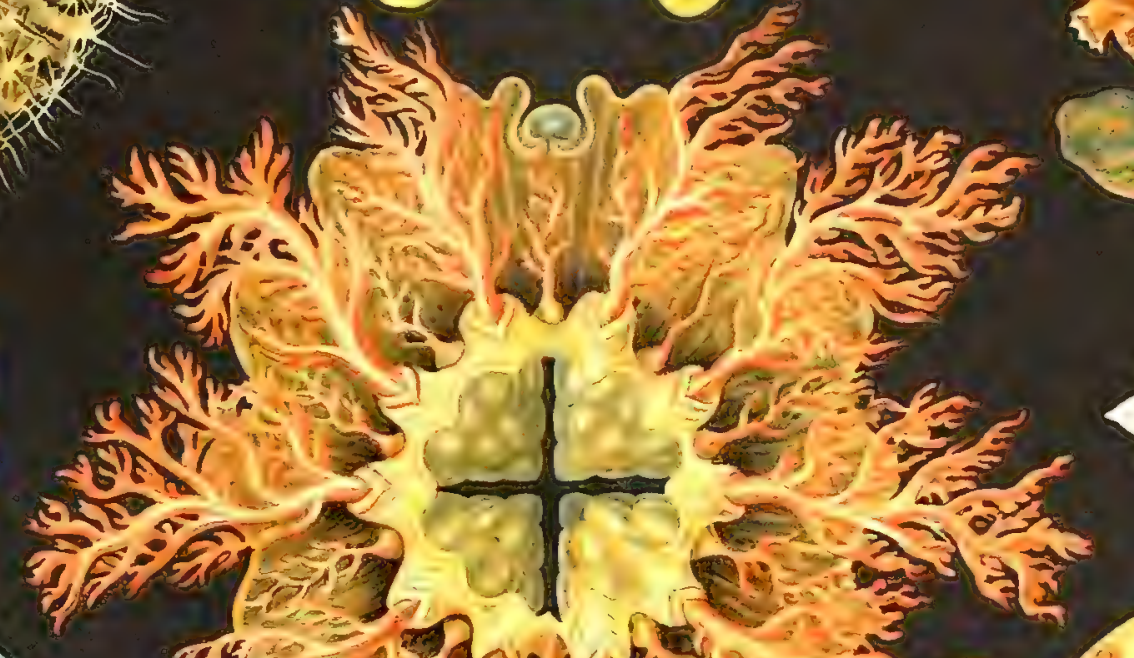

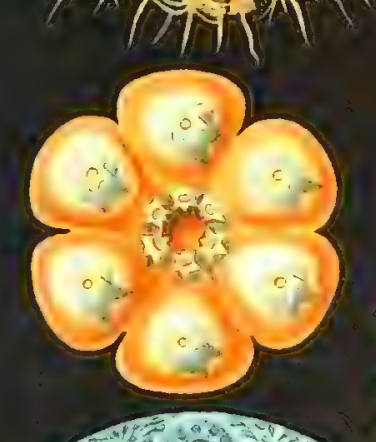

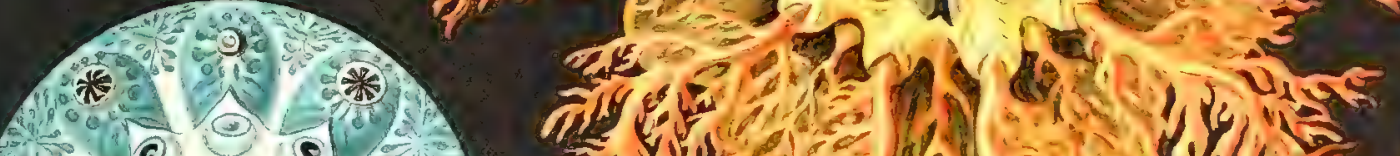

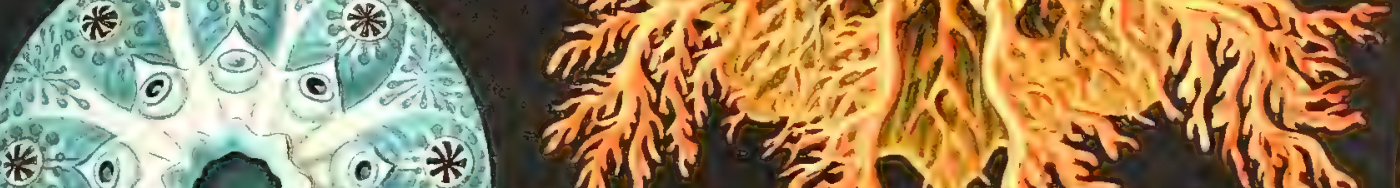
(*6.) O $0 . * 3$ 20.09 4080 (1)

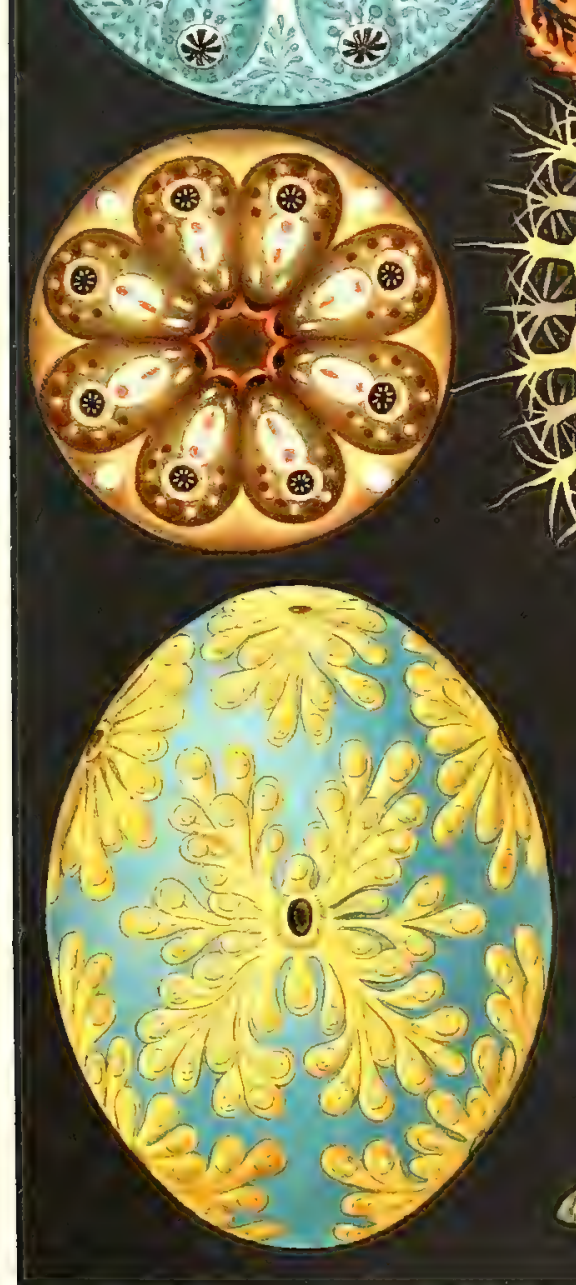
N w

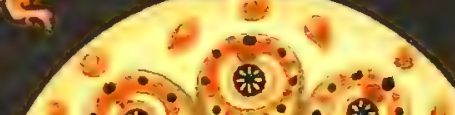

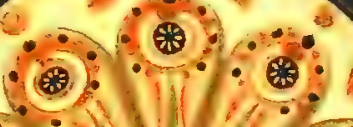
$+1$

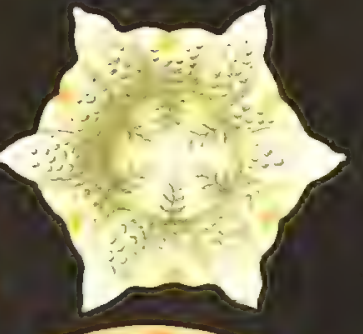

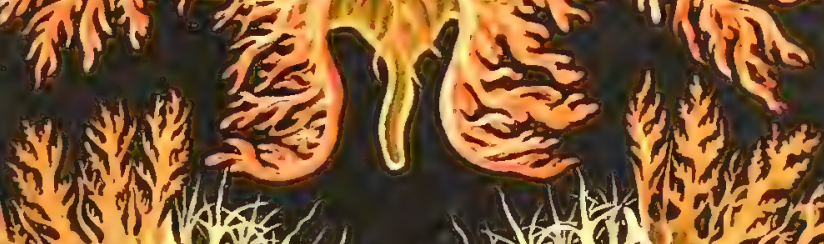
(6). 0 . 7. and 0 or (2)

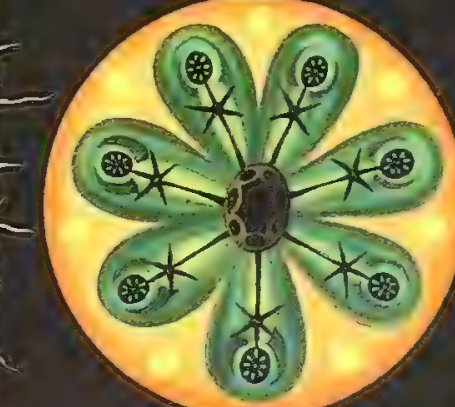





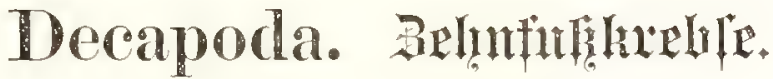

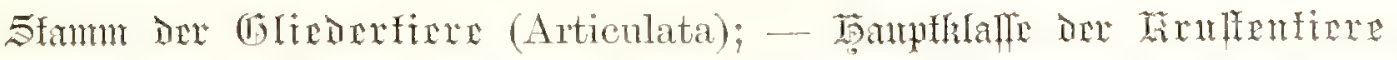

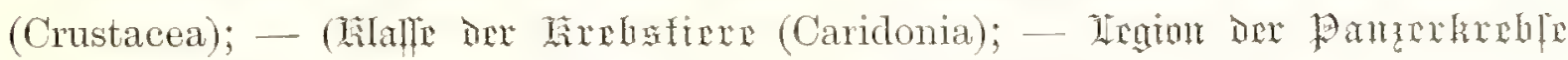

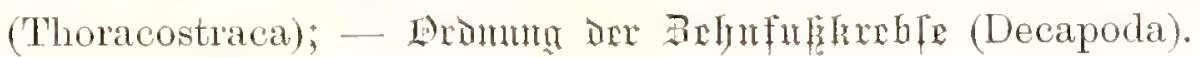

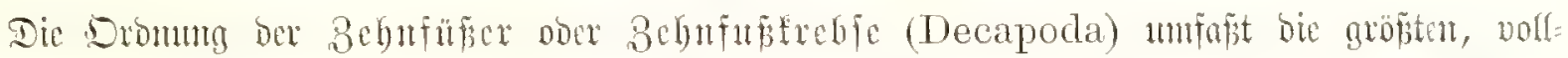

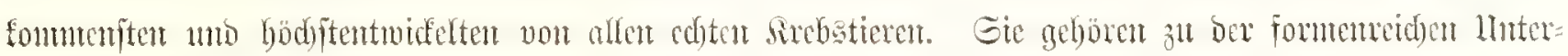

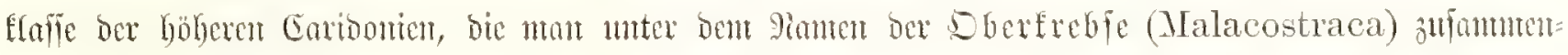

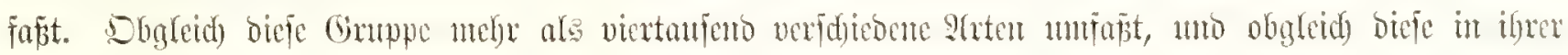

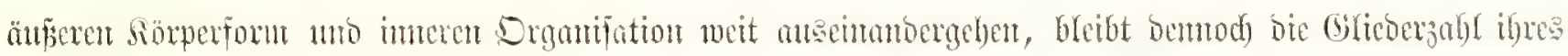

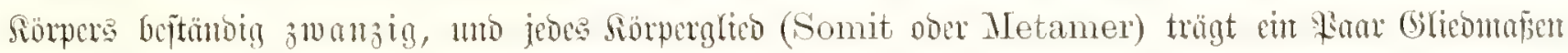

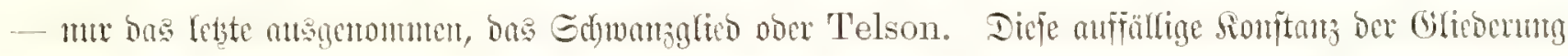

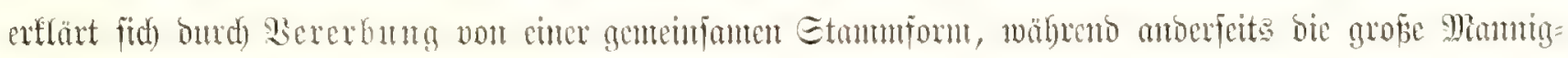

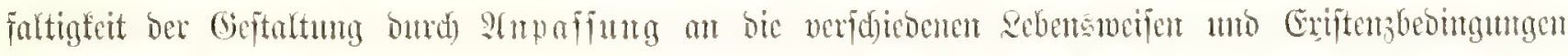
vecitünolid) wirò.

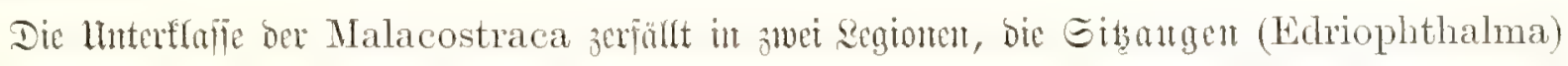

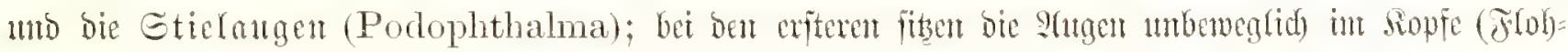

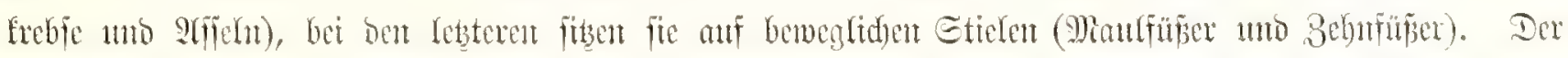

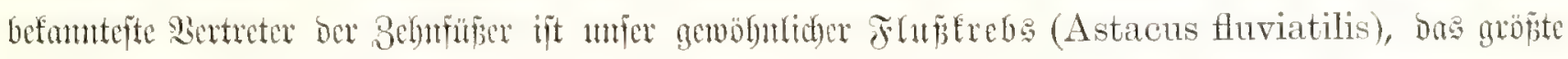

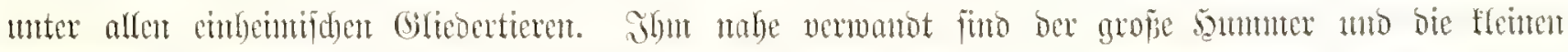

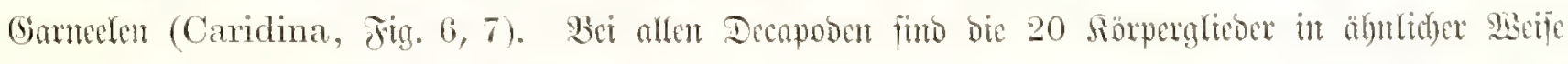

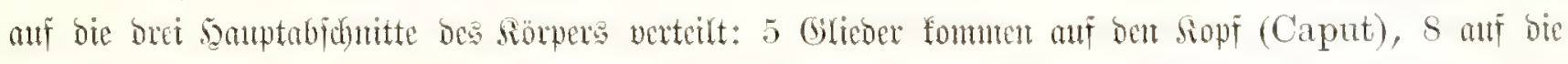

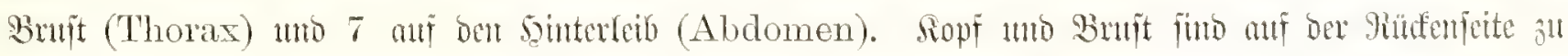
cinem eintreitficfen Sopffbuftpanzer (Cephalothorax) verjontolzen, bagegen breiben bie fieben sinter=

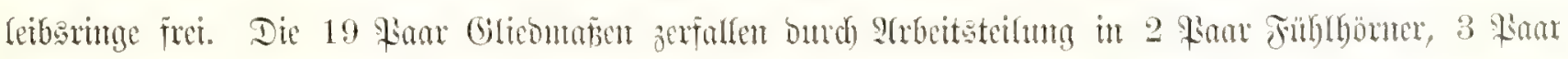

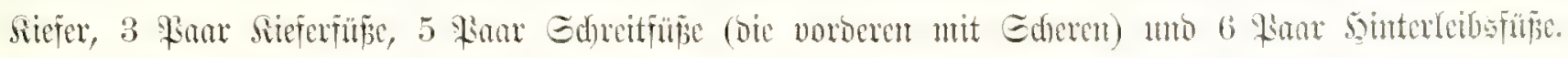

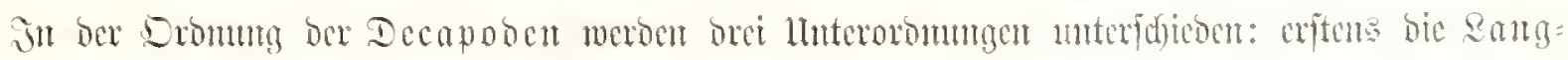

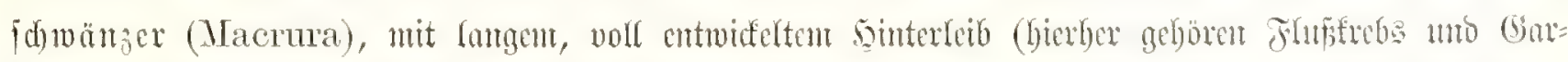

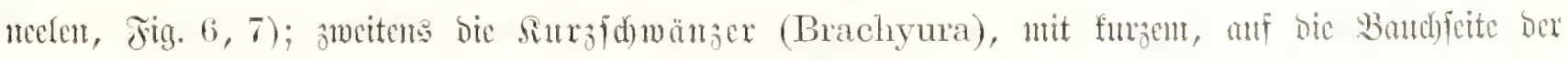

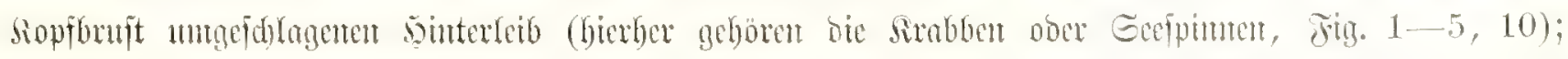

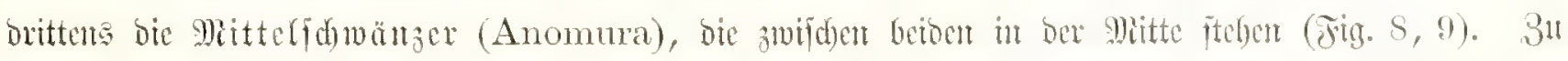

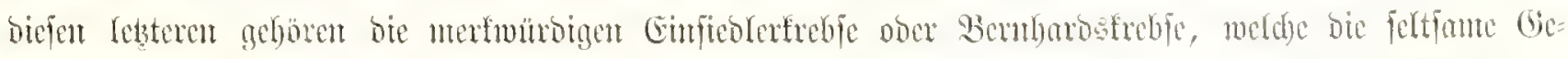

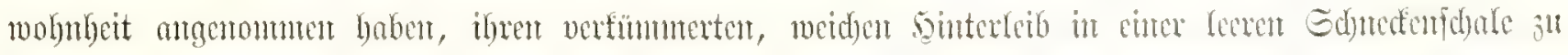

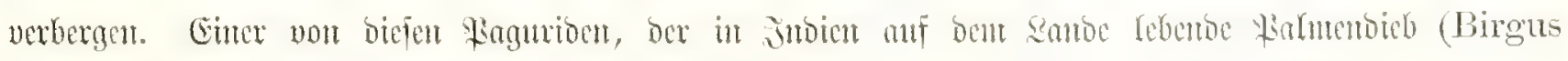

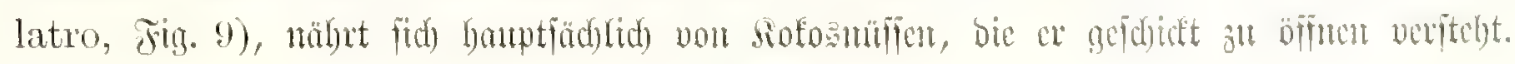




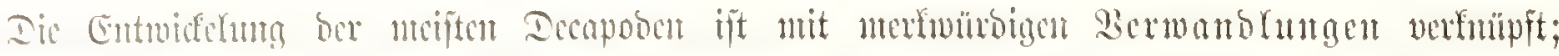

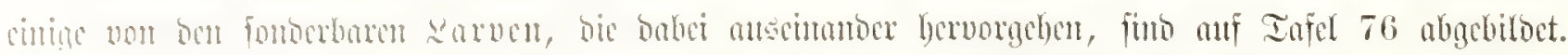

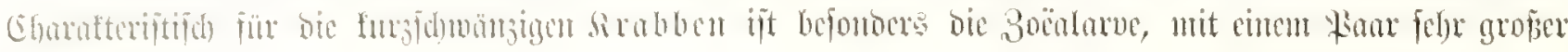

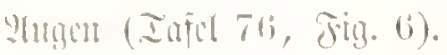

Fin. 1. Parthenope horridal (Fubricius).

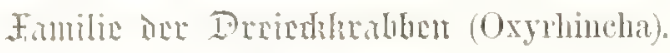

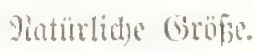

Subiface Dient. Farbe gram.

Jig. :-. Podophthalmus vigil (Leach).

Fomilir ore Enowurutheu (Cyelometopa).

galle matürlicye Gröbs.

Smbiface Djem. Farbe oliwenbrant.

Fig. 3. Pisa armata (Leach).

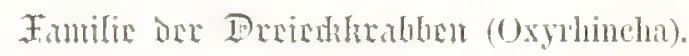
Vintürtide (Grö̈re.

Mitteluter. Farbe rot.

Fig. t. (ionoplax rlomboides (Desmarest).

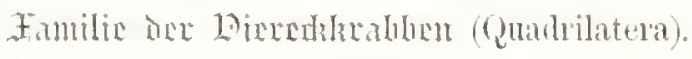
Siativltide Grobje.

Mittehener. Farbe rötlidyelf.

Jig. 5. Pisolambrus nitidus (Hilne Edtuards).

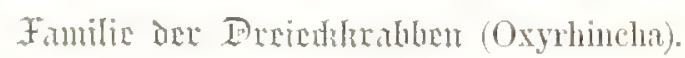

Ercimal verungäpert.

Sittantifuce Djoun. Furbe bram. gig. 6. Stenopus hispidus (Latreille).

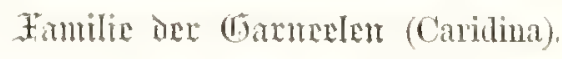

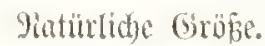

Smoifder Djean. Farbe getb.

Jig. 7. Palaemon serratus (Fabricius).

Fimilis one (Gaxmenten (Caridina). Yiatiulidge Größze.

Porofe. Foube rötlidgran.

Fig. 8. Albmea symnista (Fabricius).

Familie ber Lofherble (Hippida). 3meimal vergrö̋ett.

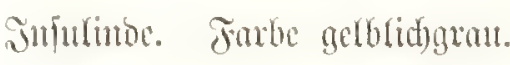

Fing. 9. Lissa chiragra (Leach).

Familie dex Deriedknaben (Oxyrhincha). Tiatürlide Gröbe.

Mittefnect. Farbe purpentot.

Fig. 10. Birgus hatro (Herbst).

Familie der erimfroulrumede (Pagurida). Silcrmal verfleinert.

Sinfulinoe. Farbe purpurbraun. 


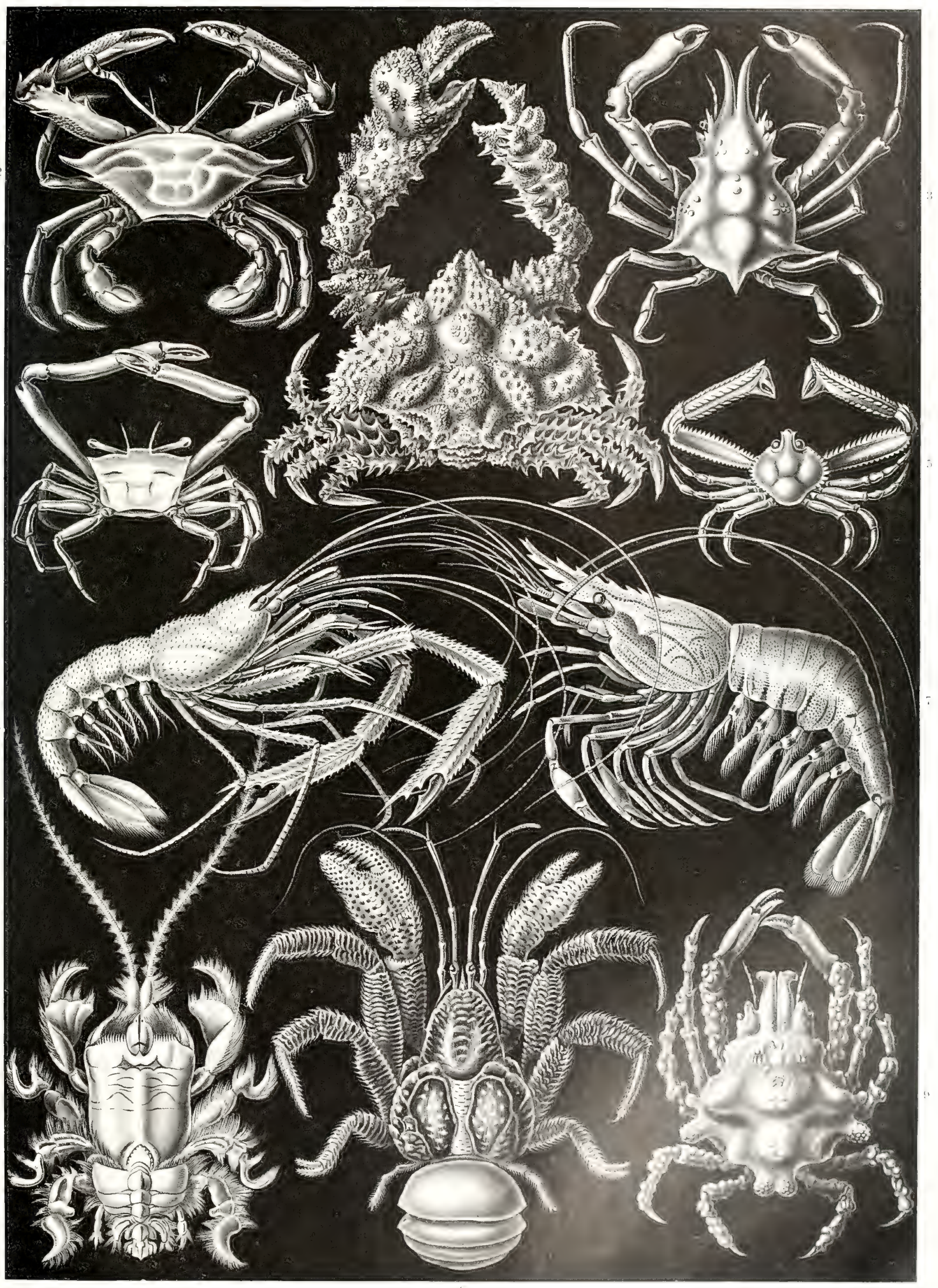

Decapoda. - Belinfullinelite 



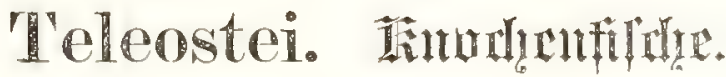

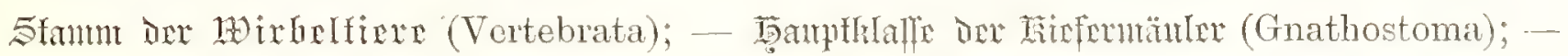

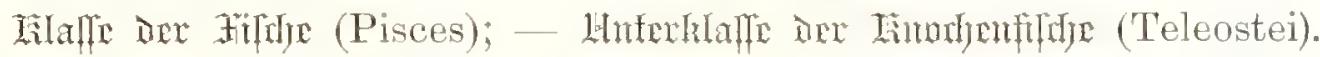

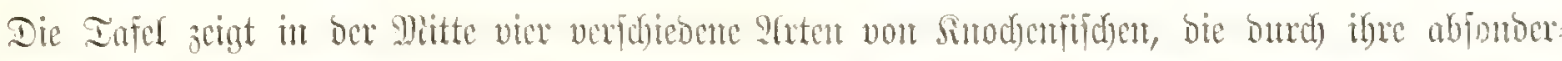

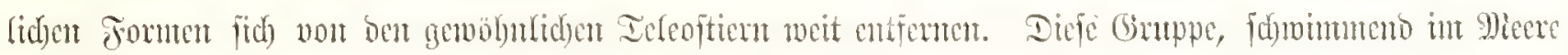

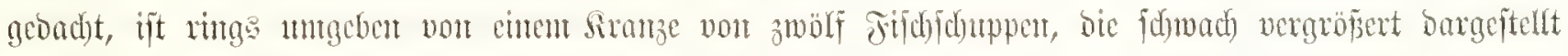

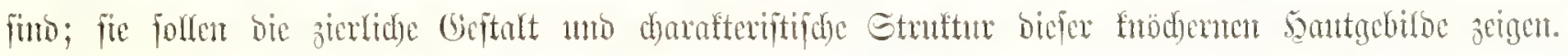

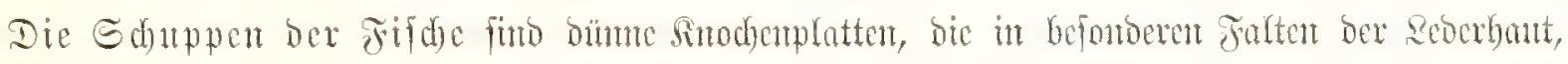

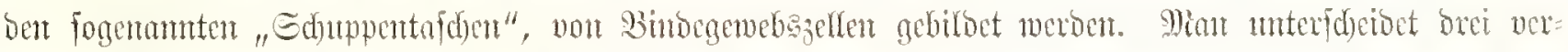

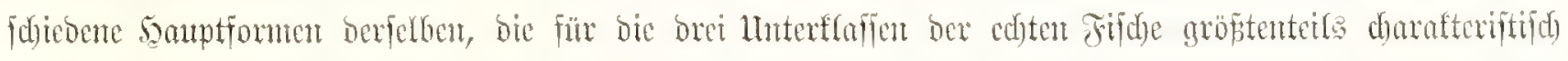

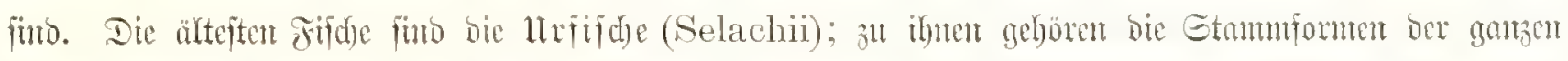

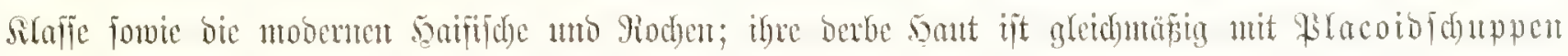

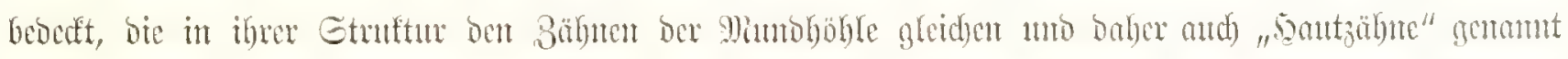

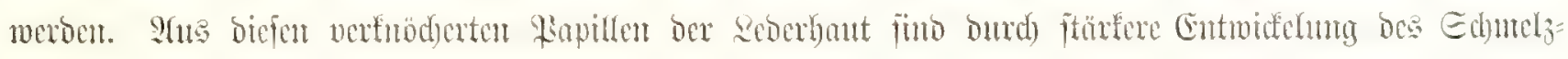

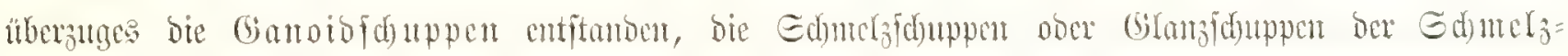

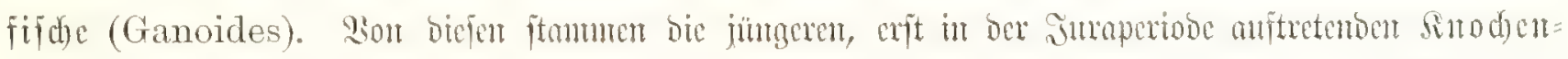

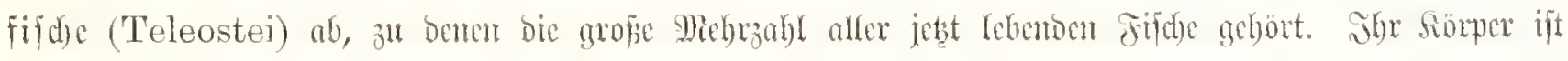

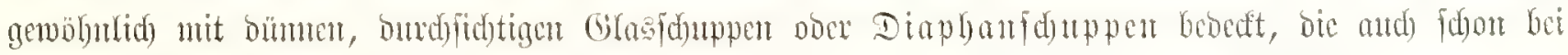

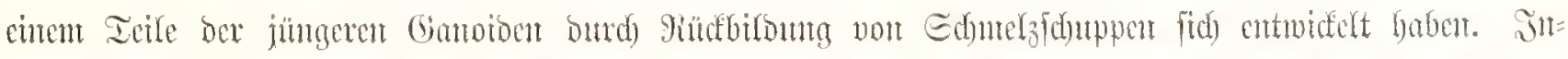

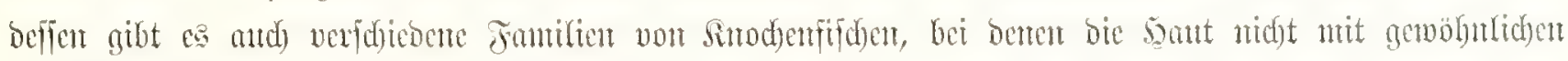

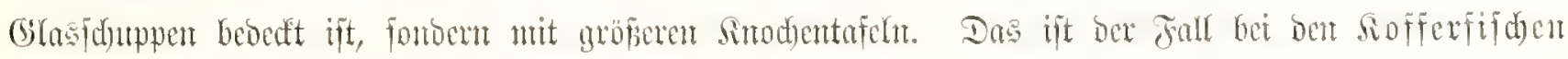

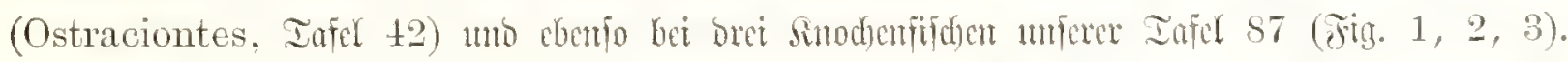

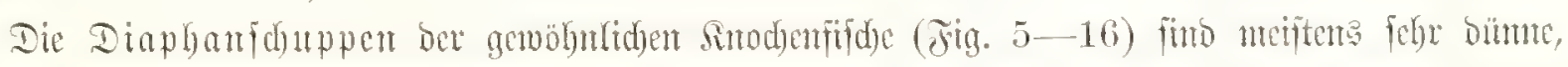

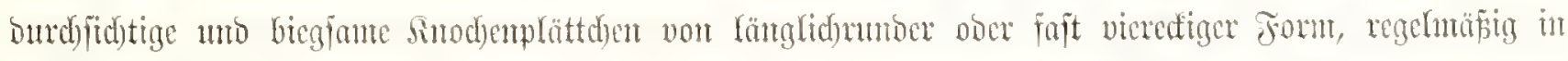

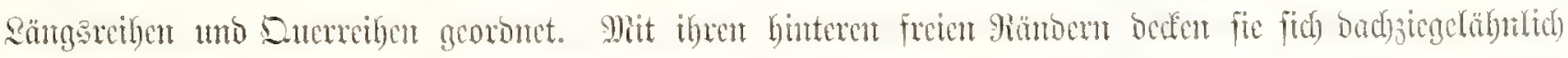

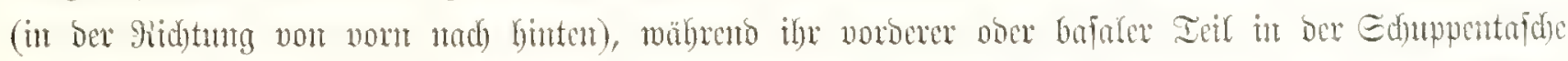

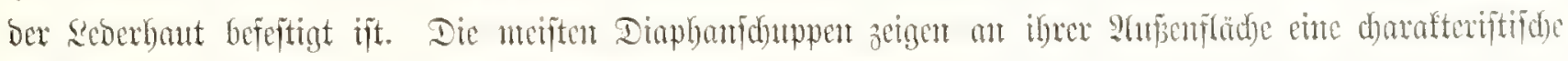

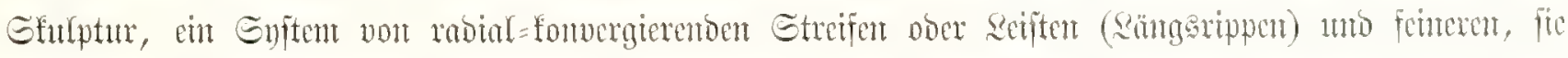

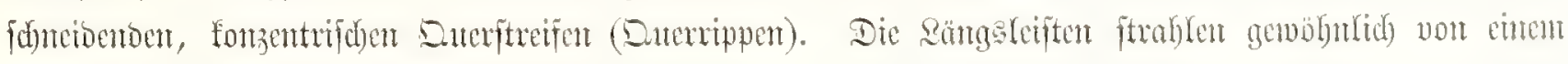

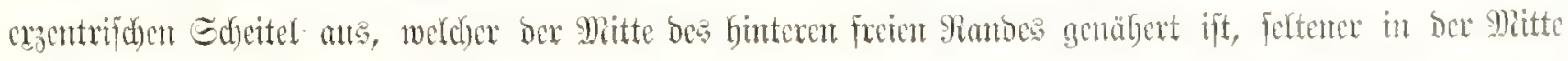

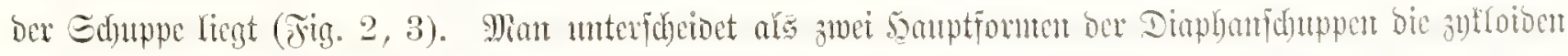

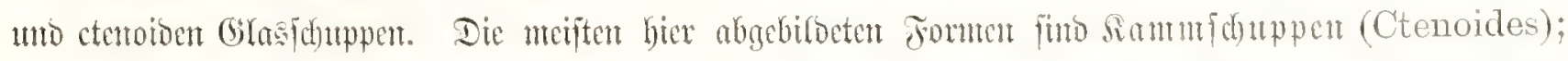

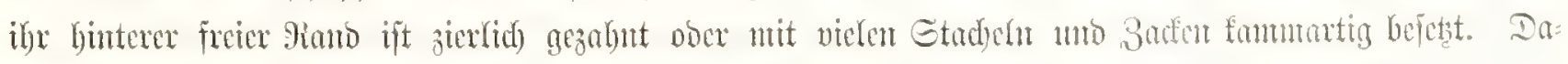

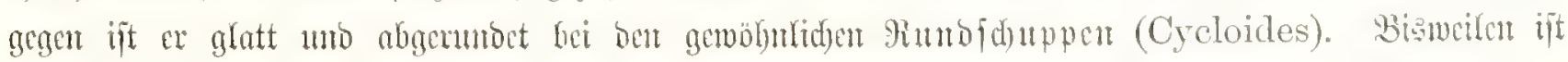

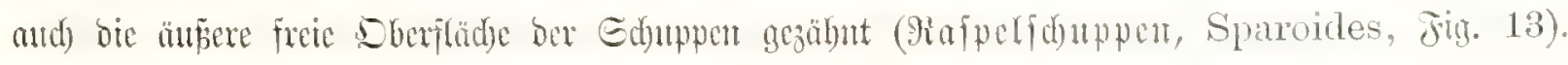




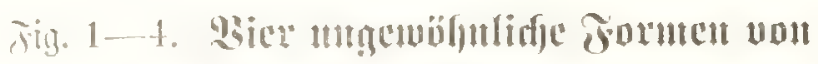
Silnorfurifiden ('T'eleostei).

Titg. 1. Pegasus (hiropterus (Haceke).

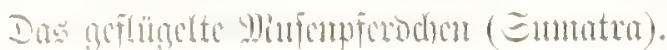

fomilie one Cataplyarfer.

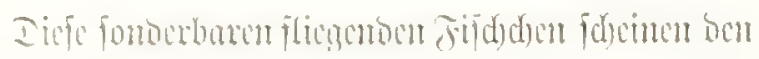

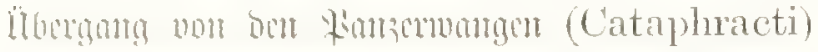

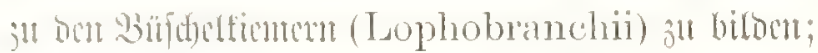
fic mäbcu fid) cincreits bom Flughah) (Dacty lopterus), amberfeits dem Eepferod)en (Syngna-

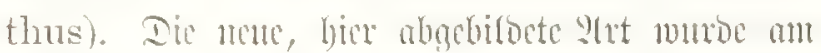
23. Fom 1901 in ber Trmanbat (an ber

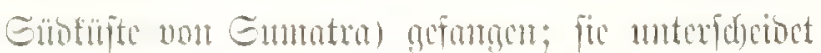

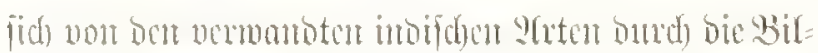

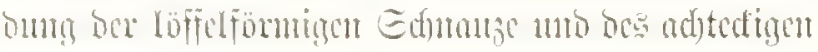

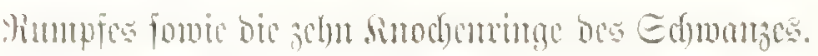

Jig. 2. Hippocampus antiquormm (Leach).

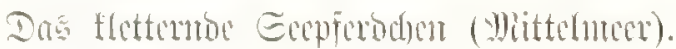
Familir one Smunthatjiom.

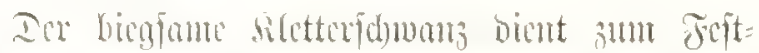

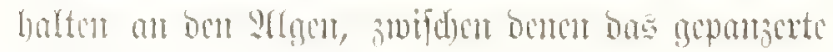

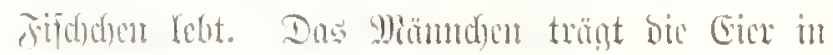

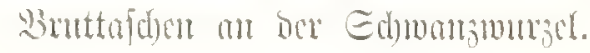

Fig 3. l'hyllopteryx eques (Giunther).

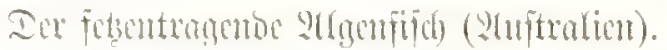
Familir ore smuntatjiom.

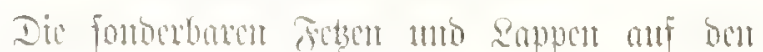

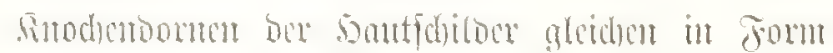

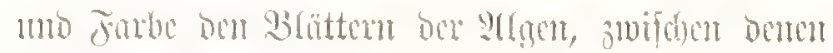

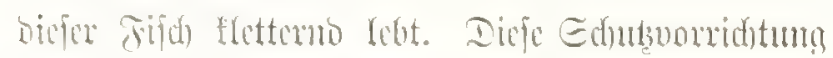

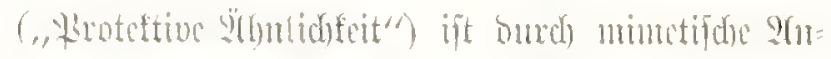

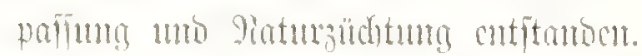

ring. t. Antennarius tridens (Blecker).

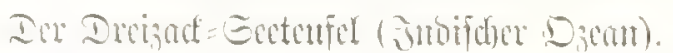

Familir iner fordiculaten.

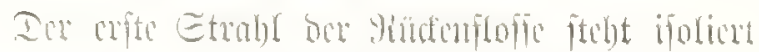

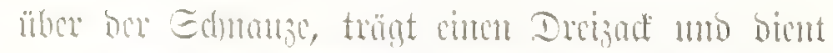

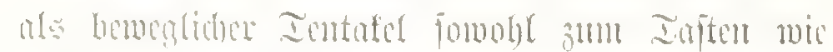

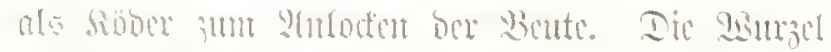

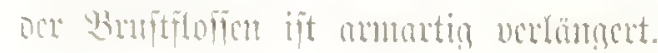

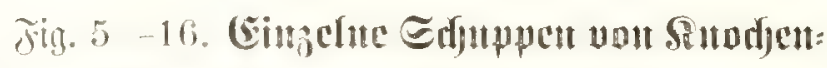

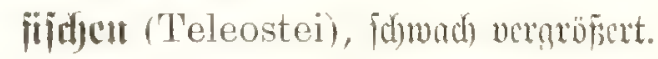

Sig. 5. (hrysophrys anrata (Cuvier). (Ed)ter Golobrofie (Mittelnter). familic ine Sparnion.

Jig. 6. Pagellus exythrinus (Cuvier). Moter Eecbrafie (Mittefmer). Fomilic Dor Spronion.

Fig. 7. Box vulgaris (Cwviev). Gabelfonänziger Gabelbraffe (Mittelnter). Fimilie one sparniour.

Jig. S. Anthias sacer (Schneider).

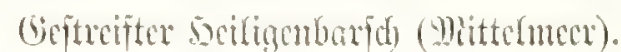
Familie sis forentom.

Jig. 9. Apogon imberbis (Günther).

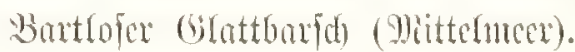
Familic ine Perentiont.

Fin. 10. Centriseus scolopax (Curier).

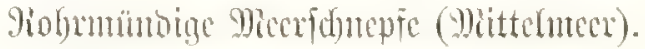
Fumilie orr contriscion.

Sig. 11. Ilypostommm plecostommun (Cuvier).

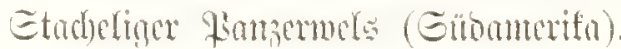
Fomilir one silnmoner.

Jị. 12. Listularia chinensis (Lacépede).

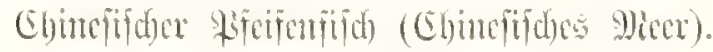
Famtic Der Fiftulaxiden.

Fin. 1\%. Solea vuluaris (Quensel). (Gimeme Eesumtge (Fiorofe).

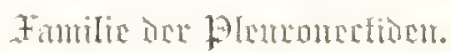

Fin. 1t. Sentus emneacanthus (Bleeter).

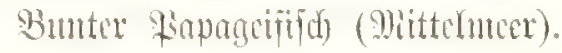
Famtilie one Tatrotion.

Fign. 15. Haemulon clegans (Cuvier).

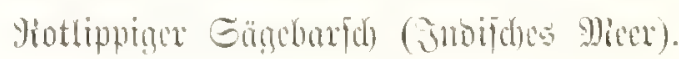
Finnilie oux frilfiznution.

Fing. 16. (antharus vulgaris (Cuier).

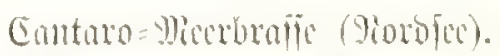
Familie one Sparnion. 


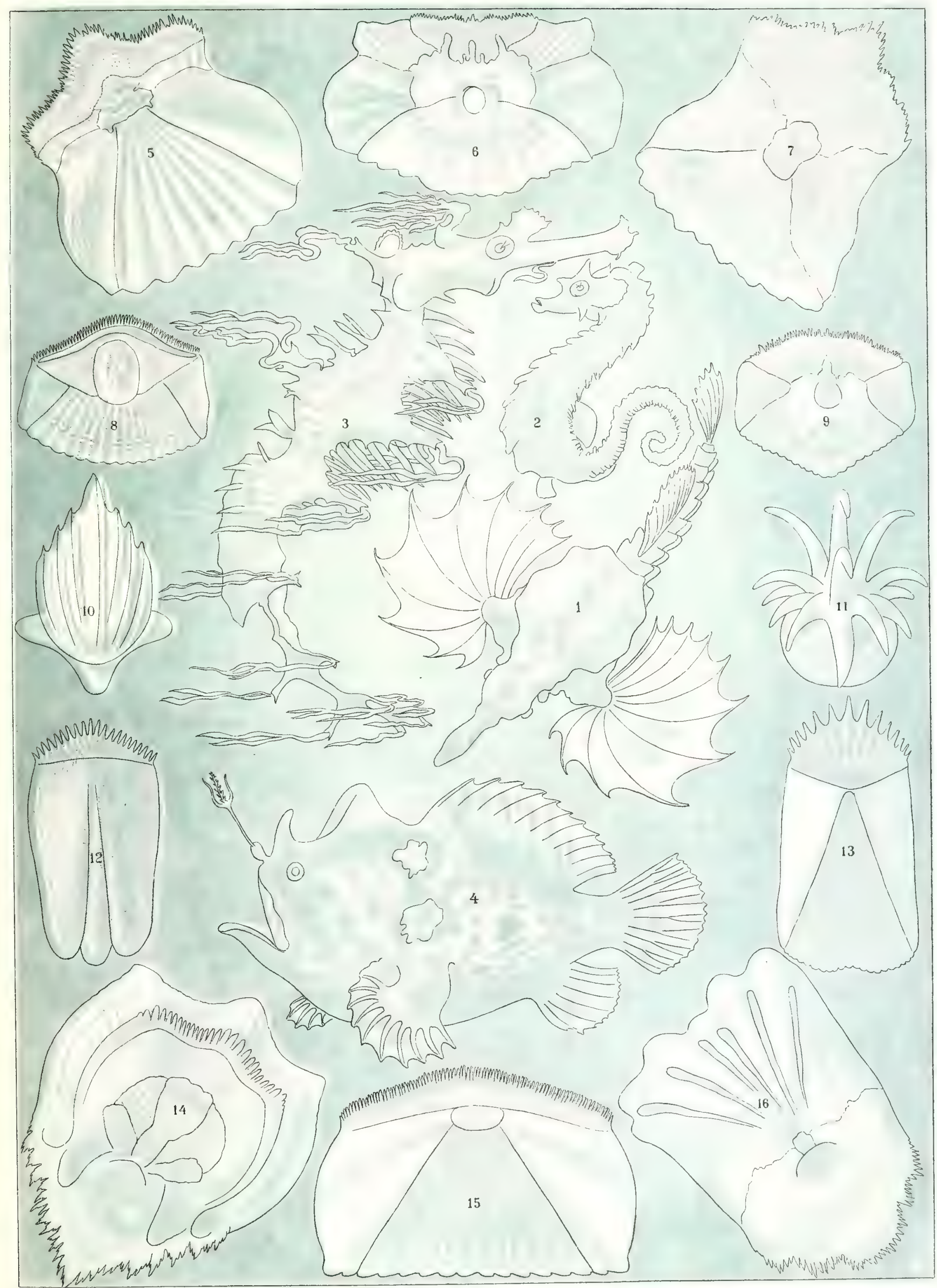





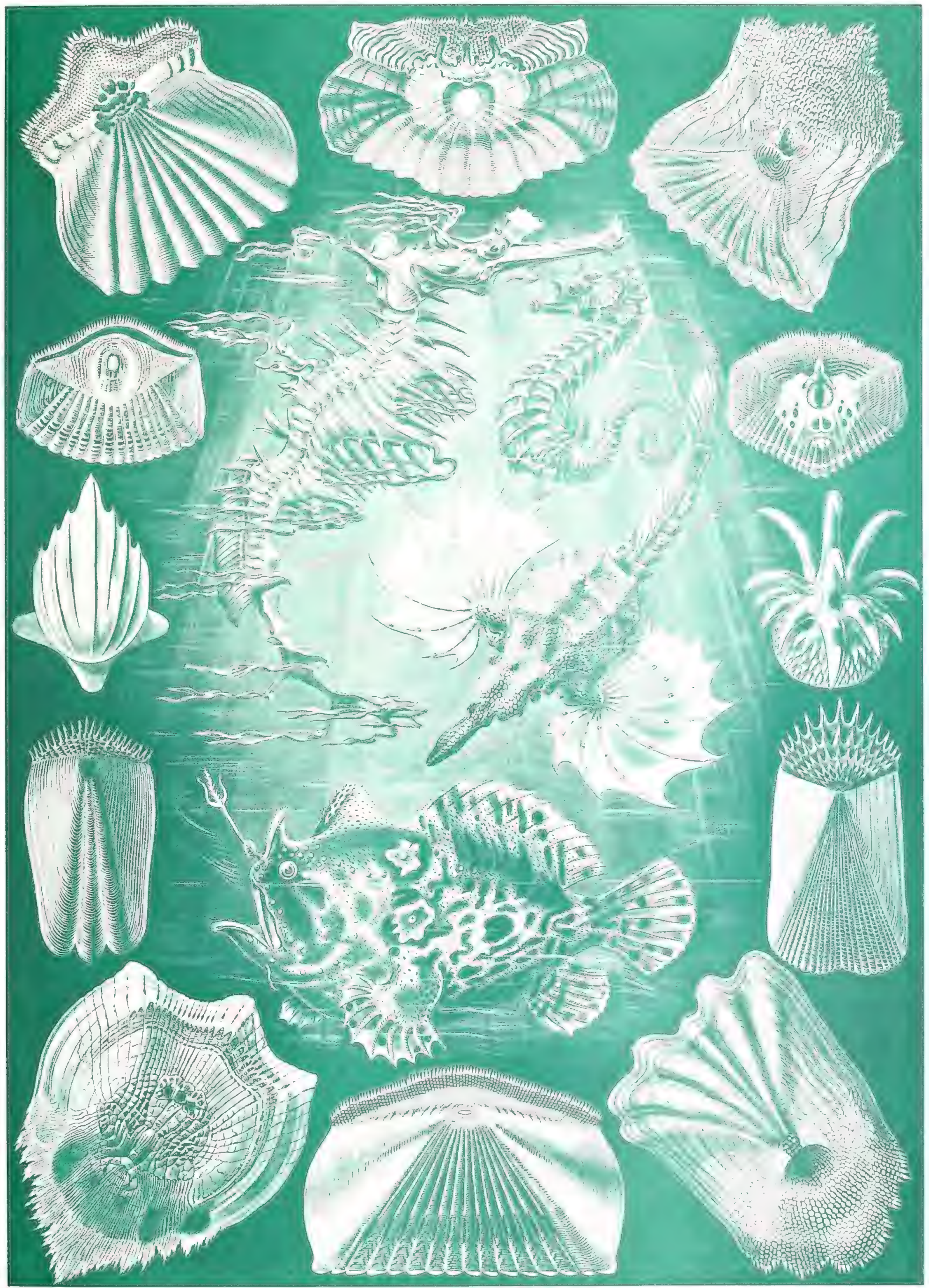

Teleostei. - sumodienfific. 



\section{Discomedusae。 Gumilnmallm.}

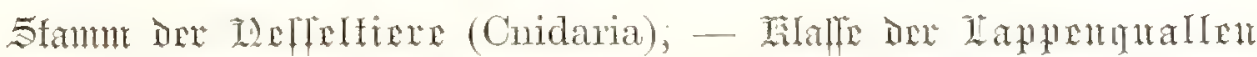

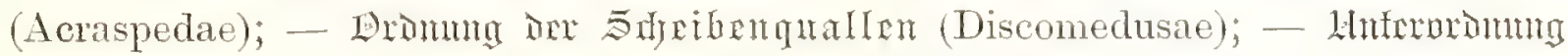

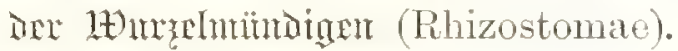

Die murzelnumbigen Edyeifentuallen, bie anf biefer Infel burgeftellt finto, gleiden in wefent-

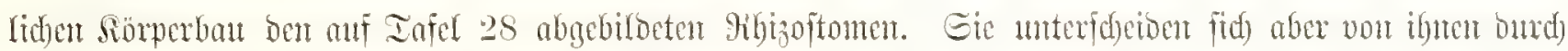

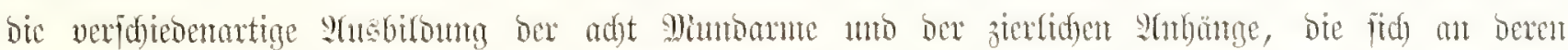

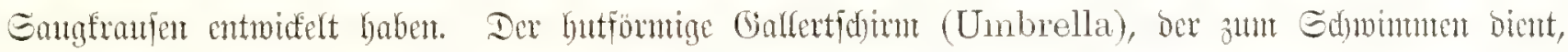

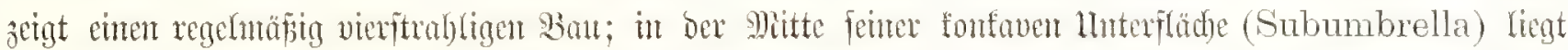

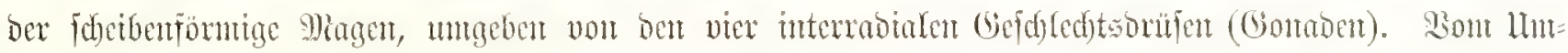

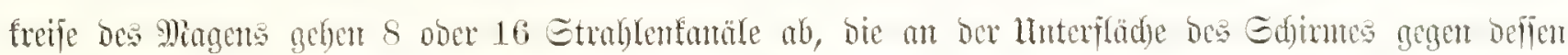

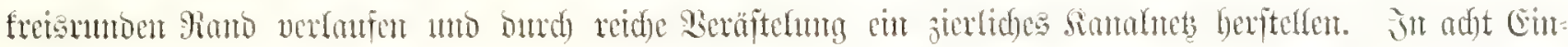

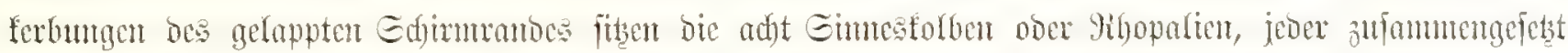

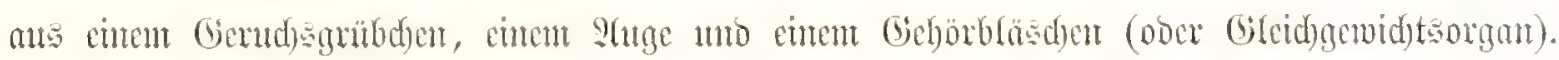

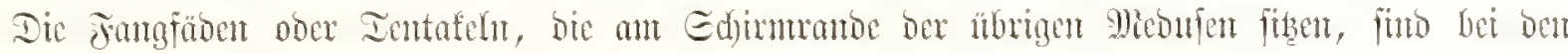

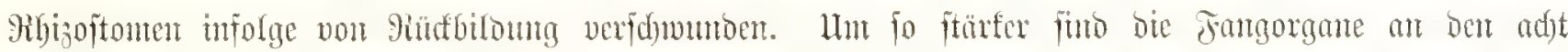

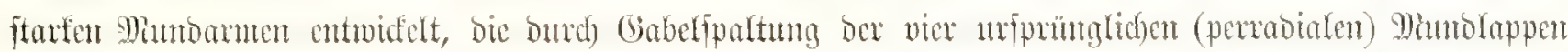

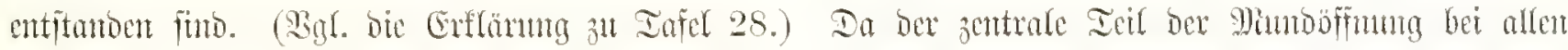

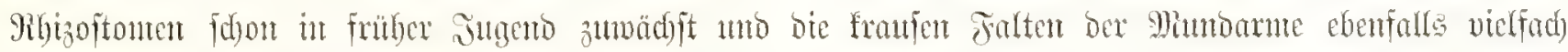

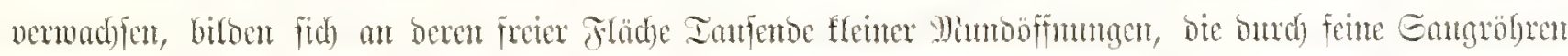

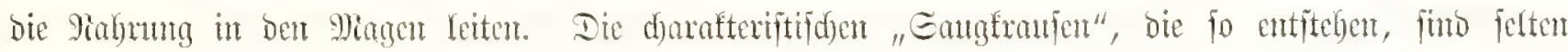

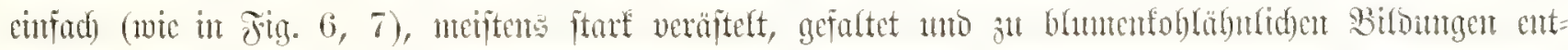

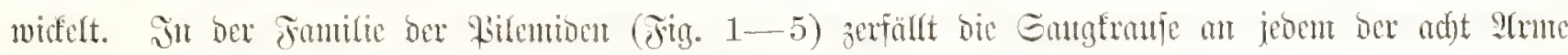

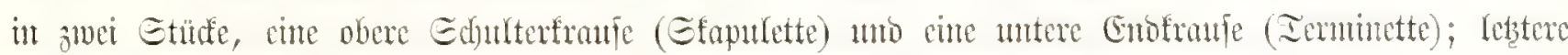

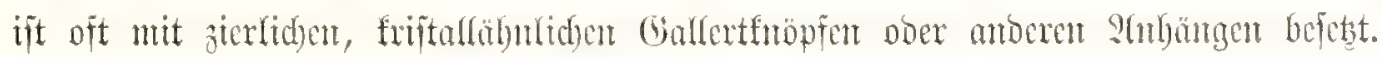

Fig. 1-3. Pilema Giltschii (Haeckel). Famtilie dex Bifrmiden.

Fig. 1. Seitenamfitht ber ganjen Miebufe, in balber natürfider Gröpie.

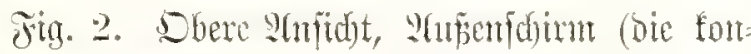
vere Exumbrella).

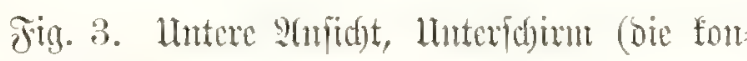
fave Subumbrella).

Dicfe neue Strt ber Gattung Pilema, am 23. Februar 1901 an Der Gibfuifte Der Jiffel
Sumatra beobadtet, ijt bor Pilema clavigera

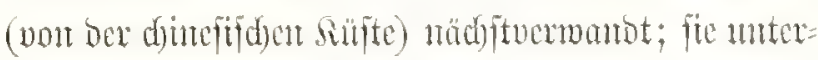

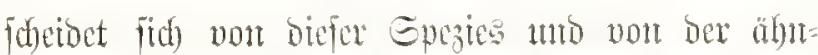
Iiden Pilema stylonectes (von Gibraltar) burd)

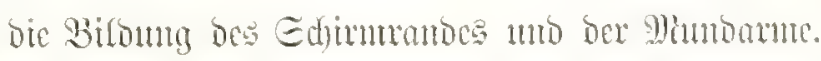
Der Edjirnmant ift in 48 sappen geteilt; jeber ber

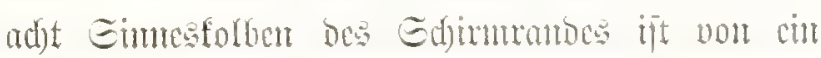

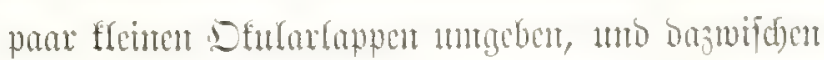

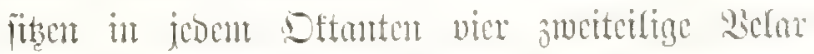
fappen. Ifr ber oberen fläd) des hutförmigun Gdjinnes (Exumbrella, Jin. 2) ift in ber mitte 


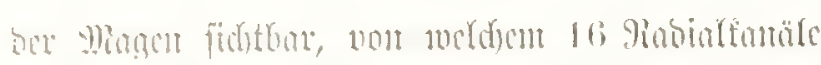

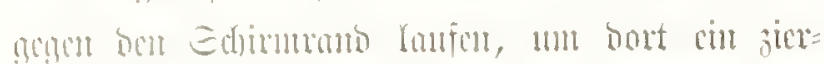

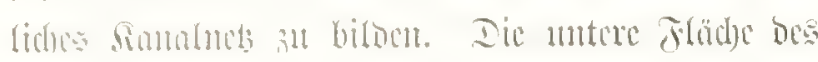
Edium (Subumbrella, Fing. 3) zcigt an um-

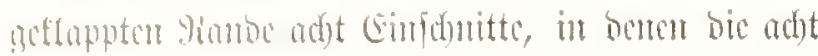

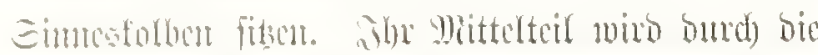

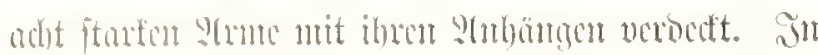

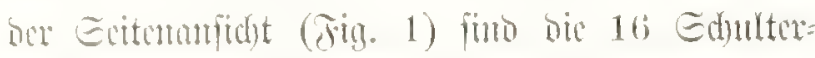

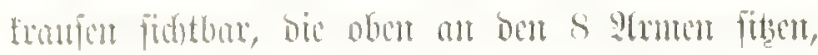

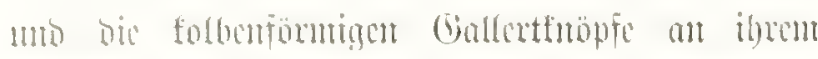

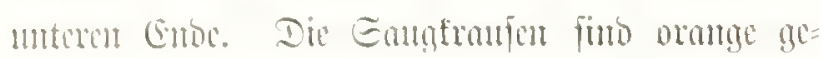

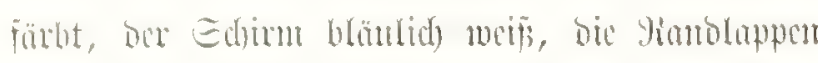

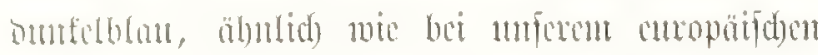
P'ilema pulno. Dicje foüne noue ?lat trägt

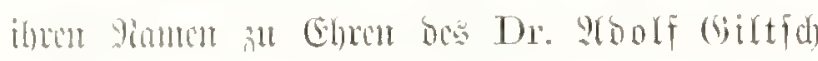

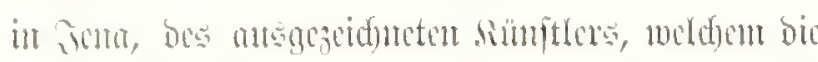

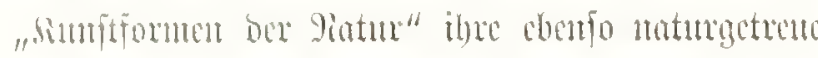

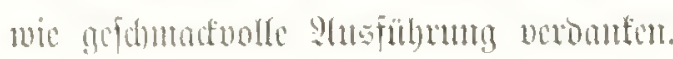

\section{Jig. t. Rhopilema frila (Haceliel).}

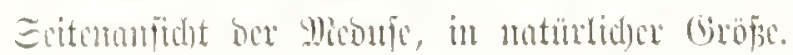

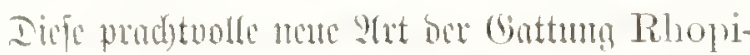

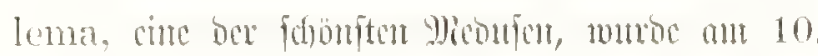

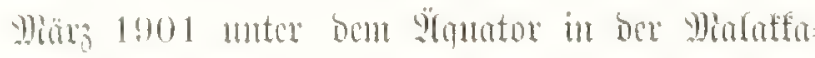

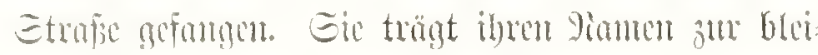

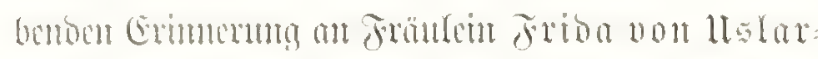

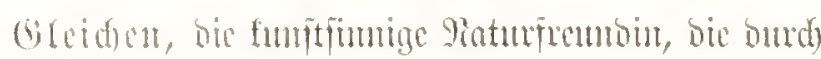

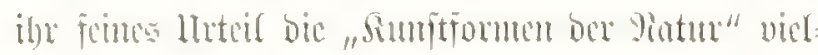

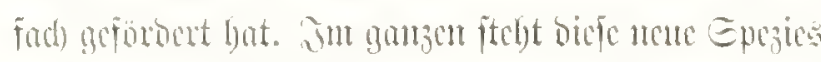
ber indifour Rhopilema rhopalophora (unn

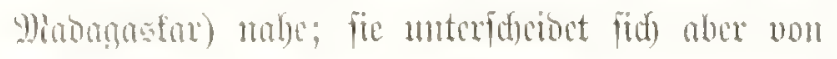

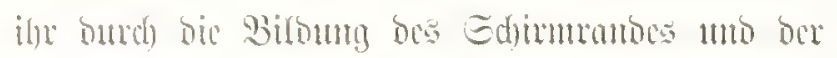

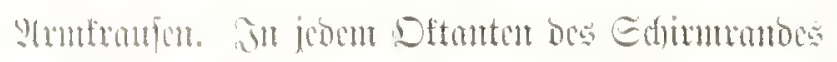

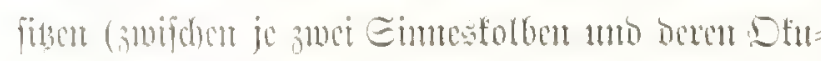

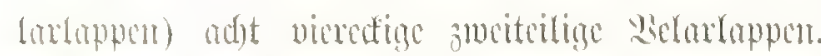
Die 16 Edultertranfar, bie in ber Mhitte ber Siörper-

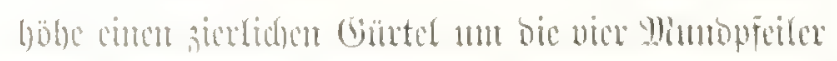

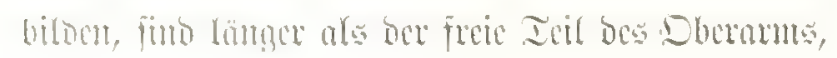

aber mur ciur Drittel fo lanty als bie ftorfen Siratifen

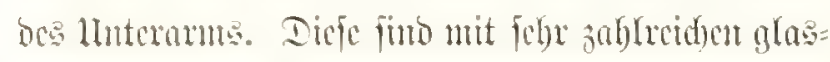
artigen Gallertfnöpfen von breifantig=pmrantioalex Form verzicrt; fie hämgen gleidh ben prismatifden

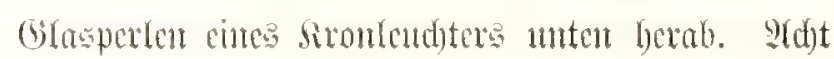
ftarfe Gallertfröpfe, viel gröpere als bie hibrigent, sicren bas untere entoe ber Dorfarframpen. Die Furbe bicfer cigentartigen 9icoufe ijt cin äartes grünlidyes Blan; bie vier Gonaben uno die strmetraten fino rofomot gefürbt; ber Magen umb bie simuäle jee= grün, bic adbt S(tugen pumpurrot. Der Durd)utejer bes Edjumes beträgt $16 \mathrm{~cm}$, bie soobe $5 \mathrm{~cm}$.

\section{gig. 5. Brachiolophus collaris (Haeckel).}

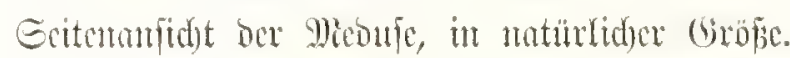

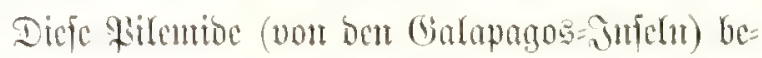
fist in ganzen ben siorperban yon Pilema (Jig.

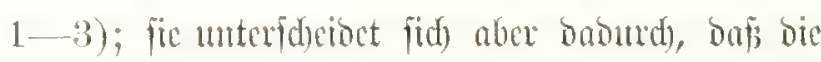
16 Ed)ulterfranfon untercinamber mit Don Eeiten= ränocu verwadjan fün, unto ebento bic Bajalteile ber gabefföming verzweinten llnterame. So biloen bic Ed)ulterfranfen cinen ftanfen Gintel mu ben mittleren Icil des sorpers.

Jig. 6, 7. Cammordhiza comnexa (Haeckel).

Jig. 6. Eeitemmitidet ber Miedufe.

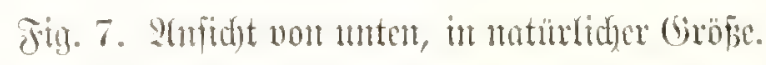

Dieje mitralifade Yhibojtonte, in ber giäbe von

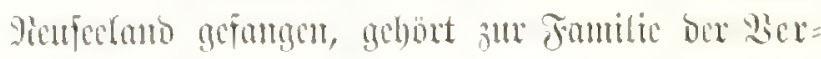

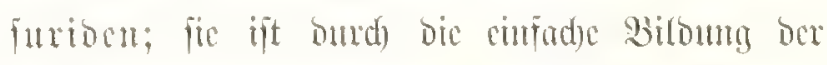

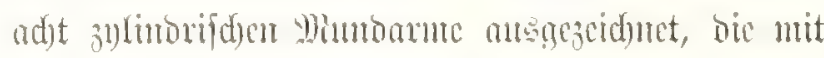

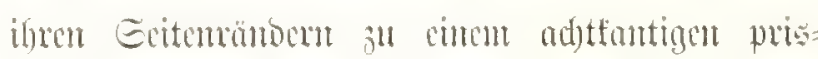

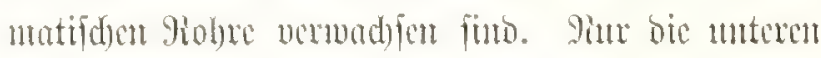

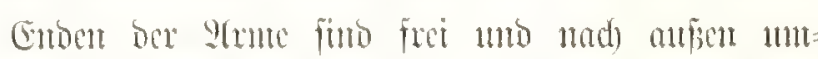

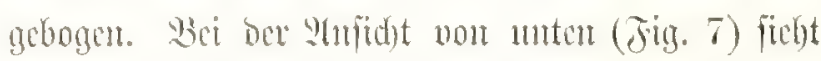

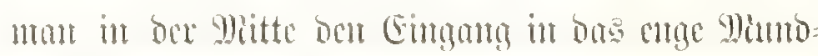

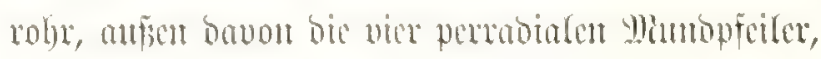
smiffent benten bie Eingünge in bic vier interra= bialen Geid) (cd)täböblen liegen. 


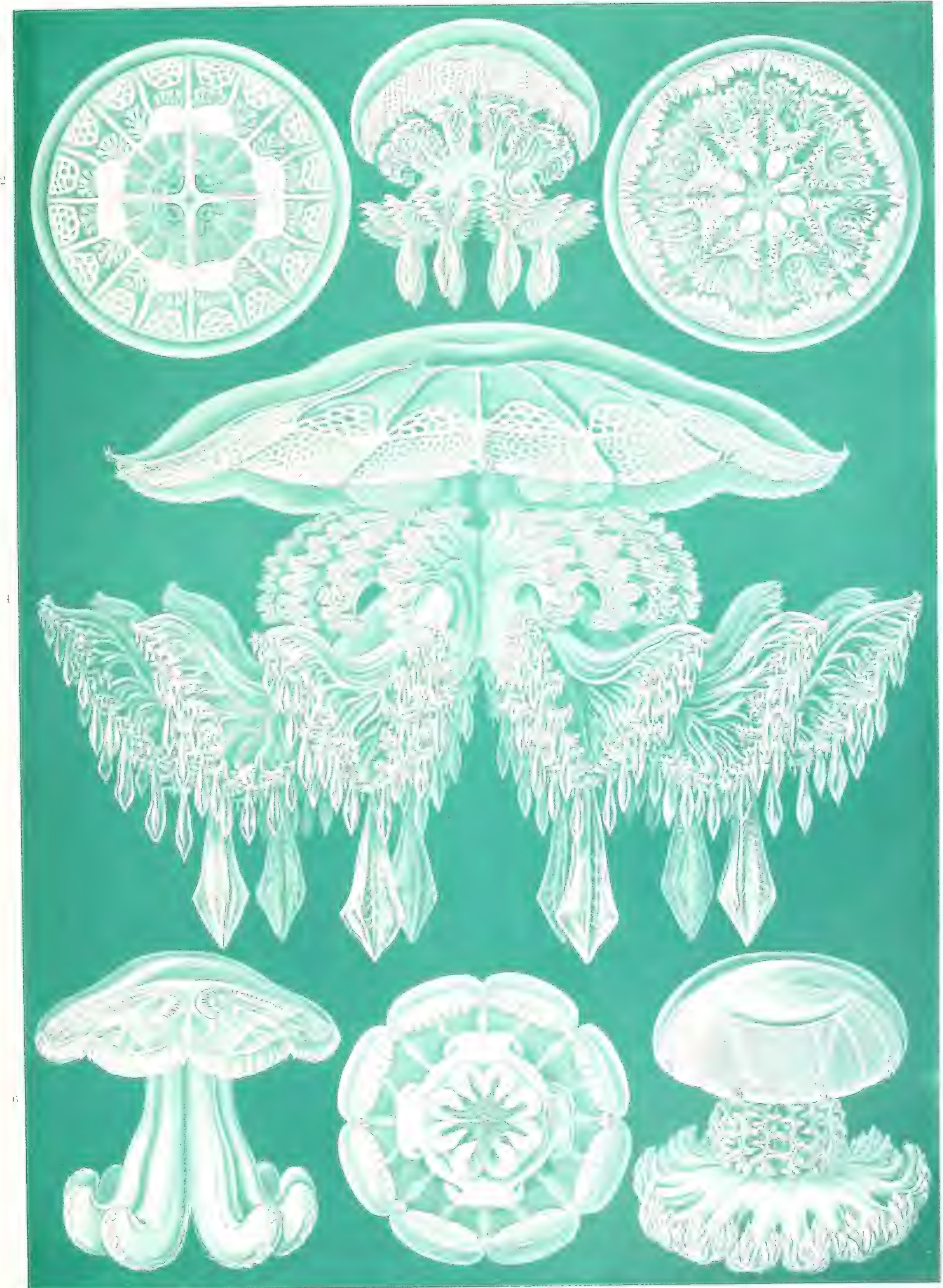

Discomedusae. - Sdivibentotallert. 



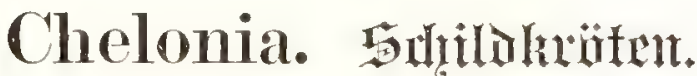

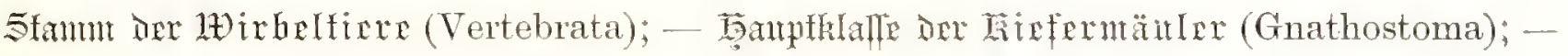

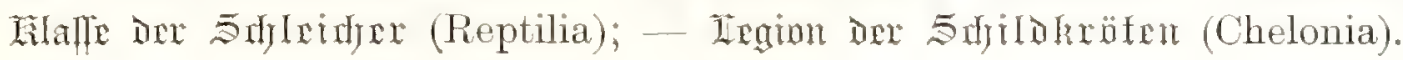

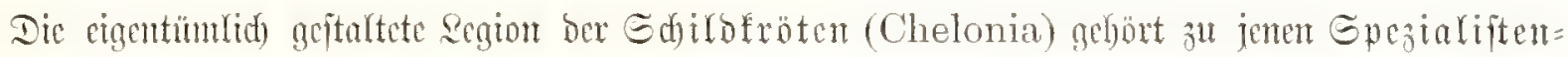

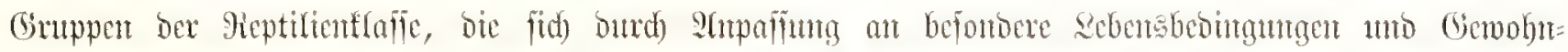

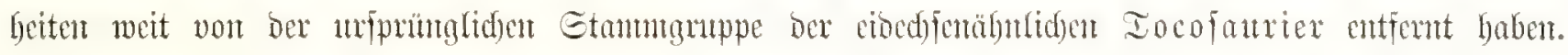

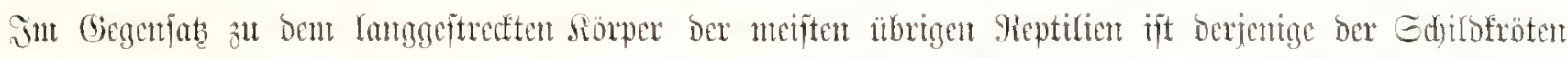

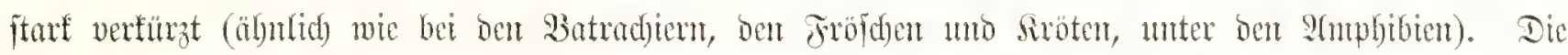

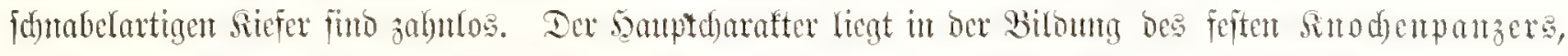

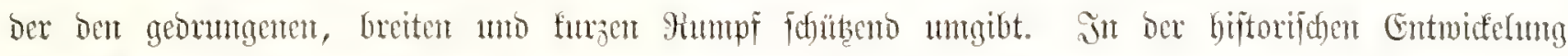

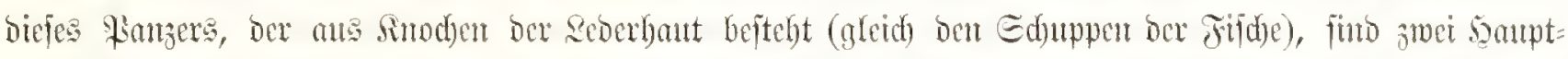

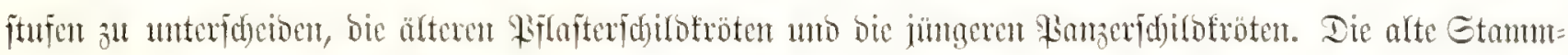

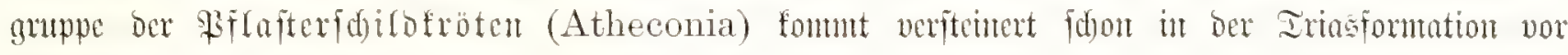

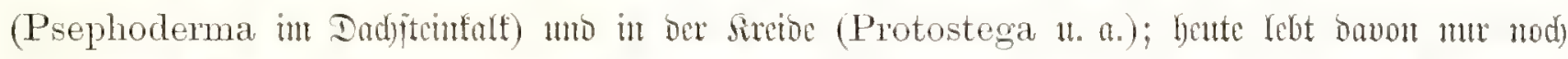

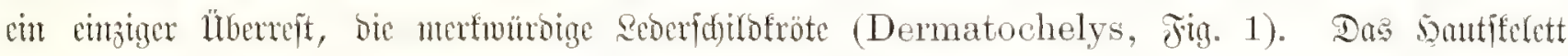

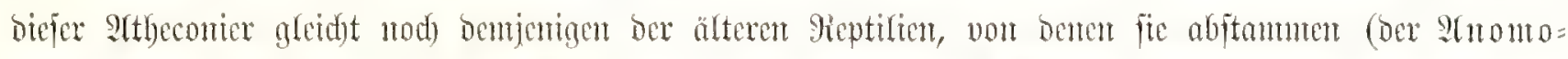

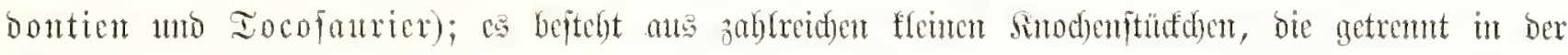

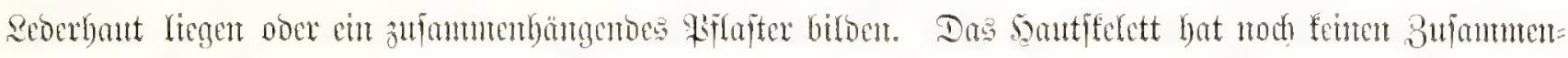

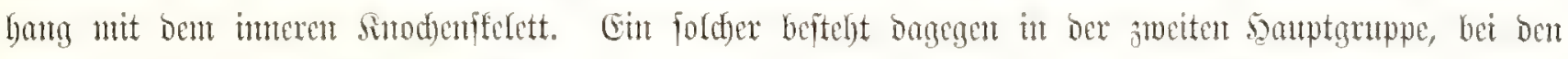

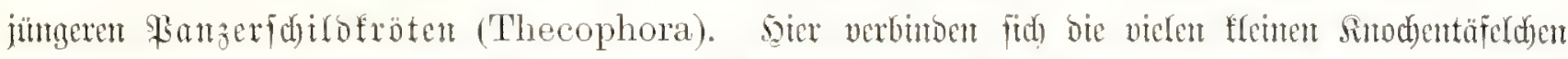

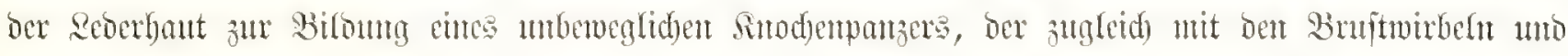

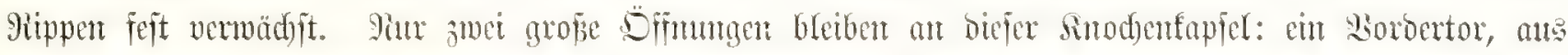

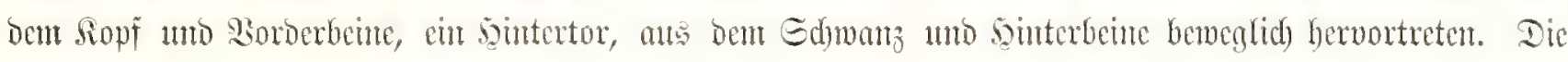

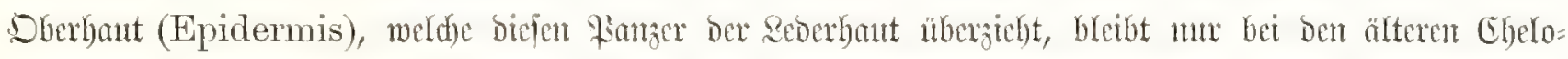

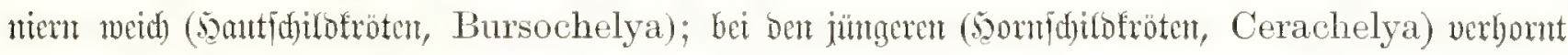

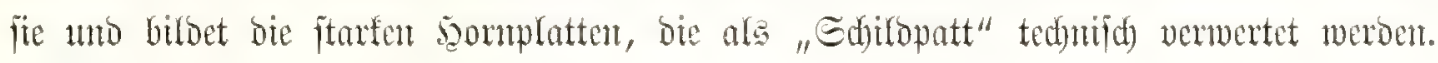

Fig. 1. Dermatochelys coriacea (Blainville). Seberfoltofröte (Tropemmeere).

Dromunn Der Atheconia, Familie dre Dermatochelyda.

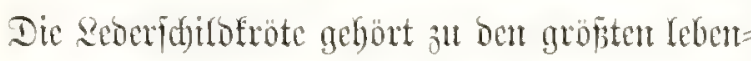
Den Chelonien; fie wiro $2 \mathrm{~m}$ lang mo über 10

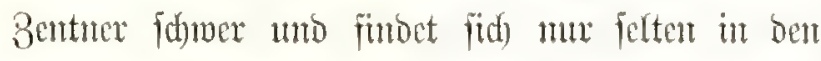
tropifaden Micerent. Sion allent antoeren lebontoen

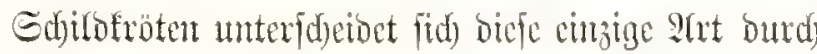

bie primtitive Bifoung des imteren umb änşeren Gfeletts, bic nod) in feimer Sierbintumg ftefyen.

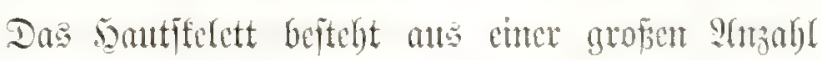

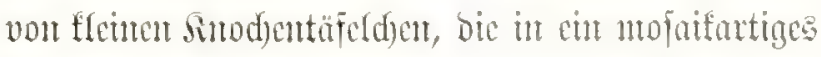

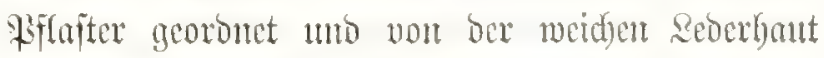

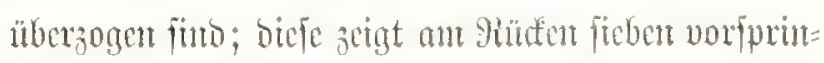

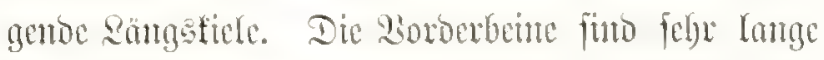
Guberflofien, boppelt fo lang als die sinterbeine. 
Xitis. 2. Caretta imbricata (Gray).

Earte Sdyilofrote (Iropemmere). Intomm in Cryptodera, Familin one Carettida.

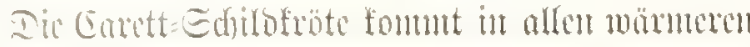

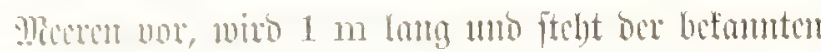
Euppen=Edhistotöte (Caretta viridis) foldr mabe;

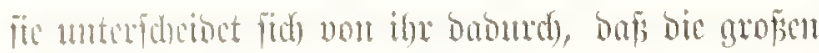

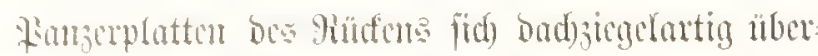
cimmortagen. Dos Edjillopatt, weldes biefe biffen Doraplatten licfern, ift von befonberer Ginte. Dis vier Bente fumb and bei biefer Geefdildofröte, wie

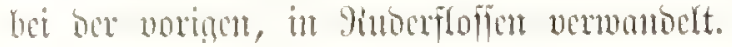

Fin. 3. Hydromeda tectifera (Wugler).

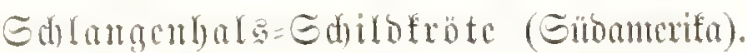
Dromm on Pleurodera, Familic sox Neochelyda.

Die Ed) (manguhats= Edrifofröte, $40-50 \mathrm{~cm}$

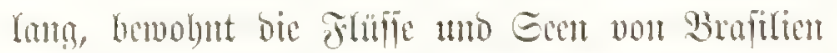

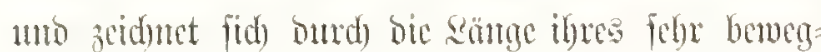
lid)en, fdelangenartigen salfes ans; biefer ift länger

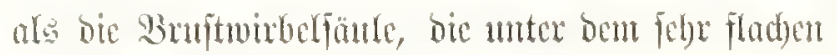

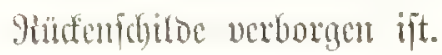

Fig. 4. Chelys fimbriata (Dumérit).

Botten=Sdutrofröte (Eubancrifu).

Drommu one Pleurodera, Familie dex Neochelyda.

Dic Bottent=Edjifofröte oocr , Matamata" wirb

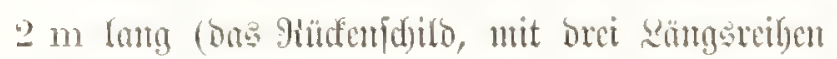
ftarter forifidger Situlgöder, $1 \mathrm{~m}$ ). Der lange, febr beneglide sats uno ber Sopf fino mit veräftelten Sentsotten befectst, bie im sisafier flottieren uno ben auf bem Grumbe ber friffie im Sd)

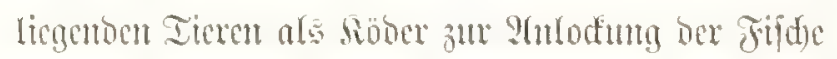
biencu. Die Tiafe ift in einen Mriffel verlängert.
Jig. 5. Testudo geometrica (Linné).

Stcru=S bitofröte (Subafrifa). Dromm ine Cryptodera, Funtie one Testudinida.

Die Etern=Edfitsfröte (20 cm lang) ift unferer

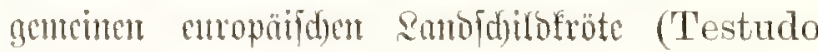
graeca) stabe verwanst, zeidunet fid aber vor bicjer umb anderen S(rten ber Gattung burd) die pura= mibalen Panzerplatten bes gitufeniftiloes aus, beren getbe Sintent auf beut brauten Grumbe eine ftem förmige geometrifde 3eid)mung bervorbringen.

Fig. 6. Testudo elephantina (Duméril).

Elefanten=Sd)irofröte (Galapagos). Dximm one Cryptodera, Familis Dex Testudinida.

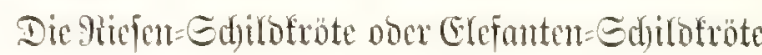

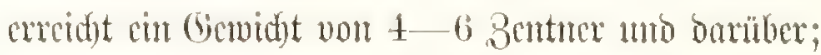

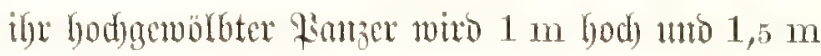

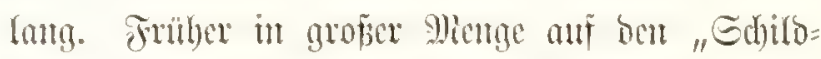
fröten = Surfeln" (Galapagos, Minäarench) vorhan= best, furto biefe folofifalen Meptilien, wegen ibres wobl=

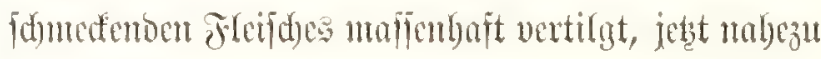
ausgeftorbert.

Fig. 7. Chelydra serpentina (Schueigger).

Mrrigator=Gdirofröte (Yoroanterifa).

Dotomm ine Cryptodera, Familic ioc Chelydrina.

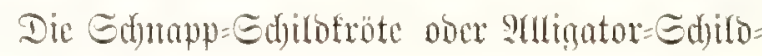

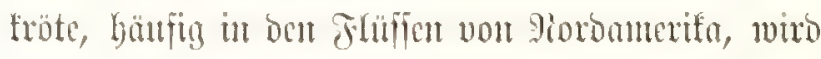
über $1 \mathrm{~m}$ lang amo $20 \mathrm{~kg}$ fofwer. Das Giüfen= fdillo (60 cm lang) trägt brei Gicihen fegerförmtiger

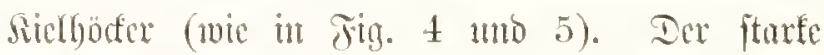

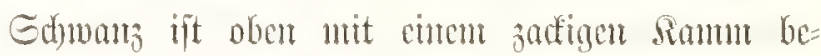

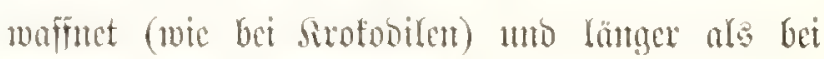
Den meiftur antoren Edjilbfröten. 


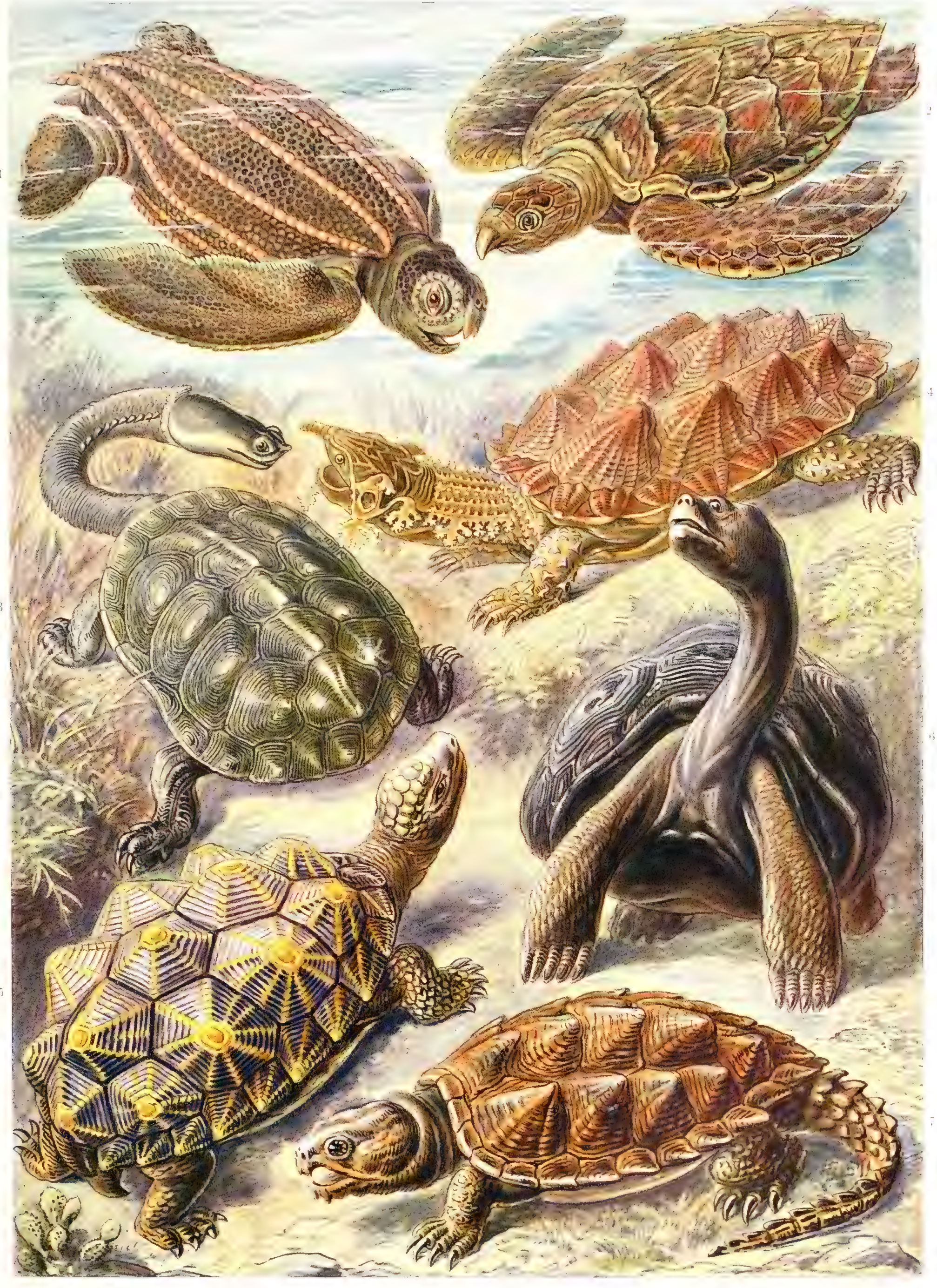

Chelonia. - Sdilotivester. 
Tim. 1, 5. Cystoblastus Lenchtenbergii (Tolbuth).

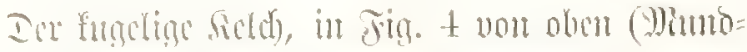
foitc), in sitg. 5 bon biuten (Mfterfeite) gejeben,

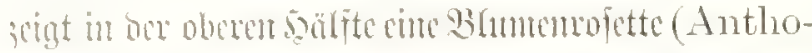
(lium), bic me fünf gefiederten, Imostformigen

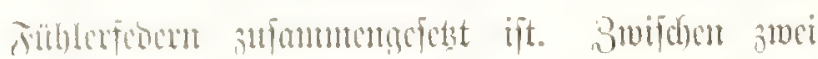

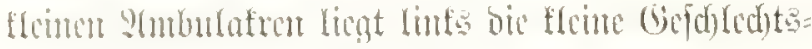

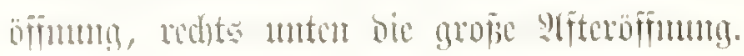

\section{Ting. 6. Psemdocriuns bifasciatus (Pearce).}

Ior limpenförmige geftelte sichd ift von zowei

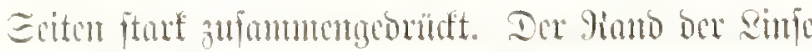

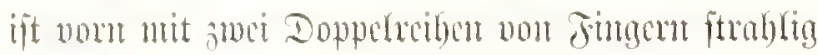

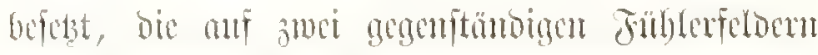

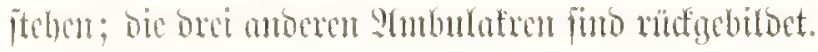

\section{jig. 7. Sycocystis angulosa (Leopold Buch).}

Sor vieledige Sield) fitht mif cinem ftarten ge=

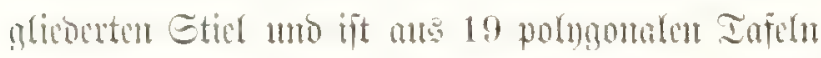

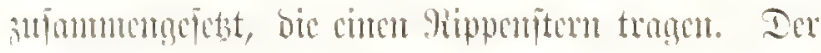

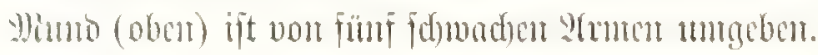

Jig. S. Callocystis Jewetti (Hall).

Dex ciförmige sedd), von binten gefehen, zeight

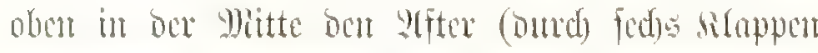

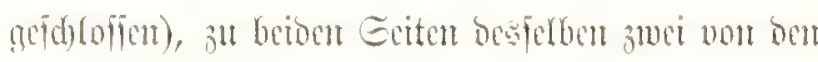

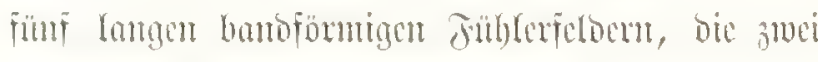
Neiben won Fimger $=$ ?miäben tragen.

\section{Tign. 9. Hemicosmites extranens (Eichuald).}

Der eiformige seld ift ats grofien fodsustigen

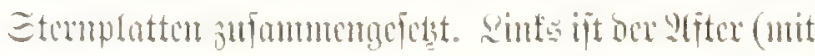

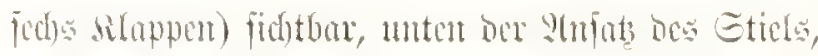

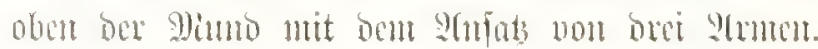

\section{Fin. 10. (ilyptocystis multipora (Billings).}

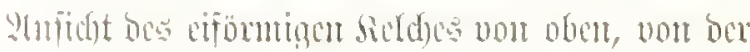
mlumbläde. Ias fumfitrablige Fublerfelo (Antho-

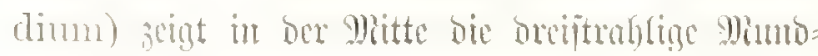

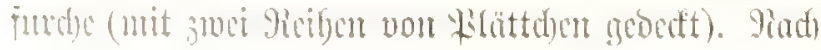

vom (in ber Jigum blen) gert bas einfadye mittlere

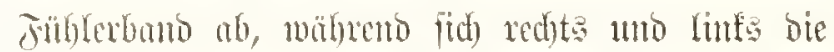

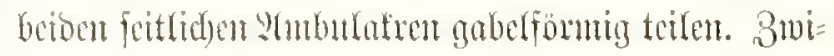

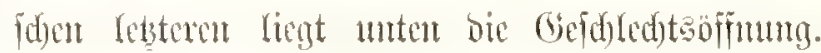

Jig. 11. Glyptocystis pentapalma (Haeckel).

Infidet bes sluntofelocs, von oben, unt bie

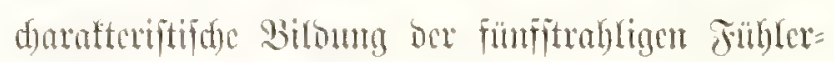
rofette jut arigen (Anthodium pentapalmare ober fogenamte Hydrophora palmata). Der zentrale

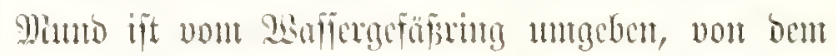

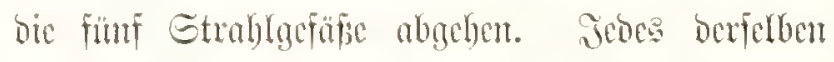

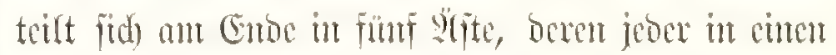

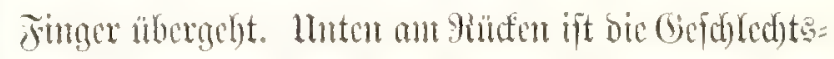

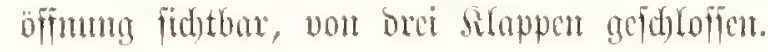

Fig. 12. Chirocrimus testudo (Haeckel).

Der ciförmige Seld ift ans brei Beiben von gropen fed)serfigen Infeln jujammengejetst; bic jtarfen Bippen, bie vou wittelpuntt ber Tafeh ansftrah= Len, bifocn cinten sirans von rautenförmigen siguren. Der sumo (obent) ift wou 25 geglieberten, jwei=

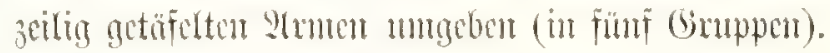

Jig. 13. Caryocrinus ormatus (Thomas Say).

Der eiförmige Selde ift me vier Gintelet von

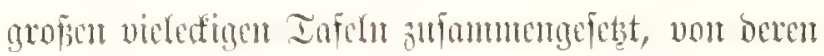

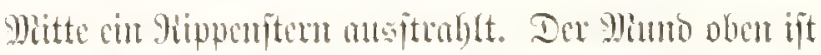
breiptrahlig, von neut geglicoerten strmen umyeben.

Jig. 14. Agelacystis hamiltonensis (Haeckel).

Ier fretsumbe, flad) fdycibentörmige Sield itt

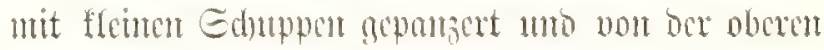

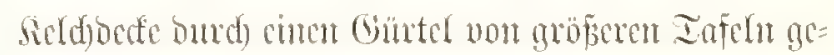

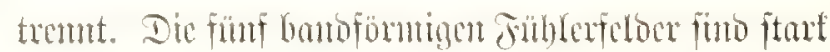

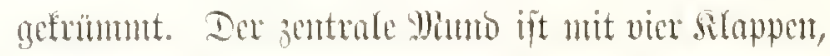

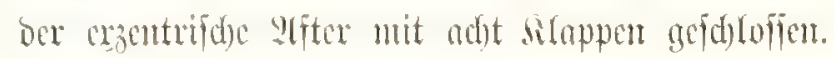

Fig. 15. Agelacrinus rorticellatus (Hall).

Der flad)e focibenfönmige selde ijt bem von Agelacystis älunlid); aber bic fünf banbfönmigen

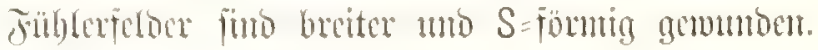

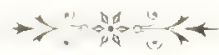




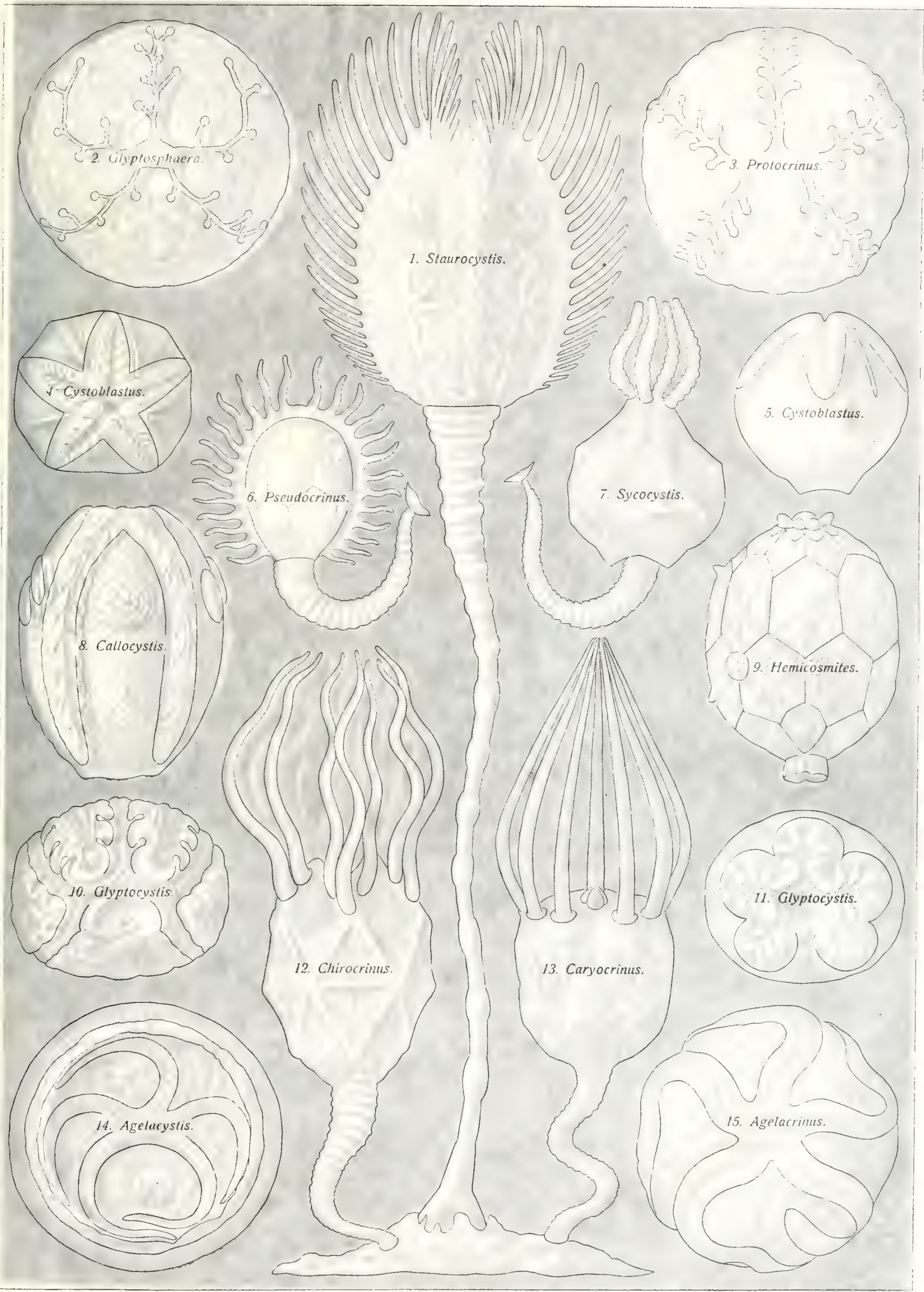




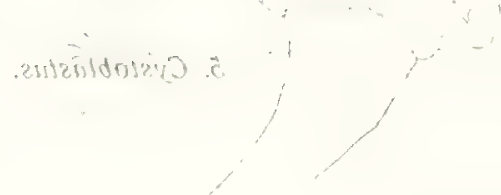

.2it2.004m12. i

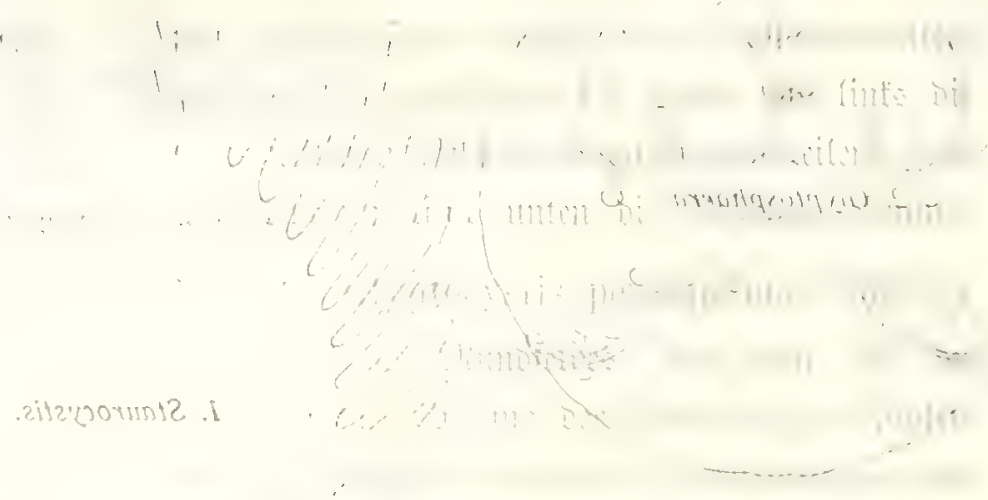

$.2112130382 \div$

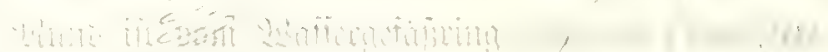

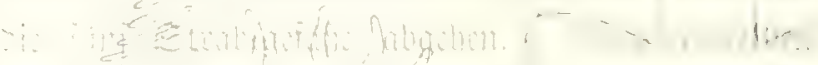

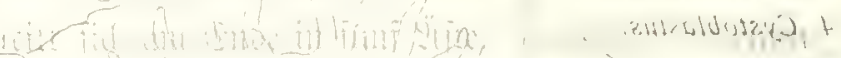

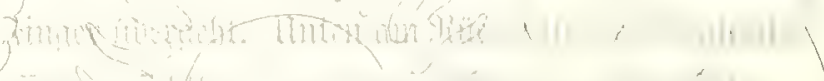

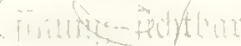

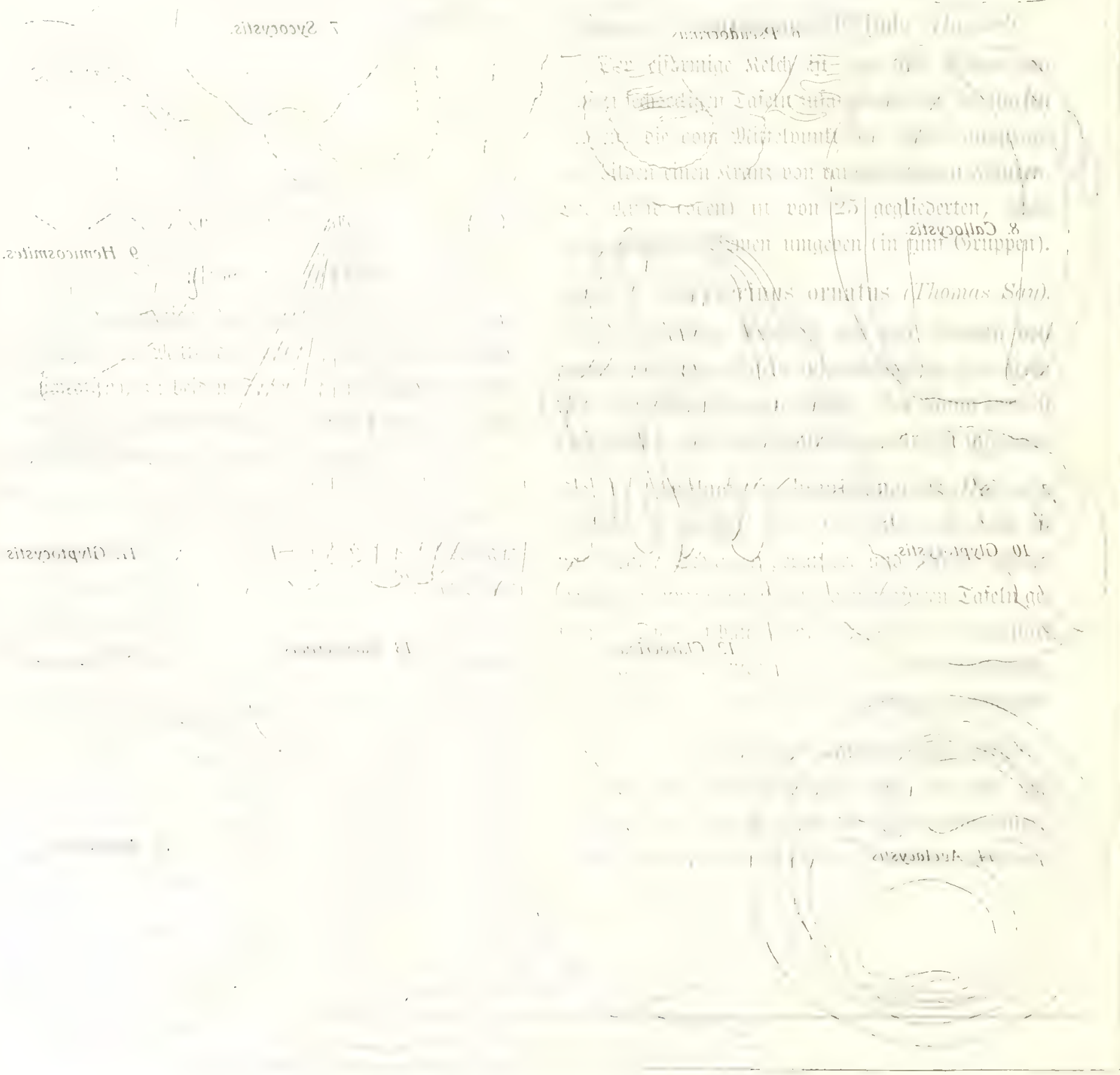




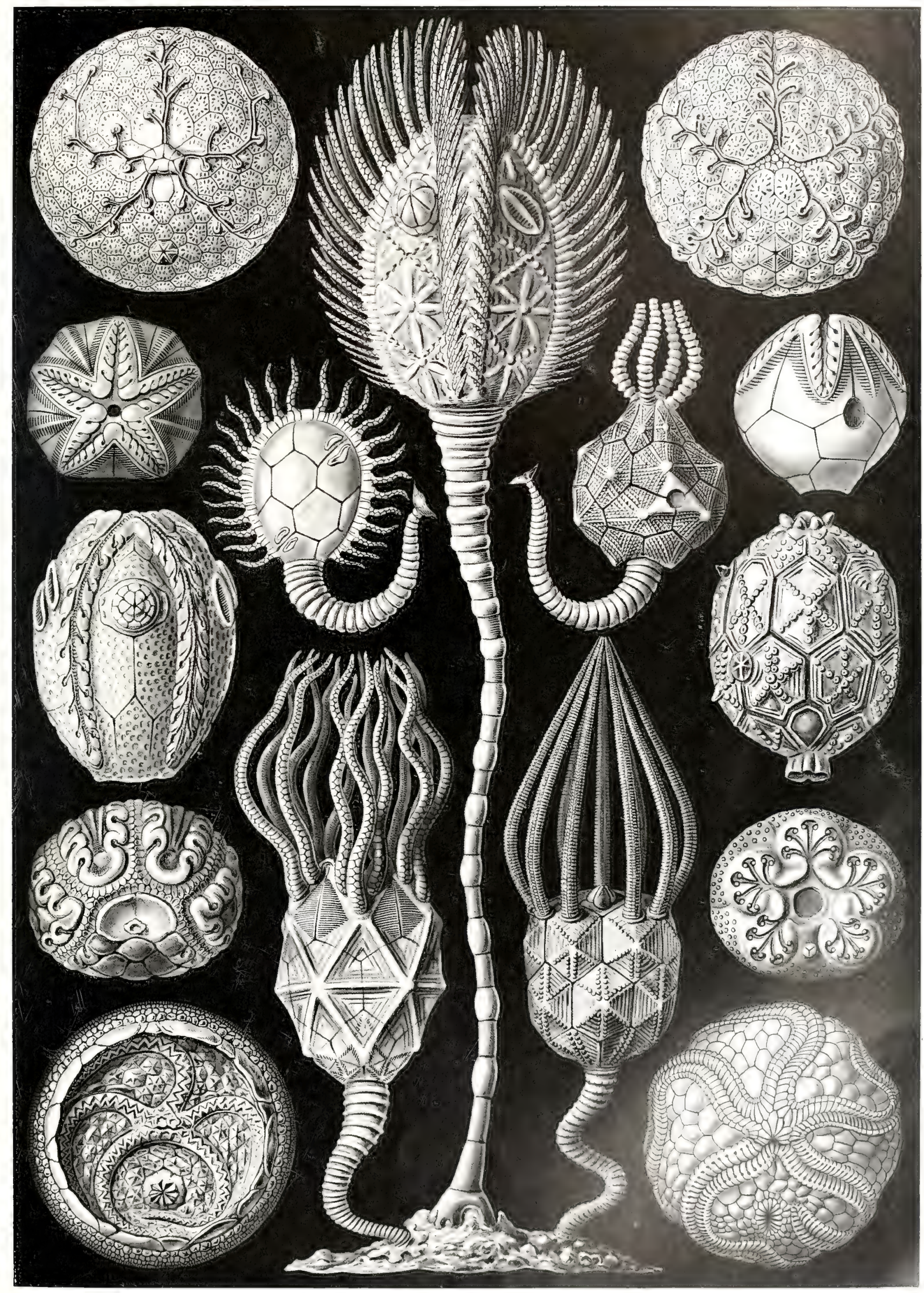

Cystoidea. - Dientelliteruc. 



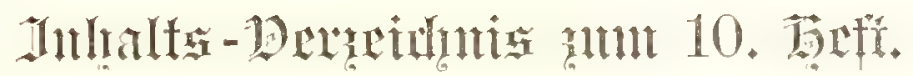

Iafer 91. Astrosphacra. lluticre me ber bauptflaffe ber sisurzerfuifice (Rhizopoda), Silafie der gabtolarien (Eegion der Epte medfarien).

Iafel 92. Alsophilat. Fampflansen (Pteridophyta) ans der silatic der Eanbrarme (Filicinae).

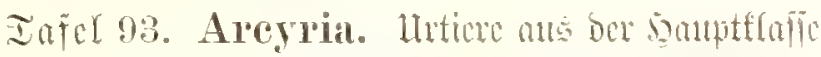

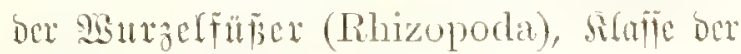
Sirstiere (Mycetozoa).

Iafel 94. Araucaria. Búntempflanzen ats Der Sautffaffe Der Parftantigen (Gymnospermae), Sifalfe bex 3 apfentö̆tne (Coniferae).

Tafel 95. Placocystis. Etcuticue m. ber rantflafie ber Mionordyonicu (Noncincta), Siraffe ber Hrucuiterne (Amphoridea).

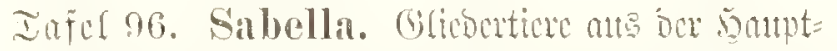

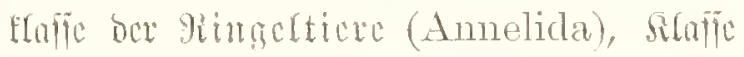
Dex 3orftenmiturer (Chaetopoda).

Tafel 97. Terebratula. Asmmatice ats ber

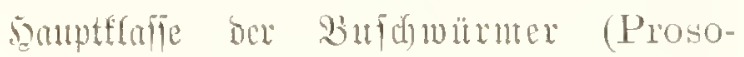
pygia), Sifafe ber Epiralficuter (Spirobranchia).

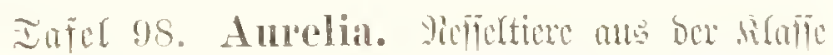

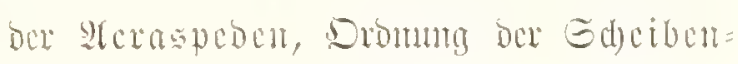
quarfen (Discomedusae).

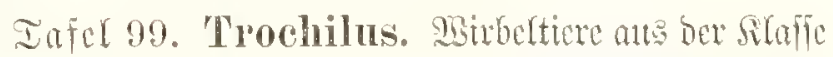
ocr äbrgel (Aves), Unterflaffe bor Sitcl= väget (Carinatae), Fumilie bor siolibris (Trochilidae).

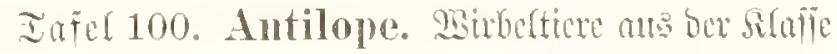
ber Gängeticre (Mammalia), Region ber Gufticre (Ungulata), Fmitic ocr venti= lopen (Antilopina). 



\section{Spumellaria. Srammltrathlingr.}

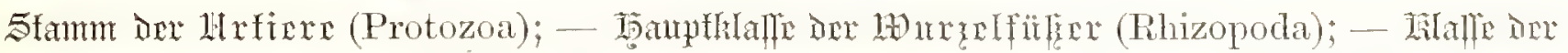

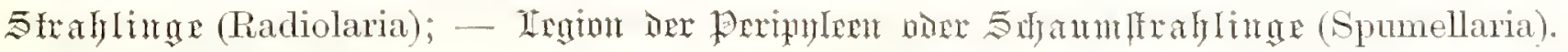

Die formemretde Region oce Sdammitrahlinge (Spumellaria), won benen über 2000 Srten

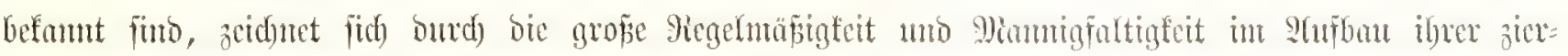

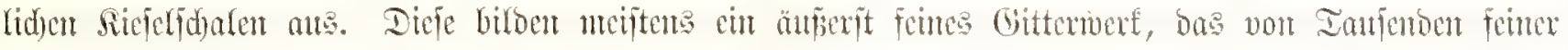

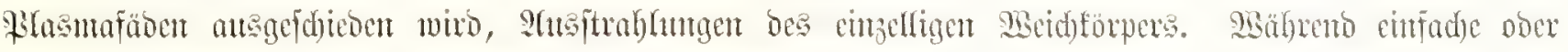

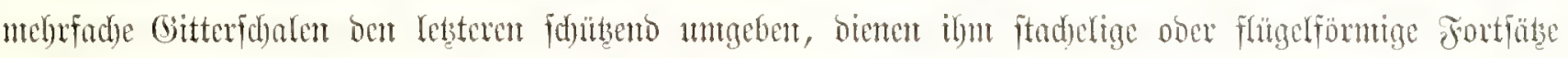

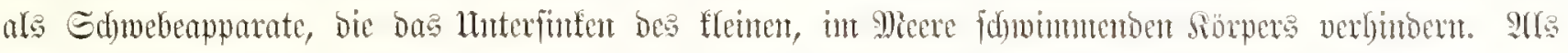
vier Srommgen biefer grofien Region weroen die fugetigen (Sphaerö̈dea), pffaunenförnigen (Pru-

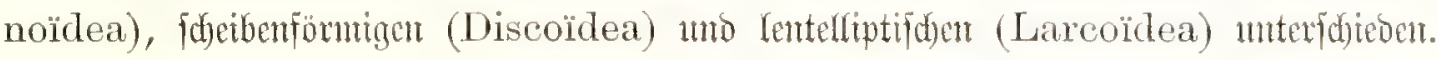

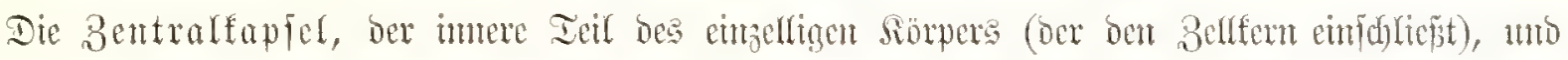
ebenfo bie än

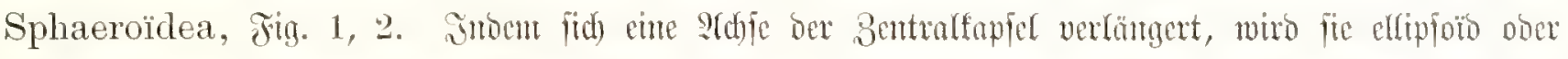

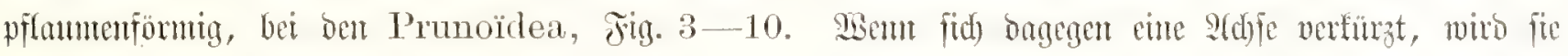

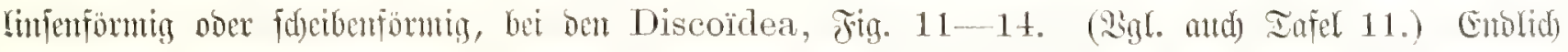

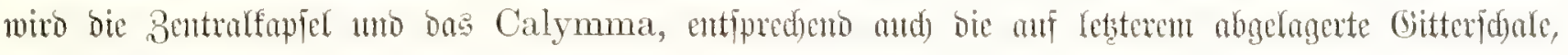

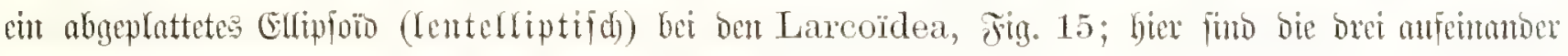
fenfred)ten SIddfent Des Siörpers von ungheid)er Ränge.

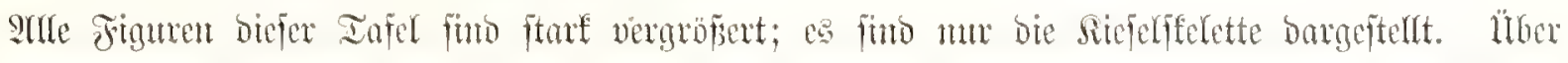

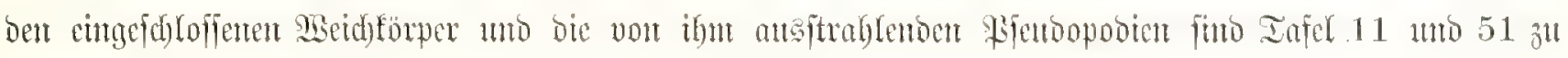
vergleidyent.

Jig. 1. Astrosphaera stellata (Haeckel).

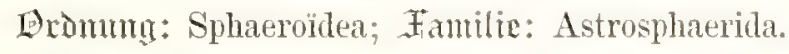

Die fugetige Gitterfatale, von $0,2 \mathrm{~mm}$ Durd $=$

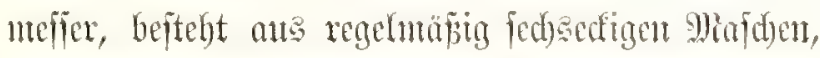

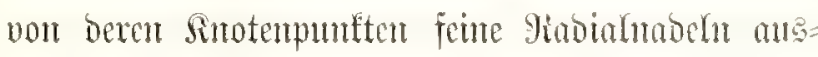
itraflen. Die (sitterbalfen merben gefrentat burd)

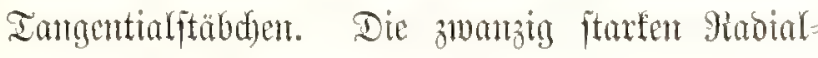

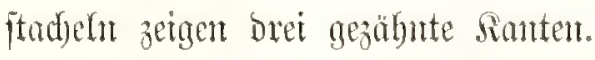

Fig. 2. Hexancistra quadricuspis (Haeckel). Bromm: Sphaeroidea; Familix: Cubosphaerida.

Die Gittenfafare, von $0,17 \mathrm{~mm}$ Durdmenter,

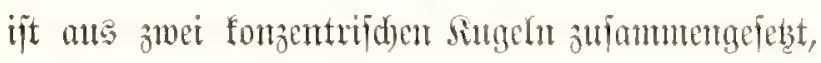

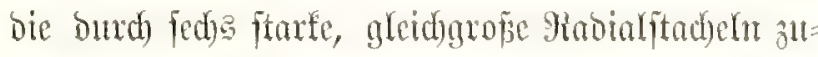

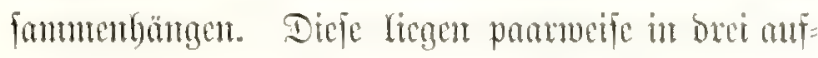

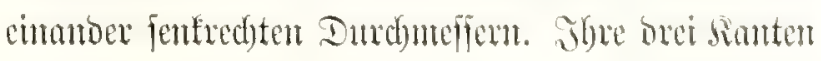

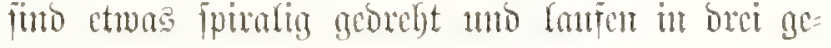
frimmte Ecitenäfte mเs.

Fig. 3. Cannartidium mammiferum (Haeckel). Dromm: Prunoidea; Famtix: Cyphinida.

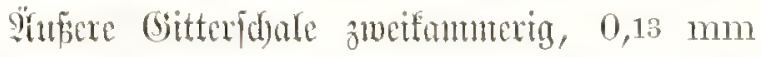

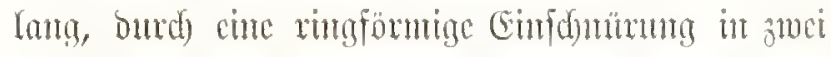
gleid)e, faft fugchige Simmemen geidjeden, bie warzen=

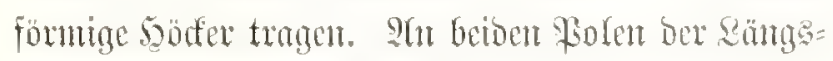
adje eime gegitterte röhre.

Fig. 4. Canmartidium mastoplerom (Hacekel). Drdmunt: Prunoider; Familix: Cyphinida.

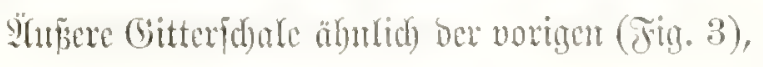

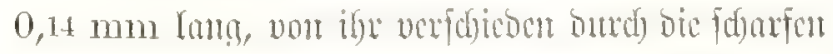

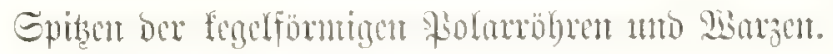

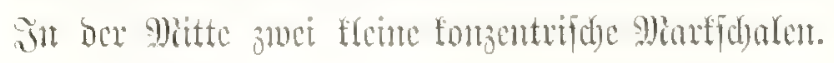


Fin. 5. Cannartisens ampliconisens (Haeckel).

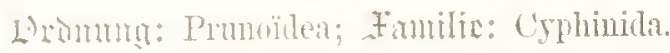

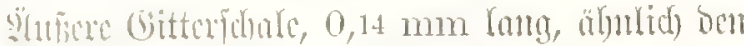

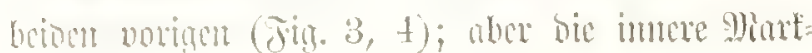
finte cimfodt).

Jị. 6. (yphinus amphilophus (Hacckel).

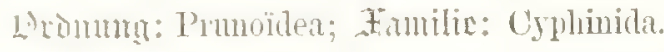

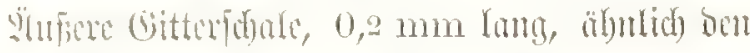

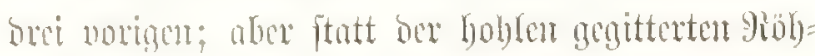

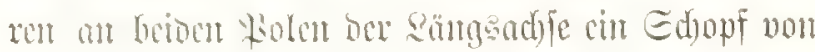

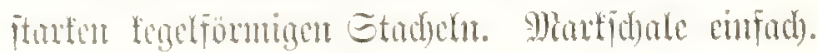

Jị̣. 万. Panartus diploconus (Haeckel).

Dromm Prunoïdea; Familie: Panartida.

Die äuñere Gitterfdyale, $0,34 \mathrm{~mm}$ lang, bejteht

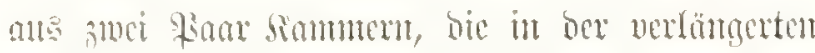

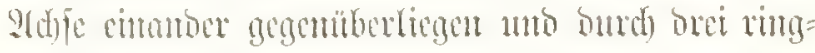

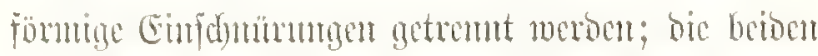

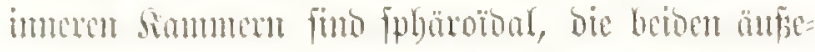

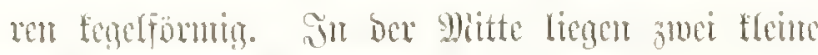
tomimatifice Dintidualen.

jig. S. Peripanartus amphiconus (Haccket).

1) stomnn: Prmoïlea; Hamilis: Pmartida.

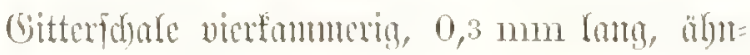
(id) ber vorigen (Fig. 7); aber you cincr òmeiten, ämferen gimbemflate von gleidger Form mutgeben.

Fing. 9. Panicium coronatum (Haeckel).

Docomma: Prunoïder; Fantis: Panartida.

(Gitterforde vicutammerig, $0,22 \mathrm{~mm}$ lanta, äbn=

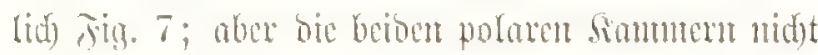

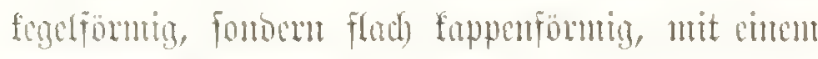
itarter Stadyelfroms.

Jin. 10. Peripanicium amphicorona (Haectel).

Notnmut: Prunoïdea; Familix: Panartida.

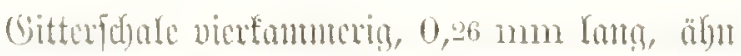
(id) ber vorigen (Jig. 9); aber von cimer jweiten,

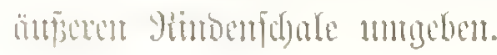

Fig. 11. Trochodisens stellaris (Haeckel).

Erommn: Diseoïlea; Fantilix: Cenodiscida.

Gitterfd)are Cinfonfömuig, einfach, von $0,25 \mathrm{~mm}$ Durd)meffer; in ber Sfonatorebene mit cinent bre

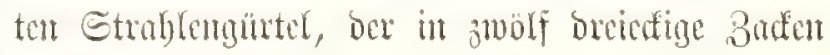
anelăıft.

Jitg. 12. Dicranastrum bifureatum(Haeckel).

Dromunt: Discoïdea; Familix: Porodiscida.

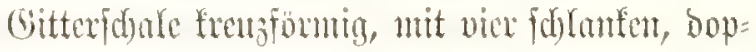

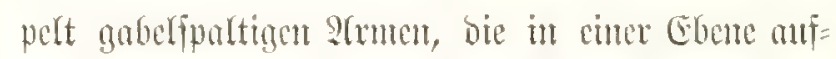

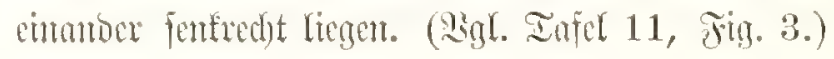

Jig. 13. Arehidiscus pylonisens (Haeckel).

Drommty: Discoïdea; Familix: Porodiscida.

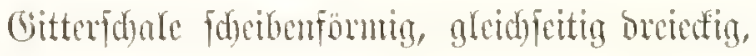
von $0,05 \mathrm{~mm}$ Durduneffer. Dis zentrale linjen=

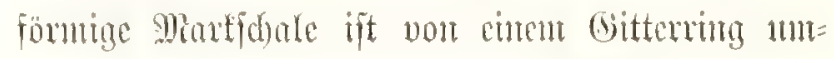

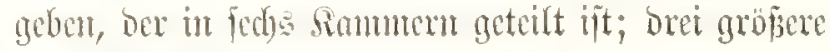
aboudgefuro mit brei fleinerent.

\section{Jin. 1t. Pylodisens triangularis (Haeckel).}

Drommn: Discoìdea; Fantilis: Pylodiscida.

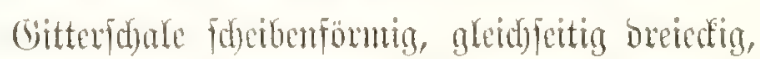
non $0,15 \mathrm{~mm}$ Durdumfifer. Hu cine intere Slarf= idente, bie ocr vorigen (Jitg. 13) glcid)t, ift cin änje=

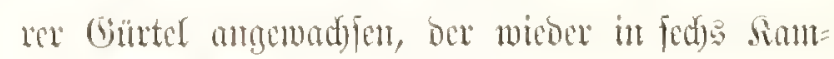
ntcru geteift iit.

\section{Fig. 15. Tholoma metallasson (Haeckel).}

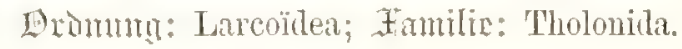

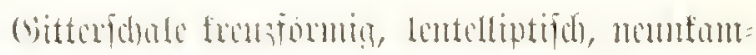

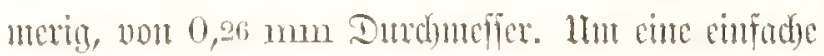
alfiptiflye Bentralfanmer find vier imsere Simmen

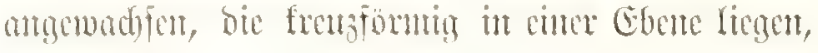

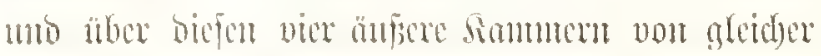
Form, je swei grgemintümige gröper afs bie zwei arberm sianmerm.

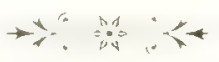




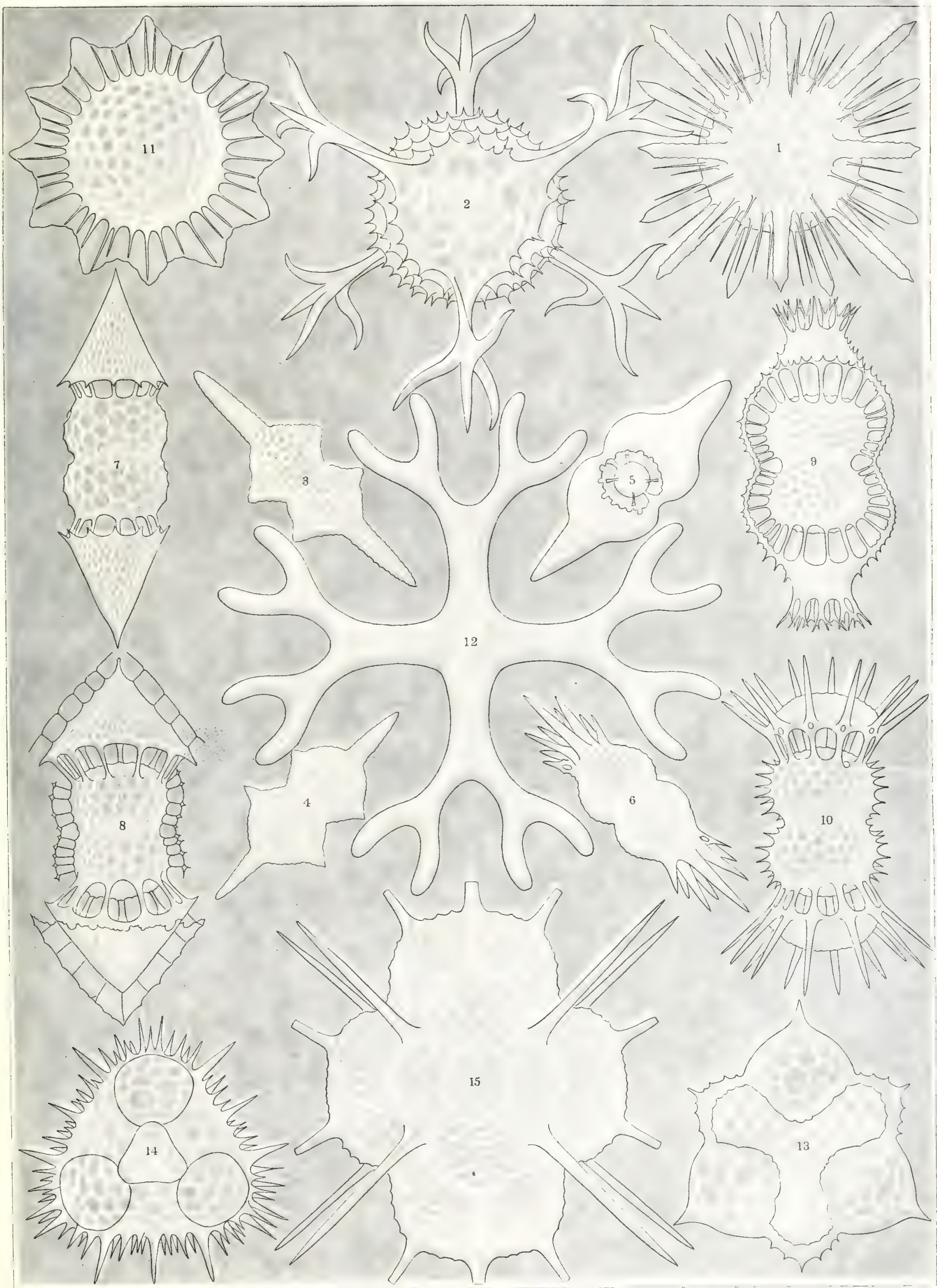




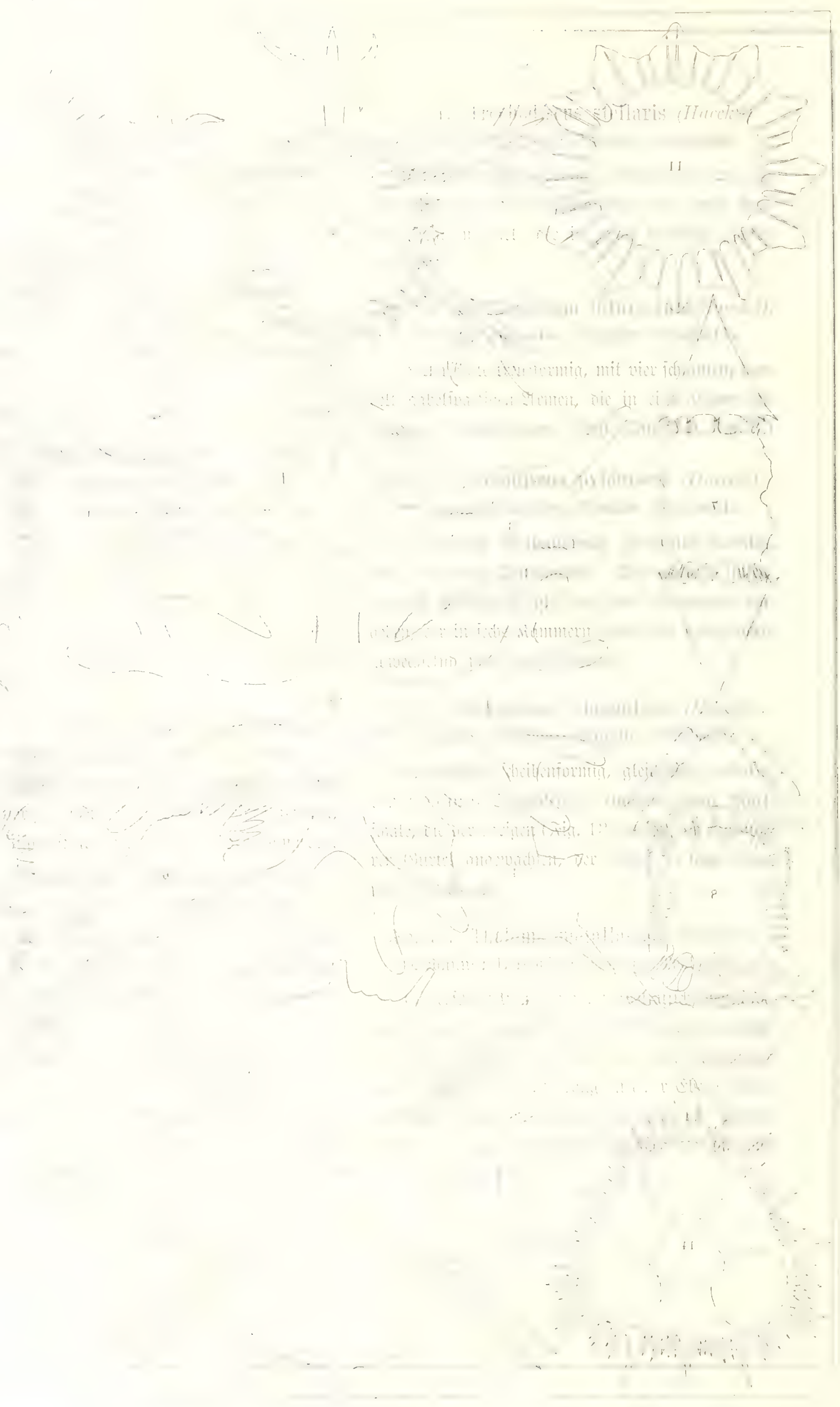




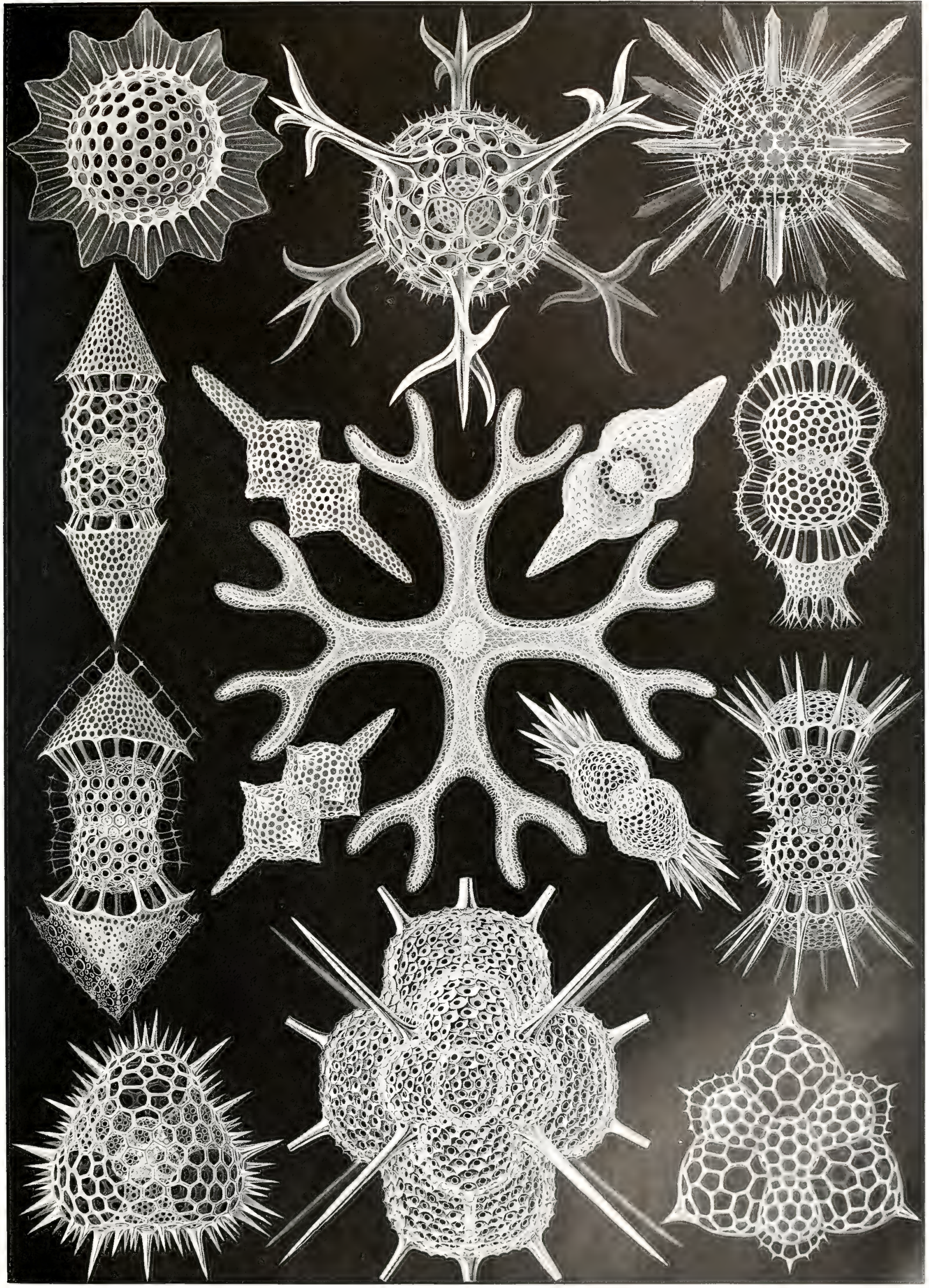



Eafel 92. - Alsophila.

\section{Filicinae. Tautlfaxute.}

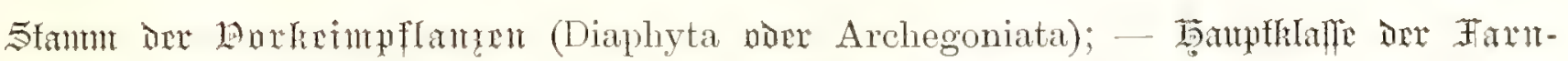

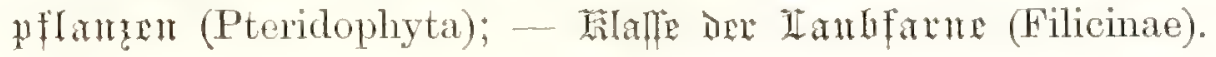

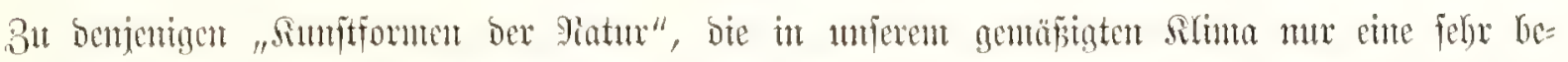

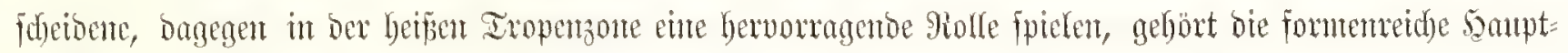

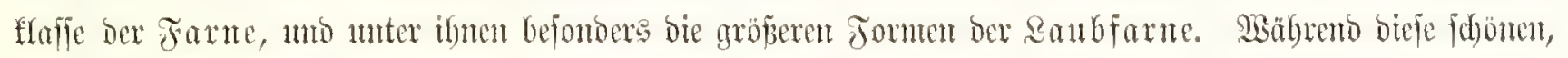

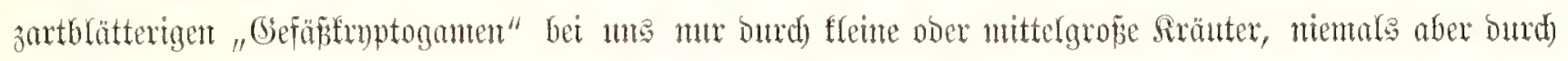

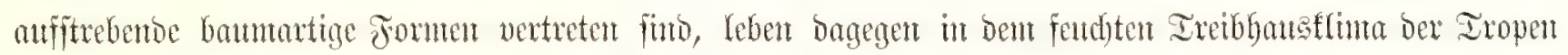

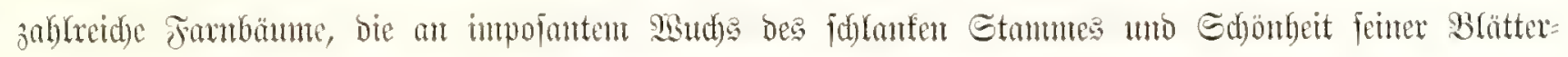
frone mit ben \&almen wetteifen; bie eimzelten Blätter unandber frmutartiger jtammlofer Farne (Angiopteris)

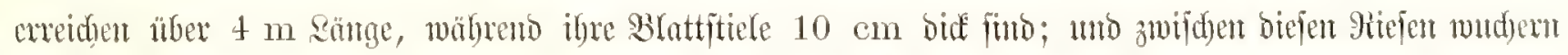

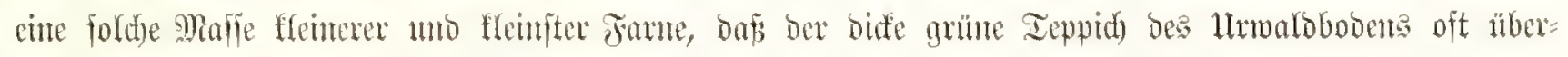

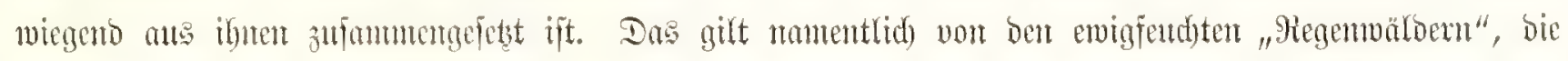

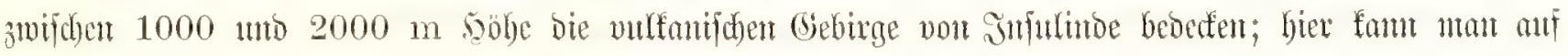

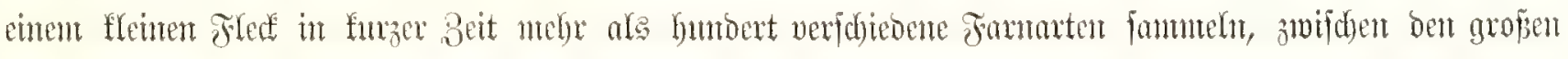

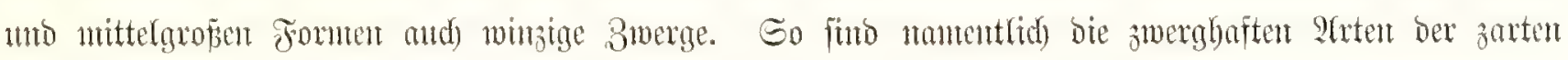
Sd) reierfante (Hymenophylleae) oft fleimer als bie bentabarten zmbmopje.

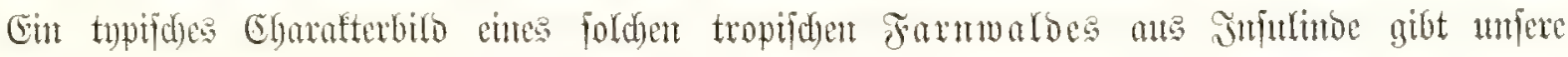

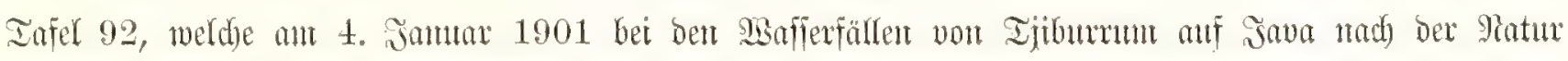

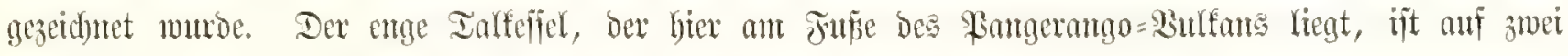

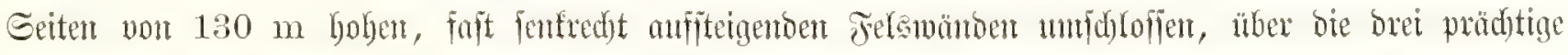
sonfierfälfe herabitürzen. Die ganze suft ijt mit

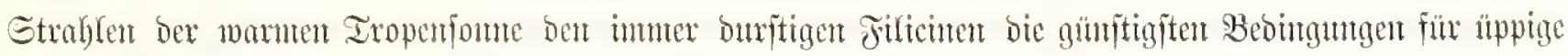

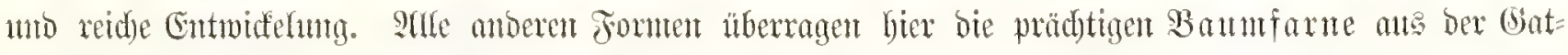

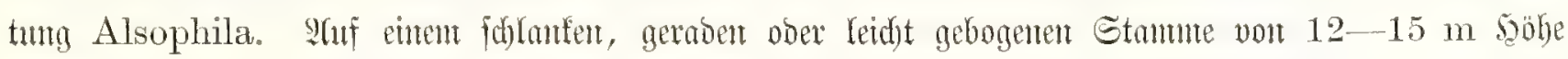

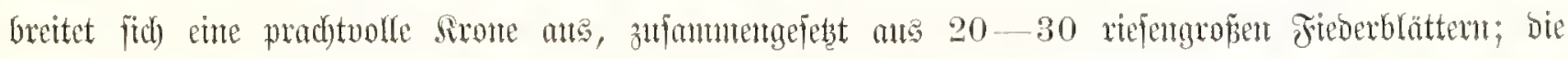
jungen, nod nidgt entwiffelten Blätter ftehen in ber Mitte der Sirone fpiralig cingerollt; ote alten $a b=$

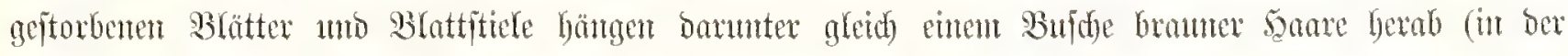

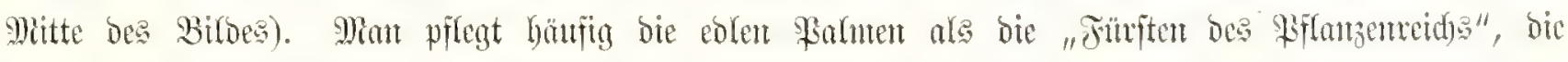

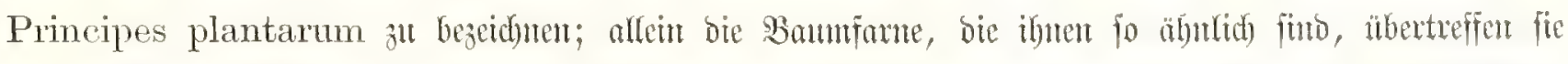

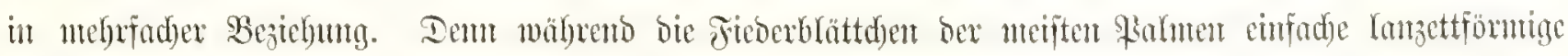

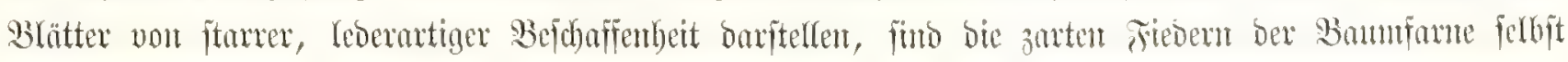

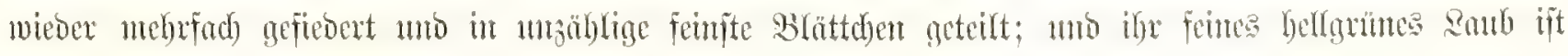

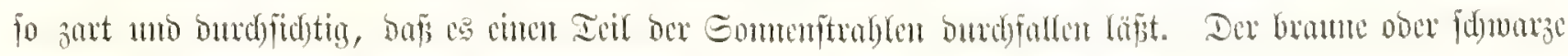

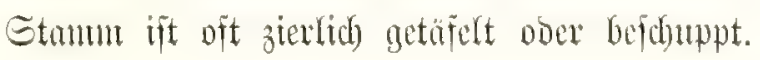




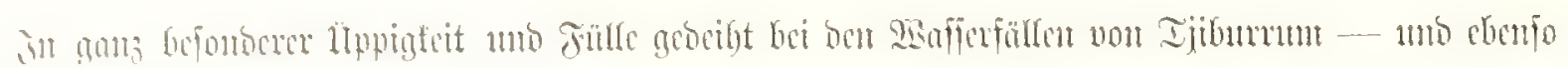

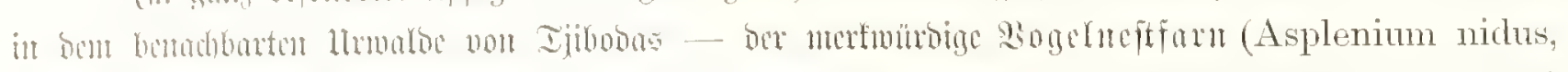

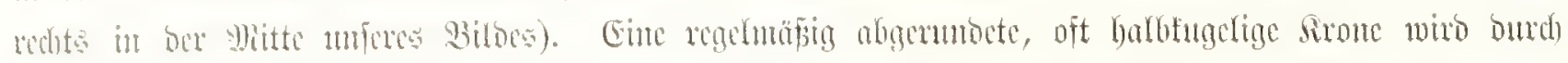

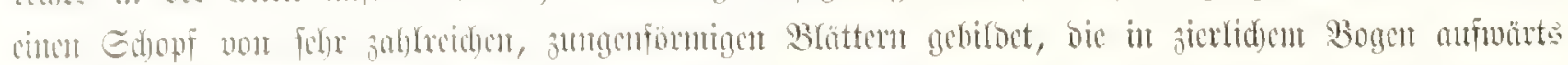

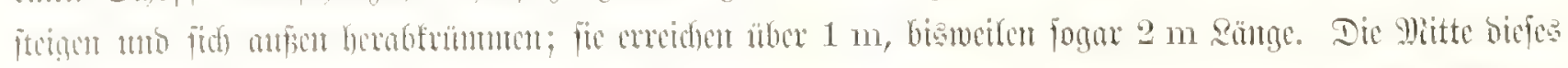

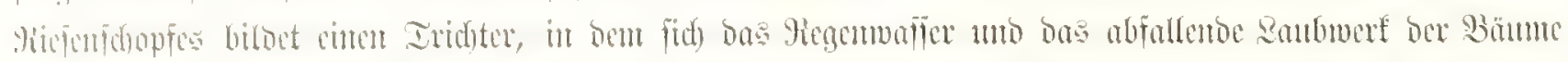

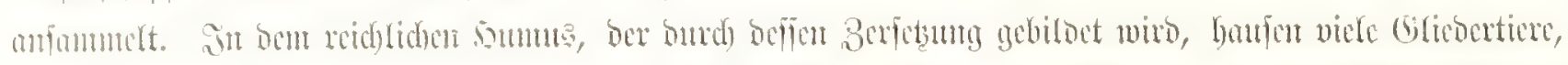

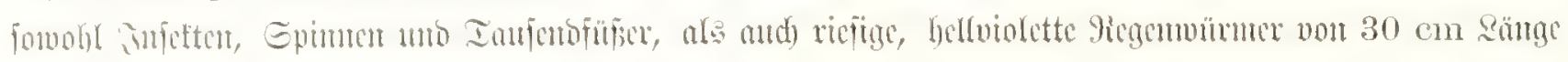

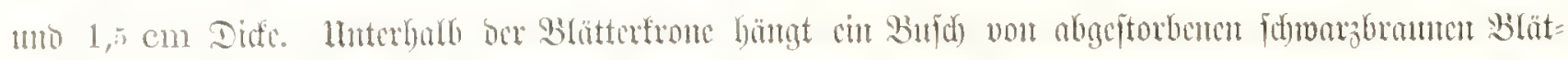

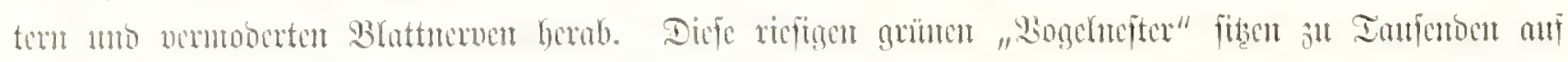

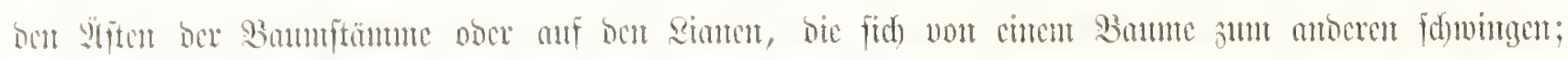

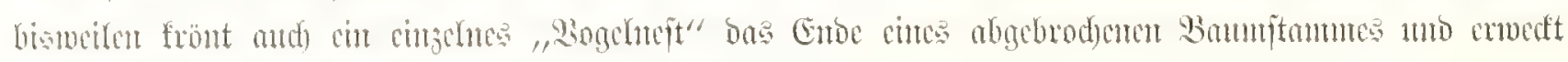

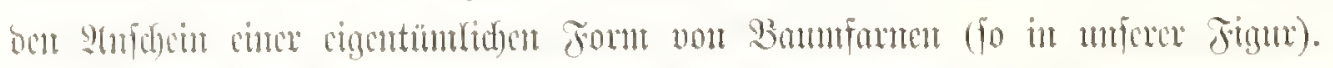

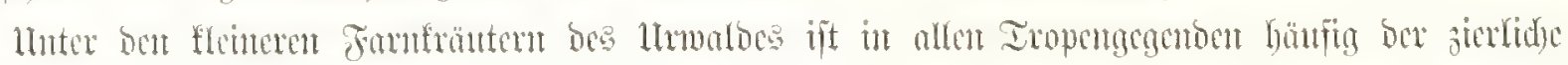

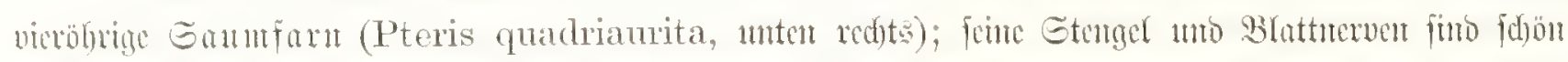

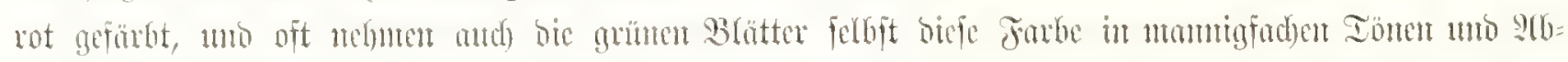

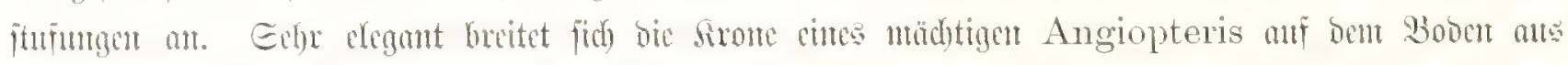

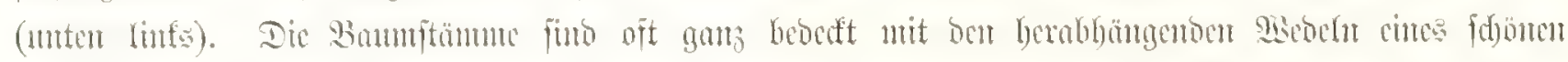

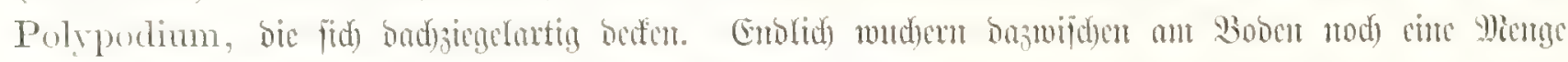

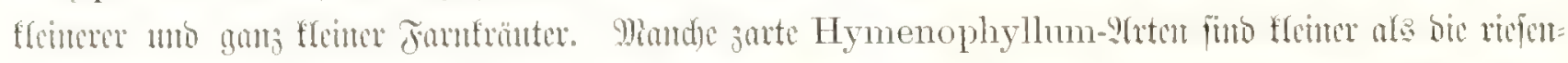

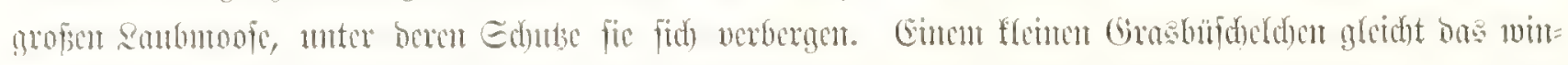

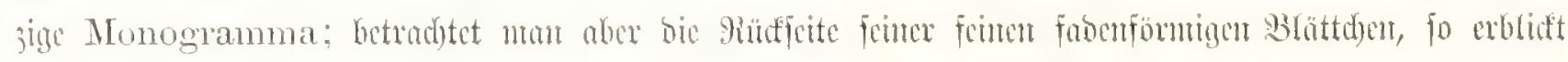

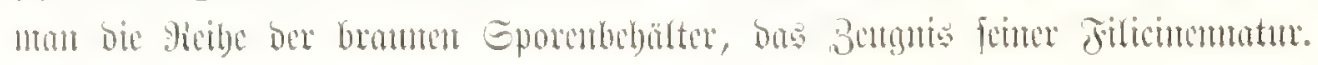




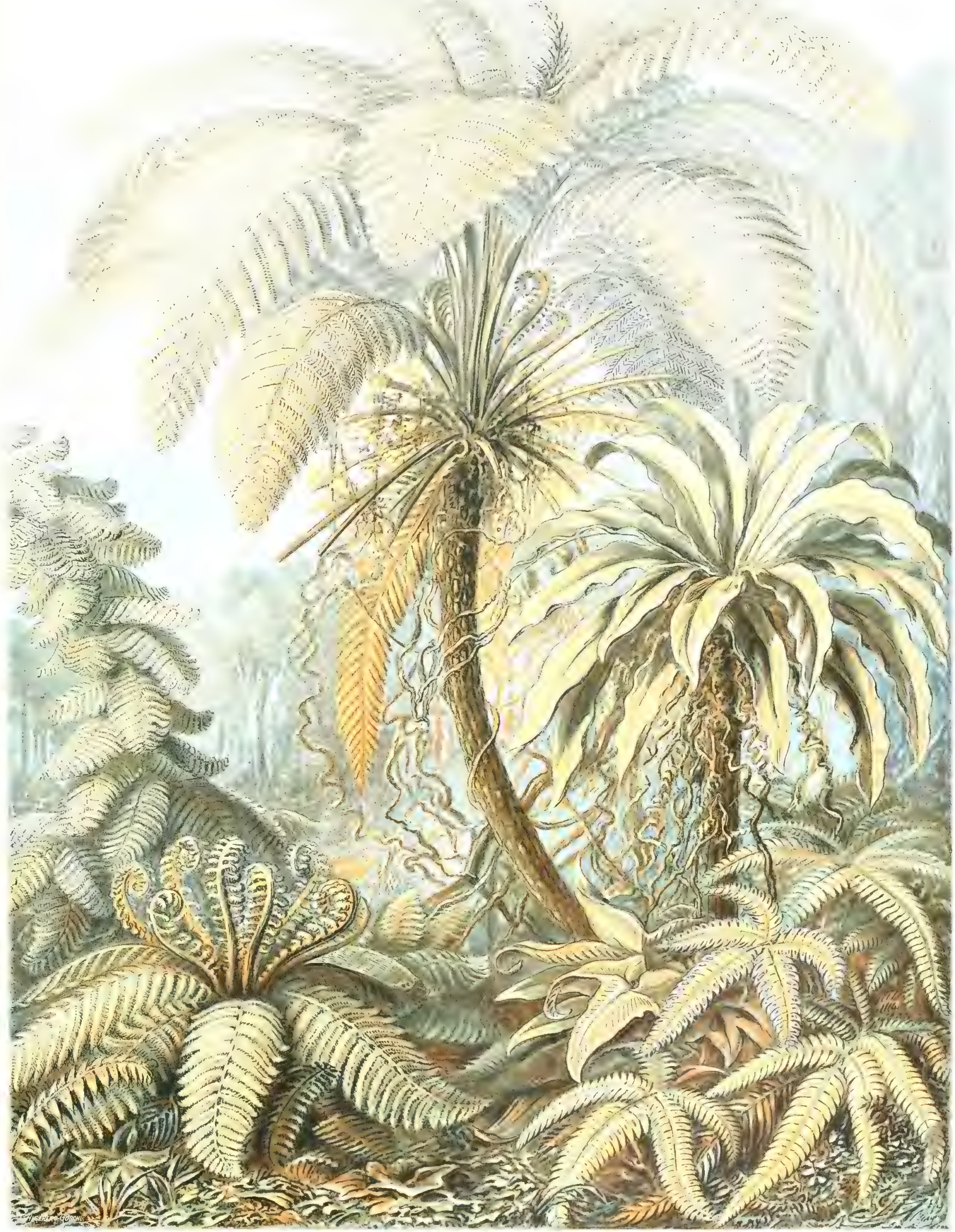

Filicinae. - soutiforme. 



\section{Mycetozoa. Dilştiexe.}

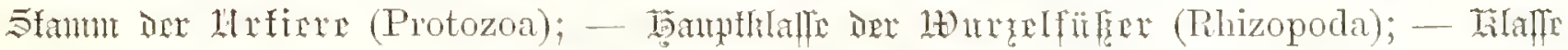
Dex Pilzinere (Mycetozoa).

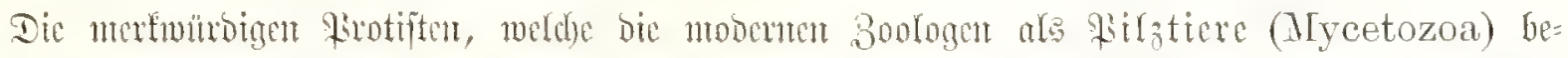

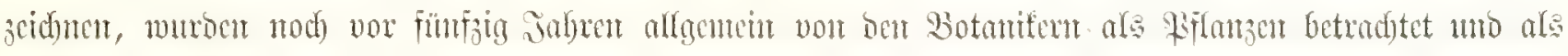

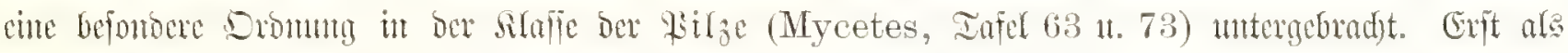

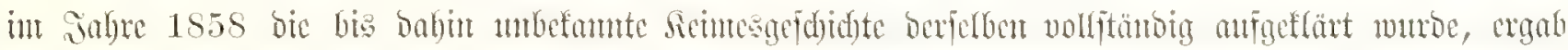

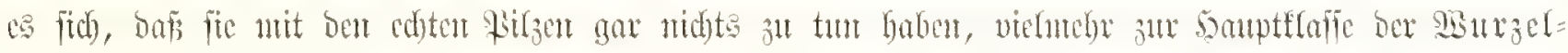

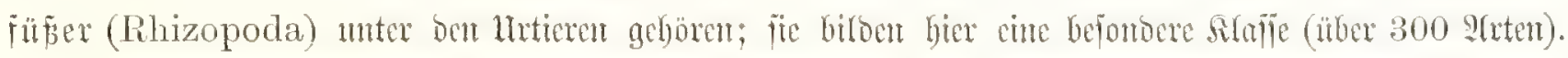

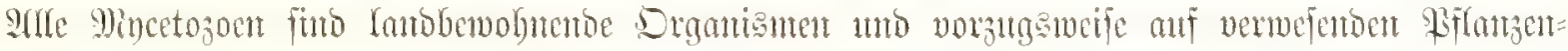

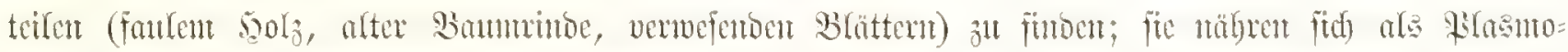

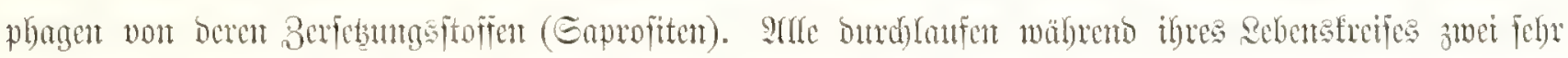

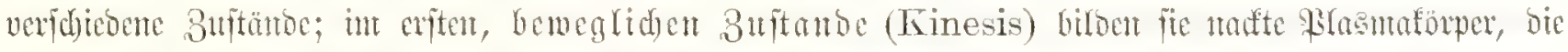

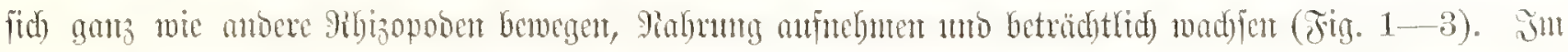

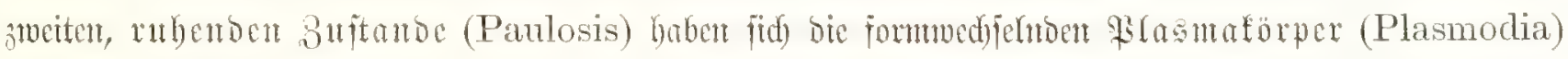

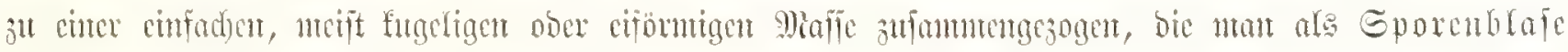

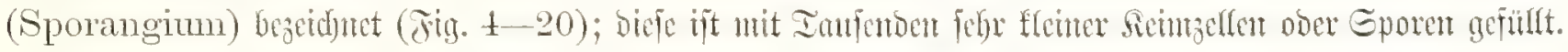

Bei ber Seinum ber Wirgtere (im .

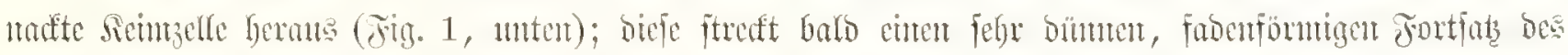

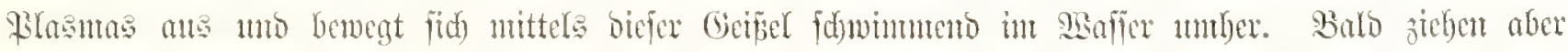

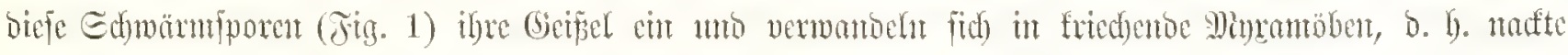

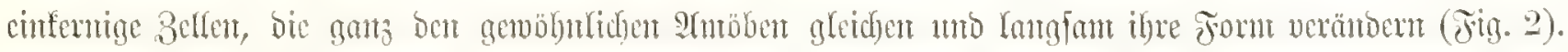

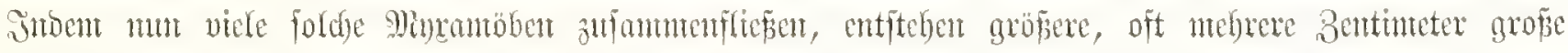

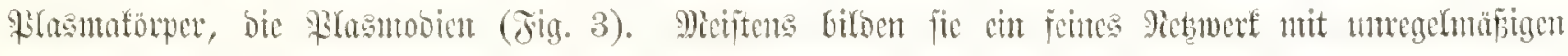

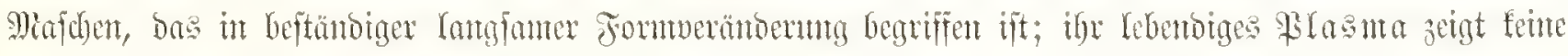

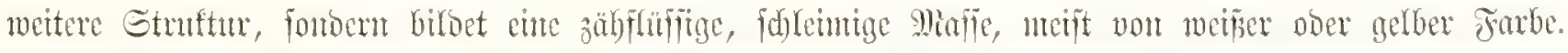

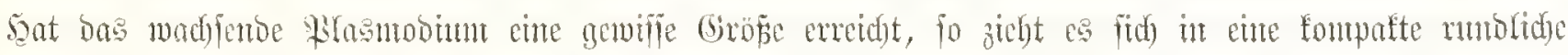

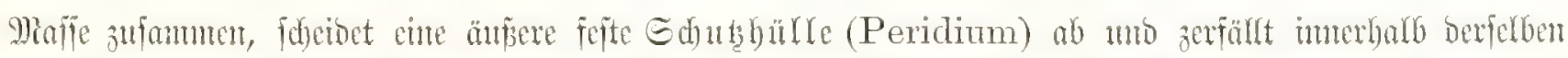

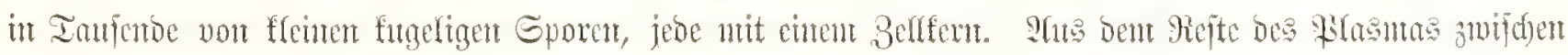

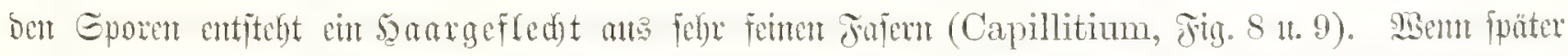

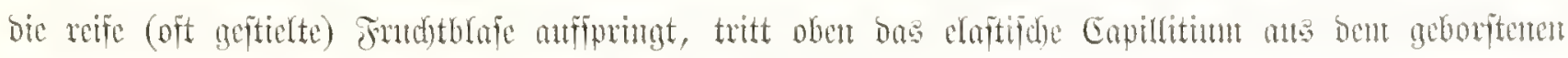

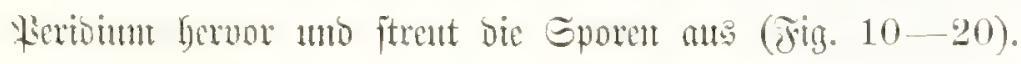

Jig. 1. Areyria punicea (Persoon).

Gime Gruppe von fünf Edfmäruriporen, beweg=

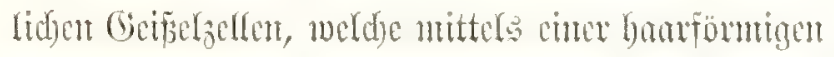

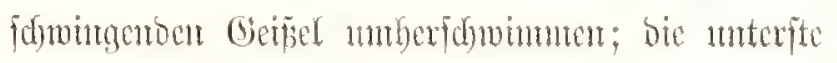

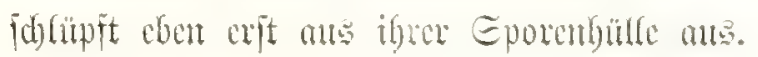

Fitg. 2. Trichia varia (Persoon).

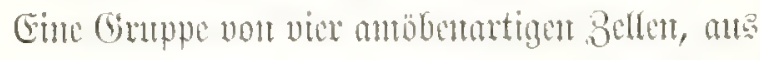

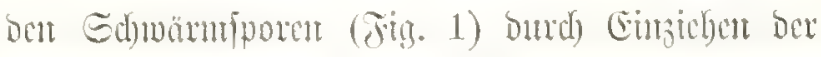

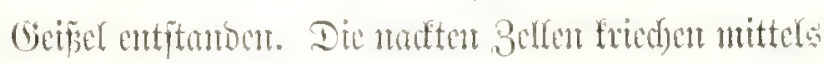

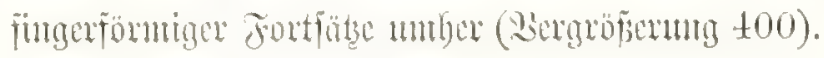


Tig. :). P'lysartum plumbeum (Micheli).

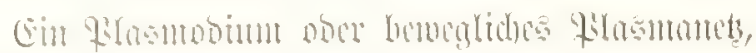

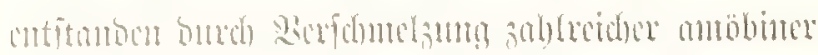

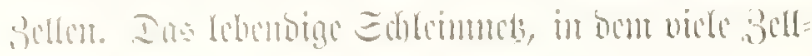

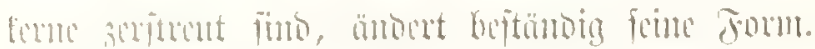

Fing. t. Ballhamia panicea (Rostafinstio).

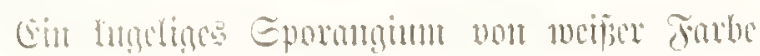

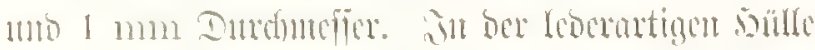
(Peridimm) ift vid fohldenfaurer falf abgelagert,

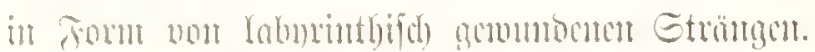

Fin. 5. I)idymium nigripes (Fries).

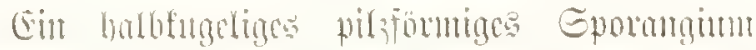

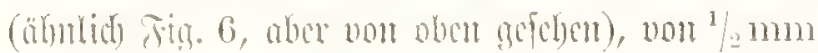

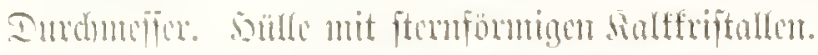

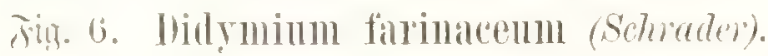

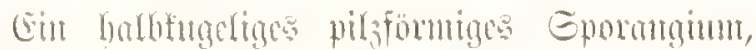

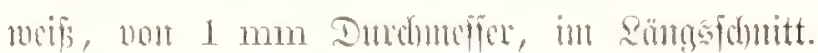

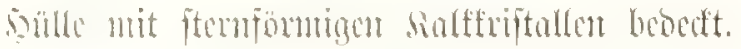

Jin. 7. Lepidoderma tigrinum (Rostufinstii).

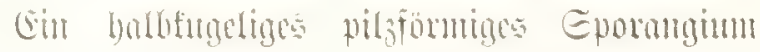

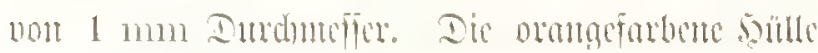
ift mit gramest triftallinifdem sinefichuppes vou am-

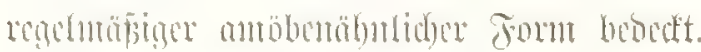

Jitu. 8. Trichia fragilis (Rostafinstit).

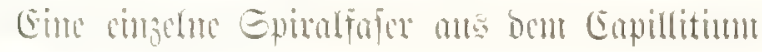
(500mal vergrofiert).

Fing. 9. Areyria serpula (Massee).

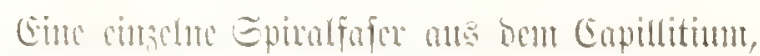
mit Iomat befolit (1200) nul nergröfort).

Ting. 10. Dietrdium cernumm (Nees).

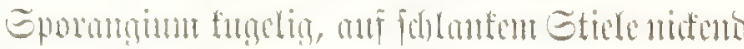

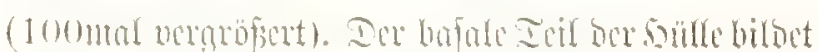

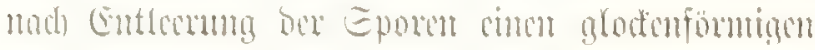

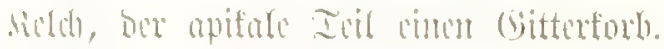

Tign. 11. Cribraria aurantiaca (Sthater).

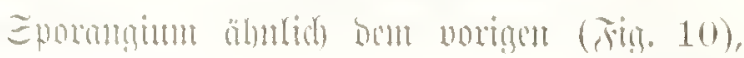

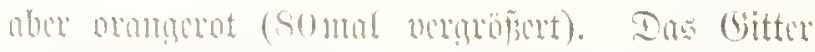

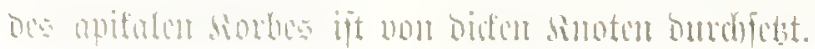

Xig. 12. Cribraria intricata (Schader).

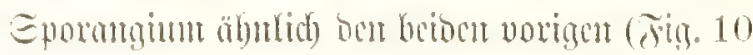
4. 11), ormaturau (200 nut vergröpert). Dis biden, fternförmigen sunten bes apitalent bitterforbes

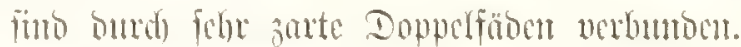

Jin. 13. Cribraria pyriformis (Scharter).

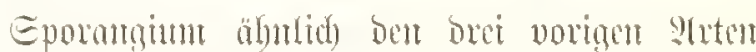
(Jig. 10-12), pumputhoum, binförmig (somat vergrofient). Der Bafalteil ber Gülle (sicld) frach

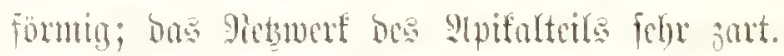

Fig. 14. Trichia rerrucosa (Lister).

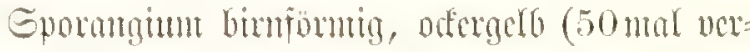
(gropert). Der bajale Ietl ber gefprengten sülle

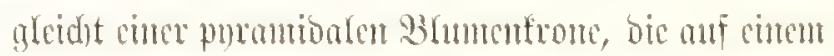
genarbten Etiel anfintst. Dbon tritt bas golbyclbe Capilfitimn mit ber Eporemntafic ats.

Jin. 15. Lreyria cinerea (Persoon).

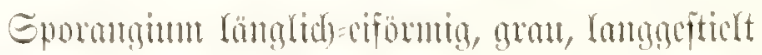

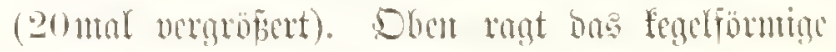
capillitimn aus bem balbfugeligen Sed b) not.

Jing. 16. Stemonitis fusea (Rothi).

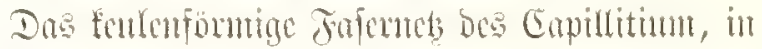

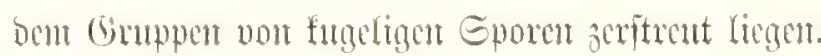
Fig. 17. Physarum didermoides (Rostafinstiv).

Eime Grappe von ciförmigen Eporantgien, bie

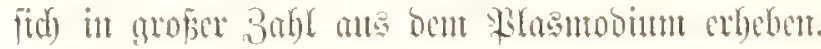

Jig. 18. Lreyria incarmata (Rostafinski).

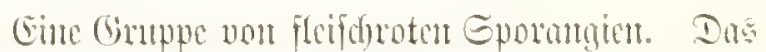
vorbere ijt aciprengt, bas Eapillitum ans ber gloctenförmigen saulle hermesgetreton (200 mal vergräpert).

Jig. 19. Trichia botrytis (Persoon).

Eime Gruppe vort fugctrunoen purpurroter Spo=

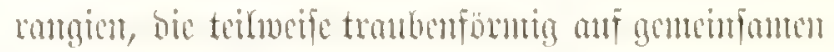
Etiefon anifitient (20mal nergrópert).

sin. 20. Areyria admata (Rostafinski).

Eme Gruppe von 3ylimbrifuen roten Eporm-

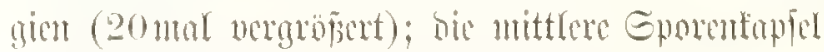

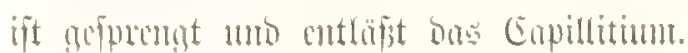




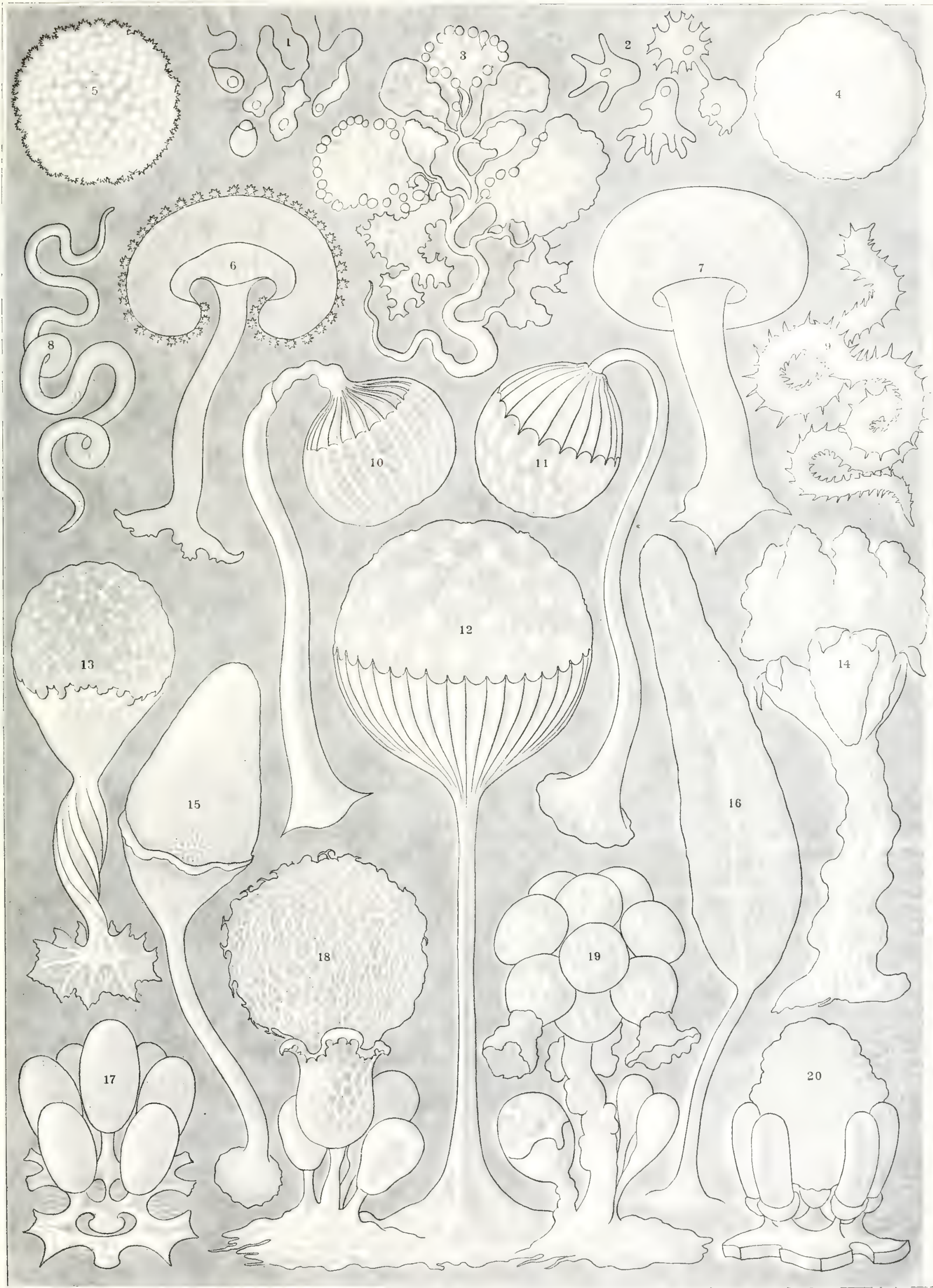




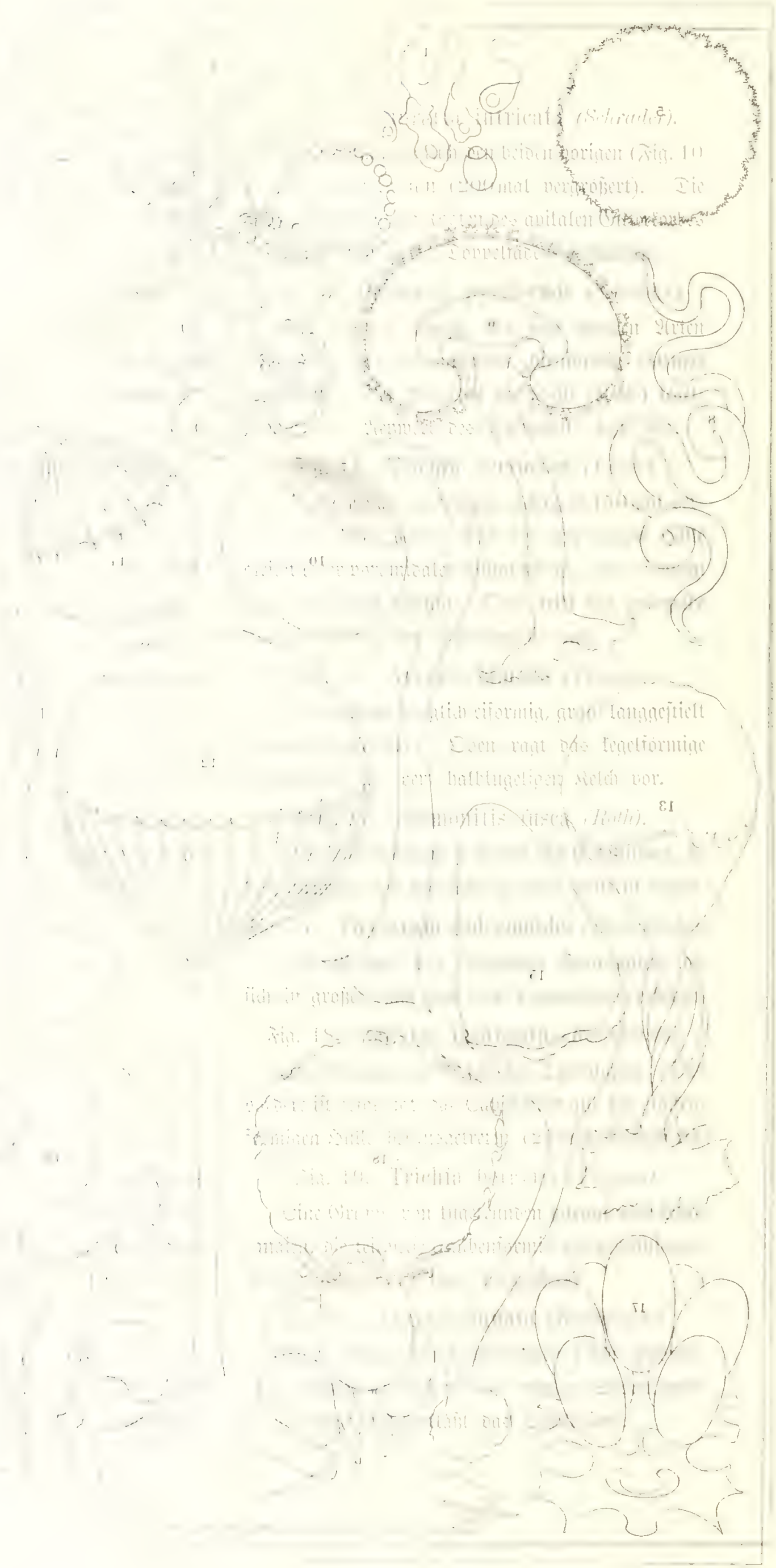




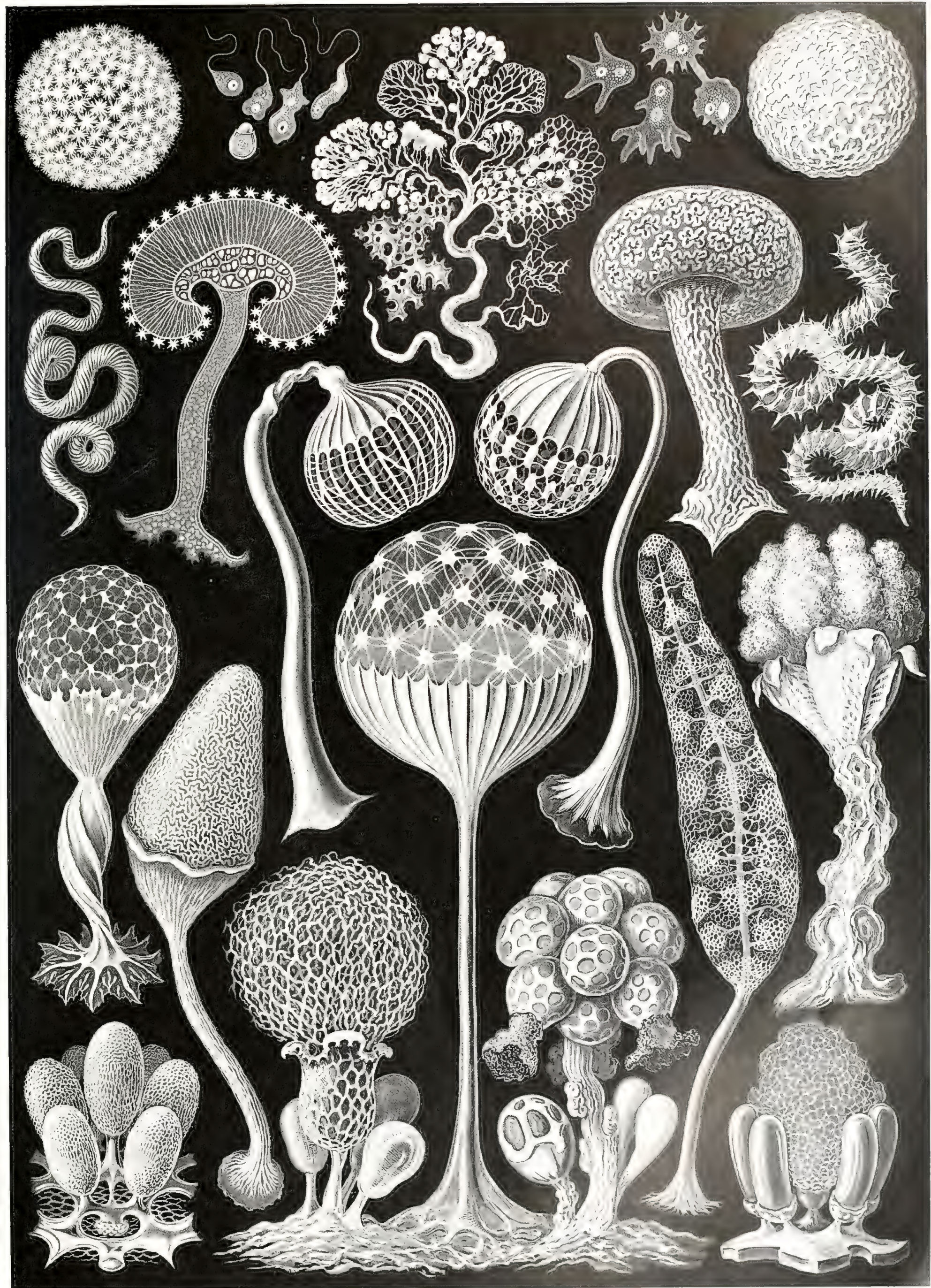





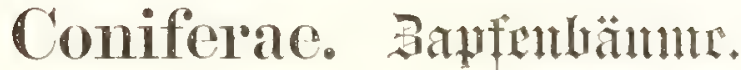

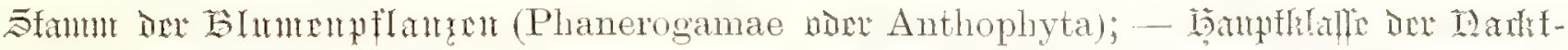

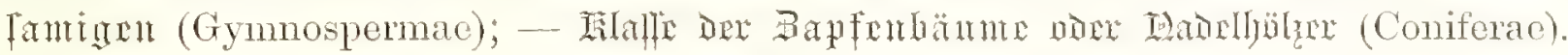

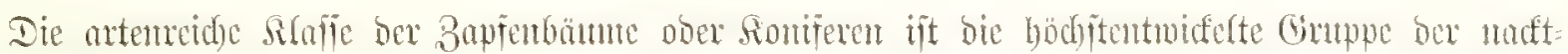

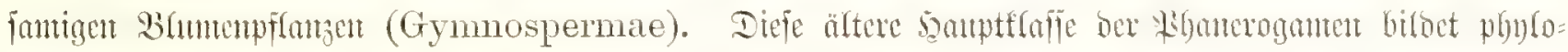

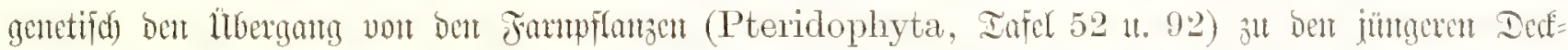

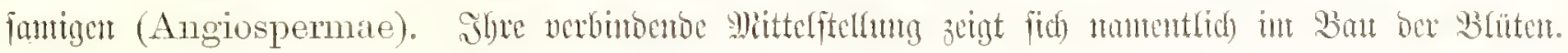

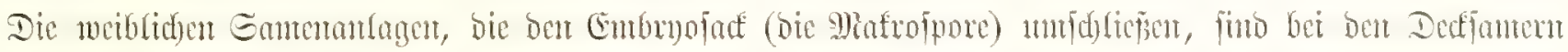

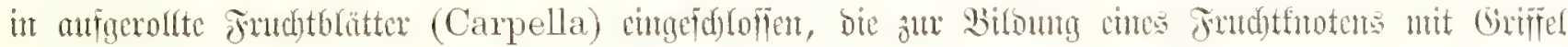

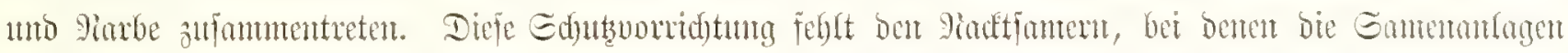

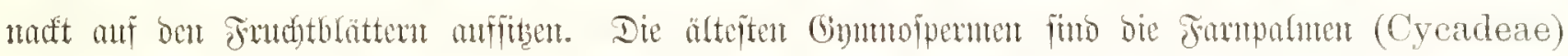

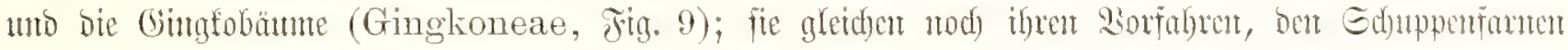

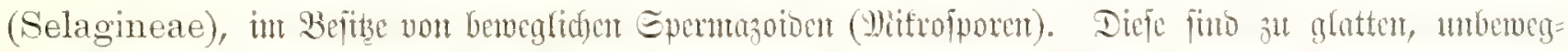

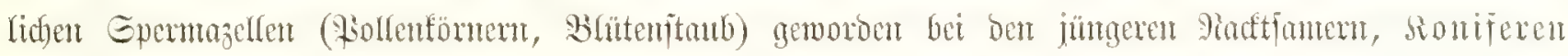

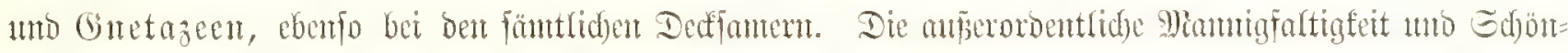

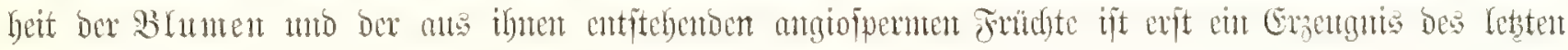

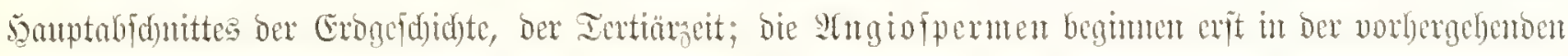

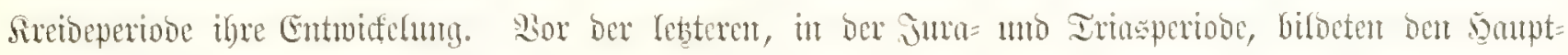

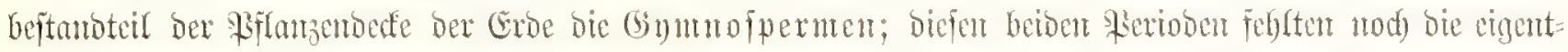

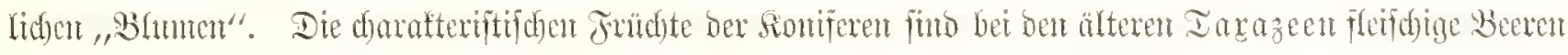

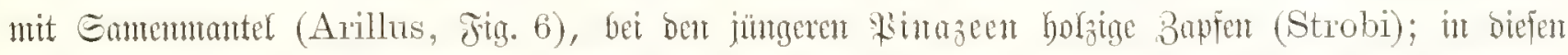

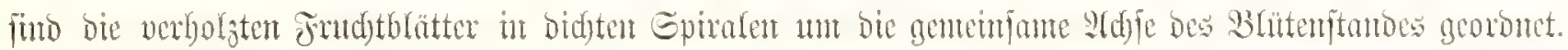

Jig. 1. Arancaria brasiliana $($ Lemb).

Familix: Pinoideae. Sulfanilie: Arancarina.

Eir weiblicher Bapfen in halber natiurlicher Gröpre. (Etanm bis $50 \mathrm{~m}$ hod). Braffitur.)

\section{Jin. 2. Picea excelsal (Link).}

Aamilix: Pinoideae. Subfamilix: Abietinae.

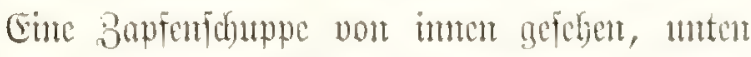

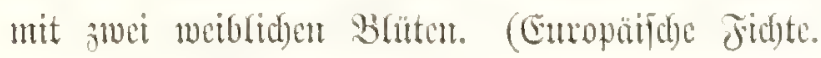
Stanu big $50 \mathrm{~m}$ bodj.)
Jig. 3. Abies bracteata (Hooker).

Himnilie: Pinoidere. Subfantilin: Abietinae.

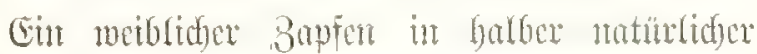

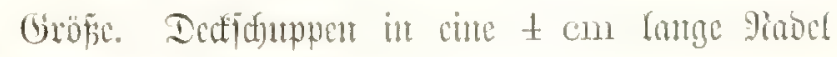
mเogezogent. (Sinliformicut.)

Jig. t. Chamaecyparis obtusa (Siebold). Ftannilis: Pinoideae. Subfimnilin: Cupressinat.

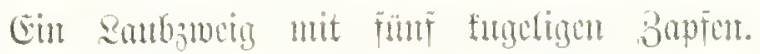

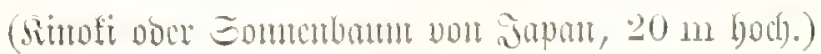


Fin. 5. Thujopsis dolabratal (siebolit).

tamilin: Pinnileate. Subfanilis: I'hnjonsilae.

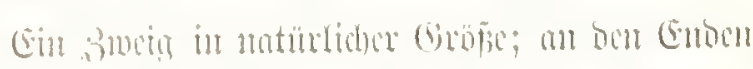
on

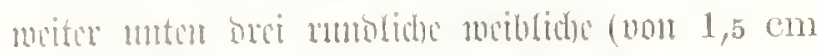

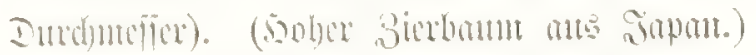

Titg. 6. Juniperus communis (Linni). Familis: Pinoideate. Sullifamilis: Cupressinae.

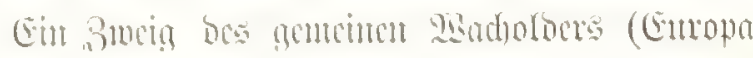

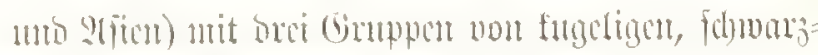
blan berciften Beren.

Tịn. 7. Libocedrus decurrens (Torr).

łamilix: Pinoidea. Subfunilis: 'Thumpsitae.

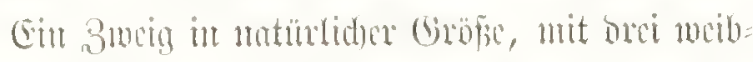

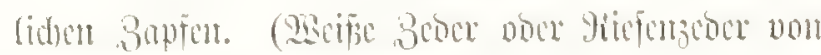
sialiformicu, bober watmm.)

Fitg. s. Phyllochadus rhomboilalis (Richerd).

Tamilin: Taxoideae, Subfantitix: Phyllodidinae.

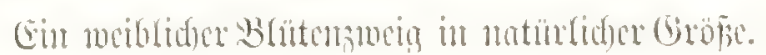
Sicfe (Gattumy seidunct fict) burd) bie abogeplatteten

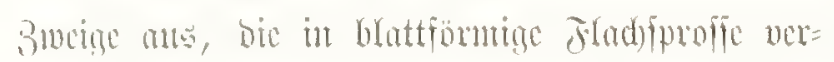

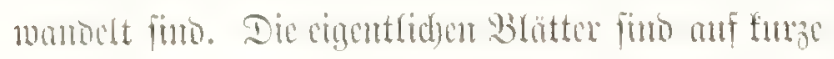

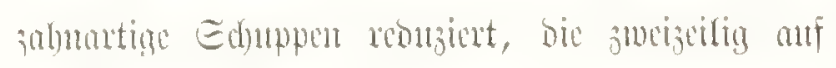
beren sumten fiticu. (Iasmantia.)

Tig. 9. Ginkgo biloba (Limni).

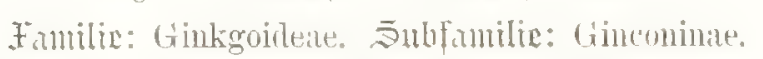

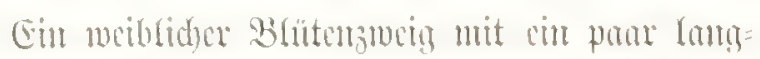

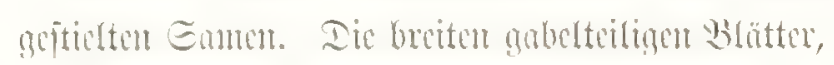
mit gabeligs=fäd)erformiger Dicroatur, gleid)en ge=

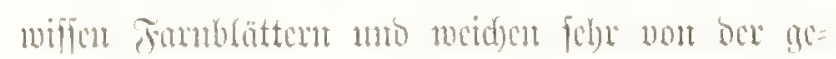

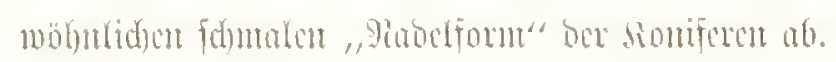

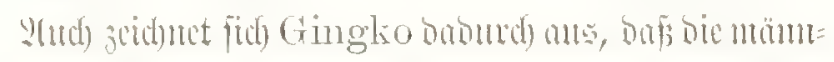

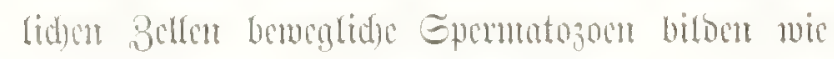

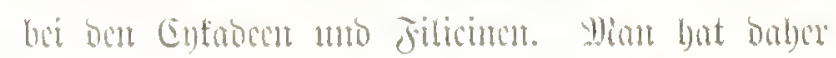

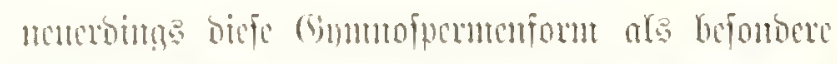
Dromung (Gingkoacene) von ben codten Sioniferen

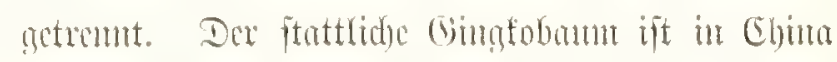

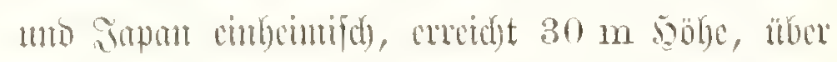

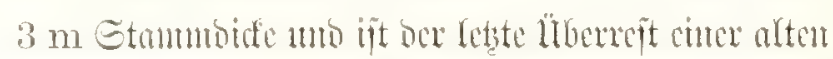

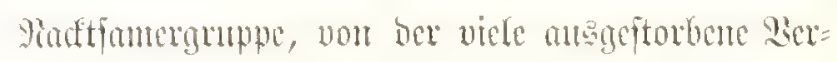

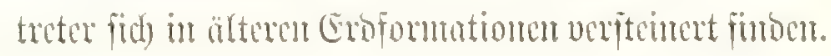

Jig. 10. Sequoya gigantea (Torr).

Familtr: Pinoidene. Sulbamilie: Thadinae.

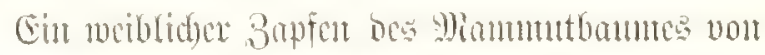

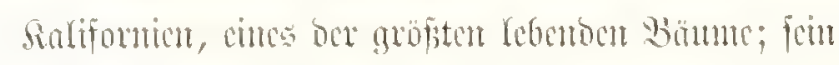

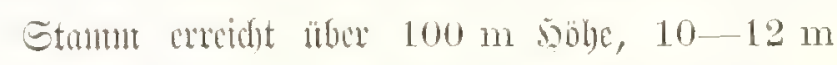

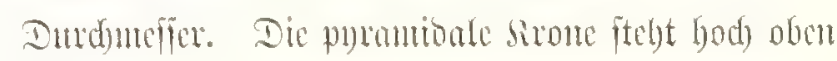
ant Gtmun.

Jig. 11. Cupressus sempervirens (Limé).

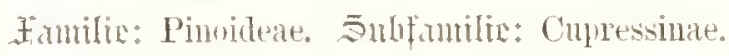

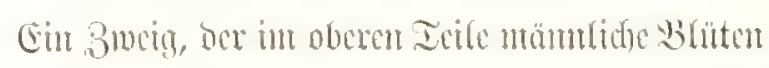
trägt, int unteren Istle zuci weiblid)e 3 apfen $(2-3 \mathrm{~cm}$ lann, mit 8-10 polngonalen Edifocm grobetit). Die puramionfe 3upreflic, feit jubrtanfenton cin

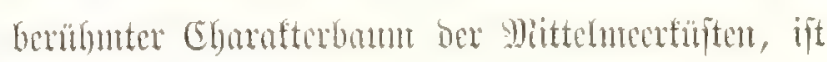

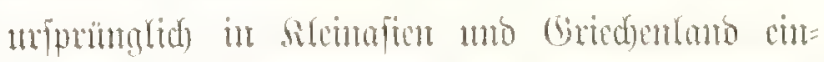

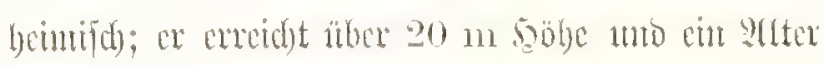

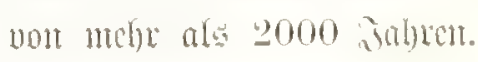

T̃ig. 12. Taxodium distichum (Richard).

Fantir: Pindidere. Sublamilin: Taxodinat.

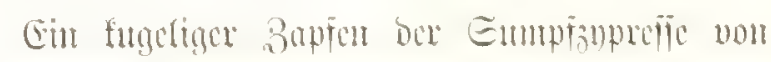

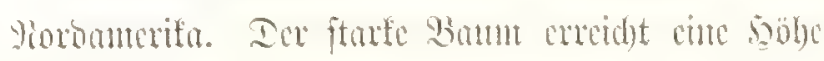
von uth) als $30 \mathrm{~mm}$, cincu Etmunumiang von $12 \mathrm{~m}$

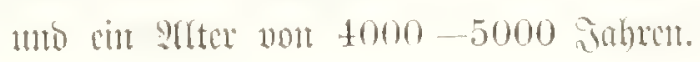

Jig. 13. Pints serotina (Lime).

Familie: Pinoideae. Sulbfamilir: Abietimae.

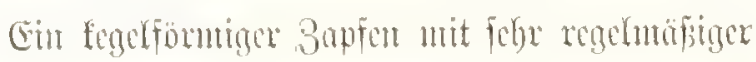
Echuppenoromm (Etrobilation). Fionomerifa.) 

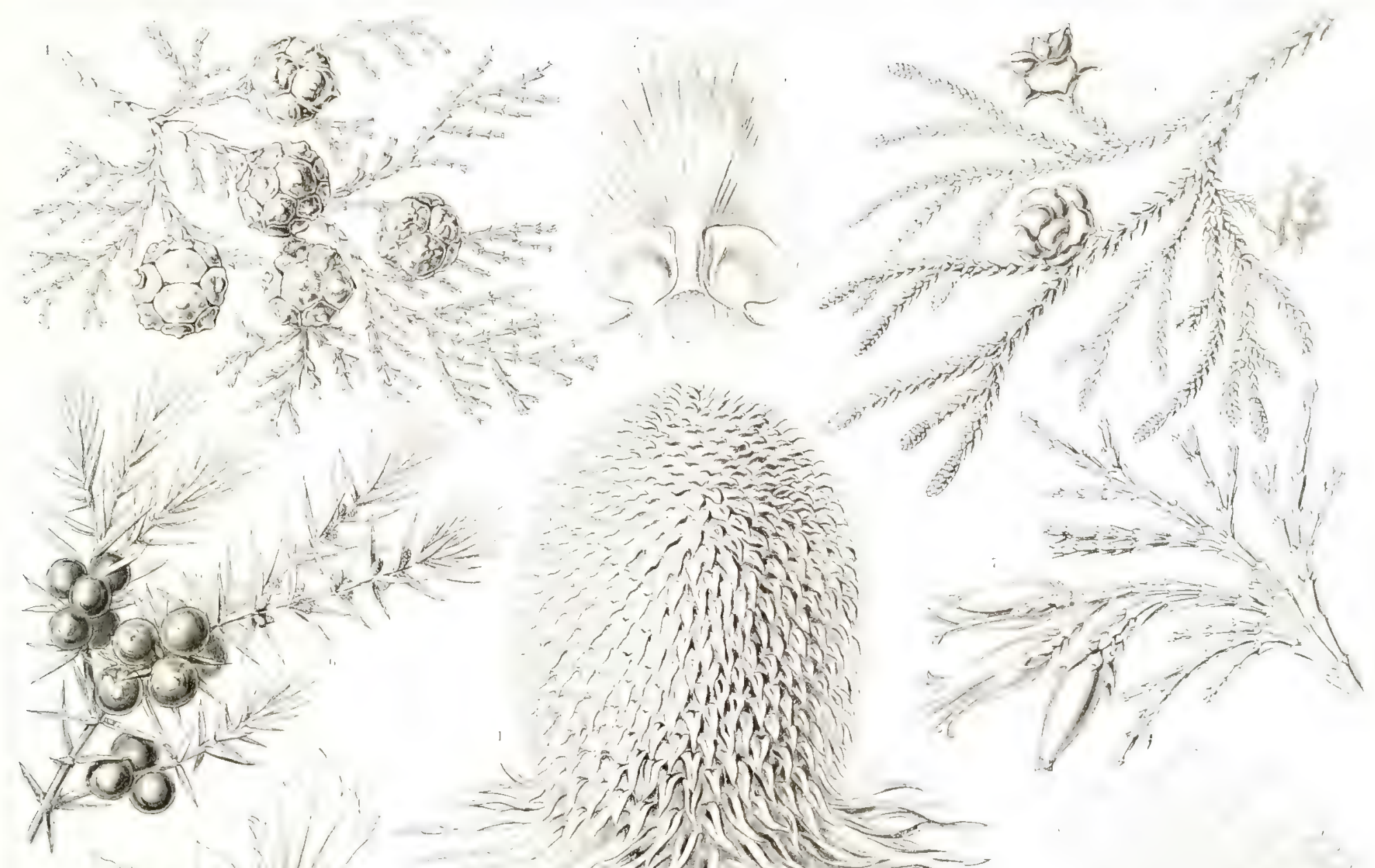

f fivint
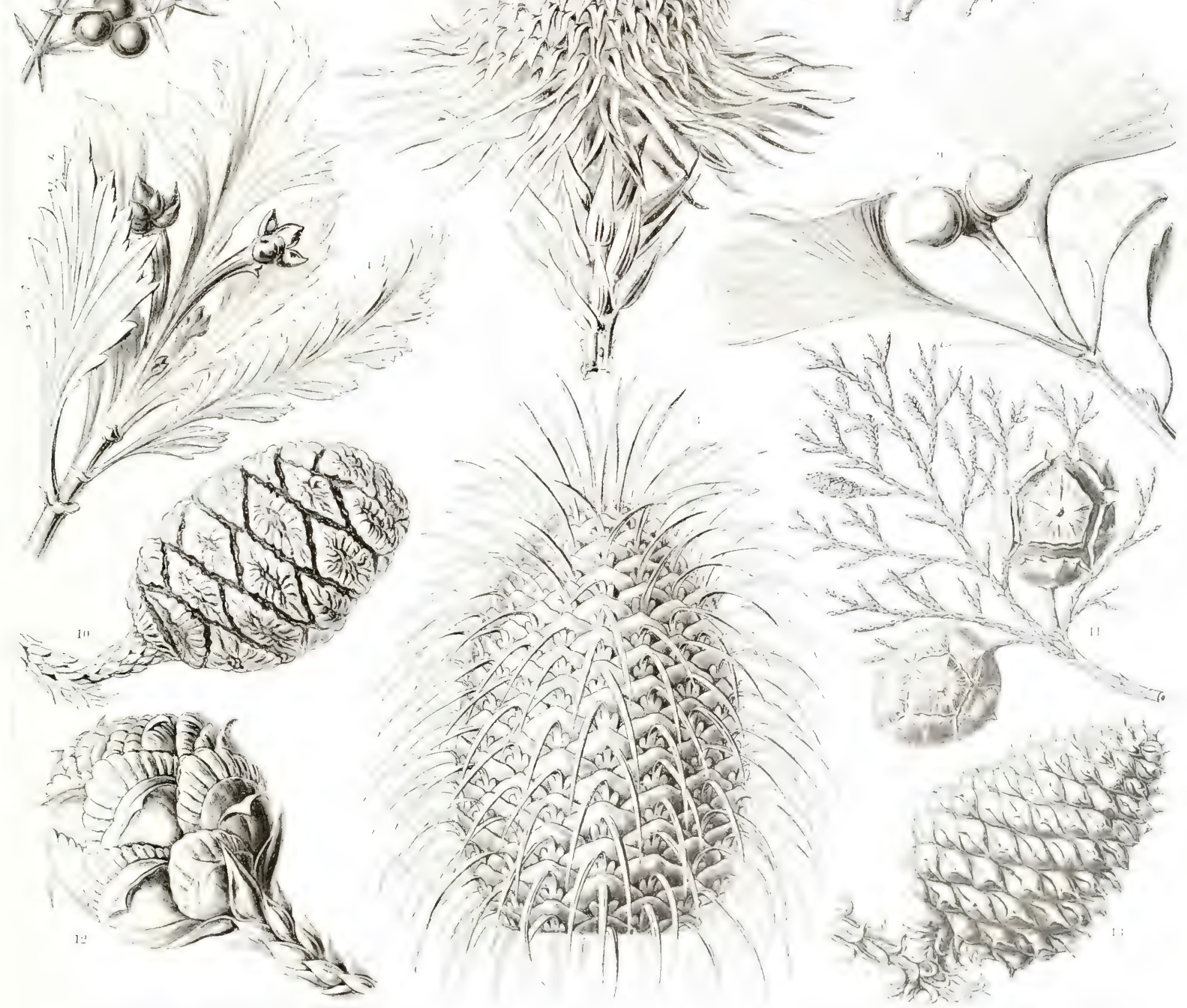

Coniferae. - Bupfontiöumt. 



\section{Amphoridea. Hum trume.}

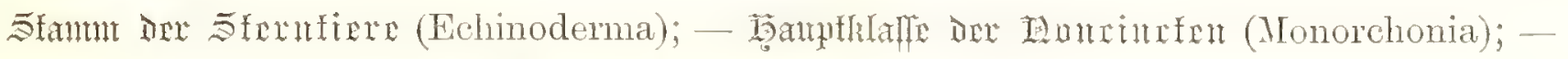

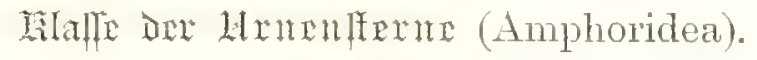

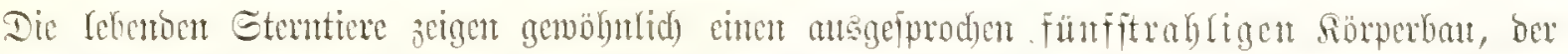

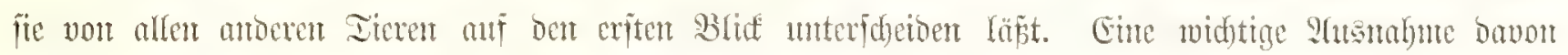

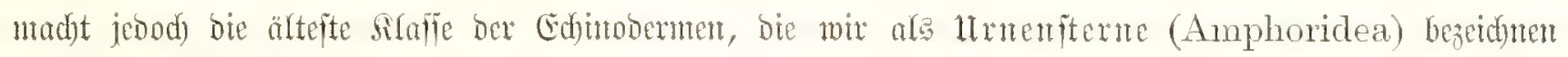

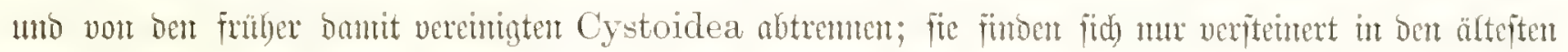

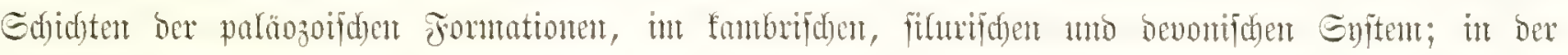

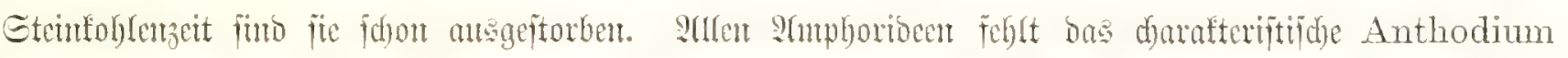

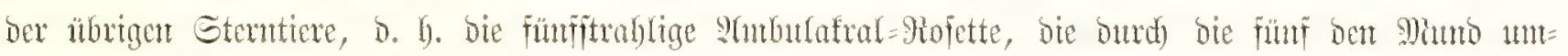

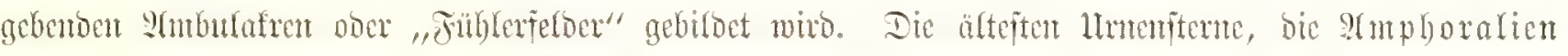

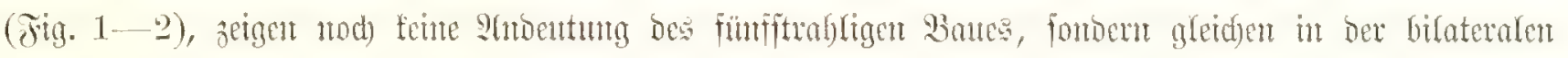

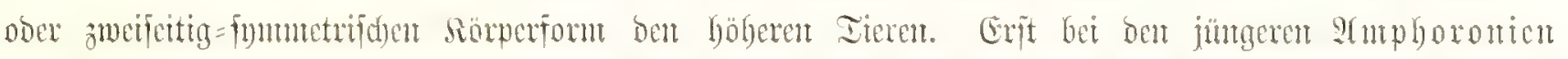

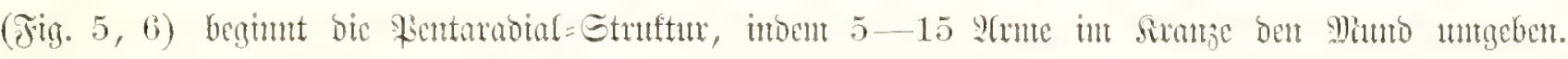

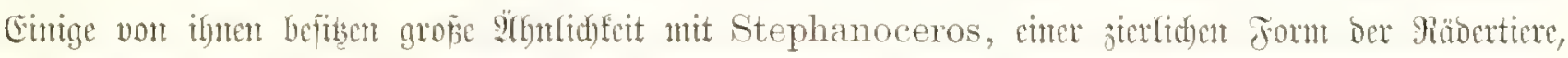

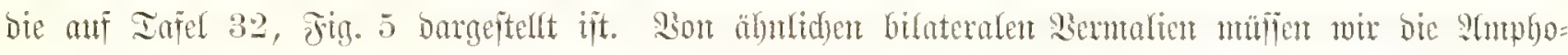

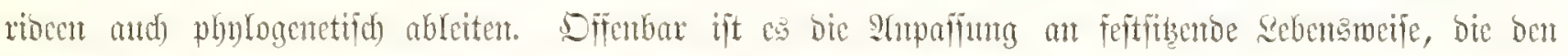

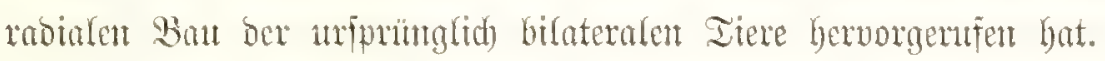

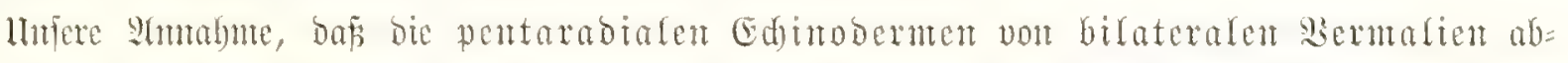

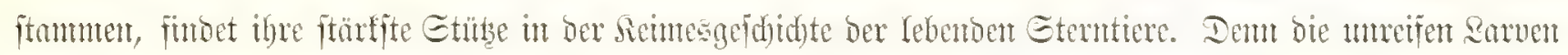
ober Ingendformen berfelben, bie wir alfgemein SGtrofarven (ober Eehinopaedia) nemen, befitzen nod)

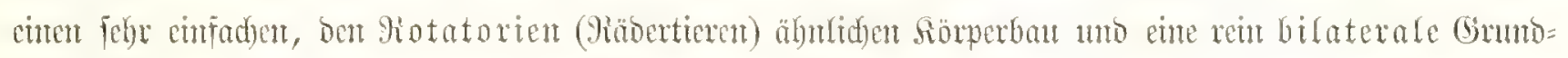
form; fo bie Auricularia-Eurven ber Ifymoben (Jig. 12; Iafel 50, Fitg. 3, t); bie Plutellus-

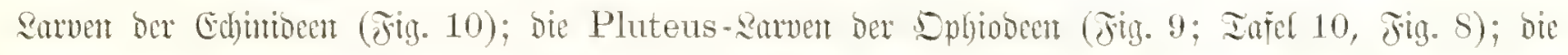

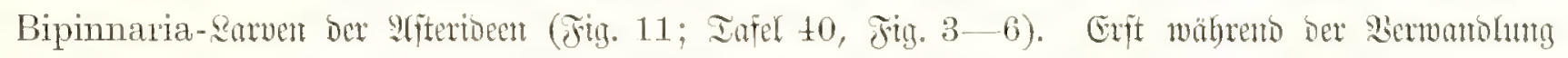
entfiteht ans ber bifateralent Astrolarva das penturabiale gefdededtereife Gterntier, Astrozoon.

jig. 1. Placoeystis crustacea (Hueckel). Dexmnn: Amphoralia. Hamilie: Anomocystida.

Die Ginttung Placocystis, verfteinert im Llttex= fifur von Borommerifa gejumben, gehört nebijt Dem Folgenden Gemi Pleurocystis (Jig. 2) zu jenen ültejten Gtentieren, beren Börper nod) feine Epur von fiumfitrahligen Ban jetht, vichnefre fo vollfom= men bifateral= funnuetrifd) gebant ijt wie bet ben

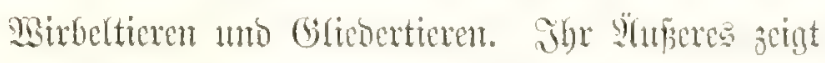

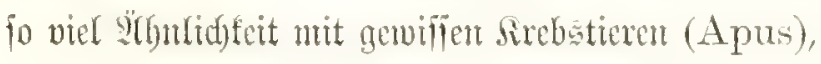

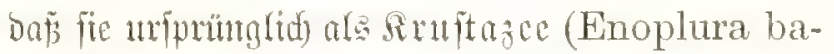
lanoides) befdriefen wutroc. Der abgeplattete, oyal=nterecfige Siorper ift fowohl auf ber forwerent

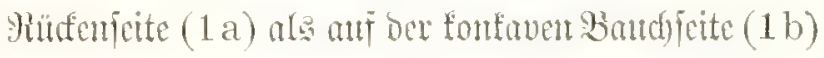

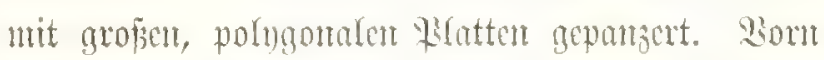
an Stimmoe liegt in ber ylitte ber \$imb, zwifden

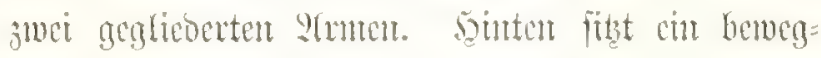
lidfer gegliederter Gtiel, ber vielleidft als Edjwants bei ber freich Drtubenomutg biente ooer als Stid bei ber Stutheftumg aut Micereaboocu. 
Tin. 2. Plenroeystis filitexta (Billinys).

L) rommut Amplonalia; Fantir: Anomocystida.

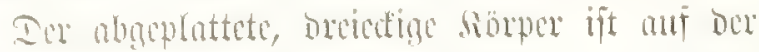

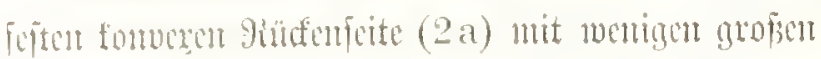

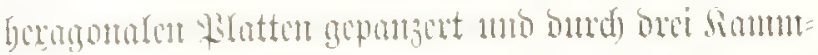

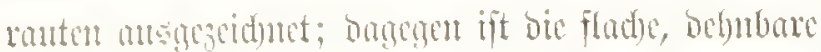

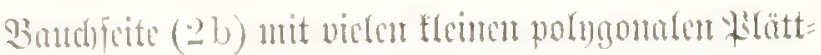

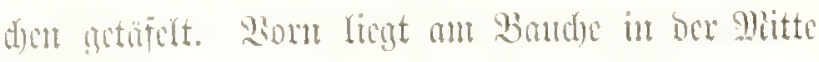

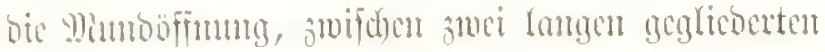

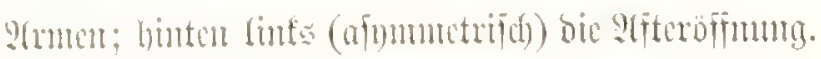

Fing. 3. Oroeystis Ilelmhackeri (Barmale).

Itrum Amphoronia; Familie: Aristocystida.

Der eifännige, 3-4 em lantge Siörper ift mit

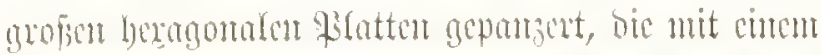

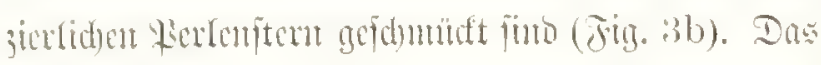
Gintere Enoe ift jugejpist; Das vorbere enoe trägt

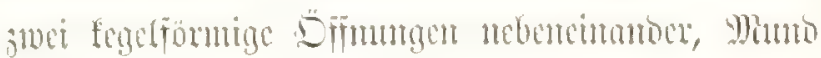

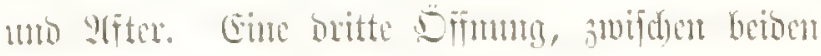

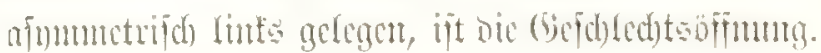

Fig. 4. Dentoeystis modesta (Barande).

Drommur: Amphoronia; Familiv: Aristocystida.

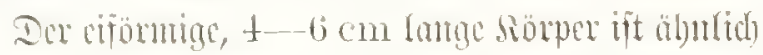

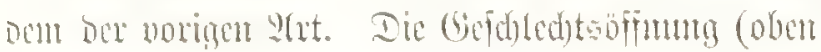

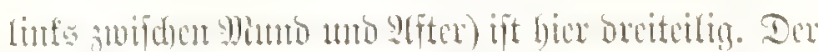
Hinner befteht ans viclen llemen polngonaten Infeh.

Fin. 5. Citroeystis citrus (Haeckel)

(= Echinosphaera citrus, Klocden).

D) rommun: Amphoronia; Fantilie: Palaeocystida.

Der sioner ift sitrontentönmia, non $2-3 \mathrm{~cm}$

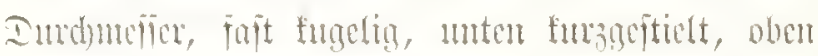

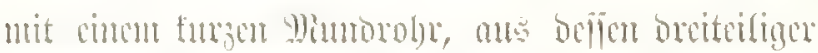

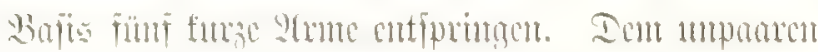

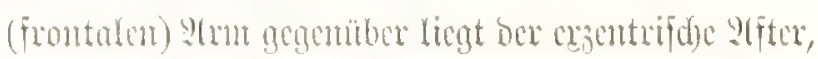

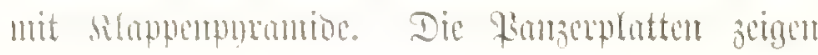
chmen berugnomalen Stem (Fign. 5b, 5c).

Titg. 6. Acanthoeystis lriareus (Burande).

Wromunt: Amphomia; Fomilis: Palatemeystilit.

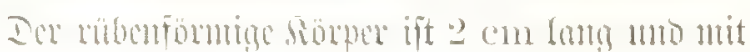

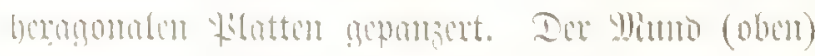

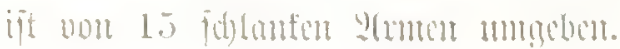

Fin. 7. Iristocystis bohemica (Barrande).

L) romun: Amphoronia; Familie: Aristocysticta.

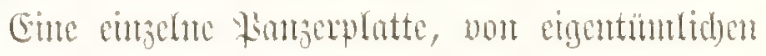

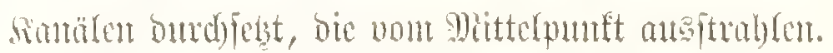

Fig. S. Ophiothrix fragilis (J. Meitler).

Lilaffe: Ophiodea; Dromun: Ophioctonia.

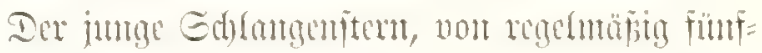

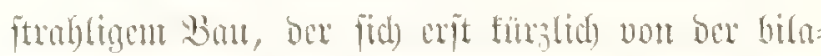

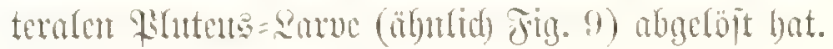
(igl. Tafel 10, Jij. 1.)

\section{sig. 9-12. Parnen vou fisentordjonicu.}

Fig. 9. Plutens bimaculatus (J. Mluiller). sarne des Gdamomitems Ophina filiformis. Filalli: Ophioder. (Nigl. Injel 10.)

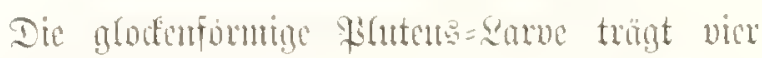

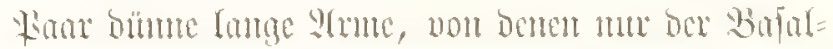

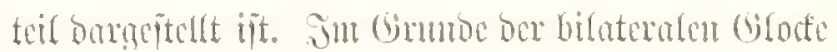

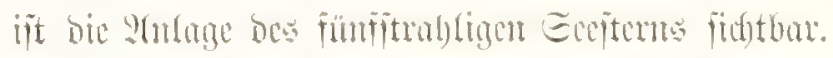
Fing. 10. Plutellus aequituberenlatus (J. 1hïllev). Surve von Echinocidaris aequitubereulata.

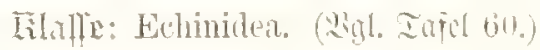

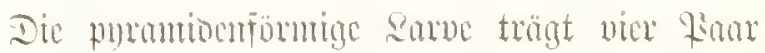

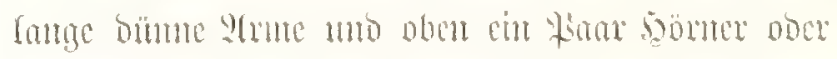

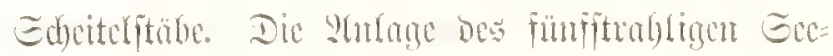
iged ift nod) nidst vorbmoen.

Fig. 11. Bipinnaria asterigera $(J$. viiller). Znue bes Eefitern Luidia. Sarsi.

Lilalle: Asteridea. (Nigl. Injol 40.)

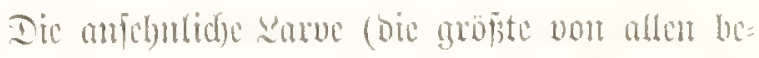

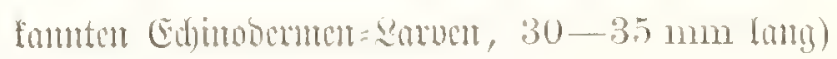

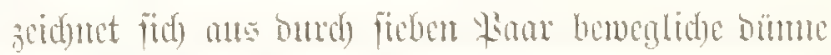

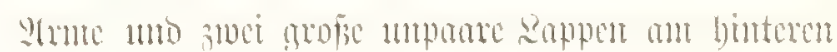

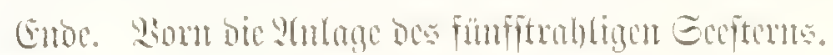

Jig. 12. Amricularial mudibranchiata (c/mun). sarue cince nototburic (Elasipoda).

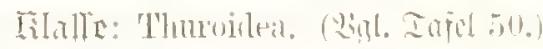

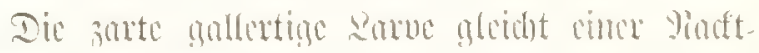

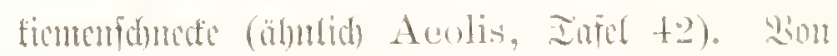

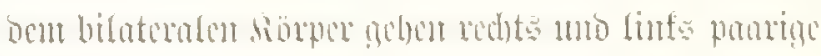

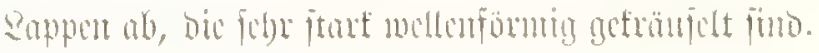



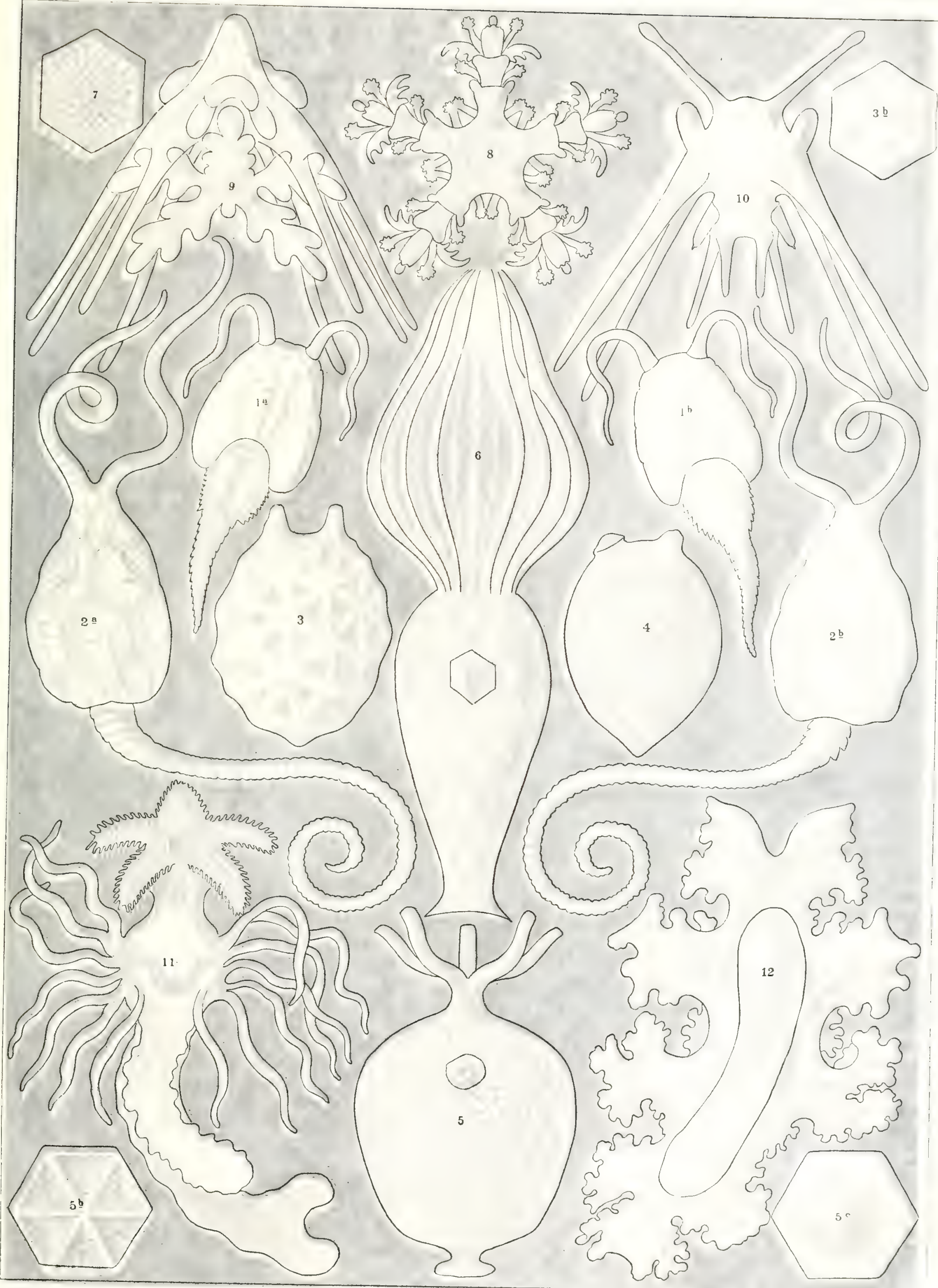


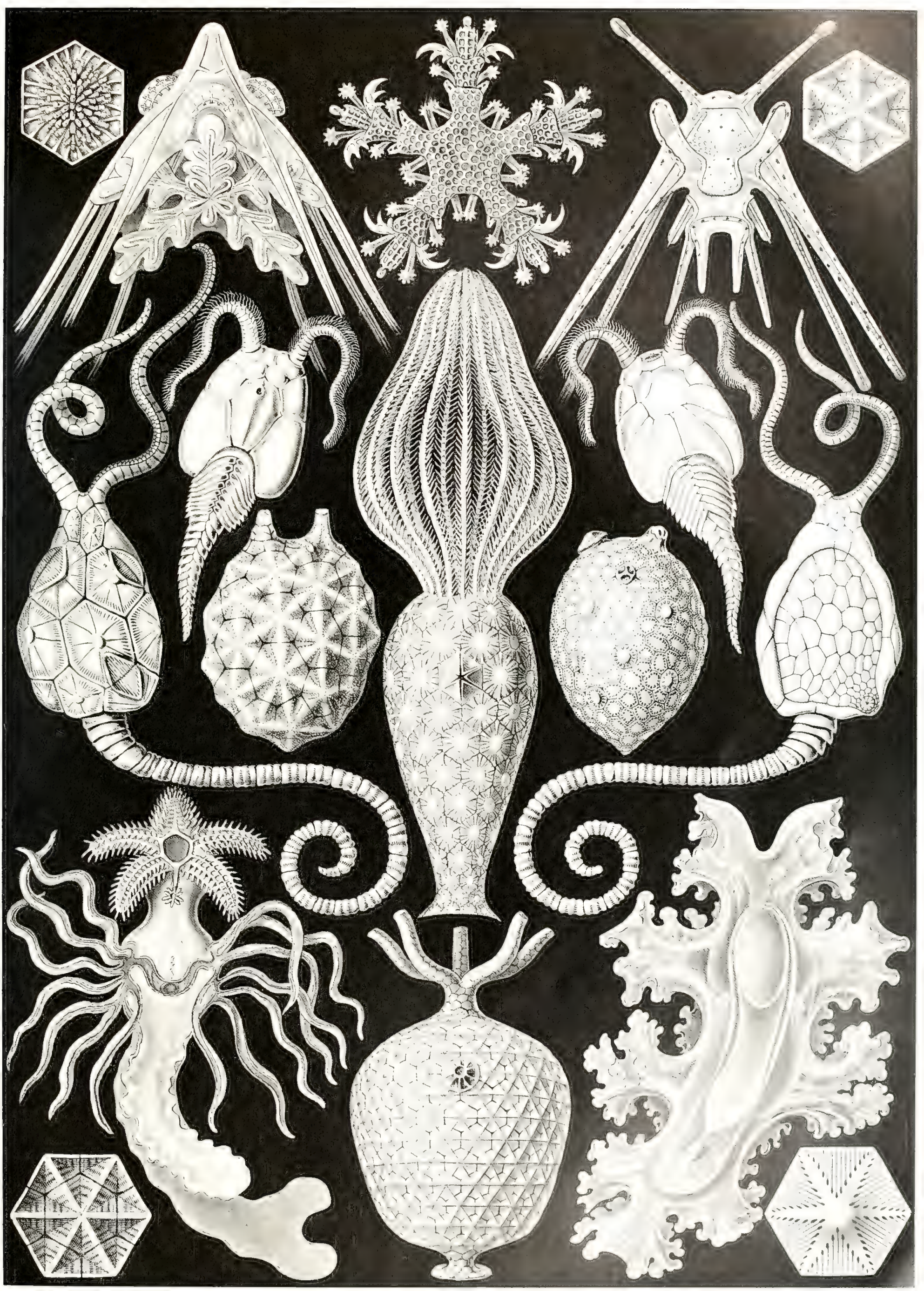

Amphoridea. Ilrumeliterite 



\section{Chaetopoda. Smiftemutimmer.}

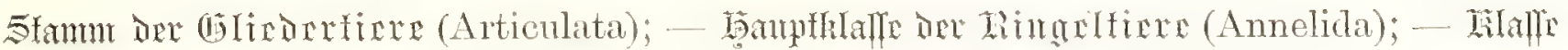

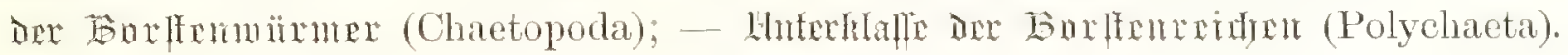

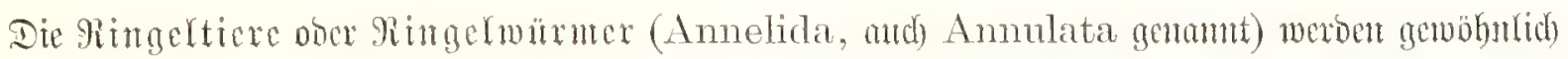

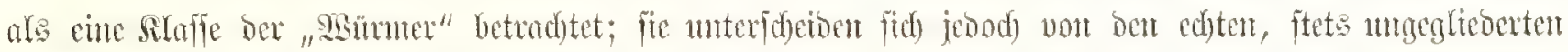

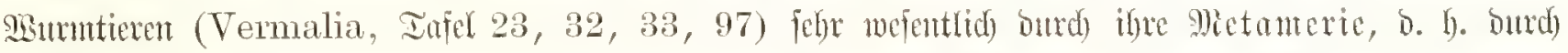

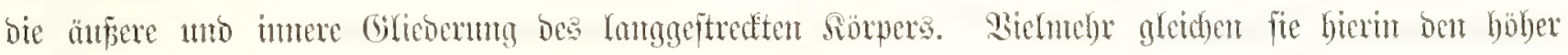

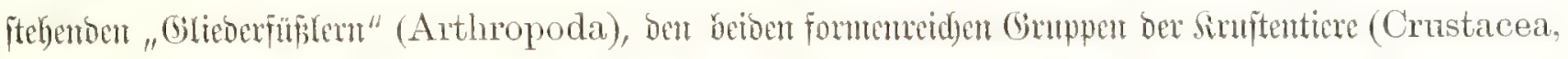

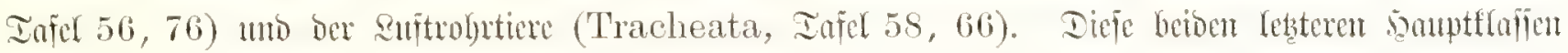

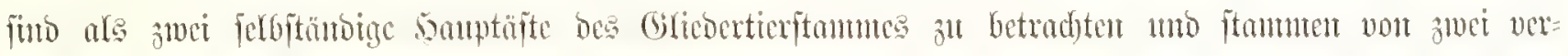

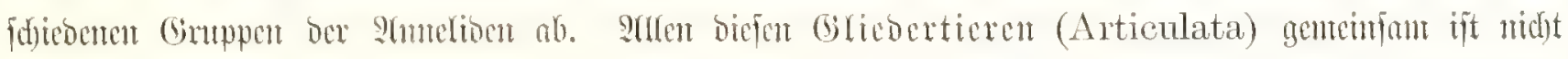

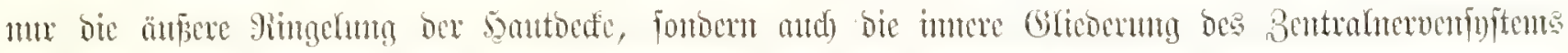

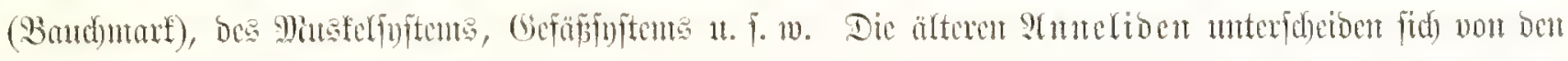

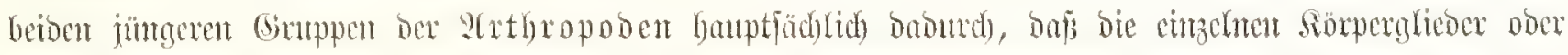
Finge (Segmenta, Somita, Metamera) bei ben crifteren meiftens fehr gledd)artia gebifoet fund (ho=

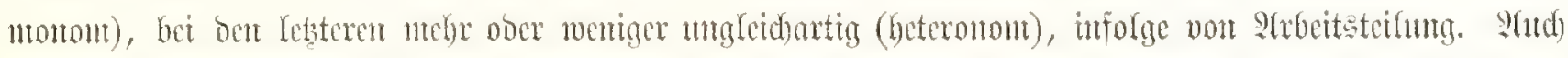

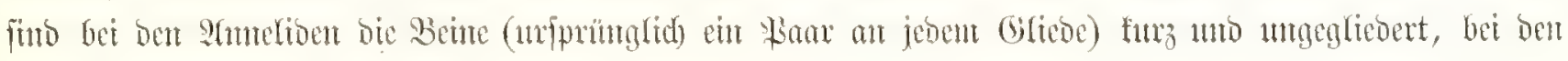
meiftent 9 Irthropobent lang uno geglicoert.

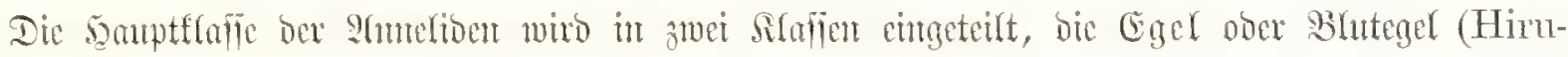

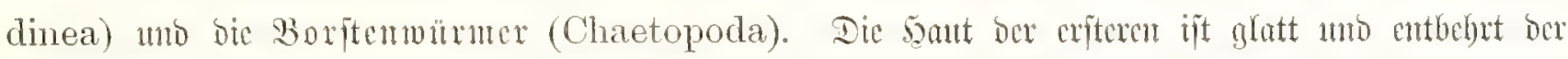

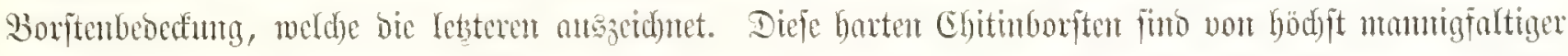

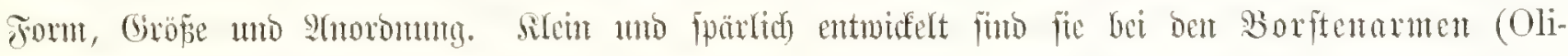
gochaeta), zu benen unter anberen ber Megenmun (Lumbriens) gefourt. Dagegen füb bie Borften

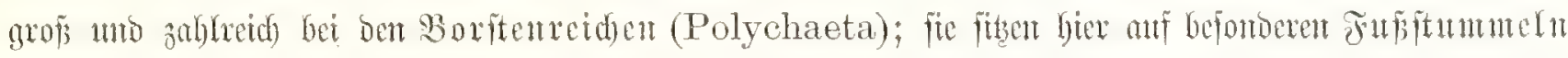

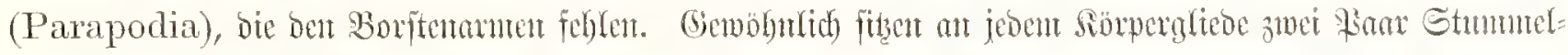

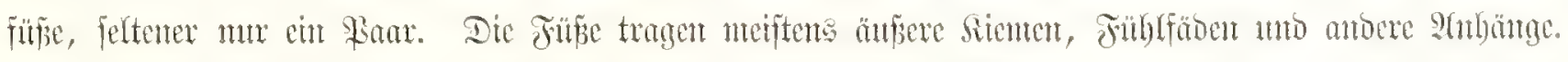

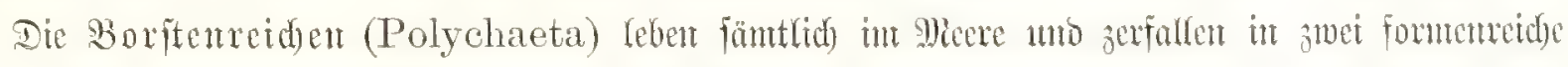

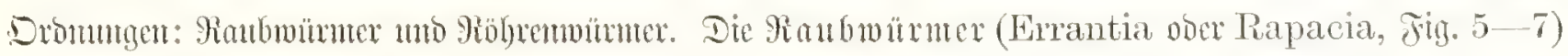

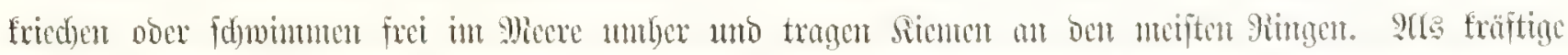

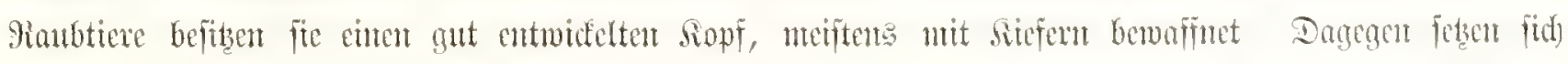

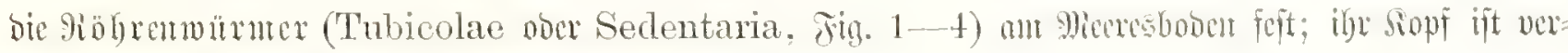
fümunert anto trägt grofic sicmen; Siefer feglen. 
Fig. 1. Sabella spectabilis (Gumbe).

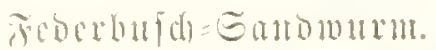

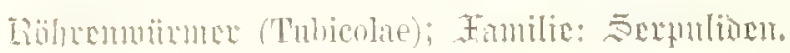

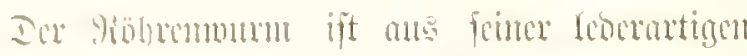

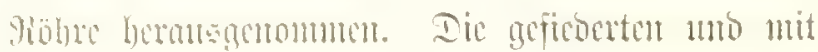

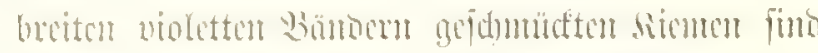

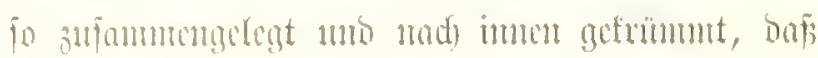

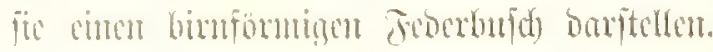

\section{Fig. 2. Serpula contortuplicata (Limé).}

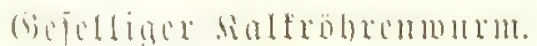

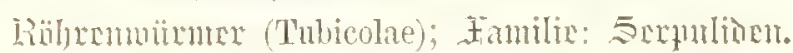

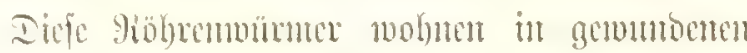
Sulfroberen, bic anf bent Miccrešboben in grofier Babl

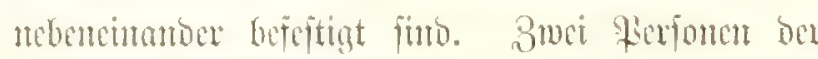

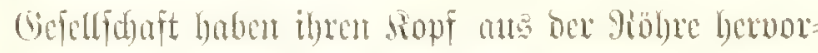

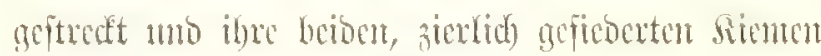
entfaltet. Bwifan beiben Sientent tritt anf einem fangen uno bünmen, fleifd)igen Etid cin trid)tex: Föminger Iutel bervor, beffar borntige Entoplatte jed)

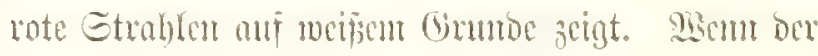

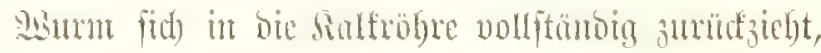

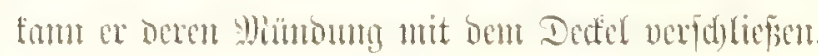

Titg. 3. Spirographis Spallanzanii (Tivani). (5emunomer Sdranbemwurm.

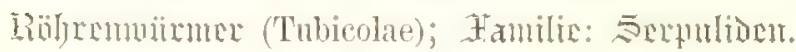

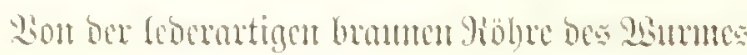

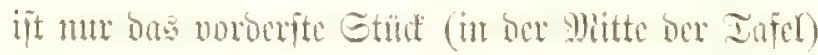

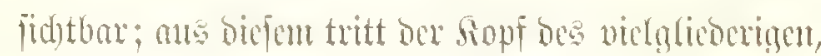

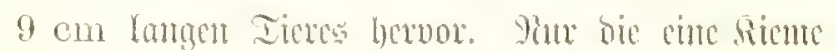
(balo bie redste, bald bie linfe) ift cutsuctelt, bie

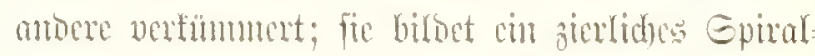

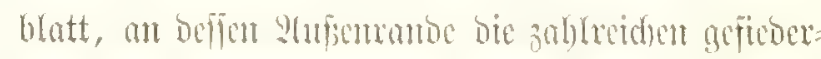

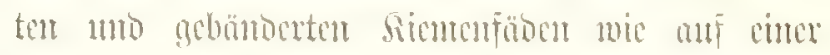

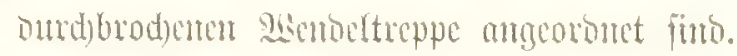

\section{Jig. t. Terebella emmalina (Quetrefages)}

Bantuturigar Fublermurm.

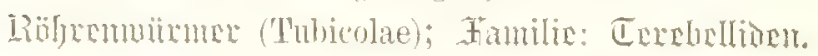

Der Lisum ift me fomer Gambrobre bermus:

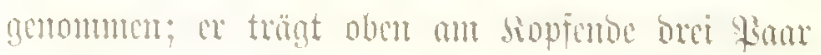

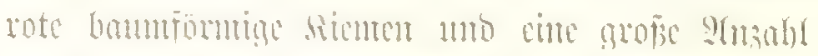

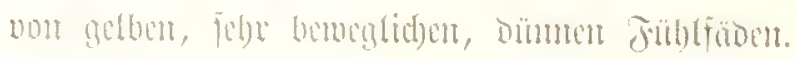

Fint. 5. Emnice magnifiea (Quatrefages).

Frübtiger Gdyangemmurm.

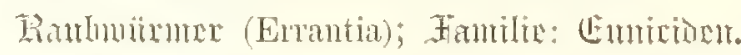

Der febre lange umo ftarfe Sism hat cinen

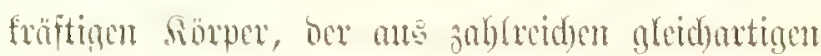

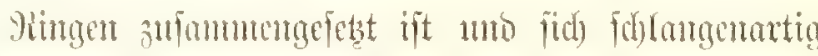
wimbet. Seber Gintg träght cin paar Fintor uno

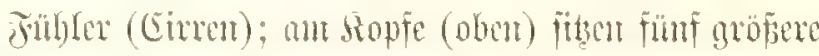

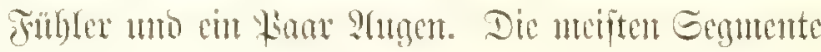
(mur bie 8-10 voroerften auegenommen) tragen cut

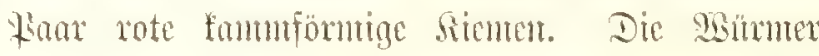

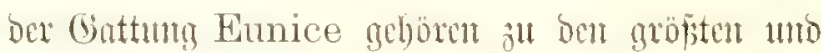

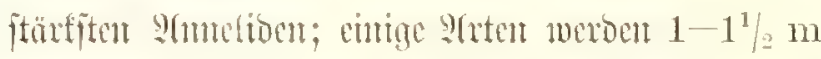
lang uno 2-3 cm breit; fie finto ferbr lebhaft, präd)tig gerärbt und greifen je(bit Fifdue und anoere gröpere Eretion an.

\section{Titg. 6. Hermione hystricella (Quatrefages).}

Stadelfducin= Sd) ирнспиит.

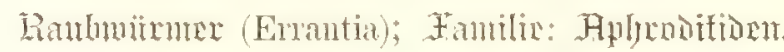

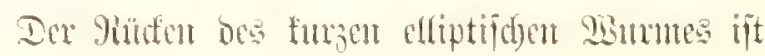
mit Greiten violetten Eduppen gepansert, bie fid Dad)ziegelartig beifen. Die Eegntente, bie je cin

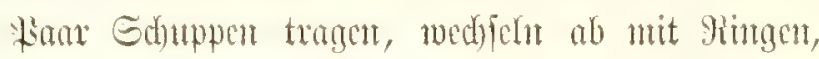

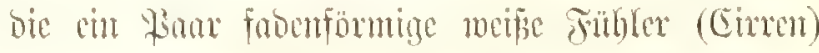

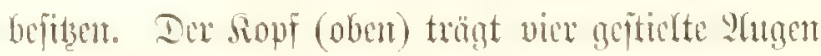

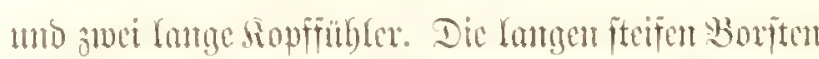

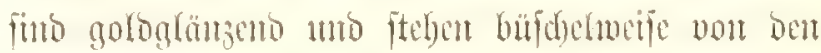
Ed)ıреси ab.

\section{Jig. 7. Chloeira englochis (Ehters).}

\section{Sciombariger Sicutmmun.}

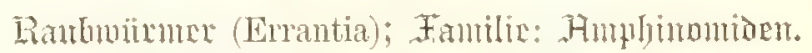

Dor geormusene Sirmenumu, in matürlicher (Gröpe abgebiloet (12 $\mathrm{cm}$ lang 1 tur $2,5 \mathrm{~cm}$ breit), trügt an beu Geiten des geibes, ber ans 36 bis 40 Genuenten beftelgt, lange Bünod uon meifien

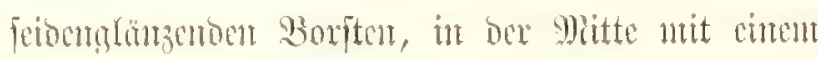

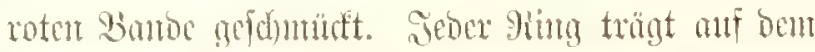

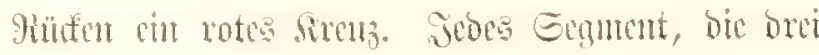

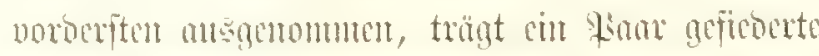
sitemen, beren joon und Ginten geridgtet füto. 

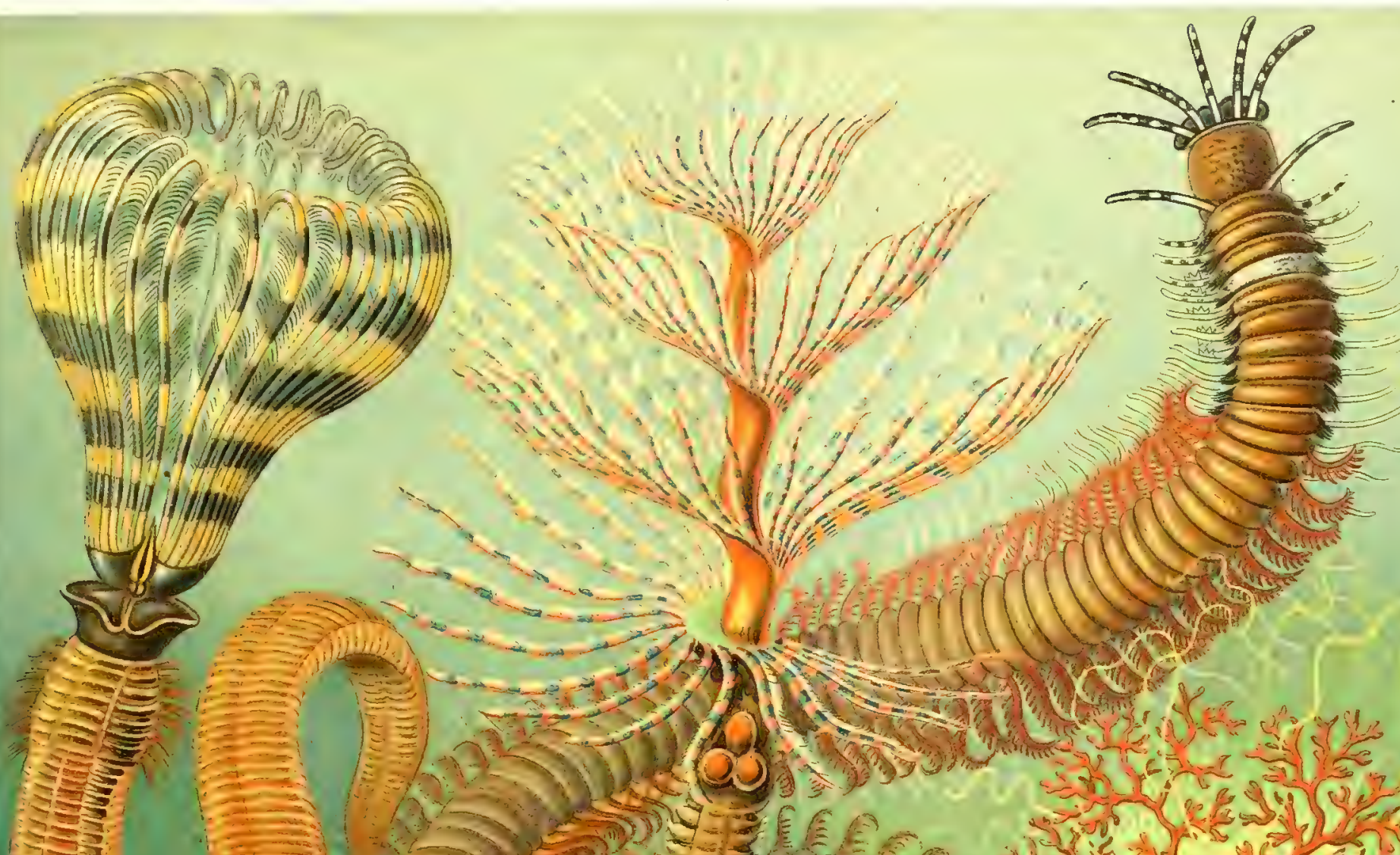
(1) 4 (1) $($ (c)

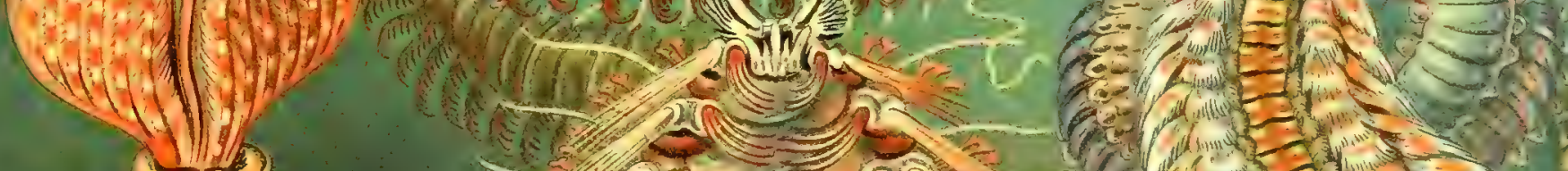

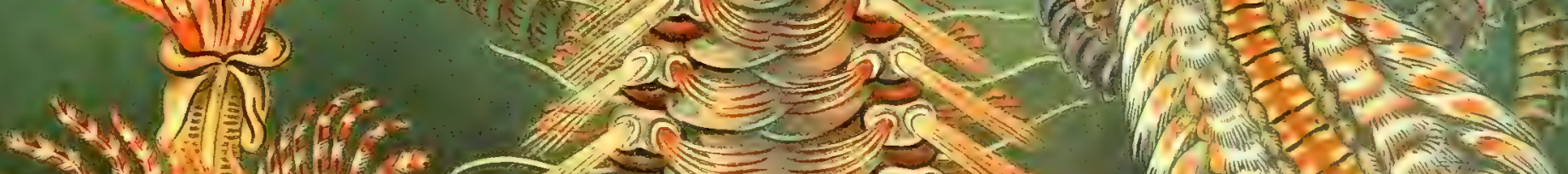

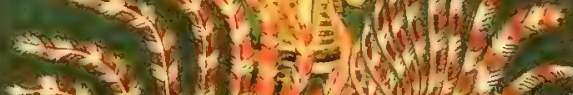
$+\infty$ y $111 \%$ m.t. - jencly

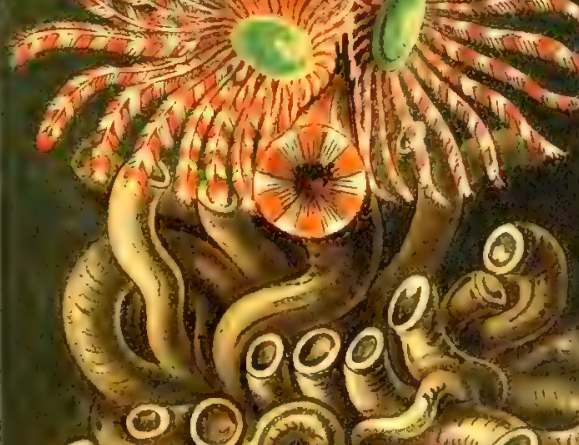
$0000-2$

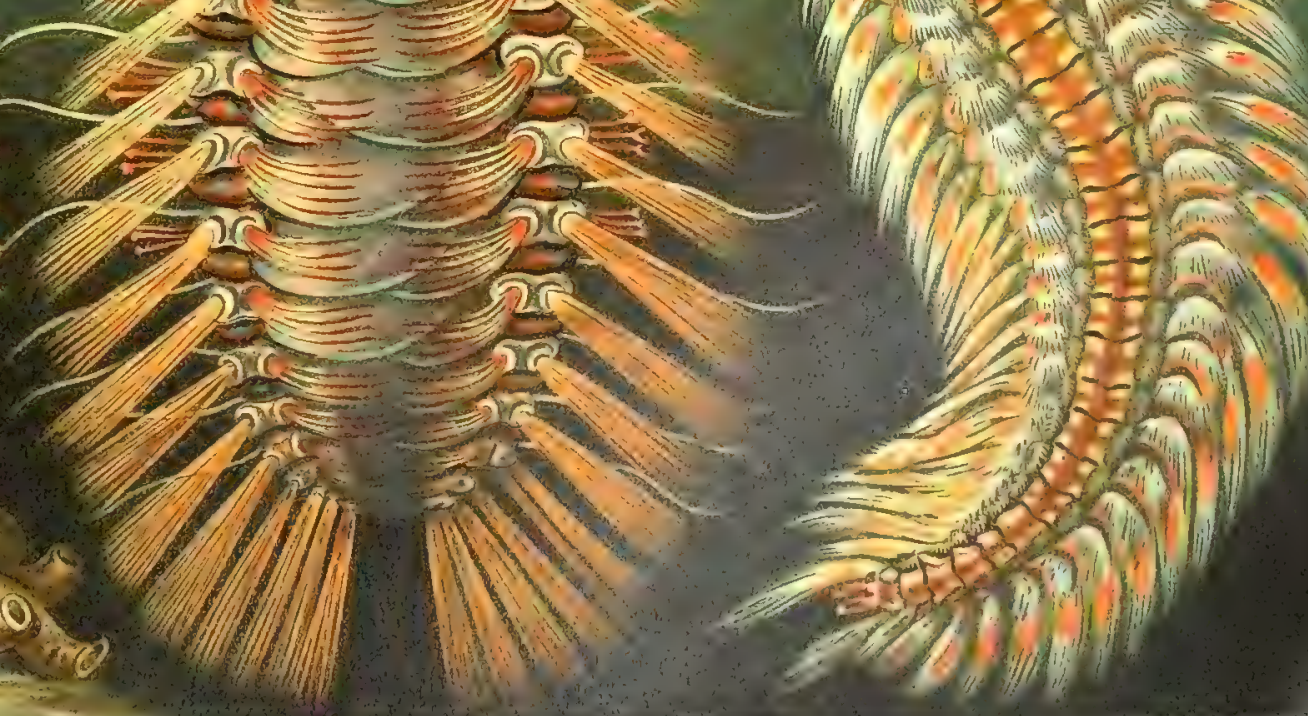

Chaetopoda. - Doxffentulinutex. 



\section{Spirobranchia. 5uitalkitum.}

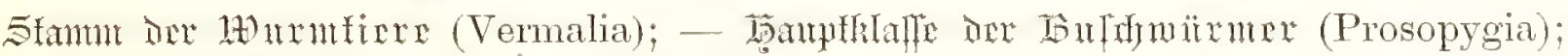

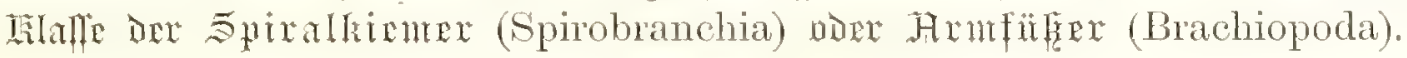

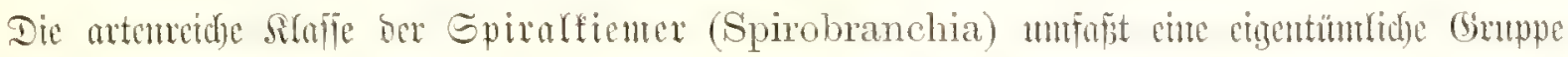

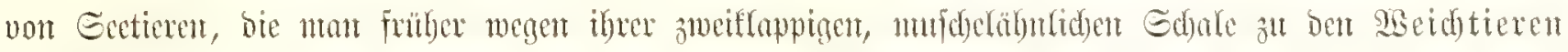

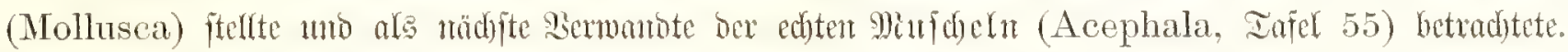

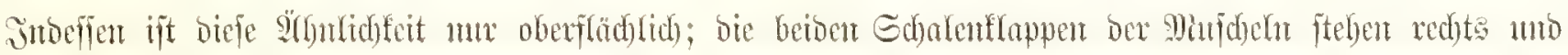

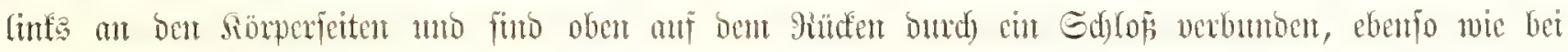

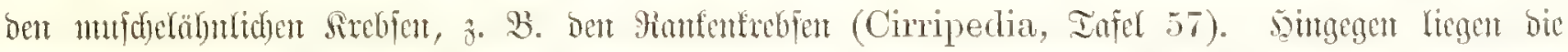

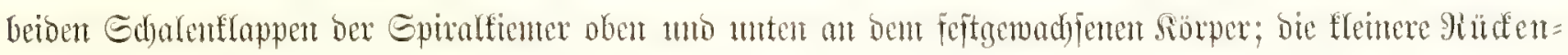

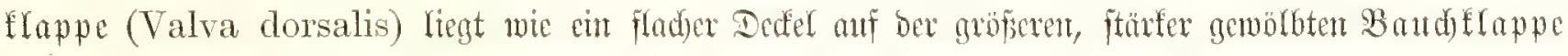

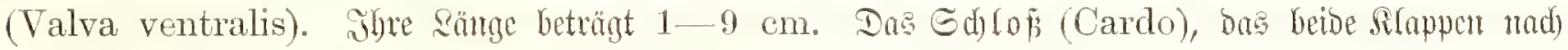

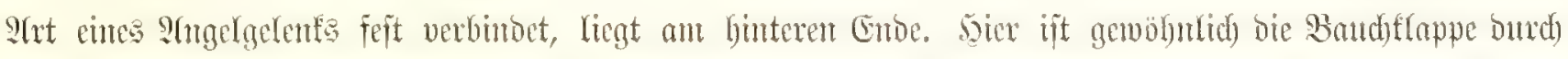

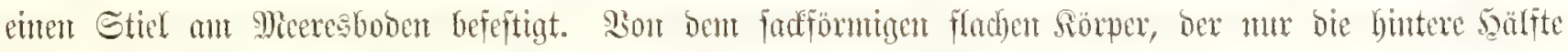

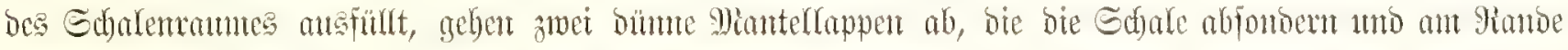

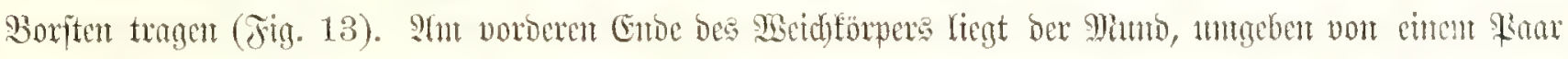

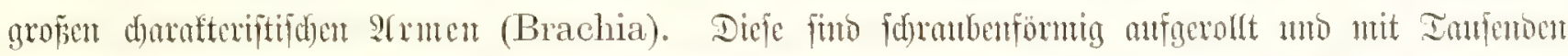

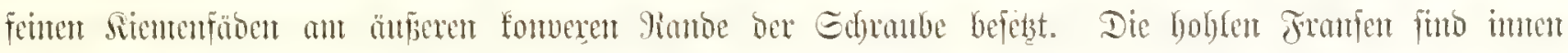

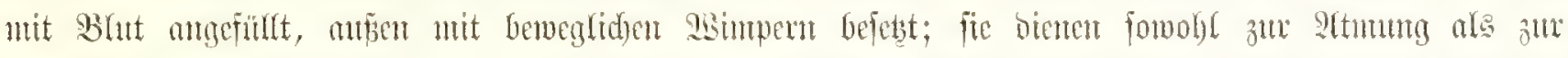

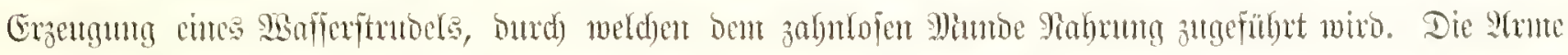

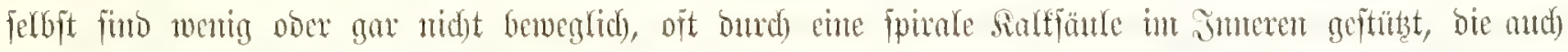

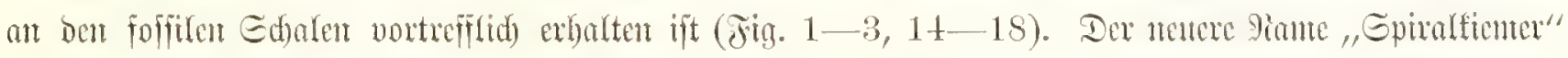

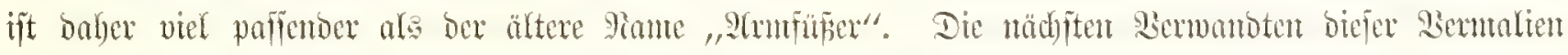

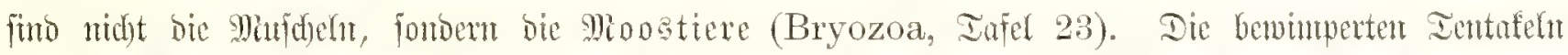

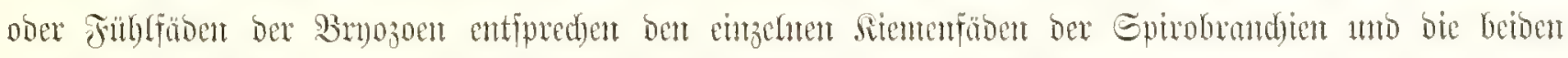

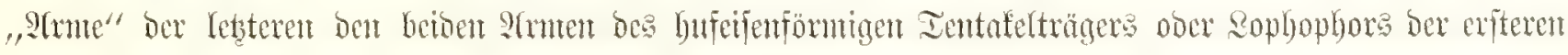

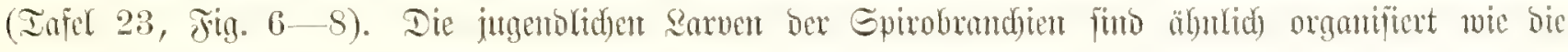

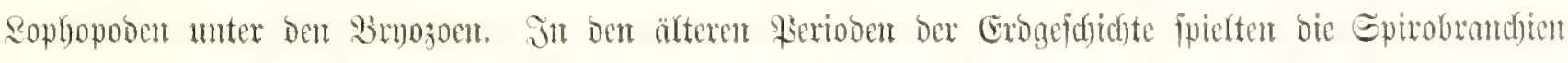

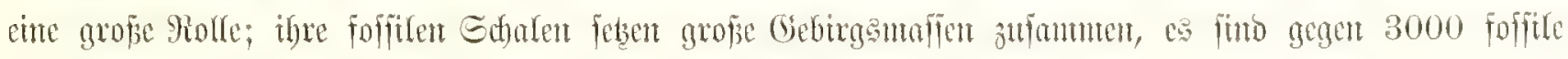

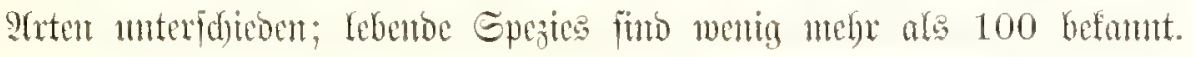

Jig. 1. Dayia navienla (Soxerby).

Siürenflappe ber Edyate, von inmen geferen, mit Dem Ralfgeritite bor betoen Epiralfiemen; oben ber Edjopitanto.

Fig. 2. Strophomena rhomboidalis (Wizckens).

Biëtenffoppe, won immen gefergen; oben ber breite Edylopiratio.
Fig. 3. Cyrtina leteroclita (Schlotheim).

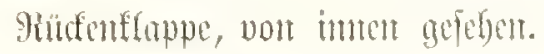

Fin. t. Spirifer gibbosis (Barrande).

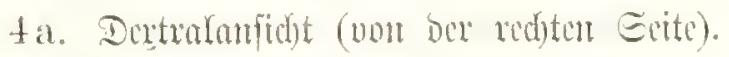

4b. Froutufarficht (vour Gtimmon).

te. Simbinalmfint (nom Goflopiranto). 
Titu. 5. Rhymehomella nympha (Barande).

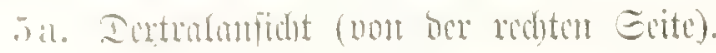

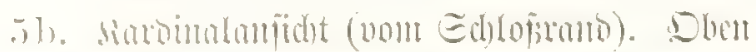

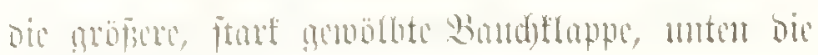

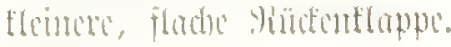

Fing. 6. Rhynchonella encharis (Berrande).

(bil. Frontalamidet (vom Etimmano).

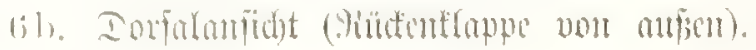

sing. 7. Rhynchonella inaurita (Sandberger).

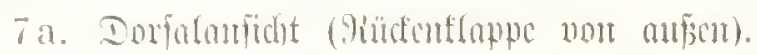

7b. Einiftralanfidst (non ber linten Geite).

Tig. S. Khynchomella psittacea (Duvidson).

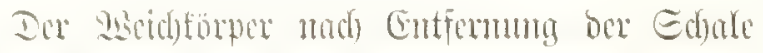

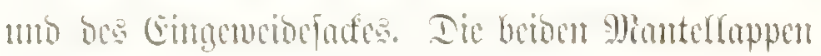

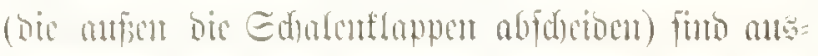

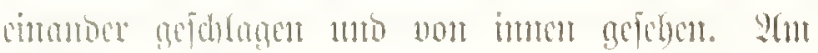

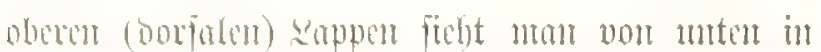

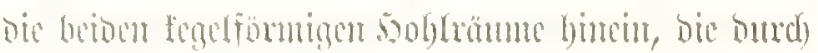

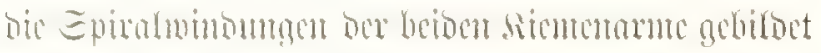

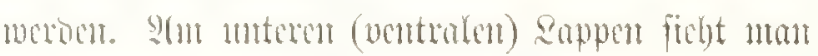

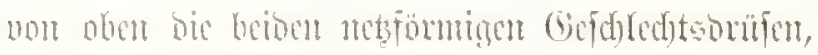

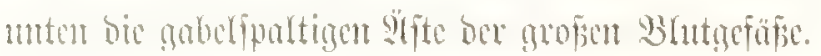

Tig. !) Lingula anatina (Tamarek).

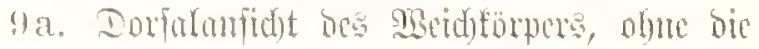

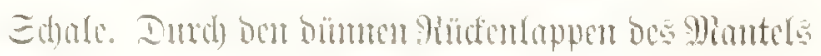

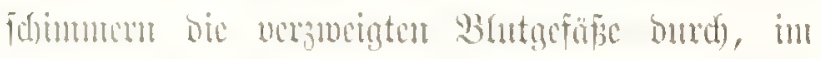

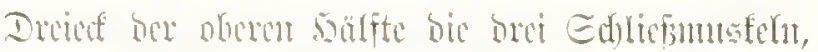

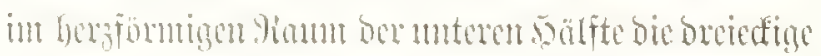

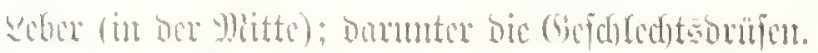

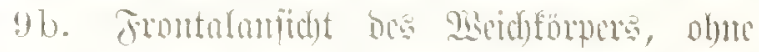

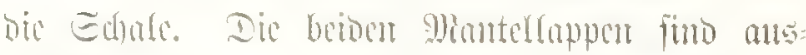

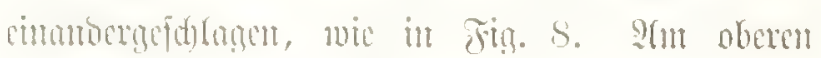

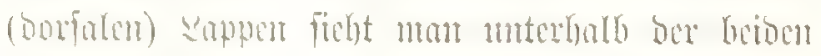

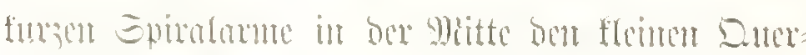
fpalt bes Mumber, ant anteren (wentralen) soppen

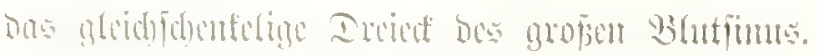

Fin. 10. Terebratula flarescens (Lemarck) Waldheimia australis (T)eridson).

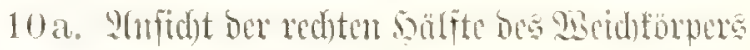

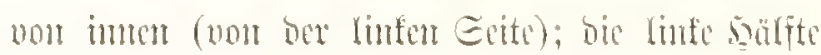

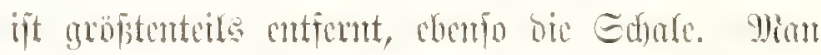

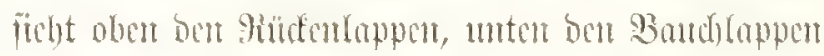

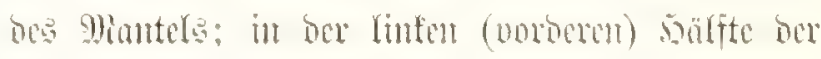
Figur bie red)te Epiralfiente, in ber red)ten (binteren)

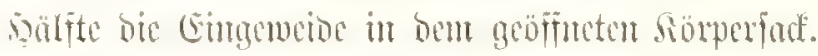

10b. Sufficht Der linfen Sörperbäffte von imtes

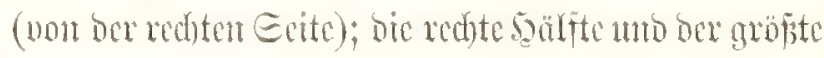
Ieif ber Eingemetoe ift entfent. Miant jiebt oben bie

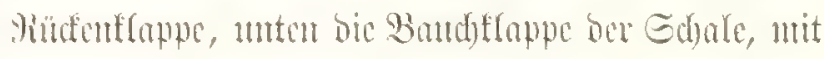
bent innen antiegenoen Miantel. Den gripten Ieil ber somtelgäble fült die linfe Epiralfiente ans.

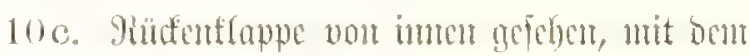

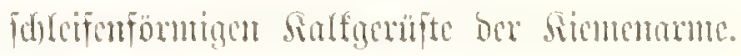

Fity. 11. Atrypa insolita (Barrame).

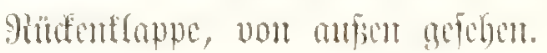

Fig. 12. Rhynchonella oblita (Barrende).

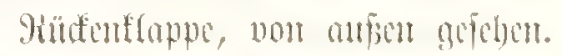

Ting. 13. Terebratulina serpentis (dombrigny).

Dorfaranfidet bes

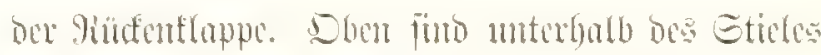

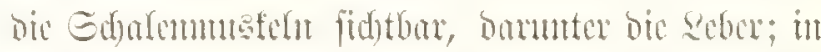

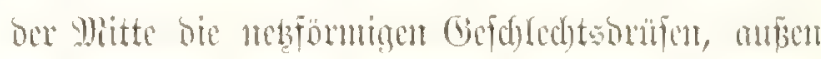

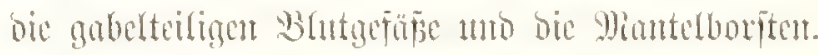

Jion. 1t. Terebratulina Murlayí (Devidson).

Giüfentfoppe mit bent Epiralfiemen, von iment.

Tign. 15. Spirigerina concentrical (t'Obigmy).

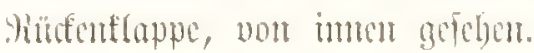

Figg. 16. Rhynchonella nigricans (Fischer).

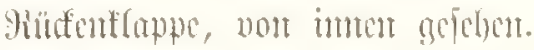

Brig. 17. Nucleospira pisum (Sonermy).

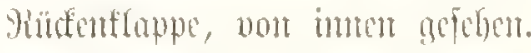

Xig. 18. Atrypa marginata (Dulmen).

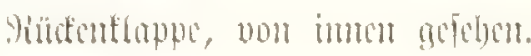




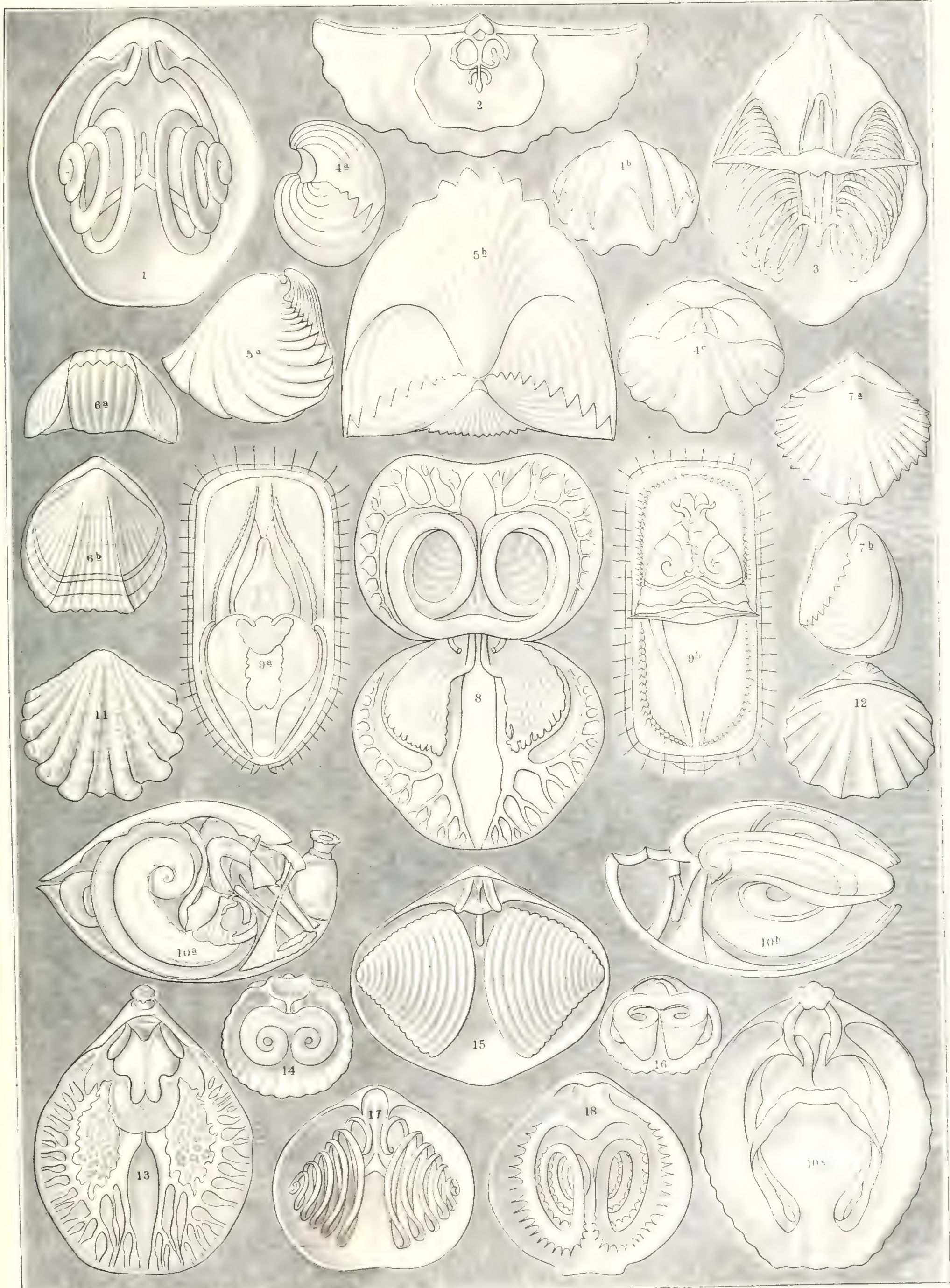




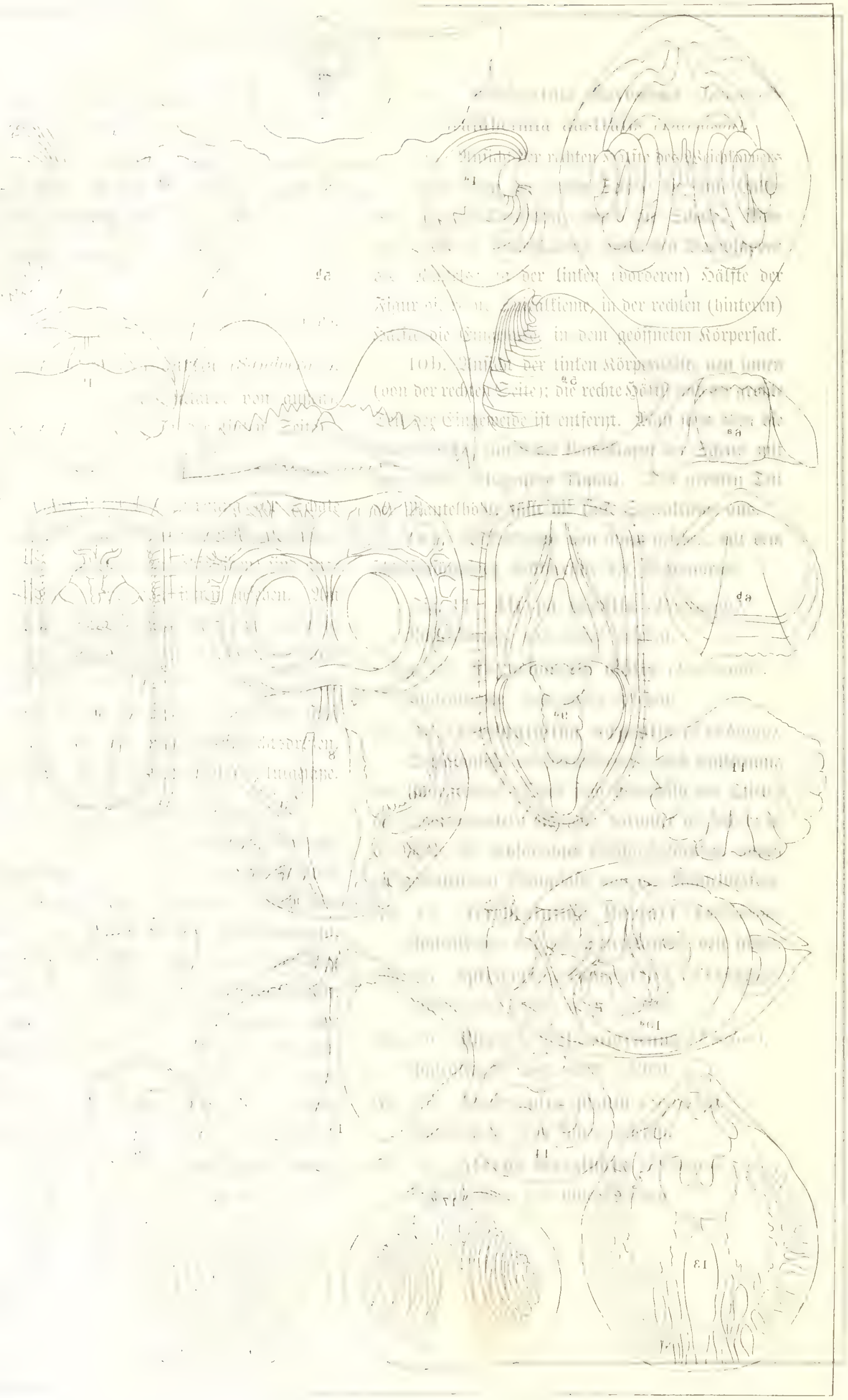




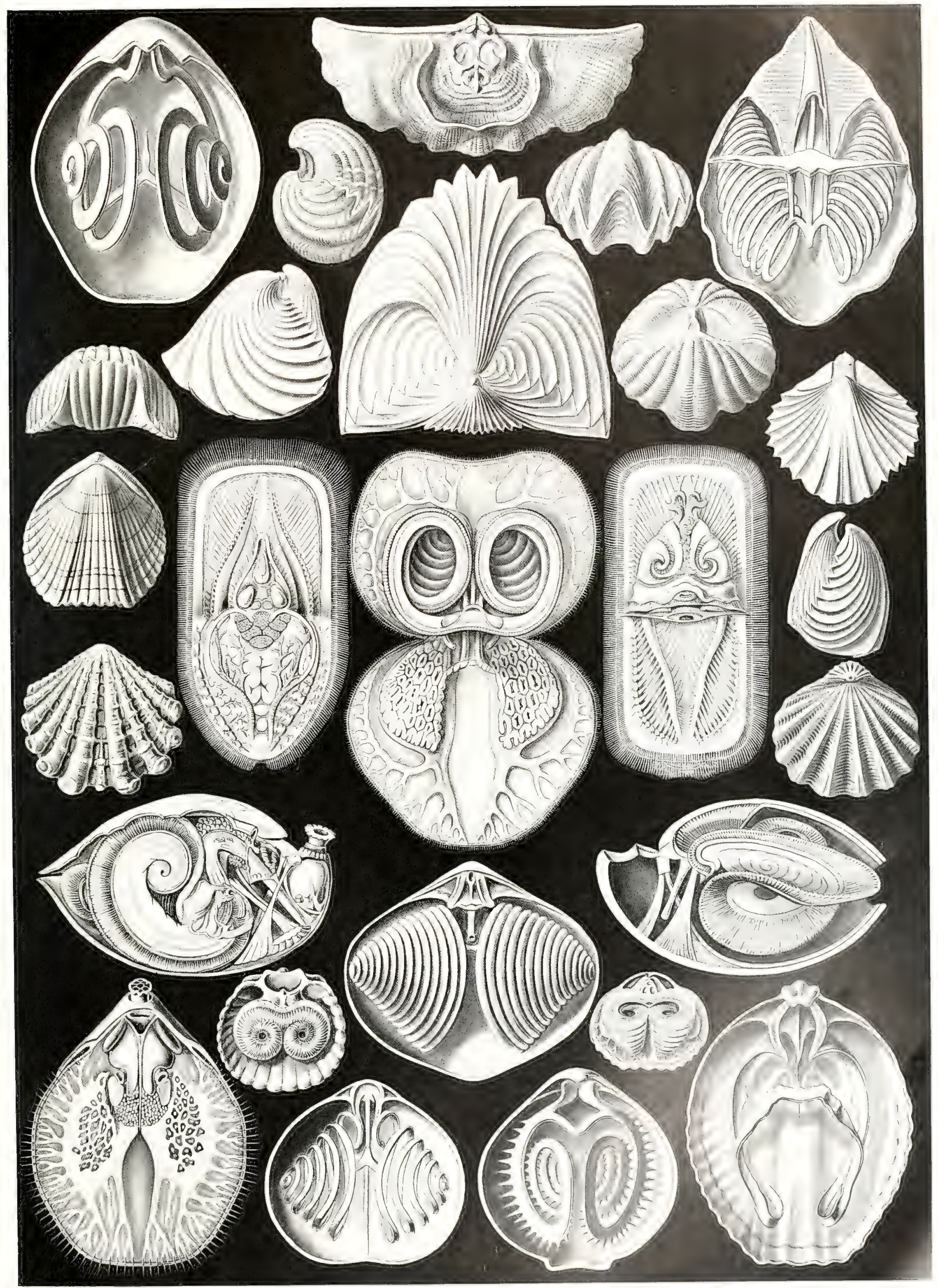





\section{Discomedusae. Frythumuatur.}

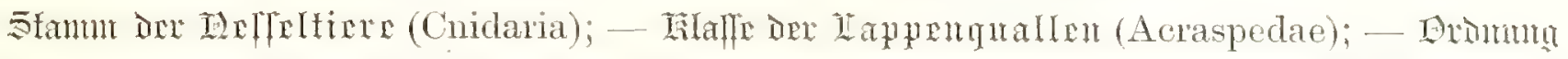

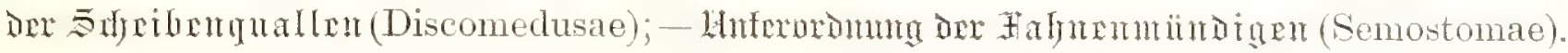

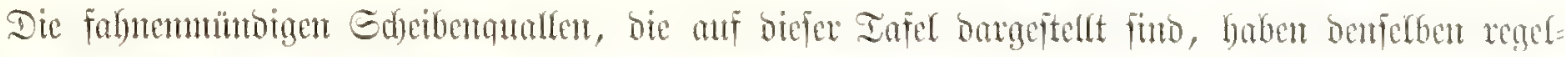

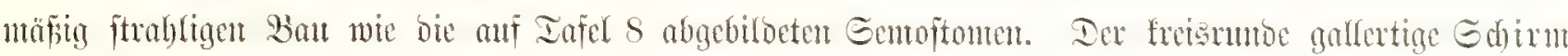

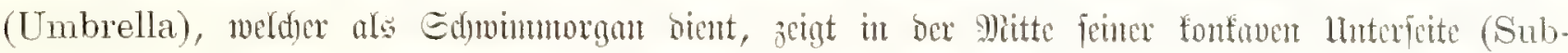

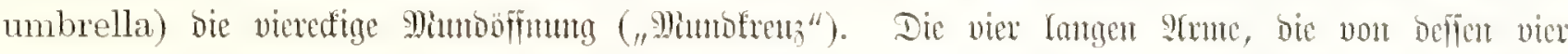

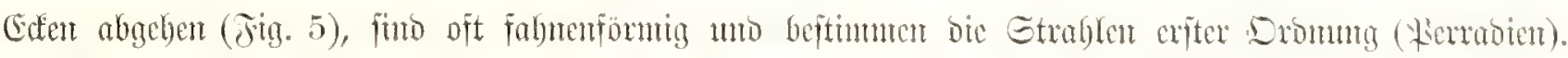

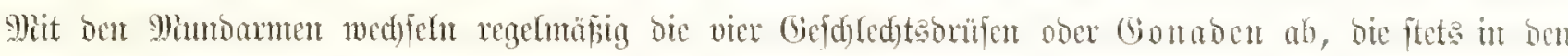

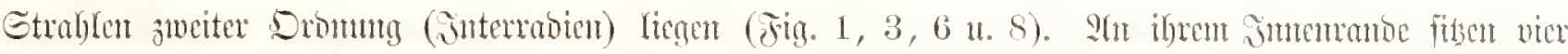

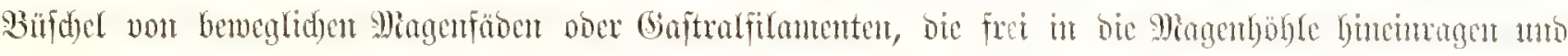

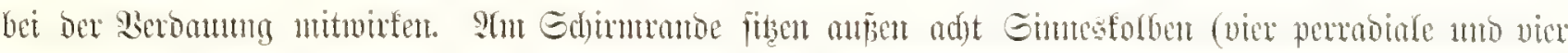

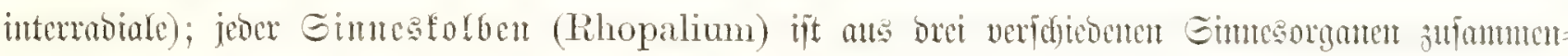

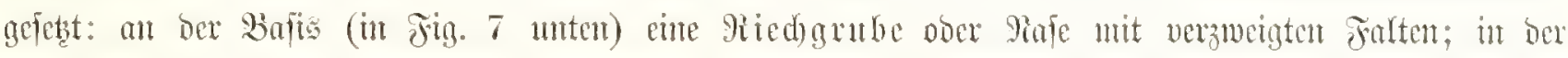

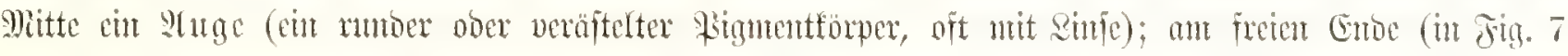

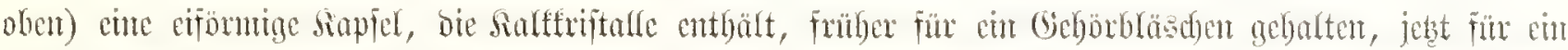

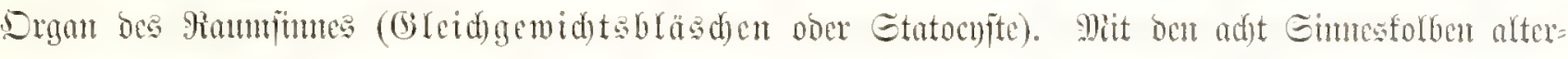

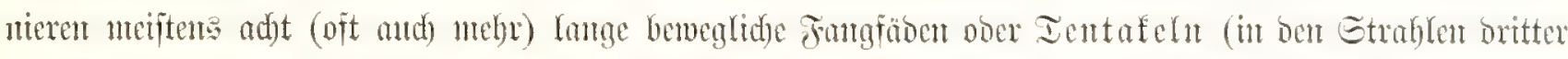

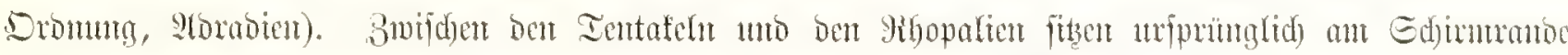

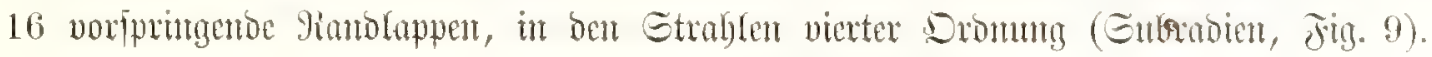

Fig. 1. Aurelia insulinda (Haeckel).

Familie der Humarion.

Das ganze Iiex, in naturlid)er Gröpe, wout

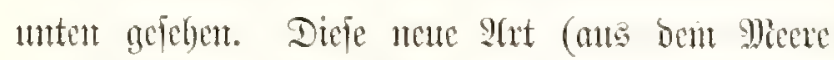
von Surfutinde, an ber Süite vou Sumatra) ijt bla rötlide) gerürubt, bie Gontaben violett; fie fitht fo= wohl ber curopäifchen A. aurita ale ber ameri= fomifden A. habanensis (vont 5abanta) nahe, unter= fdecioet fide) aber von beiben burd bie Gejtalt bee

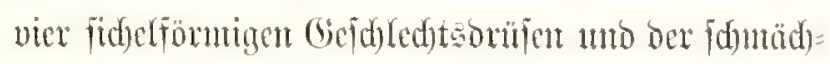
tigen fumzen Strme, fowie butd) bie ndjt tiefent Bud tent bes Gdjumrandes, in bench bic adft Gimms folben liegen. Der ganje Edjimmrand ift mit ferbe jahlreidjen furž̉n Ientafeln gefüunt.

\section{Fig. 2. Aurelia aurita (Lemerech). Familie int llutartion.}

Die Strobila noer ber finofperijapfen, welder Den cigentüntichen Generationswedfer dor Gdyeiber=

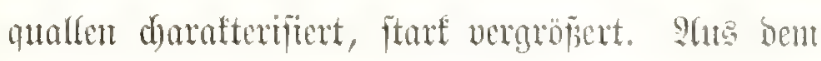

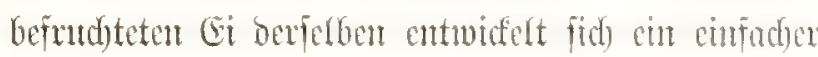
Bect)erpolyp (Scyphostoma, oberfer Ieil ber

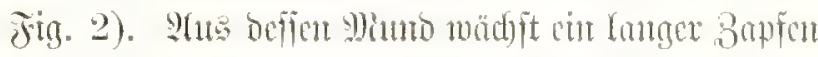

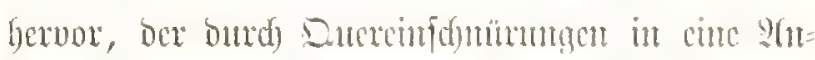

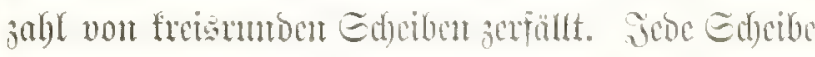

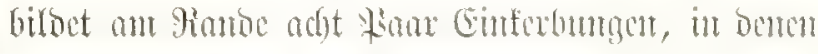

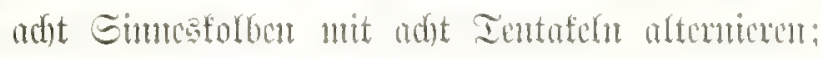

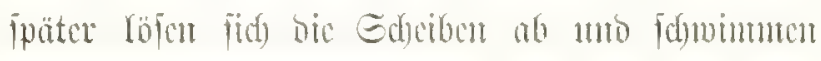
ats flente Distomedfen umber (Lphyra). 


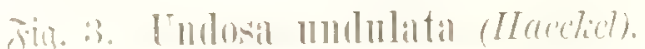

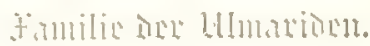

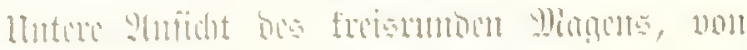

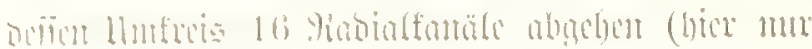

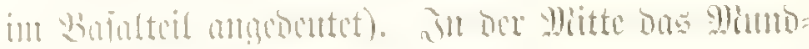

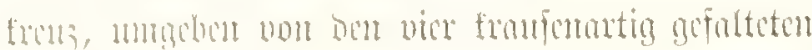

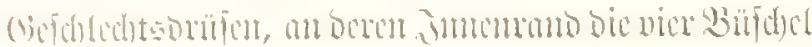

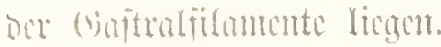

Fin. t. Foresea parthenia (Huectiel).

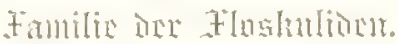

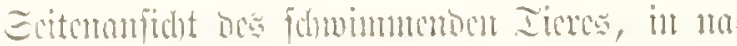

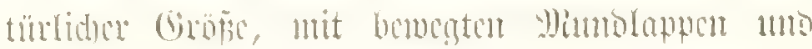

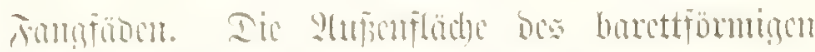
Eshimes siart am

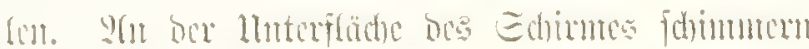

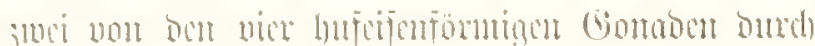

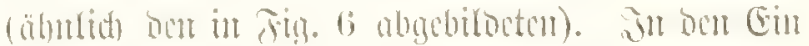

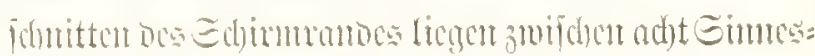

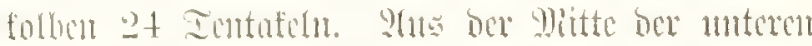

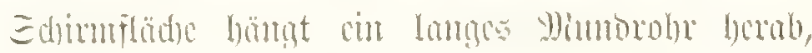

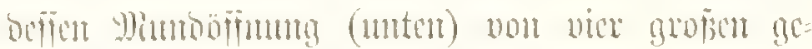

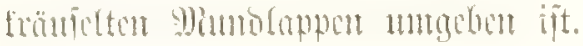

Sin. 5-7. Pelagia perla (Haecked). tamilie Dex foldanom.

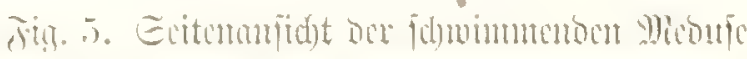

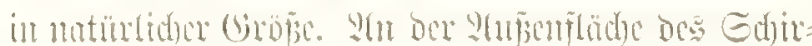

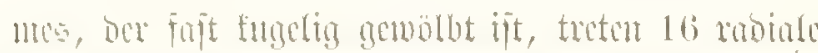

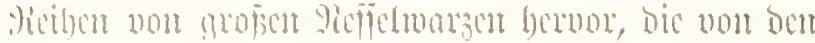

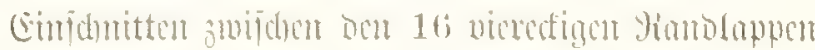

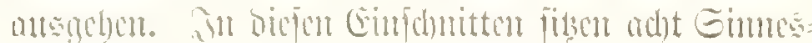

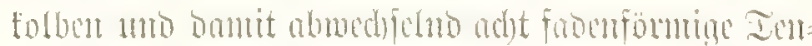

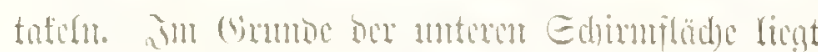

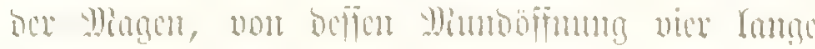

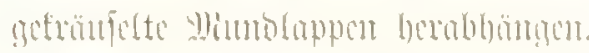

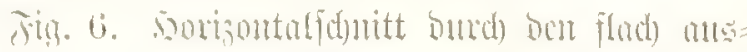

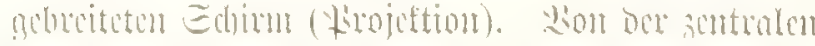

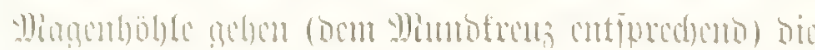

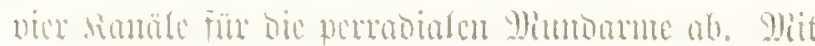

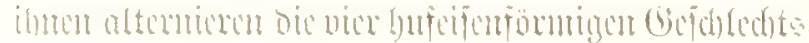

Driffen, an beren immentrans bie vier internbiaten

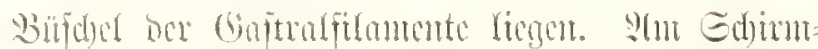

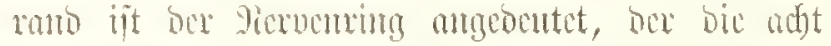
Eimentolben verbintor.

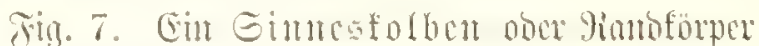

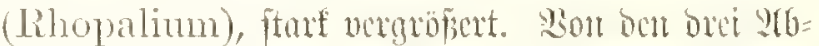
fduntten be 3Hfammengefesten Gimestörpers ent= hält ber obere bie Gtatocuite (cine eiformige, mit

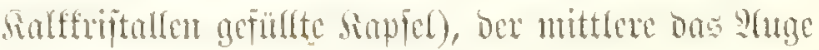

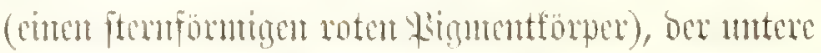

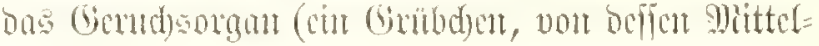

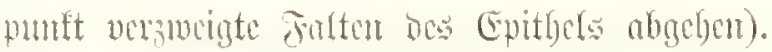

Jing. S. Drymonema victoria (Hueckel). Fimilin one Clameion.

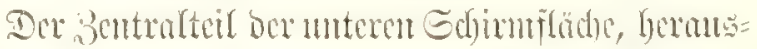

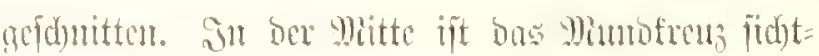
bar mit fenten vier perrabialen sippen mo ben

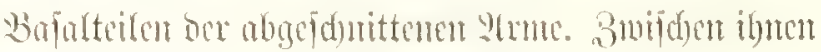

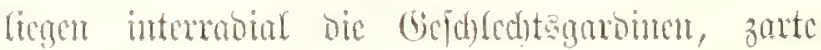
faltige Micurbronen, an benen bic acträuféten (50= mabou angebuantat finto.

\section{Jig. 9. Procyanea protosema (Hacckel).}

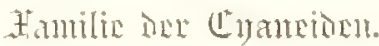

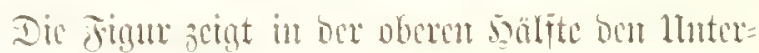

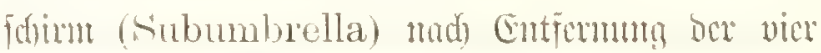

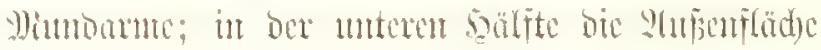
des Dborfdinte (Exumbrella) mit ibrent einen=

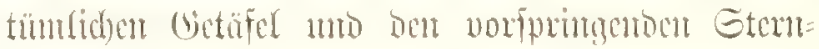

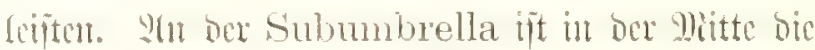

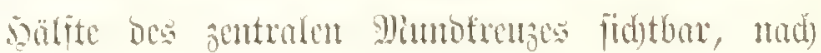

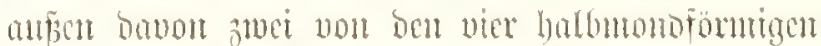

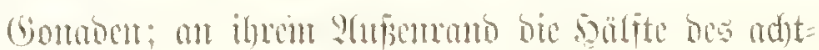

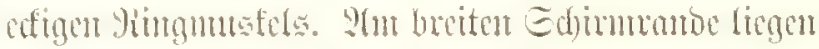
bie adht Ginnestörper (vicr perrabiale mo vier inter=

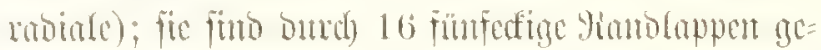
tremet vou ben altenteremoen ad)t (abrabialent) Ien=

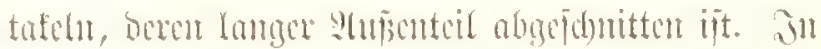
Den 16 (jubrobialen) gianolappen find bis sicrfidt)

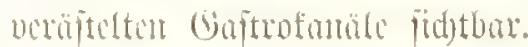




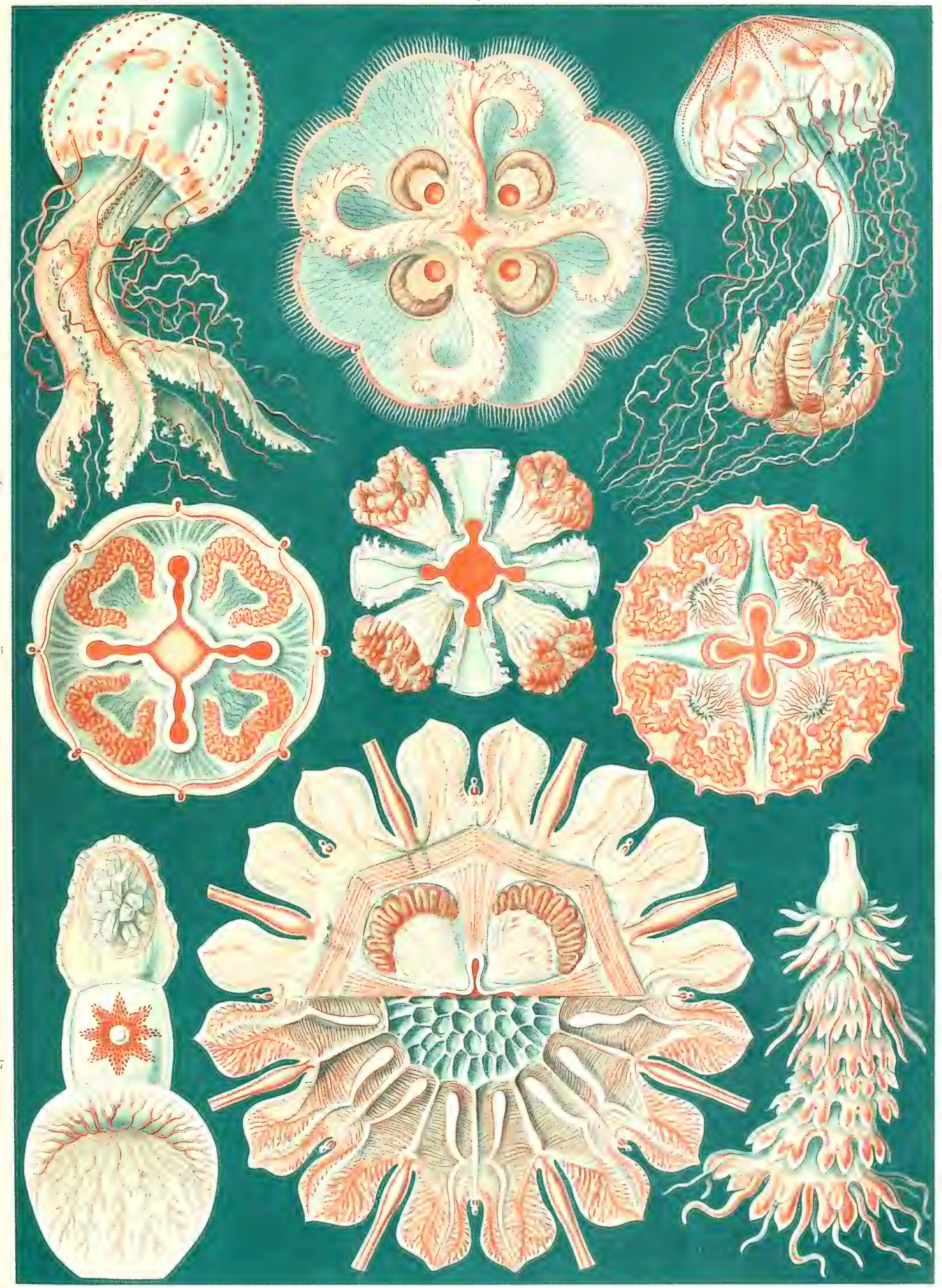

Discomedusae. - scheilientontallent. 



\section{Trochilidae. Hintimits.}

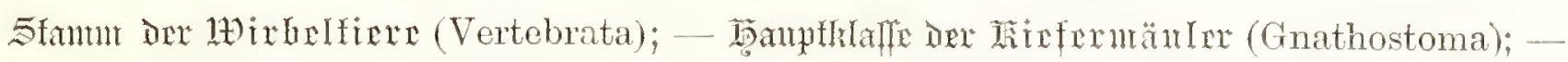

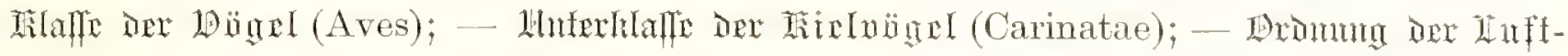

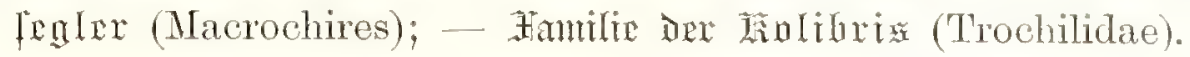

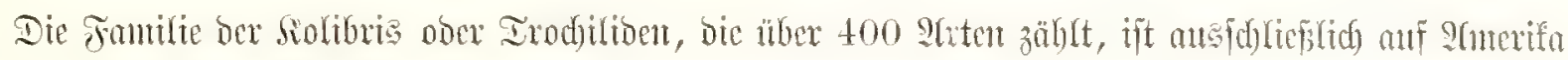

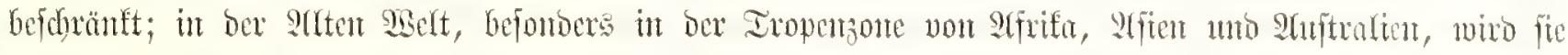

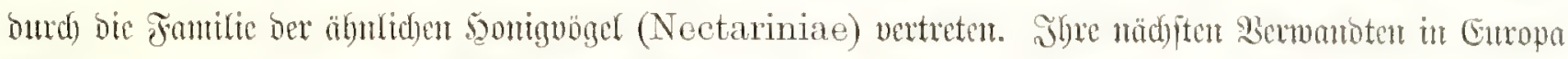

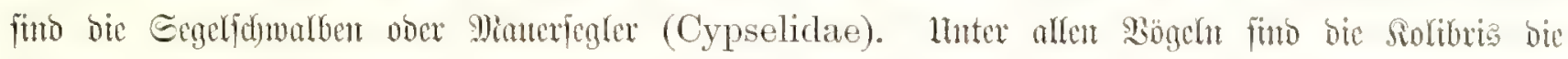

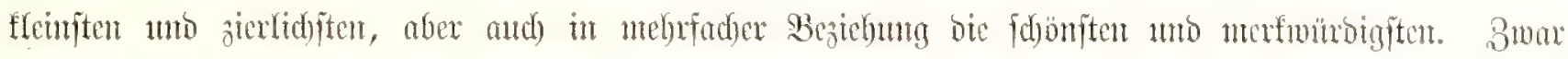

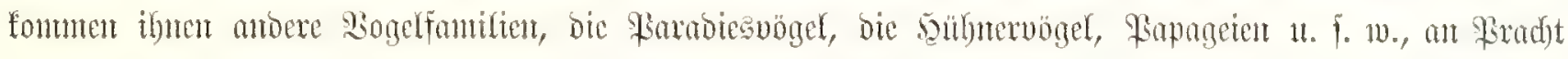

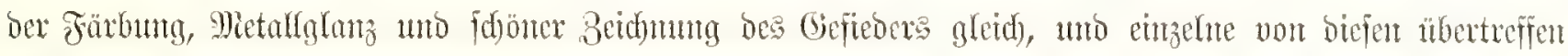

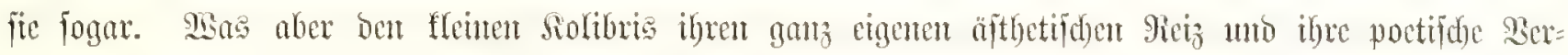

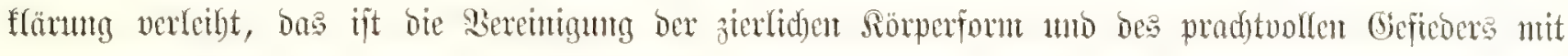

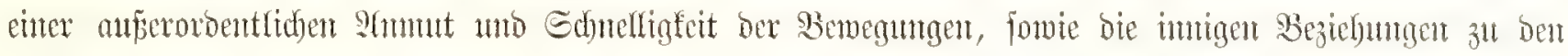

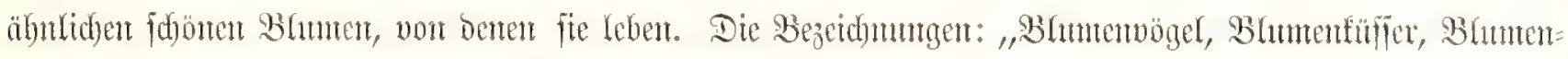

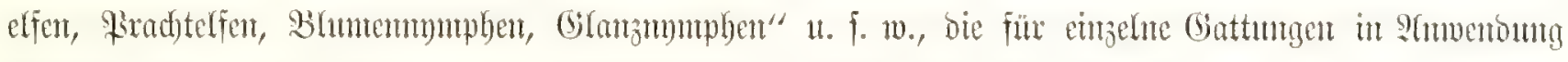

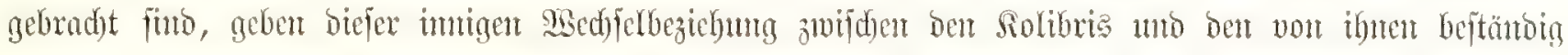

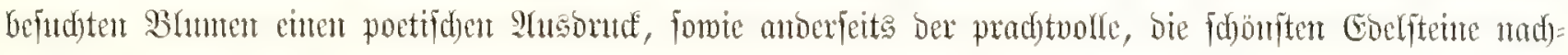

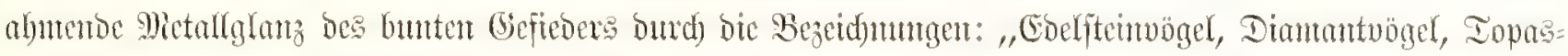

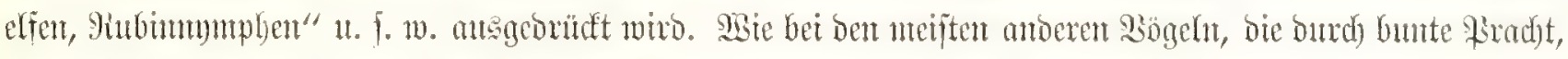

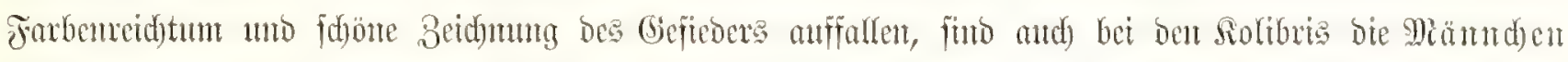

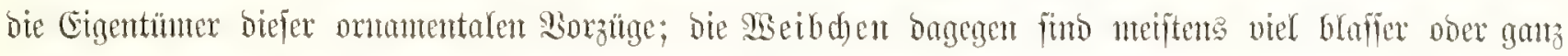

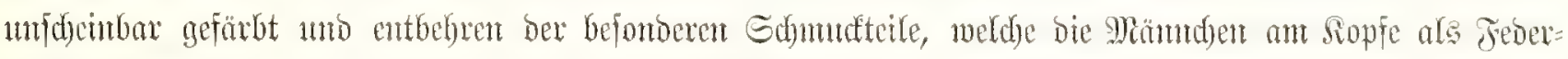

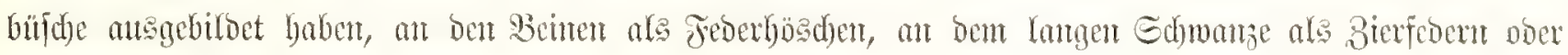

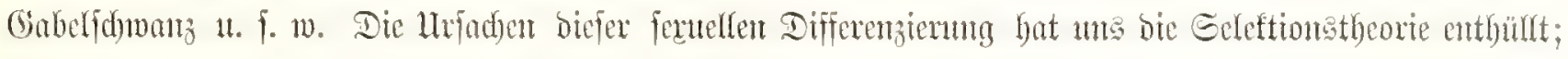

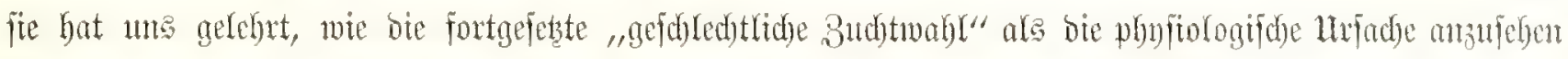

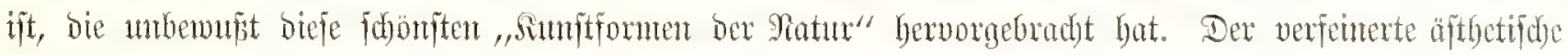

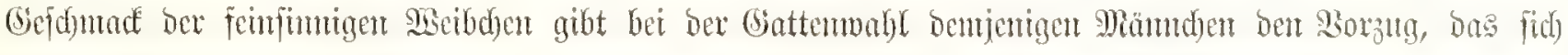

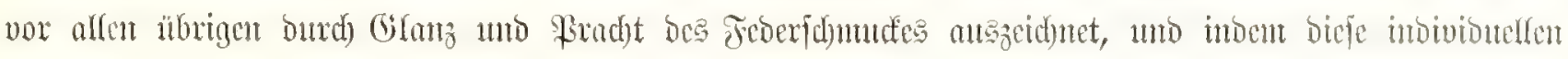

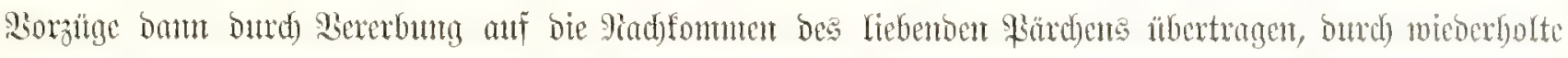

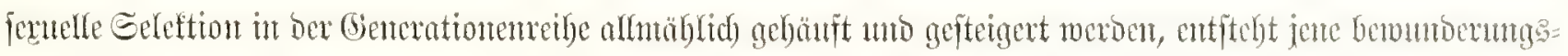

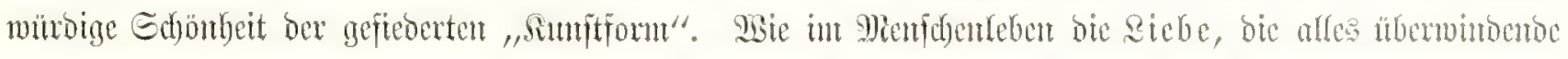

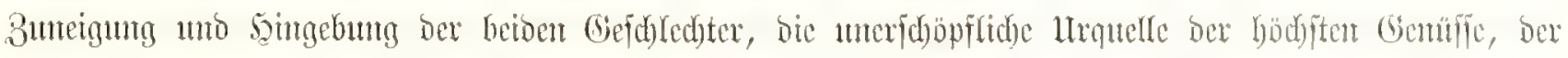

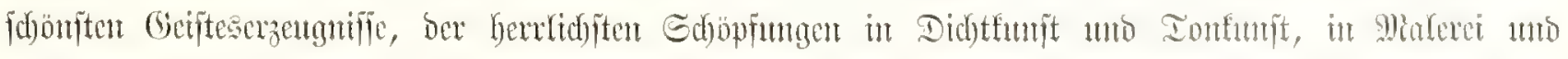

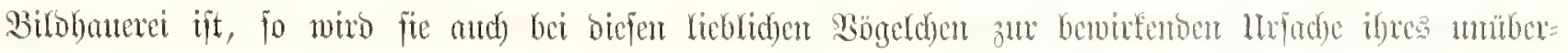

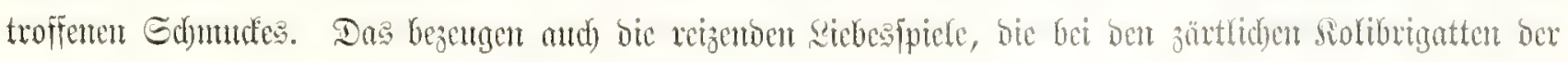




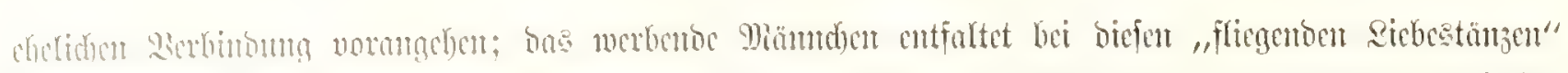

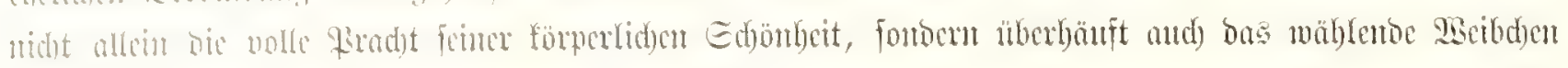

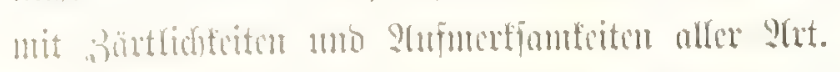

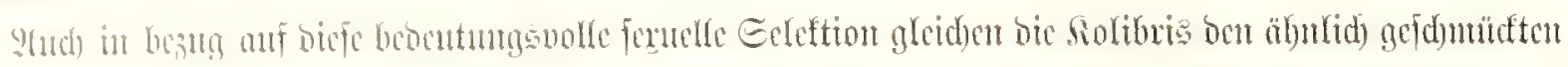

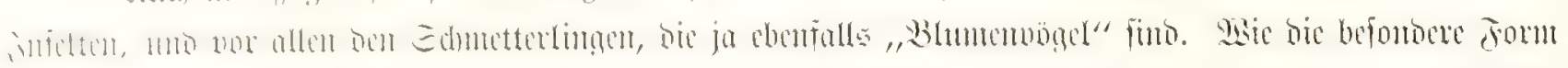

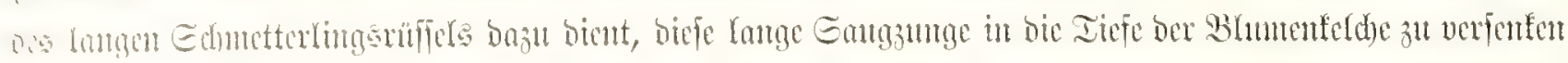

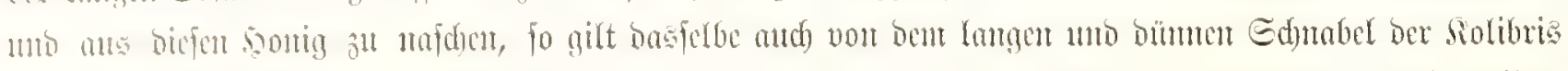

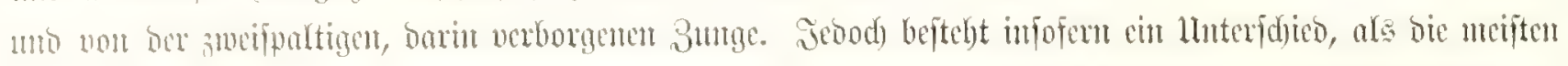

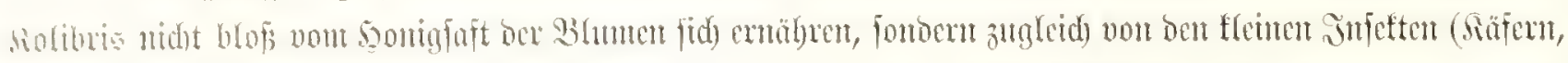

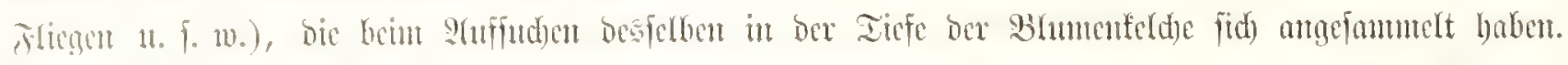

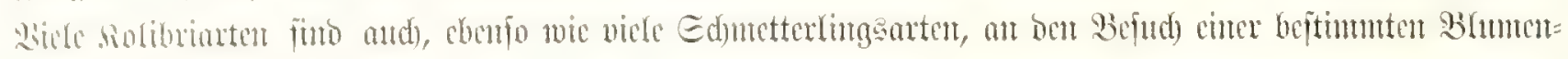

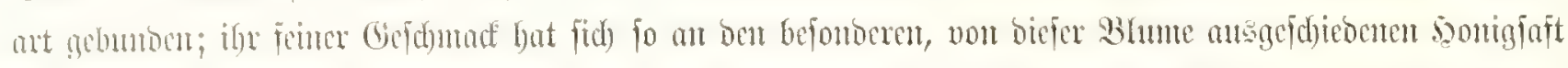

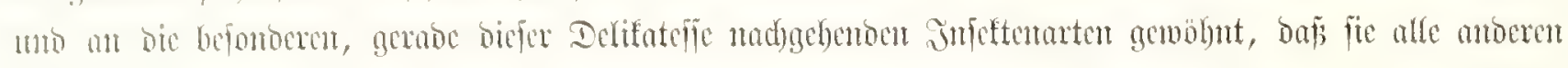

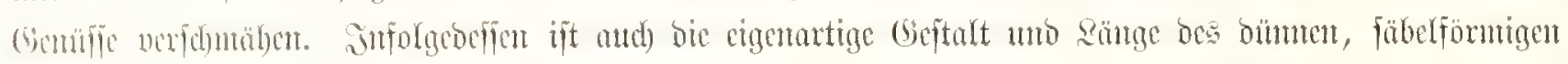

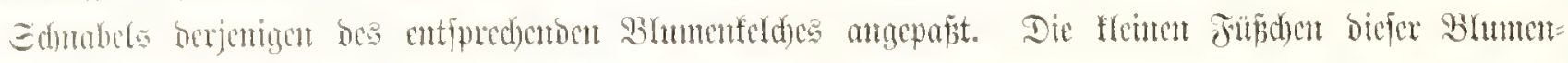

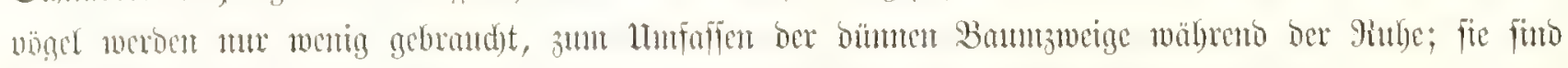

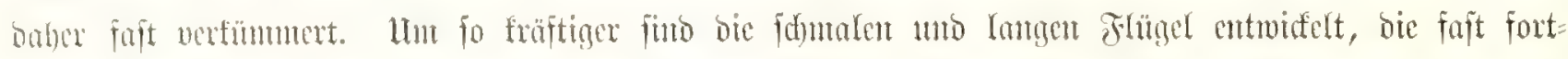

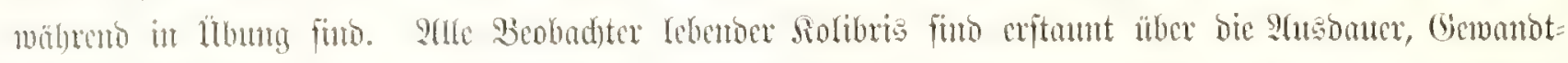

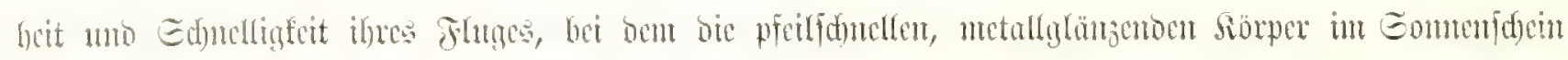

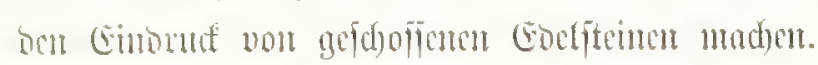

Fia. 1. Trochilus colubris (Limé). Eenfoltari (Carolima).

jig. 2. IIeliactinus cormutus (Bonaparte). Ed)meifelfutolibri (Sraftiun).

Jign. 3. Topaza pella (Gray). Iopastolibri (Ëmiman).

Fing. 4. Lophornis ornata (Lessom).

Edmuderforfolibri (Gimana).

Jiu. 5. Sparganura sapplo (Cabanis). Eapploforibri (Solinia).

Fin. 6. Docimastes ensifer (Gould).

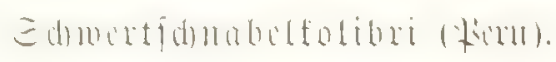

Fig. 7. Eutoxeres condamini (Reichenbach). Sirummathabelfolibri (Ecuanor).

Sig. 8. Lophornis gouldii (Gray). Aragenfolibri (Brafitien).

Jig. 9. Onnismya petasphora (Lesson). Dhrentolibri (Brafitien).

jig. 10. Angastes lumachellus (Gould). Botfanantoribri (Brafition).

Fig. 11. Hylocharis Stokesii (King).

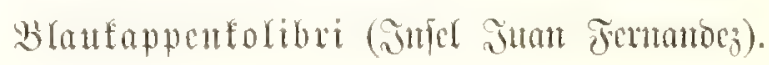

Fig. 12. Steganma underwoodi (Gould). Slaggentolibri (Brajitien). 
Hacket, Trunstformen der Natur.

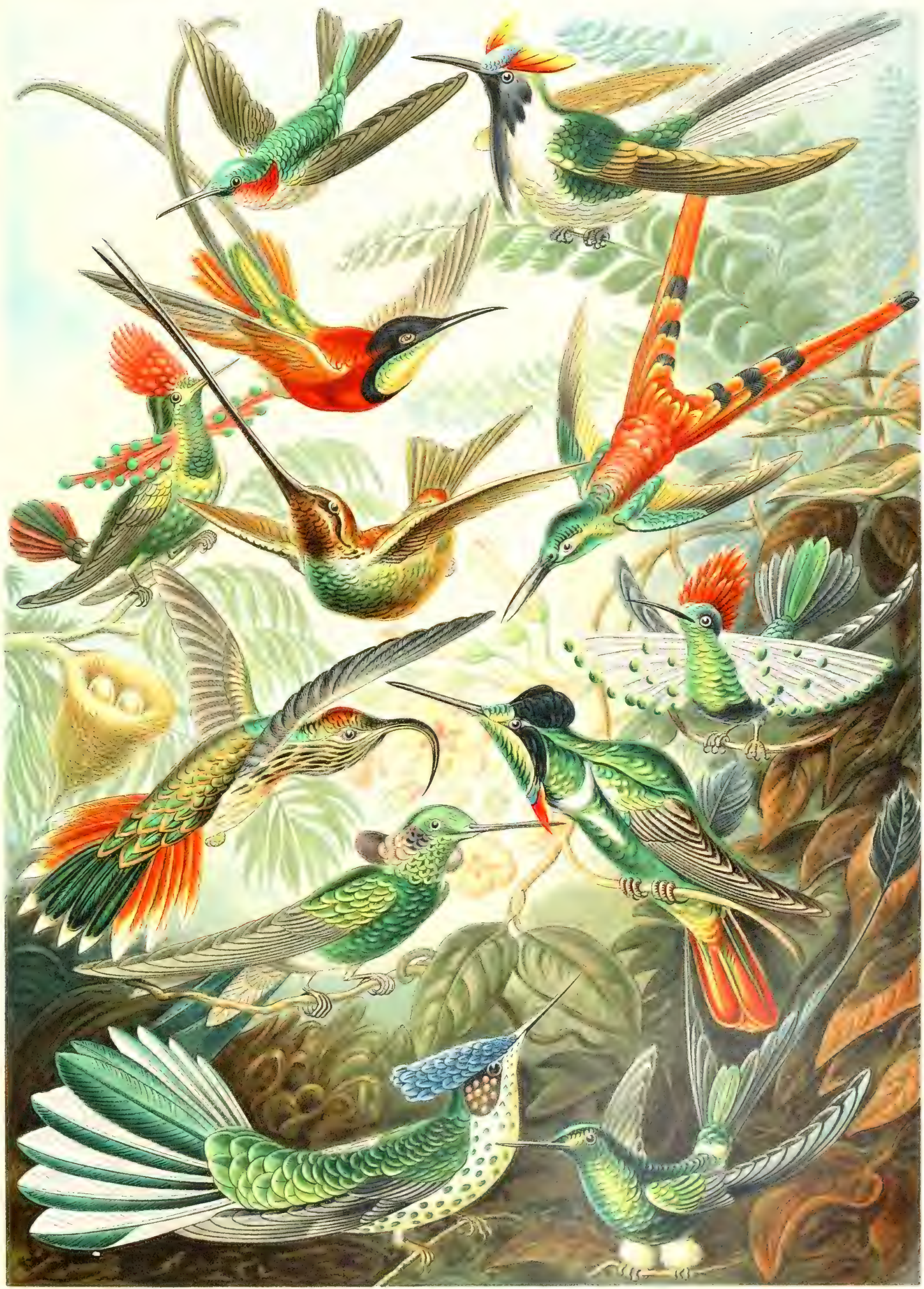

Trochilidae. - Solitixis. 



\section{Antilopina. Hntilopren.}

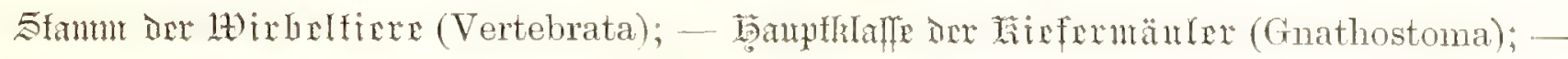

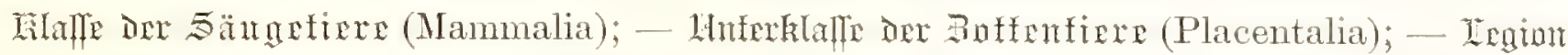

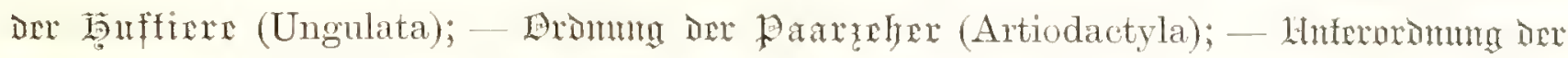

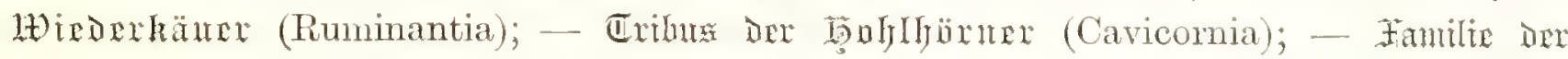
Anfiloper (Antilopina).

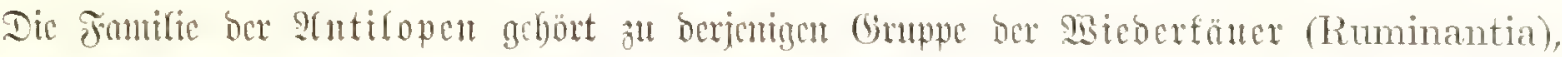

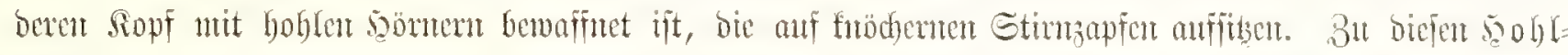

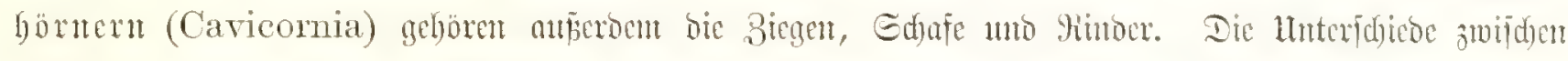

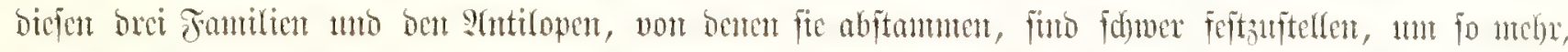

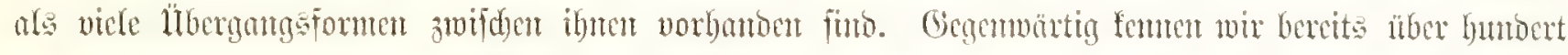

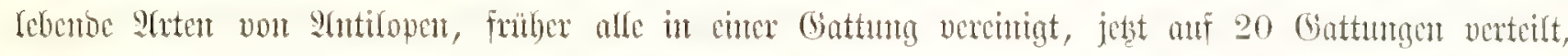

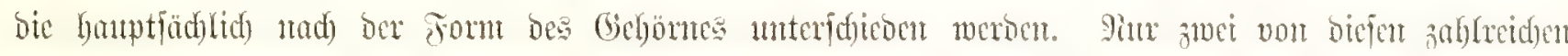

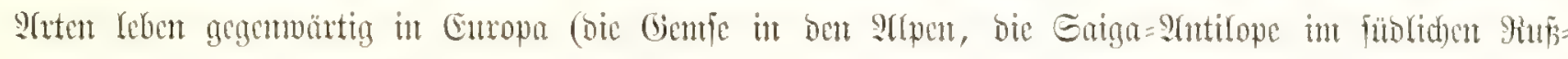

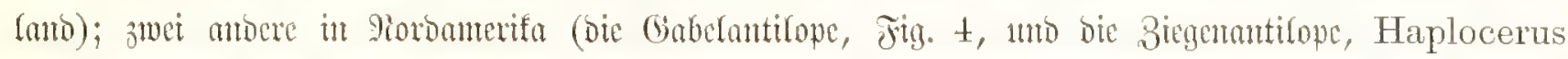

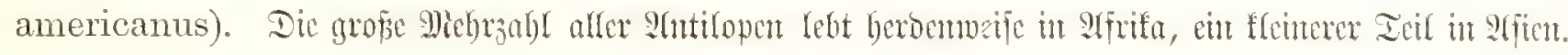

Fing. 1. Tetraceros quadricornis (Blainville). Bicrbornantilope (Snbifa): Bherki).

Siörpertänge $85 \mathrm{~cm}$, Gd)manzzlänge $15 \mathrm{~cm}$, Sdulterföhe $50 \mathrm{~cm}$, Frabe broun, unten weip. Sit Gewalbetert Sügelgegenden von Ditimbien. Dirfe Stutilope ijt bas cuntgige lebento Eängetier, bas in

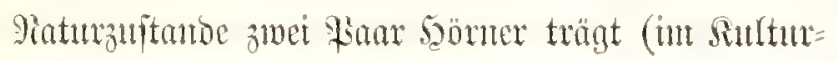
juftande find Biegen mit anci, feltener brei Pan

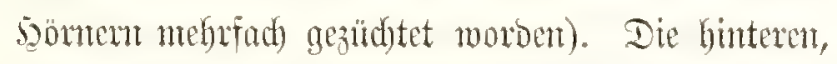

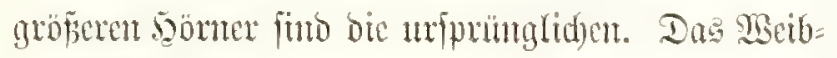
doen ift boutlos.

Jig. 2. Catoblepas ginn (Sundevall). asirbebecit ober (Gint (afrifantifd): Imbutuma).

Siörpertänge $2 \mathrm{~m}$, Edhwanz̧änge $80 \mathrm{~cm}$, Edulter: Göbe 1,2 m. Farbe ountel grautrmut, Siaffentähnte 1410 Edywerf weiflidgran. In grofien saeroen in Subafrifa. Gebr idnell, wilo mo unzülyutbar.
Fig. 3. Tragelaphus gratus (Sclater). Eumpfantilope (ofrufanifd): Situtunga).

Sörperläntge 1,2 m, Edulterhäbe $90 \mathrm{~cm}$. Farbe braun, mit helfen Strcifen und Flecten. Die fel)

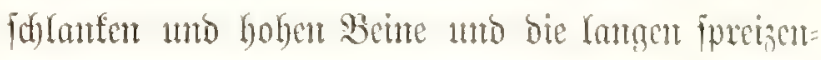

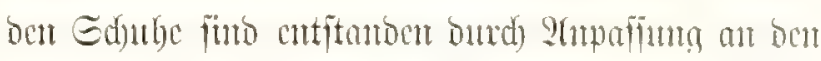
Ifufentgalt in Fluilen unt Sumpfen; cbenfo bas grobe, ftruppige saarfecio. siseptafuifa.

Fig. t. Antilocapra americana $($ Owen $)=$ Antilope furcifera (Smith).

Gabelantilope (Otnerifantifd): Nazama).

Sörpertänge 1,25 m, Edhwantäunge $20 \mathrm{~cm}$,

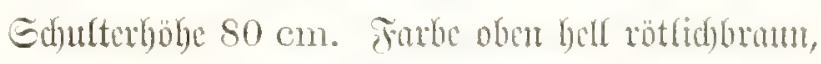

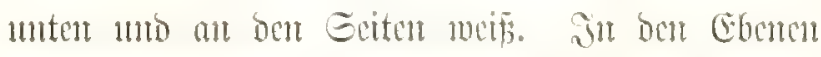

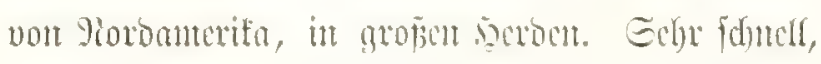

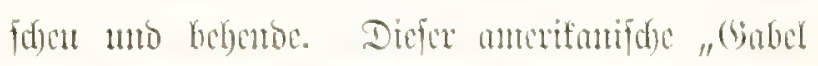

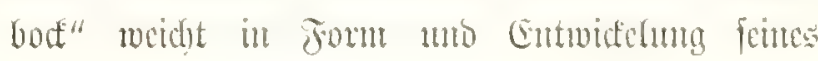




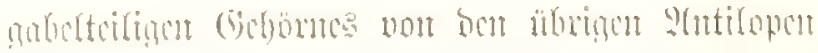

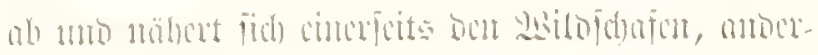

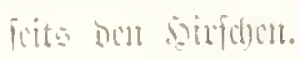

Fin. .). Intilope ellipsiprymua (Gray)-Corvi(aplat ellipsiprymua (Sundevall).

gisaffrood (s)(frifanifd): singsing).

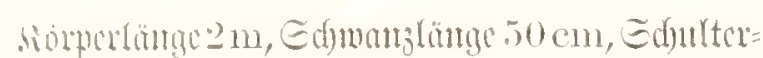

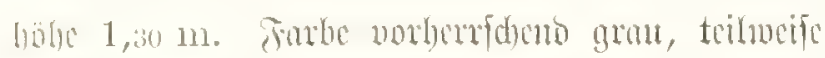
ins Getbrote jobmo, mit conem elliptifden bellen

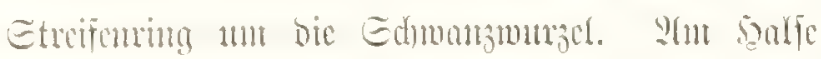

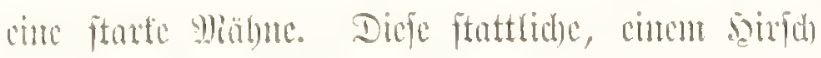

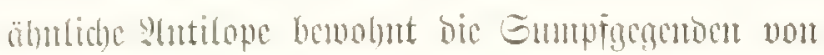

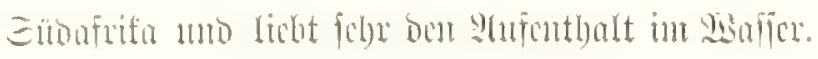

\section{Fig. 6. Ilippotragus niger (Hamis).}

Edmarisbod ober Giapenantilope.

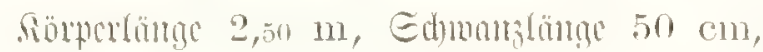

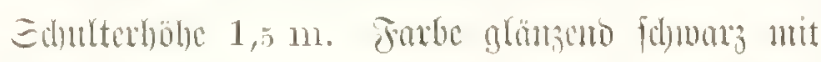

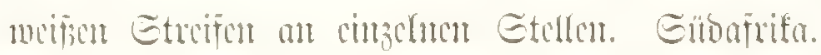
Dor sals trägt cute ftarfe stable. Dic sounter fum

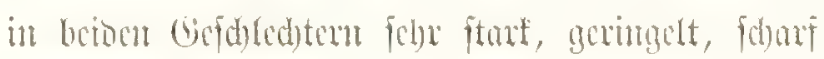
lïtmän getrummt.

\section{Jig. T. Addax masomacnlatus (Gren)).}

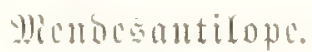

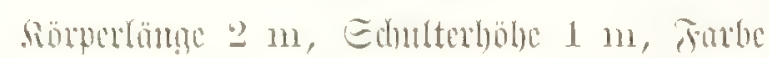

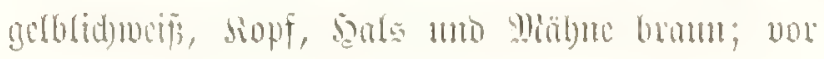

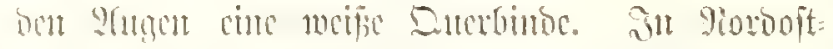

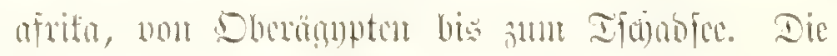

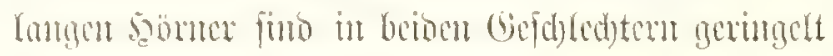

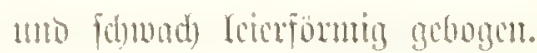

Fig. S. 'Tragelaphus kudu (Gra!) - Antilope strepsiceros (Pellas).

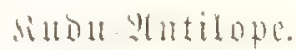

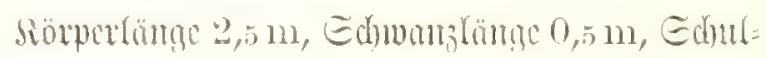

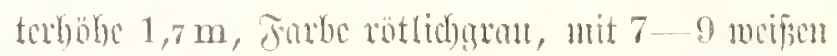

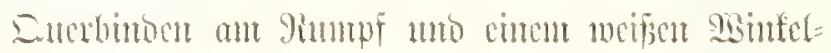

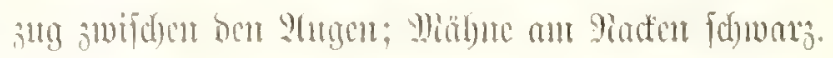

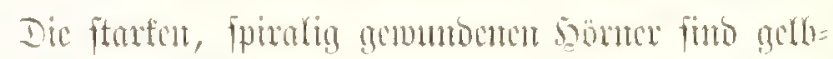

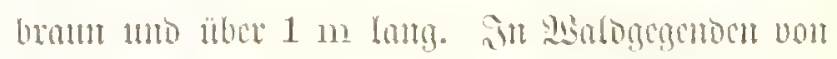
Bentralaftifa, fublid) ando offlid ber Eabma.

\section{Fin. 9. Thagelaphus seriptus (Sunderall) Antilope maculata (Pullus).}

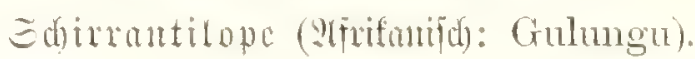

Sorpertänge 1,4 m, Ed)manglämge $15 \mathrm{~cm}$, Ed)u= terbobe $85 \mathrm{~cm}$, Frabe faftantabrant, ntit meifon

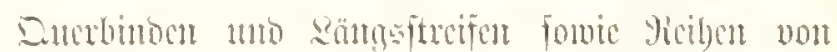

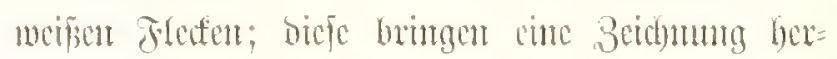

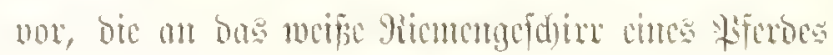

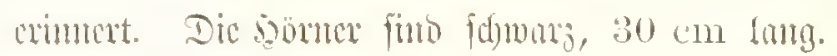
Jum weptiden Sutralatrifa. 


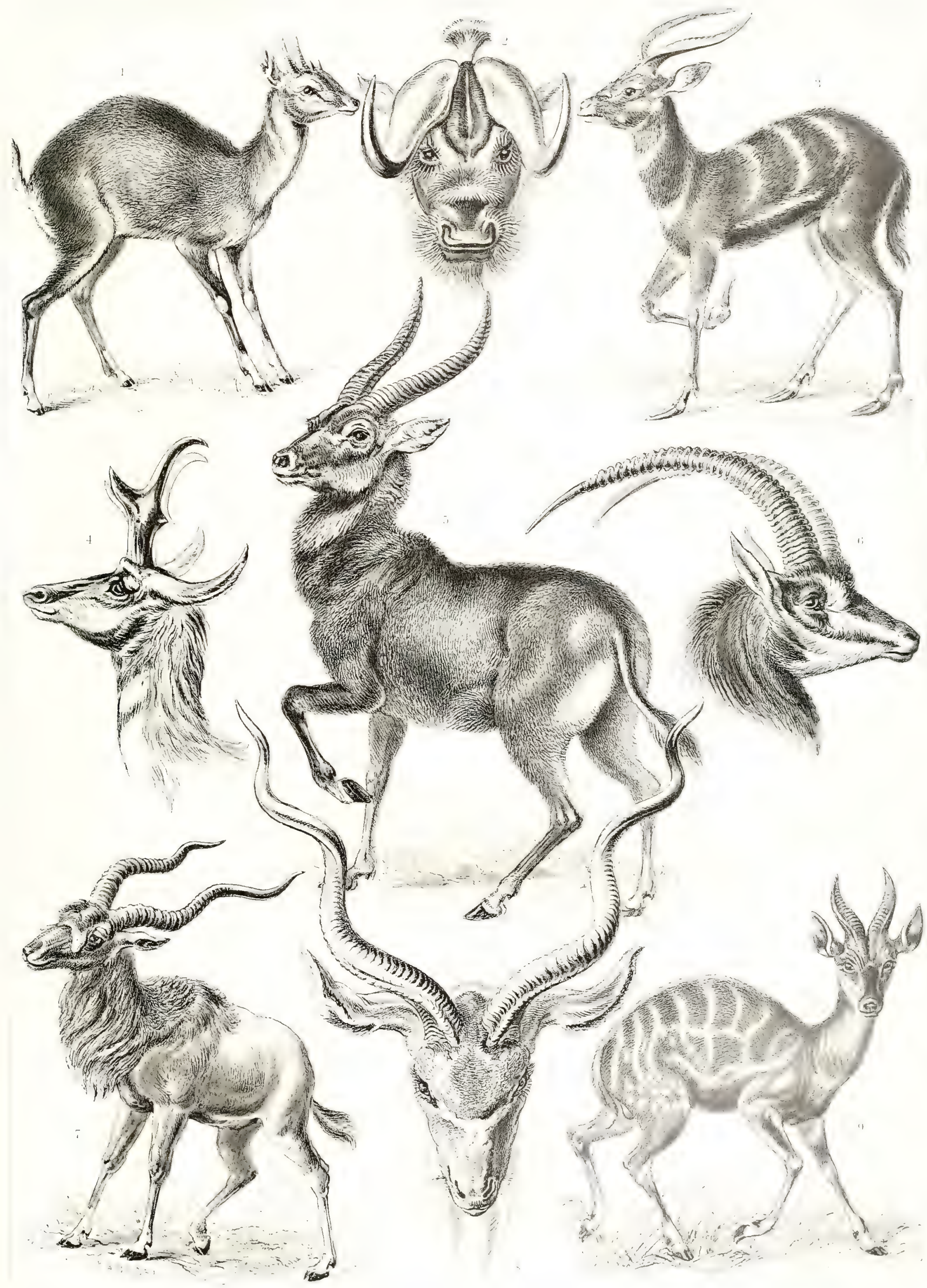

Antilopina. - Butilopent. 



\title{
Kunitformen der Ratur.
}

\author{
Supplement= ñeft,
}

Allgemeine Erläuterung und Iyltematiĺche Überlicht.

Von

Ernit Бaeckel.

Leipzig und Wien.

Verlag des Bibliograpbijcben Infituts.

1904. 
Mne Redte bom Berlegex borbefalien 


\section{Dĩadiwort.}

(D)

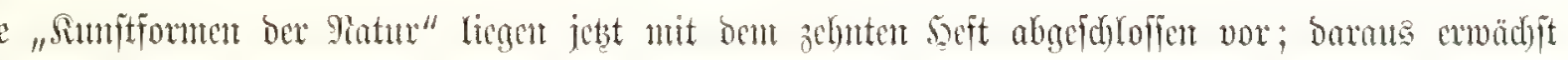

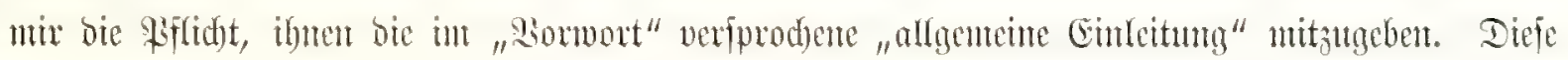

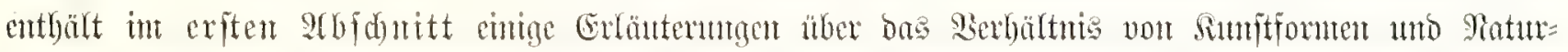

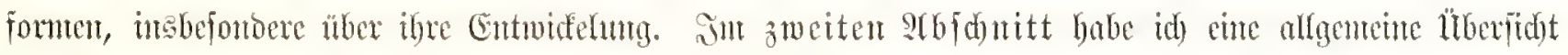

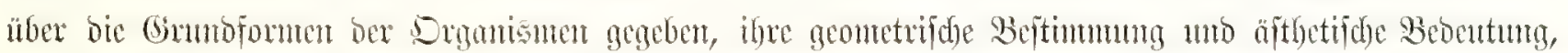

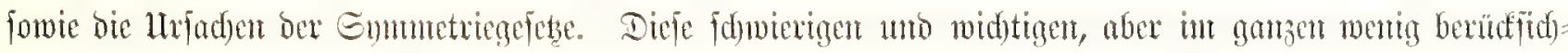

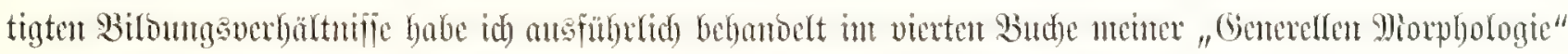

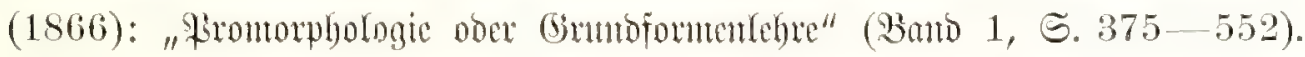

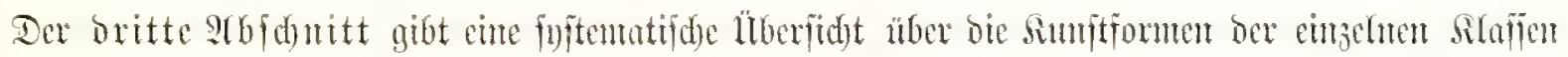

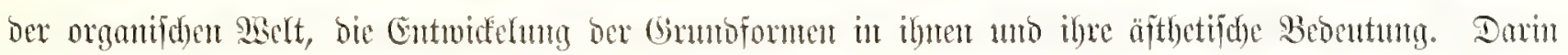

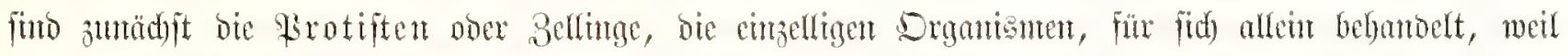

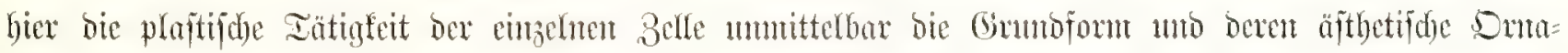
mentif bebingt; bas gilt ebenfo von den Mrpflanzen (Protophyta) wie von ben Urtieren (Protozoa).

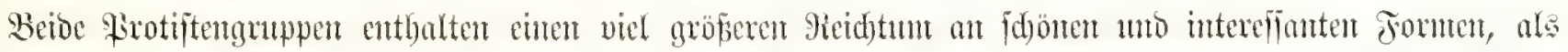

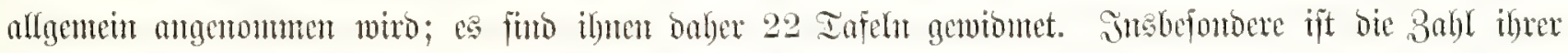

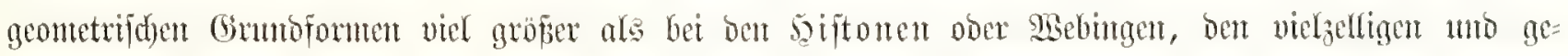

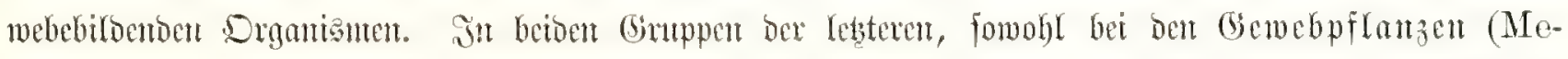

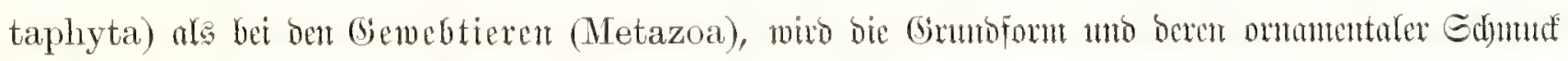

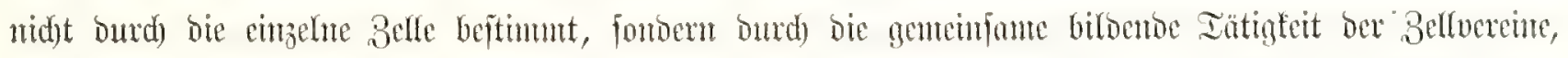

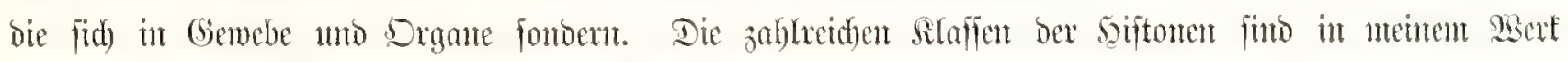

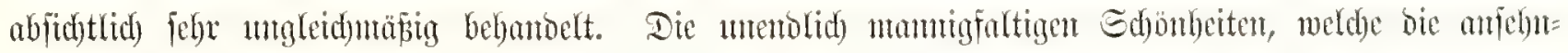

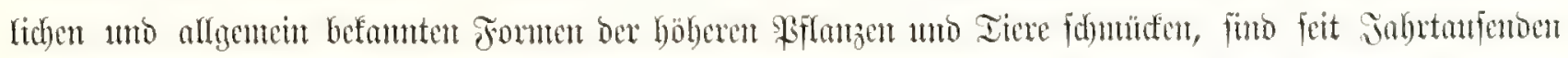

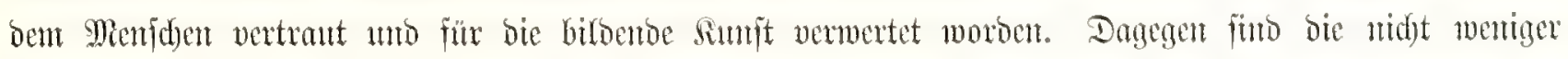
reidjen uno zum Teil ganz cigenartigen Formen ber mederen Metaphyten uno Metazocn weiteren ge

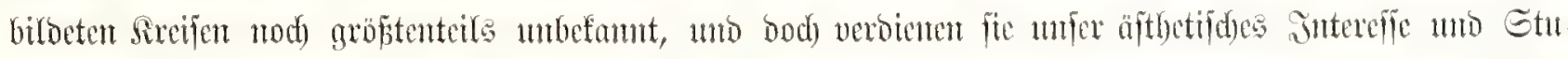

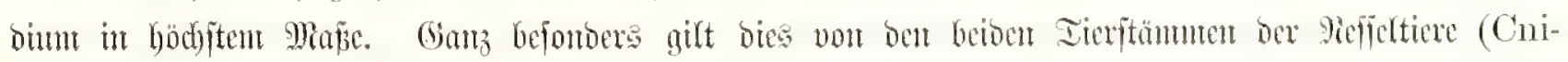

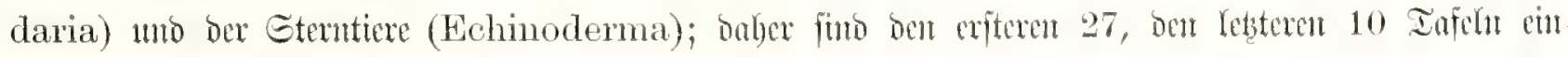

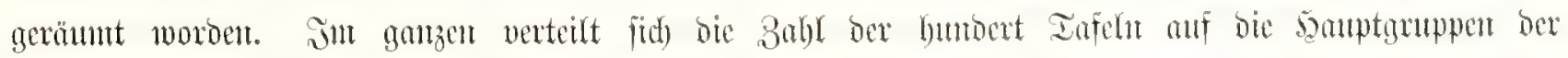

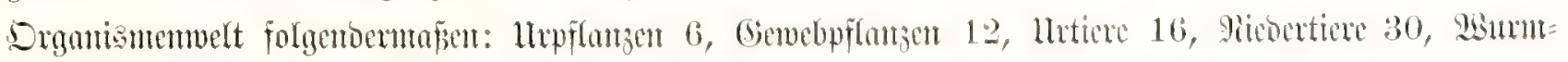

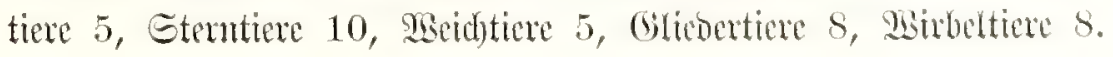




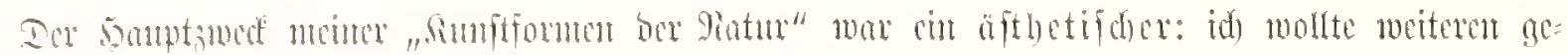

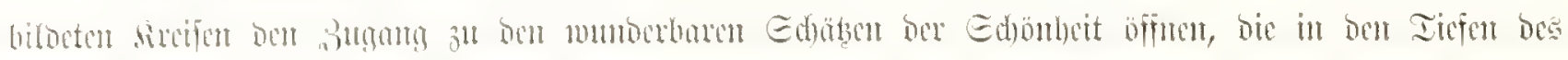

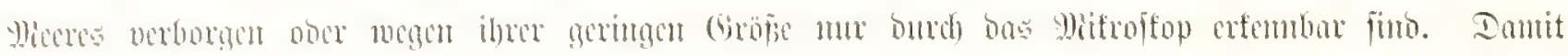

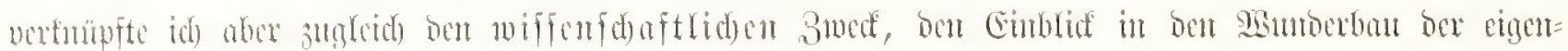

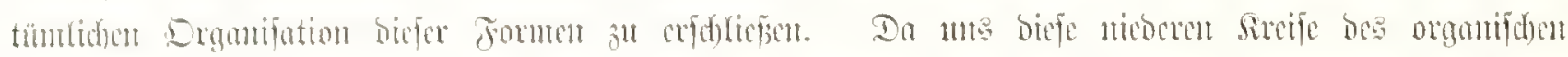

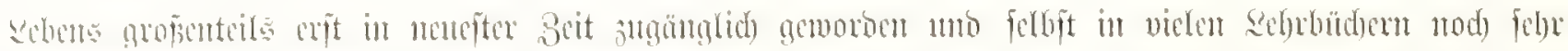

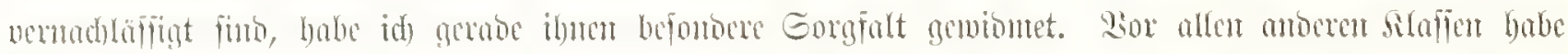

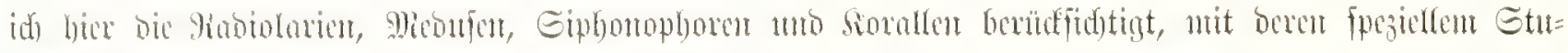

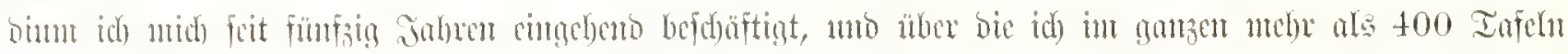

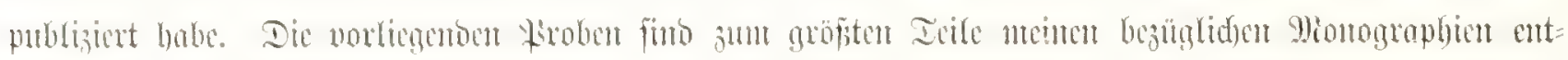

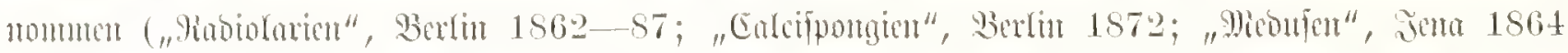

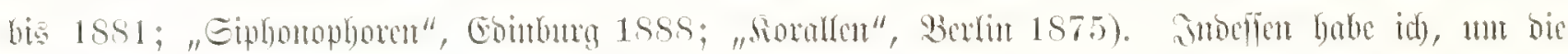

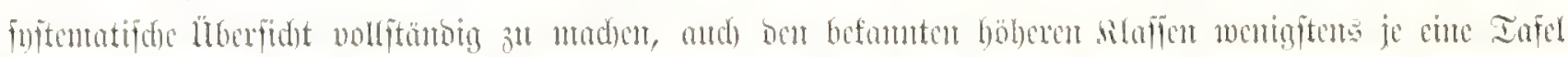

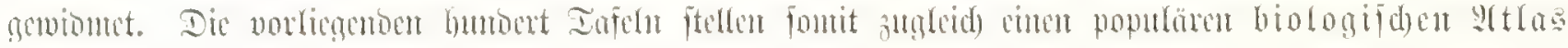

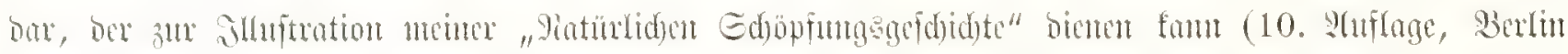

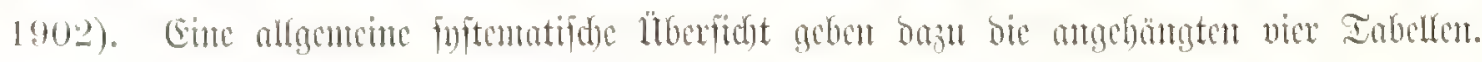

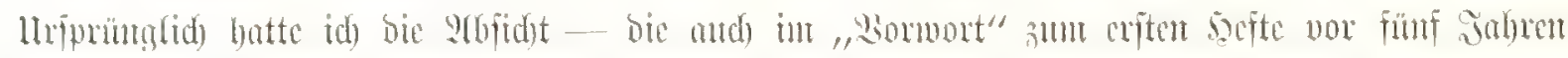

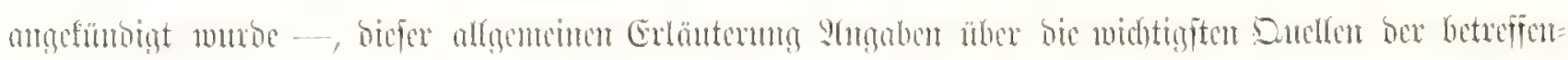

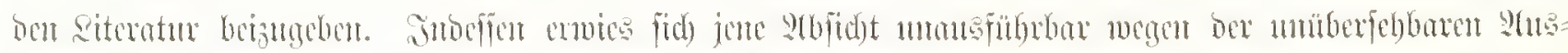

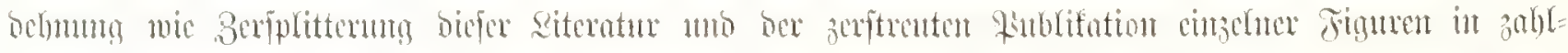

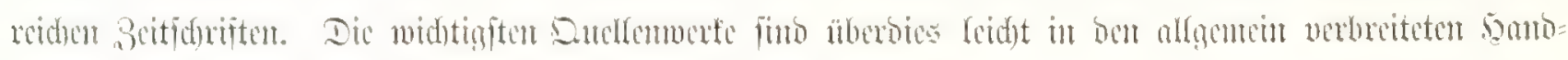

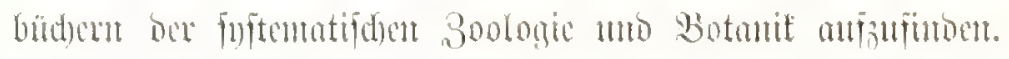

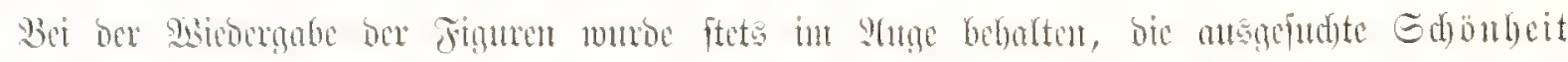

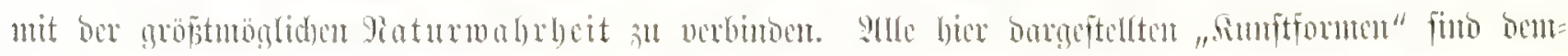

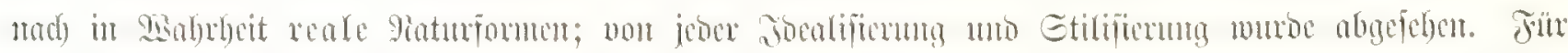

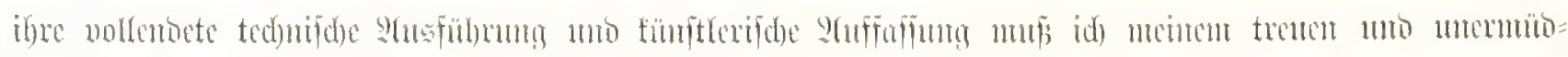

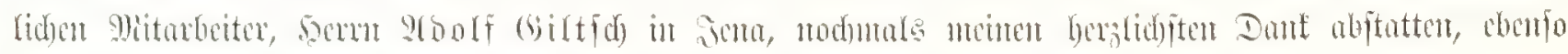

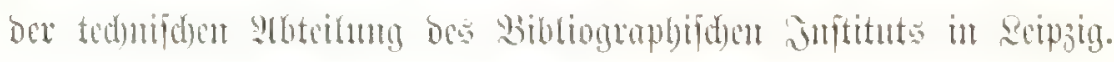

Sena, int gribjulyt 1904.

(Ex)lt Tarderl. 


\section{Inthalt bes Sunplentent=seftes}

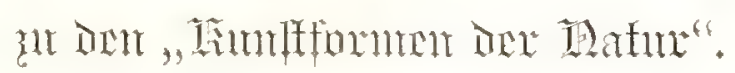

\section{Die Maturiormen.}

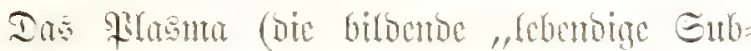
ftam"). - Dic Riatur bes RLasma. - Die Gede

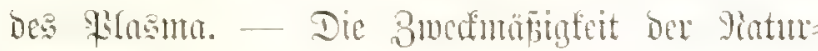
formetr.

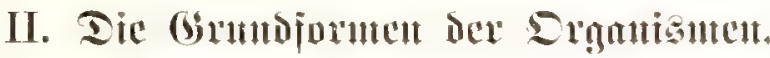

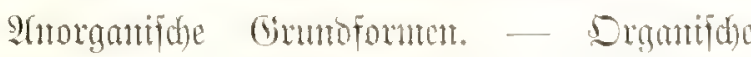

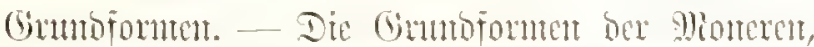
ber Bellen, Der Counbien, ber satitonen. Die Gen= metric bex Ginmoforment.

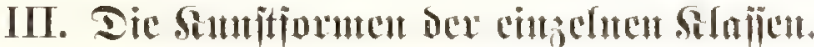

A. Die Sunftoxmen ber Bellinge (Protista). Chrontacen - Raulotonten - Diatonten

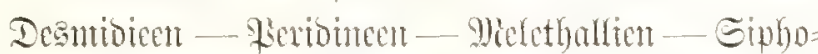
neen - Bafterion - Eporosoen - Enboien Mincetozoen - Babiolaricn - Ihafamoulgoren Jlagellaten - Ciliater.

B. Die Sumptornen ber Gemebpfanden (Netaphyta).

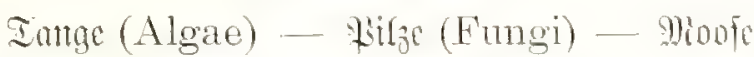
(Bryophyta) - Fame (Ptelidophyta)
Yiaftionter (Gymmospermae) - Isfontix (Angiospermae).

\section{(. Die Sumiformen ber Sicoerticre (Coelenteria).}

Itroanticre (Gastraeades) - Edmanmticre (Spongiae) - Fiffelticre (Cnidaria) - Pilot= tenticue (Platodes).

\section{1). Die Aumftoruten ber Dbertione (Coelomaria).}

gisumntice (Vemalia) - Eterntiere (Echinoderma) - Misidicre (Mollusea) - Gifrocr= ticre (Articulata) - Ssibeftice (Vertebrata).

Erite Iabefle: Drommng ber humbert Iafeln Der "fiuntformen ber gatur" mad) Der foftemati= fden Peibenfolge ber Silafient.

Bucite Iabelfe: Itberind ïber bie Sauptoruppen ber geontetrifden Ginutoroment (Fromtorpho= (ogiffes Suftem).

Dritte Iaberle: Drotphologidyes Enjten ber Pro= tiften und Gowebnflamien.

Wierte Iabelle: Miorphologifdes Enftent ber Ge mebticle. 


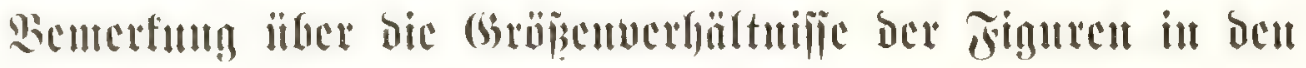 "Silmitformen ber Siatur".}

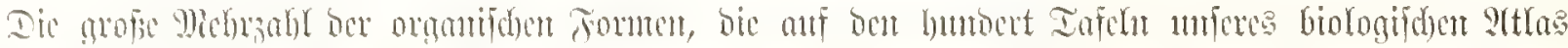

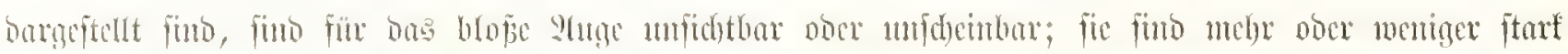

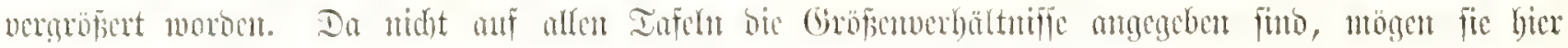

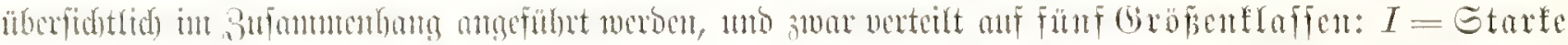

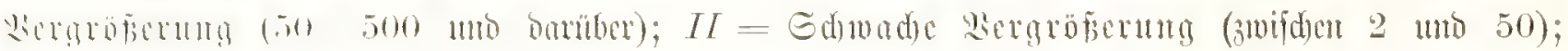

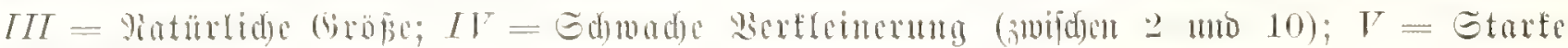

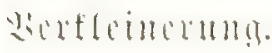
1. Cireogoniar I
2. Globigerina $I$
3. Stentol $I$
4. 'Priceratium I
5. Ascamila $I . I /$
1i. 'Tubuletta II
7. Epibulia II
$\therefore$ Desmonema $I I I$
!). Maeandrina /I. III
11). Ophinthrix /I
11. Heliondisens I
I.- Milinla $I$
13. Dinobryon $I$
14 Perilinimm I
15. Ymaria $I I I-V$
li. Pexantla $I I$
17. P'onpema $I I$
Iร. Lintuntha II
1!. Pemmatula II
201. Pentaterinus III
21. Xiphlacantha $I$
2... Elaphospris $I$
2:?. Cristitella II
-1. Stamistrum $l$
2.). Diphlasia $I I$

-16 Carmaris II. III

ㄴ.7. Hominiploxa $I I$

2.S. 'l'oreuma $I I I$

24. (Yyathophyllum II,LII

:31. Clypenster III

:31. Caloeyclas I

:2. Pertalion I

:?:. Flustra $I$

: t. Pediastrum I

i.). Farrea $I-I Y$

31. Aequorea III

:17. Discolathe II

$\therefore$ : Periphylla $I / I$

:19. Gorgonia II, I

41) Asteriats II

11. Dorataspis I

42. Ostracion III

1:i. Aeolis $I I$

14. Ammonites III

15. Campanulina $I I$

46. Gemmaria $I I$

17. Iimmlus $I I I$

1․ L alcesmaria /I

19. Heliatetis III

51). Spormtipus I, II i1. Collosphaera I

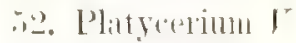

iis. Murex III

$\therefore$. Octopus $I V$

$\therefore$. $\therefore$ Cytherea III

50. Calanus I

57. Lepras III

5. Alneita II

.)!. Strobalia III. II

60. (jilaris $I I I, I I$

(i1. Aulographis $I$

i2. Nepenthes III

bi3. Dictyophora $I I I, I^{\prime}$

ibt. Cunlerpa II

(i5. Delesseria $I I I$

(iti. Epeirar $I I I$

(i). Vampyrus II

irs. Hyla III

199. 'T'ubinaria III

70. Astrophyton III, II

๙1. 'lympanidium $I$

7. Polytrichum II

$7 \therefore$. Erysiphe $I$

76. Cypripedimn $/ 1 /$

7.). Diplozoon II
76. Alima $I I$

7. Bissia $I I I, I I$

7x. Charybdea III

7!). Basilisens $I V$

:I). Pentremites $I I$

í. Lagena $I$

s.. Marchantia II

4.3. Cladonia III. II

s.t. Navicula $I$

45. Cyntlia II

sio. Parthenope III, II

'7. Pegasus $I I I, I I$

8.. Pilema III

49. Testudo $V$

10. Callocystis $I I I, I I$

!1. Astrosphaera $I$

42. Alsophila $V$

(1:.) Areyria I

91. Araucalia $I I T, I V$

9.) Placocyst is $I I I, I I$

(ui Sabella III, II

97. 'L'ereloratula III, II

!s. Amelia $I I I, I I$

(H). Trochilus III

100. Antilope $V^{\top}$ 


\section{Die Iafunfunmen.}

Das Filnamn (bie birbento "lebentige Sub= ftan $\left.{ }^{\prime \prime}\right)$. Die midytigften Fortidyrtte, bie wir in ber

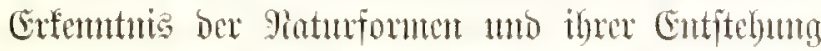
gemadyt haben, beruben auf ber Feitfellumg folgen= Dex vier Ifeorien: I. Die Belfenthenric (1838)

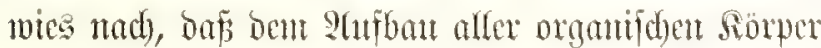

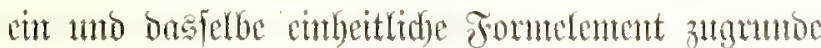
liege, bie Belle. II. Die Silasmathentie (1858)

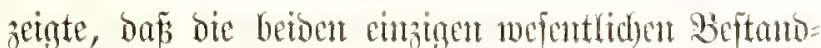
teile biefer Befle ober bes "Elcutentarorantionm"

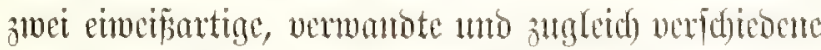
Subftanzen feien, bie feitere Subjtans bes imeren Bellferus (Karyon, Nucleus) und bic weidyere Subitunz des äuperent Berlentetbes (Protoplasma, Cytosoma); alle anocren organifacn (5e:

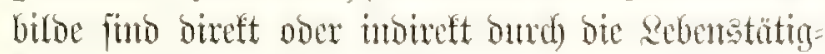
feit biefer betoen aftiven Plasmaförper entitan=

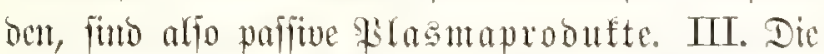
Defaendenztheorie (1859) crffärte bie Entitelum ber unzäbligen organifdent Formen, die wir als Arten (Species) bon Dieren mo

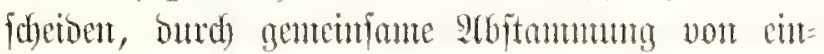

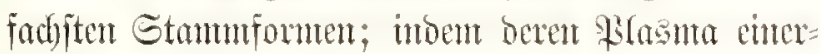

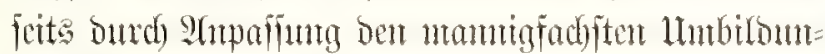
gen unterlag, moerfeits burd) Sicrerbung bie ermor= benen Cigenfdyaften von Generation żl Generation übertrutg, f(c)uf bie siatumbututung in Simmpie ums Dafen inner nete Spezies. IV. Die Protiften= theoric (1866) Ychrte, bon alfe älteven Drgantis= men, ebenfo dic Urpflomben, Protophyta, wie die Untiere, Protozoa, miprünglich cinzellig maren,

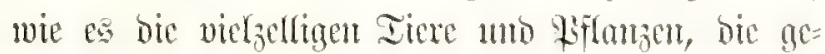
webebiloentoen Mictazoen, vorübergehento in ber erften Sugento furdo; fie zeigte aber zugleid), bur bie äl= teften und cinfad)iten von allen Drganismen, dic Moneren, nod) nidht cinmtal ben fommoert cince echten (fermbaltigen) Belle befitzen, fonbern homo gene, itrufturtoje uno fentoje Sifannaförperdan fitto (3. 3. Die Chromaceen unter ben Froto= photen, bie 氶rotantoben und Safterien unter den Sirntozoen). Dannit war zungleid) bie untent:

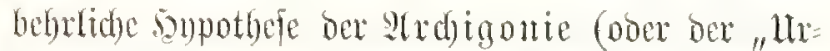
jenguntg" in cinten bejtumnten Eintre) foit begrün=

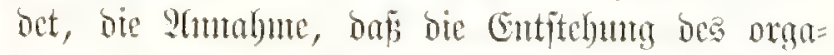
nifden Sebens auf umferex (erbe Durd) Bilomm fold)er Shoneren ans anorganifden Sierbintontagen (Maffer, Sioblenfätre, Salpeterfümre, S(mmoniaf) zu crflärent jex. Stus fold)en einfadjen, printären Moneren fomten bie ältepten edsten 3 elfen evit fefunoür entftanton fou, inocm igre unfprünglict) bonogene Pirasmafubitan (Plasson) fid in stwe veridjiedente Gubitanzen fontorte oder "Differenzierte", in bas feitere Sarnonlasma bes imeren Belffems แnto bas weidere Entoplasura des ämeren Bellen= reibes. Son bicien betoen wefentliden Beftando= teifen ber Belle ooer bes "Elententarorganisnnt" beforgt bas äñ̃ete Entoplasma bie Tütigfeit ber

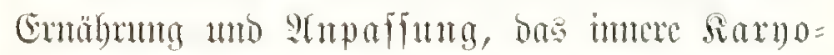
prasma bie Fumftion ber Fortpflanżng umb s:er= cubutng. Da bie moderne Entwifelungelebre bie ganze Miannigfaltigfeit ber organifden Formen uno

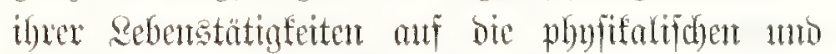
dyentifochen Beränbenumgen biefer betion aftiven

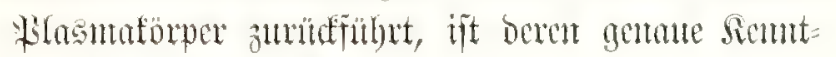
uis von hödjiter Sebeutung.

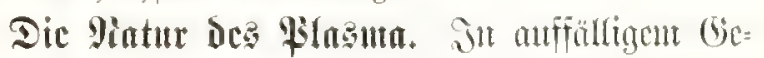

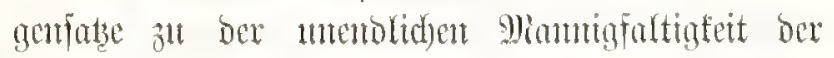
Forment, wetde bos silasuta burde feine ploftifde

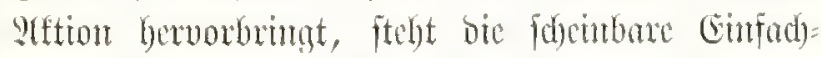

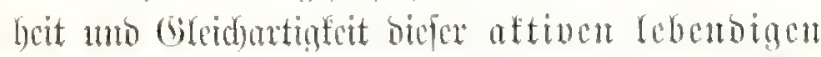

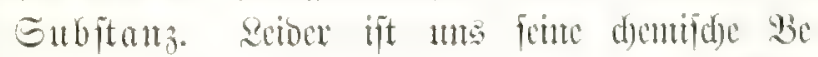

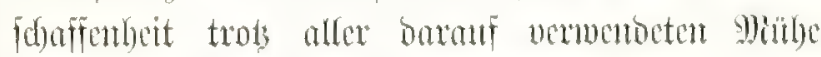

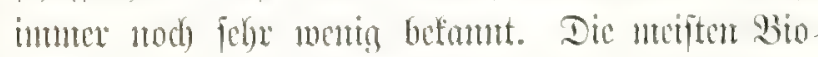
logen baltent os fill cin Gemenge von simeifartigen Siorpent Imb nebuten cine bejtimmte Elententar:

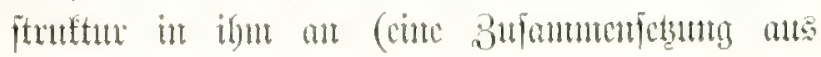




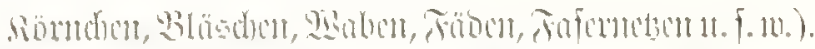

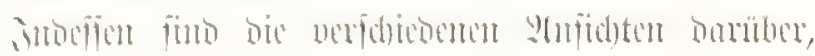

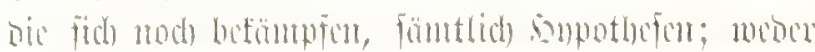

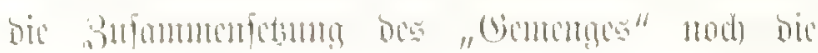

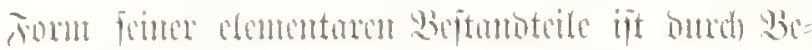

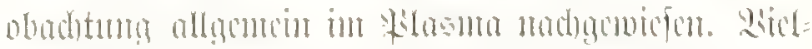

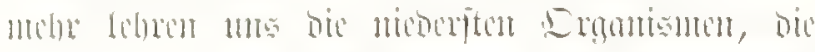

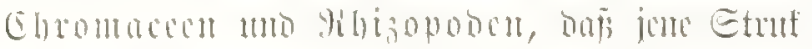

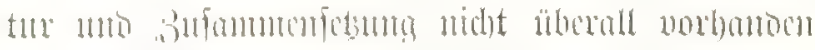
ijt, mo bafi fie als cine jefmoüre, nidht cine pri-

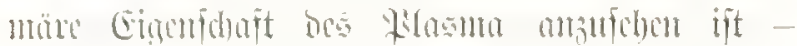

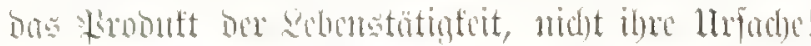

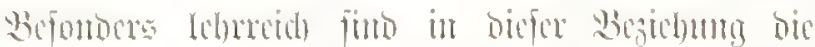

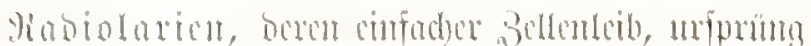

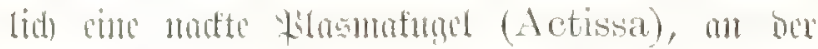

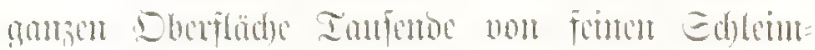

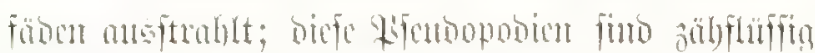

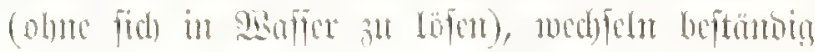

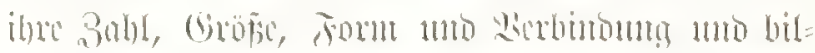

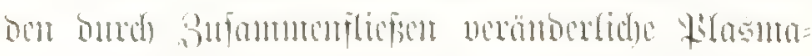

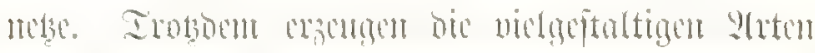

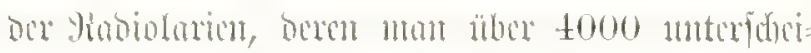

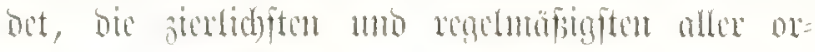

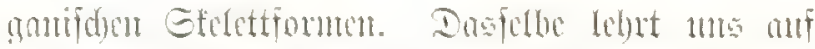

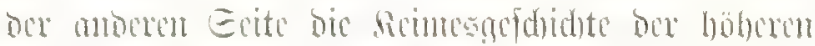

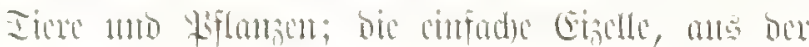

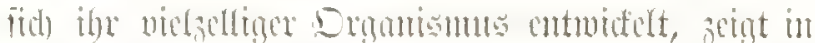

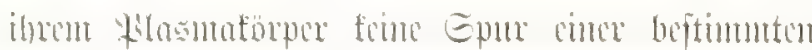

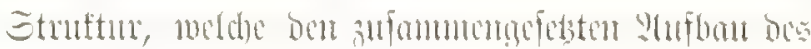

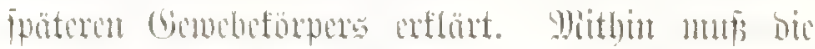

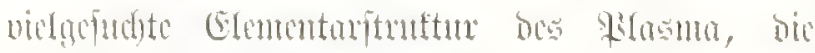

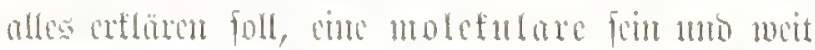

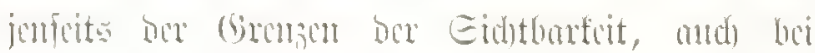

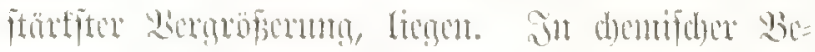

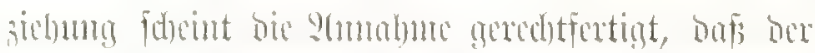

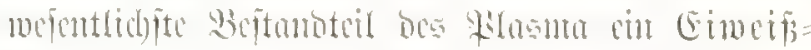

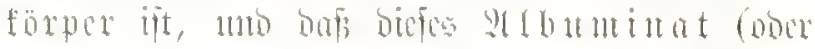

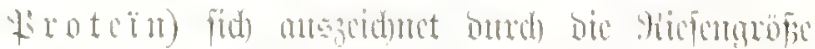

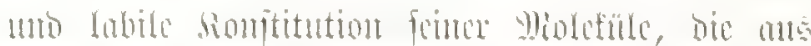

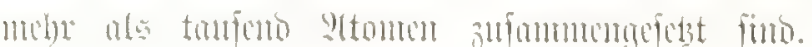

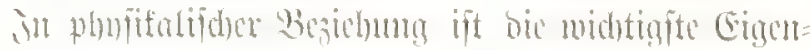

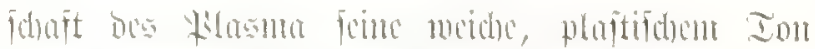

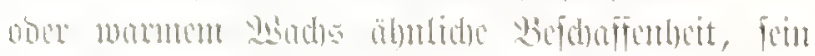

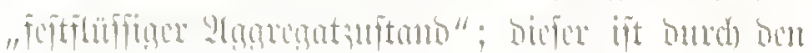

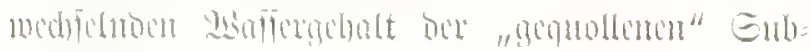
itoury bedingt.

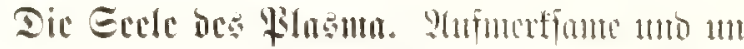

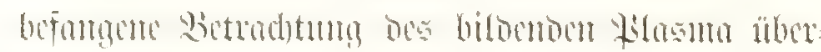

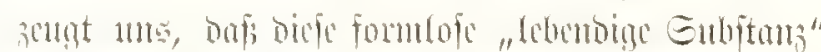

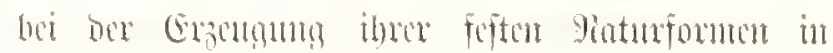

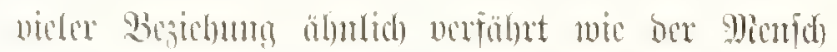

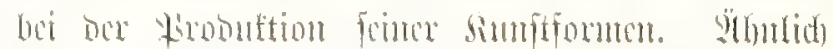

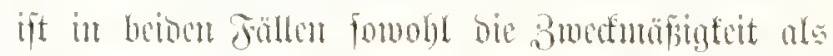

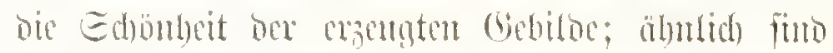

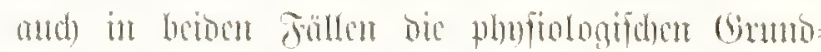

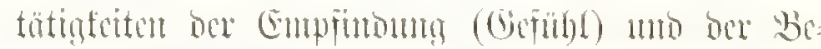

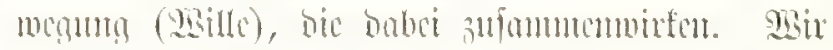

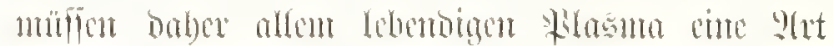

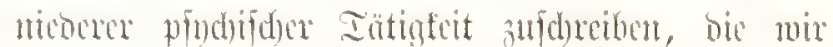

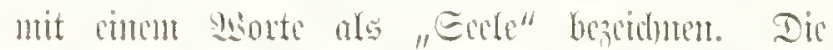

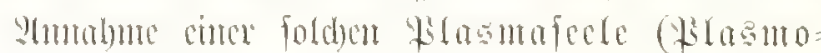
pindac) irt fon beshalb geredtifatigt, weil alle

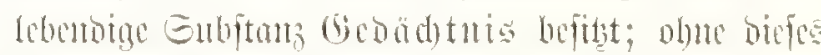

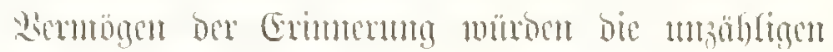

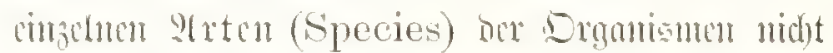

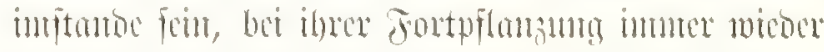

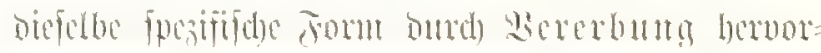

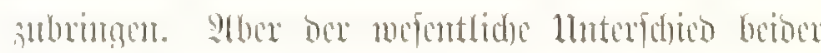

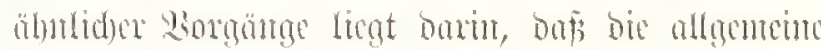

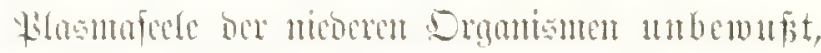

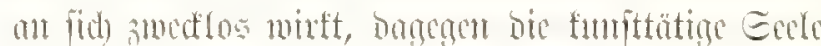

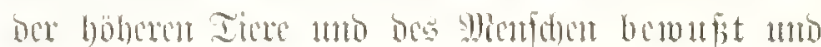
smetimition.

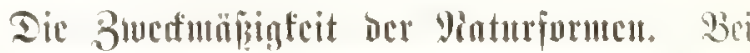

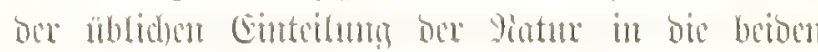

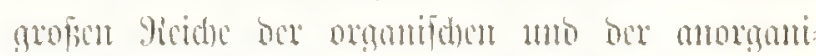

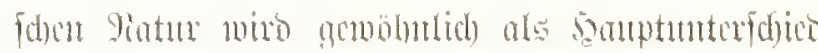

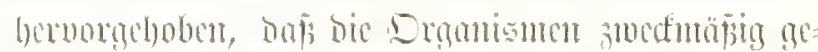

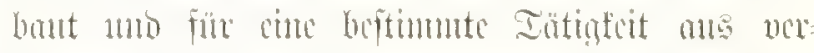

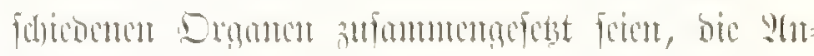

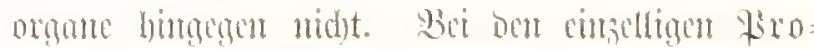

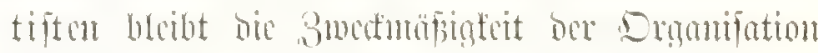

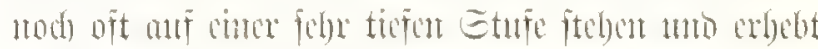

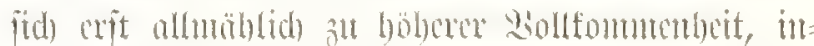

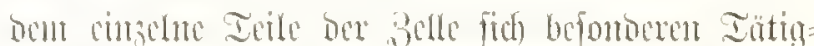

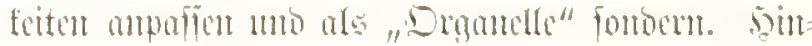

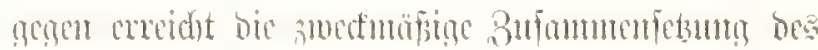

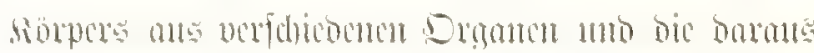

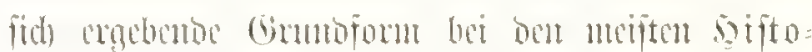

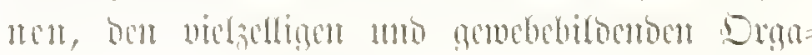

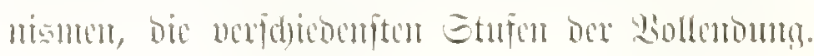




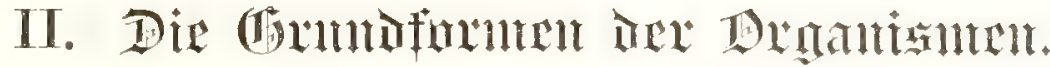

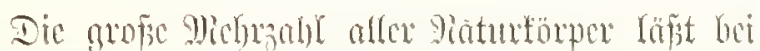

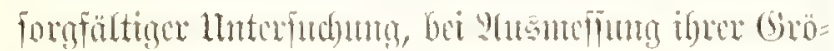

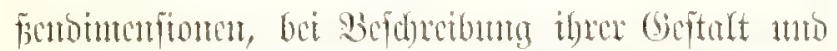

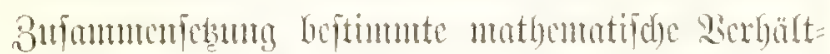

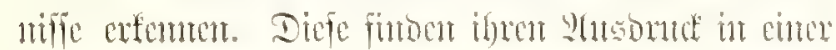

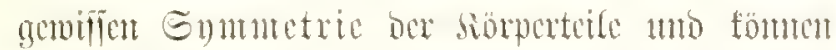

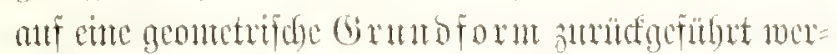

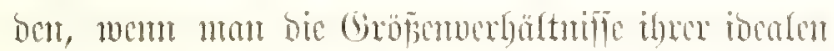

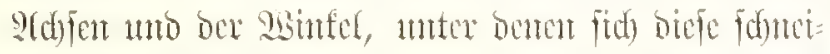

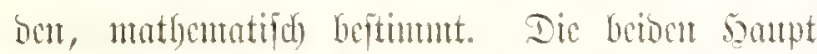

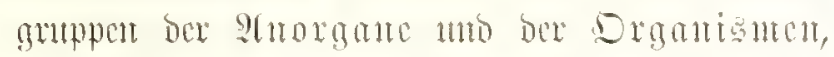

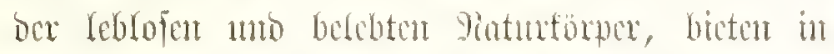
biefer Bestebung tets äbutide, teig verfoleocme sichouttume.

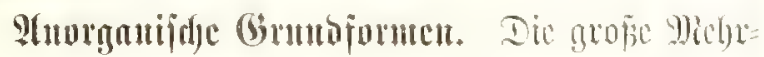

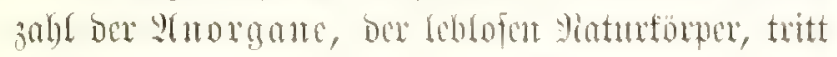

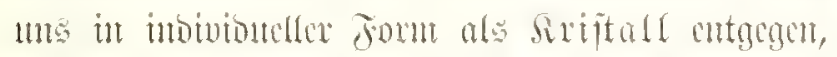

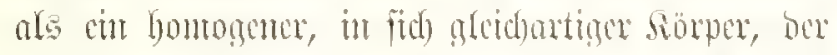
non cbenen fräden uno geroben Simien (siantent) begrentat wiro, bic fidf unter beftumnten sinfeln

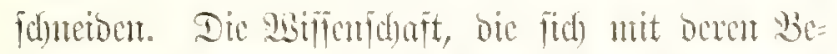

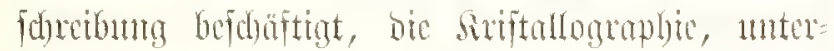
fdectoct nแ menige $(t-6)$ souptgmppen non sirt=

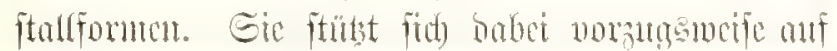

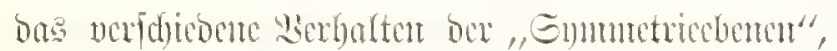

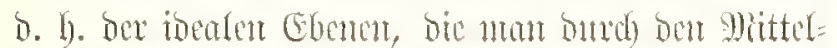
punft bes Suiftalls legen, anto burds bic man bon=

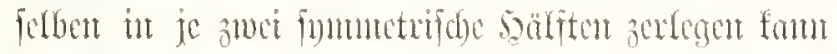

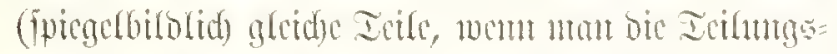
cbene als Epiegd Donft). Gicht man bic Babl min bie sage bicfer Gummetricebonen (ober Gnm=

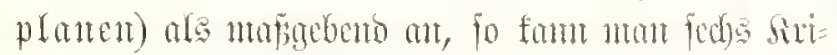

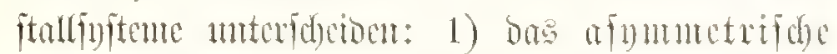

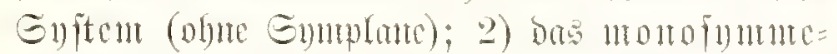
trifde Enften (nit cinte cingign Emmplane);

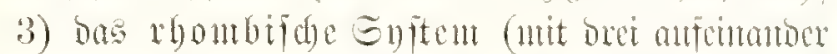

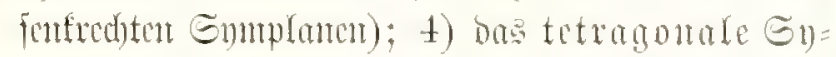
Pten (unt Finn Gumplanen, von benen bic soupt=

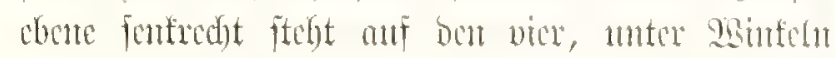

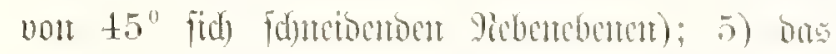
bcragonate Enften (unit fubent Emmplanten, nän=

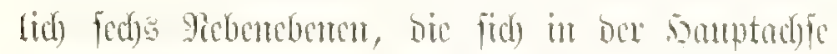

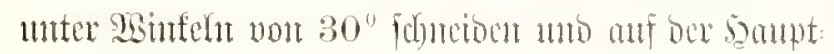

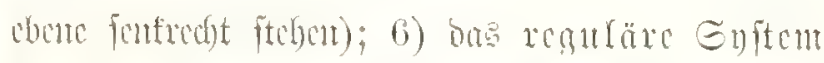
(nit ment Eumplanm, müntid) bret antentantox

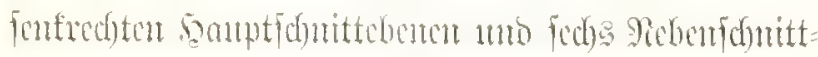

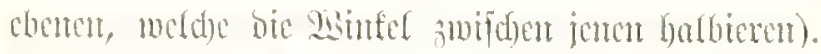

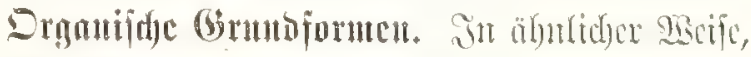

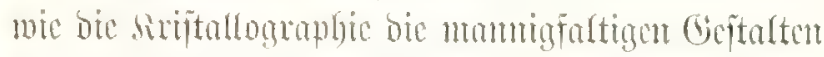

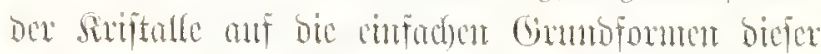

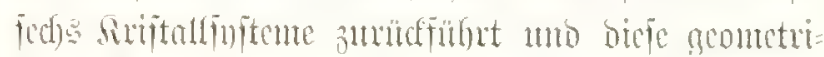

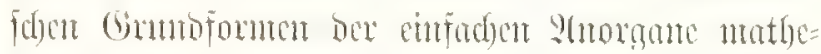

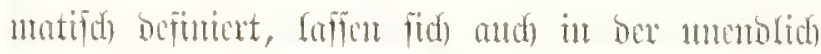

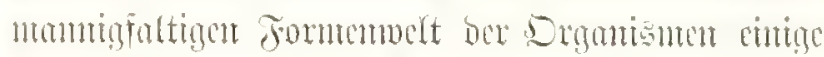

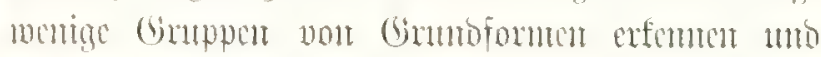

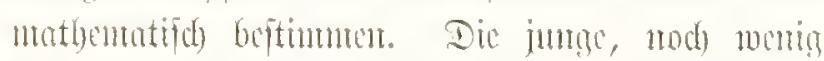

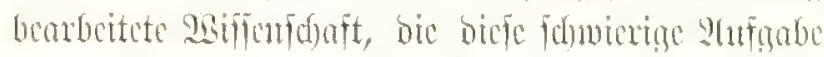

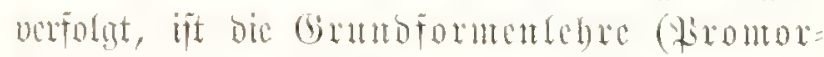

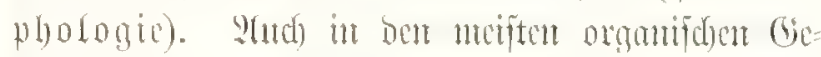

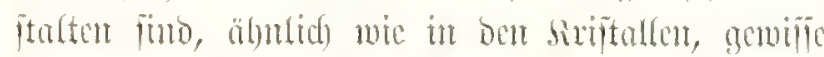

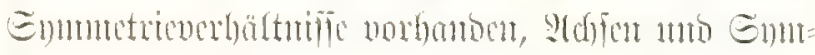

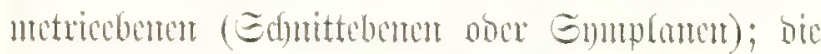

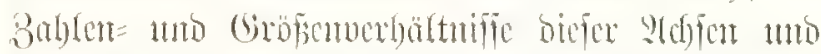

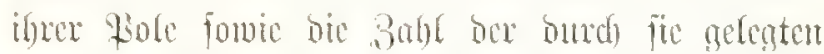

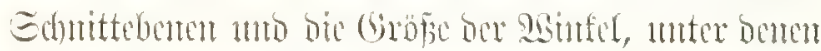

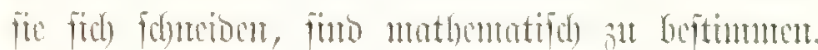

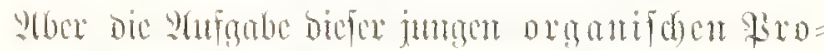

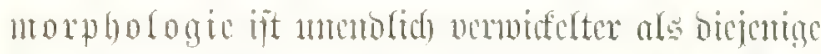

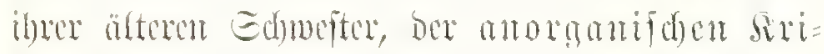

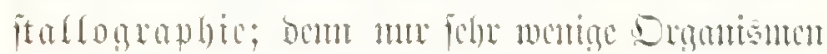
(mu bic primitiven Mioneren) find fo cinfade ano bontogente soorper wie bie fruftalle; alle atberenteben=

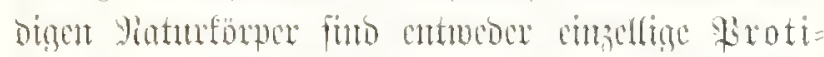

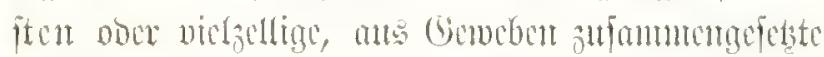
Siftonter.

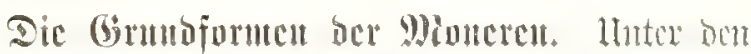

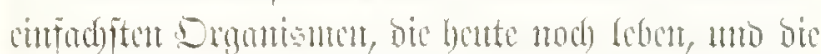

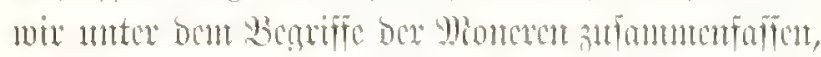

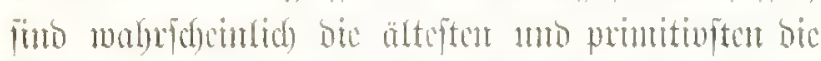

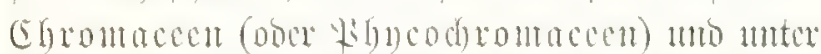
(i)men bic Gattuntur (hoococens, A phanocapsa

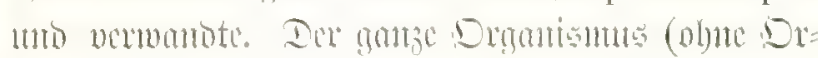

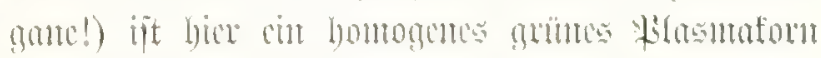

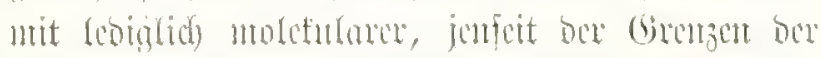

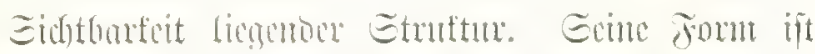

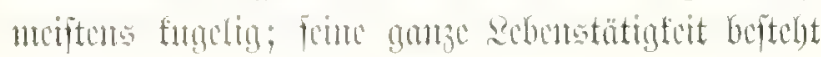




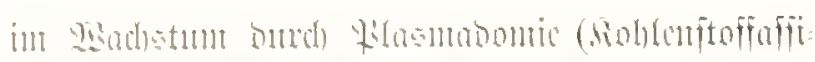

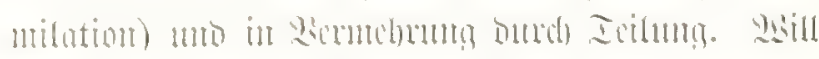

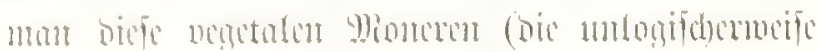

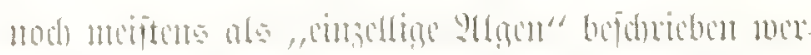

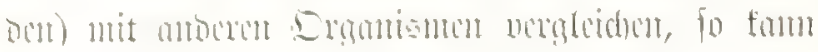

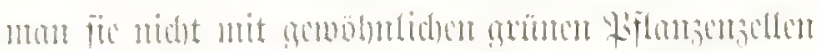

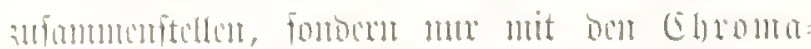

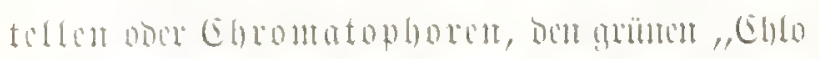

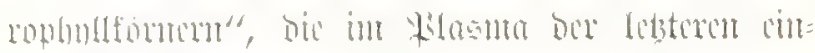

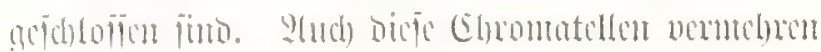

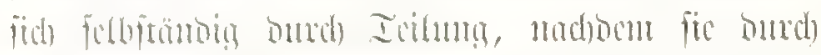
flasmobonte 2 ad

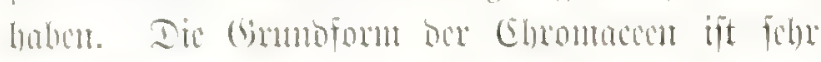

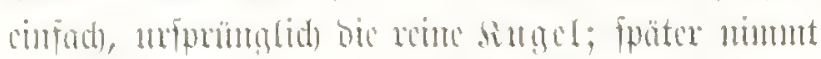

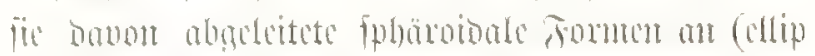

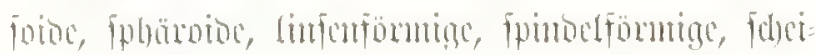

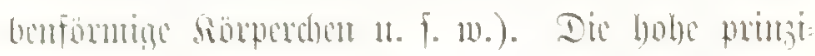

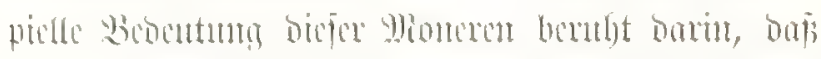

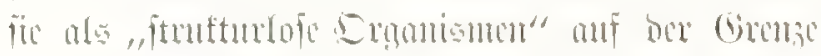

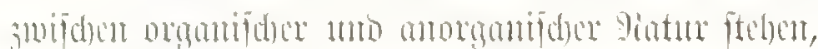

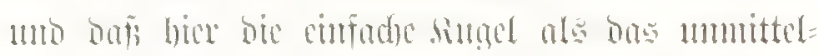

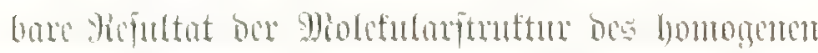

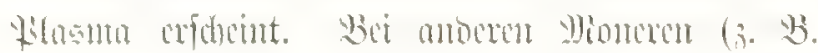
oen plasmophatgen tirotamöbon) bat bex matte,

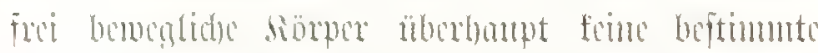
Form, nimmet aber chentalls bie sugeform an,

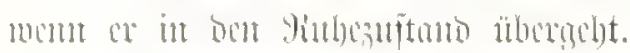

Sic Gramoformen ber Bellen. Die cinfad)m

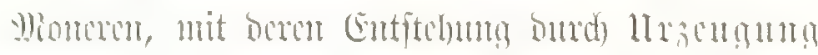

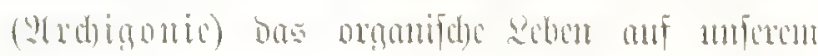

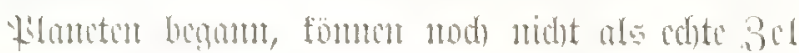

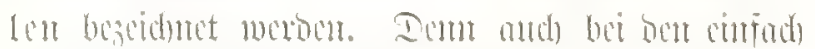

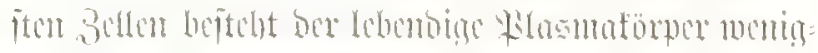

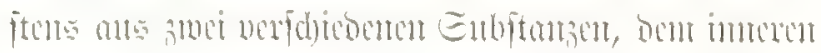

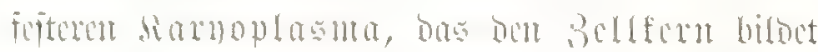

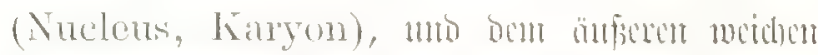
(E) toplasua noce tirotoplasma, bas bat cigat

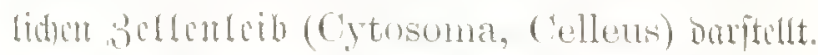

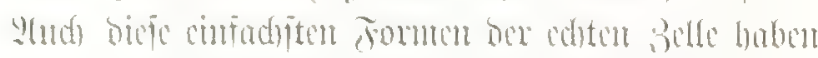

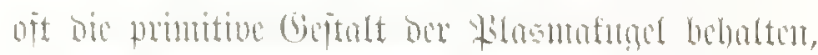
io inter bor Lirotoplunter Palmella, Xinthella. Coccusplatera, mutu bon Froto;our Actinosphacrimm. Actissa, 'Thalassiculla mo mbero

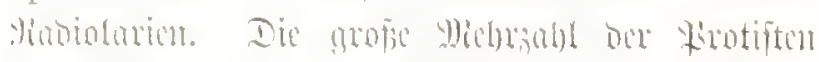

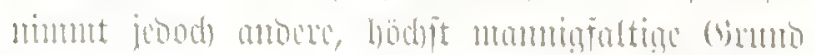

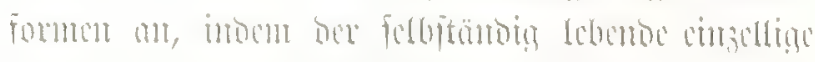

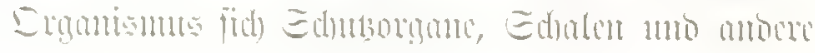

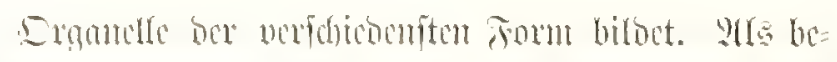

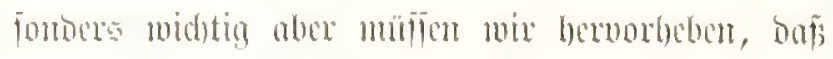

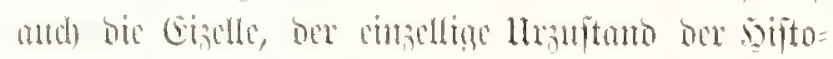

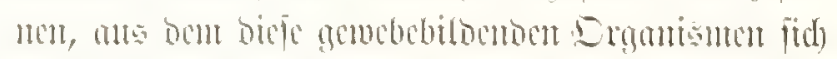

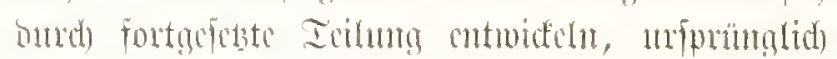

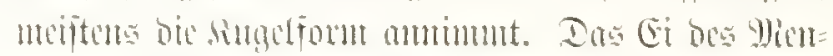

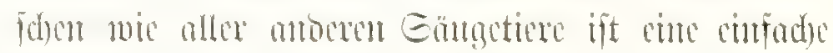

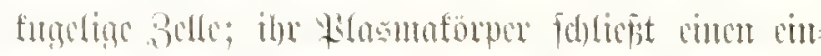

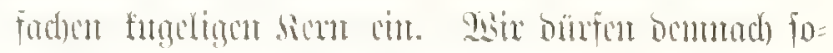

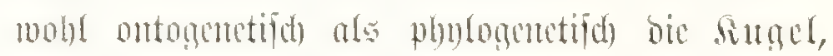

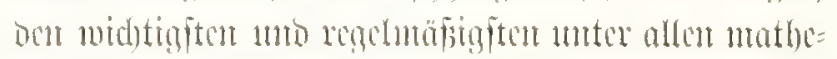

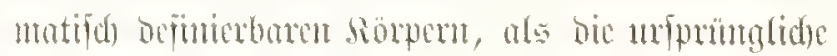
Grmoform bes cinfad)u, curscligat Drgatsmus letroditen.

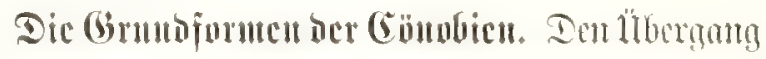

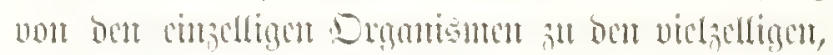

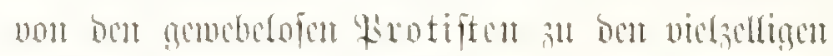
siftonen bilocn jene interefianten Befluereine noer

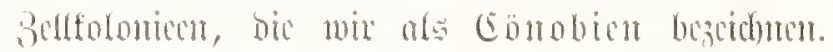

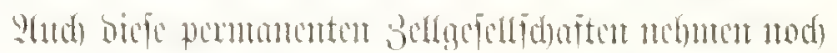
bouffin bie reme form ber dingel an, socm fie fid

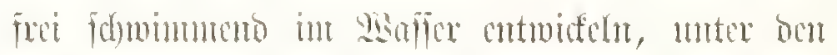

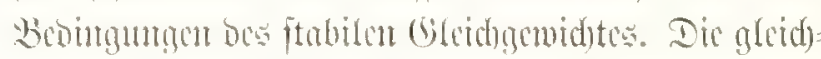

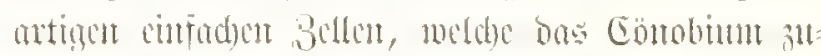

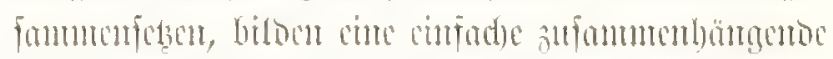

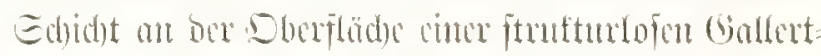

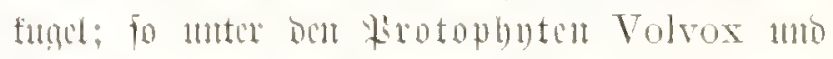
Halosphaera, unter sent \&rotosocn Symura un Magosphaera. Stber gans bicfelbe d)arafteritifde

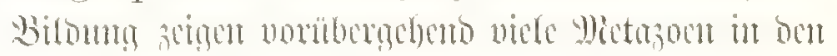

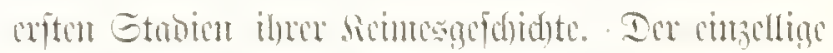

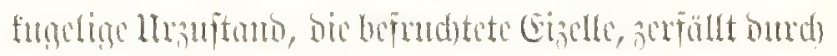

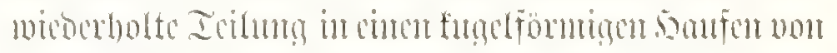
glechartigen 3ellen: Mioulberfen, Morula; inocu

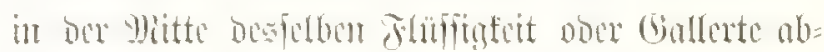

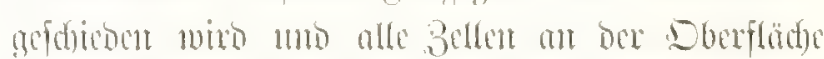
sur

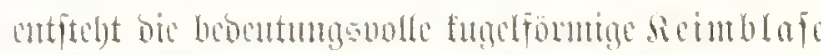
(Blastula); bie Bellemfdidet ift bic aciuthant (Blastoderma), me bex fidf alle nerfdedomen (Ge=

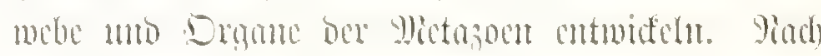

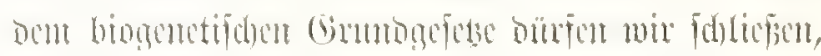

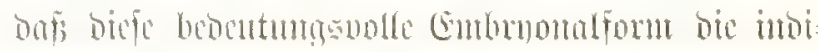

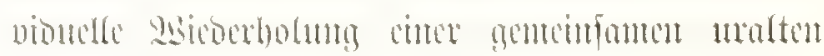
Etmumforut boritellt, ber Blastaca.

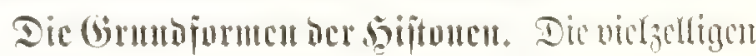

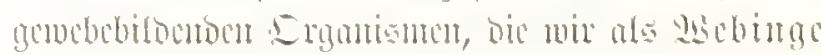


ober biftoment 3ufanmenfaliut - cinterfeits bie plas mobonen Gemebpflanzen (Metaphyta), andorfeits die plommophagent Gewebticre (Metazoa) -

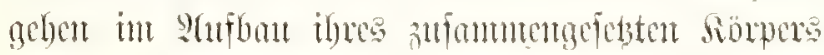

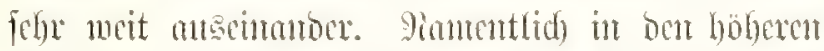

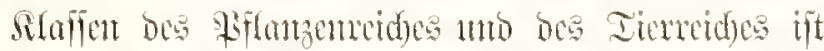

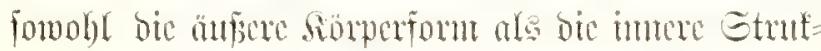

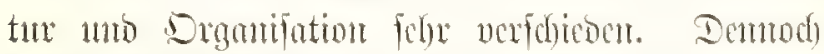

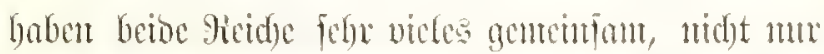

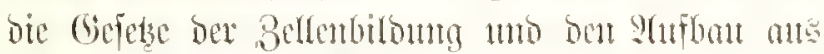

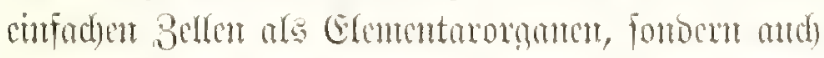
bie Gefedze der Gumbformen, wolde in ber Geftal

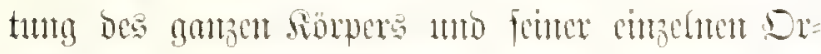
gane bie dharafteriftifide Form bedingen. Diefe Granto= formen und ibre Emunnetriegefere find aber bier

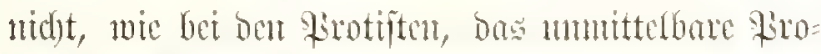

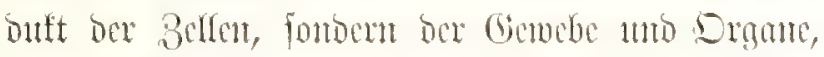
Denten fich bie fosiaten Belten unteroronten. Sion

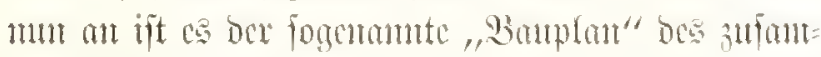

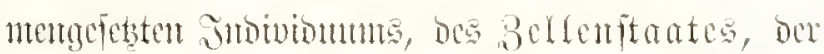
ale, "Thathe" ober "Eprop "bet ben sietaphntem,

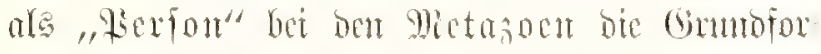

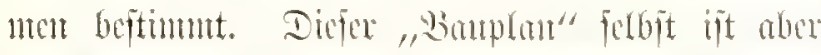

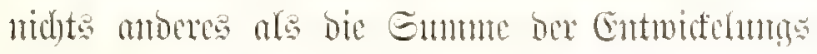

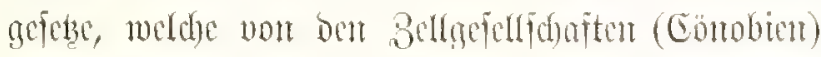

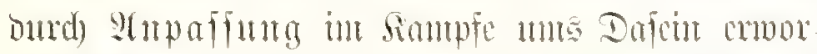

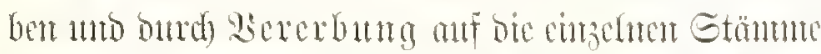
libertragen mutroen. Bhglecid mu hier burde bie

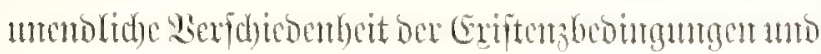

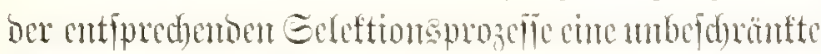
Miannigfaltigfeit ber Formbildong möglid) crfochent,

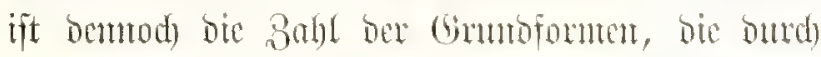

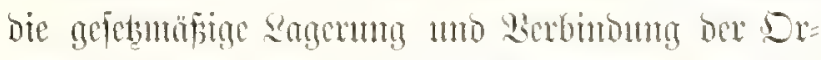

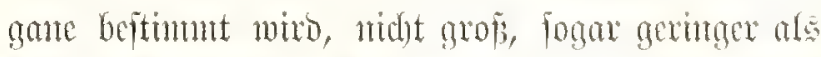

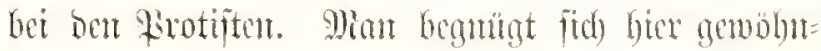

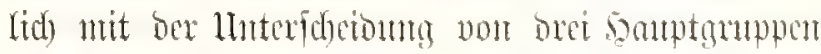

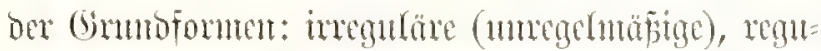
läre ober ftrablige (rabtale) mo bifaterale ober swee =

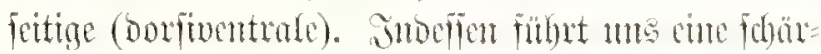

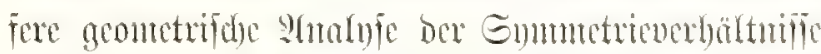

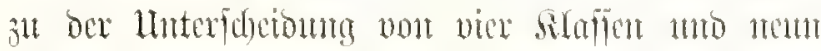

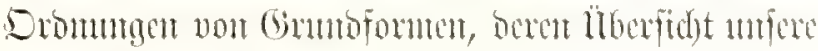
sweite Iabelle givt.

Die Geometric ocr (Brmbormmen. Dic matle

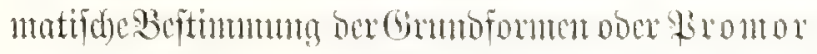

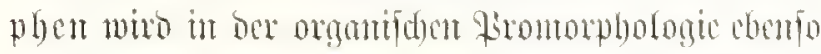
wie in bor arrorganifden sirifallograpbic burd)

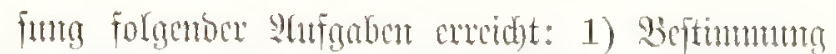

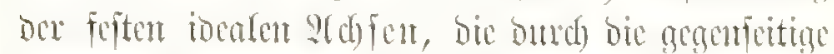

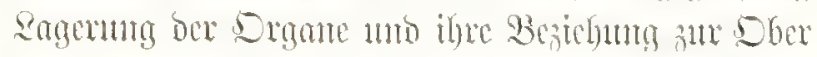

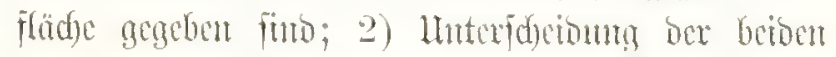

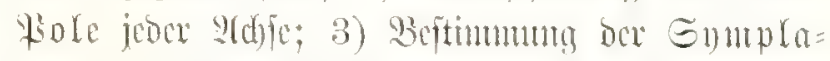

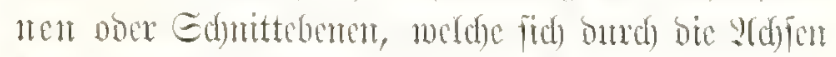

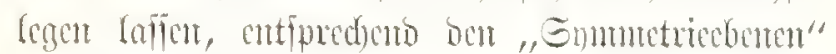
ber siriftalle; 4) Unterforetoung ber gcontetrifdyen

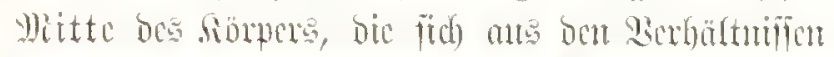
Dex श(d) iid) bas vierflaffige prourorphologifdye Guftem,

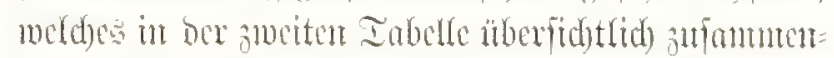

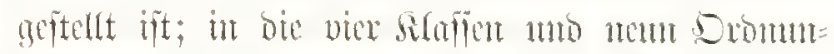

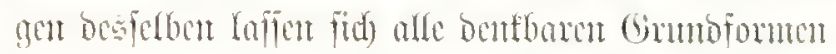
(erd)t cintoronen. I. Centrostigma (Sungefrt): bic

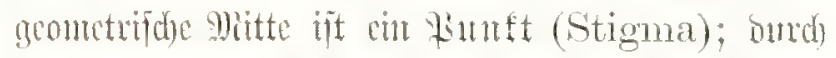

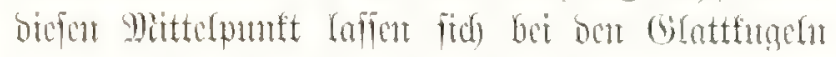

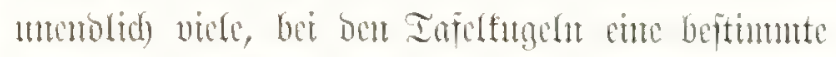

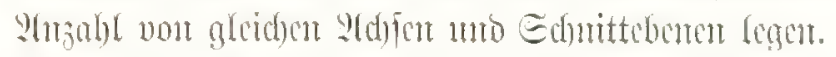

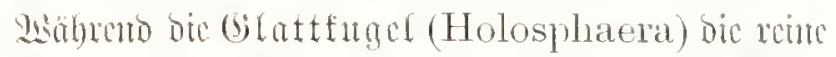

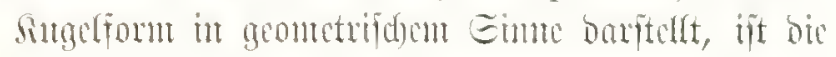
Iafelfuget (Phatnosphaera) oor on "cmos=

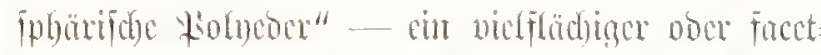

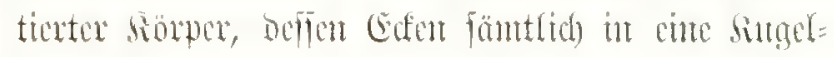
fladje fallen. II. Centraxonia: bie geonetrifge Whitte iit cine gerabe siute, bie sauptad) fe (Pro-

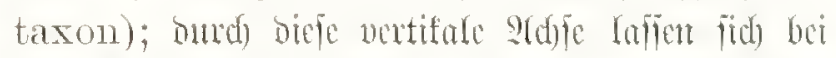
Den Einadjigen (Monaxonia) menofid) vite

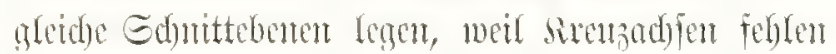

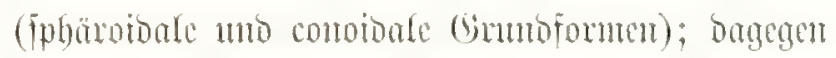
fitto be ben sivenzad)figen (Stauraxonia) jmei ober mefrese horizontale Dueradjen atsingenrägt, anto

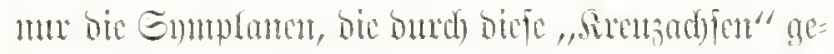

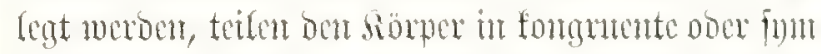

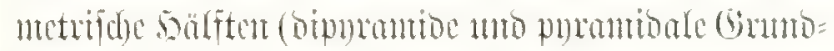
forntent). III. Centroplana: bie (geontetrifge 将itte

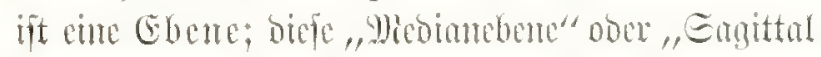

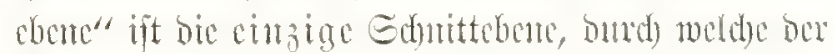

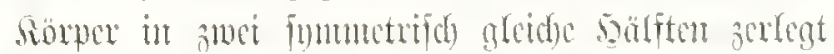

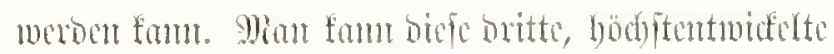

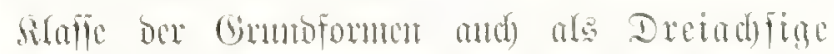
(Triaxonia) bescidunter, meil fie burd) bre metitum

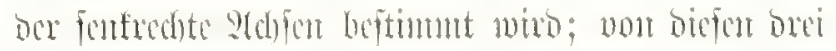

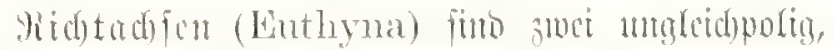

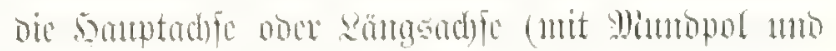

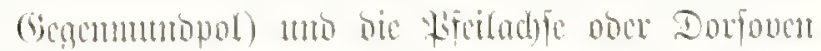

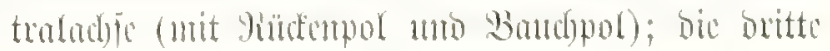




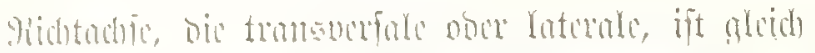
polin, rectits and linfe suble fummotrifd alcid).

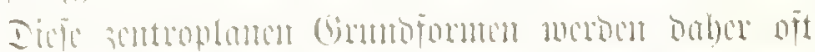
math als sucifotign (Bilateralia) bescidnet now

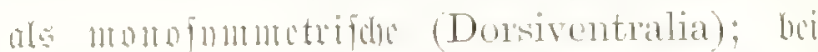

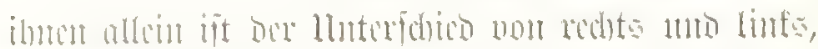

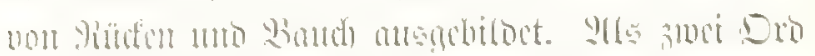

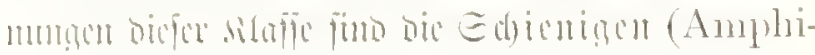

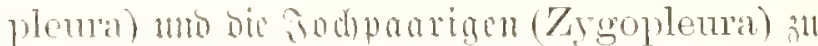

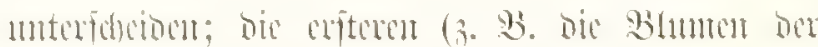

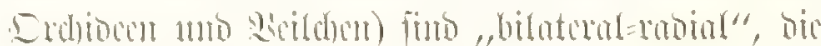

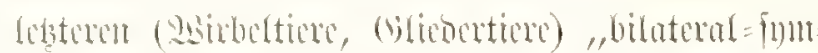
metrifin". IV. Centraporia. Die geometrifde

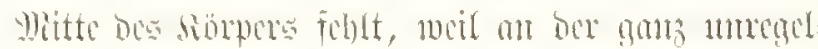

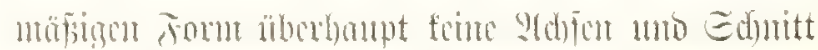
cbenen 34 bejtumen fund (iomeguläm, Anaxonia).

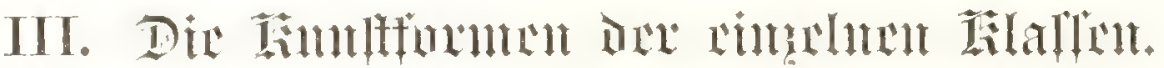

\section{Die Sitnffformen ber Bellinge (Protista).}

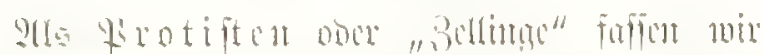

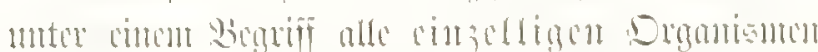

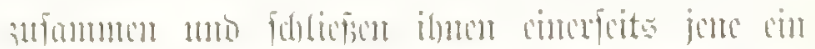

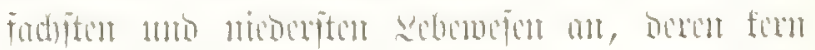

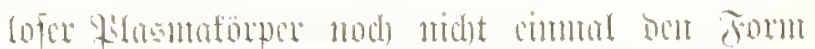

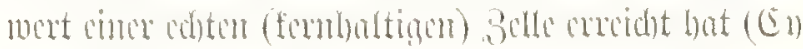

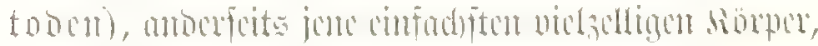

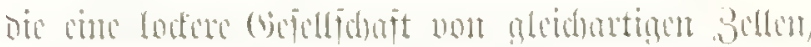

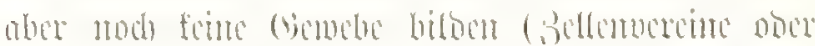

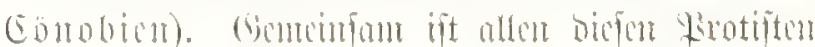

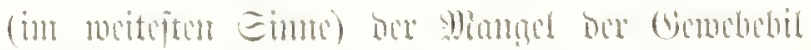

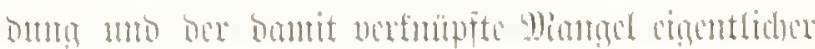

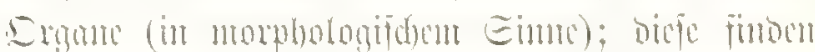

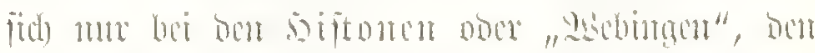

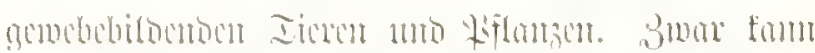

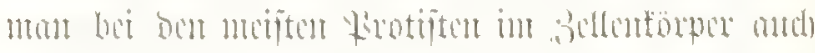

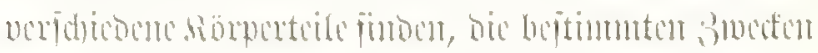

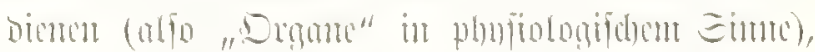

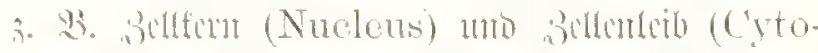

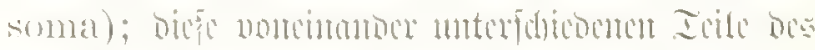

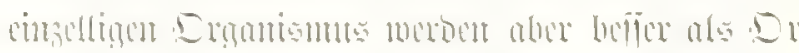

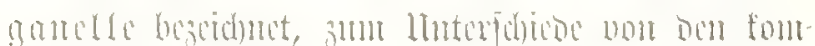

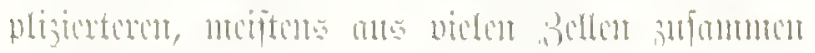

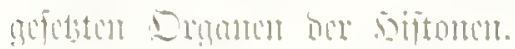

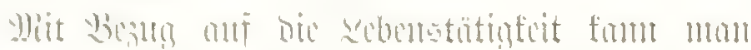

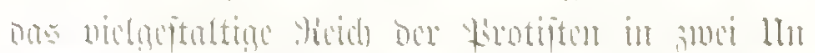

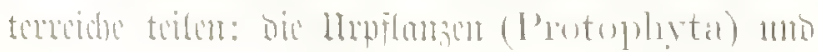

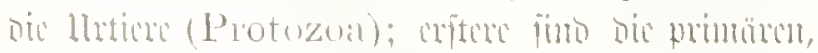

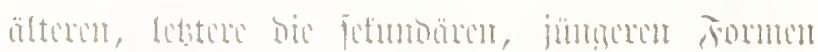

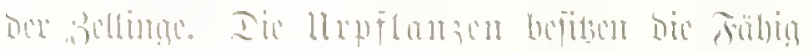

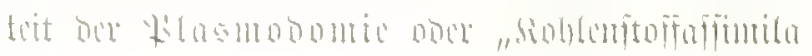

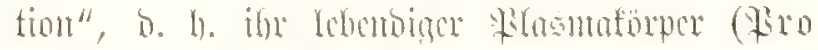

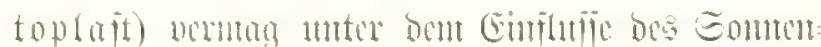

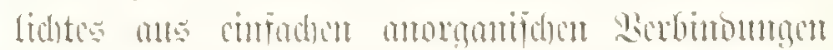

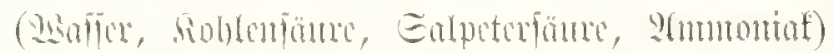

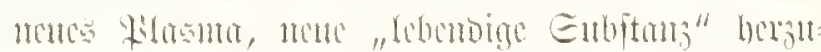

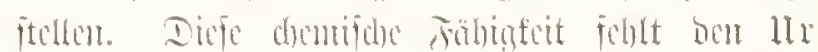

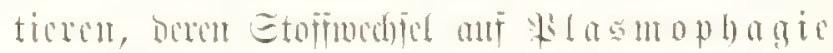

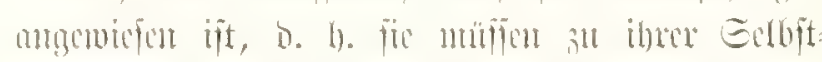
whaltumo Pifasma "freflen", non firophenten ober

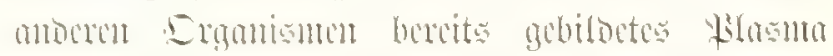

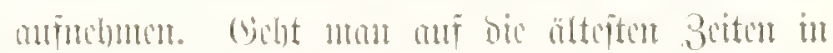

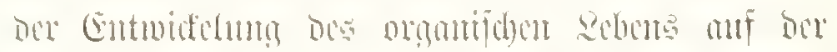

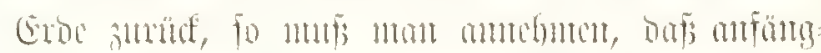

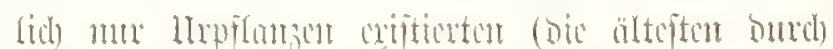

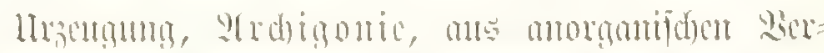

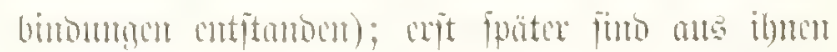

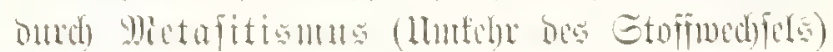

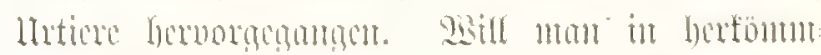

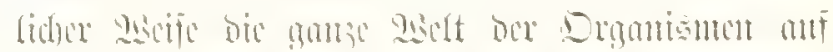

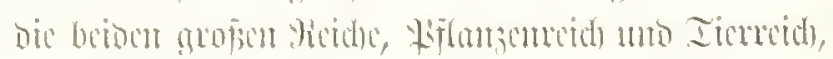

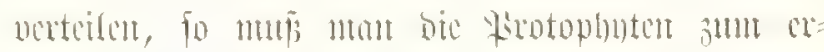

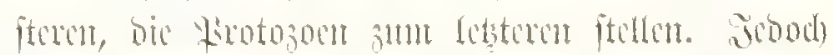

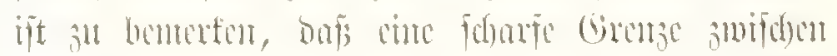

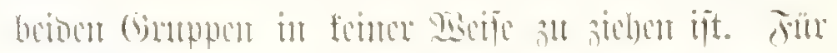

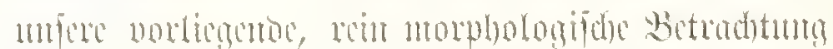

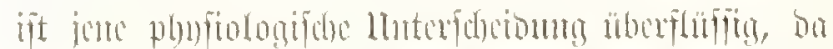

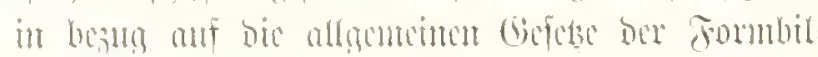

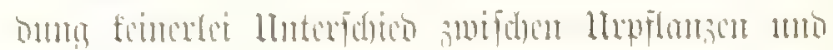

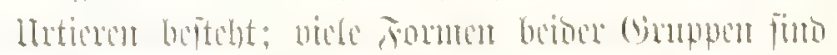

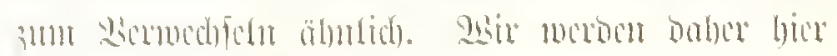

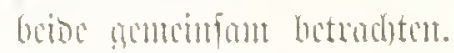

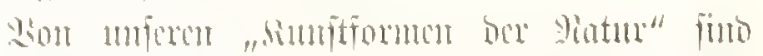

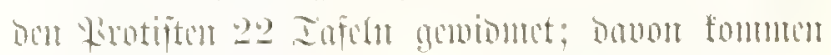
(a) anf bic tirotoplunter, 16 anf bie tirotojom. 


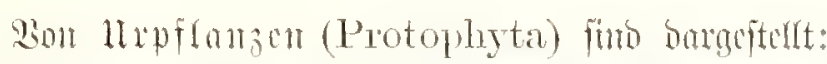
Dintonten $(t, 8 t)$, Desmionecu (2t), Ficribinem (14), Micrethatfen (3t), Eiphonten (6it). Yhif

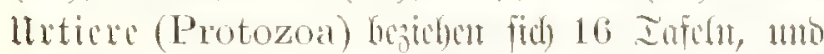

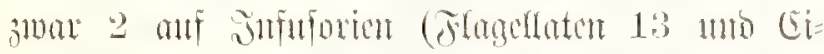

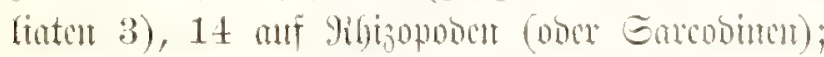
unter resteren befintom fich 1 Infer Minectozocu (93), 3 Infeln Ihalantophoren $(2,12,81)$ mtio

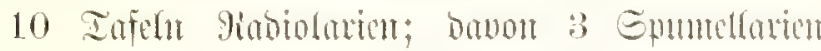
$(11,51,91), 2$ Ycanthorion $(21,41), 3$ gin

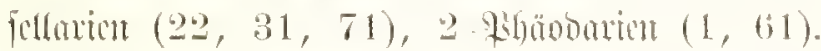

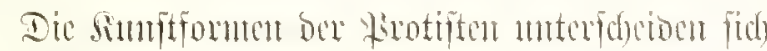

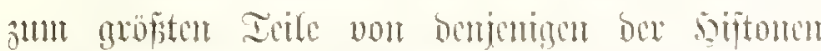

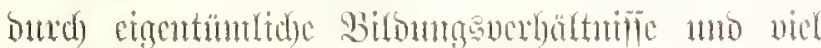

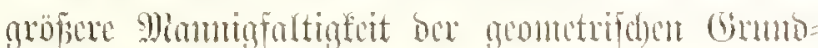

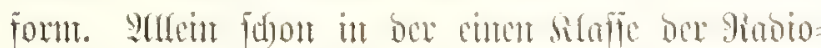

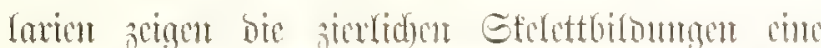

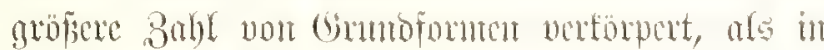

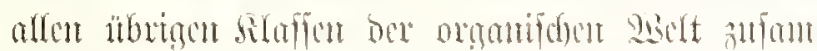

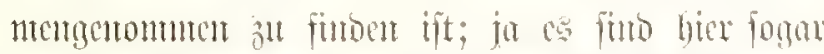

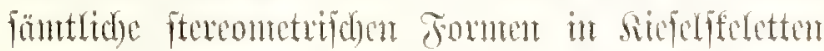

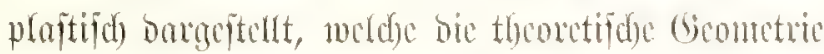

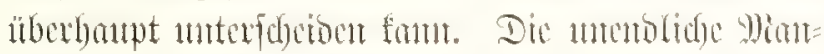

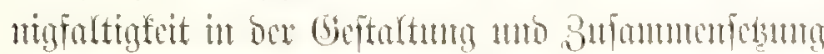

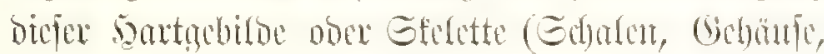
Etütsut 11. F.10.) ift unt jo merfuntrotger, ale bic fic

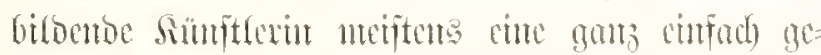

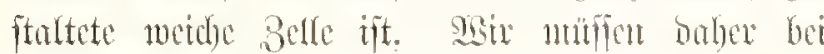

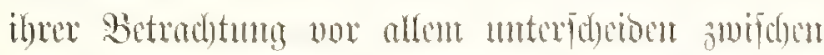
Dent weiden, Kebenoigen aftiwen Bellentcibe (Cytosoma ober Risotoplaft) unt bent fepten, ftumen, paffuen Bellintlest (Cytothelia), bie von chiterent gebilbet merden. Das Mintertal ber resteren it

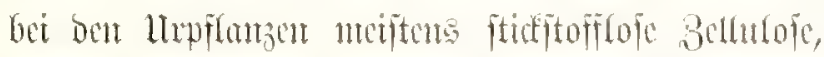

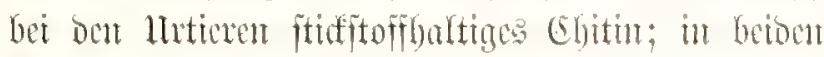

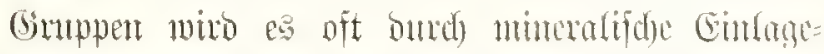

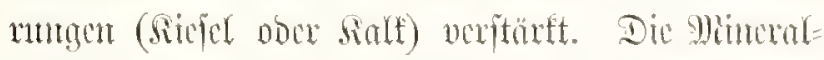

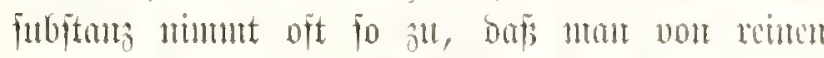
"Sireferforalen" ober "sialfidaren" fpricht.

A. 1) Chromacea (\$blycodroutacen ober

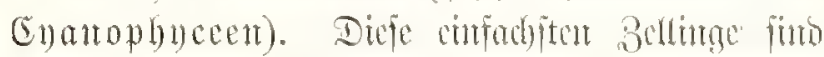
ale bie ältejten vout alfen Drganionten ät betrad)ten

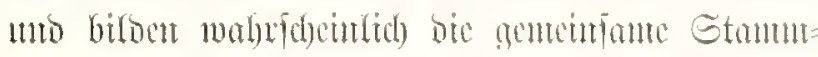

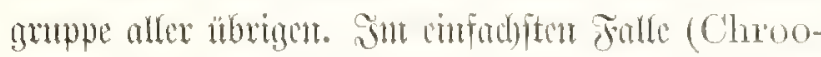

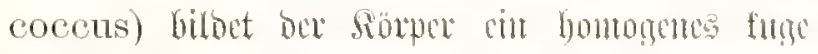

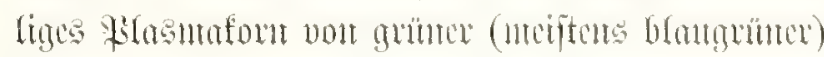

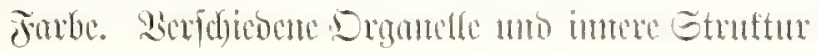

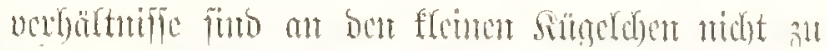

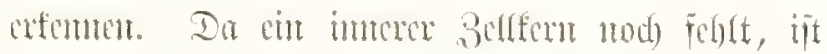

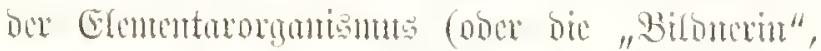

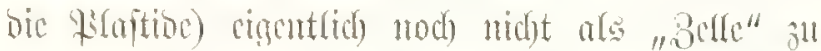

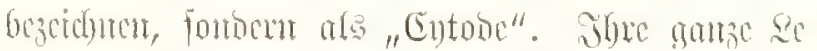

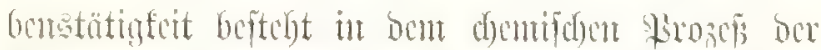

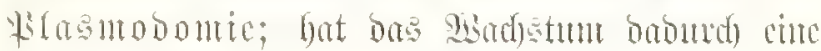

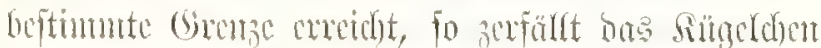

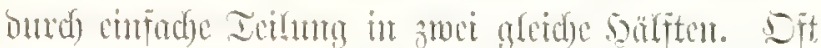

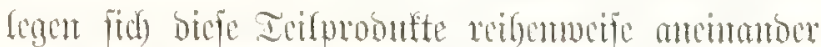

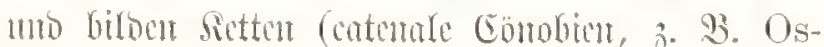

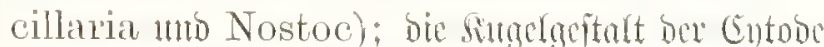

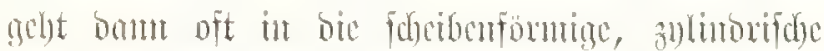

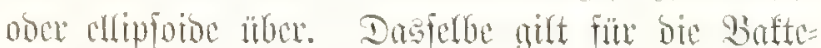

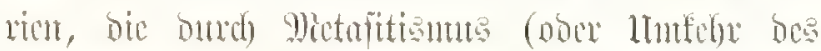

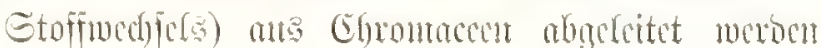
föntกtelt.

A. 2) Panlotomea. gere che cimbelline

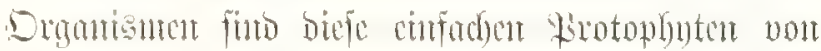

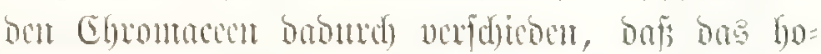

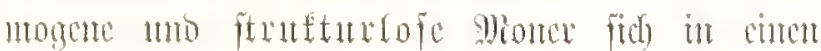
änseren Butcenteib (Cytosona) mo cinen innc=

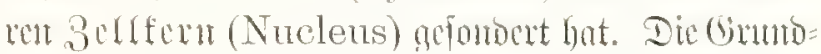

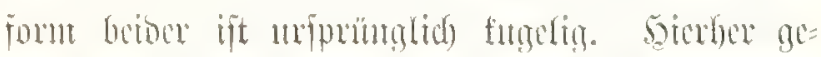

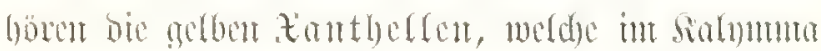

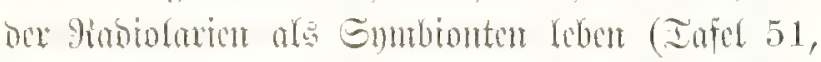
Jitg. 2, 10, 11, 12; Infel 71, Jig. 1, 10); forme

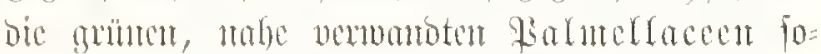
wie bie pelagifan Ealcocntear (Eoccofphären,

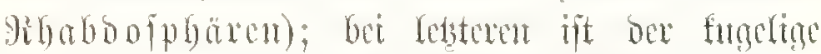

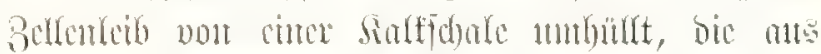

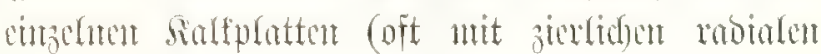

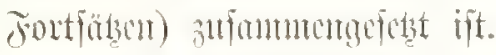

A. 3) Diatomea (Edondellinge ober Ba cifforim; Iafol $t, S t)$. Mllgemein verbutet in

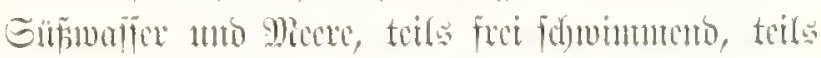

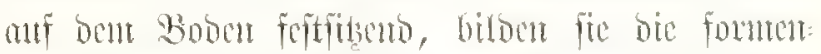

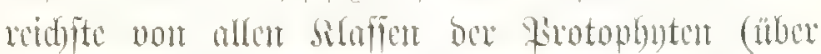

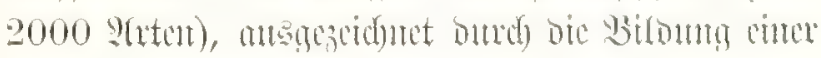

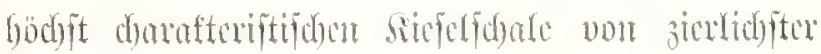

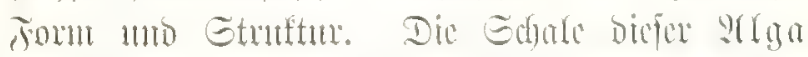

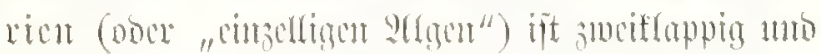

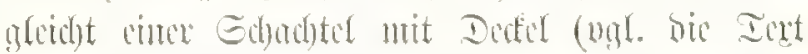

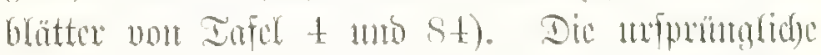

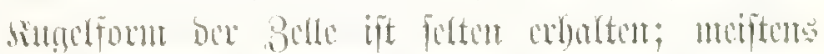

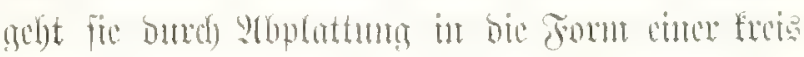

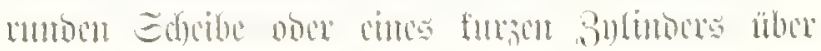




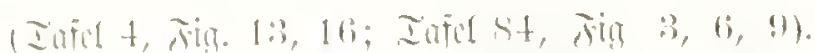

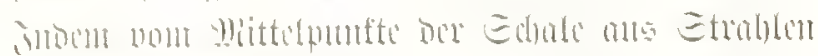

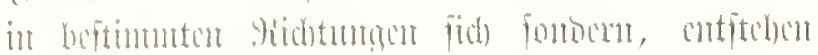

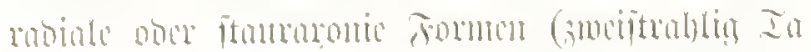

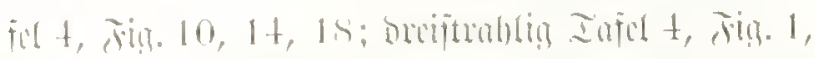

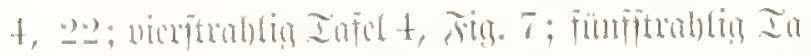

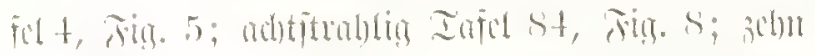

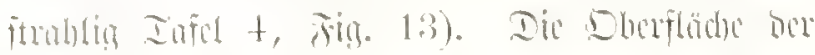

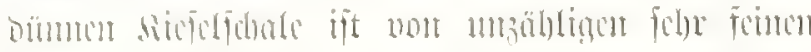

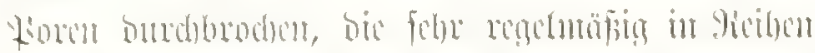

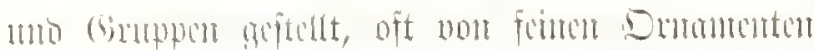

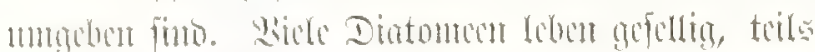

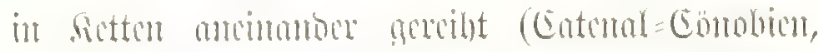

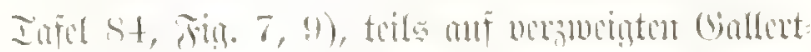

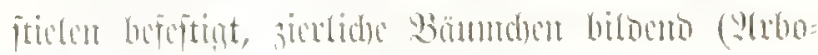
ral=comblon, Iafel st, Jig. t, 1t).

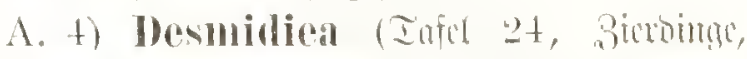

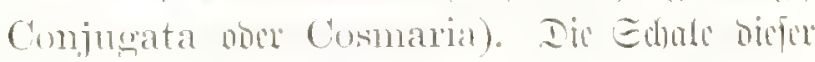

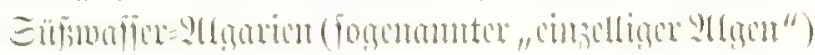

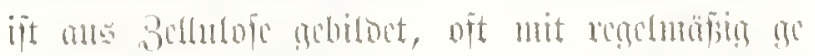

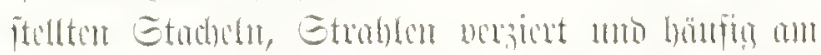

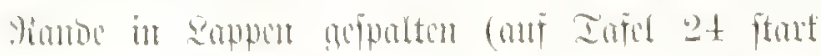

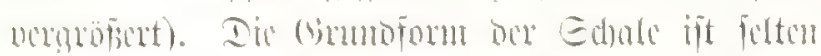

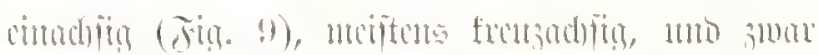

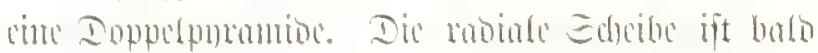

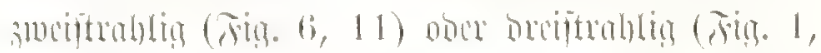

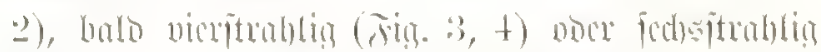

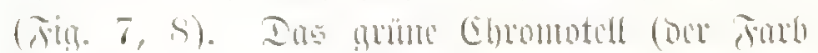

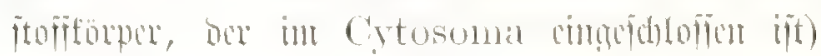

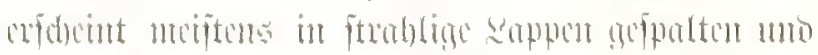

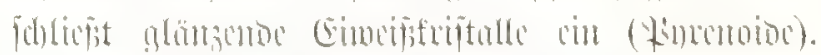

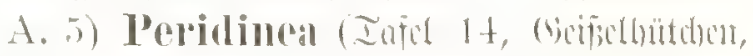

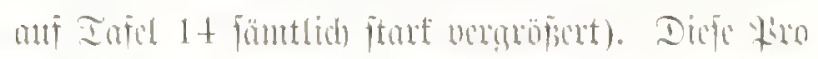

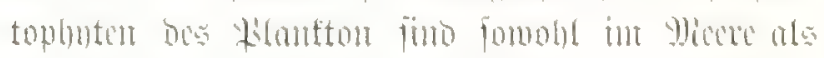

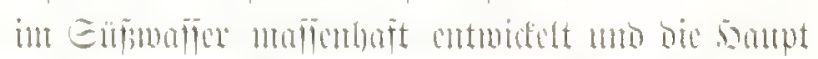

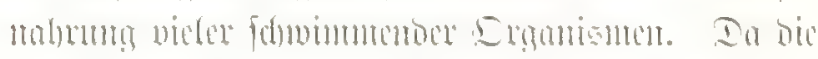

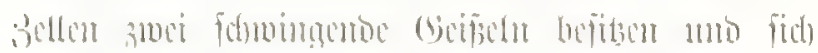

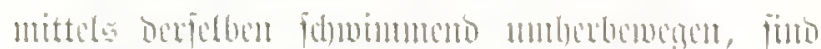

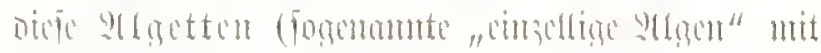

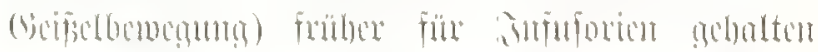

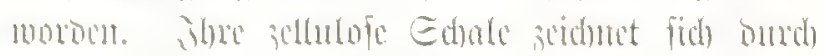

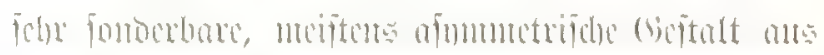

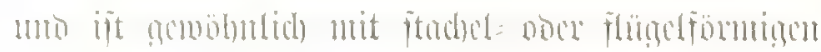

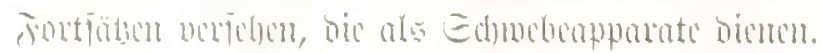

A. (i) Molethallia (Pudiastrum; Infel

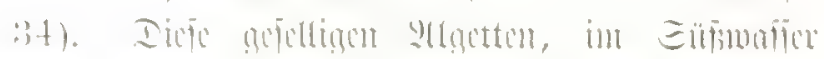

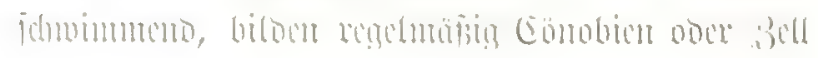

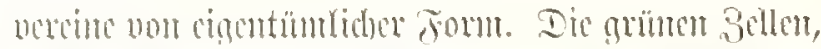

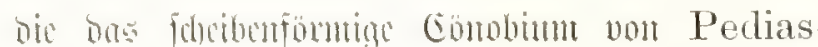

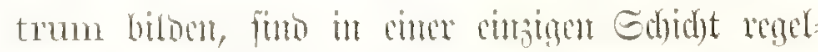

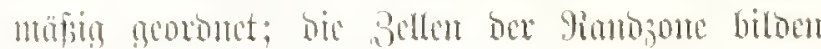

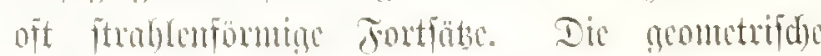

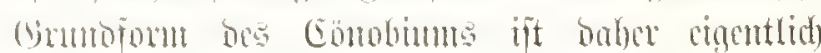

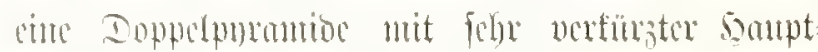

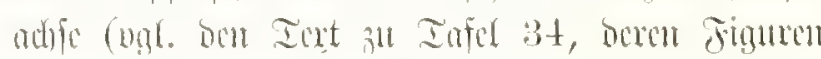
fäntlich verogrofipert futo).

A. 7) Siphoncae (Iafel 6t). Richendgettur,

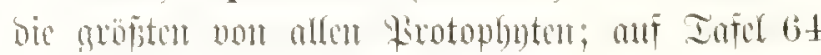

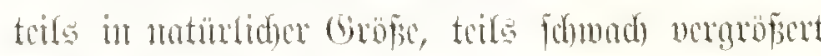

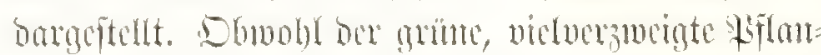

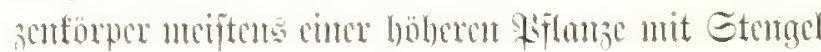

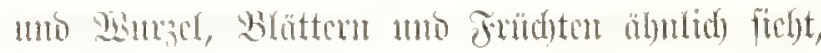

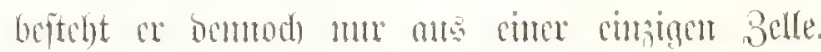

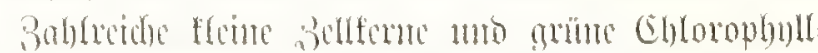

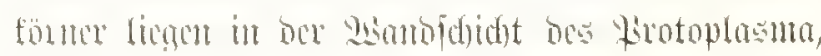

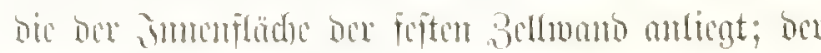

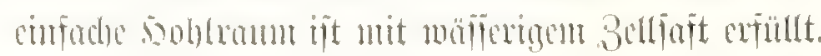

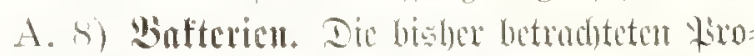
tiftentaflen (1-7) finto ats 11 peffamsu (Proto-

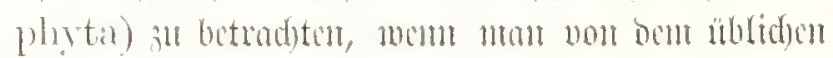

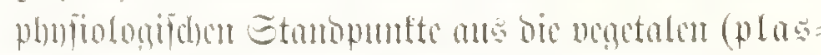

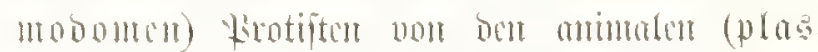

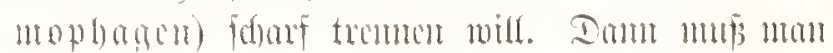

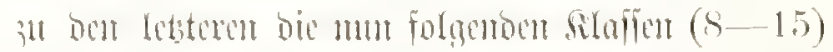

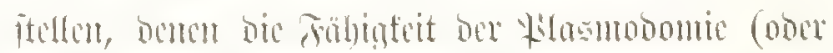

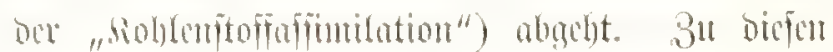

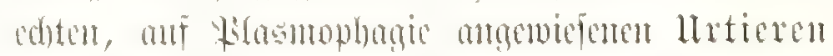

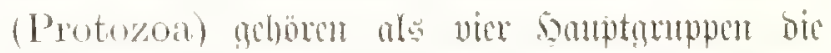

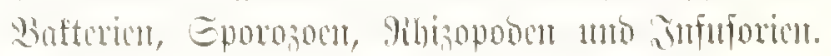

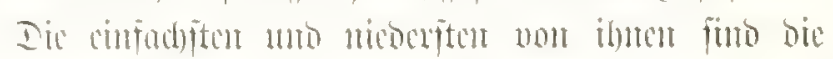

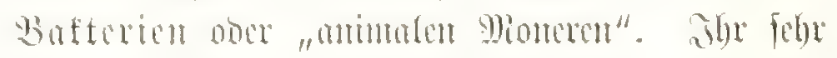

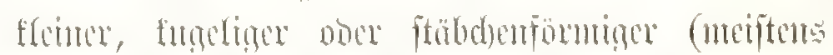

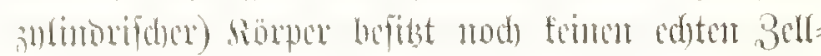

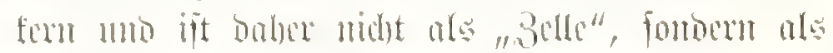
"Cutose" sul benteilen. Dic Wafterien aleiden barin ben "veactulen Diontren", Den Cbrontacen

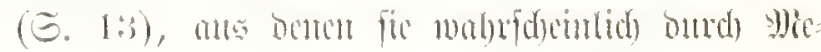

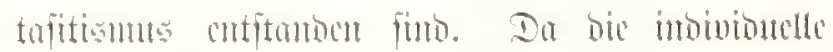

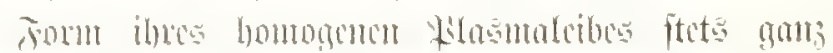

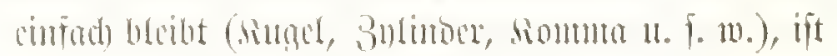

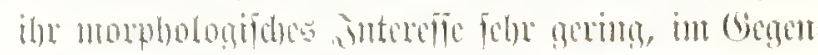

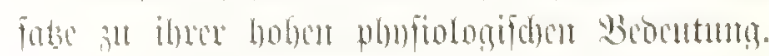

A. 4) Npolozoa (Fumgillou, Eporutiore).

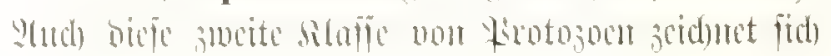




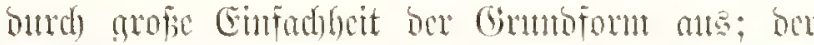

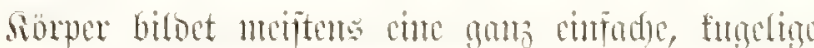

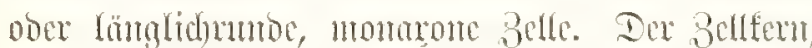

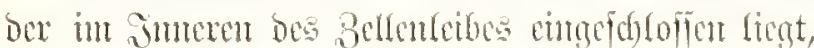

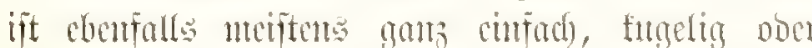

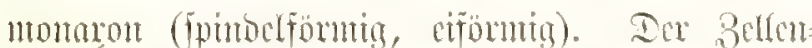

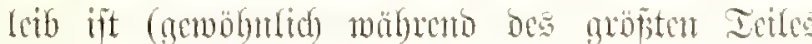

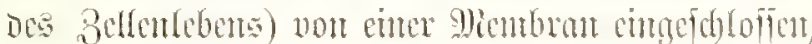

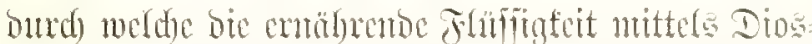

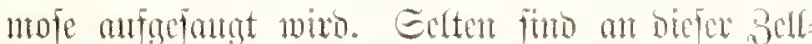

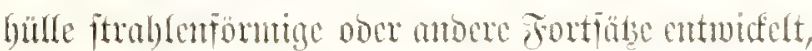
die che polnarone Gumbornt bebingen.

A. 10) Lobosa (Eappinte). Thit bicker nie

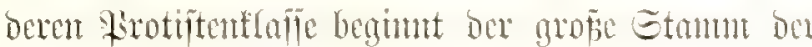
Barzolfüper (Phizopoda), jence lluticre, bic

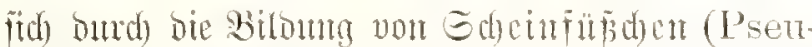
dopodia) alszetdman, D. b. vont verüntorficten

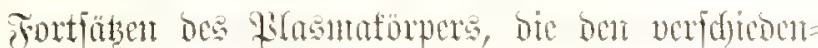

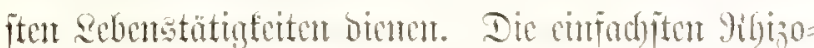

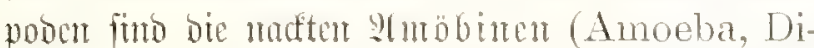

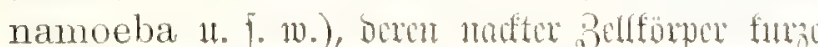

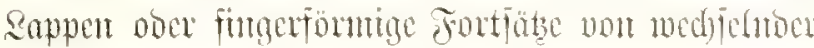

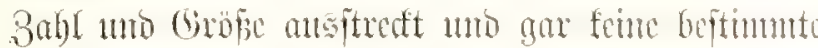

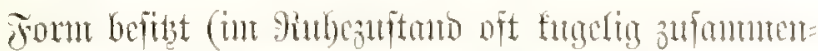

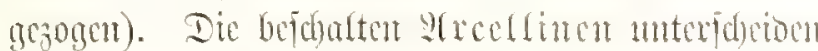

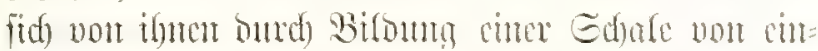

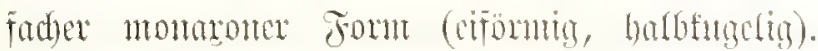

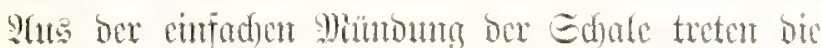
sapucufitisct)en vor.

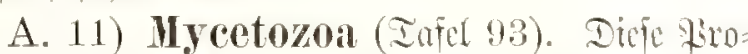
tiften, anf venucjendon \$iflanjenteden lebond, mutroen fruber ats Ed)lempilse (Myxomycetes) zu bou

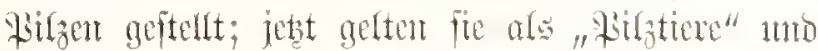

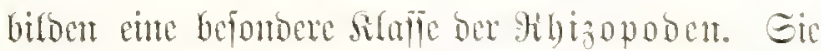
treten in swei gans verfótedenen Buftünout ant;

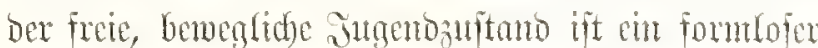

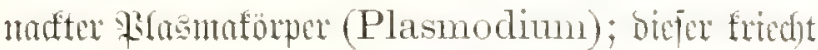
gleid) einent refigen Figisopoben muther unto bildoet

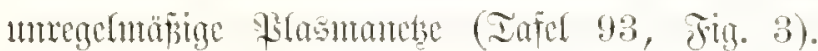

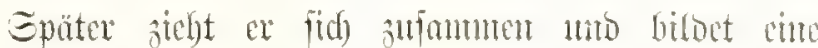
Eporenblaje (Sporangium), dic mand)a Litgen

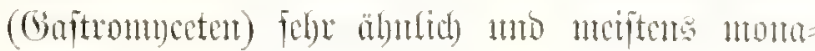
rout ift.

A. 12) Radiolaria (Etrofhuc). Divf

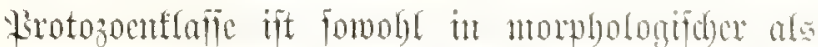

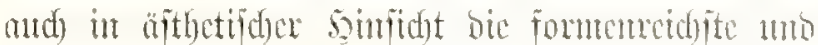
interefiantcite untex allen sirotiptenomenten, jo fo

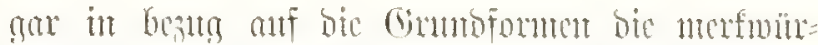

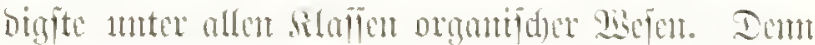

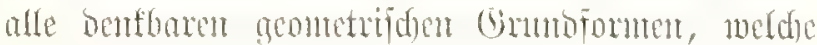
man in ber Shontorphologic nnteridectoen fam,

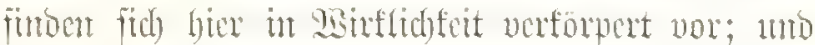

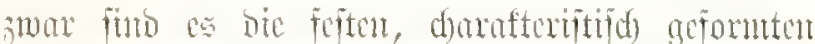

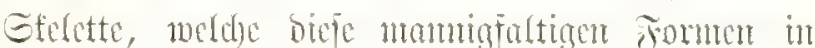

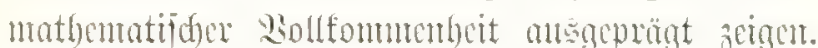

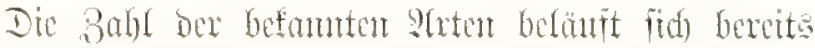

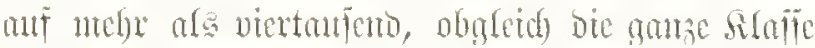

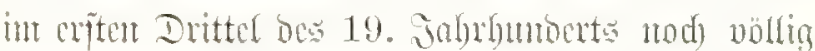

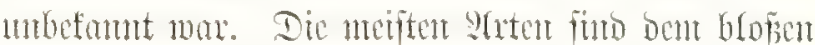

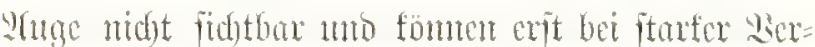

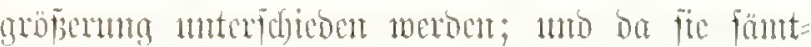

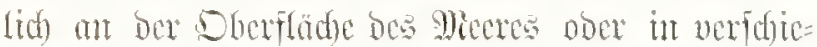

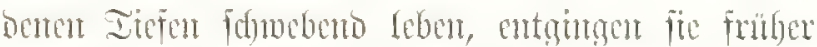

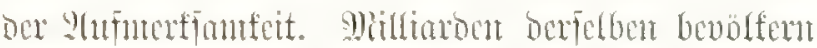

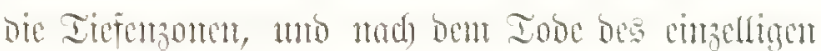

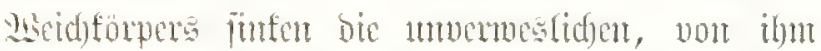
acbilbeten Sirfedfelette anf ben Boben be Disente.

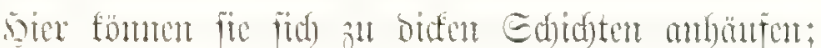

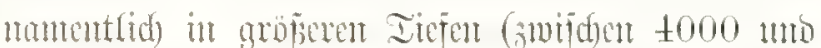

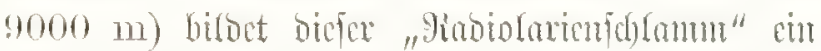

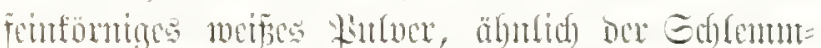

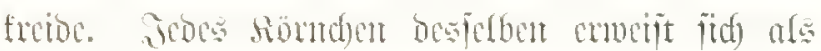

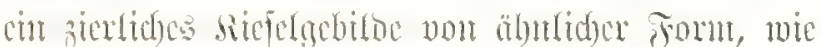

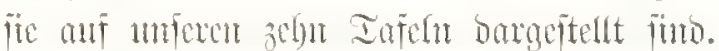

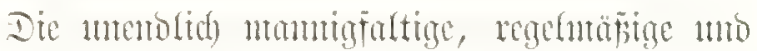
sicride Geitalt biefer zarten sartadbiloe ift un fo mertwitrotger, als ber lebenotge sioner, ber fie cr= sougt, ente gans emfad)e, mipringlid fitgelige Bulle

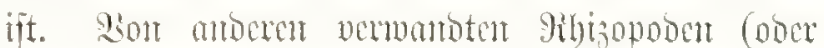

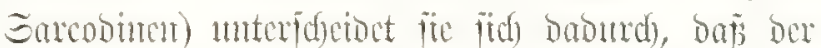

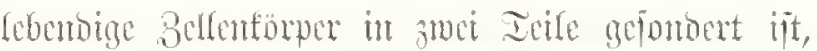

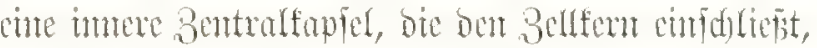

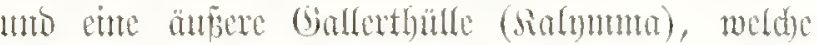

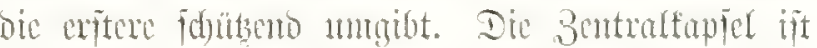
auf Iofed 11 mo 71 rot, anf 21 buntelgetb, anf 51 blan aefürbt, Das Salmunta belladb. Das

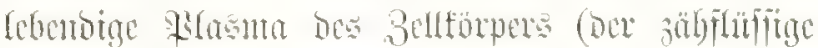

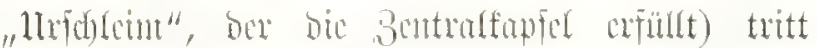

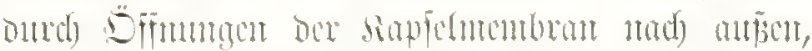

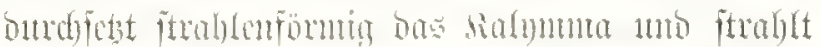

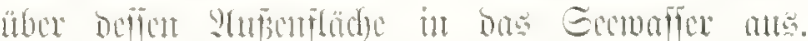

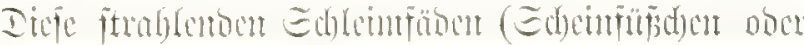

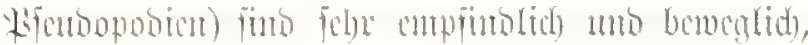

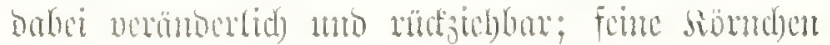




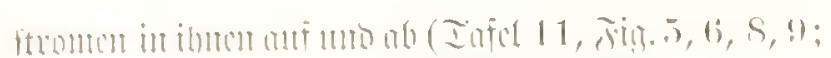

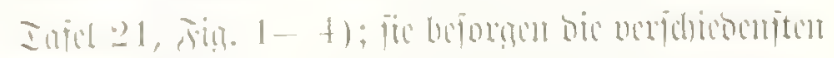

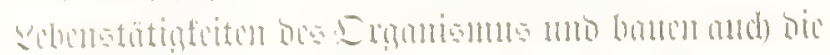

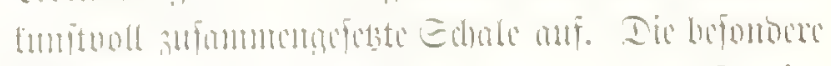

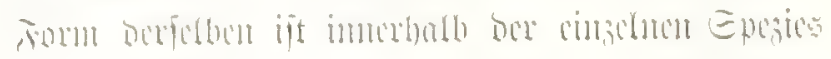

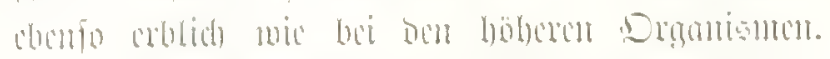

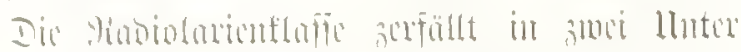

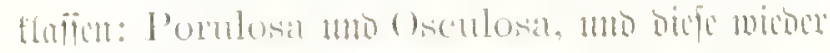

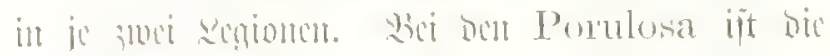

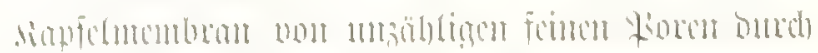

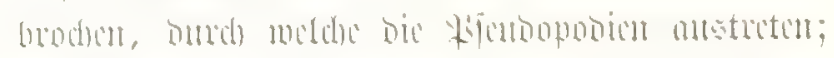

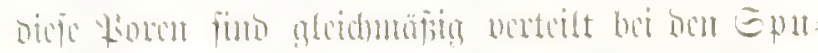

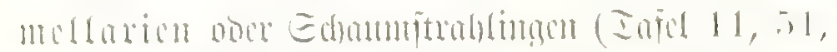

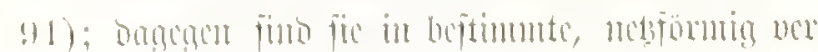

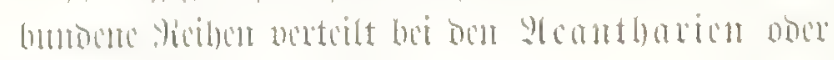

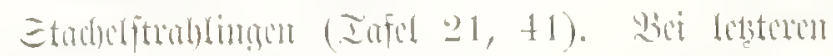

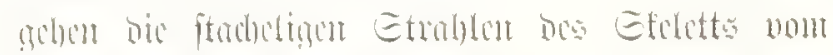

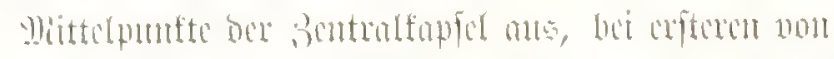

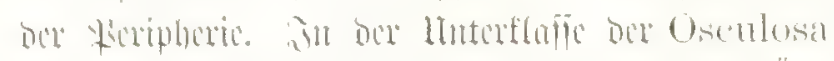

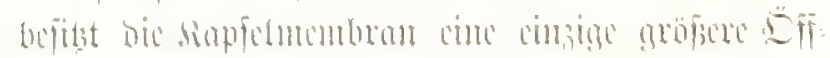

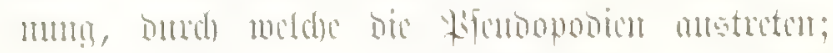

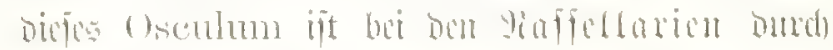

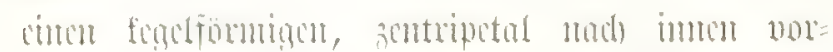

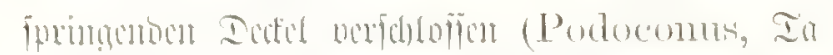

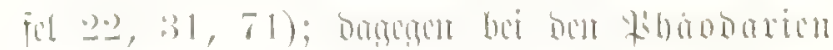

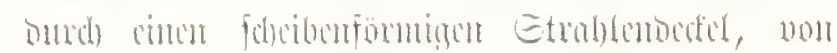

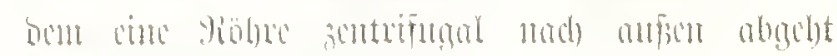
(Astropyle, Infol 1, (ii).

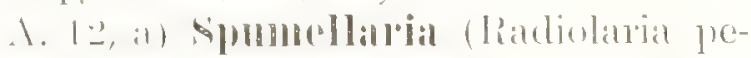

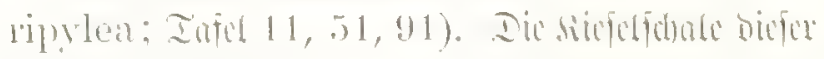

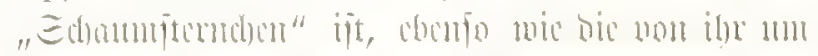

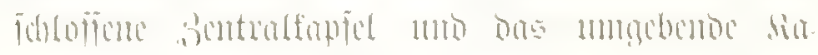

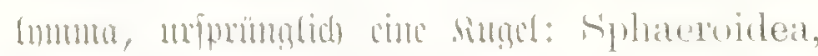

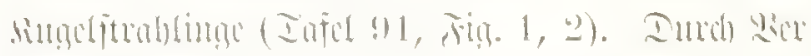

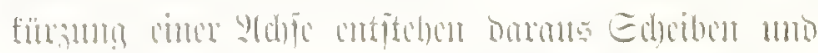

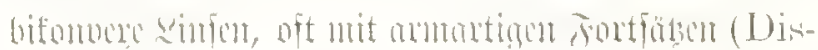

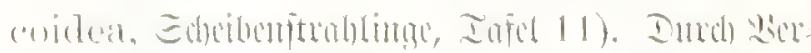

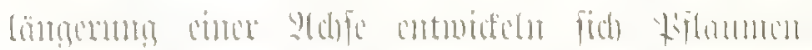

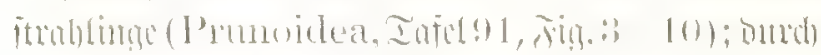

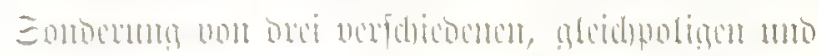

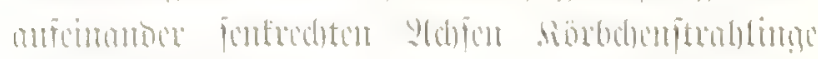

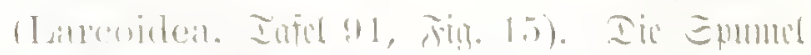

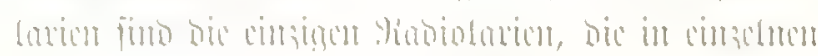
Fomblim : Polverttalial. Eofol sil).

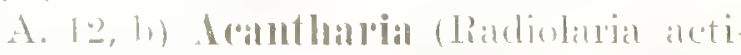

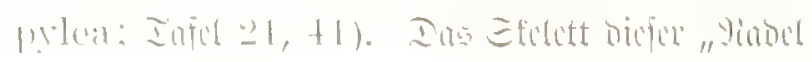

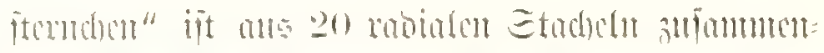

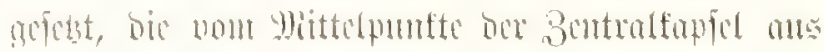

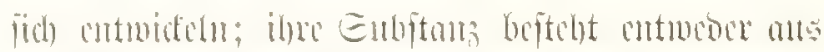

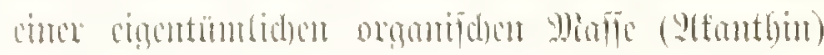

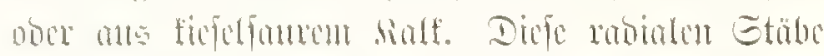

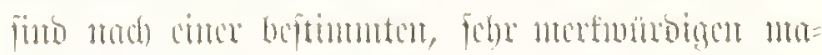

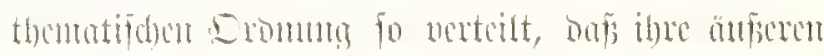

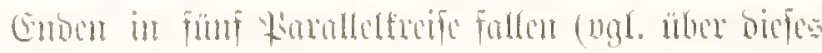

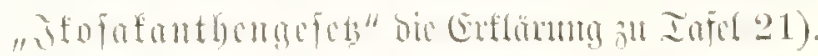
Wai bes alteren "Etadelitublingen" (Acantho-

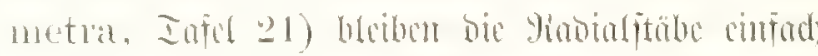

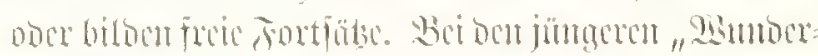
itrablingen" (Acanthophuacta, Iafel +1 ) treten

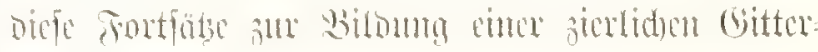
fibule intmumtit.

A. 12, c) Yassollaria (Radiolaria mono-

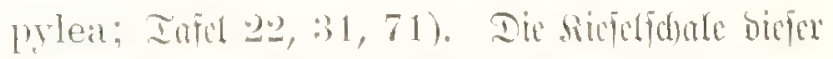

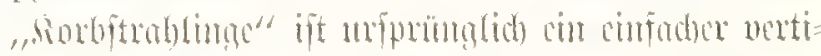

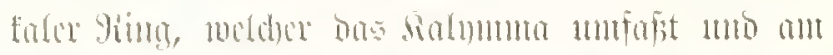

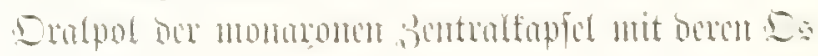

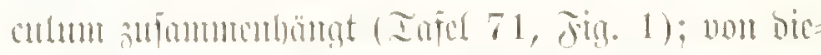

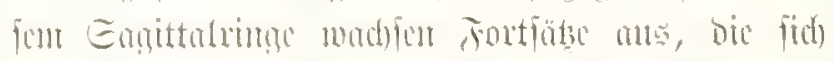

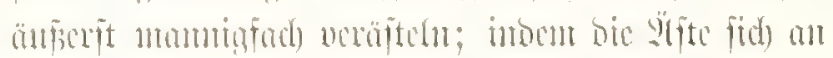

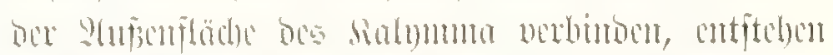

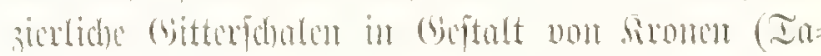

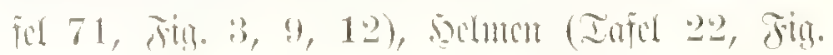

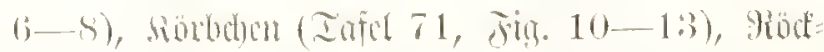

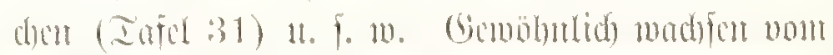

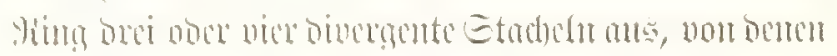

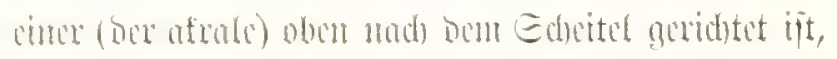

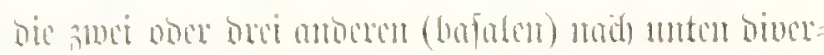

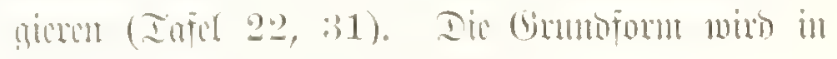

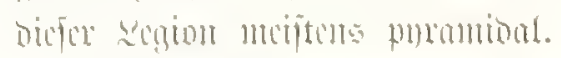

A. 12, (1) Phaconlaliat (Radiolatia cannopylea: Iafat 1, (i1). Dic Efelette bicfer, giobl:

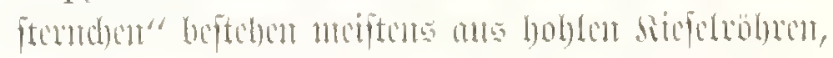

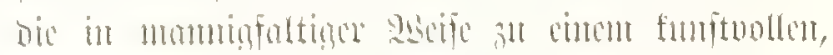

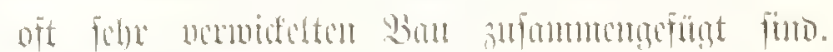

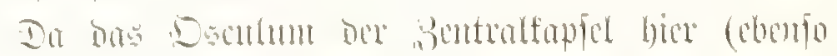

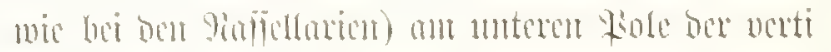

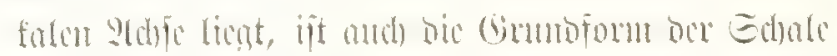

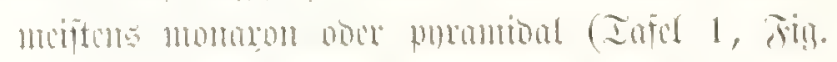

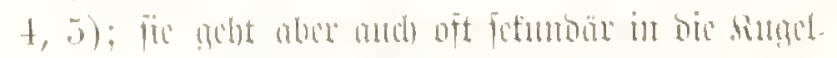

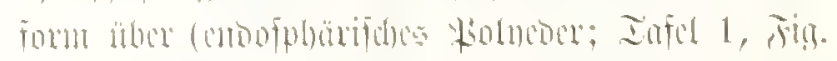

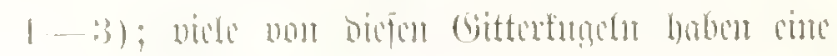

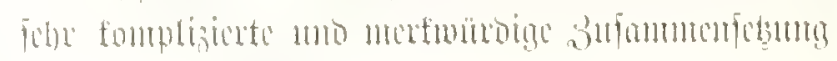
(Intel (i), Fing. (1). 


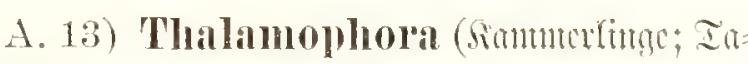

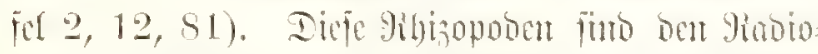

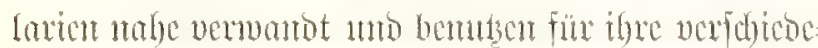

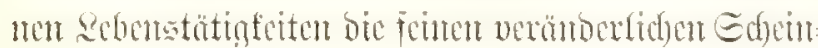

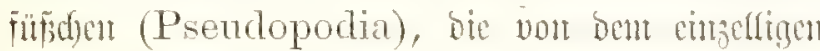

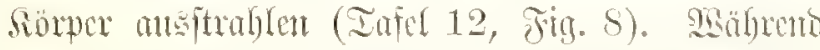

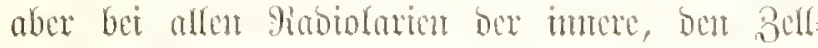

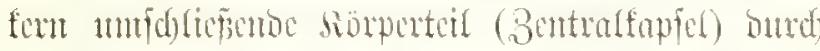

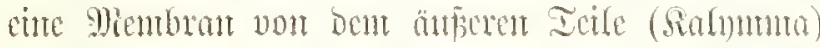

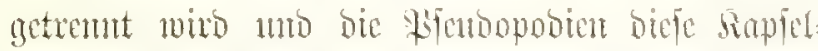
mentbran durdjetsen milfen, ift bies bei ben Thafa

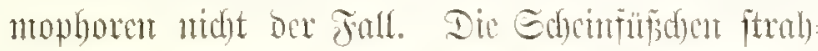
Ien hice mmittelfar von bour lebonigen Bellforper

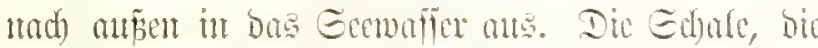

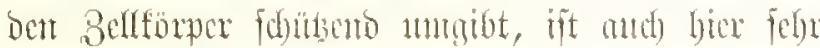

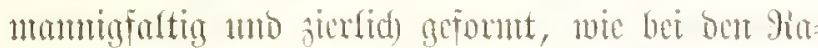

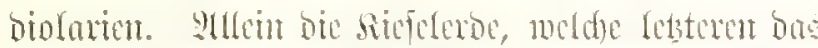

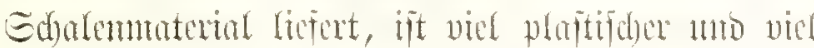

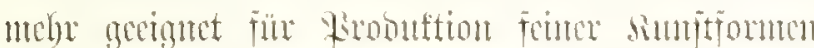
als bic Salferoc, bas aröbere Miaterial ber arö̈eren

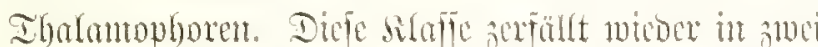
Interflafien; be ben Foraminifera (ober Perforata; Iafel 2, 81) ift bic Edratemumb porös, von Iaufonton fenter Poren burd)brodya (wie bei den Porulosa); ongegen ijt fie jolio unt obme Foren bei ben Eforaminia (oocr Imperforata:

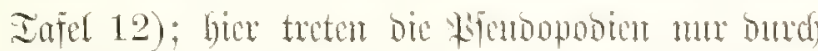

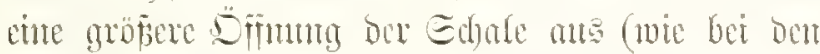
Osculosa).

Die Sulfidule ift in betom lunterferfien bor Thalamophora anfünglid cinfad), einfantuterin (Monothalamia; Iafel 2, Jig. 17-20; Iafel 81, Jig. 1-10; Monostegia; Iufel 12, Jig. t);

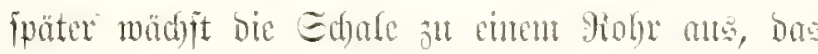

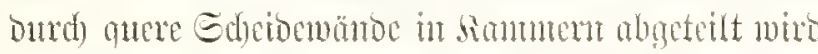
(Polythalamia; Iafel 2, Fin. 1-15; Iafel 81, Jin. 11-20; Polystegia; Infel 12, Jig. 1-3,

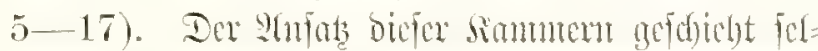
tenter in einer getaben, nteiftens in ciner getogenten

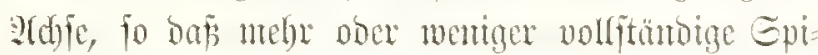
ralen entifeber. Dic Epirahombungen licgen bali

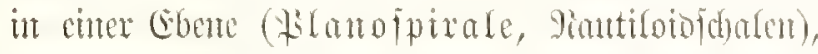

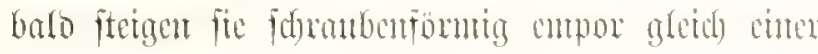

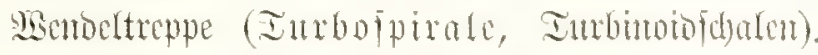
Die Salfidaten ber Ibalmophoren bifon and

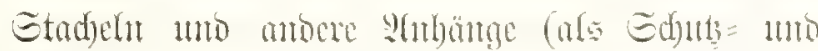
Edjwebcapparate); biefe firm aber bei ben bestho.

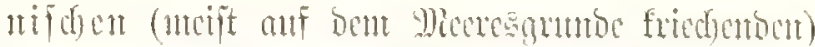

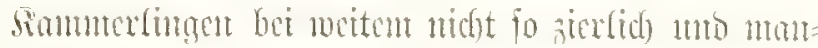

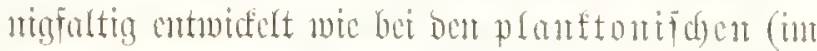

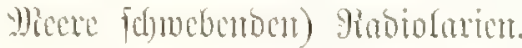

A.14) Flagellata (Iofed 13). Dic Geifict=

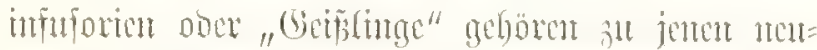
traten Wrotiften, welde mef ber Grente von Iier-

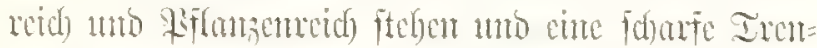

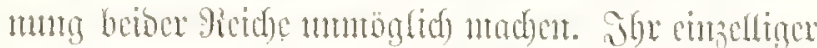

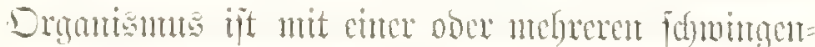

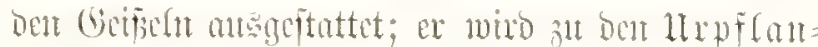

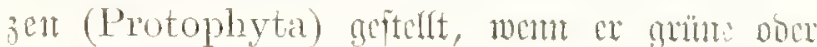

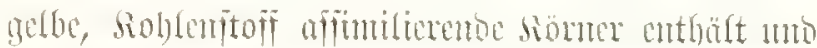

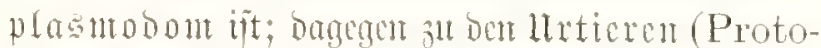

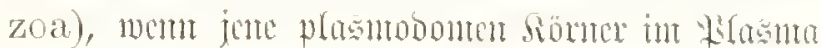

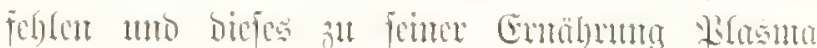

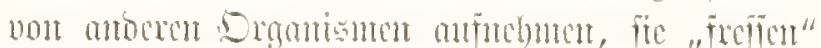

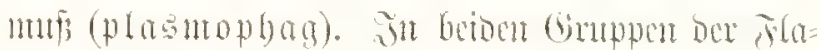

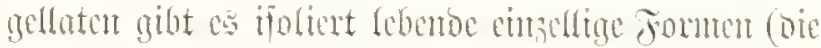

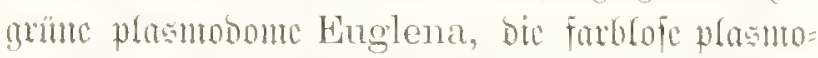
phoge Trichomonas; Infel 13, Fig. t, 5) unt

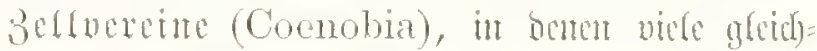
artige Bellen vereningt leden (bie grüne Volvox, Dic farblofen Conocladiceen 1. a. F Infel 13, Firn.

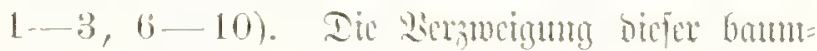

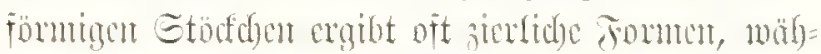

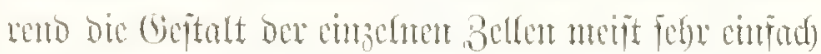

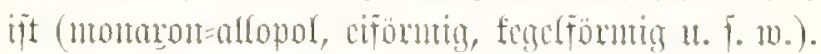

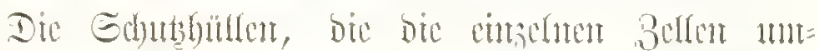
faffepien uno in ben gemeinfanten Coenobium jufantutenbalten, finto balo gallertig meidy, balo gonortion feit.

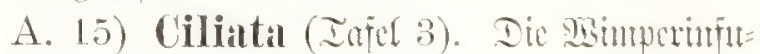

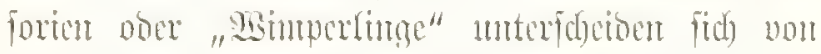

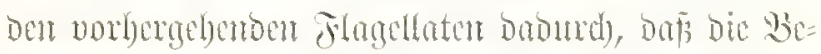

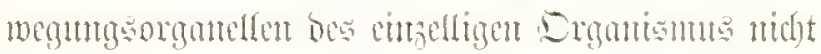

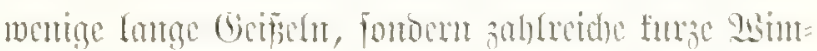

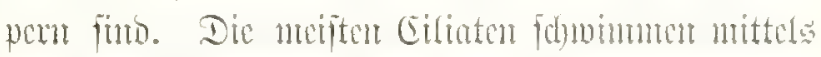
Derfelben fret unther (jog. 1-6); antore bagegut

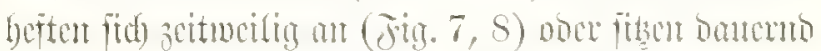

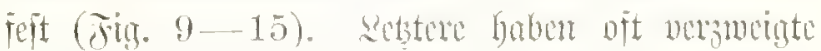

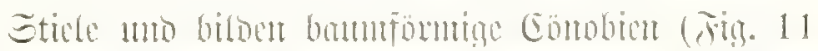

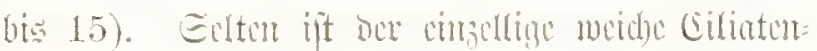

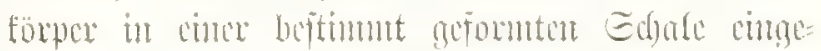

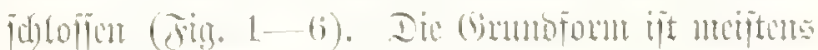

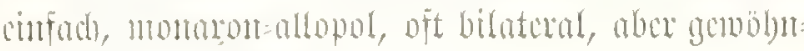
(iti) $1 m$ minumetrif(d). 


\section{IB. Die Sumfformen ber Gencliflangen (Ilotaphyta).}

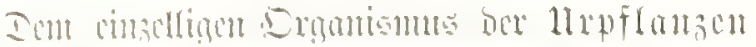
(Protophata) ftellen wir ben biedgelligen siorper

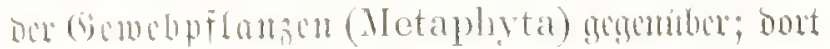
mare bie cinfache selle, bie ummittelbor bie d)and-

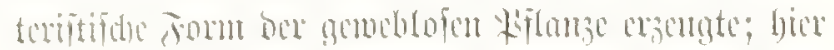

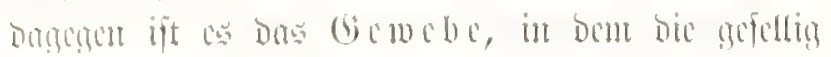

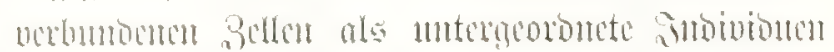

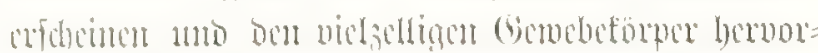

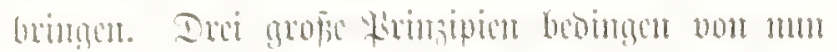

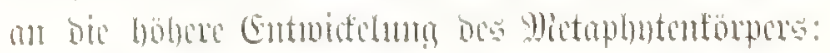

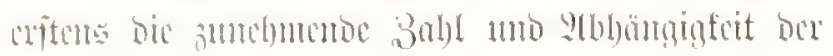

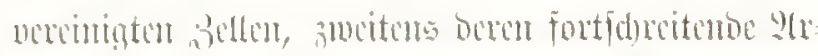

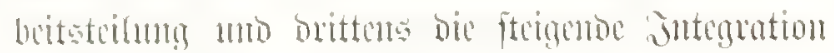

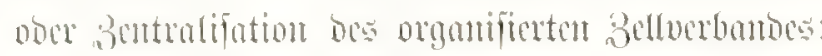

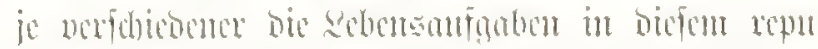

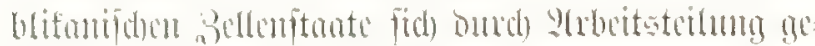

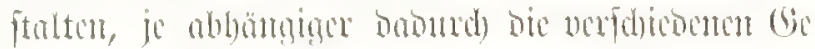

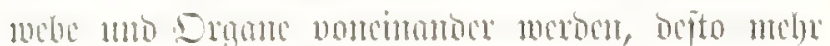

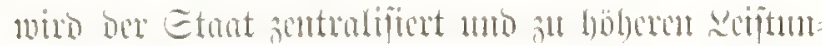

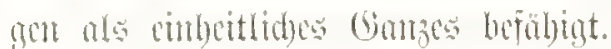

Ber allen bobleren Mietoplonten fombert fidy ber

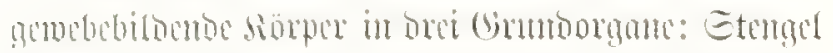
(Caulom), simat (Rhizom) mo Bhlatt (Phyl-

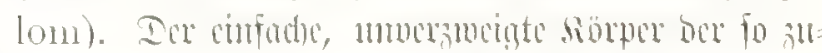

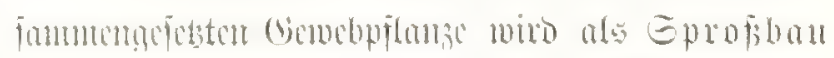

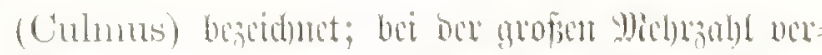
zmont ar fids) aber mo hrift bom Etod (Col-

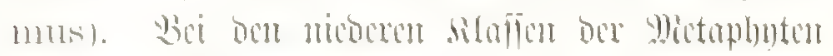

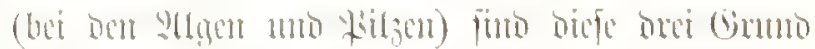

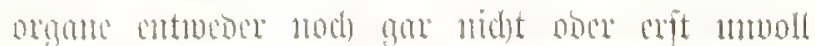

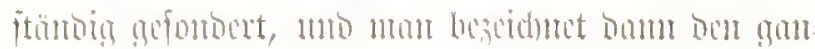

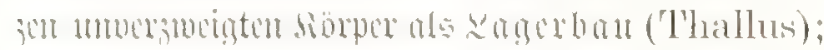

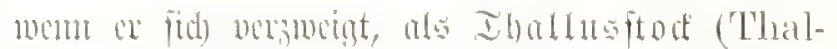

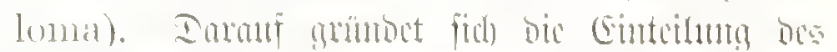

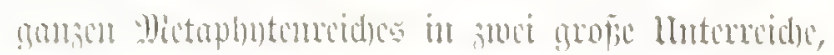

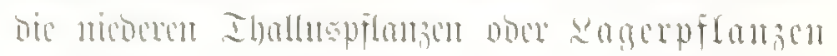
(Thallophyta) mo bic höberen Gtodfuflanim

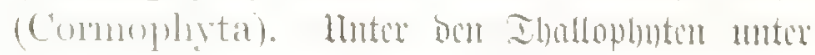

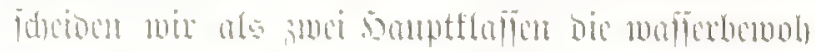

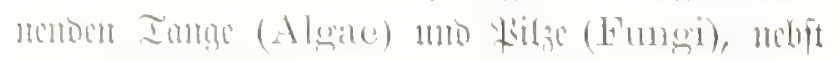

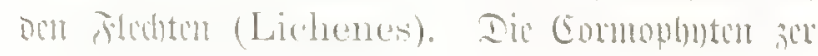

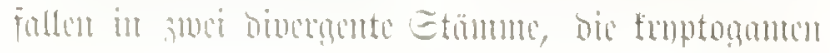

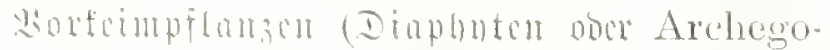

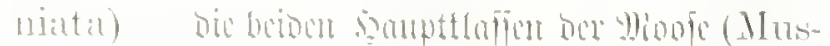

cinae) mo Fume (Filicinae) - แmo bic whancro=

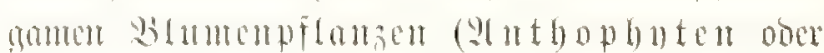

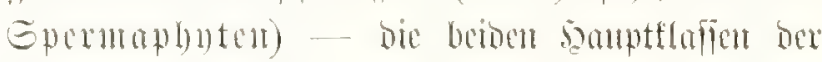
Viattfanter (Gymmospermae) und Daffanter (Anminnmater.

B. 1) Imuge (Algae; Iufd 15, 65). Dir

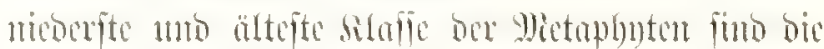

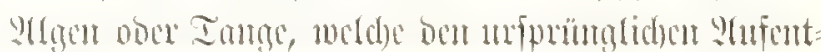

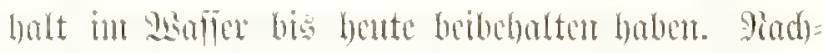

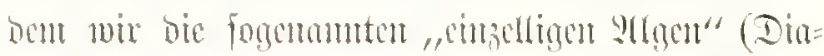

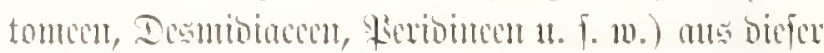

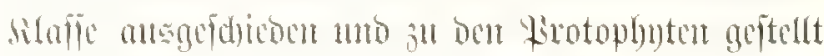

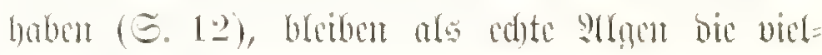

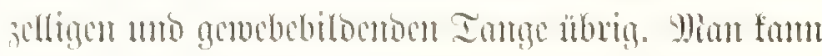

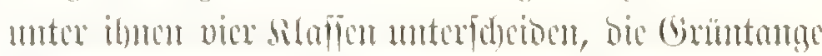
(Chlorophyceae), dic ginttamge (Rhodophyceae), die Bimmtange (Phacophyceae) mo bic Mionstange (Charaphyceae). Dic formemeidjiten

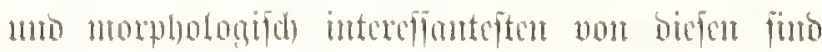
bic Mottange (Florideae obcr Rhodophyceae;

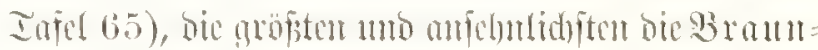
tange (Fucoidea dor Phacophyceae; Infel 15); bie crifteren zeid)men fidh burd) rote, bie leb-

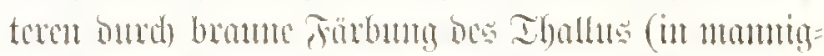

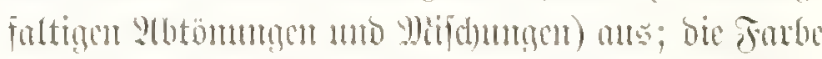
wirlo bost burd) enten befoutocren roten Farbitoff

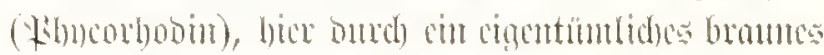

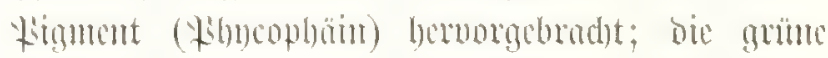

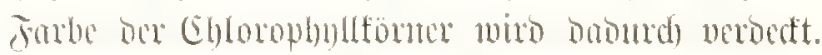

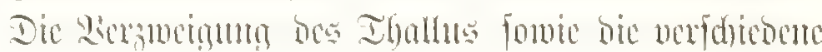

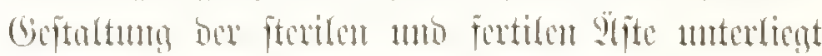

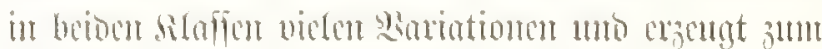

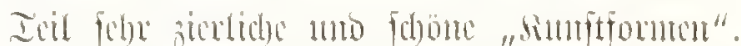

B. 2) Wilge (Fungi now Mycetes; Iafal 63,

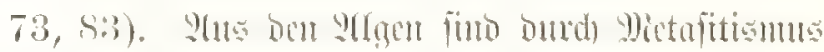

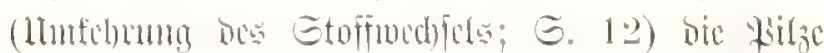

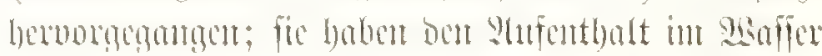

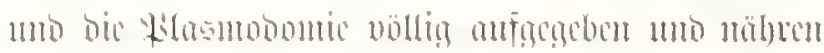

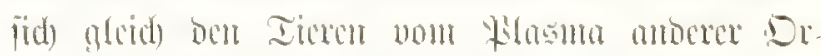

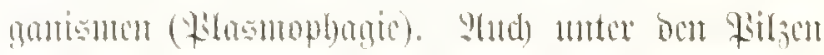

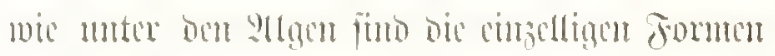

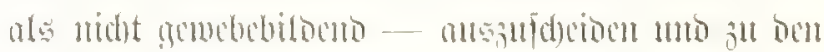
Itrpflamsen (Protophyta) ju ftellen. Sisir feben

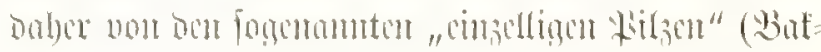

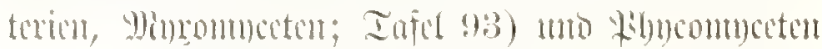

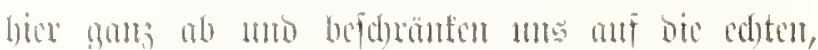

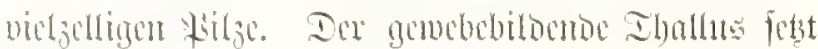




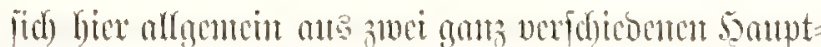

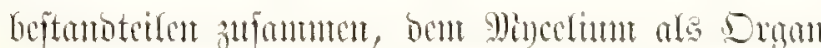

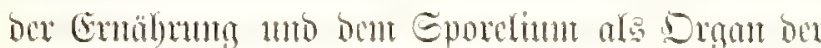
Fortpflansutg. Das Mincelium, Das vegetative

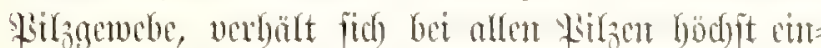

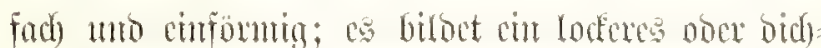
teres Fleditwert von bümen, nersuciaten Fäben, bie

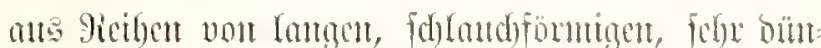

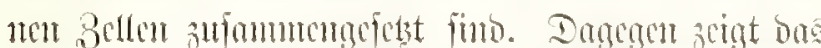

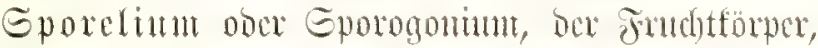

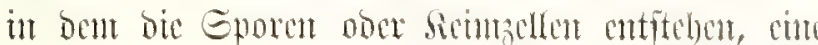

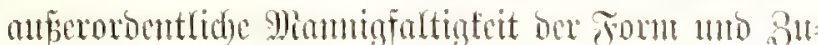
fommententutg. Bei ben Ed)land)pilsan (Ascomycetes; Iafel 73) mtfehon die Eporen in Sme-

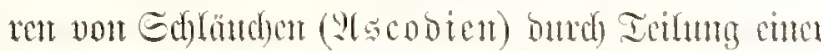
Eporcmutterzelle (Sporometra). Dic Sd)mamm pilfe hingegen (Basimycetes; Tafel 63) pflamzon fid) ourd) Eporen fort, bie ätfiscrid) ant Gipfel comer

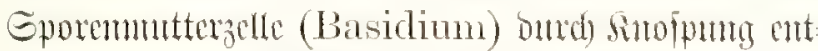

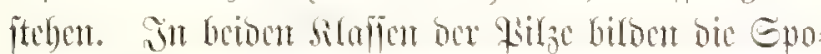

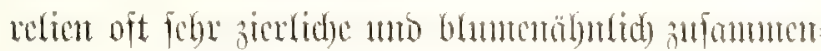

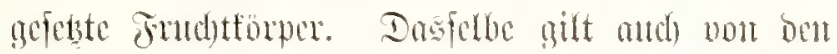
Fledten (Lichenes; Iafel S3), bie in Enftum

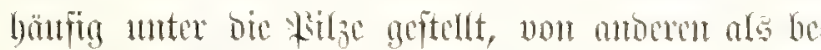
Fonbere sifafie abgetrent werocu. Die Flediten fimo

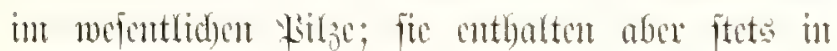

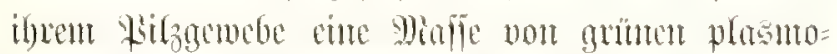

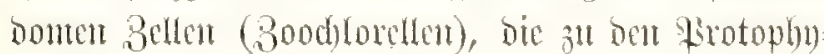
ten (Fantotonten) ober "cinzelligen stgen" gehören

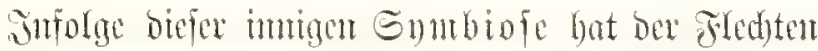
thallus ganz cigentintide Formen bes Madjetmm angenonmen; $\mathfrak{c}$ biloct cir permanentes Sonfor tium, beffon beibe Enmbionten anfinanter antgewio jat fund. (Bigl. die Erflümutg von Iafel 83.)

B. 3) Mouje (Bryophyta; Iafd 72, 82).

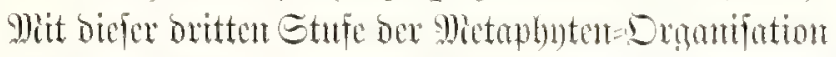
beginnt bie billomig des Eprof̈bancs (Culmus) uno ber zufanmengefetenten Etodfpflanje (Cormus). Snt

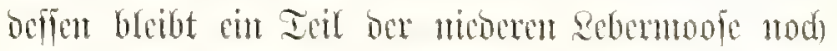
bei ber Iballubilomng Dex Stgen fteben (Thallobrya); bie gitectabinen gleiden nod) ben Itroncent.

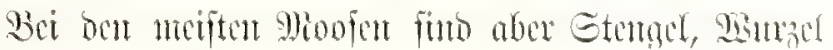

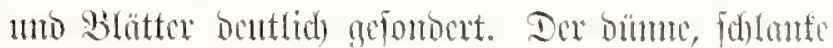

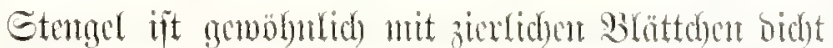

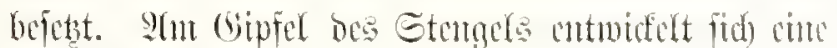

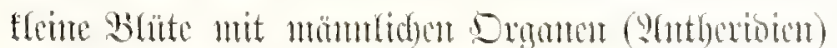

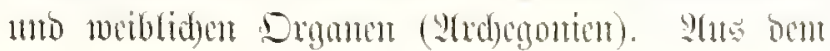

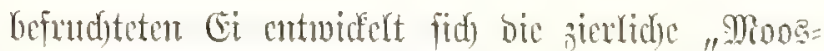
frutut" ober Eporentefplel (Sporogonium); fie fielt

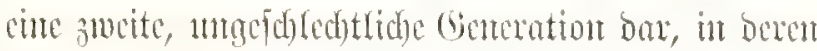
Jmterm fidh Eporen biloen. Die sanntffalle ber

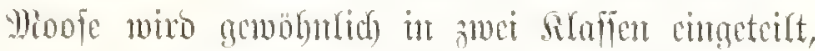

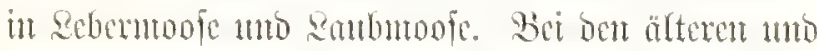

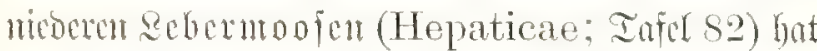
ber Gtod gewöbulich) che bifaterate (obex borïnen=

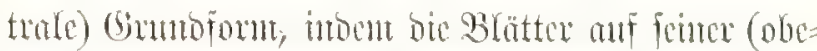
ren) Siluferfeite subciscilig georonet fino, cune red)te

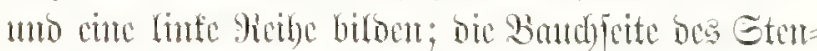
gets riegt bent Boben arf. Bei bon saubntopien bugegen (Nuscinae; Iafel 72) ituhat dic Blatter

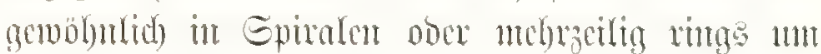

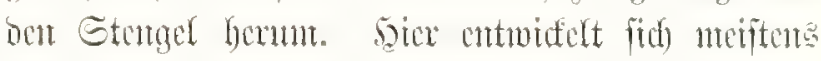
ats der Gporecu bejonderer Sorfent (Protonema), Dex bei ben sebermoofen f(t)wad) ober gat midist ant=

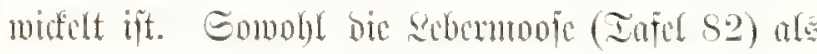

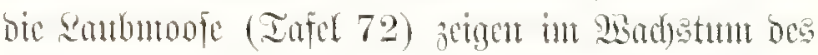

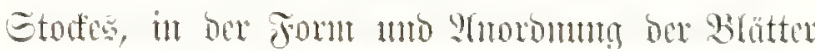

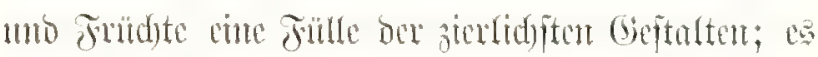

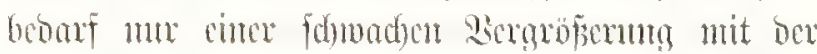

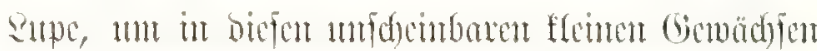

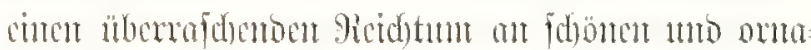
mental intereffanten Bilonngen sal entodfent.

B. 4) Furme (Pteridophyta; Iafet 52, 92). Bè birfen böber cutwidelten "Giräptruptoganen" erreidyt ber Gpropjout fowoht in ber äuperent Ge ftaltumg als in ber immeres Etruftur cine weit grobere Solfentung als bei ben Bloofen, von benten

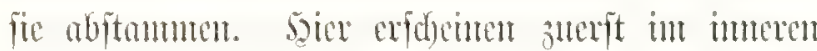
Gemebe bes Siflamsentörpers jene dyarafteritifden

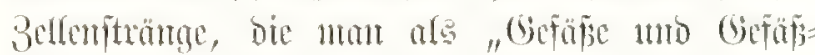

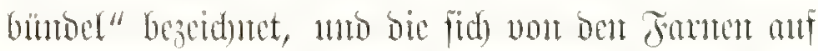

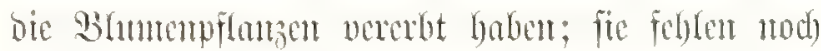
ben Mopfen fonte fäntlidgen Ihallophnten. Die Farne teilen mit ben Dionjen ben (Generationswed) fel;

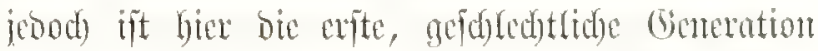
febr cinfach gebiloct, cin tirothallum oocr

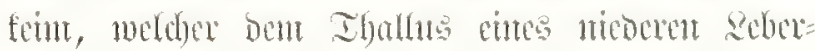

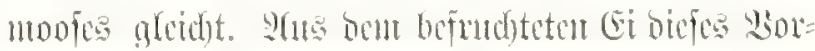

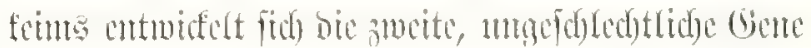

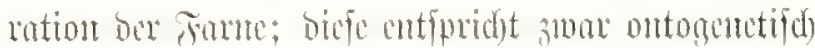

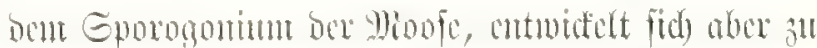

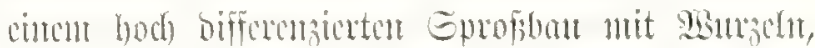

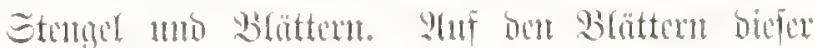

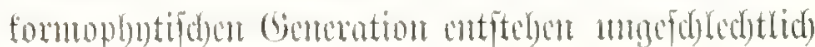




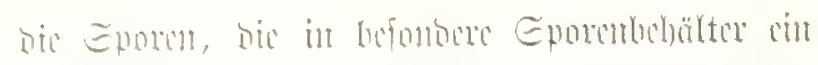

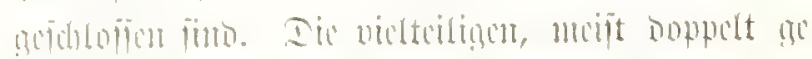

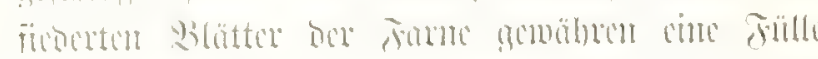

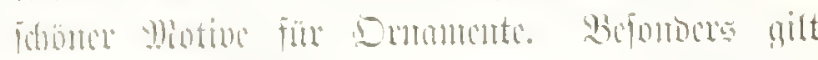

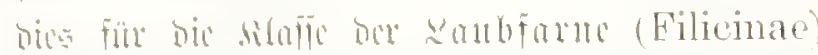

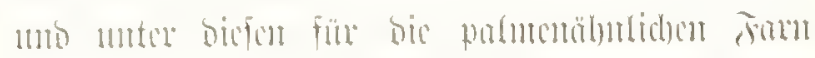

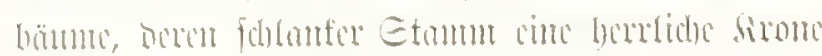

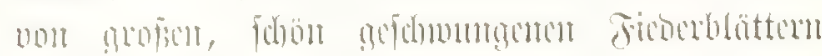

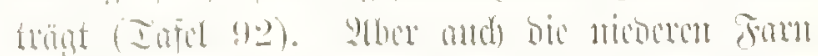

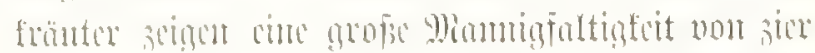

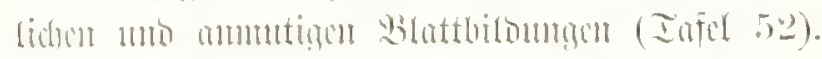

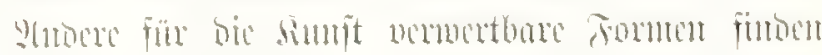

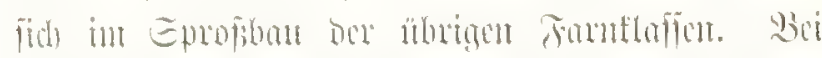
bor Enafformon (Calamariae ober Equise-

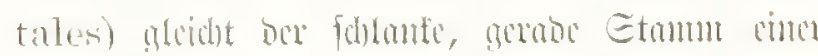

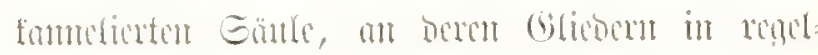

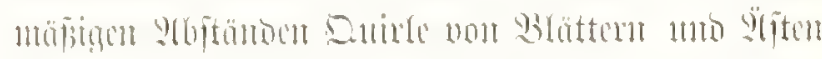

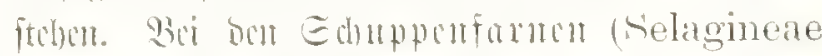
note I, ycopodales) boded fid) bor Etmm mit

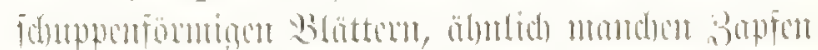

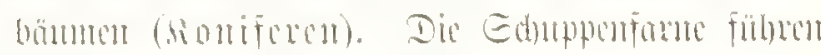

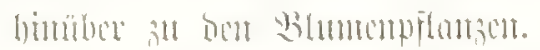

B. 5) Vinftionter (trumospelmat: Inft

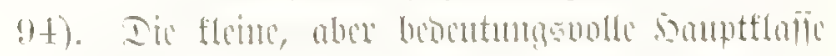

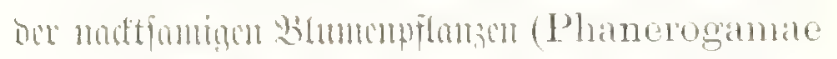

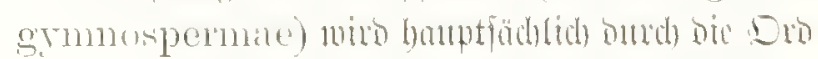

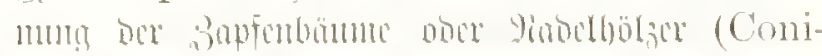

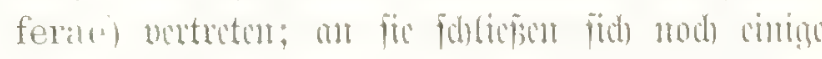

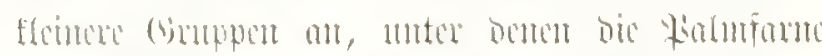

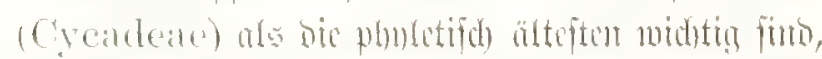

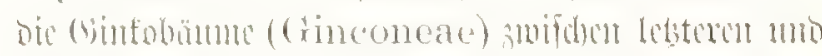

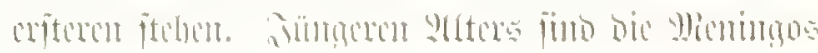

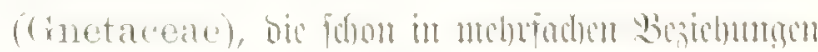

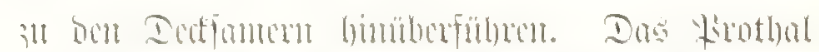

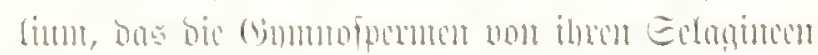

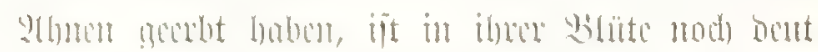

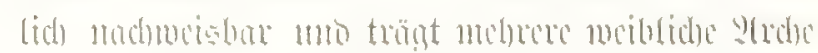

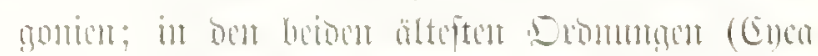

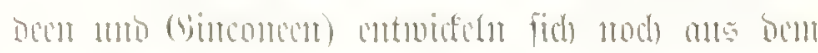

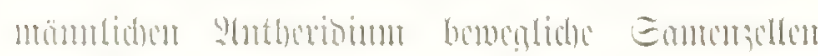

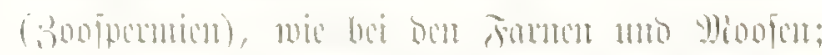

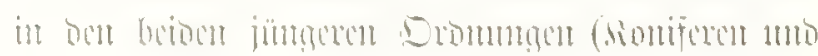

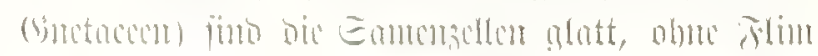

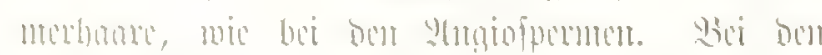

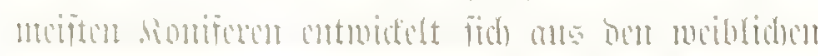

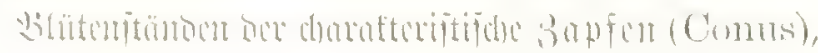

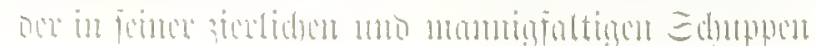

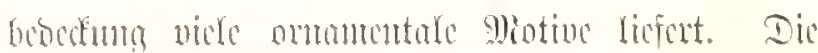

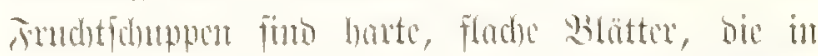

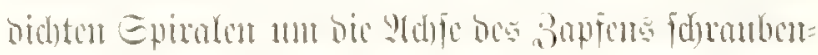

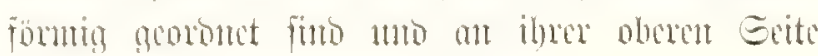
bie Inaten Emantuofpen trangu.

B. 6) Detĩnure (Angiospermat: Infat 6\%,

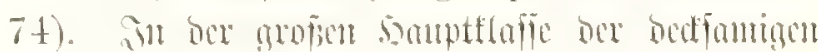

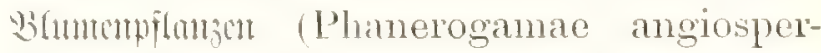

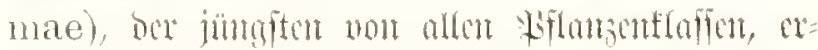

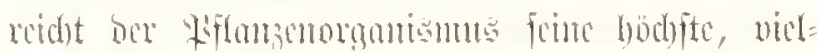

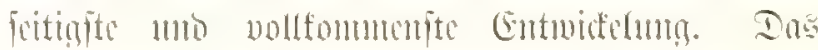

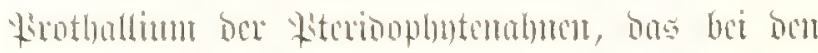

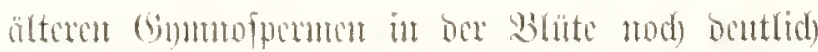

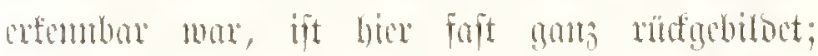

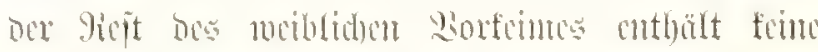

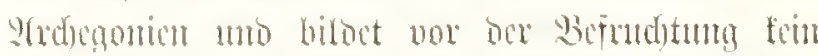

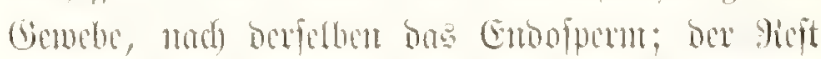

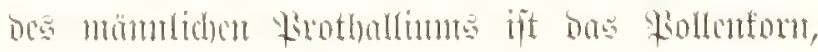

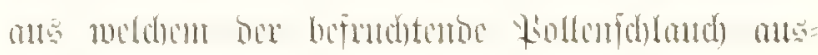

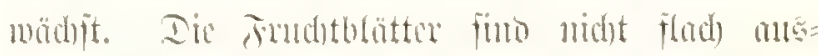

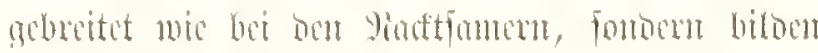

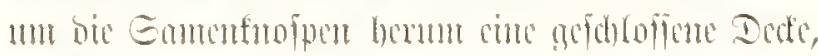

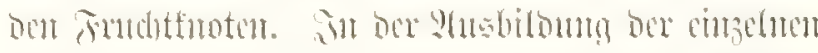

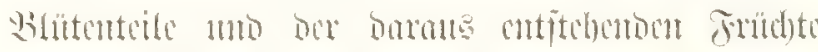

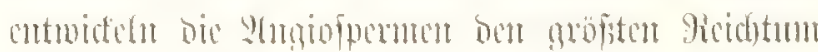

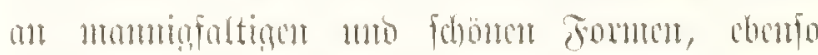

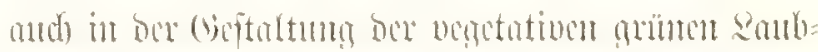

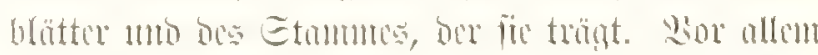

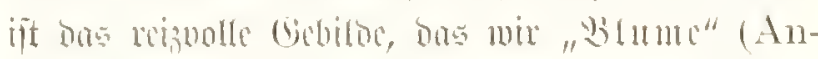

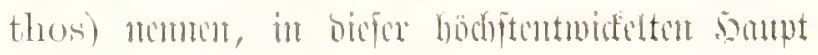

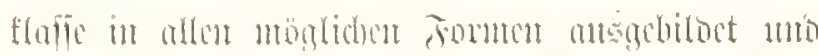

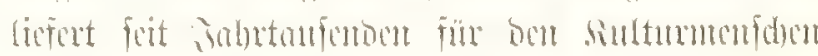

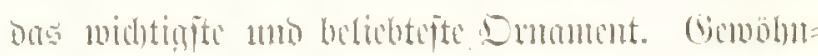

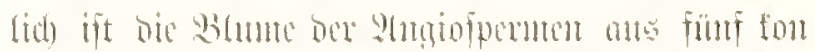

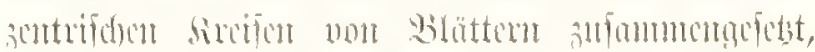

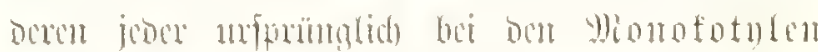
ats brei, bei bou Difotnlen ans viex ober fïn

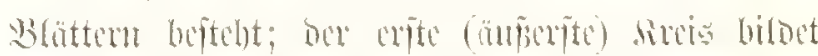

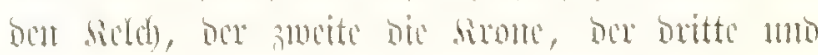

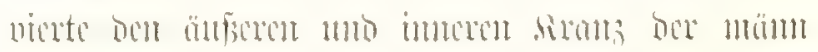

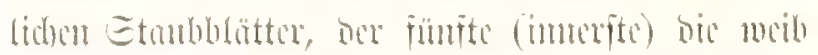

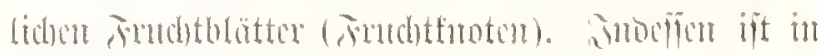

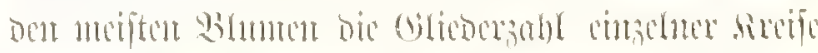

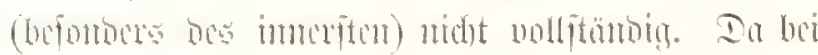

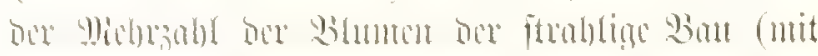

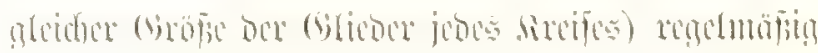

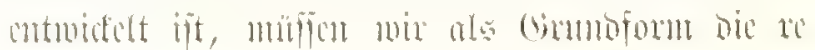




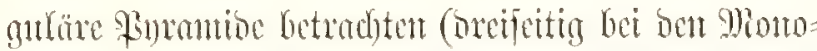
fotulen, fumfleitig bet ben Difotnlen); bicien regu=

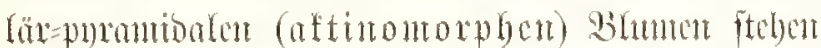

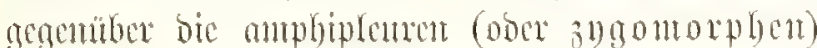

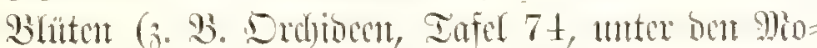

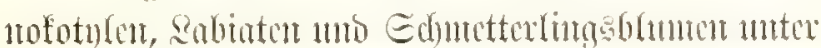
Den Difotulen); hick ift bie rabiale Gunntetrie mit ber bifateralat notulupit (ङ. 12).

\section{Die Sumfformen ber Bitederficre (Coelenteria).}

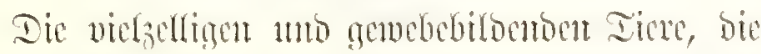
wix als Gewebtice (Metazoa) 3mfommonfolien,

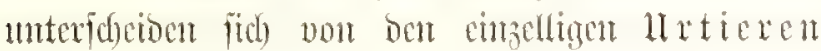

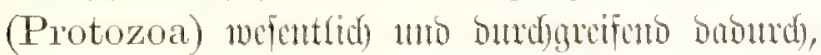

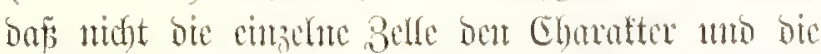
Form bes ticrifden Drganisnnte bedingt, fondoct

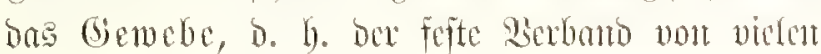

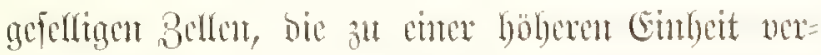
bunoen forth. Dis nerfdutebenten sebenstätigfeiten

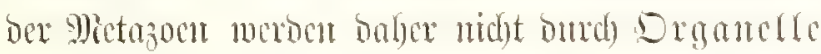

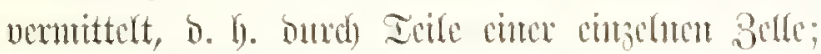

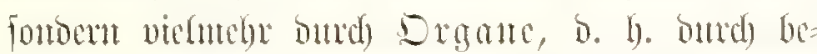
ftumut geformte mo georonte, viegellige siorper=

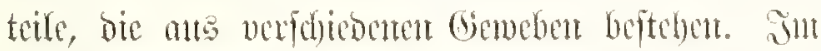
Srganismus ber boberen Gondetion ift bie Babl

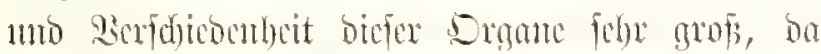

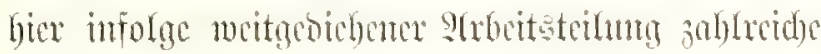

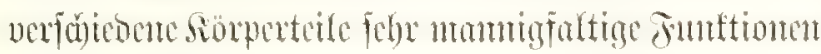
uno Fonmen ansubilbet baben. SHe ben alteren unto neberen Entwifelutgaftufen fintour wix ba=

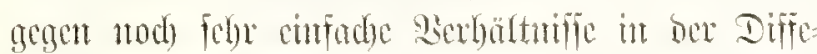
renziernty ber Gemebe uno Drganc; bie cinfadften bei dent Giaftüaben.

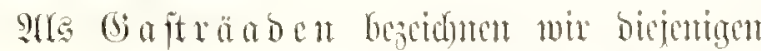
nieberiten uno curfachjten Sletasoen, bic wir anf

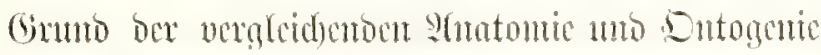

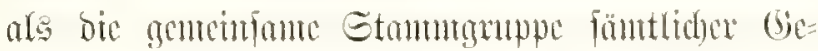

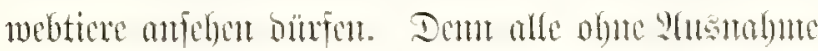

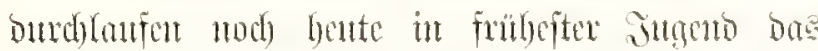
Gtobium ber Gastmla, cine hod)ft domafteriftifo Sicimfornt, bie int mefontliden ber Gastraea glcid gebilbet iit. Sie beftht trots viefer Formuntationem

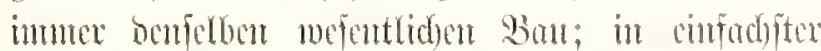

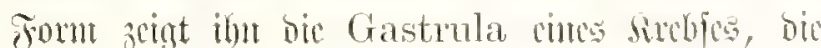
auf Iafel 76, Fia. 1, abgebiloet ift. Du tunclige,

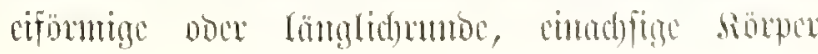

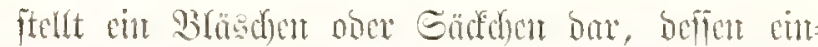

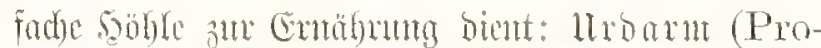

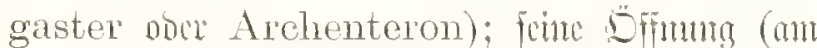

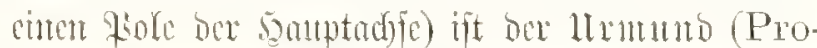

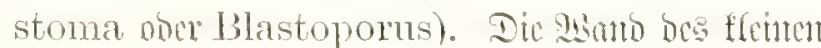

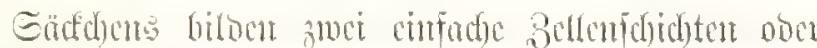
Epithelion, bic jogentanten "printeren sicintblätter" (Blastophylla); bas änicu ficublatt, 5ant

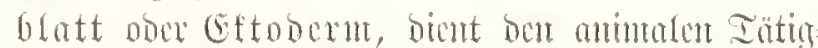

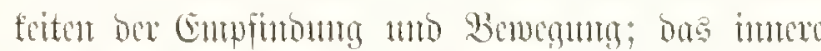
Simblatt, Darmblatt doer Eutoderan, Geforgt bic vegetalen Funftionea ber Enährmun mo Fout pflansum. Mioberate Gaftränen, bie mod) bente zeitleben anf biefex nieberfen Gtufe bet Mietasonorganiation iteben bleiben, fub bie Gaptrenarien (Pemmatodisens, Kunstleria) uno bic Cnenta ricu (Rhopalura, Dicyema). s(ber atd bic

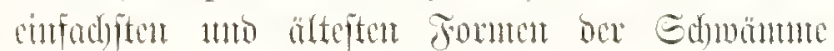

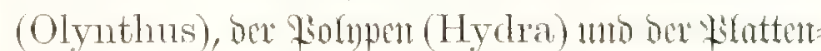
ticte (Aphanostomum) befitsen 1tod) int wejent=

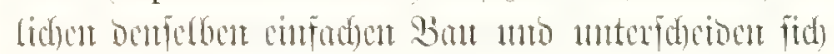

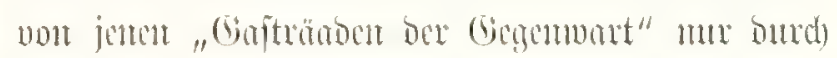
Iunvefontidbe Bututen.

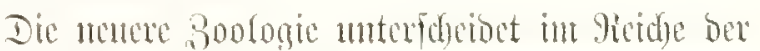

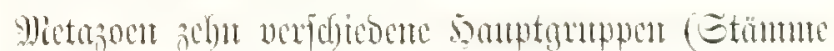

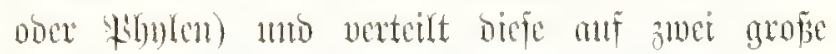

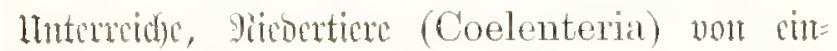
facteret Sioupcrbiloum amo Dberticre (Coelomaria) von böferer Drgunifation; bie enferen baben mu cine Diffmutg ber verbantmon boble,

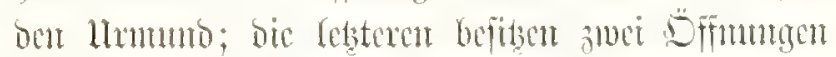

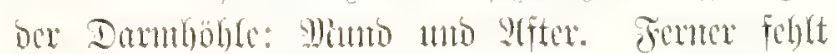
but gicouticren (Coelenteria docr Coelen-

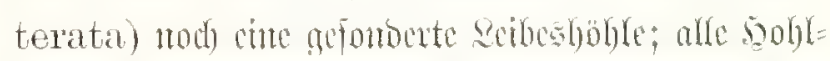

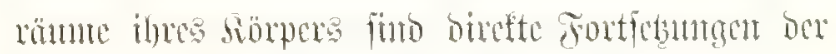

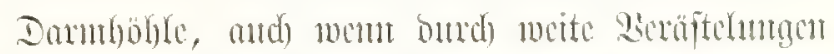

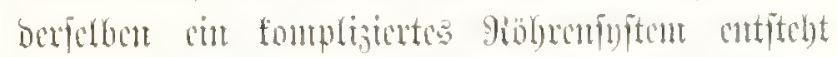
(Gajtrofanalinfent). Danegen hat fid bei bon Dberticen (Coelomaria obu Bilateria) cim befontoce Retbesboble (Coeloma) cutwitedt, cin Boblramu, bet vont Damufand gans getrement ift,

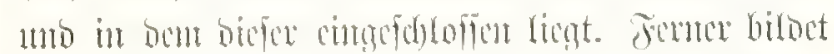

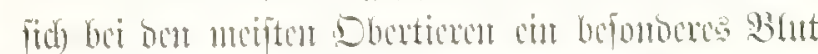

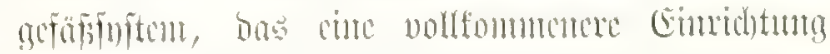

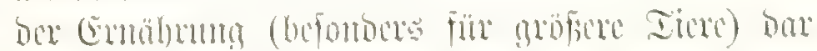

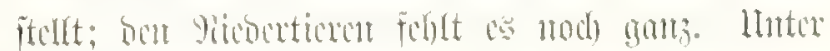

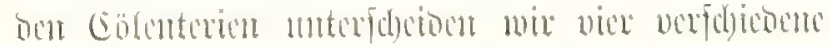




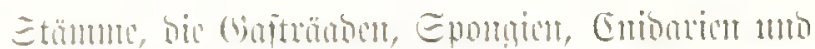

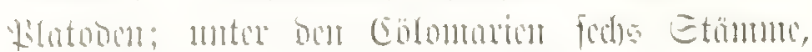

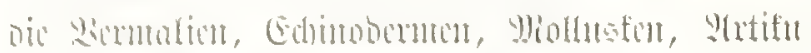

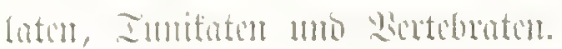

C. 1) Mronmuticre (tastraeades), bic numbur

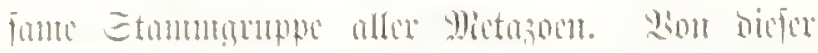

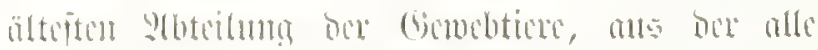

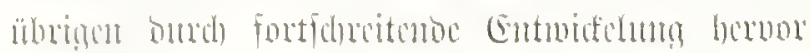

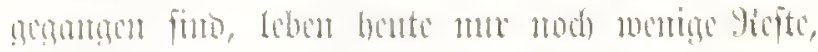

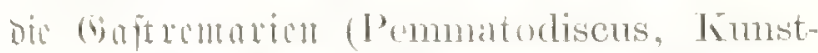
leria), bic (E) marion (I)icyemida, ()rthoneetida) mb bit 米bufomarion (Prophysema,

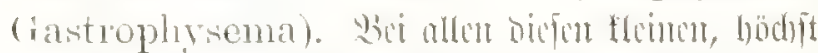

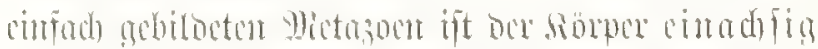

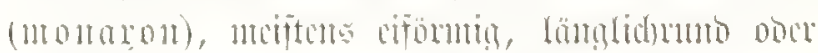

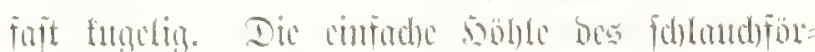

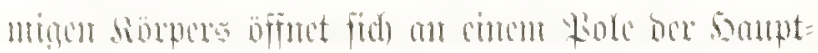

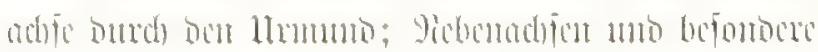

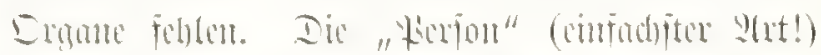

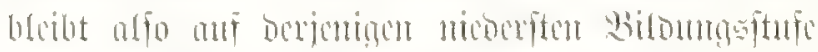

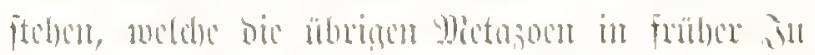

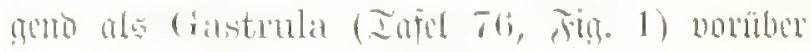

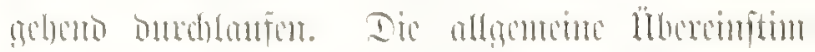

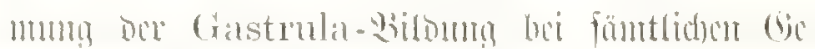

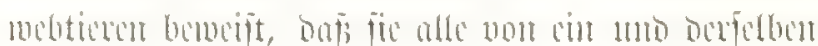

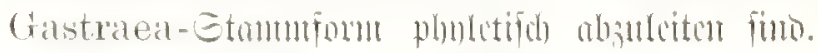

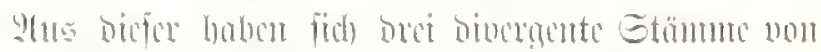

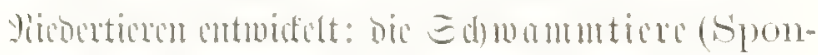

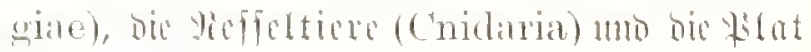
tentiere (Platodes).

C. 2) Edfmommtiere (Npongiat: Iofer 5,

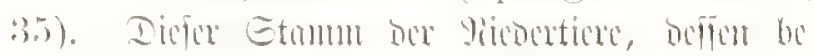

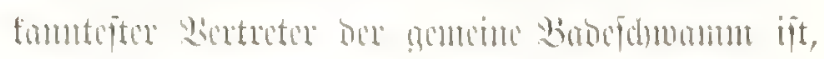

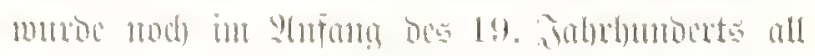

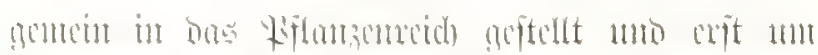

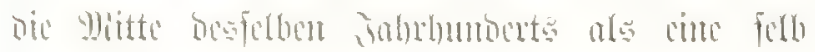

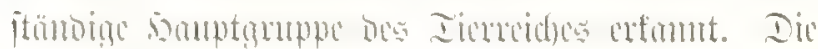

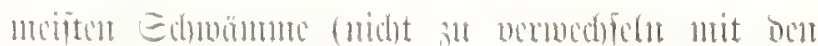

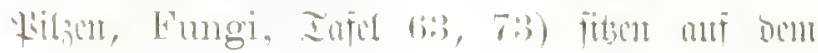

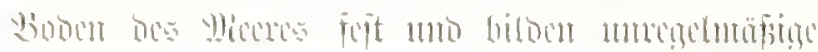

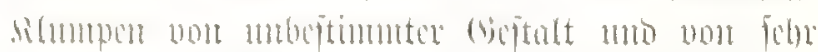

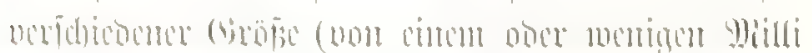

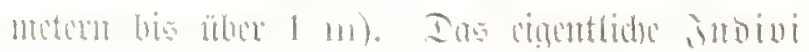

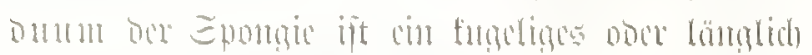

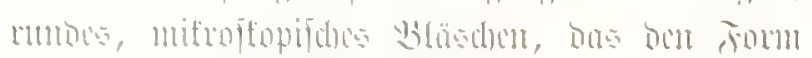

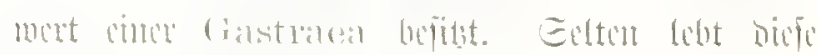

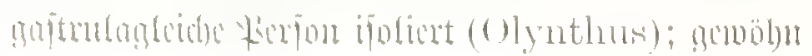

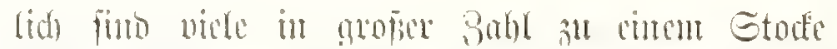

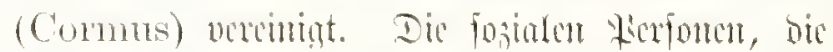

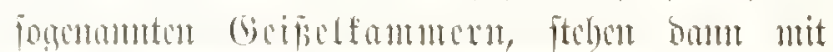

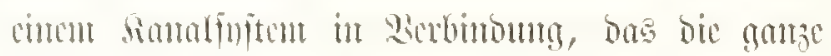

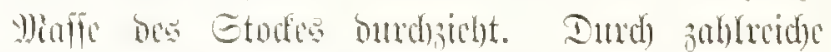

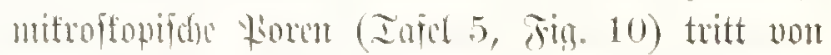

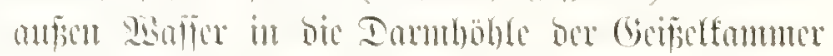

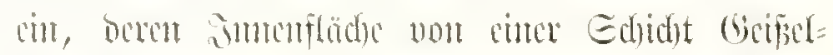

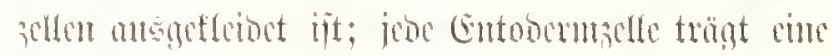

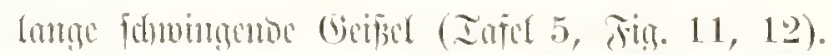
Das נmun (Osculums), bic fid) newöbntid) ann oberen

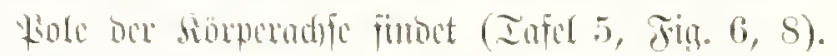

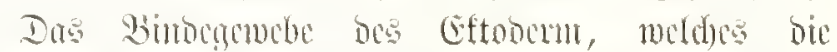

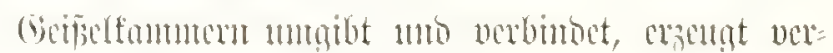

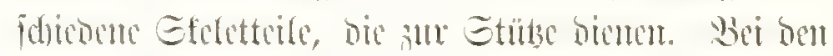
Siorffochuämntu (Malthospongiae), ju Denen

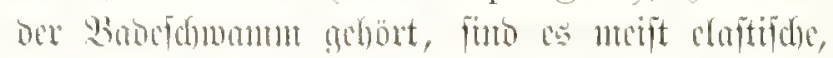

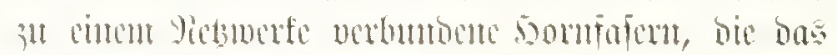

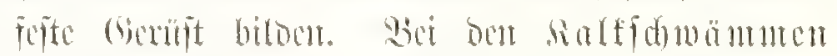
(Calciopongiae) ijt biefer ans sicrlid) geformten

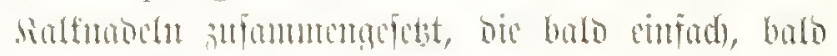

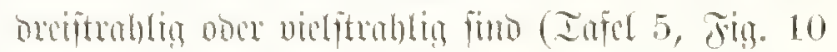

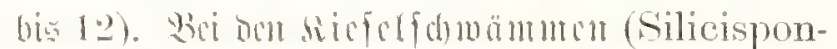

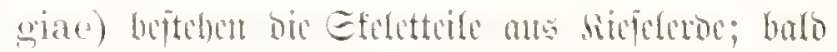

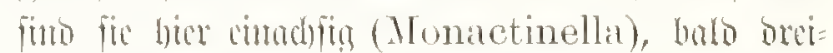
ftroblin oner vicritublig ('Tetractinella), balo

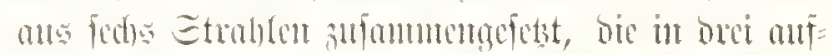
cinutow fenfredtut vdout liogen (Hexactinella,

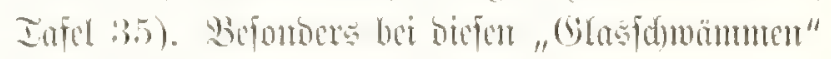

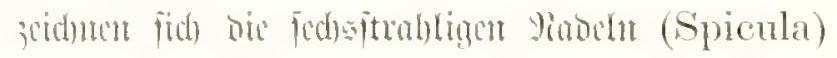

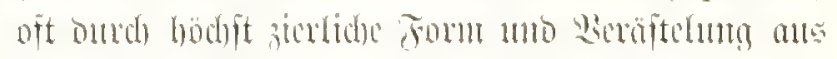

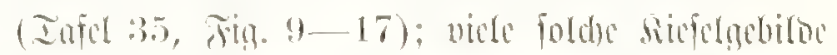

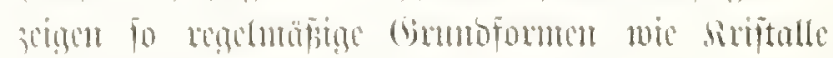

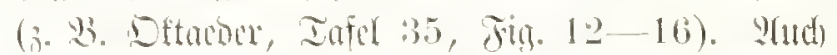

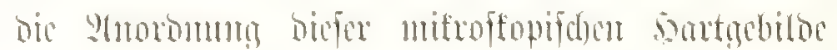

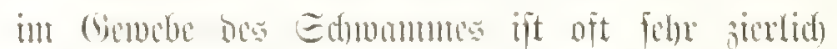

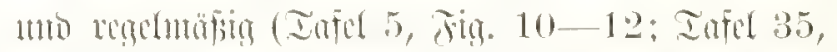

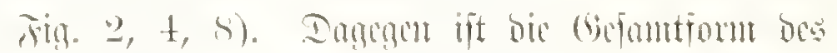

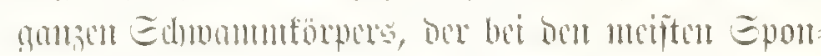

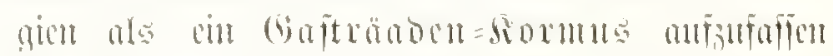
ift, folten fo regetumifing wie bei manden baum

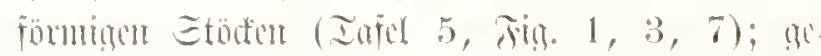

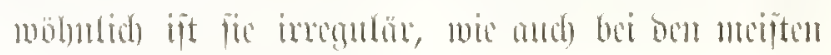

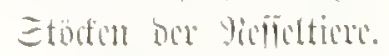

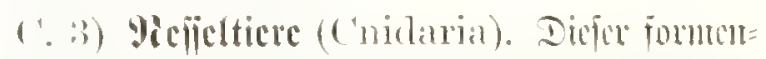

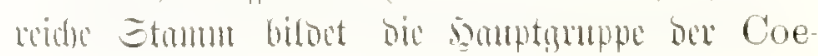


lenterata in cmocren Ginme; cr ift fomoly in

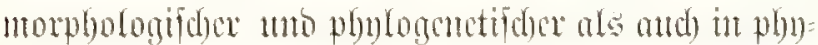

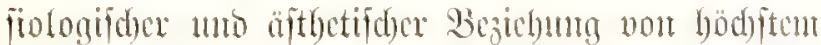

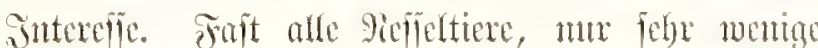

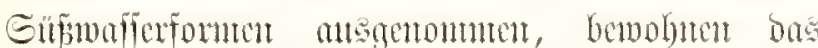

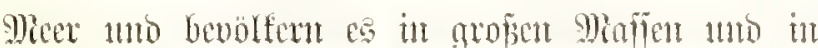

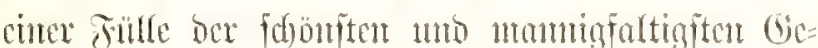
ftalten. Dicje laficu fich), änffer(id) betrad)tet, anf

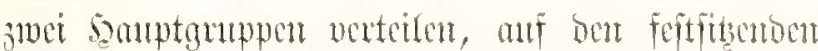

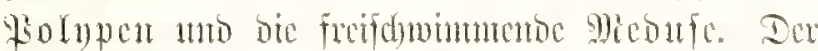

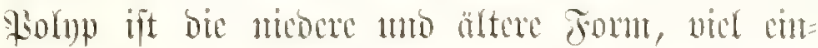

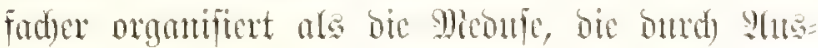

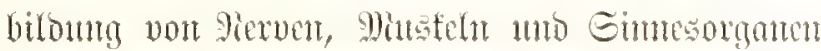
fid anf cime viel hobcre Gtufe vollfonutente $\mathrm{D}_{\mathrm{s}}$ gantifation erboben bat. Domod ptebat bcioe somet. formen vidfad) butd) Gonerationsmedjel (Micte

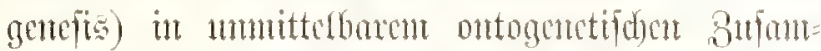
uenbang; ans ben befrudsteten (E) ber Micoufe cut=

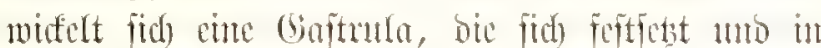

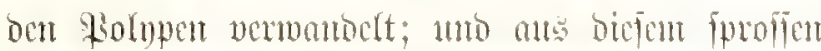
Surofpen bervor, bie fid ablofon tmo sul frei fonim:

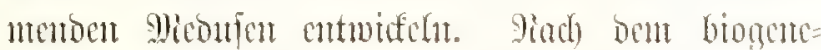

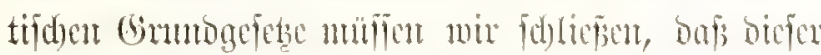

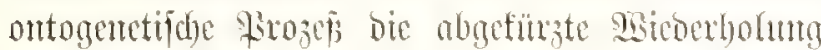

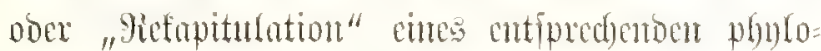
genetifiden Borganges ift: Mrprünglidg exifterten

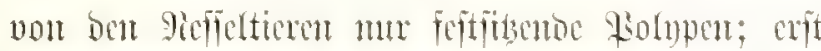
Fpäter baben jid) abgelojte funofpen berfelben burd)

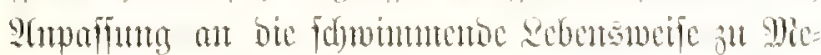
buin entwidelt.

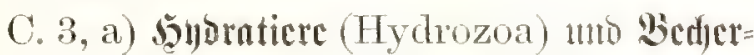
ticre (Scyphozoa). Die getamere Erforfdumg

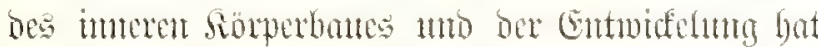
crgebor, boj ber mäd)tige Gtanm der Seffeltice

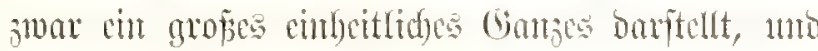

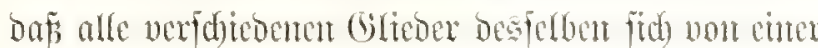

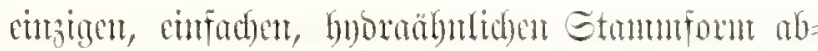

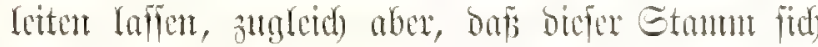
foron unten an ber sgurzel in zwei bivergieremos,

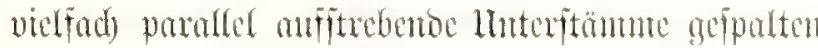
bat. Die älteren, flemeren unto neberen vou bickn find bic sobraticre (Hydrozoa) mit cmatyon

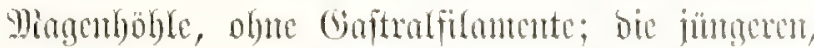

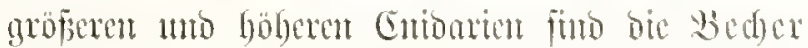

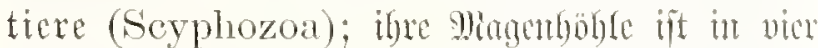
ooce mely periphere Iafden getcilt, Dund rabiale

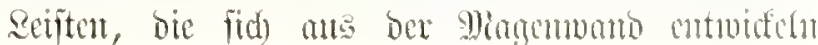

(Taeniola); ane biefen seiften jproffon bemerglide, Dräfometde föben beroor, innere Diagententafelat (Gajtalfilancute). Ju jeben bex betoen luter= itümme baben fid ans Polupen fpäter Meonjen

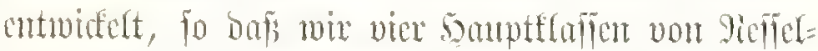
ticren anterfdection fömen. Die fiolnpen ber Sybra= tice merben ale subrotben ober subropolupen begcidnut ( Iafel 6, 25, 45); bic bavon abgeleiteten Midufu af Hychromedusae ober Craspedotae

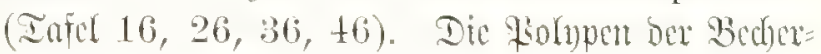
ticre furb die Sorallen (Anthozoa; Infel 9, 19, 29, 39, 49, 69); ibre 9ledufu hcip̀n Scyphomedusae obcr Acraspedae (Infel 8, 18, 28, $38,48,78,88,98)$.

C. 3, b) syornion (Hydropolypi; Tafel 6 , 25, 45). Dic llroum bes curfaden Polupen, bic

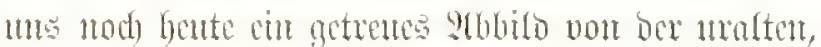

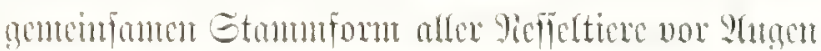

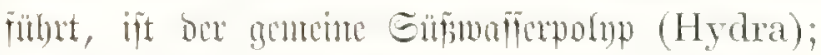
fomoln fente arime stat (H. viridis) ab and) die grome gre (H. grisea) futh thber bie ganse

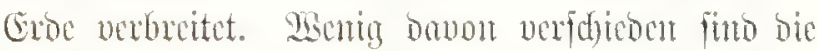

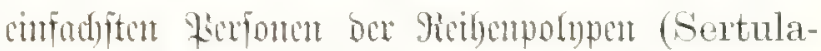

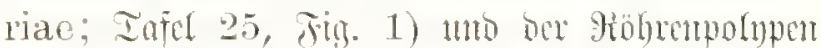
(T'ubulariae; Iafel 6, Fitu. 6, 7). Dux curfadye,

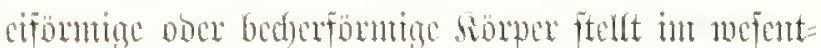

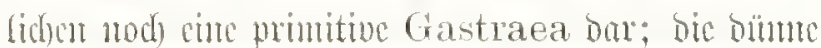

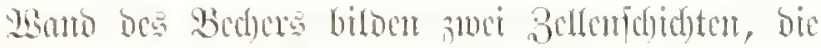

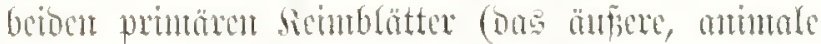

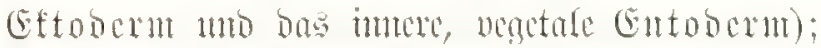

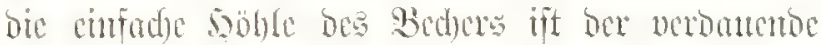

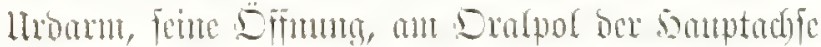

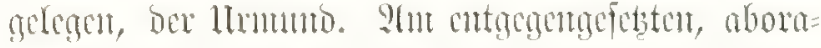

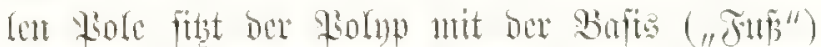

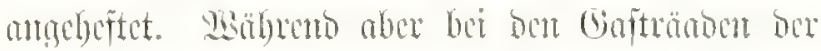

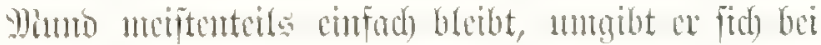

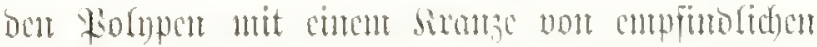

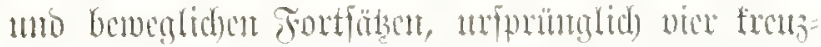

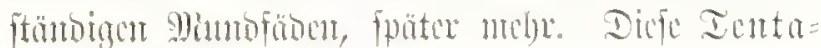

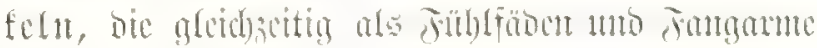

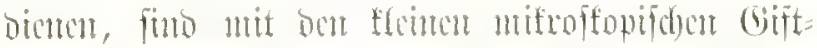

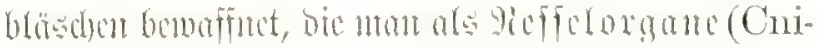

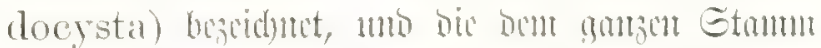

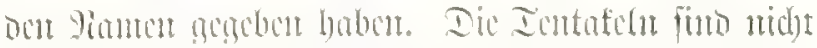

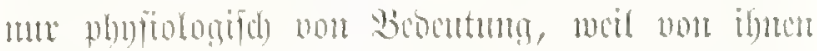

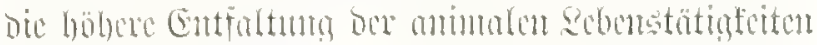

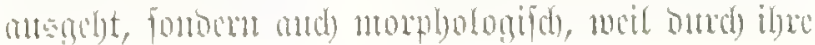




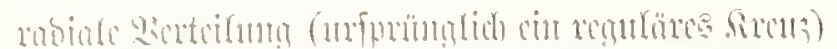

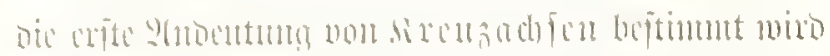

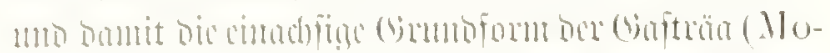

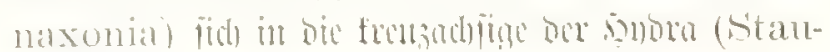

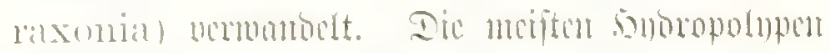

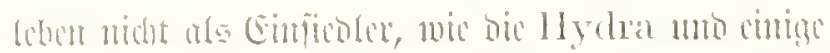

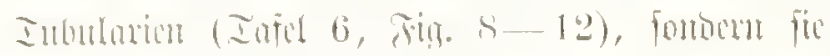

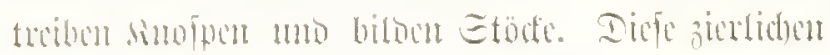

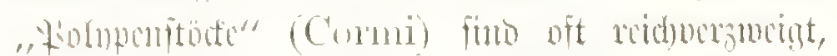

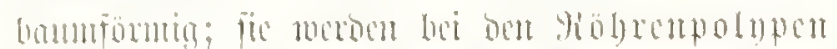

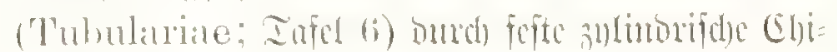

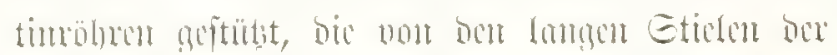

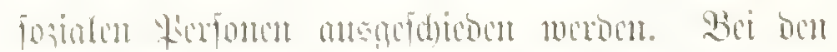
(blodemolnotu (Campanariat Tafet 45) nex=

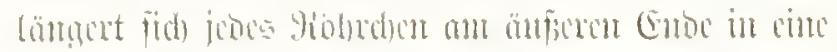

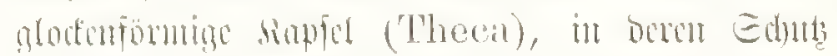

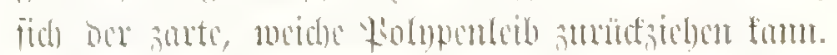

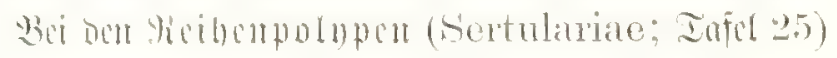

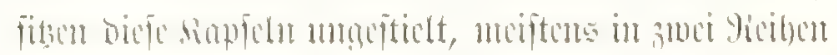

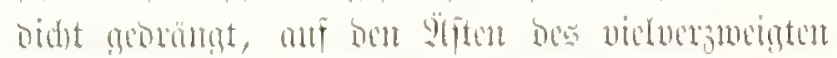

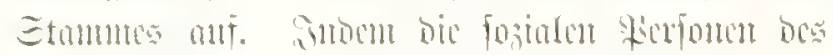

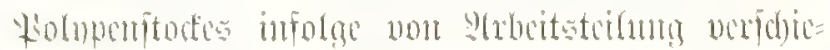

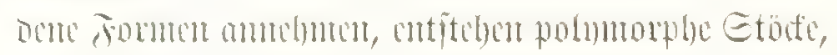

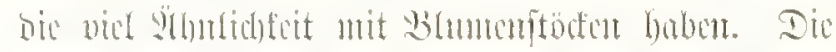

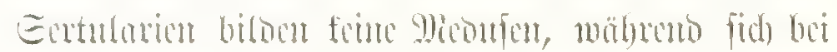

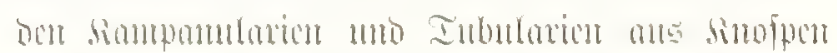

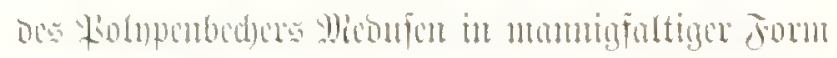
mentuifeln.

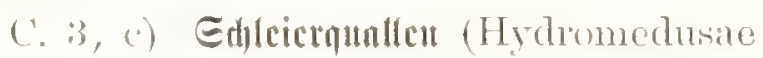
obre Craspedotale; Iafel 16, 26, 36, 46). Diffe

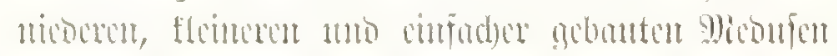

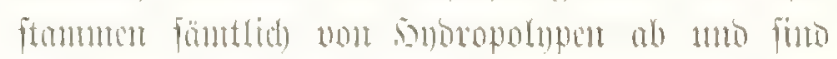

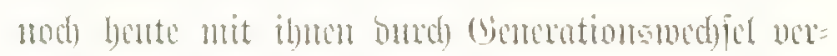

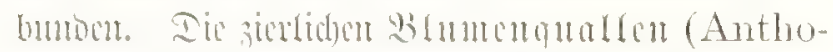

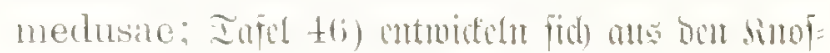

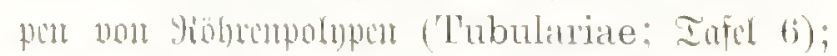
bingugen bic zarten Fa!tumantan (Leptome-

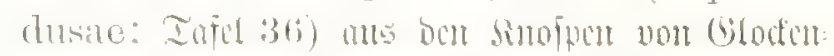
polopen (Campanariale; Iafet +5$)$. Dicfe beion

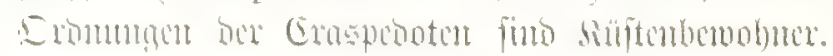

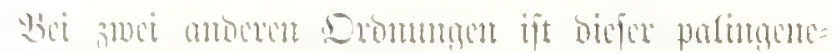

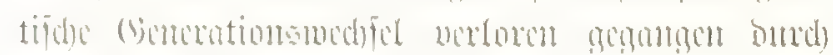

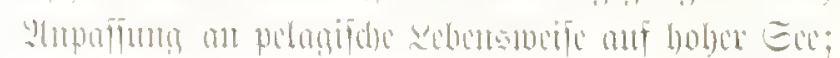

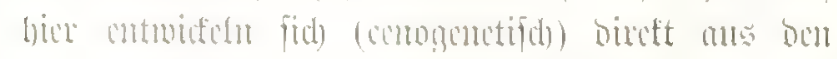

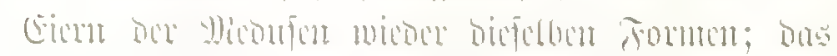

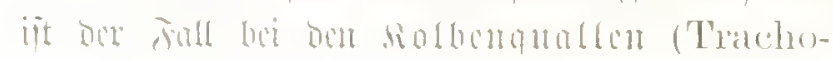

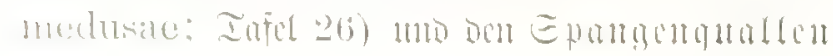

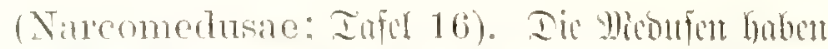

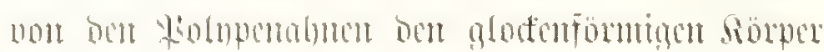

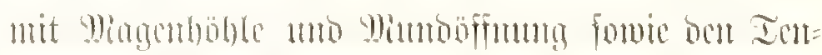

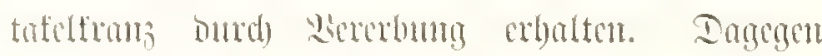
baben fic buth) S(mpafjum net crworben ben Gallert= jumu (Umbrella) ab Edmummotgan, bic Sinnc:

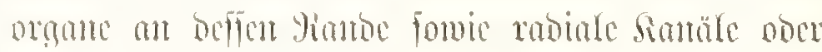
Wiagentafolest, bic voun sentralen Miagen sum peri=

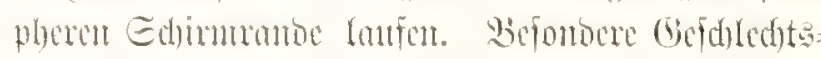

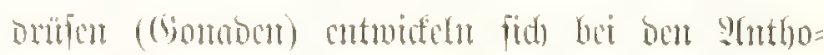

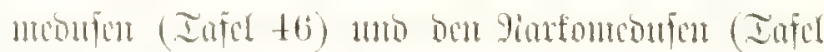

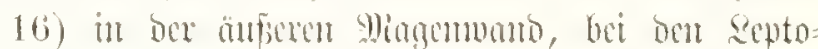

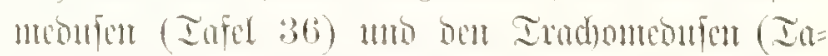

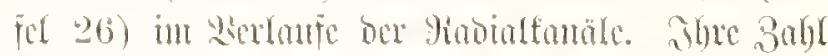

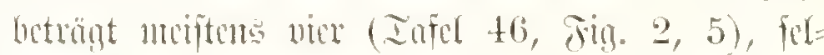
tenter feds (Iafd 20, Fig. 1), adt (Iafel 16, Fig. 4, 9) ober melu ( Iafel 36, Jig. 3, 5). Ebenfo

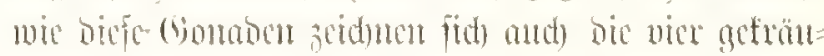

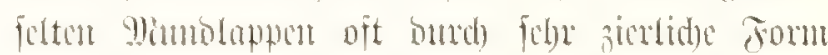

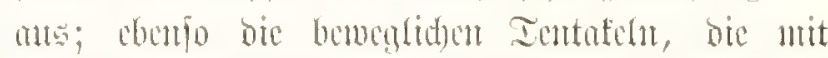

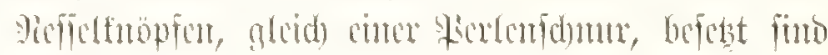

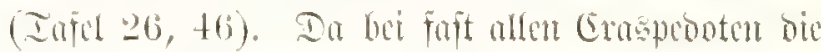

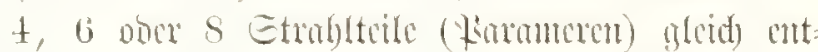
midelt furto, fo ift bic Gumbform bie reguläre

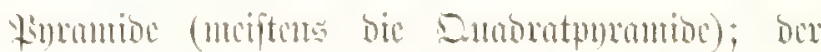

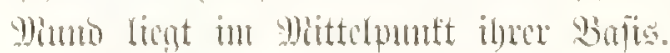

(. 3, (l) Etuntanunlleu (Siphomophora: Iafel $7,17,37,597,77$ ). Diefe nertmontige

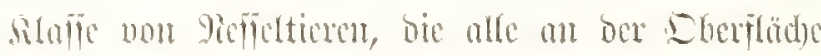

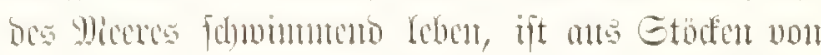

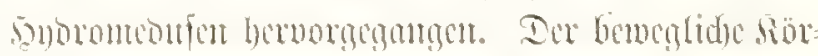

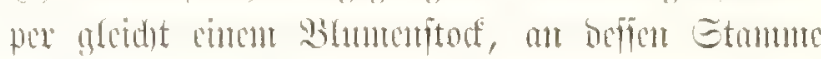

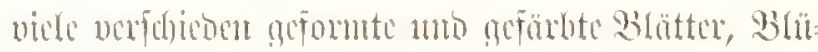
ten mo Fruthe nerteilt futo; alle Irife finto buth

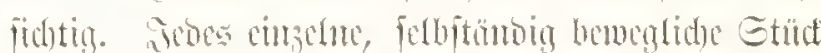

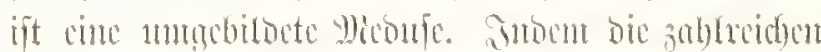

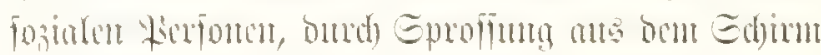

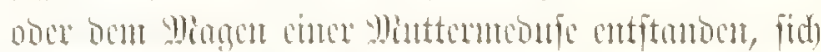
in bic strheiten bu seben teilten, bic chen jone,

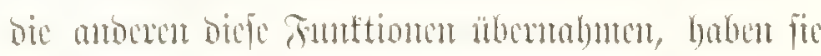

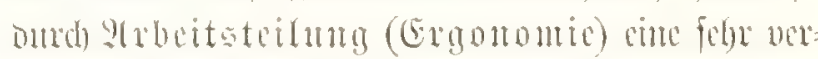

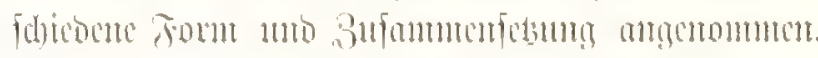

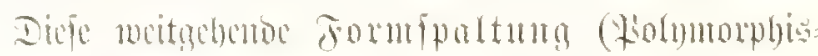
ntus) gibt bou gumbar Etode (Cormus) chr fo

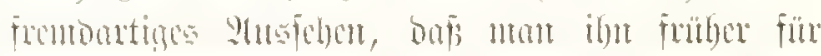

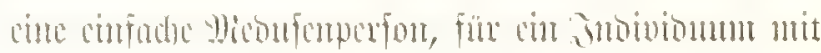

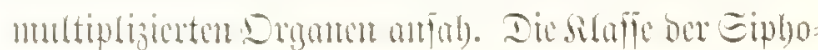


nophoren zerfällt in jued Segtoncu, Disfonantlyat Imo Giphonanthen. Set ben fodbentantigen Disto= manthen ( Tafel 17) entfeben bie zablucidacn poly=

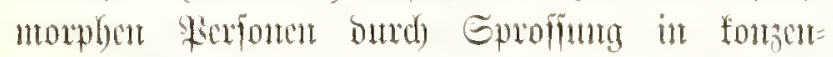
trifden Areifat an ber Interfite bes Edfuncs (Subumbrella) bes Mittertieres, Dagegen bei ben

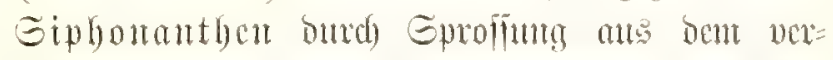

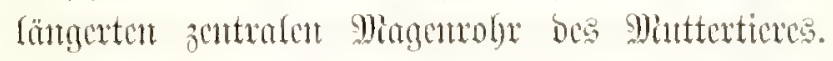
VAn bicion langen, bewolidyen Stannme fithen bic

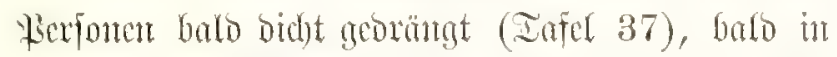
Lamgen Epiraluethen (Infel 59), balo nuf vide

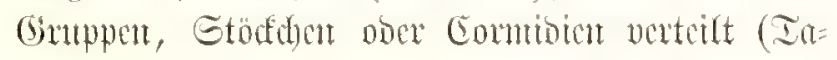
fel 7, 77). Dic Edymimnorganc ber Gipfono=

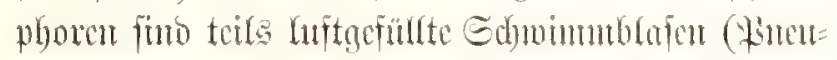
matophoren; Iafd 7 , Fig. 4, 5; Tafel 17 , Fig. 3 ; Tafel 59, Fia. 2), tcile fontraftile Ed)wimmolofon ( Iafel 37, Jig. 2, 3; Tafel 59, Jig. 1; Iafel 77 ,

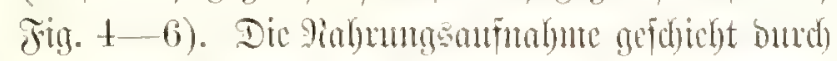

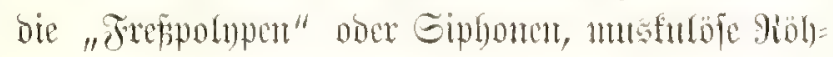

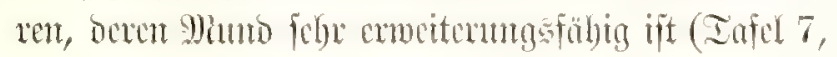
Jig. 2; Iafd 59, Fig. 3; Iafel 77, Fig. 2, 7); lantge Fangfäben, bic von ifrex Baffe abgeben, futb

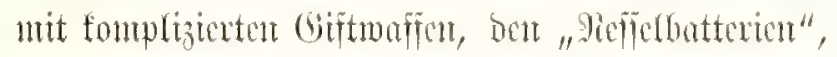
befedst (Tafel 17, Fig. 8; Iafel 37, Fig. 1; Taful 59, Fig. 3, 6). Sth Injtorgante biente die felgr

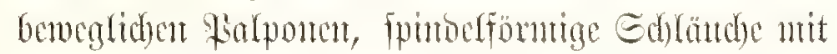
fangen Iaftiöben (Iafel 37, Fig. 1; Iafel 59,

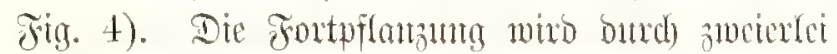

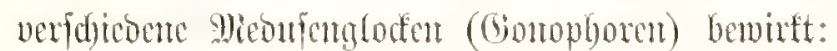

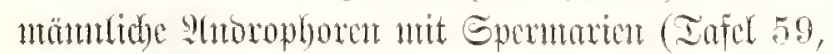
Jig. 4 11. 5 redhts) mo weiblide (Ginnophoren mit Dvarten (Iafel 59, Jig. 4 4. 5 linfs). Bei dicfen Gicidededeperionen (Gomophorent) uno cbenfo bei

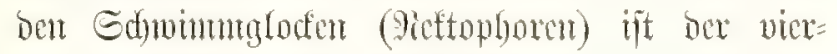

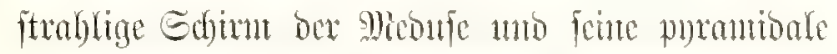
Grumbfonm meipten ntod) cthalten, bagegen bei bon

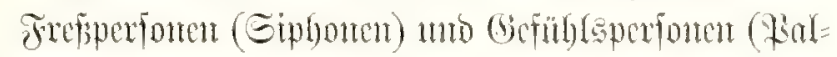
ponen) meiftens ribfgebiloct. Son ben ore Dro= mugen ber Siphonanthen bejuen bic Cafyco ueften (Iafel 77) blop Ed)winmugloden, bie Evfto

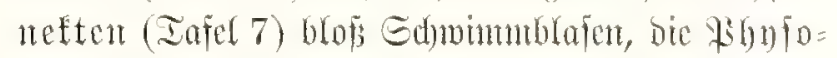

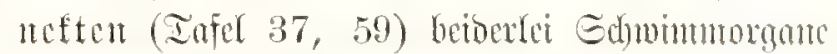

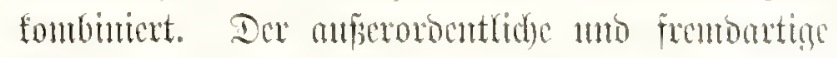

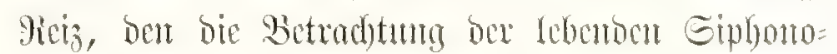

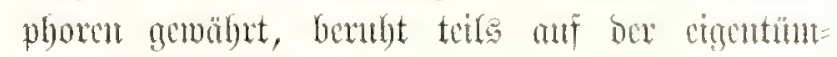

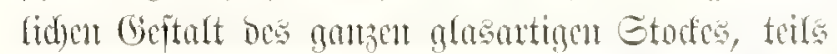
anf ber foünen uno mamigfaltigen Fon feincr

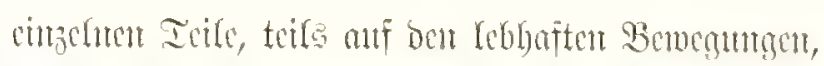
bic fowohl ber ganze Comme als aud bic cintzeluen Picrionca tuto beten Drgate ansfiblen.

C. 3, e) Sinmununlfat (Ctenophorae; Ia= fol 27). Durd mebreve ntorphologifde amo phy

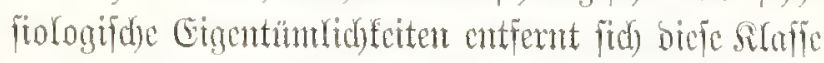

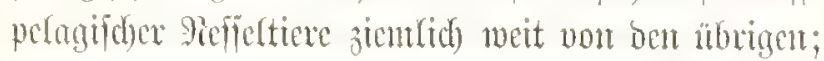

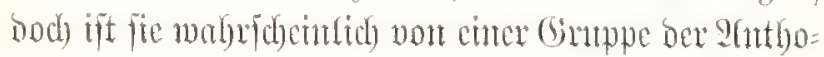
uncoujen phyletifor) absuleiten. Dic zarten, gallert=

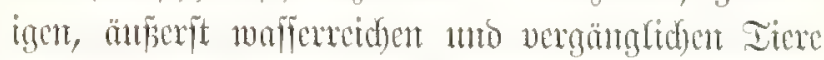

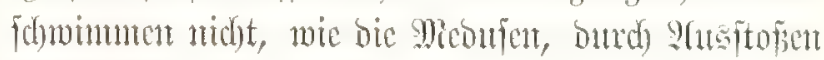

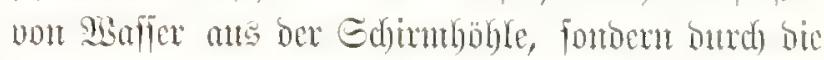
Suberbemegntugen von febr jablreid)en, willturlid) bemeglidben simperblättd)en, bie anf adyt abrabiale

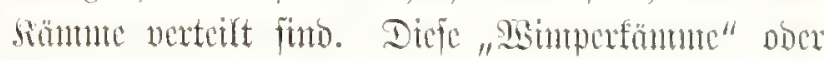

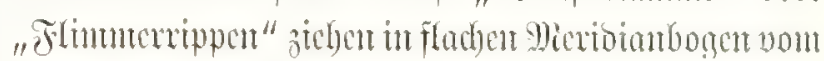

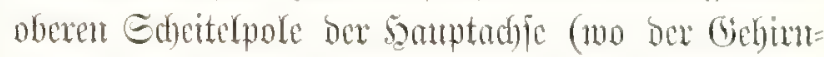
funoten liegt) 31un unteren Dimopole mit ber weiten

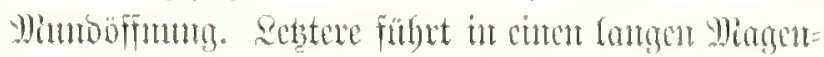

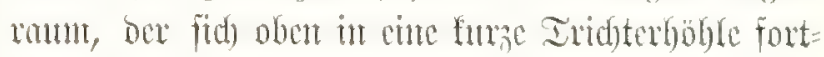

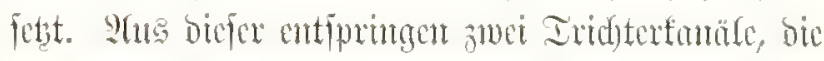

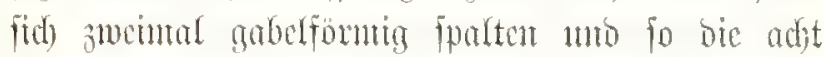

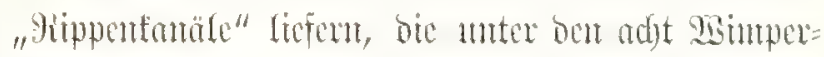
rippen verlanfur. Sale Drgate futb fo verteilt, bafs

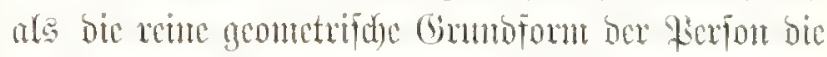

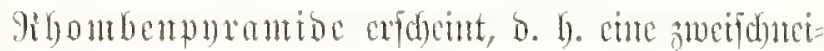

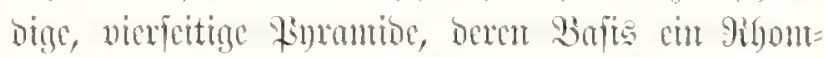
buts ift. Gic wiro beftumnt butud beci anfeinanoes

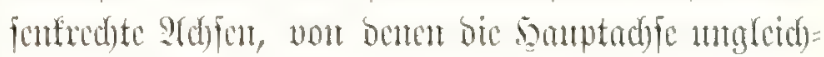

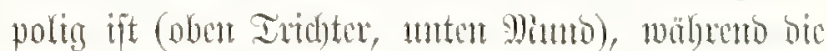

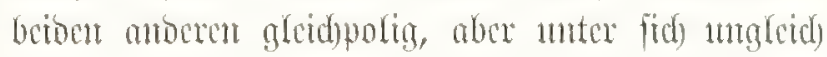

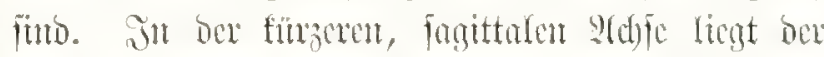

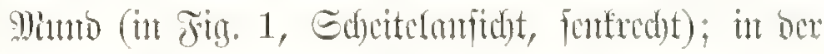

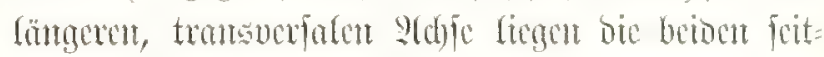
lict)ent Fangfäbon (red)to unto lints).

C. 3, f) Rupcuitullen (Scyphomedusae ober Acraspedae). Diefe föbucn แn grofjen 䍜=

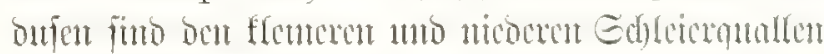

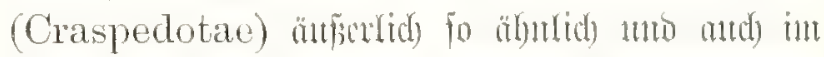

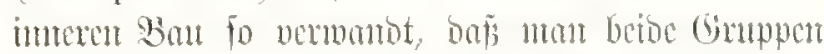

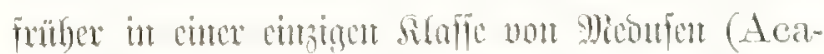

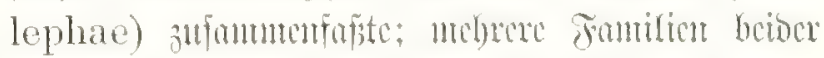

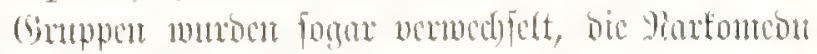

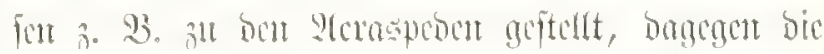

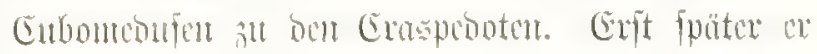

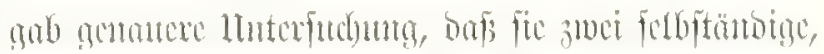

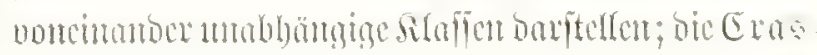




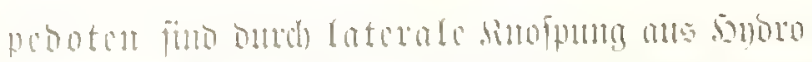

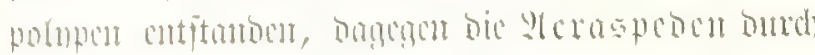

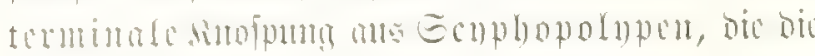
Enganfation ber cimpadyten horallen bejpen. Dio

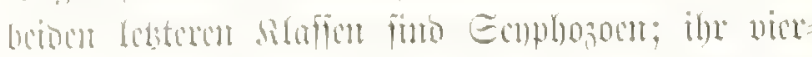

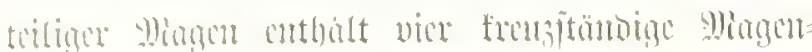

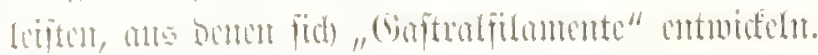

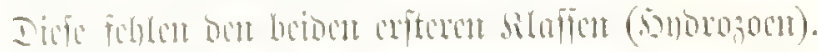

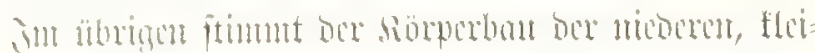

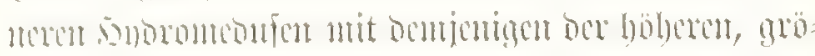

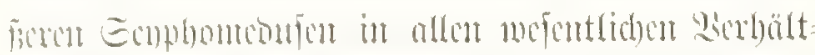

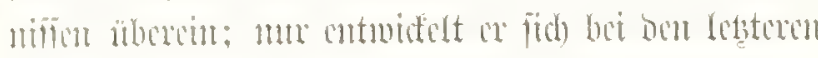

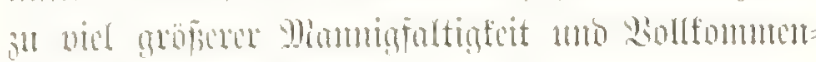

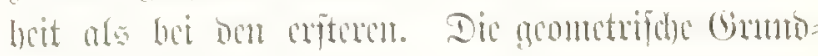

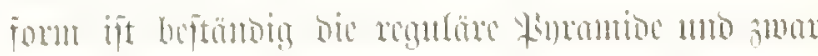

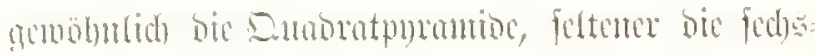

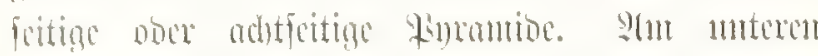

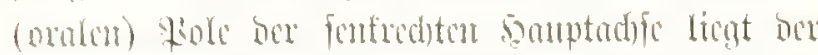

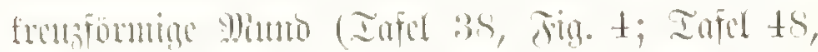
Fig. 2, 5): fonte vior getrüuferten sippen, oft 314

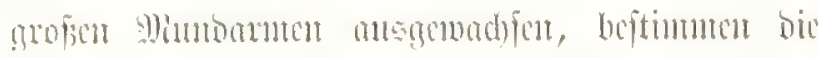

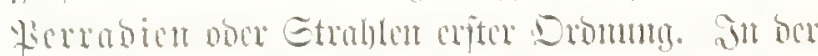

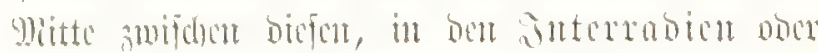

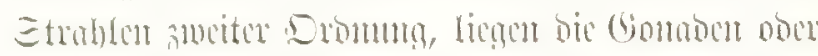

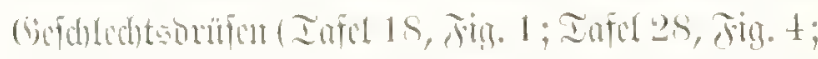

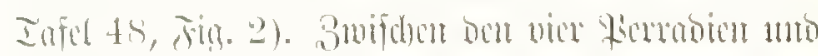

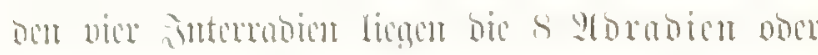
Etrablen oritter Enomma, mit beftimmtan Ergumo,

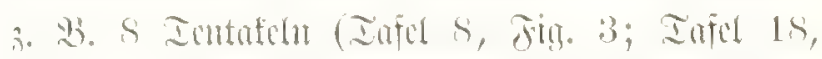

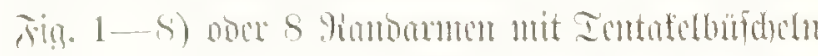
(Enfd ts, Ting. 3-7). Eft fum man and nod 16 Embradien now Etrablen viexter Dromm

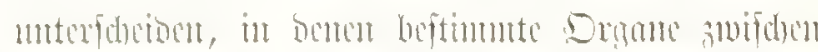

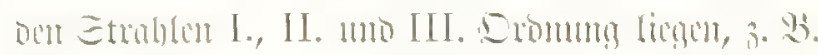

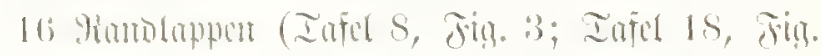

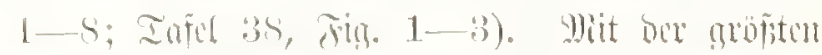

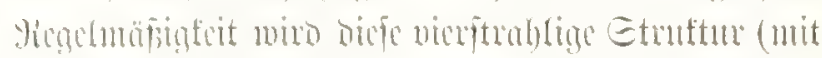

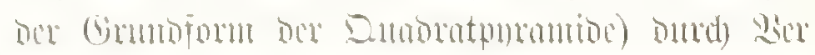

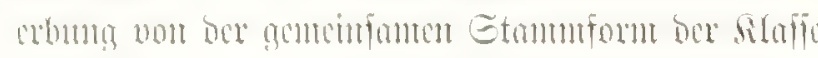

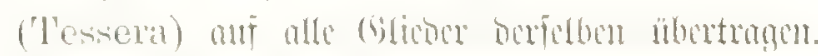

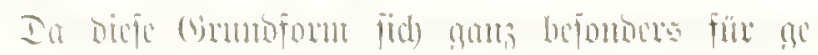

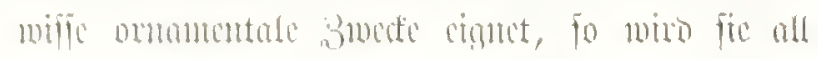

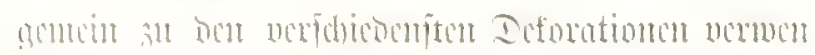

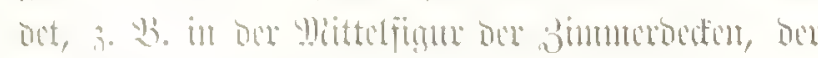
Fublobocut 11. \%. 20.

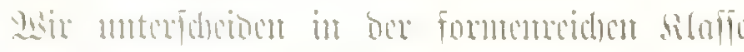

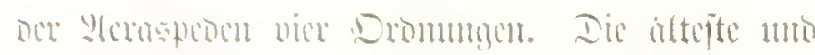

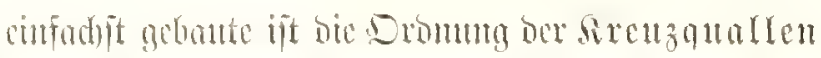
(Stamonedusate; Iafel $t S$ ); bick trägt bel

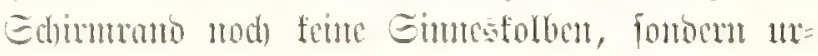

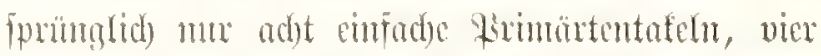

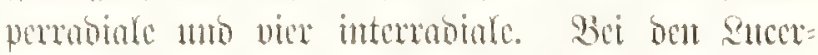

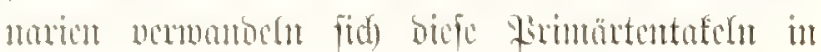
"Yambanfer" (Infel tS, Fig. 3-5), wabrento ba=

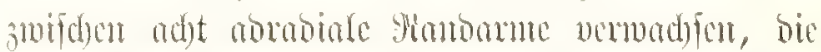

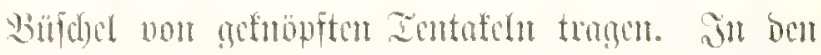

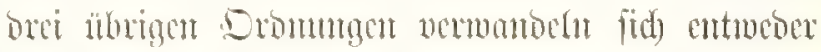
alfe acht ober mu viex firmätentafedu in cigen= tüntide Ginnestolben (Rhopalia); jeocr ber=

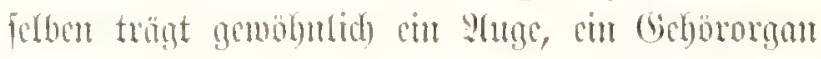
(Etatocujt) mo cin (Gerud) sorgan (cime faltige Vitudurub; Iafel 3s, Fig. 6; Iafel as, Jig. 7). Bat ban Iafdentuallen (Peromedusae; In=

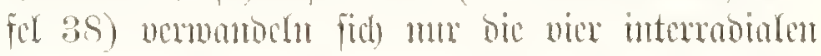

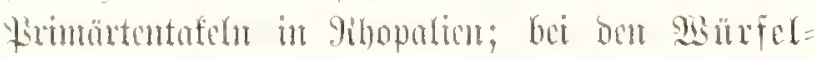
quallon (Cubonnedusate; Iafel $7 S$ ) unngefebrt

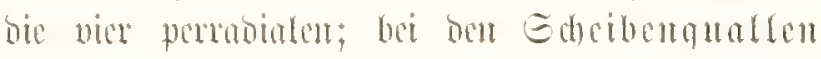
cmblid) (Disconcdusae) finb alle ad)t Frimär=

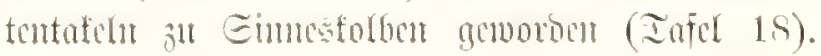

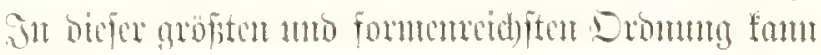

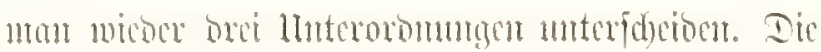

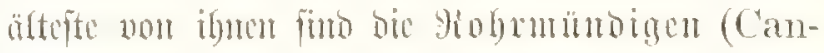

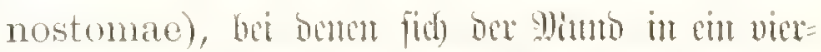

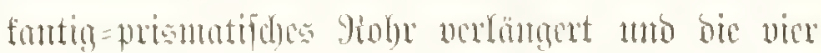

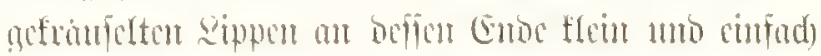

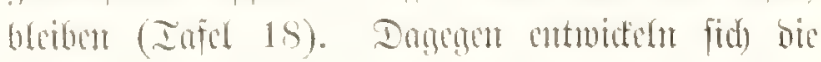

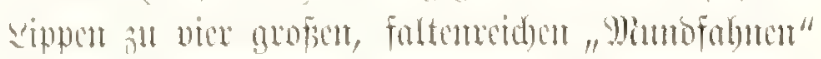

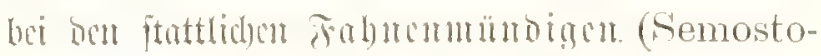

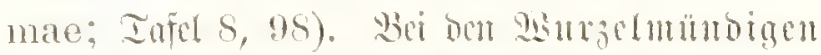
(Rhizostomat: Iufel 2S, SS) antutben barats

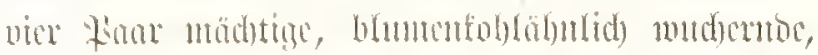

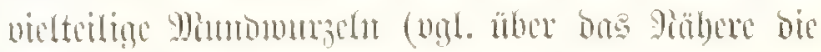

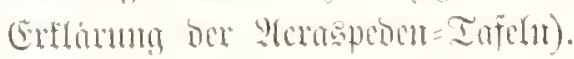

C. 3, g) Siornllen (Anthozoa; Iafil 9, 19,

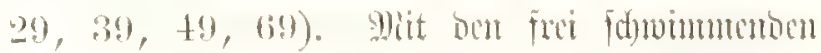

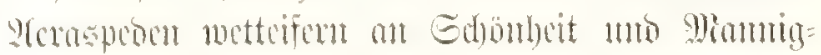

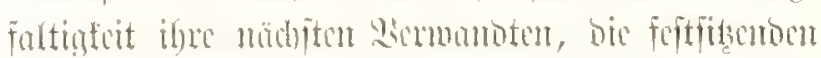

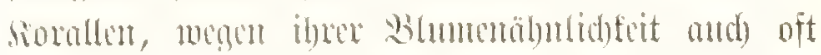
Blanention (- Anthozoa) gemont. Sitele

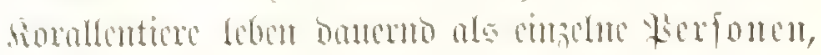

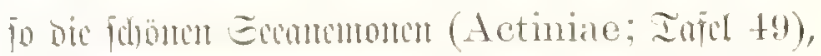
vide Ietraforallen ( Iafel 29, Fig. 1, 6-S) unto

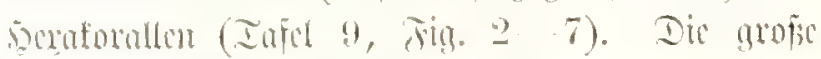

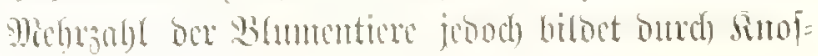


pung Stöde (Cormi), bie an vielen gejellin

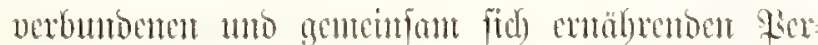

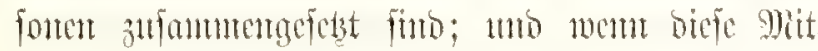

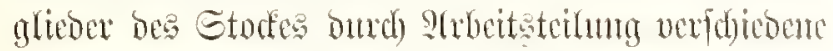

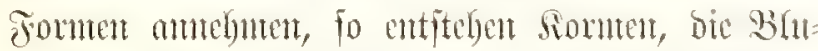

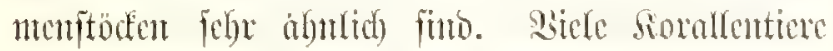

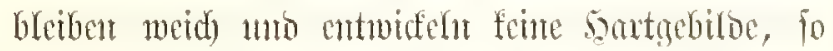

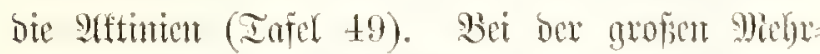

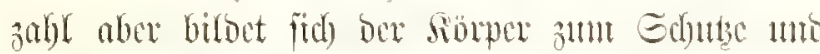

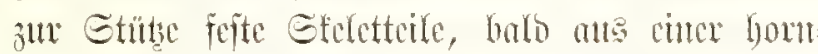

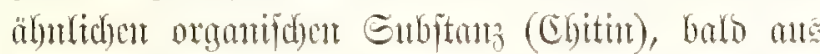
Sialferoe. Bea ben grofien, ftodbilbentoen Sioraffen cutwoiffelu fid) bant jute gewaltigen falfutafen, bic

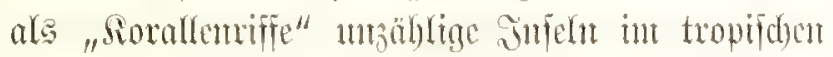

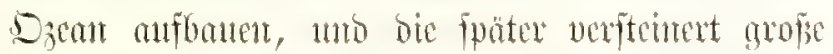

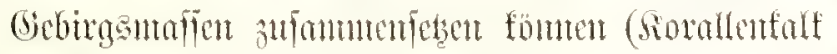
bes Эแ4

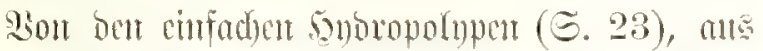
bonen bie Siorallen als Ecmphopolnpen mprünglid) entitanoen fund, unteridyeiben fie fid wejentlid) ourd

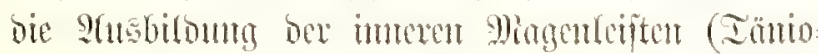

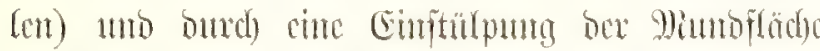

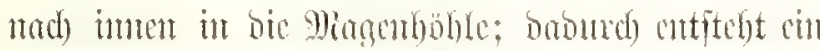
bejomberes (ctoonerntalex) Gibluth (Pharyns),

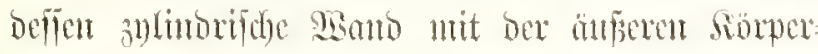

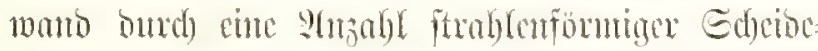
wante (Septa radialia) vertumben bleibt. Dic

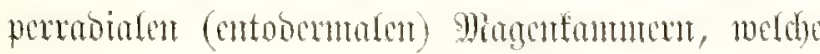

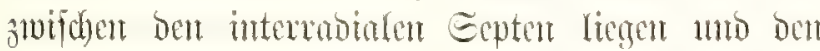
Edflumb nutgebu, fetwen fid) nad) oben fort in bie

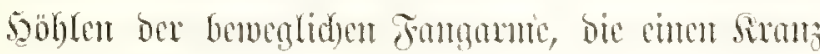
tnit ben giuno biloen (Iafel 19, Fig. 3, 5; Ia fel 49 ).

Dic Babl ber Gtuhlteile (Baramerem), die bured) biefe rabialen Siantutern und Eepten befinmt

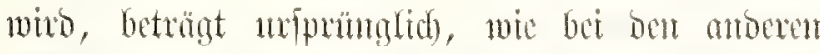
Seffertieren, vier, fo perntanent bet ben Bicrer. foraffen (Tetracolalla; Iofil 29); butd) Sexboppehung ber Samment wädjt fie anf ad)t, bei bey Steterforallen (Octocoralla; Iafel 19, 39). Jubent von ben adjt itrahligen Gepten zuei gegenulberitebeno cingeben, entitebt bie Fon ber Gediferforallum (Hexacoralla; Iafel 9, 49,

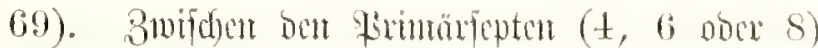

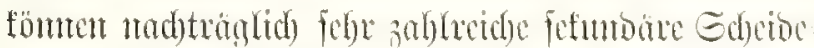

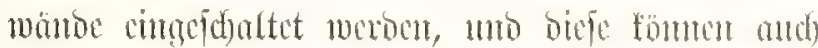
verfalfor; fo entiteben bic vielftrabligen Lerfonen,
Dic fomoht bet ben Rebentom Satraforallen ( Tafel 9,

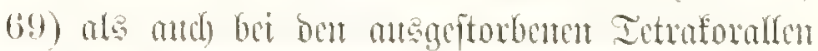

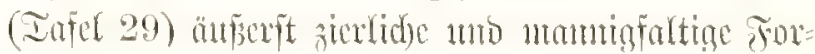

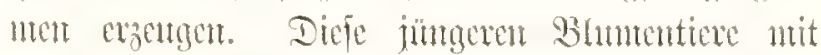
multiplizicten Gepten werom als Sternforallen (Zoantharia) bejcichnet, in Gegenfols zat beat alte nen Fornten mit fonftanter Primärabl ber Expten, ber Sramseralfen (Alcyonaria).

C. t) Plnttenticue (Platodes; Iafet 75).

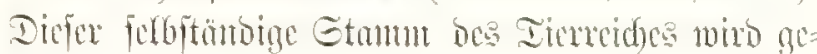

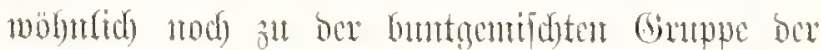

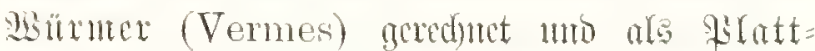
wärntu (Platyhehminthes) don Giundwirurern

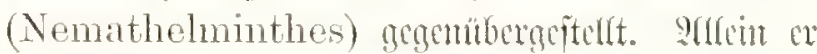

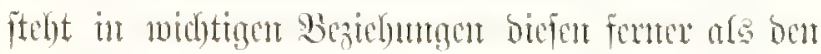

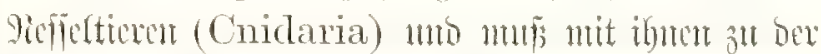
Sumptgupp bex Bitocticu (Coelenteria) grogu merben. Dem es feblt den Slatoben cbenjo wie

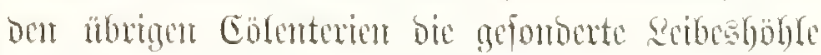

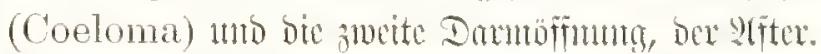

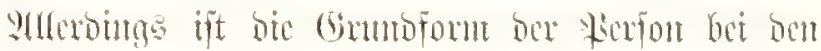
Flattenticen bilateral, wie bei Dberticren, ans nidet rabtal, wic be ben metiten Yirberticen; aber

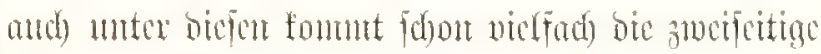

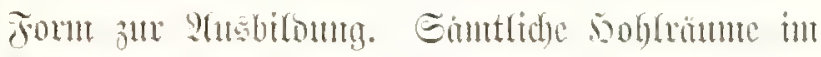

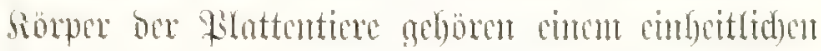

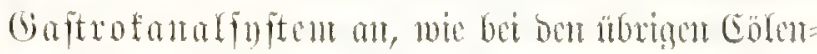

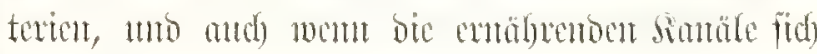

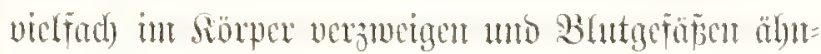
lid) cridgenen ( Tafel 75, Fig. $4,7-9$ ), bletben fic bod) ftets mit bent sentralen shagen in bireftem

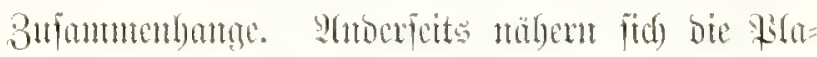
toben ben coftu Sburutieren (Vermalia), bie von ibmen abjtanmen, nidat allecin bumd bie bilate=

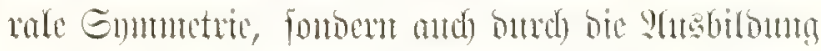
won ein par lateralen santoriffen, bic fid sal gite

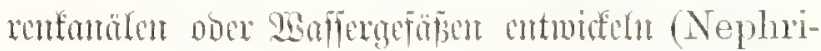
dia; Infel 75, Fin. 1, 2).

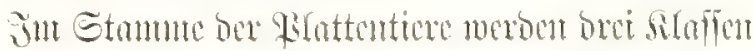
unteridicose. Dic altefte mo mapringlidofte von

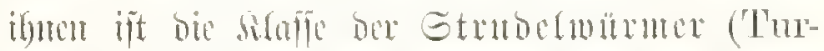

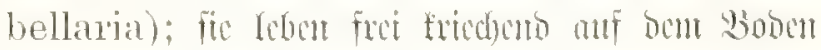
be Sirtreter (Cryptocoela mo Rhabdocoela) ant=

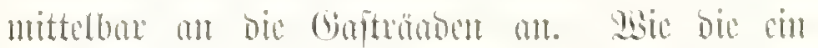

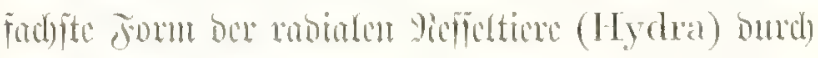

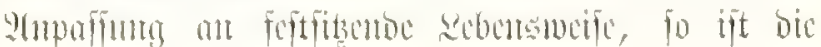




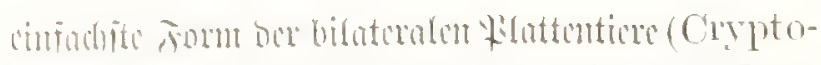

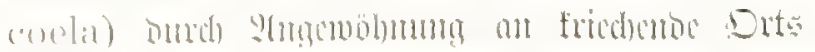

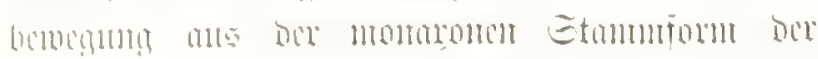

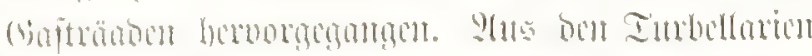

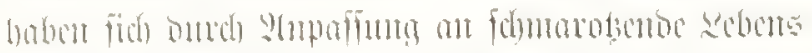

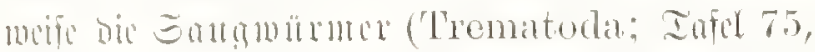

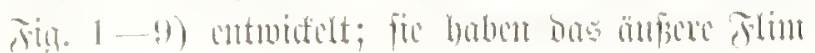

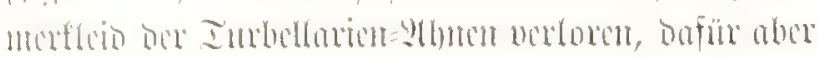

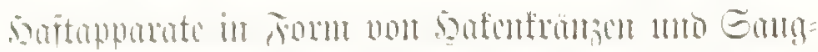

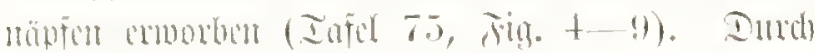

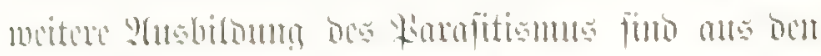

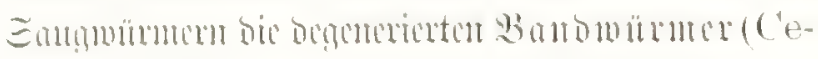

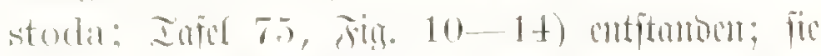

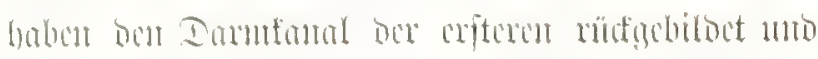

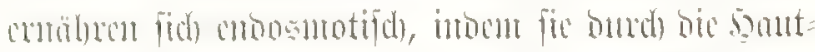

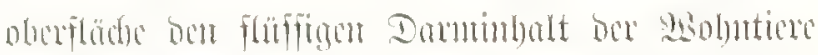

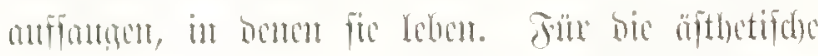

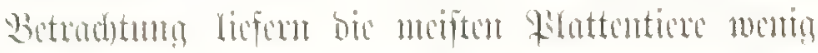

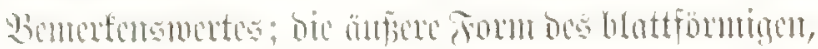

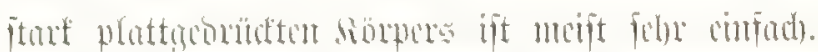

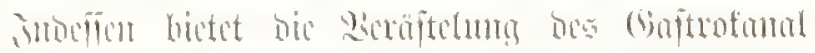

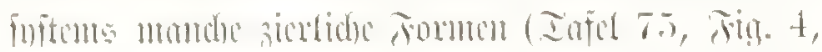

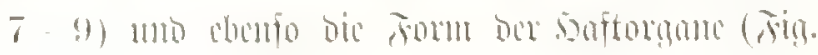
(i- 14$)$.

\section{Die Simftermen Ser Gbertiere (Coelomatria).}

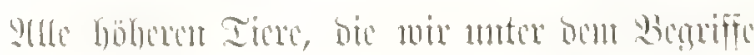

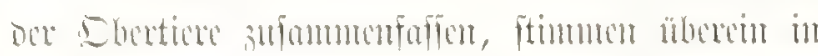

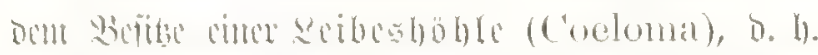

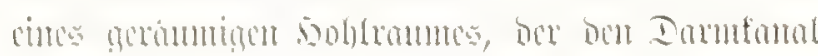

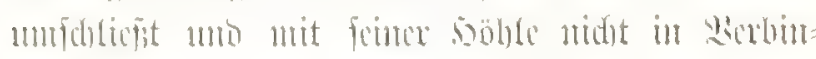

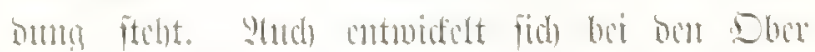

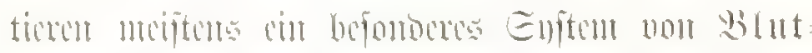

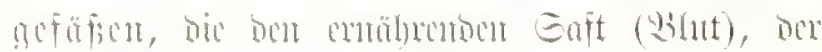

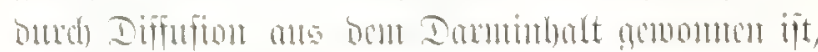

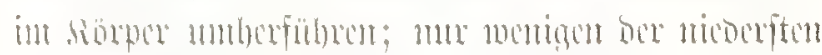

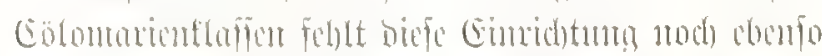

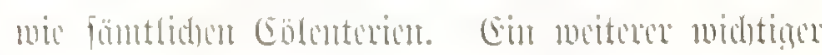

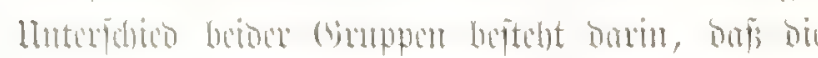

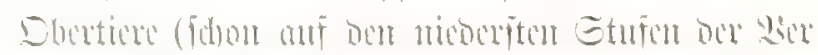

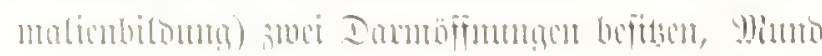

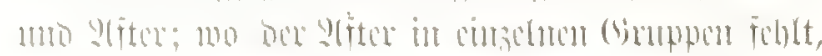

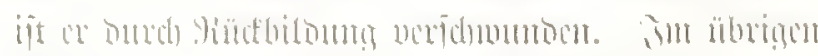

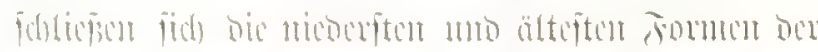

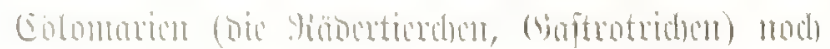

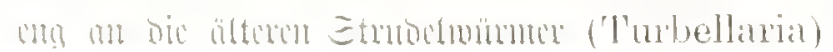

an: fie baben non bicfor Platoden bie bilaterafe

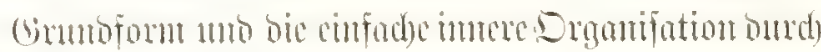
Serrbuma cubalten.

Dic Vilatcrale Grmmojorn (bic sentroplane

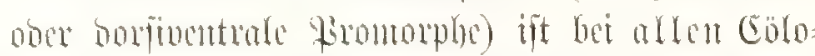

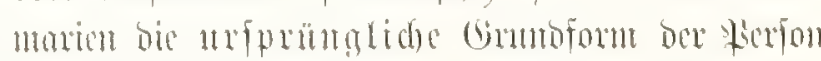

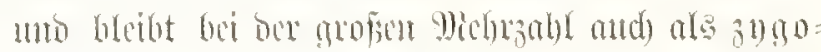

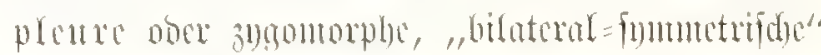

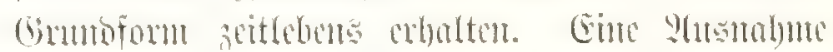

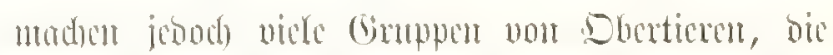

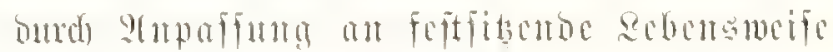

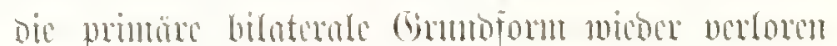

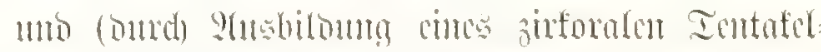
fransca) bic rabiale (attinomorpbe oner pura

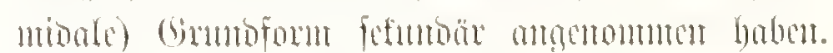

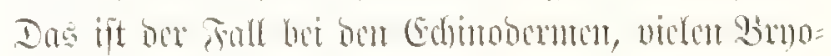

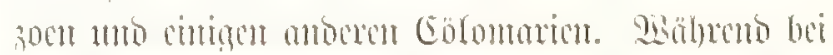

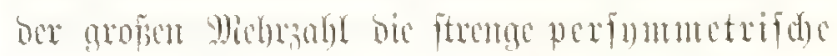

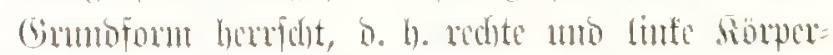

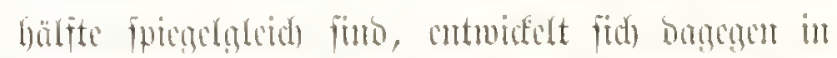

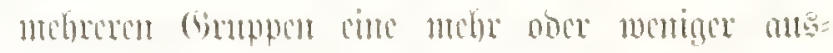

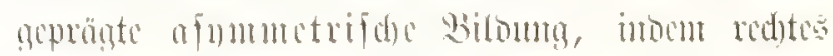

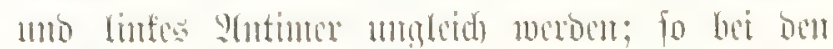

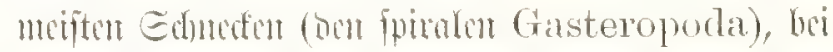

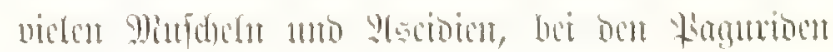

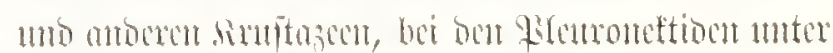

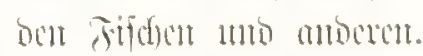

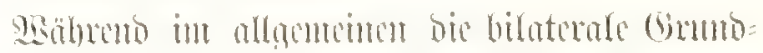

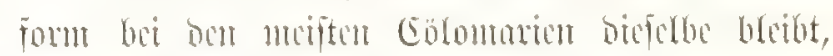

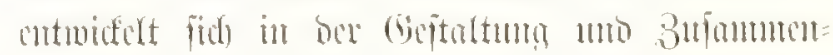

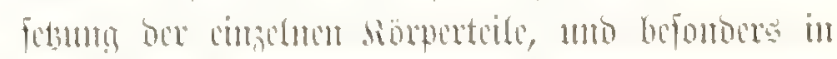

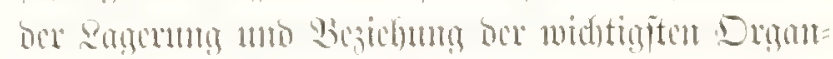

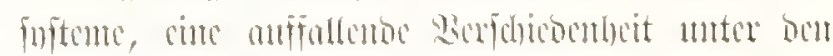
Sant

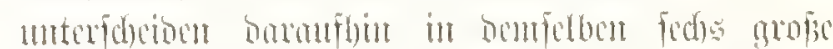

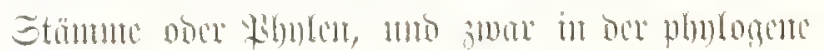

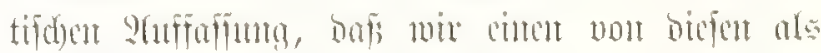

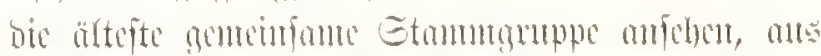

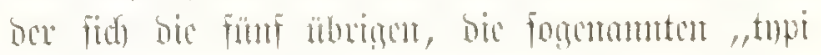

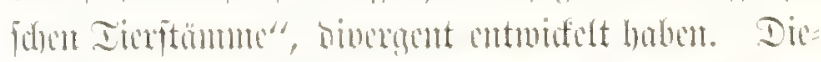

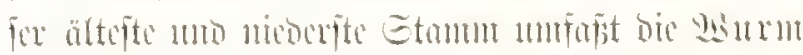

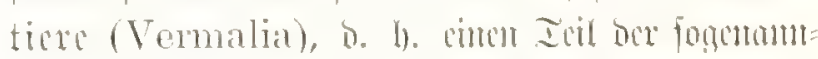

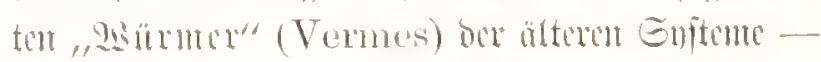

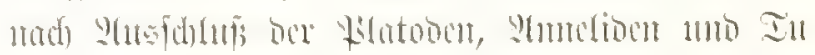

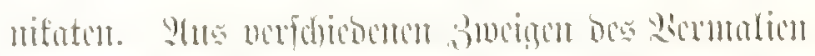

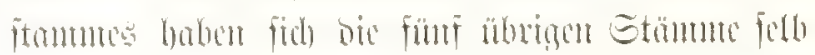

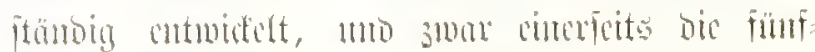


Ftrolyfigen Gterntiere (Echinoderma), bie mmge glieberten sicidtice (Mollusea) uno bic geglie berten Gifterbertere (Artieulata); andorfetes bie ungeglieberten Mionteltere (Tunicata) mo bie gegledertm sinbltice (Vertebrata). Da bife

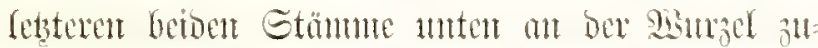
fanmenthätgen, werbout fic and) vielfad) gufumment gefast untex bent Begriffe bex Ehorbaticue (Chordonia oncr Chordata).

D. 1) Mumuticre (Vermalia). Ju ben be fdrünften llmtrange bes Benriffes, in bent wix gegen

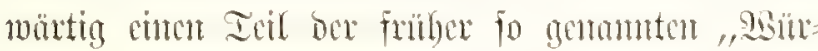

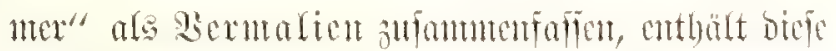

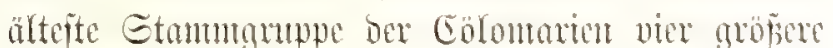
Sauptefafen, die Fotatorien, Etrongularten, Siro= fopygien und Frontonten. Bon bicfen ift afs bie ältejte und als bie gentemfanc Etammgrmppe ber

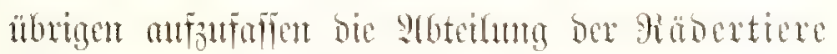
(Rotatoria; Infel 32). Die meiften von ilment

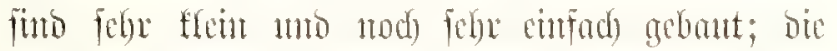

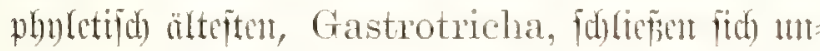
mitterbar an ibre Bifatoben=shmen an (Rhabdo-

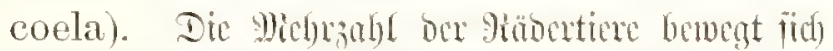

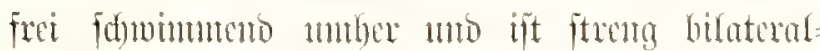

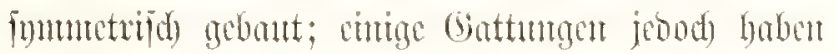

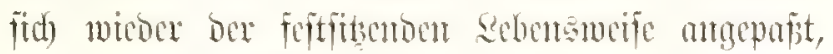

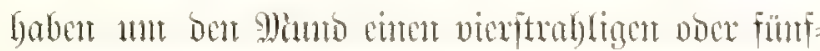
ftrabligen Ientafelfions gebildot mo futo baburd) oen rabialen \$solnpen äbntid) geworoen ( Iafel 32,

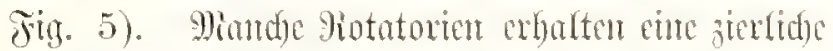

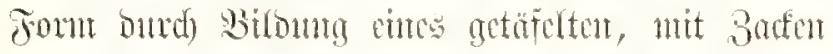

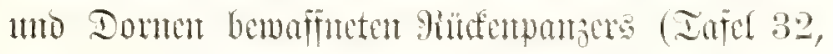
jig. 7, 8); anbere baburd), bafis fid) an beibent Sörperfeiten (reduts anto linfs) funmetrifol geitelle Boritentünded entwicfeln (Iafel 32, Fig. 3), noce

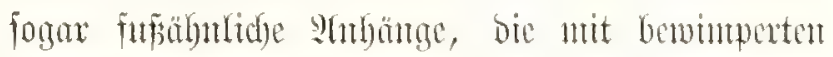

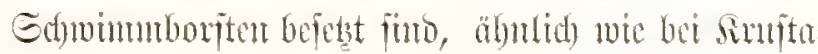
ject ( Iafel 32, Fig. 1).

Moneticre (Bryozoa; Tafel 23, 33). Dicfe

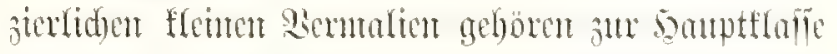

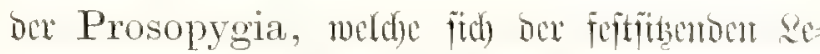
bemomeife angepart hat; fic find baburely polspen

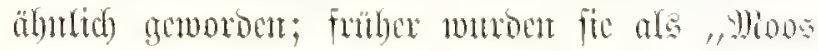
polypen" ober, "9loostorallen" neben bis Subro= polupen umb siorallen geftellt. Gic ghterben biefen

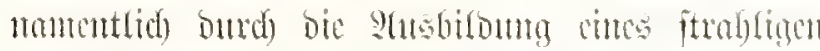

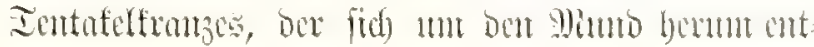

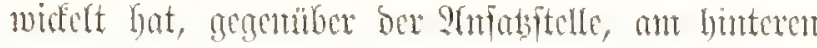

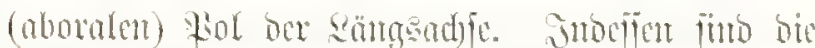

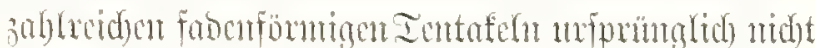

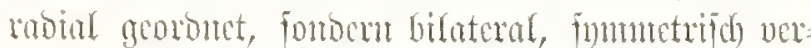

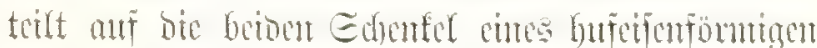
Tentafertrüuch (Eophophor; Tafer 23 , Fia. 3-12):

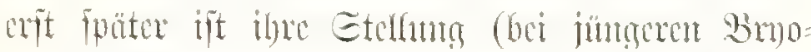
inen) vollfommen rabiär geworben. S(1ud) Der Dant=

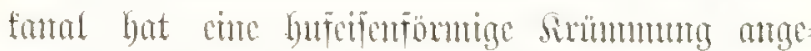

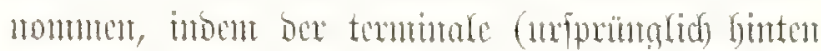

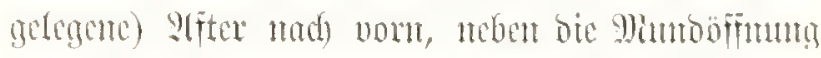

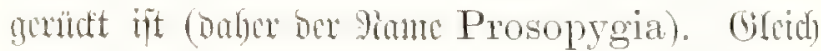
ben äbutidgen folopent reben and bie Burnozoen

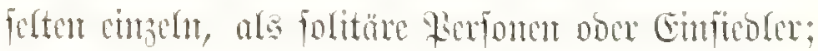

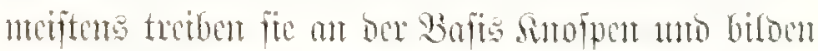
Stöfe (Comi). Dic 9tmoromm ber geflligen

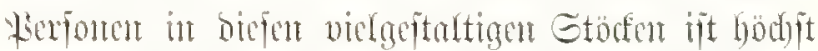

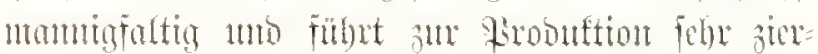

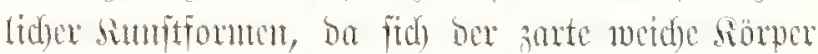

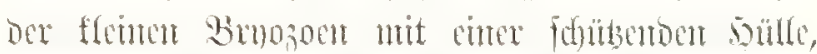

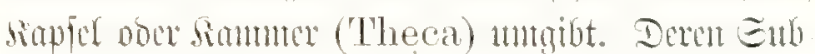

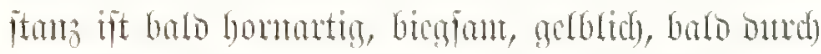
Werfalfum itciubart geworben, ftam, meip. Eo= wobl be Etmutur der Samment felbit als and

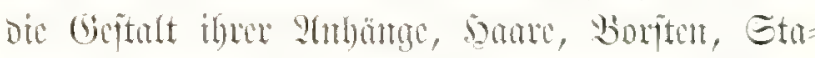

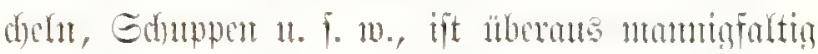

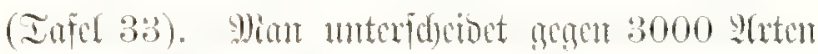

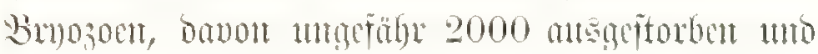

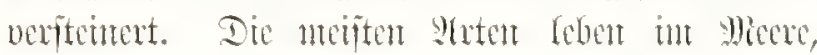
viele and) in Sunmotior.

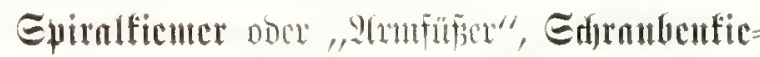
ner (Spilobranchia, Brachiopoda; Iafer 97 ). Diefe formentretde, anf bas Dicer befdränte Iter

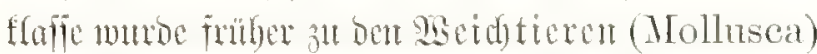

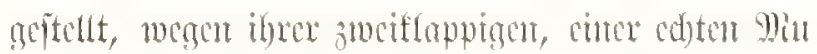

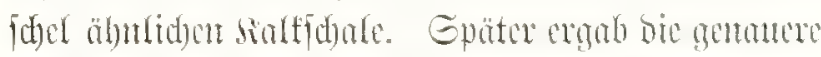

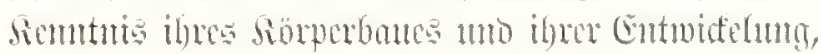

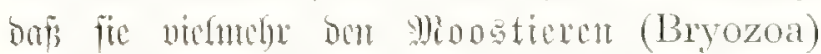

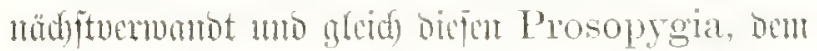

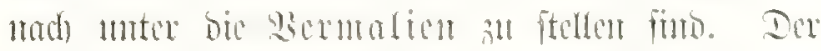

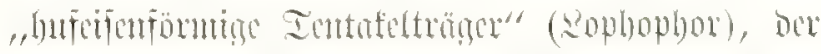

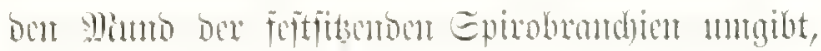

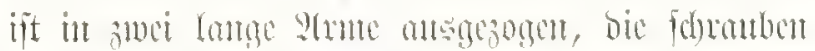

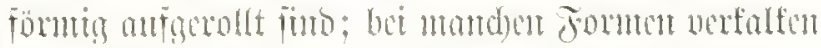

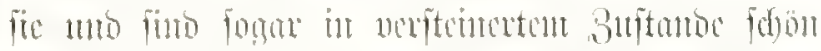

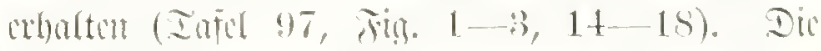

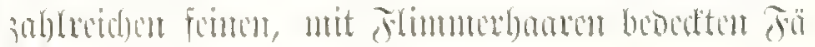




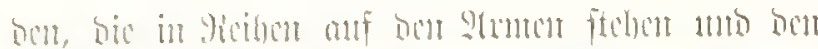

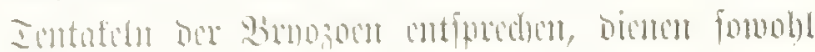

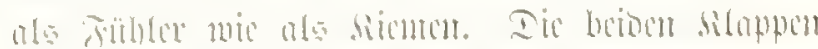

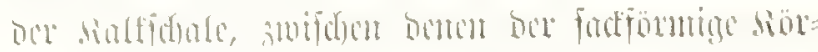

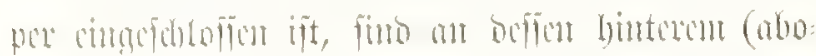

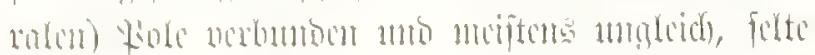

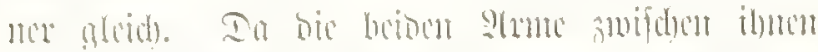

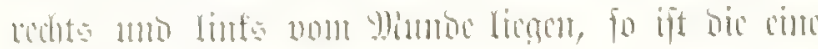

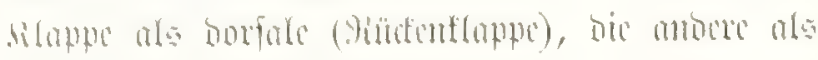

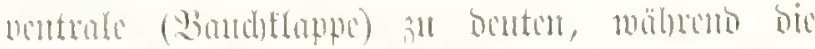

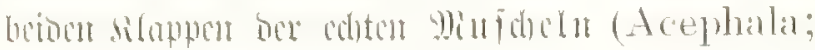

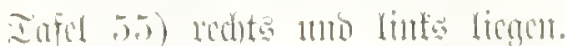

Minntefticre ('Plumidata: Infer 85). Difo

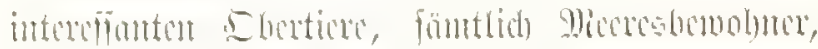

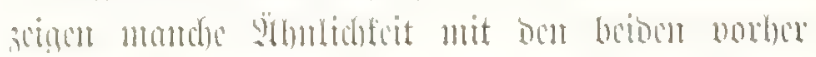

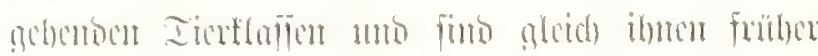

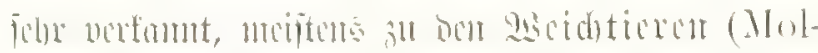

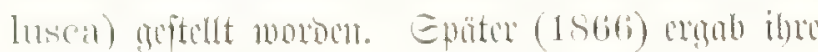

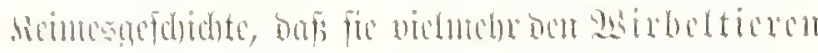

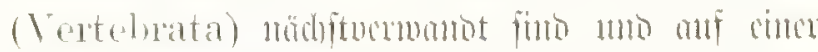

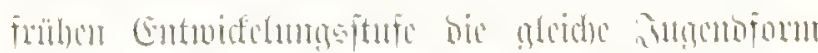

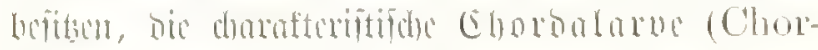

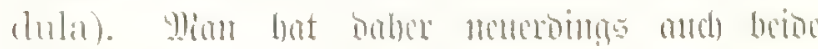

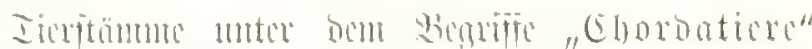

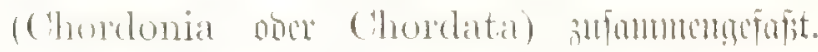

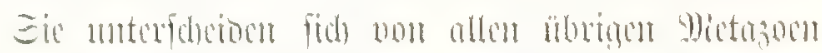

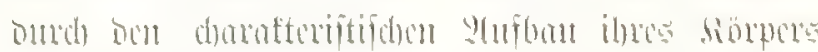

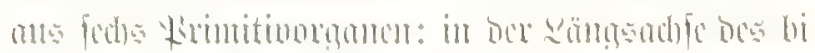

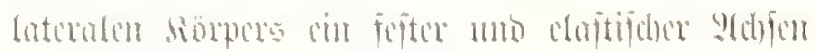

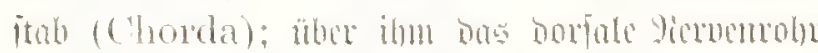

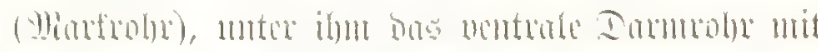

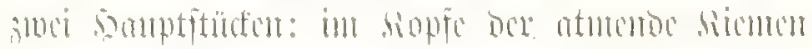

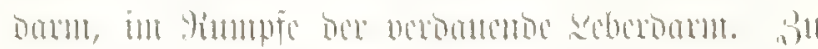

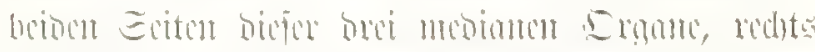

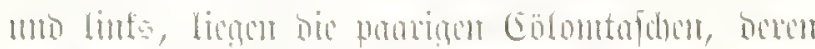

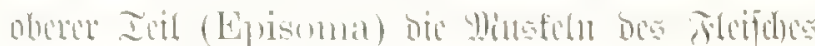

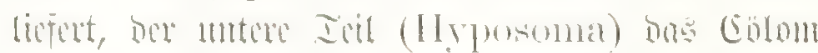

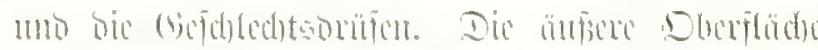

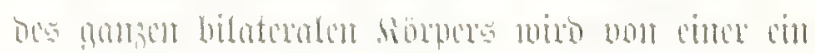

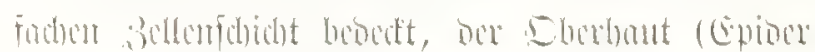

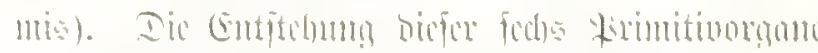

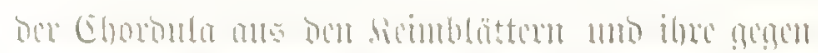

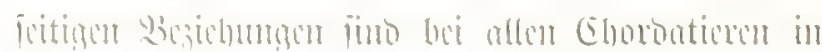

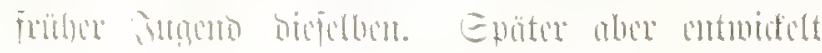

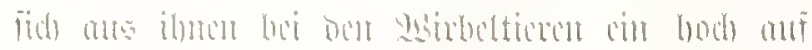

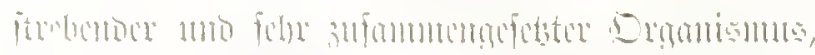

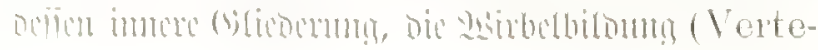

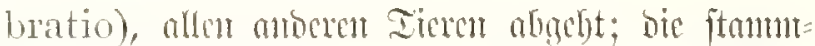

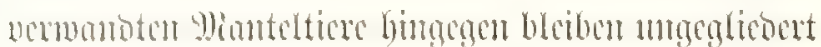

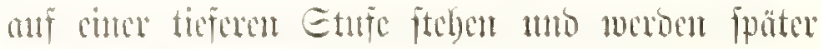
viclfact) rïflucbilot.

Der Etamm bev Mianteltice ift ans cinem

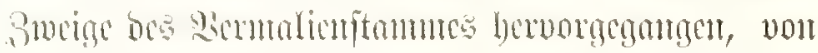

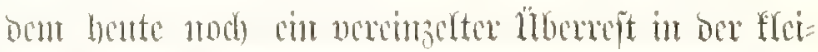

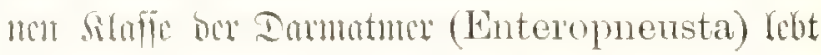
(Balanoglossus). Stant teilt bic Imtufatom in Dres silafien, non benen bie älteften bie curfod) ge

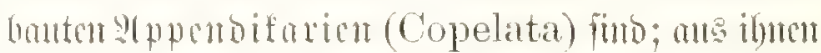

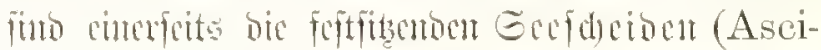

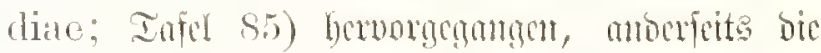
Frei fommmomon Eafpen (Thalidiae). Dic

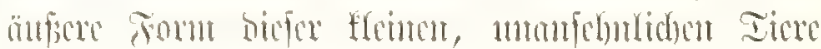

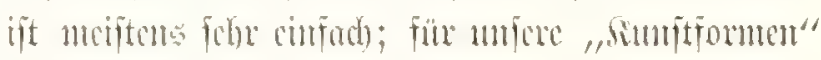

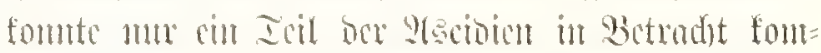

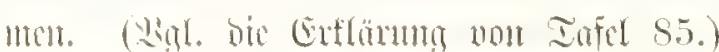

D. 2) Etcruticuc nocr Etadjelyöuter (Echino-

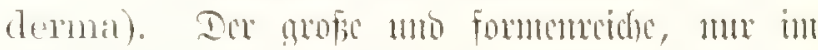

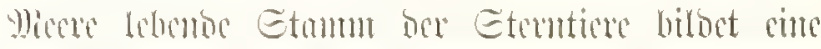

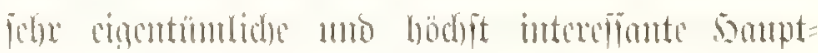
abtefums ber Dbertice (Coelomaria); a ift

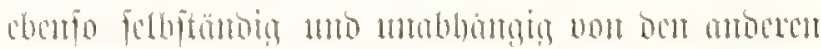

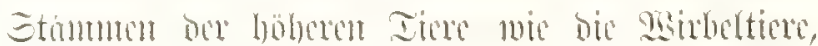

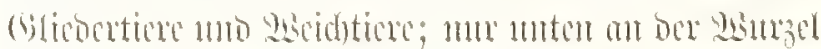

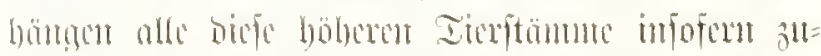

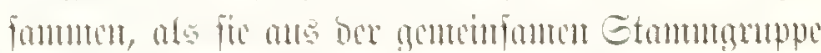
ber sturutice (Vemalia) fid) phuletifd) ent=

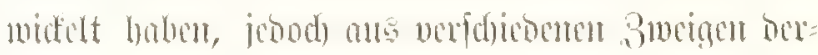

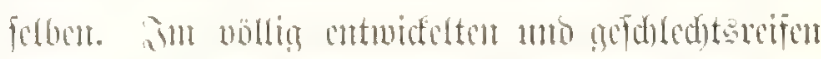

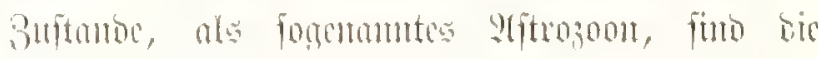

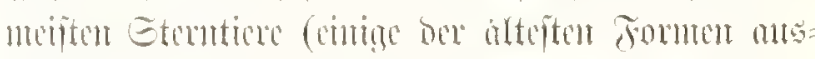

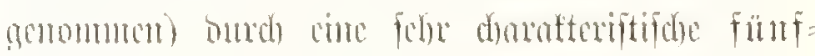

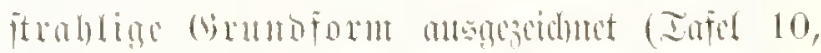

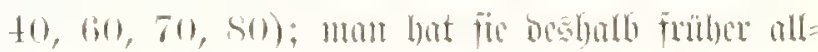

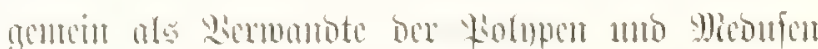
betrabtet mo mit ibnen int strife bet Etrabl:

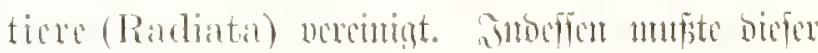

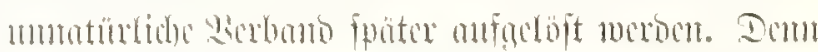

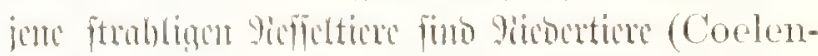

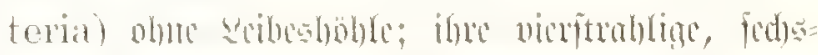

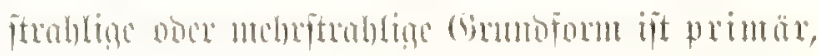

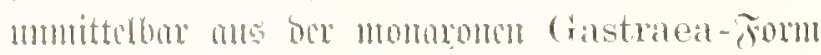

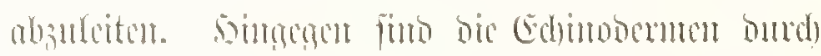

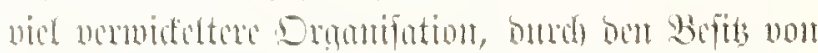

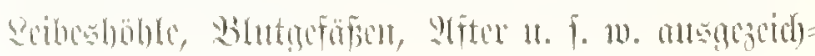


met, baber ats adte Docrticre (Coelomaria) su betradsten; ibre fïnfitublige (pentarabiale, felten multitabiale, mebritublige) Grumborm tit fefun bär entfanden; fie feblt fowohl ben phylogenetifa) ältciten Torment bes Etanmes (Ymphortoeen, Ia=

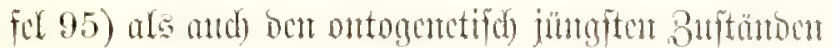
ber Fünfritubligen Stentiere. Diefe SHgenofomen berchnen mir allomen als Gtexnlaxven (Astrolarvae; Iafd 30, Jig. 5, 6; Iafel 40, Jig. 2 bis 6, Tafel 95, Fign. 1-6); fie finto von vid cinfaderer Drgantifation als bas reife atitroson

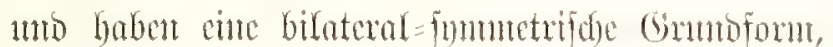

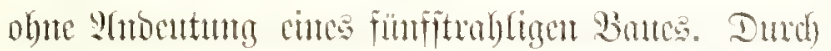

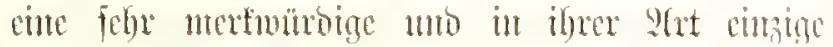

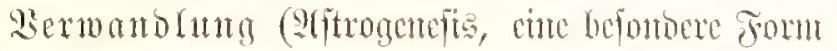

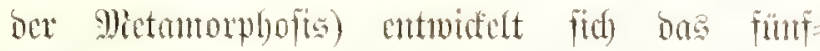
frablige, fpäter gefd)led)torcife 9(jtrozoon ats bex

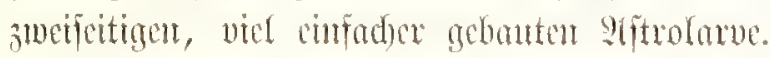

Die Gternfancu(Astrolarva ober Echinopaedia; Iufel 10, Jig. 8; Iafel 30, Jig. 5, 6; Iafel 40, Fing. 3-6; Iafel 50, Stig. 3, 4; Iafel 95, Jig. 1-6). 2(115 bent bejudbeten Gi allet

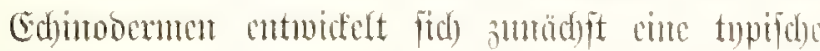
Gastrula (äbultid) Iafel 76, Jig. 1) 1tuto ats biefer ente fret jomintmento bilaterale sarve, bie

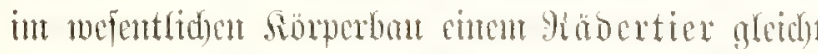
(Rotatoria; Infel 32); fic fdumunt mitters cines

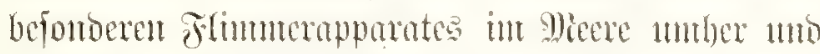
gleidyt barim ben äbnliben Sarven anoerer Colo=

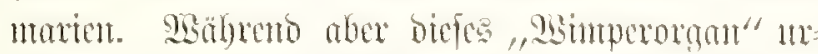

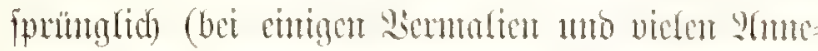
lioen) cinen suffaden ober boppelten simpertrom

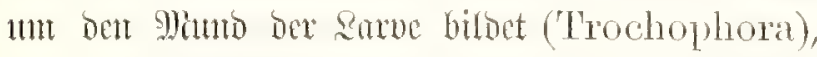
bei ben Mlollusten cin zmeilappincs simperjogel (Veliger), entwidelt os fid) bei bon Stenticm

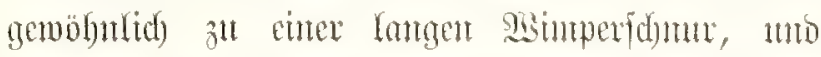

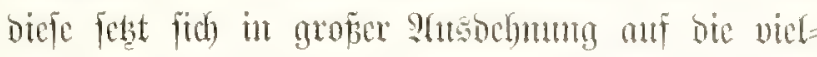

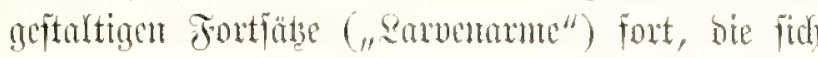

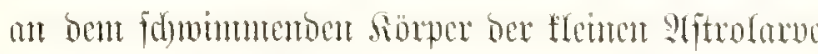

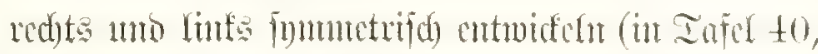

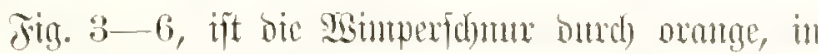
Infel 50, Jig. 3, t, oumd weifie Juthe beruns: geboben). Die mamigfaltigen mon abentenertiden

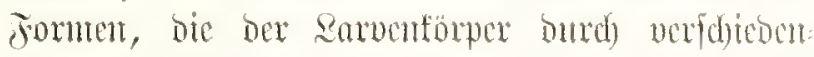

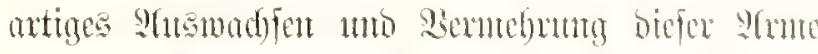

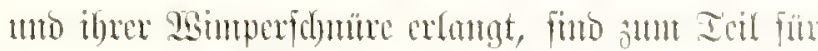

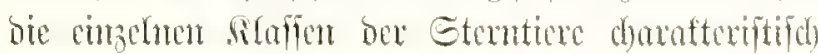

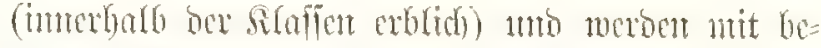

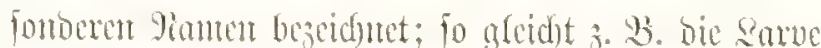

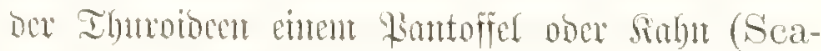
phularia; Iufel 50, Fig. 3, 4); die Smve bor

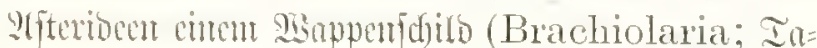
fel to, Jig. 3-6); bie sarve ber Dphtobent ener

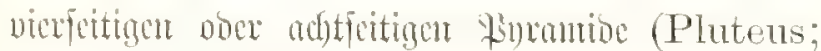
Iafel 10, Fin. S); bie Rave ber Edhimben cher Miafmitaffere (Plutelhus; Iafel 30, Fig. 3, 4).

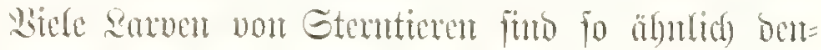

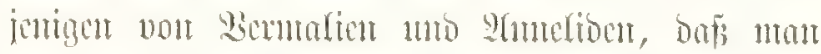

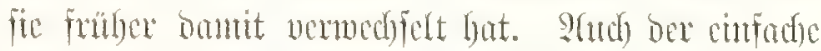
innere Ban bes bilateraten Siorpers ift mprounglid

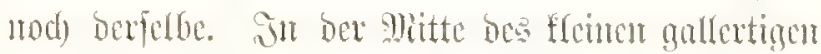

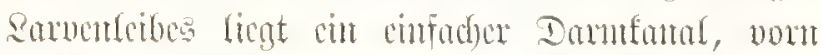
mit

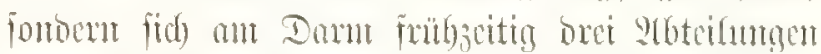

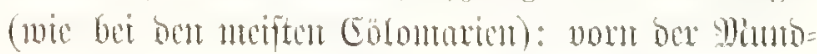
baru (Stomodaeum), in ore Mitte ber Manen

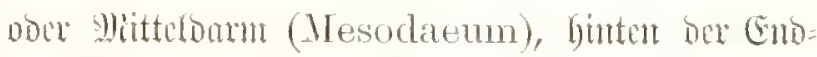
barm (Proctodaeum). Sou ocr fouterar ver=

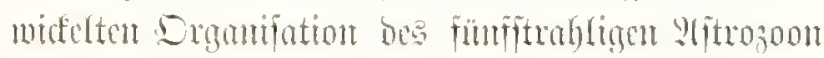

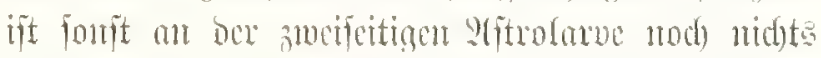

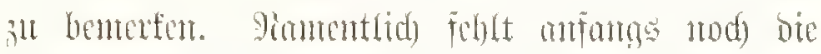

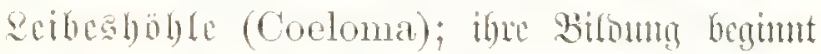

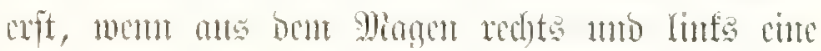

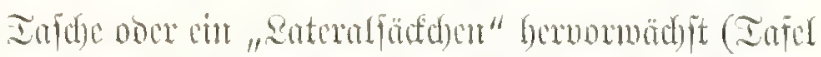
10, Jig. 8; Iafil 30 , Jig. 6); crit dom füngt

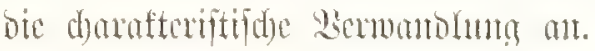

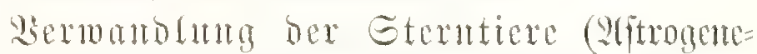

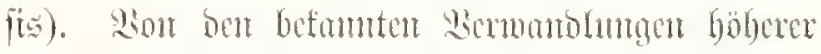

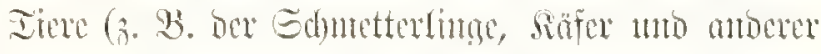

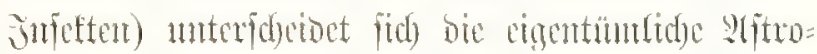

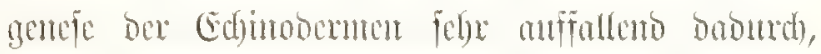

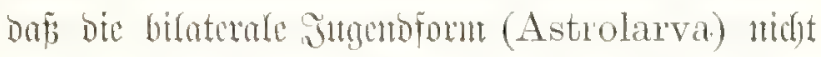

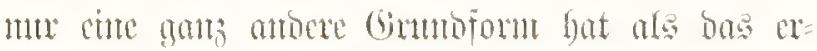

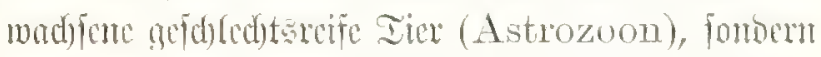

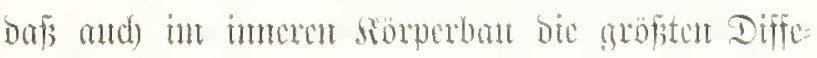

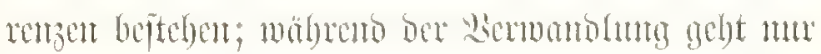
cu Iet ber Dronenc att bent curfaden siorpex ber

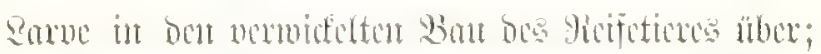

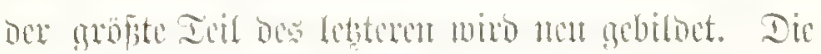

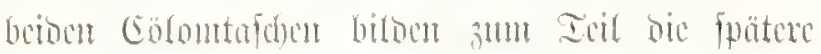

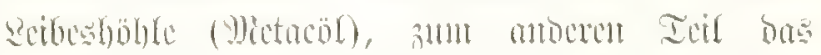

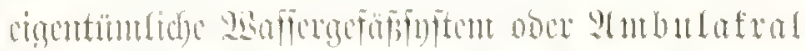

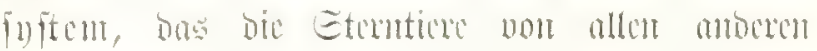

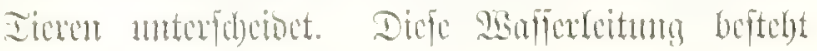




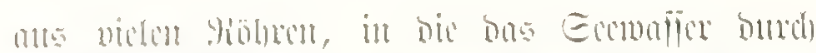

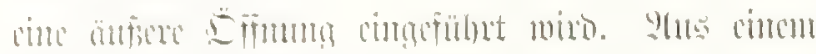

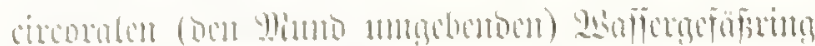

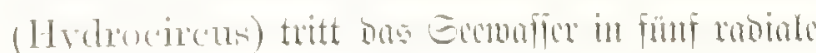

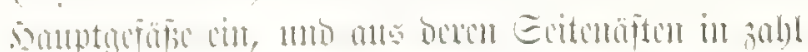

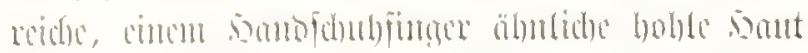

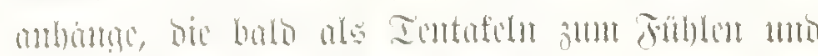

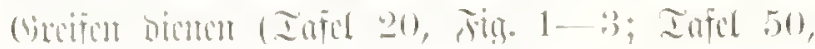

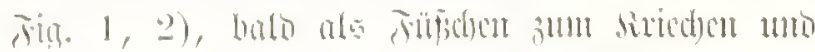

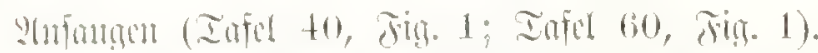

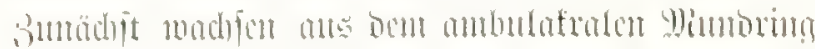

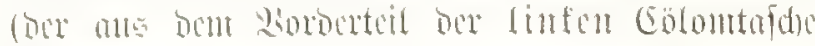

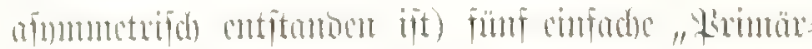

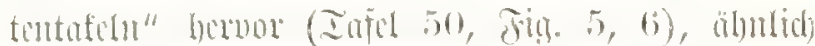

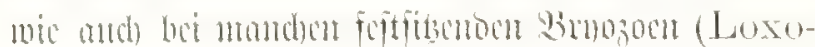
soma) mo rotatorion (Ntephanoceros; Iafel

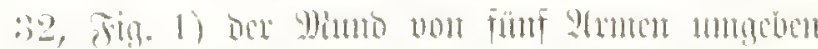

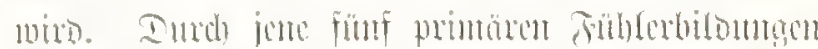

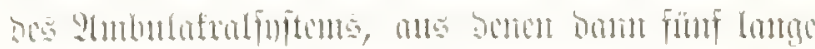

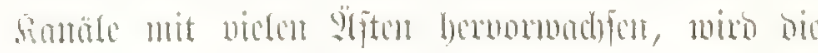

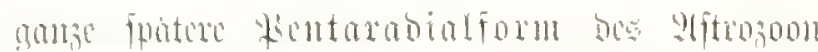

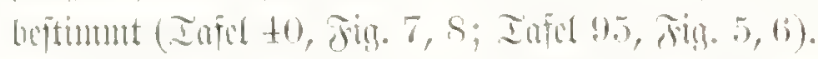

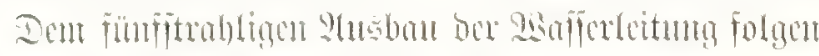

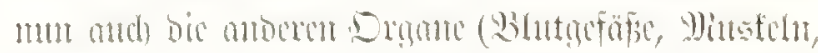

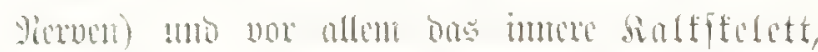

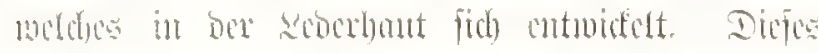

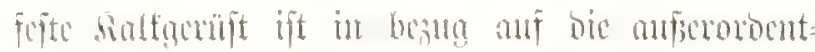

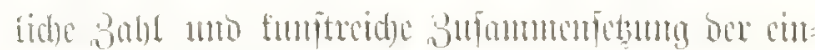

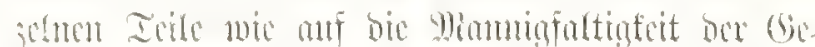

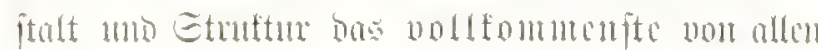

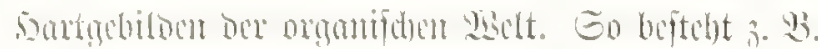

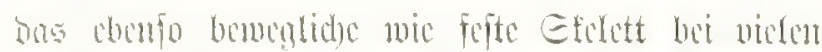
crintoton (

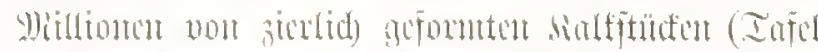
20, Fig. t-s), mo bife fum burd) (bidente,

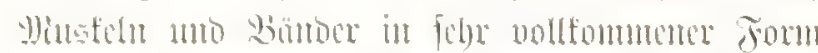

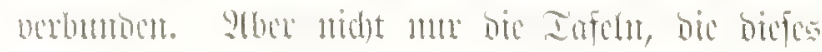

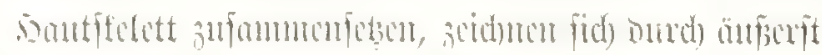

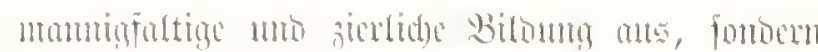

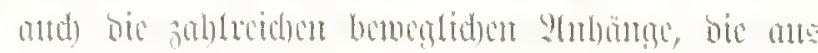
ber sant bexwomadfor, in Form non Etadidn,

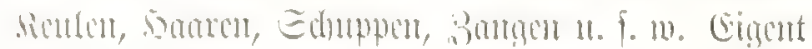

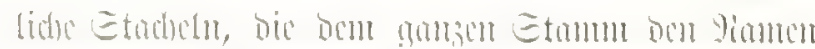

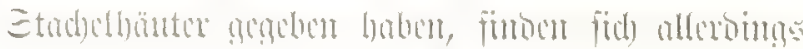

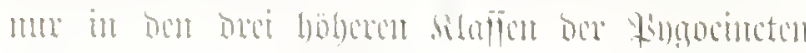

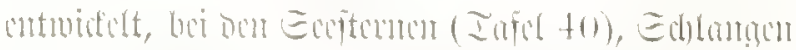

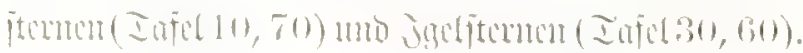

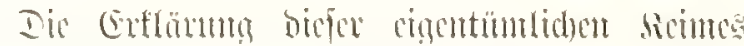

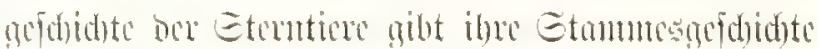

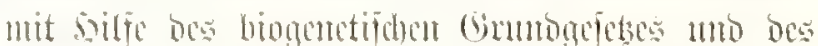

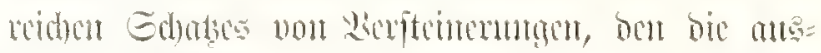

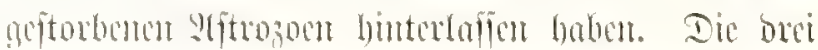

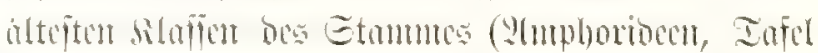

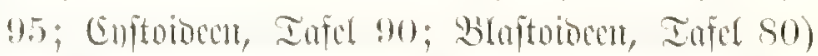

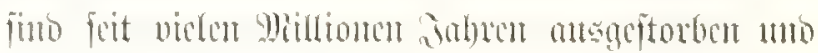

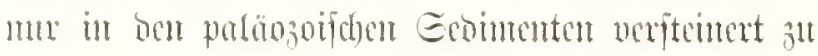

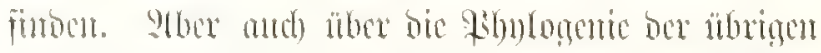

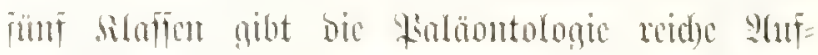
Fdhtiffe, mu bie Ihmoiben (Infel 50) magenom=

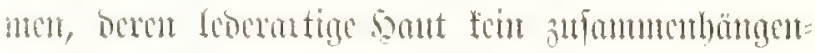

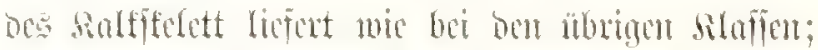
bofin setdume fid bie mifroffopifden silfforperdyen, bie mafforbaft in ibrex seberbat cingebetset futo, ourd grofien beidtum an jicliden formen ats (20fat 50, Jiln. S-2.2).

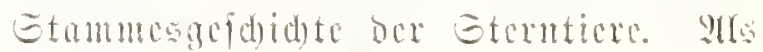

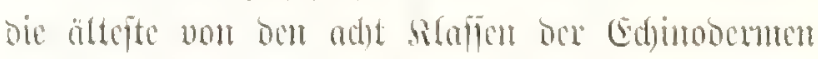

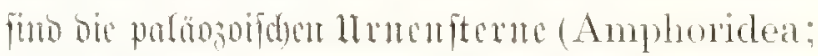

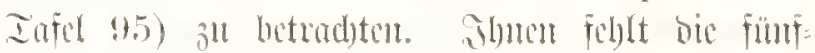

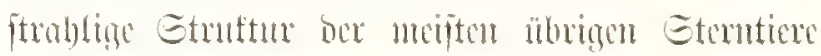

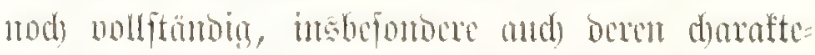

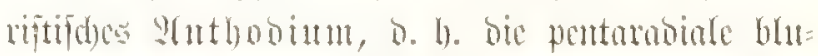

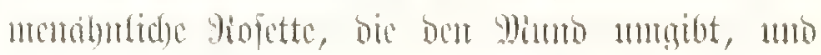

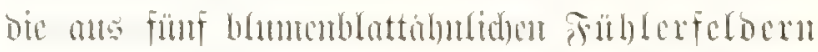

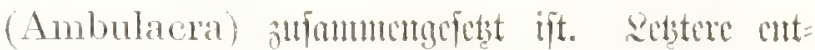

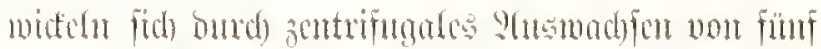

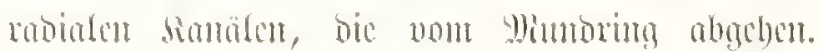

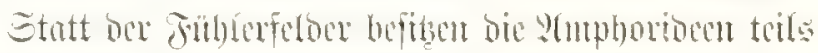

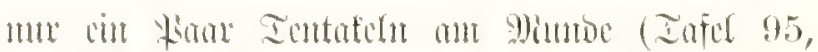

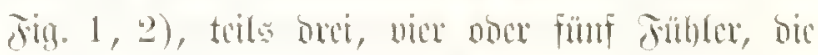

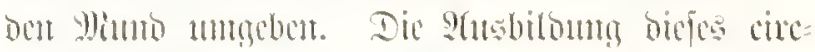

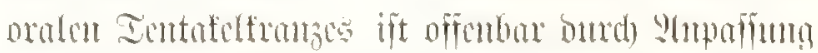

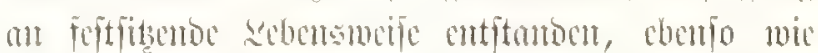

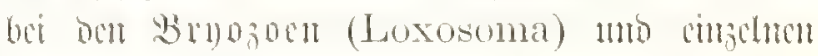
Motatorten (Stephanoceros; Iafd 32, Jitg. 1).

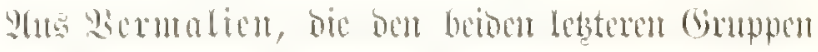

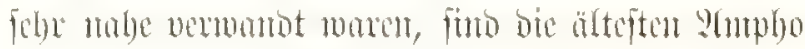
riocen antitamon.

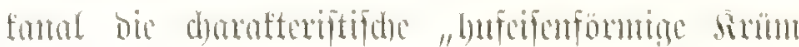

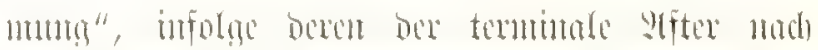

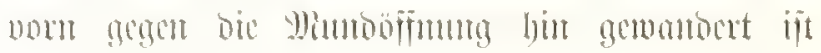
(l'lentrepygia).

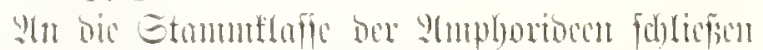

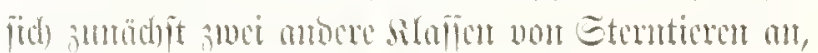


ciuterfet die Bentelfterte (Cystoidea; Infel 90), morfite bie Gurfenterme (Thuroidea now Holothuriae; Infet 50). Die eriterent haben bie

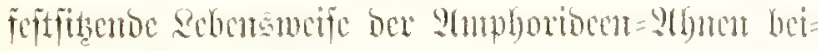
Gebalten; bie letsterent haben fie antrgegeben unb fidd)

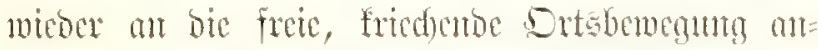

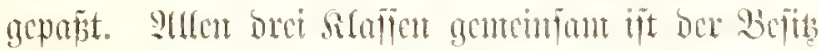

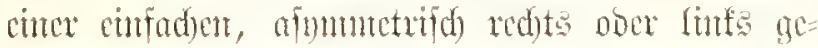

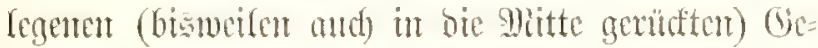

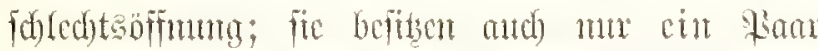

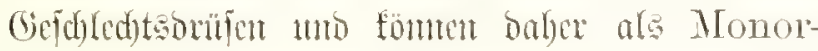
chonia zufanmentgefapt nerocn. Dic thbrigen fimf

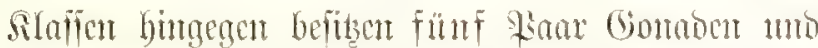

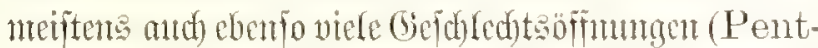
orchonia). Die (etsteren liencu bet ben feiffiten

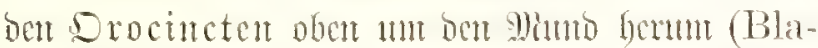
stoidea, Infel so, mo Crinoidea, Infel 20);

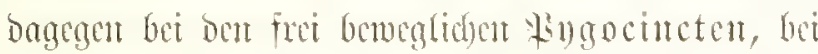

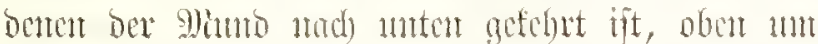
Den : Ifter bermu (Ophiodea, Infel 10, 70; Asteridea, Iafel to; Echinidea, Infer 30, 60). Die fün Gonnompane forto bet allen fisutord)o=

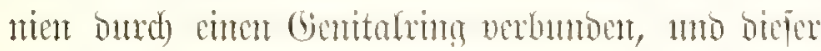
liegt ftets anf ber oberen Geite. Da ber bent feits

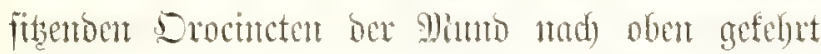

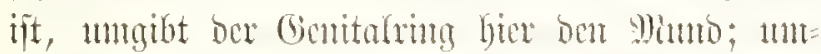

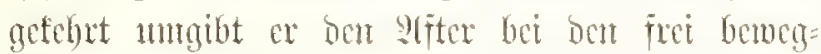

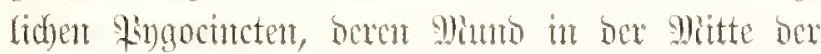
unteren Geite liegt.

Die fümfitrahlige Grumborm, berent geometri=

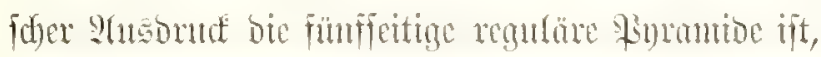

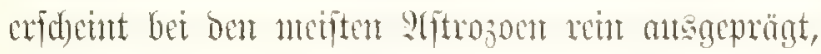

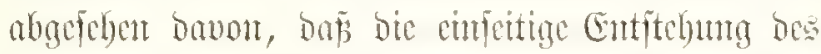

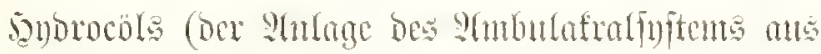

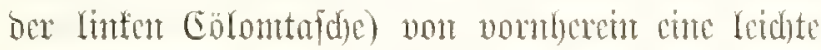

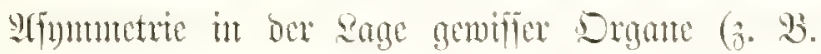
ber Mirbreporemplatte, ber (Gonabe) bebungt. Y(ber bet viden Etcutteren geldt bie pentarabtal= reguläre

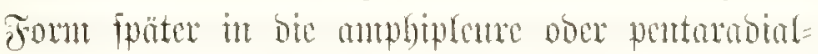
bilaterale Grumbform ïber. Stm anffallembiten ift das bei ben jüngerur Eecrigch (Clypeastronia;

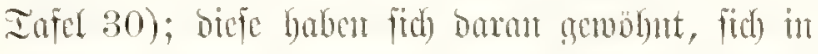

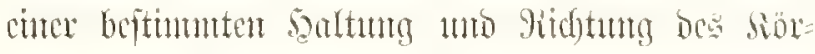

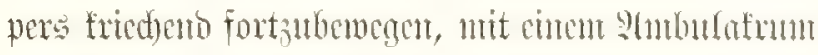
vorangehemo; infolgedeffen baben fids bie vicr an=

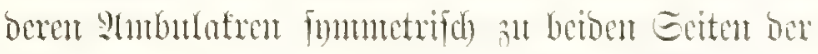
Diebiandene georontet. Bugleid) ift ber S(fter, ber

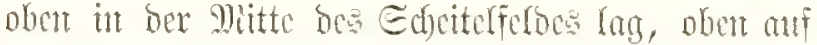

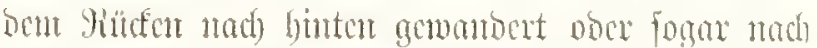

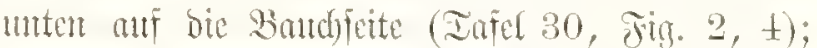
bei viden Spatangion wamoert and ber alunto anf

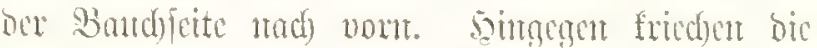
älteren regulären Eectud (Cidaronia; Iafed 60)

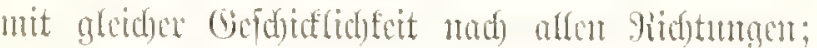

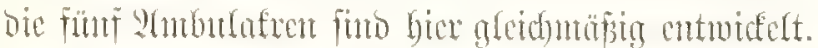

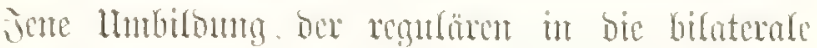
*isutarmbialform (infolge bejtinunter fintifioneller

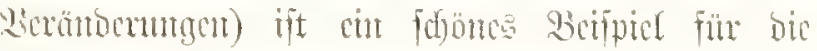

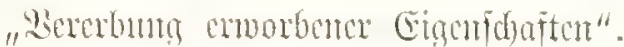

D. 3) Siscidticre (Mollusca; Infel 43,44 ,

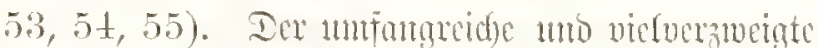

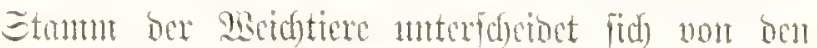

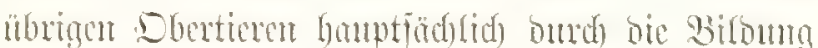

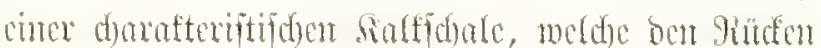

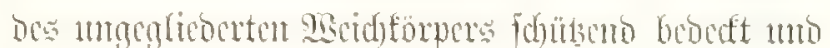

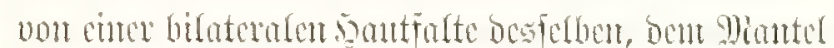

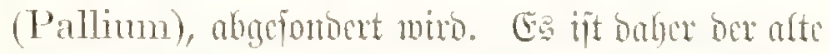
Piome Gdalticue (Testacea obcr Conchylia)

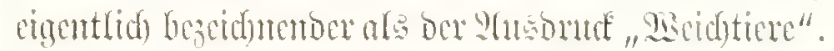
Dem borfalen siantel gegenuber liegt mif ber Band

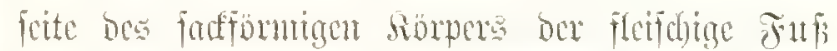
(Podium), eine itarfe Busfefplatte, bie sun Sric=

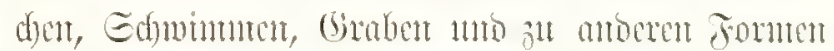

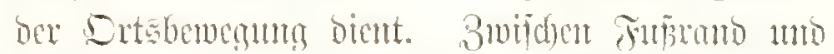

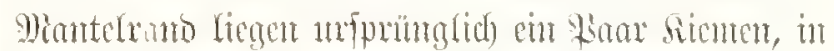

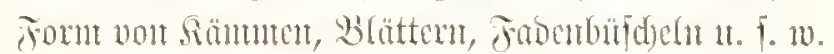

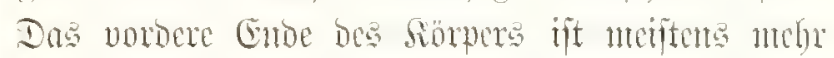
ober wemiger bentfide ate hiopf atogerest; ant ifm

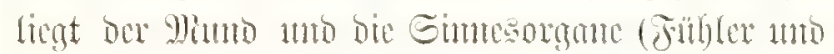

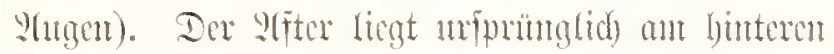

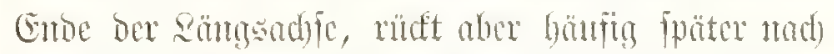
norn. Sut interen siorperban folliefent fid bic

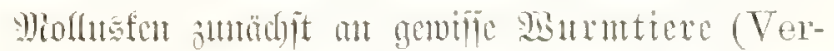
malia) an, bic wir alg ibme sireften Sorfobren

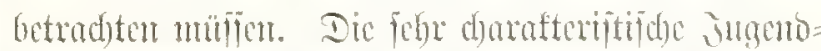

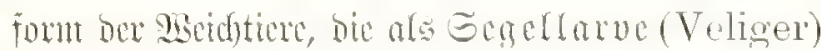

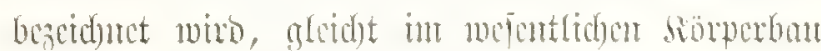
cinem Mäberticre (Rotatorium).

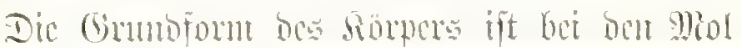
lnsten, wie bet allen amberen Cölonnarten, bie bi

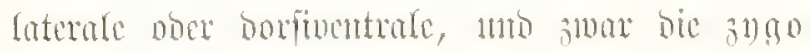

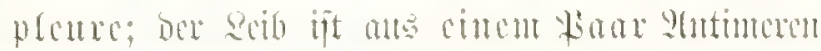

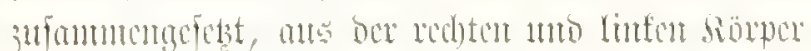

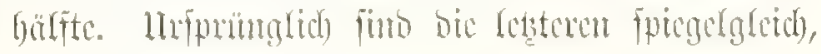




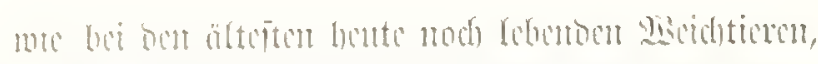

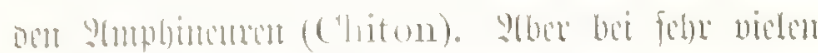

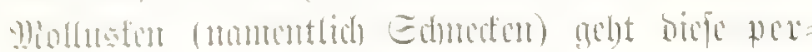

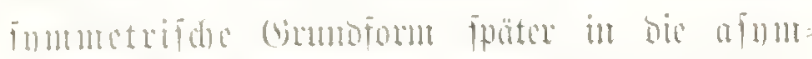

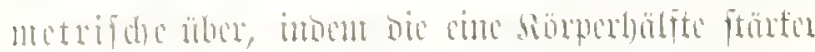
mâth

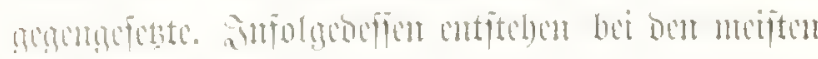

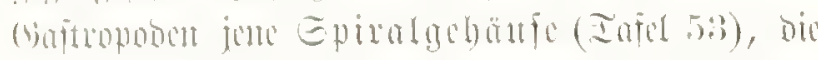

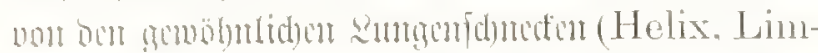

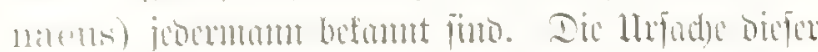

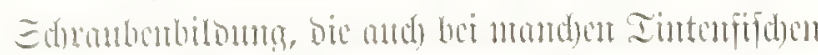

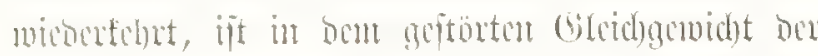

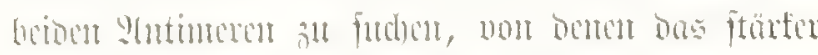

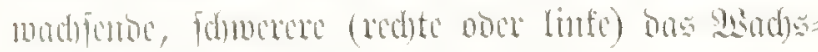

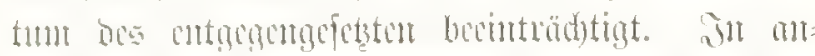

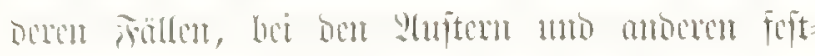

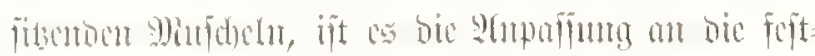

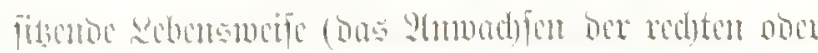

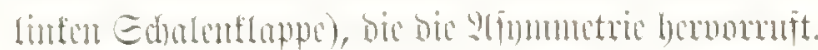

Erfucfer (Gasteropoda nocr Cochlicles;

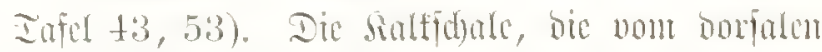

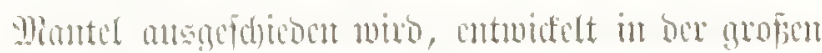

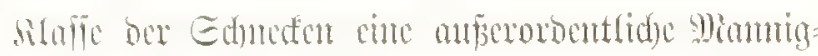

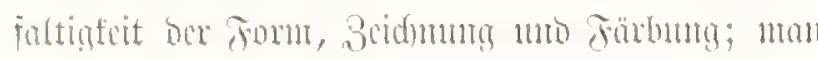

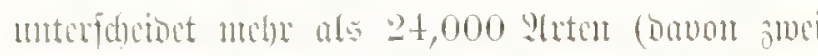

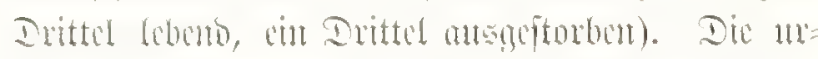

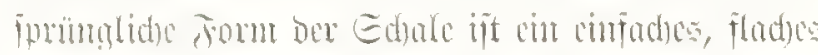

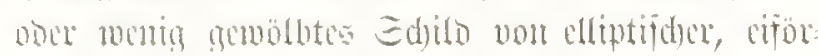

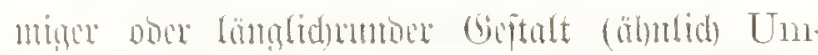

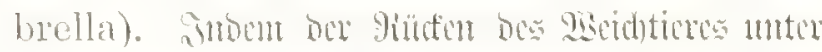

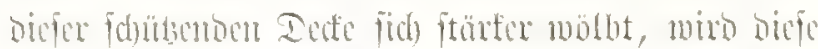
flach fenclformtig (Patella, Fissmella). Baci nod) itoufcrent gend)

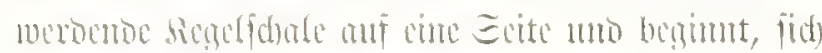

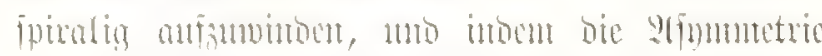

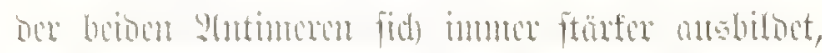

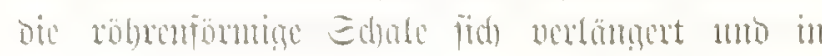

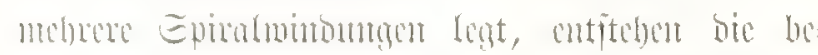

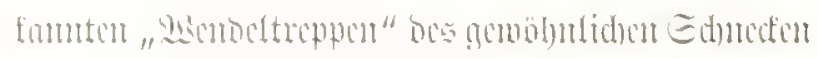

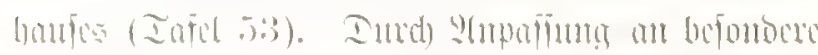

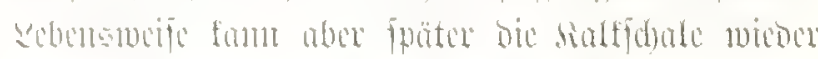

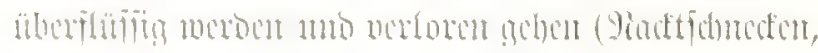

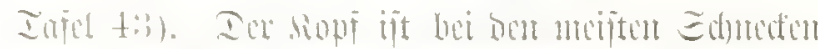

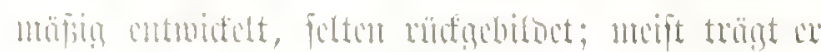

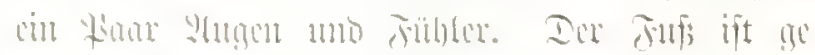
molmblid) cume breite platte Eoble, mef bex bic Embuti tulubi.
Matidfulu (Avephala obcr Bivalvat; Iafer 55).

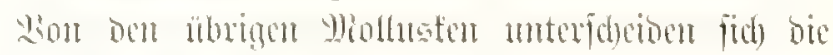

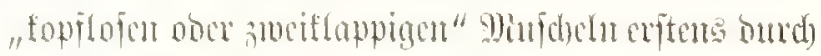

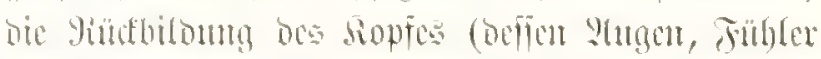

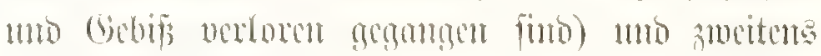

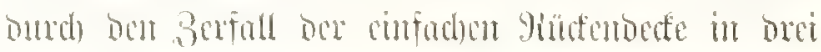

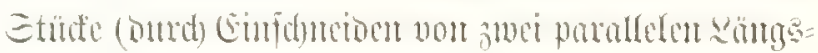

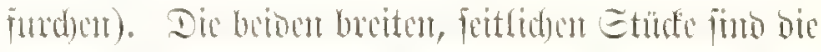
falfigen Edrafentappen, bie red)ts umb fints von

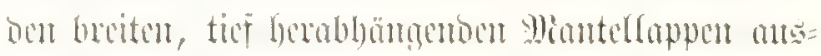

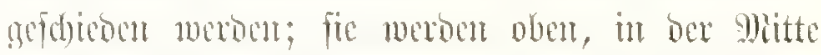
Des Küduts, sulammengebalten ound bas clajtifde

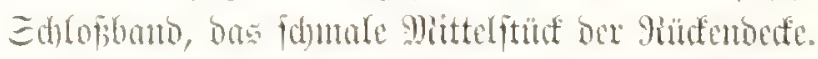

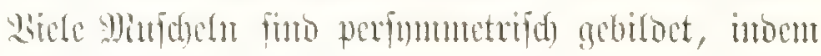

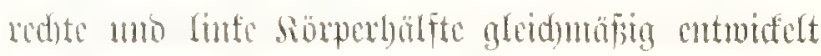

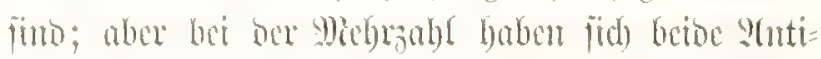

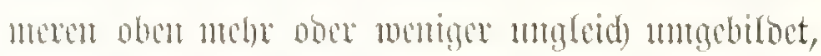

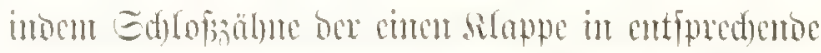

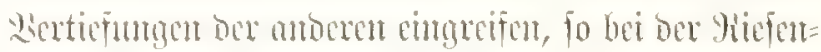
mufdel (Infel 55, Jig. 10-13). Staufer wiro

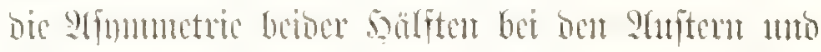

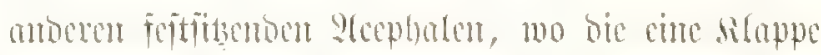

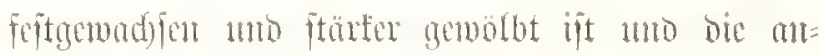
bere als flader, beweglider. Defel anf ible licgt.

Siraten (Cephalopoda; Iafel 44,54 ). Dic

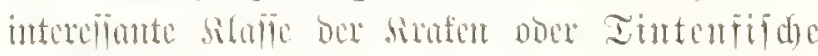

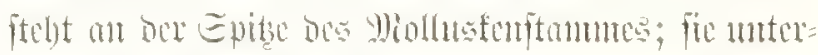

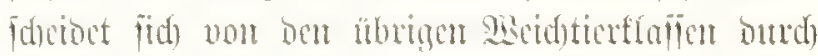

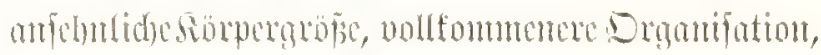

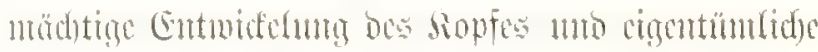

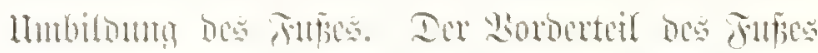

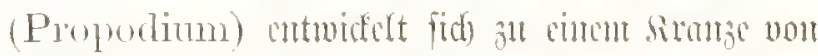

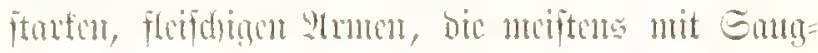
mapten befest funo, vier

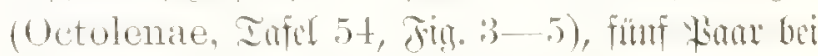

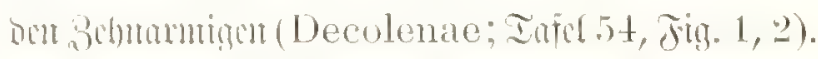

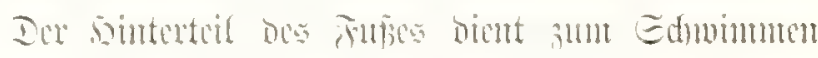

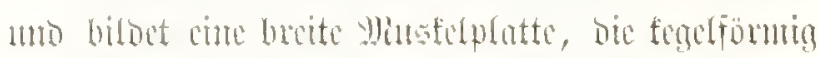
mifgrollt miro, ben Irid)tel (Lnfundibulum); bas

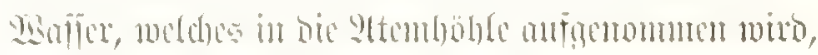

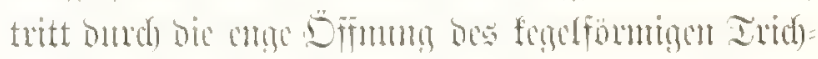

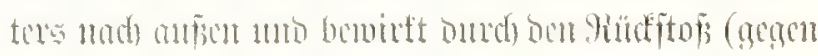

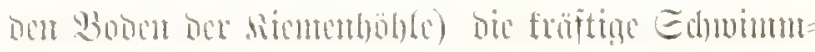

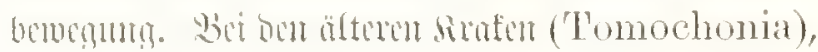

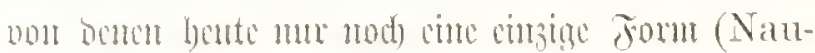

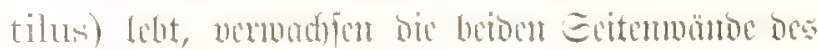

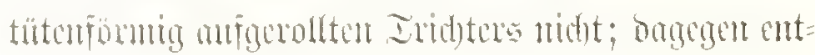




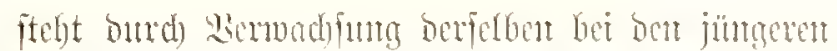

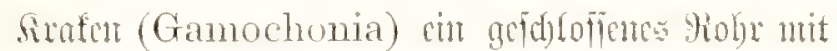

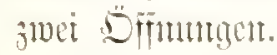

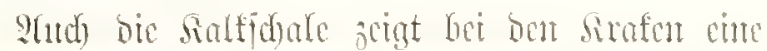

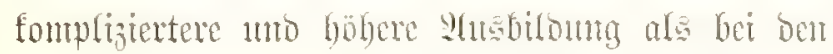

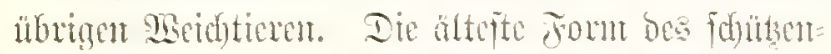
ben Gebätfes max audh biex, wic bei ben Edhmeden, cine cinfadye fegelfonnige rindenocte (äbntid) Patella). Dieje wädjut ju cimcu lamgerat puranti=

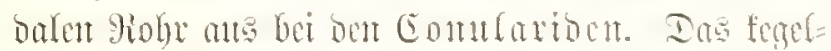

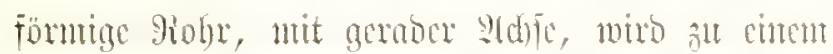

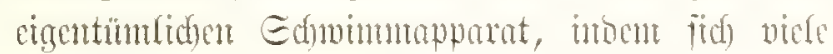

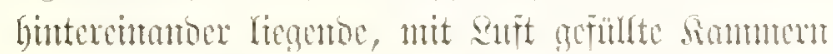

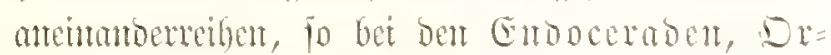
thoceraben und Gomplyoceraben. Juben bic gerabe P(d) je bicfes vidfanmerigen Edyummorgan

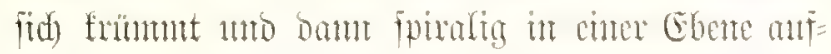

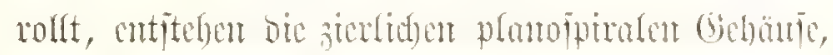
welde unter ben febenden Cenhalopoder Nautilus mo Spirula bejtien, nutev bent amgejtorbenen bie

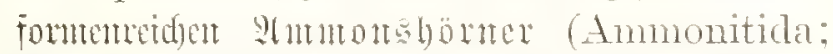

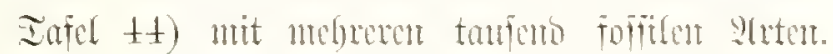

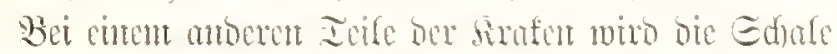

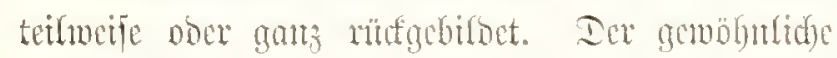
"Iinterfifich" (Sepia) befist als fetsten Gejt ber

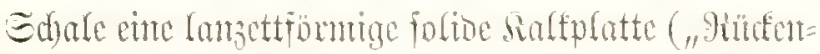

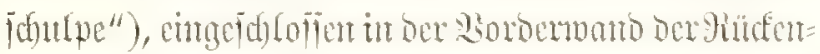

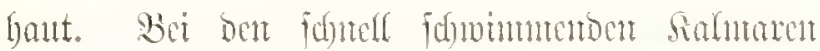

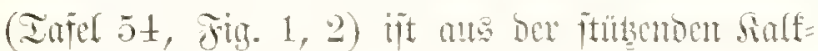

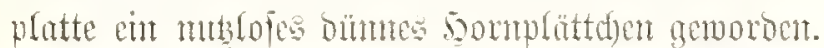

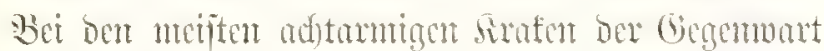
(Octolenae; Iajel 54, Fig. 3-5) ijt bic Edyate ganz verjdymuntom.

D. 4) (Gilicoerticre (Articulata). Die formen=

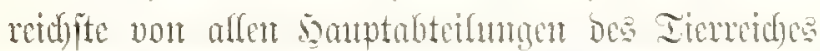
ijt Dex Etanm ber Gificoertiere, in weldent wir

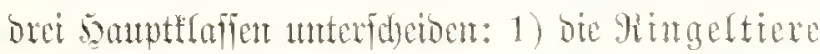
(Annelida; Iafel 96), 2) bic Aruftertiere

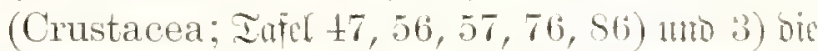
Eufrobrticre (Tracheata); 3u ben lesteren ge= Gören vor allen bie Gpinncuticre (Arachnida: Iafel 66) mo bie ferbtiere (Insecta; Iafd 5s).

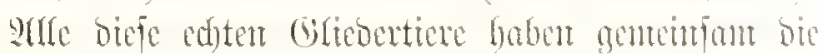

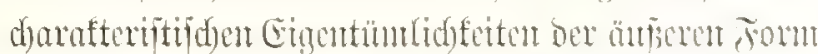

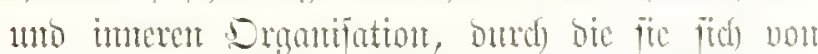

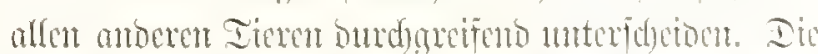
äupere Gificoerung (Articulatio), de tu fum
Domentalen Gegenfotic ân ocr interent Gilieberung

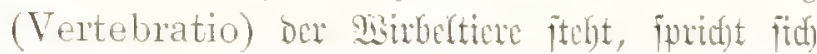

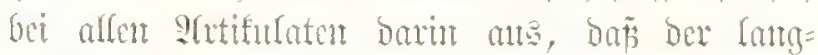

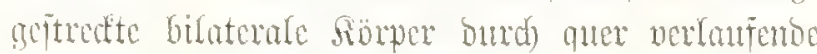

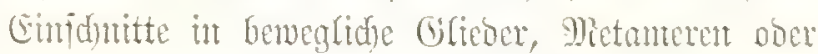

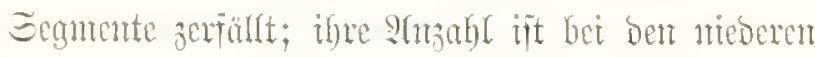
unto alteren Founten des Stanmes fefr medfelnto, oft Hber Guntoert; bei ben Göheren Fornten betringt fir neift 15-20. Shre Ebcrbant (Epidermis) Fucioct cinte fejte Cuticula ats, b. G. emte Matic,

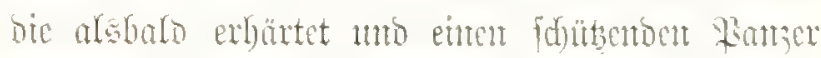

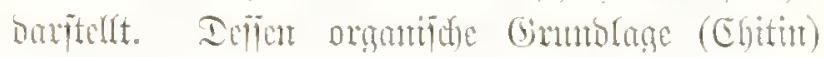

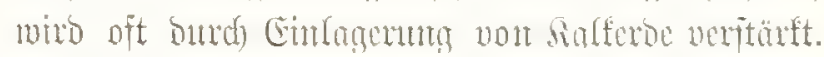
Die fefteren Cbitiminge (Bontent) ber emtzeluen

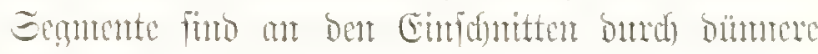

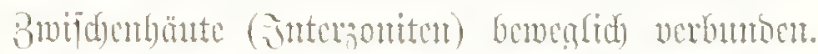

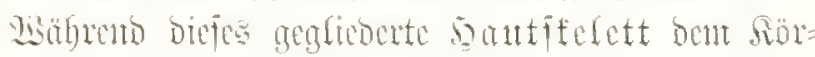

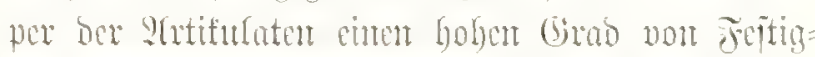

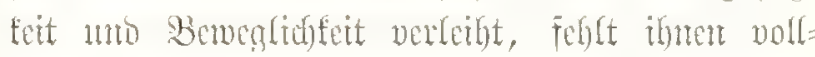

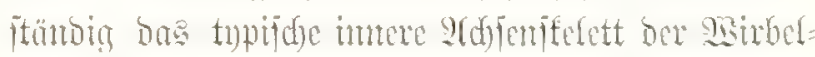
ticte (Chorda ntoto Perichorda) nuto bantit jul

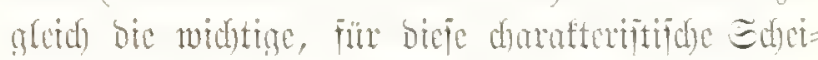

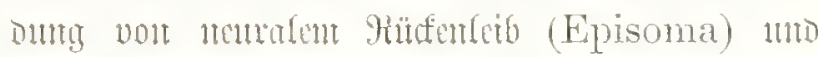
gaftralcu Bandferif (Hyposona). Ebenfo grof

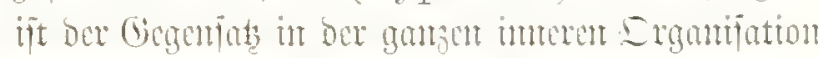

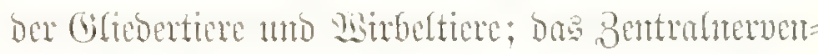

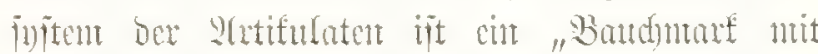

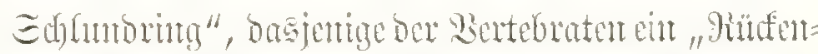

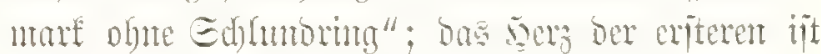

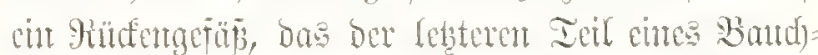

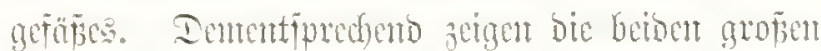

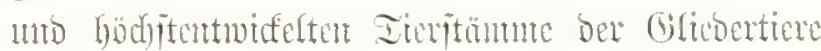

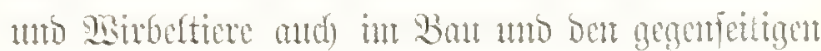

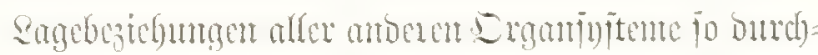

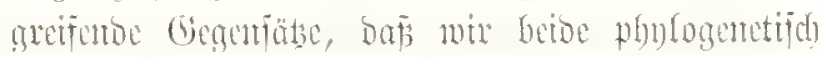
ats suci verfotedent Grupen ber 照urutiere (Vermalia) ableiten stumingt.

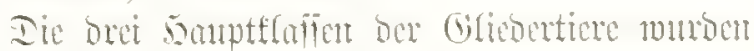

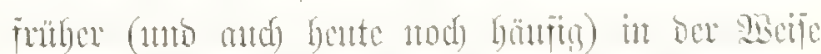

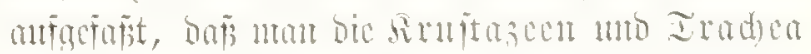

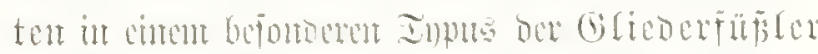

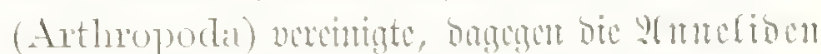

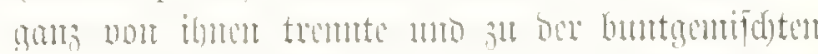

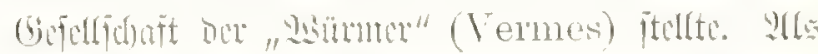

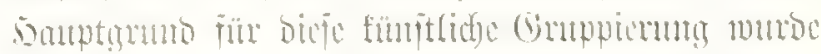

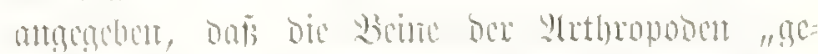

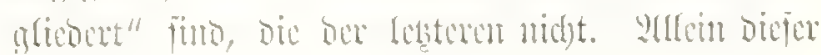




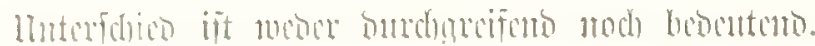

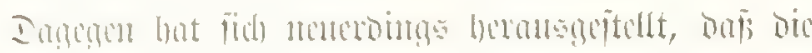

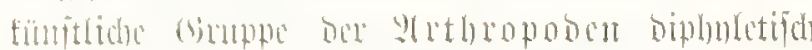

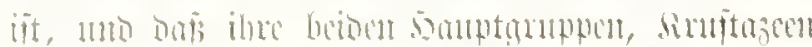

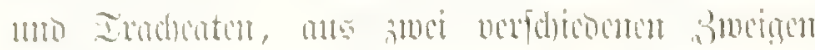

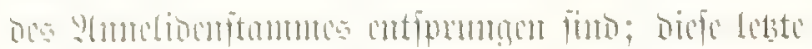

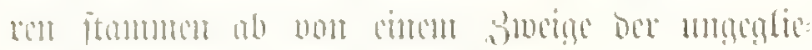

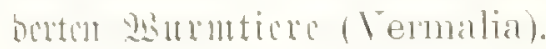

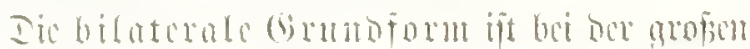

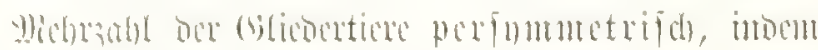

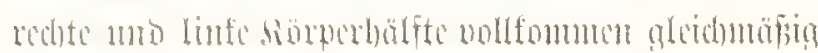

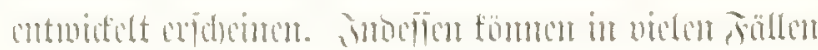

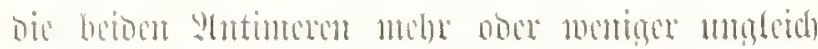

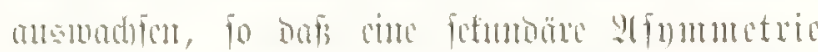

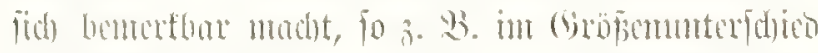

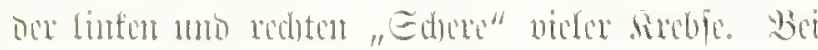

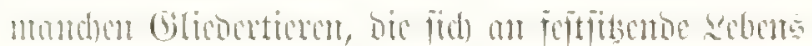

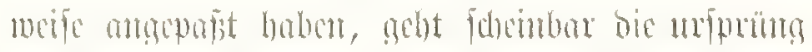

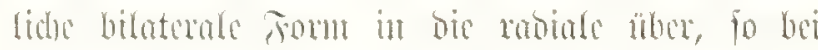

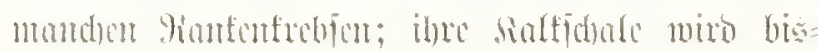

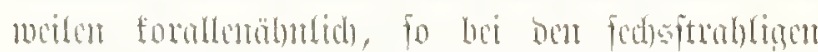
Coromula uno (hithamalus ( Iofel 57, Fig.

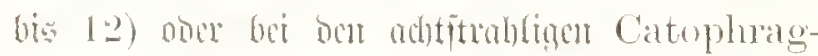
mus mo Octomeris ( Iofl 57, Fin. 1:3, 1t).

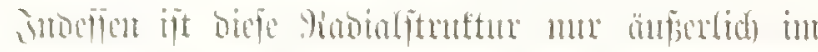

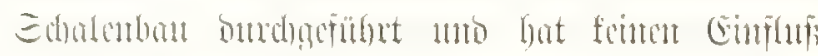

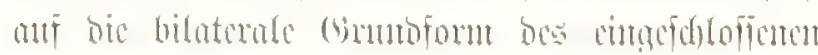

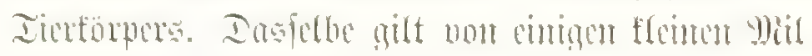

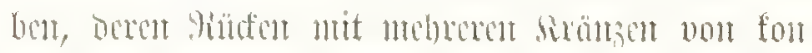

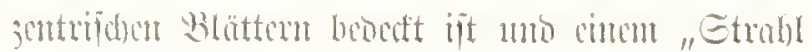

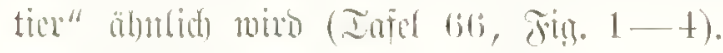

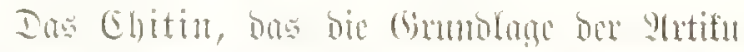

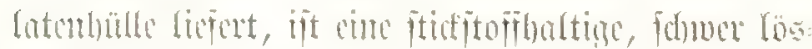

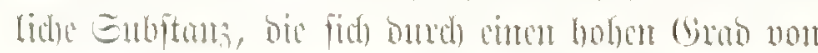

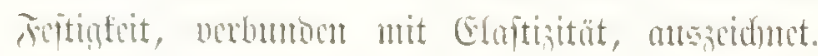

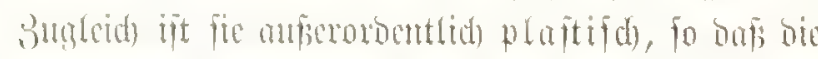
Sellen ber Epidermis (biex and) oft als Hypo-

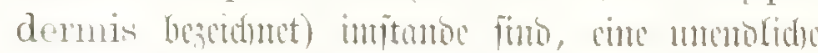

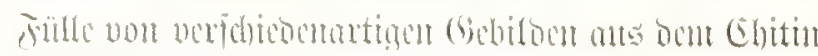

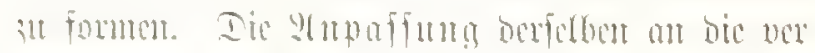

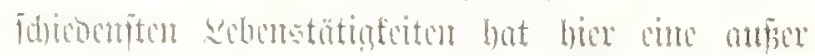

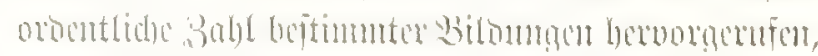

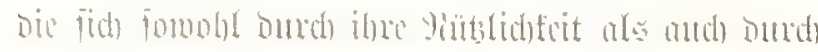

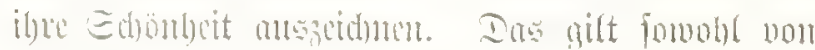

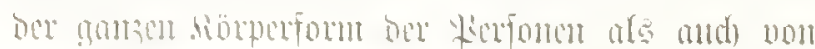

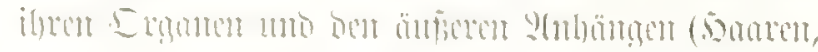

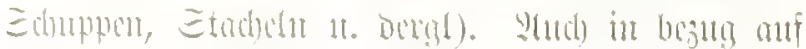

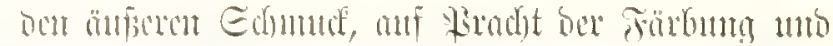

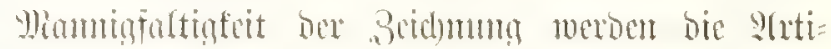

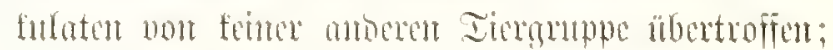

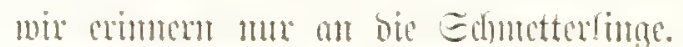

Jiugclticre ober Singelwiirnter (Annelida obcr Ammulata; Iafer 96). Diefe sampteforie ipt

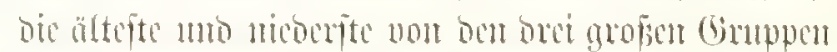

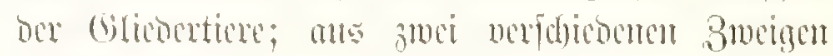

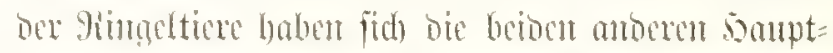
Elafion, dirntozen uno Iradjeaten, expt fpäter ent=

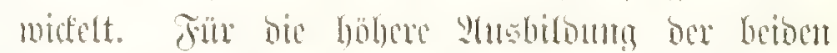

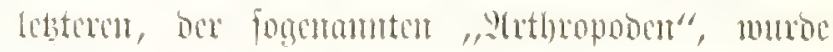

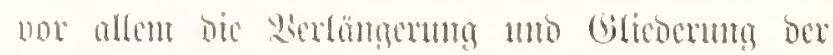

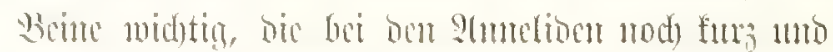

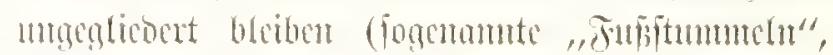
Parapodia). Whforom bleiben bie zablreidyen

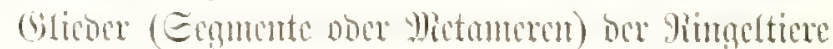

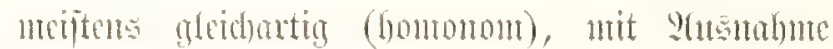

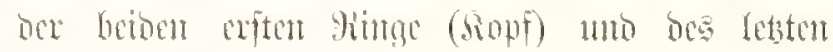
(Ielfon). Bingegen finto bie nemiger sablectden

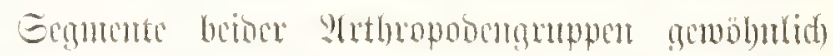

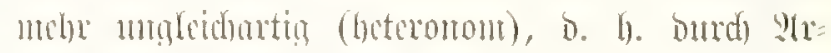

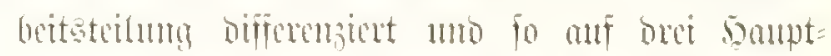

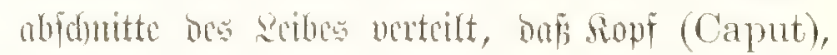
Bunt (Thoma) mo sinterteib (Abdomen) fict)

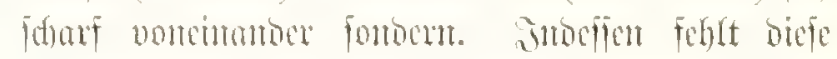
Differensionm nod) ben älteften Sumptajeen (Iri= lobiten) mo Imadeaten (Xirotradeaten), umb andoce=

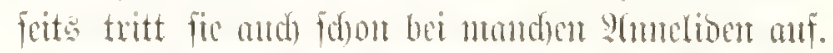

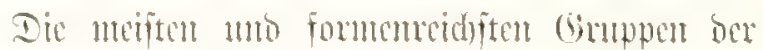

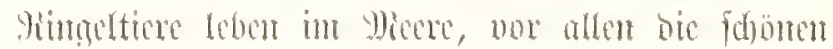

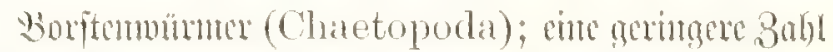

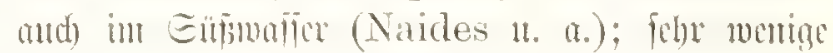

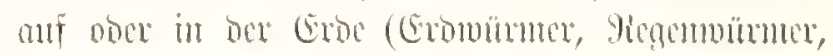

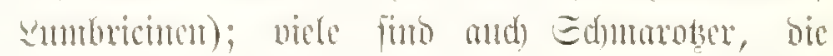
anf mberen Iinen Leben, bejonters bie Bhategel (Hirudinea). Wian teilt bie ganse samptfafe ber

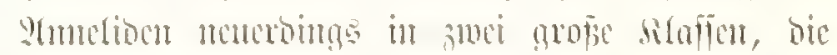
meberu (Grattwimer (Hirudinea), obne Fube mo

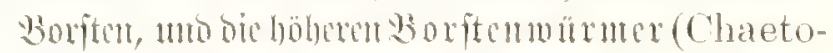

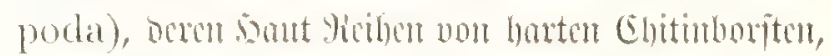

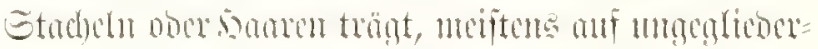

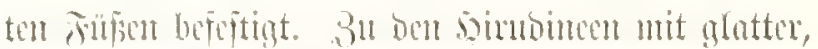

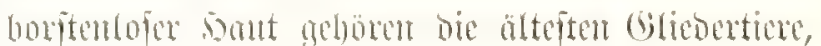
Die Imontgention (Archammelida) mo bie para= Fitifoen Eget (Himdinida). Die Ehatopoon 3er=

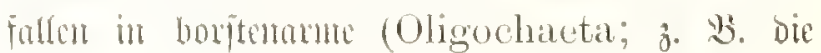


Sunbricincu) 1 mo in borfenteicle (Polychaeta:

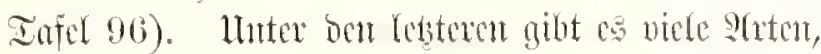

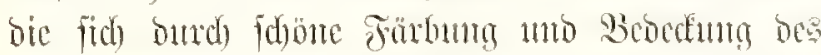

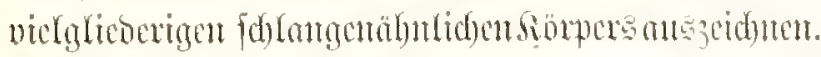

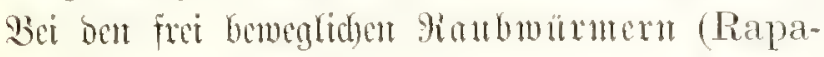
cia; Iafel 96, Fig. 5-7) hilben jicthde ?tubänge bie feserfömigen ober fammiformigen Sicmen, bie fid), ebenfo wie bie Soritubumbel, an jeocu Eeg=

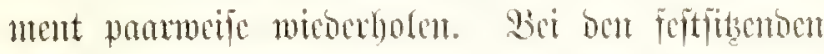
Göbrentuluncu (T'ubicolae; Iafel 96, Jig. 1-4) find bugegen bie sirumen, on ber gröpte

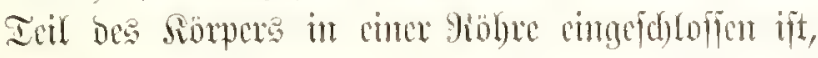
unx am Sopfe cntwidelt, lice aber 1 tm fo ftärfer,

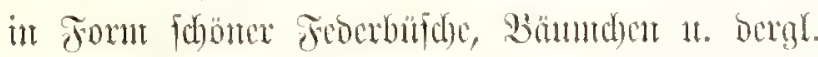

Sirujtenticre (Crustacea; Iafel 47, 56, 57, 76, 86). Diefe 5auptf(afle unterforibet fid vou

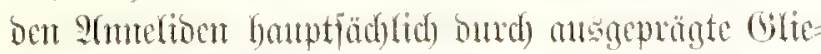
berung Der verlängerten Secure unb bic ftärfere stus= biloung ber Chitinoede, bie meiftens ourd) Ein=

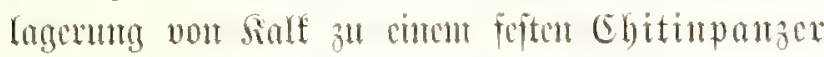
wixo. Snbefien ftelyen cinige ältepte siruftazen

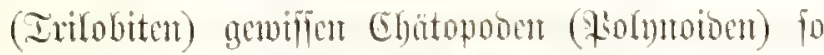

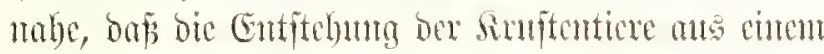

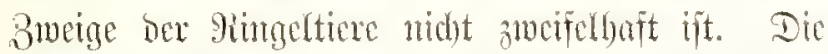

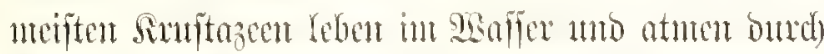

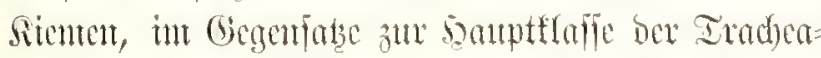

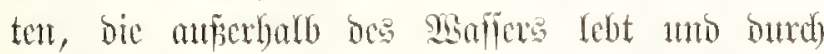

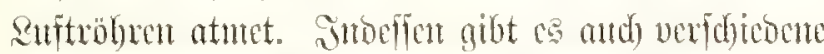
Srebstiere, bie fid) bent Reben in ber suft ange-

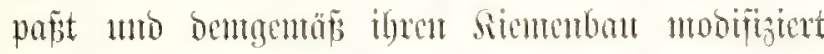

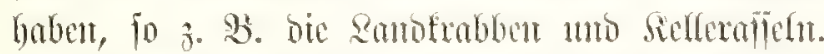

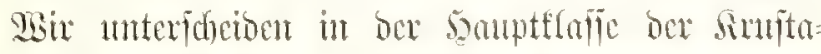

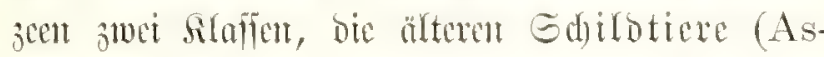
pidonia) 1mo bie jungeru Arebstiere (Caridonia). Die erfteren tragen an Sopfe cin Raat

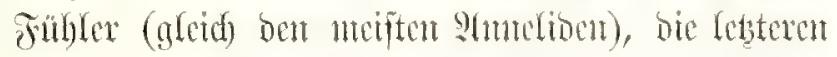

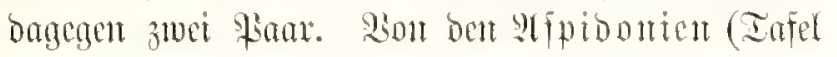
47) lebt heute mu nod) cime cimgige Gattum, Dex grope, "Moduffenfrebs" (Limulus; Jig. 1,

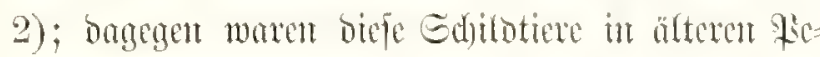
rioben ber Erogefdidste burd) felle zablreide mb merfmunoige Fonnen vertreten. Inter ben Ricjen frebjen (Gigantostraca) ureid)te Pterygotus ( Iafel 47 , Fig. 5) nidbt weniger als $1^{2} / 2$ m Sange;

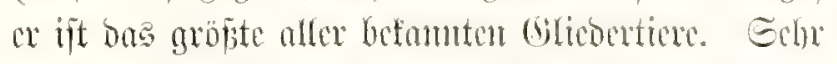

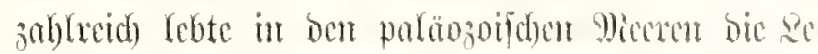
gion bex Dreiteiffebfe (Trilobita; Iafer 47 ,
Jig. 6-21). Cintge Formen berfelben (3. S3. Triarthus, Iafel 47, Fta. 20) fitto ncutifen

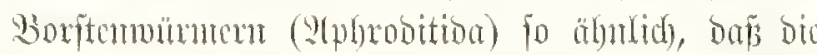

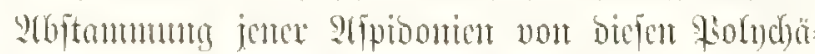
ten feutent Brocifel unterlegen famt.

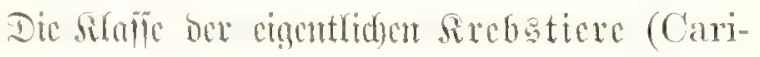
donia) ooce ber "fruftazen im engeren Gimm"

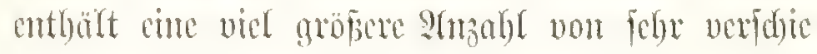
benturtigen Foumen. Sbunobl biefe in besulg anf

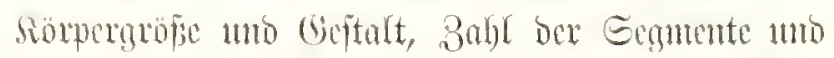

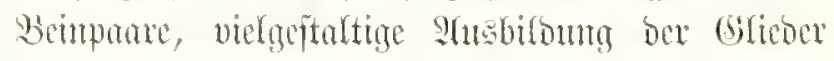

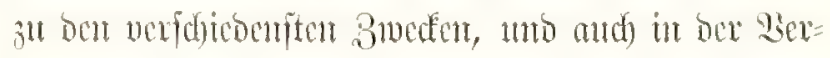

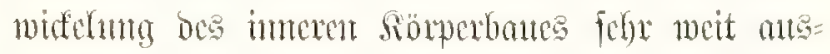
cutarbergeben, haben bod) alle gentemfan bie göd)jt dyarafterifificle S̈tgentoform bes Nauplius (Iafel

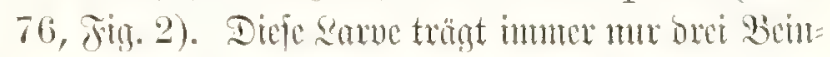

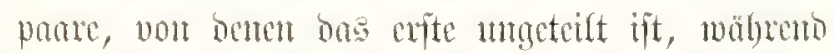
bie betocu antoren zucipaltig fino. Durd cine Feibe von merfwüroigen Serwanblutugen geben ar biejer

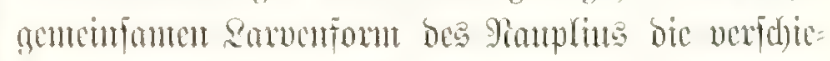
bencu formen ocr Sirebsticre berwor; babei ent widela fidh vicle bobdjt fonberbare mo abontence

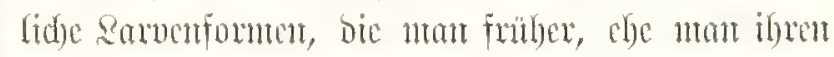

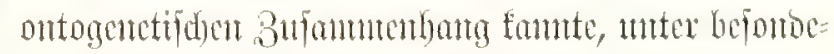

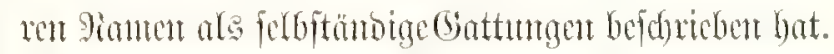

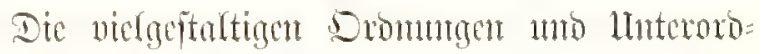
mutgen, anf bic ntan bie zabluetden Fantilen ber Srebsticre verteilt bat, fan man in bré gröferen Grmppen ober Segionen zufanmenitelfen, bie 9lie=

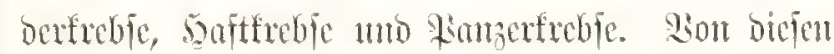
jino bie Ricocufrebic (Entomostraca) als dic ältejten แnto printitupiten anzufeben; ce gebören ba=

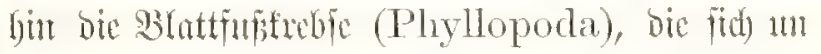
mittelbar an bie Irilobiten ( Infd 47 , Jig. 6-21) mo bie nabe verwanten Chätoposan (Iafel 96)

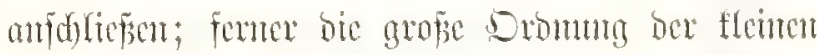

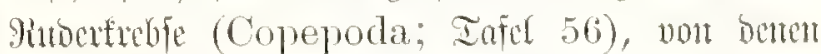

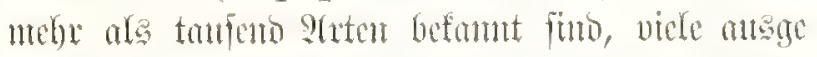

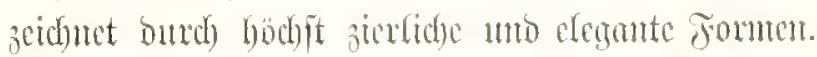

Eme rob abmedambe segion bilocn bie saft= freble (Pectostraca; Iufd 57); fic furb burth

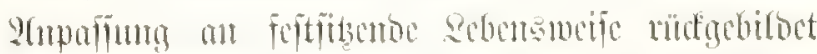

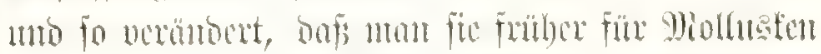

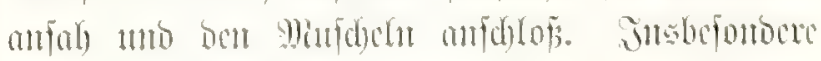

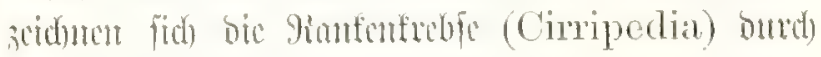

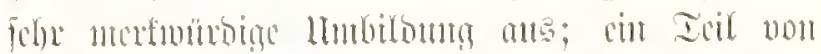

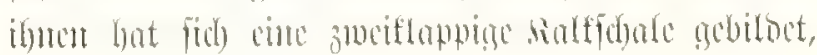




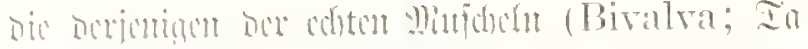

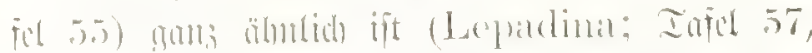

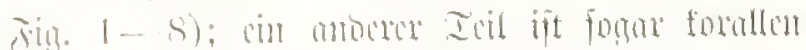

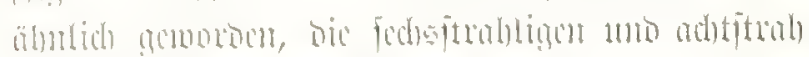

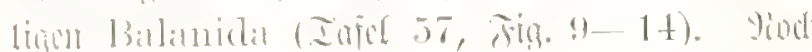

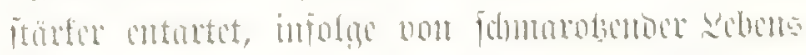

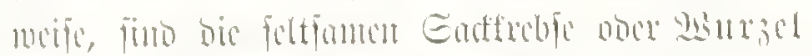

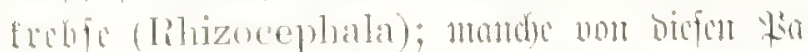

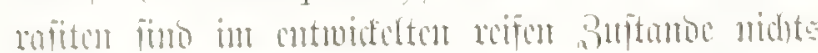

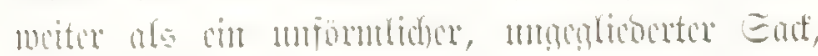

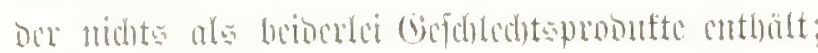

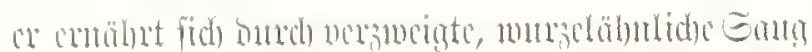

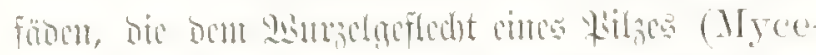

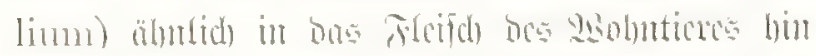

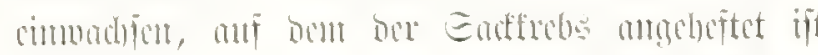

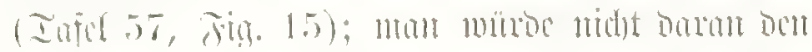

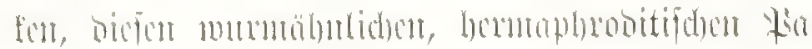

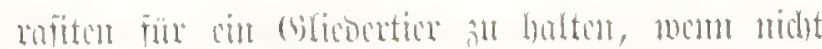

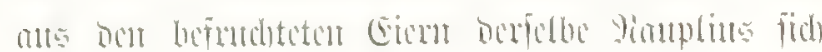

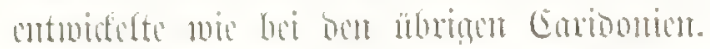

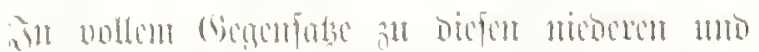

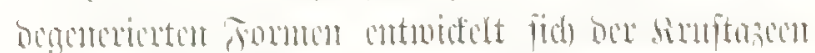

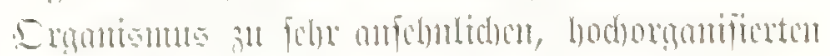

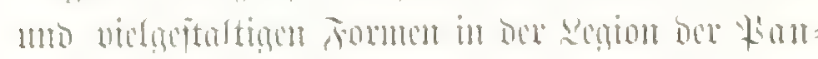

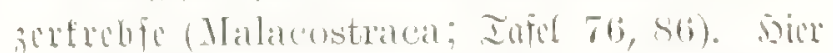

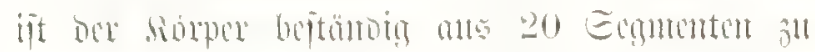

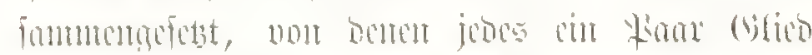

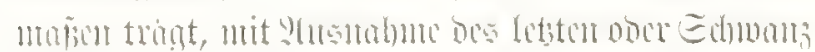

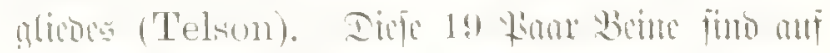

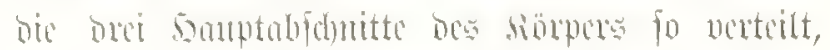

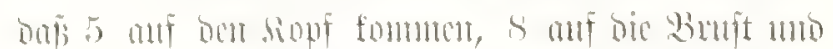

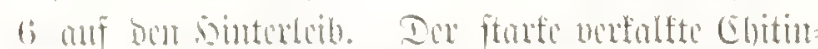

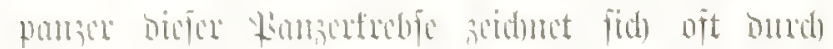

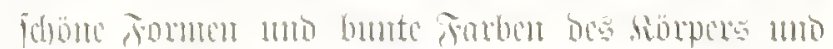

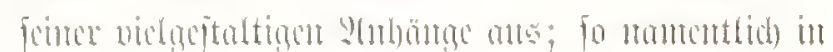

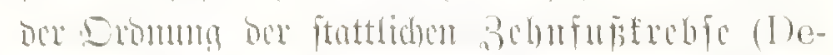

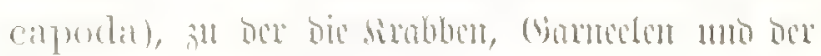

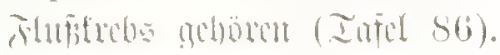

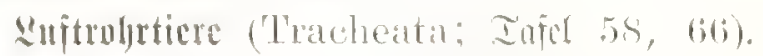

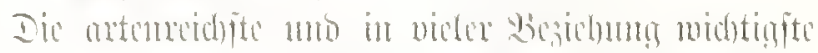

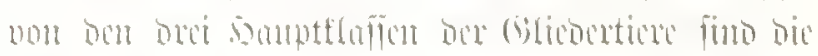

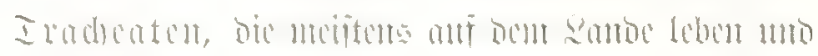

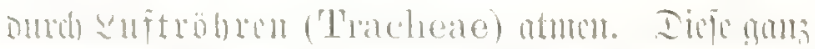

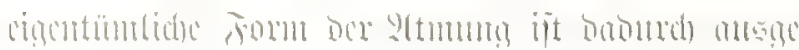

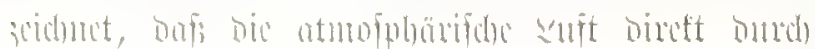

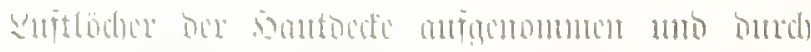

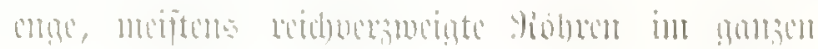

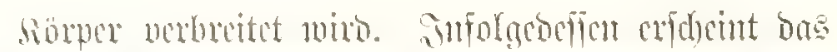

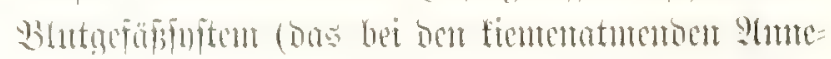

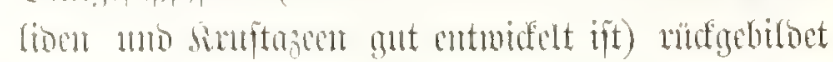
mon ift meritem mu burd cin viclfanmeriges

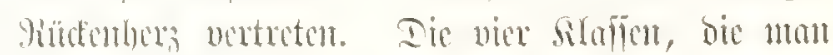

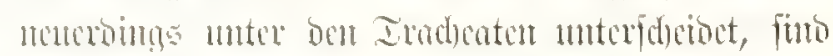

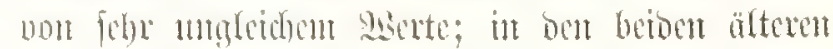

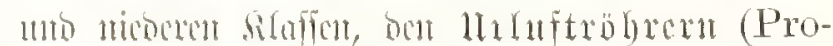
tracheata) mo Imufubfüpu (Myriapoda)

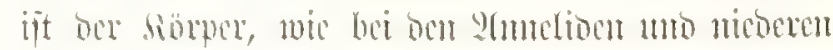

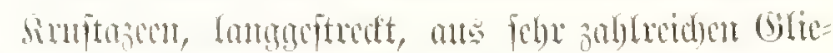

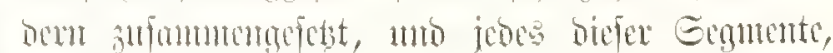

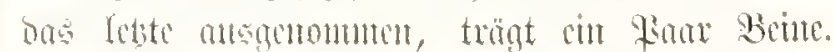

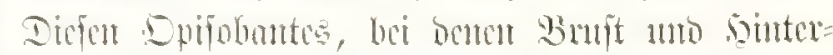

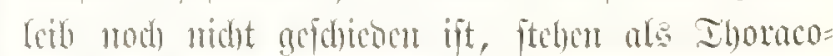

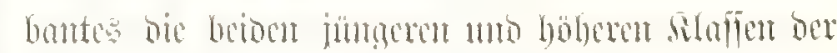
Iradenten arsmbiber, bic Gpinnentiere (Arachnida: Tafol 66) ntuto bic suchticte (Insecta;

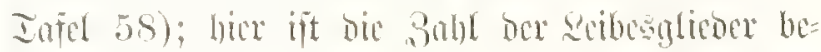
fdorintt (anf 10-1s, felten 20), wie bet ben böberen sibbotien (Malacostraca), und bicfe

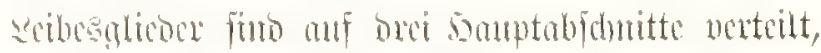
anf sopf (Caput), Binut (Thorax) tmo sinter-

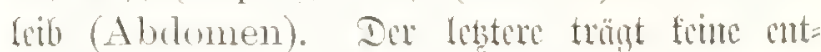

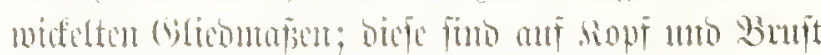

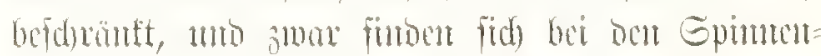

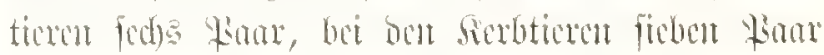
Extrentäter. Die betom Silafien bex Ihorato=

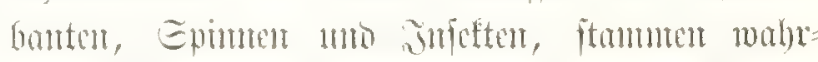

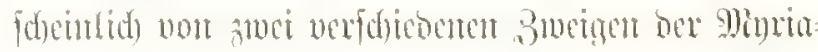

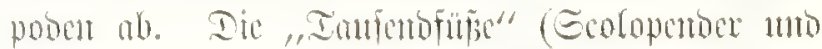

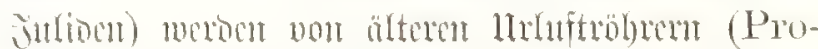
tracheata) aboglestet, bic ibrerfoits biret vont

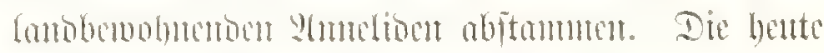

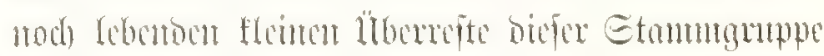

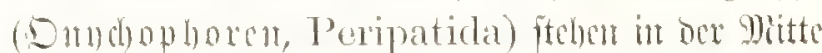
smifdar ben älteru chätopoom (Protochaeta) uno ben jüngent Hintupoben (Scolopendrina).

Epiuncuticre (Aradonida; Iofd 66). Die

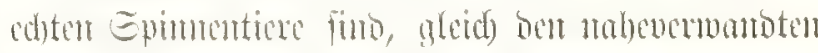

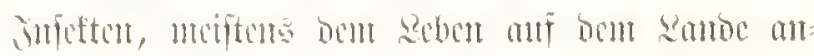

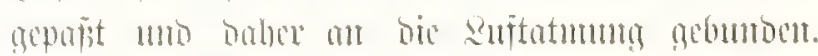

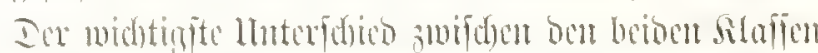
ber Ihorafobunten bejteht barin, bor bei ben

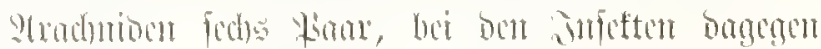

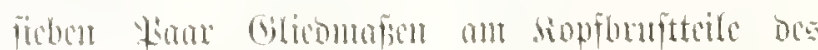

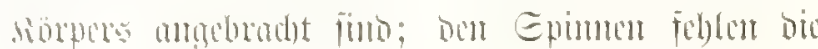




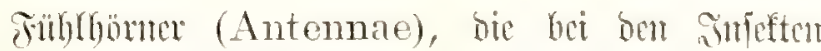

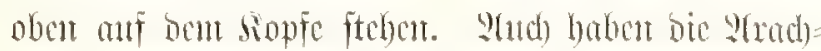

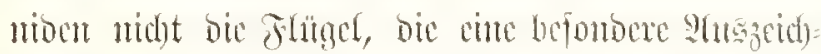

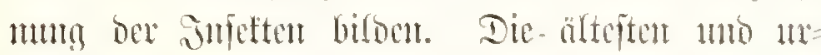

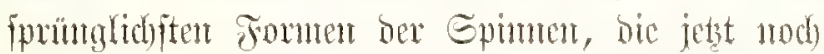
leben, bie An pipinnen (Solifugae), forlferfent fich

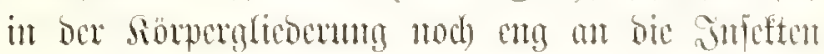

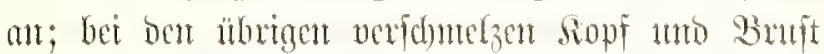
ju cinter Miafle, "Siopfonit", Cephalothorax. Die Gimge des sinterteibes (Iafel 66, grig. 613) Gleiben nod) getrent bei ben Glorpionen (Scorpionea; Iafd 66, Jig. 5); fit verfd) ntelzen

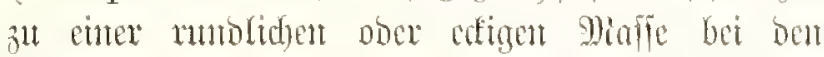
93ebefpimen (Araneae; Tofel 66, Jig. 6-

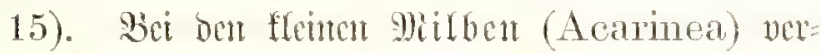

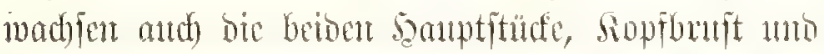
Sinterteib, zu eince rumblidgen \$ioffe, an Der von

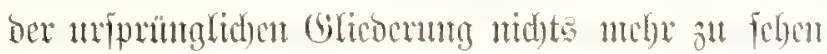

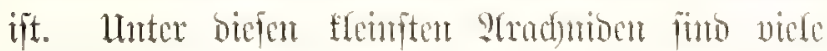

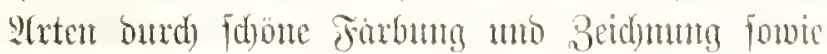

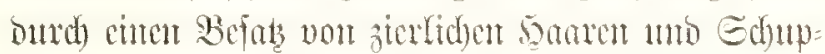
pen ausgezeid)net ( Iafjel 66, Jỉg. 1-4).

Sicrbticre (Insecta; Irifet 58). Linter allen

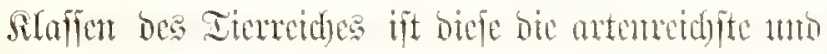

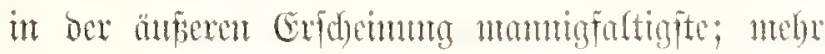

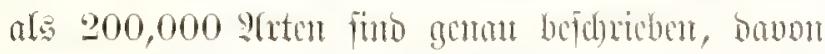
fonment 90,000 alfeit muf bie Siäfer, 30,000 anf

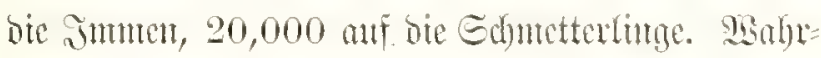
Fdecilid) beträgt aher bic (befamtzand oce nod) leben=

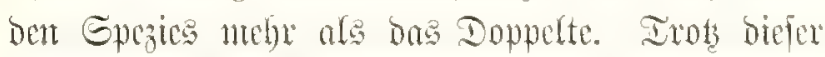

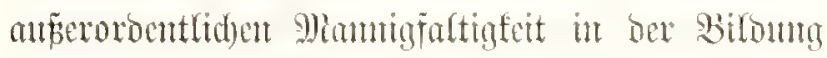

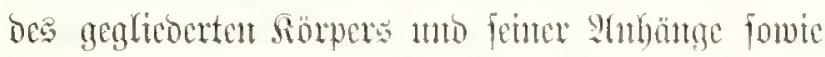

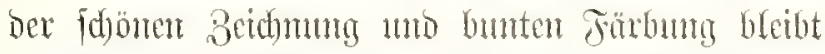

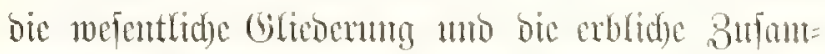

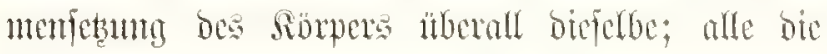

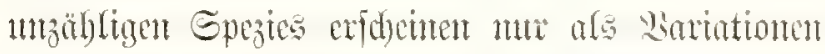

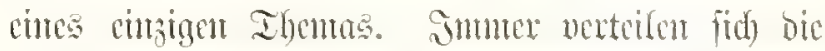
17-19 1lrfognente anf brei soutptabjdulitte, Sopf, Bruft uno seinterfeib. Son bicient trägt bor Sopf

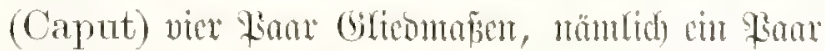
Futhlgöner (Antennae) mo bret Sinar Ricfer (I. Sberfefer, Mandibulae; II. Interficfer, Maxillae; III. Sinterficer, Postmaxillae). Dir Bruft (Thorax) beitebt an brei Genmenten mo trägt brei simpare (I. Soroermut, Prothorax. mit oen Sorberbenur; II. Mlittelfunt, Mesothorax.

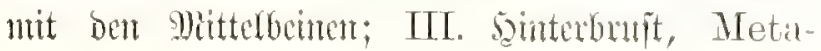

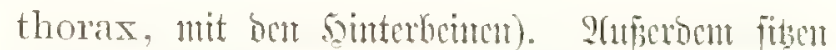

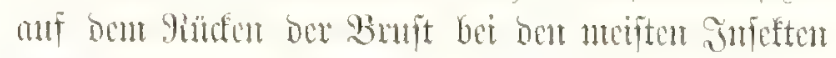

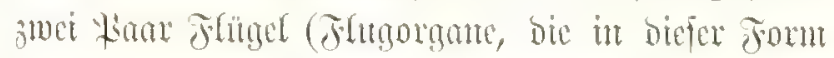
bei fcimer anderen Iierffoffe vorfonmen), unto stour bie Sorberfluged anf ber Mitteflunt, bie binter= Flitget anf der sinterbuift. Der sinterfeib (Abdomen) beftert gewöhnlid an 10-11 gimgon

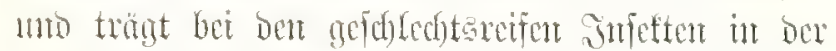

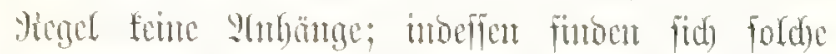
"Sifterfinge" (Pleopodia) fehr perbreitet unter bou Infieftentarven (bet Den Giaupen ber Ed)metterfurge

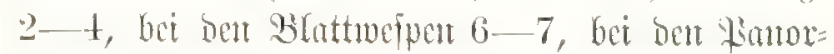

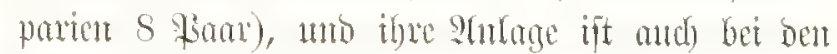

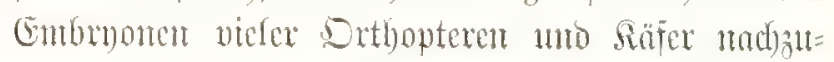
weifen (s-10 Ranr). Emolidy befitien and bic älteften mext ben lebenoen Surfeften, bie flcumen flügellofat Eampobinen (Campodea, Japyx),

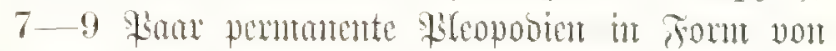

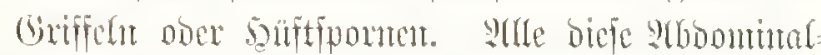

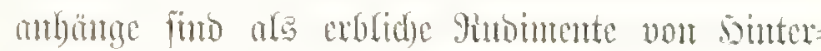

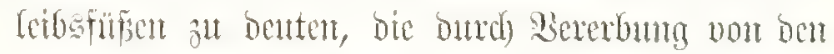

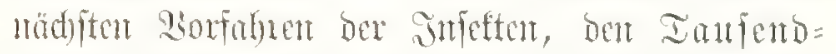
Füburn (Hyriapoda), mif biefe übertragen murom, bier aber ifre Beocutum verforen haben. Stud Die ganze intere Drganifation ber Serbtere, nament=

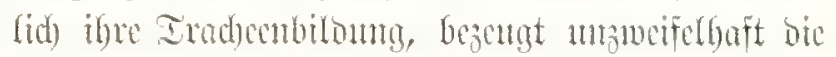

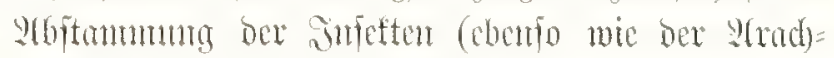
niocu) you ben älteren Minsiapoben.

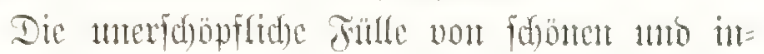

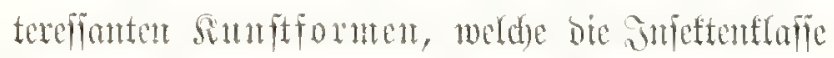
Darbictet, bie Siroportionen in ber Gifiebernutg bes

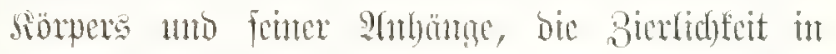

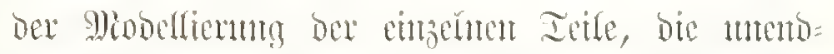

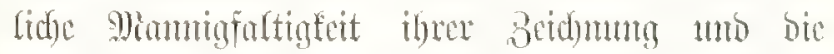

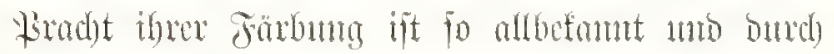

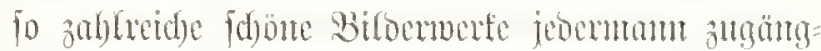

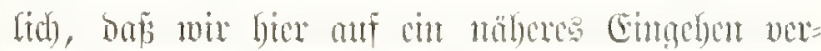

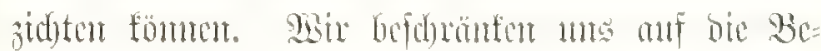

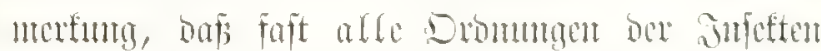

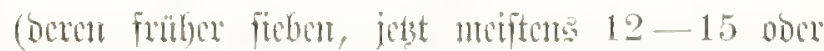

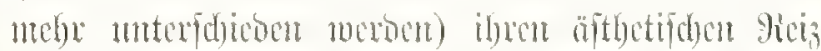

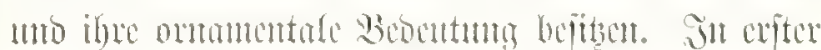

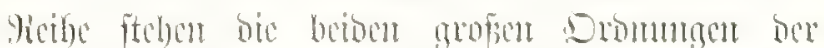

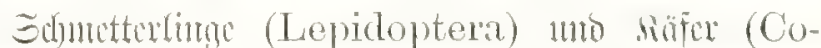
leoptera); fic fallen wegen ifrer maffenhaften

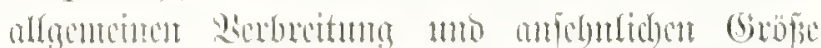

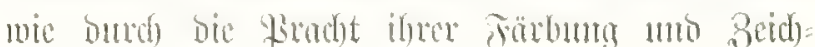




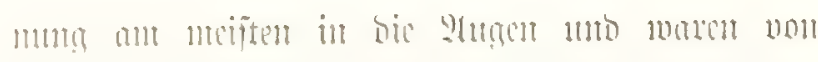

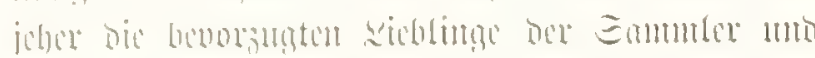

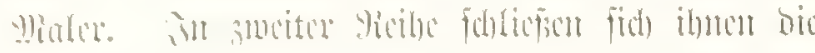

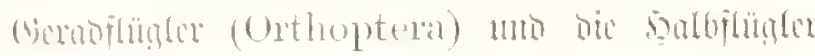
(Hemiptera) an; muncrtid) bic Edoreton (Gryl-

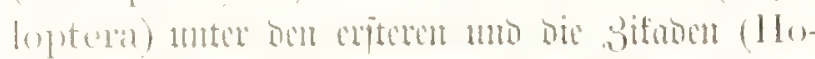
moptera) mate bou ledteren meifen viche ftatt

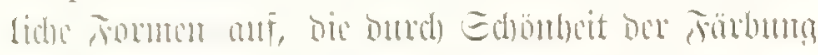
Iแth Bcidmum mic Duth materifde form ben

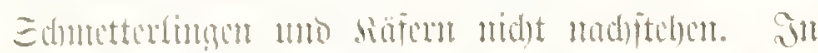

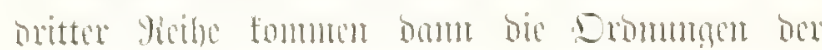
immen (Hymenopteral), bus Firgen (Diptera),

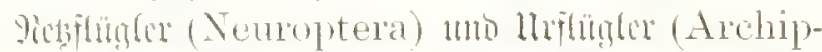

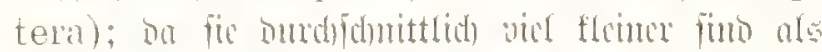

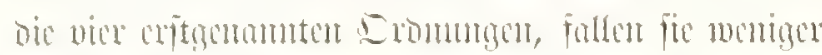

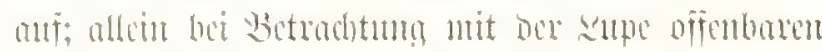

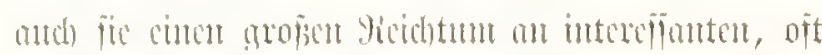

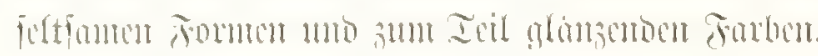

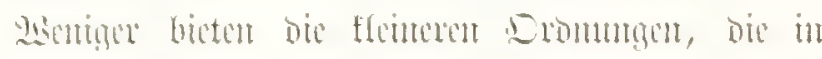

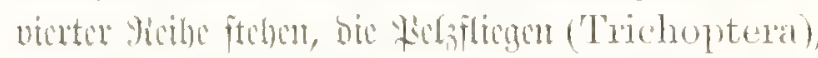
holbenflighlox (Strepsiptera), dic stobs (Niphonoptera) mo die flugullofa surfeten (Apterota).

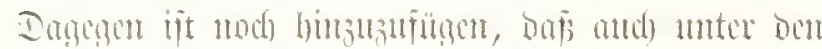

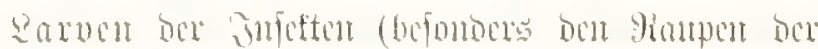

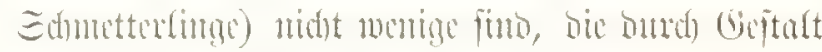

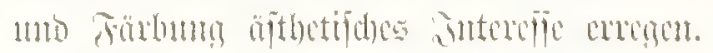

D. 5) Mirbclticre (Vertebrata; Iafel 42 , (77, 65, 79, 87, 89, 99, 100). 5m Etanm

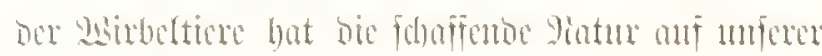

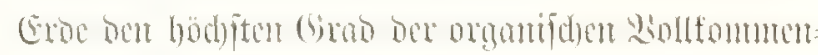

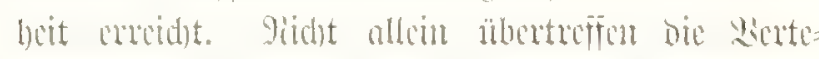

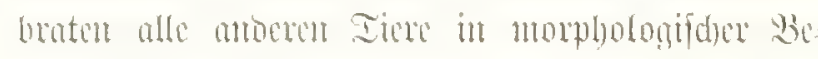

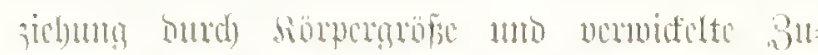

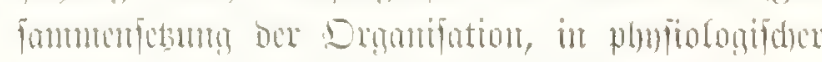

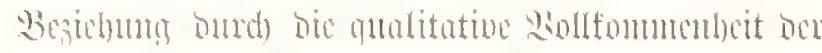

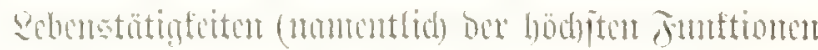

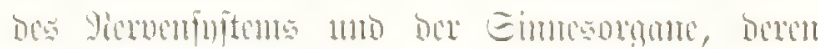
(bofantbeit mir "Escle" nomen), fonbern and in

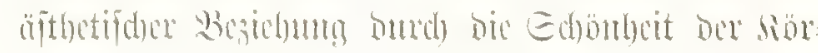

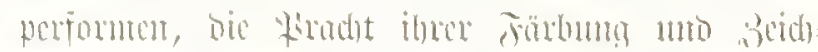

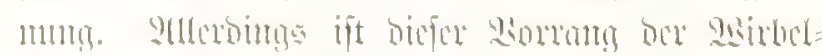

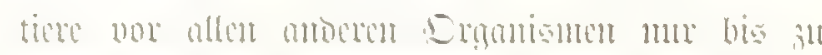

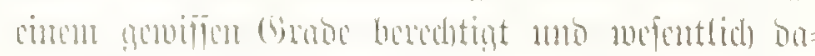

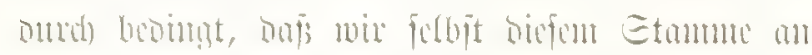

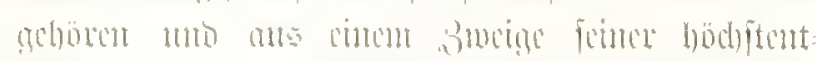

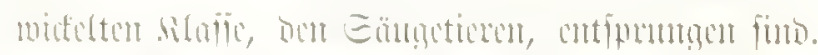

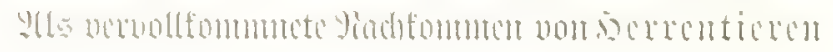

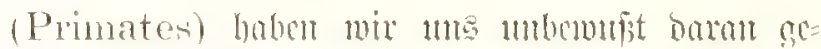

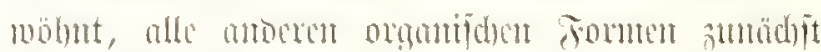

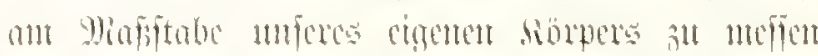

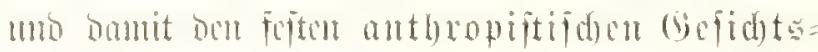

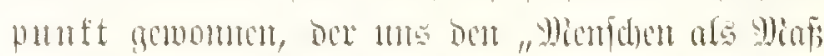

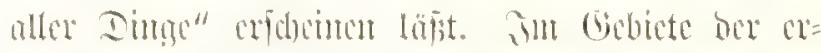

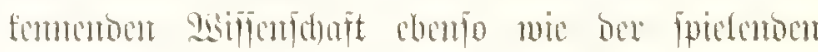

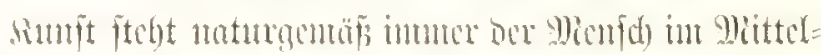

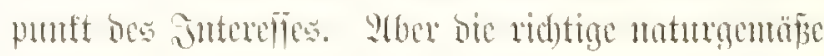

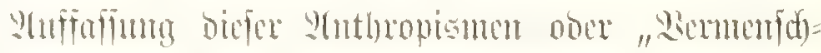

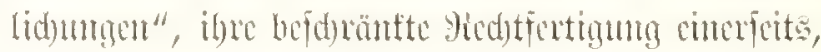

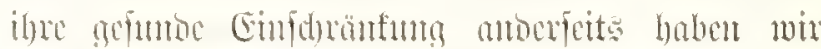

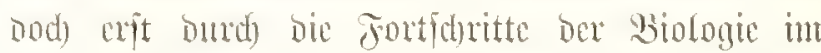

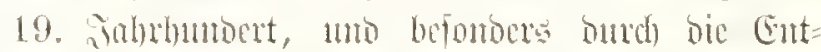

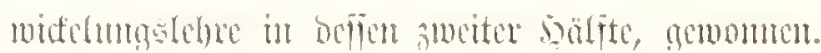

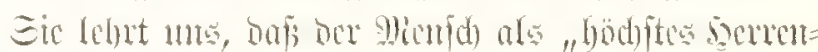

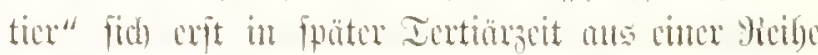

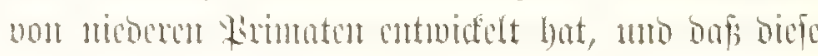

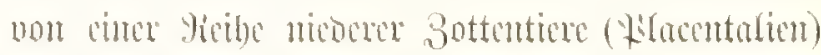
ats ber alteren Iextiäsert abftammen. Diffo wic-

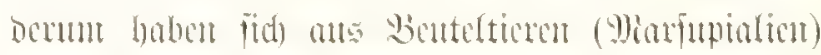

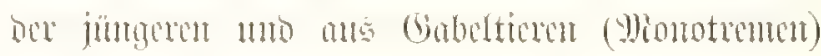

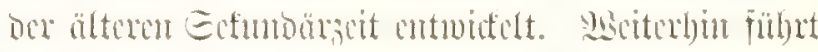

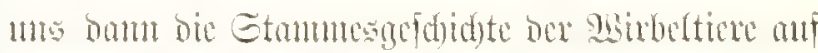

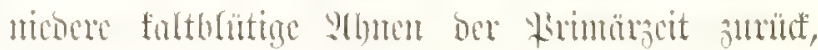

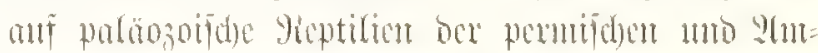

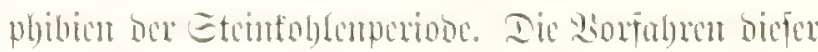

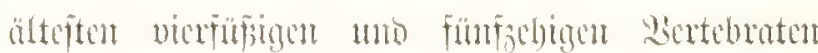

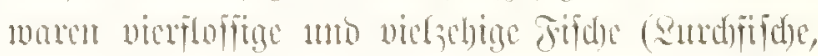

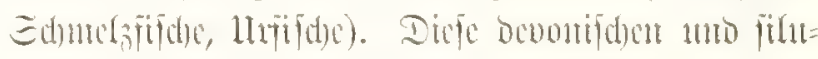

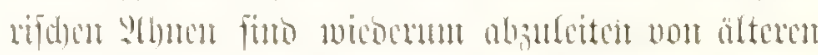

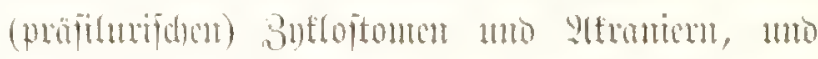

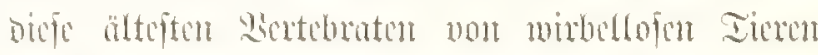

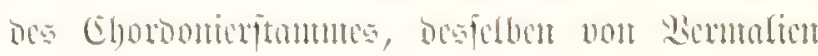

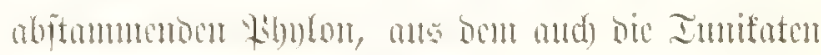
( Iafel S.J) cmtiprumgen finto.

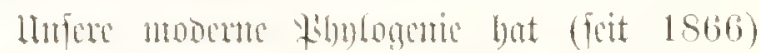

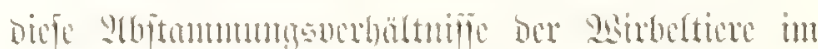

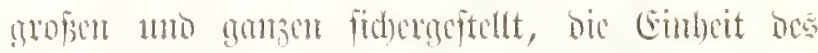

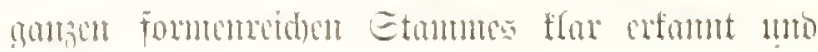

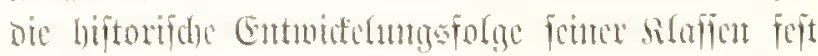

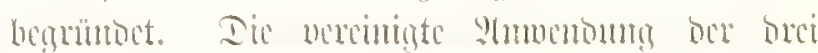

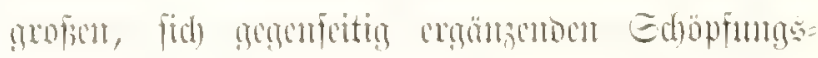

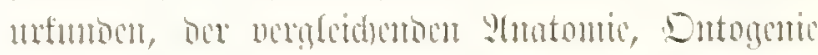

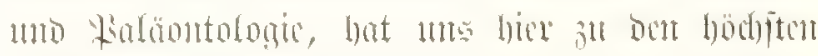

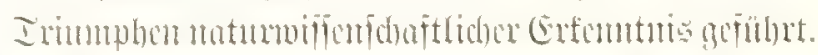

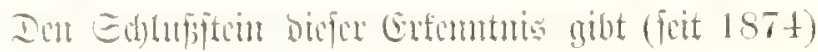




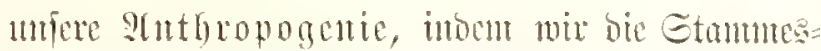
gefdidate bes Mienfdent mit berjentigen ber übrigen

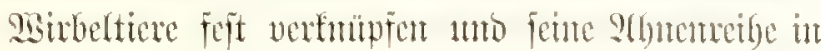

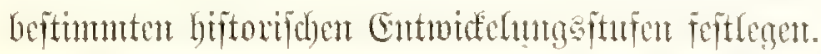
Die "Simritformen Der siribelticre", die in Mien=

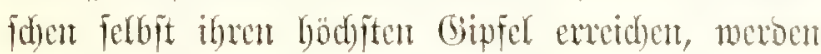
uns in sidnte der SAnthropogenie nidyt mur bas

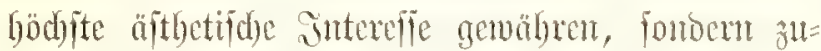

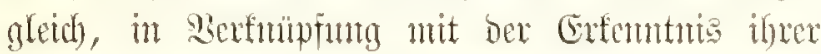
phyletifdent Entwidedung, merer Sermunt cine weit

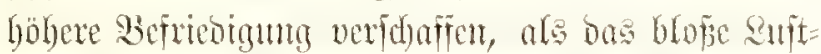

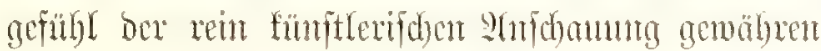

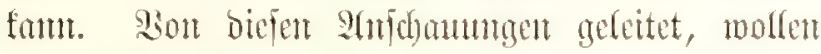

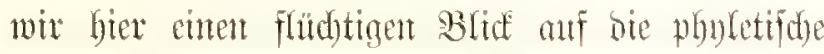
Entwiffelung ber Sintifformen in ber gicibe ber adft BSitbeltierffaflen werfen.

Edjübelloje (Acrania). \$ort ben ältejten

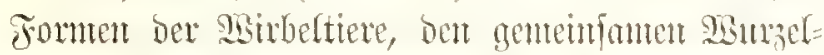
formen bes ganzat Gtonmes, gibt 1 me hente mu cinte einzige nod) febento Gattung Siemrtnis, ber beoutuntgasvolle sanzelot ober das Rmzettierden

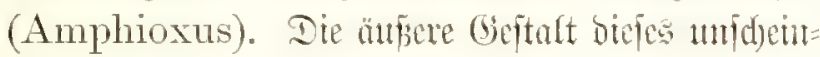
boren, im Sanbe Des Mieetes vethorgenen, wentige

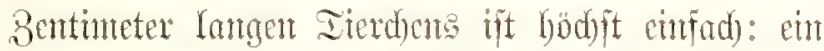
Düntus, fonzettfönniges Blatt (ähnlid) eintent \$scioen=

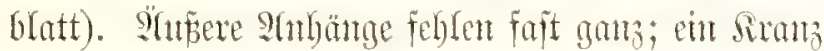

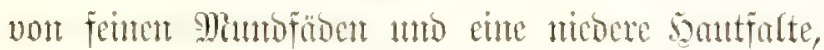
bie ale vertifaler Floffenfaum ben gröbten Teil bes

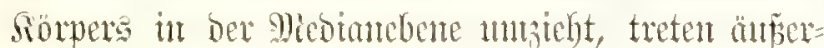
(id) wentig vor. Der imere Siörperban ftumnt int

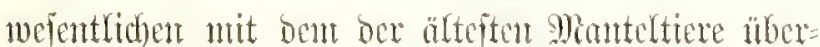
cin, befonoers im ontogentetifhen Etrobum ber Chorbatarve (Chordula), bie betoen gentemam iit (ङ. 30). Der bifnterale Sürper ber jugento

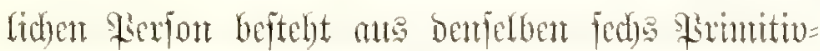
organten; in ber Rängendje bes Sörpers bie Chorba, barïber bas borjafe Sicrvemrohr (Bütfemntare), bas:

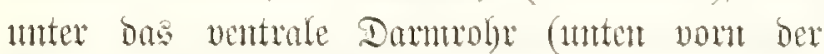
Muno, Gintent ber adfer); zu betoen Geiten (red)ts

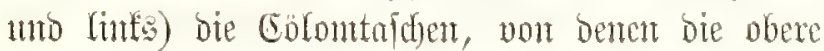

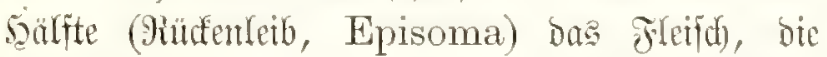
Mitsfelplatten liefert, bie untere sälfte (Baud) Hyposoma) bie (Gonaben ober (Geld) (ed)tabruifent. In ber Seimesgejdidyte bes Mienfiden wie alfer an= Deren sistrbelticre tritt frithyeitig (ocm bingente

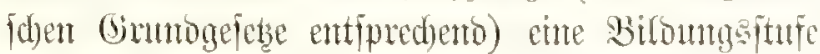
auf, in welder ber Entbryo ber Elgorbufa bee

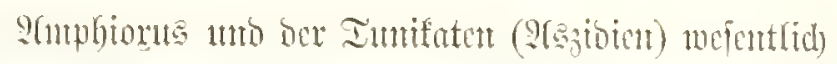

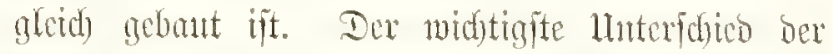
betoen resteren (unto jomit ber beioen Chorbonten=

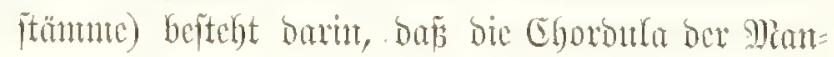
terttere nutgegfiedert bleibt wie ber fiörper ifrer

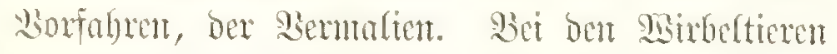
Dogegen tritt fritgeiting jene doarafterifitifoe inmere Gifiederung ber ferfon ein, bie wir Hrwirbelbit= bung (Vertebratio) mennen, und bie nut bem Berfall Der Cöromintafdent in einte Meifhe binterein= anber gelegenter Gäfden begint; ihre Dorjargälften werwantedn fid in bie Mitsfelplatten, ifre Bentrat=

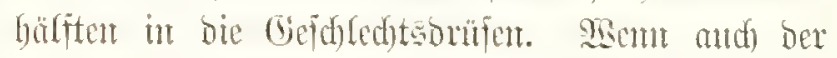
moberne Amphioxus in entigent Cinzelfeiten ber

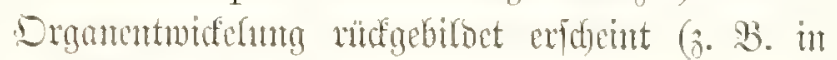

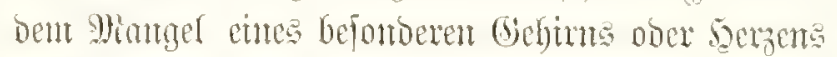
fowie höberer Eimmengane), fo bürfen woir ifn bod) int ganzen ale ein getrenes albbilo unto als

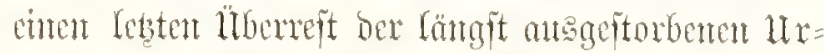
wirbeltiere (Prospondylia) betradten, jener

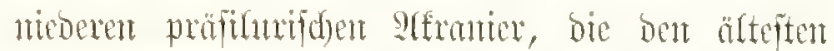
Iunifaten nabcitumoen uno fid mit ihnen gentein=

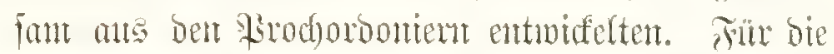
"Simniformen" bieten bieje niederitent Chorbaticre

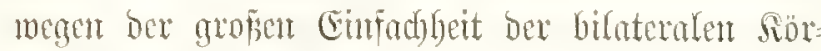
perform fein suterefie.

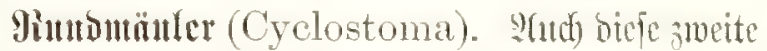

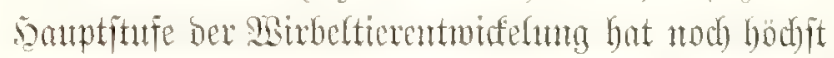

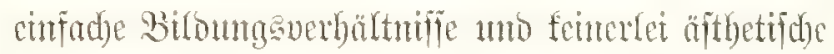

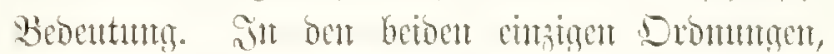

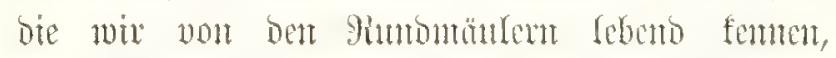
bou Jugen (Myxinoides) uno ben griffen (ober Picuntutgen, Petromyzontes), ift ber lange uno büme, mummörmige sörper fait sulinorifd),

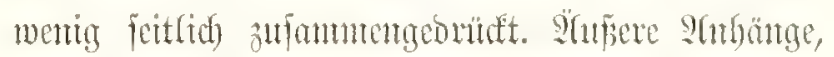
atsgentontuteat Bartfäbent ant Miutroe unto cintent bün=

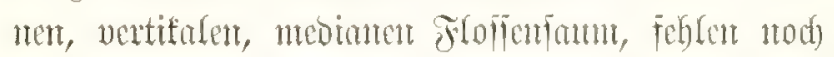

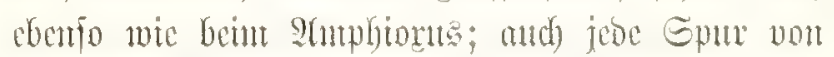

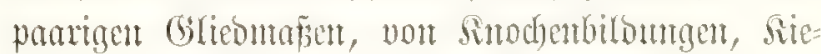

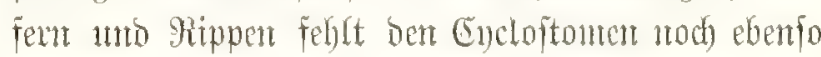
volfftünoig wie ben Iffrantert. Sie erbeben fid)

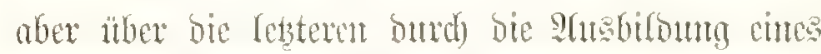

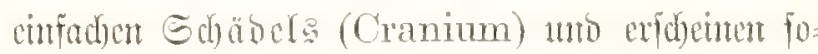
mit als bie äleften Sobitolticre (Craniota).

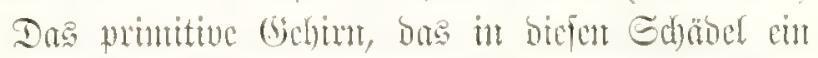

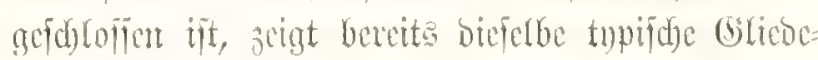
rung in brei, froitex fün bintercintunoex gelegene 


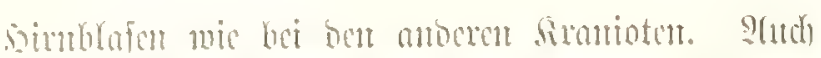

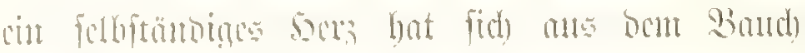

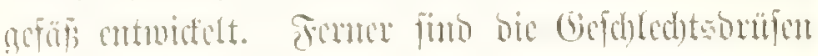

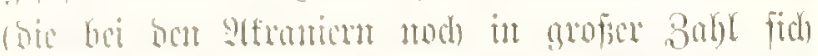

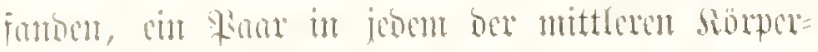

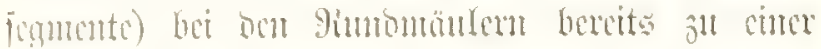

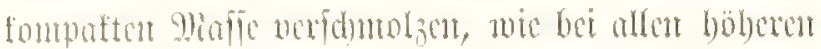

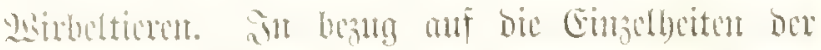

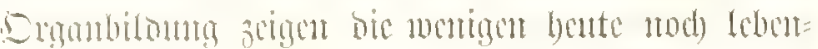

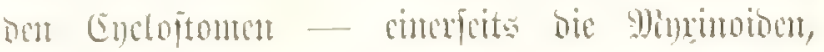
andorfeits bic Setronmsonten - nuter fid) be=

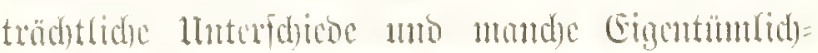

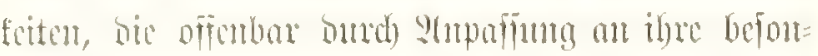

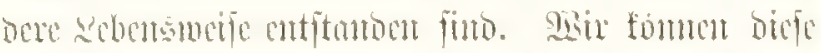

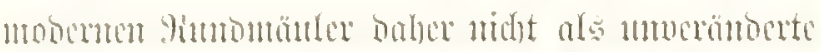

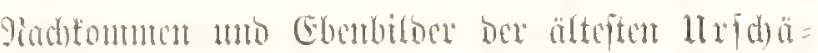

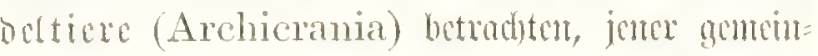

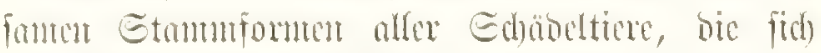

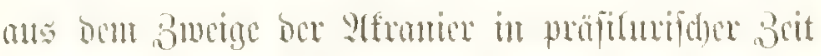

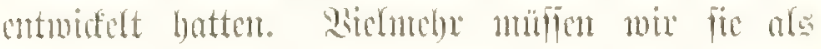

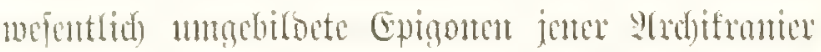

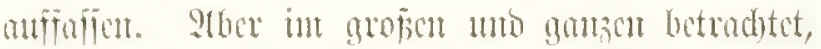

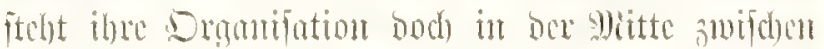

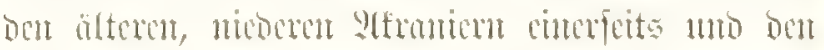

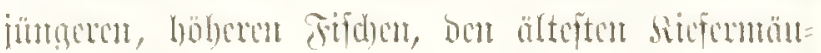
lem moncletits.

Filide (Pisces; Iafd 42, 87). Mit Dicfu

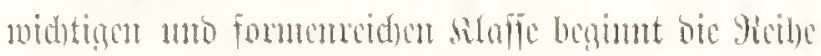

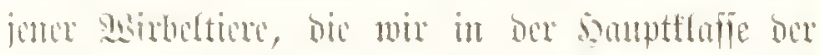

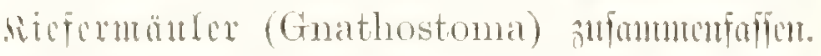

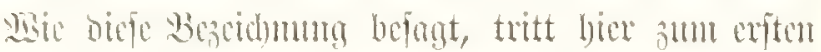

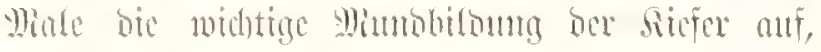
junte subutragenoen Eleletbogen, bie faitlid) an

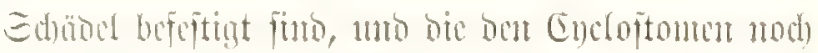

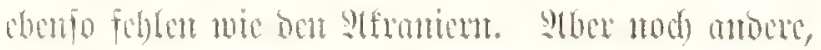

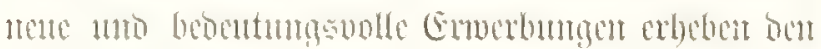

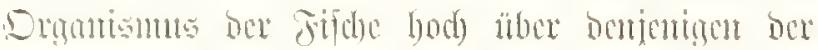

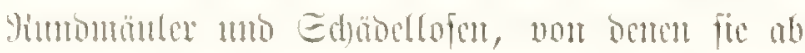

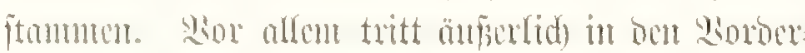

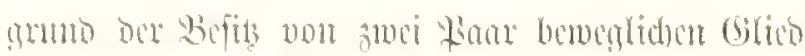

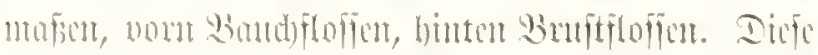

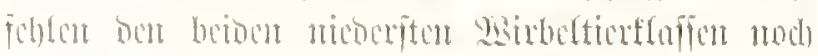

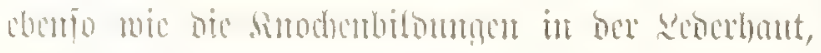

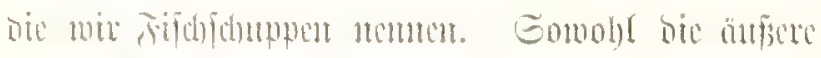

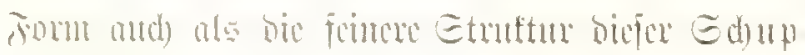

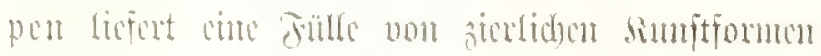

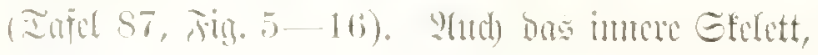

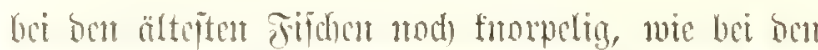

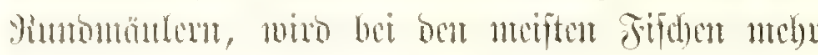

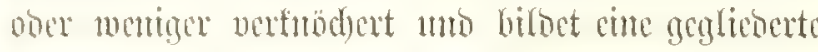

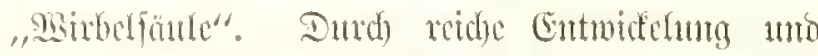
Differmiterumg von Suthen an Echäded entitebt cime nollfonmente Edyoulfapid, bie fomobl als

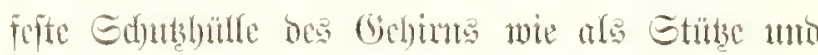

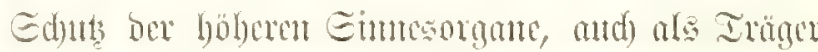

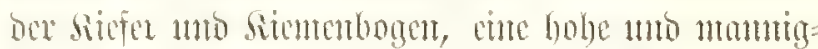

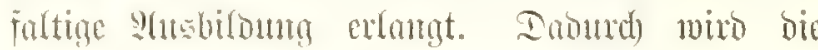

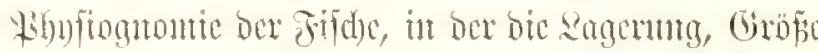
แnto Fom ber stugen und Yafen wie bes Minn=

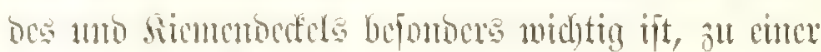
bebatention, "diunjtorm". Dasfelbe gilt aber mad vont ben Floficu, beren Gioñe, Gejtalt, Gtmultum 11. \%. 10. anferorocutfidy variert. Säbremo bic

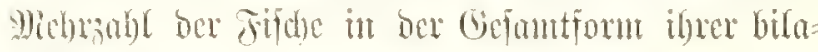

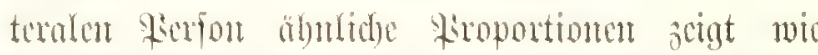

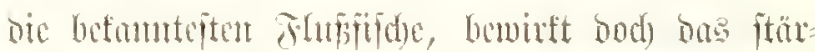

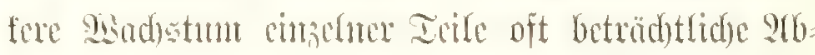

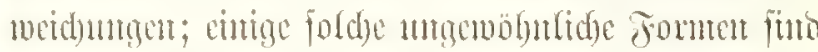
mif Safel 42 mo 87 (Fiug. 1-4) barigeftelt.

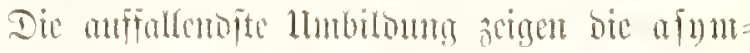
metrifden Fifde ma bex Fantic ber Gdjollen (Plemonectides), bic Grantum, Flumburn, Strimbten 16. 1. 12. Sick buben fid) bie betoen

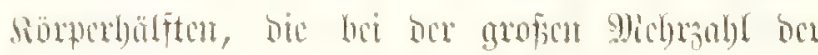

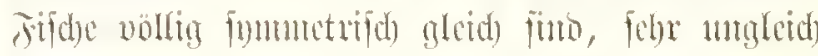
antwidelt, nno smox infolge bex (Gemolntheit, fid)

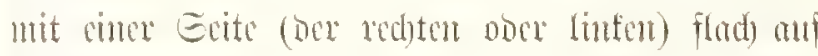

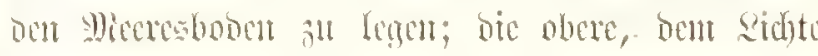

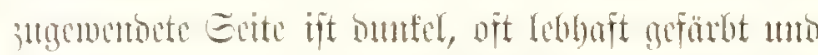

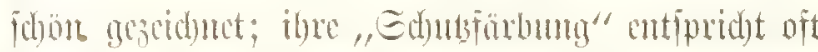

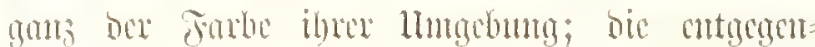
actede untere Eeite ift blaf uno farblos. Pod

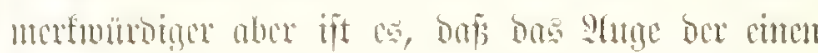
(muterut) Erite madi oben genambert nuo ber tnö=

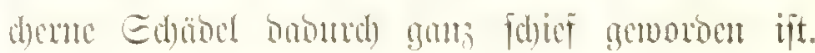

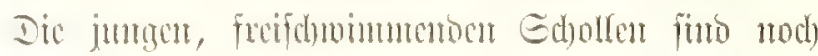

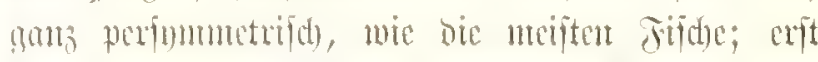
frater vermambelt fid ber bilaterale siouper in bio

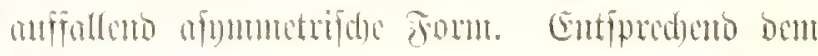

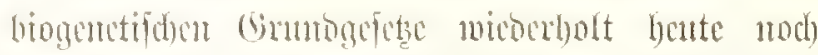

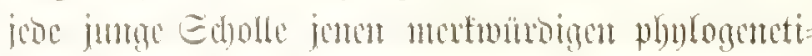

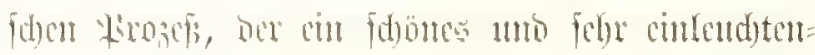

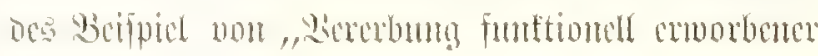
Eiguthaften" liefert. 


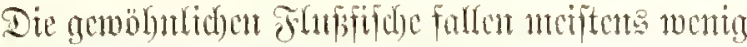

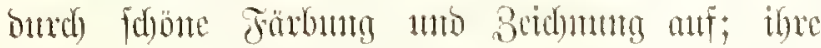
Dberfcite ijt ounfel, b(äulich), grünlich) ober grau

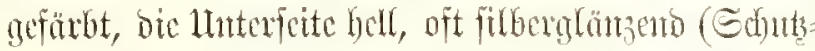
fürbuntg ber siffertiere). Dongegen futro bie See-

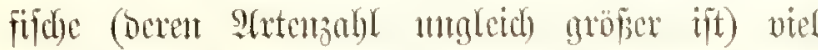
Gunter gefärot uno ntamigfaltiger geseddutet; and weidhen vide vout ifmen in ber Eduppenbeocifuta,

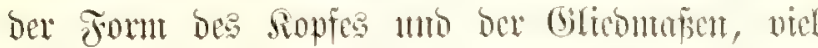

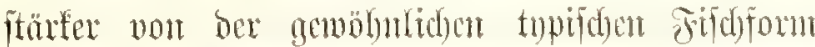
ab. Das gilt ntamentfid) vout dest jüntgerent Sintodyen fifon (Teleostei; Iajel 42, 87), wontger yon

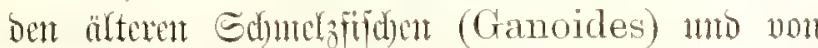
Dent primitiven Itrififhen (Selachii).

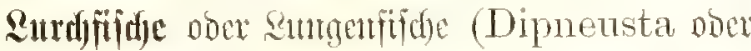
Dipnoi). Diefe intercijante silafie ift von bohem phylogentifiden sutterefie, ba bier zum enter siale bic Suftatnuma auftritt; bic Edywinumblaje, bie bet beu

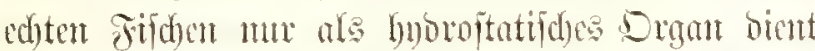

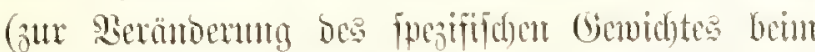

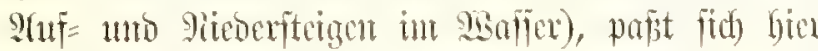

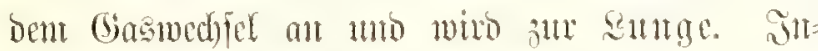

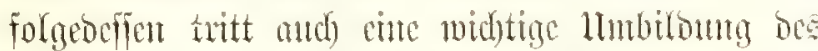

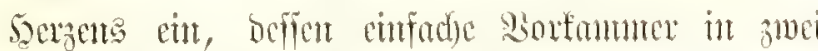
5älften zerfällt; bie redste Sorfanmere allein nimunt

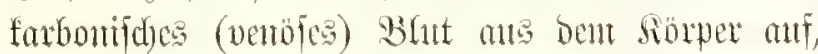

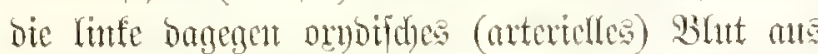

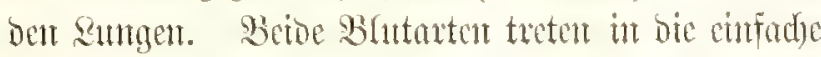

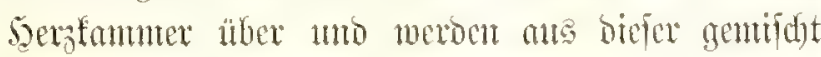
ansgetrieben. Darin gledent bie surdefifde bereits

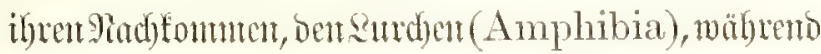

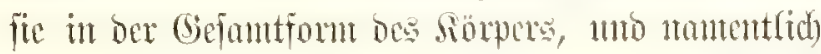

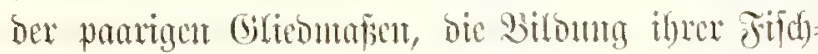
ahmen bewahet haben. Die Silaffe betbet founit ent wirffiche "libergangsonnpe" von bon fiemenatment=

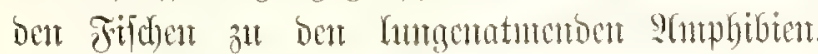

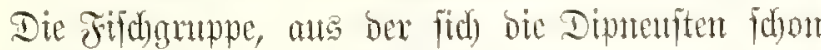

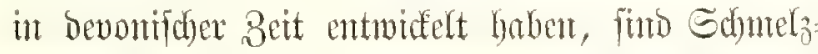
fifde (Ganoides) ans ber Familie Der Dutaftenflofier (Crossopterygii). Bicle verftenterte Bicfte

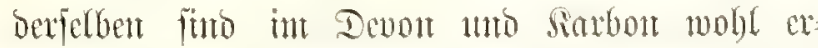
balten. Die wentigen hente stod) rebentoent Ruted

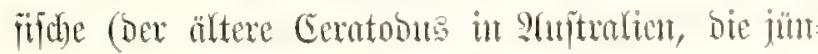

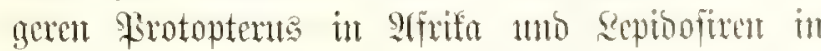

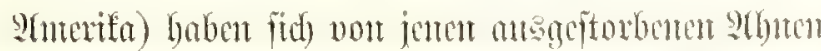

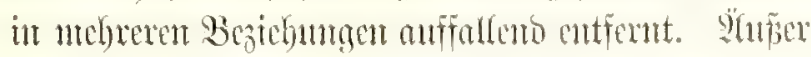

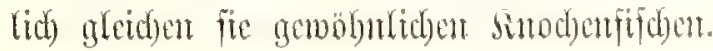

Rutrlye (Amphibia; Iaffel 6s). Dieje mitd)

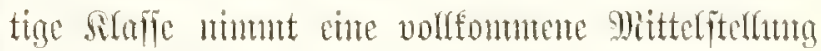

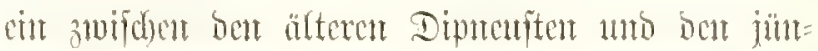
geren Beptifict; fie hat won ben exfteren burd) Wererbunt die Doppelatnunty und bie entjpredyentoc

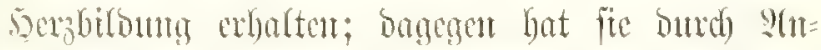
paffura an bus aeben anf bem sambe bic ltmbit=

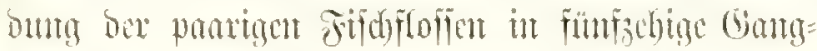

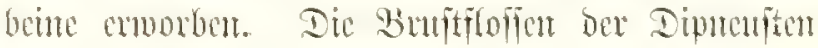

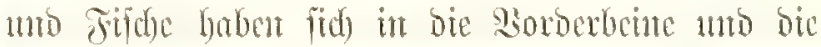

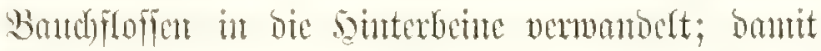
if jenes bebentungsudfe, tupifol) gegliebente Drgan

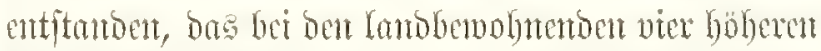

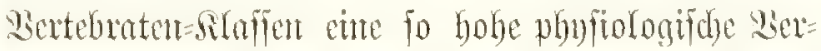

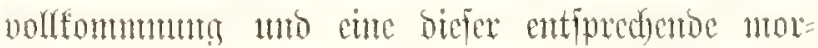

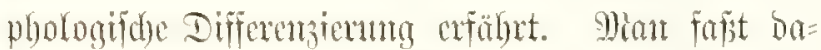
ber and) wohe biefe vier silaffen unter bem Begriffe

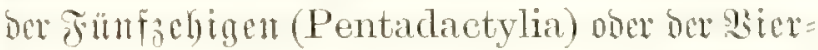
fuper (Tetrapoda, Quadrupeda) sufontutct.

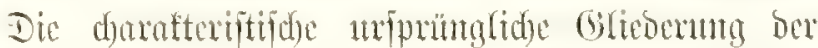

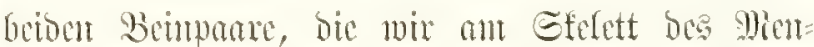

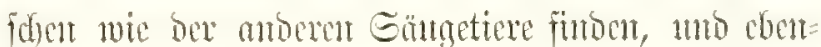

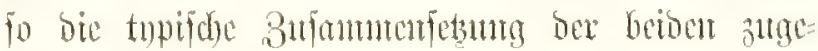

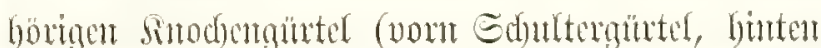
Beffengürtel) tit bexeits bet ben älteften uns be=

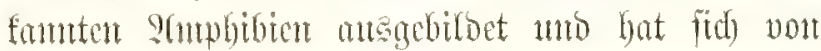

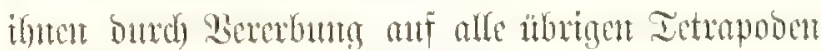

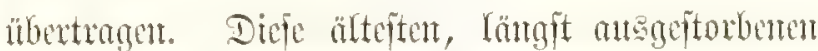

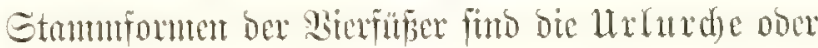
Somberfalanmonor (Stegocephala); wir fintom ifre foffith litberrefte woht erfaften in ber Etem= folfe vor. Sut ber Gefantform unb ben Sörpers proportionen gleifan fie unferen lefendon Sala

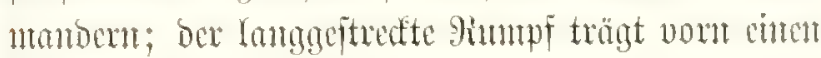
prattent Sopf, hintent einten langen Edjwantz; bie

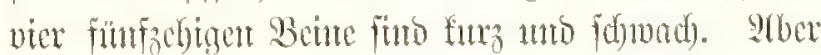

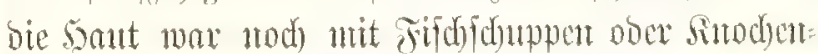

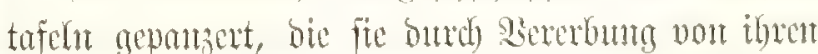

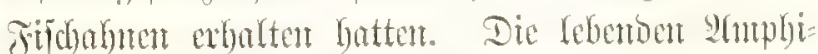

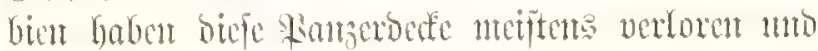
weroen baher afe Rerafturde (Lissamphibia)

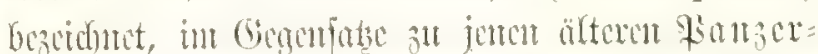
furct)en (Phractamphibia). Dic älteften Licr

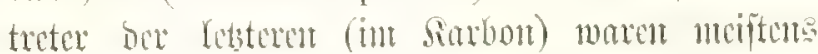

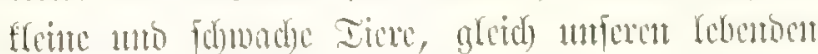

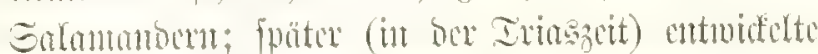

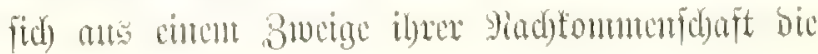




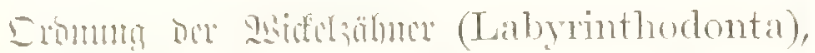

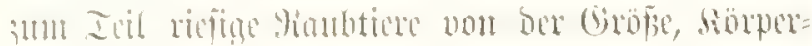

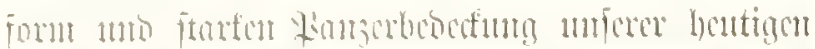

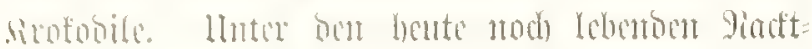

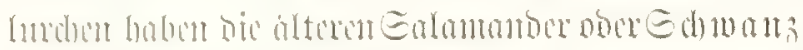

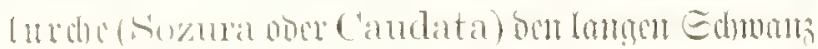

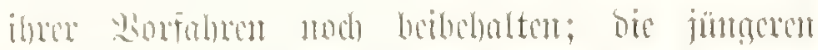
Frofolute (Anura noce Batrachia) beftien

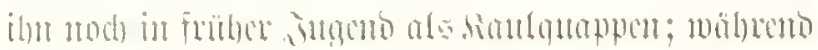

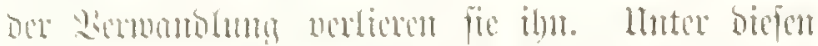

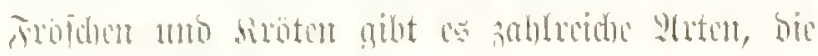

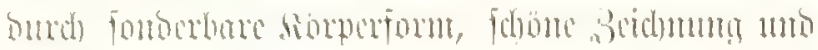

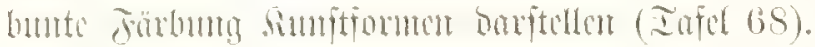

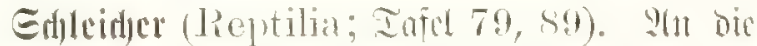

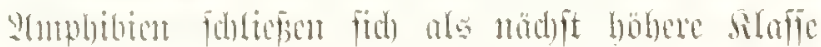

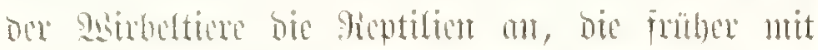

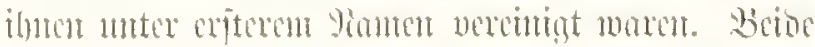

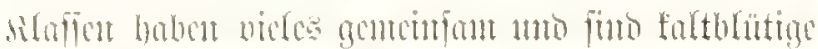

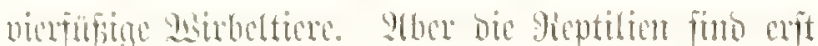

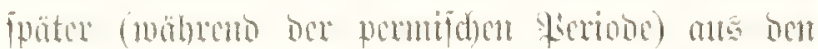

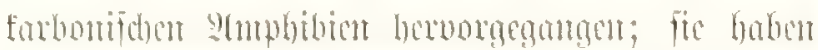

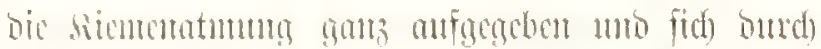

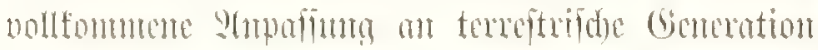

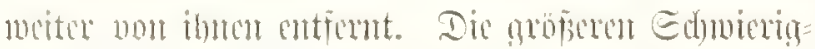

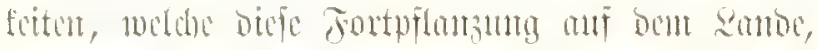

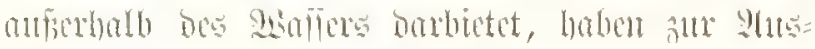

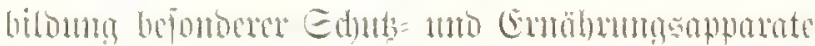

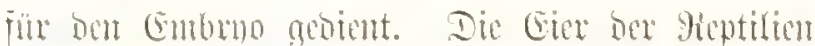

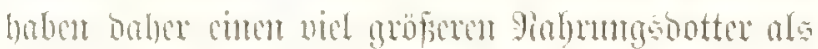

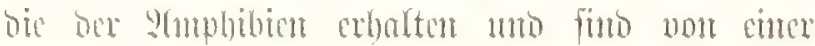

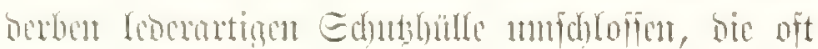

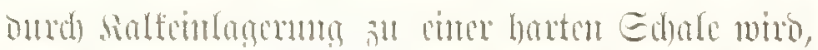

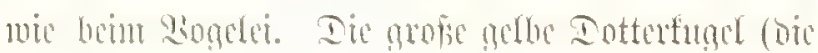

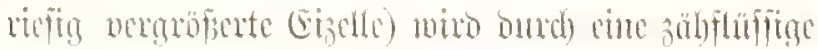

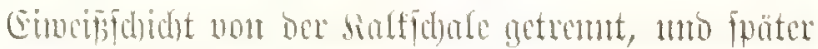

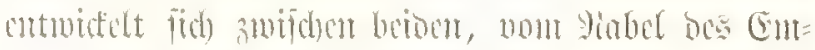

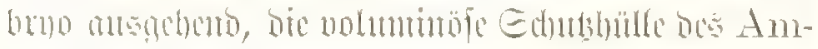
nion mo serolemma, cuncs meiten, mit mäfintiner

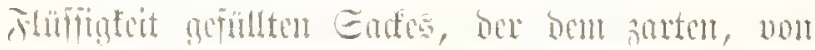

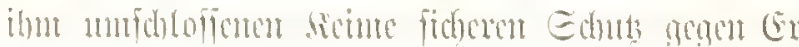

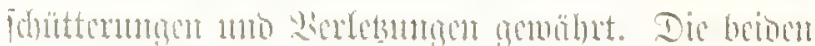

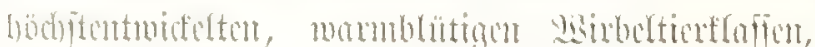
Whagel

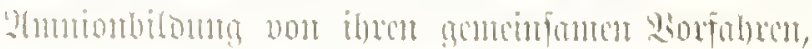

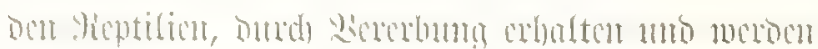

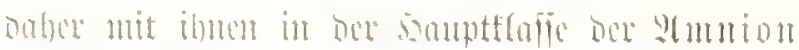

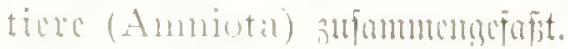

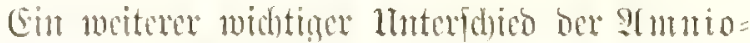

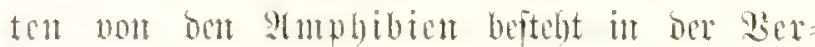

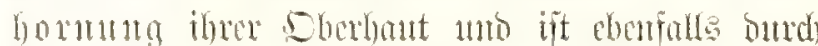

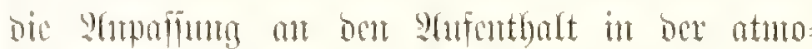

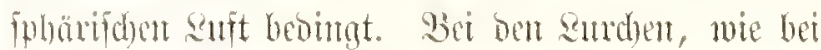

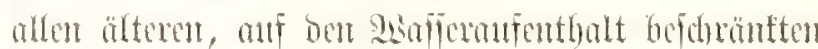

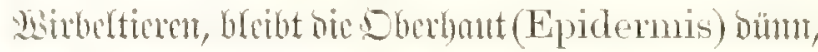

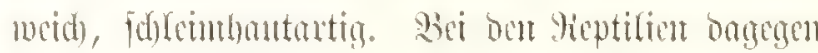
nermanbelt fie fid) in troctene barte somfubitam (ficatin), bic oft sul cinc febr barten mo foiten

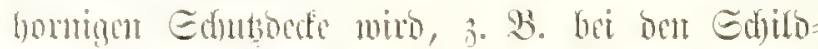

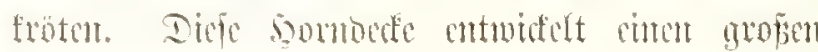

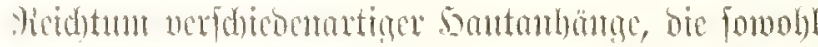

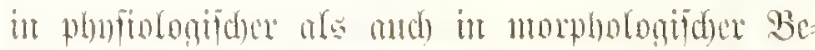

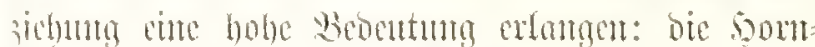

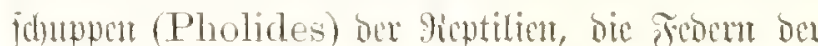

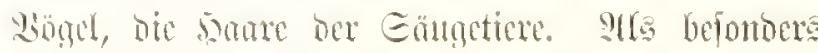
jtarte 1 mo feite, midhtigen Bueden bionenoe Lofale

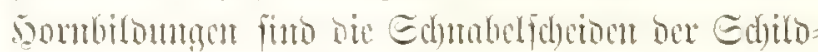

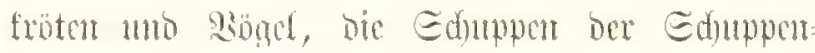

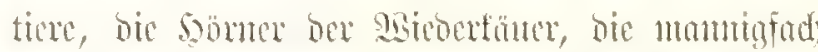
gorornten somoden ber Beben (Sirallen, sufe,

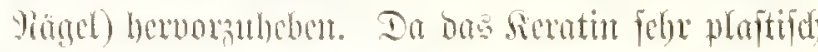
ift mo in höd)it mamigfaltinen Foment on pha

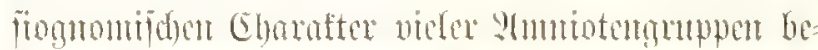

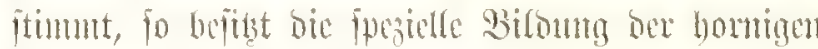

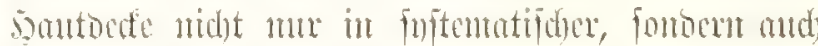
in affbetifder Besiebunt cime holse Beocutumg.

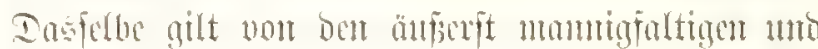

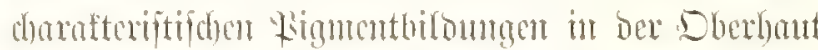
(Epidermis) uno in ber baranter lienenton seber=

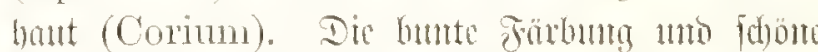
Beidmma ber sout liefert befountlid bei victen

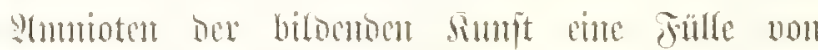
antebetrent giotivas.

Dic älteften Ficptiliun, entex benen moir bie ge=memfanten Etammformen aller stmmoten, alfo and)

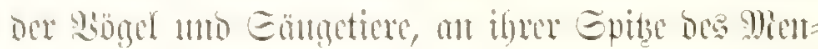
fden, futdon minfut, waxa bie Stammreptifien (Tocosamia) bex pexmifon Leriobe. Gie haben

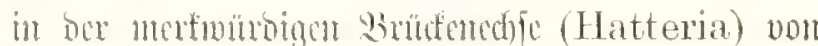

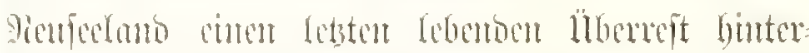

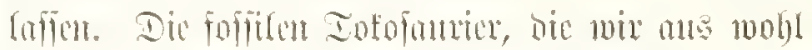

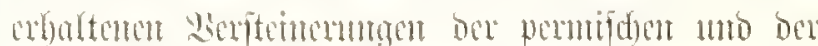
Folgenou Irinsperiobe fenten (muter amberen ber Proterosamrus an bem Ampferfdiefer von Cife-

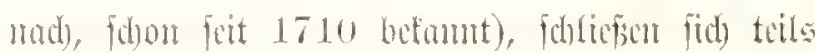


an bie Hatteria an, teile an bie Fanserfalantmoer ber Stemfohle (Stegocephala), teife an bie ntodernen Etbedfon (Lacertilia; Iafel 79). Diefe älteten Reptilien fond Gienteralijten mo babent bie uriprünglide, non mnjeren bentigen Galantan= bern wertig veridjtebente förperform bewabrt. Da=

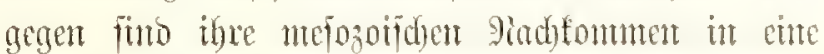

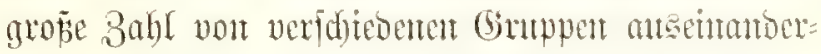
gegangen, bie als Epezialiften buth stupafinth an bie verfofiedente sebensucife hödjt mantigfaltige und abretdende Fonntent angenonmen baben. Die

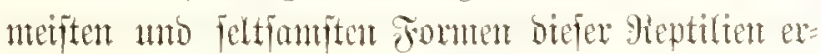

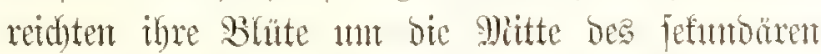

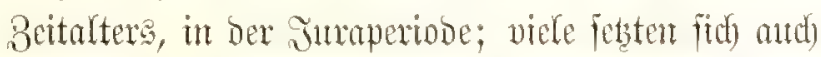
nod) in bie folgento firetiogeit fort, ftarben aber gegen beren ende ats. Shre Minfententriffedunt,

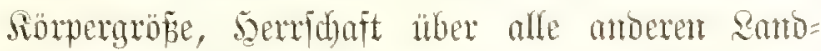
bemolner war wäbreno bes mojozoijden Beitalters

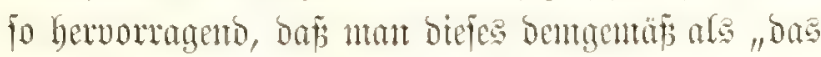
Beid) ber Feptiften" bezeddutet. Dic mertwumbigen Seebradben (Halisauria) - bie fifdfömigen Sid)=

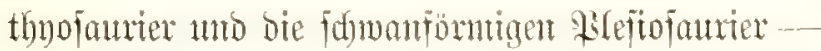
bie jeltianten fliegentoen Drad)en (Pterosauria), die fdumeriälligen luroruden (Theromorpha), yor allen abet bie rictigen satboradyen (Dinosauria), ungerüge Ungehente, bie chte Sätrge vont $30 \mathrm{~m}$

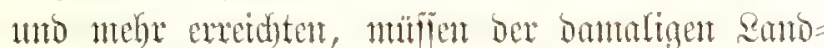

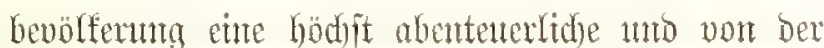

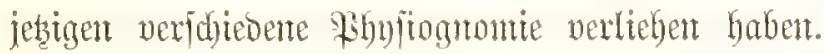

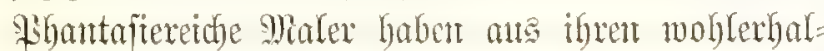
tenen veriteinerten Rejten (vollitüntoigen Gfeletten und 5autpanzerbiloutgen) neneroing interefiante Bilber aus bent Dradjenteben refonitmiert. Sitele

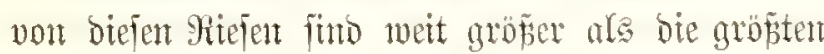
jest lebenben Gäugetiere unto entipred ent in ihrex abentenerlichen Gejtaltuntg uno Panzerbiloung, bem

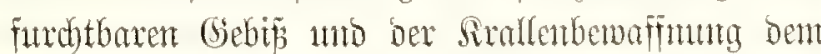
Bilde, bas fich unfere Shantafte von ben Rind=

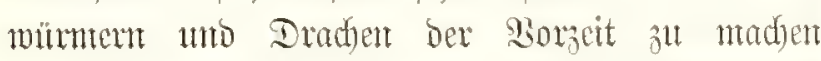

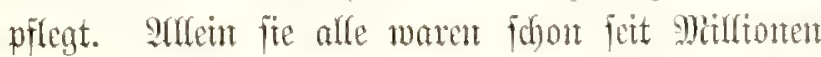
von Jahrent atsgejtorben, ehe ber glonify anf mijerem Erobalf exjoten.

Die nobernen Sieptilian, bie beute nod) ebento wie in ber ganzen Iertianzeit uber oen Eroball zer= frent uno bejonbers in ber beifist Bonte reid) cnt widfelt finto, zerfallen in bie vier Bromutgen bet Etoed)fen, Ed)Langen, Sirotobile mo Edyilotroten.

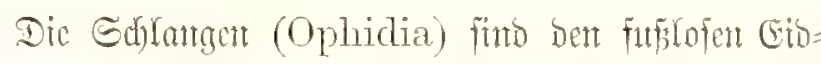

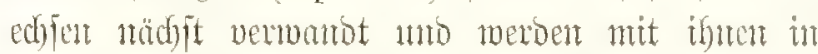
ber Segion ber Gduppentedyen neremigt (Lepidosauria). YUdu bie frofodile (Crocodilia) folliepen fid) ben Cibed)in nody nahe ant. Dagegen ent: Fantu fid) wett non ihtten bie Edhilofröten (Che lonia; Iafel 89); fie gebören au jenen Epeztalijten,

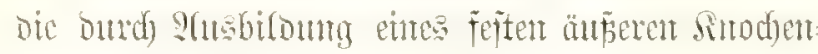

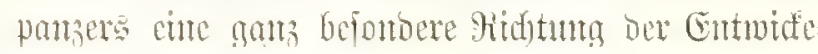

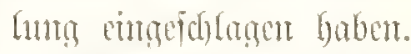

Bügel (Aves; Iajel 99). Befanntitch find

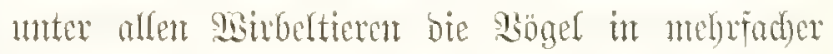
Bezicbung bie fobniten und ammutigiten uno bic-

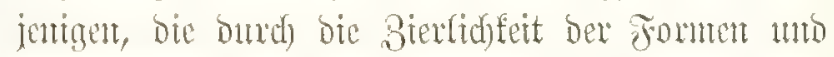

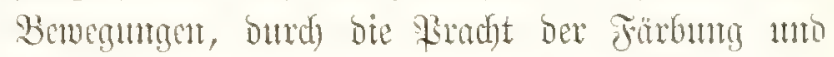
Bcidymng alfe anderen Sertebraten übertreffen; baher funo fie feit Jabrtanfenden bie bevonungten \&ieb= Cinge ber Diduter, fiumtler unto Framen. Die $B a ̈=$

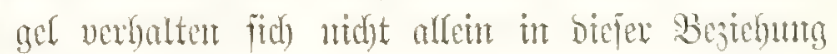

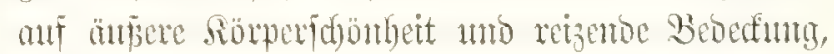

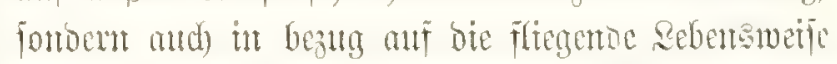

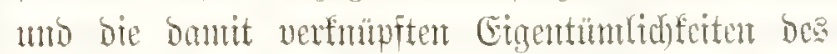

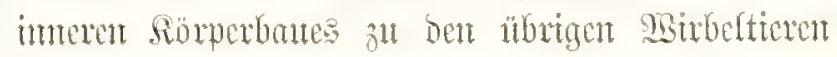

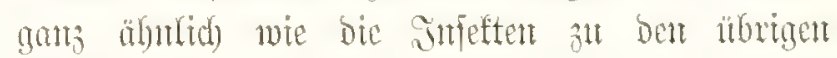

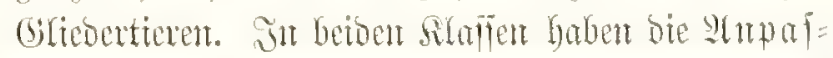
fung an bie flirgentoe Drtabemegumg tmo bie bantit verbutmoenten Eigentümlichéten ber Rebensmerje cine

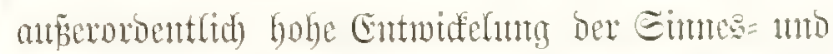
Seelentütiafeit bewirft, eine entiprechento \$ervoll= fonmmung des Gebinn uns ber Eimesorgant;

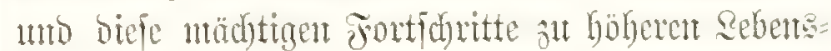
forment habent wieber anf bie vollfommentere Stus

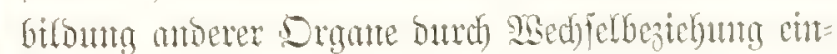
acmint. So funo 3. 3. Die Drgatte ber stumung unto Birfulation nidel Göher entwidelt als bei ben! näd)ftuermantoten nidgt fliegenden Iiergutppent. Die

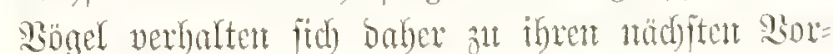

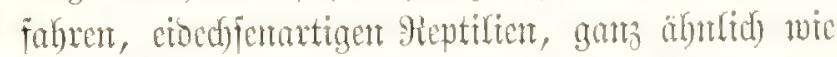
bie Jufeften zu ibren ungeflitgeltent sthmen, Dent

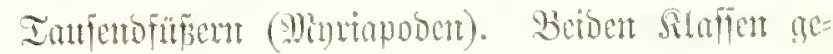

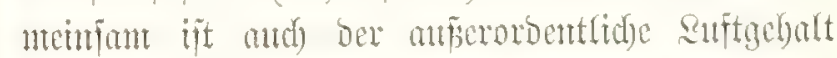

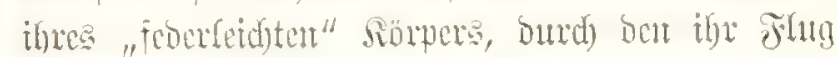

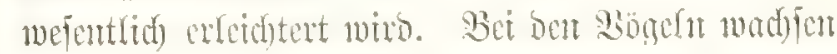

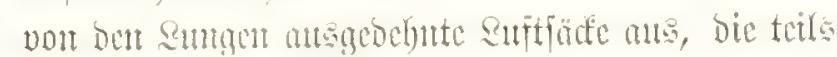

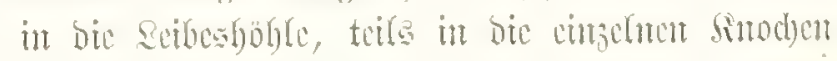

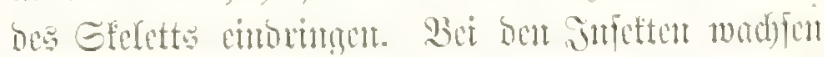

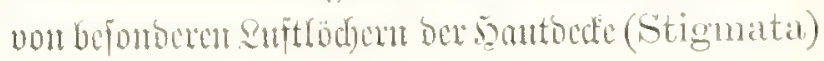




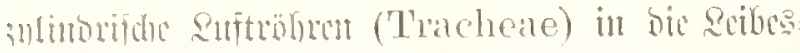

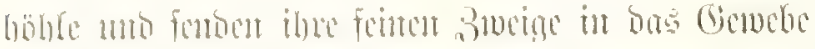

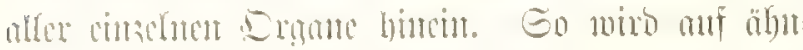

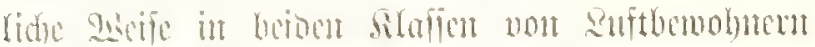

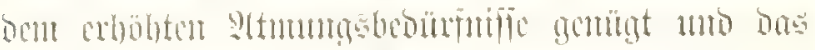

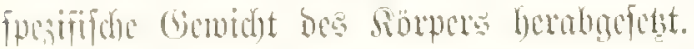

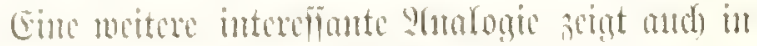

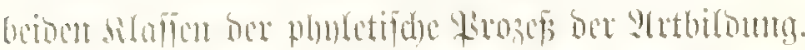

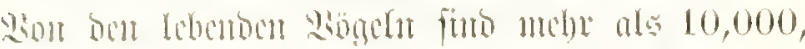

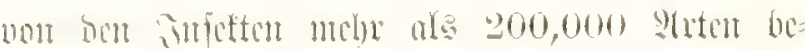

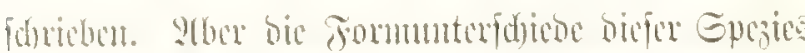

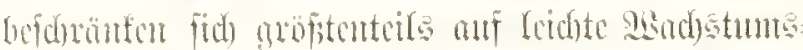

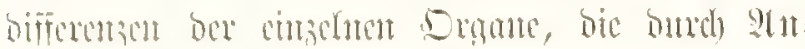
Haffung an bie befonberen zebensgemobmberten be

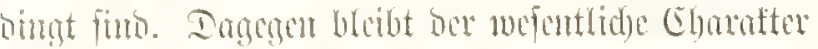

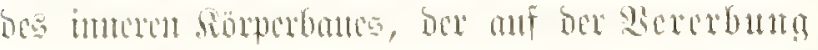

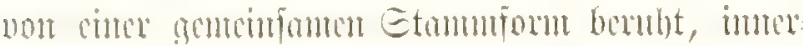

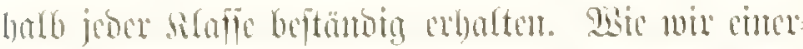

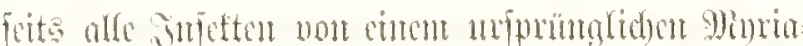

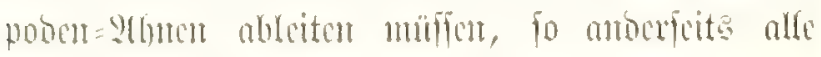

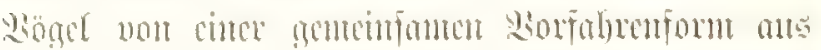

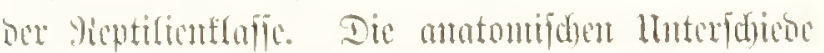

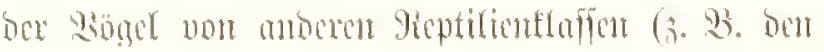

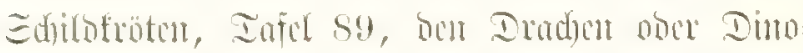

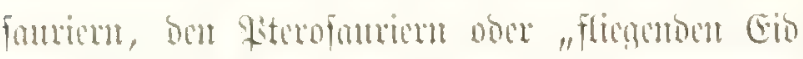

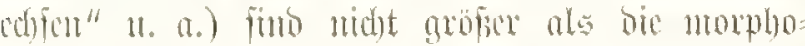

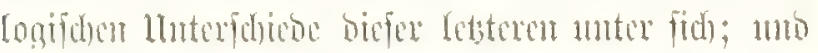

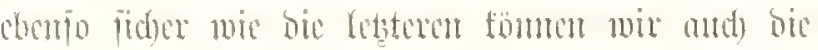

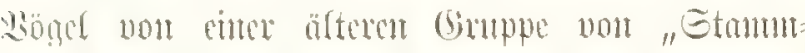
reptifien" (T'ocosauria) abreitur. Dic nene pho letifde Enftematif fofst babce and bic Sogelefalf

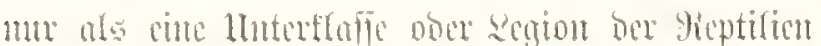

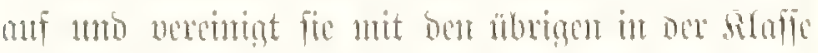

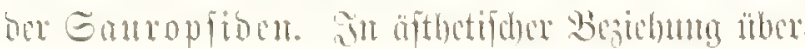

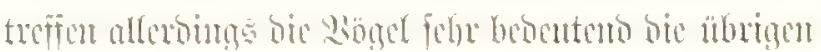

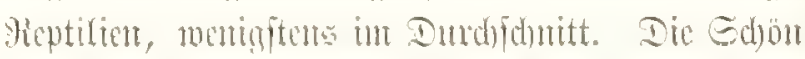

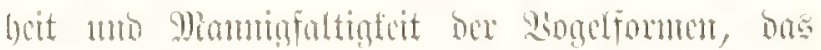

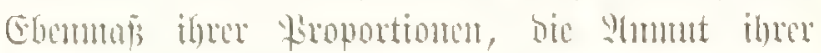

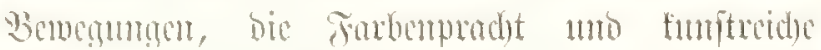

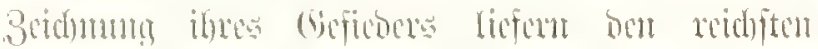

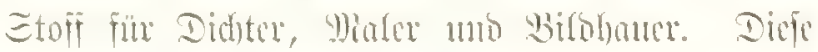

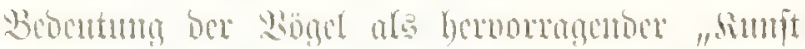

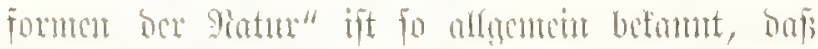

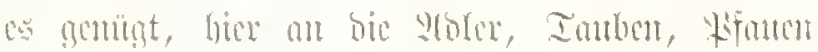

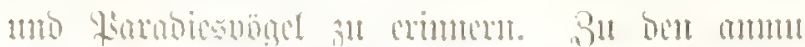

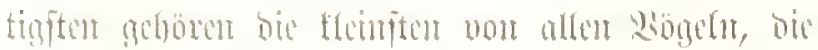
holibis (Iafil 93).
Gämgeticre (Mammalia; Iafel 67, 100). Stlle

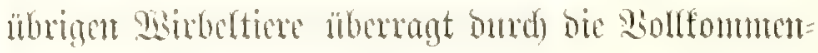

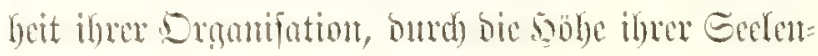

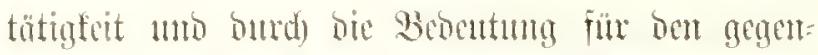

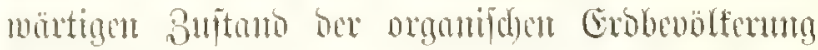
bie Slaffe ber Gangetiox (Mammalia). Dic Babl ber Britgliober biefer formenteden silajie wiro gegent=

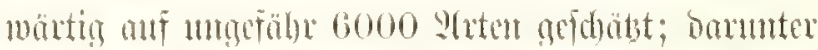

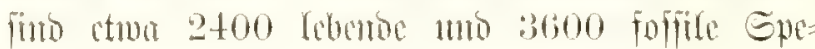

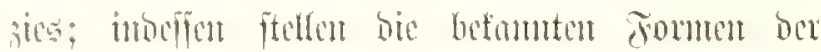

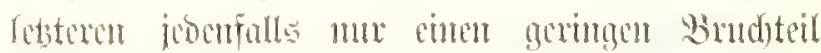
von ber viel groferen Babl antonforbenter Gätge=

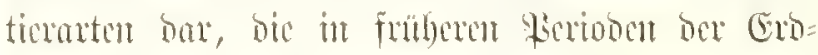

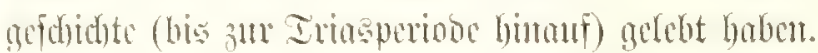

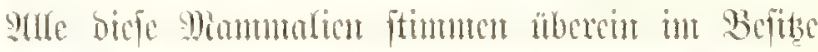

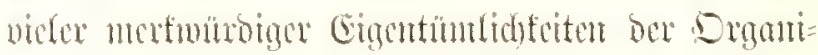

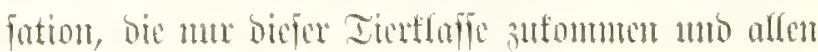

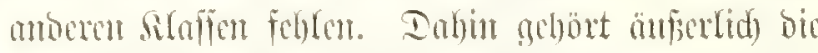
donaterififac sautboctung mit saaren. Swar gibt ca fabenformige soutansundofe, bie ntan als

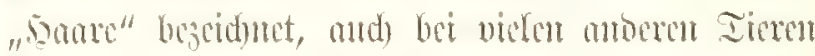

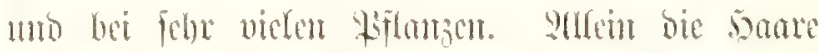
bex Eängetione funt gum cinsutumlide Sberbant=

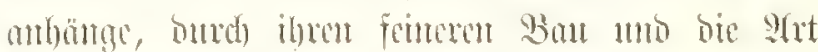
ifrel Entwidelum non allen anberen fogenantent

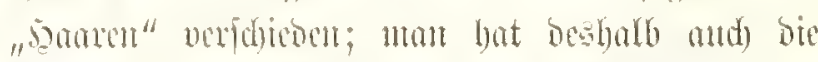

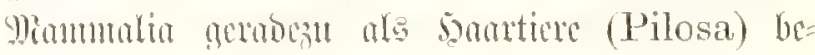

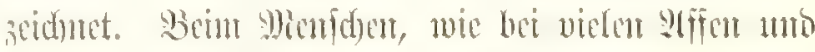
anderen Gangetien, ift bic Bebarma voxugs:

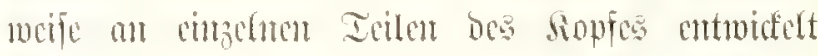

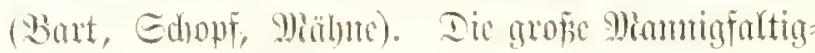

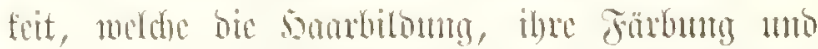

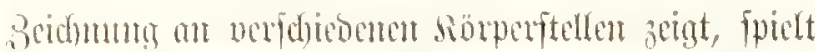

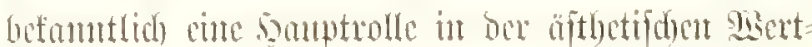
id)äbma ber Eämgetiox. s(ber mad) ambere 5om

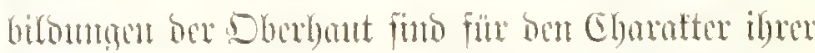

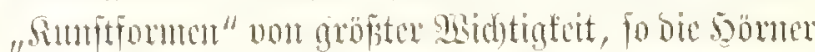

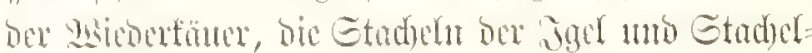

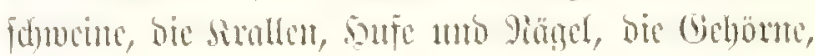

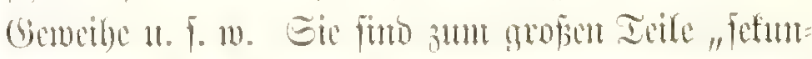

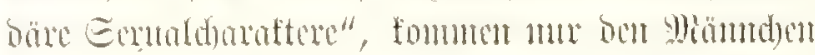

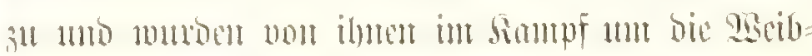

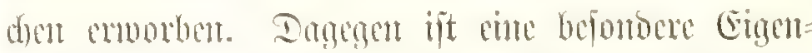

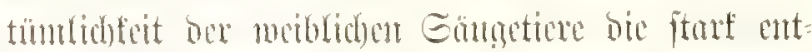

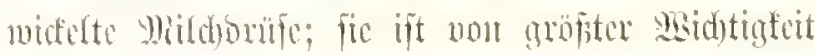

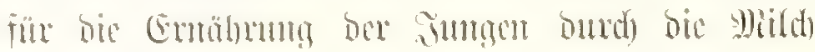
ber Wintter mo anobghat allein bas Eange- 


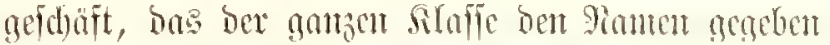
bat. Dicie bobere Foum ber Brutpflege exiducint fut bie Minterlidbe ber Gängettere und bie bont

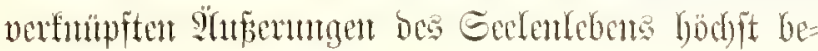
bcutumgenvoll.

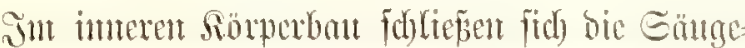
tiexe anmittelbar an bie ältepten Sieptilien 1 mo $?$ (n) phibien an, ans bonen bie Gtammesomdhidte fie ableitet. Sierbei fonmen als äterte vierfinfige mo

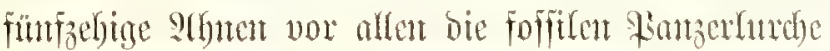

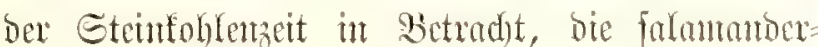
ähnlidben Stegocephalen; weiterbin beren por

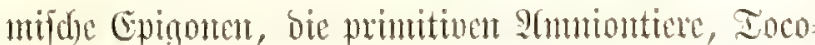
famter. Stts ibnen ging währento bet Irtas periobe bie ältefte uno mederfte Gintppe ber Gäntge tiere hervor, bie etcrlegenton Gabeltiere (Nonotrema). Son biefer Stontmontppe, non ber foffile llberrefte fowohl in ber Irtas ber grten ale and

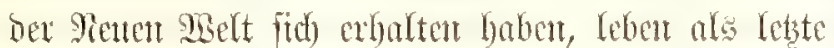
liberreite bente mu mod) brei Gattuman ber "Edurabltiere" in Patutulien: Echidna, Parechidna uno Ornithorlynchus. Don cirten

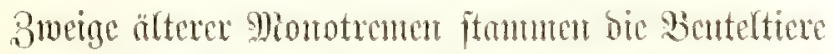
(Marsupialia) ab, bie ältejten Yebentotg gebären

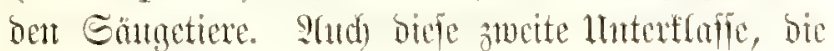

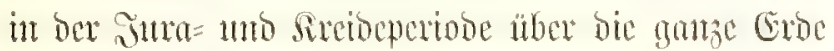

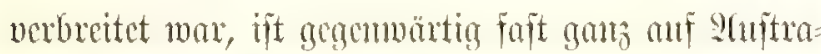

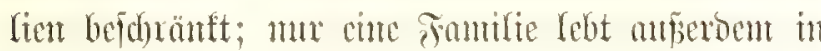

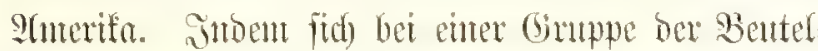

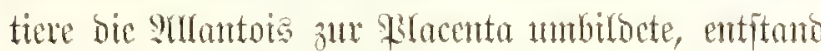

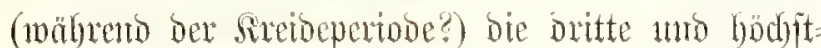
untwiderte Unterfafre, die ber Bottentiere (Placentalia). Diefe hat erit innerhalb ber Iertiäreit,

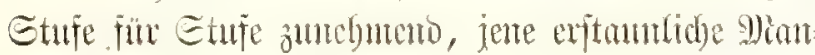

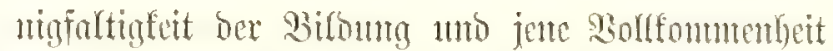

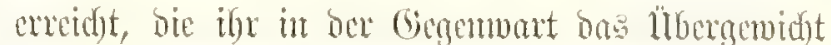
uber alfe andoren lanbbenohntenton Siere verteiht,

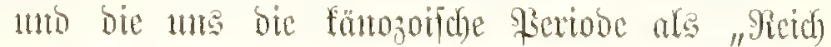

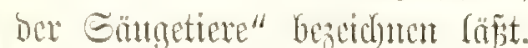

Dic zablreiden Dromungen bex Bottenticre, bie

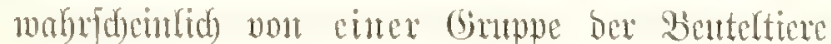

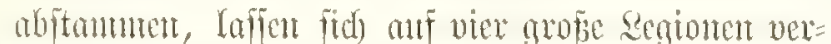
teifer, bie Pagetiere (Rodentia), sufticre (Ungulata), Ranbticre (Carnassia) mo 5erren= tiere (Primates). Cunge flentere segionen ex=

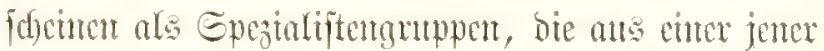
viet Santfegionen absuleiten fund; fo baben na=

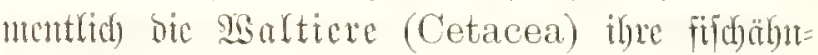

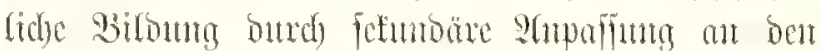

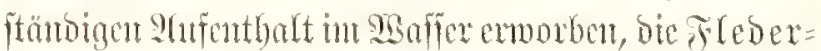
tice (Chiroptera; Iafel 67 ) ifre cigntumficte

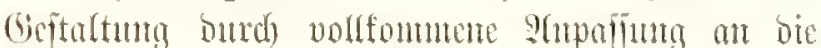
flicgenoe sebonencife.

Sboletch mtn in biefen grof̌en Segionen แmo in ben zahlreidsen burit enthaltenen Fantilten bic

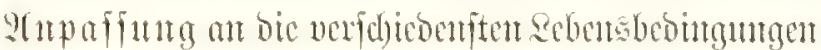

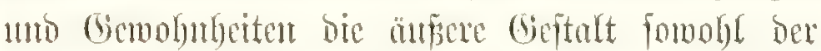
ganzen Berfon als atd ifrex emsenen Drgane in mantgfaltigfter Escife mugebtloet mo bifferengiert bat, ift bemnd ber wefentlide Charafter ber interen Drganifation mo ber Sientesentwideluma buth zähe Bererbung hberall extalten geblicben. Die nn=

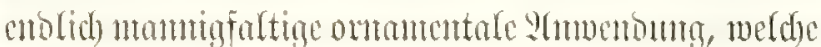

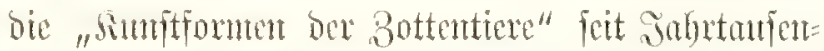
bent in allen Bweigent ber bifoenton Sumit mo bes Sunftgererbes gefunden baben, ift alloctannt; fie erretcht ibren bödjten Gipfed in ber vollfontntenter Sunfform der Pirunten, in Micnfden. 


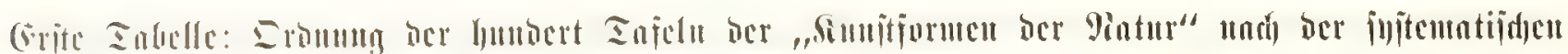
Sicijeujulge ser Silnijeu.

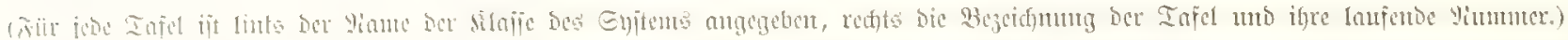

\section{Itruinamicu. l'potophyta.}

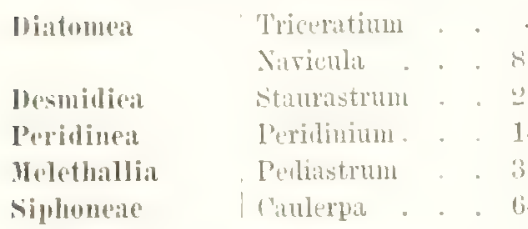

\section{Iretierc. P'rotozon.}

\begin{tabular}{|c|c|c|}
\hline Spumellaria & Heliodiscus. & \\
\hline & Astrosphacta & \\
\hline- & Collospliaeria & \\
\hline Icantharia & Siphacantla & \\
\hline- & Doratispis. & \\
\hline Sassellaria & 'Tympanilium & \\
\hline - & Caloeyclas. & \\
\hline- & Elaphlosugtri: & \\
\hline Phateodarial & Anlographis & \\
\hline- & ('ireogronia. & . \\
\hline Thalamophoral & Miliola. . & \\
\hline- & Lagena . . & . \\
\hline- & (t)bignerina & \\
\hline Mycotozon & Areyria. & . \\
\hline Ilascellata & Dinnlıryou . & \\
\hline riliata & Stentur. & \\
\hline
\end{tabular}

\section{Gesucburfouscu. Hetaphytal.}

dlsare

l'unเi

iclinesing

Museillate

Hepaticar

Filicinate

(a) ymmosperinato

Inqiospermate$$
\text { Zumariat. }
$$$$
\text { Delesceria . }
$$$$
\text { lictrouluma }
$$$$
\text { Eryiple . . } 7 i
$$$$
\text { clambia . . . 8:5 }
$$$$
\text { Pulytrichum , . 7: }
$$$$
\text { Marchantia. . Sy }
$$$$
\text { Platyceriumu . . 52 }
$$$$
\text { Alsoplilia . . 4 }
$$$$
\text { Araucaria . . 4 }
$$$$
\text { Neventhes. }
$$$$
\text { Cypripedium }
$$

IV Vicocrticrc. Coclenteria.

\begin{tabular}{|c|c|c|}
\hline Spongriae & Ascaurlra & \\
\hline- & Farrea . & \\
\hline Hyilroidae & Diphasia . & \\
\hline- & Campanulinil & \\
\hline- & Tubuletta. & \\
\hline Craspedotase & Gemmaria . & \\
\hline- & Acrquorea . & \\
\hline- & Carmaris & \\
\hline - & Pegautha. & \\
\hline siphonophorac & Porpena . & \\
\hline- & Eppibulia. & \\
\hline - & Disculatee & \\
\hline- & Strobalia & \\
\hline- & Bassia . & \\
\hline Clemophorate & Hormiphora & \\
\hline Stauromedusae & Luenernaria. & \\
\hline Peromedusae & Periplyylla . & \\
\hline Cubomedusae & Charybdea. & \\
\hline Discomedusae & Liuantha . & \\
\hline- & Desmonema & \\
\hline- & Aurelia. . & \\
\hline & Toreuma. & \\
\hline- & I'ílemin . & \\
\hline Tetracorallat & Cyathouhyllu & \\
\hline Octocorallat & Gurgmia. & \\
\hline- & l'comatula . & \\
\hline Hosacoralla & Ireliactis . & . \\
\hline - & 'l'urlbinaria . & \\
\hline - & Mataudrinat & \\
\hline Platoles & Hiplozwon. & \\
\hline
\end{tabular}

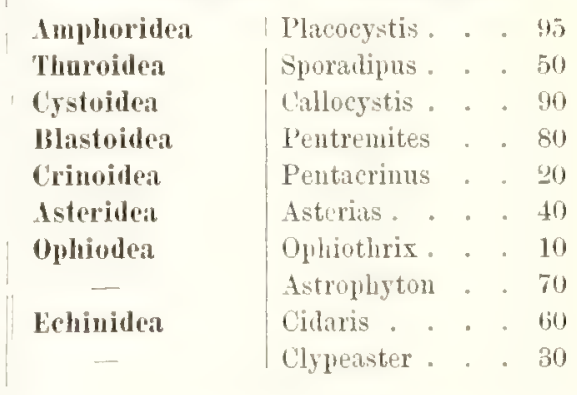

VII. Midinticre. Hollusea.

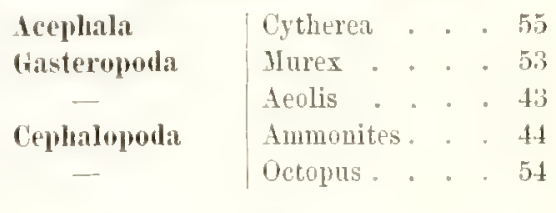

VIII. Gificoerticre. Articulata.

\begin{tabular}{|c|c|}
\hline Imnelida & Sabella. \\
\hline Crusticea & Limulus. \\
\hline- & Calanns. \\
\hline - & Lepas . \\
\hline - & Alima . \\
\hline 一 & Parthenope \\
\hline Arachuida & Epeira . \\
\hline Insecta & Alucita. \\
\hline
\end{tabular}

IX. Birberticre. Vertehrata.

\begin{tabular}{l|l} 
Pisces & Ostraciou . . 4 49
\end{tabular}

1. 96 mmticre Fermaliate $\mid$ Pegasus. . . 87

Amphibia Hyla. . . . 68

Reptilia $\mid$ Basiliscus . . 79

- Testudo ... 89

\begin{tabular}{l|l} 
Ires & Trochilus . . 99
\end{tabular}

Mammalia | Vamprus . . 197

Autilope . . 100 


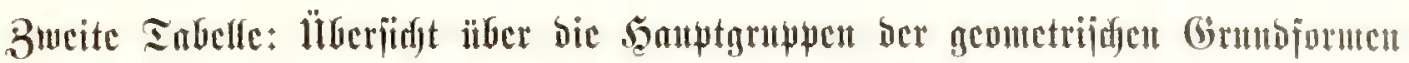

(Promorphologijdes Enitem; vergleide $\Xi .11$ ).

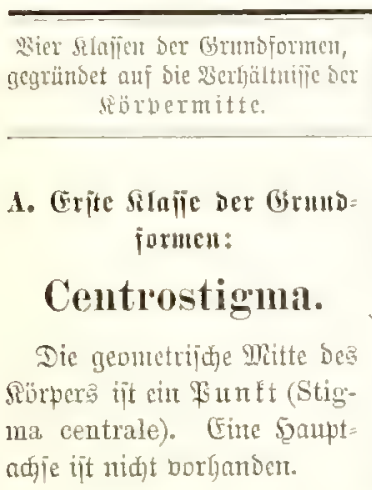

\section{B. Bucite SIajie ocr Grumb=} formen:

\section{Centraxonia.}

Die geontetrijal mitte be Rörpers ift cime getabe \&inic, Die bertitale scautadic (Axon centrale) ober $P^{3}$ rot $=$ ax̧on. - Sireuzadjen (be= ftumte tranboriale iddjen, bie auf Der longifubinalest Scauptadie fentredit iteryen feblen ben Monaxonten, fints borbanen bei den Standromicu.

\section{Dritte Slajie ser Grund formen:}

\section{Centroplana.}

Die geontctioge mitte bes Sorkers ijt sine Ebeute, Dic jagittale "Median = Ebenc" (Planum centrale). -- Mar Durdi) eincu Sdnitt (Dent Bfeilidnitt) itt Der Rörwer in 3wet fonuretrif gleidje scilf ter (redite und linte) teibrar; Rituen and baud find bex= idjteber.

\section{Sierte Siafie ber Girmo jormen:}

\section{Centraporia.}

Die geonetrijue witte bes Sörpers febit bolljtünoig (Acentra).

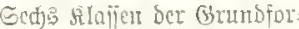
mert, acgrïrbet auf bie \$ูer hilltnije ber sobrperndjert.

\section{Homaxonia.} ĞIcidadifige Gுrumb= formen.

II. Polyaxonia. Bieladige Gratub forment

\section{Monaxonia. \\ Einadige Grumb= forment.}

Vium bie bertitafe baupts adje ift vorffanden (Duter= ifintit Dafer freišnuto); Strenzadjert feftert.

\section{Stauraxonia. \\ Rerezadige Grano formen.}

Sie sertikate bauntadic mirso bon beitimunten go: rizontalen firerzadjen ge idnitten (Ducrignnitt ba= fer poingoutal).

\section{Triaxonia.}

Dreiafige Grund= fortiter.

(Bilaterale, 3tgonorphen, Dorjibentrate, 3eugiten.)

Die Grumbform เoird Durdi orcianfeinanoer fent= recte gidjtadfer (Euthyna) bejtimut; bour Dicjen ijt bic longituomale und jagittale ungleidapolig (allopol), bie tranberjale gleidpolig (ijopol).

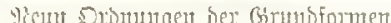

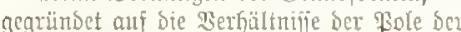
Siontradient

1. Soloiphärifde 1. Glattlugel, Grutop̧orncu. | Holosphaera. (Giatte fiugeht.) | (Sphaera, fiugel.) It)ciber.

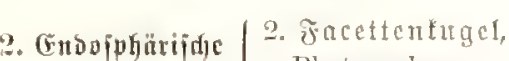
Gruntormen. Phatnosphaera. (Tafeltugeln.) $\mid$ Endoptyärifges $\mathrm{Ro}$

Becipiele fiir bic gienlifotiont sol. berffiebenen Ersmmon ber Girans forment in organichen Gétalten.

(b) fattfugelu, geontetriid) rein in bider Bellen Dertibuert (10wohl

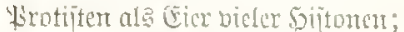

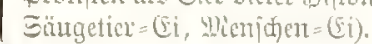

\section{Tafelfugelu, gentetriich rent in} viclent Frotijtenja)den (Ephüroi= Decrt u. a. Tinbiolmien), it Halo. sphaera, ben Follentönern bie lex Mnthophyten, bent Eiem bicler wictajoen bertibuert.
Ephäroionle Grunbiormen.

3. Ephäroibnfe Gruttiparmet. (3. Spindel, Erri

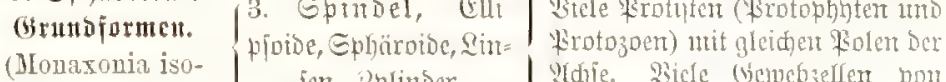
pola.)

fen, 3 ylinter.

idgle. Bicle vewebzellen bon Siptomen.

\section{Conoibale}

Brumbiormen. 14. Regel, Doifoun, (Ionaxomia allo- $\left\{\begin{array}{l}\text { Semifphäre. } \\ \text { gem }\end{array}\right.$ pola.)

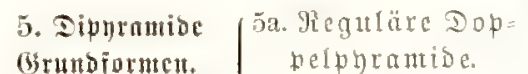

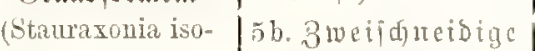
pola.) Doppelporatioe.

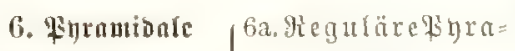
Grutbiormen. Stauraxonia allo- 66. Bwetfintreidige pola.)

suramide.

Goubisale Grutoformet. Bicle \$rotijten (Krotophinten uni \&rotojoent) mit migleiben fiolest Dor Ildje. Sicle Gowchizellen bon sifitonen.

Dimntantioc Grundiormen.

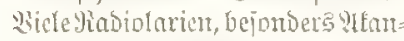
tharien. Bicle Diatonteen uni Desmident. Bicle Gemeballes bout Sijtortert.

\section{finramionale Grmbiarmen.}

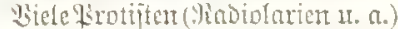
Jegulüre (attinontorphe) Blumes mD Früdte bieler Untfophnter.

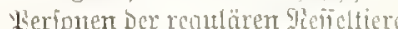
uno Etcrutiere. !niphithette Ute. troplyoren.

)

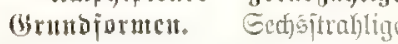
yłlüten you Cuphea, Lythrum.

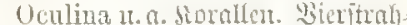

\section{9mpljiplente}

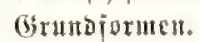
(Bzilateral= rabiale (Grundoromen-) Edicnige Grutiof = ment. (Paramphipleura.)

7b. IIt)aax= Sulenige. (Dysamplipleura.) lige bilütert von Reseda, Scaluiosa Siele Giplonophoren.

Gmphipleure ungerabaflige Grunbiormen. Jüstritrohlige Hamoroled listen (Viola, Labia ten, Bapilionazect. Dreijtrafige Erdibeen). Bifaterale (und penta=

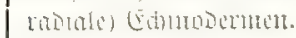

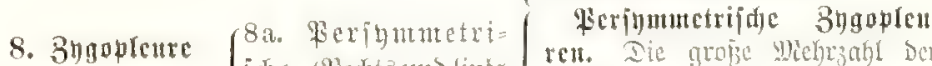

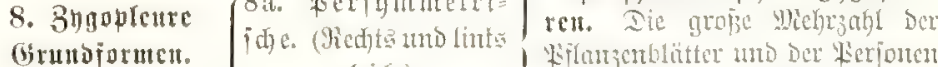

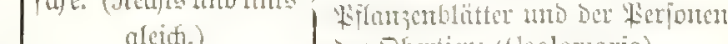

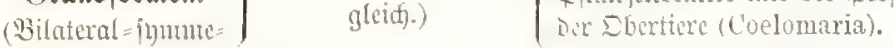

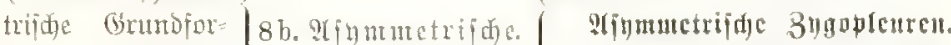

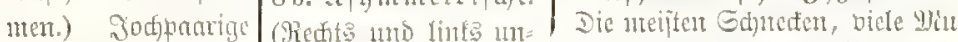
Grumbroment.

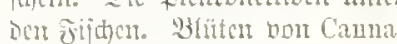

\section{Anaxonia.}

Fehlatige orund formen.

Bejtmute शlajen fint beftumte शेd
9. Irregulärc Grumb jormet.

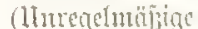
(Grunsfotntur.) Silutucn, 9olus. (3rmbiormen. Sicle antobotio

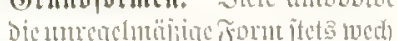
isture 3ellen. Bicle Ergme. Iit meiten Epongien (mo anders siorment.
Srregulare ober adjenloje 


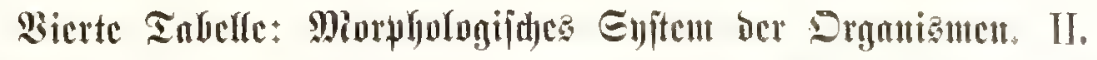

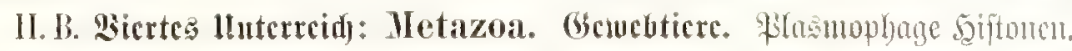

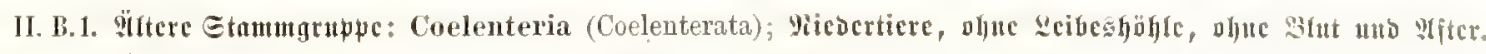

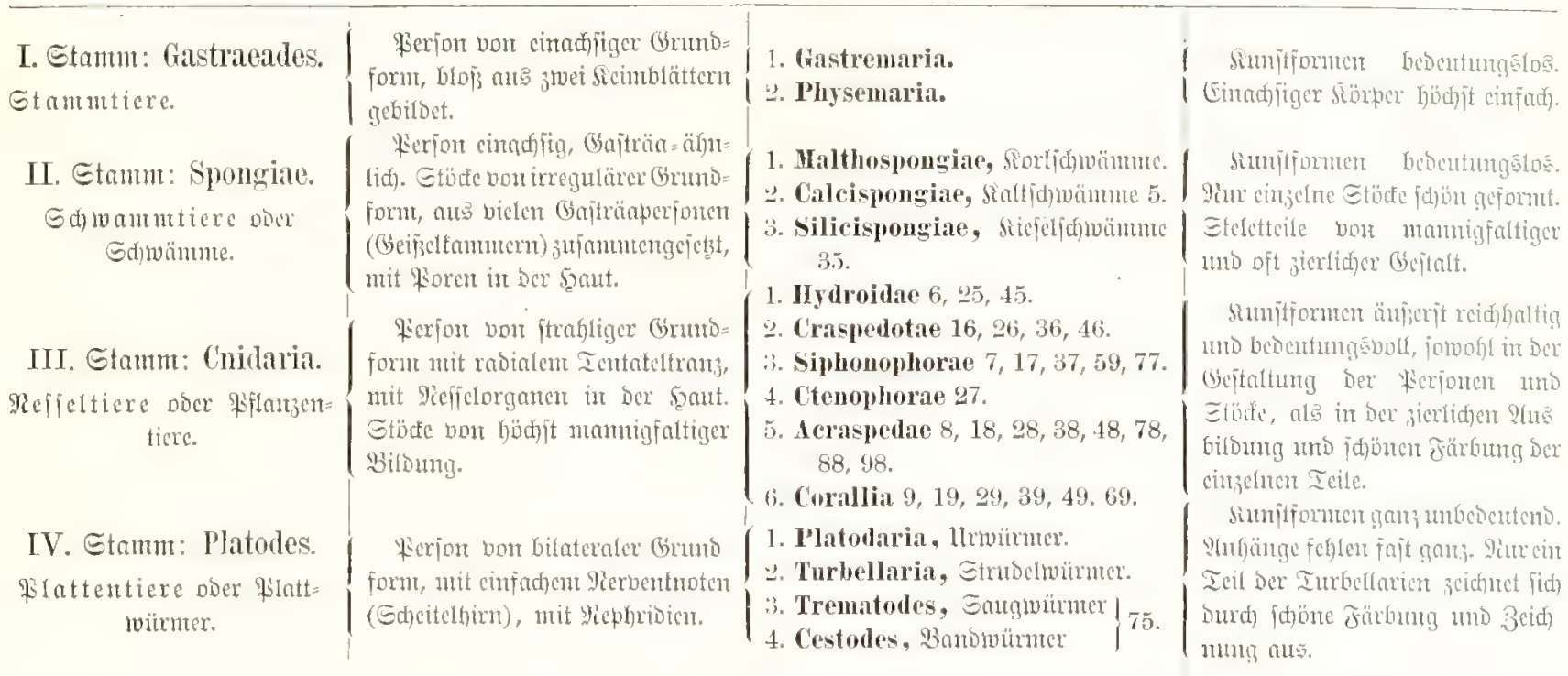

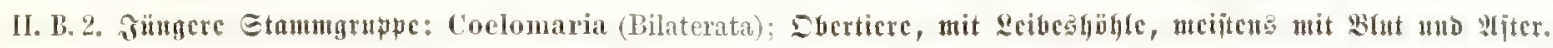

V. Stamn: Vermalia. 2isurutiere (ober, sisir: แuci", 3ut Teil).

VL. Stantnt:Echinoderma Gteruticre ober "Stadfl= bäıtter"s.

VIT. Etantm: Mlollusca. Weiditice Docr Edjattien.

VIII. Stantut: Articulata. Giliebertiere.

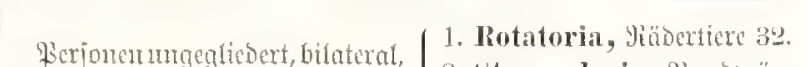

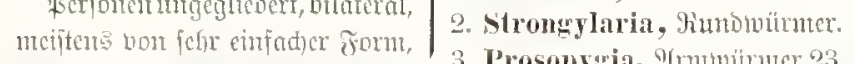

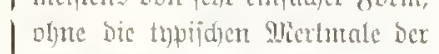

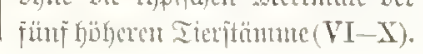

Serforen bon finfitrabliges Grumbform (iut bex Jitgano bila teral), mit pentarabialem gicroen

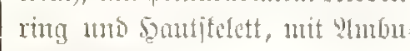
Intralimitur.

Fierjonenungegliebert, bilateraf, mit Dorfalem giantel uns Edjale, bentralent Siatelfup; sienten, , wot=

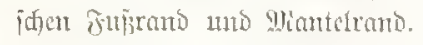
Vierbonjentum eit Ed)lutori

Rerjonen bilateral, äuperlidy ge ghiedert, nit einer fette bon Chitin: ringen. 9icrbenzentrum ift cin Baudjuart urt Edfunoring. liber Den Damt cin Mitdenforz.

Terpon ungegliesort, bilateral,

IX. Stanm: Thnicata. Manteltiere.

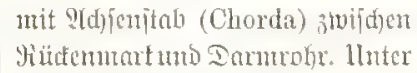
Dem Darn cin Daudbers.

Werfon bilateral, muctidy ac gliobert, unit einer fictte bon ltr

X. Etantu: Vertehrata. sivingelticre.
97.

4. Frontonia, gìifićnuintete $\quad[50$.

1. Amphoridea 95. - -2.Thuroidea

3. Cystoiden 90. - 4. BIastoidea 80.

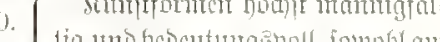

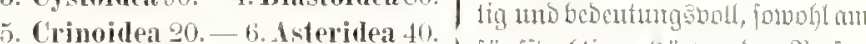

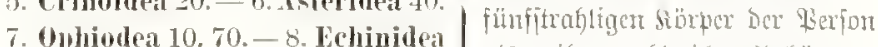
serimides 30,60 .

1. Imphineura, llruolitsten.

2. Gasteropoda, Edynctedt 43, 53 .

3. Aceplata, \$gujded 55.

1. Cephalopoda, Siraten $44,54$.

1. Annelida, Minguktere 96.

‥ Crustacea, Survifuticre 47,56 , $57,76,86$.

3. Tracheata, Euftrofitiere (Araclnida 66, Insecta 58).

1. Copelata, Wppenditarion

2. Ascidiae, Geejuetoen 85.

:Thalidiae, Galpion.

1. Lcrânia, Exäbdlote.

‥ Cyclostoma, humbutinlcx.

3. P'isces, fifthe 4:, \&7

4. Dipneusta, "urdjiid).

$\therefore$ Amphibia, Surde 68 .

6. Ireptilia, Ed)Lcid)er 79, 89

7. Ares, witigel 99.

s. Manmalia, Güngetiere 67, 100
Sumifounter tubedentend. Sut

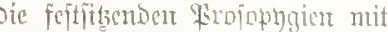
ferre ntomigfaltiger unt jdioner Edyatenbildutg. Whozomitöle.

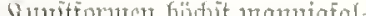
als ant ifren jablreidyen subüngent.

Sintifforment fore mannigfaltig

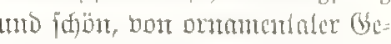
Ftaltung und oft bunter Förbung;

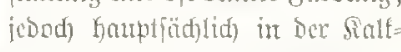

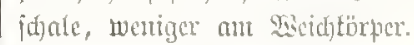

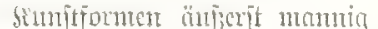
Des fobrex al and in Der feiner

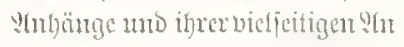

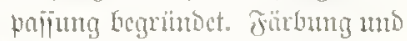

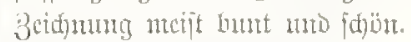

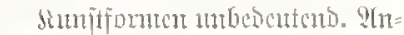
fönge ant untgegltedertent sibrper ichlen merit. Yim vide Stmonji

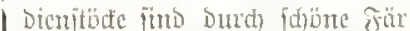
bumg urs Beid)muth benterten: wert.

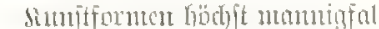
tị̧ 1410 heocutung

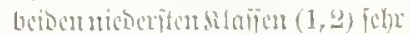
cinfuct), ohne Gliconajer. Dic

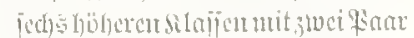
Griconajor, ferr mantigfaltiger mo fobioner sionferbedecturg.

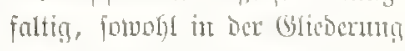


Srud bom Bibliograbhijgen gnftitut in 2cipsig. 
. 




